\title{
Epimeria of the Southern Ocean with notes on their relatives (Crustacea, Amphipoda, Eusiroidea)
}

\author{
Cédric d'UDEKEM d'ACOZ ${ }^{1, *} \&$ Marie L. VERHEYE ${ }^{2}$ \\ ${ }^{1}$ Royal Belgian Institute of Natural Sciences, Service Heritage, \\ Rue Vautier 29, B-1000 Brussels, Belgium. \\ ${ }^{2}$ Royal Belgian Institute of Natural Sciences, Operational direction Taxonomy and Phylogeny, \\ Rue Vautier 29, B-1000 Brussels, Belgium. \\ *Corresponding author: cdudekem@naturalsciences.be \\ ${ }^{2}$ Email: mverheye@naturalsciences.be \\ ${ }^{1}$ urn:1sid:zoobank.org:author:8837E5E0-20FA-42E1-A9C9-19F130B68142 \\ ${ }^{2}$ urn:Isid:zoobank.org:author:6FF6092A-6E5D-4531-8C1F-BE9422E2DD4E
}

\section{Table of contents}

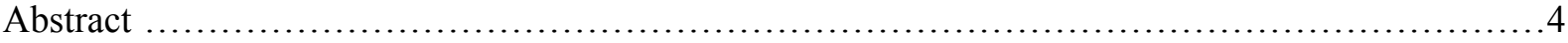

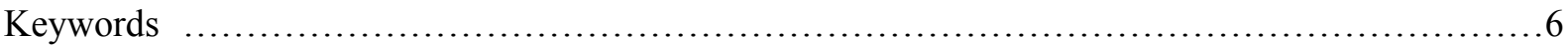

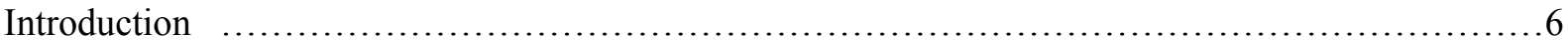

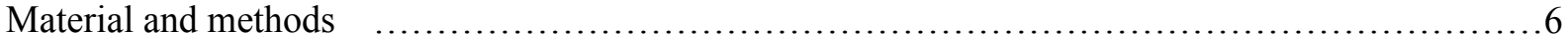

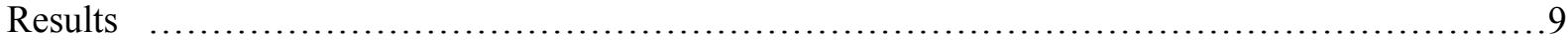

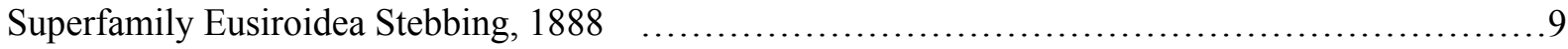

Family and sub-family key to Antarctic and sub-Antarctic Epimeriidae and their putative relatives...10

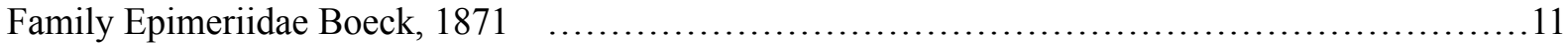

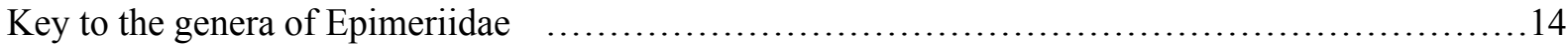

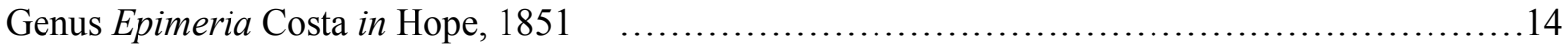

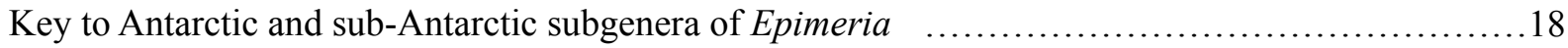

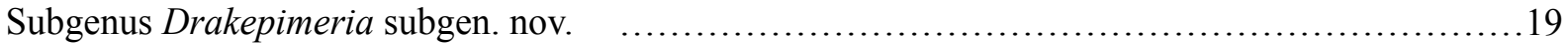

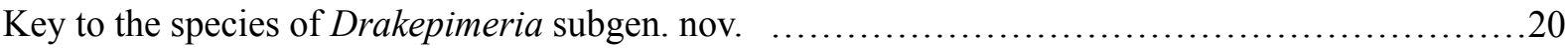

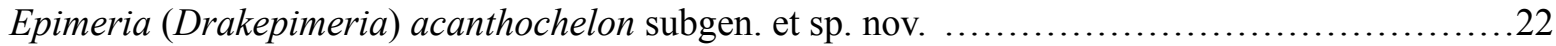

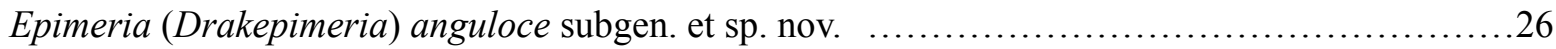

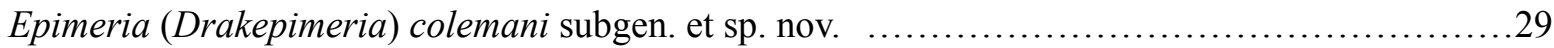

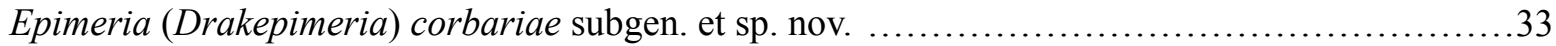

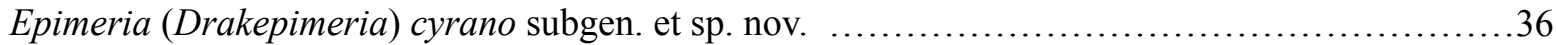

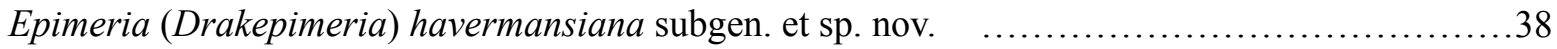

Epimeria (Drakepimeria) leukhoplites subgen. et sp. nov. .................................. 41

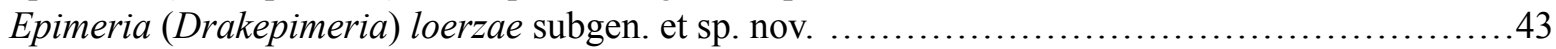

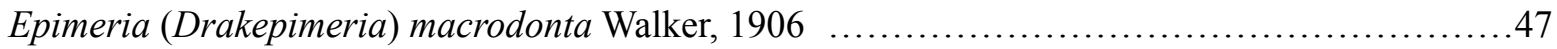

Epimeria (Drakepimeria) pandora subgen. et sp. nov. ....................................49

Epimeria (Drakepimeria) pyrodrakon subgen. et sp. nov. ...................................52 


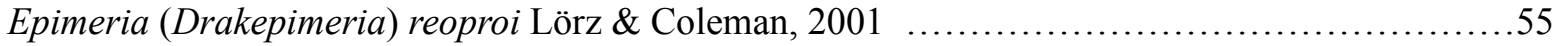

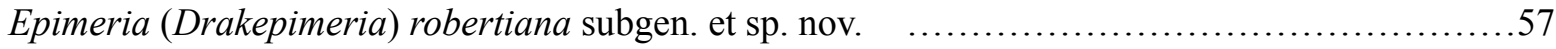

Epimeria (Drakepimeria) schiaparelli Lörz, Maas, Linse \& Fenwick, 2007 .....................59

Epimeria (Drakepimeria) similis Chevreux, 1912 ........................................60

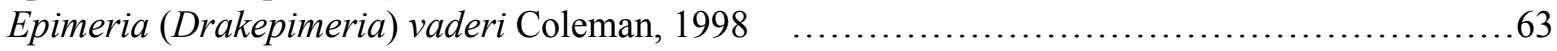

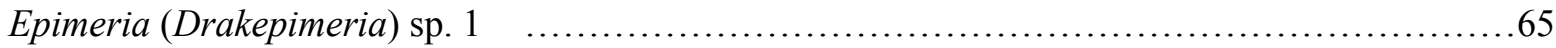

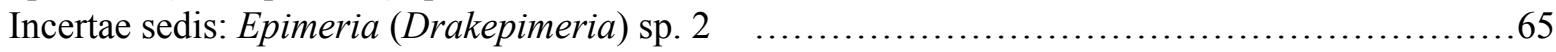

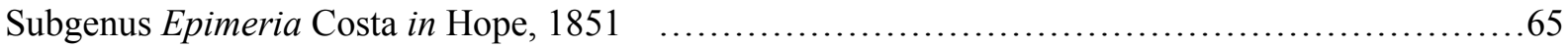

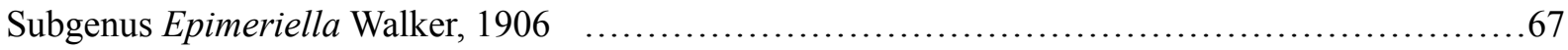

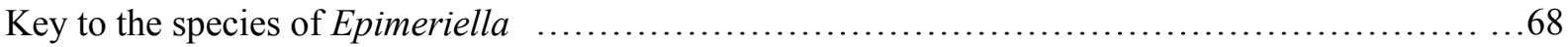

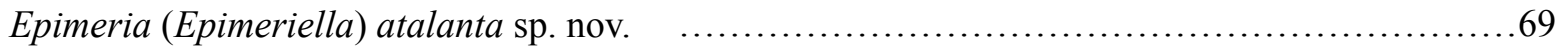

Epimeria (Epimeriella) macronyx (Walker, 1906) ….................................... 70

Epimeria (Epimeriella) scabrosa (K.H. Barnard, 1930) ................................... 71

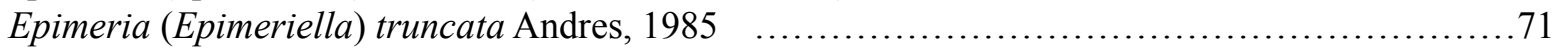

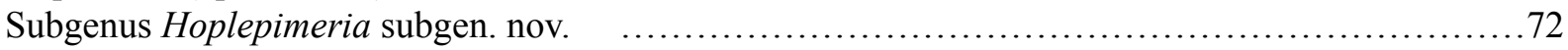

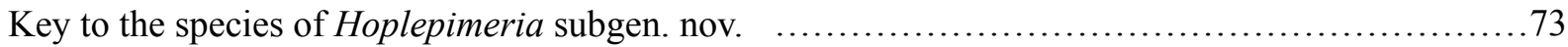

Epimeria (Hoplepimeria) angelikae Lörz \& Linse in Lörz et al., 2011 ..........................74

Epimeria (Hoplepimeria) cyphorachis subgen. et sp. nov. ................................... 77

Epimeria (Hoplepimeria) gargantua subgen. et sp. nov. ..................................... 78

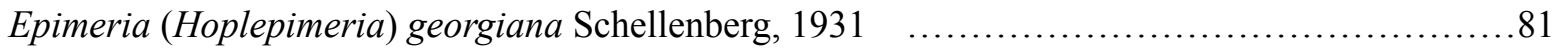

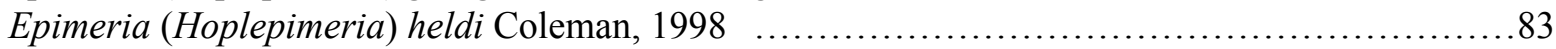

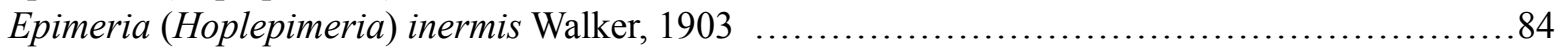

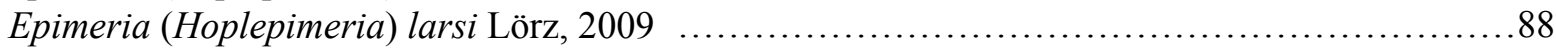

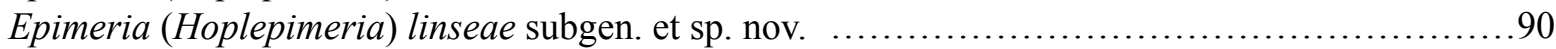

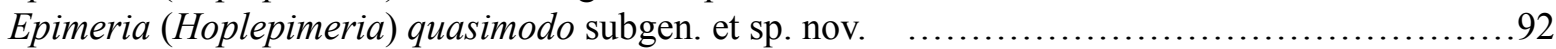

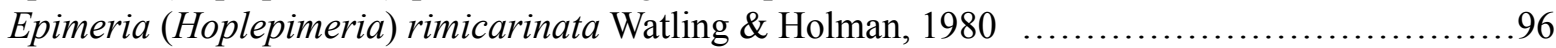

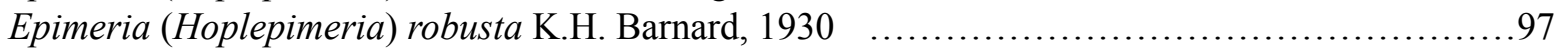

Epimeria (Hoplepimeria) robustoides Lörz \& Coleman in Lörz et al., 2009 ........................99

Epimeria (Hoplepimeria) rubrieques De Broyer \& Klages, 1991 .................................101

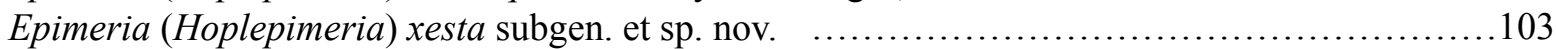

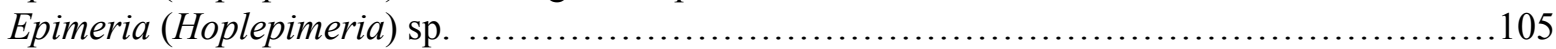

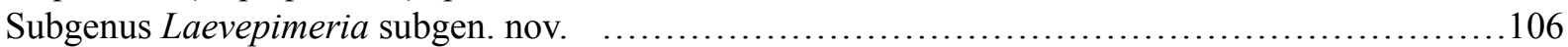

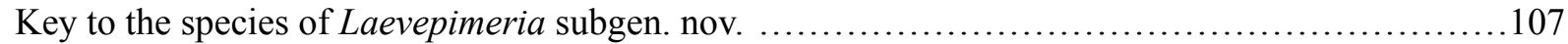

Epimeria (Laevepimeria) anodon subgen. et sp. nov. …................................... 108

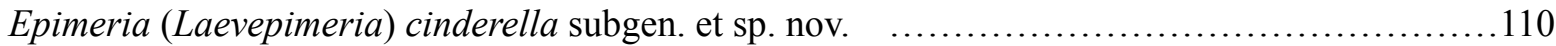

Epimeria (Laevepimeria) walkeri (K.H. Barnard, 1930) ....................................112

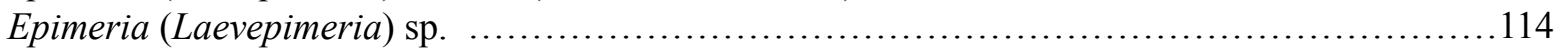

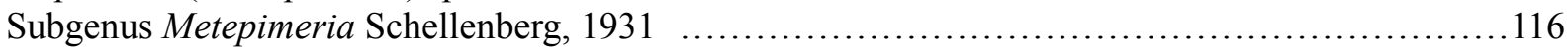

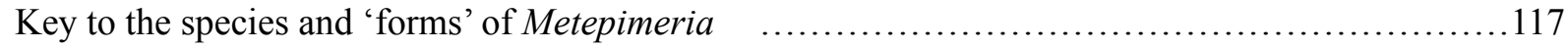

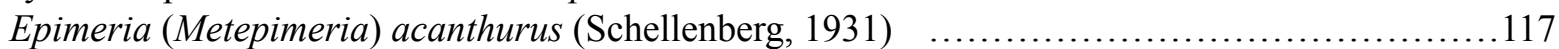

Epimeria (Metepimeria) ashleyi Lörz, 2012 .................................................. 118

Epimeria (Metepimeria) intermedia Schellenberg, 1931 forma A $\quad$............................118

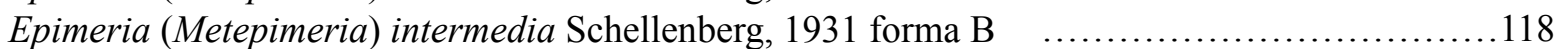

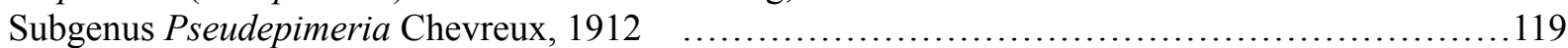

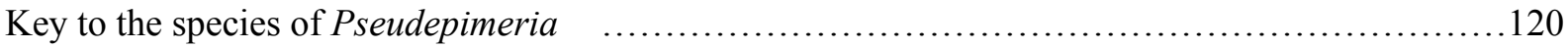

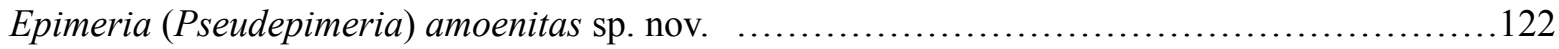

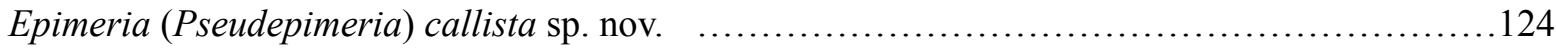

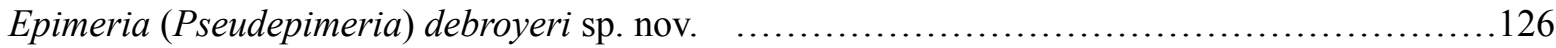

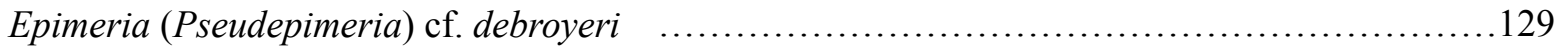

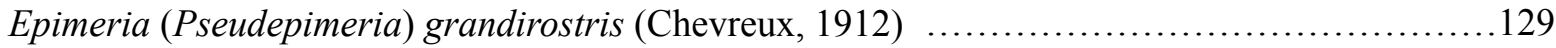




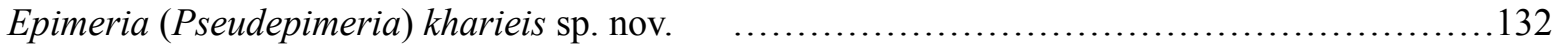

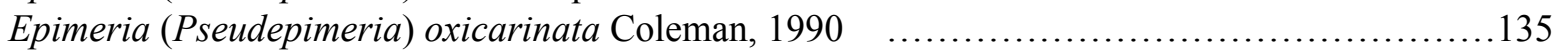

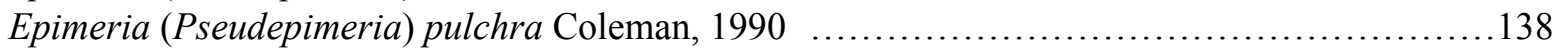

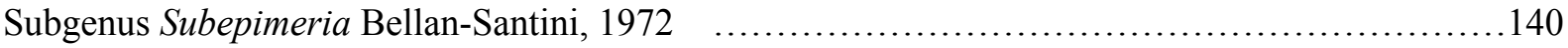

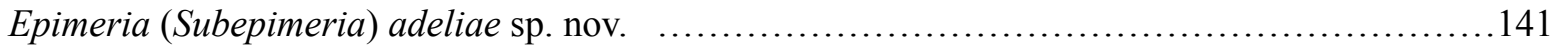

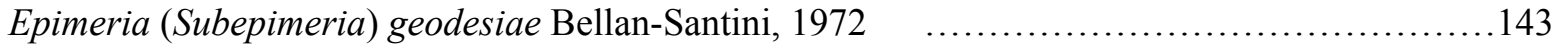

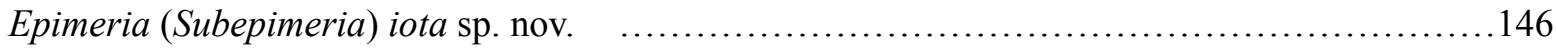

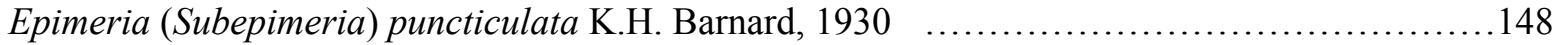

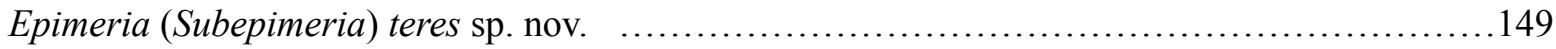

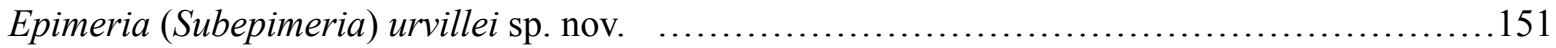

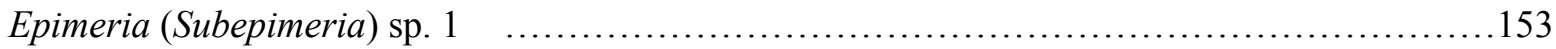

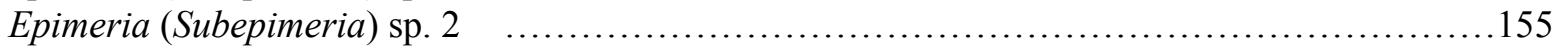

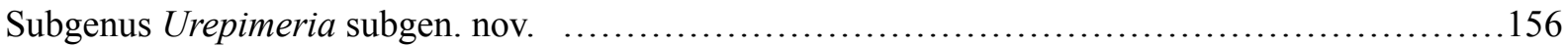

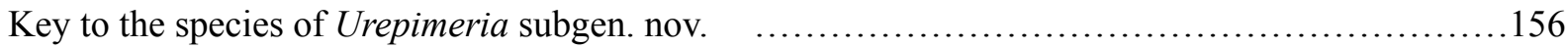

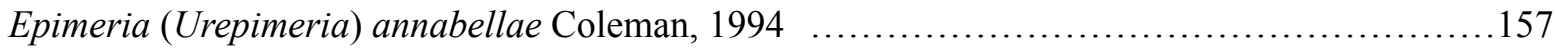

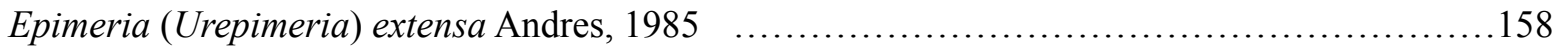

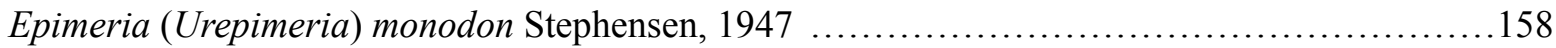

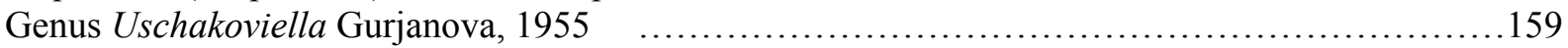

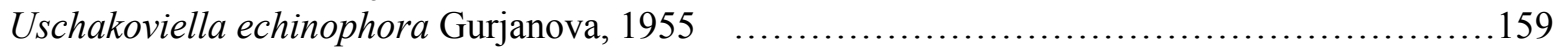

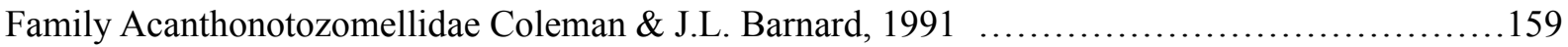

Key to the genera of Acanthonotozomellidae ............................................... 160

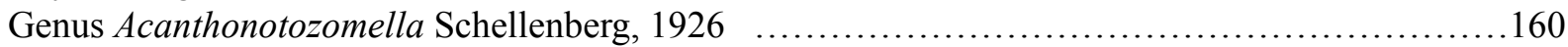

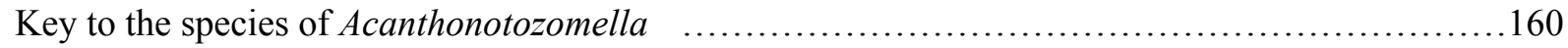

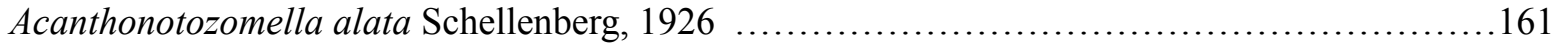

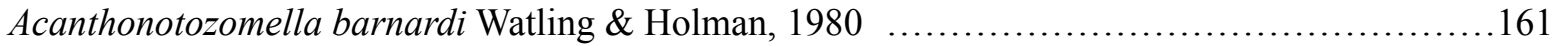

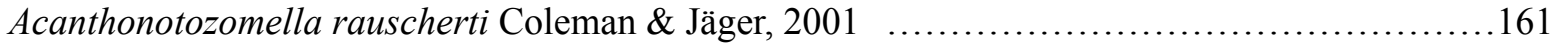

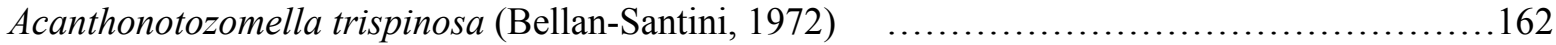

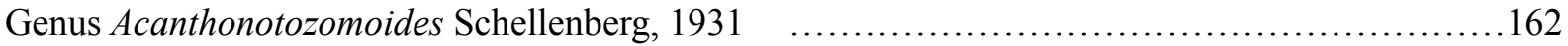

Key to the species of Acanthonotozomoides $\quad$................................................ 162

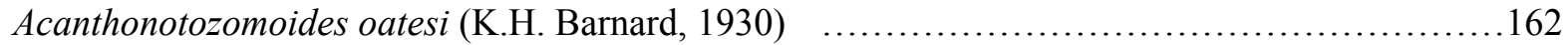

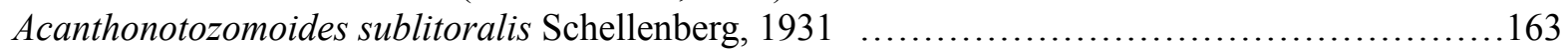

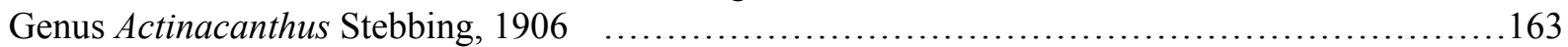

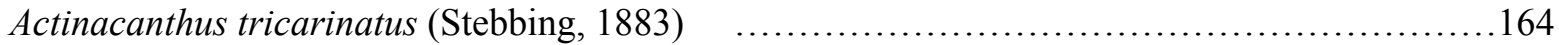

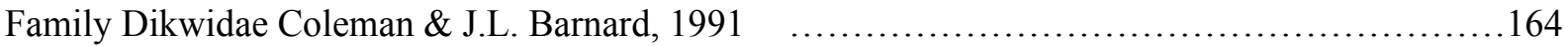

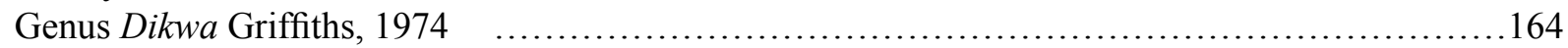

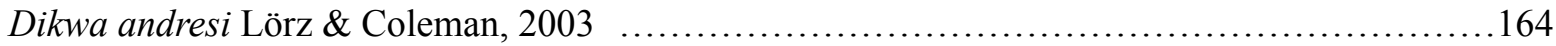

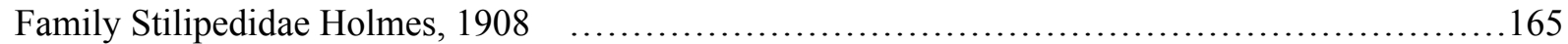

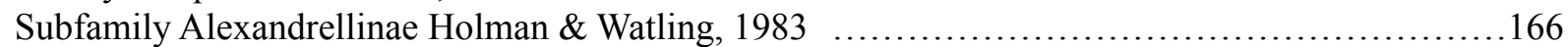

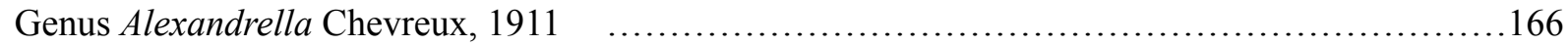

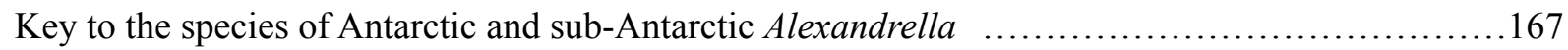

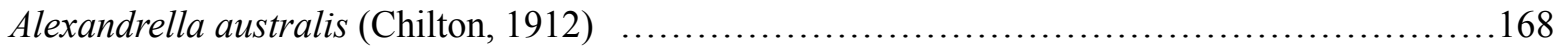

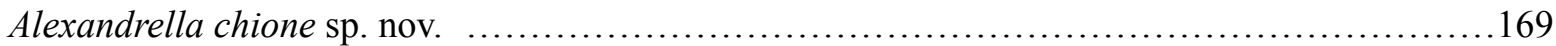

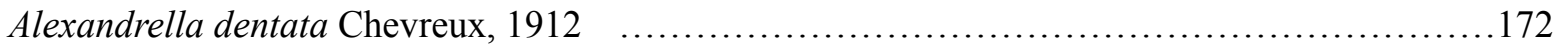

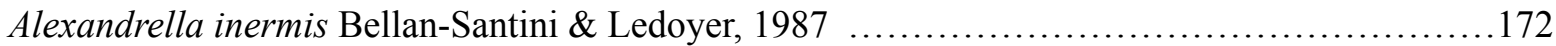

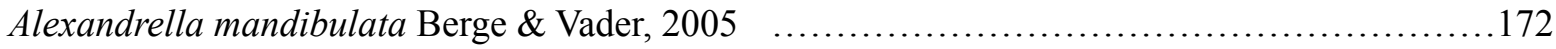

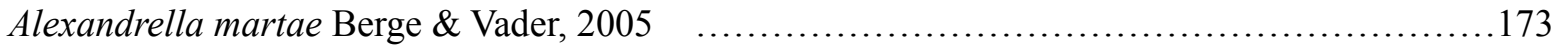

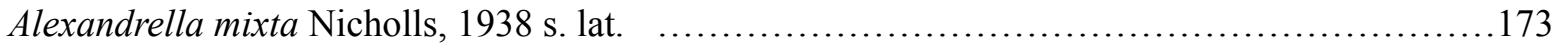

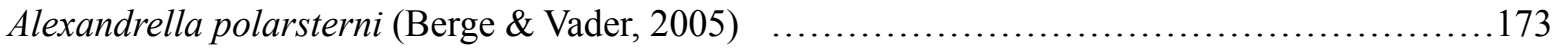

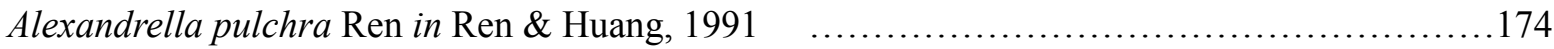

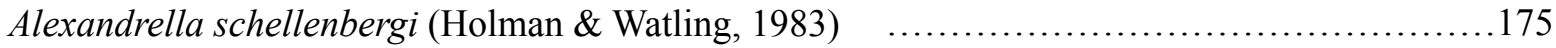


Alexandrella subchelata Holman \& Watling, 1983 s. lat. .................................. 176

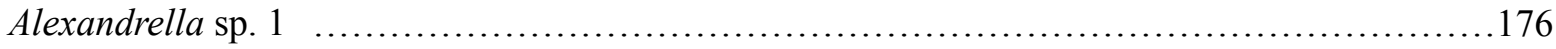

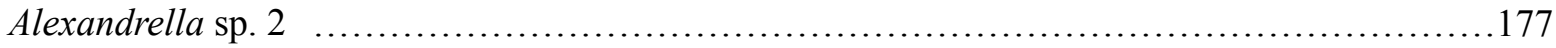

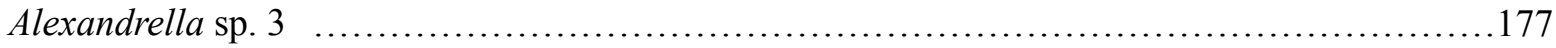

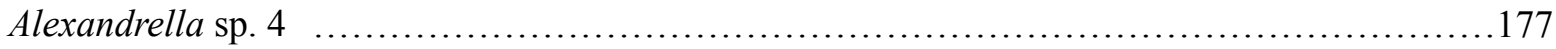

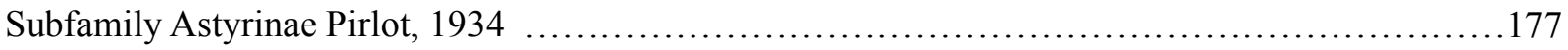

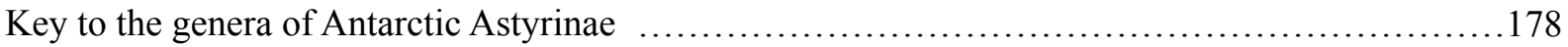

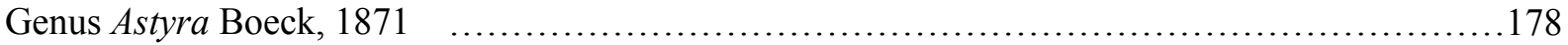

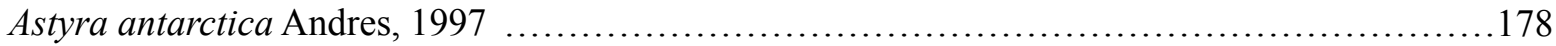

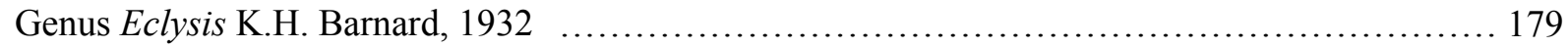

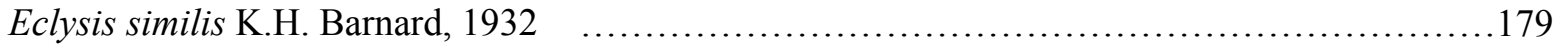

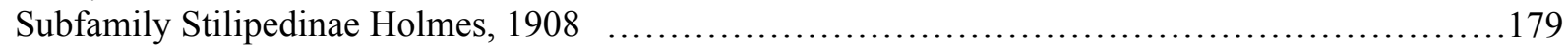

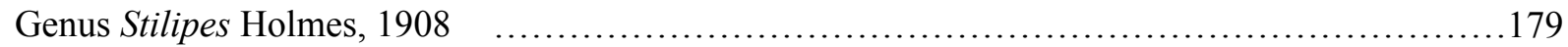

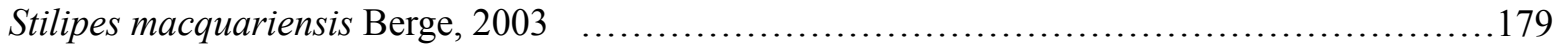

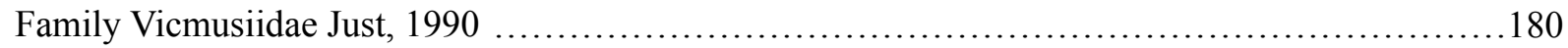

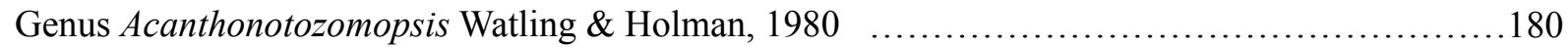

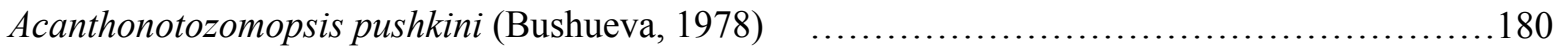

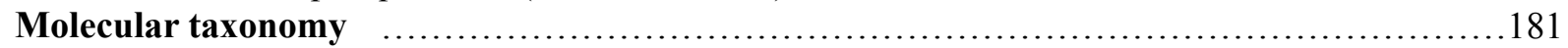

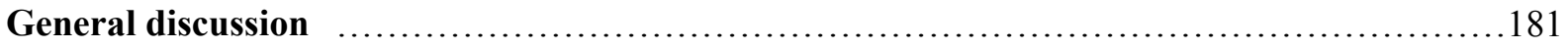

The Epimeria Pandora's box suggests that Antarctic and sub-Antarctic amphipods are

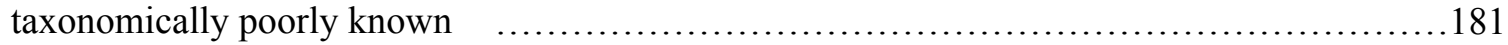

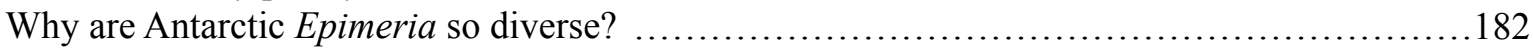

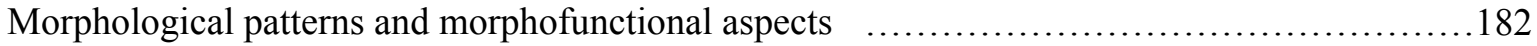

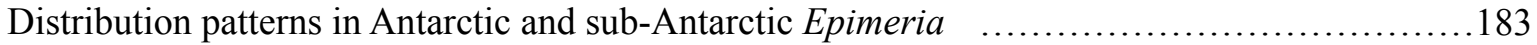

Potential persistence of Antarctic Epimeria in shelf and upper slope refugia during

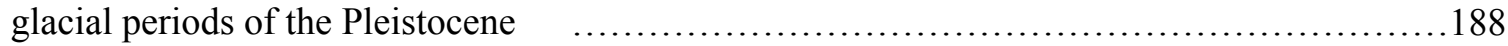

Vulnerability to anthropogenic changes, bioregionalisation and Marine Protected Areas ........190

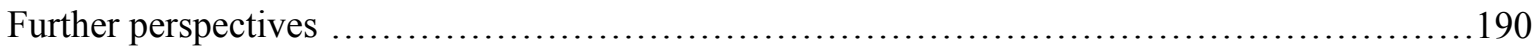

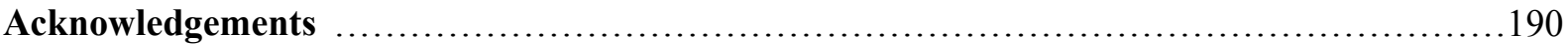

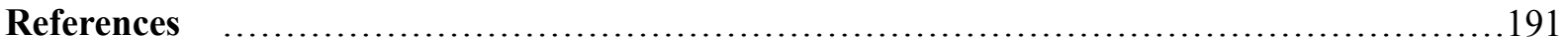

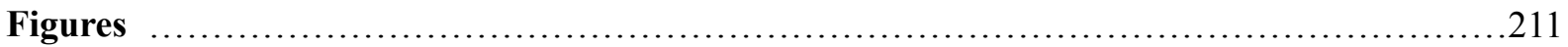

Abstract. The present monograph includes general systematic considerations on the family Epimeriidae, a revision of the genus Epimeria Costa in Hope, 1851 in the Southern Ocean, and a shorter account on putatively related eusiroid taxa occurring in Antarctic and sub-Antarctic seas. The former epimeriid genera Actinacanthus Stebbing, 1888 and Paramphithoe Bruzelius, 1859 are transferred to other families, respectively to the Acanthonotozomellidae Coleman \& J.L. Barnard, 1991 and the herein re-established Paramphithoidae G.O. Sars, 1883, so that only Epimeria and Uschakoviella Gurjanova, 1955 are retained within the Epimeriidae Boeck, 1871. The genera Apherusa Walker, 1891 and Halirages Boeck, 1891, which are phylogenetically close to Paramphithoe, are also transferred to the Paramphithoidae. The validity of the suborder Senticaudata Lowry \& Myers, 2013, which conflicts with traditional and recent concepts of Eusiroidea Stebbing, 1888, is questioned. Eight subgenera are recognized for Antarctic and sub-Antarctic species of the genus Epimeria: Drakepimeria subgen. nov., Epimeriella K.H. Barnard, 1930, Hoplepimeria subgen. nov., Laevepimeria subgen. nov., Metepimeria Schellenberg, 1931, Pseudepimeria Chevreux, 1912, Subepimeria Bellan-Santini, 1972 and Urepimeria subgen. nov. The type subgenus Epimeria, as currently defined, does not occur in the Southern Ocean. Drakepimeria species are superficially similar to the type species of the genus Epimeria: E. cornigera (Fabricius, 1779), but they are phylogenetically unrelated and substantial morphological differences are obvious at a finer level. Twenty-seven new Antarctic Epimeria species are described herein: Epimeria (Drakepimeria) acanthochelon subgen. et sp. nov., E. (D.) anguloce subgen. et sp. nov., E. (D.) colemani subgen. et 
sp. nov., E. (D.) corbariae subgen. et sp. nov., E. (D.) cyrano subgen. et sp. nov., E. (D.) havermansiana subgen. et sp. nov., E. (D.) leukhoplites subgen. et sp. nov., E. (D.) loerzae subgen. et sp. nov., E. (D.) pandora subgen. et sp. nov., E. (D.) pyrodrakon subgen. et sp. nov., E. (D.) robertiana subgen. et sp. nov., Epimeria (Epimeriella) atalanta sp. nov., Epimeria (Hoplepimeria) cyphorachis subgen. et sp. nov., E. (H.) gargantua subgen. et sp. nov., E. (H.) linseae subgen. et sp. nov., E. (H.) quasimodo subgen. et sp. nov., E. (H.) xesta subgen. et sp. nov., Epimeria (Laevepimeria) anodon subgen. et sp. nov., E. (L.) cinderella subgen. et sp. nov., Epimeria (Pseudepimeria) amoenitas sp. nov., E. (P.) callista sp. nov., E. (P.) debroyeri sp. nov., E. (P.) kharieis sp. nov., Epimeria (Subepimeria) adeliae sp. nov., E. (S.) iota sp. nov., E. (S.) teres sp. nov. and $E$. (S.) urvillei sp. nov. The type specimens of $E$. (D.) macrodonta Walker, 1906, E. (D.) similis Chevreux, 1912, E. (H.) georgiana Schellenberg, 1931 and E. (H.) inermis Walker, 1903 are re-described and illustrated. Besides the monographic treatment of Epimeriidae from the Southern Ocean, a brief overview and identification keys are given for their putative and potential relatives from the same ocean, i.e., the Antarctic and sub-Antarctic members of the following eusiroid families: Acanthonotozomellidae Coleman \& J.L. Barnard, 1991, Dikwidae Coleman \& J.L. Barnard, 1991, Stilipedidae Holmes, 1908 and Vicmusiidae Just, 1990. This overview revealed the existence of a new large and characteristic species of Alexandrella Chevreux, 1911, A. chione sp. nov. but also shows that the taxonomy of that genus remains poorly known and that several 'variable widespread eurybathic species' probably are species complexes. Furthermore, the genera Bathypanoploea Schellenberg, 1939 and Astyroides Birstein \& Vinogradova, 1960 are considered to be junior synonyms of Alexandrella. Alexandrella mixta Nicholls, 1938 and A. pulchra Ren in Ren \& Huang, 1991 are re-established herein, as valid species. It is pointed out that this insufficient taxonomic knowledge of Antarctic amphipods impedes ecological and biogeographical studies requiring precise identifications. Stacking photography was used for the first time to provide iconographic support in amphipod taxonomy, and proves to be a rapid and efficient illustration method for large tridimensionally geometric species. A combined morphological and molecular approach was used whenever possible for distinguishing Epimeria species, which were often very similar (albeit never truly cryptic) and sometimes exhibited allometric and individual variations. However in several cases, taxa were characterized by morphology only, whenever the specimens available for study were inappropriately fixed or when no sequences could be obtained. A large number of Epimeria species, formerly considered as eurybathic and widely distributed, proved to be complexes of species, with a narrower (overlapping or not) distribution. The distributional range of Antarctic Epimeria is very variable from species to species. Current knowledge indicates that some species from the Scotia Arc and the tip of the Antarctic Peninsula are narrow range endemics, sometimes confined to one island, archipelago, or ridge (South Georgia, South Orkney Islands, Elephant Island or Bruce Ridge); other species have a distribution encompassing a broader region, such as the eastern shelf of the Weddell Sea, or extending from the eastern shelf of the Weddell Sea to Adélie Coast. The most widely distributed species are $E$. (D.) colemani subgen. et sp. nov., E. (E.) macronyx (Walker, 1906), E. (H.) inermis Walker, 1903 and E. (L.) walkeri (K.H. Barnard, 1930), which have been recorded from the Antarctic Peninsula/South Shetland Islands area to the western Ross Sea. Since restricted distributions are common among Antarctic and sub-Antarctic Epimeria, additional new species might be expected in areas such as the Kerguelen Plateau, eastern Ross Sea, Amundsen Sea and the Bellingshausen Sea or isolated seamounts and ridges, where there are currently no Epimeria recorded. The limited distribution of many Epimeria species of the Southern Ocean is presumably related to the poor dispersal capacity in most species of the genus. Indeed with the exception of the pelagic and semipelagic species of the subgenus Epimeriella, they are heavy strictly benthic organisms without larval stages, and they have no exceptional level of eurybathy for Antarctic amphipods. Therefore, stretches deeper than $1000 \mathrm{~m}$ seem to be efficient geographical barriers for many Epimeria species, but other isolating factors (e.g., large stretches poor in epifauna) might also be at play. The existence of endemic shelf species with limited dispersal capacities in the Southern Ocean (like many Epimeria) suggests the existence of multiple ice-free shelf or upper slope refugia during the Pleistocene glaciations within the distributional and bathymetric range of these species. Genera with narrow range endemics like Epimeria 
would be excellent model taxa for locating hotspots of Antarctic endemism, and thus potentially play a role in proposing meaningful Marine Protected Areas (MPAs) in the Southern Ocean.

Keywords. Alexandrella, Amphipoda, Epimeria, Eusiroidea, Senticaudata, Southern Ocean.

d'Udekem d'AcozC. \& Verheye M.L. 2017. Epimeria of the Southern Ocean with notes on their relatives (Crustacea, Amphipoda, Eusiroidea). European Journal of Taxonomy 359: 1-553. https://doi.org/10.5852/ejt.2017.359

\section{Introduction}

The genus Epimeria is considered as one of the most iconic taxa of the Southern Ocean, where its species richness and morphological diversity is highest than in any other marine region. In the glacial water masses circulating south of the Polar Front, Epimeria species are unusually abundant and diverse, being represented by medium-sized to very large forms (up to $80 \mathrm{~mm}$ ), which may exhibit vibrant colourations and crested adornments reminiscent of mythological dragons. More specifically, they display an extremely wide range of morphologies (from gracile pelagic species to heavily calcified benthic forms, either globular and smooth or highly processiform). The largest previously known species, Epimeria rubrieques De Broyer \& Klages, 1991 even became an emblematic species, as it was used as the logo for the EASIZ I Antarctic cruise (Arntz \& Gutt 1997), and was illustrated on the cover art of the journal 'Marine Biodiversity' and that of the Biogeographic Atlas of the Southern Ocean edited by De Broyer et al. (2014), along with Antarctic krill and an emperor penguin. With such attributes of nobility, it is no surprise that the systematics of Antarctic Epimeria has been studied extensively. This is exemplified by the publication of the synopsis of Coleman (2007), which compiled short descriptions of the 25 species of Antarctic Epimeriidae known at that time: one species of Actinacanthus, 18 species of Epimeria, 4 species of Epimeriella, one species of Metepimeria, and one species of Uschakoviella. When Coleman's (2007) revision was published, the spontaneous feeling amongst amphipodologists was that the taxonomy of Antarctic Epimeria species was a largely settled issue. Yet, four species were described almost immediately afterwards (Lörz 2009; Lörz et al. 2007, 2009, 2011), whilst d'Udekem d'Acoz \& Robert (2008) gave a photograph of an additional undescribed Epimeria species, and Lörz et al. (2011) demonstrated that Epimeria georgiana Schellenberg, 1931 was a complex of several, very similar species, of which they described one as new. So the feeling that Antarctic Epimeria were adequately known proved to be an ephemeral illusion. Moreover, the data of Lörz et al. (2009) (based on 19 species) suggested that all Antarctic Epimeria species would belong to one single speciose clade, which was later on interpreted as a species flock (Lecointre et al. 2013). These data highlight that Epimeria could be a taxon of special interest for studying speciation and evolutionary patterns in Antarctic seas and the world oceans. This attracted the interest of the present authors, who decided to carry out an in-depth phylogenetic and taxonomic study of the genus Epimeria, at a global level. Extensive collections from West Antarctica (South Orkney and South Shetland Islands, tip and east of the Antarctic Peninsula, eastern shelf of the Weddell Sea) belonging to the Royal Belgian Institute of Natural Sciences and from the Adélie Coast belonging to the Muséum national d'Histoire naturelle, Paris, were studied, resulting in the description of 27 new Antarctic Epimeria species and one new Alexandrella species (a genus related to Epimeria according to molecular phylogenies). Moreover, a checklist of and a key to Antarctic Acanthonotozomellidae, Dikwidae, Stilipedidae and Vicmusiidae are provided, since these families were also included in our molecular studies and since our phylogenetic analyses indicate that they might form a clade with the Epimeriidae.

\section{Material and methods}

A combination of DNA-based methods and morphological observations was used to delimit species within Antarctic Epimeria. Specimens were preliminarily identified to species or species complexes 
using the handbook of Coleman (2007). Specimens presenting obvious character differences with existing species descriptions were tentatively interpreted as new species. Then, fragments of the COI and $28 \mathrm{~S}$ genes were sequenced and a phylogeny of Antarctic epimeriids was constructed. The recently introduced DNA-based methods GMYC, bPTB and BPP were used to investigate species boundaries (see Verheye et al. 2016a for details). In parallel, specimens of the different clades were re-examined and we searched for previously overlooked morphological differences. A clade was identified as a putative species if most DNA-based methods and morphology were congruent regarding its delimitation. In the following cases, however, taxonomic decisions were based on morphology only: (1) if the specimens were not fixed adequately for molecular studies (e.g., old type specimens); (2) if DNA sequences could not be obtained; (3) if the DNA sequences could not be compared with those obtained in previous studies of morphologically similar taxa because the gene sequenced fragment sequenced was different. Illustrations of more than one specimen were carried out for variable species (e.g., Epimeria corbariae sp. nov.) or for species with a wide distribution (Epimeria inermis). All these photographs are published herein, as they illustrate the individual and geographical variability of those species.

In most cases, simple records and ecological studies are not included in the species synonymies, which are focused on taxonomic studies. When relevant, they are indicated in the sections after the description. Most secondary references can be found in De Broyer et al. (2007).

Antarctic Epimeria exhibit diverse morphologies and subgenera are recognized herein. With the exception of Metepimeria, for which no DNA sequence is available, these subgenera correspond to wellsupported clades on the combined phylogeny (Fig. 342), which can be morphologically characterized by a unique combination of characters, including in some cases putative synapomorphies. For Urepimeria, the clade criterion applies only to its type species (Epimeria annabellae), as no sequences are available for its other species. In their descriptions, the most important diagnostic characters of the subgenera are indicated in bold.

Descriptions and figures were carried out following a pragmatic approach: to provide reliable identification tools, without illustrating details that are irrelevant for identification purposes, i.e., a method inspired to some extent by the so-called 'turbo-taxonomic' approach (e.g., Butcher et al. 2012; Riedel et al. 2013). The mouthparts, which exhibit little variation between similar species, were usually not illustrated. Orientation of coxae and pereiopods is important for illustrations, as the three-dimensional nature of articles is subject to parallax error and this has been problematic for interpretation of earlier works. Illustrations of the coxae in situ were considered preferable. Furthermore when the legs are dissected with the three-dimensional coxae (which is also very destructive), it becomes very difficult to flatten the legs. So, in most cases pereiopods were dissected without the coxae. On the other hand, it appeared that it was essential to illustrate complete specimens in different orientations, as the shape of the rostrum (both lateral and facial) and the level of lateral projection of the coxae prove to be taxonomically very important. For a few species not available for the present study and closely related to species examined herein, we give a description based on literature accounts, in order to facilitate comparison with their relatives.

In a few cases, the sampling depth was unavailable. In such case the Google Earth depth (https:/earth. google.com) of the station is given. This is a gross approximation and needs to be considered with extreme caution. The date of the Google Earth examination is given in each case, as the depths given by that information program change over time.

For taxonomic illustrations, the specimens were photographed, using the stacking system developed for dried biological specimens by Brecko et al. (2014), but placing the Epimeria specimens in a large cylindrical glass filled with alcohol, to prevent their desiccation. Whole specimens were ventrally mounted on a pin glued on a metallic wire, which was fixed on a small plate of stainless steel. This mounting system allowed a greater range of orientations to photograph specimens. Dissected parts 
were photographed in Petri dishes filled with alcohol. Parts were covered with a microscope slide for flattening and immobilizing them, as the camera system generates vibrations when it moves on its rail. In this set-up, we used a Canon EOS 600D camera with a resolution of $18 \mathrm{MP}$ in 'large' picture mode.

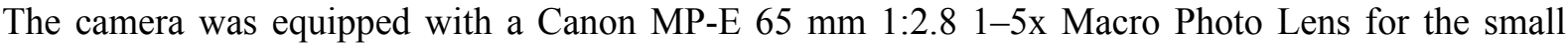
pieces or a Canon Macro Lens EF $100 \mathrm{~mm}$ 1:2.8 USM for complete animals and large structures, and two flashes. Ultra Violet (UV) lamps were tested instead of flashes but did not yield a significant improvement (for the genus Epimeria) compared to visible light (Brecko et al. 2016: 19). Photographs were taken at intervals of 250 to $400 \mu \mathrm{m}$ for the habitus of large specimens, 100 to $250 \mu \mathrm{m}$ for character details of specimens and for small specimens habitus images, and lastly 50 to $100 \mu \mathrm{m}$ for dissected appendages. Focus stacking was carried out with the Zerene Stacker software (zerenesystems.com/cms/ home). Contrasts of the photographs were enhanced with Adobe Photoshop CS3, first with the function 'curves' for increasing the darkness of the background and then with the function 'shadow/highlight' in order to maximize the contrasts. In a few cases, when the border of structures was not contrasted enough for publication, they were inked with the tool 'pen' or 'plume', either in Adobe Photoshop CS3 or in Adobe Illustrator CS, resulting in illustrations hybrid between photographs and classical line drawings.

The live colour pattern was recorded on each cruise whenever possible with various makes of cameras. These field pictures were not always of good quality but we publish them regardless, the colour pattern often being taxonomically relevant.

In the descriptions, the term "tooth" is used for non-articulated, pointed ectodermic structures, the term 'spine' for stout, inflexible, articulated structures, and the term 'seta' for slender, flexible, articulated structures (d'Udekem d'Acoz 2010).

All data mentioned in this paper have been verified in original scientific literature.

The coordinates of the RV Polarstern stations have been extracted from the published RV Polarstern cruise reports, which are available at https://www.pangaea.de/expeditions/cr.php/Polarstern [accessed on 21 Oct. 2016]:

PS06, ANT-III/3: Hempel (1985)

PS10, ANT-V/3: Schnack-Schiel (1987)

PS12, ANT-VI/2, Fütterer (1988)

PS14, ANT-VII/4, EPOS leg 3: Arntz et al. (1990)

PS39, ANT-XIII/3, EASIZ I: Arntz \& Gutt (1997)

PS42, ANT-XIV/2: Kattner (1998)

PS48, ANT-XV/3, EASIZ II: Arntz \& Gutt (1999)

PS56, ANT-XVII/3, EASIZ III: Arntz \& Brey (2001)

PS61 ANT-XIX/5, LAMPOS: Arntz \& Brey (2003)

PS65, ANT-XXI/2, BENDEX: Arntz \& Brey (2005)

PS69, ANT-XXIII/8: Gutt (2008)

PS71, ANT-XXIV/2, ANDEEP-SYSTCO: Bathmann (2010)

PS77, ANT-XXVII/3, CAMBIO: Knust et al. (2012)

PS81, ANT-XXIX/3, LASSO: Gutt (2013)

The coordinates of recent French Antarctic expeditions were communicated by Laure Corbari (Muséum national d'Histoire naturelle) and Cyril Gallut (Université Pierre et Marie Curie). The coordinates of the SIGNY expedition were extrapolated from a map communicated by Stefan Hain. The coordinates of the Belgian and Belgian-Dutch Antarctic expeditions (expéditions antarctiques belges et belgonéerlandaises) were extracted from an unpublished list compiled by Claude De Broyer (Royal Belgian Institute of Natural Sciences). The coordinates of the RV James Clark Ross cruises have been extracted 
from an unpublished list communicated by David Barnes (British Antarctic Survey). The coordinates of ancient specimens have been extracted from literature or copied from the labels in the vials.

Acronyms of repositories:

$\mathrm{BMNH}=$ British Museum (Natural History) $[=$ former name of the Natural History Museum, London, which was retained on some labels]

MNHN = Muséum National d'Histoire Naturelle, Paris

NHM $=$ Natural History Museum, London

RBINS = Royal Belgian Institute of Natural Sciences, Brussels

SMNH $=$ Swedish Museum of Natural History, Stockholm

\title{
Results
}

\author{
Phylum Arthropoda von Siebold, 1848 \\ Subphylum Crustacea Brünnich, 1772 \\ Class Malacostraca Latreille, 1802 \\ Order Amphipoda Latreille, 1816
}

Superfamily Eusiroidea Stebbing, 1888

Eusiridae Stebbing, 1888: 949, 953; elevated to the rank of superfamily by Bousfield (1979).

Calliopiidae G.O. Sars, 1893: 431; elevated to the rank of superfamily by Lowry \& Myers (2013).

Eusiridae - Stebbing 1906: 338. - J.L. Barnard 1969: 5, 27, 33, 34, 46, 47, 82, 83, 84, 87, 88, 89, 90, $106,109,114,159,164,167,171,172,213,233,291,389,392,393,421,457,476,478,481$. J.L. Barnard \& Karaman 1991: 19, 20, 21, 55, 58, 68, 69, 80, 82, 84, 91, 114, 117, 131, 132, 284 , $378,379,391,405,413,569,644,702$.

Eusiroidea - Bousfield 1979: 349, 363; 1982: 263. — Bousfield \& Hendrycks 1995: 4 (ubi syn.). — Verheye et al. 2016b: 314, appendices S1, S2 and S3.

Calliopioidea - Lowry \& Myers 2013: 38 (in part).

\section{Composition}

The study of Verheye et al. (2016b) indicates that the superfamily Eusiroidea Stebbing, 1888 is a larger taxon than previously admitted. In their appendix S2, these authors include the following families in Eusiroidea: Acanthonotozomatidae Stebbing, 1906; Acanthonotozomellidae Coleman \& J.L. Barnard, 1991; Amathillopsidae Pirlot, 1934; Bateidae Stebbing, 1906; Calliopiidae G.O. Sars, 1893 (excluding Cleippides Boeck, 1871 and Weyprechtia Stuxberg, 1880); Dikwidae Coleman \& J.L. Barnard, 1991; Epimeriidae Boeck, 1871; Eusiridae Stebbing, 1888; Iphimediidae Boeck, 1871; Laphystiopsidae Stebbing, 1899; Pleustidae Buchholz, 1874; Pontogeneiidae Stebbing, 1906; Sanchoidae Lowry, 2006; Stilipedidae Holmes, 1908 (including the subfamilies Alexandrellinae Holman \& Watling, 1983, Astyrinae Pirlot, 1934 and Stilipedinae Holmes, 1908); Thurstonellidae Lowry \& Zeidler, 2008; Vicmusiidae Just, 1990; and the orphan genera Austroregia J.L. Barnard, 1989 and Chosroes Stebbing, 1888, which were formerly included within the Gammarellidae Bousfield, 1977.

\section{Remarks}

The concept of Senticaudata Lowry \& Myers, 2013 proposed by Lowry \& Myers (2013) and adopted in major databases like the World Register of Marine Species (WoRMS, http://www.marinespecies.org/ accessed on 8 Mar. 2016) conflicts with that of Eusiroidea sensu Verheye et al. (2016b). A brief discussion on the Senticaudata issue has therefore to be given herein. Lowry \& Myers (2013) erected the suborder Senticaudata for amphipods presenting a cluster of spines on the tip of the rami of uropods 1 and 2 , 
postulating that this character state is a synapomorphy. Surprisingly, Lowry \& Myers (2013) overlooked some 'senticaudate' taxa, e.g., Idunellinae d'Udekem d'Acoz, 2010, Pleustidae, Apherusa Walker, 1891, Halirages Boeck, 1871 and Paramphithoe Bruzelius, 1859). Most senticaudate families traditionally included in the Eusiroidea (the Calliopiidae and Pontogeneiidae) were transferred by Lowry \& Myers (2013) to the superfamily Calliopioidea G.O. Sars, 1895 [sic] (real date of publication: 1893), i.e., the family Calliopiidae elevated to the rank of superfamily. The remaining eusiroid families were excluded from the suborder Senticaudata. Myers \& Lowry (2013) also transferred the Cheirocratidae and Hornelliidae to the Calliopioidea, because the two latter families formed a clade with the Calliopiidae and Pontogeneiidae in their morphological phylogenetic tree based on the analysis of 41 characters. The molecular phylogenetic analyses of Verheye et al. (2016b), which focused on eusiroids, but also included a representative sample of other amphipods, did not support the validity of the suborder Senticaudata. Indeed, senticaudate taxa do not form a clade, suggesting that the distal ornamentation of uropods would be subject to homoplasy, as it is the case for many other characters in amphipods (e.g., J.L. Barnard \& Drummond 1978: 7, 193; J.L. Barnard \& Karaman 1984: 48; J.L. Barnard \& Karaman 1991: 13, 58; Verheye et al. 2016b). In the $28 \mathrm{~S}$ and $18 \mathrm{~S}$ rDNA trees, Eusiroidea comprises senticaudate as well as nonsenticaudate taxa, and the families Calliopiidae (excluding Cleippides) and Pontogeneiidae are included in the superfamily, as it was the case in former classifications (e.g., Bousfield 1979, 1982; J.L. Barnard \& Karaman 1991). The suborder Senticaudata was erected on the assumption that the senticaudate character state is a synapomorphy. However, the morphological phylogeny of the Senticaudata of Lowry \& Myers (2013) does not test this hypothesis as it only includes senticaudate taxa. Moreover, the reliability of the nodes of Lowry \& Myers (2013) is not assessed by any support values, e.g., bootstrap support or Bremer's index. Additionally, it should be noted that the Cheirocratidae and Hornelliidae exhibit several important non-eusiroid character states. For example, they have a well developed accessory flagellum on antenna 1 as well as dorsal spines/setae on the urosome, which is never the case in Eusiroidea. Their position close to the Calliopiidae and Pontogeneiidae on the tree of Lowry \& Myers (2013) might reflect poorly supported topologies and/or a subjective choice of characters used in their analysis. A direct observation of specimens indicates that the senticaudate and non-senticaudate character states are not always clear-cut and transitional dispositions are observed among dissimilar amphipods, suggesting multiple passages between the sentidaudate and non-sentidaudate character states. Finally, the polarity of the transition proposed by Lowry \& Myers (2013): non senticaudate (plesiomorphic) to senticaudate (apomorphic) is another untested question. In conclusion, before its wide acceptance, the new classification system of amphipods based on the suborder Senticaudata should be evaluated by a combination of molecular and morphological investigations, without a priori assuming that the senticaudate character state is a synapomorphy.

Family and sub-family key to Antarctic and sub-Antarctic Epimeriidae and their putative relatives

This key includes the Epimeriidae s. str. and putatively related families and subfamilies of Eusiroidea present in the Southern Ocean.

1. Posterior border of basis of pereiopod 7 not produced into an immense median acute process

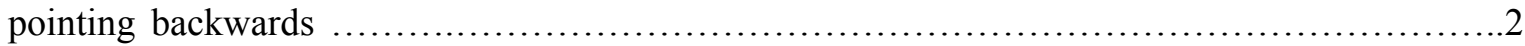

- Posterior border of basis of pereiopod 7 produced into an immense median acute process pointing backwards [all pereionites and pleosomites with mid-dorsal crest and with transverse carinae and grooves; rostrum absent; telson blunt-tipped, not cleft]

Dikwidae Coleman \& J.L. Barnard, 1991

2. Article 1 of peduncle of antenna 1 not produced into a large and broad lobe forming a hood above

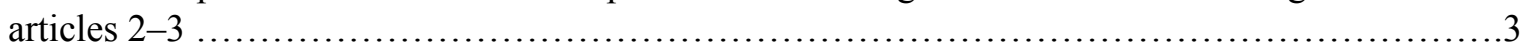

- Article 1 of peduncle of antenna 1 produced into a large and broad lobe forming a hood above articles $2-3$ Vicmusiidae Just, 1990 
3. Surface of pereion segments just above connection with coxa either smooth or with very small tooth, or surface of pereion (and most parts of body and appendages) homogeneously and densely covered by medium-sized styliform teeth (giving a hedgehog facies to the animal) .................... 4

- Surface of pereion segments just above connection with coxa with a large or huge process pointing laterally [telson entire] Acanthonotozomellidae Coleman \& J.L. Barnard, 1991

4. Coxa 1 narrow or fairly narrow; eyes bulging (rounded, elliptic or reniform), remaining distinct in alcohol; mandible with molar process present; maxilla 2 plates not broadened; teguments strongly to weakly calcified; rostrum well-developed to vestigial Epimeriidae Boeck, 1871

- Coxa 1 broad; eyes not bulging, of various shapes, often disappearing in alcohol; mandible with molar process absent; maxilla 2 with plates broadened; teguments weakly calcified; rostrum always vestigial: Stilipedidae Holmes, 1908

5. Outer plate of maxilliped well-developed but distinctly shorter than palp; pleosomites without posterodorsal tooth

- Outer plate of maxilliped immensely developed, overreaching palp; pleosomites with or without posterodorsal tooth Alexandrellinae Holman \& Watling, 1983

6. Coxae 1-3 longer than coxa 4 Stilipedinae Holmes, 1908

- Coxae 1-3 not longer than coxa 4 Astyrinae Pirlot, 1934

Family Epimeriidae Boeck, 1871

Epimerinae Boeck, 1871: 103.

Atylinae - Buchholz 1874: 366 (in part).

Epimerinae - Boeck 1876: 227. — Stebbing 1883: 204 (in part).

Epimeridae- G.O. Sars 1883: 26; 1886: 166; 1893: 362-363. — Stebbing 1888: 876-877. — Chevreux 1900: 62. - Reibisch 1906: 188.

Epimeriidae - Coleman \& J.L. Barnard 1991a: 255-257. — Coleman 1998b: 216; 2007: 28. — Lörz \& Brandt 2004: 179. — Lörz \& Held 2004: 4-15.

Paramphithoidae - Stebbing 1906: 320 (in part); 1908: 191 (in part). — Stephensen 1928: 252 (in part); 1929: 130 (in part). - Chevreux \& Fage 1925: 190 (in part). — Gurjanova 1951: 665 (in part); 1955: 187-188 (in part); 1972: 175-178 (in part). — Hurley 1957: 3, 5 (in part). — J.L. Barnard 1961: 102 (in part); 1969: 389 (in part). — Bousfield 1979: 363, 378 (in part, discussion); 1982: 265 (in part). — Lincoln 1979: 434 (in part). — Holman \& Watling 1983: 31 (in part, discussion). Andres \& Lott 1986: 134 (discussion). — Ledoyer 1986: 854 (in part); 1993: 616 (in part). Bousfield \& Shih 1994: 130 (in part, discussion). — Bousfield \& Hendrycks 1995: 5 (in part, key). 'Acanthonotozomatidae and Paramphithoidae' - Karaman \& J.L. Barnard 1979: 107 (in part).

Iphimediidae - J.L. Barnard \& Karaman, 1991: 378 (in part).

non Atylina [sic] Lilljeborg, 1865: plate p. 18.

non Iphimedinae Boeck, 1871: 98.

non Paramphithoidae G.O. Sars, 1883: 25; type genus Paramphithoe Bruzelius, 1859: 68; type species: Acanthosoma hystrix Ross, 1835 designated by J.L. Barnard \& Karaman 1991: 398.

non Acanthonotozomatidae Stebbing, 1906: 210.

non Paramphithoidae - Della Valle, 1893: 557 (discussion). — G.O. Sars 1893: 343 (full description). Chevreux 1900: 62. 


\section{Composition}

Two genera are accepted herein within the Epimeriidae: Epimeria Costa in Hope, 1851 and Uschakoviella Gurjanova, 1955. Actinacanthus Stebbing, 1888 and Paramphithoe Bruzelius, 1859 are removed from the Epimeriidae, and respectively transferred to the Acanthonotozomellidae Coleman \& J.L. Barnard, 1991 and the Paramphithoidae G.O. Sars, 1883.

Nine subgenera are recognized within Epimeria: Drakepimeria subgen. nov., Epimeria Costa in Hope, 1851; Epimeriella Walker, 1906; Hoplepimeria subgen. nov.; Laevepimeria subgen. nov.; Metepimeria Schellenberg, 1931; Pseudepimeria Chevreux, 1912; Subepimeria Bellan-santini, 1972 and Urepimeria subgen. nov.

\section{Systematic remarks and decisions}

The composition of the family Epimeriidae is in a state of flux. Coleman (2007) listed the following genera within the Epimeriidae: Actinacanthus Stebbing, 1888; Epimeria Costa in Hope, 1851; Epimeriella Walker, 1906; Metepimeria Schellenberg, 1931; Paramphithoe Bruzelius, 1859 and Uschakoviella Gurjanova, 1955. On the other hand, Lörz \& Brandt (2004) treated Epimeriella as a junior synonym of Epimeria and questioned the validity of Metepimeria. Metepimeria was initially erected as a monotypic genus for the Magellanic species Epimeria acanthurus, based on a single character state: the absence of dactylus on the palp of the maxilliped. This character state is likely autapomorphic and Metepimeria is relegated herein to the status of subgenus of Epimeria, with a new definition. A recent molecular phylogenetic analysis (Verheye et al. 2016b) demonstrated that Paramphithoe is unrelated to Epimeria but belongs to the Apherusa/Halirages clade. The senticaudate-type uropods 1-2 and the dissimilar palp of the left and right maxilla 1 (see G.O. Sars 1890-1895: pl. 130 for Paramphithoe and d'Udekem d'Acoz 2012 for Halirages) are characteristic of this clade, the second character being interpreted as a putative synapomorphy. The profound differences between Paramphithoe and Epimeria were previously pointed out by Gurjanova (1955: 188) and the affinity of Paramphithoe with the Calliopiidae s. lat. was already perceived by Bousfield (1979: 363). Paramphithoe sensu Stebbing, 1906 is therefore herein formally removed from the Epimeriidae and transferred to the Paramphithoidae G.O. Sars, 1883, which are re-established.

The study of Verheye et al. (2016b) showed that Alexandrella Chevreux, 1911, Bathypanoploea Schellenberg, 1939 (Alexandrellinae), Astyra Boeck, 1871 (Astyrinae), Dikwa Griffiths, 1974 (Dikwidae), Acanthonotozomella Schellenberg, 1926, Acanthonotozomoides Schellenberg, 1931 (Acanthonotozomellidae) and Acanthonotozomopsis Watling \& Holman, 1980 (Vicmusiidae) are part of a more inclusive clade including Epimeria. All these families are accepted herein but an alternative could indeed be to merge all taxa related to Epimeria into one large family, which we do not advocate, at least for the time being. The genus Actinacanthus, which was traditionally included within the Epimeriidae (e.g., Coleman 2007; De Broyer et al. 2007), exhibits striking morphological similarities with the Acanthonotozomellidae, such as the presence of a pair of huge sword-like teeth on pereionites just above the insertion of coxae, and a non-incised telson. While convergent evolution cannot be ruled out, it seems more likely that these characters are synapomorphies. Actinacanthus is therefore transferred herein to the Acanthonotozomellidae. The genus Uschakoviella, also traditionally assigned to the Epimeriidae, is provisionally retained within this family, in the absence of evidence against its current taxonomic position.

\section{Nomenclatural remarks}

The nomenclatural status of the family Paramphithoidae G.O. Sars, 1883 (previously considered as a junior synonym of the Epimeriidae Boeck, 1871) and of the genus Paramphithoe Bruzelius, 1859 (previously considered as an Epimeriidae) requires discussion. The genus Paramphithoe was created 
by Bruzelius (1859) for nine unrelated or distantly related species. Stebbing (1895) noted that "the nine species attributed to that genus by its author have since been distributed among half-a-dozen genera, amid which the original genus, from its vagueness, is an abiding source of confusion. It is a wandering star, of which the orbit is difficult to calculate." The family name Paramphithoidae was introduced, albeit without description by G.O. Sars (1883). According to ICZN (1999 arts. 12.1. and 12.2.4), Paramphithoidae G.O. Sars, 1883 is a valid name because it derives from an available generic name: Paramphithoe Bruzelius, 1859, an explicit description being not required for family names introduced before 1931. G.O. Sars (1883) did not explicitly define the composition of the Paramphithoidae and he designated no type species for Paramphithoe. He simply listed four species in it: Pleustes panoplus (Kröyer, 1838) (a species included in Paramphithoe by Bruzelius (1859) when he created that genus), Pleustes parvus (Boeck, 1871) (a probable junior synonym of Pleustes panoplus according to Stebbing (1906)), Paramphithoe brevicornis G.O. Sars, 1883 and Paramphithoe assimilis G.O. Sars, 1883. All these species are currently considered as members of the family Pleustidae Buchholz, 1874. G.O. Sars (1883) did not include Paramphithoe hystrix (Ross, 1835) (under the name Acanthozone cuspidata (Lepechin, 1780)) in the Paramphithoidae G.O. Sars, 1883 but put it in the Epimeriidae Boeck, 1871.

Ten years later, G.O. Sars (1893) provided a detailed description of the Paramphithoidae, in explicitly restricting it to four genera: Pleustes Spence Bate, 1858, Paramphithoe Bruzelius, 1859, Stenopleustes G.O. Sars, 1893 and Parapleustes Buchholz, 1874, and dealing only with species currently treated as Pleustidae - two of them being part of the original Paramphithoe species of Bruzelius (1859): Paramphithoe pulchella (Kröyer, 1846) and Pleustes panoplus (Kröyer, 1838). Consistently with his previous study, G.O. Sars (1893) included Paramphithoe hystrix (again under the name Acanthozone cuspidata) in the Epimeriidae, this time in explicitely listing Acanthosoma hystrix Ross, 1835 (as Acanthosoma hystrix Owen) in its synonymy. Again, he designated no type species for Paramphithoe.

Stebbing (1906) provided a new definition of the Paramphithoidae conflicting with the previous ones, without citing G.O. Sars (1883, 1893). The Paramphithoidae consisted of Actinacanthus, Epimeria and Paramphithoe. Stebbing (1906) designated no type species for Paramphithoe. He simply stated: " 3 accepted species, 1 doubtful". The three accepted species were P. buchholzi Stebbing, 1906, P. hystrix and P. polyacantha (J. Murdoch, 1885) and the "doubtful" species P. cuspidata. In other words, only one of the original Paramphithoe species of Bruzelius (1859), namely P. hystrix, was accepted by him in that genus - while the species was clearly excluded from the Paramphithoidae by G.O. Sars (1883, 1893). Stebbing's (1906) re-definition of Paramphithoe and of the Paramphithoidae was accepted in all subsequent literature, where the family Paramphithoidae was either cited without author's name (e.g. Barnard 1969) or, more rarely, attributed to Stebbing (1906) (e.g. Bousfield 1979, Coleman \& Barnard 1991a). In other words, Stebbing's (1906) proposal (not a nomenclatural act) was unanimously accepted by the community of amphipodologists as if it was the formal designation of the type species of the genus Paramphithoe; the statements of G.O. Sars $(1883,1893)$ were ignored. Finally Barnard \& Karaman (1991) designated Acanthosoma hystrix Ross, 1835 as the type species of the genus Paramphithoe hence also of the family Paramphithoidae.

Just like Stebbing (1906), Coleman \& J.L. Barnard (1991a) believed that Paramphithoe sensu J.L. Barnard \& Karaman (1991) was a close relative to the genus Epimeria and had to be included in the same family. They re-established the name Epimeriidae Boeck, 1871 for Epimeria, Paramphithoe (and other genera) because it is older than "Paramphithoidae Stebbing, 1906". It now appears that Paramphithoe is unrelated to Epimeria (Verheye et al. 2016b) and is nested within the Apherusa/ Halirages clade. The family Paramphithoidae has to be re-established for this internally poorly resolved clade including (at least) Apherusa Walker, 1891, Halirages Boeck, 1871 and Paramphithoe revealed by Verheye et al. (2016b). Additional calliopiid genera (especially from the northern hemisphere) will possibly also have to be transferred to the Paramphithoidae, when more details on their phylogenetic 
position will be known. Currently, unless ICZN 1999, Article 35.5 on the precedence for names in use at higher rank is invoked, the Calliopiidae can at best be preserved for the genus Calliopius alone, which might be the sister clade of the Paramphithoidae (Verheye et al. 2016b), and presents no close affinity with other sequenced genera traditionally included in the Calliopiidae. However in databases, we feel that the 'Calliopiidae s. lat.' should be preserved for all or most genera traditionally included within the Calliopiidae (excluding Apherusa, Halirages and Paramphithoe) as an 'adoptive' artificial family, as long as their phylogenetic and systematic position remains in a too imperfect state of knowledge.

\section{Key to the genera of Epimeriidae}

1. Body with or without large dentiform processes, but not homogeneously and densely covered by medium-sized styliform teeth Epimeria Costa in Hope, 1851

- Body homogeneously and densely covered by medium-sized styliform teeth [recorded once, doubtfully, in the Southern Ocean, below $3000 \mathrm{~m}$ ] Uschakoviella Gurjanova, 1955

Genus Epimeria Costa in Hope, 1851

Gammarellus Herbst, 1793: 106-115 (in part); type species: Gammarus homari Fabricius, 1779 [currently Gammarellus homari (Fabricius, 1779)].

Vertumnus White, 1847: 89; type species: Vertumnus cranchii Leach's manuscript name; nomen nudum. Vertumnus White, 1850a: 97 [+ pl. 16 figs 3-5 illustrating Leach's specimens, as Acanthonotus testudo] (real identity of the specimens: Epimeria cornigera (Fabricius, 1779), not Pereionotus testudo (Montagu, 1808)); Vertumnus White, $1850=$ preoccupied and invalid objective synonym of Epimeria Costa in Hope, 1851 (see remarks below).

Epimeria Costa in Hope, 1851: 24, 46; type species: Epimeria tricristata Costa in Hope, 1851: 46 (= Gammarus corniger Fabricius, 1779: 383).

Epimeriella Walker, 1906: 17; type species: Epimeriella macronyx Walker, 1906.

Pseudepimeria Chevreux, 1912: 216 (9 on reprints); type species: Pseudepimeria grandirostris Chevreux, 1912.

Metepimeria Schellenberg, 1931: 162; type species: Metepimeria acanthurus Schellenberg, 1931. Subepimeria Bellan-Santini, 1972: 225; type species: Subepimeria geodesiae Bellan-Santini, 1972.

Gammarus - Fabricius 1779: 383 (in part). - H. Milne Edwards 1840: $42-55$ (in part).

Vertumnus - White 1850b: 51. — Spence Bate \& Westwood 1862: 231. — Norman 1869: 280.

Acanthonotus - White 1850a: 97, pl. 16 figs 3-5; 1850b: 51 (in part); 1857: 177. — Gosse 1855: 139, 142. - Spence Bate 1857: 141; 1862: 120. — Spence Bate \& Westwood 1862: 231. — Carus 1885: 410.

Epimeria - Costa 1857: 175, 197; 1867: 42-44 (discussion). — Spence Bate 1862: 153-154. — Boeck 1871: 185 (105 on reprints); 1876: 232. — Stebbing 1888: 877-878 (ubi syn.); 1906: 321. — G.O. Sars 1893: 363-364. — Holmes 1904: 467: key. — Kunkel 1918: 48 (key). — Stephensen 1928: 253-254; 1929: 130. — Chevreux \& Fage 1925: 190-191. — Gurjanova 1951: 666; 1955: 189191. - J.L. Barnard 1961: 102; 1969: 394. - McCain 1971: 159. — Karaman \& J.L. Barnard 1979: 108-109. — Lincoln 1979: 434. — Watling \& Holman 1980: 642-643. - Moore 1981: 749. - Andres \& Lott 1986: 133 (discussion). — Ledoyer 1986: 860; 1993: 616. — J.L. Barnard \& Karaman 1991: 380, 393. — Coleman 1998b: 215; 2007: 31. — Wakabara \& Serejo 1999: 630631. — Lörz \& Brandt 2004: 179-190 (phylogeny). — Lörz \& Held 2004: 4-15 (phylogeny).

Amphithoë-M. Sars 1859: 130-143 (in part).

Acanthosoma - Boeck 1861: 665-666 (in part); 1869: 410 (in part).

Acanthonotosoma [sic] - Della Valle 1893: 674, in part (ubi syn.). 
Metepimeria - Gurjanova 1951: 189; 1955: 189, 209. — J.L. Barnard 1969: 396. — Watling \& Holman 1981: 215. - J.L. Barnard \& Karaman 1991: 380, 397. — Lörz \& Brandt 2004: 184, 188. — Coleman 2007: 61.

Epimeriella - Gurjanova 1955: 189. - J.L. Barnard 1969: 161, 395. - Holman \& Watling 1983: 31 (discussion). — Andres \& Lott 1986: 131-136. — J.L. Barnard \& Karaman 1991: 380, 394, 702 . Coleman 1998b: 215; 2007: 56. — Lörz \& Brandt 2004: 179, 184, 188, 189.

Pseudepimeria - Gurjanova 1955: 189, 190. — J.L. Barnard 1969: 396.

non Gammarus Fabricius, 1775: 418; type species: Cancer pulex Linnaeus, 1758.

non Acanthonotus Bloch, 1797: 112-114, pl. 431; type species: Acanthonotus nasus Bloch, 1797; objective synonym of Notacanthus Bloch, 1788: 278 (type species: Notacanthus chemnitzii Bloch, 1788) (Pisces).

non Acanthonotus Cuvier, 1800: table 4; nomen nudum (Pisces).

non Acanthonotus Goldfuss, 1809: 308; objective synonym of Echidna Cuvier, 1797: 143 (Mammalia). non Acanthonotus Gray, 1830: pl. 85, fig. 1; type species: Silurus (Acanthonotus) Cuvieri Gray, 1830 (Pisces).

non Acanthonotus Swainson \& Richardson, 1832: 168; nomen nudum (Aves).

non Acanthonotus Ross, 1835: xc; type species: Acanthonotus cristatus Ross, 1835.

non Ampithöe Leach, 1814: 432; type genus: Cancer rubricatus Montagu, 1808.

non Vertumnus Otto, 1823: 294, pl. 41 fig. 1; type species: Vertumnus thetidicola Otto, 1823 (Trematoda).

non Acanthosoma Curtis, 1824: unnumbered pagina referring to plate 20 (Hemiptera).

non Acanthosoma Ross, 1835: 91; type species: Acanthosoma hystrix Ross, 1835.

non Acanthonotozoma Boeck, 1876: 237; type species: Acanthonotus cristatus Ross, 1835.

non Amphithoë - Latreille 1816: 470 (misspelling for Ampithöe Leach, 1814).

non Vertumnus - Goës 1866: 522. — Boeck 1871: 99. — Miers 1877: 135. — G.O. Sars 1883: 26 (all

three $=$ Acanthonotozoma $)$ [unaccepted subjective use of Vertumnus White, 1850].

\section{Etymology}

"Probably so called from the epimera or side-plates" (Stebbing 1888: 1672).

\section{Description}

Body smooth or covered with teeth or processes. If processes are present on pereionites just above connection with coxae, these processes are small, not sword-like, not forming large longitudinal carinae. Head high; lateral head lobes very reduced; inferior antennal sinus very shallow; ventral lobe of head well developed, oriented obliquely downwards, sharp or rounded. Development of rostrum variable, usually well developed but sometimes small or even tiny. Urosomite 1 always with dorsal process, which can be rounded or tooth like, projecting upwards or backwards. Telson usually distinctly incised or cleft, rarely weakly emarginate or entire, without spines or setae. Eyes usually present, rarely absent (in abyssal species), medium-sized to large, bulging when present, elliptic, pyriform, rounded or reniform, usually with distinct ommatidia. Antenna 1: peduncular articles short or fairly short, with or without teeth; peduncular article 2 shorter than 1 and longer than 3; accessory flagellum present, small, consisting of one article. Mouthparts projecting quadrately. Upper lip almost entire to notched, symmetrical; epistome not very broad. Mandible: incisor ordinary, toothed; lacinia mobilis present on both mandibles (left and right one different), uniplated; setal row present and well-developed; molar process present, large, triturative or not. Lower lip inner lobes absent, outer lobes relatively broad. Maxilla 1 of basic shape, identical on left and right appendage; palp 2-articulate, article 2 with distal marginal row of conical spines and distal marginofacial row of strong setae. Maxilla 2, with plates of basic form; inner plate without facial row of setae. Maxilliped: inner and outer plates large and broad; outer plates reaching about mid of article 2 of palp, with short spines on medial border, with long spines on tip and with long stout setae on distal part of lateral border (the short spines intergrades into long spines 
which themselves intergrade in long stout setae); inner plates nearly reaching tip of article 1 of palp; palp article 4 usually well developed, but sometimes absent, with distal unguis. Coxae long. Coxae 1-4 progressively longer. Coxae 1-3 narrow. Coxa 4 five-sided: border connecting with coxa, anterodorsal border (running along the posterior margin of coxa 3 ) perpendicular to body axis or projecting obliquely forward; anteroventral border projecting posteriorly backwards (anterodorsal and anteroventral border either separated by angular discontinuity or smoothly intergrading into a regular curve, rarely produced into a tooth); posteroventral border straight or concave, separated from anteroventral border by angle or tooth (ventral angle or tooth); posterodorsal border concave, separate from posteroventral border by a tooth (posterior tooth); a carina or a groove often run on the surface separating ventral and posterior teeth/angles; when present this carina sometimes bear a tooth projecting laterally. Coxae 5-6 with or without tooth or process projecting laterally; when coxa 5 laterally dentate, its tooth can be very large. Gnathopods weak, usually similar but never identical; gnathopod 2 always longer than gnathopod 1 (usually just a bit longer, but sometimes distinctly longer); gnathopods usually subchelate, but sometimes simple; carpus and propodus short to very long, and robust to very narrow; palm well defined or not (sometimes absent), usually posteriorly with about 3 long spines; posterior border of dactylus dentate (sometimes strongly dentate), with terminal unguis. Pereiopods 3-7 with terminal unguis on dactylus, easily breaking at the merocarpal articulation. Pereiopod $6>$ pereiopod $5>$ pereiopod 7 ; basis of pereiopods 5-7 with longitudinal carina on both side, which is often very protruding; dactylus of pereiopods 5-7 usually short, rarely long. Coxal gill from gnathopod 2 to pereiopod 7 . Oostegite large and broad, from gnathopod 2 to pereiopod 6. Uropods well developed; rami sword-like. In uropods 1-2, inner ramus slightly longer than outer ramus, slightly shorter than peduncle; tip of rami tapering to form a narrow point without spines (i.e., it is not senticaudate); peduncles without ventrolateral spines. In uropod 3, rami subequal much longer than peduncle, which is very short; outer ramus entire.

\section{Body length}

8 to $80 \mathrm{~mm}$.

\section{Distribution and biology}

The genus Epimeria is almost cosmopolitan in distribution, reaching its highest diversity in Antarctic seas. It also comprises a fairly large number of tropical, deep-water Indo-Pacific species, for which the largest part remains undescribed (pers. obs.: samples from the Muséum national d'Histoire naturelle, Paris). Epimeria has been recorded from the intertidal (E. monodon Stephensen, 1947) down to $5695 \mathrm{~m}$ (E. abyssalis Shimomura \& Tomikawa 2016 - see Shimomura \& Tomikawa (2016)), but it is predominantly found between 150 and $2500 \mathrm{~m}$. No shallow-water records are known from tropical and warm-temperate seas. The majority of Epimeria species are slow moving, strictly benthic amphipods (Dauby et al. 2001a) but they are able to swim quickly over short distances (Moore 1981). At least two highly modified species are truly pelagic: E. macronyx (Walker, 1906) and E. pelagica (Birstein \& Vinogradov, 1958), and a few species, including E. scabrosa (K.H. Barnard, 1930) and E. atalanta sp. nov., are suspected by us to be semi-pelagic, as they are poorly calcified and exhibit a gracile morphology. Epimeria are usually associated with communities rich in epifauna (De Broyer et al. 2001). The material examined for this study shows that the diversity of Epimeria is directly proportional to the abundance of erect epifauna in trawl catches. The shallow-water species Epimeria monodon lives amidst macro-algae (Richardson 1977). Most species are carnivorous and feed on a fairly large range of organisms, albeit with individual preferences for each species (Dauby et al. 2001a). One European species, Epimeria parasitica (M. Sars, 1859), is an ectoparasite of holothurians (M. Sars 1859). Epimeria species are themselves frequently consumed by fishes (e.g., Olaso et al. 2000; Dauby et al. 2003). Females largely predominate in the catches. Different hypotheses may be advanced as possible explanation: differences in behavioural pattern between males and females, a smaller size and/or shorter lifespan in males, a biased sex ratio, or even protandrous hermaphroditism. Epimeria seem to be iteroparous, at least in 
some cases. Indeed, within the maxilliped of the specimen of Epimeria (Drakepimeria) sp. 1 dissected by M. Verheye, which was a mature female with fully developed and setigerous oostegites, the outline of a new cuticle bordered with spines and setae in development could be observed. This indicates that the specimen was preparing an extra moult, after a presumably fertile intermoult. Klages (1991) observed that hatchlings of "Epimeria georgiana" (possibly E. xesta), E. robustoides (under the name E. robusta) and $E$. rubrieques climb on the back of their mother and remain there for a short period of time before leaving her. In contrast, he observed that juvenile "E. macrodonta" and "E. similis" leave their mother immediately after hatching. Cryptoniscin epicaridean isopods have been reported to parasitize Epimeria robusta (see K.H. Barnard 1930), E. robustoides (see Klages 1991, as E. robusta) and E. rubrieques (see Klages 1991). According to K.H. Barnard (1930), the parasites occupy the marsupium of the female.

\section{Remarks}

The body of many Epimeria species is adorned with protrusions, crests or teeth, which can sometimes be very high. Two main conjectural explanations have been previously proposed to explain the role of the dentiform processes in Epimeria and other amphipods: defence against predation (Moore 1981; Brandt 2000) and hydrodynamic stabilizers during swimming (Moore 1981). However the second explanation seems less applicable for most Epimeria, which are benthic and swim only for short distances (Moore 1981). We herein propose a third explanation, that ornamentation might play a role of camouflage, specifically disruptive camouflage. This idea is based on the analogous observations of the first author for a tuberculate pleustid Pleustes panoplus (Kröyer, 1838) [an eusiroid amphipod species superficially similar to Epimeria] on a rocky shore near Tromsø (Norway). Their protuberances, combined with a variegated colouration, made individuals almost perfectly blend with their habitat of rocks covered in epiflora and epifauna. The protrusions of some Epimeria species might constitute a form of disruptive camouflage on substrates rich in epifauna, which are their preferential habitat. As they live at depths, where the light intensity is very low or absent, a perfect camouflage might not be necessary to avoid detection by predators like fishes. A disruptive body form in a complex tridimensional epifaunal environment could efficiently protect them from predation.

The genus Epimeria includes 84 described species (59 in the Southern Ocean). For practical reasons, Antarctic Epimeria species are distributed herein into different subgenera, presenting a homogeneous combination of morphological characters. These subgenera are clades (see Verheye et al. 2016a) or putative clades (their monophyly was assumed from morphological data when some species could not be sequenced). However, the monophyly of the subgenus Urepimeria remains conjectural, since only one of its three species has been sequenced and the morphology of these species is not fully congruent.

The name Vertumnus requires discussion. This generic name was first introduced by Otto (1823) for a trematod: Vertumnus thetidicola Otto, 1823, for which Otto (1823) gave a detailed description. The name Vertumnus was then introduced a second time by White (1847), as a nomen nudum, based on a manuscript of W.E. Leach about crustaceans. Later, White (1850a) illustrated Leach's specimens, describing them briefly as 'Vertumnus Cranchii'. These specimens correspond with the description of Epimeria cornigera (Fabricius, 1779). However, White (1850a) erroneously considered Vertumnus Cranchii as a junior synonym of Oniscus testudo Montagu, 1808 [currently Pereionotus testudo (Montagu, 1808)] and used the combination Acanthonotus testudo for it in his text and on the caption of his plate. Thus, it is clear that Epimeria Costa in Hope, 1851 and Vertumnus White, 1850 are synonyms and have the same type species. However, as indicated above, the name Vertumnus White, 1850 is preoccupied by Vertumnus Otto, 1823. Furthermore, it is unavailable in application of Article 11.6 of the International Code of Zoological Nomenclature (ICZN 1999), which states: "a name which when first published in an available work was treated as a junior synonym of a name then used as valid is not thereby made available." The confusion between Oniscus testudo and Epimeria cornigera was repeated by Gosse (1855), who used again the name Acanthonotus testudo for Epimeria cornigera. 
A sub-generic classification of non-Antarctic and non sub-Antarctic Epimeria falls out of the scope of the present paper, as these extralimital species form a clade distinct from the Antarctic Epimeria clade (Verheye et al. 2017). We simply propose a provisional definition of the type subgenus Epimeria, which occurs in the Atlantic, Arctic and Indian Oceans, and in the Mediterranean Sea.

\section{Key to the Antarctic and sub-Antarctic subgenera of Epimeria}

1. Rostrum small to large (reaching at least mid of article 1 of peduncle of antenna 1); robust

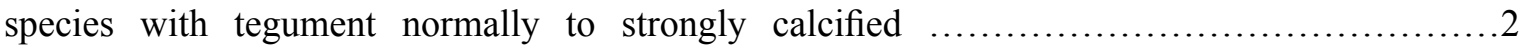

- Rostrum minute (not reaching 0.2 of article 1 of peduncle of antenna 1), reduced to a tiny blade separating the base of the first article of the peduncles of antennae 1; fragile species with very thin tegument

Epimeriella Walker, 1906

2. Some or all pereionites may have a pair of dorsolateral teeth or protrusions, but they are always devoid of a pair of ventrolateral protrusions or teeth; eyes bulging but not conical; gnathopods not reduced in size, achelate or subchelate; pereiopods 3-7 with merus, carpus and propodus slender to moderately stout, with dactylus normal-sized or long and slender, not folding on propodus ...........3

- Pereionites both with pair of dorsolateral teeth or protrusions and with pair of ventrolateral protrusions or teeth (just above coxae); eyes conical; gnathopods very small and achelate; pereiopods 3-7 with merus, carpus and propodus extremely stout and dactylus fairly long, stout, curved and folding on propodus [all pereionites and pleonites with mid-dorsal crest or tooth]

Pseudepimeria Chevreux, 1912

3. Pleonites 2-3 with or 0-2 pairs of dorsolateral protrusions or teeth; when they are two, one is disposed just above the other (and not anteriorly to the other)

- Pleonites 2-3 with at least 2 pairs of low dorsolateral protrusions, teeth or keels, of which at least two are disposed in longitudinal arrangement [propodus of gnathopods 1-2 fairly slender; pleosomites and posterior pereionites with low mid-dorsal crest]

Metepimeria Schellenberg, 1931

4. Basis of pereiopod 7 broad in all its length, with posterior border not excavated in its distal half; posterior border of basis of pereiopods 5-6 without proximal tooth directed in the same axis as basis (but a proximal rounded lobe projecting laterally can be present) $\ldots \ldots \ldots \ldots \ldots \ldots \ldots . . .5$

- Basis of pereiopod 7 narrow with straight posterior border $(E$. heldi), or basis 7 with posterior border proximally broad and slightly or strongly excavated in its distal half (distal half narrow with posterodistal lobe reduced); posterior border of basis of pereiopods 5-6 with or without proximal tooth directed in the same axis as basis [gnathopods 1-2 subchelate with palm very robust and often expanding distally]

Hoplepimeria subgen. nov

6. Some or all pereionites and pleonites 1-2 with LARGE acute-tipped and laterally compressed middorsal tooth; pleonites and some or all pereionites with one (sometimes two) pair(s) of distinct dorsolateral teeth or carinae Drakepimeria subgen. nov.

- Pereionite 7 and pleonites 1-2 with or without SMALL posterordorsal tooth; pleonites and pereionites without dorsolateral teeth or carinae; pereionites $1-6$ without ornamentation .............7

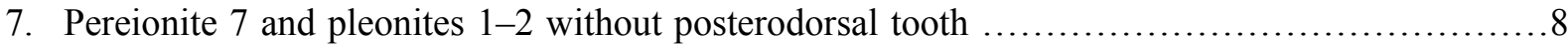

- Pleonite 2 with posterodorsal tooth; pleonite 1 and pereionite 7 with or without posterodorsal tooth

Subepimeria Bellan-Santini, 1972 
8. Teeth of the dactylus of gnathopods especially long; mandible with molar process drawn out, without triturative surface; lower lip with wide hypopharyngal gap; pleonite 3 posterodorsally rounded, at most scarcely produced into a lobe; rostrum about $0.5 \times$ as long as article 1 of peduncle of antenna 1

Laevepimeria subgen. nov.

- Teeth of the dactylus of the gnathopods normally developed; mandible with molar process normal, triturative; Lower lip with narrow (V-shaped) hypopharyngeal gap; pleonite 3 posterodorsally produced into a large and strong triangular tooth or into a blunt lobe; rostrum $0.5-1.1 \times$ as long as article 1 of peduncle of antenna 1

Urepimeria subgen. nov. *

* Without dissection, Epimeria (Urepimeria) annabellae Coleman, 1994 and E. (U.) monodon Stephensen, 1947 can be readily separated from E. (Laevepimeria) spp. by the strong posterodorsal process of their pleonite 3. The pleonite 3 of E. (U.) extensa Andres, 1985 is much less produced and at first glance, the species looks fairly similar to Laevepimeria, if the mouthparts are not examined. However, E. (U.) extensa can easily be identified by its rostrum, which is about $1.1 \times$ as long as article 1 of peduncle of antenna 1 . It is about $0.5 \times$ as long as article 1 in Laevepimeria spp.

Subgenus Drakepimeria subgen. nov. urn:Isid:zoobank.org:act:1B9E9A7F-2721-475F-9906-75F330B7F4CC

\section{Etymology}

Combination of the Greek word: $\delta \rho \alpha ́ \kappa \omega v$, dragon and Epimeria. The name, which is feminine, alludes to the highly processiform ornamentation in the species of the subgenus, which is reminiscent of mythological dragons.

\section{Type species}

Epimeria loerzae sp. nov.

\section{Description}

Body opaque, with teguments strongly calcified. Rostrum long. Ventral lobe of head acute. Pleonites 1-3 and at least some pereionites with strong mid-dorsal dentate carina and one pair of dorsolateral much smaller teeth, swelling or carina. On pleonite 2 and 3, a second pair of small dorsolateral teeth is sometimes observed between the main dorsolateral teeth and the mid-dorsal tooth (this accessory pair of small teeth is not positioned anteriorly to the main pair). Pereionites 1-7 without tooth or protrusion just above connection with coxa. Coxae 1-4 often with (but not always) with sharp tip. Coxae 1-3 usually sharply keeled along their axis. Coxa 4 with sharp carina starting at ventral tip of coxa and terminating at posterior tip of coxa; this arching carina sometimes bears a tooth projecting laterally; posteroventral border concave. Coxae 5-6 with strong sharp tooth projecting backwards. Mid of posterior border of epimeral plates 1-3 not produced into a tooth. Posteroventral tooth of epimeral plate 3 strong to very strong. Dorsal process of urosomite 1 produced into a sharp tooth, which can be directed upwards or backwards. Urosomite 2 with or without pair of small teeth pointing upwards. Lateral borders of urosomite 3 posteriorly terminated into a sharp tooth. Telson deeply bilobed. Eyes present, large to very large, not conical. Peduncle of antenna 1 with teeth (dentition sometimes reduced, but never totally absent). Mandible with molar process triturative. Lower lip with narrow (V-shaped) hypopharyngeal gap. Palp of maxilliped with 4 articles. Gnathopods small but not minute, with carpus and propodus of medium slenderness; propodus not strongly expanded distally, subcheliform, with palm obliquely transverse; posterior border of dactylus lined by row of small oblique slender teeth. Basis of pereiopods 5-6 moderately slender to broad, with posteroproximal rounded protrusion (sometimes weak) and posterodistal tooth projecting posteriorly. Posterior border of basis of pereiopod 7 proximally 
slightly convex and distally slightly concave, terminated into a tooth projecting posteriorly. Dactylus of pereiopods 5-7 short.

\section{Body length}

The maximum body length recorded in Drakepimeria species ranges between 19 and $47 \mathrm{~mm}$.

\section{Ecology}

Benthic, 33-2190 m.

\section{Distribution}

Circum-Antarctic, as far north as the South Orkney Islands.

\section{Remarks}

Drakepimeria species are superficially similar to those of the subgenus Epimeria. See e.g., illustrations of its type species, Epimeria (Epimeria) cornigera (Fabricius, 1779), given by G.O. Sars (1893). However several differences can be observed. In the subgenus Epimeria, the ventral lobe of the head is rounded instead of being sharp, the peduncle of antenna 1 is not dentate; the basis of pereiopod 5 is extremely narrow; the basis of pereiopods $5-6$ has neither posteroproximal nor posterodistal process pointing backwards; the posterior margins of the epimeral plates have a median tooth, the lobes of the telson are blunt-tipped instead of being acute and the median notch of the telson is much shallower than in Drakepimeria. Molecular data support the idea that the subgenera Drakepimeria and Epimeria are not closely related (Verheye et al. 2016b, 2017).

Drakepimeria species can be subdivided in two phenotypical categories, which are useful for identification. The species of the first category have a pair of denticles pointing upwards on urosomite 2; they are: E. (D.) anguloce subgen. et sp. nov., E. (D.) corbariae subgen. et sp. nov., E. (D.) havermansiana subgen. et sp. nov., E. (D.) loerzae subgen. et sp. nov., E. (D.) macrodonta Walker, 1906, E. (D.) pandora subgen. et sp. nov., E. (D.) pyrodrakon subgen. et sp. nov., E. (D.) schiaparelli Lörz et al., 2007, and E. (D.) reoproi Lörz \& Coleman, 2001.

The species of the second category have no pair of denticles pointing upwards on urosomite 2; they are: E. (D.) acanthochelon subgen. et sp. nov., E. (D.) colemani subgen. et sp. nov., E. (D.) cyrano subgen. et sp. nov., E. (D.) leukhoplites subgen. et sp. nov., $E$. (D.) robertiana subgen. et sp. nov., $E$. (D.) similis Chevreux, 1912, E. (D.) vaderi Coleman, 1998, and E. (D.) sp. 1.

\section{Key to the species of Drakepimeria}

1. Rostrum curving downwards; number of pereionites with mid-dorsal tooth and pair of dorsolateral teeth (or carinae) variable, but if pereionites 1 and/or 2 have a mid-dorsal tooth, it is never long and slender

- Rostrum straight and anteriorly directed; all pereionites and pleonites with long and slender middorsal tooth and pair of long dorsolateral teeth.

E. (D.) cyrano subgen. et sp. nov. [Eastern Weddell Sea, around 800-1000 m]

2. Dorsal process of urosomite 1 pointing upwards; basis of pereiopod 5 broad $\ldots \ldots \ldots \ldots \ldots \ldots \ldots \ldots \ldots . \ldots \ldots$

- Dorsal process of urosomite 1 distinctly pointing backwards; basis of pereiopod 5 narrow E. (D.) robertiana subgen. et sp. nov. [Weddell Sea, around $2000 \mathrm{~m}$ ] 
3. Lateral tooth of article 2 of peduncle of antenna 1 tiny, reaching basis of article $3 \ldots \ldots \ldots \ldots \ldots . . .4$

- Lateral tooth of article 2 of peduncle of antenna 1 large to very large, reaching or overreching tip of article 3

4. Dorsal process of urosomite 1 obtusely triangular; coxa 4 with lateral carina forming a deep curve, so that its deepest point is very distant from the posteroventral border, with ventral corner acutely pointed and strongly curving posteriorly; pleonites 1-2 with one pair of dorsolateral teeth

E. (D.) reoproi Lörz \& Coleman, 2001

- Dorsal process of urosomite 1 acutely triangular; coxa 4 with lateral carina very close to posteroventral border and parallel to it, with ventral corner angular, acute, but not strongly curving posteriorly; pleonites 1-2 with two pairs of dorsolateral teeth.

E. (D.) vaderi subgen. nov. Coleman, 1998 [Elephant Island]

5. Urosomite 2 without pair of dorsal denticles pointing upwards .............................6

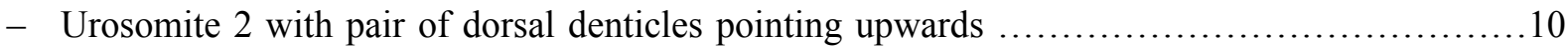

6. Lateral carina of coxa 4 without lateral tooth or any trace of angularity visible in dorsal view; merus;

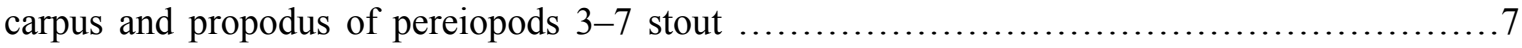

- Lateral carina of coxa 4 with lateral tooth or a very obtuse lateral angularity visible in dorsal view; merus; carpus and propodus of pereiopods 3-7 slender .8

7. Mid-dorsal carina of pereionite 7 and pleonites 1-2 with anterior border exhibiting a strong angular discontinuity; coxa 4 in lateral view with anterodorsal border more than twice longer than anteroventral border ......E. (D.) leukhoplites subgen. et sp. nov. [Elephant Island and tip of Antarctic Peninsula]

- Mid-dorsal carina of pereionite 7 and pleonites 1-2 with anterior border regularly curved; coxa 4 in lateral view with anterodorsal and anteroventral border subequal

E. (D.) sp. 1 subgen. nov. [Ross Sea]

8. Coxa 4 laterally produced into an obtuse angularity visible in dorsal view; dorsolateral teeth of pereionites laterally carinate; lateral tooth of article 2 of peduncle of antenna 1 overreaching article 3 by about 0.6 of its length E. (D.) colemani subgen. et sp. nov. [South Shetland Islands, Antarctic Peninsula, eastern Weddell Sea, eastwards to the Ross Sea]

- Coxa 4 laterally produced into a sharp tooth; dorsolateral teeth of pereionites not laterally carinate; lateral tooth of article 2 of peduncle of antenna 1 reaching about tip of article 3: E. (Drakepimeria) complex similis

9. Pereionite 1 never with posterodorsal bump or tooth; pereionite 2 with or without small mid-dorsal tooth; mid-dorsal carina of pleonite 3 with weak anterior lobe followed by very shallow notch

E. (D.) similis subgen. nov. Chevreux, 1912 [Elephant Island to tip of Antarctic Peninsula]

- Pereionite 1 usually with small posterodorsal bump or small posterodorsal tooth; pereionite 2 with well developed mid-dorsal tooth; mid-dorsal carina of pleonite 3 with strong anterior lobe followed by fairly deep notch ...Epimeria (D.) acanthochelon subgen. et sp. nov. [Eastern Weddell Sea to Adélie Coast]

10. Lateral carina of coxa 4 without lateral tooth: E. (Drakepimeria) complex pandora ................11

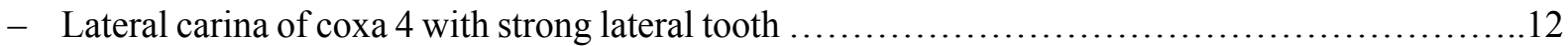


11. Pereionite 2 without mid-dorsal tooth; mid-dorsal tooth of pereionite 3 small; ventral tooth of coxa 4 moderately long and fairly broad

E. (D.) pandora subgen. et sp. nov. [Elephant Island to tip of Antarctic Peninsula]

- Pereionite 2 with small mid-dorsal tooth; mid-dorsal tooth of pereionite 3 medium-sized; ventral tooth of coxa 4 very long and narrow

E. (D.) havermansiana subgen. et sp. nov. [eastern Weddell Sea to Adélie Coast]

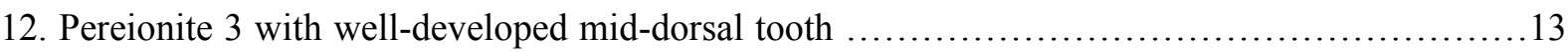

- Pereionite 3 with posterodorsal bump

E. (D.) schiaparelli subgen. nov. Lörz et al., 2007 [western Ross Sea]

13. Mid-dorsal tooth of pereionites 3-7 and pleonites 1-2 narrow to moderately broad, without angular discontinuity on their anterior border or with a very weak angular discontinuity; mid-dorsal

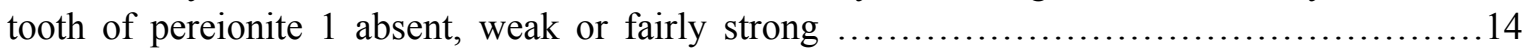

- Mid-dorsal tooth of pereionites 3-7 and pleonites 1-2 broad, the last four of these teeth presenting a strong angular discontinuity on their anterior border; mid-dorsal tooth of pereionite 1 very strong [article 2 of peduncle of antenna 1 with lateral and medial teeth overreaching article 3] ............................................... (D.) loerzae subgen. et sp. nov. [South Orkney Islands to tip of Antarctic Peninsula, very rare in the Eastern Weddell Sea]

14. Lateral and medial tooth of article 2 of peduncle of antenna 1 overreaching article 3 [ventral tooth of article 3 excluded]; ventral border of article 2 of antenna 1 at most with tiny denticle .........15

- Lateral and medial tooth of article 2 of peduncle of antenna 1 not reaching tip of article 3 [ventral tooth of article 3 excluded]; ventral border of article 2 of antenna 1 with large tooth

E. (D.) pyrodrakon subgen. et sp. nov. [Antarctic Peninsula, eastern Weddell Sea, Princess Ragnhild Coast]

15. Lateral and medial tooth of article 1 of antenna 1 long and subequal .16

- Lateral tooth of article 1 of antenna 1 long and considerably longer than medial tooth of the same article, which is short. E. (D.) macrodonta subgen. nov. Walker, 1906 [western Ross Sea]

16. Pereionite 1 always with small to medium-sized (always very distinct) mid-dorsal tooth and pair of dorsolateral protrusions; mid-dorsal tooth of pereionites 4-7 very narrow

E. (D.) anguloce subgen. et sp. nov. [Tip of Antarctic Peninsula, eastern Weddell Sea, Princess Ragnhild Coast, Prydz Bay]

- Pereionite 1 usually without mid-dorsal tooth or with a very reduced mid-dorsal tooth, rarely with a well developed mid-dorsal tooth, pair of dorsolateral protrusions rarely present; mid-dorsal tooth of pereionites $4-7$ fairly narrow

E. (D.) corbariae subgen. et sp. nov. [Adélie Coast]

Epimeria (Drakepimeria) acanthochelon subgen. et sp. nov. urn:1sid:zoobank.org:act:B878492E-3294-4449-A17D-DBD502918370

Figs 1-7

Epimeria similis - Coleman 2007: 54, in part, plate 1 fig. e only. — Lörz \& Coleman 2009: unnumbered photograph on p. 17. - Rauschert \& Arntz 2015: 62, pl. 55 unnumbered photograph.

'Clade A similis/macrodonta complex - SI3' - Verheye et al. 2016a, supplement: 2 (online).

non Epimeria similis Chevreux, 1912: 215. 


\section{Etymology}

From the Greek $\alpha \kappa \alpha \nu \theta \alpha$, spine; $\chi \varepsilon \lambda \omega \dot{v \eta}$, tortoise. The name, which is a noun in apposition, alludes to the toothed and heavily calcified body of the species, which can be compared to a spiny tortoise.

\section{Type material}

\section{Holotype}

RV Polarstern cruises:

SOUTHERN OCEAN: $q$, cruise CEAMARC, sample CEAMARC 1421, stn 62EV303, Adélie Coast, $66^{\circ} 10^{\prime} 34^{\prime \prime} \mathrm{S}, 143^{\circ} 20^{\prime} 45^{\prime \prime} \mathrm{E}, 532-550 \mathrm{~m}$, beam trawl, 4 Jan. 2008 (coll. IPEV-AAD-MNHN, removed from MNHN-IU-2014-4342, now MNHN-IU-2014-7321) [extraction M7; Genbank nr, 28S: KU759674].

\section{Paratypes}

RV Polarstern cruises:

SOUTHERN OCEAN: 4 specs, cruise PS39, ANT-XIII/3, EASIZ I, stn 1, GSN 1, eastern Weddell Sea, $71^{\circ} 03.10^{\prime} \mathrm{S}, 11^{\circ} 25.50^{\prime} \mathrm{W}$ to $71^{\circ} 02.10^{\prime} \mathrm{S}, 11^{\circ} 19.30^{\prime} \mathrm{W}, 462-481 \mathrm{~m}$, bottom trawl, 5 Feb. 1996 (previously identified as Epimeria cf. similis and used for gut content studies), coll. C. De Broyer and G. Chapelle (RBINS, INV. 132698); 1 spec., cruise PS39, ANT-XIII/3, EASIZ I, stn 1, GSN 1, eastern Weddell Sea, $71^{\circ} 03.10^{\prime} \mathrm{S}, 11^{\circ} 25.50^{\prime} \mathrm{W}$ to $71^{\circ} 02.10^{\prime} \mathrm{S}, 11^{\circ} 19.30^{\prime} \mathrm{W}, 462-481 \mathrm{~m}$, bottom trawl, 5 Feb. 1996, coll. C. De Broyer and G. Chapelle (RBINS, INV. 132699); 1 spec., cruise PS39, ANT-XIII/3, EASIZ I, stn 6, AGT 1, eastern Weddell Sea, $71^{\circ} 31.80^{\prime} \mathrm{S}, 13^{\circ} 34.50^{\prime} \mathrm{W}$ to $71^{\circ} 31.86^{\prime} \mathrm{S}, 13^{\circ} 35.50^{\prime} \mathrm{W}$, 254-261 m, Agassiz trawl, 8 Jan. 1996, coll. C. De Broyer and G. Chapelle, (RBINS, INV. 132697); 1 spec., cruise PS39, ANT-XIII/3, EASIZ I, stn 6, AGT 1, eastern Weddell Sea, $71^{\circ} 31.80^{\prime} \mathrm{S}, 13^{\circ} 34.50^{\prime} \mathrm{W}$ to $71^{\circ} 31.86^{\prime} \mathrm{S}, 13^{\circ} 35.50^{\prime} \mathrm{W}, 254-261 \mathrm{~m}$, Agassiz trawl, 8 Jan. 1996, coll. C. De Broyer and G. Chapelle, (RBINS, INV. 132706); 1 spec., cruise PS39, ANT-XIII/3, EASIZ I, stn 9, AGT 10, eastern Weddell Sea, $71^{\circ} 34.70^{\prime} \mathrm{S}, 12^{\circ} 26.60^{\prime} \mathrm{W}$ to $71^{\circ} 34.80^{\prime} \mathrm{S}, 12^{\circ} 25.90^{\prime} \mathrm{W}, 560-571 \mathrm{~m}$, Agassiz trawl, 26 Feb. 1996, coll. C. De Broyer (RBINS, INV. 132696); ca 30 specs of all sizes, cruise PS39, ANT-XIII/3, EASIZ I, stn 29, BPN 4, eastern Weddell Sea, $71^{\circ} 31.50^{\prime} \mathrm{S}, 12^{\circ} 25.50^{\prime} \mathrm{W}$ to $71^{\circ} 30.30^{\prime} \mathrm{S}, 12^{\circ} 27.80^{\prime} \mathrm{W}, 204-529 \mathrm{~m}, 28 \mathrm{Feb}$. 1996, coll. C. De Broyer (RBINS, INV. 132705);

RV Aurora Australis cruises:

SOUTHERN OCEAN: 1 spec., cruise CEAMARC, sample CEAMARC 300, stn 30EV66, Adélie

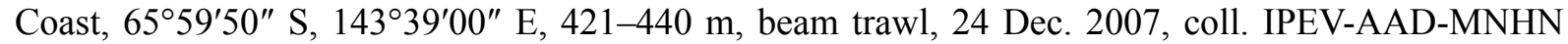
(MNHN-IU-2014-4340) [extraction M5; Genbank nr, 28S: KU759672]; 2 specs, cruise CEAMARC,

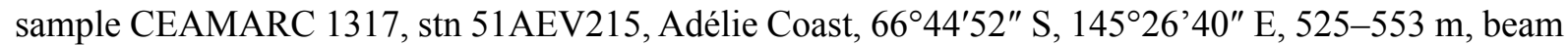
trawl, 30 Dec. 2007, coll. IPEV-AAD-MNHN (MNHN-IU-2014-4279); 1 spec. (possibly ठ)), cruise CEAMARC, sample CEAMARC 1383, stn 50AEV220, Adélie Coast, 66 45'09" S, 145'20'04" E, 567604 m, beam trawl, 30-31 Dec. 2007, coll. IPEV-AAD-MNHN (MNHN-IU-2014-4271); 3 specs, cruise CEAMARC, sample CEAMARC 1384, stn 50AEV220, Adélie Coast, 66 45'09" S, 14520'04" E, 567604 m, beam trawl, 30-31 Dec. 2007, coll. IPEV-AAD-MNHN (MNHN-IU-2014-4332); 1 spec., cruise CEAMARC, sample CEAMARC 1384, stn 50AEV220, Adélie Coast, 66 45'09" S, 145 20'04" E, 567604 m, beam trawl, 30-31 Dec. 2007, coll. IPEV-AAD-MNHN (MNHN-IU-2014-4333) [extraction M8; Genbank nr, 28S: KU759675]; 2 specs, in one specimen lateral points of coxa 4 broken, cruise CEAMARC, sample CEAMARC 1421, stn 62EV303, Adélie Coast, 66 $6^{\circ} 10^{\prime} 34^{\prime \prime} \mathrm{S}, 143^{\circ} 20^{\prime} 45^{\prime \prime}$ E, 532$550 \mathrm{~m}$, beam trawl, 4 Jan. 2008, coll. IPEV-AAD-MNHN (MNHN-IU-2014-4342); 3 specs, 1 adult and 2 immatures, cruise CEAMARC, sample CEAMARC 1643, stn 31EV268, Adélie Coast, 66⒊ $34^{\prime} 30^{\prime \prime}$ S, $145^{\circ} 01^{\prime} 15^{\prime \prime}$ E, 429-451 m, beam trawl, 3 Jan. 2008, coll. IPEV-AAD-MNHN (MNHN-IU-2014-4322) [extraction M9; Genbank nr, 28S: KU759676]; 2 specs, cruise CEAMARC, sample CEAMARC 1951,

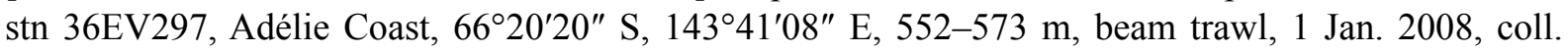


IPEV-AAD-MNHN (MNHN-IU-2014-4280); 1 spec., cruise CEAMARC, sample CEAMARC 2724, stn 71EV447, Adélie Coast, 66 23'60" S, 140 32'21" E, 683-791 m, beam trawl, 14 Jan. 2008, coll. IPEV-AAD-MNHN (MNHN-IU-2014-4337).

RV L'Astrolabe cruises:

SOUTHERN OCEAN: 3 specs, cruise REVOLTA III, stn none (Dumont d'Urville Sea), Collect ID: REVO_449, Field_ID: CE-000002101, Adélie Coast, $66^{\circ} 38^{\prime} \mathrm{S}, 140^{\circ} 42^{\prime} \mathrm{E}$ to $66^{\circ} 38^{\prime} \mathrm{S}, 140^{\circ} 40^{\prime} \mathrm{E}$, 718-729 m, mud, beam trawl, 20 Jan. 2012, coll. G. Lecointre, A. Dettaï, J. Lanshere, C. Gallut and C. Ozouf (MNHN-IU-2009-2539) [extraction K7 (largest specimen); Genbank nr, 28S: KU759659]; 1 spec., cruise REVOLTA III, stn none (Dumont d'Urville Sea), Collect_ID: REVO_449, Field_ID: CE000002239 , Adélie Coast, $66^{\circ} 38^{\prime} \mathrm{S}, 140^{\circ} 42^{\prime} \mathrm{E}$ to $66^{\circ} 38^{\prime} \mathrm{S}, 140^{\circ} 40^{\prime} \mathrm{E}, 718-729 \mathrm{~m}$, mud, beam trawl, 20 Jan. 2012, coll. G. Lecointre, A. Dettaï, J. Lanshere, C. Gallut and C. Ozouf (MNHN-IU-2009-2532) [extraction K6; Genbank nr, 28S: KU759658].

Belgian and Belgian-Dutch Antarctic expedition:

SOUTHERN OCEAN: 1 spec., Princess Ragnhild Coast, stn 133, Baie Léopold, $70^{\circ} 19^{\prime} 09^{\prime \prime}$ S, $24^{\circ} 13^{\prime} 05^{\prime \prime} \mathrm{E}$ to $70^{\circ} 19^{\prime} 08^{\prime \prime}$ S, $24^{\circ} 12^{\prime} 06^{\prime \prime}$ E, 240 m, trawl, year 1961, coll. A. Capart (RBINS, INV. 132748); 1 spec., Princess Ragnhild Coast, stn 139, coordinates unavailable, year 1961, coll. A. Capart (RBINS, INV. 132749); 1 spec. (possibly ô), Princess Ragnhild Coast, stn 150, Baie Léopold, $70^{\circ} 20^{\prime} 04^{\prime \prime} \mathrm{S}, 24^{\circ} 13^{\prime} \mathrm{E}$, 255 m, dredge, 20 Jan. 1961, coll. A. Capart (RBINS, INV. 132746); 1 spec., Princess Ragnhild Coast,

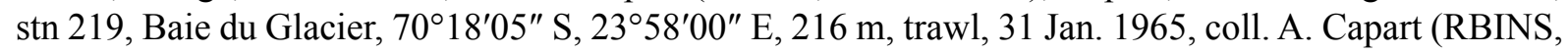
INV. 132745); 1 spec., Princess Ragnhild Coast, stn 220, Baie du Glacier, exact coordinates unavailable [presumably about $70^{\circ} 18^{\prime} \mathrm{S}, 23^{\circ} 58^{\prime} \mathrm{E}$ ], 414-450 m, 1 Feb. 1965, trawl, coll. A. Capart (RBINS, INV. 132734).

\section{Description}

RostRum. Long, reaching about tip of article 1 of peduncle of antenna 1 (teeth excluded), weakly curved, sharp-tipped in lateral view.

EYE. Very large, elliptic.

Pereion-Pleosome tooth pattern. Mid-dorsal tooth on all segments or from pereionite 2 onwards; pair of non-carinate posterodorsal teeth or swellings on all segments; pereionite 1 often with small but distinct mid-dorsal tooth or scarcely distinct bump, with pair of very low non-carinate dorsolateral swellings; pereionite 2 nearly as broad as pereionite 1, with mid-sized blunt-tipped mid-dorsal tooth and pair of dorsolateral swellings or very blunt teeth; pereionite 3 with well-developed blunt-tipped regularly curved broad, mid-dorsal tooth and pair of dorsolateral blunt teeth; pereionite 3 to pleonite 2 with acute-tipped broad and regularly curved mid-dorsal tooth (nearly same shape and size on all these segments) and pair of small non-carinate acute-tipped dorsolateral teeth (pleonites 1-2 without second pair of dorsolateral teeth); pleonite 3 with dorsal sharp carina with distinct median notch (lobe anterior to notch distinctly curved) and obliquely produced posteriorly into an a broad acute and sharp triangular tooth, and pair of dorsolateral non-carinate acute-tipped teeth.

COXAE 1-3. Strongly carinate and distally sharp.

Coxa 4. Anterodorsal and anteroventral border nearly straight, joined by low and blunt angular discontinuity, anterior angle not strongly projecting forward; ventral tooth very long and styliform; lateral carina with lateral long and sharp triangular tooth pointing obliquely backwards, carina very distant from margin of coxa at its deepest point.

Coxa 5. With long, sharp and narrowly triangular, carinate, lateral tooth pointing obliquely backwards. 
Coxa 6. With mid-sized, sharp and narrowly triangular, carinate, lateral tooth pointing obliquely backwards; posteroventral corner produced into a triangular tooth.

Coxa 7. With ventral and posterior border straight, with posteroventral angle produced into a strong tooth.

EPIMERAL PLATES 1-3. Posteroventral angle produced into a very long styliform tooth.

UROSOME TOOTH PATTERN. Urosomite 1 with sharp triangular process pointing upwards; urosomite 2 without pair of small posterior dorsolateral teeth pointing upwards.

TELSON. Cleft on 0.3; tips of lobes sharp, slit narrow.

Peduncle of antenna 1. Article 1 with long lateral and medial teeth reaching mid of article 2 (teeth excluded) and long ventral tooth reaching tip of article 2 (teeth excluded); article 2 with long lateral tooth nearly reaching tip of article 3 , with medial tooth slightly overreaching article 3 (ventral tooth excluded), with ventral tooth slightly overreaching tip of article 3 (tooth excluded); article 3 with very long ventral tooth, longer than article itself.

GNATHOPODS 1-2. Carpus and propodus of normal slenderness; propodus not narrowing distally, palm distinct.

Pereiopods 5-7. Merus, carpus and propodus very slender; basis of pereiopods 5-6 of normal width, with posteroproximal process rounded and strongly protruding, with posterodistal tooth strong; basis of pereiopod 7 very broad with posterodistal tooth sharp, followed more proximally by small concavity, directed posteriorly.

\section{Colour pattern}

Body and appendages white with a pinkish hue on posterior dorsal crests, peduncles of antennae and the distal half of pereiopods; eyes red (photograph of a specimen from Adélie Coast, MNHN-IU-2009-2539). The specimen from the eastern shelf of the Weddell Sea illustrated by Rauschert \& Arntz (2015) under the name of Epimeria similis exhibits a diffuse orange pattern on a whitish background.

\section{Body length}

Up to $45 \mathrm{~mm}$.

\section{Distribution}

Eastern shelf of the Weddell Sea, Princess Ragnhild Coast, Adélie Coast; depth range 204-791 m.

\section{Biology}

Dauby et al. (2001a) observed the following items in the gut content of Epimeria from the eastern Weddell Sea identified by them as E. similis: cnidocysts of various size and shape, some of them identified as from hydrozoans of the genera Tubularia and Campanula, and others to actiniids. Other items observed were: planktonic cells (diatoms and foraminifers), spicules of sponges and setae of polychaetes. Dauby et al. (2001b) concluded that it is a micropredatory browser. These specimens were presumably Epimeria acanthochelon sp. nov., as that species was collected in large numbers during the cruise EASIZ I, and as the material studied by these authors was largely based on material collected during that cruise. Epimeria similis s. str. is not present in the eastern Weddell Sea. 


\section{Remarks}

Epimeria acanthochelon sp. nov. (type locality: Adélie Coast) is morphologically extremely similar to E. similis from the tip of the Antarctic Peninsula and South Shetland Islands. However, results of molecular analyses based on 28S rDNA suggest that they would be distinct species (Verheye et al. 2016a; this paper Fig. 342). Specimens from the eastern shelf of the Weddell Sea are also identified as E. acanthochelon sp. nov., albeit on basis of their morphology only. A genetic characterization of specimens from that area would be desirable whenever possible. Epimeria acanthochelon sp. nov. often has a small tooth or a trace of mid-dorsal tooth on pereionite 1, which is absent in E. similis. The dorsal teeth of other segments have a slightly different form, with those of the second and third segments being more developed in E. acanthochelon sp. nov. than in E. similis. The carina of pleonite 3 also has a stronger anterior lobe followed by a deeper median notch in E. acanthochelon sp. nov. than in E. similis. Coxa 7 often has a stronger posteroventral tooth in E. acanthochelon sp. nov. than in E. similis. Finally, the telson notch is also slightly deeper in E. acanthochelon sp. nov. than in E. similis.

The specimen illustrated by a photograph in Coleman (2007: plate 1 fig. e), Lörz \& Coleman (2009: unnumbered photograph on p. 17) and Rauschert \& Arntz (2015: 62, plate 55) and identified by them as Epimeria similis is probably E. acanthochelon sp. nov. On page 125, Rauschert \& Arntz (2015) indicated that it was collected on the eastern shelf of the Weddell Sea and in an early draft of their book made available to the authors, it is specified that it was collected during the cruise ANT-XIII/3, which indeed sampled on the eastern shelf of the Weddell Sea (Arntz \& Gutt 1997). Its morphology matches perfectly with the description of E. acanthochelon sp. nov.: the posteroventral tooth of its coxa 7 is stronger and the anterior lobe of the dorsal crest of pleonite 3 is more developed than in E. similis.

Epimeria (Drakepimeria) anguloce subgen. et sp. nov. urn:1sid:zoobank.org:act:9F72B38E-2322-43C3-A48A-DCD9823693A0

Figs $8-16$

Epimeria macrodonta - ? Andres 1985: 124 (in part: form with "schlankeren, spitzen Dorsalzähnen"). Klages 1988: 72, unnumbered fig. (drawing of antenna 1 incorrect), 75, 77, fig. 15c. - Coleman 2007: 43, in part, colour plate 1 fig. d only, not fig. 21a-b (=E. pyrodrakon sp. nov.). - Rauschert \& Arntz 2015: 61, pl. 54, unnumbered photograph [picture incorrectly retouched].

'Clade A similis/macrodonta complex - MA1' - Verheye et al. 2016a, supplement: 2 (online).

non Epimeria macrodonta Walker, 1906: 16.

\section{Etymology}

Angulócë, dragon - Tolkien's Quenya language (Faulskanger 2008). The name, which is a noun in apposition, alludes to the dragon-like facies of the species.

\section{Type material}

\section{Holotype}

RV Polarstern cruises:

SOUTHERN OCEAN: 1 q, cruise PS77, ANT-XXVII/3, CAMBIO, stn 228-3, Larsen A, 64⒌96' S, $60^{\circ} 31.97^{\prime} \mathrm{W}$ to $64^{\circ} 54.43^{\prime} \mathrm{S}, 60^{\circ} 30.44^{\prime} \mathrm{W}, 277-309 \mathrm{~m}$, bottom trawl, $27 \mathrm{Feb}$. 2011, coll. C. Havermans and H. Robert (RBINS, INV. 132961) [extraction I6; Genbank nr, COI: KU870850, 28S: KU759627].

\section{Paratypes}

RV Polarstern cruises:

SOUTHERN OCEAN: 8 specs, cruise PS69, ANT-XXIII/8, stn 702-9, southeast of Larsen B, $65^{\circ} 57.85^{\prime} \mathrm{S}, 60^{\circ} 28.42^{\prime} \mathrm{W}$ to $65^{\circ} 57.42^{\prime} \mathrm{S}, 60^{\circ} 28.12^{\prime} \mathrm{W}, 215-221 \mathrm{~m}$, Agassiz trawl, $12 \mathrm{Jan}$. 2007, coll. 
C. d'Udekem d'Acoz and H. Robert (RBINS, INV. 122565); 1 immature spec., cruise PS69, ANTXXIII/8, stn 702-9, southeast of Larsen B, $65^{\circ} 57.85^{\prime} \mathrm{S}, 60^{\circ} 28.42^{\prime} \mathrm{W}$ to $65^{\circ} 57.42^{\prime} \mathrm{S}, 60^{\circ} 28.12^{\prime} \mathrm{W}, 215-$ 221 m, Agassiz trawl, 12 Jan. 2007, coll. C. d'Udekem d'Acoz and H. Robert (RBINS, INV. 122563); 1 small juv., cruise PS69, ANT-XXIII/8, stn 702-9, southeast of Larsen B, 65 $57.85^{\prime} \mathrm{S}, 60^{\circ} 28.42^{\prime} \mathrm{W}$ to $65^{\circ} 57.42^{\prime} \mathrm{S}, 60^{\circ} 28.12^{\prime} \mathrm{W}, 215-221 \mathrm{~m}$, Agassiz trawl, $12 \mathrm{Jan}$. 2007, coll. C. d'Udekem d'Acoz and H. Robert (RBINS, INV. 122562); 4 specs, cruise PS69, ANT-XXIII/8, stn 725-10, south of Larsen A, $64^{\circ} 55.89^{\prime} \mathrm{S}, 60^{\circ} 40.06^{\prime} \mathrm{W}$ to $64^{\circ} 55.92^{\prime} \mathrm{S}, 60^{\circ} 40.31^{\prime} \mathrm{W}, 189-192 \mathrm{~m}$, Rauschert dredge, $22 \mathrm{Jan}$. 2007, coll. C. d'Udekem d'Acoz and H. Robert (RBINS, INV. 122561); 2 specs, cruise PS69, ANT-XXIII/8, stn $725-10$, south of Larsen A, $64^{\circ} 55.89^{\prime} \mathrm{S}, 60^{\circ} 40.06^{\prime} \mathrm{W}$ to $64^{\circ} 55.92^{\prime} \mathrm{S}, 60^{\circ} 40.31^{\prime} \mathrm{W}, 189-192 \mathrm{~m}$, Rauschert dredge, 22 Jan. 2007, coll. C. d'Udekem d'Acoz and H. Robert ( MNHN-IU-2014-7322, removed from RBINS, INV. 122561); 7 specs, cruise PS77, ANT-XXVII/3, CAMBIO, stn 248-2, Larsen B, $65^{\circ} 57.51^{\prime}$ S, $60^{\circ} 28.15^{\prime} \mathrm{W}$ to $65^{\circ} 57.69^{\prime} \mathrm{S}, 60^{\circ} 28.30^{\prime} \mathrm{W}, 196-202 \mathrm{~m}$, Agassiz trawl, 7 Mar. 2011, coll. C. Havermans and H. Robert (RBINS, INV. 122893); 1 juv., cruise PS77, ANT-XXVII/3, CAMBIO, stn 248-2, Larsen $\mathrm{B}, 65^{\circ} 57.51^{\prime} \mathrm{S}, 60^{\circ} 28.15^{\prime} \mathrm{W}$ to $65^{\circ} 57.69^{\prime} \mathrm{S}, 60^{\circ} 28.30^{\prime} \mathrm{W}, 196-202 \mathrm{~m}$, Agassiz trawl, 7 Mar. 2011, coll. C. Havermans and H. Robert (RBINS, INV. 122895); 2 specs, cruise PS77, ANT-XXVII/3, CAMBIO, stn $248-2$, Larsen B, $65^{\circ} 57.51^{\prime} \mathrm{S}, 60^{\circ} 28.15^{\prime} \mathrm{W}$ to $65^{\circ} 57.69^{\prime} \mathrm{S}, 60^{\circ} 28.30^{\prime} \mathrm{W}, 196-202 \mathrm{~m}$, Agassiz trawl, 7 Mar. 2011, coll. C. Havermans and H. Robert (RBINS, INV. 122900); 1 juv., posterior half missing,

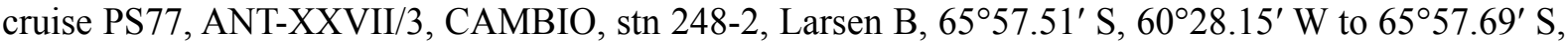
60²8.30' W, 196-202 m, Agassiz trawl, 7 Mar. 2011, coll. C. Havermans and H. Robert (RBINS, INV.

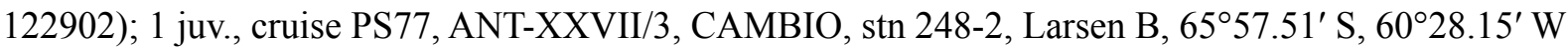
to $65^{\circ} 57.69^{\prime} \mathrm{S}, 60^{\circ} 28.30^{\prime} \mathrm{W}, 196-202 \mathrm{~m}$, Agassiz trawl, 7 Mar. 2011, coll. C. Havermans and H. Robert (RBINS, INV. 132975) [extraction I7; Genbank nr COI: KU870851, 28S: KU759628]; 1 small spec.,

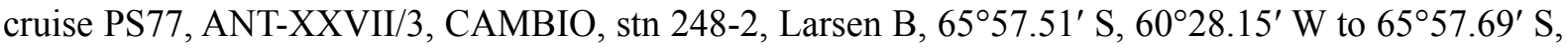
60²8.30' W, 196-202 m, Agassiz trawl, 7 Mar. 2011, coll. C. Havermans and H. Robert (RBINS, INV. 132655) [extraction A20; Genbank nr COI: KU870817, 28S: KU759589]; 1 spec., cruise PS77, ANT-XXVII/3, CAMBIO, stn 257-2, Larsen A, $64^{\circ} 54.75^{\prime} \mathrm{S}, 60^{\circ} 39.01^{\prime} \mathrm{W}$ to $64^{\circ} 54.62^{\prime} \mathrm{S}, 60^{\circ} 39.50^{\prime} \mathrm{W}$, 159-169 m, Agassiz trawl, 13 Mar. 2011, coll. C. Havermans and H. Robert (RBINS, INV. 122904); 1 spec., cruise PS81, ANT-XXIX/3, stn 185-3, south east of Dundee Island, 63⒌ $51.34^{\prime} \mathrm{S}, 55^{\circ} 41.11^{\prime} \mathrm{W}$, to $63^{\circ} 51.52^{\prime} \mathrm{S}, 55^{\circ} 41.43^{\prime} \mathrm{W}, 238-244 \mathrm{~m}$, non muddy bottom with a lot of life (sponges, starfishes, ophiuroids, crinoids, Pentapora-like bryozoans), Agassiz trawl, 19 Feb. 2013, coll. C. d'Udekem d'Acoz and M. Verheye (RBINS, INV. 122941) [extraction ANT34; Genbank nr, COI: KU870821, 28S: KU759593]; 1 \%, cruise PS81, ANT-XXIX/3, stn 193-8, Bransfield Strait, $62^{\circ} 43.73^{\prime}$ S, $57^{\circ} 29.04^{\prime} \mathrm{W}$ to $62^{\circ} 43.80^{\prime} \mathrm{S}, 57^{\circ} 29.40^{\prime} \mathrm{W}, 428-431 \mathrm{~m}$, Agassiz trawl, 23 Feb. 2013, absolute alcohol, coll. C. d'Udekem d'Acoz and M. Verheye (RBINS, INV. 132962).

\section{Other material examined}

RV Polarstern cruises:

1 spec., cruise PS10, ANT-V/3, stn 527, eastern Weddell Sea, $72^{\circ} 23.5^{\prime} \mathrm{S}, 16^{\circ} 37.4^{\prime} \mathrm{W}$, depth uncertain (it is indicated 582-631 m on the specimen label, but there are no depth record in the cruise report: Schnack-Schiel 1987), Agassiz trawl, 22 Oct. 1986 (RBINS, INV. 132725); 1 spec., cruise PS39, ANTXXIII/3, EASIZ I, eastern Weddell Sea, no station, specimen kept in aquarium, 18 Feb. 1996, coll. C. De Broyer and G. Chapelle (RBINS, INV. 132995); 1 spec., cruise PS69, ANT-XXIII/8, stn 603-5, eastern Weddell Sea, $70^{\circ} 30.99^{\prime} \mathrm{S}, 08^{\circ} 48.08^{\prime} \mathrm{W}$ to $70^{\circ} 30.40^{\prime} \mathrm{S}, 08^{\circ} 48.13^{\prime} \mathrm{W}, 274-297 \mathrm{~m}$, sponge bottom, 7 Dec. 2006, coll. C. d'Udekem d'Acoz and H. Robert (RBINS, INV. 132978).

RV Marion Dufresne cruises:

SOUTHERN OCEAN: 2 specs, cruise MD42 (SIBEX), stn 22-CP66, Prydz Bay, 66 55'45" S, $74^{\circ} 04^{\prime} 11^{\prime \prime}$ E, depth missing [Google Earth coordinates for that position: $427 \mathrm{~m}$ (accessed $27 \mathrm{Sep} .2016$ )], 26 Jan. 1985 (MNHN-IU-2014-4264). 
Belgian and Belgian-Dutch expeditions:

SOUTHERN OCEAN: 1 ovigerous , , Princess Ragnhild Coast, stn 220, Baie du Glacier, exact coordinates unavailable [presumably about $70^{\circ} 18^{\prime} \mathrm{S}, 23^{\circ} 58^{\prime} \mathrm{E}$ ], 414-450 m, trawl, 1 Feb 1965, coll. A. Capart (RBINS, INV. 132728).

\section{Description}

Rostrum. Long, reaching mid of article 2 of peduncle of antenna 1 (teeth excluded), very strongly curved, sharp-tipped in lateral view.

EYE. Large, broadly elliptic.

Pereion-pleosome tooth pattern. Pereionite 1 with small broad and blunt mid-dorsal tooth pointing backwards, with pair of low and blunt, conical, dorsolateral teeth; pereionite 2 much narrower than pereionites 1 and 3, without mid-dorsal tooth and without pair of dorsolateral teeth; pereionite 3 with medium-sized broad and blunt mid-dorsal tooth pointing backwards and pair of low and blunt, conical, dorsolateral teeth; pereionite 4 to pleonite 2 with large, narrow, acute mid-dorsal tooth, of which the anterior border is regularly curved and the posterior border is slightly concave (except for pleonite 2 where the posterior border is straight), with pair of conical dorsolateral teeth, of which the size gradually increases posteriorly (these pairs of teeth are never duplicate); pleonite 3 with large nearly styliform acute-tipped symmetrical mid-dorsal tooth, and pair of large narrowly conical dorsolateral teeth (size of mid-dorsal teeth very weakly increasing from pereionite 4 to pleonite 2 ; mid-dorsal tooth of pleonite 3 almost as long as tooth of pleonite 2).

COXAE $1-3$. Strongly carinate and distally sharp.

Coxa 4. Anterodorsal border straight, anteroventral border distally straight, these two borders being joined by a long curve (anterior angle), this anterior angle is weakly projecting forward; ventral tooth long and acute; lateral carina with small tooth obliquely pointing backwards (in dorsal view this tooth form a broad U-shaped concavity with the coxa); carina very distant from margin of coxa at its deepest point.

Coxa 5. With long, sharp, narrowly triangular, carinate, lateral tooth pointing backwards (its anterior margin is parallel to body axis or weakly divergent and its posterior margin is oblique).

Coxa 6. With mid-sized, sharp, triangular, carinate, lateral tooth pointing obliquely backwards and with anterior border very weakly convex); posteroventral corner rounded, without angular discontinuity.

Coxa 7. With ventral border slightly curved, with posterior border straight, their convergence forming a blunt squared angle.

EPIMERAL PLATES 1-3. Posteroventral angle produced into a very long and very sharp tooth.

UROSOME TOOTH PATTERN. Urosomite 1 with large and sharp narrow tooth pointing upwards; urosomite 2 with pair of mid-sized posterior dorsolateral teeth pointing upwards; urosomite 3 with pair of mid-sized posterior dorsolateral teeth pointing obliquely upwards.

Telson. Cleft on 0.35 ; tips of lobes subacute, notch broadly and bluntly V-shaped.

Peduncle of antenna 1. Article 1 with long lateral and medial teeth reaching mid of article 2 (teeth excluded) and long ventral tooth slightly overreaching tip of article 2 (teeth excluded); article 2 with large lateral tooth of which 0.3 is overreaching tip of article 3 , and huge medial tooth of which 0.6 is 
overreaching tip of article 3 , without ventral tooth; article 3 with medium-sized ventral tooth, about 0.3 times as long as article itself.

GNATHOPODs 1-2. Carpus and propodus of normal slenderness; very slightly broadening distally, palm distinct.

PeReIOPODS 5-7. Merus, carpus and propodus slender; basis of pereiopods 5-6 of normal width, with posteroproximal process rounded and strongly protruding, with posterodistal tooth very strong (as long as basis width); basis of pereiopod 7 broad with posterodistal tooth acute and very large, followed more proximally by distinct concavity, directed posteriorly.

\section{Colour pattern}

Whitish to yellowish with orange plain markings (pigmented parts not arranged in dots); rostrum, antennae orange; distal half of walking pereiopods orange or striped with orange; mouthparts and tip of gnathopods red; eyes red.

\section{Body length}

Up to $37 \mathrm{~mm}$.

\section{Distribution}

Bransfield Strait, Dundee Island, Larsen A and B area, eastern shelf of the Weddell Sea, Princess Ragnhild Coast, Prydz Bay; 189-431 m and possibly $631 \mathrm{~m}$.

\section{Remarks}

Epimeria anguloce sp. nov. is morphologically similar to E. corbariae. See key to the subgenus and account for the latter species for differences. Two E. anguloce sp. nov. from the eastern shelf of the Weddell Sea were examined. These specimens were not adequately fixed for genetic studies and were not in very good condition. However they showed traces of an orange mottled colour pattern similar to that of specimens from the Antarctic Peninsula region. The mid-dorsal tooth of their pereionite 1 and 3 is a bit stronger and the posterodistal tooth of the basis of their pereiopod 7 a bit shorter than in Peninsular specimens. The same form was found off Princess Ragnhild Coast and Prydz Bay.

The collection locality of the 'Epimeria macrodonta' illustrated by Rauschert \& Arntz (2015: 61 plate 54) was given in a preliminary draft of the book made available to the present authors. The specimen was collected during cruise ANT-XV/3, at stn 355: north west of King George Island, $61^{\circ} 60^{\prime} \mathrm{S}, 59^{\circ} 15^{\prime} \mathrm{W}$, $128-130 \mathrm{~m}$. On the published picture, the mid-dorsal tooth of pereionite 3 appears as almost as long as the tooth of pereionite 4, i.e., much longer than in any known species of the macrodonta complex, and acute-tipped. Coleman (2007) published a photograph, which was absolutely identical (plate 1 fig. d), except for the mid-dorsal tooth of pereionite 3, which is less than half as long as that of pereionite 4, and blunt-tipped (i.e., as in all known species of the macrodonta complex). It seems therefore that the photograph has been erroneously altered in the book of Rauschert \& Arntz (2015). One of the authors presumably believed that the tooth was broken and tried to 'repair' it.

Epimeria (Drakepimeria) colemani subgen. et sp. nov. urn:1sid:zoobank.org:act:74A8958B-6C00-4D92-89B6-AA6977F51D3A

Figs $17-26$

Epimeria aff. schiaparelli - d'Udekem d'Acoz \& Verheye 2013: 63, fig. 3.8.2h (photograph in colour). 'Clade A similis/macrodonta complex - SI5' - Verheye et al. 2016a, supplement: 2 (online).

non Epimeria schiaparelli Lörz, Maas, Linse \& Fenwick, 2007: 25, figs 1-7. 


\section{Etymology}

The species is dedicated to Charles Oliver Coleman (Museum für Naturkunde, Berlin), as a recognition of his important contribution to the knowledge of the taxonomy of the genus Epimeria. The name is a genitive.

\section{Type material}

\section{Holotype}

RV Polarstern cruises:

SOUTHERN OCEAN: ovigerous $q$, cruise PS81, ANT-XXIX/3, Bransfield Strait, stn 196-8, 62 $47.80^{\prime}$ S, $57^{\circ} 5.35^{\prime} \mathrm{W}$ to $62^{\circ} 47.63^{\prime} \mathrm{S}, 57^{\circ} 5.63^{\prime} \mathrm{W}, 542-580 \mathrm{~m}$, Agassiz trawl, 24 Feb. 2013, coll. C. d'Udekem d'Acoz and M. Verheye (RBINS, INV. 122942) [extraction ANT37; Genbank nr, COI: KU870823, 28S: KU759596].

\section{Paratypes}

RV Polarstern cruises:

SOUTHERN OCEAN: 2 specs, cruise PS06, ANT-III/3, stn 348, eastern Weddell Sea, $72^{\circ} 50^{\prime} \mathrm{S}, 19^{\circ} 23^{\prime} \mathrm{W}$, 490 m, bottom trawl, 20 Feb. 1985, coll. J. Plötz (RBINS, INV. 132740); 1 spec., cruise PS06, ANTIII/3, station unknown, eastern Weddell Sea, Feb. 1985, coll. J. Plötz (RBINS, INV. 132742); 1 small spec., cruise PS39, ANT-XIII/3, EASIZ I, stn 1, GSN 1, eastern Weddell Sea, $71^{\circ} 03.10^{\prime} \mathrm{S}, 11^{\circ} 25.50^{\prime} \mathrm{W}$ to $71^{\circ} 02.10^{\prime} \mathrm{S}, 11^{\circ} 19.30^{\prime} \mathrm{W}, 462-481 \mathrm{~m}$, bottom trawl, 5 Feb. 1996, coll. C. De Broyer and G. Chapelle (RBINS, INV. 132703); 1 small spec., cruise PS39, ANT-XIII/3, EASIZ I, stn 1, GSN 1, eastern Weddell Sea, $71^{\circ} 03.10^{\prime} \mathrm{S}, 11^{\circ} 25.50^{\prime} \mathrm{W}$ to $71^{\circ} 02.10^{\prime} \mathrm{S}, 1^{\circ} 19.30^{\prime} \mathrm{W}, 462-481 \mathrm{~m}$, bottom trawl, $5 \mathrm{Feb}$. 1996, coll. C. De Broyer and G. Chapelle (RBINS, INV. 132709); 1 spec., cruise PS39, ANT-XIII/3, EASIZ I, stn 12, GSN 5, eastern Weddell Sea, $73^{\circ} 18.10^{\prime} \mathrm{S}, 21^{\circ} 10.10^{\prime} \mathrm{W}$ to $73^{\circ} 17.10^{\prime} \mathrm{S}, 21^{\circ} 08.20^{\prime} \mathrm{W}, 457-459 \mathrm{~m}$, bottom trawl, 14 Feb. 1996, coll. C. De Broyer and G. Chapelle (RBINS, INV. 132695); 1 spec., cruise PS39, ANT-XIII/3, EASIZ I, stn 17, GSN 10, eastern Weddell Sea, $73^{\circ} 18.00^{\prime} \mathrm{S}, 21^{\circ} 09.90^{\prime} \mathrm{W}$ to $73^{\circ} 19.10^{\prime} \mathrm{S}$, 21ำ14.90' W, 465-468 m, bottom trawl, 16 Feb. 1996, coll. C. De Broyer and G. Chapelle (RBINS, INV. 132693); 4 specs, cruise PS69, ANT-XXIII/8, stn 661-2, between Elephant Island and King George Island, $61^{\circ} 39.29^{\prime} \mathrm{S}, 57^{\circ} 02.89^{\prime} \mathrm{W}$ to $61^{\circ} 39.20^{\prime} \mathrm{S}, 57^{\circ} 04.75^{\prime} \mathrm{W}, 466-467 \mathrm{~m}$, bottom trawl, $30 \mathrm{Dec} .2006$, coll. C. d'Udekem d'Acoz and H. Robert (RBINS, INV. 122549); 3 alcohol-fixed specs, cruise PS69, ANT-XXIII/8, stn 662-1, between Elephant Island and King George Island, $61^{\circ} 35.91^{\prime} \mathrm{S}, 57^{\circ} 17.04^{\prime} \mathrm{W}$ to $61^{\circ} 35.41^{\prime} \mathrm{S}, 57^{\circ} 20.60^{\prime} \mathrm{W}, 425-432 \mathrm{~m}$, bottom trawl, 30 Dec. 2006, coll. C. d'Udekem d'Acoz and H. Robert (RBINS, INV. 122492); 2 specs, initially fixed with formalin, cruise PS69, ANT-XXIII/8, stn $663-1$, north of King George Island, $61^{\circ} 38.18^{\prime} \mathrm{S}, 57^{\circ} 33.17^{\prime} \mathrm{W}$ to $61^{\circ} 38.02^{\prime} \mathrm{S}, 57^{\circ} 37.16^{\prime} \mathrm{W}, 432-434$ m, bottom trawl, 30 Dec. 2006, coll. C. d'Udekem d'Acoz and H. Robert (RBINS, INV. 122537); 1 immature spec., cruise PS71, ANT-XXIV/2, ANDEEP-SYSTCO, eastern Weddell Sea, stn 48-1, $70^{\circ} 23.94^{\prime} \mathrm{S}, 8^{\circ} 19.14^{\prime} \mathrm{W}$ to $70^{\circ} 23.89^{\prime} \mathrm{S}, 8^{\circ} 18.67^{\prime} \mathrm{W}, 595-602 \mathrm{~m}$, bryozoan bottom (exceptional diversity of bryozoans), Agassiz trawl, 12 Jan. 2008, coll. H. Robert (RBINS, INV. 122901); 1 spec., dissected and illustrated by unpublished line drawings, cruise PS71, ANT-XXIV/2, ANDEEP-SYSTCO, eastern Weddell Sea, stn $48-1,70^{\circ} 23.94^{\prime} \mathrm{S}, 8^{\circ} 19.14^{\prime} \mathrm{W}$ to $70^{\circ} 23.89^{\prime} \mathrm{S}, 8^{\circ} 18.67^{\prime} \mathrm{W}, 595-602 \mathrm{~m}$, bryozoan bottom (exceptional diversity of bryozoans), Agassiz trawl, 12 Jan. 2008, coll. H. Robert (RBINS, INV. 132977) [extraction P41; Genbank nr, COI: KU870895, 28S: KU759684]; 8 specs, fixed in formalin, cruise PS71, ANT-XXIV/2, ANDEEP-SYSTCO, eastern Weddell Sea, stn 48-1, 70²3.94' S, $8^{\circ} 19.14^{\prime}$ W to $70^{\circ} 23.89^{\prime} \mathrm{S}, 8^{\circ} 18.67^{\prime} \mathrm{W}, 595-602 \mathrm{~m}$, bryozoan bottom (exceptional diversity of bryozoans), Agassiz trawl, 12 Jan. 2008, coll. H. Robert (RBINS, INV. 132455); 2 specs, fixed in alcohol, cruise PS71, ANTXXIV/2, ANDEEP-SYSTCO, eastern Weddell Sea, stn 48-1, 70²3.94' S, $8^{\circ} 19.14^{\prime} \mathrm{W}$ to $70^{\circ} 23.89^{\prime} \mathrm{S}$, $8^{\circ} 18.67^{\prime} \mathrm{W}, 595-602 \mathrm{~m}$, bryozoan bottom (exceptional diversity of bryozoans), Agassiz trawl, 12 Jan. 2008, coll. H. Robert (RBINS, INV. 132986); 1 immature spec., cruise PS77, ANT-XXVII/3, CAMBIO, eastern Weddell Sea, stn 265-2, 7047.34' S, $10^{\circ} 40.39^{\prime} \mathrm{W}$ to $70^{\circ} 47.13^{\prime} \mathrm{S}, 10^{\circ} 40.54^{\prime} \mathrm{W}, 500-600 \mathrm{~m}$, 
Agassiz trawl, 22 Mar. 2011, coll. C. Havermans and H. Robert (RBINS, INV. 132965) [extraction I9; Genbank nr, COI: KU870853, 28S: KU759630]; 1 ㅇ, cruise PS81, ANT-XXIX/3, Bransfield Strait, stn 193-8, 62 ${ }^{\circ} 43.73^{\prime} \mathrm{S}, 57^{\circ} 29.04^{\prime} \mathrm{W}$ to $62^{\circ} 43.80^{\prime} \mathrm{S}, 57^{\circ} 29.40^{\prime} \mathrm{W}, 428-431 \mathrm{~m}$, Agassiz trawl, $23 \mathrm{Feb} .2013$, coll. C. d'Udekem d'Acoz and M. Verheye (RBINS, INV. 132976) [extraction I13; Genbank nr, COI: KU870839, 28S: KU759615]; 1 ovigerous + , cruise PS81, ANT-XXIX/3, Bransfield Strait, stn 193$9,62^{\circ} 43.50^{\prime} \mathrm{S}, 57^{\circ} 27.92^{\prime} \mathrm{W}$ to $62^{\circ} 43.53^{\prime} \mathrm{S}, 57^{\circ} 28.28^{\prime} \mathrm{W}, 420-428 \mathrm{~m}$, sponge bottom, Agassiz trawl, 23 Feb. 2013, coll. C. d'Udekem d'Acoz and M. Verheye (RBINS, INV. 132966) [extraction ANT36; Genbank nr, COI: KU870822, 28S: KU759595]; 1 large spec., cruise PS81, ANT-XXIX/3, Bransfield Strait, stn $193-9,62^{\circ} 43.50^{\prime} \mathrm{S}, 57^{\circ} 27.92^{\prime} \mathrm{W}$ to $62^{\circ} 43.53^{\prime} \mathrm{S}, 57^{\circ} 28.28^{\prime} \mathrm{W}, 420-428 \mathrm{~m}$, sponge bottom, Agassiz trawl, 23 Feb. 2013, coll. C. d'Udekem d'Acoz and M. Verheye (RBINS, INV. 122962); 3 large specs, cruise PS81, ANT-XXIX/3, Bransfield Strait, stn 196-8, 62 $47.80^{\prime} \mathrm{S}, 57^{\circ} 5.35^{\prime} \mathrm{W}$ to $62^{\circ} 47.63^{\prime}$ S, 57 5.63'W, 542-580 m, Agassiz trawl, 24 Feb. 2013, coll. C. d'Udekem d'Acoz and M. Verheye (RBINS, INV. 122959); 3 specs, cruise PS81, ANT-XXIX/3, Bransfield Strait, stn 217-6, 62 ${ }^{\circ} 53.45^{\prime}$ S, $58^{\circ} 13.06^{\prime} \mathrm{W}$ to $62^{\circ} 53.42^{\prime} \mathrm{S}, 58^{\circ} 13.41^{\prime} \mathrm{W}, 461-483 \mathrm{~m}$, rich sponge bottom, Agassiz trawl, 2 Mar. 2013, coll. C. d'Udekem d'Acoz and M. Verheye (RBINS, INV. 122922A) [extraction K39, largest specimen; Genbank nr, COI: KU870871, 28S: KU759651].

\section{Other material examined}

RV Aurora Australis cruises:

SOUTHERN OCEAN: 1 spec., cruise CEAMARC, sample CEAMARC 1317, stn 51AEV215, Adélie Coast, 66 $44^{\prime} 52^{\prime \prime} \mathrm{S}, 145^{\circ} 26^{\prime} 40^{\prime \prime} \mathrm{E}, 525-553 \mathrm{~m}$, beam trawl, 30 Dec. 2007, coll. IPEV-AAD-MNHN (MNHN-IU-2014-7323, removed from MNHN-IU-2014-4279); 1 spec., cruise CEAMARC, sample CEAMARC 2724, stn 71EV447, Adélie Coast, 6624'00" S, 140³2'21" E, 683-791 m, beam trawl, 14 Jan. 2008, coll. IPEV-AAD-MNHN (MNHN-IU-2014-7324, removed from MNHN-IU-2014-4337) [extraction M6; Genbank nr, COI: KU870889, 28S: KU759673]; 3 specs, cruise CEAMARC, sample CEAMARC 3532, stn 87EV524, Adélie Coast, 6529'29" S, 139¹8'37" E, 397-411 m, beam trawl, 17 Jan. 2008, coll. IPEV-AAD-MNHN (MNHN-IU-2014-4353); 5 specs, cruise CEAMARC, sample

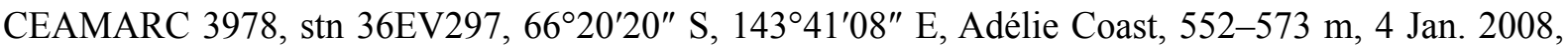
coll. IPEV-AAD-MNHN (MNHN-IU-2014-4329).

RV Marion Dufresne cruises:

SOUTHERN OCEAN: 1 spec., cruise MD42 (SIBEX), stn 22-CP73, Prydz Bay, 66 57'25" S, 72 $41^{\prime} 25^{\prime \prime}$ E, depth missing [Google Earth depth for that position: $540 \mathrm{~m}$ (accessed 27 Sep. 2016)] 26 Jan. 1985 (MNHN-IU-2014-4259) (typed label); 1 spec., cruise MD42 (SIBEX), stn 22-CP66, Prydz Bay, 66 $55^{\prime} 45^{\prime \prime} \mathrm{S}, 74^{\circ} 4^{\prime} 11^{\prime \prime} \mathrm{E}$, depth missing [Google Earth depth for that position: $427 \mathrm{~m}$ (accessed 27 Sep. 2016)], 26 Jan. 1985 (MNHN-IU-2014-4266) (typed label).

Belgian and Belgian-Dutch Antarctic expedition:

SOUTHERN OCEAN: 2 specs, Princess Ragnhild Coast, stn 220, Baie du Glacier, exact coordinates unavailable [presumably about $70^{\circ} 18^{\prime} \mathrm{S}, 23^{\circ} 58^{\prime} \mathrm{E}$ ], 414-450 m, trawl, 1 Feb. 1965, coll. A. Capart (RBINS, INV. 132737); 2 specs, Princess Ragnhild Coast, stn 220, Baie du Glacier, exact coordinates unavailable [presumably about $70^{\circ} 18^{\prime} \mathrm{S}, 2^{\circ} 58^{\prime} \mathrm{E}$ ], 414-450 m, trawl, 1 Feb. 1965, coll. A. Capart (RBINS, INV. 132738); 5 specs, Princess Ragnhild Coast, stn 220, Baie du Glacier, exact coordinates unavailable [presumably about $70^{\circ} 18^{\prime} \mathrm{S}, 23^{\circ} 58^{\prime} \mathrm{E}$ ], 414-450 m, trawl, 1 Feb. 1965, coll. A. Capart (RBINS, INV. 132739).

RV Discovery cruises (National Antarctic Expedition 1901-1904):

SOUTHERN OCEAN: 1 adult +, Ross Sea, $\mathrm{n}^{\circ}$ 13, $914 \mathrm{~m}$ (500 fathoms), 22 Jan. 1902, together in the same tube with a juvenile Epimeria, which is identified herein as E. macrodonta s.str., obviously 
representing paralectotypes of Epimeria macrodonta designated by Lörz et al. (2007), albeit no label indicated their status of paralectotypes (BMNH 1907.6.6.259-262) (in part).

\section{Description}

Rostrum. Long, overreaching tip of article 1 of peduncle of antenna 1 (teeth excluded), weakly curved, sharp-tipped in lateral view.

EYE. Very large, elliptic.

Pereion-Pleosome tooth pattern. Pereionites 3 to pleonite 3 with mid-dorsal tooth; pereionite 1 to pleonite 3 with pair of posterodorsal teeth or protrusions (those of the pereion are distinctly carinate); pereionites 1-2 without any trace of mid-dorsal tooth, with pair of carinate dorsolateral protrusions; pereionite 2 slightly narrower than pereionite 1 ; pereionite 3 with small blunt-tipped posterior middorsal tooth and pair of small dorsolateral carinate teeth; pereionite 4 to 6 with medium-sized blunttipped broad and regularly curved mid-dorsal tooth and pair of small dorsolateral carinate teeth; pereionite 7 with large acute-tipped and regularly curved mid-dorsal tooth and pair of small dorsolateral carinate teeth; pleonites 1-2 with large acute-tipped and regularly curved mid-dorsal tooth and pair of small dorsolateral non-carinate teeth; on pleonite 1 a second pair of (much smaller) dorsolateral teeth is observed between the mid-dorsal tooth and the main pair of dorsolateral teeth; pleonite 3 with large acute-tipped mid-dorsal tooth bearing a weak median notch and pair of small dorsolateral non-carinate teeth (teeth from pereionite 7 to pleonite 3 distinctly longer than more anterior teeth, the size difference being more important in immatures than in adults)

COXAE 1-3. Strongly carinate and distally sharp.

Coxa 4. Anterodorsal and anteroventral border nearly straight joined by low and blunt angular discontinuity, anterior angle slightly but distinctly projecting forward; ventral tooth long and acute; lateral carina with obtuse angularity or very obtuse tooth, carina very distant from margin of coxa at its deepest point.

Coxa 5. With long, sharp, triangular, carinate, lateral tooth pointing obliquely backwards.

Coxa 6. With mid-sized, sharp, triangular, carinate, lateral tooth pointing obliquely backwards; posteroventral corner rounded, with trace of angular discontinuity.

Coxa 7. With ventral border slightly curved, with posterior border straight, their convergence forming a sharp squared angle.

Epimeral PLAtes 1-3. Posteroventral angle produced into a long and very sharp tooth.

UROSOME TOOTH PATTERN. Urosomite 1 with sharp triangular process pointing upwards; urosomite 2 without pair of small posterior dorsolateral teeth pointing upwards.

TeLson. Cleft on 0.2 ; tips of lobes rounded, slit fairly narrow.

Peduncle of antenna 1. Article 1 with long lateral and medial teeth nearly reaching mid of article 2 (teeth excluded) and long ventral tooth reaching tip of article 2 (teeth excluded); article 2 with huge lateral tooth and very large medial tooth considerably overreaching tip of article 3 , with ventral tooth slightly overreaching tip of article 3 (tooth excluded); article 3 with well developed ventral tooth, about as long as article itself. 
GNATHOPODs 1-2. Carpus and propodus of normal slenderness; propodus not narrowing distally, palm distinct.

Pereiopods 5-7. Merus, carpus and propodus slender; basis of pereiopods 5-6 of normal width, with posteroproximal process rounded and strongly protruding in pereiopod 5, weakly protruding in pereiopod 6, with posterodistal tooth strong; basis of pereiopod 7 very broad with posterodistal tooth sharp, followed more proximally by small concavity, directed posteriorly.

\section{Colour pattern}

Whitish, with vague reddish marks on the mid-dorsal tooth of the posterior body segments (pereionite 7 to urosomite 1), tip of rostrum, tip of pereiopods. Eyes reddish.

\section{Body length}

Up to $47 \mathrm{~mm}$.

\section{Distribution}

Between King George Island and Elephant Island, Bransfield Strait, eastern shelf of the Weddell Sea, Princess Ragnhild Coast, Prydz Bay, Adélie Coast, western Ross Sea, 397-914 m.

\section{Remarks}

In immature E. colemani sp. nov., the mid-dorsal tooth of pereionite 7 and pleonites 1-2 are much longer than in adults and much longer than more anterior mid-dorsal teeth. Epimeria colemani sp. nov. specimens from western stations (South Shetland Islands, Antarctic Peninsula, Eastern Weddell Sea) and the only sequenced specimen from the Adélie Coast (MNHN-IU-2014-7324, extraction M6) have identical COI haplotypes, whereas the divergence between their $28 \mathrm{~S}$ sequences is in the range expected between distinct species (from comparison with other species in this complex) (fig. 1 in Verheye et al. 2016a as Epimeria SI5). Additional data would be needed to explain this discrepancy. As morphologically, the specimens from the Adélie Coast cannot be distinguished from the remaining E. colemani, they are provisionally considered as conspecifics.

\section{Epimeria (Drakepimeria) corbariae sp. nov. urn:1sid:zoobank.org:act:74519DD0-1C75-4392-AA0D-5FB811B108F4}

Figs $27-43$

Epimeria macrodonta - ? Chilton 1912: 486.

'Clade A similis/macrodonta complex - MA2' - Verheye et al. 2016a, supplement: 2 (online).

non Epimeria macrodonta Walker, 1906: 16.

\section{Etymology}

The species is dedicated to Laure Corbari (Muséum national d'Histoire naturelle, Paris), who gave us the opportunity to study the very interesting collections of the CEAMARC and REVOLTA expeditions. The name is a genitive.

\section{Type material}

\section{Holotype}

REVOLTA cruises: (RV Seatruck)

SOUTHERN OCEAN: 1 क, cruise REVOLTA I, stn REVO-007b, Collect_ID: 249, Field_ID: CE000004589, Adélie Coast, 66³8'25" S, 13949'43" E, 127-133 m, 22 Jan. 2010, coll. M. Eléaume, L. 
Hemery and A. D'Hont, (MNHN-IU-2009-2570) [extraction K4; Genbank nr, COI: KU870872, 28S: KU759652].

\section{Paratypes}

RV Aurora Australis cruises:

SOUTHERN OCEAN: 3 specs, cruise CEAMARC, sample CEAMARC 933, stn 40EV152, Adélie

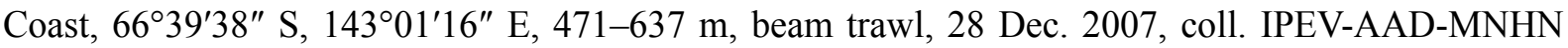
(MNHN-IU-2014-4283); 1 + , cruise CEAMARC, sample CEAMARC 1643, stn 31EV268, Adélie Coast, $66^{\circ} 34^{\prime} 30^{\prime \prime} \mathrm{S}, 145^{\circ} 01^{\prime} 15^{\prime \prime} \mathrm{E}, 429-451 \mathrm{~m}$, beam trawl, 3 Jan. 2008, coll. IPEV-AAD-MNHN (MNHNIU-2014-7326, removed from MNHN-IU-2014-4322); 5 specs, cruise CEAMARC, sample CEAMARC

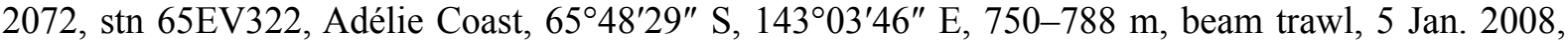
coll. IPEV-AAD-MNHN (MNHN-IU-2014-4286); 1 ㅇ, cruise CEAMARC, sample CEAMARC 2724, stn 71EV447, Adélie Coast, 66²4'00" S, 140³2'21" E, 683-791 m, v14 Jan. 2008, coll. IPEV-AADMNHN (MNHN-IU-2014-7327, removed from MNHN-IU-2014-4337); 6 specs, cruise CEAMARC,

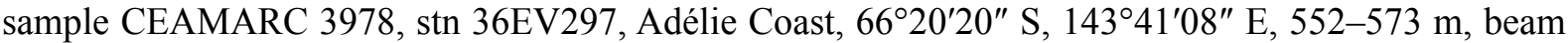
trawl, 4 Jan. 2008, coll. IPEV-AAD-MNHN (MNHN-IU-2014-4330); 1 spec., cruise REVOLTA II, stn REVO_133, Collect_ID: REVO_133, Adélie Coast, 66 37'04" S, 14000'13" E, 103-107 m, 11 Jan. 2011, coll. N. Améziane, N. Bax, C. Gallut, A.C. Lautrédou and C. Robineau (MNHN-IU-2014-4297); 1 ovigerous + , cruise REVOLTA II, stn REVO_091, Collect_ID: REVO_162, Field_ID: CE-000001166, Adélie Coast, 66²41'07" S, 13956'41" E, 33-34 m, 19 Jan. 2011, coll. N. Améziane, N. Bax, C. Gallut, A.C. Lautrédou and C. Robineau (MNHN-IU-2014-7325, removed from MNHN-2014-4299) [extraction M10; Genbank nr, COI: KU870878, 28S: KU759661]; 1 spec., cruise REVOLTA II, stn REVO_091, Collect_ID: REVO_162, Field_ID: CE-000001166, 66²41'07" S, 13956'41" E, 33-34 m, 19 Jan. 2011, coll. N. Améziane, (MNHN-IU-2014-4299); 1 spec., cruise REVOLTA II, stn REVO_091, Collect_ID: REVO_162, Adélie Coast, 66 41'07" S, 139 56'41" E, 33-34 m, 19 Jan. 2011, coll. N. Améziane, N. Bax, C. Gallut, A.C. Lautrédou and C. Robineau (MNHN-IU-2014-4298); 1 juv., cruise REVOLTA II, stn REVO_085, Collect_ID: REVO_191, Field_ID: CE-000001559, 66 ${ }^{\circ} 40^{\prime} 12^{\prime \prime}$ S, 139 55'56" E, Adélie Coast, 37-44 m, 29 Jan. 2011, coll. N. Améziane, N. Bax, C. Gallut, A.C. Lautrédou and C. Robineau, (MNHN-IU-2014-4296) [extraction M11; Genbank nr, 28S: KU759662]; 1 spec., cruise REVOLTA II, stn REVO 037, Collect ID: REVO 209, Adélie Coast, 66 39'13" S, 139 52'04" E, 105-107 m, 1 Feb. 2011, coll. N. Améziane, N. Bax, C. Gallut, A.C. Lautrédou and C. Robineau (MNHN-IU-2014-4305); 2 specs, cruise REVOLTA II, stn REVO_037, Collect_ID: REVO_209, Adélie Coast, 66³9'13" S, 139 52'04" E, 105-107 m, 1 Feb. 2011, coll. N. Améziane, N. Bax, C. Gallut, A.C. Lautrédou and C. Robineau (RBINS 132717, formerly MNHN-IU-2014-4305); 1 spec., cruise REVOLTA III, stn REVO_039, Collect_ID: REVO_464, Adélie Coast, 66 $38.370^{\prime}$ S, $139^{\circ} 55.863^{\prime}$ E to $66^{\circ} 38.406^{\prime}$ S, $139^{\circ} 56.030^{\prime}$ E, 100 m, beam trawl, 30 Jan. 2012, coll. G. Lecointre, A. Dettaï, J. Lanshere, C. Gallut and C. Ozouf (MNHN number-IU-2009-2542); 1 juv., cruise REVOLTA III, stn REVO_040, Collect_ ID: REVO_470, Adélie Coast, $66^{\circ} 38.50^{\prime} \mathrm{S}, 139^{\circ} 57.02^{\prime} \mathrm{E}$ to $66^{\circ} 38.41^{\prime} \mathrm{S}, 139^{\circ} 57.14^{\prime} \mathrm{W}, 98-100 \mathrm{~m}$, beam trawl, 31 Jan. 2012, coll. G. Lecointre, A. Dettaï, J. Lanshere, C. Gallut and C. Ozouf (MNHNIU-2009-2551); 1 small spec., cruise REVOLTA III, stn REVO_064, Collect_ID: REVO_481, Adélie Coast, $66^{\circ} 36.371^{\prime} \mathrm{S}, 140^{\circ} 05.075^{\prime} \mathrm{E}$ to $66^{\circ} 36.394^{\prime} \mathrm{S}, 140^{\circ} 04.966^{\prime} \mathrm{E}, 110-120 \mathrm{~m}$, beam trawl, $3 \mathrm{Jan}$. 2012, coll. G. Lecointre, A. Dettaï, J. Lanshere, C. Gallut and C. Ozouf (MNHN-IU-2009-2562); 1 adult spec., cruise REVOLTA III, stn REVO_068, Collect_ID: REVO_493, Field_ID: CE-000002621, Adélie Coast, 66 $35^{\prime} 18^{\prime \prime} \mathrm{S}, 140^{\circ} 03^{\prime} 15^{\prime \prime} \mathrm{E}$ to $66^{\circ} 35^{\prime} 22^{\prime \prime} \mathrm{S}, 140003^{\prime} 23^{\prime \prime} \mathrm{E}, 57-118 \mathrm{~m}$, beam trawl, 7 Feb. 2012, coll. G. Lecointre, A. Dettaï, J. Lanshere, C. Gallut and C. Ozouf (MNHN-IU-2009-2581).

RV L'Astrolabe cruises:

5 specs, cruise REVOLTA III, stn none (Dumont d'Urville sea), Collect_ID: REVO_449, Field_ID: CE-000002109 Adélie Coast, $66^{\circ} 38^{\prime} \mathrm{S}, 140^{\circ} 42^{\prime}$ E to $66^{\circ} 38^{\prime} \mathrm{S}, 140^{\circ} 40^{\prime} \mathrm{E}, 718^{-}-729 \mathrm{~m}$, mud, beam trawl, 20 Jan. 2012, coll. G. Lecointre, A. Dettaï, J. Lanshere, C. Gallut and C. Ozouf(MNHN-IU-2009-2543); 
1 †, cruise REVOLTA III, stn REVO_064, Collect_ID: REVO_481, Field_ID: CE-000003196, Adélie Coast, $66^{\circ} 36.371^{\prime} \mathrm{S}, 140^{\circ} 05.075^{\prime} \mathrm{E}$ to $66^{\circ} 36.394^{\prime} \mathrm{S}, 140^{\circ} 04.966^{\prime} \mathrm{E}, 110-120 \mathrm{~m}$, beam trawl, 3 Feb. 2012 , coll. G. Lecointre, A. Dettaï, J. Lanshere, C. Gallut and C. Ozouf (MNHN-IU-2009-2563) [extraction K5; Genbank nr, COI: KU870876, 28S: KU759657].

\section{Description}

Rostrum. Long, reaching base of article 2 of peduncle of antenna 1 (teeth excluded), very strongly curved, sharp-tipped in lateral view.

EYE. Large, broadly elliptic.

Pereion-Pleosome tooth pattern. Pereionite 1 usually without mid-dorsal tooth or with a posterior bump, rarely with small subacute tooth pointing upwards (tooth with anterior border oblique and posterior border vertical), without pair of dorsolateral protrusions when pereionite has no mid-dorsal tooth or only a posterior bump, with pair of low protrusions when mid-dorsal tooth present; pereionite 2 much narrower than pereionites 1 and 3, without mid-dorsal tooth and without pair of dorsolateral teeth; pereionite 3 with medium-sized, broad, subacute to acute tooth pointing upwards or slightly backwards and pair of low and blunt, conical, dorsolateral teeth; pereionite 4 to pleonite 2 with large, narrow to fairly narrow, acute mid-dorsal tooth, of which the anterior border is regularly curved or curved with very faint angular discontinuity and the posterior border is slightly concave, with pair of conical dorsolateral teeth of which the size gradually increases posteriorly (these pairs of teeth are never duplicate); pleonite 3 with large nearly styliform acute-tipped symmetrical mid-dorsal tooth, and pair of large narrowly conical dorsolateral teeth (size of mid-dorsal teeth weakly increasing from pereionite 4 to pleonite 2; mid-dorsal tooth of pleonite 3 slightly but distinctly shorter than tooth of pleonite 2 ).

COXAE $1-3$. Strongly carinate and distally sharp.

Coxa 4. Anterodorsal border straight, anteroventral border distally slightly curved, these two borders being joined by a fairly short blunt angular discontinuity (anterior angle), this anterior angle is weakly projecting forward; ventral tooth long and acute; lateral carina with small tooth pointing backwards (its anterior border is parallel to body axis or nearly so; in dorsal view this tooth form a narrow V-shaped notch with the coxa); carina fairly distant from margin of coxa at its deepest point.

CoxA 5. With long, sharp, narrowly triangular, carinate, lateral tooth pointing backwards (its anterior margin is distinctly oblique to nearly parallel to body axis and its posterior margin is oblique.

Coxa 6 . With mid-sized, sharp and triangular, carinate, lateral tooth pointing obliquely backwards; its anterior border is distinctly convex); posteroventral corner broadly rounded.

Coxa 7. With ventral border slightly curved, with posterior border straight or very weakly concave, their convergence forming a sharp squared angle.

EPIMERAL Plates 1-3. Posteroventral angle produced into a very long and very sharp tooth.

UROSOME TOOTH PATTERN. Urosomite 1 with large and sharp narrow tooth pointing upwards; urosomite 2 with pair of mid-sized posterior dorsolateral teeth pointing upwards; urosomite 3 with pair of mid-sized posterior dorsolateral teeth pointing obliquely upwards.

TELSON. Cleft on $0.45-0.55$; tips of lobes subacute, notch narrowly U-shaped. 
Peduncle of antenna 1. Article 1 with long lateral and medial teeth reaching mid of article 2 (teeth excluded) and long ventral tooth distinctly overreaching tip of article 2 (teeth excluded); article 2 with large lateral tooth of which 0.3 is overreaching tip of article 3, and huge medial teeth of which 0.6 is overreaching tip of article 3 , without ventral tooth; article 3 with medium-sized ventral tooth, about 0.3 times as long as article itself.

GNATHOPODS 1-2. Carpus and propodus of normal slenderness; very slightly broadening distally, palm distinct.

Pereiopods 5-7. Merus, carpus and propodus slender; basis of pereiopods 5-6 of normal width, with posteroproximal process rounded and strongly protruding, with posterodistal tooth very strong (as long as basis width); basis of pereiopod 7 broad with posterodistal tooth acute and large, followed more proximally by distinct concavity, directed posteriorly.

\section{Colour pattern}

Homogeneously bright red, or red marks on a whitish or pale reddish background.

\section{Body length}

Up to $31 \mathrm{~mm}$.

\section{Distribution}

Adélie Coast, 33-827 m.

\section{Remarks}

Epimeria corbariae sp. nov. exhibits variation in the dentition of the first body segment and the robustness of the mid-dorsal teeth (see figs $27,28,34,38$ ). The angle of divergence of the lateral tooth of coxa 5 with body axis is also variable. Due to these variations, the most extreme forms of $E$. corbariae sp. nov. were initially interpreted as two separate species. However, genetic data (COI, 28S) suggest that they are indeed conspecific (Fig. 342). Epimeria corbariae sp. nov. (Adélie Coast) is morphologically similar to E. anguloce sp. nov. (Weddell Sea and Bransfield Strait), but molecular analyses based on the $28 \mathrm{~S}$ gene suggest that they are distinct species (Fig. 342). The following morphological differences were observed. In E. corbariae sp. nov., pereionite 1 is usually smooth or with a posterior bump (rarely with a small tooth); in E. anguloce sp. nov. a small tooth is always present. In E. corbariae sp. nov. the mid-dorsal tooth of pereionite 3 to pleonite 2 are a bit shorter and a bit broader than in E. anguloce sp. nov. and those of pereionite 3 to pleonite 2 have a trace of anterior angular discontinuity, which is not present in E. anguloce sp. nov. The tooth of the lateral carina of coxa 4 is more posteriorly directed in E. corbariae sp. nov. and forms a narrower notch with the coxa (when examined in dorsal view) than in E. anguloce sp. nov. The junction between the ventral and the posterior border of coxa 7 forms a sharp squared angle in E. corbariae sp. nov. vs a blunt squared angle in $E$. anguloce sp. nov., this difference being very clear. In E. corbariae sp. nov., the posterodistal tooth of basis of pereiopod 7 is shorter than in E. anguloce sp. nov. Epimeria corbariae sp. nov. is also very similar to E. schiaparelli, but the middorsal ornamentation of pereionite 3 is much more developed in the first species.

Epimeria (Drakepimeria) cyrano subgen. et sp. nov. urn:1sid:zoobank.org:act:7E682282-1C82-4A2B-BEEC-54B05FEEA37C

Figs $44-50$

'Clade A similis/macrodonta complex - SP1' - Verheye et al. 2016a, supplement: 2 (online). 


\section{Etymology}

Cyrano de Bergerac is the central character of the eponymous play by Edmond Rostand. In the play, Cyrano is described as endowed with a prominent nose. The name, which is a noun in apposition, alludes to the long, straight and anteriorly directed rostrum of the species.

\section{Type material}

\section{Holotype}

RV Polarstern cruises:

SOUTHERN OCEAN: 1 q, cruise PS77, ANT XXVII/3, CAMBIO, stn 263-6, eastern Weddell Sea, BENDEX area, $70^{\circ} 38.66^{\prime} \mathrm{S}, 10^{\circ} 28.16^{\prime} \mathrm{W}$ to $70^{\circ} 39.50^{\prime} \mathrm{S}, 10^{\circ} 32.91^{\prime} \mathrm{W}$, depth not given [Google Earth depth range for the coordinates: 867-955 m (accessed 27 Sep. 2016)], gear: "BPT" (presumably benthopelagic trawl), 21 Mar. 2011, coll. Ch. Havermans and H. Robert (RBINS, INV. 132967) [extraction I16; Genbank nr, COI: KU870842, 28S: KU759618].

\section{Description}

Rostrum. Very long, reaching about tip of article 2 of peduncle of antenna 1, straight and anteriorly directed, sharp-tipped in lateral view.

EYE. Medium-sized, elliptic.

Pereion-Pleosome tooth PATtern. All pereionites and pleosomites with large styliform mid-dorsal tooth and pair of large styliform dorsolateral teeth; the mid-dorsal tooth of pereionite 1 is oriented forward, the others are directed posteriorly, the most posterior ones being the most backwards directed; the size of the mid-dorsal teeth slightly increase backwards; pereionite 2 nearly as broad as pereionite 1 .

COXAE 1-3. Strongly carinate, curving forward and laterally, distally very sharp.

Coxa 4. Anterodorsal border weakly concave, and anteroventral border straight, the two border are joined by obtuse but very distinct angular discontinuity; anterior angle slightly projecting forward; ventral tooth medium-sized, long and styliform, curving laterally; lateral carina with lateral long and sharp styliform tooth pointing laterally (scarcely oriented backwards).

Coxa 5 . With sharp, broadly styliform, carinate, lateral tooth pointing laterally or rather slightly obliquely backwards.

Coxa 6. With large, sharp and narrowly triangular, carinate, lateral tooth pointing obliquely backwards; posteroventral corner broadly rounded.

Coxa 7. With ventral border rounded, and posterior border nearly straight, with posteroventral angle bluntly rounded.

EPIMERAL PLATES 1-3. Posteroventral angle produced into a very long styliform tooth.

UROSOME TOOTH PATTERN. Urosomite 1 with very long styliform tooth pointing upwards (or very slightly backwards); urosomite 2 without pair of small posterior dorsolateral teeth pointing upwards.

TeLson. Cleft on half of its length; tips of lobes blunt-tipped, slit of medium width, U-shaped.

Peduncle of antenna 1. Article 1-2 with trace of medial tooth or teeth; articles 1-3 with tiny ventral tooth, otherwise without ornamentation. 
GNATHOPODS 1-2. Gnathopods 1 and 2 a bit different, not narrowing distally: gnathopod 1 with propodus and especially carpus rather stout, with palm oblique and large; gnathopod 2 of normal slenderness, with palm oblique and large.

Pereiopods 5-7. Merus, carpus and propodus of pereiopods 5-7 very slender, dactylus fairly long; basis of pereiopods 5-6 narrow, with posteroproximal process reduced to a very low proximal protrusion merging without angular discontinuity with the posterior border, with posterodistal tooth very small, reduced to a broad acute angle scarcely projecting posteriorly; basis of pereiopod 7 fairly narrow with posterodistal tooth triangular and sharp, followed more proximally by low inconspicuous concavity, directed obliquely.

\section{Colour pattern}

White, with antennae and anterior part of body with a very pale pinkish hue; gnathopods and mouthparts blood red; eyes white.

\section{Body length}

$23 \mathrm{~mm}$.

\section{Distribution}

Eastern shelf of the Weddell Sea at about $867-955 \mathrm{~m}$.

\section{Remarks}

The only other species with long styliform teeth is E. oxicarinata, but it belongs to a separate subgenus. The holotype and unique specimen of $E$. cyrano sp. nov. was apparently collected with a benthopelagic trawl. As the morphology of the species suggests a benthic life style, it is possible that the trawl operated close to the seafloor or hit the seafloor.

Epimeria (Drakepimeria) havermansiana subgen. et sp. nov. urn:Isid:zoobank.org:act:A9A0D4D2-5D0E-4E40-A553-94013735FC7F

Figs $51-57$

'Clade A similis/macrodonta complex - SI1' - Verheye et al. 2016a, supplement: 2 (online).

\section{Etymology}

The species is dedicated to Charlotte Havermans (formerly RBINS, currently Alfred-Wegener-Institute Helmholtz-Zentrum für Polar- und Meeresforschung), who collected the holotype of the species. Havermansiana is the feminine of havermansianus, which is a Latin adjective of the second declension derived from her name.

\section{Type material}

\section{Holotype}

RV Polarstern cruises:

SOUTHERN OCEAN: 1 spec., sex undetermined, cruise PS77, ANT-XXVII/3, CAMBIO, stn 300-1, eastern Weddell Sea, BENDEX area, $70^{\circ} 50.99^{\prime} \mathrm{S}, 10^{\circ} 35.23^{\prime} \mathrm{W}$ to $70^{\circ} 50.34^{\prime} \mathrm{S}, 10^{\circ} 34.92^{\prime} \mathrm{W}, 227-266 \mathrm{~m}$, bottom trawl, 1 Apr. 2011, (RBINS, INV. 132964) [extraction I12; Genbank nr, 28S: KU759614]. 


\section{Paratypes}

RV Polarstern cruises:

SOUTHERN OCEAN: 1 spec., cruise PS39, ANT-XIII/3, EASIZ I, stn 1, GSN 1, eastern Weddell Sea, $71^{\circ} 03.10^{\prime} \mathrm{S}, 11^{\circ} 25.50^{\prime} \mathrm{W}$, to $71^{\circ} 02.10^{\prime} \mathrm{S}, 11^{\circ} 19.30^{\prime} \mathrm{W}, 462-481 \mathrm{~m}$, bottom trawl, 5 Feb. 1996, specimen kept in aquarium on board, coll. C. De Broyer and G. Chapelle (RBINS, INV. 132700); 1 spec., cruise PS39, ANT-XIII/3, EASIZ I, stn 17, GSN 10, eastern Weddell Sea, $73^{\circ} 18.00^{\prime} \mathrm{S}, 21^{\circ} 09.90^{\prime} \mathrm{W}$, to $73^{\circ} 19.10^{\prime} \mathrm{S}, 21^{\circ} 14.90^{\prime} \mathrm{W}, 465-468 \mathrm{~m}$, bottom trawl, 16 Feb. 1996, coll. C. De Broyer and G. Chapelle (RBINS, INV. 132694).

RV Aurora Australis cruises:

SOUTHERN OCEAN: 3 specs, cruise CEAMARC, sample CEAMARC 3226, stn 20EV490, Adélie Coast, 66 $06^{\circ} 59^{\prime \prime} \mathrm{S}, 140^{\circ} 00^{\prime} 02^{\prime \prime} \mathrm{E}, 189-196 \mathrm{~m}$, beam trawl, 15 Jan. 2008, coll. IPEV-AAD-MNHN (MNHN-IU-2014-4347); 1 spec., cruise CEAMARC, sample CEAMARC 3978, stn 36EV297, Adélie Coast, 66 $20^{\prime} 20^{\prime \prime} \mathrm{S}, 1^{\circ} 3^{\circ} 41^{\prime} 08^{\prime \prime} \mathrm{E}, 552-573 \mathrm{~m}$, beam trawl, 4 Jan. 2008 (MNHN-IU-2014-7328n, removed from MNHN-IU-2014-4329).

RV Marion Dufresne cruises:

SOUTHERN OCEAN: 3 specs (2 large specs and 1 juv.) cruise MD42 (SIBEX), stn 22-CP73, Prydz Bay, 66 $57^{\prime} 25^{\prime \prime} \mathrm{S}, 72^{\circ} 41^{\prime} 25^{\prime \prime} \mathrm{E}$, depth missing [Google Earth depth for that position: $540 \mathrm{~m}$ (accessed 27 Sep. 2016)], 26 Jan. 1985 (MNHN-IU-2014-4260); 1 q, cruise MD42 (SIBEX), stn 22-CP71, Prydz Bay, 66 $6^{\circ} 7^{\prime} 37^{\prime \prime}$ S, 72 $52^{\prime} 07^{\prime \prime}$ E, depth missing [Google Earth depth for that position: $513 \mathrm{~m}$ (accessed 27 Sep. 2016)], 26 Jan. 1985 (MNHN-IU-2014-4268).

Belgian and Belgian-Dutch Antarctic expedition:

SOUTHERN OCEAN: 9 specs, Princess Ragnhild Coast, stn 219, Baie du Glacier, $70^{\circ} 18^{\prime} 05^{\prime \prime}$ S, 2358'00" E, 216 m, trawl, 31 Jan. 1965 (RBINS, INV. 132743); 10 specs, Princess Ragnhild Coast, stn

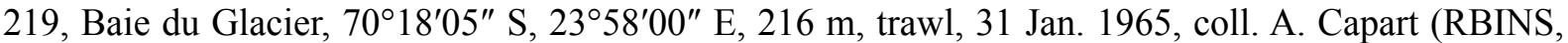
INV. 132744); 1 spec., Princess Ragnhild Coast, stn 219, Baie du Glacier, 70 $18^{\prime} 05^{\prime \prime}$ S, $23^{\circ} 58^{\prime} 00^{\prime \prime}$ E, 216 m, trawl, 31 Jan. 1965 (RBINS, INV. 132747); 1 spec., Princess Ragnhild Coast, stn 219, Baie du

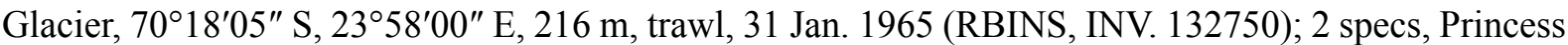
Ragnhild Coast, stn 220, Baie du Glacier, exact coordinates unavailable [presumably about $70^{\circ} 18^{\prime} \mathrm{S}$, 235'ㄹ E], 414-450 m, 1 Feb. 1965, trawl, coll. A. Capart (RBINS, INV. 132733); 1 spec., Princess Ragnhild Coast, stn 220, Baie du Glacier, exact coordinates unavailable [presumably about $70^{\circ} 18^{\prime} \mathrm{S}$, 235' E], 414-450 m, 1 Feb. 1965, trawl, coll. A. Capart (RBINS, INV. 132735); 1 spec., Princess Ragnhild Coast, stn 220, Baie du Glacier, exact coordinates unavailable [presumably about $70^{\circ} 18^{\prime} \mathrm{S}$, 235'ㄹ E], 414-450 m, 1 Feb. 1965, trawl, coll. A. Capart (RBINS, INV. 132736); 1 spec., Princess Ragnhild Coast, stn 220 , Baie du Glacier, exact coordinates unavailable [presumably about $70^{\circ} 18^{\prime} \mathrm{S}$, 235'ㄹ E], 414-450 m, 1 Feb. 1965, trawl, coll. A. Capart (RBINS, INV. 132751).

\section{Description}

Rostrum. Long, reaching about tip of article 1 of peduncle of antenna 1 (teeth excluded), moderately curved, sharp-tipped in lateral view.

EYE. Very large, broadly elliptic (nearly circular).

Pereion-Pleosome tooth pattern. Pereionite 1 with indistinct posterior bump, with pair of low noncarinate dorsolateral swellings; pereionite 2 slightly narrower than pereionite 1 , with small but distinct blunt mid-dorsal tooth and pair of low dorsolateral swellings; pereionite 3 with medium-sized blunttipped mid-dorsal tooth and pair of well-developed dorsolateral blunt teeth; pereionite 4 to pereionite 7 with large, broad, regularly curved, acute-tipped mid-dorsal tooth (dorsal length of teeth slightly 
and gradually increasing posteriorly) and pair of well developed conical dorsolateral teeth (pleonites 1-2 without second pair of dorsolateral teeth); pleonite 3 with dorsal sharp carina with weak median notch and produced posteriorly into an a broad acute and sharp triangular tooth, and pair of fairly large dorsolateral non-carinate acute-tipped teeth.

COXAE $1-3$. Strongly carinate and distally sharp.

CoxA 4. Anterodorsal + anteroventral borders forming a curve projecting forward (anterodorsal and anteroventral borders becoming straight respectively only at their upper and lower extremities); ventral tooth very sharp and very long; lateral carina without tooth, without distinct angularity, carina very distant from margin of coxa at its deepest point.

Coxa 5. With sharp and narrowly triangular carinate, lateral tooth pointing backwards (its lateral border is nearly parallel to body axis or weakly divergent).

CoxA 6. With mid-sized, sharp, triangular, carinate, lateral tooth pointing obliquely backwards; posteroventral corner bluntly angular.

Coxa 7. With ventral and posterior border straight, converging to form a sharp acute, nearly squared angle.

Epimeral PLATES 1-3. Posteroventral angle produced into a very long sharp tooth.

UROSOME TOOTH PATTERN. Urosomite 1 with strong triangular process pointing upwards; urosomite 2 with pair of small sharp posterior dorsolateral teeth pointing upwards.

Telson. Cleft on 0.25; tips of lobes sharp, broadly V-shaped.

Peduncle of antenna 1. Article 1 with long lateral and medial teeth reaching beyond mid and nearly mid of article 2 (teeth excluded) and long ventral tooth nearly reaching tip of article 2 (teeth excluded); article 2 with very long lateral and medial teeth overreaching tip of article 3 , with ventral tooth slightly overreaching tip of article 3 (tooth excluded); article 3 with long ventral tooth, about as long as article itself.

GNATHOPODS 1-2. Carpus and propodus of normal slenderness; propodus not narrowing distally, palm distinct.

Pereiopods 5-7. Merus, carpus and propodus fairly slender; basis of pereiopods 5-6 of normal width, with posteroproximal process rounded and strongly protruding, with posterodistal tooth strong; basis of pereiopod 7 very broad with posterodistal tooth angulate, followed more proximally by small concavity, directed posteriorly.

\section{Body length}

Up to $33 \mathrm{~mm}$.

\section{Distribution}

Eastern shelf of the Weddell Sea, Princess Ragnhild Coast, Prydz Bay, Adélie Coast; 189-573 m.

\section{Remarks}

Epimeria havermansiana sp. nov. is morphologically very similar to E. pandora sp. nov., but delimitation methods based on the 28S phylogeny indicate that they are indeed distinct species (Verheye et al. 2016a, 
and this paper Fig. 342). On pereionite 1, E. havermansiana sp. nov. may have a trace of posterior middorsal bump, which is absent in E. pandora sp. nov. On pereionite 2, E. havermansiana sp. nov. has a posterior tooth, while E. pandora sp. nov. has only a slight bump. In E. havermansiana sp. nov., the dorsolateral teeth of the pereion pleosome and urosomite 2 are larger than in E. pandora sp. nov. Coxa 4 is anteriorly more curved than in E. pandora sp. nov. and its ventral tooth is longer and narrower.

Epimeria (Drakepimeria) leukhoplites subgen. et sp. nov. urn:Isid:zoobank.org:act:E52DDFA4-14DA-4458-9A3B-403A37E19A4B

Figs 58-65

Epimeria sp aff reoproi-d'Udekem d'Acoz \& Robert 2008: 56, fig. 2.5B

non Epimeria reoproi Lörz \& Coleman, 2001: 991-1001, figs 1-5.

\section{Etymology}

From the Greek, $\lambda \varepsilon v \kappa о \varsigma$, white; o $\pi \lambda \imath \tau\rceil$, hoplite, citizen-soldier of the ancient Greece. The name, which is a noun in apposition, alludes to the armoured facies and the white or whitish colour of the species.

\section{Type material}

\section{Holotype}

RV Polarstern cruises:

SOUTHERN OCEAN: 1 ovigerous + , fixed in alcohol 70\%, cruise PS69, ANT-XXIII/8, stn 605-5, Elephant Island, $61^{\circ} 20.27^{\prime} \mathrm{S}, 55^{\circ} 30.92^{\prime} \mathrm{W}$ to $61^{\circ} 20.37^{\prime} \mathrm{S}, 55^{\circ} 28.99^{\prime} \mathrm{W}, 131-152 \mathrm{~m}$, Agassiz trawl, 20 Dec. 2006, coll. C. d'Udekem d'Acoz and H. Robert (RBINS, INV. 122470).

\section{Paratypes}

RV Polarstern cruises:

SOUTHERN OCEAN: 3 specs, initially fixed in formalin, cruise PS69, ANT-XXIII/8, stn 605-3, Elephant Island, $61^{\circ} 20.33^{\prime} \mathrm{S}, 55^{\circ} 31.53^{\prime} \mathrm{W}$ to $61^{\circ} 20.35^{\prime} \mathrm{S}, 55^{\circ} 30.18^{\prime} \mathrm{W}, 148-154 \mathrm{~m}$, Agassiz trawl, 20 Dec. 2006, coll. C. d'Udekem d'Acoz and H. Robert (RBINS, INV. 122536); 1 ovigerous $P$, fixed in alcohol $70 \%$, cruise PS69, ANT-XXIII/8, stn 614-3, Elephant Island, $60^{\circ} 52.37^{\prime} \mathrm{S}, 55^{\circ} 29.80^{\prime} \mathrm{W}$ to $60^{\circ} 52.71^{\prime} \mathrm{S}$, $55^{\circ} 27.83^{\prime}$ W, 248-265 m, a lot of epifauna, Rauschert dredge and Agassiz trawl, 22 Dec. 2006, coll. C. d'Udekem d'Acoz and H. Robert (RBINS, INV. 122473); 1 spec., fixed in alcohol 70\%, cruise PS69, ANT-XXIII/8, stn 671-1, northwest of King George Island, $61^{\circ} 59.98^{\prime} \mathrm{S}, 59^{\circ} 14.78^{\prime} \mathrm{W}$ to $61^{\circ} 60.00^{\prime} \mathrm{S}$, $59^{\circ} 10.74^{\prime} \mathrm{W}, 131-144 \mathrm{~m}$, bottom trawl, 1 Jan. 2007, coll. C. d'Udekem d'Acoz and H. Robert (RBINS, INV. 122538); 1 juv., initially fixed in formalin, cruise PS69, ANT-XXIII/8, stn 728-2, northwest of Weddell Sea, south of Dundee Island, $63^{\circ} 42.63^{\prime} \mathrm{S}, 56^{\circ} 01.63^{\prime} \mathrm{W}$ to $63^{\circ} 42.25^{\prime} \mathrm{S}, 56^{\circ} 02.16^{\prime} \mathrm{W}, 293-$ 298 m, Agassiz trawl, 24 Jan. 2007, coll. C. d'Udekem d'Acoz and H. Robert (RBINS, INV. 122539).

\section{Description}

RoBustNEss. Body and pereiopods more robust than in most Drakepimeria.

Rostrum. Medium-sized, just reaching tip of article 1 of peduncle of antenna 1 (teeth excluded), weakly curved, sharp-tipped in lateral view.

EYE. Large, elliptic.

Pereion-pleosome tooth pattern. Pereionites 4 to pleonite 3 with mid-dorsal tooth; pereionite 1 to pleonite 3 with pair of dorsolateral teeth or protrusions (those of pereionites 1-2 so low that they are nearly inconspicuous); pereionites 1-3 without any trace of mid-dorsal tooth, with pair of extremely 
low, nearly inconspicuous, dorsolateral protrusions; pereionite 2 slightly but distinctly narrower than pereionite 1; pereionite 4 with very small blunt-tipped posterior mid-dorsal tooth and pair of very low blunt dorsolateral protrusions; pereionite 5-6 with medium-sized blunt-tipped broad mid-dorsal tooth and pair of small blunt dorsolateral teeth, which are anteriorly prolonged by a blunt carina; pereionite 7 with well-developed acute-tipped broad mid-dorsal tooth, which is anteriorly broadly angulate, and pair of small blunt dorsolateral teeth, which are anteriorly prolonged by a blunt carina; pleonites 1-3 with very broad and not very elevated, acute-tipped mid-dorsal tooth, which is anteriorly angulate and pair of small dorsolateral non-carinate teeth; on pleonite 1 a trace of second pair of (much smaller) dorsolateral teeth is observed between the mid-dorsal tooth and the main pair of dorsolateral teeth; pleonite 3 with large acute-tipped mid-dorsal tooth bearing an inconspicuous median concavity.

COXAE $1-3$. Strongly carinate and distally sharp.

Coxa 4. Anterodorsal border nearly straight (inconspicuously convex) and unusually long, anteroventral border nearly straight (inconspicuously concave) and short, joined by blunt but very distinct angular discontinuity, anterior corner not projecting forward; ventral tooth narrowly triangular, not long, apically subacute; lateral carina without tooth or angularity, not projecting laterally, carina very distant from margin of coxa at its deepest point.

CoxA 5. With well developed sharp and broadly triangular, carinate, lateral tooth, of which the anterior border diverges backwards and the posterior border is nearly perpendicular to body axis.

Coxa 6. With mid-sized, blunt, broadly triangular, carinate, lateral tooth, of which the anterior border diverges backwards and the posterior border is perpendicular to body axis; posteroventral corner broadly rounded.

Coxa 7. With ventral border distinctly curved, with posterior border nearly straight (inconspicuously convex), their convergence forming a very blunt angular discontinuity; surface of coxa posteriorly with a blunt and very low carina oriented in the dorsoventral axis.

EPIMERAL PLATES 1-3. Posteroventral angle produced into a long and sharp tooth.

UROSOME TOOTH PATTERN. Urosomite 1 with sharp triangular process pointing upwards; urosomite 2 without pair of small posterior dorsolateral teeth pointing upwards.

Telson. Cleft on 0.33; tips of lobes subacute.

Peduncle of antenna 1. Article 1 with short lateral, medial and ventral teeth reaching the base of article 2; article 2 with large lateral and medial teeth reaching about tip of article 3 (ventral tooth excluded), with ventral tooth reduced to a tiny denticle; article 3 with small ventral tooth, distinctly shorter than article itself.

GNATHOPODS 1-2. Carpus and propodus fairly robust, propodus narrowing distally, palm indistinct.

PeREIOPODS 5-7. Merus, carpus and propodus very stout; basis of pereiopods 5-6 of normal width, with posteroproximal process rounded and distinctly protruding, with posterodistal tooth strong; basis of pereiopod 7 very broad with posterodistal tooth sharp, not followed more proximally by small concavity, directed posteriorly. 


\section{Colour pattern}

Uniformly whitish, or whitish with a few extremely pale, small, brownish/yellowish spots. Appendages whitish. Eyes pale reddish.

\section{Body length}

Up to $43 \mathrm{~mm}$.

\section{Distribution}

Elephant Island and tip of Antarctic Peninsula, 131-298 m.

\section{Remark}

E. leukhoplites sp. nov. is superficially similar to E. vaderi but important differences are observed. In E. leukhoplites sp. nov., coxa 5 and 6 have large triangular carinae projecting laterally, which are very distinct in dorsal view, whilst $E$. vaderi has no such lateral projections; this is the most obvious difference. In E. leukhoplites sp. nov., the mid-dorsal tooth of pereionite 7 and pleonites 1-2 are anteriorly very angulate, whilst they form a regular curve in E. vaderi. In E. leukhoplites sp. nov., only the pair of dorsolateral teeth of pleonite 1 is duplicated, whilst this is also the case for pleonite 2 in E. vaderi. In E. leukhoplites sp. nov., the profile of the dorsal crest of pleonite 3 is nearly straight, with an inconspicuous trace of notch just on the middle, whilst in $E$. vaderi it presents a shallow but long concavity. In E. leukhoplites sp. nov., the central point of the lateral carina of coxa 4 is very distant from posterior border of coxa, whilst in E. vaderi the carina remains very close to the border of the coxa. The angle joining the anterodorsal and the anteroventral angle is also more distinct in E. leukhoplites sp. nov. than in E. vaderi. The posteroventral tooth of the epimeral plates is much stronger in E. leukhoplites sp. nov. than in E. vaderi, especially for the third one. Finally, in E. leukhoplites sp. nov., the propodus of the gnathopods narrows anteriorly and the palm is indistinct, whilst in E. vaderi the propodus is not tapering and the palm is normally developed.

E. leukhoplites sp. nov. is also similar to Epimieria (Drakepimeria) subgen. nov. sp. 1 from the Ross Sea, which will be named and described in a separate paper by Verheye, Lörz \& d'Udekem d'Acoz. The most obvious differences between the two species are given in the key.

Epimeria (Drakepimeria) loerzae subgen. et sp. nov. urn:Isid:zoobank.org:act:878EF97D-A2F9-486F-B109-701B7A93840A

Figs 66-71

Epimeria macrodonta forma similis - K.H. Barnard 1932: 172, in part, fig. 105.

Epimeria macrodonta - Andres 1985: 124 (in part: "breite Form") — Andres in Sieg \& Wägele 1990:

136, fig. 270. — Lörz \& Coleman 2009: unnumbered photograph p. 17.

Epimeria aff. macrodonta - d'Udekem d'Acoz \& Verheye 2013: 62, fig. 3.8.2F.

Epimeria sp. nov. 3 - Rauschert \& Arntz 2015: 61, pl. 54, unnumbered photograph (non Epimeria sp. nov. 3 p. 125).

'Clade A similis/macrodonta complex - MA3' - Verheye et al. 2016a, supplement: 2 (online).

non Epimeria macrodonta Walker, 1906: 16.

non Epimeria similis Chevreux, 1912: 215.

\section{Etymology}

The species is dedicated to Anne-Nina Lörz (formerly NIWA), as a recognition of her important contribution to the taxonomy of the genus Epimeria. The name is a genitive. 


\section{Type material}

\section{Holotype}

RV Polarstern cruises:

SOUTHERN OCEAN: $q, 36 \mathrm{~mm}$, cruise PS81, ANT-XXIX/3, stn 116-9, north of Joinville Island, $62^{\circ} 33.79^{\prime} \mathrm{S}, 56^{\circ} 27.81^{\prime} \mathrm{W}$ to $62^{\circ} 33.71^{\prime} \mathrm{S}, 56^{\circ} 28.31^{\prime} \mathrm{W}, 248 \mathrm{~m}$, muddy bottom with stones, Pentaporalike bryozoans and a lot of life, Agassiz trawl, 26 Jan. 2013, coll. C. d'Udekem d'Acoz and M. Verheye (RBINS, INV. 122929A) [extraction K35; Genbank nr, 28S: KU759647].

\section{Paratypes}

RV Polarstern cruises:

SOUTHERN OCEAN: 1 spec., photographed, cruise PS14, ANT-VII/4, EPOS leg 3, stn 230, eastern Weddell Sea, $75^{\circ} 14.2^{\prime} \mathrm{S}, 26^{\circ} 59.4^{\prime} \mathrm{W}$ to $75^{\circ} 14.5^{\prime} \mathrm{S}, 26^{\circ} 59.9^{\prime} \mathrm{W}, 270-275 \mathrm{~m}$, Agassiz trawl, 30 Jan. 1989 , coll. C. De Broyer (RBINS, INV. 132721); 4 specs, cruise PS69, ANT-XXIII/8, stn 605-1, Elephant Island, $61^{\circ} 20.35^{\prime} \mathrm{S}, 55^{\circ} 29.16^{\prime} \mathrm{W}$ to $61^{\circ} 19.98^{\prime} \mathrm{S}, 55^{\circ} 32.67^{\prime} \mathrm{W}, 146-151 \mathrm{~m}$, bottom trawl, $19 \mathrm{Dec} .2006$, coll. C. d'Udekem d'Acoz and H. Robert (RBINS, INV. 122571); 2 specs, cruise PS69, ANT-XXIII/8, stn $605-1$, Elephant Island, $61^{\circ} 20.35^{\prime} \mathrm{S}, 55^{\circ} 29.16^{\prime} \mathrm{W}$ to $61^{\circ} 19.98^{\prime} \mathrm{S}, 55^{\circ} 32.67^{\prime} \mathrm{W}, 146-151 \mathrm{~m}$, bottom trawl, 19 Dec. 2006, coll. C. d'Udekem d'Acoz and H. Robert, (MNHN-IU-2014-7329, removed from RBINS, INV. 122571); 7 medium-sized and small specs, cruise PS69, ANT-XXIII/8, stn 605-1, Elephant Island, $61^{\circ} 20.35^{\prime} \mathrm{S}, 55^{\circ} 29.16^{\prime} \mathrm{W}$ to $61^{\circ} 19.98^{\prime} \mathrm{S}, 55^{\circ} 32.67^{\prime} \mathrm{W}, 146-151 \mathrm{~m}$, bottom trawl, 19 Dec. 2006, coll. C. d'Udekem d'Acoz and H. Robert (RBINS, INV. 122573); 3 specs, cruise PS69, ANTXXIII/8, stn 605-5, Elephant Island, $61^{\circ} 20.27^{\prime} \mathrm{S}, 55^{\circ} 30.92^{\prime} \mathrm{W}$ to $61^{\circ} 20.37^{\prime} \mathrm{S}, 55^{\circ} 28.99^{\prime} \mathrm{W}, 131-152 \mathrm{~m}$, Agassiz trawl, 20 Dec. 2006, coll. C. d'Udekem d'Acoz and H. Robert (RBINS, INV. 122567); 1 spec., cruise PS69, ANT-XXIII/8, stn 614-3/4/5, Elephant Island, $60^{\circ} 52.37^{\prime} \mathrm{S}, 55^{\circ} 29.80^{\prime} \mathrm{W}$ to $60^{\circ} 52.71^{\prime} \mathrm{S}$, $55^{\circ} 27.83^{\prime} \mathrm{W}, 248-265 \mathrm{~m}$, a lot of epifauna, Rauschert dredge and Agassiz trawl, 22 Dec. 2006, coll. C. d'Udekem d'Acoz and H. Robert (RBINS, INV. 122568); 1 large spec., cruise PS69, ANT-XXIII/8, stn $686-1$, Bransfield Strait, $62^{\circ} 34.12^{\prime} \mathrm{S}, 55^{\circ} 26.66^{\prime} \mathrm{W}$ to $62^{\circ} 35.38^{\prime} \mathrm{S}, 55^{\circ} 23.67^{\prime} \mathrm{W}, 149 \mathrm{~m}$, bottom trawl, 4 Jan. 2007, coll. C. d'Udekem d'Acoz and H. Robert (RBINS, INV. 122474); 2 large specs, cruise PS69, ANT-XXIII/8, stn 689-1, north of Joinville Island, $62^{\circ} 27.28^{\prime} \mathrm{S}, 55^{\circ} 18.23^{\prime} \mathrm{W}$ to $62^{\circ} 27.63^{\prime} \mathrm{S}$, 55 $14.81^{\prime}$, 224-229 m, bottom trawl, 4 Jan. 2007, coll. C. d'Udekem d'Acoz and H. Robert (RBINS, INV. 122566); 1 spec., cruise PS69, ANT-XXIII/8, stn 692-1, north of Joinville Island, $62^{\circ} 21.76^{\prime}$ S, $55^{\circ} 36.96^{\prime} \mathrm{W}$ to $62^{\circ} 23.62^{\prime} \mathrm{S}, 55^{\circ} 36.42^{\prime} \mathrm{W}, 263-277 \mathrm{~m}$, bottom trawl, 5 Jan. 2007, coll. C. d'Udekem d'Acoz and H. Robert (RBINS, INV. 122572); 2 very large specs, cruise PS69, ANT-XXIII/8, stn $693-1$, north of Joinville Island, $62^{\circ} 25.84^{\prime} \mathrm{S}, 55^{\circ} 35.07^{\prime} \mathrm{W}$ to $62^{\circ} 25.87^{\prime} \mathrm{S}, 55^{\circ} 32.62^{\prime} \mathrm{W}, 243-291 \mathrm{~m}$, bottom trawl, 5 Jan. 2007, coll. C. d'Udekem d'Acoz and H. Robert (RBINS, INV. 122471); 6 specs, cruise PS69, ANT-XXIII/8, stn 726-1, Snow Hill Island, 6430.86' S, 56 ${ }^{\circ} 40.23^{\prime} \mathrm{W}$ to $64^{\circ} 31.16^{\prime} \mathrm{S}$, $56^{\circ} 40.51^{\prime}$ W, 197-199 m, Rauschert dredge, 22 Jan. 2007, coll. C. d'Udekem d'Acoz and H. Robert (RBINS, INV. 122574); 2 large specs, cruise PS69, ANT-XXIII/8, stn 728-2, south of Dundee Island, $63^{\circ} 42.63^{\prime} \mathrm{S}, 56^{\circ} 01.63^{\prime} \mathrm{W}$ to $63^{\circ} 42.25^{\prime} \mathrm{S}, 56^{\circ} 02.16^{\prime} \mathrm{W}, 293-298 \mathrm{~m}$, Agassiz trawl, $24 \mathrm{Jan} .2007$, coll. C. d'Udekem d'Acoz and H. Robert (RBINS, INV. 122570); 1 q, 36 mm, cruise PS81, ANT-XXIX/3, stn 116-9, north of Joinville Island, $62^{\circ} 33.79^{\prime} \mathrm{S}, 56^{\circ} 27.81^{\prime} \mathrm{W}$ to $62^{\circ} 33.71^{\prime} \mathrm{S}, 56^{\circ} 28.31^{\prime} \mathrm{W}, 248 \mathrm{~m}$, muddy bottom with stones and Pentapora-like bryozoans and a lot of life, Agassiz trawl, 26 Jan. 2013, coll. C. d'Udekem d'Acoz and M. Verheye (RBINS, INV. 122929B) [extraction K36; Genbank nr, COI: KU870868, 28S: KU759648]; 2 우, cruise PS81, ANT-XXIX/3, stn 116-9, north of Joinville Island, $62^{\circ} 33.79^{\prime} \mathrm{S}, 56^{\circ} 27.81^{\prime} \mathrm{W}$ to $62^{\circ} 33.71^{\prime} \mathrm{S}, 56^{\circ} 28.31^{\prime} \mathrm{W}, 248 \mathrm{~m}$, muddy bottom with stones and Pentapora-like bryozoans and a lot of life, Agassiz trawl, 26 Jan. 2013 (RBINS, INV. 122951); 4 specs, cruise PS81, ANT-XXIX/3, stn 162-7, east of James Ross Island, 63 $58.78^{\prime} \mathrm{S}, 56^{\circ} 46.24^{\prime}$ W to $63^{\circ} 59.02^{\prime} \mathrm{S}, 56^{\circ} 46.26^{\prime} \mathrm{W}, 214-216 \mathrm{~m}$, bottom with Glyptonotus and Echiniphimedia cf. hodgsoni, Agassiz trawl, 10 Feb. 2013 (RBINS, INV. 122940) [extraction ANT35: largest specimen; Genbank nr, 28S: KU759594]; 3 specs, cruise PS81, ANT-XXIX/3, stn 162-7, east of James Ross Island, 6358.78' S, $56^{\circ} 46.24^{\prime} \mathrm{W}$ to $63^{\circ} 59.02^{\prime} \mathrm{S}, 56^{\circ} 46.26^{\prime} \mathrm{W}, 214-216 \mathrm{~m}$, bottom with Glyptonotus and Echiniphimedia 
cf. hodgsoni, Agassiz trawl, 10 Feb. 2013 (RBINS, INV. 122955); 2 specs, cruise PS81, ANT-XXIX/3,

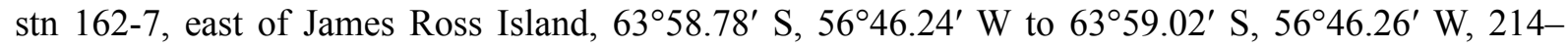
$216 \mathrm{~m}$, bottom with Glyptonotus and Echiniphimedia cf. hodgsoni, Agassiz trawl, 10 Feb. 2013, coll. C. d'Udekem d'Acoz and M. Verheye (RBINS, INV. 122958); 2 specs, cruise PS81, ANT-XXIX/3, stn $164-4$, south of Dundee Island, $63^{\circ} 37.28^{\prime} \mathrm{S}, 56^{\circ} 9.11^{\prime} \mathrm{W}$ to $63^{\circ} 37.29^{\prime} \mathrm{S}, 56^{\circ} 9.58^{\prime} \mathrm{W}, 102-114 \mathrm{~m}$, nonmuddy bottom with a lot of life, including Molgula, big red ophiuroids, and a lot of Glyptonotus, Agassiz trawl, 11 Feb. 2013, coll. C. d'Udekem d'Acoz and M. Verheye (RBINS, INV. 132974) [extraction I19: largest specimen; Genbank nr, COI: KU870844, 28S: KU759621]; 16 specs, cruise PS81, ANT-XXIX/3, stn 185-3, southeast of Dundee Island, 63⒌ $51.34^{\prime} \mathrm{S}, 55^{\circ} 41.11^{\prime} \mathrm{W}$ to $63^{\circ} 51.52^{\prime} \mathrm{S}, 55^{\circ} 41.43^{\prime} \mathrm{W}, 261-296$ $\mathrm{m}$, non muddy bottom (a lot of life: sponges, starfishes, ophiuroids, crinoids, Pentapora-like bryozoans), Agassiz trawl, 19 Feb. 2013, coll. C. d'Udekem d'Acoz and M. Verheye (RBINS, INV. 122960); 4 small specs, cruise PS81, ANT-XXIX/3, stn 185-4 southeast of Dundee Island, $63^{\circ} 51.53^{\prime} \mathrm{S}, 55^{\circ} 40.74^{\prime} \mathrm{W}$ to $63^{\circ} 51.53^{\prime} \mathrm{S}, 55^{\circ} 40.43^{\prime} \mathrm{W}, 253-255 \mathrm{~m}$, extremely fine sand mixed with some mud and gravel, Rauschert dredge, 19 Feb. 2013, coll. C. d'Udekem d'Acoz and M. Verheye (RBINS, INV. 122971); 13 juvs, cruise PS81, ANT-XXIX/3, 185-4 southeast of Dundee Island, $63^{\circ} 51.53^{\prime} \mathrm{S}, 55^{\circ} 40.74^{\prime} \mathrm{W}$ to $63^{\circ} 51.53^{\prime} \mathrm{S}$, $55^{\circ} 40.43^{\prime} \mathrm{W}, 253-255 \mathrm{~m}$, extremely fine sand mixed with some mud and gravel, Rauschert dredge, 19 Feb. 2013, coll. C. d'Udekem d'Acoz and M. Verheye (RBINS, INV. 122968).

Expedition SIGNY 1991/92:

SOUTHERN OCEAN: 1 adult, SIGNY 1991/92, AGT 24, transect 2, South Orkney Plateau: Signy Island, 60.704 ${ }^{\circ} \mathrm{S}, 45.452^{\circ} \mathrm{W}, 190-200 \mathrm{~m}, 15$ Feb. 1992, coll. Stefan Hain (RBINS, INV. 132686); 1 juv., SIGNY 1991/92, AGT 21, transect 2, South Orkney Plateau: Signy Island, $60.707^{\circ} \mathrm{S}, 45.437^{\circ} \mathrm{W}$, 150 m, 14 Feb. 1992, coll. Stefan Hain (RBINS, INV. 132692).

\section{Description}

Rostrum. Long, overreaching tip of article 1 of peduncle of antenna 1 (teeth excluded), very strongly curved, sharp-tipped in lateral view.

EYE. Very large, broadly elliptic.

Pereion-pleosome tooth pattern. Pereionite 1 with medium-sized broad and blunt mid-dorsal tooth pointing upwards, with pair of well-developed, conical, dorsolateral teeth; pereionite 2 much narrower than pereionites 1 and 3, without mid-dorsal tooth and without pair of dorsolateral teeth; pereionite 3 with well-developed broad and blunt mid-dorsal tooth pointing upwards, of which the anterior margin is strongly convex and the posterior margin weakly convex, and pair of fairly large, conical, dorsolateral teeth; pereionites 4-5 with large, fairly broad, acute to subacute mid-dorsal tooth, of which the anterior border is regularly curved and the posterior border is slightly concave, with pair of large narrowly conical dorsolateral teeth; pereionites 6 to pleonite 2 with large and fairly broad, acute mid-dorsal tooth of which the anterior border is subdivided into a proximal part pointing obliquely upwards and a posterior part nearly parallel to body axis, both parts being joined by distinct blunt angular discontinuity, with pair of large narrowly conical dorsolateral teeth (these pairs of teeth are never duplicate); pleonite 3 with large narrowly triangular acute-tipped symmetrical mid-dorsal tooth, and pair of large narrowly conical dorsolateral teeth (size of mid-dorsal teeth increasing from pereionite 1 to 5 , those of pereionite 6 to pleonite 3 subequal to tooth of pereionite 5 .

COXAE $1-3$. Strongly carinate and distally sharp.

Coxa 4. Anterodorsal border straight, anteroventral border weakly curved, these two borders being joined by obtuse, blunt but distinct angular discontinuity, anterior angle scarcely projecting forward; ventral tooth long and acute; lateral carina with large tooth, which is anteriorly convex and posteriorly 
concave, strongly projecting laterally and obliquely pointing backwards, carina very distant from margin of coxa at its deepest point.

Coxa 5. With long, sharp, narrowly triangular, carinate, lateral tooth pointing obliquely backwards; posteroventral corner broadly rounded.

Coxa 6. With long, sharp and narrowly triangular (nearly styliform), carinate lateral tooth pointing obliquely backwards.

Coxa 7. With ventral border slightly curved, with posterior border straight, their convergence forming a sharp squared angle.

Epimeral PLATES 1-3. Posteroventral angle produced into a very long and very sharp tooth.

UROSOME TOOTH PATTERN. Urosomite 1 with large and sharp narrow tooth pointing upwards; urosomite 2 with pair of mid-sized posterior dorsolateral teeth pointing upwards; urosomite 3 with pair of mid-sized posterior dorsolateral teeth pointing upwards.

TELSON. Cleft on 0.45 ; tips of lobes blunt and narrow, notch narrowly and bluntly V-shaped.

Peduncle of antenNa 1. Article 1 with long lateral and medial teeth reaching mid of article 2 (teeth excluded) and long ventral tooth reaching about tip of article 2 (teeth excluded); article 2 with large lateral and medial teeth overreaching tip of article 3 , without ventral tooth (ventral margin with scarcely distinct denticle); article 3 with medium-sized ventral tooth, about half as long as article itself.

GNATHOPODS 1-2. Carpus and propodus of normal slenderness; propodus not narrowing distally, palm distinct.

PeReIOPODS 5-7. Merus, carpus and propodus slender; basis of pereiopods 5-6 of normal width, with posteroproximal process rounded and strongly protruding, with posterodistal tooth very strong (as long as basis width for pereiopod 5, nearly as long as basis width for pereiopod 6); basis of pereiopod 7 broad with posterodistal tooth subacute, followed more proximally by small concavity, directed posteriorly but somewhat obliquely.

\section{Colour pattern}

Whitish with irregular orange-red marks and dots arranged in complex patterns and in some places merging into small irregular transverse lines. Eyes reddish. This colour pattern is very constant and highly characteristic of the species.

\section{Body length}

Up to $30 \mathrm{~mm}$.

\section{Distribution}

South Orkney Islands; South Shetland Islands, including Elephant Island; Bransfield Strait; tip of Antarctic Peninsula; eastern shelf of the Weddell Sea (where it is very rare), 102-298 m.

\section{Remarks}

Epimeria loerzae sp. nov. is a common species off the South Shetland Islands and near the tip of the Antarctic Peninsula. It is also present off the South Orkney Islands, but it is very rare in the Eastern Weddell Sea, where only one specimen was found. Its bathymetrical range is apparently rather limited, 
since this species was not found in samples collected below $300 \mathrm{~m}$. The colour pattern and the broad angulate mid-dorsal teeth of E. loerzae sp. nov. are unique in macrodonta-like Epimeria, making its identification easy (it is most similar to E. pyrodrakon sp. nov.). The collection locality of the specimen of Epimeria loerzae sp. nov. illustrated as Epimeria sp. n. 3 by Rauchert \& Arntz (2015) was given in an early draft of their book made available to the authors: ANT-XV/3 stn 355. Its coordinates are: $61^{\circ} 59.8^{\prime} \mathrm{S}, 59^{\circ} 14.8^{\prime} \mathrm{W}$ to $62^{\circ} 00.1^{\prime} \mathrm{S}, 59^{\circ} 14.8^{\prime} \mathrm{W}, 128-130 \mathrm{~m}$, which corresponds to a position northwest of King George Island.

Epimeria (Drakepimeria) macrodonta subgen. nov. Walker, 1906

Figs $72-76$

Epimeria macrodonta Walker, 1906: 16 (in part).

Epimeria macrodonta - Walker 1907: 24 (in part), pl. 8 fig. 14. — Lockyer 1907: 35. - J.L. Barnard 1961: 103 (key, in part). — McCain 1971: 161. — Dell 1972: 71, fig. 7a (after Walker). — De Broyer \& Klages 1991: 165 (key, in part). — Wakabara \& Serejo 1999: 642 (key, in part). — Lörz et al. 2007: 32, table 1 (lectotype designation).

Epimeria macrodonta macrodonta - Gurjanova 1955: 195.

\section{Type material}

\section{Lectotype}

National Antarctic Expedition 1901-1904, RV Discovery:

SOUTHERN OCEAN: 1 spec., sex undetermined, Ross Sea, W.Q. [Winter Quarters - hole 12] 2-4 Sep. 1903, "236", "237" (these two enigmatic numbers are put in a circle), J.107, depth not stated, lectotype designated by Lörz et al. (2007), although no label by Lörz indicating its status as lectotype is present (BMNH 1907.6.6.259-262) (in part).

\section{Paralectotypes}

National Antarctic Expedition 1901-1904, RV Discovery:

SOUTHERN OCEAN: 1 juv., mixed in the same tube with an adult + of Epimeria colemani, Ross Sea, no locality but presumably McMurdo Sound, $\mathrm{n}^{\circ}$ 13, $914 \mathrm{~m}$ (500 fathoms), 22 Jan. 1902, obviously 2 of the paralectotypes of Epimeria macrodonta designated by Lörz et al. (2007), albeit no label by Lörz indicating their status as paralectotypes (BMNH 1907.6.6.259-262) (in part); 1 spec., sex undetermined, dissected by Walker, Ross Sea, no locality but presumably McMurdo Sound, $914 \mathrm{~m}$ (500 fathoms), 22 Jan. 1902, obviously 1 of the paralectotypes of Epimeria macrodonta designated by Lörz et al. (2007), albeit no label by Lörz indicating its status as paralectotype, 3 tubes (BMNH 1907.6.6.259-262) (in part).

\section{Description}

Basis of description. Description based on lectotype.

Rostrum. Long, reaching base of article 2 of peduncle of antenna 1 (teeth excluded), strongly curved, sharp-tipped in lateral view.

EYE. Large, broadly elliptic.

Pereion-Pleosome tooth pattern. Pereionite 1 with small and blunt posterior mid-dorsal protrusion, with pair of low dorsolateral protrusions; pereionite 2 much narrower than pereionites 1 and 3 , without mid-dorsal tooth and without pair of dorsolateral teeth; pereionite 3 with medium-sized fairly broad and fairly blunt mid-dorsal tooth pointing upwards and pair of low and blunt, conical, dorsolateral teeth; pereionite 4 to pleonite 2 with large, narrow to very narrow, acute mid-dorsal tooth, of which the anterior 
border is almost regularly curved, with inconspicuous trace of angular discontinuity (pereionites 4-6) or with weak but distinct angular discontinuity (pereionite 7 and pleonites 1-2), and the posterior border is slightly concave, with pair of conical dorsolateral teeth of which the size gradually increases posteriorly (these pairs of teeth are never duplicate); pleonite 3 with large narrowly triangular acute-tipped subsymmetrical mid-dorsal tooth, and pair of large narrowly conical dorsolateral teeth (size of mid-dorsal teeth weakly and gradually increasing from pereionite 4 to pleonite 2 ; mid-dorsal tooth of pleonite 3 distinctly shorter than tooth of pleonite 2).

COXAE $1-3$. Strongly carinate and distally sharp; in dorsal view, the tip coxa 3 appears as projecting laterally.

Coxa 4. Anterodorsal border straight, anteroventral border distally nearly straight, these two borders being joined by a long weak curve (anterior angle), this anterior angle is weakly projecting forward; ventral tooth extremely long, very narrow and acute, weakly arching backwards; lateral carina with well developed tooth pointing obliquely backwards (in dorsal view its anterior border strongly diverges from body axis; in dorsal view this tooth form a narrow U-shaped notch with the coxa); carina very distant from margin of coxa at its deepest point.

Coxa 5. With long, sharp and narrowly triangular, carinate, lateral tooth pointing obliquely backwards (its anterior and posterior margins are distinctly oblique to body axis).

Coxa 6. With mid-sized, sharp and narrowly triangular, carinate, lateral tooth pointing obliquely backwards; its anterior border is distinctly convex); posteroventral corner broadly rounded.

Coxa 7. With ventral border distinctly curved, with posterior border nearly straight (inconspicuously convex), their convergence forming a curve (a very blunt squared angle).

EPIMERAL PLATES 1-3. Posteroventral angle produced into a very long and very sharp tooth.

UROSOME TOOTH PATTERN. Urosomite 1 with large and sharp narrow tooth pointing upwards; urosomite 2 with pair of mid-sized posterior dorsolateral teeth pointing upwards; urosomite 3 with pair of mid-sized posterior dorsolateral teeth pointing obliquely backwards.

TELSON. Cleft on 0.33; tips of lobes subacute, notch narrowly V-shaped.

Peduncle of antenna 1. Article 1 with long lateral tooth and short medial tooth reaching respectively 0.9 and 0.33 of article 2 (teeth excluded) and long ventral tooth overreaching tip of article 2 (teeth excluded) by 0.4 of its length; article 2 with huge lateral tooth of which 0.6 is overreaching tip of article 3 , and very huge medial teeth of which 0.7 is overreaching tip of article 3, without ventral tooth; article 3 with tiny ventral tooth, about 0.25 times as long as article itself.

GNATHOPODS 1-2. Carpus and propodus of normal slenderness; palm distinct.

Pereiopods 5-7. Merus, carpus and propodus slender; basis of pereiopods 5-6 of normal width, with posteroproximal process rounded and strongly protruding, with posterodistal tooth very strong (nearly as long as basis width); basis of pereiopod 7 broad with posterodistal tooth acute, triangular, mid-sized, followed more proximally by distinct concavity, directed posteriorly.

\section{Body length}

Up to $25 \mathrm{~mm}$. 


\section{Variations}

The juvenile specimen has no posterodorsal bump on pereionite 1 .

\section{Distribution}

Ross Sea: Winter Quarters Bay [about $77^{\circ} 50^{\prime} \mathrm{S}, 166^{\circ} 39^{\prime}$ E], no depth record [lectotype]; Ross Sea, no locality, $914 \mathrm{~m}$ [paralectotypes] (Walker 1906, 1907). The paralectotypes were presumably collected in McMurdo Sound because Hodgson (1907) stated that "on the 20th of January 1902, the 'Discovery' passed across the mouth of the McMurdo Sound" and the specimens were collected shortly afterwards, on 22 Jan. 1902.

\section{Remarks}

Epimeria macrodonta is morphologically similar to E. anguloce sp. nov. (Antarctic Peninsula, eastern Weddell Sea and Prydz Bay) and E. corbariae sp. nov. (Adélie Coast). Epimeria macrodonta can be distinguished from its relatives by the length of the teeth on article 1 of antenna 1 peduncle. In E. macrodonta, the lateral tooth is indeed considerably longer than the medial tooth, whilst in other species the teeth are subequal. It also exhibits other distinctive characters: lateral and medial tooth of article 2 of peduncle of antenna 1 especially long; ornamentation of pereionite 1 weak or absent; middorsal tooth of pereionite 4 to pleonite 2 especially long and slender (those of pereionite 6 and pleonite 1-2 exhibiting a slight angular discontinuity on their anterior border); ventral tooth of coxa 4 especially long; lateral tooth of coxae 4 and 5 very oblique in dorsal view; coxa 7 with posterior border nearly straight (inconspicuously convex), with posteroventral angle rounded; posterodistal tooth of basis of pereiopod 7 not very strong.

The type locality of E. macrodonta is Ross Island (Ross Sea). Lörz et al. (2007) mistakenly reported Ross Island as being located off the Antarctic Peninsula. This lapsus might result from a confusion between Ross Island (Ross Sea) and James Ross Island (Antarctic Peninsula).

E. macrodonta s. lat. has previously been recorded throughout the Southern Ocean, south of the Polar Front at depths shallower than $1000 \mathrm{~m}$. However, all specimens except the lectotype and two of the three paralectotypes of E. macrodonta belong to other species.

Epimeria (Drakepimeria) pandora subgen. et sp. nov. urn:1sid:zoobank.org:act:EABBCBFE-2ADE-49F4-B739-35CC145CE6A9

Figs $77-82$

Epimeria similis - Lörz 2003: 85, 86, in part, fig. 3B (not fig. 3A). — d'Udekem d'Acoz \& Verheye 2013: 58 (in part), 63, fig. 3.8.2G.

'Clade A similis/macrodonta complex - SI2' - Verheye et al. 2016a, supplement: 2 (online).

non Epimeria similis Chevreux, 1912: 215.

\section{Etymology}

П $\alpha \delta \delta \omega \rho \rho$ is a well-known character of the Greek mythology. According to the myth, Pandora opened a jar, in modern accounts usually mistranslated as "Pandora's box", releasing all the evils of humanity, leaving only Hope inside once she had closed it again. She opened the jar out of simple curiosity and not as a malicious act. The name, which is a noun in apposition, should be considered as an allegory to the present study. The authors initially believed that the taxonomy of Antarctic Epimeria, was easy and fairly well-known, with perhaps a few attractive new species to describe; hence they had the curiosity to open glass jars filled with Epimeria specimens. In doing so, they opened the door to an inexhaustible 
flow of new species, often very difficult to separate from each other, and erased any hope of easy taxonomy for the genus.

\section{Type material}

\section{Holotype}

RV Polarstern cruises:

SOUTHERN OCEAN: ovigerous + , cruise PS81, ANT-XXIX/3, $\operatorname{stn} 217-6$, Bransfield Strait, $62^{\circ} 53.45^{\prime}$ S, $58^{\circ} 13.06^{\prime} \mathrm{W}$ to $62^{\circ} 53.42^{\prime} \mathrm{S}, 58^{\circ} 13.41^{\prime} \mathrm{W}, 461-483 \mathrm{~m}$, rich sponge bottom, Agassiz trawl, 2 Mar. 2013 , coll. C. d'Udekem d'Acoz and M. Verheye (RBINS, INV. 122931A) [extraction K31; Genbank nr, COI: KU870865, 28S: KU759644].

\section{Paratypes}

RV Polarstern cruises:

SOUTHERN OCEAN: 6 specs, cruise PS69, ANT-XXIII/8, stn 604-1, Elephant Island, $61^{\circ} 20.52^{\prime} \mathrm{S}$, $55^{\circ} 09.72^{\prime} \mathrm{W}$ to $61^{\circ} 20.11^{\prime} \mathrm{S}, 55^{\circ} 07.26^{\prime} \mathrm{W}, 286-407 \mathrm{~m}$, bottom trawl, 19 Dec. 2006 , coll. C. d'Udekem d'Acoz and H. Robert (RBINS, INV. 122545); 1 spec., cruise PS69, ANT-XXIII/8, stn 604-1, Elephant Island, $61^{\circ} 20.52^{\prime} \mathrm{S}, 55^{\circ} 09.72^{\prime} \mathrm{W}$ to $61^{\circ} 20.11^{\prime} \mathrm{S}, 55^{\circ} 07.26^{\prime} \mathrm{W}, 286-407 \mathrm{~m}$, bottom trawl, $19 \mathrm{Dec}$. 2006, coll. C. d'Udekem d'Acoz and H. Robert (MNHN-IU-2014-7330, removed from RBINS, INV. 122545); 1 spec., alcohol-fixed, cruise PS69, ANT-XXIII/8, stn 604-1, Elephant Island, 61 $20.52^{\prime} \mathrm{S}, 55^{\circ} 09.72^{\prime} \mathrm{W}$ to $61^{\circ} 20.11^{\prime} \mathrm{S}, 55^{\circ} 07.26^{\prime} \mathrm{W}, 286-407 \mathrm{~m}$, bottom trawl, 19 Dec. 2006, coll. C. d'Udekem d'Acoz and H. Robert (RBINS, INV. 122478); 2 specs, cruise PS69, ANT-XXIII/8, stn 604-1, Elephant Island, $61^{\circ} 20.52^{\prime} \mathrm{S}, 55^{\circ} 09.72^{\prime} \mathrm{W}$ to $61^{\circ} 20.11^{\prime} \mathrm{S}, 55^{\circ} 07.26^{\prime} \mathrm{W}, 286-407 \mathrm{~m}$, bottom trawl, 19 Dec. 2006, coll. C. d'Udekem d'Acoz and H. Robert (RBINS, INV. 122547); 4 specs, cruise PS69, ANT-XXIII/8, stn $608-1$, Elephant Island, $61^{\circ} 11.34^{\prime} \mathrm{S}, 54^{\circ} 43.17^{\prime} \mathrm{W}$ to $61^{\circ} 11.80^{\prime} \mathrm{S}, 54^{\circ} 40.05^{\prime} \mathrm{W}, 284-293 \mathrm{~m}$, bottom trawl, 20 Dec. 2006, coll. C. d'Udekem d'Acoz and H. Robert (RBINS, INV. 122542); 1 spec., cruise PS69, ANT-XXIII/8, stn 611-1, Elephant Island, $60^{\circ} 58.90^{\prime} \mathrm{S}, 55^{\circ} 11.31^{\prime} \mathrm{W}$ to $60^{\circ} 58.52^{\prime} \mathrm{S}, 55^{\circ} 07.82^{\prime} \mathrm{W}, 215-$ 297 m, bottom trawl, 21 Dec. 2006, coll. C. d'Udekem d'Acoz and H. Robert (RBINS, INV. 122546); 6 small specs, cruise PS69, ANT-XXIII/8, stn 614-3/4/5, Elephant Island, $60^{\circ} 52.37^{\prime} \mathrm{S}, 55^{\circ} 29.80^{\prime} \mathrm{W}$ to $60^{\circ} 52.71^{\prime} \mathrm{S}, 55^{\circ} 27.83^{\prime} \mathrm{W}, 248-265 \mathrm{~m}$, a lot of epifauna, Rauschert dredge and Agassiz trawl, 22 Dec. 2006, coll. C. d'Udekem d'Acoz and H. Robert (RBINS, INV. 122552); 1 spec., cruise PS69, ANTXXIII/8, stn 627-1, Elephant Island, $60^{\circ} 59.00^{\prime} \mathrm{S}, 55^{\circ} 42.36^{\prime} \mathrm{W}$ to $60^{\circ} 57.62^{\prime} \mathrm{S}, 55^{\circ} 40.19^{\prime} \mathrm{W}, 90-102 \mathrm{~m}$, bottom trawl, 24 Dec. 2006, coll. C. d'Udekem d'Acoz and H. Robert (RBINS, INV. 122559); 2 specs, cruise PS69, ANT-XXIII/8, stn 642-1, Elephant Island, $61^{\circ} 04.38^{\prime} \mathrm{S}, 55^{\circ} 59.81^{\prime} \mathrm{W}$ to $61^{\circ} 04.27^{\prime} \mathrm{S}$, 55 58.88' W, 254 m, Agassiz trawl, 27 Dec. 2006, coll. C. d'Udekem d'Acoz and H. Robert (RBINS, INV. 122548); 2 specs, cruise PS69, ANT-XXIII/8, stn 654-6, Elephant Island, $61^{\circ} 22.80^{\prime} \mathrm{S}, 56^{\circ} 03.84^{\prime} \mathrm{W}$ to $61^{\circ} 23.35^{\prime} \mathrm{S}, 56^{\circ} 04.89^{\prime} \mathrm{W}, 341-342 \mathrm{~m}$, Agassiz trawl, 29 Dec. 2006, coll. C. d'Udekem d'Acoz and H. Robert (RBINS, INV. 122543); 1 large spec., cruise PS69, ANT-XXIII/8, stn 726-4, southeast of Snow Hill Island, $64^{\circ} 37.83^{\prime} \mathrm{S}, 56^{\circ} 42.10^{\prime} \mathrm{W}$ to $64^{\circ} 38.03^{\prime} \mathrm{S}, 56^{\circ} 42.57^{\prime} \mathrm{W}, 292 \mathrm{~m}$, Agassiz trawl, $23 \mathrm{Jan} .2007$, coll. C. d'Udekem d'Acoz and H. Robert (RBINS, INV. 122551); 1 ovigerous ${ }^{\text {, }}$, posterior part missing, cruise PS81, ANT-XXIX/3, stn 217-6, Bransfield Strait, $62^{\circ} 53.45^{\prime} \mathrm{S}, 58^{\circ} 13.06^{\prime} \mathrm{W}$ to $62^{\circ} 53.42^{\prime} \mathrm{S}$, $58^{\circ} 13.41^{\prime} \mathrm{W}, 461-483 \mathrm{~m}$, rich sponge bottom, Agassiz trawl, 2 Mar. 2013, coll. C. d'Udekem d'Acoz and M. Verheye (RBINS, INV. 122931B); 1 ovigerous 9 , cruise PS81, ANT-XXIX/3, stn 217-6, Bransfield Strait, $62^{\circ} 53.45^{\prime} \mathrm{S}, 58^{\circ} 13.06^{\prime} \mathrm{W}$ to $62^{\circ} 53.42^{\prime} \mathrm{S}, 58^{\circ} 13.41^{\prime} \mathrm{W}, 461-483 \mathrm{~m}$, rich sponge bottom, Agassiz trawl, 2 Mar. 2013, coll. C. d'Udekem d'Acoz and M. Verheye (RBINS, INV. 122935) [extraction K32; Genbank nr, COI: KU870866, 28S: KU759645].

\section{Description}

Rostrum. Long, reaching about tip of article 1 of peduncle of antenna 1 (teeth excluded), moderately curved, sharp-tipped in lateral view. 
EYE. Very large, broadly elliptic (nearly circular).

Pereion-Pleosome tooth pattern. Pereionite 1 without any trace of mid-dorsal tooth, with pair of very low non-carinate dorsolateral swellings; pereionite 2 nearly as broad as pereionite 1 , with weak posterior mid-dorsal bump, and pair of indistinct dorsolateral swellings; pereionite 3 with small blunt-tipped middorsal tooth and pair of small dorsolateral blunt teeth; pereionite 4 with well-developed blunt-tipped mid-dorsal tooth and pair of small dorsolateral blunt teeth; pereionite 5 to pleonite 2 with large, acutetipped, broad, regularly curved mid-dorsal tooth (dorsal length of teeth slightly and gradually increasing posteriorly) and pair of dorsolateral non-carinate acute teeth (pleonites 1-2 without second pair of dorsolateral teeth); pleonite 3 with dorsal sharp carina with very weak median notch (lobe anterior to notch extremely low) and produced posteriorly into an a broad acute and sharp triangular tooth, and pair of dorsolateral non-carinate acute teeth.

COXAE 1-3. Strongly carinate and distally sharp.

Coxa 4. Anterodorsal and anteroventral border nearly straight, joined by low and very blunt angular discontinuity, anterior angle not projecting forward; ventral tooth sharp and strong; lateral carina without tooth, without sharp angularity, carina very distant from margin of coxa at its deepest point.

CoxA 5. With sharp and narrowly triangular, carinate, lateral tooth pointing obliquely backwards.

Coxa 6. With mid-sized, sharp and narrowly triangular, carinate lateral tooth pointing obliquely backwards; posteroventral corner bluntly angular.

Coxa 7. With ventral and posterior border straight, converging to form a sharp acute angle (i.e. a tooth).

Epimeral PLATes 1-3. Posteroventral angle produced into a very long sharp tooth.

UROSOME TOOTH PATTERN. Urosomite 1 with strong triangular process pointing upwards; urosomite 2 with pair of small sharp posterior dorsolateral teeth pointing upwards.

Telson. Cleft on 0.25 ; tips of lobes blunt, broadly V-shaped.

Peduncle of ANTEnNa 1 . Article 1 with long lateral and medial teeth respectively nearly reaching beyond mid and nearly reaching mid of article 2 (teeth excluded) and long ventral tooth reaching tip of article 2 (teeth excluded); article 2 with very long lateral and medial teeth overreaching tip of article 3 , with ventral tooth slightly overreaching tip of article 3 (tooth excluded); article 3 with long ventral tooth, about as long as article itself.

GNATHOPODs 1-2. Carpus and propodus of normal slenderness; propodus not narrowing distally, and palm distinct.

PereIOPODS 5-7. Merus, carpus and propodus fairly slender; basis of pereiopods 5-6 of normal width, with posteroproximal process rounded and strongly protruding, with posterodistal tooth strong; basis of pereiopod 7 very broad with posterodistal tooth angulate, followed more proximally by small concavity, directed posteriorly.

\section{Colour pattern}

Body whitish with intense orange colour marks. Peduncle of antenna 1 orange-tinged. Rostrum, and posterior part of pereiopods vaguely orange-tinged; Eyes reddish. 


\section{Body length}

Up to $45 \mathrm{~mm}$.

\section{Distribution}

Elephant Island and tip of Antarctic Peninsula: Bransfield Strait and Snow Hill Island; 90-483 m.

\section{Remarks}

Epimeria pandora sp. nov. is morphologically similar to the sympatric E. similis and E. colemani sp. nov. Epimeria pandora sp. nov. has a pair of small teeth pointing upwards on urosomite 2, which are absent in the two other species. It has no lateral tooth or angularity on the lateral carina of coxa 4 , whilst $E$. similis has a well developed tooth and E. colemani sp. nov. a very obtuse tooth or angularity. Finally, the dorsolateral teeth of the pereion are conical in E. pandora sp. nov., whilst they are carinate in E. colemani sp. nov. The Peninsular E. pandora sp. nov. is replaced by the extremely similar E. havermansiana subgen. et sp. nov. in the eastern Weddell Sea, off Princess Ragnhild Coast, Prydz Bay and Adélie Coast. See also key to E. (Drakepimeria) subgen. et sp. nov. and account on E. havermansiana subgen. et sp. nov. for differences.

Epimeria (Drakepimeria) pyrodrakon subgen. et sp. nov. urn:1sid:zoobank.org:act:BC42CFAC-0277-4B3D-B6FD-06A9C2020D25

Figs $83-89$

Epimeria macrodonta - Coleman 2007: 43, in part, fig. 21a-b, not colour plate 1d (= E. anguloce sp. nov.).

'Clade A similis/macrodonta complex - MA4' - Verheye et al. 2016a, supplement: 2 (online).

non Epimeria macrodonta Walker, 1906: 16.

\section{Etymology}

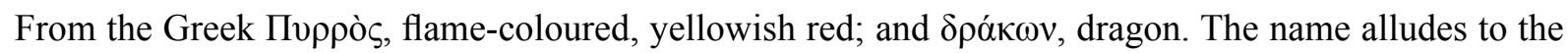
Great Red Dragon of the Book of Revelation, because its highly intricate ornamentation is not unlike that of a dragon and its colour accurately matches with the description given by John the Apostle. The

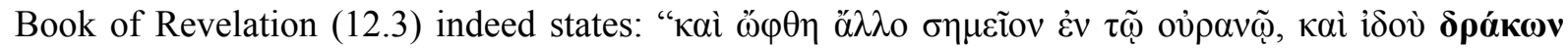

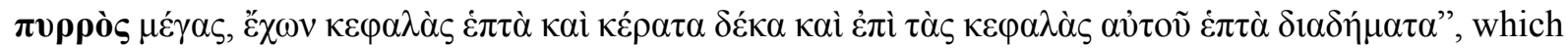
is translated as follows in the Holman Christian Standard Bible: "Then another sign appeared in heaven: There was a great fiery red dragon having seven heads and ten horns, and on his heads were seven diadems". The name is a noun in apposition.

\section{Type material}

\section{Holotype}

RV Polarstern cruises:

SOUTHERN OCEAN: $q$, in absolute alcohol, cruise PS81, ANT-XXIX/3, stn 193-8, Bransfield Strait, 62 $43.73^{\prime} \mathrm{S}, 57^{\circ} 29.04^{\prime} \mathrm{W}$ to $62^{\circ} 43.80^{\prime} \mathrm{S}, 57^{\circ} 29.40^{\prime} \mathrm{W}, 428-431 \mathrm{~m}$, Agassiz trawl, $23 \mathrm{Feb} 2013$, coll. C. d'Udekem d'Acoz and M. Verheye (RBINS, INV. 132973) [extraction N1; Genbank nr, 28S: KU759677].

\section{Paratypes}

RV Polarstern cruises:

SOUTHERN OCEAN: 2 specs, cruise PS06, ANT-III/3, stn 348, eastern Weddell Sea, $72^{\circ} 50^{\prime}$ S, 19²3' W, 490 m, bottom trawl, 20 Feb. 1985, coll. J. Plötz (RBINS, INV. 132724); 1 spec., cruise PS14, 
ANT-VII/4, EPOS leg 3, stn 230, eastern Weddell Sea, $75^{\circ} 14.2^{\prime} \mathrm{S}, 26^{\circ} 59.4^{\prime} \mathrm{W}$ to $75^{\circ} 14.5^{\prime} \mathrm{S}, 26^{\circ} 59.9^{\prime} \mathrm{W}$, 270-275 m, Agassiz trawl, 30 Jan. 1989, coll. C. De Broyer (RBINS, INV. 132722); 2 specs, kept on board in aquarium, cruise PS39, ANT-XIII/3, EASIZ I, stn 8, AGT 2, eastern Weddell Sea, $71^{\circ} 18.70^{\prime}$ S, $12^{\circ} 17.10^{\prime} \mathrm{W}$ to $71^{\circ} 18.45^{\prime} \mathrm{S}, 12^{\circ} 16.30^{\prime} \mathrm{W}, 170-174 \mathrm{~m}, 9$ Feb. 1996, coll. C. De Broyer and G. Chapelle (RBINS, INV. 132685); 1 spec., kept on board in aquarium, cruise PS39, ANT-XIII/3, EASIZ I, stn 8, AGT 2 , eastern Weddell Sea, $71^{\circ} 18.70^{\prime} \mathrm{S}, 12^{\circ} 17.10^{\prime} \mathrm{W}$ to $71^{\circ} 18.45^{\prime} \mathrm{S}, 12^{\circ} 16.30^{\prime} \mathrm{W}, 170-174 \mathrm{~m}, 9$ Feb. 1996, coll. C. De Broyer and G. Chapelle (MNHN-IU-2014-7331, removed from RBINS, INV. 132685); $1 \mathrm{spec}$. (used for gut content analysis and previously misidentified as E. macrodonta), cruise PS39, ANT-XIII/3, EASIZ I, stn 6, AGT 1, eastern Weddell Sea, $71^{\circ} 31.80^{\prime} \mathrm{S}, 13^{\circ} 34.50^{\prime} \mathrm{W}$ to $71^{\circ} 31.86^{\prime} \mathrm{S}$, $13^{\circ} 35.50^{\prime}$ W, 254-261 m, Agassiz trawl, 8 Jan. 1996, coll. C. De Broyer and G. Chapelle (RBINS, INV. 132681); 4 specs, cruise PS69, ANT-XXIII/8, stn 603-5, eastern Weddell Sea, $70^{\circ} 30.99^{\prime}$ S, $08^{\circ} 48.08^{\prime} \mathrm{W}$ to $70^{\circ} 30.40^{\prime} \mathrm{S}, 08^{\circ} 48.13^{\prime} \mathrm{W}, 274-297 \mathrm{~m}$, sponge bottom, Agassiz trawl, 7 Dec. 2006, coll. C. d'Udekem d'Acoz and H. Robert (RBINS, INV. 122560); 1 spec., alcohol-fixed, cruise PS69, ANT-XXIII/8, stn 603-5, eastern Weddell Sea, $70^{\circ} 30.99^{\prime} \mathrm{S}, 08^{\circ} 48.08^{\prime} \mathrm{W}$ to $70^{\circ} 30.40^{\prime} \mathrm{S}, 08^{\circ} 48.13^{\prime} \mathrm{W}, 274-297 \mathrm{~m}$, sponge bottom, Agassiz trawl, 7 Dec. 2006, coll. C. d'Udekem d'Acoz and H. Robert (RBINS, INV. 122475); 1 spec., cruise PS69, ANT-XXIII/8, stn 726-4, southeast of Snow Hill Island, $64^{\circ} 37.83^{\prime}$ S, $56^{\circ} 42.10^{\prime}$ W to 64 $4^{\circ} 38.03^{\prime}$ S, 56 $6^{\circ} 42.57^{\prime}$ W, 292 m, Agassiz trawl, 23 Jan. 2007, coll. C. d'Udekem d'Acoz and H. Robert (RBINS, INV. 122564); 2 specs, cruise PS69, ANT-XXIII/8, stn 728-2, south of Dundee Island, $63^{\circ} 42.63^{\prime} \mathrm{S}, 56^{\circ} 01.63^{\prime} \mathrm{W}$ to $63^{\circ} 42.25^{\prime} \mathrm{S}, 56^{\circ} 02.16^{\prime} \mathrm{W}, 293-298 \mathrm{~m}$, Agassiz trawl, $24 \mathrm{Jan} .2007$, coll. C. d'Udekem d'Acoz and H. Robert (RBINS, INV. 122569); 1 \%, dissected, absolute alcohol, cruise PS81, ANT-XXIX/3, stn 193-8, Bransfield Strait, $62^{\circ} 43.73^{\prime} \mathrm{S}, 57^{\circ} 29.04^{\prime} \mathrm{W}$ to $62^{\circ} 43.80^{\prime} \mathrm{S}, 57^{\circ} 29.40^{\prime} \mathrm{W}$, 428-431 m, Agassiz trawl, 23 Feb. 2013, coll. C. d'Udekem d'Acoz and M. Verheye (RBINS, INV. 132960) [extraction I17; Genbank nr, 28S: KU759619].

Belgian and Belgian-Dutch Antarctic expedition:

SOUTHERN OCEAN: 1 spec., Princess Ragnhild Coast, stn 215, Baie Léopold, exact position missing, 234 m, trawl, 28 Jan. 1965, coll. A. Capart (RBINS, INV. 132730); 1 spec., Princess Ragnhild Coast, stn 219, Baie du Glacier, 70 $18^{\prime} 05^{\prime \prime}$ S, $2^{\circ} 58^{\prime} 00^{\prime \prime}$ E, 216 m, trawl, 31 Jan. 1965, coll. A. Capart (RBINS, INV. 132727); 1 spec., Princess Ragnhild Coast, stn 219, Baie du Glacier, $70^{\circ} 18^{\prime} 05^{\prime \prime}$ S, $23^{\circ} 58^{\prime} 00^{\prime \prime}$ E, 216 m, trawl, 31 Jan. 1965, coll. A. Capart (RBINS, INV. 132729); 1 spec., Princess Ragnhild Coast, stn 219, Baie du Glacier, 70¹8'05" S, 2358'00" E, 216 m, trawl, 31 Jan. 1965, coll. A. Capart (RBINS, INV. 132727); 1 spec., Princess Ragnhild Coast, stn 234, between 'Baie des Pingouins' and 'Baie du Polarhav', 70¹9' S, 2426' E, 200 m, trawl, 2 Feb. 1967, coll. A. Capart (RBINS, INV. 132276).

\section{Description}

Rostrum. Long, reaching mid of article 2 of peduncle of antenna 1 (teeth excluded), strongly curved, subacute in lateral view.

EYE. Large, elliptic.

Pereion-pleosome tooth pattern. Pereionite 1 with medium-sized broad and blunt mid-dorsal tooth pointing backwards, with pair of small conical, dorsolateral teeth; pereionite 2 much narrower than pereionites 1 and 3, without mid-dorsal tooth and without pair of dorsolateral teeth; pereionite 3 with medium-sized broad and blunt mid-dorsal tooth pointing backwards and pair of fairly blunt, conical, dorsolateral teeth; pereionite 4 to pleonite 2 with large, moderately narrow, acute mid-dorsal tooth, of which the anterior border exhibits a slight angular discontinuity, and the posterior border is slightly concave, with pair of conical dorsolateral teeth of which the size gradually increases posteriorly (these pairs of teeth are never duplicate); pleonite 3 with large narrowly triangular, nearly symetrical, acutetipped mid-dorsal tooth, and pair of large styliform dorsolateral teeth (size of mid-dorsal tooth very 
weakly increasing from pereionite 4 to pleonite 2; mid-dorsal tooth of pleonite 3 as long as tooth of pleonite 2).

COXAE $1-3$. Strongly carinate and distally sharp.

Coxa 4. Anterodorsal border straight, anteroventral border weakly curved, these two borders being joined by a long curve (anterior angle), this anterior angle is weakly projecting forward; ventral tooth very long and acute; lateral carina with very large tooth obliquely pointing backwards; carina very distant from margin of coxa at its deepest point.

CoxA 5. With long, sharp, narrowly triangular, carinate, lateral tooth pointing obliquely backwards.

Coxa 6. With mid-sized, sharp and narrowly triangular, carinate, lateral tooth pointing obliquely backwards; posteroventral angle rounded, without angular discontinuity.

Coxa 7. With ventral border slightly curved, with posterior border straight, their convergence forming a blunt squared angle.

EPIMERAL PLATES 1-3. Posteroventral angle produced into a very long and very sharp tooth.

UROSOME TOOTH PATTERN. Urosomite 1 with large and sharp narrow tooth pointing upwards; urosomite 2 with pair of mid-sized posterior dorsolateral teeth pointing upwards; urosomite 3 with pair of mid-sized posterior dorsolateral teeth pointing obliquely upwards.

TELSON. Cleft on 0.3; tips of lobes subacute, notch narrowly and sharply V-shaped.

Peduncle of antenna 1. Article 1 with medium-sized lateral, medial and ventral teeth reaching mid of article 2 (teeth excluded) or less; article 2 with medium-sized lateral, medial and ventral teeth, not reaching tip of article 3 (ventral tooth excluded); article 3 with well developed ventral tooth, $0.5-0.8$ times as long as article itself.

GNATHOPODs 1-2. Carpus and propodus of normal slenderness; not broadening distally, palm distinct.

Pereiopods 5-7. Merus, carpus and propodus slender; basis of pereiopods 5-6 of normal width, with posteroproximal process rounded and strongly protruding, with posterodistal tooth very strong (as long as basis width); basis of pereiopod 7 broad with posterodistal tooth acute and very large, followed more proximally by distinct concavity, directed posteriorly.

\section{Colour pattern}

Whitish with large orange red marks; eye reddish.

\section{Body length}

Up to $35 \mathrm{~mm}$.

\section{Distribution}

Tip of Antarctic Peninsula, eastern shelf of the Weddell Sea, Princess Ragnhild Coast; 170-490 m.

\section{Biology}

Specimens previously identified as Epimeria macrodonta collected during the cruises ANT-VII/4 and ANT-XIII/3, and apparently used by Dauby et al. (2001a, 2001b) for their trophic studies were examined. They proved to be E. pyrodrakon sp. nov. According to Dauby et al. (2001a), gut contents of their freshly 
collected "Epimeria macrodonta" (i.e., at least in part E. pyrodrakon sp. nov.) showed a wide variety of food items: cnidarians (hydroid perisarcs, gorgonian ossicles), crustaceans (pieces of euphausiids) and pycnogonids, sea cucumbers (ossicles), and plankton (foraminifers, diatoms, ostracods); sponge spicules and sand grains completed the diet. On the basis of these observations, Dauby et al. (2001a, 2001b) concluded that the species was an opportunistic feeder or an opportunistic predator, coupling microbrowsing on colonial organisms with active capture of small live prey and with microdetritivory.

\section{Remarks}

Epimeria pyrodrakon sp. nov. is superficially similar to the sympatric $E$. anguloce sp. nov., but exhibits a different size arrangement of teeth on the peduncle of antenna 1, a larger mid-dorsal tooth on pereionite 1 and a much longer tooth on the lateral carina of coxa 4. The 'Epimeria macrodonta' illustrated in fig. 21 by Coleman (2007) corresponds to the description of E. pyrodrakon sp. nov. based on the size and disposition of the teeth on the peduncle of antenna 1. The station of the specimen is not given in the book. It is $62^{\circ} 59.38^{\prime} \mathrm{S}, 57^{\circ} 4.82^{\prime} \mathrm{W}$ [tip of Antarctic Peninsula]; 3 Dec. 1984, leg. Wägele, 200-300 m, Agassiz trawl (Coleman pers. com.).

Epimeria (Drakepimeria) reoproi subgen. nov. Lörz \& Coleman, 2001 Figs 90-98

Epimeria reoproi Lörz \& Coleman, 2001: 991-1001, figs 1-5.

Epimeria reoproi - Lörz \& Coleman in Lörz 2003: 20, figs 1-5. — Coleman 2007: 49, in part, fig. 26, Map 13 (open square), not colour plate 2h (= E. robertiana sp. nov.) — d'Udekem d'Acoz \& Robert 2008.

non Epimeria reoproi - Lörz \& Coleman 2009: unnumbered photograph on p. 17 (= E. robertiana sp. nov.).

\section{Material examined}

RV Polarstern cruises:

SOUTHERN OCEAN: + , partly dissected, stacking photographs, probably photographed on board dotted colour morph without red patch, cruise PS69, ANT-XXIII/8, stn 614-3/4/5, Elephant Island, $60^{\circ} 52.37^{\prime} \mathrm{S}, 55^{\circ} 29.80^{\prime} \mathrm{W}$ to $60^{\circ} 52.71^{\prime} \mathrm{S}, 55^{\circ} 27.83^{\prime} \mathrm{W}, 248-265 \mathrm{~m}$, a lot of epifauna, Rauschert dredge and Agassiz trawl, 22 Dec. 2006, coll. C. d'Udekem d'Acoz and H. Robert (RBINS, INV. 122477); 1 spec., probably photographed on board - dotted colour morph without red patch, cruise PS69, ANTXXIII/8, stn 614-3/4/5, Elephant Island, $60^{\circ} 52.37^{\prime} \mathrm{S}, 55^{\circ} 29.80^{\prime} \mathrm{W}$ to $60^{\circ} 52.71^{\prime} \mathrm{S}, 55^{\circ} 27.83^{\prime} \mathrm{W}, 248-265$ m, a lot of epifauna, Rauschert dredge and Agassiz trawl, 22 Dec. 2006, coll. C. d'Udekem d'Acoz and H. Robert (RBINS, INV. 122477); 2 specs, cruise PS69, ANT-XXIII/8, stn 608-1, Elephant Island, $61^{\circ} 11.34^{\prime} \mathrm{S}, 54^{\circ} 43.17^{\prime} \mathrm{W}$ to $61^{\circ} 11.80^{\prime} \mathrm{S}, 54^{\circ} 40.05^{\prime} \mathrm{W}, 284-293 \mathrm{~m}, 20$ Dec. 2006 , coll. C. d'Udekem d'Acoz and H. Robert (RBINS, INV. 122541); 2 specs, one of these specimens was photographed on board, colour morph with both red dots and red patch, cruise PS69, ANT-XXIII/8, stn 614-3/4/5 ?3-5?, Elephant Island, $60^{\circ} 52.37^{\prime} \mathrm{S}, 55^{\circ} 29.80^{\prime} \mathrm{W}$, to $60^{\circ} 52.71^{\prime} \mathrm{S}, 55^{\circ} 27.83^{\prime} \mathrm{W}, 248-265 \mathrm{~m}$, a lot of epifauna, Rauschert dredge and Agassiz trawl, 22 Dec. 2006, coll. C. d'Udekem d'Acoz and H. Robert (RBINS, INV. 122481A); 1 spec., cruise PS69, ANT-XXIII/8, stn 614-3/4/5, Elephant Island, $60^{\circ} 52.37^{\prime} \mathrm{S}$, $55^{\circ} 29.80^{\prime} \mathrm{W}$, to $60^{\circ} 52.71^{\prime} \mathrm{S}, 55^{\circ} 27.83^{\prime} \mathrm{W}, 248-265 \mathrm{~m}$, a lot of epifauna, Rauschert dredge and Agassiz trawl, 22 Dec. 2006, coll. C. d'Udekem d'Acoz and H. Robert (RBINS, INV.122481B); ca 20 specs, cruise PS69, ANT-XXIII/8, stn 614-3/4/5, Elephant Island, $60^{\circ} 52.37^{\prime} \mathrm{S}, 55^{\circ} 29.80^{\prime} \mathrm{W}$ to $60^{\circ} 52.71^{\prime} \mathrm{S}$, $55^{\circ} 27.83^{\prime} \mathrm{W}, 248-265 \mathrm{~m}$, a lot of epifauna, Rauschert dredge and Agassiz trawl, initially fixed with formalin, 22 Dec. 2006, coll. C. d'Udekem d'Acoz and H. Robert (RBINS, INV. 122535); 1 spec., cruise PS69, ANT-XXIII/8, stn 614-3/4/5, Elephant Island, $60^{\circ} 52.37^{\prime} \mathrm{S}, 55^{\circ} 29.80^{\prime} \mathrm{W}$ to $60^{\circ} 52.71^{\prime} \mathrm{S}, 55^{\circ} 27.83^{\prime}$ W, 248-265 m, a lot of epifauna, Rauschert dredge and Agassiz trawl, initially fixed with formalin, 22 
Dec. 2006, coll. C. d'Udekem d'Acoz and H. Robert (MNHN-IU-2014-7332, removed from RBINS, INV. 122535); 1 spec., initially fixed with formalin, cruise PS69, ANT-XXIII/8, stn 622-1, Elephant Island, $60^{\circ} 56.70^{\prime} \mathrm{S}, 55^{\circ} 52.71^{\prime} \mathrm{W}$ to $60^{\circ} 55.93^{\prime} \mathrm{S}, 55^{\circ} 50.79^{\prime} \mathrm{W}, 218-307 \mathrm{~m}$, Agassiz trawl, $23 \mathrm{Dec} .2006$, coll. C. d'Udekem d'Acoz and H. Robert (RBINS, INV. 122540).

\section{Description}

Rostrum. Long, just reaching tip of article 1 of peduncle of antenna 1 (teeth excluded), distinctly curved on both sides, subacute in lateral view.

EYE. Very large, broadly elliptic.

Pereion-Pleosome tooth pattern. Pereionites 1-4 without any trace of mid-dorsal tooth, without pair of dorsolateral teeth or protrusions; pereionite 2 slightly narrower than pereionite 1 ; pereionite 5 with trace of dorsoventrally flattened posterior mid-dorsal tooth (very obtuse in dorsal view, subacute in lateral view), with pair of flattened and indistinct dorsolateral protrusions or small teeth; pereionites 6-7 with small and low subacute mid-dorsal tooth, with pair of flattened dorsolateral protrusions; pleonites 1-3 with low, acute-tipped mid-dorsal tooth (apically broader on pleonite 3 ), which are not anteriorly angulate (but more or less regularly curved) and pair of small dorsolateral non-carinate teeth (of which none is duplicated); pleonite 3 with large acute-tipped mid-dorsal tooth bearing an inconspicuous trace of median concavity.

COXAE 1-3. Carinate; coxa 1 not tapering, distally very broad and very blunt; coxae $2-3$ distally blunt and fairly broad.

CoxA 4. Anteriorly forming a strong curve (not projecting much forward), where the anterodorsal and the anteroventral borders merge into each other without angular discontinuity; ventral tooth fairly long, narrow, apically acute, arching backwards, lateral carina without tooth but forming a very low, very bluntly angular lobe projecting laterally, carina very distant from margin of coxa at its deepest point.

CoxA 5. With well developed, sharp and broadly triangular, lateral carinate tooth, of which the anterior border weakly diverges backwards and the posterior border is nearly perpendicular to body axis.

Coxa 6. With mid-sized, subacute and broadly subtriangular, carinate, lateral tooth, of which the proximal half of the anterior border diverges backwards, the distal half of the anterior border is nearly parallel with body axis (transition between anterior and posterior half with angular discontinuity), and the posterior border is nearly perpendicular to body axis; posteroventral corner produced broadly rounded.

Coxa 7 . With ventral border distinctly curved, with posterior border weakly curved, their convergence forming a very blunt angular discontinuity.

Epimeral Plates 1-3. Posteroventral angle produced into a long and sharp tooth (especially the third one).

UROSOME TOOTH PATTERN. Urosomite 1 with low and blunt triangular process pointing upwards; urosomite 2 with pair of small but sharp posterior dorsolateral teeth pointing upwards.

TELson. Cleft on 0.3 ; tips of lobes subacute, slit forming a fairly broad V.

Peduncle of antenna 1. Article 1 with tiny lateral and medial teeth and fairly small ventral tooth reaching half of article 2; article 2 without lateral tooth (it is replaced by a weak lobe) and two tiny medial teeth, 
with small ventral tooth reaching about $0.3-0.5$ of article 3 ; article 3 with well developed ventral tooth, slightly longer than article itself.

GNATHOPODS 1-2. Carpus and propodus fairly robust, propodus not narrowing distally, palm distinct.

PeReIOPODS 5-7. Merus, carpus and propodus slender; basis of pereiopods 5-6 of normal width, with posteroproximal process rounded, distinctly but not strongly protruding, with posterodistal tooth broadly triangular and strong; basis of pereiopod 7 very broad with posterodistal tooth triangular and sharp, followed more proximally by shallow concavity, directed posteriorly.

\section{Colour pattern}

Body, coxae and pereiopods studded with bright red or reddish small dots on a whitish background. In some specimens there is a large irregular red patch on the anterior half of the body. Eyes reddish to red.

\section{Body length}

Up to $40 \mathrm{~mm}$.

\section{Distribution}

RV Polarstern cruise, PS56, ANT-XVI1/3, Stn. 171-3 (Lörz \& Coleman 2001). Exact position: $63^{\circ} 00.10^{\prime} \mathrm{S}, 060^{\circ} 30.70^{\prime} \mathrm{W}$ to $63^{\circ} 00.10^{\prime} \mathrm{S}, 60^{\circ} 31.00^{\prime} \mathrm{W}$ [Bransfield Strait: Deception Island, outside of the caldera, near South East Point], 45-48 m (Arntz \& Brey 2001). Elephant Island, 218-307 m (present material).

\section{Remark}

All the specimens of Epimeria reoproi examined by us have a pair of small postero-dorsolateral teeth on urosomite 2. Lörz \& Coleman (2001) stated that urosomite 2 was smooth in the type material. However, a tiny postero-dorsolateral tooth pointing backwards is visible on their figure $1 \mathrm{~b}$, suggesting that their description is incorrect.

Epimeria (Drakepimeria) robertiana subgen. et sp. nov. urn:1sid:zoobank.org:act:8433E457-9757-41B0-BC19-2A95EE5E3176

Figs 99-105

Epimeria reoproi - Coleman 2007: in part, only plate 2 fig. h, not p. 49, not fig. 6, not map 13. Lörz \& Coleman 2009: unnumbered photograph on p. 17. - Rauschert \& Arntz 2015: 62, pl. 55, unnumbered photograph.

'Clade A similis/macrodonta complex - SP2' - Verheye et al. 2016a, supplement: 2 (online).

non Epimeria reoproi Lörz \& Coleman, 2001: 991-1001, figs 1-5.

\section{Etymology}

The species is dedicated to Henri Robert (Royal Belgian Institute of Natural Sciences), who collected a large part of the type material. Robertianus, $-a,-u m$ is an adjective derived from his name.

\section{Type material}

\section{Holotype}

RV Polarstern cruises:

SOUTHERN OCEAN: $\widehat{\jmath}$, initially fixed in formalin, cruise PS71, ANT-XXIV/2, ANDEEP-SYSTCO, eastern Weddell Sea, given by colleagues to H. Robert on 22 Dec. 2007, presumably stn 17-10, of which 
the coordinates are: $70^{\circ} 4.58^{\prime} \mathrm{S}, 3^{\circ} 19.66^{\prime} \mathrm{W}$ to $70^{\circ} 4.48^{\prime} \mathrm{S}, 3^{\circ} 19.20^{\prime} \mathrm{W}, 2163-2190 \mathrm{~m}$, Agassiz trawl, coll. H. Robert (RBINS, INV. 132413).

\section{Paratypes}

RV Polarstern cruises:

SOUTHERN OCEAN: 1 spec., cruise PS48, ANT-XV/3, EASIZ II, stn 134, eastern Weddell Sea, $74^{\circ} 32.2^{\prime} \mathrm{S}, 27^{\circ} 13.8^{\prime} \mathrm{W}$ to $74^{\circ} 32.5^{\prime} \mathrm{S}, 2^{\circ} 14.5^{\prime} \mathrm{W}, 2054-2081 \mathrm{~m}$, Agassiz trawl, 9 Feb. 1998, coll. C. De Broyer (RBINS, INV. 132991); 1 immature spec., sex undetermined, cruise PS71, ANT-XXIV/2, ANDEEP-SYSTCO, stn 17-11, eastern Weddell Sea, $70^{\circ} 5.13^{\prime} \mathrm{S}, 3^{\circ} 23.50^{\prime} \mathrm{W}$ to $70^{\circ} 4.66^{\prime} \mathrm{S}, 3^{\circ} 21.37^{\prime} \mathrm{W}$, 1724-2091 m, epibenthic sledge, 22 Dec. 2007, coll. H. Robert (RBINS, INV. 132963) [extraction K44; Genbank nr, COI: KU870842, 28S: KU759618]; 2 specs, initially fixed in formalin, cruise PS71, ANTXXIV/2, ANDEEP-SYSTCO, eastern Weddell Sea, given by colleagues to H. Robert on 22 Dec. 2007, presumably stn $17-10$, of which the coordinates are: $70^{\circ} 4.58^{\prime} \mathrm{S}, 3^{\circ} 19.66^{\prime} \mathrm{W}$ to $70^{\circ} 4.48^{\prime} \mathrm{S}, 3^{\circ} 19.20^{\prime} \mathrm{W}$, 2163-2190 m, Agassiz trawl, coll. H. Robert (RBINS, INV. 132413).

\section{Description}

RostRum. Long, overreaching mid of article 2 of peduncle of antenna 1, scarcely curved, sharp-tipped in lateral view.

EYE. Very large, elliptic.

Pereion-Pleosome tooth pattern. Pereionites 1-4 without any trace of mid-dorsal tooth and dorsolateral protrusions or teeth; pereionite 2 nearly as broad as pereionite 1 ; pereionite 5 with very distinct posterodorsal bump and pair of weak dorsolateral teeth; pereionite 6 with small mid-dorsal tooth (of which the anterior border is straight) and pair of weak dorsolateral teeth; pereionite 7 with low mediumsized mid-dorsal tooth (of which the anterior border is weakly curved) and pair of small dorsolateral non-carinate teeth; pleonites 1-2 with low but large and very sharp, anteriorly weakly curved mid-dorsal tooth and pair of small dorsolateral non-carinate teeth; on pleonite 1 a second pair of (much smaller) dorsolateral teeth is observed between the mid-dorsal tooth and the main pair of dorsolateral teeth; pleonite 3 with low but large acute-tipped mid-dorsal tooth bearing an inconspicuous median notch and pair of small dorsolateral non-carinate teeth (mid-dorsal teeth gradually increasing in size in a backwards direction).

COXAE $1-3$. Weakly carinate and distally very sharp.

Coxa 4. Not broad; anterodorsal and anteroventral border straight joined by low and blunt angular discontinuity, anterior angle not projecting forward; ventral tooth medium-sized and acute; lateral carina not sharp, without tooth or angularity, carina very distant from margin of coxa at its deepest point.

CoxA 5. With long, sharp and broadly triangular, carinate, lateral tooth.

Coxa 6. With mid-sized, sharp and broadly triangular, carinate, lateral tooth; posteroventral corner broadly rounded.

Coxa 7. With ventral border strongly convex, with posterior border distinctly convex, their convergence forming a very rounded angular discontinuity.

Epimeral Plates 1-3. Posteroventral angle: produced into a medium-sized and very sharp tooth, especially the plate 3 . 
UROSOME TOOTH PATTERN. Urosomite 1 with sharp tooth pointing backwards of which the anterior border is weakly convex and longer than the posterior border, and of which the posterior border is strongly curved and concave; urosomite 2 without pair of small posterior dorsolateral teeth pointing upwards.

Telson. Cleft on 0.2 ; tips of lobes acute, separated by very broad V-shaped notch.

PedunCle of Antenna 1. Article 1 without lateral tooth, with very short medial tooth, and medium-sized ventral tooth reaching 0.4 of article 2 ; article 2 without lateral tooth, with very short medial tooth, and short ventral tooth reaching 0.3 of article 2 ; article 3 with well developed ventral tooth, about as long as article itself.

GNATHOPODS 1-2. Carpus and propodus of normal slenderness; propodus not narrowing distally, palm distinct.

PeREIOPODS 5-7. Merus, carpus and propodus slender; basis of pereiopods 5-6 narrow, with posteroproximal process rounded and very weak, not well individualized, with posterodistal tooth small but acute and obliquely directed in pereiopod 5, reduced to a squared angle in pereiopod 6; basis of pereiopod 7 broad with posterodistal tooth sharp, not followed more proximally by distinct concavity, directed obliquely.

\section{Colour pattern}

Body and appendages uniformly pink or pale purple, except for eyes and gnathopods, which are red (colour photograph published by Coleman 2007 and Rauschert \& Arntz 2015, both as E. reoproi).

\section{Body length}

Up to $31 \mathrm{~mm}$.

\section{Distribution}

Eastern shelf of the Weddell Sea, 1724-2190 m.

\section{Remarks}

Rauschert \& Arntz (2015) published a colour photograph of E. robertiana sp. nov. (as E. reoproi), without indicating the origin of the specimen. However, that information was given in an early draft of the book made available to the authors: ANT-XV/3, stn 134. The coordinates of that station are: $74^{\circ} 32.2^{\prime} \mathrm{S}$, $27^{\circ} 13.8^{\prime} \mathrm{W}$ to $74^{\circ} 32.5^{\prime} \mathrm{S}, 27^{\circ} 14.5^{\prime} \mathrm{W}, 2054-2081 \mathrm{~m}$. The same photograph was previously published (also as E. reoproi) by Coleman (2007) and Lörz \& Coleman (2009). The inclusion of E. robertiana sp. nov. in the subgenus Drakepimeria is supported by molecular data. However, its narrow basis of pereiopod 5 and its posteriorly directed process of urosomite 1 are character states unusual for the subgenus Drakepimeria. On the other hand, these character states are frequent in non-Antarctic Epimeria species, which are predominantly deep-sea forms, just like $E$. robertiana sp. nov.

Epimeria (Drakepimeria) schiaparelli subgen. nov. Lörz, Maas, Linse \& Fenwick, 2007

Epimeria schiaparelli Lörz, Maas, Linse \& Fenwick, 2007: 25, figs 1-7.

Epimeria schiaparelli - Lörz \& Coleman 2009: unnumbered photograph on p. 17.

\section{Diagnosis}

Diagnosis based on the figures of Lörz et al. (2007). 
Pereionites 1-2 smooth; pereionite 3 with posterior mid-dorsal bump and pair of dorsolateral protrusions; pereionites 3-7 with moderately slender mid-dorsal tooth of length increasing posteriorly and pair of dorsolateral smaller teeth; mid-dorsal tooth of pleonite 3 narrow and without median notch. Urosomite 2 with pair of small dorsolateral teeth pointing upwards. lateral carina of coxa 4 with well-developed tooth pointing backwards. Peduncle of antenna 1: article 1 with short lateral and medial teeth, with long ventral tooth reaching tip of article 2 (teeth excluded); article 2 with long lateral and medial teeth overreaching article 3 ; article 3 with short ventral tooth shorter than article itself.

\section{Colour pattern}

Usually whitish with irregular pale orange patches, more rarely whitish with red transverse stripes (one stripe per body segment).

\section{Body length}

$30 \mathrm{~mm}$.

\section{Distribution}

Western Ross Sea, 130-350 m.

\section{Remarks}

Epimeria schiaparelli is very similar to E. corbariae sp. nov. They can be differentiated by the dorsal ornamentation of pereionite 3: a posterior bump in E. schiaparelli vs a tooth in E. corbariae sp. nov.

Epimeria (Drakepimeria) similis subgen. nov. Chevreux, 1912

Figs 106-124

Epimeria similis Chevreux, 1912: 215.

Epimeria similis - Chevreux 1913: 149, fig. 41. - Andres 1985: 124-125 (in part) - De Broyer \& Klages 1991: 165 (key, in part). — Coleman 2007: 54, in part, fig. 30a-b, map 11 (circle, at least in part), not plate 1 fig. e (=Epimeria acanthochelon sp. nov.).

Epimeria macrodonta f. similis - Gurjanova 1955: 195.

'Clade A similis/macrodonta complex - SI4' - Verheye et al. 2016a, supplement: 2 (online).

\section{Type material}

Lectotype (designated here)

RV Pourquoi Pas? Cruises:

SOUTHERN OCEAN: undissected ovigerous + , second French Antarctic expedition 1908-1910, Draguage XVII, South Shetlands, King George Island, Admiralty Bay, 420 m (n ${ }^{\circ}$ 713) (MNHN Am. 5984 and MNHN-IU-2013-17865).

\section{Paralectotype (designated here)}

RV Pourquoi Pas? Cruises:

SOUTHERN OCEAN: 1 + dissected by E. Chevreux, second French Antarctic expedition 1908-1910, Draguage XVII, South Shetlands King George Island, Admiralty Bay, 420 m (MNHN Am. 3095 and MNHN-IU-2013-17864). 


\section{Other material examined}

RV Polarstern cruises:

SOUTHERN OCEAN: 3 specs, cruise PS69, ANT-XXIII/8, stn 604-1, Elephant Island, $61^{\circ} 20.52^{\prime}$ S, $55^{\circ} 09.72^{\prime} \mathrm{W}$ to $61^{\circ} 20.11^{\prime} \mathrm{S}, 55^{\circ} 07.26^{\prime} \mathrm{W}, 286-407 \mathrm{~m}$, bottom trawl, 19 Dec. 2006, coll. C. d'Udekem d'Acoz and H. Robert (RBINS, INV. 132980); 1 spec. with a true posterodorsal bump on second body segment, cruise PS69, ANT-XXIII/8, stn 604-1, Elephant Island, $61^{\circ} 20.52^{\prime} \mathrm{S}, 55^{\circ} 09.72^{\prime} \mathrm{W}$ to $61^{\circ} 20.11^{\prime} \mathrm{S}, 55^{\circ} 07.26^{\prime} \mathrm{W}, 286-407 \mathrm{~m}$, bottom trawl, 19 Dec. 2006, coll. C. d'Udekem d'Acoz and H. Robert (RBINS, INV. 122555); 2 specs, cruise PS69, ANT-XXIII/8, stn 608-1, Elephant Island, $61^{\circ} 11.34^{\prime} \mathrm{S}, 54^{\circ} 43.17^{\prime} \mathrm{W}$ to $61^{\circ} 11.80^{\prime} \mathrm{S}, 54^{\circ} 40.05^{\prime} \mathrm{W}, 284-293 \mathrm{~m}$, bottom trawl, 20 Dec. 2006, coll. C. d'Udekem d'Acoz and H. Robert (RBINS, INV. 132982); 1 spec., cruise PS69, ANT-XXIII/8, stn 610-1, Elephant Island, $60^{\circ} 58.59^{\prime} \mathrm{S}, 55^{\circ} 08.39^{\prime} \mathrm{W}$ to $60^{\circ} 58.05^{\prime} \mathrm{S}, 55^{\circ} 05.00^{\prime} \mathrm{W}, 287-311 \mathrm{~m}$, bottom trawl, 21 Dec. 2006, coll. C. d'Udekem d'Acoz and H. Robert (RBINS, INV. 122550); 2 specs, cruise PS69, ANT-XXIII/8, stn 614-3/4/5, Elephant Island, $60^{\circ} 52.37^{\prime} \mathrm{S}, 55^{\circ} 29.80^{\prime} \mathrm{W}$ to $60^{\circ} 52.71^{\prime} \mathrm{S}$, 55 27.83' W, 248-265 m, a lot of epifauna, Rauschert dredge and Agassiz trawl, 22 Dec. 2006, coll. C. d'Udekem d'Acoz and H. Robert (RBINS, INV. 132984); 2 juvs, cruise PS69, ANT-XXIII/8, stn $614-3 / 4 / 5$, Elephant Island, $60^{\circ} 52.37^{\prime} \mathrm{S}, 55^{\circ} 29.80^{\prime} \mathrm{W}$ to $60^{\circ} 52.71^{\prime} \mathrm{S}, 55^{\circ} 27.83^{\prime} \mathrm{W}, 248-265 \mathrm{~m}$, a lot of epifauna, Rauschert dredge and Agassiz trawl, 22 Dec. 2006, coll. C. d'Udekem d'Acoz and H. Robert (RBINS, INV. 122554); 1 spec., alcohol-fixed, cruise PS69, ANT-XXIII/8, stn 624-3, Elephant Island, Agassiz trawl, $61^{\circ} 00.23^{\prime} \mathrm{S}, 55^{\circ} 58.53^{\prime} \mathrm{W}$ to $61^{\circ} 00.76^{\prime} \mathrm{S}, 55^{\circ} 59.20^{\prime} \mathrm{W}, 287-319 \mathrm{~m}, 23 \mathrm{Dec} .2006$, coll. C. d'Udekem d'Acoz and H. Robert (RBINS, INV. 122479); 4 specs, cruise PS69, ANT-XXIII/8, stn 627-1, Elephant Island, $60^{\circ} 59.00^{\prime} \mathrm{S}, 55^{\circ} 42.36^{\prime} \mathrm{W}$ to $60^{\circ} 57.62^{\prime} \mathrm{S}, 55^{\circ} 40.19^{\prime} \mathrm{W}, 90-102 \mathrm{~m}$, bottom trawl, 24 Dec. 2006, coll. C. d'Udekem d'Acoz and H. Robert (RBINS, INV. 132979); 5 specs, cruise PS69, ANT-XXIII/8, stn $642-1$, Elephant Island, $61^{\circ} 04.38^{\prime} \mathrm{S}, 55^{\circ} 59.81^{\prime} \mathrm{W}$ to $61^{\circ} 04.27^{\prime} \mathrm{S}, 55^{\circ} 58.88^{\prime} \mathrm{W}, 254 \mathrm{~m}$, Agassiz trawl, 27 Dec. 2006, coll. C. d'Udekem d'Acoz and H. Robert (RBINS, INV. 132981); 1 small spec., cruise PS69, ANT-XXIII/8, stn 642-2, Elephant Island, $61^{\circ} 04.28^{\prime} \mathrm{S}, 55^{\circ} 58.93^{\prime} \mathrm{W}$ to $61^{\circ} 04.24^{\prime} \mathrm{S}$, 55 59.27' W, 255-277 m, Rauschert dredge, 27 Dec. 2006, coll. C. d'Udekem d'Acoz and H. Robert (RBINS, INV. 122557); 2 specs, alcohol-fixed, cruise PS69, ANT-XXIII/8, stn 654-6, Elephant Island, $61^{\circ} 22.80^{\prime} \mathrm{S}, 56^{\circ} 03.84^{\prime} \mathrm{W}$ to $61^{\circ} 23.35^{\prime} \mathrm{S}, 56^{\circ} 04.89^{\prime} \mathrm{W}, 341-342 \mathrm{~m}$, Agassiz trawl, 29 Dec. 2006, coll. C. d'Udekem d'Acoz and H. Robert (RBINS, INV. 122480); 1 small spec., cruise PS69, ANT-XXIII/8, stn 654-6, Elephant Island, $61^{\circ} 22.80^{\prime} \mathrm{S}, 56^{\circ} 03.84^{\prime} \mathrm{W}$ to $61^{\circ} 23.35^{\prime} \mathrm{S}, 56^{\circ} 04.89^{\prime} \mathrm{W}, 341-342 \mathrm{~m}$, Agassiz trawl, 29 Dec. 2006, coll. C. d'Udekem d'Acoz and H. Robert (RBINS, INV. 122556); 2 + , cruise PS69, ANT-XXIII/8, stn 654-6, Elephant Island, $61^{\circ} 22.80^{\prime} \mathrm{S}, 56^{\circ} 03.84^{\prime} \mathrm{W}$ to $61^{\circ} 23.35^{\prime} \mathrm{S}, 56^{\circ} 04.89^{\prime} \mathrm{W}$, 341-342 m, Agassiz trawl, 29 Dec. 2006, coll. C. d'Udekem d'Acoz and H. Robert (RBINS, INV. 132983); 5 specs, cruise PS69, ANT-XXIII/8, stn 676-1, north of Livingstone Island, $62^{\circ} 11.06^{\prime} \mathrm{S}$, $60^{\circ} 47.49^{\prime} \mathrm{W}$ to $62^{\circ} 09.65^{\prime} \mathrm{S}, 60^{\circ} 49.56^{\prime} \mathrm{W}, 418-472 \mathrm{~m}$, bottom trawl, 2 Dec. 2007 , coll. C. d'Udekem d'Acoz and H. Robert (RBINS, INV. 122544); 2 specs, cruise PS69, ANT-XXIII/8, stn 680-5, northeast of Livingstone Island, $62^{\circ} 23.37^{\prime} \mathrm{S}, 61^{\circ} 25.58^{\prime} \mathrm{W} 62^{\circ} 22.75^{\prime} \mathrm{S}, 61^{\circ} 25.97^{\prime} \mathrm{W}, 324-349 \mathrm{~m}$, Agassiz trawl, 3 Jan. 2007, coll. C. d'Udekem d'Acoz and H. Robert (RBINS, INV. 122553); 1 q, specimen used for detailed illustrations, cruise PS81, ANT-XXIX/3, stn 193-8, Bransfield Strait, 62 $43.73^{\prime}$ S, 57 $29.04^{\prime}$ W to $62^{\circ} 43.80^{\prime} \mathrm{S}, 57^{\circ} 29.40^{\prime} \mathrm{W}, 426-431 \mathrm{~m}, 23 \mathrm{Feb}$. 2013, coll. C. d'Udekem d'Acoz and M. Verheye (RBINS, INV. 122956A) [extraction P36; Genbank nr, 28S: KU759680]; 3 우, cruise PS81, ANTXXIX/3, stn 193-8, Bransfield Strait, $62^{\circ} 43.73^{\prime} \mathrm{S}, 57^{\circ} 29.04^{\prime} \mathrm{W}$ to $62^{\circ} 43.80^{\prime} \mathrm{S}, 57^{\circ} 29.40^{\prime} \mathrm{W}, 426-431$ m, 23 Feb. 2013, coll. C. d'Udekem d'Acoz and M. Verheye (RBINS, INV. 122956B); 6 specs, cruise PS81, ANT-XXIX/3, stn 193-9, Bransfield Strait, $62^{\circ} 43.50^{\prime} \mathrm{S}, 57^{\circ} 27.92^{\prime} \mathrm{W}$ to $62^{\circ} 43.53^{\prime} \mathrm{S}, 57^{\circ} 28.28^{\prime} \mathrm{W}$, 420-431 m, sponge bottom, 23 Feb. 2013, coll. C. d'Udekem d'Acoz and M. Verheye (RBINS, INV. 122961); 1 spec., cruise PS81, ANT-XXIX/3, stn 217-6, Bransfield Strait, $62^{\circ} 53.45^{\prime} \mathrm{S}, 58^{\circ} 13.06^{\prime} \mathrm{W}$ to $62^{\circ} 53.42^{\prime} \mathrm{S}, 58^{\circ} 13.41^{\prime} \mathrm{W}, 461-483 \mathrm{~m}$, rich sponge bottom, Agassiz trawl, 2 Mar. 2013, coll. C. d'Udekem d'Acoz and M. Verheye (RBINS, INV. 122922B) [extraction P38; Genbank nr, 28S: KU759682]. 


\section{Description}

Rostrum. Long, reaching about tip of article 1 of peduncle of antenna 1 (teeth excluded), weakly curved, sharp-tipped in lateral view.

EYE. Very large, elliptic.

Pereion-Pleosome tooth pattern. Pereionite 1 without any trace of mid-dorsal tooth, with pair of very low non-carinate dorsolateral swellings; pereionite 2 nearly as broad as pereionite 1 , with or without very small blunt-tipped mid-dorsal tooth or bump, and with pair of dorsolateral non-carinate swellings or very blunt teeth; pereionite 3 with medium-sized blunt-tipped mid-dorsal tooth and pair of small dorsolateral non-carinate blunt teeth; pereionite 3 to pleonite 2 with acute-tipped broad regularly curved mid-dorsal tooth (nearly same shape and size on all these segments) and pair of dorsolateral non-carinate acute-tipped teeth (pleonites 1-2 without second pair of dorsolateral teeth); pleonite 3 with dorsal sharp carina with very weak median notch (lobe anterior to notch very low) and obliquely produced posteriorly into an a broad acute and sharp triangular tooth, and pair of dorsolateral non-carinate acute-tipped teeth.

COXAE $1-3$. Strongly carinate and distally sharp.

Coxa 4. Anterodorsal and anteroventral border nearly straight, joined by low and blunt angular discontinuity, anterior angle not strongly projecting forward; ventral tooth very long and styliform; lateral carina with lateral well-developed and sharp triangular tooth pointing obliquely backwards.

Coxa 5. With sharp and broadly triangular, carinate, lateral tooth pointing obliquely backwards.

Coxa 6. With mid-sized, sharp and narrowly triangular, carinate, lateral tooth pointing obliquely backwards; posteroventral corner produced into a triangular tooth.

Coxa 7. With ventral and posterior border straight, with posteroventral angle produced into a strong tooth.

EPIMERAL PLATES 1-3. Posteroventral angle produced into a very long styliform tooth.

UROSOME TOOTH PATTERN. Urosomite 1 with sharp triangular process pointing upwards; urosomite 2 without pair of small posterior dorsolateral teeth pointing upwards.

TELSON. Cleft on 0.25 ; tips of lobes rounded, slit fairly narrow.

Peduncle of antenna 1. Article 1 with long lateral and medial teeth nearly reaching mid of article 2 (teeth excluded) and long ventral tooth reaching tip of article 2 (teeth excluded); article 2 with long lateral tooth nearly reaching tip of article 3 (tooth excluded), with medial tooth slightly overreaching article 3 (tooth excluded), with ventral tooth slightly overreaching tip of article 3 (tooth excluded); article 3 with very long ventral tooth, longer than article itself.

GNATHOPODS 1-2. Carpus and propodus of normal slenderness; propodus not narrowing distally, palm distinct.

PeReIOPODS 5-7. Merus, carpus and propodus slender; basis of pereiopods 5-6 of normal width, with posteroproximal process rounded and strongly protruding, with posterodistal tooth strong; basis of pereiopod 7 very broad with posterodistal tooth sharp, followed more proximally by small concavity, directed posteriorly. 


\section{Colour pattern}

Whitish with faint orange marks on body; peduncle of antenna 1 carpus and propodus of pereiopods and uropods also tinged with orange. Eyes reddish.

\section{Body length}

Up to $40 \mathrm{~mm}$.

\section{Distribution}

Elephant Island to Bransfield Strait, 90-483 m (present data).

\section{Remarks}

The tip of the lateral tooth of coxa 4 is slightly damaged in the syntype of Epimeria similis illustrated by Chevreux (1913). This explains why the orientation of that tooth does not seem accurate on the drawings made by that author. Specimens of E. similis from Elephant Island look identical to specimens recorded further south, except for the absence of a mid-dorsal tooth on pereionite 2, which is either smooth or with a trace of bump. The difference is presumably size-related. Epimeria similis from Bransfield Strait and King George Island often reach a larger size than those of Elephant Island, and only the large ones have the extra tooth. So the specimens from Elephant Island are considered herein as small E. similis s. str.

The collecting station of the E. similis illustrated by Coleman (2007) on his figure 30 are $61^{\circ} 03.6^{\prime} \mathrm{S}$, 544ㄴ.6' W [Elephant Island]; 15 Dec. 1987, leg. Coleman, 358-332 m, bottom trawl (Coleman pers. com.). This specimen appears to be a true E. similis. On the other hand, the specimen illustrated by a colour photograph on his plate 1, fig. e is presumably Epimeria acanthochelon sp. nov. (see discussion on that species).

It seems that $E$. similis and the similar and closely related $E$. acanthochelon sp. nov. have non-overlapping distributions. Epimeria similis was recorded from the South Shetland Islands and the tip of the Antarctic Peninsula. Epimeria acanthochelon sp. nov. was recorded on the Adélie Coast (supported by 28S rDNA) and on the eastern shelf of the Weddell Sea (identification based on morphology only). See key of Drakepimeria and account on E. acanthochelon sp. nov. for differences with E. similis.

Epimeria (Drakepimeria) vaderi subgen. nov. Coleman, 1998

Epimeria vaderi Coleman, 1998b: 215-224, figs 1-6.

Epimeria vaderi - Coleman 2007: 55, figs 31a-b, map 14 (circle).

\section{Description}

Description based on the figures of Coleman (1998b).

RoBustness. More robust than most Drakepimeria. Rostrum: medium-sized, just overreaching tip of article 1 of peduncle of antenna 1 (teeth excluded), weakly curved, sharp-tipped in lateral view.

EYE. Very large, elliptic.

Pereion-pleosome tooth pattern. Pereionites 1-3 without any trace of mid-dorsal tooth, without dorsolateral protrusions; pereionite 2 slightly narrower than pereionite 1 ; pereionite 4 with very faint posterodorsal bump and no dorsolateral protrusions; pereionite 5 to pleonite 2 with broad and low, regularly curved, dorsolateral tooth, and pair of small posterodorsal swelling or teeth; on pleonites 1-2 a second pair of (a bit smaller) dorsolateral teeth is observed between the mid-dorsal tooth and the main 
pair of dorsolateral teeth; pleonite 3 with large subacute mid-dorsal tooth bearing a shallow but long median concavity.

COXAE 1-3. Carinate and distally sharp.

Coxa 4. Anterodorsal border proximally nearly straight (inconspicuously convex) and unusually long, of curvature gradually increasing downwards and followed by anteroventral border without any angular discontinuity or visible transition; posteroventral border weakly convex and short; coxa scarcely projecting forward; ventral tooth narrowly triangular, not long, apically subacute; lateral carina without tooth or angularity, not projecting laterally, carina very close from margin of coxa at its deepest point.

Coxa 5. Without laterally projecting carina (hence scarcely visible in dorsal view), with posteroventral corner produced into a blunt tooth oriented backwards.

Coxa 6. With mid-sized, blunt, triangular, lateral tooth pointing obliquely backwards (scarcely projecting laterally); posteroventral corner produced into a rounded lobe pointing downwards (posterior margin nearly straight).

Coxa 7. With ventral border distinctly curved, with posterior border, their convergence forming a blunt angular discontinuity; surface of coxa posteriorly without low carina oriented in the dorsoventral axis.

EPIMERAL PLATES 1-3. Posteroventral angle produced into a small but sharp tooth.

UROSOME TOOTH PATTERN. Urosomite 1 with very sharp narrow triangular process pointing upwards; urosomite 2 without pair of small posterior dorsolateral teeth pointing upwards.

Telson. Cleft on 0.25 ; tips of lobes subacute, slit fairly broad and V-shaped.

Peduncle of ANTENNa 1 . Article 1 with short lateral medial and ventral teeth reaching the base of article 2 [some teeth apparently duplicated]; article 2 with medium-sized lateral and medial teeth reaching about tip of article 3, with ventral tooth very reduced to a denticle [some teeth apparently duplicated]; article 3 with small ventral tooth, about as long as article itself.

GNATHOPODS 1-2. Carpus and propodus of normal slenderness; propodus not narrowing distally, palm distinct.

PEREIOPODS 5-7. Merus, carpus and propodus very stout; basis of pereiopods 5-6 of normal width, with posteroproximal process rounded and distinctly protruding, with posterodistal tooth strong and broad; basis of pereiopod 7 very broad with posterodistal tooth forming a squared angle, not followed more proximally by small concavity, directed posteriorly.

\section{Body length}

$19 \mathrm{~mm}$.

\section{Distribution}

RV Polarstern, PS12, stn 231, Elephant Island. Coleman (1998b) gives the following coordinates for station 231 : $61^{\circ} 03.8^{\prime} \mathrm{S}, 54^{\circ} 37.6^{\prime} \mathrm{W}, 332 \mathrm{~m}$, and Fütterer (1988) the following ones: $61^{\circ} 03^{\prime} \mathrm{S}, 54^{\circ} 45^{\prime} \mathrm{W}$ (start position), $331 \mathrm{~m}$. 


\section{Remarks}

Superficially similar to the sympatric and larger E. leukhoplites sp. nov. See account on E. leukhoplites sp. nov. for differences.

Epimeria (Drakepimeria) subgen. nov. sp. 1

\section{Distribution}

Ross Sea, $151-300 \mathrm{~m}$.

\section{Remarks}

This undescribed species, which is similar to E. leukhoplites sp. nov. (see key) was discovered in the Ross Sea by A.-N. Lörz. It will be described as new in a forthcoming paper by M. Verheye, A.- N. Lörz \& C. d'Udekem d'Acoz.

\section{Incertae sedis: Epimeria (Drakepimeria) subgen. nov. sp. 2}

Epimeria sp. - Andres 1985: 127, fig. 10, 11A.

\section{Distribution}

South Shetland Islands: Clarence Island, 0-145 m.

\section{Remark}

The description of Epimeria sp. by Andres (1985) is based on two tiny ( $7 \mathrm{~mm}$ ) male specimens. It exhibits similarities with E. leukhoplites sp. nov., E. reoproi and E. vaderi, of which the description is based on much larger specimens. It is likely that Andres' (1985) specimens are juveniles of one of these species.

\section{Subgenus Epimeria Costa in Hope, 1851}

Gammarellus Herbst, 1793: 106-115 (in part); type species: Gammarus homari Fabricius, 1779 [currently Gammarellus homari (Fabricius, 1779)].

Vertumnus White, 1847: 89; type species: Vertumnus cranchii Leach's manuscript name; nomen nudum. Vertumnus White, 1850a: 97 [+ pl. 16 figs 3-5 illustrating Leach's specimens, as Acanthonotus testudo] (real identity of the specimens: Epimeria cornigera (Fabricius, 1779), not Pereionotus testudo (Montagu, 1808)); Vertumnus White, 1850 = preoccupied and invalid objective synonym of Epimeria Costa in Hope, 1851 (see remarks below).

Epimeria Costa in Hope, 1851: 24, 46; type species: Epimeria tricristata Costa in Hope, 1851: 46 (= Gammarus corniger Fabricius, 1779: 383).

Gammarus - Fabricius 1779: 383 (in part). - H. Milne Edwards, 1840: $42-55$ (in part). Vertumnus - White 1850b: 51. — Spence Bate \& Westwood 1862: 231. — Norman 1869: 280.

Acanthonotus - White 1850a: 97, pl. 16 figs 3-5; 1850b: 51 (in part); White 1857: 177. — Gosse 1855: 139, 142. — Spence Bate 1857: 141; 1862: 120. — Spence Bate \& Westwood 1862: 231. — Carus 1885: 410.

Epimeria - Costa 1857: 175, 197. — Spence Bate 1862: 153-154. — Boeck 1871: 185 (105 on reprints); 1876: 232. — Stebbing 1888: 877-878 (ubi syn.); 1906: 321. — G.O. Sars 1893: 363-364. — Chevreux \& Fage 1925: 190-191. — Lincoln 1979: 434.

Acanthonotosoma [sic] - Della Valle 1893: 674, in part (ubi syn.). Amphithoё-M. Sars 1859: 130-143 (in part). 
Acanthosoma - Boeck 1861: 665-666 (in part); 1869: 410 (in part).

Acanthonotosoma [sic] - Della Valle 1893: 674, in part (ubi syn.).

non Gammarus Fabricius, 1775: 418; type species: Cancer pulex Linnaeus, 1758.

non Acanthonotus Bloch, 1797: 112-114, pl. 431; type species: Acanthonotus nasus Bloch, 1797; objective synonym of Notacanthus Bloch, 1788: 278 (type species: Notacanthus chemnitzii Bloch, 1788) (Pisces).

non Acanthonotus Cuvier, 1800: table 4; nomen nudum (Pisces).

non Acanthonotus Goldfuss, 1809: 308; objective synonym of Echidna Cuvier, 1797: 143 (Mammalia). non Acanthonotus Gray, 1830: pl. 85, fig. 1; type species: Silurus (Acanthonotus) Cuvieri Gray, 1830 (Pisces).

non Acanthonotus Swainson \& Richardson, 1832: 168; nomen nudum (Aves). non Acanthonotus Ross, 1835: xc; type species: Acanthonotus cristatus Ross, 1835. non Ampithöe Leach, 1814: 432; type genus: Cancer rubricatus Montagu, 1808. non Vertumnus Otto, 1823: 294, pl. 41 fig. 1; type species: Vertumnus thetidicola Otto, 1823 (Trematoda). non Acanthosoma Curtis, 1824: unnumbered pagina referring to plate 20 (Hemiptera). non Acanthosoma Ross, 1835: 91; type species: Acanthosoma hystrix Ross, 1835. non Acanthonotozoma Boeck, 1876: 237; type species: Acanthonotus cristatus Ross, 1835. non Amphithoë - Latreille, 1816: 470 (misspelling for Ampithöe Leach, 1814).

non Vertumnus - Goës 1866: 522. — Boeck 1871: 99. — Miers 1877: 135. — G.O. Sars 1883: 26 (all three $=$ Acanthonotozoma Boeck, 1876).

\section{Type species}

Epimeria tricristata Costa in Hope, 1851 (= Gammarus corniger Fabricius, 1779). Good illustrated descriptions: G.O. Sars (1893); Chevreux \& Fage (1925); Lincoln (1979); Ledoyer (1993).

\section{Description}

Body opaque, with teguments strongly calcified. Rostrum medium-sized to long. Ventral lobe of head rounded to angular. Eyes present, not conical. Pleonites 1-3 and at least pereionites 6-7 (sometimes all pereionites) with low mid-dorsal dentate carina projecting backwards and one pair of dorsolateral much smaller carinate teeth (sometimes duplicate or triplicate on pleonites) or carina. Pereionites 1-7 sometimes with low carina or trace of protrusion just above connection with coxa. Coxae 1-4 subacute to blunt-tipped. Coxae 1-3 sharply keeled along their axis. Coxa 4 with sharp carina starting at ventral tip of coxa and terminating at posterior tip of coxa; this never bears a tooth projecting laterally; posteroventral border concave. Coxae 5-6 with strong sharp tooth projecting backwards. Mid of posterior border of epimeral plates 1-3 or 1-2 produced into a tooth. Dorsal process of urosomite 1 produced into a tooth, which can be directed upwards or backwards. Urosomite 2 without pair of small teeth pointing upwards. Lateral borders of urosomite 3 posteriorly blunt or bluntly angular, not produced into a sharp tooth. Telson weekly bilobed. Eyes present, large, rounded or pyriform. Peduncle of antenna 1 without teeth. Mandible with molar process triturative. Lower lip with narrow (V-shaped) hypopharyngeal gap. Palp of maxilliped with 4 articles. Gnathopods of normal size, with carpus and propodus of medium slenderness, with palm obliquely transverse (gnathopods subcheliform); propodus not expanded distally; posterior border of dactylus lined by row of small oblique slender teeth. Basis of pereiopods 5 very slender, quadrate, without posteroproximal protrusion and with trace of posterodistal tooth projecting posteriorly (or posterodistal corner angulate). Basis of pereiopod 6 fairly slender, elliptic or narrowly ovate (then broad part proximal), without posteroproximal rounded protrusion and without posterodistal tooth projecting posteriorly, without posterodistal angle: the basis is distally tapering and at its apex it has the same width as the ischium, hence there is not projecting angularity. basis of pereiopod 7 fairly narrow to fairly broad, with posterior border proximally slightly convex and distally slightly concave, 
with posterodistal corner rounded or with a tooth projecting posteriorly. Dactylus of pereiopods 5-7 short. Benthic.

\section{Body length}

The maximum body length recorded in species of the subgenus Epimeria ranges between 9 and $40 \mathrm{~mm}$ (G.O. Sars 1893).

\section{Ecology.}

Benthic, $50 \mathrm{~m}$ (Lincoln 1979) to $3028 \mathrm{~m}$ (Jones et al. 2003).

\section{Distribution}

European western and northern seas, Mediterranean and South Africa.

\section{Remarks}

As eight Antarctic and sub-Antarctic subgenera are erected herein for Epimeria, the extralimital (Atlantic) type subgenus Epimeria had to be redefined. It is cautiously restricted herein to the following species: Epimeria cornigera (Fabricius, 1779), Epimeria loricata G.O. Sars, 1879, Epimeria parasitica (M. Sars, 1858), Epimeria tuberculata G.O. Sars, 1893, an undescribed Northwest European species discovered by Beerman \& Raupach (2015), and an undescribed Mediterranean deepsea species, of which specimens are deposited in the Museum of Verona (J. Beerman, pers. com.).

Subgenus Epimeriella Walker, 1906

Epimeriella Walker, 1906: 17 (in part).

Epimeriella - Gurjanova 1955: 189, 206 (in part). — J.L. Barnard 1961: 102 (in part); 1969: 161, 395 (in part). - McCain 1971: 160 (in part). — Karaman \& J.L. Barnard 1979: 109-110 (in part). Holman \& Watling 1983: 31 (in part, discussion). — Andres \& Lott 1986: 131-136 (in part). — J.L. Barnard \& Karaman 1991: 380, 394, 702 (in part). — Coleman 1998b: 215 (in part); 2007: 56 (in part). — Lörz \& Brandt 2004: 179, 184, 188, 189 (in part).

\section{Type species}

Epimeriella macronyx Walker, 1906.

\section{Description}

Body pellucid with teguments very weakly calcified. Rostrum minute (not reaching 0.2 of length of article 1 of peduncle of antenna 1), reduced to a narrow tiny blade-shaped process separating the bases of the first articles. Ventral lobe of head rounded. Eyes present, extremely large, not conical. Pereionite 7 and pleonites 1-3 with or without small posterodorsal tooth directed backwards; all pereionites and pleonites without dorsolateral pair of teeth, swelling or carina. Pereionites 1-7 without tooth or protrusion just above connection with coxa. Coxae 1-3 with rounded tip; coxa 4 with tip of variable sharpness. Coxae 1-3 not keeled or not strongly keeled along their axis. Coxa 4 narrow, not carinate; posteroventral border straight or very weakly concave. Coxae 5-6 without tooth. Mid of posterior border of epimeral plates 1-3 not produced into a tooth. Posteroventral tooth of epimeral plate 3 very small. Dorsal process of urosomite 1 produced into a low rounded process or into a carina posteriorly terminated in tooth directed backwards. Urosomite 2 without pair of small teeth pointing upwards. Lateral borders of urosomite 3 posteriorly terminated into an acute angle. Telson deeply cleft. Peduncle of antenna 1 with dentition very reduced (tiny ventral denticles may be present). Mandible with molar process drawn out, without triturative surface. Lower lip with wide hypopharyngeal gap. Palp of maxilliped 
with 4 articles. Gnathopods of normal size, with carpus and propodus broad to very broad, with palm obliquely transverse (gnathopods subcheliform); propodus not expanded distally; posterior border of dactylus lined by row of small oblique slender teeth. Basis of pereiopods 5-6 moderately broad, without posteroproximal protrusion or tooth and without posterodistal tooth projecting posteriorly. Posterior border of basis of pereiopod 7 convex along all its length, with tip angular or rounded. Dactylus of pereiopods 5-7 long to very long.

\section{Body length}

The maximum body length recorded in Epimeriella species ranges between 8 and $28 \mathrm{~mm}$.

\section{Ecology}

Epimeria (Epimeriella) macronyx is obviously pelagic, as it is usually found in plankton nets. The fragile and poorly caclified morphology of other species suggest that they might also be pelagic or semipelagic. $0-1200 \mathrm{~m}$.

\section{Distribution}

Circum-Antarctic, as far north as the South Orkney Islands.

\section{Remarks}

Epimeriella was initially erected as a genus (Walker 1906), on the basis of the non triturative molar process of the mandibles. This character is considered as a synapomorphy since Epimeriella sensu Walker, 1906 forms a clade in our phylogenetic trees. It is herein split into two subgenera corresponding to two sub-clades with very different morphotypes. The robust benthic forms of the group walkeri are now placed into the new subgenus Laevepimeria subgen. nov. Only the slender pelagic or semipelagic forms (Epimeria macronyx, E. scabrosa and their relatives) are retained within the subgenus Epimeriella. The extralimital species Epimeria pelagica Birstein \& Vinogradov, 1958 also exhibits adaptations to a pelagic lifestyle: enlarged eyes and elongation of the posterior pereiopods (Birstein \& Vinogradov 1958). However, this species exhibits many other characters not observed in Epimeriella species such as the shape of the mandible.

\section{Key to the species of Epimeriella}

1. Pleonites 1-3 (and sometimes pereionite 7) with small posterodorsal tooth; dorsal process of urosomite 1 not produced into a tooth

- Pleonites 1-3 without posterodorsal tooth; dorsal process of urosomite 1 posteriorly produced into a tooth directed backwards macronyx (Walker, 1906) [Antarctic Peninsula to Ross Sea, usually caught in plankton nets]

2. Pereionite 7 with posterodorsal tooth; eye broadly elliptic; coxa 4 fairly wide, ventrally produced into a blunt angle

E. (Epimeriella) atalanta sp. nov. [Weddell Sea]

- Pereionite 7 without posterodorsal tooth; eye narrowly elliptic; coxa 4 fairly wide, ventrally pointed E. (Epimeriella) scabrosa (K.H. Barnard, 1930) [Oates Coast]

- Pereionite 7 without posterodorsal tooth; eye broadly elliptic; coxa 4 slender, ventrally rounded E. (Epimeriella) truncata (Andres, 1985) [west of Antarctic Peninsula] 
Epimeria (Epimeriella) atalanta sp. nov. urn:1sid:zoobank.org:act:B0214FB1-ED96-4CEF-B267-21FC4B356C39

Figs $125-130$

Epimeriella cf. scabrosa '4 dorsal teeth' - d'Udekem d'Acoz \& Robert 2008: 53 (list). Epimeria cf. scabrosa - Rauschert \& Arntz 2015: 62, pl. 55 unnumbered photograph.

non Epimeriella scabrosa K.H. Barnard, 1930: 378, fig. 43.

\section{Etymology}

A $\tau \alpha \lambda \alpha$ óv $\eta$ is a character of the Greek mythology. She was the only woman, who took part in the nautical expedition of the Argonauts (the genus Epimeria being feminine). The name alludes to the presumed good swimming capacities of the species and its possibly pelagic life style. The name is a noun in apposition.

\section{Type material}

\section{Holotype}

RV Polarstern:

SOUTHERN OCEAN: specimen initially fixated in formalin, cruise PS69, ANT-XXIII/8, stn 725-10, south of Larsen A, $64^{\circ} 55.89^{\prime} \mathrm{S}, 60^{\circ} 40.06^{\prime} \mathrm{W}$ to $64^{\circ} 55.92^{\prime} \mathrm{S}, 60^{\circ} 40.31^{\prime} \mathrm{W}, 189-192 \mathrm{~m}$, Rauschert dredge, 22 Jan. 2007, coll. C. d'Udekem d'Acoz and H. Robert (RBINS, INV. 122527).

\section{Description}

Rostrum. Very minute, reduced to a narrow tiny process reaching a bit more than 0.1 of article 1 of peduncle of antenna 1 .

EYE. Very large, elliptic.

Pereion-Pleosome tooth pattern. Pereionite 7 and pleonites 1-3 carinate and posterodorsally produced into a tooth; other body segments without mid-dorsal tooth; pereionites 1-7 and pleonites 1-3 without pair of lateral teeth.

COXAE 1-3. Not carinate; coxa 1 distally broadly rounded; coxa 2-3 distally narrow but very blunt.

Coxa 4. Fairly broad; anterodorsal and anteroventral border nearly straight, joined by low and blunt angular discontinuity, anterior angle not strongly projecting forward; ventral projection short, bluntly but distinctly angular; no lateral carina; posteroventral border nearly straight.

Coxa 5-7. Toothless, posteriorly, ventrally and posteroventrally rounded.

EPimeral PLATES 1-3. Posteroventral angle produced into a tiny tooth.

UROSOME TOOTH PATTERN. Urosomite 1 with elongate carinate process, forming a broad and regularly rounded process in lateral view.

Telson. Cleft on 0.3 ; tips of lobes sharp, notch broadly V-shaped.

GNATHOPODs 1-2. Carpus and propodus short and broad; propodus not narrowing distally, palm very distinct, oblique. 
Pereiopods 5-7. Propodus and dactylus of pereiopods 5-6 very long and very slender; basis of pereiopod 5 of normal width, without posteroproximal process, with posterior border nearly straight on most of its length, posterodistally produced into a rounded lobe; basis of pereiopods 6 broad, without posteroproximal process, with posterior border rounded on proximal half and straight on distal half, posterodistally forming a rounded angle; basis of pereiopod 7 extremely broad with posterodistal corner forming a sharp squared angle, not followed more proximally by small concavity.

\section{Colour pattern}

Body and appendages (including gnathopods and mouthparts) whitish/pellucid studded with red chromatophores arranged in large pigmented zones. Eyes reddish.

\section{Body length}

$15 \mathrm{~mm}$.

\section{Distribution}

Western side of the Weddell Sea: Larsen A, 189-192 m; eastern shelf of the Weddell Sea, 402-405 m (see remarks).

\section{Remarks}

Epimeria atalanta sp. nov. is very similar to E. scabrosa, but differs by the presence of a posterodorsal tooth on pereionite 7 and its broader eyes (see illustrations by K.H. Barnard 1930 and Coleman 2007). Rauschert \& Arntz (2015) give a photograph of a specimen that we identify as E. atalanta sp. nov. The station was given in an early draft of their book made available to us: ANT-XXI/2 stn 145 [145-1]. Its coordinates are: ANT-XXI/2 stn $145-1,70^{\circ} 56.99^{\prime} \mathrm{S}, 10^{\circ} 48.26^{\prime} \mathrm{W}$ to $70^{\circ} 56.97^{\prime} \mathrm{S}, 10^{\circ} 47.71^{\prime} \mathrm{W}$ (eastern Weddell Sea), 402-405 m.

Epimeria (Epimeriella) macronyx (Walker, 1906)

Fig 131

Epimeriella macronyx Walker, 1906: 17.

Epimeriella macronyx - Walker 1907: 26, pl. 15. - K.H. Barnard 1930: 378; 1932: 178, pl. 1 fig. 3. Andres 1985: 129, fig. 11H-I, 12A-D. - Andres \& Lott 1986: 133, fig. 1 (E. mac.). - Andres in Sieg \& Wägele 1990: 137-138, fig. 271. — Coleman 2007: 57, fig. 32a-b, map 15 (rhomb).

\section{Material examined}

RV Polarstern cruises:

SOUTHERN OCEAN: 1 spec., cruise PS81, ANT-XXIX/3, 182-1, south east of Snow Hill Island, $64^{\circ} 47.21^{\prime} \mathrm{S}, 56^{\circ} 41.90^{\prime} \mathrm{W}$ to $64^{\circ} 46.02^{\prime} \mathrm{S}, 56^{\circ} 42.50^{\prime} \mathrm{W}, 0-200 \mathrm{~m}$, rectangular mid-water trawl, formalinfixed, 17 Feb. 2013, coll. C. d'Udekem d'Acoz and M. Verheye (RBINS, INV. 121486); 2 specs, cruise PS81, ANT-XXIX/3, stn 238-1, north of Livingstone Island, $62^{\circ} 22.65^{\prime} \mathrm{S}, 61^{\circ} 17.63^{\prime} \mathrm{W}$ to $62^{\circ} 20.89^{\prime} \mathrm{S}$, $61^{\circ} 19.82^{\prime} \mathrm{W}, 0-200 \mathrm{~m}$, rectangular midwater trawl, 8 Mar. 2013, coll. C. d'Udekem d'Acoz and M. Verheye (RBINS, INV. 122943) [extraction ANT38 (largest specimen); Genbank nr, COI: KU870824, 28S: KU759597 and ANT39 (smallest specimen); Genbank nr, COI: KU870825, 28S: KU759598].

RV Aurora Australis cruises:

SOUTHERN OCEAN: 1 spec., cruise CEAMARC, sample CEAMARC 1295, stn 51AEV215, Adélie

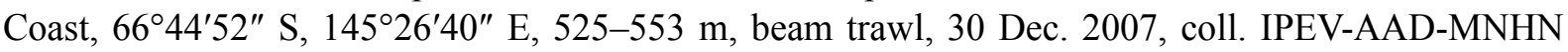
(MNHN-IU-2016-6559); 1 spec., cruise CEAMARC, sample CEAMARC 1317, stn 51AEV215, Adélie 
Coast, 66 $44^{\prime} 52^{\prime \prime} \mathrm{S}, 145^{\circ} 26^{\prime} 40^{\prime \prime}$ E, 525-553 m, beam trawl, 30 Dec. 2007, coll. IPEV-AAD-MNHN (MNHN-IU-2014-4276) [extraction M19); Genbank nr, COI: KU870885, 28S: KU759668].

\section{Colour pattern}

Body and appendages whitish to colourless, semi-translucent; dorsal part of body orange; eyes orange; oral field and tip of gnathopods blood red.

\section{Body length}

Up to $28 \mathrm{~mm}$.

\section{Distribution}

South Orkney Islands; South Shetland Islands; Antarctic Peninsula; eastern shelf of the Weddell Sea; Davis Sea; Adélie Coast, Ross Sea; 0-1200 m (Coleman 2007; present data). As many records of E. macronyx come from pelagic nets (De Broyer et al. 2007; present data), and as the species is very slender with large eyes reminiscent to those of hyperiids, it is obviously a true pelagic species.

\section{Epimeria (Epimeriella) scabrosa (K.H. Barnard, 1930)}

Epimeriella scabrosa K.H. Barnard, 1930: 378, fig. 43.

Epimeriella scabrosa - Coleman 2007: 58, fig. 33, map 15 (circle).

\section{Body length}

Up to $14 \mathrm{~mm}$.

\section{Distribution}

Oates Coast, 329-366 m (K.H. Barnard 1930).

\section{Remarks}

Coleman (pers. com.) informed us that the specimen illustrated in the figure 33 of Coleman (2007) is drawn from the type series. De Broyer et al. (2007) mention imprecise records of E. scabrosa from the southern and eastern shelf of the Weddell Sea, but they might refer to its very close relative E. atalanta sp. nov.

\section{Epimeria (Epimeriella) truncata Andres, 1985}

Epimeriella truncata Andres, 1985: 130-132, figs 12I-O, 13, 14, 15A-D.

Epimeriella truncata Andres \& Lott 1986: 133, fig. 1 (E. tru.).

\section{Body length}

$8 \mathrm{~mm}$.

\section{Distribution}

Palmer Archipelago [type material], eastern shelf of the Weddell Sea, 100-622 m (De Broyer et al. 2007). 


\section{Subgenus Hoplepimeria subgen. nov. urn:1sid:zoobank.org:act:A5102FE5-2D1C-4365-BFE8-D5163A0748D1}

\section{Etymology}

Combination of the Greek word o $\pi \lambda \alpha$, armour and Epimeria. The name, which is feminine, alludes to the thick and heavily calcified teguments of the members of that subgenus.

\section{Type species}

Epimeria quasimodo sp. nov.

\section{Description}

Body opaque, with teguments very strongly calcified. Rostrum medium-sized to large. Eyes not conical. Pereionites and pleonites with a wide diversity of ornamentation. Most species have a low and broad mid-dorsal crest on their pleonites and often on their anterior pereionites. However all the pereionites and pleonites can have a very long non-flattened mid-dorsal tooth (E. rubrieques), or the body can be strongly sculptured (E. rimicarinata). Dorsolateral processes are absent except for E. rimicarinata, where they are part of its sculpured pattern. Pereionites 1-7 without ventrolateral tooth or protrusion just above connection with coxa. Coxae 1-4 with sharp or blunt tip. Coxae 1-3 usually weakly keeled along their axis. Coxa 4 with or without groove along the posteroventral border; when present, the anterior border of this groove forms a kind of blunt carina; when present this carina never bears a tooth projecting laterally; posteroventral border straight or concave. Coxa 5 with tooth or blunt protrusion projecting backwards (size and development very variable). Coxa 6 with or without blunt protrusion projecting backwards. Posteroventral tooth of epimeral plate 3 small to medium-sized. Dorsal process of urosomite 1 produced into a blunt tooth or a rounded lobe directed upwards. Urosomite 2 without pair of small teeth pointing upwards. Lateral borders of urosomite 3 posteriorly terminated into an acute angle. Peduncle of antenna 1 with dentition very reduced (a small ventral tooth can be present on article 1). Mandible with molar process triturative. Lower lip with narrow (V-shaped) hypopharyngeal gap. Palp of maxilliped with 4 articles. Gnathopods of normal size, with carpus and propodus very robust, with palm obliquely transverse (gnathopods subcheliform); propodus often expanded distally; posterior border of dactylus lined by row of small oblique slender teeth. Basis of pereiopods 5-6 broad, with posteroproximal process, which can be a (very low) rounded protrusion or a large (sometimes swordlike) tooth orientated in the same direction as the basis, with or without posterodistal tooth projecting posteriorly. Basis of pereiopod 7 narrow on its distal half; posterior border proximally slightly convex and distally either slightly concave, or deeply concave or deeply angularly notched; the posterior border of the basis of pereiopod 7 can be terminated into a small tooth projecting posteriorly or not. Dactylus of pereiopods 5-7 short.

\section{Body length}

The maximum body length recorded in Hoplepimeria subgen. nov. species ranges between 35 and $80 \mathrm{~mm}$.

\section{Ecology}

Benthic, 33-2154 m.

\section{Distribution}

Circum-Antarctic, as far north as the South Georgia. 


\section{Remarks}

Hoplepimeria subgen. nov. includes species with diverse body shapes. Most species are globular with only low teeth or crests, whilst E. rubrieques is one of the Epimeria with the longest teeth. However, E. rubrieques has the same robust and distally expanded gnathopods as in other Hoplepimeria subgen. nov. and has the same proximally toothed basis of pereiopods 5-6 as in many other Hoplepimeria subgen. nov. The absence of dorsolateral teeth, and the non- or scarcely laterally flattened dorsal processes of E. rubrieques distinguishes it at first glance from the dentate Antarctic Epimeria of the subgenus Drakepimeria subgen. nov. Hoplepimeria subgen. nov. includes the largest known Epimeria species, namely E. gargantua sp. nov., which can reach up to $80 \mathrm{~mm}$.

\section{Key to the species of Hoplepimeria subgen. nov.}

1. Proximal part of posterior border of basis of pereiopod 6 with rounded protrusion (which can be very low)

- Proximal part of posterior border of basis of pereiopod 6 with triangular or sword-like tooth directed in the axis of the basis ...3

2. Coxa 4 without lateral carina, with posteroventral border straight; posterior border of basis of pereiopod 7 weakly excavate; eye medium-sized and broadly elliptic ......Epimeria (Hoplepimeria) inermis subgen. nov. Walker, 1903 [Elephant Island, to Adélie Coast and western Ross Sea]

- Coxa 4 with lateral carina widely separate from posterior border, with posteroventral border deeply concave; posterior border of basis of pereiopod 7 straight; eye large and narrowly elliptic E. (Hoplepimeria) heldi subgen. nov. Coleman, 1998 [Elephant Island]

3. Pereionites and pleonites naked, or with low mid-dorsal crest or tooth

- Pereionites 1-7 and pleonites 1-2 with very large elongate mid-dorsal tooth; pleonite 3 with large triangular tooth

E. (Hoplepimeria) rubrieques subgen. nov. De Broyer \& Klages, 1991 [Eastern Weddell Sea to Davis Sea]

4. Mid-dorsal crest of pereionites 3-7 and pleonites 1-3 very slightly notched or not notched; these segments are not laterally sculptured

- Mid-dorsal crest of pereionites 3-7 and pleonites 1-3 deeply notched; these segments are laterally strongly sculptured rimicarinata subgen. nov. Watling \& Holman, 1980 [Prydz Bay, western Ross Sea]

5. Coxa 5 sometimes angular but not with a distinct tooth when seen in dorsal view; ventral part of coxa 4 moderately produced

- Coxa 5 with a distinct tooth pointing laterally or obliquely backwards when seen in dorsal view; ventral part of coxa 4 very strongly produced ........................ (Hoplepimeria) larsi subgen. nov. Lörz, 2009 [Adélie Coast and western Ross Sea, 1900-2200 m]

6. Pleonite 3 with small but well defined, narrow, posterodorsal tooth pointing upwards: E. (Hoplepimeria) complex robusta ..................................................

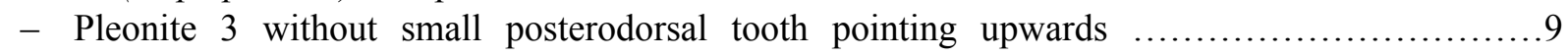

7. Pleonite 2 with posterodistal tooth (pointing backwards) .8

- Pleonite 2 without posterodistal tooth E. (Hoplepimeria) robusta subgen. nov. K.H. Barnard, 1930 [Western Ross Sea and Adélie Coast] 
8. Dorsolateral margins of urosomite 3 deeply concave; posterodistal corner of the basis of pereiopods 5-7 bluntly angular; body either pure white or with coloured motives on a white background

E. (Hoplepimeria)

robustoides subgen. nov. Lörz \& Coleman in Lörz et al., 2009 [Eastern Weddell Sea]

- Dorsolateral margins of urosomite 3 weakly concave; posterodistal corner of the basis of pereiopods 5-7 produced into a sharp tooth; body always pure white.

E. (Hoplepimeria) gargantua subgen. et sp. nov. [Tip of Antarctic Peninsula]

9. Dorsal keels of body segments not strongly laterally compressed; eyes elliptic; rostrum ventrally straight or weakly concave, usually longer than article 1 of peduncle of antenna 1; coxa 4 with anteroventral border slightly to significantly concave, with ventral tip fairly blunt to sharp, with more or less distinct groove running along posteroventral border; notch of basis of pereiopod 7 forming a squared or acute angle in adults: E. (Hoplepimeria) complex georgiana .............10

- Dorsal keels of body segments strongly laterally compressed; eyes distinctly reniform; rostrum ventrally distinctly concave, as long as article 1 of peduncle of antenna 1; coxa 4 with anteroventral border straight and ventral tip very blunt, without any trace of posterior groove running along posteroventral border; notch of basis of pereiopod 7 forming a very obtuse angle in adults ................................ (Hoplepimeria) angelikae subgen. nov. Lörz \& Linse in Lörz et al., 2011 [eastern Weddel Sea, Adélie Coast; lower shelf species]

10. Anterior corner of coxa 4 broadly rounded

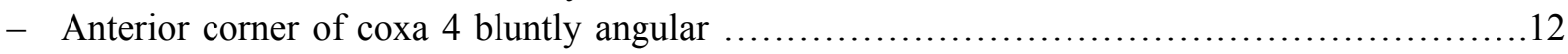

11. Rostrum broad in frontal view; ventral corner of coxa 4 sharply angular; posterior notch of basis of pereiopods 5-7 broad, that of pereiopod 7 forming a squared angle (or nearly so) in adults ........E. (Hoplepimeria) cyphorachis sp. nov. [South Shetland Islands, mostly lower shelf]

- Rostrum fairly slender in frontal view; ventral corner of coxa 4 bluntly angular; posterior notch of basis of pereiopods 5-7 narrow, that of pereiopod 7 forming an acute angle in adults E. (Hoplepimeria) xesta subgen. et sp. nov. [Eastern Weddell Sea]

12. Rostrum broad in frontal and lateral view, not ventrally concave

- Rostrum fairly slender in frontal and lateral view, ventrally slightly concave ...E. (Hoplepimeria) linseae subgen. et sp. nov. [Plateau of the South Orkney Islands, upper shelf]

13. Coxa 4 with anterior corner angular and not so blunt, with ventral corner forming an acute angle, of which the tip is sharp; anteroventral border markedly concave; basis of pereiopod 5 very broad; posterodistal corner of basis of pereiopods 5-7 laterally strongly produced .....E. (Hoplepimeria) georgiana subgen. nov. Schellenberg, 1931 [South Georgia, upper shelf]

- Coxa 4 with anterior border broadly angular and blunt, with ventral corner forming a squared angle of which the tip is not especially sharp; anteroventral border inconspicuously concave; basis of pereiopod 5 not especially broad; posterodistal corner of basis of pereiopods 5-7 laterally weakly produced ....................... (Hoplepimeria) quadimodo subgen. et sp. nov. [Elephant Island to tip of Antarctic Peninsula, upper shelf]

Epimeria (Hoplepimeria) angelikae subgen. nov. Lörz \& Linse in Lörz et al., 2011 Figs 132-137

Epimeria angelikae Lörz \& Linse in Lörz et al., 2011: 6, figs 6, 7, 8, 9, 10, 11, 12.1, 12.2.

'Epimeria inermis 3' - Rauschert \& Arntz 2015: 61, pl. 54. 
'Clade E georgiana-rimicarinata-rubriequies [sic] complex - GE5' - Verheye et al. 2016a, supplement: 4 (online).

non Epimeria inermis Walker, 1903: 54, pl. 10 fig. 69.

\section{Material examined}

RV Polarstern cruises:

SOUTHERN OCEAN: 1 spec., exuvia, cruise PS39, ANT-XIII/3, EASIZ I, eastern Weddell Sea, no station, specimen kept in aquarium, 26 Mar. 1996, coll. C. De Broyer and G. Chapelle (RBINS, INV. 132682); 2 specs, cruise PS48, ANT-XV/3, EASIZ II, stn 95, eastern Weddell Sea, $73^{\circ} 33.5^{\prime} \mathrm{S}, 2^{\circ} 15.3^{\prime} \mathrm{W}$ to $73^{\circ} 34.0^{\prime} \mathrm{S}, 22^{\circ} 12.3^{\prime} \mathrm{W}, 866-920 \mathrm{~m}$, bottom trawl, 5 Feb. 1998, coll. C. De Broyer (RBINS, INV. 13992); 1 spec., cruise PS48, ANT-XV/3, EASIZ II, stn 120, eastern Weddell Sea, $73^{\circ} 33.5^{\prime} \mathrm{S}, 22^{\circ} 14.8^{\prime} \mathrm{W}$ to $73^{\circ} 34.0^{\prime} \mathrm{S}, 22^{\circ} 12.2^{\prime} \mathrm{W}, 812-928 \mathrm{~m}$, bottom trawl, 7 Feb. 1998, coll. C. De Broyer (RBINS, INV. 13993).

RV Aurora Australis cruises:

SOUTHERN OCEAN: 4 specs including an ovigerous $q$, cruise CEAMARC, sample CEAMARC

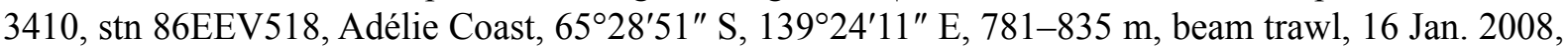
coll. IPEV-AAD-MNHN (MNHN-IU-2014-4278); 1 dissected ovigerous 9 , cruise CEAMARC, sample CEAMARC 3410, stn 86EEV518, Adélie Coast, 65²8'51" S, 139²4'11" E, 781-835 m, beam trawl, 16 Jan. 2008, coll. IPEV-AAD-MNHN (MNHN-IU-2014-7343) [removed from MNHN-IU-2014-4278] [extraction M17; Genbank nr, COI: KU870883, 18S: KU759666]; 1 spec., cruise CEAMARC, sample

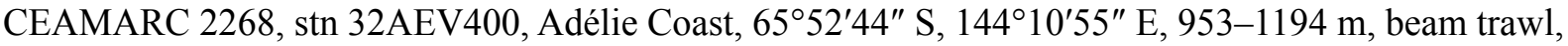
12 Jan. 2008, coll. IPEV-AAD-MNHN (MNHN-IU-2014-4285); 1 ovigerous $q$, cruise CEAMARC, sample CEAMARC 2271, stn 32AEV400, Adélie Coast, 6552'44" S, 144¹0'55" E, 953-1194 m, beam trawl, 12 Jan. 2008, coll. IPEV-AAD-MNHN (MNHN-IU-2014-4281) [extraction M18; Genbank nr, COI: KU870884, 18S: KU759667]; 3 specs, cruise CEAMARC, sample CEAMARC 2271, stn 32AEV400, Adélie Coast, 6552'44" S, 144¹0'55" E, 953-1194 m, beam trawl, 12 Jan. 2008, coll. IPEV-AAD-MNHN, (MNHN-IU-2014-7344, formerly MNHN-IU-2014-4281).

\section{Description}

Rostrum. Medium-sized, reaching tip of article 1 of peduncle of antenna 1, anteriorly distinctly curved, ventrally distinctly concave, subacute in lateral view; narrow and with nearly straight converging borders in frontal view.

EYE. Very large, distinctly reniform.

Pereion-Pleosome tooth Pattern. Pereionite 1 with trace of mid-dorsal carina and no posterior bump; pereionites 2 to pleonite 3 with low and fairly blunt mid-dorsal carina, which becomes more and more laterally compressed in the posterior body segments; profile of carina of pereionite 2 straight, of pereionites 3 to pleonite 3 with median notch (more distinct on pleonites than on pereionites); profile of carina of pleonite 3 straight with anterior very low protrusion followed by shallow notch, then nearly straight (slightly irregular), posteriorly bluntly angular; dorsolateral ornamentation absent.

COXAE $1-3$. Not carinate and apically forming a blunt squared angle.

Coxa 4. Anterodorsal border nearly straight (very slightly concave), anteroventral border straight, these two borders being joined by blunt but distinct angular discontinuity (anterior corner), which is weakly projecting forward; ventral corner forming a blunt squared angle (ventral projection well developed); lateral carina absent; posteroventral border distinctly concave. 
Coxa 5. Broad, with surface smooth, with posteroventral corner forming a blunt-tipped nearly squared angle, weakly expanded laterally, forming a blunt obtuse angle in dorsal view.

Coxa 6 . With posteroventral corner forming a blunt acute but nearly squared angle, with low projection arising from its surface (forming a very low indistinct lobe in dorsal view).

Coxa 7. Posteriorly rounded.

EPIMERAL PLATES 1-3. Posteroventral angle: very obtusely rounded in plate 1; produced into a small tooth in plate 2 and into a medium-sized tooth in plate 3 .

UROSOME TOOTH PATTERN. Urosomite 1 with very low dorsal process, irregularly convex on both sides; urosomite 3 with dorsolateral borders nearly straight.

Telson. Cleft on 0.2 ; tips of lobes triangular and subacute, notch broadly V-shaped and rounded at its deepest point.

GNATHOPODs 1-2. Carpus and propodus broad; propodus expanding distally, palm distinct.

Pereiopods 5-7. Merus, carpus and propodus of medium width; dactylus medium-sized; basis of pereiopods 5-6 of normal width, with posteroproximal process present, sword-like, parallel to axis of basis, with posterodistal corner rounded, very weakly pointing in posterior direction; basis of pereiopod 7 broad with posterior border weakly convex, with distinct notch on distal 0.8 , forming a blunt-tipped obtuse (nearly square) angle, with posterodistal corner bluntly angular and not pointing backwards.

\section{Colour pattern}

Uniformly whitish, eyes yellowish (Lörz et al. 2011), or uniformly pale orange, eyes golden (Rauschert \& Arntz 2015 as 'Epimeria inermis 3', p. 61, pl. 54), or uniformly salmon pink with reddish eyes (picture made by G. Chapelle published herein).

\section{Body length}

Up to $40 \mathrm{~mm}$.

\section{Distribution}

Eastern shelf of the Weddell Sea; Adélie Coast; 781-1194 m.

\section{Remarks}

The new records of E. angelikae off Adélie Coast considerably extend eastwards the distribution of the species. No morphological differences were detected between these specimens, the illustrations given by Lörz et al. (2011) and the specimens examined from the Weddell Sea. One of the main diagnostic characters proposed by Lörz et al. (2011) for distinguishing E. angelikae from other species of the georgiana complex is the obtusely notched posterior border of the basis of pereiopod 7 . This character is valid for adults. However, the depth and the angularity of that notch is a character to be used with caution, as it is partly size-dependent: the notch is shallow in juveniles of all species of the georgiana complex and becomes gradually deeper and more angulate in some species only, as size increases. Epimeria angelikae is superficially similar to E. xesta sp. nov. The two species coexist on the eastern shelf of the Weddell Sea, but have apparently different depth optima. The 'Epimeria inermis 3' of Rauschert \& Arntz (2015) corresponds to the description of E. angelikae and not to that of E. inermis, as it has a short rostrum, reniform eyes, the posteroventral border of coxa 4 concave and a median spur on the basis of pereiopods 5 and 6 . The station of this specimen was given in an early draft of their book made available 
to the authors: ANT-XXI/2 stn 233 [233-1]. Its coordinates are: $71^{\circ} 18.99^{\prime} \mathrm{S}, 13^{\circ} 56.56^{\prime} \mathrm{W}$ to $71^{\circ} 19.19^{\prime} \mathrm{S}$, $13^{\circ} 57.45^{\prime} \mathrm{W}$ (eastern Weddell Sea), 844-848 m.

Epimeria (Hoplepimeria) cyphorachis subgen. et sp. nov. urn:1sid:zoobank.org:act:5A5D8439-3793-4124-A65B-C6EB65A1587E

Figs 138-144

Epimeria georgiana Clade A - Lörz et al. 2011: 1, fig. 1 (triangle), 3, 4, 5, 12.4, 12.5, 12.6, 13 row 1, 14A, 14B, table 3.

Epimeria georgiana - Rauschert \& Arntz 2015: 61, pl. 54, unnumbered photograph.

'Clade E georgiana-rimicarinata-rubriequies [sic] complex - GE3' - Verheye et al. 2016a, supplement: 4 (online).

\section{Etymology}

From the Greek, кvழós, humpbacked; $\rho \alpha \chi 1 \varsigma$, spine, spinal column. The name, which is a noun in apposition, alludes to the humpbacked silhouette of the species.

\section{Type material}

\section{Holotype}

RV Polarstern cruises:

SOUTHERN OCEAN: + , cruise PS81, ANT-XXIX/3, stn. 249-2, Drake Passage, north of Livingstone Island, $61^{\circ} 56.05^{\prime} \mathrm{S}, 60^{\circ} 5.56^{\prime} \mathrm{W}$ to $61^{\circ} 56.21^{\prime} \mathrm{S}, 60^{\circ} 5.80^{\prime} \mathrm{W}, 413-421 \mathrm{~m}$, mud, Agassiz trawl, $12 \mathrm{Mar}$. 2013 (RBINS, INV. 122936) [extraction K25; Genbank nr, COI: KU870859, 28S: KU759637].

\section{Description}

Rostrum. Medium-sized, overreaching tip of article 1 of peduncle of antenna 1, anteriorly weakly curved, ventrally straight, acute in lateral view; broad and with weakly curved converging borders in frontal view.

EYE. Very large, broadly elliptic.

Pereion-Pleosome tooth pattern. Pereionites 1-3 smooth, pereionites 4 to pleonite 3 with extremely low and extremely blunt mid-dorsal carina; profile of carina of pereionite 4 inconspicuously curved; profile of carinae of pereionites 5 to pleonites 3 straight, those of pleonite 2 with inconspicuous concavity; profile of carina of pleonite 3 straight with anterior low very protrusion followed by shallow notch, then nearly straight, posteriorly blunt; dorsolateral ornamentation absent.

COXAE $1-3$. Weakly carinate and distally subacute to narrowly blunt-tipped.

Coxa 4. Anterodorsal border nearly straight (very slightly concave), anteroventral border very weakly concave, these two borders being joined by a very large rounded lobe (anterior corner), which is weakly projecting forward; ventral corner forming a sharp squared angle (ventral projection well developed); lateral carina very obtuse, parallel and close to posteroventral border; posteroventral border distinctly concave.

Coxa 5. Broad, with surface smooth, with posteroventral corner forming a blunt-tipped nearly squared angle, weakly laterally produced, forming a low very rounded obtuse angle in dorsal view (coxa 5 distinctly visible in dorsal view). 
Coxa 6. With posteroventral corner broadly rounded, with low projection arising from its surface (forming a distinct lobe in dorsal view).

Coxa 7. Posteriorly rounded.

EPIMERAL PLATES 1-3. Posteroventral angle: very obtusely rounded, with indistinct trace of tooth in plate 1 ; produced into a small tooth in plate 2 and into a medium-sized tooth in plate 3 .

UROSOME TOOTH PATTERN. Urosomite 1 with very low dorsal process: anteriorly nearly straight, apically very blunt, posteriorly regularly convex large; urosomite 3 with dorsolateral borders nearly straight.

TELsOn. Cleft on 0.2 ; tips of lobes bluntly triangular, notch narrowly V-shaped.

GNATHOPODS 1-2. Carpus and propodus broad; propodus expanding distally, palm distinct.

Pereiopods 5-7. Merus, carpus and propodus of medium width; dactylus long; basis of pereiopods 5-6 of normal width, with posteroproximal process present, triangular (pereiopod 5) or sword-like (pereiopod 6), parallel to axis of basis, with posterodistal corner obtuse, scarcely projecting posteriorly; basis of pereiopod 7 broad with posterior border distinctly convex, with deep notch on distal 0.8 , forming a blunt-tipped squared angle, with posterodistal corner obtuse, scarcely projecting posteriorly.

\section{Colour pattern}

Red with a diffuse finely mottled pattern; some parts of the coxae and epimeral plates are white; eyes red.

\section{Body length}

Up to $42 \mathrm{~mm}$.

\section{Distribution}

South Shetland Islands: north of Livingstone Island, 413-421 m (present material); south of Elephant Island, 463-990 m (Lörz et al. 2011 as Epimeria georgiana Clade A).

\section{Remarks}

Epimeria cyphorachis sp. nov. can be easily distinguished from the similar sympatric species E. quasimodo sp. nov. by the shape of the anterior corner of coxa 4 : it is broadly rounded in the first species, angulate in the second. Actually, E. cyphorachis sp. nov. (South Shetland Islands) is morphologically more similar to E. xesta sp. nov. (eastern shelf of the Weddell Sea). In E. xesta sp. nov., the rostrum is narrower, the ventral corner of coxa 4 is more blunt, the coxa 5 less projecting laterally and the notch of the basis of pereiopods 5-7 is narrower than in E. cyphorachis sp. nov.

Epimeria (Hoplepimeria) gargantua subgen. et sp. nov. urn:1sid:zoobank.org:act:E5FDFA56-F77B-46D9-9665-644728A7970C

Figs $145-151$

Epimeria robusta Klages, 1988: 73, unnumbered fig., 76, 82, figs 20a-b.

Epimeria robustoides ? Lörz \& Coleman in Lörz et al., 2009: 10, possibly in part, possibly fig. 10A, not figs $2-5$ (=E. robustoides).

Epimeria robusta - Coleman 1994: 560, in part, fig. 5D only.

'Clade G robustoides/robusta complex - RO1' - Verheye et al. 2016a, supplement: 4 (online). 
non Epimeria robusta K.H. Barnard, 1930: 375, figs 40a, 41.

non Epimeria robustoides Lörz \& Coleman in Lörz et al., 2009: 10, figs 2-5.

\section{Etymology}

Gargantua is a giant and one of the main characters in the tales of François Rabelais, such as 'La vie très horrifique du grand Gargantua, père de Pantagruel'. The name, which is a noun in apposition, alludes to the huge size of the species, which is the largest known Epimeria species.

\section{Type material}

\section{Holotype}

RV Polarstern cruises:

SOUTHERN OCEAN: $q$, cruise PS81, ANT-XXIX/3, Bransfield Strait, stn 196-8, 62 ${ }^{\circ} 47.80^{\prime}$ S, $57^{\circ} 5.35^{\prime} \mathrm{W}$ to $62^{\circ} 47.63^{\prime} \mathrm{S}, 57^{\circ} 5.63^{\prime} \mathrm{W}, 542-580 \mathrm{~m}$, trawl haul with huge stones and a lot of life, Agassiz trawl, 24 Feb. 2013, coll. C. d'Udekem d'Acoz and M. Verheye (RBINS, INV. 122937A) [extraction ANT33; Genbank nr, COI: KU870820, 28S: KU759592].

\section{Paratypes}

RV Polarstern cruises:

SOUTHERN OCEAN: 1 medium-sized spec., cruise PS69, ANT-XXIII/8, stn 662-1, between Elephant Island and King George Island, 61 $35.91^{\prime} \mathrm{S}, 57^{\circ} 17.04^{\prime} \mathrm{W}$ to $61^{\circ} 35.41^{\prime} \mathrm{S}, 57^{\circ} 20.60^{\prime} \mathrm{W}, 425-432 \mathrm{~m}$, bottom trawl, 30 Dec. 2006, coll. C. d'Udekem d'Acoz and H. Robert (RBINS, INV. 122491); 2 large specs, cruise PS69, ANT-XXIII/8, stn 663-1, northeast of King George Island, 61 ${ }^{\circ} 38.18^{\prime}$ S, 57 $33.17^{\prime}$ W to $61^{\circ} 38.02^{\prime} \mathrm{S}, 57^{\circ} 37.16^{\prime} \mathrm{W}$, bottom trawl, $432-434 \mathrm{~m}, 30$ Dec. 2006, coll. C. d'Udekem d'Acoz and H. Robert (RBINS, INV. 122494); 5 specs, cruise PS81, ANT-XXIX/3, Bransfield Strait, stn 196-8, $62^{\circ} 47.80^{\prime} \mathrm{S}, 57^{\circ} 5.35^{\prime} \mathrm{W}$ to $62^{\circ} 47.63^{\prime} \mathrm{S}, 57^{\circ} 5.63^{\prime} \mathrm{W}, 542-580 \mathrm{~m}$, trawl haul with huge stones and a lot of life, Agassiz trawl, 24 Feb. 2013, coll. C. d'Udekem d'Acoz and M. Verheye (RBINS, INV. 122937B); 1 spec., cruise PS81, ANT-XXIX/3, Bransfield Strait, stn 217-6, 62 $53.45^{\prime} \mathrm{S}, 58^{\circ} 13.06^{\prime} \mathrm{W}$ to $62^{\circ} 53.42^{\prime} \mathrm{S}$, $58^{\circ} 13.41^{\prime} \mathrm{W}, 461-483 \mathrm{~m}$, rich sponge bottom, Agassiz trawl, 2 Mar. 2013, coll. C. d'Udekem d'Acoz and M. Verheye (RBINS, INV. 122927) [extraction K37; Genbank nr, COI: KU870869, 28S: KU759649]; 1 spec., cruise PS81, ANT-XXIX/3, Bransfield Strait, stn 217-6, 62 $2^{\circ} 53.45^{\prime} \mathrm{S}, 58^{\circ} 13.06^{\prime} \mathrm{W}$ to $62^{\circ} 53.42^{\prime} \mathrm{S}$, $58^{\circ} 13.41^{\prime} \mathrm{W}, 461-483 \mathrm{~m}$, rich sponge bottom, Agassiz trawl, 2 Mar. 2013, coll. C. d'Udekem d'Acoz and M. Verheye (RBINS, INV. 122928) [extraction K38; Genbank nr, COI: KU870870, 28S: KU759650]; 7 specs, cruise PS81, ANT-XXIX/3, Bransfield Strait, stn $217-6,62^{\circ} 53.45^{\prime} \mathrm{S}, 58^{\circ} 13.06^{\prime} \mathrm{W}$ to $62^{\circ} 53.42^{\prime} \mathrm{S}$, $58^{\circ} 13.41^{\prime} \mathrm{W}, 461-483 \mathrm{~m}$, rich sponge bottom, Agassiz trawl, 2 Mar. 2013, coll. C. d'Udekem d'Acoz and M. Verheye (RBINS, INV. 132957); 1 spec., cruise PS81, ANT-XXIX/3, Bransfield Strait, stn 217$6,62^{\circ} 53.45^{\prime} \mathrm{S}, 58^{\circ} 13.06^{\prime} \mathrm{W}$ to $62^{\circ} 53.42^{\prime} \mathrm{S}, 58^{\circ} 13.41^{\prime} \mathrm{W}, 461-483 \mathrm{~m}$, rich sponge bottom, Agassiz trawl, 2 Mar. 2013, coll. C. d'Udekem d'Acoz and M. Verheye (MNHN-IU-2014-7333, removed from RBINS, INV. 132957); 1 spec., cruise PS81, ANT-XXIX/3, Bransfield Strait, stn 227-2, 62 ${ }^{\circ} 55.83^{\prime}$ S, $58^{\circ} 41.09^{\prime} \mathrm{W}$ to $62^{\circ} 55.76^{\prime} \mathrm{S}, 58^{\circ} 41.46^{\prime} \mathrm{W}, 562-564 \mathrm{~m}$, mud, Agassiz trawl, $5 \mathrm{Mar}$. 2013, RBINS, coll. C. d'Udekem d'Acoz and M. Verheye (RBINS, INV. 122939) [extraction ANT40; Genbank nr, COI: KU870826, 28S: KU759599].

\section{Description}

Rostrum. Medium-sized, not reaching tip of article 1 of peduncle of antenna 1, anteriorly distinctly and regularly curved, ventrally straight, fairly narrow and subacute in lateral view; fairly narrow and with very weakly convex converging borders in frontal view.

EYE. Very large, broadly elliptic to more or less reniform. 
Pereion-Pleosome tooth pattern. Pereionites 1-7 smooth; pleonite 1 dorsally weakly carinate, very weakly convex, with distinct posterior bump; pleonite 2 dorsally distinctly carinate, with extremely low (nearly inconspicuous) proximal rounded lobe followed by extremely weak (nearly inconspicuous) concavity, posteriorly produced into a bluntly triangular tooth projecting backwards; pleonite 3 dorsally distinctly carinate with median very low rounded lobe, followed by distinct concavity, terminated by a blunt tooth directed upwards.

COXAE $1-3$. Not carinate, apically subacute.

Coxa 4. Anterodorsal border nearly straight (inconspicuously concave), anteroventral border straight, these two borders being joined by blunt but broad, very distinct squared angle (anterior corner), which is slightly projecting forward; ventral corner forming a very obtuse angle (ventral projection very short and very broad); lateral carina absent; posteroventral border nearly straight (inconspicuously convex).

CoxA 5. Broad, with surface smooth, with posterior border inconspicuously concave (nearly straight), with posteroventral corner forming a blunt tooth (shape: acute triangle) projecting backwards and not laterally (no tooth or corner visible in dorsal view).

Coxa 6 . With posterior border very weakly concave, with posteroventral corner forming a blunt tooth (shape: narrow acute triangle) projecting backwards and not laterally (no tooth or corner visible in dorsal view).

Coxa 7. Posteriorly weakly rounded.

EPIMERAL PLATES 1-3. Posteroventral angle: angulate in plate 1, produced into a medium-sized tooth in plates 2-3.

Urosome tOOth PATtern. Urosomite 1 with well developed blunt-tipped process of which both the anterior and the posterior borders have an angulate concavity (the anterior deeper); urosomite 3 with dorsolateral borders weakly concave and posteriorly produced into a sharp triangular tooth.

TeLson. Cleft nearly on 0.2 ; tips of lobes triangular and subacute, notch very broadly V-shaped and subacute at its deepest point.

GNATHOPODs 1-2. Carpus and propodus very broad; propodus expanding distally, palm distinct.

PeREIOPODS 5-7. Merus, carpus and propodus fairly broad; dactylus small, very curved, with long unguis; basis of pereiopods 5-6 broad, with posteroproximal process present, sword-like, projecting obliquely, with posterodistal corner produced into a triangular tooth (with tip subacute), projecting backwards; basis of pereiopod 7 broad; posterior border with proximal 0.4 with weak concavity, with distal 0.6 deeply concave, with posterodistal corner forming a narrowly triangular tooth projecting backwards.

\section{Colour pattern}

Body and coxae pure white, gnathopods and oral field purplish; antennae and pereiopods 3-4 pale pink; pereiopods 5-7 and tailfan pure white; eyes red. This colour pattern was very consistent in all specimens examined during ANT-XXIX/3; none had spots or marks on their immaculate body.

\section{Body length}

Up to $80 \mathrm{~mm}$. 


\section{Distribution}

Between Elephant Island and King George Island; northeast of King George Island, Bransfield Strait; 404-580 m (present material; Coleman 1994: "Epimeria robusta from Elephant Island" (specimen actually collected between Elephant and King George Islands)).

\section{Remarks}

Epimeria gargantua sp. nov. is the largest known Epimeria species, both in length and body volume. Epimeria gargantua sp. nov. (tip of Antarctic Peninsula) is morphologically similar to E. robustoides (eastern shelf of the Weddell Sea), but these two species were identified as separate species by methods based on COI and 28S genes (Fig. 342). In E. gargantua sp. nov., the dorsolateral margins of urosomite 3 are less concave and the posterodistal corner of the basis of pereiopods 5-7 sharper than in $E$. robustoides. The colour pattern of E. gargantua sp. nov. is very constant (body white, without coloured marks), whilst it is more variable in $E$. robustoides.

Epimeria (Hoplepimeria) georgiana subgen. nov. Schellenberg, 1931

Figs $152-158$

Epimeria georgiana Schellenberg, 1931: 160.

Epimeria excisipes K.H. Barnard, 1932: 174, in part but well the types, presumably figs 104e, 107, not fig. 106 (presumably another Epimeria of the complex georgiana).

Epimeria georgiana - Gurjanova 1955: 197. — J.L. Barnard 1961: 103 (key). — McCain 1971: 161. — Watling \& Holman 1981: 211, in part, not fig. 19 (=E. quasimodo sp. nov.). — De Broyer \& Klages 1991: 165 (key, in part). — Wakabara \& Serejo 1999: 642 (key, in part). — Lörz et al. 2011: 1, figs 1 (star), 13 row 5 , table 3.

Epimeria excisipes - Gurjanova 1955: 198 (in part). — J.L. Barnard 1961: 103 (key, in part). — McCain 1971: 161 (in part).

\section{Type material}

\section{Lectotype}

Swedish South Polar Expedition 1901-1903:

SOUTHERN OCEAN: $q$, from the syntype series, stn 34, South Georgia, in front of mouth of Cumberland Bay, $54^{\circ} 11^{\prime} \mathrm{S}, 36^{\circ} 18^{\prime} \mathrm{W}$, grey clay, some stones, $252-310 \mathrm{~m}, \mathrm{~T}=+1.45^{\circ} \mathrm{C}$, Skottsberg pinx. (SMNH - type 673).

\section{Description}

Rostrum. Medium-sized, just overreaching tip of article 1 of peduncle of antenna 1, anteriorly distinctly curved, ventrally straight, subacute in lateral view; broad and with proximally nearly straight converging borders in frontal view.

EYE. Fairly large, broadly elliptic.

Pereion-pleosome tooth pattern. Pereionite 1 smooth; pereionites 2-3 with weak posterior bump; pereionites 4 to pleonite 3 with low, non-toothed, very broad carina (not reduced on pereionites 2-3), those of pleonites 1-3 with trace of concavity in anterior 0.4 ; posterodorsal angle of pleonite 3 very bluntly angular; dorsolateral ornamentation absent.

COXAE $1-3$. Scarcely carinate and apically tapering and blunt. 
Coxa 4. Anterodorsal border weakly sigmoid, anteroventral border distinctly concave, these two borders being joined by very distinct and not so blunt angle (anterior corner), which is strongly projecting forward; ventral corner forming a sharp acute angle (ventral projection short); lateral carina present, not sharp; broad hollow surface between carina and posteroventral border of coxa; posteroventral border distinctly concave.

CoxA 5. Broad, with surface smooth, with posteroventral corner forming a rounded lobe, weakly expanded laterally, forming a blunt squared angle which is very distinct in dorsal view.

Coxa 6. With posteroventral corner rounded, with lateral projection arising from its surface (broadly triangular in dorsal view).

Coxa 7. Posteriorly rounded.

EPIMERAL Plates 1-3. Posteroventral angle: forming an angle with a trace of tooth in plate 1, produced into a small tooth in plate 2 and into a medium-sized tooth in plate 3.

UROSOME TOOTH PATteRn. Urosomite 1 with very low dorsal process, regularly convex on both sides; urosomite 3 with dorsolateral borders nearly straight (inconspicuously convex), with tip bluntly angular.

TELSON. Cleft on 0.4 ; lobes with rate of divergence abruptly increasing on their distal half, triangular and subacute in their distal half, median notch narrowly V-shaped.

GNATHOPODS 1-2. Carpus and propodus very broad; propodus expanding distally, palm distinct.

Pereiopods 5-7. Merus, carpus and propodus of medium width; dactylus medium-sized; basis of pereiopods 5-6 very broad, with posteroproximal process present, tooth-like, parallel to axis of basis, with posterodistal corner bluntly angular, distinctly produced and pointing in posterior direction; basis of pereiopod 7 broad with posterior border weakly convex, with distinct notch on distal 0.8 , forming a blunt-tipped acute angle, with posterodistal corner bluntly angular and not projecting backwards.

\section{Body length}

Up to $40 \mathrm{~mm}$.

\section{Distribution}

South Georgia, 75-310 m (Schellenberg 1931).

\section{Remarks}

Epimeria georgiana s. str. is considered endemic to South Georgia and all extralimital records are presumably based on related species. The mention 'Skottsberg pinx.' (i.e., Skottsberg pinxit) on one of the labels of the lectotype suggests that Carl Johan Skottsberg made a painting of it during the Swedish Antarctic Expedition. Nothing is known about the fate of that painting. Besides the adult female examined and designated herein as the lectotype, Schellenberg (1931) recorded a mid-sized $(20 \mathrm{~mm})$ specimen and three juveniles $(7-8 \mathrm{~mm})$ of Epimeria georgiana, which become paralectotypes. These specimens were not examined. 
Epimeria (Hoplepimeria) heldi subgen. nov. Coleman, 1998

Epimeria heldi Coleman, 1998a: 17-25, figs 1-5.

Epimeria heldi - Wakabara \& Serejo 1999: 642 (key). — Coleman 2007: 39, figs 18a-b, colour plate 1f, map 9 (rhomb).

\section{Description}

Description based on illustrations of Coleman (1998a).

Rostrum. Medium-sized, just overreaching tip of article 1 of peduncle of antenna 1, anteriorly weakly curved, ventrally straight, tip subacute in lateral view.

EYE. Very large, narrowly elliptic.

Pereion-Pleosome tooth pattern. Pereionites 1-5 smooth; pereionite 6 with weak mid-dorsal straight carina, pereionite 7 to pleonite 3 with low carina, each with median slight concavity and posterior corner bluntly angular; the carinae are strongly laterally compressed.

COXAE $1-3$. Scarcely carinate and apically broadly rounded.

Coxa 4. Anterodorsal border nearly straight (very slightly concave), anteroventral border weakly but distinctly concave, these two borders being joined by broad rounded angle (anterior corner), which is distinctly projecting forward; ventral corner forming a fairly narrow rounded projection; lateral carina present and projecting laterally (it appears as a low rounded lobe in dorsal view); at its deepest point the carina is very distant from the posteroventral border of the coxa; posteroventral border deeply concave.

CoxA 5. Broad, with rounded lateral projection pointing laterally. In dorsal view, the lateral projection of coxa 4 and 5 looks like a mirror version of each other, the unit coxa $4+$ coxa 5 forming a low concave structure on each side of the body.

CoxA 6. Posteriorly broadly rounded, with very low projection arising from its surface (forming a very low rounded lobe in dorsal view).

Coxa 7. Posterior and ventral border strongly convex; transition between these borders indistinct.

Epimeral Plates 1-3. Posteroventral angle: rounded in plates 1-2, produced into a small tooth in plate 2 and into a medium-sized tooth in plate 3 .

Urosome tooth pattern. Urosomite 1 with low rounded dorsal process; urosomite 3 with dorsolateral borders straight, distally forming a rounded lobe.

TeLson. Cleft on 0.15 ; tips of lobes broadly rounded, notch broadly V-shaped.

GNATHOPODs 1-2. Carpus and propodus broad; propodus not expanding distally, palm distinct.

Pereiopods 5-7. Merus, carpus and propodus slender, dactylus medium-sized; basis of pereiopods 5-6 of normal width, with posteroproximal half forming a very low rounded projection; with posterodistal corner not produced; basis of pereiopod 7 narrow with posterior border straight, with posterodistal corner very bluntly angular, not projecting. 


\section{Colour pattern}

Body and coxae whitish with a very faint dull purplish hue. Basis of pereiopods 5-7 pale dull purple. Antennae, other pereiopods, distal part of pereiopods 5-7 and tailfan dull brownish pink. Eyes pale yellow.

\section{Body length}

$52 \mathrm{~mm}$.

\section{Distribution}

Northwest of Elephant Island. Said to have been collected at $60^{\circ} 54.60^{\prime} \mathrm{S}, 55^{\circ} 45.90^{\prime} \mathrm{W}$ at $235 \mathrm{~m}$ depth (RV Polarstern, PS42, ANT-XIV/2, stn 31) (Coleman 1998a). The coordinates of station 31 given by Kattner (1998) are slightly different and deeper: $60^{\circ} 53^{\prime} \mathrm{S}, 55^{\circ} 47^{\prime} \mathrm{W}$ to $60^{\circ} 54^{\prime} \mathrm{S}, 55^{\circ} 57^{\prime} \mathrm{W}, 443-734 \mathrm{~m}$. However, Coleman (pers. com.) informed us that the depth record given in his logbook is $230-235 \mathrm{~m}$.

\section{Remarks}

This highly characteristic species, which shares a number of character states with Epimeria georgiana and E. inermis, is presumably rare, as it was not found in the abundant Epimeria material from Elephant Island collected during the cruise ANT-XXIII/8. Epimeria heldi is tentatively assigned to the subgenus Hoplepimeria subgen. nov. based on morphological assessment only.

Epimeria (Hoplepimeria) inermis subgen. nov. Walker, 1903

Figs 159-184

Epimeria inermis Walker, 1903: 54, pl. 10 fig. 69.

Epimeria inermis - K.H. Barnard 1930: 374 (in part); 1932: 173 (in part), fig. 104a. — Nicholls 1938: 95, fig. 50. — Gurjanova 1955: 198. — J.L. Barnard 1961: 103 (key). — McCain 1971: 161. — Bellan-Santini 1972: 223, plate 32. — De Broyer \& Klages 1991: 165 (key). — Ren \& Huang 1991: 262, fig. 48. — Wakabara \& Serejo 1999: 642 (key). — Coleman 2007: 41, fig. 19a-b, colour plate 1c, map 10 (rhomb). - Lörz \& Coleman 2009: unnumbered photographs on p. 17. - Lörz et al. 2011: 2, fig. 13 row 6 [holotype], table 3.

'Epimeria inermis 2, 4, 5, 6' - Rauschert \& Arntz 2015: 61, pl. 54.

non 'Epimeria inermis 1' - Rauschert \& Arntz 2015: 61, pl. 54 (= Epimeria (Metepimeria) acanthurus (Schellenberg, 1931)).

non 'Epimeria inermis 3'- Rauschert \& Arntz 2015: 61, pl. 54 (= Epimeria (Hoplepimeria) angelikae subgen. nov. Lörz \& Linse in Lörz et al., 2011).

\section{Type material}

\section{Holotype}

British Antarctic Expedition 1898-1900, RV Southern Cross:

SOUTHERN OCEAN: , , Cape Adare, 51 m (28 fathoms) (BMNH 1903.10.5.19).

\section{Other material examined}

RV Polarstern cruises:

SOUTHERN OCEAN: 2 specs, previously identified as E. georgiana, cruise PS39, ANT-XIII/3, EASIZ I, stn 11, GSN 4, eastern Weddell Sea, $73^{\circ} 22.60^{\prime} \mathrm{S}, 21^{\circ} 10.60^{\prime} \mathrm{W}$ to $73^{\circ} 23.00^{\prime} \mathrm{S}, 21^{\circ} 12.90^{\prime} \mathrm{W}, 333-$ 338 m, bottom trawl, 13 Feb. 1996, coll. C. De Broyer and G. Chapelle (RBINS, INV. 132707); 1 juv., cruise PS39, ANT-XIII/3, EASIZ I, stn 11, GSN 4, eastern Weddell Sea, $73^{\circ} 22.60^{\prime}$ S, $21^{\circ} 10.60^{\prime} \mathrm{W}$ to 
$73^{\circ} 23.00^{\prime} \mathrm{S}, 21^{\circ} 12.90^{\prime} \mathrm{W}, 333-338 \mathrm{~m}$, bottom trawl, 13 feb. 1996, coll. C. De Broyer and G. Chapelle (RBINS, INV. 132710); 9 specs, previously mixed with 1 E. xesta sp. nov., misidentified as E. georgiana and used for gut content analysis, cruise PS39, ANT-XIII/3, EASIZ I, stn 12, GSN 5, eastern Weddell Sea, $73^{\circ} 18.10^{\prime} \mathrm{S}, 21^{\circ} 10.10^{\prime} \mathrm{W}$ to $73^{\circ} 17.10^{\prime} \mathrm{S}, 21^{\circ} 08.20^{\prime} \mathrm{W}, 457-459 \mathrm{~m}$, bottom trawl, 14 Feb. 1996, coll. C. De Broyer and G. Chapelle (RBINS, INV. 132996); 1 spec., cruise PS39, ANT-XIII/3, EASIZ I, stn 17, GSN 10, eastern Weddell Sea, $73^{\circ} 18.00^{\prime} \mathrm{S}, 21^{\circ} 09.90^{\prime} \mathrm{W}$ to $73^{\circ} 19.10^{\prime} \mathrm{S}, 21^{\circ} 14.90^{\prime} \mathrm{W}, 465-$ 468 m, bottom trawl, 16 Feb. 1996, coll. C. De Broyer and G. Chapelle (RBINS, INV. 132708); 1 spec., cruise PS39, ANT-XIII/3, EASIZ I, eastern Weddell Sea, station lost, specimen kept in aquarium, 27 Feb. 1996, coll. C. De Broyer and G. Chapelle (RBINS, INV. 132684); 1 spec., cruise PS69, ANTXXIII/8, stn 605-1, Elephant Island, $61^{\circ} 20.35^{\prime} \mathrm{S}, 55^{\circ} 29.16^{\prime} \mathrm{W}$ to $61^{\circ} 19.98^{\prime} \mathrm{S}, 55^{\circ} 32.67^{\prime} \mathrm{W}, 146-$ $151 \mathrm{~m}$, bottom trawl, 19 Dec. 2006, coll. C. d'Udekem d'Acoz and H. Robert (RBINS, INV. 122513); 1 large spec., cruise PS69, ANT-XXIII/8, stn 608-1, Elephant Island, $61^{\circ} 11.34^{\prime} \mathrm{S}, 54^{\circ} 43.17^{\prime} \mathrm{W}$ to $61^{\circ} 11.80^{\prime} \mathrm{S}, 54^{\circ} 40.05^{\prime} \mathrm{W}, 284-293 \mathrm{~m}$, bottom trawl, 20 Dec. 2006, coll. C. d'Udekem d'Acoz and H. Robert (RBINS, INV. 122520); 1 small spec., cruise PS69, ANT-XXIII/8, stn 609-6, Elephant Island, $61^{\circ} 08.58^{\prime} \mathrm{S}, 54^{\circ} 31.86^{\prime} \mathrm{W}$ to $61^{\circ} 08.58^{\prime} \mathrm{S}, 54^{\circ} 31.86^{\prime} \mathrm{W}, 437-442 \mathrm{~m}$, Rauschert dredge, $21 \mathrm{Dec}$. 2006, coll. C. d'Udekem d'Acoz and H. Robert (RBINS, INV. 122486); 4 q $q$, cruise PS69, ANT-XXIII/8, stn $614-3 / 4 / 5$, Elephant Island, $60^{\circ} 52.37^{\prime} \mathrm{S}, 55^{\circ} 29.80^{\prime} \mathrm{W}$ to $60^{\circ} 52.71^{\prime} \mathrm{S}, 55^{\circ} 27.83^{\prime} \mathrm{W}, 248-265 \mathrm{~m}$, a lot of epifauna, Rauschert dredge and Agassiz trawl, 22 Dec. 2006, coll. C. d'Udekem d'Acoz and H. Robert (RBINS, INV. 122512); 5 우, cruise PS69, ANT-XXIII/8, stn 654-6, Elephant Island, $61^{\circ} 22.80^{\prime} \mathrm{S}$, $56^{\circ} 03.84^{\prime} \mathrm{W}$ to $61^{\circ} 23.35^{\prime} \mathrm{S}, 56^{\circ} 04.89^{\prime} \mathrm{W}, 341-342 \mathrm{~m}$, Agassiz trawl, 29 Dec. 2006, coll. C. d'Udekem d'Acoz and H. Robert (RBINS, INV. 122511); 6 우, cruise PS69, ANT-XXIII/8, stn 654-7, Elephant Island, $61^{\circ} 23.37^{\prime} \mathrm{S}, 56^{\circ} 04.35^{\prime} \mathrm{W}$ to $61^{\circ} 23.94^{\prime} \mathrm{S}, 56^{\circ} 03.79^{\prime} \mathrm{W}, 318-345 \mathrm{~m}$, Rauschert dredge, 29 Dec. 2006, coll. C. d'Udekem d'Acoz and H. Robert (RBINS, INV. 122514); 1 spec., cruise PS71, ANTXXIV/2, ANDEEP-SYSTCO, stn 48-1, eastern Weddell Sea, 70²3.94' S, $8^{\circ} 19.14^{\prime} \mathrm{W}$ to $70^{\circ} 23.89^{\prime} \mathrm{S}$, $8^{\circ} 18.67^{\prime} \mathrm{W}, 595-602 \mathrm{~m}$, bryozoan bottom (exceptional bryozoan diversity), Rauschert dredge, 12 Jan. 2008, coll. H. Robert (RBINS, INV. 132954) [extraction I3; Genbank nr, COI: KU870847, 28S: KU759624]; 2 small specs, cruise PS71, ANT-XXIV/2, ANDEEP-SYSTCO, stn 48-1, eastern Weddell Sea, $70^{\circ} 23.94^{\prime} \mathrm{S}, 8^{\circ} 19.14^{\prime} \mathrm{W}$ to $70^{\circ} 23.89^{\prime} \mathrm{S}, 8^{\circ} 18.67^{\prime} \mathrm{W}, 595-602 \mathrm{~m}$, bryozoan bottom (exceptional bryozoan diversity), Rauschert dredge, 12 Jan. 2008, coll. H. Robert (RBINS, INV. 122897); 1 small spec., cruise PS71, ANT-XXIV/2, ANDEEP-SYSTCO, stn 48-1, eastern Weddell Sea, 70²3.94' S, $8^{\circ} 19.14^{\prime} \mathrm{W}$ to $70^{\circ} 23.89^{\prime} \mathrm{S}, 8^{\circ} 18.67^{\prime} \mathrm{W}, 595-602 \mathrm{~m}$, bryozoan bottom (exceptional bryozoan diversity), Agassiz trawl, 12 Jan. 2008, coll. H. Robert (RBINS, INV. 122905); 1 large spec., cruise PS71, ANTXXIV/2, ANDEEP-SYSTCO, stn 48-1, eastern Weddell Sea, $70^{\circ} 23.94^{\prime} \mathrm{S}, 8^{\circ} 19.14^{\prime} \mathrm{W}$ to $70^{\circ} 23.89^{\prime} \mathrm{S}$, $8^{\circ} 18.67^{\prime} \mathrm{W}, 595-602 \mathrm{~m}$, bryozoan bottom (exceptional bryozoan diversity), Agassiz trawl, 12 Jan. 2008, initially fixed in formalin, coll. H. Robert (RBINS, INV. 132459); 1 spec., cruise PS77, ANT-XXVII/3, $\operatorname{stn} 281-1$, eastern Weddell Sea, BENDEX area, $70^{\circ} 48.93^{\prime} \mathrm{S}, 10^{\circ} 32.69^{\prime} \mathrm{W}$ to $70^{\circ} 49.46^{\prime} \mathrm{S}, 10^{\circ} 33.66^{\prime} \mathrm{W}$, $283 \mathrm{~m}$, bottom trawl, 28 Mar. 2011, bottom trawl, coll. C. Havermans and H. Robert (RBINS, INV. 132955) [extraction I11, Genbank nr, 28S: KU759613]; 1 q, cruise PS81, ANT-XXIX/3, stn 1994, Bransfield Strait, $62^{\circ} 57.22^{\prime} \mathrm{S}, 58^{\circ} 14.60^{\prime} \mathrm{W}$ to $62^{\circ} 57.33^{\prime} \mathrm{S}, 58^{\circ} 14.95^{\prime} \mathrm{W}, 325-339 \mathrm{~m}$, non-muddy bottom (content of the net dominated by sponges; also small stones, Stylasteridae and crinoids) Agassiz trawl, 27 Feb. 2013, coll. C. d'Udekem d'Acoz and M. Verheye (RBINS, INV. 132953) [extraction I18; Genbank nr, COI: KU870843, 28S: KU759620]; 1 spec., cruise PS81, ANT-XXIX/3, stn 224-2, Bransfield Strait, $63^{\circ} 0.50^{\prime} \mathrm{S}, 58^{\circ} 37.53^{\prime} \mathrm{W}$ to $63^{\circ} 0.54^{\prime} \mathrm{S}, 58^{\circ} 37.50^{\prime} \mathrm{W}, 254-256 \mathrm{~m}$, black sand, Rauschert dredge, 4 Mar. 2013, coll. C. d'Udekem d'Acoz and M. Verheye (RBINS, INV. 122972); 1 ovigerous ㅇ, cruise PS81, ANT-XXIX/3, stn 224-3, Bransfield Strait, $63^{\circ} 0.53^{\prime} \mathrm{S}, 58^{\circ} 35.67^{\prime} \mathrm{W}$ to $63^{\circ} 0.58^{\prime} \mathrm{S}$, 58 36.11' W, 257-261 m, mud, Agassiz trawl, 4 Mar. 2013 (RBINS, INV. 122945A) [extraction ANT45; Genbank nr, COI: KU870831, 28S: KU759604]; 1 immature spec., cruise PS81, ANT-XXIX/3, stn 224-3, Bransfield Strait, $63^{\circ} 0.53^{\prime} \mathrm{S}, 58^{\circ} 35.67^{\prime} \mathrm{W}$ to $63^{\circ} 0.58^{\prime} \mathrm{S}, 58^{\circ} 36.11^{\prime} \mathrm{W}, 257-261 \mathrm{~m}$, mud, Agassiz trawl, 4 Mar. 2013 (RBINS, INV. 122945B); 1 spec., cruise PS81, ANT-XXIX/3, stn 227-2, Bransfield 
Strait, $62^{\circ} 55.83^{\prime} \mathrm{S}, 58^{\circ} 41.09^{\prime} \mathrm{W}$ to $62^{\circ} 55.76^{\prime} \mathrm{S}, 58^{\circ} 41.46^{\prime} \mathrm{W}, 562-564 \mathrm{~m}$, mud, Agassiz trawl, 5 Mar. 2013 (RBINS, INV. 122948) [extraction ANT44, Genbank nr, COI: KU870830, 28S: KU759603].

RV Marion Dufresne cruises:

SOUTHERN OCEAN: 3 specs, cruise MD42 (SIBEX), stn 22-CP73, PrydzBay, 66 57'25" S, 7241'25" E, depth missing [Google depth for that position: 533 m], 26 Jan. 1985, (MNHN-IU-2014-4261) (typed label).

RV Aurora Australis cruises:

SOUTHERN OCEAN: 1 ovigerous $q$, cruise CEAMARC, sample CEAMARC 971, stn 42EV167,

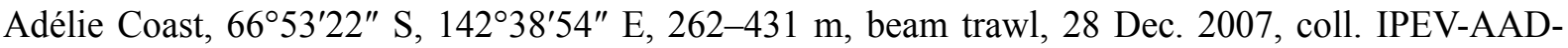
MNHN (MNHN-IU-2014-4272) [extraction M1; Genbank nr, COI: KU870877, 28S: KU759660]; 1 spec., cruise CEAMARC, sample CEAMARC 1317, stn 51AEV215, Adélie Coast, 66 $44^{\prime} 52^{\prime \prime}$ S, $145^{\circ} 26^{\prime} 40^{\prime \prime}$ E, 525-553 m, beam trawl, 30 Dec. 2007, coll. IPEV-AAD-MNHN (MNHN-IU-2014-4274); 1 o, cruise CEAMARC, sample CEAMARC 2724, stn 71EV447, Adélie Coast, 66 24'00" S, 140³2'21" E, 683-791 m, beam trawl, 14 Jan. 2008, coll. IPEV-AAD-MNHN (MNHN-IU-2014-4338) [extraction M2; Genbank nr, COI: KU870886, 28S: KU759669]; 3 specs, cruise CEAMARC, sample CEAMARC 3226, stn 20EV490, Adélie Coast, 6600'59" S, 14000'02" E, 189-196 m, beam trawl, 15 Jan. 2008, coll. IPEV-AAD-MNHN (MNHN-IU-2014-4346); 5 specs, cruise CEAMARC, sample CEAMARC 3532, stn 87EV524, Adélie Coast, 6529'29" S, 139¹8'37" E, 397-411 m, beam trawl, 17 Jan. 2008, coll. IPEV-AAD-MNHN (MNHN-IU-2014-4351); 5 very large specs, cruise CEAMARC,

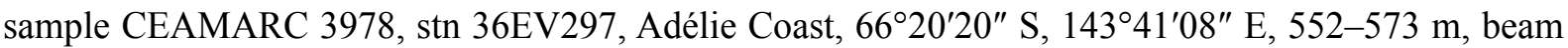
trawl, 4 Jan. 2008, coll. IPEV-AAD-MNHN (MNHN-IU-2014-4328).

RV Seatruck, cruise REVOLTA I:

SOUTHERN OCEAN: 1 ovigerous +, stn REVO_020b, Collect_ID: 143, Field_ID: CE-000004560,

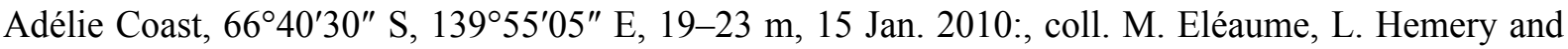
A. D’Hont, (MNHN-IU-2009-2569) [extraction K3; Genbank nr, 28S: KU759642].

RV Seatruck, cruise REVOLTA II:

SOUTHERN OCEAN: 2 specs, stn REVO_091, Collect_ID: REVO_162, Adélie Coast, 66 $41^{\prime} 07^{\prime \prime}$ S, 13956'41" E, 33-34 m, 19 Jan. 2011, coll. N. Améziane, N. Bax, C. Gallut, A.C. Lautrédou and C. Robineau (MNHN-IU-2014-4308).

RV L'Astrolabe, cruise REVOLTA III:

SOUTHERN OCEAN: 1 spec., stn none (Dumont d'Urville Sea), Collect_ID: REVO_449, Adélie Coast, $66^{\circ} 38^{\prime} \mathrm{S}, 140^{\circ} 42^{\prime} \mathrm{E}$ to $66^{\circ} 38^{\prime} \mathrm{S}, 140^{\circ} 40^{\prime} \mathrm{E}, 718-729 \mathrm{~m}$, mud, beam trawl, $20 \mathrm{Jan}$. 2012, coll. G. Lecointre, A. Dettaï, J. Lanshere, C. Gallut and C. Ozouf (MNHN-IU-2009-2545); 1 large spec., stn none (Dumont d'Urville Sea), Collect_ID: REVO_449, Adélie Coast, $66^{\circ} 38^{\prime} \mathrm{S}, 140^{\circ} 42^{\prime}$ E to $66^{\circ} 38^{\prime} \mathrm{S}$, $140^{\circ} 40^{\prime}$ E, 718-729 m, mud, beam trawl, 20 Jan. 2012, coll. G. Lecointre, A. Dettaï, J. Lanshere, C. Gallut and C. Ozouf (MNHN-IU-2009-2584).

RV Seatruck, cruise REVOLTA III:

SOUTHERN OCEAN: 1 ovigerous + , stn REVO_032, Collect_ID: REVO_509, Field_ID: CE000002403 , Adélie Coast, $66^{\circ} 39.306^{\prime} \mathrm{S}, 140^{\circ} 01.635^{\prime} \mathrm{W}$ to $66^{\circ} 39.370^{\prime} \mathrm{S}, 140^{\circ} 01.686^{\prime} \mathrm{W}, 72-100 \mathrm{~m}$, beam trawl, 8 Feb. 2012, coll. G. Lecointre, A. Dettaï, J. Lanshere, C. Gallut and C. Ozouf, (MNHNIU-2009-2531) [extraction K2; Genbank nr, 28S: KU759632].

\section{Description}

Description based on holotype. 
Rostrum. Medium-sized, reaching mid of article 2 of peduncle of antenna 1, anteriorly strongly curved, ventrally straight, acute-tipped in lateral view; blunt-tipped, broad and with borders scarcely convex in frontal view.

EYE. Medium-sized, elliptic.

Pereion-Pleosome tooth pattern. Pereionites 1-2 smooth; pereionite 3 with trace of carina and trace of posterodorsal bump; pereionite 4 to pleonite 3 with low and blunt mid-dorsal carina, which is strongly laterally compressed (especially the posterior ones); all these carinae with very weak median concavity, that of pleonite 3 with a second weak concavity and posteriorly forming a blunt squared angle.

COXAE $1-3$. Weakly carinate and apically subacute.

Coxa 4. Anterodorsal border nearly straight (very slightly concave), anteroventral border very weakly convex, these two borders being joined by blunt but distinct squared angle (anterior corner), which is distinctly projecting forward; ventral corner forming an obtuse angle (ventral projection moderately developed); lateral carina absent; posteroventral border straight.

Coxa 5. Broad, with surface smooth, with posteroventral corner forming a blunt-tipped projection, weakly expanded laterally, forming a blunt squared angle in dorsal view.

Coxa 6 . With posteroventral corner forming a blunt squared angle, with very low projection arising from its surface (forming a very low indistinct lobe in dorsal view).

Coxa 7. Posterior and ventral border weakly convex, joined by blunt squared angle.

EPIMERAL PLATES 1-3. Posteroventral angle: rounded in plate 1, produced into a small tooth in plate 2 and into a medium-sized tooth in plate 3 .

UROSOME TOOTH PATTERN. Urosomite 1 with very low rounded dorsal process; urosomite 3 with dorsolateral borders distinctly concave.

TELSON. Cleft on 0.035; tips of lobes obtusely triangular and very blunt, notch very broadly V-shaped.

GNATHOPODS 1-2. Carpus and propodus broad; propodus expanding distally, palm distinct.

Pereiopods 5-7. Merus, carpus and propodus of medium width; dactylus medium-sized; basis of pereiopods 5-6 of normal width, with posteroproximal process present, forming a very low rounded projection in pereiopod 5 , forming a well-developed asymmetrical rounded lobe in pereiopod 6; with posterodistal corner rounded, small, projecting forward; basis of pereiopod 7 broad with posterior border weakly convex, with distinct but very shallow notch on distal 0.8 , forming a blunt-tipped extremely obtuse angle, with posterodistal corner rounded, small, projecting ventrally.

\section{Colour pattern}

Holotype red (Walker 1903). The colour of specimens from the Antarctic Peninsula, the Weddell Sea and Adélie Coast is very variable: uniformly orange, orange red with a finely mottled/doted pattern, whitish with sparse small mottling or body divided between white zones and red zones with a finely mottled/doted pattern; eyes always reddish.

\section{Body length}

$36 \mathrm{~mm}$ (holotype). The holotype is one of the largest specimens examined. 


\section{Distribution}

Elephant Island, tip of Antarctic Peninsula, eastern shelf of the Weddell Sea, Davis Sea, Adélie Coast, western Ross Sea; 33-791 m.

\section{Remarks}

Examination of the holotype of Epimeria inermis (Ross Sea) revealed morphological differences with the specimens from the South Shetland Islands, the Antarctic Peninsula, the eastern Weddell Sea and Adélie Coast. The most striking difference is the telson, which is scarcely emarginate in the holotype of E. inermis, whilst it exhibits an acutely triangular V-shaped notch in all other specimens examined. However, the notch is also quite small in the specimen from the Adélie Coast illustrated by BellanSantini (1972). The rostrum is also shorter and more distinctly curved in the holotype of E. inermis. The dorsal carina of pereionite 4 is posteriorly slightly projecting upwards, which is not the case in other specimens. The ventral part of coxa 4 is less developed, forming a blunt-tipped obtuse angle instead of a sharp squared angle. The posterior notch of the basis of pereiopod 7 is a bit shallower. Finally, the process of urosomite 1 is more obtuse.

Molecular data would be needed to investigate if the specimens from the Ross Sea (topotypical E. inermis) are conspecific with or distinct from specimens from other seas. On the other hand, the COI corrected mean distance $(\mathrm{GTR}+\mathrm{G}+\mathrm{I})$ between the haplotypes from the Scotia Arc area and the Adélie Coast is $1.3 \%$. This distance is much higher than intraspecific distances observed in other Epimeria species $(0-0.5 \%$; table 2 in Verheye et al. 2016a). However, additional intraspecific sampling might increase these values. It is unclear from the molecular data if these two clades are distinct species or populations of the same widespread species (Verheye et al. 2016a). As the single specimen from the eastern Weddell Sea was only sequenced for $28 \mathrm{~S}$, it is possible that the more variable COI would show some differentiation with the haplotypes from the Adélie Coast and Scotia Arc area as well. But as no morphological differences were observed between the specimens from the three regions (compare Figs 167-172: Bransfield Strait and Figs 173-184: eastern Weddell Sea and Adélie Coast), they are provisionally considered as conspecifics.

The record of E. inermis from the Falkland Islands by K.H. Barnard (1930) seems very dubious. It is possibly based on E. (Metepimeria) acanthurus (Schellenberg, 1931), which is the only Magellanic Epimeria species known to date.

Epimeria (Hoplepimeria) larsi subgen. nov. Lörz, 2009

Figs 185-191

Epimeria larsi Lörz, 2009: 61, figs 2-6.

'Clade E georgiana-rimicarinata-rubriequies [sic] complex - GE4'-Verheye et al. 2016a, supplement: 4 (online).

\section{Material examined}

RV Aurora Australis cruises:

SOUTHERN OCEAN: 3 small specs, cruise CEAMARC, sample CEAMARC 2173, stn 67AEV326,

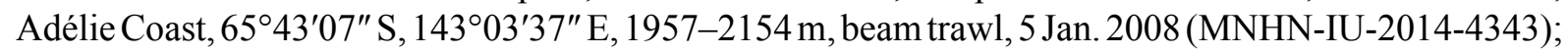
1 adult + , cruise CEAMARC, sample CEAMARC 2173, stn 67AEV326, Adélie Coast, $65^{\circ} 43^{\prime} 07^{\prime \prime} \mathrm{S}$,

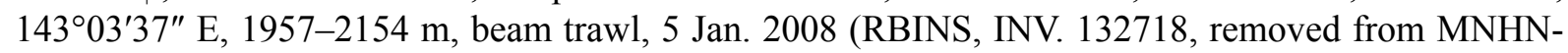
IU-2014-4344) [extraction M16; Genbank nr, COI: KU870882, 28S: KU759665]; 2 우, cruise

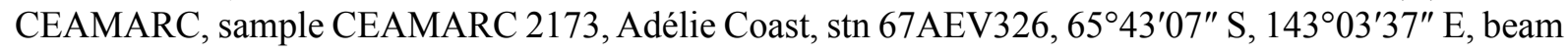
trawl, 1957-2154 m, 5 Jan. 2008 (MNHN-IU-2014-4344). 


\section{Description}

RosTRUM. Well-developed, reaching tip of article 2 of peduncle of antenna 1, anteriorly weakly curved, posteriorly nearly straight (inconspicuously concave), narrow and subacute in lateral view; narrow and with straight converging borders in dorsal view.

EYE. Very large, distinctly reniform.

Pereion-Pleosome tooth pattern. Pereionites 1-3 smooth; pereionite 4 with trace of posterodorsal bump; pereionite 5 with small and low posterodorsal tooth; pereionite 6 to pleonite 2 with very low mid-dorsal carina posteriorly produced into a tooth pointing backwards and very shallow median notch; pleonite 3 with very low rounded protrusion on median 0.4 followed posteriorly by a straight line and terminated by a medium-sized broad bluntly triangular tooth pointing obliquely upwards; dorsolateral ornamentation absent.

COXAE 1-3. Not carinate, apically rounded (coxa 1) and bluntly angular (coxae 2-3).

Coxa 4. Anterodorsal border straight, anteroventral border straight, these two borders being joined by blunt but distinct squared angle (anterior corner), which is distinctly projecting forward; ventral corner forming an acute (nearly squared) angle (ventral projection longer than in most Hoplepimeria); lateral carina absent; posteroventral border weakly concave.

Coxa 5. Broad, with surface smooth, with posteroventral corner forming a triangular tooth projecting laterally: in dorsal view the anterior border of the tooth points obliquely backwards (it forms a low concave curve with the more anterior part of the coxa), the tip of the tooth is blunt or subacute; the posterior border of the tooth is perpendicular with the body axis.

Coxa 6 . With posteroventral corner forming a blunt acute but nearly squared angle, with low projection arising from its surface (forming blunt lobe in dorsal view).

Coxa 7. Posteriorly rounded.

EPIMERAL PLATES 1-3. Posteroventral angle: very obtusely rounded in plate 1, produced into a small tooth in plate 2 and into a medium-sized tooth in plate 3 .

UROSOME TOOTH PATTERN. Urosomite 1 with very low dorsal process, forming a symmetrical and blunttipped obtuse triangle; urosomite 3 with dorsolateral borders nearly straight (very weakly convex) and posteriorly produced into a sharp triangular tooth.

TeLson. Cleft on 0.2; tips of lobes triangular and sharp, notch broadly V-shaped and sharp at its deepest point.

GNATHOPODs 1-2. With carpus and propodus very broad; propodus expanding distally, palm distinct.

PeReIOPODS 5-7. Merus, carpus and propodus of medium width; dactylus medium-sized; basis of pereiopods 5 of normal width, with posteroproximal process present, acutely triangular, parallel to axis of basis, far from reaching tip of basis, with posterodistal corner produced into a bluntly quadrate lobe; basis of pereiopod 6 of normal width, with posteroproximal process present, sword-like, parallel to axis of basis, nearly reaching tip of basis, with posterodistal corner produced into a bluntly quadrate lobe; basis of pereiopod 7 broad with posterior border proximally distinctly convex, with very shallow concavity on distal 0.8 ; with posterodistal corner produced into a bluntly quadrate lobe. 


\section{Variations}

Epimeria larsi exhibits variations (possibly related to size) in the shape of the lateral projection of coxa 5. It is very long and projecting backwards in the large holotype illustrated by Lörz (2009: 66, fig. 6). It is shorter and apparently projecting laterally in the smaller paratype illustrated by Lörz (2009: 62, fig. 2); the same disposition is observed in the material studied herein. In our specimens, coxa 1 is also less blunt and the spur of the basis of pereiopod 6 a bit longer than in the specimens illustrated by Lörz (2009). On the other hand, the colour pattern is the same.

\section{Colour pattern}

Body pale pink, with a brighter pink hue on the tip of the dorsal crests; coxae bright pink; lateral border of rostrum, antennae, pereiopods and tailfan blood red. Eyes orange.

\section{Body length}

Up to $58 \mathrm{~mm}$ (Lörz 2009). The specimen illustrated herein is $55 \mathrm{~mm}$ long.

\section{Distribution}

Western Ross Sea, 1954-1990 m (type material); Adélie Coast, 1957-2154 m (present material).

\section{Remarks}

The coordinates of the type station (TAN0802/167) as given by Lörz et al. (2009): 71 $51^{\prime} 21^{\prime \prime} \mathrm{S}$, $71^{\circ} 53^{\prime} 24^{\prime \prime} \mathrm{E}$ are incorrect, this position being located on the Antarctic mainland far away from the Ross Sea area. The correct coordinates of this station are: $71.8557^{\circ} \mathrm{S} 174.033^{\circ} \mathrm{E}$ (Vargas et al. 2015: supplement 2).

Epimeria (Hoplepimeria) linseae subgen. et sp. nov. urn:1sid:zoobank.org:act:261E7087-B67B-47ED-905B-FB8FF8C636D8

Figs 192-197

Epimeria georgiana - Coleman 2007: 37, fig. 16a-b.

Epimeria georgiana Clade B - ? Lörz et al. 2011: 3, fig. 1 (circle), fig. 13 row 2, 14C, 14D, table 3.

'Clade E georgiana-rimicarinata-rubriequies [sic] complex - GE2' - Verheye et al. 2016a, supplement: 4 (online).

non Epimeria georgiana Schellenberg, 1931: 160.

\section{Etymology}

The species is dedicated to Katrin Linse (British Antarctic Survey, Cambridge), who played an important role in the study of the Epimeria georgiana complex. The name is a genitive.

\section{Type material}

\section{Holotype}

RV Polarstern Cruises:

SOUTHERN OCEAN: + , cruise PS77, ANT-XXVII/3, South Orkney Islands, stn 217-6, 61 $09.62^{\prime}$ S, $44^{\circ} 02.37^{\prime} \mathrm{W}$ to $61^{\circ} 10.52^{\prime} \mathrm{S}, 44^{\circ} 04.91^{\prime} \mathrm{W}, 350-354 \mathrm{~m}$, bottom trawl, 19 Feb. 2011, coll. C. Havermans and H. Robert (RBINS, INV. 132958) [extraction I10; Genbank nr, COI: KU870838, 28S: KU759612]. 


\section{Paratypes}

Expedition SIGNY 1991/92 (name of ship unavailable):

SOUTHERN OCEAN: 1 large + , Transect 1, AGT 8, South Orkney Plateau: Signy Island, $60.679^{\circ} \mathrm{S}$, 45.557 ${ }^{\circ}$ W, 150-160 m, 14 Jan. 1992, coll. Stefan Hain (RBINS, INV. 132688); 1 fairly small spec., Transect 2, AGT 23, South Orkney Plateau: Signy Island, 60.691 ${ }^{\circ} \mathrm{S}, 45.443^{\circ} \mathrm{W}, 150-160 \mathrm{~m}, 14 \mathrm{Feb}$. 1992, coll. Stefan Hain (RBINS, INV. 132689); 1 large 9 , Transect 2, AGT 14, South Orkney Plateau: Signy Island, $60.705^{\circ} \mathrm{S}, 45.557^{\circ} \mathrm{W}, 150 \mathrm{~m}, 5$ Feb. 1992, coll. Stefan Hain (RBINS, INV. 132690); 1 adult $ᄋ$, Transect 1, AGT 4, South Orkney Plateau: Signy Island, $60.685^{\circ} \mathrm{S}, 45.573^{\circ} \mathrm{W}, 100-140 \mathrm{~m}$, 9 Jan. 1992, coll. Stefan Hain (RBINS, INV. 132691).

\section{Description}

RostRum. Large, nearly reaching tip of article 2 of peduncle of antenna 1, anteriorly slightly curved, ventrally inconspicuously concave, blunt-tipped in lateral view; narrow and with borders weakly convex in frontal view.

EYE. Fairly large, nearly round.

Pereion-Pleosome tooth pattern. Pereionite 1-3 smooth; pereionites 4 with posterior bump and trace of carina; pereionites 5 to pleonite 3 with low, non-toothed, very broad carina, that of pleonite 2 with trace of concavity on anterior 0.4 ; pleonite 3 with weak dorsal protuberance followed by weak concavity followed by trace of second concavity; posterodorsal angle of pleonite 3 bluntly angular; dorsolateral ornamentation absent.

COXAE $1-3$. Scarcely carinate and apically tapering, sharp to subacute.

Coxa 4. Anterodorsal border nearly straight (very weakly sigmoid), anteroventral border weakly concave, these two borders being joined by blunt but very distinct angle (anterior corner), which is distinctly projecting forward; ventral corner forming a sharp or subacute squared angle (ventral projection short); lateral carina present but not sharp; broad hollow surface between carina and posteroventral border of coxa; posteroventral border distinctly concave.

Coxa 5. Broad, with surface smooth, with posteroventral corner forming a rounded lobe, weakly expanded laterally, forming a broadly rounded obtuse (nearly square) angle which is very distinct in dorsal view.

Coxa 6. With posteroventral corner rounded, with projection arising from its surface (broadly triangular in dorsal view).

Coxa 7. Posteriorly rounded.

EPIMERAL Plates 1-3. Posteroventral angle: produced into a small tooth in plates 1-2 and into a mediumsized tooth in plate 3 .

UROSOME TOOTH PATTERN. Urosomite 1 with very low dorsal process, anteriorly slightly concave, apically rounded and posteriorly oblique and straight; urosomite 3 with dorsolateral borders nearly straight (inconspicuously concave), with tip sharply angular.

TeLson. Cleft on 0.25 ; lobes broad, forming subacute triangle; notch V-shaped, neither very narrow nor very broad.

GNATHOPODs 1-2. Carpus and propodus very broad; propodus expanding distally, palm distinct. 
PeREIOPODS 5-7. Merus, carpus and propodus of medium width; dactylus rather long; basis of pereiopods 5-6 of normal width, with posteroproximal process present, tooth-like, parallel to axis of basis, with posterodistal corner bluntly angular, very weakly pointing in posterior direction; basis of pereiopod 7 broad with posterior border weakly convex, with distinct notch on distal 0.8 , forming a blunt-tipped squared or acute angle, with posterodistal corner rounded and not projecting backwards.

\section{Colour pattern}

Body and appendages with a diffuse orange dotted/mottled pattern, more intense in some parts; eye reddish.

\section{Body length}

Up to $35 \mathrm{~mm}$.

\section{Distribution}

Plateau of the South Orkney Islands. Our specimens were collected between 100 and $354 \mathrm{~m}$. If we are correct in identifying the 'Epimeria georgiana clade B' of Lörz et al. (2011) as E. linseae sp. nov., the species descends down to 964-1014 m.

\section{Remarks}

E. linseae sp. nov. is morphologically similar to E. quasimodo sp. nov. The best differential character is the shape of the rostrum, which is narrower (both in lateral and dorsal view) and laterally more curved in the first than in the second species. The dorsal profile of pleonite 3 and urosomite 3 is also slightly different. Material from Coleman (2007) is here attributed to E. linseae sp. nov. based on morphology (especially for the shape of the rostrum) and collection location: $60^{\circ} 43.12^{\prime} \mathrm{S}, 45^{\circ} 30.86^{\prime} \mathrm{W}$ (South Orkney Islands), 141-190 m, Agassiz trawl, 3.1.1985, leg. Wägele (Coleman pers. com.).

Epimeria (Hoplepimeria) quasimodo subgen. et sp. nov. urn:1sid:zoobank.org:act:DA484D99-BC6E-4E9D-B06E-9D775DCB7FD1

Figs 198-207

Epimeria georgiana - Watling \& Holman 1981: 211, in part, fig. 19. - Coleman 1991: 3, fig. 1A-C. Epimeria georgiana Clade C - Lörz et al. 2011: 3, fig. 1 (square), 12.3, 13 row 3, 14E, 14F, table 3. 'Clade E georgiana-rimicarinata-rubriequies [sic] complex - GE1' - Verheye et al. 2016a, supplement: 4 (online).

non Epimeria georgiana Schellenberg, 1931: 160.

\section{Etymology}

Quasimodo, the hunchback of Notre-Dame, is a well-known character from the novel 'Notre-Dame de Paris' by Victor Hugo. The name, which is a noun in apposition, alludes to the humpbacked silhouette of the species.

\section{Type material}

\section{Holotype}

RV Polarstern cruises:

SOUTHERN OCEAN: $q$, cruise PS81, ANT-XXIX/3, stn 160-3, East of Joinville Island, $63^{\circ} 10.57^{\prime} \mathrm{S}$, $54^{\circ} 06.66^{\prime} \mathrm{W}$ to $63^{\circ} 10.71^{\prime} \mathrm{S}, 54^{\circ} 06.37^{\prime} \mathrm{W}, 238-244 \mathrm{~m}$, Agassiz trawl, 8 Feb. 2013 (RBINS, INV. 122930A) [extraction K23; Genbank nr, COI: KU870857, 28S: KU759635]. 


\section{Paratypes}

RV Polarstern cruises:

SOUTHERN OCEAN: 1 q, cruise PS14, ANT-VII/4, EPOS leg 3, stn 211, Elephant Island, 60 59.8' S, $55^{\circ} 12.1^{\prime} \mathrm{W}$ to $60^{\circ} 59.3^{\prime} \mathrm{S}, 55^{\circ} 10.5^{\prime} \mathrm{W}, 207-213 \mathrm{~m}$, bottom trawl, 15 Jan. 1989, coll. C. De Broyer (RBINS, INV. 132950); 3 specs, cruise PS69, ANT-XXIII/8, stn 604-1, Elephant Island, 61 ${ }^{\circ} 20.52^{\prime}$ S, $55^{\circ} 09.72^{\prime} \mathrm{W}$ to $61^{\circ} 20.11^{\prime} \mathrm{S}, 55^{\circ} 07.26^{\prime} \mathrm{W}, 286-407 \mathrm{~m}$, bottom trawl, 19 Dec. 2006, coll. C. d'Udekem d'Acoz and H. Robert (RBINS, INV. 122467); 3 specs, cruise PS69, ANT-XXIII/8, stn 604-1, Elephant Island, $61^{\circ} 20.52^{\prime} \mathrm{S}, 55^{\circ} 09.72^{\prime} \mathrm{W}$ to $61^{\circ} 20.11^{\prime} \mathrm{S}, 55^{\circ} 07.26^{\prime} \mathrm{W}, 286-407 \mathrm{~m}$, bottom trawl, 19 Dec. 2006 , coll. C. d'Udekem d'Acoz and H. Robert (RBINS, INV. 122496); 2 specs, cruise PS69, ANT-XXIII/8, stn 604-1, Elephant Island, $61^{\circ} 20.52^{\prime} \mathrm{S}, 55^{\circ} 09.72^{\prime} \mathrm{W}$ to $61^{\circ} 20.11^{\prime} \mathrm{S}, 55^{\circ} 07.26^{\prime} \mathrm{W}, 286-407 \mathrm{~m}$, bottom trawl, 19 Dec. 2006, coll. C. d'Udekem d'Acoz and H. Robert (RBINS, INV. 122500); 1 juv., cruise PS69, ANT-XXIII/8, stn 604-1, Elephant Island, $61^{\circ} 20.52^{\prime} \mathrm{S}, 55^{\circ} 09.72^{\prime} \mathrm{W}$ to $61^{\circ} 20.11^{\prime} \mathrm{S}, 55^{\circ} 07.26^{\prime} \mathrm{W}$, 286-407 m, bottom trawl, 19 Dec. 2006, coll. C. d'Udekem d'Acoz and H. Robert (RBINS, INV. 122508); 1 spec., cruise PS69, ANT-XXIII/8, stn 605-1, Elephant Island, $61^{\circ} 20.35^{\prime} \mathrm{S}, 55^{\circ} 29.16^{\prime} \mathrm{W}$ to $61^{\circ} 19.98^{\prime} \mathrm{S}, 55^{\circ} 32.67^{\prime} \mathrm{W}, 146-151 \mathrm{~m}$, bottom trawl, 19 Dec. 2006, coll. C. d'Udekem d'Acoz and H. Robert (RBINS, INV. 122504); 1 juv., cruise PS69, ANT-XXIII/8, stn 605-1, Elephant Island, $61^{\circ} 20.35^{\prime} \mathrm{S}, 55^{\circ} 29.16^{\prime} \mathrm{W}$ to $61^{\circ} 19.98^{\prime} \mathrm{S}, 55^{\circ} 32.67^{\prime} \mathrm{W}, 146-151 \mathrm{~m}$, bottom trawl, 19 Dec. 2006 , coll. C. d'Udekem d'Acoz and H. Robert (RBINS, INV. 122506); 4 specs, cruise PS69, ANT-XXIII/8, stn 605-5, Elephant Island, $61^{\circ} 20.27^{\prime} \mathrm{S}, 55^{\circ} 30.92^{\prime} \mathrm{W}$ to $61^{\circ} 20.37^{\prime} \mathrm{S}, 55^{\circ} 28.99^{\prime} \mathrm{W}, 131-152 \mathrm{~m}$, Agassiz trawl, 20 Dec. 2006, coll. C. d'Udekem d'Acoz and H. Robert (RBINS, INV. 122501); 1 spec., cruise PS69, ANT-XXIII/8, stn 608-1, Elephant Island, $61^{\circ} 11.34^{\prime} \mathrm{S}, 54^{\circ} 43.17^{\prime} \mathrm{W}$ to $61^{\circ} 11.80^{\prime} \mathrm{S}, 54^{\circ} 40.05^{\prime} \mathrm{W}$, 284-293 m, bottom trawl, 20 Dec. 2006, coll. C. d'Udekem d'Acoz and H. Robert (RBINS, INV. 122515); 3 specs, cruise PS69, ANT-XXIII/8, stn 608-1, Elephant Island, $61^{\circ} 11.34^{\prime} \mathrm{S}, 54^{\circ} 43.17^{\prime} \mathrm{W}$ to $61^{\circ} 11.80^{\prime} \mathrm{S}, 54^{\circ} 40.05^{\prime} \mathrm{W}, 284-293 \mathrm{~m}$, bottom trawl, 20 Dec. 2006, coll. C. d'Udekem d'Acoz and H. Robert (RBINS, INV. 122498); 2 specs, cruise PS69, ANT-XXIII/8, stn 608-1, Elephant Island, $61^{\circ} 11.34^{\prime} \mathrm{S}, 54^{\circ} 43.17^{\prime} \mathrm{W}$ to $61^{\circ} 11.80^{\prime} \mathrm{S}, 54^{\circ} 40.05^{\prime} \mathrm{W}, 284-293 \mathrm{~m}$, bottom trawl, 20 Dec. 2006, coll. C. d'Udekem d'Acoz and H. Robert (MNHN-IU-2014-7334, removed from RBINS, INV. 122498); 1 spec., cruise PS69, ANT-XXIII/8, stn 611-1, Elephant Island, $60^{\circ} 58.90^{\prime} \mathrm{S}, 55^{\circ} 11.31^{\prime} \mathrm{W}$ to $60^{\circ} 58.52^{\prime} \mathrm{S}$, $55^{\circ} 07.82^{\prime} \mathrm{W}, 215-297 \mathrm{~m}$, bottom trawl, 21 Dec. 2006, coll. C. d'Udekem d'Acoz and H. Robert (RBINS, INV. 122558); 1 spec., initially fixed with formalin, cruise PS69, ANT-XXIII/8, stn 622-1, Elephant Island, $60^{\circ} 56.70^{\prime} \mathrm{S}, 55^{\circ} 52.71^{\prime} \mathrm{W}$ to $60^{\circ} 55.93^{\prime} \mathrm{S}, 55^{\circ} 50.79^{\prime} \mathrm{W}, 218-307 \mathrm{~m}$, Agassiz trawl, $23 \mathrm{Dec} .2006$, coll. C. d'Udekem d'Acoz and H. Robert (RBINS, INV. 122505); 7 specs, cruise PS69, ANT-XXIII/8, stn 654-6, Elephant Island, $61^{\circ} 22.80^{\prime} \mathrm{S}, 56^{\circ} 03.84^{\prime} \mathrm{W}$ to $61^{\circ} 23.35^{\prime} \mathrm{S}, 56^{\circ} 04.89^{\prime} \mathrm{W}, 341-342 \mathrm{~m}$, Agassiz trawl, 29 Dec. 2006, coll. C. d'Udekem d'Acoz and H. Robert (RBINS, INV. 122499); 1 spec., cruise PS69, ANT-XXIII/8, stn 668-1, north of King George Island, $61^{\circ} 49.32^{\prime} \mathrm{S}, 58^{\circ} 34.74^{\prime} \mathrm{W}$ to $61^{\circ} 50.05^{\prime} \mathrm{S}$, $58^{\circ} 30.67^{\prime} \mathrm{W}, 152-193 \mathrm{~m}$, bottom trawl, 31 Dec. 2006, coll. C. d'Udekem d'Acoz and H. Robert (RBINS, INV. 122503); 1 spec., cruise PS69, ANT-XXIII/8, stn; 688-1, north of Joinville Island, $62^{\circ} 32.27^{\prime}$ S, $54^{\circ} 57.55^{\prime} \mathrm{W}$ to $62^{\circ} 33.59^{\prime} \mathrm{S}, 55^{\circ} 0.22^{\prime} \mathrm{W}$, bottom trawl, 4 Jan. 2007 , coll. C. d'Udekem d'Acoz and H. Robert (RBINS, INV. 122495); 1 very large spec., cruise PS69, ANT-XXIII/8, stn 692-1, north of Joinville Island, $62^{\circ} 21.76^{\prime} \mathrm{S}, 55^{\circ} 36.96^{\prime} \mathrm{W}$ to $62^{\circ} 23.62^{\prime} \mathrm{S}, 55^{\circ} 36.42^{\prime} \mathrm{W}, 263-277 \mathrm{~m}$, bottom trawl, $5 \mathrm{Jan}$. 2007, coll. C. d'Udekem d'Acoz and H. Robert (RBINS, INV. 122497); 1 juv., cruise PS69, ANTXXIII/8, stn 726-4, southwest of Snow Hill Island, $64^{\circ} 37.83^{\prime} \mathrm{S}, 56^{\circ} 42.10^{\prime} \mathrm{W}$ to $64^{\circ} 38.03^{\prime} \mathrm{S}, 56^{\circ} 42.57^{\prime} \mathrm{W}$, 292 m, Agassiz trawl, 23 Jan. 2007, coll. C. d'Udekem d'Acoz and H. Robert (RBINS, INV. 122507); 2 우우, cruise PS81, ANT-XXIX/3, stn 116-9, north of Joinville Island, $62^{\circ} 33.79^{\prime} \mathrm{S}, 56^{\circ} 27.81^{\prime} \mathrm{W}$ to $62^{\circ} 33.71^{\prime} \mathrm{S}, 56^{\circ} 28.31^{\prime} \mathrm{W}, 248 \mathrm{~m}$, muddy bottom with stones, Pentapora-like bryozoans and a lot of life, Agassiz trawl, 26 Jan. 2013 (RBINS, INV. 122920) [extractions K27 (largest specimen); Genbank nr, COI: KU870861, 28S: KU759639 and K28 (smallest specimen), Genbank nr, COI: KU870862, 28S: KU759640]; 1 juv., cruise PS81, ANT-XXIX/3, stn 160-3, East of Joinville Island, 63 $10.57^{\prime} \mathrm{S}$, $54^{\circ} 6.66^{\prime} \mathrm{W}$ to $63^{\circ} 10.71^{\prime} \mathrm{S}, 54^{\circ} 6.37^{\prime} \mathrm{W}, 238-244 \mathrm{~m}$, Agassiz trawl, 8 Feb. 2013 (RBINS, INV. 122930B); 1 o, cruise PS81, ANT-XXIX/3, stn 160-3, East of Joinville Island, $63^{\circ} 10.57^{\prime} \mathrm{S}, 54^{\circ} 6.66^{\prime} \mathrm{W}$ to 


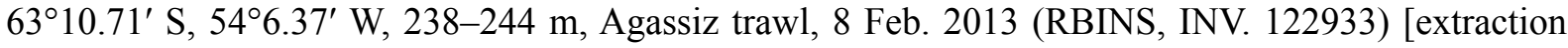
K24; Genbank nr, COI: KU870858, 28S: KU759636]; 1 immature spec., cruise PS81, ANT-XXIX/3, stn 162-7, east of James Ross Island, $63^{\circ} 58.78^{\prime} \mathrm{S}, 56^{\circ} 46.24^{\prime} \mathrm{W}$ to $63^{\circ} 59.02^{\prime} \mathrm{S}, 56^{\circ} 46.26^{\prime} \mathrm{W}, 214-216 \mathrm{~m}$, muddy bottom with a lot of life, Agassiz trawl, 10 Feb. 2013, coll. C. d'Udekem d'Acoz and M. Verheye (RBINS, INV. 122952); 1 very large spec., cruise PS81, ANT-XXIX/3, stn 162-7, east of James Ross Island, $63^{\circ} 58.78^{\prime} \mathrm{S}, 56^{\circ} 46.24^{\prime} \mathrm{W}$ to $63^{\circ} 59.02^{\prime} \mathrm{S}, 56^{\circ} 46.26^{\prime} \mathrm{W}, 214-216 \mathrm{~m}$, muddy bottom with a lot of life, Agassiz trawl, 10 Feb. 2013, coll. C. d'Udekem d'Acoz and M. Verheye (RBINS, INV. 122952); 1 very large spec., cruise PS81, ANT-XXIX/3, stn 164-4, south of Dundee Island, $63^{\circ} 37.28^{\prime} \mathrm{S}, 56^{\circ} 9.11^{\prime} \mathrm{W}$ to $63^{\circ} 37.29^{\prime} \mathrm{S}, 56^{\circ} 9.58^{\prime} \mathrm{W}, 102-114 \mathrm{~m}$, non-muddy bottom with a lot of life, including Molgula, big red ophiuroids, and a lot of Glyptonotus, 11 Feb. 2013, coll. C. d'Udekem d'Acoz and M. Verheye (RBINS, INV. 122923) [extraction K29; Genbank nr, COI: KU870863, 28S: KU759641]; 1 very large ${ }^{\circ}$, cruise PS81, ANT-XXIX/3, stn 164-4, south of Dundee Island, $63^{\circ} 37.28^{\prime} \mathrm{S}, 56^{\circ} 9.11^{\prime} \mathrm{W}$ to $63^{\circ} 37.29^{\prime} \mathrm{S}, 56^{\circ} 9.58^{\prime}$ W, 102-114 m, non-muddy bottom with a lot of life, including Molgula, big red ophiuroids, and a lot of Glyptonotus, Agassiz trawl, 11 Feb. 2013, coll. C. d'Udekem d'Acoz and M. Verheye (RBINS, INV. 122925) [extraction K30; Genbank nr, COI: KU870864, 28S: KU759643]; 1 q, cruise PS81, ANTXXIX/3, stn 185-3, south east of Dundee Island, $63^{\circ} 51.34^{\prime} \mathrm{S}, 55^{\circ} 41.11^{\prime} \mathrm{W}$ to $63^{\circ} 51.52^{\prime} \mathrm{S}, 55^{\circ} 41.43^{\prime} \mathrm{W}$, Agassiz trawl, 238-244 m, not muddy bottom with a lot of life (sponges, starfishes, ophiuroids, crinoids, Pentapora-like bryozoans), Agassiz trawl, 19 Feb. 2013, coll. C. d'Udekem d'Acoz and M. Verheye (RBINS, INV. 122921A) [extraction K26; Genbank, COI nr: KU870860, 28S: KU759638] [the station given by Verheye et al. (2016a) is incorrect]; 1 adult $q$, cruise PS81, ANT-XXIX/3, stn 185-3, south east of Dundee Island, $63^{\circ} 51.34^{\prime} \mathrm{S}, 55^{\circ} 41.11^{\prime} \mathrm{W}$ to $63^{\circ} 51.52^{\prime} \mathrm{S}, 55^{\circ} 41.43^{\prime} \mathrm{W}$, Agassiz trawl, 238-244 m, not muddy bottom with a lot of life (sponges, starfishes, ophiuroids, crinoids, Pentapora-like bryozoans), Agassiz trawl, 19 Feb. 2013, coll. C. d'Udekem d'Acoz and M. Verheye, dissected and photographed (RBINS, INV. 122921B) [extraction P35; Genbank nr, COI: KU870893, 28S: KU759679]; 2 immature spec., cruise PS81, ANT-XXIX/3, stn 185-3, south east of Dundee Island, $63^{\circ} 51.34^{\prime} \mathrm{S}, 55^{\circ} 41.11^{\prime} \mathrm{W}$ to $63^{\circ} 51.52^{\prime} \mathrm{S}, 55^{\circ} 41.43^{\prime} \mathrm{W}$, Agassiz trawl, 238-244 m, not muddy bottom with a lot of life (sponges, starfishes, ophiuroids, crinoids, Pentapora-like bryozoans), Agassiz trawl, 19 Feb. 2013, coll. C. d'Udekem d'Acoz and M. Verheye (RBINS, INV. 122921C) [extraction P37; Genbank nr, COI: KU870894, 28S: KU759681]; 1 spec., cruise PS81, ANT-XXI/3, stn 185-4, south east of Dundee Island, $63^{\circ} 51.53^{\prime} \mathrm{S}, 55^{\circ} 40.74^{\prime} \mathrm{W}$ to $63^{\circ} 51.53^{\prime} \mathrm{S}, 55^{\circ} 40.43^{\prime} \mathrm{W}, 253-255 \mathrm{~m}$, extremely fine sand mixed with some mud and gravel, Rauschert dredge, 19 Feb. 2013 coll. C. d'Udekem d'Acoz and M. Verheye (RBINS, INV. 132971) [extraction I20; Genbank nr, COI: KU870846, 28S: KU759623]; 1 \&, cruise PS81, ANT-XXIX/3, stn 197-5, Bransfield Strait, $62^{\circ} 44.73^{\prime} \mathrm{S}, 57^{\circ} 26.79^{\prime} \mathrm{W}$ to $62^{\circ} 45.05^{\prime} \mathrm{S}, 57^{\circ} 26.68^{\prime} \mathrm{W}$, 258-273 m, Agassiz trawl, 25 Feb. 2013, coll. C. d'Udekem d'Acoz and M. Verheye (RBINS, INV. 122867) [extraction ANT41; Genbank nr, COI: KU870827, 28S: KU759600]; 1 9, cruise PS81, ANTXXIX/3, stn 197-6, Bransfield Strait, $62^{\circ} 45.05^{\prime} \mathrm{S}, 57^{\circ} 26.68^{\prime} \mathrm{W}$ to $62^{\circ} 45.09^{\prime} \mathrm{S}, 57^{\circ} 26.47^{\prime} \mathrm{W}, 210-222$ $\mathrm{m}$, black gravel mixed with sand and a little bit of mud, Rauschert dredge, 25 Feb. 2013, coll. C. d'Udekem d'Acoz and M. Verheye (RBINS, INV. 122954); 1 juv., cruise PS81, ANT-XXIX/3, stn 197-6, Bransfield Strait, $62^{\circ} 45.05^{\prime} \mathrm{S}, 57^{\circ} 26.68^{\prime} \mathrm{W}$ to $62^{\circ} 45.09^{\prime} \mathrm{S}, 57^{\circ} 26.47^{\prime} \mathrm{W}, 210-222 \mathrm{~m}$, black gravel mixed with sand and a little bit of mud, Rauschert dredge, 25 Feb. 2013, coll. C. d'Udekem d'Acoz and M. Verheye (RBINS, INV. 122954); 1 spec., cruise PS81, ANT-XXIX/3, stn 205-1, Bransfield Strait, $63^{\circ} 2.35^{\prime}$ S, $58^{\circ} 3.63^{\prime} \mathrm{W}$ to $63^{\circ} 2.67^{\prime} \mathrm{S}, 58^{\circ} 6.46^{\prime} \mathrm{W}$, depth unrecorded [Google Earth coordinates for these positions: 155-178 m (accessed 27 Sep. 2016], rectangular midwater trawl (which presumably hit the sea floor, as it was supposed to sample between 0 and $200 \mathrm{~m}$ depth), 28 Feb. 2013, coll. C. d'Udekem d'Acoz and M. Verheye (RBINS, INV. 122970); 1 , cruise PS81, ANT-XXIX/3, stn 224-3, Bransfield Strait, $63^{\circ} 0.53^{\prime} \mathrm{S}, 58^{\circ} 35.67^{\prime} \mathrm{W}$ to $63^{\circ} 0.58^{\prime} \mathrm{S}, 58^{\circ} 36.11^{\prime} \mathrm{W}, 257-261 \mathrm{~m}$, mud, Agassiz trawl, 4 Mar. 2013, coll. C. d'Udekem d'Acoz and M. Verheye (RBINS, INV. 122924) [extraction K22; Genbank nr, COI: KU870856, 28S: KU759634]; 1 very large + , cruise PS81, ANT-XXIX/3, stn 224-3, Bransfield Strait, $63^{\circ} 0.53^{\prime} \mathrm{S}, 58^{\circ} 35.67^{\prime} \mathrm{W}$ to $63^{\circ} 0.58^{\prime} \mathrm{S}, 58^{\circ} 36.11^{\prime} \mathrm{W}, 257-261 \mathrm{~m}$, mud, Agassiz trawl, 4 Mar. 2013, red colour, coll. C. d'Udekem d'Acoz and M. Verheye (RBINS, INV. 122926) [extraction K21; Genbank nr, 
COI: KU870855, 28S: KU759633]; 1 क, cruise PS81, ANT-XXIX/3, stn 224-3, Bransfield Strait, $63^{\circ} 0.53^{\prime} \mathrm{S}, 58^{\circ} 35.67^{\prime} \mathrm{W}$ to $63^{\circ} 0.58^{\prime} \mathrm{S}, 58^{\circ} 36.11^{\prime} \mathrm{W}, 257-261 \mathrm{~m}$, mud, Agassiz trawl, 4 Mar. 2013, coll. C. d'Udekem d'Acoz and M. Verheye (RBINS, INV. 122953); 3 large specs, cruise PS81, ANT-XXIX/3, stn 224-3, Bransfield Strait, $63^{\circ} 0.53^{\prime} \mathrm{S}, 58^{\circ} 35.67^{\prime} \mathrm{W}$ to $63^{\circ} 0.58^{\prime} \mathrm{S}, 58^{\circ} 36.11^{\prime} \mathrm{W}, 257-261 \mathrm{~m}$, mud, Agassiz trawl, 4 Mar. 2013, coll. C. d'Udekem d'Acoz and M. Verheye (RBINS, INV. 122957); 1 \%, cruise PS81, ANT-XXIX/3, stn 234-5, north of Livingstone Island, $62^{\circ} 17.36^{\prime} \mathrm{S}, 61^{\circ} 12.06^{\prime} \mathrm{W}$ to $62^{\circ} 17.31^{\prime}$ $\mathrm{S}, 61^{\circ} 12.63^{\prime} \mathrm{W}, 248-251 \mathrm{~m}$, mud with a lot of specimens of a small reddish ophiuroid with very long and flexible legs, Agassiz trawl, 7 Mar. 2013, coll. C. d'Udekem d'Acoz and M. Verheye (RBINS, INV. 132970) [extraction I14; Genbank nr, COI: KU870840, 28S: KU759616].

\section{Description}

Rostrum. Medium-sized, overreaching tip of article 1 of peduncle of antenna 1, anteriorly slightly curved, ventrally straight, blunt-tipped in lateral view; broad and with proximally nearly straight converging borders in frontal view.

EYE. Fairly large, broadly elliptic.

Pereion-Pleosome tooth pattern. Pereionite 1 smooth; pereionites 2-3 with weak posterior bump; pereionites 4 to pleonite 3 with low, non-toothed, very broad carina (very reduced in pereionites $2-3$ ), those of pereionite 7 and pleonites $1-3$ with very shallow concavity on anterior 0.4 ; posterodorsal angle of pleonite 3 broadly rounded; dorsolateral ornamentation absent.

COXAE $1-3$. Scarcely carinate and apically tapering and blunt (coxae $1-2$ ) or subacute (coxa 3 ).

Coxa 4. Anterodorsal border nearly straight (very weakly sigmoid), anteroventral border weakly concave, these two borders being joined by blunt but very distinct angle (anterior corner), which is distinctly projecting forward; ventral corner forming a sharp squared angle (ventral projection short); lateral carina present not sharp; broad hollow surface between carina and posteroventral border of coxa; posteroventral border distinctly concave.

Coxa 5. Broad, with surface smooth, with posteroventral corner forming a rounded lobe, weakly expanded laterally, forming a broadly rounded obtuse (nearly squared) angle which is very distinct in dorsal view.

CoxA 6. With posteroventral corner rounded, with projection arising from its surface (broadly triangular in dorsal view).

Coxa 7. Posteriorly rounded.

Epimeral PLATES 1-3. Posteroventral angle: forming an angle with a trace of tooth in plate 1, produced into a small tooth in plate 2 and into a medium-sized tooth in plate 3.

UROSOME TOOTH PATTERN. Urosomite 1 with very low dorsal process, regularly convex on both sides; urosomite 3 with dorsolateral borders nearly straight (inconspicuously convex), with tip bluntly angular.

TELSON. Cleft on 0.4 ; lobes broad becoming apically broadly and bluntly triangular, notch narrowly V-shaped.

GNATHOPODS 1-2. Carpus and propodus very broad; propodus expanding distally, palm distinct. 
Pereiopods 5-7. Merus, carpus and propodus of medium width; dactylus medium-sized; basis of pereiopods 5-6 of normal width, with posteroproximal process present, tooth-like, parallel to axis of basis, with posterodistal corner bluntly angular, very weakly pointing in posterior direction; basis of pereiopod 7 broad with posterior border weakly convex, with distinct notch in distal 0.8 , forming a blunt-tipped squared or acute angle, with posterodistal corner rounded and not projecting backwards.

\section{Colour pattern}

Red-coloured with the red pigmentation forming an irregular, finely mottled/dotted pattern; or whitish with very irregular and diffuse red patches, in which the red pigmentation is forming an irregular finely peppered pattern. Eyes reddish.

\section{Body length}

Up to $50 \mathrm{~mm}$.

\section{Distribution}

Elephant Island to tip of Antarctic Peninsula, 131-407 m.

\section{Biology}

Examination of the stomach content of fifteen specimens indicates that the species is carnivorous (Coleman 1991, as Epimeria georgiana).

\section{Remarks}

A juvenile E. quasimodo sp. nov. is illustrated herein (Fig. 207) to show the notch of the basis of pereiopod 7, which is much shallower than in adults. Epimeria quasimodo sp. nov. is a very common species, which was previously confused with E. georgiana. The latter is presumably endemic to South Georgia.

Epimeria (Hoplepimeria) rimicarinata subgen. nov. Watling \& Holman, 1980 Fig. 208

Epimeria rimicarinata Watling \& Holman, 1980: 642, figs 22-23.

Epimeria rimicarinata - De Broyer \& Klages 1991: 165 (key). — Wakabara \& Serejo 1999: 642 (key). - Coleman 2007: 51, fig. 27a-c, colour plate 2e, map 13 (circle). — Lörz \& Coleman 2009: unnumbered photograph on p. 17.

'Clade E georgiana-rimicarinata-rubriequies [sic] complex - RI' - Verheye et al. 2016a, supplement: 4 (online).

\section{Material examined}

RV Marion Dufresne cruises:

SOUTHERN OCEAN: 1 spec., specimen used for illustrations, cruise MD42 (SIBEX), stn 22-CP66, Prydz Bay, 66 55'45" S, 7404'11" E, depth not given [Google Earth depth for that position: $427 \mathrm{~m}$ (accessed 27 Sep. 2016)], 26 Jan. 1985 (MNHN-IU-2014-4265) [extraction M24; Genbank nr, COI: KU870887]; 1 spec., previously identified as Epimeria grandirostris, cruise MD42 (SIBEX), stn 22CP73, Prydz Bay, 66 57'25" S, 7241'24' E, depth not given [Google Earth depth for that position: $540 \mathrm{~m}$ (accessed 27 Sep. 2016)], 26 Jan. 1985 (MNHN-IU-2014-4256). 


\section{Diagnosis}

Morphology unique in the genus Epimeria. Pereionite 2 with small but broad posterodorsal tooth; pereionite 3 to pleonite 3 laterally sculptured, with tridimentionally sculptured and medially notched mid-dorsal tooth. Posteroventral border of coxa 4 very concave, surface just in front of this border forming a very deep groove.

\section{Colour pattern}

Red with on each side a broad white longitudinal stripe running along the upper part of the coxae (Coleman 2007: plate 2 fig. e) or blood red with white patches (Lörz \& Coleman 2009: unnumbered photograph p. 17).

\section{Distribution}

Western Ross Sea, 337-474 m (Watling \& Holman 1980); Prydz Bay, 427-540 m (present material).

Epimeria (Hoplepimeria) robusta subgen. nov. K.H. Barnard, 1930

Figs 209-211

Epimeria robusta K.H. Barnard, 1930: 375, figs 40a, 41.

Epimeria inermis - Walker 1907: 23, pl. 8 fig. 13.

Epimeria robusta - Gurjanova 1955: 198. - J.L. Barnard 1961: 103 (key). — McCain 1971: 161. — De Broyer \& Klages 1991: 164 (key, in part). — Coleman 1994: 560, in part, fig. 5C only.; 1998b: 223 (in part) — Wakabara \& Serejo 1999: 643 (key). — Lörz et al. 2009: 16, figs 6-9. — Lörz \& Coleman 2009: 17, unnumbered photograph.

'Clade G robusta-robustoides complex - R03' - Verheye et al. 2016a, supplement: 4 (online).

non Epimeria inermis Walker, 1903: 54, pl. 10 fig. 69.

non Epimeria robusta - Klages \& Gutt 1990: 73, fig. 1A, 4A-D (=Epimeria (Hoplepimeria) robustoides subgen. nov. Lörz \& Coleman in Lörz et al., 2009).

\section{Material examined}

RV Seatruck cruises:

SOUTHERN OCEAN: 1 q, cruise REVOLTA I, stn REVO-043, Collect_ID: 436, Adélie Coast, $66^{\circ} 38^{\prime} 28^{\prime \prime} \mathrm{S}, 140^{\circ} 01^{\prime} 50^{\prime \prime} \mathrm{E}, 85-86 \mathrm{~m}, 26$ Jan. 2010, coll. M. Eléaume, L. Hemery and A. D’Hont (MNHN-IU-2009-2571) [extraction K1; Genbank nr, COI: KU870854, 28S: KU759631].

\section{Description}

Rostrum. Medium-sized, nearly reaching tip of article 1 of peduncle of antenna 1, anteriorly straight, ventrally straight, narrow and subacute in lateral view; of medium width and with weakly curved converging borders in frontal view.

EYE. Very large, narrowly elliptic.

Pereion-Pleosome tooth pattern. Pereionites 1-7 smooth; pereionite 7 dorsally scarcely carinate; pleonite 1 with weak, straight mid-dorsal carina; pleonite 2 with weak straight mid-dorsal carina, posteriorly simply angulate but not forming a tooth; pleonite 3 dorsally weakly carinate with median extremely low (inconspicuous) rounded lobe, followed by inconspicuous concavity, terminated by a narrow but blunt-tipped tooth directed upwards.

COXAE $1-3$. Not carinate, apically blunt. 
Coxa 4. Anterodorsal border very weakly sigmoid, anteroventral border straight, these two borders being joined by very broad, blunt but very distinct squared angle (anterior corner), which is slightly projecting forward; ventral corner forming an obtuse sharp angle (ventral projection short and fairly broad); lateral carina absent; posteroventral border straight.

CoxA 5. Broad, with surface smooth, with posterior border straight, with posteroventral corner forming a very blunt tooth (shape: acute triangle) projecting backwards and not laterally (no tooth or corner visible in dorsal view).

CoxA 6. With posterior border straight, with posteroventral corner forming a blunt tooth (shape: narrow acute triangle) projecting backwards and not laterally (no tooth or corner visible in dorsal view).

Coxa 7. Posteriorly very weakly rounded.

Epimeral Plates 1-3. Posteroventral angle: angulate in plate 1, produced into a medium-sized tooth in plates $2-3$.

Urosome tooth PATTERn. Urosomite 1 with well developed blunt-tipped process of which the anterior border is distinctly concave and the posterior border is nearly straight; urosomite 3 with dorsolateral borders distinctly concave and posteriorly produced into a sharp triangular tooth.

Telson. Cleft on 0.15 ; tips of lobes triangular and blunt, notch very broadly V-shaped and blunt at its deepest point.

GNATHOPODS 1-2. Carpus and propodus very broad; propodus expanding distally, palm distinct.

PeREIOPODS 5-7. Merus, carpus and propodus fairly broad; dactylus small, normally curved, with unguis normally developed; basis of pereiopods 5-6 broad, with posteroproximal process present, swordlike, projecting obliquely, with posterodistal corner produced into a subacute to sharp triangular tooth projecting obliquely backwards; basis of pereiopod 7 broad; posterior border with proximal 0.4 weakly rounded, with distal 0.6 deeply concave, with posterodistal corner forming a sharp triangular tooth projecting obliquely backwards.

\section{Colour pattern}

Body and coxae either yellowish, sometimes with two pairs of small yellowish spots transversally ordered on some body segments or alternatively pale yellowish with a few tiny dark dots; pereiopods and mouthparts often tinged with pink; eyes red (Lörz et al. 2009: 111, fig. 10 B-D).

\section{Body length}

Up to $43 \mathrm{~mm}$.

\section{Distribution}

Adélie Coast to western Ross Sea, 85-814 m (Lörz et al. 2009; present material).

\section{Biology}

K.H. Barnard (1930) found epicaridean isopods in the marsupium of E. robusta.

\section{Remarks}

Epimeria robusta s. str. is known from Adélie Coast and the western Ross Sea. Records from the Weddell Sea and the Scotia Region are based on its close relatives E. robustoides and E. gargantua sp. nov. 
Epimeria robusta can be easily distinguished from its relatives by the dentition of its pleosome (see key of Hoplepimeria subgen. nov. species).

Epimeria (Hoplepimeria) robustoides subgen. nov. Lörz \& Coleman in Lörz et al., 2009 Figs 212-219

Epimeria robustoides Lörz \& Coleman in Lörz et al., 2009: 10, figs 2-5, possibly fig. 10A [it might also be E. gargantua sp. nov.].

Epimeria robusta - Coleman 1994: 560, in part, figs 5A-B, 5E-G, 6-8 (not figs 5C-D). - Klages \& Gutt 1990: 73, fig. 1A, 4A-D.

'Epimeria robustoides 2' - Rauschert \& Arntz 2015: 62, pl. 55, unnumbered photograph.

'Clade G robusta/robustoides complex - R02' - Verheye et al. 2016a, supplement: 4 (online).

non 'Epimeria robustoides 1'- Rauschert \& Arntz 2015: 62, pl. 55, unnumbered photograph (= Epimeria (Hoplepimeria) sp.).

\section{Material examined}

RV Polarstern cruises:

SOUTHERN OCEAN: 3 specs, dorsally opened for gut content analysis, cruise PS14, ANT-VII/4, EPOS 3, stn 290 (AGT 24), $71^{\circ} 05.9^{\prime} \mathrm{S}, 12^{\circ} 34.0^{\prime} \mathrm{W}$ to $71^{\circ} 06.5^{\prime} \mathrm{S}, 12^{\circ} 42.3^{\prime} \mathrm{W}, 522-531 \mathrm{~m}, 19$ Feb. 1989 , coll. C. De Broyer (RBINS, INV. 132944); 1 q, cruise PS69, ANT-XXIII/8, stn 603-5, eastern Weddell Sea, $70^{\circ} 30.99^{\prime} \mathrm{S}, 08^{\circ} 48.08^{\prime} \mathrm{W}$ to $70^{\circ} 30.40^{\prime} \mathrm{S}, 08^{\circ} 48.13^{\prime} \mathrm{W}, 274-297 \mathrm{~m}$, sponge bottom, Agassiz trawl, 7 Dec. 2006, coll. C. d'Udekem d'Acoz and H. Robert (RBINS, INV. 132985); 1 juv., cruise PS71, ANTXXIV/2, ANDEEP-SYSTCO, stn 48-1, eastern Weddell Sea, $70^{\circ} 23.94^{\prime} \mathrm{S}, 8^{\circ} 19.14^{\prime} \mathrm{W}$ to $70^{\circ} 23.8^{\prime} 9^{\prime} \mathrm{S}$, $8^{\circ} 18.67^{\prime} \mathrm{W}, 595-602 \mathrm{~m}$, bryozoan bottom (exceptional bryozoan diversity), Rauschert dredge, $12 \mathrm{Jan}$. 2008:, coll. H. Robert (RBINS, INV. 132969) [extraction I8; Genbank nr, COI: KU870852, 28S: KU759629]; 1 + , cruise PS77, ANT-XXVII/3, CAMBIO, stn 265-2, eastern Weddell Sea, 70 47.34' S, $10^{\circ} 40.39^{\prime} \mathrm{W}$ to $70^{\circ} 47.13^{\prime} \mathrm{S}, 10^{\circ} 40.54^{\prime} \mathrm{W}, 500-600 \mathrm{~m}, 22 \mathrm{Mar}$. 2011, coll. C. Havermans and H. Robert (RBINS, INV. 122894) [extraction Ex114; Genbank nr, COI: KU870834, 28S: KU759608].

\section{Description}

Rostrum. Medium-sized, nearly reaching tip of article 1 of peduncle of antenna 1, anteriorly straight, ventrally straight, narrow and subacute in lateral view; of medium width and with straight converging borders in frontal view.

EYE. Very large, narrowly elliptic.

Pereion-Pleosome tooth Pattern. Pereionites 1-6 smooth; pereionite 7 with weak posterior bump; pleonite 1 dorsally distinctly carinate, straight, with distinct posterior bump or small very blunt tooth; pleonite 2 dorsally distinctly carinate, with very low proximal rounded lobe followed by weak concavity, posteriorly produced into a bluntly triangular tooth projecting obliquely upwards; pleonite 3 dorsally distinctly carinate with median very low rounded lobe, followed by distinct concavity, terminated by a blunt tooth directed upwards.

COXAE 1-3. Not carinate, apically subacute.

Coxa 4. Anterodorsal border very weakly sigmoid, anteroventral border nearly straight (extremely weakly convex), these two borders being joined by very broad blunt, very distinct squared angle (anterior corner), which is slightly projecting forward; ventral corner forming an obtuse sharp angle (ventral projection short and fairly broad); lateral carina absent; posteroventral border straight. 
Coxa 5. Broad, with surface smooth, with posterior border straight, with posteroventral corner forming a very blunt tooth (shape: acute triangle) projecting backwards and not laterally (no tooth or corner visible in dorsal view).

Coxa 6. With posterior border straight, with posteroventral corner forming a blunt tooth (shape: narrow acute triangle) projecting backwards and not laterally (no tooth or corner visible in dorsal view).

Coxa 7. Posteriorly very weakly rounded.

EPIMERAL Plates 1-3. Posteroventral angle: angulate with tiny tooth in plate 1, produced into a mediumsized tooth in plates $2-3$.

UROSOME TOOTH PATTERN. Urosomite 1 with well developed blunt-tipped process of which the anterior border is distinctly concave and the posterior border is straight; urosomite 3 with dorsolateral borders strongly concave and posteriorly produced into a sharp triangular tooth.

Telson. Cleft on 0.25 ; tips of lobes triangular and blunt, notch very broadly V-shaped and subacute at its deepest point.

GnATHOPODs 1-2. Carpus and propodus very broad; propodus expanding distally, palm distinct.

PeREIOPODS 5-7. Merus, carpus and propodus fairly broad; dactylus small, normally curved, with unguis normally developed; basis of pereiopods 5-6 broad, with posteroproximal process present, swordlike, projecting obliquely, with posterodistal corner produced into a rounded lobe projecting obliquely backwards (pereiopod 5) or a blunt triangular tooth projecting obliquely backwards (pereiopod 6); basis of pereiopod 7 broad; posterior border with proximal 0.4 with weak concavity, with distal 0.6 deeply concave, with posterodistal corner forming a blunt triangular tooth projecting obliquely backwards.

\section{Colour pattern}

Body and coxae either pure white, or white with two pairs of small yellow spots transversally ordered on some body segments; gnathopods and oral field deep purple; antennae yellowish; pereiopods 3-4 pink; pereiopods 5-7 with basis white and distal articles pale yellowish to orange; tailfan white or whitish; eye red.

\section{Body length}

Up to $40 \mathrm{~mm}$.

\section{Distribution}

Eastern shelf of the Weddell Sea, 274-605 m (Lörz et al. 2009; present data).

\section{Biology}

According to Klages \& Gutt (1990), the digestive tract of specimens identified as E. robusta (but presumably belonging to E. robustoides as they were collected in the eastern Weddell Sea) contained mainly (42\%) miscellaneous organic matter. Only in some specimens were siliceous sigma and other types of microspiculae of Demospongiae and calcareous spiculae of Calcispongiae found among sediment particles and organic material. In all the E. robusta stomachs examined by them, some $10 \%$ of the contents consisted of tentacles and body wall sclerites of holothurians. The tentacle sclerites of Abyssocucumis cf. liouvillei [i.e. Staurocucumis cf. liouvillei (Vaney, 1914)] (Holothuroidea: Dendrochirotida) in one single specimen were identified. On the other hand, Dauby et al. (2001a) recorded a wider range of organisms in the digestive tract of the species (also specimens from the Eastern Weddell Sea identified 
as E. robusta): ophiuroids, plankton remains, sponges, cnidarians, polychaetes and crustaceans. Dauby et al. (2001b) concluded that E. robustoides would be an opportunistic predator. Klages (1991, as Epimeria robusta) indicates that the species is sometimes parasitized by cryptoniscin isopods. Klages (1991, as E. robusta) also observed that hatchlings of E. robustoides climb on the back of their mother and remain there for a short period of time.

\section{Remarks}

Epimeria robustoides is extremely similar to E. gargantua sp. nov., but the two species appear to have allopatric distributions. Epimeria robustoides has been recorded from the eastern shelf of the Weddell Sea, whilst E. gargantua sp. nov. has been found around the tip of the Antarctic Peninsula. Rauschert \& Arntz (2015) do not indicate the coordinates of their illustrated 'Epimeria robustoides', but the origin of the specimens was listed in an early draft of their book made available to the authors. The specimen 2 of Rauschert \& Arntz (2015) was collected during the Polarstern cruise ANT-XIII/3 (EASIZ 1), which sampled on the eastern shelf of the Weddell Sea; hence it is presumably E. robustoides. The specimen 1 of Rauschert \& Arntz (2015) was collected on the Bruce Ridge (a small isolated shallow bank situated midway between the South Orkney Islands and the South Sandwich Islands) and presumably belongs to an undescribed species, which is referred herein as Epimeria (Hoplepimeria) sp. subgen. nov.

Epimeria (Hoplepimeria) rubrieques subgen. nov. De Broyer \& Klages, 1991

Figs 220-221

Epimeria rubrieques De Broyer \& Klages, 1991: 159-166, figs 1-5.

Epimeria rubrieques - Klages 1991: 95-96, unnumbered figs. - Wakabara \& Serejo 1999: 641 (key). - Chapelle 2002: 20, unnumbered photograph. - Barnes 2007: 5, plate 5, unnumbered photograph. - Lörz 2003: 85, 86, fig. 3. - Coleman 2007: 53, fig. 29a-b, colour plate 2a, map 7 (circle). — Lörz \& Coleman 2009: unnumbered photograph on p. 17. — De Broyer \& Jażdżewska 2014: 155, photo 1. - Rauschert \& Arntz 2015: 62, pl. 55, unnumbered photographs.

Epimeria sp. 1 (nov.) - Klages 1988: 73, unnumbered fig.

Epimeria sp. nov. - Klages 1988: 75, 77, figs 15a-b.

'Clade E georgiana-rimicarinata-rubriequies [sic] complex - RU' - Verheye et al. 2016a, supplement: 4 (online).

\section{Material examined}

RV Polarstern cruises:

SOUTHERN OCEAN: 3 specs, in 3 different tubes, cruise PS10, ANT-V/3, station missing, eastern Weddell Sea, fixed on board [presumably after aquarium observations] on 20 Nov. 1986, coll. C. De Broyer (RBINS, INV. 132732); 1 spec., cruise PS39, ANT-XIII/3, EASIZ I, stn 17, GSN 10, eastern Weddell Sea, $73^{\circ} 18.00^{\prime} \mathrm{S}, 21^{\circ} 09.90^{\prime} \mathrm{W}$ to $73^{\circ} 19.10^{\prime} \mathrm{S}, 21^{\circ} 14.90^{\prime} \mathrm{W}, 465-468 \mathrm{~m}$, bottom trawl, specimen kept on board in aquarium, 16 Feb. 1996, coll. C. De Broyer and G. Chapelle (RBINS, INV. 132680); 1 spec., cruise PS48, ANT-XV/3, EASIZ II, stn 206, eastern Weddell Sea, $71^{\circ} 00.4^{\prime} \mathrm{S}, 11^{\circ} 42.6^{\prime} \mathrm{W}$ to $71^{\circ} 00.7^{\prime} \mathrm{S}$,

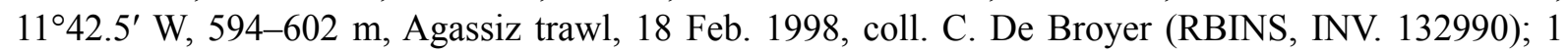
spec., cruise PS71, ANT-XXIV/2, ANDEEP-SYSTCO, stn 48-1, eastern Weddell Sea, 70²3.94' S, $8^{\circ} 19.14^{\prime} \mathrm{W}$ to $70^{\circ} 23.89^{\prime} \mathrm{S}, 8^{\circ} 18.67^{\prime} \mathrm{W}, 595-602 \mathrm{~m}$, bryozoan bottom (exceptional bryozoan diversity), Rauschert dredge, 12 Jan. 2008, coll. H. Robert (RBINS, INV. 132943) [extraction K41; Genbank nr, COI: KU870874, 28S: KU759654]; 1 spec., fixed in formalin, cruise PS71, ANT-XXIV/2, ANDEEPSYSTCO, stn 48-1, eastern Weddell Sea, $70^{\circ} 23.94^{\prime} \mathrm{S}, 8^{\circ} 19.14^{\prime} \mathrm{W}$, to $70^{\circ} 23.89^{\prime} \mathrm{S}, 8^{\circ} 18.67^{\prime} \mathrm{W}, 595-602 \mathrm{~m}$, bryozoan bottom (exceptional bryozoan diversity), Rauschert dredge, 12 Jan. 2008, coll. H. Robert (RBINS, INV. 132410); 1 small badly damaged spec., cruise PS77, ANT-XXVII/3, CAMBIO, stn 265 - 
2, eastern Weddell Sea, BENDEX area, $70^{\circ} 47.34^{\prime} \mathrm{S}, 10^{\circ} 40.39^{\prime} \mathrm{W}$ to $70^{\circ} 47.13^{\prime} \mathrm{S}, 10^{\circ} 40.54^{\prime} \mathrm{W}$, depth not recorded [Google Earth depth range for these coordinates: 571-599 m (accessed 27 Sep. 2016)], Agassiz trawl, 22 Mar. 2011:, coll. Ch. Havermans and H. Robert (RBINS, INV. 132968) [extraction I5; Genbank nr, COI: KU870849, 28S: KU759626].

\section{Diagnosis}

RostRum. Curved and very long, nearly reaching tip of article 2 of peduncle of antenna 1.

BoDY SEGMENTS. All pereionites and pleonites with strong mid-dorsal tooth, without pair of dorsolateral teeth or projections (however there is a very faint trace of dorsolateral protrusions on posterior segments); pereionites without pair of ventrolateral teeth or projections; mid-dorsal tooth of pereionites nearly cylindrical, very long, with tip not acute; mid-dorsal tooth of pleonites 1-2 very narrowly triangular in lateral view, scarcely laterally compressed, with slight anterior notch; pleonite 3 with low rounded lobe followed by notch which is itself followed by a subacute broad triangular tooth.

Coxa 4. Anteriorly produced into a blunt angle, strongly projecting forward, ventrally produced into a fairly narrow, subacute tooth, with posteroventral border very concave.

Coxa 5. Produced into very long styliform tooth projecting obliquely backwards.

UROSOMITE 1. With rounded dorsal process.

Peduncle of AnTENNA 1. Not toothed.

GNATHOPODS 1-2. Carpus and propodus robust; propodus distally expanding, with palm oblique.

PeReIOPOD 5. Basis with posteroproximal tooth forming a blunt squared angle with the basis, with posterodistal corner not produced into a tooth.

PeReIOPOD 6. Basis with posteroproximal acutely triangular tooth pointing obliquely, with posterodistal corner not produced into a tooth.

PEREIOPOD 7. Basis with distinct notch forming a blunt obtuse angle on 0.8 of posterior border, with posterodistal corner not produced into a tooth.

\section{Colour pattern}

Body orange red. Rostrum laterally lined with white. Coxae 1-4 largely whitish. Posterior coxae and epimeral plates with diffuse whitish zones. Pereiopods largely whitish. Eyes orange.

\section{Body length}

Up to $70 \mathrm{~mm}$.

\section{Distribution}

Eastern shelf of Weddell Sea (De Broyer et al. 2007), Davis Sea: Tressler Bank (Pyper 2010); 254$1030 \mathrm{~m}$ (De Broyer et al. 2007).

\section{Biology}

Analyses of digestive tract contents revealed the following items: diatoms, sponge spicules, fragments of hydroids of the genus Staurotheca, spicules of Clavularia, crustacean remains (mainly amphipods), polychaete setae, and sclerites of holothurians (Sigmodota contorta (Ludwig, 1875) as Taeniogyrus 
contortus) (Dauby et al. 2001a). These authors conclude that E. rubrieques is rather an opportunistic feeder with both scavenging and predatory behaviour. Dauby et al. (2001b) stated that it is anopportunistic predator. Klages (1991) observed that the species is sometimes parasitized by cryptoniscin isopods. Klages (1991) also observed that hatchlings of E. rubrieques climb on the back of their mother and remain there for a short period of time.

\section{Remarks}

The collection data of the specimens illustrated on figure 29 by Coleman (2007) are: $73^{\circ} 12.39^{\prime} \mathrm{S}$, $20^{\circ} 46.24^{\prime} \mathrm{W}$ (eastern shelf of the Weddell Sea), 650-710 m, 22.1.1985, leg. Wägele (Coleman pers. com.). The collection data of the "specimen 2" illustrated by Rauschert \& Arntz (2015) were given in an early draft of their book accessed by us: ANT-XV/3 stn 222 . Its coordinates are $70^{\circ} 49.1^{\prime} \mathrm{S}, 10^{\circ} 39.2^{\prime} \mathrm{W}$ $70^{\circ} 50.5^{\prime} \mathrm{S}, 10^{\circ} 41.8^{\prime} \mathrm{W}$ (eastern Weddell Sea) at 234-385 $\mathrm{m}$. The photograph of Pyper (2010: cover art of the Australian Antarctic Magazine, as "amphipod") shows E. rubrieques. That specimen came from the Tressler bank, which considerably extends eastwards the distribution of the species.

Epimeria (Hoplepimeria) xesta subgen. et sp. nov. urn:1sid:zoobank.org:act:85ED0CCE-6EB7-4010-AFB3-29894C55616C

Figs 222-228

\section{Etymology}

Xestus, $-a,-u m$ is a Latinization of the Greek adjective $\xi \varepsilon \sigma \tau$ ós, which means smooth or polished. The name alludes to the smooth body surface of the species.

\section{Type material}

\section{Holotype}

RV Polarstern cruises:

SOUTHERN OCEAN: dissected 9 , cruise PS14, ANT-VII/4, EPOS leg 3, stn 226, eastern Weddell Sea, $75^{\circ} 15.9^{\prime} \mathrm{S}, 25^{\circ} 58.3^{\prime} \mathrm{W}$ to $75^{\circ} 15.7^{\prime} \mathrm{S}, 25^{\circ} 54.2^{\prime} \mathrm{W}, 569-574 \mathrm{~m}$, bottom trawl, 28 Jan. 1989, coll. C. De Broyer (RBINS, INV. 132946).

\section{Paratypes}

RV Polarstern cruises:

SOUTHERN OCEAN: 1 juv., cruise PS14, ANT-VII/4, EPOS leg 3, stn 226, eastern Weddell Sea, $75^{\circ} 15.9^{\prime} \mathrm{S}, 25^{\circ} 58.3^{\prime} \mathrm{W}$ to $75^{\circ} 15.7^{\prime} \mathrm{S}, 25^{\circ} 54.2^{\prime} \mathrm{W}, 569-574 \mathrm{~m}$, bottom trawl, 28 Jan. 1989 , coll. C. De Broyer (RBINS, INV. 132947); 2 adult specs, cruise PS14, ANT-VII/4, EPOS leg 3, stn 226, eastern Weddell Sea, $75^{\circ} 15.9^{\prime} \mathrm{S}, 25^{\circ} 58.3^{\prime} \mathrm{W}$ to $75^{\circ} 15.7^{\prime} \mathrm{S}, 25^{\circ} 54.2^{\prime} \mathrm{W}, 569-574 \mathrm{~m}$, bottom trawl, 28 Jan. 1989 , subsample, coll. C. De Broyer (RBINS, INV. 132948); 1 ovigerous 9 , cruise PS14, ANT-VII/4, EPOS leg 3, stn 226, eastern Weddell Sea, $75^{\circ} 15.9^{\prime} \mathrm{S}, 25^{\circ} 58.3^{\prime} \mathrm{W}$ to $75^{\circ} 15.7^{\prime} \mathrm{S}, 25^{\circ} 54.2^{\prime} \mathrm{W}, 569-574 \mathrm{~m}$, bottom trawl, 28 Jan. 1989, coll. C. De Broyer (RBINS, INV. 132949); 3 very large specs, presumably including specimen photographed on board, cruise PS39, ANT-XIII/3, EASIZ I, no locality, aquarium, 3 Mar. 1996, coll. C. De Broyer and G. Chapelle (RBINS, INV. 132994); 1 spec., previously mixed with 9 E. inermis, misidentified as E. georgiana and used for gut content analysis, cruise PS39, ANT-XIII/3, EASIZ I, stn 12, GSN 5, eastern Weddell Sea, $73^{\circ} 18.10^{\prime} \mathrm{S}, 21^{\circ} 10.10^{\prime} \mathrm{W}$ to $73^{\circ} 17.10^{\prime} \mathrm{S}, 21^{\circ} 08.20^{\prime} \mathrm{W}$, 457-459 m, bottom trawl, 14 Feb. 1996, coll. C. De Broyer and G. Chapelle (RBINS, INV. 132997); 1 large spec., misidentified as E. georgiana and used for gut content analysis, cruise PS39, ANT-XIII/3, EASIZ I, stn 29 , BPN 4, eastern Weddell Sea, $71^{\circ} 31.50^{\prime} \mathrm{S}, 12^{\circ} 25.50^{\prime} \mathrm{W}$ to $71^{\circ} 30.30^{\prime} \mathrm{S}, 12^{\circ} 27.80^{\prime} \mathrm{W}$, 504-529 m, 28 Feb. 1996, coll. C. De Broyer and G. Chapelle (RBINS, INV. 132998). 


\section{Description}

Rostrum. Medium-sized, overreaching tip of article 1 of peduncle of antenna 1, anteriorly weakly curved, ventrally straight, subacute in lateral view; of medium width and with nearly straight converging borders in frontal view.

EYE. Very large, broadly elliptic.

Pereion-Pleosome tooth pattern. Pereionites 1-3 smooth; pereionite 4 to pleonite 3 with very low and very blunt mid-dorsal carina; profile of carinae of pereionites 4-7 weakly and regularly curved; profile of carinae of pleonites 1-2 straight, profile of carina of pleonite 3 straight with anterior low protrusion followed by shallow notch, then nearly straight (slightly irregular), posteriorly blunt; dorsolateral ornamentation absent.

COXAE $1-3$. Weakly carinate and distally subacute.

Coxa 4. Anterodorsal border nearly straight (very slightly concave), anteroventral border slightly but distinctly concave, these two borders being joined by a very large rounded lobe (anterior corner), which is weakly projecting forward; ventral corner forming a blunt squared angle (ventral projection well developed); lateral carina very obtuse, parallel and close to posteroventral border; posteroventral border distinctly concave.

Coxa 5. Broad, with surface smooth, with posteroventral corner forming a blunt-tipped nearly squared angle, not expanded laterally, not forming an angle in dorsal view (scarcely visible in dorsal view).

Coxa 6. With posteroventral corner broadly rounded, with low projection arising from its surface (forming a very low indistinct lobe in dorsal view).

Coxa 7. Posteriorly rounded.

Epimeral PLATes 1-3. Posteroventral angle very obtusely rounded in plate 1, produced into a small tooth in plate 2 and into a medium-sized tooth in plate 3 .

UROSOME TOOTH PATTERN. Urosomite 1 with very low dorsal process: anteriorly nearly straight, apically very blunt, posteriorly regularly convex large and sharp narrow tooth pointing upwards; urosomite 3 with dorsolateral borders nearly straight.

Telson. Cleft on 0.2 ; tips of lobes very broad and very rounded, notch narrowly V-shaped.

GNATHOPODS 1-2. Carpus and propodus broad; propodus expanding distally, palm distinct.

PeReIOPODS 5-7. Merus, carpus and propodus of pereiopods 5-7 of medium width; dactylus long; basis of pereiopods 5-6 of normal width, with posteroproximal process present, sword-like, parallel to axis of basis, with posterodistal corner bluntly angular and pointing in posterior direction; basis of pereiopod 7 broad with posterior border very convex, with deep notch on distal 0.8 , forming a blunt-tipped acute angle, with posterodistal corner very bluntly angular and pointing backwards.

\section{Colour pattern}

Body and appendages with a homogeneous and diffuse orange dotted/mottled pattern; legs with colour more intense; eyes reddish. 


\section{Body length}

Up to $55 \mathrm{~mm}$.

\section{Distribution}

Eastern shelf of Weddell Sea, 457-574 m.

\section{Biology}

Dauby et al. (2001a, as E. georgiana) state that "this weakly mobile large amphipod (up to $40 \mathrm{~mm}$ ) can be found, sometimes in abundance, on coarse sediment bottoms or at the base of animal colonies". According to them, "digestive tract analyses of 31 specimens revealed a wide variety of food items identifiable by hard remnants: crustaceans (mysids and amphipods), polychaetes (setae of terebellids), holothurioid ossicles and hydrozoan perisarcs; planktonic items (diatoms, radiolarians, foraminifers) also form a significant part of the diet; finally, as for the other deposit-feeders, sponge spicules (which form a major component of bottom mats) and mineral particles complete the food, the latter providing evidence of feeding on the sediment; both these items, albeit 'inorganic', are likely to be of considerable nutritional value, since they may be densely coated with bacteria, the importance of which has been shown in the Weddell Sea." Dauby et al. (2001b) concluded that E. xesta (as E. georgiana) is a deposit feeder.

\section{Remarks}

Epimeria xesta is sympatric with E. angelikae, though they have different bathymetric ranges, with E. angelikae being found at greater depths: $781-1194 \mathrm{~m}$ vs $457-574 \mathrm{~m}$. The morphologically most similar species to E. xesta is E. cyphorachis from the South Shetland Islands and from the tip of the Antarctic Peninsula. In E. xesta, the rostrum is narrower in frontal view than in E. cyphorachis, the ventral corner of coxa 4 bluntly angulate instead of being sharply angulate, and the posterior notch of pereiopods $5-7$ is narrower.

Epimeria (Hoplepimeria) sp. subgen. nov.

'Epimeria robustoides 1' - Rauschert \& Arntz, 2015: 62, pl. 55.

non Epimeria robustoides Lörz \& Coleman in Lörz et al., 2009: 10.

\section{Character states and colour pattern}

Similar to Epimeria gargantua but with a different colour pattern. Background colour of the body: white; all pereionites with two pairs of small red spots disposed transversally; pereionite $1+$ coxa 1 , pereionite $4+$ coxa 4 , pereionite $7+$ coxa 7 with broad orange red stripe; urosomite 1 and basis of pereiopod 7 orange red; basis of pereiopods 5-6 white; antennae and pereiopods (except basis of pereiopods 5-7) pink; mouthparts purple; eyes red.

\section{Distribution}

PS61, ANT-XIX/5, LAMPOS, stn 229-1, Bruce Ridge [a geomorphologic elevation situated midway between the South Orkney Islands and the southern tip of the archipelago of the South Sandwich Islands], $60^{\circ} 08.77^{\prime} \mathrm{S}, 34^{\circ} 54.83^{\prime} \mathrm{W}$ to $60^{\circ} 07.81^{\prime} \mathrm{S}, 34^{\circ} 56.17^{\prime} \mathrm{W}, 362-371 \mathrm{~m}$.

\section{Remarks}

Rauschert \& Arntz (2015) do not indicate the coordinates of their 'Epimeria robustoides 1', but this information is given in an early draft of the book made available to the authors: ANT-XIX/5, LAMPOS, stn 229-1, Bruce Ridge. It is not known where the specimen is stored; in November 2015, it was not 
deposited at the Berlin Museum (Coleman pers. com.).As its colour pattern, with large red patches, is very different from the purely white E. gargantua sp. nov. found more southernly, this specimen possibly belongs to a distinct species. It should be noted that the colour pattern of all E. gargantua sp. nov. collected during the cruises ANT-XXIII/8 and ANT-XXIX/3 (20 specimens) was examined on board and exhibited no variation.

Subgenus Laevepimeria subgen. nov. urn:Isid:zoobank.org:act:D1B62023-FFE4-4AEB-A345-89459C1063AC

Epimeriella Walker, 1906: 17 (in part).

Epimeriella - Gurjanova 1955: 189, 206 (in part). - J.L. Barnard 1961: 102 (in part); 1969: 161, 395 (in part). - McCain 1971: 160 (in part). — Karaman \& J.L. Barnard 1979: 109-110 (in part). Holman \& Watling 1983: 31 (in part, discussion). — Andres \& Lott 1986: 131-136 (in part). — J.L. Barnard \& Karaman 1991: 380, 394, 702 (in part). — Coleman 1998b: 215; 2007: 56 (in part). — Lörz \& Brandt 2004: 179, 184, 188, 189 (in part).

\section{Etymology}

Combination of laevis, smooth in Latin, and Epimeria. That name, which is feminine, alludes to the absence of ornamentation in the species of that subgenus.

\section{Type species}

Epimeria walkeri (K.H. Barnard, 1930).

\section{Description}

Body opaque, with teguments moderately calcified. Rostrum small but not minute (reaching about mid of article 1 of antenna 1). Eyes not conical. Pereionites and pleonites completely smooth (only pleonite 3 can be posterodorsally produced into a low bump). Coxae 1-4 with sharp or blunt tip. Coxae 1-3 not keeled along their axis. Coxa 1 with anterior margin proximally concave and with subdistal dilatation. Coxa 4 without carina or groove; posteroventral border straight or nearly so. Coxae 5-6 toothless. Mid of posterior border of epimeral plates 1-3 not produced into a tooth. Posteroventral tooth of epimeral plate 3 small. Dorsal process of urosomite 1 produced into a large blunt tooth, of which the anterior border is shorter than the posterior border (the posterior border of the tooth extend to the posterior border of urosomite 1). Urosomite 2 without pair of small teeth pointing upwards. Lateral borders of urosomite 3 posteriorly terminated into a blunt angle. Peduncle of antenna 1 without teeth. Mandible with molar process drawn out, without triturative surface. Lower lip with wide hypopharyngeal gap. Palp of maxilliped with 4 articles. Gnathopods of normal size, with carpus and propodus very stout, with palm reduced or normal; propodus not expanded distally; dactylus very stout, with long slender posterior teeth perpendicular (or nearly perpendicular) to axis of dactylus (as in a comb). Basis of pereiopods 5-6 fairly broad, with indistinct trace of posteroproximal process, with or without trace posterodistal blunt process projecting posteriorly. Basis of pereiopod 7 with posterior border convex along all its length or with slight distal concavity, with large distal lobe reaching 0.3 of merus. Merus of pereiopod 7 broad. In pereiopod 7, the sum of the merus, carpus and propodus is short: only about as long as basis or a little bit more. Dactylus of pereiopods 5-7 short.

\section{Body length}

The maximum body length recorded in Laevepimeria species ranges between 15 and $32 \mathrm{~mm}$. 


\section{Ecology}

Benthic, 170-889 m.

\section{Distribution}

Circum-Antarctic, as far north as Elephant Island.

\section{Remarks}

Laevepimeria subgen. nov. and Epimeriella form a large clade together. These subgenera share synapomorphies in the morphology of the mandible (molar process non triturative) and the lower lip (wide hypopharyngeal gap), and were formerly grouped into the genus Epimeriella s. lat. However, Laevepimeria subgen. nov. and Epimeriella s. str. exhibit striking differences in the morphology of the body, gnathopods and pereiopods. These differences are presumably related to their benthic lifestyle (Laevepimeria subgen. nov.) versus a pelagic or semi-pelagic lifestyle (Epimeriella). These subgenera can be identified without dissection, which was not possible with the former concept of Epimeriella.

\section{Key to the species of Laevepimeria}

1. Coxa 4 narrow; palm of gnathopods not reduced (gnathopods subcheliform); posterior border of basis of pereiopod 7 regularly rounded

- Coxa 4 broad; palm of gnathopods reduced (gnathopods nearly achelate); posterior border of basis of pereiopod 7 sinuate

2. Tip of coxae 1-2 subacute

E. (Laevepimeria)

cinderella subgen. et sp. nov. [Elephant Island and tip of Antarctic Peninsula]

- Tip of coxae 1-2 very broadly rounded

E. (Laevepimeria) sp. subgen. nov. [Bransfield Strait]

3. Rostrum narrow in frontal view; eyes huge (interocular distance about $1.3 \times$ as wide as eye size when seen in frontal view) and oriented forward (in frontal view the eyes appears about as high as wide); in lateral view the eyes almost reach the tip of head and the head appears as very strongly curved; posterodistal corner of basis of pereiopod 5 produced into a blunt angle, posterodistal corner of basis of pereiopod 6 forming a well defined squared angle; posterodistal corner of basis of pereiopod 7 forming a triangular tooth; pleonites 1-3 not carinate and not posteriorly produced............. E. (Laevepimeria) walkeri subgen. nov. (K.H. Barnard, 1930). [Elephant Island, tip of Antarctic Peninsula, Weddell Sea, Adélie Coast, Ross Sea]

- Rostrum broad in frontal view; eyes medium-sized (interocular distance about $3 \times$ as wide as eye size when seen in frontal view) and their orientation is no more lateral than frontal (in frontal view the eyes appears as higher than wide); in lateral view the eyes are far from reaching the tip of head and the head appears as moderately curved; posteroventral corner of basis of pereiopod 5 and pereiopod 6 rounded; posterodistal corner of basis of pereiopod 7 forming a tiny rounded lobe; pleonites 1-3 weakly carinate and posterodorsally weakly produced E. (Laevepimeria) anodon subgen. et sp. nov. [Adélie Coast] 
Epimeria (Laevepimeria) anodon subgen. et sp. nov. urn:Isid:zoobank.org:act:4328C52C-34BA-4DDF-A984-7BDE24BADE7F

Figs 229-234

'Clade C walkeri complex - WA4' - Verheye et al. 2016a, supplement: 3 (online).

\section{Etymology}

Combination of the prefix an-, which means 'lack of' and of the Greek noun, ó $\delta o v$ s, which means 'teeth'. The name, which is an apposition, alludes to the absence of tooth in the species.

\section{Type material}

\section{Holotype}

RV Aurora Australis cruises:

SOUTHERN OCEAN: + , cruise CEAMARC, sample CEAMARC 2724, stn 71EV447, Adélie Coast, $66^{\circ} 24^{\prime} 00^{\prime \prime} \mathrm{S}, 140^{\circ} 32^{\prime} 21^{\prime \prime} \mathrm{E}, 683-791 \mathrm{~m}$, beam trawl, 14 Jan. 2008, coll. IPEV-AAD-MNHN (MNHNIU-2014-4336) [extraction M13; Genbank nr, COI: KU870880, 28S: KU759664].

\section{Paratypes}

RV Aurora Australis cruises:

SOUTHERN OCEAN: 1 spec., cruise CEAMARC, sample CEAMARC 1317, stn 51AEV215, Adélie

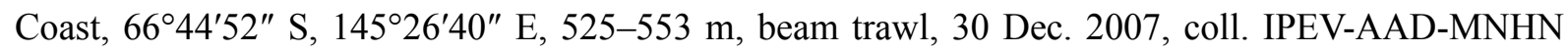
(MNHN-IU-2014-4275); 1 adult spec., cruise CEAMARC, sample CEAMARC 1384, stn 50AEV220,

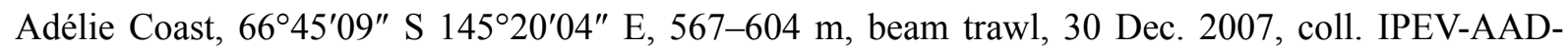
MNHN (MNHN-IU-2014-4331) [extraction M12; Genbank nr, COI: KU870879, 28S: KU759663]; 1 , , cruise CEAMARC, sample CEAMARC 2724, stn 71EV447, Adélie Coast, 66²4'00" S, 140³2'21" E, 683-791 m, beam trawl, 14 Jan. 2008, coll. IPEV-AAD-MNHN (MNHN-IU-2014-7335) [removed from MNHN-IU-2014-4336].

\section{Description}

HEAD + Rostrum. Normally curved in lateral view.

Rostrum. In lateral view short and very broad, reaching mid of article 1 of peduncle of antenna 1 , anteriorly distinctly curved, ventrally weakly convex, tip subacute; in frontal view very broad and with nearly straight converging borders, tip blunt.

EYEs. Medium-sized, elliptic, laterally oriented (interocular distance about $3 \times$ as wide as eye size when seen in frontal view).

Pereion-Pleosome tooth pattern. Pereionites $1-7$ totally smooth; pleonites $1-2$ with trace of mid-dorsal keel and with trace of posterior bump; pleonite 3 with trace of mid-dorsal carina and with posterior bump.

COXAE 1-3. Tip sharp.

Coxa 4. Broad, anterodorsal border straight; anteroventral border nearly straight (inconspicuously convex), these two borders being joined by broad rounded convexity, which is distinctly projecting forward; anterodorsal border $1.35 \times$ as long as anteroventral border; posteroventral border nearly straight (inconspicuously sinuate). 
Coxa 5 . Very broad, posteroventral corner very broadly rounded in lateral view, very obtusely rounded in dorsal view (almost not projecting laterally).

Coxa 6. Posterior border weakly convex; posteroventral corner very broadly rounded.

Coxa 7. Posterior border nearly straight (inconspicuously concave); posteroventral corner broadly rounded.

EPIMERAL Plates 1-3. Posteroventral angle very obtusely rounded in plate 1 (without any trace of tooth), produced into a small tooth in plates $2-3$.

UROSOME TOOTH PATtERn. Urosomite 1 with distinct asymmetrical dorsal process, anteriorly nearly straight, apically blunt, posteriorly strongly convex; urosomite 3 with dorsolateral borders weakly convex, with tip broadly rounded.

TeLSON. Cleft on 0.2 ; lobes laterally very convex, medially nearly straight, with tips subacute; notch with borders weakly convergent and end rounded.

GNATHOPODS 1-2. Carpus and propodus short and very broad; propodus not expanding distally, palm very reduced (dactylus $4 \times$ as long as palm; gnathopods achelate or nearly so).

PEREIOPOD 4. Merus, carpus and propodus long and slender, dactylus short.

PEREIOPOD 5. Basis of normal width, with posteroproximal process absent, with posterodistal corner forming a very obtuse angle (not projecting posteriorly) of which the tip is very blunt; merus, carpus and propodus long and slender, dactylus short.

PEREIOPOD 6. Basis of normal width, with posteroproximal process absent, with posterodistal corner very broadly rounded (not angulate); merus, carpus and propodus long and slender, dactylus short.

PEREIOPOD 7. Basis broad; posterior border weakly convex and slightly diverging in proximal 0.8 , at this level forming a blunt but strong angular discontinuity and abruptly and very strongly converging (border becoming inconspicuously concave, terminated into a small, blunt but distinctly protruding lobe; merus very broad and short, carpus of medium width and short, propodus slender and short, dactylus short.

\section{Colour pattern}

Uniformly pale yellowish; eyes blood red.

\section{Body length}

Up to $32 \mathrm{~mm}$.

\section{Distribution}

Adélie Coast, 525-791 m.

\section{Remarks}

Epimeria anodon sp. nov. and E. walkeri are very similar in morphology. Epimeria anodon sp. nov. has smaller eyes and the posterodistal corner of the basis of its pereiopods 5 and 6 is very broadly rounded, which is not the case for the other two species. In dorsal view, pleonites 1-3 are also less smooth than in E. walkeri. 
Epimeria (Laevepimeria) cinderella subgen. et sp. nov. urn:1sid:zoobank.org:act:A77C9AD4-391F-4101-8DFA-F15A45185A0E

Figs $235-240$

‘Clade C walkeri complex - WA3' - Verheye et al. 2016a, supplement: 3 (online).

\section{Etymology}

Cinderella, heroin of humble origin in a well-known folk tale. The name, which is a noun in apposition, alludes to the modest size and the absence of ornamentation of the species, which contrasts with the extravagant adornment and the impressive size of many 'rival' Epimeria species.

\section{Type material}

\section{Holotype}

RV Polarstern cruises:

SOUTHERN OCEAN: $\hat{\sigma}$, cruise PS81, ANT-XXIX/3, stn 188-5, south east of Dundee Island, $63^{\circ} 50.92^{\prime} \mathrm{S}, 55^{\circ} 37.66^{\prime} \mathrm{W}$ to $63^{\circ} 50.93^{\prime} \mathrm{S}, 55^{\circ} 37.52^{\prime} \mathrm{W}, 402-407 \mathrm{~m}$, Rauschert dredge, 20 Dec. 2013 , coll. C. d'Udekem d'Acoz and M. Verheye (RBINS, INV. 132656) [extraction I15; Genbank nr, COI: KU870841, 28S: KU759617].

\section{Paratypes}

RV Polarstern cruises:

SOUTHERN OCEAN: 1 spec., cruise PS69, ANT-XXIII/8, stn 605-1, Elephant Island, $61^{\circ} 20.35^{\prime}$ S, $55^{\circ} 29.16^{\prime} \mathrm{W}$ to $61^{\circ} 19.98^{\prime} \mathrm{S}, 55^{\circ} 32.67^{\prime} \mathrm{W}, 146-151 \mathrm{~m}$, bottom trawl, 19 Dec. 2006, coll. C. d'Udekem d'Acoz and H. Robert (RBINS, INV. 122528); 1 spec., cruise PS81, ANT-XXIX/3, stn 185-3, south east of Dundee Island, $63^{\circ} 51.53^{\prime} \mathrm{S}, 55^{\circ} 40.74^{\prime} \mathrm{W}$ to $63^{\circ} 51.53^{\prime} \mathrm{S}, 55^{\circ} 40.43^{\prime} \mathrm{W}, 253-255 \mathrm{~m}$, extremely fine sand mixed with some mud and gravel, Rauschert dredge, 19 Feb. 2013, coll. C. d'Udekem d'Acoz and M. Verheye (RBINS, INV. 122965); 1 spec., cruise PS81, ANT-XXIX/3, stn 234-5, north of Livingstone Island, $62^{\circ} 17.36^{\prime} \mathrm{S}, 61^{\circ} 12.06^{\prime} \mathrm{W}$ to $62^{\circ} 17.31^{\prime} \mathrm{S}, 61^{\circ} 12.63^{\prime} \mathrm{W}, 248-251 \mathrm{~m}$, mud with a lot of specimens of a small reddish ophiuroid with very long and flexible legs, Agassiz trawl, 7 Mar. 2013, coll. C. d'Udekem d'Acoz and M. Verheye (RBINS, INV. 122949) [extraction ANT43; Genbank nr, COI: KU870829, 28S: KU759602].

RV James Clark Ross cruises:

SOUTHERN OCEAN: 2 specs, cruise JR144, stn EI-EBS-4-supra, south of Elephant Island,

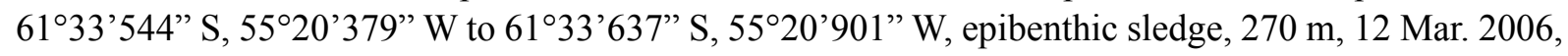
coll. BAS (RBINS, INV. 132959) [extraction I4; Genbank nr, COI: KU870848, 28S: KU759625].

\section{Other material}

RV Seatruck, cruise REVOLTA II:

SOUTHERN OCEAN: 1 spec., stn REVO_140, Collect_ID: REVO_140, Adélie Coast, 66³7'53.4" S, 139 51'18" E, 106-172 m, 12 Jan. 2011, coll. N. Améziane, C. Gallut and A.C. Lautrédou (MNHNIU-2016-6885).

\section{Description}

HEAD + ROSTRUM. Very strongly curved in lateral view.

RosTRUM. In lateral view short and broad, reaching 0.6 of article 1 of peduncle of antenna 1, anteriorly and ventrally straight, subacute; in dorsal view narrow, with straight converging borders, with tip blunt. 
EYEs. Huge, broadly elliptic, partly anteriorly oriented (interocular distance about $1.5 \times$ as wide as eye size when seen in frontal view).

Pereion-Pleosome tooth pattern. Pereionites $1-7$ and pleonites $1-2$ totally smooth; pleonite 3 with weak posterior bump.

COXAE 1-3. Coxa 1 blunt-tipped, coxa 2 with tip subacute, coxa 3 blunt-tipped.

Coxa 4. Narrow; anterodorsal border straight; anteroventral border nearly straight (inconspicuously convex), these two borders being joined by very broad rounded convexity, which is distinctly projecting forward; anterodorsal border $1.75 \times$ as long as anteroventral border; posteroventral border nearly straight.

CoxA 5. Broad, posteroventral corner rounded in lateral view, not projecting laterally.

Coxa 6. Posterior border weakly convex; posteroventral corner very broadly rounded.

Coxa 7. Posterior border nearly straight (inconspicuously concave); posteroventral corner broadly rounded.

EPIMERAL PLATES 1-3. Posteroventral angle very obtusely rounded in plate 1 (without any trace of tooth), produced into a small tooth in plates $2-3$.

UROSOME TOOTH PATteRn. Urosomite 1 with distinct asymmetrical dorsal process, anteriorly nearly straight, apically bluntly angulate, posteriorly weakly convex; urosomite 3 with dorsolateral borders very weakly convex, with tip very bluntly angulate.

TeLson. Cleft on 0.2 ; lobes laterally very convex, medially nearly straight, with tips rounded; notch with borders weakly convergent and end rounded.

GNATHOPODS 1-2. Carpus and propodus short and very broad; propodus not expanding distally, palm not reduced.

PEREIOPOD 4. Merus, carpus and propodus long and slender, dactylus short.

PEREIOPOD 5. Basis of normal width, with posteroproximal process absent, with posterodistal corner forming a blunt squared angle (not projecting posteriorly); merus, carpus and propodus long and slender, dactylus short.

PeReIOPOD 6. Basis of normal width, with posteroproximal process absent, with posterodistal corner forming a blunt squared angle (not projecting posteriorly); merus, carpus and propodus long and slender, dactylus short.

PEREIOPOD 7. Basis broad; posterior border strongly convex along all its length, terminated in a large rounded lobe projecting ventrally; merus very broad and short, carpus of medium width and short, propodus slender and short, dactylus short.

\section{Body length}

Up to $15 \mathrm{~mm}$.

\section{Distribution}

Elephant Island, tip of Antarctic Peninsula, Adélie Coast; 106-270 m. 


\section{Remarks}

Epimeria cinderella sp. nov. can be easily distinguished from the related E. anodon sp. nov. and E. walkeri by its much narrower and more asymetrical coxa 4 . The gnathopods and the basis of pereiopod 7 are also different. Epimeria cinderella sp. nov. seems more similar to Epimeria (Laevepimeria) sp. subgen. nov., which is only known from a very small juvenile. The tip of the coxae $1-2$ of the young Epimeria (Laevepimeria) sp. subgen. nov. examined are, however, much more rounded than in Epimeria cinderella sp. nov., but this difference might disappear in adults.

Epimeria (Laevepimeria) walkeri subgen. nov. (K.H. Barnard, 1930)

Figs 241-249

Epimeriella walkeri K.H. Barnard, 1930: 380-381, fig. 44.

Epimeriella walkeri - McCain, 1971: 160, fig. 1.

Epimeria walkeri - Coleman 2007: 60, fig. 35a-b, plate 3 fig. a, map 16 (circles, in part). — Rauschert \& Arntz 2015: 62, pl. 55 unnumbered photograph.

'Clade C walkeri complex - WA1' - Verheye et al. 2016a, supplement: 3 (online).

non Epimeriella walkeri subgen. nov. K.H. Barnard, 1930: 380-381, fig. 44.

\section{Material examined}

RV Polarstern cruises:

SOUTHERN OCEAN: 1 spec., cruise PS39, ANT-XIII/3, EASIZ I, stn 8, AGT 2, eastern Weddell Sea, $71^{\circ} 18.70^{\prime} \mathrm{S}, 12^{\circ} 17.10^{\prime} \mathrm{W}$ to $71^{\circ} 18.45^{\prime} \mathrm{S}, 1^{\circ} 16.30^{\prime} \mathrm{W}, 170-174 \mathrm{~m}, 9$ Feb. 1996, coll. C. De Broyer and G. Chapelle (RBINS, INV. 132683); 1 spec., alcohol-fixed, cruise PS69, ANT-XXIII/8, stn 603-5, eastern Weddell Sea, $70^{\circ} 30.99^{\prime} \mathrm{S}, 08^{\circ} 48.08^{\prime} \mathrm{W}$ to $70^{\circ} 30.40^{\prime} \mathrm{S}, 08^{\circ} 48.13^{\prime} \mathrm{W}, 274-297 \mathrm{~m}$, sponge bottom, Agassiz trawl, 7 Dec. 2006, coll. C. d'Udekem d'Acoz and H. Robert (RBINS, INV. 122485); 4 specs, cruise PS69, ANT-XXIII/8, stn 614-3/4/5, Elephant Island, $60^{\circ} 52.37^{\prime} \mathrm{S}, 55^{\circ} 29.80^{\prime} \mathrm{W}$ to $60^{\circ} 52.71^{\prime} \mathrm{S}$, $55^{\circ} 27.83^{\prime}$ W, 248-265 m, a lot of epifauna, Rauschert dredge and Agassiz trawl, 22 Dec. 2006, coll. C. d'Udekem d'Acoz and H. Robert (RBINS, INV. 122516); 1 spec., cruise PS71, ANT-XXIV/2, ANDEEP-SYSTCO, stn 48-1, eastern Weddell Sea, $70^{\circ} 23.94^{\prime} \mathrm{S}, 8^{\circ} 19.14^{\prime} \mathrm{W}$ to $70^{\circ} 23.89^{\prime} \mathrm{S}, 8^{\circ} 18.67^{\prime} \mathrm{W}$, 595-602 m, bryozoan bottom (exceptional diversity of bryozoans), Agassiz trawl, 12 Jan. 2008, coll. H. Robert (RBINS, INV. 132448); 1 spec., cruise PS77, ANT-XXVII/3, CAMBIO, stn 222-5, southwest of King George Island, $62^{\circ} 17.60^{\prime} \mathrm{S}, 58^{\circ} 41.19^{\prime} \mathrm{W}$ to $62^{\circ} 17.49^{\prime} \mathrm{S}, 58^{\circ} 41.46^{\prime} \mathrm{W}, 445-889 \mathrm{~m}$, Agassiz trawl, 23 Feb. 2011, coll. C. Havermans and H. Robert (RBINS, INV. 132667) [extraction A6; Genbank nr, COI: KU870819, 28S: KU759591]; 1 spec., specimen missing, DNA extraction products only, PS77, ANT-XXVII/3, CAMBIO, stn 288-3, Eastern Weddell Sea, $70^{\circ} 56.40^{\prime} \mathrm{S}, 10^{\circ} 32.60^{\prime} \mathrm{W}$ to $70^{\circ} 56.42^{\prime} \mathrm{S}$, $10^{\circ} 32.25^{\prime} \mathrm{W}, 303-311 \mathrm{~m}$, Rauschert Dredge, 30 Mar. 2011, coll. C. Havermans and H. Robert [extraction Ex169; Genbank nr, COI: KU870836, 28S: KU759610]; đ̃, cruise PS81, ANT-XXIX/3, stn 217-7, Bransfield Strait, $62^{\circ} 53.64^{\prime} \mathrm{S}, 58^{\circ} 12.52^{\prime} \mathrm{W}$ to $62^{\circ} 53.64^{\prime} \mathrm{S}, 58^{\circ} 12.37^{\prime} \mathrm{W}, 387-395 \mathrm{~m}$, heterogeneous bottom (black muddy sand and gravel; small stones with incrusting bryozoans; gorgonians; sea urchins), Rauschert dredge, 2 Mar. 2013, coll. C. d'Udekem d'Acoz and M. Verheye (RBINS, INV. 122944) [extraction ANT42; Genbank nr, COI: KU870828, 28S: KU759601].

RV Aurora Australis cruises:

SOUTHERN OCEAN: 1 spec., cruise CEAMARC, sample CEAMARC 631, stn 4EV112, Adélie Coast, 66 $20^{\prime} 16^{\prime \prime} \mathrm{S}, 141^{\circ} 59^{\prime} 17^{\prime \prime}$ E, 237-257 m, beam trawl, 26 Dec. 2007, coll. IPEV-AAD-MNHN (MNHNIU-2014-4324); 1 spec., cruise CEAMARC, sample CEAMARC 1643, Adélie Coast, 66 34'30" S, $145^{\circ} 01^{\prime} 15^{\prime \prime}$ E, 429-451 m, beam trawl, 3 Jan. 2008, coll. IPEV-AAD-MNHN (MNHN-IU-2014-4323); 
4 specs, cruise CEAMARC, sample CEAMARC 3532, Adélie Coast, 6529'29" S, 139¹8'37" E, 397$411 \mathrm{~m}$, beam trawl, 17 Jan. 2008, coll. IPEV-AAD-MNHN (MNHN-IU-2014-4352).

\section{Description}

HEAD + ROSTRUM. Very curved in lateral view.

Rostrum. In lateral view short and broad, reaching mid of article 1 of peduncle of antenna 1, anteriorly weakly curved, ventrally straight, acute-tipped; in frontal view narrow and with straight converging borders, with tip acute.

EYES. Huge, broadly elliptic, largely oriented forward (interocular distance about $1.3 \times$ as wide as eye size when seen in frontal view).

Pereion-Pleosome tooth pattern. Pereionites $1-7$ and pleonites $1-2$ totally smooth; pleonite 3 with posterior bump.

COXAE 1-3. Tip blunt.

Coxa 4. Broad, anterodorsal border nearly straight (inconspicuously concave); anteroventral border weakly convex, these two borders being joined by broad rounded convexity, which is distinctly projecting forward; anterodorsal border $1.12 \times$ as long as anteroventral border; posteroventral border nearly straight (inconspicuously sinuate).

Coxa 5. Very broad, posteroventral corner very broadly rounded in lateral view, very obtusely rounded in dorsal view (almost not projecting laterally).

Coxa 6. Posterior border weakly convex; posteroventral corner very broadly rounded.

Coxa 7. Posterior border nearly straight (inconspicuously concave); posteroventral corner broadly rounded.

EPimeral plates 1-3. Posteroventral angle very obtusely rounded in plate 1 (without any trace of tooth), produced into a small tooth in plates $2-3$.

UROSOME TOOTH PATteRn. Urosomite 1 with distinct asymmetrical dorsal process, anteriorly nearly straight, apically blunt, posteriorly moderately convex; urosomite 3 with dorsolateral borders nearly straight (very weakly convex), with tip bluntly angulate.

TeLson. Cleft on 0.15 ; lobes laterally very convex, medially nearly straight, with tips blunt; notch with borders weakly convergent and end rounded.

GNATHOPODs 1-2. Carpus and propodus short and very broad; propodus not expanding distally, palm very reduced (dactylus $4 \times$ as long as palm; gnathopods achelate or nearly so).

PeREIOPOD 4. Merus, carpus and propodus long and slender, dactylus short.

Pereiopod 5. Basis of normal width, with posteroproximal process absent, with posterodistal corner forming a blunt squared angle (slightly projecting posteriorly); carpus and propodus long and slender, dactylus short.

PEREIOPOD 6. Basis of normal width, with posteroproximal process absent, with posterodistal corner forming a sharp squared angle; carpus and propodus long and slender, dactylus short. 
Pereiopod 7. Basis broad; posterior border weakly convex and slightly diverging in proximal 0.8 , at this level the curvature slightly and gradually increases and becomes convergent with the anterior border; just before tip the curve becomes slightly concave; the posterior border of the basis is terminated into a small, sharp tooth (forming a small squared angle); merus very broad and short, carpus of medium width and short, propodus slender and short, dactylus short.

\section{Colour pattern}

Background whitish or very pale greyish; pereionites 3-7 yellowish/brownish; indistinct pale orange marks present here and there; peduncle of antenna 1 tinged with pale orange; urosome (especially urosomite 1) and tailfan tinged with orange; a proximal orange mark on the basis of pereiopod 7; eyes red.

\section{Body length}

Up to $30 \mathrm{~mm}$.

\section{Distribution}

Type locality: Ross Sea, McMurdo Sound, 256-379 m (K.H. Barnard 1930). Other records: King George Island and Bransfield Strait, eastern shelf of the Weddell Sea, Adélie Coast; 170-889 m.

\section{Biology}

Dauby et al. (2001a) provide some information on the gut content of Epimeria walkeri (as Epimeriella walkeri). According to them, the commonest items were ophiuroids (ossicles and parts of arms), striated muscle and diatoms. Less prevalent were sponge spicules and cnidocysts, while crustacean pieces and holothurian ossicles were infrequent. Dauby et al. (2001b) concluded that it is a macropredator/ scavenger.

\section{Remarks}

The illustrations of E. walkeri given by K.H. Barnard (1930) are difficult to understand. On his figures, the rostrum appears as broader than in specimens examined by us, but this might be related the orientation of the specimen. On the other hand, the shapes of coxa 4 and of the basis of pereiopods 5-7 are similar to that of our specimens. Our identification is only tentative. A comparison between topotypical E. walkeri (from the Ross Sea) and specimens from other Antarctic seas should be carried out whenever possible.

The collection details of the specimen illustrated by Coleman (2007: 60, fig. 35a-b) are: $72^{\circ} 27.7^{\prime} \mathrm{S}$, 17\%42.32' W (eastern shelf of the Weddell Sea), 240-254 m, Agassiz trawl, leg. Wägele, 15 Feb. 1985 (Coleman pers. com.). The station of the specimen illustrated by Rauschert \& Arntz (2015) was indicated in an early draft made available to the authors. It is ANT-XVII/3, stn 85 [85-1], of which the coordinates are: $71^{\circ} 11.30^{\prime} \mathrm{S}, 12^{\circ} 15.40^{\prime} \mathrm{W}$ to $71^{\circ} 12.19^{\prime} \mathrm{S}, 12^{\circ} 19.01^{\prime} \mathrm{W}$ (eastern shelf of the Weddell Sea), 309-318 m.

Epimeria (Laevepimeria) sp. subgen. nov.

Fig. 250

'Clade C walkeri complex - WA2' - Verheye et al. 2016a, supplement: 3 (online).

\section{Material examined}

RV Polarstern cruise: 
SOUTHERN OCEAN: 1 tiny juv., cruise PS81, ANT-XXIX/3, stn 197-5, Bransfield Strait, 62 $44.73^{\prime}$ S, 57 $26.79^{\prime} \mathrm{W}$ to $62^{\circ} 45.05^{\prime} \mathrm{S}, 5^{\circ} 26.68^{\prime} \mathrm{W}, 258-273 \mathrm{~m}$, Agassiz trawl, 25 Feb. 2013 (RBINS, INV. 122932) [extraction K40; Genbank nr, COI: KU870873, 28S: KU759653].

\section{Description}

HEAD + ROSTRUM. Weakly curved in lateral view.

RostRum. In lateral view short and very broad, reaching about 0.6 of article 1 of peduncle of antenna 1 , anteriorly weakly convex and ventrally straight, blunt-tipped.

EYES. Huge, broadly elliptic.

Pereion-Pleosome tooth pattern. Pereionites $1-7$ and pleonites $1-2$ totally smooth; pleonite 3 missing.

COXAE $1-3$. Tip broadly rounded.

Coxa 4. Fairly narrow; anterodorsal border straight; anteroventral border slightly convex, these two borders being joined by very broad rounded convexity, which is distinctly projecting forward (anterior corner and anteroventral border forming a regular curve, without discontinuity); anterodorsal border $1.4 \mathrm{x}$ as long as anteroventral border; ventral corner bluntly and obtusely angulate; posteroventral border nearly straight.

Coxa 5. Broad, posteroventral corner very broadly rounded in lateral view.

Coxa 6. Posterior border weakly convex; posteroventral corner very broadly rounded.

Coxa 7. Posterior border nearly straight (inconspicuously concave); posteroventral corner broadly rounded.

EPIMERAL PLATES 1-2. Posteroventral angle very obtusely rounded in plate 1 (without any trace of tooth), produced into a small tooth in plate 2 .

UROSOME. Missing.

GNATHOPODS 1-2. Carpus and propodus short and very broad; propodus not expanding distally, palm not reduced.

PEREIOPOD 6. Basis of normal width, with posteroproximal process absent, with posterodistal corner rounded or very bluntly angulate.

Pereiopod 7. Basis broad; posterior border strongly convex along all its length, terminated in a large rounded lobe projecting ventrally.

\section{Body length}

$5 \mathrm{~mm}$.

\section{Distribution}

Tip of Antarctic Peninsula: Bransfield Strait, 258-273 m. 


\section{Remarks}

A COI phylogenetic analysis (Verheye et al. 2016a) indicates that this specimen would belong to a distinct species of the subgenus Laevepimeria subgen. nov. Since it is an incomplete and very small juvenile (about $5 \mathrm{~mm}$ long), it is considered inappropriate for formal description and naming. Only a photograph and a description of the morphological details visible without dissection are given herein. Within Laevepimeria subgen. nov., this specimen is more similar to E. cinderella sp. nov. regarding the shape of its coxa 4 and of the basis of its pereiopod 7. On the other hand, the tip of coxae 1-2 are broadly rounded, whilst they are subacute in E. cinderella sp. nov. However, these structures might differ in adults, as seen in other Epimeria.

Subgenus Metepimeria Schellenberg, 1931

Metepimeria Schellenberg, 1931: 162.

Metepimeria - Gurjanova 1955: 189, 209. — J.L. Barnard 1961: 102; 1969: 396. — Watling \& Holman 1981: 215. - J.L. Barnard \& Karaman 1991: 380, 397. — Coleman 1998b: 215; 2007: 61. — Lörz \& Brandt 2004: 184, 188.

\section{Type species}

Metepimeria acanthurus Schellenberg, 1931.

\section{Description}

Body opaque, with teguments strongly calcified. Rostrum medium-sized. Eyes not conical. Pleonites and at least posterior pereionites with low mid-dorsal carina, which is sometimes posteriorly produced into a tooth pointing backwards; some carinae with slight or strong median concavity. Dorsolateral processes (small teeth or low carinae) always present on pleosomites and posterior pereionite(s); some body segments have 2 or more dorsolateral processes, some in longitudinal arrangement. Pereionites 1-7 without tooth or protrusion just above connection with coxa. Coxae 1-4 with sharp to fairly sharp tip. Coxae 1-3 distinctly keeled along their axis. Coxa 4 with groove along the posteroventral border; this groove might be limited by a distinct carina; when present this carina never bears a tooth projecting laterally; posteroventral border concave. Coxae 5-6 without tooth or distinct protrusion. Mid of posterior border of epimeral plates 1-3 not produced into a tooth. Posteroventral tooth of epimeral plate 3 small to medium-sized. Dorsal process of urosomite 1 produced into a sharp tooth directed upwards. Urosomite 2 without pair of small teeth pointing upwards. Lateral borders of urosomite 3 posteriorly terminated into an acute angle. Peduncle of antenna 1 without teeth. Mandible with molar process triturative. Lower lip with narrow (V-shaped) hypopharyngeal gap. Palp of maxilliped with 3 or 4 articles. Gnathopods of normal size, with carpus and propodus elongate, with palm very reduced, forming a weak oblique convexity in continuity with the axis of the propodus (gnathopods nearly achelate); propodus not expanded distally; ornamentation of posterior border of dactylus weak. Basis of pereiopods 5-6 broad, with posteroproximal process present, of variable development (strong nearly dentiform lobe at the base of basis; weak lobe at the base of basis; or a low lobe occupying half of posterior border), with or without posterodistal tooth or lobe (if present not distinctly projecting posteriorly). Posterior border of basis of pereiopod 7 with distinct median blunt angle; the distal half is slightly to distinctly concave; distal corner rounded. Dactylus of pereiopods 5-7 short.

\section{Body length}

The body length recorded in Metepimeria species ranges between 15 and $22.6 \mathrm{~mm}$.

\section{Ecology.}

Benthic, 27-1025 m. 


\section{Distribution}

Sub-Antarctic and low Antarctic seas: Patagonia; Falkland Islands; Shag Rocks; South Georgia; Macquarie Ridge.

\section{Remarks}

Metepimeria was initially erected as a monotypic genus for the Magellanic species Epimeria acanthurus, based on a single character state: the absence of dactylus on the palp of the maxilliped. This character state is most likely autapomorphic, and the recognition of a separate genus for E. acanthurus is not supported here. Epimeria acanthurus is morphologically similar to Epimeria intermedia (South Georgia endemic) and E. ashleyi from Macquarie Ridge. In the present paper, Metepimeria is redefined, as a subgenus for these three species only. However, the New Zealand species, E. sophie Lörz \& Coleman, 2014 (see Lörz \& Coleman 2014) exhibits morphological similarities with them and a future transfer of E. sophie to Metepimeria seems possible.

\section{Key to the species and "forms" of Metepimeria}

1. Palp of maxilliped with 4 articles; posterior border of basis of pereiopods 5-6 with a weak or a strong lobe occupying no more than 0.3 of the border ...................................

- Palp of maxilliped with 3 articles; posterior border of basis of pereiopods 5-6 with a proximal very low expansion occupying half of posterior border E. (Metepimeria) acanthurus (Schellenberg, 1931) [Falkland Islands and Patagonia]

2. Posterior border of basis of pereiopods 5-6 with very strong (nearly dentiform) posteroproximal

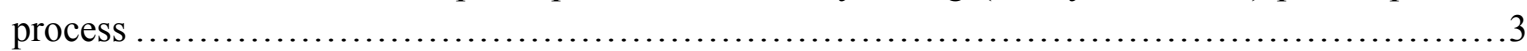

- Posterior border of basis of pereiopods 5-6 with low rounded posteroproximal process........... E. (Metepimeria) ashleyi Lörz, 2012 [Macquarie Ridge: Hjort Seamount]

3. Dorsal carina starting at pereionite 3 ; pleonite 3 posterodorsally terminated in a trapezoidal process E. (Metepimeria) intermedia Schellenberg, 1931 forma A [South Georgia]

- Dorsal carina starting at pereionite 1; pleonite 3 posterodorsally terminated in a triangular process E. (Metepimeria) intermedia Schellenberg, 1931 forma B [South Georgia, Shag Rocks]

Epimeria (Metepimeria) acanthurus (Schellenberg, 1931)

Metepimeria acanthurus Schellenberg, 1931: 162, fig. 85, pl. 1. fig. G.

Epimeria acanthurus - K.H. Barnard 1932: 176, fig. 104B, 108, pl. 1. fig. 2.

Metepimeria acanthurus - Watling \& Holman 1981: 216-217, fig. 22. — Coleman 2007: 61, fig. 36, map 1 (rhomb).

'Epimeria inermis 1' - Rauschert \& Arntz 2015: 61, pl. 54.

non Epimeria inermis Walker, 1903: 54, pl. 10, fig. 69.

\section{Body length}

$22 \mathrm{~mm}$ (Coleman 2007).

\section{Colour pattern}

White with scarce suffusions of orange; eyes reddish (photograph of Rauschert \& Arntz 2015 as 'Epimeria inermis 1'). 


\section{Distribution}

Magellanic Region: Patagonia, Falkland Islands, 27-494 m (De Broyer et al. 2007), Burdwood Bank, 296-299 m (see remarks).

\section{Remarks}

The specimen labelled 'Epimeria inermis 1' in Rauschert \& Arntz (2015) does not correspond to the description of E. inermis: it exhibits important differences in the shape of coxa 4, and the dorsal profiles of pleonite 3 and urosomite 1 . The morphology of this specimen is more similar to E. acanthurus as illustrated by Coleman (2007), and it is therefore identified as such. Rauschert \& Arntz (2015) do not indicate the collection details of their specimen, but this information was found in an early draft of their book made available to the authors: ANT XIX [obviously ANT-XIX/5], LAMPOS, station 153 [i.e., 153-1]. The coordinates of this station are: $54^{\circ} 32.75^{\prime} \mathrm{S} 56^{\circ} 09.84^{\prime} \mathrm{W}$ to $54^{\circ} 31.22^{\prime} \mathrm{S} 56^{\circ} 08.93^{\prime} \mathrm{W}$ [Burdwood Bank], 296-299 m.

Epimeria (Metepimeria) ashleyi Lörz, 2012

Epimeria ashleyi Lörz, 2012: 51, figs 2-7.

\section{Body length}

$22.6 \mathrm{~mm}$.

\section{Distribution}

Hjort Seamount, Macquarie Ridge, 676-1025 m.

\section{Epimeria (Metepimeria) intermedia Schellenberg, 1931 forma A}

Epimeria intermedia Schellenberg, 1931: 161, fig. 84, pl. 1 fig. F.

Epimeria intermedia - Gurjanova 1955: 197. — J.L. Barnard 1961: 103 (key). — De Broyer \& Klages 1991: 165 (key). - Wakabara \& Serejo 1999: 642 (key, in part). — Coleman 2007: 42 (in part), fig. 20a-b, map 10 (circle, in part).

non Epimeria intermedia - K.H. Barnard, 1932: 177, figs 104c, 109 (= Epimeria (Metepimeria) intermedia Schellenberg, 1931 forma B).

\section{Body length}

$18 \mathrm{~mm}$ (Schellenberg 1931).

\section{Distribution}

South Georgia: Cumberland Bay, 75 m (Schellenberg 1931).

\section{Remarks}

See notes on Epimeria (Metepimeria) intermedia forma B.

\section{Epimeria (Metepimeria) intermedia Schellenberg, 1931 forma B}

Epimeria intermedia - K.H. Barnard, 1932: 177, figs 104c, 109. — Wakabara \& Serejo, 1999: 642 (key, in part). - Coleman, 2007: 42 (in part), not fig. 20a-b (= Epimeria (Metepimeria) intermedia forma A), map 10 (circle, in part). 
Epimeria sp. n. 2 - Rauschert \& Arntz, 2015: 60, plate 53, unnumbered photograph.

Epimeria sp. n. 3 - Rauschert \& Arntz, 2015: 125 (non Epimeria sp. n. 3 p. 54 pl. 61).

non Epimeria intermedia Schellenberg, 1931: 161, fig. 84, pl. 1 fig. F. (=Epimeria (Metepimeria) intermedia Schellenberg, 1931 forma A).

\section{Body length}

15 mm (K.H. Barnard 1932).

\section{Colour pattern}

Pure white (Rauschert \& Arntz 2015: 60, as Epimeria sp. n. 2).

\section{Distribution}

South Georgia, 88-273 m (K.H. Barnard 1932); Shag Rocks, 284 m (see remarks).

\section{Remarks}

There are substantial differences between the illustrations of E. intermedia given by Schellenberg (1931) and Coleman (2007) on one hand, and those of K.H. Barnard (1932). Coleman (2007) questions the conspecificity of these specimens. We agree and treat them as separate forma A and B. However we refrain to attribute them a formal taxonomic status, as no direct examination of these specimens was possible.

Rauschert \& Arntz (2015) gave a colour photograph of a juvenile (6 mm) named "Epimeria sp. n. 2", which corresponds to the drawings of Epimeria intermedia forma B given by K.H. Barnard (1932). The collection details of the specimen were given in an early draft of the book: ANT-XIX/5 in stn 169-1, $53^{\circ} 22.94^{\prime} \mathrm{S}, 42^{\circ} 41.37^{\prime} \mathrm{W}$ to $53^{\circ} 22.89^{\prime} \mathrm{S}, 42^{\circ} 41.50^{\prime} \mathrm{W}$ (Shag Rocks), at $284 \mathrm{~m}$.

Subgenus Pseudepimeria Chevreux, 1912

Pseudepimeria Chevreux, 1912: 216 (9 on reprints).

Pseudepimeria - Gurjanova 1955: 189, 190. — J.L. Barnard 1969: 396. — De Broyer 1983: 305 (discussion). — Coleman 1998a: 22 (discussion).

\section{Type species}

Pseudepimeria grandirostris Chevreux, 1912.

\section{Description}

Body opaque, with teguments strongly calcified, very strongly ornamented and sculptured by teeth and carinae. Rostrum long. Eyes conical. Pleonites 1-3 and pereionites 1-7 with strong mid-dorsal tooth. Each pereionite is entirely lined by a strong and sharp transverse carina starting on the mid-dorsal tooth and terminating at the connection with coxa; these transverse carinae bear two pairs of small teeth: a dorsolateral one and a second one just above the connection with coxa. Pleonites 1-2 with one pair of well developed dorsolateral teeth and smaller teeth in various arrangement more ventrally; pleonite 3 with 3 pairs of dorsolateral teeth and smaller teeth in various arrangements more ventrally. Coxae 1-3 (and often coxa 4) with sharp tip. Coxae 1-3 sharply keeled along their axis. Coxa 4 with sharp carina starting at ventral tip of coxa and terminating at posterior tip of coxa; this carina sometimes bears a tooth or a lobe projecting laterally; carina very distant from posteroventral border of coxa at its deepest point; posteroventral border of coxa concave; anterior corner of coxa strongly bulging anteriorly and 
sometimes produced into a tooth. Coxa 5 with strong lateral carina which is laterally or posterolaterally produced into a tooth, which is sometimes very large. Coxa 6 with strong lateral carina which is laterally or posterolaterally produced into a tooth, which is much smaller than that of coxa 5. Posteroventral tooth of epimeral plate 3 strong to very strong. Dorsal process of urosomite 1 produced into a sharp tooth directed upwards. Urosomite 2 with pair of small teeth pointing upwards. Lateral borders of urosomite 3 posteriorly terminated into a sharp tooth or an acute angle. Peduncle of antenna 1 with teeth. Mandible with molar process triturative. Lower lip with narrow (V-shaped) hypopharyngeal gap. Palp of maxilliped with 4 articles. Gnathopods very small, achelate; gnathopod 2 distinctly more slender than gnathopod 1. Basis of pereiopods 5-6 broad, with strong posteroproximal protrusion (which can be acute but not sword-like and which is directed posteriorly) and posterodistal tooth projecting posteriorly. Posterior border of basis of pereiopod 7 with strong median angle followed by deep excavation, terminated into a tooth projecting posteriorly. Merus, carpus and propodus of pereiopods 3-7 very short and very stout; dactylus medium-sized, stout and strongly curved, partly folding on propodus (as if they were designed to clasp on the branches of bushy organisms). Benthic.

\section{Body length}

The maximum body length recorded in Pseudepimeria species ranges between 22 and $35 \mathrm{~mm}$.

\section{Ecology}

Benthic, 50-573 m.

\section{Distribution}

Circum-Antarctic, as far north as the South Orkney Islands.

\section{Remarks}

Of all the Epimeria subgenera, Pseudepimeria is probably the most distinctive. Their highly sculptured and processiform body, and their strong clasping pereiopods 4-7 presumably reflect a specialized habitat. Hydroid remains were found in the stomach of E. (Pseudepimeria) oxicarinata (Coleman 1990a) and pictures of this species clinging on hydroids have been published (Coleman 2007). Coleman (1988) also observed E. grandirostris eating branches of hydroids in an aquarium on the RV Polarstern. Some species are morphologically very similar to each others, but the most similar forms appear to be allopatric. These complexes include the tetrad amoenitas/debroyeri/cf. debroyeri/pulchra and the triad callistal grandirostris/kharieis. Molecular data were not available for all taxa, hence some taxonomic decisions were taken based on morphology alone. Some observed morphological differences are possibly sizedependant, which did not facilitate taxonomic decisions (descriptions are based on adult females only). Immature specimens are assumed to be conspecific with adults of the most similar species found in the same region.

\section{Key to the species of Pseudepimeria}

This key applies to adult females only.

1. Mid-dorsal tooth of pereionite 1 short and not arching forward; mid-dorsal tooth of pereionite 2 equal or slightly shorter than mid-dorsal tooth of pereionite 1; mid-dorsal tooth of pereionites 3-7 and pleonites $1-2$ blunt or not very sharp

- Mid-dorsal tooth of pereionite 1 long and arching forward; mid-dorsal tooth of pereionite 2 considerably shorter than mid-dorsal tooth of pereionite 1; mid-dorsal tooth of pereionites 3-7 and pleonites 1-2 very sharp, sword-like E. (Pseudepimeria) oxicarinata Coleman, 1990 [Elephant Island, North of Nelson Island (Drake Passage)] 
2. Mid-dorsal tooth of pereionites 3-7 and pleonites 1-2 very large and narrow; mid-dorsal tooth of pereionite 1 with anterior border (nearly) straight and perpendicular to body axis; in dorsal view, carina of coxa 4 strongly protruding; in lateral view anterior corner of coxa 4 forming a lobe or tooth well separated (by deep notch) from anteroventral border; carina of coxa 5 posteriorly produced into a very strong tooth pointing obliquely backwards or laterally, of which the tip is narrow: E. (Pseudepimeria) pulchra complex ............................................ 3

- Mid-dorsal tooth of pereionites 3-7 and pleonites 1-2 medium-sized and fairly broad; mid-dorsal tooth of body segment 1 with anterior border convex and/or oblique with body axis; in dorsal view, carina of coxa 4 weakly protruding; in lateral view anterior corner of coxa 4 forming a low lobe poorly separated (by shallow concavity) from anteroventral border; carina of coxa 5 posteriorly produced into a strong to medium-sized tooth pointing backwards or obliquely backwards, of which the tip is broad: E. (Pseudepimeria) grandirostris complex ............................. 5

3. Pleonite 3 with broad to fairly broad triangular mid-dorsal tooth; carina of coxa 4 rounded in dorsal view; posterior border of third epimeral plate convex, curved, not produced into a tooth; gnathopod 1 with carpus and propodus of medium width; gnathopod 2 with carpus and propodus

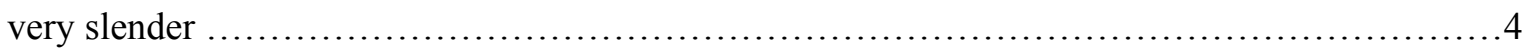

- Pleonite 3 with long sword-like mid-dorsal tooth; carina of coxa 4 bluntly triangular in dorsal view; posterior border of third epimeral plate produced into a tooth; gnathopod 1 with carpus and propodus very robust; gnathopod 2 with carpus and propodus of medium width E. (Pseudepimeria) pulchra Coleman, 1990 [South Orkney Islands]

4. Pleonite 3 with very broad, blunt, triangular mid-dorsal tooth; posterior border of third epimeral plate forming a strongly protruding curved projection; tip of lateral carina of coxa 5 blunt (in dorsal view) ...............E. (Pseudepimeria) debroyeri sp. nov. [eastern and possibly western Weddell Sea]

- Pleonite 3 with fairly broad and acute-tipped mid-dorsal tooth; posterior border of third epimeral plate weakly curved; tip of lateral carina of coxa 5 sharp (in dorsal view)

E. (Pseudepimeria) amoenitas sp. nov. [Adélie Coast]

5. Posteroproximal projection of basis of pereiopod 5 rounded; posterior border of basis of pereiopod 7 bluntly angulate in proximal 0.75

- Posteroproximal projection of basis of pereiopod 5 acutely triangular; posterior border of basis of pereiopod 7 with rounded discontinuity in proximal 0.75

E. (Pseudepimeria) grandirostris (Chevreux, 1912) [Antarctic Peninsula and South Shetland Islands]

6. In dorsal view, lateral border carina of coxa 5 distinctly oblique; posteroproximal projection of basis of pereiopod 6 produced into a sharp triangular tooth; dactylus of gnathopod 2 very broad E. (Pseudepimeria) callista sp. nov. [Adélie Coast]

- In dorsal view, lateral border of carina of coxa 5 almost parallel to body axis; posteroproximal projection of basis of pereiopod 6 produced into a bluntly angulate lobe; dactylus of gnathopod 2 moderately broad E. (Pseudepimeria) kharieis sp. nov. [Eastern Weddell Sea] 
Epimeria (Pseudepimeria) amoenitas sp. nov. urn:1sid:zoobank.org:act:191AE45C-F84D-412A-B0E1-CFA3251C5824

Figs 251-256

'Clade H grandirostris-pulchra-oxicarinata complex - PUL1' - Verheye et al. 2016a, supplement: 5 (online).

\section{Etymology}

From the Latin, amoenitas, -tatis: pleasantness, delightfulness, loveliness. This name, which is a noun in apposition, has been coined because the species is as elegant as its close relative Epimeria pulchra, of which the specific epithet means beautiful.

\section{Type material}

\section{Holotype}

RV Aurora Australis cruises:

SOUTHERN OCEAN: + with hatchlings, cruise CEAMARC, sample CEAMARC 3978, stn 36EV297,

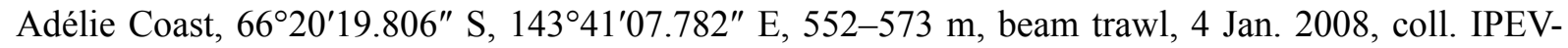
AAD-MNHN (MNHN-IU-2014-4327).

\section{Paratype}

RV Aurora Australis cruises:

SOUTHERN OCEAN: 1 spec., cruise CEAMARC, sample 'CEAMARC V3 stn 158', stn 28EV53,

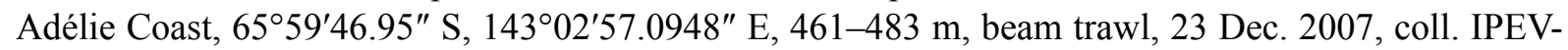
AAD-MNHN (MNHN-IU-2014-4284) [extraction M14; Genbank nr, COI: KU870881].

\section{Description}

RosTRUM. Long, overreaching tip of peduncle of antenna 1; in lateral view, anteriorly weakly curved in its middle and forming a blunt very obtuse angle with head, ventrally straight, tip not abruptly curving downwards; in frontal view, fairly narrow, with weakly convex borders, with subacute tip.

EYE. Medium-sized, conical.

Pereion-Pleosome tooth pattern. Pereionite 1 with medium-sized fairly broad and blunt-tipped middorsal tooth pointing upwards, of which the anterior border is straight and the posterior border is strongly convex, with pair of well-developed, blunt, dorsolateral teeth and pair of small ventrolateral teeth; pereionite 2 much narrower than pereionites 1 and 3, with small narrow blunt-tipped tooth pointing upwards (a bit shorter than mid-dorsal tooth of pereionite 1 and much shorter than mid-dorsal tooth of pereionite 3), with pair of small very blunt dorsolateral teeth, and pair of small ventrolateral teeth; pereionite 3 with large, broad and blunt mid-dorsal tooth pointing upwards, of which the anterior and the posterior borders are both strongly convex, with pair of medium-sized, low and blunt dorsolateral teeth, and pair of small ventrolateral teeth; pereionites 4-7 with large and broad mid-dorsal tooth pointing upwards, of which the anterior border is strongly convex and the posterior border weakly convex to nearly straight, and of which the tip is bluntly angulate to subacute, and with pair of medium-sized, low and blunt dorsolateral teeth, and pair of small ventrolateral teeth; pleonites 1-2 with large and broad mid-dorsal tooth pointing upwards, of which the anterior border is strongly convex (regularly convex for pleonite 1, with weak median angular discontinuity in pleonite 2) and the posterior border straight, of which the tip is subacute, with pair of large subacute dorsolateral teeth (anteriorly preceded by small but sharp denticle); pleonite 3 with medium-sized mid-dorsal tooth pointing upwards, of medium width, of which the anterior border is proximally convex and distally weakly concave, the tip narrow and acute 
and the posterior border nearly straight, with 5 pairs of dorsolateral teeth (the most posterior one very large and blunt).

COXAE $1-3$. Strongly carinate and distally sharp.

Coxa 4. Anterodorsal border straight; anteroventral border with proximal very distinct notch forming an obtuse angle, with distal part straight; anterior angle rounded and projecting forward; ventral tooth long, narrow and acute, directed backwards; lateral carina with rounded lobe strongly projecting laterally, posteriorly followed by fairly deep rounded concavity; in lateral view, inner corner of carina forming a distinct squared angle; in lateral view posteroventral border of coxa deeply concave, the deepest point of this concavity forming a blunt squared angle (more anteriorly and more distally the posterior border is nearly straight).

Coxa 5. In dorsal view, with very long, triangular, carinate, lateral tooth, of which the anterior border points obliquely backwards and the posterior border is nearly perpendicular to body axis (very weakly pointing backwards); tip of carina sharp.

Coxa 6. With triangular carinate lateral tooth of which the anterior border points obliquely backwards and the posterior border is nearly perpendicular to body axis (very weakly pointing onwards) (character to be examined in dorsal view); tip of carina sharp.

Coxa 7. With ventral border distinctly curved, with posterior border very weakly concave, these two borders being joined by a broad curve.

EPIMERAL PLATES 1-3. Plate 1 with posteroventral angle bluntly angulate, with distinct lateral carina and 2 lateral teeth; plate 2 with posteroventral angle sharply angulate (forming a sharp tooth in squared angle), with distinct lateral carina and 2 lateral teeth; plate 3 with posteroventral angle produced into a long tooth, with distinct lateral carina and 1 lateral tooth, with posterior margin weakly convex.

UROSOME TOOTH PATTERN. Urosomite 1 with sharp narrow tooth pointing upwards, not anteriorly preceded by pair of denticles; urosomite 2 with pair of mid-sized posterior dorsolateral teeth pointing upwards; urosomite 3 with pair of mid-sized posterior dorsolateral teeth pointing upwards.

TELSON. Cleft on 0.4; tips of lobes subacute, notch forming a narrow slit.

Peduncle of antenna 1. Article 1 with anterior border concave, with strong anterior and posterior tooth; article 2 with strong lateral triangular tooth; article 3 with strong ventral tooth.

GNATHOPODS 1-2. Very small, achelate; carpus and propodus of normal slenderness in gnathopod 1 (propodus tapering), extremely narrow in gnathopod 2; dactylus of gnathopod 2 moderately broad and posteriorly straight.

Pereiopods 3-4. Merus, carpus and propodus extremely broad and short; dactylus fairly large, strongly curved on both sides, clasping.

Pereiopods 5-6. Basis of normal width, with posteroproximal process sharply triangular, with posterodistal tooth strong, narrow and sharp; merus, carpus and propodus extremely broad and short; dactylus fairly large, strongly curved on both sides, clasping.

PeReIOPOD 7. Basis broad; posterior border parallel to axis of basis in proximal 0.75; at this level it forms a distinct squared angle, which is followed by a deep concavity; this concavity forms a rounded obtuse (nearly squared) angle; the posterodistal corner is produced into a long narrow tooth pointing 
obliquely backwards; merus, carpus and propodus extremely broad and short; dactylus fairly large, strongly curved on both sides, clasping.

\section{Body length}

Up to $35 \mathrm{~mm}$.

\section{Distribution}

Adélie Coast, 461-573 m.

\section{Remarks}

Epimeria amoenitas sp. nov. (Adélie Coast) is very similar to E. debroyeri sp. nov. (eastern shelf of the Weddell Sea). In E. amoenitas sp. nov., pleonite 3 has a fairly broad and acute-tipped mid-dorsal tooth, whilst in E. debroyeri sp. nov., the same tooth is very broad and bluntly triangular. In E. amoenitas sp. nov., the posterior border of third epimeral plate is weakly curved, whilst in E. debroyeri sp. nov., it forms a strongly protruding curved projection. Finally, in E. amoenitas sp. nov., the tip of the lateral carina of coxa 5 is sharp in dorsal view, whilst in E. debroyeri sp. nov., it is blunt.

Epimeria (Pseudepimeria) callista sp. nov. urn:1sid:zoobank.org:act:8E717EF2-0CC3-4796-859D-90F60B661961

Figs 257-264

Epimeria grandirostris - Bellan-Santini, 1972: 223.

'Clade H grandirostris-pulchra-oxicarinata complex - GR2' - Verheye et al. 2016a, supplement: 5 (online).

non Pseudepimeria grandirostris Chevreux, 1912: 216.

\section{Etymology}

From the Greek, $\kappa \alpha \lambda \lambda \iota \sigma \tau \varsigma$, Latinized as callistus, $-a,-u m$, adjective meaning very beautiful, the most beautiful.

\section{Type material}

\section{Holotype}

RV Aurora Australis cruises:

SOUTHERN OCEAN: adult $q$, cruise CEAMARC, sample CEAMARC 3978, stn 36EV297, Adélie Coast, $6^{\circ} 20^{\prime} 20^{\prime \prime} \mathrm{S}, 143^{\circ} 41^{\prime} 08^{\prime \prime} \mathrm{E}, 552-573 \mathrm{~m}$, beam trawl, 4 Jan. 2008, coll. IPEV-AAD-MNHN (MNHN-IU-2014-7336, removed from MNHN-IU-2014-4327) [Extraction P40; Genbank nr, 28S: KU759683].

\section{Paratypes}

RV Aurora Australis cruises:

SOUTHERN OCEAN: 1 dissected adult + , cruise CEAMARC, sample CEAMARC 3978, stn 36EV297, Adélie Coast, $66^{\circ} 20^{\prime} 20^{\prime \prime} \mathrm{S}, 143^{\circ} 41^{\prime} 08^{\prime \prime} \mathrm{E}, 552-573 \mathrm{~m}$, beam trawl, 4 Jan. 2008, coll. IPEV-AAD-MNHN, (MNHN-IU-2014-7337, removed from MNHN-IU-2014-4327).

RV Seatruck cruises:

SOUTHERN OCEAN: 1 small and damaged spec., cruise REVOLTA II, stn REVO_029, Collect_ID: REVO_183, Adélie Coast, 66³9'30" S, 14001'59" E, 97-103 m, beam trawl, 26 Jan. 2011, coll. N. Améziane, N. Bax, C. Gallut, A.C. Lautrédou and C. Robineau (MNHN-IU-2014-4300). 


\section{Description}

RosTRUM. Long, overreaching tip of peduncle of antenna 1; in lateral view, regularly curved along all its length, not forming an angle with head, ventrally straight, tip not abruptly curving downwards; in frontal view, fairly narrow, with weakly convex borders, with acute tip.

EyE. Medium-sized, conical.

Pereion-Pleosome tooth pattern. Pereionite 1 with low, very broad, rounded mid-dorsal tooth of which the anterior border is very oblique, with pair of well-developed, rounded, dorsolateral teeth and pair of small ventrolateral teeth; pereionite 2 much narrower than pereionites 1 and 3 , with small broad rounded tooth pointing upwards (as high as mid-dorsal tooth of pereionite 1 and distinctly shorter than middorsal tooth of pereionite 3), with pair of very small dorsolateral teeth, and pair of small ventrolateral teeth; pereionite 3 with medium-sized, broad and rounded mid-dorsal tooth of which the anterior and the posterior borders are both strongly convex, with pair of medium-sized, low and blunt dorsolateral teeth, and pair of small ventrolateral teeth; pereionites 4-7 with fairly large and broad mid-dorsal tooth pointing upwards, of which the anterior border is strongly convex and the posterior border nearly straight, and of which the tip is bluntly angulate, and with pair of medium-sized, low and blunt dorsolateral teeth, and pair of small ventrolateral teeth; pleonites 1-2 with large and broad mid-dorsal tooth pointing upwards, of which the anterior border is strongly and regularly convex and the posterior border straight, and of which the tip is subacute, and with pair of large subacute dorsolateral teeth and 4 pairs of much smaller denticles; pleonite 3 with medium-sized, fairly broad, triangular mid-dorsal tooth pointing upwards, of which the anterior border is proximally convex, medially concave and distally straight, the tip subacute and the posterior border nearly straight, with 5 pairs of dorsolateral teeth.

COXAE $1-3$. Strongly carinate and distally sharp.

Coxa 4. Anterodorsal border nearly straight; anteroventral border with proximal very shallow concavity, with distal part distinctly convex; anterior angle very broadly rounded and slightly projecting forward; ventral tooth long, broad and subacute, directed backwards; lateral carina with broadly rounded lobe distinctly projecting laterally, posteriorly followed by fairly deep rounded concavity and small extremely low second lobe; in lateral view, inner corner of carina forming a distinct squared angle; in lateral view posteroventral border of coxa deeply concave; the concavity is rounded, not distinctly angulate.

Coxa 5. In dorsal view, with medium-sized, triangular, carinate, lateral tooth, of which the anterior border points weakly obliquely backwards and the posterior border is nearly perpendicular to body axis; tip of carina broadly rounded.

Coxa 6. With triangular carinate lateral tooth of which the anterior border points obliquely backwards and the posterior border is nearly perpendicular to body (character to be examined in dorsal view); tip of carina subacute.

CoxA 7. With ventral + posterior borders forming a regular curve, with small lateral tooth.

EPIMERAL PLATES 1-3. Plate 1 with posteroventral angle angulate, with distinct lateral carina and 2 lateral teeth; plate 2 with posteroventral angle sharply angulate (forming a distinct blunt-tipped tooth in squared angle), with distinct lateral carina and 2 lateral teeth; plate 3 with posteroventral angle produced into a fairly long tooth, with distinct lateral carina and 1 lateral tooth, with posterior margin weakly convex.

UROSOME TOOTH PATTERN. Urosomite 1 with sharp narrow tooth pointing upwards, not anteriorly preceded by pair of denticles; urosomite 2 with pair of tiny posterior dorsolateral teeth pointing upwards; urosomite 3 with pair of mid-sized posterior dorsolateral teeth pointing upwards. 
TeLson. Cleft on 0.35 ; tips of lobes rounded, notch forming a fairly narrow slit.

Peduncle of antenna 1. Article 1 with anterior border weakly concave, with trace of anterior and posterior tooth; article 2 with medium-sized lateral triangular tooth; article 3 with weak ventral tooth.

GNathopods 1-2. Very small, achelate; carpus and propodus of normal slenderness in gnathopod 1 (propodus tapering), extremely narrow in gnathopod 2; dactylus of gnathopod 2 very broad and posteriorly strongly convex.

Pereiopods 3-4. Merus, carpus and propodus extremely broad and short; dactylus fairly large, strongly curved on both sides, clasping.

PEREIOPOD 5. Basis of normal width, with posteroproximal process rounded and strongly protruding, with posterodistal tooth fairly strong, triangular and sharp; merus, carpus and propodus extremely broad and short; dactylus fairly large, strongly curved on both sides, clasping.

PEREIOPOD 6. Basis of normal width, with posteroproximal process acutely triangular, with posterodistal tooth strong, narrow and sharp; merus, carpus and propodus extremely broad and short; dactylus fairly large, strongly curved on both sides, clasping.

PeREIOPOD 7. Basis broad; posterior border distinctly diverging from axis of basis in proximal 0.75 ; at this level it forms a distinct nearly squared (very slightly obtuse) angle, which is followed by a deep concavity; this concavity forms a broadly rounded curve; the posterodistal corner is produced into a long narrow tooth pointing obliquely backwards.

\section{Body length}

Up to $22 \mathrm{~mm}$.

\section{Distribution}

Adélie Coast, $97-573 \mathrm{~m}$.

\section{Remarks}

Epimeria callista sp. nov. (Adélie Coast) is very similar to E. kharieis sp. nov. (eastern shelf of the Weddell Sea) and E. grandirostris (Antarctic Peninsula and surrounding islands). Molecular phylogenetic analysis of 28S rDNA (Verheye et al. 2016a) supports the species status of E. callista sp. nov. and E. grandirostris. Epimeria kharieis sp. nov. is herein recognized as a distinct species based on morphology alone, as the type material was not suitable for genetic studies. See key of the subgenus Pseudepimeria for differences between the three species. Allometric differences have been observed in immatures and juveniles of these species, therefore the morphological characters given in the key and descriptions refer to adult females only.

Epimeria (Pseudepimeria) debroyeri sp. nov. urn:1sid:zoobank.org:act:05C0B30A-F5BD-40C0-A3FC-07DE05BFB375

Figs 265-271

Epimeria pulchra - Coleman 2007: 47, in part, colour plate 2 fig. f, not fig. 24a-b (= E. pulchra). Lörz \& Coleman 2009: unnumbered photograph on p. 17. - Rauschert \& Arntz 2015: 62, pl. 55, unnumbered photograph.

non Epimeria pulchra Coleman, 1990a: 166-176, pls 10-16. 


\section{Etymology}

The species is dedicated to Claude De Broyer (Royal Belgian Institute of Natural Sciences), who collected the holotype of the species. The name is a genitive.

\section{Type material}

\section{Holotype}

RV Polarstern cruises:

SOUTHERN OCEAN: large +, cruise PS14, ANT-VII/4, EPOS leg 3, stn 291 (GSN 14), eastern Weddell Sea, $71^{\circ} 06.1^{\prime} \mathrm{S}, 12^{\circ} 33.5^{\prime} \mathrm{W}$ to $71^{\circ} 05.9^{\prime} \mathrm{S}, 12^{\circ} 34.8^{\prime} \mathrm{W}, 499-515 \mathrm{~m}$, bottom trawl, 19 Feb. 1989 , coll. C. De Broyer (RBINS, INV. 132940).

\section{Description}

Rostrum. Long, overreaching tip of peduncle of antenna 1; in lateral view, anteriorly weakly curved in its middle and forming a blunt very obtuse angle with head, ventrally straight, tip abruptly curving downwards; in frontal view, fairly narrow, with weakly convex borders, with subacute tip.

EYE. Medium-sized, conical.

Pereion-Pleosome tooth pattern. Pereionite 1 with medium-sized broad and blunt-tipped mid-dorsal tooth pointing upwards of which the anterior border is straight and the posterior border is strongly convex, with pair of well-developed, blunt, dorsolateral teeth and pair of small ventrolateral teeth; pereionite 2 much narrower than pereionites 1 and 3, with small narrow blunt-tipped tooth pointing upwards (a bit shorter than mid-dorsal tooth of pereionite 1 and much shorter than mid-dorsal tooth of pereionite 3 ), with pair of small very blunt dorsolateral teeth, and pair of small ventrolateral teeth; pereionites 3-4 with large, broad and blunt to subangulate mid-dorsal tooth pointing upwards, of which the anterior and the posterior borders are both strongly convex, with pair of medium-sized, low and blunt dorsolateral teeth, and pair of small ventrolateral teeth; pereionites 5-7 with large and broad mid-dorsal tooth pointing upwards, of which the anterior border is strongly convex and the posterior border weakly convex, of which the tip is bluntly angulate to subacute, with pair of medium-sized, low and blunt dorsolateral teeth, and pair of small ventrolateral teeth; pleonites 1-2 with large and broad mid-dorsal tooth pointing upwards, of which the anterior border is strongly convex (with weak median angular discontinuity) and the posterior border nearly straight, of which the tip is subacute, with pair of large subacute dorsolateral teeth (anteriorly preceded by small but sharp denticle); pleonite 3 with very broad medium-sized middorsal tooth pointing upwards, of which the anterior border is convex, the tip broad and subangulate and the posterior border weakly convex, with 5 pairs of dorsolateral teeth.

COXAE $1-3$. Strongly carinate and distally blunt.

Coxa 4. Anterodorsal border weakly but distinctly concave; anteroventral border with proximal very distinct notch forming an obtuse angle, with distal part convex; anterior angle rounded to very bluntly angulate and projecting forward; ventral tooth long, narrow and acute, directed backwards; lateral carina with rounded to very bluntly angulate lobe strongly projecting laterally, posteriorly followed by fairly shallow rounded concavity, and more backwards by a second, very low lobe projecting laterally; in lateral view, inner corner of carina forming a distinct obtuse (nearly squared) angle; in lateral view posteroventral border of coxa deeply concave, the deepest point of this concavity forming a blunt squared angle (more anteriorly and more distally the posterior border is nearly straight).

Coxa 5. In dorsal view, with very long, triangular, carinate, lateral tooth, of which the anterior border points obliquely strongly backwards and the posterior border is also distinctly pointing backwards); tip of carina blunt. 
Coxa 6. With triangular carinate lateral tooth of which the anterior border points obliquely backwards and the posterior border is nearly perpendicular to body axis (very weakly pointing onwards) (character to be examined in dorsal view); tip of carina subacute.

Coxa 7. With ventral border distinctly curved, with posterior border straight, these two borders being joined by a broad curve.

Epimeral PLATES 1-3. Plate 1 with posteroventral angle broadly rounded, with distinct lateral carina and 1 lateral tooth; plate 2 with posteroventral angle sharply angulate (forming a sharp tooth in squared angle), with distinct lateral carina and 1 lateral tooth; plate 3 with posteroventral angle produced into a long tooth, with distinct lateral carina and 1 lateral tooth, with posterior margin very strongly convex.

UROSOME TOOTH PATTERN. Urosomite 1 with sharp narrow tooth pointing upwards, anteriorly preceded by pair of denticles; urosomite 2 with pair of mid-sized posterior dorsolateral teeth pointing upwards; urosomite 3 with pair of mid-sized posterior dorsolateral teeth pointing obliquely backwards.

Telson. Cleft on 0.2 ; tips of lobes subacute, notch forming a broad V.

Peduncle of antenna 1. Article 1 with anterior border concave, with strong anterior and posterior tooth; article 2 with strong lateral triangular tooth; article 3 with strong ventral tooth.

GNATHOPODs 1-2. Very small, achelate; carpus and propodus of normal slenderness in gnathopod 1 (propodus tapering), extremely narrow in gnathopod 2; dactylus of gnathopod 2 fairly narrow and posteriorly straight.

Pereiopods 3-4. Merus, carpus and propodus extremely broad and short; dactylus fairly large, strongly curved on both sides, clasping.

PeREIOPODS 5-6. Basis of normal width, with posteroproximal process sharply triangular, with posterodistal tooth strong, narrow and sharp; merus, carpus and propodus extremely broad and short; dactylus fairly large, strongly curved on both sides, clasping.

PEREIOPOD 7. Basis broad; posterior border parallel to axis of basis in proximal 0.75; at this level it forms a distinct acute (nearly squared) angle, which is followed by a deep concavity; this concavity forms a rounded obtuse (nearly squared) angle; the posterodistal corner is produced into a long narrow tooth pointing obliquely backwards; merus, carpus and propodus extremely broad and short; dactylus fairly large, strongly curved on both sides, clasping.

\section{Colour pattern}

Body and appendages entirely white; eye reddish (Coleman 2007: 47, colour plate 2f; Rauschert \& Arntz 2015: 62, pl. 55, both as Epimeria pulchra).

\section{Body length}

$33 \mathrm{~mm}$.

\section{Distribution}

Eastern shelf of the Weddell Sea, 499-515 m. 


\section{Remarks}

Epimeria debroyeri sp. nov. (eastern shelf of the Weddell Sea) is very similar to E. amoenitas sp. nov. (Adélie Coast). See key and account on E. amoenitas sp. nov. The specimen of E. debroyeri sp. nov. illustrated by a photograph as E. pulchra in Coleman (2007) and reproduced in Rauschert \& Arntz (2015) was collected on the eastern shelf of the Weddell Sea. Indeed, in an early draft of Rauschert \& Arntz's (2015) book, it was indicated that this specimen was collected during the cruise ANT-XIII/3 dedicated to the study of that region.

\section{Epimeria (Pseudepimeria) cf. debroyeri}

Fig 272

\section{Material examined}

RV Polarstern cruises:

SOUTHERN OCEAN: 1 juv., cruise PS69, ANT-XXIII/8, stn 614-3/4/5, Elephant Island, 60 $52.37^{\prime}$ S, $55^{\circ} 29.80^{\prime} \mathrm{W}$ to $60^{\circ} 52.71^{\prime} \mathrm{S}, 55^{\circ} 27.83^{\prime} \mathrm{W}, 248-265 \mathrm{~m}$, a lot of epifauna, Rauschert dredge and Agassiz trawl, 22 Dec. 2006, coll. C. d'Udekem d'Acoz and H. Robert (RBINS, INV. 132941); 1 white juv., photographed, cruise PS69, ANT-XXIII/8, stn 728-2, south of Dundee Island, $63^{\circ} 42.63^{\prime} \mathrm{S}, 56^{\circ} 01.63^{\prime} \mathrm{W}$ to $63^{\circ} 42.25^{\prime} \mathrm{S}, 56^{\circ} 02.16^{\prime} \mathrm{W}, 293-298 \mathrm{~m}$, Agassiz trawl, 24 Jan. 2007, coll. C. d'Udekem d'Acoz and H. Robert (RBINS, INV. 122524).

\section{Colour pattern}

Body and appendages entirely white; eyes reddish.

\section{Remarks}

These two specimens possibly belong to Epimeria debroyeri sp. nov. However, they are much smaller $(8 \mathrm{~mm}$ instead of $33 \mathrm{~mm})$ and exhibit a number of differences, especially in the development of their mid-dorsal crests. It has to be noted that these differences might be size-related. The two specimens are therefore referred as E. cf. debroyeri.

Epimeria (Pseudepimeria) grandirostris (Chevreux, 1912)

Figs 273-282

Pseudepimeria grandirostris Chevreux, 1912: 216.

Pseudepimeria grandirostris - Chevreux 1913: 154, figs 44-46. - De Broyer 1983: 305 (in part), pl. 100.

Epimeria grandirostris - Coleman 1990a: 151-158, pls 1-4. — De Broyer \& Klages 1991: 165 (key). Wakabara \& Serejo 1999: 641 (key). - Coleman 2007: 38, in part, fig. 17a-b, not colour plate $2 \mathrm{~b}$ (=E. kharieis sp. nov.), map 8 (rhomb), in part.

'Clade H grandirostris-pulchra-oxicarinata complex - GR1' - Verheye et al. 2016a, supplement: 5 (online).

\section{Material examined}

RV Polarstern cruises:

SOUTHERN OCEAN: 1 very small juv., PS69, ANT-XXIII/8, stn 614-3/4/5, Elephant Island, $60^{\circ} 52.37^{\prime}$ $\mathrm{S}, 55^{\circ} 29.80^{\prime} \mathrm{W}$ to $60^{\circ} 52.71^{\prime} \mathrm{S}, 55^{\circ} 27.83^{\prime} \mathrm{W}, 248-265 \mathrm{~m}$, a lot of epifauna, Agassiz trawl, $22 \mathrm{Dec} .2006$, coll. C. d'Udekem d'Acoz and H. Robert (RBINS, INV. 122523); 1 small spec., PS69, ANT-XXIII/8, stn 605-1, Elephant Island, $61^{\circ} 20.35^{\prime} \mathrm{S}, 55^{\circ} 29.16^{\prime} \mathrm{W}$ to $61^{\circ} 19.98^{\prime} \mathrm{S}, 55^{\circ} 32.67^{\prime} \mathrm{W}, 146-151 \mathrm{~m}$, bottom trawl, 19 Dec. 2006, coll. C. d'Udekem d'Acoz and H. Robert (RBINS, INV. 122530); 1 small spec., 
PS69, ANT-XXIII/8, stn 608-1, Elephant Island, $61^{\circ} 11.34^{\prime} \mathrm{S}, 54^{\circ} 43.17^{\prime} \mathrm{W}$ to $61^{\circ} 11.80^{\prime} \mathrm{S}, 54^{\circ} 40.05^{\prime}$ W, 284-293 m, bottom trawl, 20 Dec. 2006, coll. C. d'Udekem d'Acoz and H. Robert (RBINS, INV. 122626); 1 small spec., PS69, ANT-XXIII/8, stn 654-6, Elephant Island, $61^{\circ} 22.80^{\prime} \mathrm{S}, 56^{\circ} 03.84^{\prime} \mathrm{W}$ to 61 ${ }^{\circ} 23.35^{\prime} \mathrm{S}, 56^{\circ} 04.89^{\prime} \mathrm{W}, 341-342 \mathrm{~m}$, Agassiz trawl, 29 Dec. 2006, coll. C. d'Udekem d'Acoz and H. Robert (RBINS, INV. 122484); 1 adult +, PS81, ANT-XXIX/3, stn 185-3, south east of Dundee Island, $63^{\circ} 51.34^{\prime} \mathrm{S}, 55^{\circ} 41.11^{\prime} \mathrm{W}$ to $63^{\circ} 51.52^{\prime} \mathrm{S}, 55^{\circ} 41.43^{\prime} \mathrm{W}$, bottom not muddy with a lot of life (sponges, starfishes, ophiuroids, crinoids, Pentapora-like bryozoans), 261-296 m, Agassiz trawl, 19 Feb. 2013:, coll. C. d'Udekem d'Acoz and M. Verheye (RBINS, INV. 122946) [extraction ANT46; Genbank nr, COI: KU870832, 28S: KU759605]; 1 badly damaged small spec., PS81, ANT-XXIX/3, stn 197-6, Bransfield Strait, $62^{\circ} 45.05^{\prime}$ S, $57^{\circ} 26.68^{\prime} \mathrm{W}$ to $62^{\circ} 45.09^{\prime} \mathrm{S}, 57^{\circ} 26.47^{\prime} \mathrm{W}, 210-222 \mathrm{~m}$, black gravel mixed with sand and a little bit of mud, Rauschert dredge, 25 Feb. 2013, coll. C. d'Udekem d'Acoz and M. Verheye (RBINS, INV. 122950) [extraction ANT47; Genbank nr, COI: KU870833, 28S: KU759606]

\section{Description}

Description based on adult female of ANT-XXIX/3, stn 185-3 (RBINS, INV. 122946).

Rostrum. Long, overreaching tip of peduncle of antenna 1; in lateral view, proximally nearly straight, distinctly curved on second 0.3 , not forming a distinct angle with head, ventrally straight, tip not abruptly curving downwards; in frontal view, fairly broad, with weakly convex borders, with acute tip.

Eye. Medium-sized, conical.

Pereion-Pleosome tooth pattern. Pereionite 1 with low, very broad, rounded mid-dorsal tooth, of which the anterior border is very oblique, with pair of well-developed, rounded, dorsolateral teeth and pair of small ventrolateral teeth; pereionite 2 much narrower than pereionites 1 and 3 , with small broad rounded tooth pointing upwards (as high as mid-dorsal tooth of pereionite 1 and distinctly shorter than mid-dorsal tooth of pereionite 3), with pair of very small dorsolateral teeth, and pair of small ventrolateral teeth; pereionites 3-7 with fairly large, broad and rounded mid-dorsal tooth of which the anterior and posterior borders are both strongly convex, with pair of medium-sized, low and blunt dorsolateral teeth, and pair of small ventrolateral teeth; pleonites 1-2 with large and broad mid-dorsal tooth pointing upwards, of which the anterior border is strongly and regularly convex (less convex in pleonite 2 ) and the posterior border straight, and of which the tip is subacute, and with pair of large subacute dorsolateral teeth and 4 pairs of much smaller denticles; pleonite 3 with medium-sized, fairly broad, triangular mid-dorsal tooth pointing upwards, of which the anterior border is straight (except for proximal tiny protrusion), the tip acute and the posterior border slightly but distinctly convex, with 5 pairs of dorsolateral teeth.

COXAE $1-3$. Strongly carinate and distally sharp.

Coxa 4. Anterodorsal border nearly straight; anteroventral border with inconspicuous concavity, with distal part distinctly convex; anterior angle extremely broadly rounded and not projecting forward; ventral tooth well developed, very broad and subacute directed backwards; lateral carina with low, very broadly rounded lobe distinctly projecting laterally, posteriorly not followed by concavity and not followed by second smaller lobe; in lateral view, the carina is forming a regular, strongly arching curve and is not at all angulate; in lateral view posteroventral border of coxa deeply concave; the concavity is rounded, not distinctly angulate.

Coxa 5. In dorsal view, with medium-sized, triangular, carinate, lateral tooth, of which the anterior border points distinctly obliquely backwards and the posterior border is nearly perpendicular to body axis; tip of carina broadly rounded. 
Coxa 6. Triangular carinate lateral tooth of which the anterior border points obliquely backwards and the posterior border is nearly perpendicular to body (character to be examined in dorsal view); tip of carina very blunt.

Coxa 7. With ventral + posterior borders forming a regular curve, with small lateral tooth.

EPimeral Plates 1-3. Plate 1 with posteroventral angle sharply angulate and with small triangular tooth, with distinct lateral carina and 2 lateral teeth; plate 2 with posteroventral angle sharply angulate and produced into a small triangular tooth, with distinct lateral carina and 2 lateral teeth; plate 3 with posteroventral angle produced into a fairly long tooth, with distinct lateral carina and 1 lateral tooth, with posterior margin distinctly convex.

UROSOME TOOTH PATTERN. Urosomite 1 with sharp narrow tooth pointing upwards, not anteriorly preceded by pair of denticles; urosomite 2 with pair of tiny posterior dorsolateral teeth pointing upwards; urosomite 3 with pair of mid-sized posterior dorsolateral teeth pointing upwards.

TeLson. Cleft on 0.25 ; lobes laterally very convex, blunt-tipped, notch fairly narrow.

PedunCle of ANTEnNa 1. Article 1 with anterior border weakly concave, with low anterior and posterior tooth; article 2 with medium-sized lateral triangular tooth; article 3 with weak ventral tooth.

GNATHOPODS 1-2. Very small, achelate; carpus and propodus of normal slenderness in gnathopod 1 (propodus tapering), extremely narrow in gnathopod 2; dactylus of gnathopod 2 very broad and posteriorly weakly convex.

PEREIOPODS 3-4. Merus, carpus and propodus extremely broad and short; dactylus fairly large, strongly curved on both sides, clasping.

PEREIOPOD 5. Basis of normal width, with posteroproximal process triangular and sharp, with posterodistal tooth fairly strong, triangular and sharp; merus, carpus and propodus extremely broad and short; dactylus fairly large, strongly curved on both sides, clasping.

PEREIOPOD 6. Basis 6 of normal width, with posteroproximal process triangular and subacute, with posterodistal tooth strong, narrow and sharp; merus, carpus and propodus extremely broad and short; dactylus fairly large, strongly curved on both sides, clasping.

PEREIOPOD 7. Basis broad; posterior border distinctly diverging from axis of basis in proximal 0.75 ; at this level it forms a very blunt obtuse angle, which is followed by a distinct concavity; this concavity forms a broadly rounded curve; the posterodistal corner is produced into a long triangular tooth pointing obliquely backwards; merus, carpus and propodus extremely broad and short; dactylus fairly large, strongly curved on both sides, clasping.

\section{Allometric variations}

See photographs of immatures (Figs 279-282).

\section{Colour pattern}

Orange red mottling on a whitish background.

\section{Body length}

Up to $25 \mathrm{~mm}$. 


\section{Distribution}

Marguerite Bay, 254 m [type locality] (Chevreux 1912, 1913); Elephant Island, Bransfield Strait, northwestern Weddell Sea (Dundee Island); 146-342 m (present material). For an inventory of older records of Epimeria of the grandirostris complex, see De Broyer et al. (2007), as Epimeria grandirostris.

\section{Biology}

Coleman (1988) observed E. grandirostris eating branches of hydroids in an aquarium on the RV Polarstern.

\section{Remarks}

The populations of the E. grandirostris complex sampled in the eastern Weddell Sea and Adélie Coast are described herein as distinct species, respectively E. kharieis sp. nov. and E. callista sp. nov. See key of the subgenus Pseudepimeria for the main diagnostic characters of adult females.

Epimeria (Pseudepimeria) kharieis sp. nov. urn:1sid:zoobank.org:act:1B3DC61B-C54C-4D63-AAC6-29A5BD8807A7

Figs 283-290

Pseudepimeria grandirostris - Klages 1988: 74, 75, unnumbered fig., 78, fig. 16c.

Epimeria grandirostris - Coleman 2007: 38, in part, colour plate 2 fig. b only. - Rauschert \& Arntz 2015: 61, 125, pl. 54 (adult and juvenile).

non Pseudepimeria grandirostris Chevreux, 1912: 216.

\section{Etymology}

Derived from the Greek adjective $\chi \alpha \rho i \varepsilon 1 \varsigma$, meaning graceful and beautiful, and Latinized herein as kharieis, $-i s,-e$.

\section{Type material}

\section{Holotype}

RV Polarstern cruises:

SOUTHERN OCEAN: adult + , cruise PS48, ANT-XV/3, EASIZ II, stn 77 (AGT7), eastern Weddell Sea, $71^{\circ} 08.6^{\prime} \mathrm{S}, 12^{\circ} 26.6^{\prime} \mathrm{W}$ to $71^{\circ} 10.2^{\prime} \mathrm{S}, 12^{\circ} 30.7^{\prime} \mathrm{W}, 330-433 \mathrm{~m}$, Agassiz trawl, 2 Feb. 1998, coll. C. De Broyer and Y. Scailteur (RBINS, INV. 132937).

\section{Paratypes}

RV Polarstern cruises:

SOUTHERN OCEAN: 1 fairly large spec., cruise PS14, ANT-VII/4, EPOS leg 3, stn 281, eastern Weddell Sea, $71^{\circ} 39.0^{\prime} \mathrm{S}, 12^{\circ} 21.1^{\prime} \mathrm{W}$ to $71^{\circ} 36.9^{\prime} \mathrm{S}, 1^{\circ} 25.0^{\prime} \mathrm{W}, 389-450 \mathrm{~m}$, Agassiz trawl, $17 \mathrm{Jan}$. 1989, coll. C. De Broyer (RBINS, INV. 132939); 1 spec., cruise PS48, ANT-XV/3, EASIZ II, stn 77 (AGT7), eastern Weddell Sea, $71^{\circ} 08.6^{\prime} \mathrm{S}, 12^{\circ} 26.6^{\prime} \mathrm{W}$ to $71^{\circ} 10.2^{\prime} \mathrm{S}, 12^{\circ} 30.7^{\prime} \mathrm{W}, 330-433 \mathrm{~m}$, Agassiz trawl, 2 Feb. 1998, coll. C. De Broyer and Y. Scailteur (RBINS, INV. 132938); 1 immature spec., cruise PS65, ANT-XXI/2, BENDEX, stn 144-1, eastern Weddell Sea, 7057.02' S, $10^{\circ} 48.43^{\prime} \mathrm{W}$ to $70^{\circ} 56.98^{\prime} \mathrm{S}$, 1048.04’ W, 401-407 m, 13 Dec. 2003, coll. C. De Broyer (RBINS, INV. 132988). 


\section{Description}

Description based on adult females.

Rostrum. Long, overreaching tip of peduncle of antenna 1; in lateral view, straight on proximal half, regularly curved on second half, forming a very obtuse angle with head, ventrally straight, tip not abruptly curving downwards; in frontal view, fairly broad, with weakly convex borders, with acute tip.

EYE. Medium-sized, conical.

Pereion-Pleosome tooth pattern. Pereionite 1 with low, broad, rounded mid-dorsal tooth pointing upwards of which the anterior border is distinctly oblique, with pair of well-developed, rounded, dorsolateral teeth and pair of small ventrolateral teeth; pereionite 2 much narrower than pereionites 1 and 3, with small elliptic tooth pointing upwards (as high as mid-dorsal tooth of pereionite 1 and distinctly shorter than mid-dorsal tooth of pereionite 3), with pair of very small dorsolateral teeth, and pair of small ventrolateral teeth; pereionites 3-7 with medium-sized, very broad and rounded mid-dorsal tooth of which the anterior and the posterior borders are both strongly convex, with pair of mediumsized, low and blunt dorsolateral teeth, and pair of small ventrolateral teeth; pleonites 1-2 with large and broad mid-dorsal tooth pointing upwards, of which the anterior border is strongly and regularly convex and the posterior border slightly less convex, and of which the tip is bluntly angulate, and with pair of large subacute dorsolateral teeth and 4 pairs of much smaller denticles; pleonite 3 with medium-sized, broad, triangular mid-dorsal tooth pointing upwards, of which the anterior border may have (holotype) a low obtuse angulate protrusion on proximal 0.6 , of which the tip is subacute and the posterior border weakly sinuate, with 5 pairs of dorsolateral teeth.

COXAE $1-3$. Strongly carinate and distally sharp.

Coxa 4. Anterodorsal border nearly straight; anteroventral border with proximal very shallow concavity, with distal part distinctly convex; anterior angle very broadly rounded and slightly projecting forward; ventral tooth long, broad and subacute, directed backwards; lateral carina with very low rounded lobe slightly projecting laterally, in the holotype posteriorly followed by very shallow rounded concavity and small extremely low second lobe; in lateral view, inner corner of carina forming a distinct squared angle; in lateral view posteroventral border of coxa deeply concave; the concavity is rounded, not distinctly angulate.

Coxa 5. In dorsal view, with low, triangular, carinate, lateral tooth, of which the anterior border is nearly parallel to body axis and the posterior border is obliquely pointing backwards; tip of carina blunt.

Coxa 6. With triangular carinate lateral tooth, of which the anterior border (which is nearly straight, inconspicuously convex) points obliquely backwards; the posterior border is nearly perpendicular to body axis (character to be examined in dorsal view); tip of carina blunt.

Coxa 7. With ventral + posterior borders forming a regular curve, with small lateral tooth.

EPIMERAl Plates 1-3. Plate 1 with posteroventral angle angulate, with distinct lateral carina and 2 lateral teeth; plate 2 with posteroventral angle sharply angulate (forming a distinct sharp tooth), with distinct lateral carina and 2 lateral teeth; plate 3 with posteroventral angle produced into a fairly long tooth, with distinct lateral carina and 1 lateral tooth, with posterior margin weakly convex.

UROSOME TOOTH PATTERN. Urosomite 1 with sharp narrow tooth pointing upwards, more anteriorly with or without pair of low dorsolateral denticles; urosomite 2 with 2 pairs of posterior dorsolateral teeth pointing upwards; urosomite 3 with pair of mid-sized posterior dorsolateral teeth pointing upwards. 
Telson. Cleft on 0.30; tips of lobes blunt, notch forming a fairly narrow slit.

PEDUNCLE OF ANTENNA 1. Article 1 with anterior border weakly concave, with well-developed anterior and posterior tooth; article 2 with medium-sized lateral triangular tooth; article 3 with weak ventral tooth.

GNATHOPODS 1-2. Very small; gnathopod 1 incomplete in dissected specimen; gnathopod 2 achelate; carpus and propodus extremely narrow; dactylus of gnathopod 2 fairly broad and posteriorly weakly convex.

Pereiopods 3-4. Merus, carpus and propodus extremely broad and short; dactylus fairly large, strongly curved on both sides, clasping.

PEREIOPOD 5. Basis of normal width, with posteroproximal process rounded and strongly protruding, with posterodistal tooth small, triangular; merus, carpus and propodus extremely broad and short; dactylus fairly large, strongly curved on both sides, clasping.

PEREIOPOD 6. Basis of normal width, with posteroproximal process very protruding (with proximal border very convex, with tip angulate or bluntly angulate, with distal border concave), with posterodistal tooth fairly small, triangular; merus, carpus and propodus extremely broad and short; dactylus fairly large, strongly curved on both sides, clasping.

PEREIOPOD 7. Basis broad; posterior border strongly diverging from axis of basis in proximal 0.75 ; at this level it form a distinct, blunt, nearly squared (very slightly obtuse) angle, which is followed by a deep concavity; this concavity form a broadly rounded curve; the posterodistal corner is produced into a long narrow tooth pointing obliquely backwards; merus, carpus and propodus extremely broad and short; dactylus fairly large, strongly curved on both sides, clasping.

\section{Allometric variations}

See pictures of immature specimen.

\section{Colour pattern}

Red mottled on a white background (photographs of Rauschert \& Arntz 2015).

\section{Body length}

Up to $26 \mathrm{~mm}$.

\section{Distribution}

Eastern shelf of the Weddell Sea, 330-450 m.

\section{Remarks}

Based on morphological characters, Epimeria of the grandirostris complex from the eastern shelf of the Weddell Sea are herein considered as the new species E. kharieis sp. nov. See key of the subgenus Pseudepimeria for characters. The 'Epimeria grandirostris' specimens illustrated by Rauschert \& Arntz (2015) are presumably E. kharieis sp. nov. based on the collection location: eastern shelf of the Weddell Sea. However, as many morphological characters cannot be observed on their photographs, this identification is tentative. The precise localities are given in an early draft of their book. They are indicated as respectively coming from stations F42 and 121 of the cruise ANT-XXI (obviously ANT$\mathrm{XXI} / 2$ ). Station 42 corresponds to a photo sledge. The letter " $\mathrm{F}$ " would suggest that it is not an error, as the official acronym of the photo sledge used during ANT-XXI/2 is FTS (Arntz \& Brey 2005: 120). The coordinates of station 42 are $70^{\circ} 29.66^{\prime} \mathrm{S}, 08^{\circ} 58.73^{\prime} \mathrm{W}$ to $70^{\circ} 29.65^{\prime} \mathrm{S}, 08^{\circ} 58.55^{\prime} \mathrm{W}, 428-429 \mathrm{~m}$. Those 
of station 121 are $70^{\circ} 50.08^{\prime} \mathrm{S}, 10^{\circ} 35.54^{\prime} \mathrm{W}$ to $70^{\circ} 50.08^{\prime} \mathrm{S}, 10^{\circ} 34.76^{\prime} \mathrm{W}, 268-274 \mathrm{~m}$. The 'Epimeria grandirostris' illustrated on plate 2 fig. b (colour photograph) by Coleman (2007) is also presumably E. kharieis sp. nov. A copy of the photograph used by Coleman (2007) was found in the archives of RBINS, indicating that it was made during the cruise ANT-XIII (obviously ANT-XIII/3), which was focused on the study of the eastern shelf of the Weddell Sea.

\section{Epimeria (Pseudepimeria) oxicarinata Coleman, 1990}

Figs 291-292

Epimeria oxicarinata Coleman, 1990b: 158-166, 175, 177-178, pls 5-9, 17.

"Eine neue, noch unbekannte Epimeria-Art" - Andres in Sieg \& Wägele 1990: pl. 8, lower photograph. Epimeria oxicarinata - De Broyer \& Klages 1991: 166 (key). - Coleman 2007: 46, fig. 23a-b, colour pl. 2 fig. g, map 13 (rhomb). - Lörz \& Coleman 2009: unnumbered photograph on p. 17. Rauschert \& Arntz 2015: 61, pl. 54, unnumbered photograph.

Epimeria oxycarinata - Wakabara \& Serejo 1999: 641 (key). — Barnes 2007: 5, pl. 5, unnumbered photograph (misspelling).

'Clade H grandirostris-pulchra-oxicarinata complex - OX' - Verheye et al. 2016a, supplement: 5 (online).

\section{Material examined}

\section{RV Polarstern cruises:}

SOUTHERN OCEAN: 1 spec., cruise PS14, ANT-VII/4, EPOS leg 3, stn 211, Elephant Island, $60^{\circ} 59.8^{\prime} \mathrm{S}, 55^{\circ} 12.1^{\prime} \mathrm{W}$ to $60^{\circ} 59.3^{\prime} \mathrm{S}$, to $55^{\circ} 10.5^{\prime} \mathrm{W}, 207-213 \mathrm{~m}$, bottom trawl, $15 \mathrm{Jan}$. 1989 , coll. C. De Broyer (RBINS, INV. 132945); 1 spec., cruise PS48, ANT-XV/3, EASIZ II, stn 353, north of Nelson Island, $61^{\circ} 59.4^{\prime} \mathrm{S}, 59^{\circ} 14.4^{\prime} \mathrm{W}$ to $61^{\circ} 58.2^{\prime} \mathrm{S}, 59^{\circ} 14.3^{\prime} \mathrm{W}, 129-132 \mathrm{~m}$, Agassiz trawl, 20 Mar. 1998, coll. C. De Broyer (RBINS, INV. 132723); 1 spec., cruise PS69, ANT-XXIII/8, stn 605-3, Elephant Island, $61^{\circ} 20.33^{\prime} \mathrm{S}, 55^{\circ} 31.53^{\prime} \mathrm{W}$ to $61^{\circ} 20.35^{\prime} \mathrm{S}, 55^{\circ} 30.18^{\prime} \mathrm{W}, 148-154 \mathrm{~m}$, Agassiz trawl, 20 Dec. 2006 , coll. C. d'Udekem d'Acoz and H. Robert (RBINS, INV. 122483) [extraction N8; Genbank nr, COI:

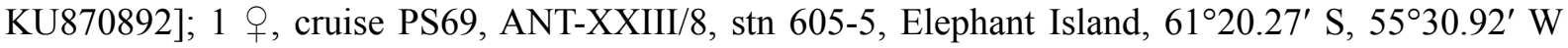
to $61^{\circ} 20.37^{\prime} \mathrm{S}, 55^{\circ} 28.99^{\prime} \mathrm{W}, 131-152 \mathrm{~m}, 20$ Dec. 2006, Agassiz trawl, coll. C. d'Udekem d'Acoz and H. Robert (RBINS, INV. 122482); 8 specs, cruise PS69, ANT-XXIII/8, stn 614-3/4/5, Elephant Island, $60^{\circ} 52.37^{\prime} \mathrm{S}, 55^{\circ} 29.80^{\prime} \mathrm{W}$ to $60^{\circ} 52.71^{\prime} \mathrm{S}, 55^{\circ} 27.83^{\prime} \mathrm{W}, 248-265 \mathrm{~m}$, a lot of epifauna, Rauschert dredge and Agassiz trawl, 22 Dec. 2006, coll. C. d'Udekem d'Acoz and H. Robert (RBINS, INV. 122517); 1 spec., PS69, ANT-XXIII/8, stn 614-3/4/5, Elephant Island, $60^{\circ} 52.37^{\prime} \mathrm{S}, 55^{\circ} 29.80^{\prime} \mathrm{W}$ to $60^{\circ} 52.71^{\prime} \mathrm{S}, 55^{\circ} 27.83^{\prime} \mathrm{W}, 248-265 \mathrm{~m}$, a lot of epifauna, Rauschert dredge and Agassiz trawl, 22 Dec. 2006, coll. C. d'Udekem d'Acoz and H. Robert (MNHN-IU-2014-7338, removed from RBINS, INV. 122517); 1 spec., cruise PS69, ANT-XXIII/8, stn 614-3/4/5, Elephant Island, $60^{\circ} 52.37^{\prime} \mathrm{S}, 55^{\circ} 29.80^{\prime} \mathrm{W}$ to $60^{\circ} 52.71^{\prime} \mathrm{S}, 55^{\circ} 27.83^{\prime} \mathrm{W}, 248-265 \mathrm{~m}$, a lot of epifauna, Rauschert dredge and Agassiz trawl, $22 \mathrm{Dec}$. 2006, coll. C. d'Udekem d'Acoz and H. Robert (RBINS, INV. 132942); 1 spec., cruise PS69, ANT$\mathrm{XXIII} / 8$, stn $614-3 / 4 / 5$, Elephant Island, $60^{\circ} 52.37^{\prime} \mathrm{S}, 55^{\circ} 29.80^{\prime} \mathrm{W}$ to $60^{\circ} 52.71^{\prime} \mathrm{S}, 55^{\circ} 27.83^{\prime} \mathrm{W}, 248$ 265 m, a lot of epifauna, Rauschert dredge and Agassiz trawl, 22 Dec. 2006, coll. C. d'Udekem d'Acoz and H. Robert (RBINS, INV. 132972); 1 spec., cruise PS69, ANT-XXIII/8, stn 614-3/4/5, Elephant Island, $60^{\circ} 52.37^{\prime} \mathrm{S}, 55^{\circ} 29.80^{\prime} \mathrm{W}$ to $60^{\circ} 52.71^{\prime} \mathrm{S}, 55^{\circ} 27.83^{\prime} \mathrm{W}, 248-265 \mathrm{~m}$, a lot of epifauna, Rauschert dredge and Agassiz trawl, 22 Dec. 2006, coll. C. d'Udekem d'Acoz and H. Robert (RBINS, INV. 122468) [extraction N7; Genbank nr, COI: KU870891]; 1 spec., cruise PS69, ANT-XXIII/8, stn 614$3 / 4 / 5$, Elephant Island, $60^{\circ} 52.37^{\prime} \mathrm{S}, 55^{\circ} 29.80^{\prime} \mathrm{W}$ to $60^{\circ} 52.71^{\prime} \mathrm{S}, 55^{\circ} 27.83^{\prime} \mathrm{W}, 248-265 \mathrm{~m}$, a lot of epifauna, Rauschert dredge and Agassiz trawl, 22 Dec. 2006, coll. C. d'Udekem d'Acoz and H. Robert (RBINS, INV. 122472); 1 spec., cruise PS69, ANT-XXIII/8, stn 614-3, Elephant Island, 60 $52.37^{\prime}$ S, $55^{\circ} 29.80^{\prime} \mathrm{W}$ to $60^{\circ} 52.71^{\prime} \mathrm{S}, 55^{\circ} 27.83^{\prime} \mathrm{W}, 248-265 \mathrm{~m}$, Agassiz trawl, 22 Dec. 2006, coll. C. d'Udekem 
d'Acoz and H. Robert (RBINS, INV. 122521); 1 spec., cruise PS69, ANT-XXIII/8, stn 639-1, Elephant Island, $61^{\circ} 10.27^{\prime} \mathrm{S}, 55^{\circ} 56.52^{\prime} \mathrm{W}$ to $61^{\circ} 11.12^{\prime} \mathrm{S}, 55^{\circ} 53.03^{\prime} \mathrm{W}, 127-128 \mathrm{~m}$, bottom trawl, 26 Dec. 2006 , coll. C. d'Udekem d'Acoz and H. Robert (RBINS, INV. 122518); 2 specs, cruise PS69, ANT-XXIII/8, stn 644-1, Elephant Island, $61^{\circ} 03.19^{\prime} \mathrm{S}, 55^{\circ} 54.36^{\prime} \mathrm{W}$ to $61^{\circ} 01.78^{\prime} \mathrm{S}, 55^{\circ} 51.83^{\prime} \mathrm{W}, 150-187 \mathrm{~m}$, bottom trawl, 27 Dec. 2006, coll. C. d'Udekem d'Acoz and H. Robert (RBINS, INV. 122522).

\section{Description}

Rostrum. Long, overreaching tip of peduncle of antenna 1; in lateral view, regularly curved, forming a distinct obtuse angle with head, ventrally very weakly concave, tip scarcely curving downwards; in frontal view, fairly broad, with weakly convex borders, with acute tip.

EYE. Medium-sized, conical.

Pereion-Pleosome tooth pattern. Pereionite 1 with very long, narrow, sharp mid-dorsal tooth arching forward (anterior border strongly concave, posterior border strongly convex), with pair of long, sharp, dorsolateral teeth, and pair of small ventrolateral teeth; pereionite 2 much narrower than pereionites 1 and 3 , with small, narrow and sharp tooth pointing upwards $(5 \times$ shorter than mid-dorsal tooth of pereionites 1 and 3), with pair of small dorsolateral teeth, and pair of small ventrolateral teeth; pereionites 3-7 with very long, very narrow, very sharp mid-dorsal tooth of which the anterior and the posterior borders are nearly straight, with pair of large and sharp dorsolateral teeth, and pair of small ventrolateral teeth; pleonites 1-2 with very long, very narrow, very sharp mid-dorsal tooth of which the anterior and the posterior borders are nearly straight, with pair of large acute dorsolateral teeth and very small denticles; pleonite 3 very long, very narrow, very sharp mid-dorsal tooth of which the anterior and the posterior borders are nearly straight, with about 5 pairs of dorsolateral teeth, of which 2 are large and sharp and the others small to very small.

COXAE 1-3. Strongly carinate and distally sharp.

Coxa 4. Anterodorsal border weakly but distinctly concave; anteroventral border with deep notch, with distal part nearly straight; anterior angle produced into a large and sharp tooth pointing downwards; ventral tooth long, narrow and sharp, directed ventrally (scarcely arching backwards); lateral carina with long and sharp tooth projecting laterally; in lateral view, inner corner of carina forming a distinct obtuse angle; in lateral view posteroventral border of coxa deeply concave; the concavity is rounded.

Coxa 5. In dorsal view, with very large, narrowly triangular, carinate, lateral tooth, of which the anterior and the posterior borders point obliquely backwards; tip of carina sharp.

Coxa 6. With narrowly triangular carinate lateral tooth of which the anterior border (which is convex) and the posterior border (which is concave) points obliquely backwards (character to be examined in dorsal view); tip of carina very sharp.

Coxa 7. With ventral + posterior borders forming a regular curve, with small lateral tooth.

EPIMERAL PLATES 1-3. Plate 1 with posteroventral angle angulate, with distinct lateral carina and 2 lateral teeth; plate 2 with posteroventral angle sharply angulate (forming a distinct sharp triangular tooth), with distinct lateral carina and 2 lateral teeth; plate 3 with posteroventral angle produced into a very long tooth, with distinct lateral carina and 1 lateral tooth, with posterior margin weakly convex.

UROSOME TOOTH PATTERN. Urosomite 1 with sharp narrow mid-dorsal tooth pointing upwards, with pair of lateral denticles at the same level as mid-dorsal tooth; urosomite 2 with 2 pairs of small posterior 
dorsolateral teeth pointing upwards (a very small triangular one followed by a longer styliform one); urosomite 3 with pair of mid-sized posterior dorsolateral teeth pointing upwards.

TeLson. Cleft on 0.4; tips of lobes sharp, notch V-shaped.

Peduncle of Antenna 1. Article 1 with anterior border weakly concave, with well-developed anterior and posterior tooth; article 2 with medium-sized lateral triangular tooth; article 3 with weak ventral tooth.

GNATHOPODS 1-2. Very small, achelate; carpus and propodus of medium stoutness in gnathopod 1 (propodus tapering), of fairly narrow in gnathopod 2; dactylus of gnathopod 2 fairly broad and posteriorly slightly convex.

Pereiopods 3-4. Merus, carpus and propodus extremely broad and short; dactylus fairly large, strongly curved on both sides, clasping.

Pereiopods 5-6. Basis of normal width, with posteroproximal process sharply triangular and strongly protruding, with posterodistal tooth large and sharp; merus, carpus and propodus extremely broad and short; dactylus fairly large, strongly curved on both sides, clasping.

PEREIOPOD 7. Basis of medium-width; posterior border distinctly diverging from axis of basis in proximal 0.75; at this level it forms a triangular tooth (i.e., blunt-tipped acute, nearly straight angle), which is followed by a deep concavity; this concavity form a broadly rounded curve; the posterodistal corner is produced into a long narrow tooth pointing obliquely backwards; merus, carpus and propodus extremely broad and short; dactylus fairly large, strongly curved on both sides, clasping.

\section{Colour pattern}

Transversally striped of white, red and orange.

\section{Body length}

Up to $26 \mathrm{~mm}$.

\section{Distribution}

Elephant Island, 127-267 m (Coleman 2007; present data), Drake Passage: north of Nelson Island (present data).

\section{Biology}

Coleman (1990a) found thecate hydrozoans (cf. Oswaldella antarctica (Jäderholm, 1904)) in the stomachs of several E. oxicarinata specimens. A photograph of the species clinging onto a thecate hydrozoan with an long strong stem and thin lateral branches was published by Coleman (2007). So it is likely that $E$. oxicarinata is a hydroid-associated and hydroid-feeding species.

\section{Remarks}

There is an unconfirmed record of E. oxicarinata from the eastern shelf of the Weddell Sea (Klages 1991; De Broyer et al. 2007), but this might be a misidentification, possibly a confusion with E. cyrano sp. nov., which is also a very spiny, albeit very different in other morphological characters. The collection station of the specimen of Epimeria oxicarinata illustrated by Rauchert \& Arntz (2015) was mentioned in an early draft of their book accessed by the authors: ANT-XV/3 stn 355 . This corresponds to $61^{\circ} 59.8^{\prime} \mathrm{S}$, $59^{\circ} 14.8^{\prime} \mathrm{W}$ to $62^{\circ} 00.1^{\prime} \mathrm{S}, 59^{\circ} 14.8^{\prime} \mathrm{W}$ (north of Nelson Island), $128-130 \mathrm{~m}$. 
Epimeria (Pseudepimeria) pulchra Coleman, 1990

Fig. 293

Epimeria pulchra Coleman, 1990a: 166-176, pls 10-16.

Epimeria pulchra - De Broyer \& Klages 1991: 166 (key). — Wakabara \& Serejo 1999: 641 (key). Coleman 2007: 47, in part, fig. 24a-b, not colour plate $2 \mathrm{f}$ (=E. debroyeri sp. nov.).

\section{Material examined}

SOUTHERN OCEAN: 2 adult specs, SIGNY 1991/92, AGT 5, transect 1, South Orkney Plateau: Signy

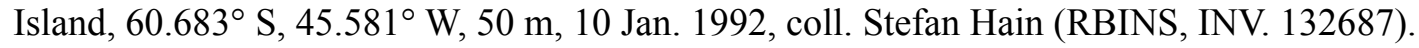

\section{Description}

Rostrum. Long, overreaching tip of peduncle of antenna 1; in lateral view, anteriorly weakly curved in its middle and forming a blunt very obtuse angle with head, ventrally weakly curved, tip sometimes abruptly curving downwards; in frontal view, fairly narrow, with weakly convex borders, with subacute tip.

EYE. Medium-sized, conical.

Pereion-Pleosome tooth pattern. Pereionite 1 with medium-sized broad and blunt-tipped mid-dorsal tooth pointing upwards of which the anterior border is straight and the posterior border is strongly convex, with pair of well-developed, blunt, dorsolateral teeth and pair of small ventrolateral teeth; pereionite 2 much narrower than pereionites 1 and 3, with small narrow blunt-tipped tooth pointing upwards (a bit shorter than mid-dorsal tooth of pereionite 1 and much shorter than mid-dorsal tooth of pereionite 3 ), with pair of small very blunt dorsolateral teeth, and pair of small ventrolateral teeth; pereionites 3-7 with very large, slender and blunt-tipped mid-dorsal tooth pointing upwards, of which the anterior and the posterior borders are similarly convex, with pair of small, low and blunt dorsolateral teeth, and pair of small ventrolateral teeth; pleonite 1 with very large and slender mid-dorsal tooth pointing upwards, of which the anterior and posterior borders are convex (anterior border with distinct subdistal angular discontinuity), and of which the tip is blunt to angulate, and with pair of large subacute dorsolateral teeth (associated with several pairs of smaller denticles); pleonite 2 with very large and slender mid-dorsal tooth pointing upwards, of which the anterior and posterior borders are convex, and of which the tip is angulate, and with pair of large subacute dorsolateral teeth (associated with several pairs of smaller denticles); pleonite 3 with very narrow and very large mid-dorsal tooth pointing upwards, of which the anterior border is not convex, and the tip sharp and narrow, with 5 pairs of dorsolateral teeth.

COXAE $1-3$. Strongly carinate and distally subacute.

Coxa 4. Anterodorsal border straight; anteroventral border with median very deep angulate concavity (anterior border of concavity concave; posterior border of concavity straight); anterior angle produced into a large broad tooth projecting forward; ventral tooth fairly long, narrow and subacute, pointing weakly obliquely backwards; lateral carina with bluntly angulate lobe strongly projecting laterally, posteriorly followed by fairly deep rounded concavity, and more backwards by a second, lower but distinct lobe projecting laterally; in lateral view, inner corner of carina forming a distinct squared angle; in lateral view posteroventral border of coxa deeply concave, the deepest point of this concavity forming a very rounded, obtuse (nearly squared) angle. 
Coxa 5. In dorsal view, with extremely long, triangular, carinate, lateral tooth, of which the anterior border points obliquely strongly backwards and the posterior border is almost perpendicular to body axis; tip of carina sharp.

Coxa 6. With triangular carinate lateral tooth of which the anterior border points obliquely backwards and the posterior border is nearly perpendicular to body axis (very weakly pointing onwards); tip of carina subacute; posteriorly with a second, much smaller obtuse triangular tooth directed backwards.

Coxa 7. With ventral border strongly curved, with posterior border straight, these two borders being joined by a long broad curve.

Epimeral plates 1-3. Plate 1 with posteroventral angle angulate and with posterior border distinctly angulate, with distinct lateral carina and 2 lateral teeth; plate 2 with posteroventral angle produced into a medium-sized sharp tooth, with distinct lateral carina and 2 lateral teeth; plate 3 with posteroventral angle produced into a long tooth, with distinct lateral carina and 1 lateral tooth, with posterior margin produced into a large triangular tooth.

UROSOME TOOTH PATTERN. Urosomite 1 with sharp narrow tooth pointing upwards, with pair of denticle just in front of the main tooth; urosomite 2 with pair of mid-sized posterior dorsolateral teeth pointing upwards; urosomite 3 with pair of mid-sized posterior dorsolateral teeth pointing upwards.

Telson. Cleft on 0.3 ; tips of lobes acute, notch forming a narrow V.

Peduncle of antenna 1. Article 1 with anterior border concave, with strong anterior and posterior tooth; article 2 with strong lateral triangular tooth; article 3 with strong ventral tooth.

GNATHOPODS 1-2. Very small, achelate; carpus and propodus broad in gnathopod 1 (propodus tapering), of medium width in gnathopod 2; dactylus of gnathopod 2 extremely broad and posteriorly straight.

PEREIOPOD 3-4. Merus, carpus and propodus extremely broad and short; dactylus fairly large, strongly curved on both sides, clasping.

PEREIOPODS 5-6. Basis of pereiopods 5-6 of normal width, with posteroproximal process produced into a sharp tooth, with posterodistal tooth strong, narrow and sharp; merus, carpus and propodus extremely broad and short; dactylus fairly large, strongly curved on both sides, clasping.

PEREIOPOD 7. Basis broad; posterior border nearly parallel to basis axis of proximal 0.75 ; at this level it forms a medium-sized sharp to very sharp tooth, which is followed by a deep rounded concavity; the posterodistal corner is produced into a medium to long narrow tooth pointing obliquely backwards; merus, carpus and propodus extremely broad and short; dactylus fairly large, strongly curved on both sides, clasping.

\section{Body length}

Up to $35 \mathrm{~mm}$.

\section{Distribution}

Plateau of the South Orkney Islands, 50-190 m (Coleman 1990; present material).

\section{Remarks}

Epimeria pulchra is superficially similar to E. amoenitas sp. nov. and E. debroyeri sp. nov., but it differs from these two species by a number of characters such as: longer mid-dorsal teeth on pereionites 3-7 
and pleonites 1-2, much longer mid-dorsal tooth on pleonite 3, anterior corner of coxa 4 much more produced, posterior border of third epimeral plate produced into a tooth instead of being simply convex, gnathopods much broader. It is likely that E. pulchra s. str. is endemic to the South Orkney Islands, just as E. linseae sp. nov.

Subgenus Subepimeria Bellan-Santini, 1972

Subepimeria Bellan-Santini, 1972: 225.

Subepimeria - Karaman \& J.L. Barnard 1979: 108-109 (in part).

\section{Type species}

Subepimeria geodesiae Bellan-Santini, 1972.

\section{Description}

Body opaque, with teguments moderately calcified. Rostrum medium-sized. Eyes not conical. Pleonite 2 posteriorly produced into a small sharp tooth oriented backwards; pleonite 1 and pereionite 7 sometimes also posteriorly produced into a tooth or bump; dorsal border of pleonite 3 keeled; in lateral view that keel posteriorly terminated into a rounded bump or a squared angle. With the exception of the aforementioned mid-dorsal ornamentations, pereionites and pleosomites perfectly smooth. Coxae 1-3 with blunt tip, not sharply keeled. Coxa 4 with indistinct carina starting at ventral tip of coxa and terminating at posterior tip of coxa; this carina remains very close to the posteroventral border of coxa, the space in-between forming a very shallow groove; posteroventral border of coxa 4 very weakly concave, nearly straight. Coxae 5-6 without tooth or distinct protrusion. Mid of posterior border of epimeral plates 1-3 not produced into a tooth. Posteroventral tooth of epimeral plate 3 medium-sized to strong. Dorsal process of urosomite 1 produced into a triangular tooth directed upwards. Urosomite 2 without pair of small teeth pointing upwards. Lateral borders of urosomite 3 posteriorly terminated into a sharp tooth or bluntly angular. Peduncle of antenna 1 without teeth or with dentition vestigial. Mandible with pars molar process triturative. Lower lip with narrow (V-shaped) hypopharyngeal gap. Palp of maxilliped with 4 articles. Gnathopods of normal size, with carpus and propodus of medium slenderness, with palm obliquely transverse but poorly developed (gnathopods subcheliform); propodus not expanded distally; posterior border of dactylus lined by row of small oblique slender teeth. Basis of pereiopods 5-6 moderately broad, with posteroproximal rounded protrusion (sometimes very weak and scarcely distinct); a posterodistal tooth projecting posteriorly can be present on basis of pereiopod 5 , otherwise basis posterodistally angulate or bluntly angulate. Posterior border of basis of pereiopod 7 slightly convex in proximal 0.8 ; at this level there is a slight angular discontinuity and the distal 0.2 can be slightly concave; posterior border terminated into a blunt angle or a blunt tooth directed in the axis of the basis. Dactylus of pereiopods 5-7 short. Benthic. Small species.

\section{Body length}

The maximum body length recorded in Subepimeria species ranges between 14 and $16 \mathrm{~mm}$.

\section{Ecology.}

Benthic, 52-840 m. 


\section{Distribution}

Circum-Antarctic, as far north as South Georgia.

\section{Remarks}

Molecular data (COI, 28S) (Verheye et al. 2016a) indicate that Subepimeria and Drakepimeria are sister clades (Fig. 342). The morphology of their gnathopods and pereiopods is similar. However, Subepimeria species are much smaller $(<20 \mathrm{~mm})$ and have only one or two (smaller) mid-dorsal teeth and no dorsolateral teeth on pereionites and pleosomites. The lateral carina of coxa 4 is also vestigial in Subepimeria, whilst it is very strongly developed in Drakepimeria. We believe that these conspicuous morphological differences justify the recognition of distinct subgenera for these clades. The morphological identification of species within the subgenus Subepimeria is very difficult. Interspecific differences are based on ill-defined characters, such as the curves of coxa 4 . The species are also rare, which largely prevents the study of individual and allometric differences within species. The link between immatures and adult specimens of Epimeria (Subepimeria) iota is tentative as only immature specimens were available for sequencing. As Subepimeria species can only be distinguished by a combination of illdefined characters, we delineate their differences in a tabular format (Table 1) instead of an identification key.

Epimeria (Subepimeria) adeliae sp. nov. urn:1sid:zoobank.org:act:76F9695C-487B-434F-B09C-52CA334ACD5B

Figs 294-298

'Clade B puncticulata complex - PUN4' - Verheye et al. 2016a, supplement: 3 (online).

\section{Etymology}

The noun Adelia, -ae is a Latinization of Adèle (referring to Adèle Pépin, the wife of Jules Sébastien César Dumont d'Urville), and alludes to Adélie Coast (discovered by J.S.C. Dumont d'Urville), where the type material of the species was collected. The name is a genitive.

\section{Type material}

\section{Holotype}

RV Aurora Australis cruises:

SOUTHERN OCEAN: , cruise CEAMARC, sample CEAMARC 2072, stn 65EV322, Adélie Coast, $65^{\circ} 48^{\prime} 09^{\prime \prime} \mathrm{S}, 143^{\circ} 03^{\prime} 46^{\prime \prime}$ E, 750-788 m, beam trawl, 5 Jan. 2008, coll. IPEV-AAD-MNHN (MNHNIU-2014-4288) [extraction M4; Genbank nr, COI: KU870888, 28S: KU759671].

\section{Paratypes}

RV Aurora Australis cruises:

SOUTHERN OCEAN: 1 spec., cruise CEAMARC, sample CEAMARC 2072, stn 65EV322, Adélie

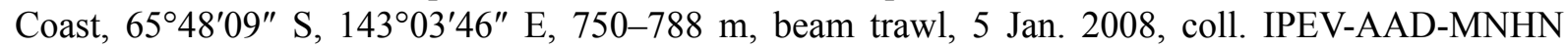
(MNHN-IU-2014-7339, removed from MNHN-IU-2014-4288); 1 spec., cruise CEAMARC, sample

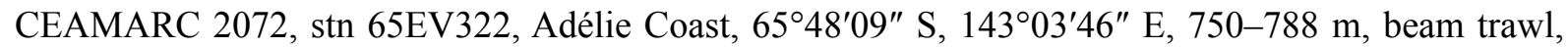
5 Jan. 2008, coll. IPEV-AAD-MNHN (MNHN-IU-2014-7340, removed from MNHN-IU-2014-4288) [extraction M3; Genbank nr, 28S: KU759670].

\section{Description}

RostRum. In lateral view short and narrow, nearly reaching tip of article 1 of peduncle of antenna 1 , distinctly curved on the proximal half of its anterior border, posterior border straight, tip acute; in frontal view triangular: fairly broad and with straight converging borders, with tip blunt. 
EYEs. Large, broadly elliptic.

Pereion-Pleosome tooth pattern. Pereionites 1-6 totally smooth; pereionite 7 keeled with small blunt posterodorsal tooth; pleonites 1-2 keeled with well developed acute posterodorsal tooth; pleonite 3 keeled with posterodorsal tip forming a distinct squared angle.

COXAE 1-3. Tip blunt but narrow.

Coxa 4. Of medium width; anterodorsal border proximally nearly straight, curving ventrally and followed by curved anteroventral border (transition between anterodorsal and anteroventral border very gradual, without distinct anterior corner); the coxa is not projecting forward; ventral corner forming a squared angle of which the tip is blunt but not rounded; posteroventral border nearly straight (very weakly concave); posterodorsal border as long as posteroventral border.

Coxa 5. Very broad, posteroventral corner forming a blunt but distinct angle.

Coxa 6. Posterior border regularly rounded.

Coxa 7. Posterior border nearly straight (very weakly convex); posteroventral corner broadly rounded.

Epimeral Plates 1-3. Posteroventral angle blunt and squared in plate 1, produced into a medium-sized tooth in plate 2 , into a large tooth in plate 3 .

UROSOME TOOTH PATTERN. Urosomite 1 with distinct triangular dorsal process, anteriorly weakly concave, tip subacute, posterior border weakly convex.

TeLson. Cleft on 0.4; lobes with tips bluntly angulate; notch narrowly V-shaped.

GNATHOPODS 1-2. Carpus and propodus of normal slenderness; propodus not narrowing distally, and palm distinct.

PEREIOPOD 5. Basis of normal width, with posteroproximal process forming a low but distinct rounded lobe, with posterodistal corner forming a long, narrowly triangular blunt-tipped tooth; merus, carpus and propodus stout.

PEREIOPOD 6. Basis of normal width, with posteroproximal process very low and rounded, posterior border nearly straight, diverging from anterior border and terminated in blunt squared angle; merus, carpus and propodus stout.

PEREIOPOD 7. Basis broad; posterior border weakly convex, with inconspicuous trace of concavity in distal 0.9 , terminated into a blunt, obtuse (nearly squared) angle.

\section{Body length}

Up to $16 \mathrm{~mm}$.

\section{Distribution}

Adélie Coast, $750-788 \mathrm{~m}$.

\section{Remarks}

The pattern of dorsal teeth of Epimeria adeliae sp. nov. is reminiscent to that of E. (Subepimeria) sp. 1 from South Georgia and different from that of other species of the subgenus Subepimeria. 
Epimeria (Subepimeria) geodesiae Bellan-Santini, 1972

Subepimeria geodesiae Bellan-Santini, 1972: 225, pls 33-34.

Epimeria puncticulata - Watling \& Holman 1981: 213-215 (discussion, in part), not fig. 21 (=E. (Subepimeria) iota sp. nov.); Coleman 1998b: 223-224 (in part).

Subepimeria geodesiae - De Broyer 1983: 305 (discussion).

\section{Description}

Description based on the illustrations of Bellan-Santini (1972).

Rostrum. Reaching tip of article 1 of peduncle of antenna 1, broad in lateral view.

EYEs. Large, rounded.

Pereion-Pleosome tooth Pattern. Pereionites 1-7 totally smooth; pleonite 1 toothless; pleonite 2 with small, posterodorsal tooth; pleonite 3 with posterodorsal tip forming a small, distinct rounded (very broadly triangular) lobe projecting backwards.

COXAE 1-3. Tip subacute in coxae 1-2, blunt in coxa 3.

Coxa 4. Very narrow; anterodorsal border weakly convex, directly followed by very broadly rounded ventral lobe (anteroventral border absent); posteroventral border nearly straight (weakly concave); ratio length of posterodorsal border / length of posteroventral border: 0.5 .

Coxa 5. Very broad, posteroventral corner with broadly rounded angular discontinuity.

Coxa 6. Posterior border regularly rounded.

Coxa 7. Posterior border nearly straight (very weakly convex); posteroventral corner broadly rounded.

EPimeral Plates 1-3. Posteroventral angle angulate in plate 1, produced into a small tooth in plate 2; produced into a medium-sized tooth in plate 3 .

UROSOME TOOTH PATTERN. Urosomite 1 with narrow triangular dorsal process; urosomite 3 with dorsolateral borders straight, with tip produced into a long tooth pointing obliquely.

Telson. Cleft on 0.25 .

GNATHOPODS 1-2. Carpus and propodus of normal slenderness; propodus not narrowing distally, and palm distinct.

PeReIOPOD 5. Basis of normal width, with posteroproximal process indistinct (reduced to very low proximal dilatation in continuity with the more distal part of the posterior border), with posterodistal corner forming a blunt-tipped broadly triangular process (acute angle) projecting backwards; merus, carpus and propodus stout.

PEREIOPOD 6. Basis of normal width, with posteroproximal process indistinct (reduced to very low proximal dilatation in continuity with the more distal part of the posterior border), with posterior border nearly straight and parallel to anterior border, with posterodistal corner forming a blunt-tipped broadly triangular process (acute but nearly squared angle) scarcely projecting backwards; merus, carpus and propodus stout. 
Table 1. (continued on next page). Tentative table of character states and distribution for Subepimeria species.

\begin{tabular}{|c|c|c|c|c|c|}
\hline \multicolumn{6}{|c|}{ GROUPS OF SUBEPIMERIA } \\
\hline & \multicolumn{2}{|c|}{$\begin{array}{c}\text { Epimeria (Subepimeria) group } \\
\text { adeliae }\end{array}$} & \multicolumn{3}{|c|}{ Epimeria (Subepimeria) group puncticulata } \\
\hline Pereionite 7 & \multicolumn{2}{|c|}{$\begin{array}{l}\text { with posterodorsal bump or } \\
\text { reduced tooth }\end{array}$} & \multicolumn{3}{|c|}{ without posterodorsal bump or tooth } \\
\hline Pleonite 1 & \multicolumn{2}{|c|}{ with well-developed sharp tooth } & \multicolumn{3}{|c|}{$\begin{array}{l}\text { toothless or with slight bump or with trace of } \\
\text { tooth }\end{array}$} \\
\hline \multicolumn{6}{|c|}{ SUBEPIMERIA GROUP ADELIAE } \\
\hline & \multicolumn{2}{|c|}{ E. (Subep.) adeliae sp. nov. } & \multicolumn{3}{|c|}{ E. (Subep.) sp. 1} \\
\hline $\begin{array}{l}\text { Pleonite } 3 \\
\text { posterodorsal } \\
\text { process }\end{array}$ & \multicolumn{2}{|c|}{$\begin{array}{l}\text { distinctly triangular, forming a } \\
\text { squared angle }\end{array}$} & \multicolumn{3}{|c|}{ regularly rounded } \\
\hline Distribution & \multicolumn{2}{|c|}{ Adélie Coast } & \multicolumn{3}{|c|}{ South Georgia, «Scotia Arc» } \\
\hline \multicolumn{6}{|c|}{ SUBEPIMERIA GROUP PUNCTICULATA } \\
\hline & $\begin{array}{l}\text { E. (Subep.) } \\
\text { geodesiae }\end{array}$ & $\begin{array}{l}\text { E. (Subep.) } \\
\text { iota sp. nov. }\end{array}$ & $\begin{array}{l}\text { E. (Subep.) } \\
\text { puncticulata }\end{array}$ & $\begin{array}{l}\text { E. }(\text { Subep. }) \\
\text { teres sp. nov. }\end{array}$ & $\begin{array}{l}\text { E. (Subep.) } \\
\text { urvillei } \\
\text { sp. nov. }\end{array}$ \\
\hline $\begin{array}{l}\text { Rostrum } \\
\text { shape, in } \\
\text { lateral view }\end{array}$ & broad & broad & very narrow & very narrow & narrow \\
\hline $\begin{array}{l}\text { Rostrum size } \\
\text { (better seen in } \\
\text { dorsal view) }\end{array}$ & $\begin{array}{l}\text { reaching tip } \\
\text { of art. } 1 \text { of } \\
\text { peduncle of } \\
\text { antenna } 1\end{array}$ & $\begin{array}{l}\text { not reaching } \\
\text { tip of art. } 1 \text { of } \\
\text { peduncle of } \\
\text { antenna } 1\end{array}$ & - & $\begin{array}{l}\text { reaching tip } \\
\text { of art. } 1 \text { of } \\
\text { peduncle of } \\
\text { antenna } 1\end{array}$ & $\begin{array}{l}\text { not reaching } \\
\text { tip of art. } 1 \text { of } \\
\text { peduncle of } \\
\text { antenna } 1\end{array}$ \\
\hline Eye & $\begin{array}{l}\text { medium-sized, } \\
\text { rounded }\end{array}$ & $\begin{array}{l}\text { large, broadly } \\
\text { elliptic, nearly } \\
\text { rounded }\end{array}$ & $\begin{array}{l}\text { medium-sized, } \\
\text { narrowly } \\
\text { elliptic }\end{array}$ & $\begin{array}{l}\text { large, broadly } \\
\text { elliptic, nearly } \\
\text { rounded }\end{array}$ & $\begin{array}{l}\text { large, } \\
\text { narrowly } \\
\text { elliptic }\end{array}$ \\
\hline $\begin{array}{l}\text { Coxa } 4 \\
\text { anterior } \\
\text { margin }\end{array}$ & $\begin{array}{l}\text { forming a weak } \\
\text { curve, which } \\
\text { dramatically } \\
\text { increases near } \\
\text { its tip }\end{array}$ & $\begin{array}{l}\text { with distinct } \\
\text { angular } \\
\text { discontinuity } \\
\text { of ventral } 0.6\end{array}$ & $\begin{array}{l}\text { with distinct } \\
\text { angular } \\
\text { discontinuity } \\
\text { of ventral } 0.6\end{array}$ & $\begin{array}{l}\text { forming a } \\
\text { regular curve, } \\
\text { anteroventral } \\
\text { part very } \\
\text { weakly arching } \\
\text { backwards }\end{array}$ & $\begin{array}{l}\text { forming a } \\
\text { regular curve, } \\
\text { anteroventral } \\
\text { part weakly } \\
\text { arching } \\
\text { backwards }\end{array}$ \\
\hline $\begin{array}{l}\text { Coxa } 4 \text { ventral } \\
\text { corner }\end{array}$ & $\begin{array}{l}\text { forming a very } \\
\text { broad curve }\end{array}$ & $\begin{array}{l}\text { forming a blunt } \\
\text { squared angle }\end{array}$ & $\begin{array}{l}\text { forming a } \\
\text { sharp squared } \\
\text { angle }\end{array}$ & $\begin{array}{l}\text { forming a blunt } \\
\text { acute angle }\end{array}$ & $\begin{array}{l}\text { forming a } \\
\text { very distinct } \\
\text { acute (nearly } \\
\text { squared) } \\
\text { angle }\end{array}$ \\
\hline $\begin{array}{l}\text { Basis of } \\
\text { pereiopod } 5, \\
\text { posterodistal } \\
\text { corner }\end{array}$ & $\begin{array}{l}\text { produced } \\
\text { into a broadly } \\
\text { triangular } \\
\text { tooth }\end{array}$ & $\begin{array}{l}\text { produced } \\
\text { into a broadly } \\
\text { triangular } \\
\text { tooth }\end{array}$ & $\begin{array}{l}\text { produced into } \\
\text { a narrowly } \\
\text { triangular } \\
\text { tooth }\end{array}$ & $\begin{array}{l}\text { produced into } \\
\text { a narrowly } \\
\text { triangular } \\
\text { tooth }\end{array}$ & $\begin{array}{l}\text { produced into } \\
\text { a narrowly } \\
\text { triangular } \\
\text { tooth }\end{array}$ \\
\hline
\end{tabular}


Table 1. Tentative table of character states and distribution for Subepimeria species.

\begin{tabular}{|c|c|c|c|c|c|}
\hline \multicolumn{6}{|c|}{ SUBEPIMERIA GROUP PUNCTICULATA } \\
\hline & $\begin{array}{l}\text { E. (Subep.) } \\
\text { geodesiae }\end{array}$ & $\begin{array}{l}\text { E. (Subep.) } \\
\text { iota sp. nov. }\end{array}$ & $\begin{array}{c}\text { E. (Subep.) } \\
\text { puncticulata }\end{array}$ & $\begin{array}{l}\text { E. (Subep.) } \\
\text { teres sp. nov. }\end{array}$ & $\begin{array}{l}\text { E. (Subep.) } \\
\text { urvillei } \\
\text { sp. nov. }\end{array}$ \\
\hline $\begin{array}{l}\text { Basis of } \\
\text { pereiopod 6, } \\
\text { posterodistal } \\
\text { corner }\end{array}$ & $\begin{array}{l}\text { produced into } \\
\text { a sharp squared } \\
\text { angle }\end{array}$ & $\begin{array}{l}\text { produced into } \\
\text { a sharp squared } \\
\text { angle in adults, } \\
\text { into a blunt one } \\
\text { in immatures }\end{array}$ & $\begin{array}{c}\text { produced } \\
\text { into a sharp } \\
\text { acute (nearly } \\
\text { squared) angle }\end{array}$ & $\begin{array}{c}\text { produced } \\
\text { into a sharp } \\
\text { acute (nearly } \\
\text { squared) angle }\end{array}$ & $\begin{array}{l}\text { produced into } \\
\text { an acute angle }\end{array}$ \\
\hline $\begin{array}{l}\text { Basis of } \\
\text { pereiopod } 7, \\
\text { posterodistal } \\
\text { corner }\end{array}$ & $\begin{array}{l}\text { produced into } \\
\text { a sharp tooth } \\
\text { forming a } \\
\text { squared angle }\end{array}$ & $\begin{array}{l}\text { produced into } \\
\text { a blunt obtuse } \\
\text { angle }\end{array}$ & $\begin{array}{l}\text { produced into } \\
\text { a blunt obtuse } \\
\text { angle }\end{array}$ & $\begin{array}{l}\text { produced into } \\
\text { a sharp tooth } \\
\text { forming a } \\
\text { squared angle }\end{array}$ & $\begin{array}{l}\text { produced into } \\
\text { a blunt obtuse } \\
\text { angle }\end{array}$ \\
\hline $\begin{array}{l}\text { Posterodorsal } \\
\text { corner of } \\
\text { pleonite } 3\end{array}$ & $\begin{array}{l}\text { with rounded } \\
\text { or very broadly } \\
\text { triangular } \\
\text { protrusion } \\
\text { pointing } \\
\text { backwards }\end{array}$ & $\begin{array}{l}\text { with rounded } \\
\text { or very broadly } \\
\text { triangular } \\
\text { protrusion } \\
\text { very weakly } \\
\text { pointing } \\
\text { backwards }\end{array}$ & $\begin{array}{l}\text { with very } \\
\text { broadly } \\
\text { triangular } \\
\text { protrusion } \\
\text { pointing } \\
\text { backwards }\end{array}$ & $\begin{array}{l}\text { with very } \\
\text { broadly } \\
\text { triangular } \\
\text { protrusion } \\
\text { pointing } \\
\text { backwards }\end{array}$ & $\begin{array}{l}\text { with bluntly } \\
\text { triangular } \\
\text { protrusion } \\
\text { strongly } \\
\text { pointing } \\
\text { backwards }\end{array}$ \\
\hline $\begin{array}{l}\text { Dorsal } \\
\text { protrusion of } \\
\text { urosomite } 1\end{array}$ & fairly strong & $\begin{array}{l}\text { fairly weak to } \\
\text { weak }\end{array}$ & weak & fairly strong & fairly strong \\
\hline Distribution & Adélie Coast & $\begin{array}{l}\text { Elephant } \\
\text { Island to tip } \\
\text { of Antarctic } \\
\text { Peninsula }\end{array}$ & $\begin{array}{c}\text { western Ross } \\
\text { Sea }\end{array}$ & $\begin{array}{c}\text { western } \\
\text { Weddell Sea }\end{array}$ & Adélie Coast \\
\hline
\end{tabular}

PeREIOPOD 7. Basis broad; posterior border weakly convex, with shallow concavity in distal 0.8 , terminated into a sharp triangular tooth (forming a squared angle).

\section{Body length}

$15 \mathrm{~mm}$.

\section{Distribution}

Adélie Coast: Cape Géodésie, 115-135 m, on coarse sand with abundant epifauna: hydroids, bryozoans and sponges (Bellan-Santini 1972).

\section{Remarks}

Watling \& Holman (1981) synonymised Subepimeria geodesiae with Epimeria puncticulata, which they considered as a widely distributed variable species. Molecular data (COI, 28S) revealed different species within E. puncticulata s. lat. (Verheye et al. 2016a; this paper Fig. 342), leading to the resurrection of Subepimeria, as a subgenus. The shape of coxa 4 of E. geodesiae as illustrated by Bellan-Santini (1972) is unique and does not fit with the descriptions of the holotype of E. puncticulata (K.H. Barnard 1930; Coleman 1994) or any other Subepimeria species. Epimeria geodesiae is considered here to be a valid species. 
Epimeria (Subepimeria) iota sp. nov. urn:1sid:zoobank.org:act:7A557F8F-058F-413B-998C-AED9C9D23EE6

Figs 299-306

Epimeria puncticulata - Watling \& Holman 1981: 213, in part, fig. 21.

Epimeria aff. puncticulata - ? Rauschert \& Arntz 2015: 61, pl. 54, unnumbered photograph.

'Clade B puncticulata complex - PUN1' - Verheye et al. 2016a, supplement: 3 (online).

non Epimeria puncticulata K.H. Barnard, 1930: 377, fig. 42.

\section{Etymology}

Iota is the smallest letter of the Greek alphabet. The name, which is a noun in apposition, alludes to the small size of the species.

\section{Type material}

\section{Holotype}

RV Polarstern cruises:

SOUTHERN OCEAN: sex undetermined, cruise PS81, ANT-XXIX/3, stn 197-6, Bransfield Strait, $62^{\circ} 45.05^{\prime} \mathrm{S}, 57^{\circ} 26.68^{\prime} \mathrm{W}$ to $62^{\circ} 45.09^{\prime} \mathrm{S}, 57^{\circ} 26.47^{\prime} \mathrm{W}, 210-222 \mathrm{~m}$, black gravel mixed with sand and a little bit of mud, Rauschert dredge, 25 Feb. 2013, coll. C. d'Udekem d'Acoz and M. Verheye (RBINS, INV. 122947) [extraction ANT48; Genbank nr, 28S: KU759607].

\section{Paratypes}

RV Polarstern cruises:

SOUTHERN OCEAN: 1 spec., cruise PS69, ANT-XXIII/8, stn 605-3, Elephant Island, 61 ${ }^{\circ} 20.33^{\prime}$ S, $55^{\circ} 31.53^{\prime} \mathrm{W}$ to $61^{\circ} 20.35^{\prime} \mathrm{S}, 55^{\circ} 30.18^{\prime} \mathrm{W}, 148-154 \mathrm{~m}$, Agassiz trawl, 20 Dec. 2006, coll. C. d'Udekem d'Acoz and H. Robert (RBINS, INV. 122519); 2 specs, cruise PS69, ANT-XXIII/8, stn 614-3/4/5, Elephant Island, $60^{\circ} 52.37^{\prime} \mathrm{S}, 55^{\circ} 29.80^{\prime} \mathrm{W}$ to $60^{\circ} 52.71^{\prime} \mathrm{S}, 55^{\circ} 27.83^{\prime} \mathrm{W}, 248-265 \mathrm{~m}$, a lot of epifauna, Rauschert dredge and Agassiz trawl, 22 Dec. 2006, coll. C. d'Udekem d'Acoz and H. Robert (RBINS, INV. 122525); 1 spec., sex undetermined, cruise PS81, ANT-XXIX/3, stn 164-5, south of Dundee Island, $63^{\circ} 36.84^{\prime} \mathrm{S}, 56^{\circ} 10.28^{\prime} \mathrm{W}$ to $63^{\circ} 36.72^{\prime} \mathrm{S}, 56^{\circ} 10.46^{\prime} \mathrm{W}, 121-122 \mathrm{~m}$, Rauschert dredge, $11 \mathrm{Feb} .2013$, coll. C. d'Udekem d'Acoz and M. Verheye (RBINS, INV. 122934) [extraction K42; Genbank nr, 28S: KU759655].

\section{Description}

Basis of description. Description based on holotype.

Rostrum. In lateral view fairly short and fairly narrow; distinctly curved, posterior border straight, tip acute; in frontal view narrowly triangular, fairly narrow and with almost straight converging borders, with tip blunt; not reaching tip of article 1 of peduncle of antenna 1 .

EYES. Very large, nearly circular (very broadly elliptic).

Pereion-Pleosome tooth pattern. Pereionites $1-7$ and pleonite 1 totally smooth; pleonite 2 with small, posterodorsal tooth; pleonite 3 carinate, with posterodorsal tip forming a small, low, rounded lobe very weakly projecting backwards.

COXAE 1-3. Tip blunt. 
Coxa 4. Narrow; anterodorsal border nearly straight, curving ventrally and followed by weakly curved anteroventral border; anterior corner very rounded but distinct, projecting forward; ventral corner forming a broadly rounded squared angle; posteroventral border distinctly concave; ratio length of posterodorsal border / length of posteroventral border: 0.7 .

Coxa 5. Very broad, posteroventral corner with broadly rounded angular discontinuity.

Coxa 6. Posterior border rounded.

Epimeral plates 1-3. Posteroventral angle rounded in plate 1, produced into a small tooth in plate 2; produced into a medium-sized tooth in plate 3 .

UROSOME TOOTH PATTERN. Urosomite 1 with medium-sized blunt triangular dorsal process; urosomite 3 with dorsolateral borders straight, with tip bluntly angulate.

TELSON. Broad, with lateral border strongly converging, with lobes distally broad, slit narrowly U-shaped, cleft on 0.3 .

GNATHOPODS 1-2. Carpus and propodus of normal slenderness; propodus not narrowing distally, and palm weak but distinct.

PEREIOPOD 5. Basis of normal width, with posteroproximal process indistinct (reduced to very low proximal dilatation in continuity with the more distal part of the posterior border), with posterodistal corner forming a blunt-tipped broadly triangular process (squared angle), not projecting backwards; merus, carpus and propodus stout.

PEREIOPOD 6. Basis of normal width, with posteroproximal process indistinct (reduced to very low proximal dilatation in continuity with the more distal part of the posterior border), with posterior border parallel to anterior border, with posterodistal corner forming a rounded triangular process (very rounded squared angle) not projecting backwards; merus, carpus and propodus stout.

PEREIOPOD 7. Basis broad; posterior border nearly straight, with trace of concavity in distal 0.8 , terminated into an obtuse rounded lobe.

\section{Variations}

The sequenced holotype is obviously immature. Adult specimens preserved in formalin interpreted as adult Epimeria iota sp. nov. have broader coxa 4, a stronger posterodistal tooth on the basis of pereiopods 5 and 6 , sometimes a trace of a posterodorsal tooth or bump on pleonite 1 and a more obtuse dorsal process on urosomite 1 .

\section{Colour pattern}

Holotype: background whitish (some areas very pale pinkish or very pale yellowish); head, pereionites $3-5$, lower part of epimeral plates, posterior border of pleonite 3 and urosomites 1-2 suffused with orange-red; two red dots on the anterior part of coxa 4; a large red dot on first epimeral plate; eyes reddish.

\section{Body length}

The holotype is $9.5 \mathrm{~mm}$. Non sequenced specimens interpreted as adult E. iota sp. nov. reach $16 \mathrm{~mm}$. 


\section{Distribution}

Tip of Antarctic Peninsula and Elephant Island, 121-265 m.

\section{Remarks}

The specimens from the stations $605-3$ and $614-3 / 4 / 5$ of ANT-XXIII/8 are interpreted as adult Epimeria (Subepimeria) iota sp. nov. They possess the following character states of E. iota sp. nov.: (1) the anterior margin of their coxa 4 has an angular discontinuity (forming a regular curve in E. teres sp. nov.), and (2) the margins of the basis of pereiopod 6 are parallel (diverging in E. teres sp. nov.). The 'Epimeria puncticulata' illustrated by Watling \& Holman (1981) and the 'Epimeria aff. puncticulata' illustrated by Rauschert \& Arntz (2015: 61, pl. 54) presumably belong to the same morphospecies as well. The collection details are not given by Rauschert \& Arntz (2015), but are indicated in an early draft of their book made available to the authors: ANT-XXI/2 stn 276 [i.e., 276-1], $71^{\circ} 06.44^{\prime} \mathrm{S}, 11^{\circ} 27.76^{\prime} \mathrm{W}$ to $71^{\circ} 06.64^{\prime} \mathrm{S}, 11^{\circ} 27.28^{\prime} \mathrm{W}, 268-277 \mathrm{~m}$, eastern shelf of the Weddell Sea.

Epimeria (Subepimeria) puncticulata K.H. Barnard, 1930

Epimeria puncticulata K.H. Barnard, 1930: 377, fig. 42.

Epimeria puncticulata - Gurjanova 1955: 197. - McCain 1971: 161. - De Broyer 1983: 305 (discussion). — De Broyer \& Klages 1991: 164 (key). — Coleman 1994: 569, figs 13-16 [holotype]; 1998b: 223-224 (in part). - Wakabara \& Serejo 1999: 643 (key). — Coleman 2007: 48, in part, fig. 25 [holotype], not plate 2 fig. d [= Epimeria (Subepimeria) sp.], map 12 (circle) [in part].

\section{Description}

Basis of description. Description based on the accounts on the holotype published by K.H. Barnard (1930) and Coleman (1994); when illustrations are conflicting, description based on Coleman (1994).

RosTRUM. In lateral view very narrow.

EYEs. Medium-sized, narrowly elliptic.

Pereion-Pleosome tooth pattern. Pereionites 1-7 totally smooth; pleonite 1 with feeble indication of a keel; pleonite 2 keeled with well developed acute posterodorsal tooth; pleonite 3 keeled with posterodorsal tip forming a distinct blunt process distinctly projecting backwards.

COXAE 1-2 (cf. Coleman 1994). Tip subacute to rather blunt; coxa 3: tip rounded.

Coxa 4 (cf. Coleman 1994). Fairly narrow; anterodorsal border nearly straight (inconspicuously convex); anteroventral border weakly convex; anterior corner very broadly rounded but forming a distinct angular discontinuity; the coxa is slightly projecting forward; ventral corner forming a squared angle of which the tip is subacute; posteroventral border distinctly concave; posterodorsal border $0.8 \times$ as long as posteroventral border.

Coxa 5. Very broad, posteroventral corner forming a blunt but distinct squared angle.

Coxa 6. Posterior border regularly rounded.

Coxa 7. Posterior border straight; posteroventral corner forming a distinct obtuse angle.

Epimeral Plates 1-3. Posteroventral angle with trace of tooth in plate 1, produced into a small tooth in plate 2 , produced into a medium-sized tooth in plates 3 . 
UROSOME TOOTH PATTERN. Urosomite 1 with triangular dorsal process.

Telson. Cleft on 0.2; lobes with tips rounded; notch V-shaped.

GNATHOPODs 1-2. With carpus and propodus of normal slenderness; propodus not narrowing distally, and palm distinct but weak.

PEREIOPOD 5. Basis of normal width, with posteroproximal process reduced to low proximal dilatation in continuity with the more distal part of the posterior border, with posterodistal corner forming a fairly narrow, acutely triangular tooth projecting backwards; merus, carpus and propodus stout.

PEREIOPOD 6. Basis of normal width, with posteroproximal process reduced to very low proximal dilatation nearly in continuity with the more distal part of the posterior border), with posterior border parallel to anterior border, with posterodistal corner forming a triangular process (acute, nearly squared angle) very weakly projecting backwards; merus, carpus and propodus stout.

Pereiopod 7. Basis broad; posterior border weakly convex, with inconspicuous trace of concavity in distal 0.9 , terminated into a very blunt, obtuse angle.

\section{Body length}

Up to $16 \mathrm{~mm}$.

\section{Distribution}

Ross Sea, McMurdo Sound, 175 m (K.H. Barnard 1930).

\section{Remarks}

Watling \& Holman (1981) and Coleman (2007) considered Epimeria puncticulata as a single widespread and variable species. Yet, genetic data (COI, 28S) (Verheye et al. 2016a) based on a limited material indicate the existence of four different species refered herein as E. adeliae sp. nov., E. iota sp. nov., E. teres sp. nov. and E. urvillei sp. nov. (Fig. 342). Examination of published illustrations suggest the existence of four additional species: E. geodesiae, E. puncticulata s. str., E. (Subepimeria) sp. 1 and E. (Subepimeria) sp. 2. Coxa 4 of the holotype of E. puncticulata is different in the drawings of K.H. Barnard (1930) and those of Coleman (1994). This might result from different orientations of the specimens.

Epimeria (Subepimeria) teres sp. nov. urn:1sid:zoobank.org:act:87DB1EDA-29A4-493E-84BF-9A68EFF422ED

Figs 307-313

Epimeria aff. puncticulata - ? Rauschert \& Arntz 2015: 61, pl. 54.

'Clade B puncticulata complex - PUN2' - Verheye et al. 2016a, supplement: 3 (online).

Epimeria puncticulata K.H. Barnard, 1930: 377, fig. 42.

\section{Etymology}

Teres, teres, terete, Latin adjective meaning round and smooth, which seems appropriate for a very smooth Epimeria species. 


\section{Type material}

\section{Holotype}

RV Polarstern cruises:

SOUTHERN OCEAN: adult, sex undetermined, cruise PS77, ANT-XXVII/3, CAMBIO, stn 2482, Larsen B, $65^{\circ} 57.51^{\prime} \mathrm{S}, 60^{\circ} 28.15^{\prime} \mathrm{W}$ to $65^{\circ} 57.69^{\prime} \mathrm{S}, 60^{\circ} 28.30^{\prime} \mathrm{W}, 196-202 \mathrm{~m}$, Agassiz trawl and Rauschert dredge, 7 Mar. 2011, coll. C. Havermans and H. Robert (RBINS, INV. 132951) [extraction I2; Genbank nr, COI: KU870845, 28S: KU759622].

\section{Paratype}

RV Polarstern cruises:

SOUTHERN OCEAN: 1 juv., sex undetermined, cruise PS77, ANT-XXVII/3, CAMBIO, stn 2482, Larsen B, $65^{\circ} 57.51^{\prime} \mathrm{S}, 60^{\circ} 28.15^{\prime} \mathrm{W}$ to $65^{\circ} 57.69^{\prime} \mathrm{S}, 60^{\circ} 28.30^{\prime} \mathrm{W}, 196-202 \mathrm{~m}$, Agassiz trawl and Rauschert dredge, 7 Mar. 2011, coll. C. Havermans and H. Robert (RBINS, INV. 122896).

\section{Description}

Rostrum. In lateral view fairly short and narrow, reaching tip of article 1 of peduncle of antenna 1 , weakly and regularly curved on anterior border, posterior border straight, tip very acute; in frontal view triangular: narrow, with straight converging borders, with tip blunt.

EYEs. Large, broadly elliptic.

Pereion-Pleosome tooth pattern. Pereionites 1-7 totally smooth; pleonite 1 keeled along all its length, posteriorly terminated by tiny but distinct bump; pleonite 2 keeled with well developed acute posterodorsal tooth; pleonite 3 keeled with posterodorsal tip forming a distinct blunt process (shape: acute angle) distinctly projecting backwards.

CoXae 1-3. Tip acute.

Coxa 4. Narrow; anterodorsal and anteroventral border forming a continuous curve without any trace of discontinuity (there is no distinct anterior corner), not curving significantly more ventrally; the coxa is not projecting forward; ventral corner forming an acute (nearly squared) angle of which the tip is blunt but not broadly rounded; posteroventral border distinctly concave; posterodorsal border $0.9 \times$ as long as posteroventral border.

CoXa 5. Very broad, posteroventral corner forming a blunt but distinct obtuse (nearly squared) angle.

Coxa 6. Posterior border regularly rounded.

Coxa 7. Posterior border straight; posteroventral corner forming a distinct obtuse angle.

EPIMERAL PLATES 1-3. Posteroventral angle: forming a squared angle in plate 1, produced into a tiny tooth in plate 2 , produced into a small tooth in plate 3 .

UROSOME TOOTH PATTERN. Urosomite 1 with distinct triangular dorsal process, anteriorly weakly concave, tip straight, posterior border nearly straight (inconspicuously concave); urosomite 3 with dorsolateral borders straight, with tip forming a squared angle.

Telson. Cleft on 0.20; lobes with tips broad; notch broadly V-shaped.

Gnathopods 1-2. Carpus and propodus of normal slenderness; propodus not narrowing distally, and palm distinct but weak. 
Pereiopod 5. Basis of normal width, with posteroproximal process reduced to low proximal dilatation in continuity with the more distal part of the posterior border, with posterodistal corner forming a long, narrowly triangular tooth projecting backwards; merus, carpus and propodus stout.

Pereiopod 6. Basis of normal width, with posteroproximal process reduced to low proximal dilatation in continuity with the more distal part of the posterior border, with posterior border distinctly diverging from anterior border, with posterodistal corner forming a triangular process (acute, nearly squared angle) weakly projecting backwards; merus, carpus and propodus stout.

PEREIOPOD 7. Basis broad; posterior border nearly straight, with weak but distinct concavity in distal 0.8 , terminated into a tooth forming a squared angle.

\section{Body length}

Up to $16 \mathrm{~mm}$.

\section{Distribution}

Western Weddell Sea: Larsen B, 196-202 m; probably eastern shelf of the Weddell Sea, 268-277 m (see remarks).

\section{Remarks}

Epimeria (Subepimeria) teres sp. nov. is morphologically very similar to $E$. (S.) urvillei sp. nov., while genetic data (COI, 28S) Verheye et al. (2016a) suggests that they are different species (Fig. 342). In $E$. $(S$.) teres sp. nov., the rostrum is a bit longer, the eyes slightly more rounded, coxa 4 a bit narrower, and the tip of the basis of pereiopod 7 more produced than in $E$. (S.) urvillei sp. nov. It is likely that the 'Epimeria aff. puncticulata' illustrated by Rauschert \& Arntz (2015) is E. (S.) teres sp. nov., as it has a narrow coxa 4 , a very strong posterodorsal protrusion on pleonite 3 , a very strong dorsal protrusion on urosomite 1 and a posterodistal tooth on the basis of pereiopod 7. Rauschert \& Arntz (2015) did not give the collection details of their specimen, but this information was present in an early draft of their book made available to the authors. It is indicated that the specimen was collected during the cruise ANT-XXI (obviously ANT-XXI/2) at station 276 (i.e., 276-1 as there are no other sub-stations). The coordinates of this station are: $71^{\circ} 06.44^{\prime} \mathrm{S}, 11^{\circ} 27.76^{\prime} \mathrm{W}$ to $71^{\circ} 06.64^{\prime} \mathrm{S}, 11^{\circ} 27.28^{\prime} \mathrm{W}$ [eastern shelf of the Weddell Sea], 268-277 m.

Epimeria (Subepimeria) urvillei sp. nov. urn:Isid:zoobank.org:act:524C2AA7-3B7D-4EDF-B336-0A2D2D5BE294

Figs 314-319

'Clade B puncticulata complex - PUN3' - Verheye et al. 2016a, supplement: 3 (online).

\section{Etymology}

The species is dedicated to the memory of the French explorer Jules Sébastien César Dumont d'Urville (23 May 1790 - 8 May 1842), who discovered Adélie Coast, where the species was collected. The name is a genitive.

\section{Type material}

\section{Holotype}

RV Seatruck cruises:

SOUTHERN OCEAN: ovigerous + , cruise REVOLTA III, stn. REVO_084, Collect_ID: REVO_477, Field_ID: CE-000003093, Adélie Coast, $66^{\circ} 39.279^{\prime}$ S, $139^{\circ} 55.846^{\prime}$ E to $66^{\circ} 39.291^{\prime}$ S, $139^{\circ} 56.043^{\prime}$ E, 
52-54 m, beam trawl, 1 Feb. 2012, Coll. G. Lecointre, A. Dettaï, J. Lanshere, C. Gallut and C. Ozouf, (MNHN-IU-2009-2578) [Extraction K33; Genbank nr, COI: KU870867, 28S: KU759646].

\section{Description}

Rostrum. In lateral view short and narrow, not reaching tip of article 1 of peduncle of antenna 1, very weakly and regularly curved on anterior border, posterior border very weakly concave, tip acute; in frontal view triangular: fairly narrow, with straight converging borders, with tip blunt.

EyEs. Large, narrowly elliptic.

Pereion-Pleosome tooth pattern. Pereionites 1-7 totally smooth; pleonite 1 keeled all along its length, posteriorly terminated by tiny but distinct bump; pleonite 2 keeled with well developed acute posterodorsal tooth; pleonite 3 keeled with posterodorsal tip forming a distinct blunt triangular process distinctly projecting backwards.

COXAE 1-2. Tip subacute.

Coxa 4. Fairly narrow; anterodorsal border nearly straight, followed by anterior angle + anteroventral border, which form a very regular curve (without discontinuity) - there is no distinct anterior corner; the coxa is not projecting forward; ventral corner forming an acute (nearly squared) angle of which the tip is subacute; posteroventral border distinctly concave; posterodorsal border $1.2 \times$ as long as posteroventral border.

Coxa 5. Very broad, posteroventral corner forming a blunt but distinct obtuse (nearly squared) angle.

Coxa 6. Posterior border regularly rounded.

Coxa 7. Posterior border straight; posteroventral corner forming a distinct obtuse angle.

Etimeral Plates 1-3. Posteroventral angle broadly rounded in plate 1, produced into a medium-sized tooth in plates $2-3$.

UROSOME TOOTH PATTERN. Urosomite 1 with distinct triangular dorsal process, anteriorly weakly concave, tip subacute, posterior border nearly straight (inconspicuously concave); urosomite 3 with dorsolateral borders straight, with tip forming a squared angle.

Telson. Cleft on 0.25 ; lobes with tips bluntly angulate; notch narrowly V-shaped.

GNATHOPODS 1-2. With carpus and propodus of normal slenderness; propodus not narrowing distally, and palm distinct but weak.

PEREIOPOD 5. Basis of normal width, with posteroproximal process reduced to low proximal dilatation in continuity with the more distal part of the posterior border, with posterodistal corner forming a long, narrowly triangular sharp tooth projecting backwards; merus, carpus and propodus stout.

PereIOPOD 6. Basis of normal width, with posteroproximal process indistinct (reduced to very low proximal dilatation in continuity with the more distal part of the posterior border), with posterior border slightly but distinctly diverging from anterior border, with posterodistal corner forming a triangular process (acute, nearly squared angle) weakly projecting backwards; merus, carpus and propodus stout.

PEREIOPOD 7. Basis broad; posterior border weakly convex, with inconspicuous trace of concavity in distal 0.9 , terminated into a very blunt, obtuse angle. 


\section{Colour pattern}

Whitish with scattered orange dots. Rostrum, coxae $1-4$, anterior 0.2 of coxa 5 , pleon suffused with pale orange. Eyes reddish.

\section{Body length}

$16 \mathrm{~mm}$.

\section{Distribution}

Adélie Coast, 52-54 m.

\section{Remarks}

Epimeria urvillei $\mathrm{sp}$. nov. is morphologically very similar to E. teres sp. nov. and E. puncticulata. Further molecular and morphological studies are necessary to sort out completely the taxonomy of this complex.

\section{Epimeria (Subepimeria) sp. 1}

Epimeria puncticulata - K.H. Barnard 1932: 175, fig. 104d.

Epimeria sp. n. 1 - Rauschert \& Arntz 2015: 60, pl. 53.

non Epimeria puncticulata K.H. Barnard, 1930: 377, fig. 42.

\section{Material (not examined)}

\section{Discovery Investigations 1926-1927:}

R.V. Discovery cruises:

SOUTHERN OCEAN: 1 q,13 mm, stn 45, South Georgia, 2.7 miles S 85 $\mathrm{E}$ of Jason Light, N 4-T (net with mesh of $4 \mathrm{~mm}$ attached to the back of the trawl) and NCS-T (tow-net of coarse silk, with 16 meshes to the linear inch, attached to trawl), 238-270 m, grey mud, 6 Mar. 1926 (NHM 1936.11.2. 1581-1590); 3 우, 11-13 mm, stn 123, South Georgia, off mouth of Cumberland Bay, N 4-T (net with mesh of $4 \mathrm{~mm}$ attached to the back of the trawl) and OTL (large otter trawl), 230-250 m, grey mud, 15 Dec. 1926 (NHM 1936.11.2. 1581-1590); 8 q $ᄋ, 10-13$ mm, stn 140, South Georgia, Stromness Harbour to Larsen Point, N 4-T (net with mesh of $4 \mathrm{~mm}$ attached to the back of the trawl), 122-136 m, green mud, stn, 23 Dec. 1926, (NHM 1936.11.2. 1581-1590); 1 ô, 10.5 mm, stn 148, South Georgia, off Cape Saunders, $\mathrm{N}$ 4-T (net with mesh of $4 \mathrm{~mm}$ attached to the back of the trawl) and OTL (large otter trawl), 200-234 m, grey mud, stn, 10 Jan. 1927 (NHM 1936.11.2. 1581-1590).

R.V. William Scoresby cruises:

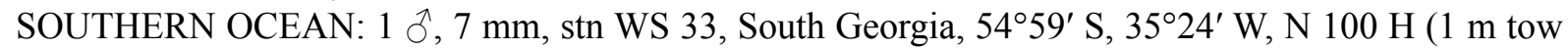
net), 135 m, grey mud, 21 Dec. 1926 (NHM 1936.11.2. 1581-1590); 1 juv., 5.5 mm, Marine Biological Station, stn MS 71, South Georgia, East Cumberland bay, BTS (small beam trawl) and NCS-T (townet of coarse silk, with 16 meshes to the linear inch, attache to trawl), 60-110 m, 9 Mar. 1926 (NHM 1936.11.2. 1581-1590).

\section{Description}

Description based on the photograph of Rauschert \& Arntz (105) and K.H. Barnard's (1932) account.

Rostrum. in lateral view short reaching about tip of article 1 of peduncle of antenna 1, distinctly curved on the proximal half of its anterior border.

EYES. Large, broadly elliptic. 
Pereion-Pleosome tooth pattern. Pereionites 1-6 totally smooth; pereionite 7 keeled with small blunt posterodorsal tooth; pleonites 1-2 keeled with well developed acute posterodorsal tooth; pleonite 3 keeled with posterodorsal tip forming a very strong blunt protrusion.

COXAe 1-3. Tip blunt.

CoxA 4. Of medium width; anterodorsal border proximally nearly straight; anteroventral border straight (transition between anterodorsal and anteroventral border gradual, but with rather distinct anterior corner); the coxa is not projecting forward; ventral corner forming a squared angle, of which the tip is blunt but not rounded; posteroventral border nearly straight (very weakly concave); posterodorsal border as long as posteroventral border.

EPIMERAL PLATES 2-3. Produced into a medium-sized tooth.

UROSOME TOOTH PATTERN. Urosomite 1 with low and blunt triangular dorsal process.

BASIS OF PEREIOPOD 7. Broad; posterior border weakly convex, terminated into a blunt, obtuse (nearly squared) angle.

\section{Colour pattern}

"Pale yellow. Each of first 7 segments with a transverse pale brown band dorsally along both anterior and posterior margins. Large side-plate of 4th segment largely red-brown. Posterior segments yellow mottled with brown. Caudal appendages and legs pale yellow. Eyes red" (K.H. Barnard 1932). Whitish with scattered orange dotting and mottling; peduncle of antennae and dorsal process of urosomite 1 red; eyes red (specimen photographed by M. Rauschert).

\section{Body length}

$13 \mathrm{~mm}$ (K.H. Barnard 1932) or $14 \mathrm{~mm}$ (specimen photographed by M. Rauschert).

\section{Distribution}

South Georgia, 60-270 m (K.H. Barnard 1932 as Epimeria puncticulata); "Scotia Arc", $280 \mathrm{~m}$ (Rauschert \& Arntz 2015 as Epimeria sp. 1).

\section{Remarks}

From discussions with C.O. Coleman and W. Arntz, it transpires that large parts of Rauschert's collections are not yet registered and thus currently inaccessible. Therefore, the "Epimeria sp. n. 1" from Rauschert \& Arntz (2015) could not be found and its precise collection locality is unknown. An early draft of the book of Rauschert \& Arntz (2015) simply indicated that it was collected during the cruise 'ANT XIX' in the 'Scotia Arc'. However, the diagnosis of 'Epimeria puncticulata' from South Georgia by K.H. Barnard (1932) is in agreement with the photograph of 'Epimeria sp. n. 1': "the $7^{\text {th }}$ peraeon segment ends in a short medio-dorsal point, the keels on pleon segments 1 and 2 end in slightly more prominent points, and the triangular projection on segment 4 is more sharply pointed than in the Terra Nova specimens." M. Rauschert took part in cruise ANT-XIX/5, which sampled extensively around South Georgia (Arntz \& Brey 2003). Therefore, there is a high probability that Rauschert's specimens were collected off South Georgia, just as the specimens of K.H. Barnard (1932). Because of time constraints, it was impossible to borrow and to re-examine K.H. Barnard's (1932) specimens, deposited in the Natural History Museum in London: NHM 1936.11.2. 1581-1590, six tubes together in the same jar, no specific number allocated to each tube (M. Lowe pers. com.). The species is treated herein as Epimeria (Subepimeria) sp. 1. When examination of specimens will be possible, it will presumably have to be described as a new species. 
The dorsal tooth pattern of the Epimeria (Subepimeria) sp. 1 is very different from that of other West-Antarctic Subepimeria examined. It is similar to that of Epimeria adeliae sp. nov. from Adélie Coast. However, the shape of the posterodorsal protrusion on pleonite 3 is different: blunt in Epimeria (Subepimeria) sp. 1 (see Rauschert \& Arntz 2015, as Epimeria sp. 1), whereas it forms a squared angle in $E$. adeliae sp. nov. The anteroventral border of coxa 4 is also more straight and the protrusion on urosomite 1 lower in Epimeria (Subepimeria) sp. 1 than in E. adeliae sp. nov.

\section{Epimeria (Subepimeria) sp. 2}

Epimeria puncticulata - Coleman 2007: 48, in part, plate 2 fig. d only, not fig. 25 (=E. puncticulata). Rauschert \& Arntz 2015: 62, pl. 55.

non Epimeria puncticulata K.H. Barnard, 1930: 377, fig. 42.

\section{Discription}

EYEs. Large and narrowly elliptic.

Pereionite 7. Posterodorsally smooth.

PLeONITE 1. Posterodorsally smooth.

PleONITE 2. With small sharp posterodorsal tooth.

PLEONITE 3. Posterodorsally produced into a blunt acute (nearly squared) angle.

Coxa 4. with ventral corner produced into a distinct tooth (Coleman 2007), or apparently blunt (Rauschert \& Arntz 2015) [specimen not photographed in a flat orientation?].

UROSOME TOOTH PATTERN. Urosomite 1 with well developed triangular dorsal process.

\section{Colour pattern}

Eyes red. Body whitish to yellowish, with some areas more brownish. Distinct brown transverse stripes on body segment 4 and coxa 4.

\section{Body length}

17 mm (Rauschert \& Arntz 2015).

\section{Distribution}

Eastern shelf of the Weddell Sea, 765-840 m (see remarks).

\section{Remarks.}

The identity of the E. puncticulata illustrated by colour photographs in the books of Coleman (2007: plate 2 figure d) and Rauschert \& Arntz (2015: plate 55) is not clear. The photograph examined are not sharp enough to reveal all relevant details. The species is similar to E. iota sp. nov., E. teres sp. nov., E. puncticulata and E. urvillei sp. nov. Unlike E. iota sp. nov., E. teres sp. nov. and E. urvillei sp. nov., E. (Subepimeria) sp. 2 exhibits a distinct brown stripe on each side of pereionite 4 and on coxa 4 . The colour pattern of E. puncticulata s. str. is unknown. The collection details of the specimen of Rauschert \& Arntz (2015) is given in an early draft of their book made available to the authors: ANT-XVII/3 stn 138 [138-1]. The coordinates of this station are: $71^{\circ} 08.90^{\prime} \mathrm{S}, 013^{\circ} 12.80^{\prime} \mathrm{W}$ to $71^{\circ} 08.80^{\prime} \mathrm{S}, 013^{\circ} 13.20^{\prime} \mathrm{W}$ [eastern shelf of the Weddell Sea], 765-840 m. 


\section{Subgenus Urepimeria subgen. nov. urn:1sid:zoobank.org:act:95595B3C-33A1-4111-BEB0-ACD96A55BD12}

\section{Etymology}

Combination of oúpó, tail and Epimeria. The name, which is feminine, refers to the fact that the only ornamentation of the species is located on the posterior part of the animal.

\section{Type species}

Epimeria annabellae Coleman, 1994.

\section{Description}

Body fairly opaque with teguments moderately calcified. Rostrum small to medium-sized: 0.5 to $1.1 \times$ as long as article 1 of peduncle of antenna 1 . Eyes not conical. Pereionites 1-7 and pleonites 1-2 completely smooth; pleonite 3 posterodorsally produced into a triangular tooth or a blunt lobe directed backwards, without other ornamentation. Coxae 1-3 with tip blunt or sharp, keeled or not. Coxa 4 without groove or carina, with posteroventral border distinctly concave. Coxae 5-6 without tooth or distinct protrusion. Mid of posterior border of epimeral plates 1-3 not produced into a tooth. Posteroventral tooth of epimeral plate 3 small to strong. Dorsal process of urosomite 1 produced into a triangular tooth or a rounded lobe directed upwards. Urosomite 2 without pair of small teeth pointing upwards. Lateral borders of urosomite 3 posteriorly bluntly angular. Peduncle of antenna 1 without teeth or with dentition vestigial. Mandible with molar process triturative. Lower lip with narrow (V-shaped) hypopharyngeal gap. Palp of maxilliped with 4 articles. Gnathopods of normal size, with carpus and propodus fairly stout, with palm obliquely transverse (gnathopods subcheliform); propodus not expanded distally or slightly expanded distally; posterior border of dactylus lined by row of small oblique slender teeth. Basis of pereiopods 5-6 broad and quadrato-elliptic, without posteroproximal protrusion, without posterodistal tooth. Posterior border of basis of pereiopod 7 either completely rounded or concave on distal 0.25 and terminated into a tooth. Dactylus of pereiopods 5-7 short. Benthic.

\section{Body length}

The maximum body length recorded in Urepimeria species ranges between 11 and $29 \mathrm{~mm}$.

\section{Ecology}

Benthic, 0-459 m.

\section{Distribution}

South Orkney Islands, South Shetland Islands, Palmer Archipelago, Antarctic Peninsula, eastern Weddell Sea.

\section{Remarks}

Epimeria annabellae, E. extensa, and E. monodon together constitute the subgenus Urepimeria, based on their morphological similarity.

\section{Key to the species of Urepimeria}

1. Posterodorsal projection of pleonite 3 large and triangular

- Posterodorsal projection of pleonite 3 weak and blunt. extensa subgen. nov. Andres, 1985 [Southeastern tip of Antarctic Peninsula, 230-260 m] 
2. Coxa 4 with sharp ventral triangular protrusion; dorsal process of urosomite 1 sharply triangular; basis of pereiopod 7 with posterodistal lobe produced into a tooth, with distal part of posterior border concave

...E. (Urepimeria) annabellae subgen. nov. Coleman, 1994 [Eastern Weddell Sea, 159-459 m]

- Coxa 4 with low ventral triangular protrusion; dorsal process of urosomite 1 bluntly rounded; basis of pereiopod 7 with posterodistal lobe broadly rounded, with posterior border convex along all its length E. (Urepimeria) monodon subgen. nov. Stephensen, 1947 [South Orkney Islands to Palmer Archipelago, infralittoral species: 0-15 m]

Epimeria (Urepimeria) annabellae subgen. nov. Coleman, 1994

Figs 320-321

Epimeria annabellae Coleman, 1994: 555-560, figs 1-4.

Epimeria annabellae - Coleman 1998b: 224; 2007: 35, fig. 14a-b, colour pl. 1 fig. h, map 6 (rhomb). Wakabara \& Serejo 1999: 644 (key). — Rauschert \& Arntz 2015: 61, pl. 54, unnumbered photograph.

\section{Material examined}

RV Polarstern cruises:

SOUTHERN OCEAN: 1 spec., cruise PS39, ANT-XIII/3, EASIZ I, stn 2, MG 29, eastern Weddell Sea, $71^{\circ} 18.60^{\prime} \mathrm{S}, 12^{\circ} 25.40^{\prime} \mathrm{W}, 181 \mathrm{~m}, 22$ Feb. 1996, coll. C. De Broyer and G. Chapelle (RBINS, INV. 132701); 1 spec., cruise PS39, ANT-XIII/3, EASIZ I, stn 2 AGT 2, eastern Weddell Sea, $71^{\circ} 18.70^{\prime}$ S, $12^{\circ} 17.10^{\prime} \mathrm{W}$, to $71^{\circ} 18.45^{\prime} \mathrm{S}, 12^{\circ} 16.30^{\prime} \mathrm{W}, 170-174 \mathrm{~m}$, Agassiz trawl, 9 Feb. 1996, coll. C. De Broyer and G. Chapelle (RBINS, INV. 132715); 10 specs, cruise PS39, ANT-XIII/3, EASIZ I, stn 6, AGT 1, eastern Weddell Sea, $71^{\circ} 31.80^{\prime} \mathrm{S}, 13^{\circ} 34.50^{\prime} \mathrm{W}$ to $71^{\circ} 31.86^{\prime} \mathrm{S}, 13^{\circ} 35.50^{\prime} \mathrm{W}, 254-261 \mathrm{~m}$, Agassiz trawl, 8 Jan. 1996, coll. C. De Broyer and G. Chapelle (RBINS, INV. 132679); 2 specs, cruise PS39, ANT-XIII/3, EASIZ I, stn 6, AGT 1, eastern Weddell Sea, $71^{\circ} 31.80^{\prime} \mathrm{S}, 13^{\circ} 34.50^{\prime} \mathrm{W}$ to $71^{\circ} 31.86^{\prime} \mathrm{S}, 13^{\circ} 35.50^{\prime} \mathrm{W}$, 254-261 m, Agassiz trawl, 8 Jan. 1996, coll. C. De Broyer and G. Chapelle (MNHN-IU-2014-7341, removed from RBINS, INV. 132679); 1 spec., cruise PS39, ANT-XIII/3, EASIZ I, stn 8, AGT 2, eastern Weddell Sea, $71^{\circ} 18.70^{\prime} \mathrm{S}, 12^{\circ} 17.10^{\prime} \mathrm{W}$ to $71^{\circ} 18.45^{\prime} \mathrm{S}, 1^{\circ} 16.30^{\prime} \mathrm{W}, 170-174 \mathrm{~m}, 9$ Feb. 1996, coll. C. De Broyer and G. Chapelle (RBINS, INV. 132999); 5 specs, cruise PS39, ANT-XIII/3, EASIZ I, stn 8 , AGT 2, eastern Weddell Sea, $71^{\circ} 18.70^{\prime} \mathrm{S}, 12^{\circ} 17.10^{\prime} \mathrm{W}$ to $71^{\circ} 18.45^{\prime} \mathrm{S} 12^{\circ} 16.30^{\prime} \mathrm{W}, 170-174 \mathrm{~m}$, 9 Feb. 1996, coll. C. De Broyer and G. Chapelle (RBINS, INV. 132713); 2 large specs, cruise PS39, ANT-XIII/3, EASIZ I, stn 12, GSN 5, eastern Weddell Sea, $73^{\circ} 18.10^{\prime} \mathrm{S}, 21^{\circ} 10.10^{\prime} \mathrm{W}$, to $73^{\circ} 17.10^{\prime} \mathrm{S}$, $21^{\circ} 08.20^{\prime} \mathrm{W}, 457-459 \mathrm{~m}$, bottom trawl, 14 Feb. 1996, coll. C. De Broyer and G. Chapelle (RBINS, INV. 132704); 1 spec., cruise PS69, ANT-XXIII/8, stn 603-5, eastern Weddell Sea, 70 30.99' S, 08 ${ }^{\circ} 48.08^{\prime}$ W to $70^{\circ} 30.40^{\prime} \mathrm{S}, 08^{\circ} 48.13^{\prime} \mathrm{W}, 274-297 \mathrm{~m}$, sponge bottom, Agassiz trawl, 7 Dec. 2006, coll. C. d'Udekem d'Acoz and H. Robert (RBINS, INV. 122476) [extraction N2; Genbank nr, COI: KU870890, 28S: KU759678]; 1 spec., cruise PS77, ANT-XXVII/3, CAMBIO, stn 260-6, eastern Weddell Sea, BENDEX area, $70^{\circ} 50.56^{\prime} \mathrm{S}, 10^{\circ} 36.20^{\prime} \mathrm{W}$ to $70^{\circ} 50.71^{\prime} \mathrm{S}, 10^{\circ} 36.56^{\prime} \mathrm{W}, 251-253 \mathrm{~m}$, Agassiz trawl, 20 Mar. 2011, coll. Ch. Havermans and H. Robert (RBINS, INV. 132952) [extraction I1; Genbank nr, COI: KU870837, 28S: KU759611] [the station number given by Verheye et al. (2016a) is incorrect]; 1 spec., cruise PS77, ANT-XXVII/3, CAMBIO, stn 275-3, eastern Weddell Sea, 70 56.01' S, $10^{\circ} 29.28^{\prime} \mathrm{W}$ to $70^{\circ} 56.01^{\prime} \mathrm{S}$, $10^{\circ} 28.72^{\prime} \mathrm{W}, 219-226$ m, coll. Ch. Havermans and H. Robert (RBINS, INV. 122898).

\section{Colour pattern}

Whitish, often speckled with scattered orange dots; peduncle of antenna 1 often orange; eyes reddish. 


\section{Body length}

Up to $25 \mathrm{~mm}$.

\section{Distribution}

Eastern shelf of Weddell Sea, 159-459 m (De Broyer et al. 2007).

Epimeria (Urepimeria) extensa subgen. nov. Andres, 1985

Epimeria extensa Andres, 1985: 125-127, figs 7d-f, 8, 9.

Epimeria extensa - De Broyer \& Klages 1991: 164 (key). — Coleman 1994: 574 (table). — Wakabara \& Serejo 1999: 644 (key). — Coleman 2007: 36, fig. 15a-f, map 6 (circle).

\section{Body length}

$11 \mathrm{~mm}$. The species is known by a single specimen and it is possible that it can reach a larger size.

\section{Distribution}

Southeast of tip of Antarctic Peninsula, 230-260 m.

Epimeria (Urepimeria) monodon Stephensen, 1947

Epimeria monodon Stephensen, 1947: 53, fig. 19.

Epimeria monodon - J.L. Barnard 1961: 103 (key). — McCain 1971: 161. — Thurston 1972: 34. — De Broyer \& Klages 1991: 164 (key). — Coleman 1994: 560, 565-569, figs 9-12; 1998b: 224; 2007: 44, fig. 22a-b, colour plate 2c, map 12 (rhomb). - Watling 1981: 206. — Wakabara \& Serejo 1999: 644 (key).

\section{Material examined}

SOUTHERN OCEAN: 1 exuvia, King George Island, Admiralty Bay, kept in aquarium, 14 Apr. 1992, coll. C. De Broyer (RBINS, INV. 132831); 1 exuvia, expedition ARCTOWSKI 1992, King George Island, Admiralty Bay, kept in aquarium, 1 Apr. 1992, coll. C. De Broyer (RBINS, INV. 132832); 1 exuvia, expedition ARCTOWSKI 1992, King George Island, Admiralty Bay, kept in aquarium, 16 Apr. 1992, coll. C. De Broyer (RBINS, INV. 132833); 1 exuvia, expedition ARCTOWSKI 1992, King George Island, Admiralty Bay, kept in aquarium, 30 Mar. 1992, coll. C. De Broyer (RBINS, INV. 132834); 2 specs, expedition ARCTOWSKI 1992, King George Island, Admiralty Bay, kept in aquarium, year 1992, coll. C. De Broyer (RBINS, INV. 132835).

\section{Body length}

Up to $29 \mathrm{~mm}$.

\section{Distribution}

South Orkney Islands; South Shetland Islands; Palmer Archipelago; 0-15 m (De Broyer et al. 2007). Epimeria monodon was recorded from rocky intertidal communities (Aghmich et al. 2016) and was found amidst macro-algae (Richardson 1977). Thurston (1972) stated: "apparently associated with algae growing on rocks, boulder or gravel bottoms, 3-15 m". 


\section{Remarks}

The record of E. monodon from the eastern shelf of the Weddell Sea at $254 \mathrm{~m}$ listed in the data compilation of De Broyer et al. (2007) falls outside of the usual geographical and bathymetric range of the species. It is considered as very suspect. It might be based on E. annabellae, which is common at such depth in the eastern Weddell Sea. It seems possible that E. monodon, which is a very shallow-water species, uses algal rafting as a method of dispersal between islands and archipelagoes. Thurston (1972) recorded a slight sexual dimorphism in the species: "the male has larger eyes and a slightly more prominent projection on pleon segment 3".

Genus Uschakoviella Gurjanova, 1955

Uschakoviella Gurjanova, 1955: 199; type species: Uschakoviella echinophora Gurjanova, 1955.

Uschakoviella echinophora Gurjanova, 1955

Uschakoviella - J.L. Barnard 1961: 102; 1969: 397. — Watling \& Holman 1981: 217. — J.L. Barnard \& Karaman 1991: 381, 387, 401. — Coleman 1998b: 215; 2007: 62.

Uschakoviella echinophora Gurjanova, 1955: 200, figs 14, 15.

Uschakoviella echinophora echinophora Gurjanova, 1955: 203.

Uschakoviella echinophora abyssalis Gurjanova, 1955: 203, figs 16-18.

Uschakoviella echinophora - Shoemaker 1964: 417, fig. 12. - J.L. Barnard 1969: 397. — ? Watling \& Holman 1981: 217, fig. 23. — J.L. Barnard \& Karaman 1991: 387, fig. 75B. — Coleman 2007: 62, fig. 37. - Tomikawa \& Komatsu 2009: 455, figs 7-10.

\section{Distribution}

Boreal North Pacific, Antarctica (?), 54-2550 m, possibly below $3000 \mathrm{~m}$.

\section{Remarks}

Uschakoviella echinophora has been recorded only once in the Southern Ocean: north of the South Orkney Islands, $59^{\circ} 48^{\prime} \mathrm{S}, 45^{\circ} 06^{\prime} \mathrm{W}$ (Watling \& Holman 1981). These authors do not give the depth of their record. The Google Earth depth for that position is $3553 \mathrm{~m}$ [Google Earth accessed on 27.09.2016], suggesting a depth between 3000 and $4000 \mathrm{~m}$. The specimen, which was a juvenile, is lost (Coleman 2007). The real identity of the Antarctic specimen is questionable (De Broyer et al. 2007). Klages (1991: 51) also listed a Uschakoviella sp. from the eastern Weddell Sea, without giving precise information on his material. It is usually assumed that Uschakoviella echinophora echinophora Gurjanova, 1955 and U. e. abyssalis Gurjanova, 1955 are the same species. However, examination of Gurjanova's (1955) drawings reveals slight morphological differences in the basis of pereiopod 7 and there might therefore be two taxa involved.

\section{Family Acanthonotozomellidae Coleman \& J.L. Barnard, 1991}

Acanthonotozomellidae Coleman \& J.L. Barnard, 1991a: 257 (in part).

Epimerinae - Stebbing 1883: 204 (in part).

Iphimedidae - Stebbing 1888: 882 (in part). — Watling \& Thurston 1989: 304, 309, 310 (in part). J.L. Barnard \& Karaman 1991: 378 (in part).

Acanthonotozomatidae - Schellenberg 1926: 327 (in part). - K.H. Barnard 1930: 345 (in part). - K.H. Barnard 1932: 115. — Schellenberg 1931: 116 (in part). — J.L. Barnard 1969: 120 (in part).

Paramphithoidae - J.L. Barnard 1969: 389 (in part). 
Acanthonotozomellidae - Coleman \& J.L. Barnard, 1991b: 279 (in part). — Coleman 2007: 12.

non Iphimedidae Boeck, 1871: 98

non Epimerinae Boeck, 1871: 103..

non Paramphithoidae G.O. Sars, 1883: 25.

non Acanthonotozomatidae Stebbing, 1906: 210.

In earlier literature, only Acanthonotozomella Schellenberg, 1926, Acanthonotozomoides Schellenberg, 1931 and the extralimital Amatiguakius Coleman \& J.L. Barnard, 1991 were included in the Acanthonotozomellidae (Coleman 2007). Actinacanthus Stebbing, 1888, which is traditionally included in the Epimeriidae (e.g., Coleman \& J.L. Barnard 1991a; Coleman 2007; De Broyer et al. 2007) is herein transferred to the Acanthonotozomellidae. The entire telson and the large ventrolateral processes on the lower part of the pereionites are characters, which are typical of the Acanthonotozomellidae.

\section{Key to the genera of Acanthonotozomellidae}

1. Pereionites $2-7$ and pleonites $1-2$ with an odd number of teeth 2

- Pereionites 2-7 and pleonites 1-2 with an even number of teeth

Acanthonotozomoides Schellenberg, 1931

2. Pereionite 1 with and one large anteriorly directed and one large posteriorly directed rounded mid-

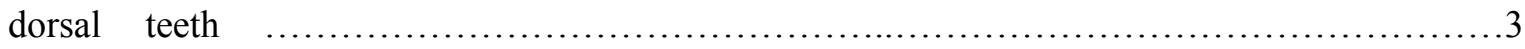

- Pereionite 1 with one mid dorsal carina ..................Acanthonotozomella Schellenberg, 1926

3. Projections of pereionites $2-7$ and of pleonites huge and styliform; coxae 1-7 each produced into a long sword-like process; pereiopods 3-7 slender ...............Actinacanthus Stebbing, 1888

- Projections of pereionites 2-7 and of pleonites medium-sized, forming broad carinae; coxae 1-7 not produced into a sword-like process; pereiopods 3-7 robust

Amatiguakius Coleman \& Barnard, 1991 [Extralimital: Alaska]

Genus Acanthonotozomella Schellenberg, 1926

Acanthonotozomella Schellenberg, 1926: 332; type species: Acanthonotozomella alata Schellenberg, 1926.

Paracanthonotozoma Bellan-Santini, 1972: 177; type species: Paracanthonotozoma trispinosum Bellan-Santini, 1972.

Acanthonotozomella - K.H. Barnard 1930: 346 (in part). - J.L. Barnard 1969: 122. — Bushueva 1978: 450 (in part). — De Broyer 1983: 292. — Watling \& Thurston 1989: 304, 305. — Watling \& Holman 1980: 609. — J.L. Barnard \& Karaman 1991: 380, 385. — Coleman \& J.L. Barnard 1991a: 257; 1991b: 279. — Coleman 2007: 13.

\section{Key to the species of Acanthonotozomella}

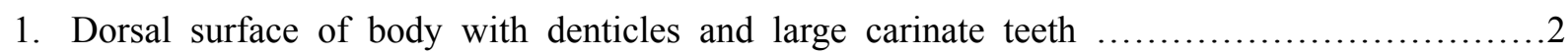

- Dorsal surface of body without denticles; body with large carinate teeth only ...............

2. Coxae smooth; mid-dorsal crest of pereionite 1 broad and medium-sized

Acanthonotozomella barnardi Watling \& Holman, 1980

- Surface of coxae covered with denticles; mid-dorsal crest of pereionite 1 forming a large narrow tooth Acanthonotozomella rauscherti Coleman \& Jäger, 2001 
3. Ventral border of coxae 1 and 3 straight ........Acanthonotozomella alata Schellenberg, 1926

- Ventral border of coxae 1 and 3 with shallow concavity Acanthonotozomella trispinosa (Bellan-Santini, 1972)

\section{Acanthonotozomella alata Schellenberg, 1926}

Acanthonotozomella alata Schellenberg, 1926: 332, fig. 45.

Acanthonotozomella alata - Bushueva 1978: 452. - Watling \& Thurston 1989: 310. - Coleman 2007: 14, fig. 1a-b, map 1 (rhomb).

\section{Distribution}

Davis Sea, 385 m (Schellenberg 1926).

Acanthonotozomella barnardi Watling \& Holman, 1980

Acanthonotozomella barnardi Watling \& Holman, 1980: 612-614, figs 1-3.

Acanthonotozomella barnardi - Watling \& Thurston 1989: 303, 310, fig. 2d. - Coleman 2007: 15, fig. $1 \mathrm{c}-\mathrm{d}$, map 1 (circle).

\section{Distribution}

Off extreme southern Patagonia, 384-494 m (Watling \& Holman 1980).

Acanthonotozomella rauscherti Coleman \& Jäger, 2001

Acanthonotozomella rauscherti Coleman \& Jäger, 2001: 475-483, figs 1-5.

Acanthonotozomella rauscherti - Coleman 2007: 15, fig. 2, map 1 (open square).

Acanthonotozomella cf. rauscherti - ? Rauschert \& Arntz 2015: 59, pl. 52.

\section{Distribution}

Drake Passage, North of King George Island, $61^{\circ} 26.8^{\prime} \mathrm{S}, 58^{\circ} 06.2^{\prime} \mathrm{W}$ to $61^{\circ} 27.1^{\prime} \mathrm{S}, 58^{\circ} 05.2^{\prime} \mathrm{W}, 1047-$ $1227 \mathrm{~m}$.

\section{Remarks}

Coleman \& Jäger (2001) indicate that the locus typicus of Acanthonotozomella rauscherti is: RV Polarstern, cruise PS48, ANT-XV/3, station 336, Drake Passage, $62^{\circ} 21.9528^{\prime} \mathrm{S}, 58^{\circ} 41.1854^{\prime} \mathrm{W}$, depth $1000 \mathrm{~m}, 19.03 .1998$. The coordinates of station 336 are actually $61^{\circ} 26.8^{\prime} \mathrm{S}, 58^{\circ} 06.2^{\prime} \mathrm{W}$ (gear on ground) to $61^{\circ} 27.1^{\prime} \mathrm{S}, 58^{\circ} 05.2^{\prime} \mathrm{W}$ (start of heaving), 1047-1227 m, 19.03.1998 (Arntz \& Gutt 1999).

Rauschert \& Arntz (2015) give a photograph of an Acanthonotozomella cf. rauscherti, which almost certainly really belongs to the present species. The apparent slight differences might be size-related, as the specimen photographed is a juvenile. Rauschert \& Arntz (2015) give very little information on their specimen. However, in the photographic archives of RBINS, an annotated version of the same photograph is present. The specimen is said to be $5 \mathrm{~mm}$ long and was collected at station 232 of ANT$\mathrm{XXI} / 2$. The coordinates of this station are: $71^{\circ} 18.61^{\prime} \mathrm{S}, 13^{\circ} 56.12^{\prime} \mathrm{W}$ to $71^{\circ} 18.73^{\prime} \mathrm{S}, 13^{\circ} 56.57^{\prime} \mathrm{W}$ (eastern shelf of the Weddell Sea), 900-910 m. 
Acanthonotozomella trispinosa (Bellan-Santini, 1972)

Paracanthonotozoma trispinosum Bellan-Santini, 1972: 177, pl. 6.

Acanthonotozomella trispinosa - Watling \& Holman 1980: 610. — Watling \& Thurston 1989: 310. — Coleman 2007: fig. 3a-j, map 1 (triangle).

\section{Material examined}

RV Polarstern cruises:

SOUTHERN OCEAN: 1 spec., cruise PS77, ANT-XXVII/3, CAMBIO, stn 248-2, Larsen B, $65^{\circ} 57.51^{\prime} \mathrm{S}$, $60^{\circ} 28.15^{\prime} \mathrm{W}$ to $65^{\circ} 57.69^{\prime} \mathrm{S}, 60^{\circ} 28.30^{\prime} \mathrm{W}, 196-202 \mathrm{~m}$, Agassiz trawl, 7 Mar. 2011, coll. C. Havermans and H. Robert (RBINS, INV. 132673) [extraction E16 of 23 Aug. 2012; Genbank nr, 28S: KT808684, 18S: KT808770].

\section{Distribution}

Adélie Coast: Cape Géodésie; Scotia Sea; eastern shelf of Weddell Sea; 120-130 m (De Broyer et al. 2007); Larsen B, 196-202 m (present material).

\section{Remarks}

Rauschert \& Arntz (2015: 59, pl. 52) give a photograph of an Acanthonotozomella cf. trispinosa, which might be a species distinct from the true $A$. trispinosa. In the archives of RBINS, there is an annotated copy of this photograph. It indicates that the specimen is $6 \mathrm{~mm}$ long and was collected at the station 293 of ANT-XXI/2. The coordinates of stn $293-1$ are $72^{\circ} 51.90^{\prime} \mathrm{S}, 19^{\circ} 39.31^{\prime} \mathrm{W}$ to $72^{\circ} 48.65^{\prime} \mathrm{S}, 19^{\circ} 39.62^{\prime} \mathrm{W}$ (eastern shelf of the Weddell Sea), 518-542 m.

Genus Acanthonotozomoides Schellenberg, 1931

Acanthonotozomoides Schellenberg, 1931: 124; type species: Acanthonotozomoides sublittoralis Schellenberg, 1931.

Acanthonotozomella - K.H. Barnard 1930: 346 (in part).

Acanthonotozomoides - J.L. Barnard 1969: 122. — Bushueva 1978: 452. — De Broyer 1983: 292. — Watling \& Thurston 1989: 304, 310. — J.L. Barnard \& Karaman 1991: 380, 385. — Coleman \& J.L. Barnard 1991a: 257; 1991b: 279. _ Coleman 2007: 18.

non Acanthonotozomella Schellenberg, 1926: 332.

\section{Key to the species of Acanthonotozomoides}

1. Pereionite 1 with 1 pair of rounded dorsolateral processes

Acanthonotozomoides oatesi (K.H. Barnard, 1930)

- Pereionite 1 with 2 pairs of styliform processes

Acanthonotozomoides sublitoralis Schellenberg, 1931

Acanthonotozomoides oatesi (K.H. Barnard, 1930)

Fig. 322

Acanthonotozomella oatesi K.H. Barnard, 1930: 346, figs 20, 21.

Acanthonotozomella oatesi-K.H. Barnard 1932: 117, fig. 65. 
Acanthonotozomoides oatesi - Bellan-Santini 1972: 167, pl. 1. - Watling \& Holman 1980: 611, table 1. - De Broyer 1983: 289. - Watling \& Thurston 1989: 303, 310, fig. 2e. - Coleman 2007: 18, fig. 4a-b, colour pl. 1 fig. a, map 2 (rhomb). - Rauschert \& Arntz 2015: 59, pl. 52, unnumbered photograph.

\section{Material examined}

RV Polarstern cruises:

SOUTHERN OCEAN: 1 spec., cruise PS69, ANT-XXIII/8, stn 721-2, south-east of Larsen B, $65^{\circ} 55.41^{\prime} \mathrm{S}, 60^{\circ} 34.01^{\prime} \mathrm{W}$ to $65^{\circ} 55.79^{\prime} \mathrm{S}, 60^{\circ} 33.96^{\prime} \mathrm{W}, 295-299 \mathrm{~m}$, hard bottom with hydrocorals (Stylasteridae), Agassiz trawl, 20 Jan. 2007, coll. C. d'Udekem d'Acoz and H. Robert (RBINS, INV. 122307); 1 spec., cruise PS77, ANT-XXVII-3, CAMBIO, stn 211-6, Shag Rocks, 53²3.94' S, $42^{\circ} 40.10^{\prime} \mathrm{W}$ to $53^{\circ} 23.86^{\prime} \mathrm{S}, 42^{\circ} 40.11^{\prime} \mathrm{W}, 285 \mathrm{~m}$, Agassiz Trawl, $14 \mathrm{Feb}$. 2011, coll. C. Havermans and H. Robert (RBINS, INV. 132669) [extraction EB12 of 27 Feb. 2012; Genbank nr, 28S: KT808686, 18S: KT808782]; 2 specs, cruise PS81, ANT-XXIX/3, stn 197-6, Bransfield Strait, $62^{\circ} 45.05^{\prime}$ S, $57^{\circ} 26.68^{\prime}$ W to $62^{\circ} 45.09^{\prime} \mathrm{S}, 57^{\circ} 26.47^{\prime} \mathrm{W}, 210-222 \mathrm{~m}$, black gravel mixed with sand and a little bit of mud, Rauschert dredge, 25 Feb. 2013, coll. C. d'Udekem d'Acoz and M. Verheye (RBINS, INV. 122868).

RV Aurora Australis cruises:

SOUTHERN OCEAN: 1 spec., cruise CEAMARC, sample CEAMARC 933, stn 40EV152, Adélie Coast, 6639'38" S, 14301'15.78" E, 471-637 m, beam trawl, 28 Dec. 2007, coll. IPEV-AAD-MNHN (MNHN-IU-2014-7342, removed from the sample MNHN-IU-2014-4283).

\section{Distribution}

Palmer Archipelago, South Georgia, South Shetland Islands, eastern shelf of Weddell Sea, Davis Sea, Adélie Coast, Ross Sea, (De Broyer et al. 2007), Shag Rocks, Bransfield Strait, Larsen B (present material), between $68 \mathrm{~m}$ (De Broyer et al. 2007) and $637 \mathrm{~m}$ (present material).

\section{Acanthonotozomoides sublitoralis Schellenberg, 1931}

Acanthonotozomoides sublitoralis Schellenberg, 1931: 124, figs 66, 67.

Acanthonotozomoides sublitoralis - Watling \& Thurston 1989: 310. — Coleman 2007: 19, fig. 5, map 2 (circle).

\section{Distribution}

Falkland Islands, $197 \mathrm{~m}$ (Schellenberg 1931).

\section{Genus Actinacanthus Stebbing, 1906}

Acanthechinus Stebbing, 1888: 883; type species: Acanthozone tricarinata Stebbing, 1883. Actinacanthus Stebbing, 1906: 326 (replacement name for Acanthechinus Stebbing, 1888).

Acanthozone - Stebbing 1883: 205 (in part).

Actinacanthus - Gurjanova 1955: 189, 199. - J.L. Barnard 1961: 102; 1969: 390, 393 - J.L. Barnard \&

Karaman 1991: 383, 386, 389-390. — Coleman 1998b: 215; 2007: 30.

non Acanthechinus Duncan \& Sladen, 1882: 34; type species: Acanthechinus nodulosus Duncan \&

Sladen, 1882 (Echinodermata).

non Acanthozone Boeck, 1871: 104; type species: Oniscus cuspidatus Lepechin, 1780. 
Actinacanthus tricarinatus (Stebbing, 1883)

Acanthozone tricarinata Stebbing, 1883: 205.

Acanthozone tricarinata - Tizard et al. 1885: 621, fig. 208.

Acanthechinus tricarinatus - Stebbing 1888: 884, pls 69, 70 .

Actinacanthus tricarinatus - Stebbing 1906: 326, fig. 74-76. - J.L. Barnard 1969: 390, 393, fig. 140a. -

J.L. Barnard \& Karaman 1991: 386, fig. 74a. - Coleman 2007: 30, fig. 13, map 5 (triangle).

Amphipoda spl (Cru74) - Hibbert \& Moore 2009: 95, unnumbered photograph.

\section{Distribution}

Heard Island, 274 m (Stebbing 1888).

\section{Remarks}

Actinacanthus tricarinatus has been recorded only once since its original description, by Hibbert \& Moore (2009, as 'Amphipoda spl (Cru74)') in the same area as the type material, the archipelago of the Heard and McDonald Islands. The species is currently considered as endemic to the Kerguelen Plateau.

\section{Family Dikwidae Coleman \& J.L. Barnard, 1991}

Dikwidae Coleman \& J.L. Barnard, 1991a: 260.

Acanthonotozomatidae - Griffiths 1974: 265 (in part).

Iphimediidae - Watling \& Thurston 1989: 304, 310 (in part). — J.L. Barnard \& Karaman 1991: 378 (in part).

Dikwidae - Coleman 2007: 27.

non Iphimedidae Boeck, 1871: 98.

non Acanthonotozomatidae Stebbing, 1906: 210.

Genus Dikwa Griffiths, 1974

Dikwa Griffiths, 1974: 266; type species: Dikwa acrania Griffiths, 1974.

Dikwa - Griffiths 1977: 108-109. - Watling \& Thurston 1989: 304, 307, 310. - J.L. Barnard \& Karaman 1991: 381, 392-393. — Coleman 2007: 27.

Dikwa andresi Lörz \& Coleman, 2003

Fig. 323

Dikwa andresi Lörz \& Coleman, 2003: 785-788, figs 1-5.

Dikwa andresi - Lörz \& Coleman in Lörz 2003: 99, figs 1-5. - Coleman 2007: 27, fig. 12a-c, map 5 (square). - Rauschert \& Arntz 2015: 66, pl. 59, unnumbered photograph.

\section{Material examined}

RV Polarstern cruises:

SOUTHERN OCEAN: 1 spec., cruise PS77, ANT-XXVII/3, CAMBIO, stn 208-2, Burdwood Bank, $54^{\circ} 32.27^{\prime} \mathrm{S}, 56^{\circ} 9.78^{\prime} \mathrm{W}$ to $54^{\circ} 30.84^{\prime} \mathrm{S}, 56^{\circ} 9.06^{\prime} \mathrm{W}, 282-283 \mathrm{~m}$, bottom trawl, $11 \mathrm{Feb} .2011$, coll. C. Havermans and H. Robert (RBINS, INV. 132666) [extraction EB11; Genbank nr, 28S: KT808704, 18S: KT808771] [the lat./long. coordinates given by Verheye et al. (2016b) are incorrect]. 


\section{Distribution}

Burdwood Bank (Lörz \& Coleman 2003; present material), 272-290 m (Lörz \& Coleman 2003).

\section{Ecology}

Dikwa andresi was caught clinging to the stylasterid hydrocoral Errinopsis reticulum Broch, 1951 (Lörz \& Coleman 2003).

\section{Family Stilipedidae Holmes, 1908}

Amphilochinae Boeck, 1871: 129-130 (in part).

Tironidae Stebbing, 1906: 273 (in part).

Stilipedidae Holmes, 1908: 535.

Astyridae Pirlot, 1934: 175.

Amphilochinae - Boeck 1876: 430-431 (in part).

Amphilochidae - Stebbing 1888: 743 (in part). - G.O. Sars 1892: 212-213 (in part).

Tironidae - Stephensen 1928: 225 (in part). - K.H. Barnard 1931: 427 (in part); 1932: 148, 153 (in part). - Hurley 1954: 803 (in part).

Acanthonotozomatidae - Schellenberg 1931: 116 (in part).

Paramphithoidae - K.H. Barnard, 1932: 170 (in part). - J.L. Barnard 1969: 389 (in part).

Stegocephalidae - Nicholls 1938: 40 (in part).

Astyridae - Gurjanova 1951: 596. — Birstein \& Vinogradov 1955: 253. — Birstein \& Vinogradova 1960: 152 (in part). — J.L. Barnard 1969: 159. — Bousfield 1979: 369 (discussion); 1982: 274. — Coleman \& J.L. Barnard 1991a: 263. — Andres \& Lott 1986: 133.

Stilipedidae - J.L. Barnard 1969: 451. — Bousfield 1979: 369 (discussion). — Bousfield 1982: 275. — Holman \& Watling 1983: 27. — Andres \& Lott 1986: 131. — J.L. Barnard \& Karaman 1991: 379, 702. — Coleman \& J.L. Barnard 1991a: 80, 263-264. — Lowry \& Stoddart 2003: 262.

Astryidae [sic] - Coleman \& J.L. Barnard 1991a: 263 (misspelling).

Iphimediidae - J.L. Barnard \& Karaman 1991: 378 (in part).

non Stegocephalinae Dana, 1852: 310.

non Iphimedinae Boeck, 1871: 98.

non Paramphithoidae G.O. Sars, 1883: 25.

non Acanthonotozomatidae Stebbing, 1906: 210.

\section{Remarks}

Holman \& Watling (1983) proposed a classification scheme where the Stilipedidae consisted of an assemblage of three well distinct homogeneous subfamilies: Alexandrellinae Holman \& Watling, 1983, Astyrinae Pirlot, 1934 and Stilipedinae Holmes, 1908. The monophyly of this assemblage was questioned by Andres \& Lott (1986) and was not supported by a recent phylogenetic analysis including two of these subfamilies: the Alexandrellinae and the Astyrinae (Verheye et al. 2016b, 2017). The classification of Holman \& Watling (1983) is retained herein for convenience only. In the past, members of the family Stilipedidae have been attributed to a wide range of families. For example Schellenberg (1931) included Alexandrella schellenbergi (as Iphimediopsis australis) in the Acanthonotozomatidae; K.H. Barnard (1932) put Eclysis similis in the Paramphithoidae, and Nicholls (1938) put Alexandrella mixta (as Parandaniexis mixtus) in the Stegocephalidae. 
Subfamily Alexandrellinae Holman \& Watling, 1983

Alexandrellinae Holman \& Watling, 1983: 28.

Tironidae - Chevreux 1911: 1167 (in part).

Acanthonotozomatidae - Schellenberg 1931: 116 (in part).

Stegocephalidae - Nicholls 1938: 40 (in part)

Astyridae - Birstein \& Vinogradova 1960: 152 (in part).

Stilipedidae - J.L. Barnard 1969: 451 (in part).

Alexandrellinae - Andres \& Lott 1986: 134 (discussion).

non Stegocephalinae Dana, 1852: 310.

non Acanthonotozomatidae Stebbing, 1906: 210.

non Tironidae Stebbing, 1906: 273

non Stilipedidae Holmes, 1908: 535.

non Astyridae Pirlot, 1934: 175.

\section{Remarks}

According to the phylogenetic analyses of Verheye et al. (2016b, 2017), the Alexandrellinae are extremely close to the Epimeriidae, and might even be nested within Epimeria.

\section{Genus Alexandrella Chevreux, 1911}

Alexandrella Chevreux, 1911: 1167 (genus described without referring to any species).

Epimeriopsis K.H. Barnard, 1931: 428; type species: Acanthonotozoma australis Chilton, 1912.

Iphimediopsis Schellenberg, 1931: 126, invalid junior homonym of Iphimediopsis Della Valle, 1893; type-species, by original designation and monotypy: Acanthonotozoma australis Chilton, 1912.

Bathypanoploea Schellenberg, 1939: 137 (footnote), replacement name for Iphimediopsis Schellenberg, 1931, non Della Valle, 1893; type species: Bathypanoploea schellenbergi Holman \& Watling, 1983, designated by Berge \& Vader (2005b).

Parandaniexis Nicholls, 1938: 42; type-species, by original designation and monotypy: Parandaniexis mixtus, an invalid junior homonym of Parandaniexis Schellenberg, 1929.

Pseudandaniexis Nicholls, 1938: corrigendum, replacement name for Parandaniexis Nicholls, 1938, non Schellenberg, 1929.

Pseudiphimediopsis Ruffo, 1949: 18, replacement name for Iphimediopsis Schellenberg, 1931, non Della Valle, 1893.

Astyroides Birstein \& Vinogradova, 1960: 152; type species: Astyroides carinatus Birstein \& Vinogradova, 1960.

Alexandrella - Chevreux 1912: 213 (Alexandrella dentata designated as type species, by monotypy). Chevreux 1913: 134. - K.H. Barnard 1932: 153. - J.L. Barnard 1969: 161, 263, 453-454. Holman \& Watling 1983: 32. — Andres \& Lott 1986: 132. - J.L. Barnard \& Karaman 1991: 703, 704. - Berge 2003b: 2 (discussion). — Berge \& Vader 2005a: 1329 (discussion). - Serejo 2014: 135 (discussion).

Acanthonotozoma - Chilton 1912: 487.

Bathypanoploea - J.L. Barnard 1969: 122. — Holman \& Watling 1983: 46-47. - J.L. Barnard \& Karaman 1991: 380, 391-392, 702, 706. — Berge \& Vader 2005b: 81-83. — Berge \& Vader 2005c: 3-4.

Astyroides - Holman \& Watling 1983: 46. 
Bathypanoplea - d'Udekem d'Acoz \& Robert 2008: 55. — Serejo 2014: 133, 135 (misspelling for Bathypanoploea).

non Acanthonotozoma Boeck, 1876: 237; type species: Acanthonotus cristatus Ross, 1835.

\section{Etymology}

The name Alexandrella presumably refers to Alexander Island, where the type species of the genus was collected.

\section{Remarks}

We decided to include the description of a new Alexandrella species herein because this genus belong to the same large clade as Epimeria (Verheye et al. 2016b, 2017) and because the new species is large, very characteristic and was already mentioned and illustrated in the cruise report of ANT-XXIX/3 (d'Udekem d'Acoz \& Verheye 2013). Moreover, we felt that a quick overview of Alexandrella taxonomy would be a good test for checking whether the underestimated biodiversity found in Epimeria was unique for large Antarctic amphipods or representative of a general situation. This led us to draw a dire conclusion, that the taxonomy of Antarctic Alexandrella is even messier than for Epimeria before our present revision, and a significant number of undescribed species obviously occur in the Southern Ocean. The uniform morphology of Alexandrella species simply contributed to mask its true taxonomic diversity and to promote the convenient but spurious concept of 'variable widespread species'. The morphological differences between the genera Alexandrella and Bathypanoploea as proposed by Holman \& Watling (1983) are ill-defined (Berge \& Vader 2005b, 2005c) and genetic data (Verheye et al. 2016b) confirm that Bathypanoploea pulchra (as A. schellenbergi) and Alexandrella cf. mixta (as A. aff. dentata) are very close relatives. The two genera are therefore considered herein as synonyms. Besides the species from the temperate and polar parts of the southern hemisphere treated herein, Alexandrella includes an Atlantic abyssal species: A. setosa Serejo, 2014 (see Serejo 2014) and two abyssal species from the North Pacific: Alexandrella carinata (Birstein \& Vinogradova, 1960) and a second, undescribed species examined by the first author. The species described and illustrated as Astyroides carinatus by Birstein \& Vinogradova (1960) exhibits almost all the characters of Alexandrella. J.L. Barnard (1969) considered Astyroides as a junior synonym of Alexandrella, and it is only reluctantly that Holman \& Watling (1983) accepted Astyroides as valid. In the reprint of Birstein \& Vinogradova (1960) available to us, there is a handwritten comment by Vinogradova relegating Astyroides into the synonymy of Alexandrella. This synonymization is formally adopted herein.

\section{Key to the species of Antarctic and sub-Antarctic Alexandrella}

This key to Antarctic and sub-Antarctic Alexandrella is tentative and has not the pretention to be a rigorous identification tool. Characters visible without dissection have been used whenever possible.

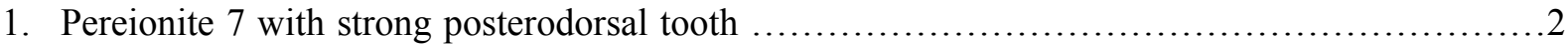

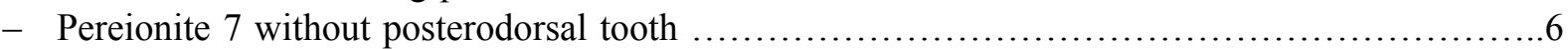

2. Article 1 of peduncle of antenna 1 with short dorsomedial tooth; dactylus of pereiopods 3-4 long; posteroventral border of coxa 4 straight or nearly so .....................................

- Article 1 of peduncle of antenna 1 with long dorsomedial tooth; dactylus of pereiopods 3-4 short;

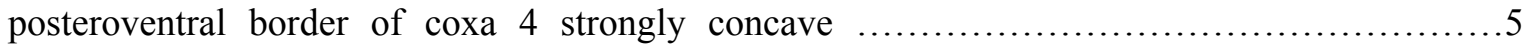

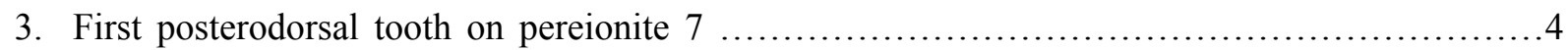

- First posterodorsal tooth on pereionite 6 .................Alexandrella sp. 1 [High Antarctic]

- First posterodorsal tooth on pereionite 5 or more anterior pereionite(s).... 
4. Telson cleft on 0.37 Alexandrella schellenbergi (Holman \& Watling, 1983) [north-east of Falkland Islands, $2675 \mathrm{~m}$ ]

- Telson cleft on 0.2 or less ..................Alexandrella pulchra Ren in Ren \& Huang, 1991 [South Shetland Islands, tip of Antarctic Peninsula, eastern Weddell Sea, at about 300-700 m]

5. Anteroventral lobe of head moderately developed, triangular or bluntly triangular; dorsal carina of pleonite 3 with straight profile; posterodistal corner of basis of pereiopod 6 broadly rounded ......6

- Anteroventral lobe of head very strong, hemi-elliptic; dorsal carina of pleonite 3 with distinctly sigmoid profile; posterodistal corner of basis of pereiopod 6 forming a blunt squared angle [pereionite 6 without posterodorsal tooth; posterior tooth of carina of first urosomite $0.23 \times$ as long as whole carina and forming a fairly deep notch with carina] ........Alexandrella chione sp. nov.

6. Pereionite 6 with small posterodorsal tooth; crest of urosomite 1 with long posterior tooth and deep posterior notch ................................Alexandrella australis (Chilton, 1912)

- Pereionite 6 without posterodorsal tooth; crest of urosomite 1 with small posterior tooth and no posterior notch Alexandrella sp. 3

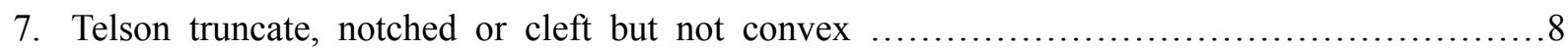

- Telson convex and entire [carina of urosomite 1 compact, not elongate] Alexandrella polarsterni (Berge \& Vader, 2005)

8. Pleonites 1-3 strongly toothed; gnathopod 1 with oostegite [deepsea species recorded below $2500 \mathrm{~m}]$

- Pleonites 1-3 weakly toothed (or not toothed); gnathopod 1 without oostegite [shelf species] ...10

9. Right mandible with lacinia mobilis reduced to simple tooth.

Alexandrella mandibulata Berge \& Vader, 2005

- Right mandible with lacinia mobilis smaller than left, but broad, with two teeth, of which one is bicuspid Alexandrella martae Berge \& Vader, 2005

10. Gnathopods 1-2 simple; body dorsally weakly or not carinate .11

- Gnathopods 1-2 subchelate, body dorsally strongly carinate [telson scarcely emarginate]......... Alexandrella subchelata Holman \& Watling, 1983 s. lat.

11. Telson emarginate; mandibular incisors not toothed along entire margin; antennae subequal [Antarctic species]

- Telson truncate with tiny median notch; mandibular incisors toothed along the entire margin; antenna 1 shorter than antenna 2

Alexandrella inermis Bellan-Santini \& Ledoyer, 1987 [Prince Edward Island]

12. Pereionites $1-7$ with a pair of lateral triangular teeth

Alexandrella dentata Chevreux, 1912 [Bellingshausen Sea]

- pereionites $1-7$ smooth

Alexandrella mixta Nichols, 1938 s. lat. [circum-Antarctic complex of species]

Alexandrella australis (Chilton, 1912)

Acanthonotozoma australis Chilton, 1912: 205, pl. 2 fig. 19.

Acanthonotozoma australis - Dell 1972: 71, fig. 7 (after Chilton).

Alexandrella australis - Serejo 2014: 139, in part (key). 
non Alexandrella australis - Holman \& Watling 1983: 33-37, figs 1-3. — Berge \& Vader 2005a: 13301332, fig. 1.

\section{Distribution}

Eastern Weddell Sea: Scottish National Antarctic Expedition 1902-1904, RV Scotia, stn 417, 71²2' S, 16³4' W, 2578 m (Chilton 1912).

\section{Remarks}

There are significant morphological differences between the Alexandrella australis specimens illustrated by Chilton (1912) and Holman \& Watling (1983), as follows: ventral margin of coxa 1 concave vs convex; pereionite 6 with vs without small mid-dorsal tooth; crest of urosomite 1 with long vs small posterior tooth. It is probable that they are not conspecific and that the specimen illustrated by Holman \& Watling (1983) belongs to an undescribed species. It is referred herein as Alexandrella sp. 3. The second (nonillustrated) specimen listed by these authors might be $A$. chione sp. nov. (see account on that species).

\section{Alexandrella chione sp. nov. urn:Isid:zoobank.org:act:90F1FE7A-F36C-4411-A7A8-833B300A0862}

Figs 324-335

Alexandrella australis - ? Holman \& Watling, 1983a: 33, in part [specimen from RV Eltanin only], not figs 1-3. — ? Klages 1988: 82, fig. 20c. — ? Berge \& Vader 2005a: 1330-1332, fig. 1. Alexandrella sp. - d'Udekem d'Acoz \& Verheye 2013: 62, fig. 3.8.1B (in colour).

non Acanthonotozoma australis Chilton, 1912: 205, pl. 2 fig. 19.

\section{Etymology}

From the Greek, $\chi 1 \omega v$, snow. The name, which is a noun in apposition, alludes to the pure white colour of the species.

\section{Type material}

\section{Holotype}

RV Polarstern cruises

SOUTHERN OCEAN: immature 9 , cruise PS81, ANT-XXIX/3, stn 227-2, Bransfield Strait, $62^{\circ} 55.83^{\prime}$ S, $58^{\circ} 41.09^{\prime} \mathrm{W}$ to $62^{\circ} 55.76^{\prime} \mathrm{S}, 58^{\circ} 41.46^{\prime} \mathrm{W}, 562-564 \mathrm{~m}$, muddy bottom, Agassiz Trawl, $5 \mathrm{Mar}$. 2013, coll. C. d'Udekem d'Acoz and M. Verheye (RBINS, INV. 122887).

\section{Description}

HEAD. Rostrum tiny, extremely narrow in frontal view, reaching 0.3 of article 1 of peduncle of antenna 1 (dorsomedial tooth included); lateral head lobes triangular (forming a sharp squared angle); ventral lobe forming an extremely strong hemi-elliptic protrusion; connection between this protrusion and head forming a deep notch (shape: sharp squared angle).

EYEs. Circular, small, pale, non-ommatidian, disappearing in alcohol.

Pereion-Pleosome tooth pattern. Pereionites 1-6 totally smooth; pereionite 7 posteriorly carinate and with medium-sized tooth projecting backwards; pleonites 1-2 carinate, with medium-sized tooth projecting backwards; pleonite 3 carinate, with distinctly sigmoid profile (distinctly convex in anterior 0.8 , distinctly concave in posterior 0.2 ), with medium-sized tooth projecting backwards. 
EPimeral Plates 1-3. Posteroventral angle: very obtusely rounded in plate 1, produced into a mediumsized tooth in plates $2-3$.

Urosome ornamentation. Urosomite 1 with deep notch on proximal third, followed by elevated carina, anteriorly rounded and slightly produced forward, dorsally nearly straight (posteriorly very slightly concave), posteriorly produced into a well-developed, narrowly triangular sharp tooth overreaching urosomite 1 and forming a blunt squared angle with it (tooth $0.23 \times$ as long as carina); urosomite 2 toothless; urosomite 3 lateral borders distally produced into a well-developed lobe, of which the tip forms a squared angle.

TELSON. Broadly rectangular, distally broad and emarginate; with very shallow broad V-shaped notch (cleft on 0.08 ); lobes very broad, medially forming a rounded very low projection, more laterally with shallow concavity, at their connection with lateral border forming a broad and blunt triangular tooth.

ANTENNA 1. Articles of peduncle very broad; article one with large and broad dorsomedial tooth reaching tip of article two, with strong ventral tooth reaching mid of article two; article two with broadly rounded lateral lobe; article three with broadly rounded lateral lobe; accessory flagellum distinct, uniarticulate.

AnTENNA 2. Article four with posterodistal blunt dentiform process; article five $1.3 \times$ as long as article four.

UPPER LIP. Strongly asymmetrical, right lobe well developed, bluntly triangular and very protruding, left lobe low and very rounded.

MANDIBLES. Incisor very broad, straight and toothless (or with trace of tiny denticles near lateral corner); left lacinia mobilis very large $(0.7 \times$ as broad as incisor process $)$; right lacinia mobilis small $(0.25 \times$ as broad as incisor process); molar absent; palp with article 1 very short, posterodistally produced into a tooth; article 2 and 3 long and narrow, posteriorly ciliate; article 2 slightly longer than article 3.

LOWER LIP. Lower lip without inner lobes, outer lobes broad with small acute projection at outer corners.

MaXILLA 1. Inner plate setose along medial margin and along a row on inner face, notched at the level of this row to allow imbrication of outer plate; palp biarticulate, expanded distally with 1 marginal row of spines + row of short setae.

MaXILLA 2. Inner plate distinctly larger than outer, rounded, posterior setae conspicuously longer than those more anterior but not strongly plumose, also sparse setae on surface of plate; outer plate triangular.

MAXILLIPED. Outer plate exceeding palp, setose medially; inner plate extending beyond distal margin of palp article 1, setae on distal margin of moderate length; palp 4-articulate, article 2 longest, article 4 less than 0.5 length of article 3 .

GILLs. From gnathopod 2 to pereiopod 7.

Oostegites. From gnathopod 2 to pereiopod 5.

GNATHOPOD 1. Coxa very broad, expanding distally, anteroventral corner very broadly rounded, ventral margin straight; leg achelate; carpus very broad, $1.8 \times$ as long as propodus; propodus strongly tapering.

GNATHOPOD 2. Coxa broad, anteriorly rounded, posterodistally angulate; leg achelate; carpus very broad, $1.5 \times$ as long as propodus; propodus weakly tapering. 
Pereiopod 3. Coxa broad, with anterior border rounded, distally produced into a large blunt tooth, posterior margin very slightly concave; leg robust: propodus $4.8 \times$ as long as wide; dactylus short: $3.6 \times$ as long as broad, $0.4 \times$ as long as propodus, with row of small spines on posterior border.

PeREIOPOD 4. Coxa anteriorly forming a strong regular curve, with ventral corner angulate (forming a distinct acute angle), with posteroventral border strongly concave; leg robust very similar to that of pereiopod 3 .

PEREIOPOD 5. Coxa posteriorly produced into a triangular tooth (forming a squared angle), posteroventrally also produced into a triangular tooth (forming a blunt acute, nearly squared angle); basis fairly narrow, posterior border very weakly concave, posterodistal corner broadly rounded, posteromedial carina distally produced into a small rounded lobe; carpus, propodus and dactylus missing.

PEREIOPOD 6. Coxa posteriorly forming a rounded obtuse angle, posteroventrally produced into a triangular tooth (forming a blunt acute angle); basis of medium width; posterior border very weakly concave, posterodistal corner forming a blunt squared angle (not rounded); carpus, propodus and dactylus missing.

PEREIOPOD 7. Coxa posteriorly straight, posteroventrally forming an obtuse (nearly squared) angle; basis extremely broad, with posteroproximal strong rounded process, posterodistally produced into a sharp triangular tooth forming an acute angle projecting forward (that tooth is $0.17 \times$ as long as basis, tooth included).

\section{Colour pattern}

White, except for mouthparts, gnathopods (red) and carpus, propodus and dactylus of pereiopods 3-4 (pale pink); eyes pale yellow.

\section{Body length}

$30 \mathrm{~mm}$.

\section{Distribution}

Bransfield Strait, 562-564 m (present data).

\section{Remarks}

Alexandrella chione sp. nov. (Bransfield Strait shelf) is similar to Alexandrella australis (eastern Weddell Sea abyss) and Alexandrella sp. 3 (South Sandwich Islands abyss). The most visible difference concerns the ventral lobe of head, which is much stronger and proximally narrower in Alexandrella chione sp. nov. than in other species. In addition to the characters given in the key, it must be mentioned that the lacinia mobilis of the right mandible is more developed and the posterodistal tooth of the basis of pereiopod 7 is longer in Alexandrella chione sp. nov. than in Alexandrella sp. 3 as illustrated by Holman \& Watling (1983). Very little information is given on the adult specimens of 'Alexandrella australis' recorded at $935 \mathrm{~m}$ in the Bransfield Strait by Holman \& Watling (1983) and Berge \& Vader (2005a), but they may be $A$. chione sp. nov., which is described herein from a specimen collected at similar depths in the same area. 
Alexandrella dentata Chevreux, 1912

Alexandrella dentata Chevreux, 1912: 213.

Alexandrella dentata - Chevreux 1913: 134, figs 31-33. - J.L. Barnard 1958: 133; 1969: 452, fig. 163a. - Holman \& Watling 1983: 37-39, fig. 4. - J.L. Barnard \& Karaman 1991: 704, fig. 127C. - Serejo 2014: 139, in part (key).

non Alexandrella dentata - Berge \& Vader 2005a: 1332-1335, figs 2, 3 (= A. mixta s. lat.). — J.L. Barnard 1961: 77, fig. 46. (= A. subchelata).

\section{Distribution}

Bellingshausen Sea: Alexander Island, 297 m (Chevreux 1913).

\section{Biology}

The holotype of $A$. dentata was found inside a sponge (Chevreux 1913).

\section{Remarks}

Chevreux (1913) explicitly described and illustrated a tooth on the side of each segments of the pereion of the holotype of Alexandrella dentata, hence the name of the species. They were not reproduced, however, in the figures of J.L. Barnard (1969) and J.L. Barnard \& Karaman (1991), which were copied from Chevreux (1913). Neither are they mentioned in the account of the holotype of A. dentata by Holman \& Watling (1983), who only studied the appendages and not the body. Berge \& Vader (2005a) also did not mention these teeth on their specimens and put Alexandrella mixta, which is not supposed to have such teeth, in synonymy with $A$. dentata. The specimens of Berge \& Vader (2005a) are without lateral teeth, which indicates that the species is not $A$. dentata. The presence or absence of these lateral teeth is here considered as a species level character distinguishing A. mixta from A. dentata. A. mixta has been recorded in widely separate localities and across a wide bathymetric range. Moreover, small differences exist between the various descriptions and illustrations. Therefore, $A$. mixta might be a species complex.

\section{Alexandrella inermis Bellan-Santini \& Ledoyer, 1987}

Alexandrella inermis Bellan-Santini \& Ledoyer, 1987: 430-432, fig. 31.

Alexandrella inermis - Branch et al. 1991: 10, unnumbered fig. — Berge \& Vader 2005a: 1335. — Serejo 2014: 139 (key).

\section{Distribution}

Prince Edward Islands, 46 $56.3^{\prime}$ S, 37 55.6' E, 120 m (Bellan-Santini \& Ledoyer 1987); Prince Edward

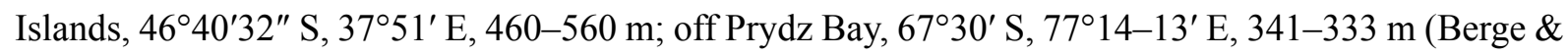
Vader 2005a).

\section{Alexandrella mandibulata Berge \& Vader, 2005}

Alexandrella mandibulata Berge \& Vader, 2005a: 1335-1339, figs 4-6.

Alexandrella mandibulata - Serejo 2014: 139 (key). 


\section{Distribution}

East of South Georgia, $55^{\circ} 04^{\prime} \mathrm{S}, 33^{\circ} 57^{\prime} \mathrm{W}$ to $55^{\circ} 00^{\prime} \mathrm{S}, 33^{\circ} 59^{\prime} \mathrm{W}, 3138-3239 \mathrm{~m}$ (Berge \& Vader 2005a).

Alexandrella martae Berge \& Vader, 2005

Alexandrella martae Berge \& Vader, 2005a: 1340-1346, figs 7-9.

Alexandrella martae - Serejo 2014: 139 (key).

\section{Distribution}

Middle of Scotia Sea, at the same longitude as South Georgia, $58^{\circ} 53^{\prime} \mathrm{S}, 37^{\circ} 15^{\prime} \mathrm{W}$ to $58^{\circ} 54^{\prime} \mathrm{S}, 37^{\circ} 19^{\prime} \mathrm{W}$, $2901 \mathrm{~m}$; Drake Passage, north of Livingstone Island, 61 ${ }^{\circ} 43.08^{\prime} \mathrm{S}, 60^{\circ} 41.8^{\prime} \mathrm{W}, 2830-2862 \mathrm{~m}$; Somov Sea: longitude of Cape Adare and latitude of (east of) Balleny Islands, $68^{\circ} 05^{\prime} \mathrm{S}, 173^{\circ} 38^{\prime} \mathrm{E}$ to $68^{\circ} 06^{\prime} \mathrm{S}$, $173^{\circ} 44^{\prime}$ E, 2608-3175 m (Berge \& Vader 2005a).

Alexandrella mixta Nicholls, 1938 s. lat.

Fig. 336

Parandaniexis mixtus Nicholls, 1938: 42, fig. 22.

Pseudandaniexis mixta - Nicholls 1938: corrigendum. - J.L. Barnard 1958: 127. - Bellan-Santini 1972: 229, pl. 36.

Alexandrella mixta - Holman \& Watling 1983: 39-41, fig. 5.

Alexandrella dentata - Berge \& Vader 2005a: 1332-1335, figs 2, 3. — Rauschert \& Arntz 2015: 79, pl. 72 [ANT-XXI/2, stn 233, $200 \mathrm{~m}, 13 \mathrm{~mm}]$.

\section{Material examined}

RV Polarstern cuises

SOUTHERN OCEAN: 1 spec., cruise PS69, ANT-XXIII/8, stn 725-6, Larsen A, 64 $54.80^{\prime} \mathrm{S}, 60^{\circ} 37.46^{\prime} \mathrm{W}$ to $64^{\circ} 54.80^{\prime} \mathrm{S}, 60^{\circ} 38.28^{\prime} \mathrm{W}, 105-207 \mathrm{~m}$, amongst large grey hexactinellid sponges, Agassiz trawl, 22 Jan. 2007, coll. C. d'Udekem d'Acoz and H. Robert (RBINS, INV. 122305).

\section{Distribution}

Adélie Coast, Weddell Sea; 60-1543 m (De Broyer et al. 2007 as A. dentata, excluding type record).

\section{Biology}

One specimen identified as Alexandrella mixta was found by the first author amongst large grey hexactinellid sponges and its colour pattern matched perfectly with that of these sponges (fig. 338). Some kind of symbiosis might be involved.

\section{Remarks}

See account on $A$. dentata for the taxonomic history of $A$. mixta.

Alexandrella polarsterni (Berge \& Vader, 2005)

Bathypanoploea polarsterni Berge \& Vader, 2005b: 81-83, fig. 1.

Bathypanoploea polarsterni - Berge \& Vader 2005c: 5, figs 7-9.

Alexandrella sp. n. - Rauschert \& Arntz 2015: 79, pl. 72. 


\section{Distribution}

Northwest of Elephant Island, 60 $54.60^{\prime} \mathrm{S}, 55^{\circ} 45.90^{\prime} \mathrm{W}, 235 \mathrm{~m}$ (holotype); southwestern Atlantic, off

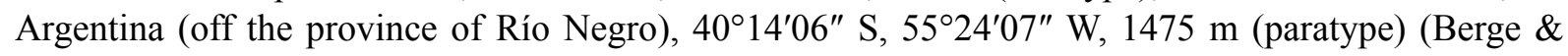
Vader 2005b, 2005c).

\section{Remarks}

The conspecificity between the holotype of Alexandrella polarsterni collected off Elephant Island at $235 \mathrm{~m}$ and the paratype collected off Argentina at $1475 \mathrm{~m}$ looks a priori suspect, based on the differences in location and depth, but cannot be refuted herein. The photograph of "Alexandrella sp. nov." given by Rauschert \& Arntz (2015) matches very well with the figures of Berge \& Vader (2005b, 2005c), especially for the shape of the mid-dorsal carina of urosomite 1 ; hence this specimen is identified as such. Rauschert \& Arntz (2015) do not indicate the coordinates of their specimen, but in an early draft of their book made available to the authors, the following information was given: ANT-XXI/2, stn 145, $400 \mathrm{~m}, 7 \mathrm{~mm}$. The coordinates of the station $145-1$ (epibenthic sledge) are: $70^{\circ} 56.99^{\prime} \mathrm{S}, 10^{\circ} 48^{\prime} 26^{\prime \prime} \mathrm{W}$ to $70^{\circ} 56.97^{\prime} \mathrm{S}, 10^{\circ} 47.7^{\prime} \mathrm{W}$ [eastern shelf of the Weddell Sea], 402-405 m.

Alexandrella pulchra Ren in Ren \& Huang, 1991

Fig. 337

Bathypanoploea schellenbergi Holman \& Watling, 1983: 47, in part, figs 9a, 9c-f, 11g-h only (not the holotype).

Alexandrella pulchra Ren in Ren \& Huang, 1991: 291-292, 321-323, fig. 64.

Bathypanoploea schellenbergi - Coleman 1990b: 197, figs 1-3. - Coleman 1992: 140, fig. 3-4. Nyssen 2005: 130, unnumbered fig. — Berge \& Vader 2005b: 83 (in part). — Berge \& Vader 2005b: 83 (in part). - Berge \& Vader 2005c: 4 (in part), fig. 5.

Alexandrella sp. - ? Rauschert \& Arntz 2015: 79, pl. 72 [Bentart 94, Livingston Island].

\section{Material examined}

RV Polarstern cruises:

SOUTHERN OCEAN: 1 spec., orange form, cruise PS69, ANT-XXIII/8, stn 654-6, Elephant Island, $61^{\circ} 22.80^{\prime} \mathrm{S}, 56^{\circ} 03.84^{\prime} \mathrm{W}$ to $61^{\circ} 23.35^{\prime} \mathrm{S}, 56^{\circ} 04.89^{\prime} \mathrm{W}, 341-342 \mathrm{~m}$, Agassiz trawl, 29 Dec. 2006, coll. C. d'Udekem d'Acoz and H. Robert (RBINS, INV. 122440); 1 spec., orange form, cruise PS69, ANTXXIII/8, stn 662-1, between Elephant Island and King George Island, 61 ${ }^{\circ} 35.91^{\prime} \mathrm{S}, 57^{\circ} 17.04^{\prime} \mathrm{W}$ to $61^{\circ} 35.41^{\prime} \mathrm{S}, 57^{\circ} 20.60^{\prime} \mathrm{W}, 425-432 \mathrm{~m}$, bottom trawl, 30 Dec. 2006, coll. C. d'Udekem d'Acoz and H. Robert (RBINS, INV. 122304); 1 spec., colour unrecorded, cruise PS71, ANT-XXIV/2, ANDEEPSYSTCO, stn $48-1$, east of Weddell Sea, $70^{\circ} 23.94^{\prime} \mathrm{S}, 8^{\circ} 19.14^{\prime} \mathrm{W}$ to $70^{\circ} 23.89^{\prime} \mathrm{S}, 8^{\circ} 18.67^{\prime} \mathrm{W}, 595-602$ $\mathrm{m}$, bryozoan bottom (exceptional bryozoan diversity), Rauschert dredge, 12 Jan. 2008, coll. H. Robert (RBINS, INV. 132623) [extraction EAS of 10 Feb. 2012; Genbank nr, 28S: KT808699, 18S: KT808768]; 1 spec., orange and white form, cruise PS81, ANT-XXIX/3, stn 217-6, Bransfield Strait, 62 $2^{\circ} 53.45^{\prime}$ S, $58^{\circ} 13.06^{\prime} \mathrm{W}$ to $62^{\circ} 53.42^{\prime} \mathrm{S}, 58^{\circ} 13.41^{\prime} \mathrm{W}, 421-483 \mathrm{~m}$, rich sponge bottom, Agassiz trawl, 2 Mar. 2013, coll. C. d'Udekem d'Acoz and M. Verheye (RBINS, INV. 122865); 1 spec., orange and white form, cruise PS81, ANT-XXIX/3, stn 227-2, Bransfield Strait, 62 ${ }^{\circ} 55.83^{\prime} \mathrm{S}, 58^{\circ} 41.09^{\prime} \mathrm{W}$ to $62^{\circ} 55.76^{\prime} \mathrm{S}$, 58 41.46' W, 562-564 m, muddy bottom, Agassiz Trawl, 5 Mar. 2013, coll. C. d'Udekem d'Acoz and M. Verheye (RBINS, INV. 122864).

\section{Colour pattern and eyes description}

Head whitish; eyes very large, non-ommatidian and white, forming a large V pointing forwards; body entirely orange (orange form) or orange except for mid-dorsal crests of pleon, which are largely white 
(orange and white form); pereiopods and antennae orange (orange form) or largely white (orange and white form). The eyes disappear in alcohol.

\section{Distribution}

Reliable records are from the South Shetland Islands, Bransfield Strait and the eastern shelf of the Weddell Sea, 341-602 m.

\section{Biology}

The analyses of gut contents by Coleman (1990b) revealed the occurrence of ossicles of holothurians in the digestive tract of Alexandrella pulchra (as Bathypanoploea schellenbergi). Gut content analyses of the latter species by Dauby et al. (2001a) revealed gorgonian remains (cnidocysts and ossicles), plankton and hard remains of crustaceans, bryozoans and holothurioids.

\section{Remarks}

The reasons for re-establishing Alexandrella pulchra as a distinct species are given in the remarks section on A. schellenbergi. In A. pulchra, some specimens have orange pereiopods and antennae and others nearly entirely white appendages. Two explanations are possible: Either the specimens exhibit individual colour variation or two very similar species are involved. The identity of the Alexandrella $\mathrm{sp}$. of Rauschert \& Arntz (2015) is not clear but it might be A. pulchra. The shape of the eye and the number of body segments with a tooth match with $A$. pulchra but coxa 4 seems to be apically rounded instead of subacute.

\section{Alexandrella schellenbergi (Holman \& Watling, 1983)}

Bathypanoploea schellenbergi Holman \& Watling, 1983: 47 (in part: holotype only) figs 11a-e only (not figs 9, 10, 11f-h: presumably A. pulchra and Alexandrella sp. 1).

Iphimediopsis australis - Schellenberg 1931: 127, pl. 1 fig. c.

Bathypanoploea australis - Schellenberg 1939: 137 (footnote, by implication).

non Acanthonotozoma australis Chilton, 1912: 205, pl. 2 fig. 19.

\section{Distribution}

Sub-Antarctic Region: south of Argentine Basin: north east of Falkland Islands: $50^{\circ} 19^{\prime} \mathrm{S}, 50^{\circ} 50^{\prime} \mathrm{W}$, 2675 m (Holman \& Watling 1983).

\section{Remarks}

It has been reported that Alexandrella schellenbergi has a very wide geographical and bathymetric distribution across the Southern Ocean (Holman \& Watling 1983, Berge \& Vader 2005b, 2005c, De Broyer et al. 2007). This widespread distribution is questioned here. The holotype of $A$. schellenbergi was collected north of the Antarctic Polar Front and north of the line joining the Falkland Islands to South Georgia, at $2675 \mathrm{~m}$. Its telson is more deeply cleft than in similar Alexandrella specimens from the continental shelf of the South Shetland Islands and the tip of the Antarctic Peninsula. This telson character state is consistent with the specimens illustrated in literature (Holman \& Watling 1983, Ren \& Huang 1991) and examined by us. On the poor quality photograph given by Schellenberg (1931), the posterior pereiopods also appear more slender than in the forms of the Antarctic continental shelf; however, this might be an illusion created by the possibly not flattened orientation of the legs on the picture. The telson difference, the geographical wide separation and the bathymetric differences suggest that two species are involved. The name Alexandrella pulchra Ren in Ren \& Huang, 1991 is available for the form of the 
South Shetland Islands and the tip of the Antarctic Peninsula, and it is herein resurrected for them. All topotypical shelf specimens of Alexandrella pulchra examined by us were devoid of posterodorsal tooth on pereionite 6. However, specimens similar to A. schellenbergi with a tooth on pereionite 6 are present in the Ross Sea (Holman \& Watling 1983: 49, fig. 10a), off Adélie Coast (present material) and in the Atlantic sector of the Southern Ocean (Rauschert \& Arntz 2015). They are treated herein as a separate taxon: Alexandrella sp. 1.

Alexandrella subchelata Holman \& Watling, 1983 s. lat.

Alexandrella subchelata Holman \& Watling, 1983: 42.

Alexandrella subchelata - Berge \& Vader 2005a: 1327-1346. — Serejo 2014: 139 (key).

Alexandrella dentata - J.L. Barnard 1961: 77, fig. 46.

non Alexandrella dentata Chevreux, 1912: 213.

\section{Distribution}

For clarity, it seems necessary to give the station details in full for all known specimens identified as Alexandrella subchelata in literature: holotype: RV Galathea, stn 554, 5 December 1951, 37 $28^{\prime}$ S, 138 55' E, Great Australian Bight, 1320-1340 m (J.L. Barnard 1961 as A. dentata, Holman \& Watling

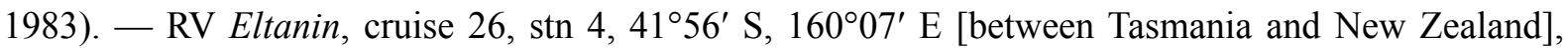

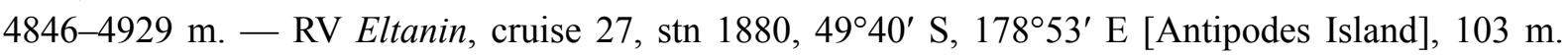

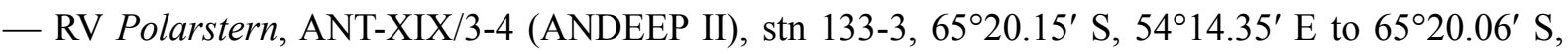
541․ $4^{\prime}$ E [Antarctica: Kong Håkon VII Sea], 1119-1122 m (Berge \& Vader 2005a).

Alexandrella sp. 1

Figs 338-339

Bathypanoploea schellenbergi Holman \& Watling, 1983: 47, in part (not holotype), fig. 9b, 10, ? $11 \mathrm{f}$.

Bathypanoploea schellenbergi - ? Rauschert \& Arntz 2015: 79, pl. 72 [ANT-XXI].

\section{Material examined}

RV l'Astrolabe cruises:

SOUTHERN OCEAN: 1 very large spec., cruise REVOLTA III, no station (Dumont d'Urville Sea), Collect_ID: REVO_449, Adélie Coast, $66^{\circ} 38^{\prime} \mathrm{S}, 140^{\circ} 42^{\prime}$ E to $66^{\circ} 38^{\prime} \mathrm{S}, 140^{\circ} 40^{\prime} \mathrm{E}, 718-729 \mathrm{~m}$, mud, beam trawl, 20 Jan. 2012, CE-000002100 (MNHN-IU-2009-2540).

\section{Remarks}

The specimen examined has a mid-dorsal tooth on pereionite 6 in addition to the usual teeth on pereionite 7 and pleonites 1-3. Otherwise, it looks very similar to Alexandrella pulchra. Only minor differences in the form of coxae 1 and 4 were observed. The shape of the eye is similar to that of A. pulchra, but the body and leg pigmentation is less pronounced. A small tooth is also present in the specimen from the continental shelf of the Ross Sea illustrated by Holman \& Watling (1983) and a specimen from the eastern Weddell Sea illustrated by Rauschert \& Arntz (2015). The latter specimen has much smaller eyes than A. pulchra, and according to an early draft of Rauschert \& Arntz's book, it was collected during the cruise ANT-XXI (obviously ANT-XXI/2), which almost exclusively sampled on the continental shelf. 
Alexandrella sp. 2

Fig 339

\section{Distribution}

RV Polarstern, PS77, ANT-XXVII/3, stn 211 (there were several sub-stations for stn 211), Shag Rocks. The species is known from a photograph taken by $\mathrm{H}$. Robert and Ch. Havermans. The specimen was unavailable for study.

\section{Remark}

This species looks similar to A. pulchra and A. schellenbergi but displays some differences. Pereionites 5 and 6 have each a conspicuous posterodorsal tooth, which is absent in A. pulchra and A. schellenbergi. The pereiopods are striped, which is not the case or not so pronounced in A. pulchra.

\section{Alexandrella sp. 3}

Alexandrella australis - Holman \& Watling, 1983: 33-37, in part, figs 1-3. - Berge \& Vader 2005a: 1330-1332, fig. 1.

non Acanthonotozoma australis Chilton, 1912: 205, pl. 2 fig. 19.

\section{Distribution}

This taxon has been recorded once at the following station: RV Islas Orcadas, cruise 575, Stn 54, $57^{\circ} 39^{\prime} \mathrm{S}, 26^{\circ} 00.4^{\prime} \mathrm{W}$ [South Sandwich Islands], 2380-2609 m (Holman \& Watling 1983, Berge \& Vader 2005a).

\section{Remarks}

The specimen identified as Alexandrella australis by Holman \& Watling (1983) exhibits striking differences with the illustration of the holotype given by Chilton (1912). The carina of urosomite 1 presents a much stronger posterior tooth and deeper anterior notch on the drawing of Chilton (1912) than in that of Holman \& Watling (1983). The specimen of Chilton (1912) has a small posterodorsal tooth on pereionite 6, which is missing in the one illustrated by Holman \& Watling (1983). The specimen of Chilton (1912) is illustrated as having a more truncated coxa 1 than the one of Holman \& Watling (1983). Finally, the posterodistal tooth of the basis of pereiopod 7 looks longer in the specimen of Chilton (1912) than in the one of Holman \& Watling (1983). As the conspecificity of the two specimens is questionable, the name Alexandrella sp. 3 is used herein for the one studied by Holman \& Watling (1983).

\section{Alexandrella sp. 4}

Bathypanoploea sp. Berge \& Vader, 2005c: 4, fig. 6.

\section{Distribution}

Northeast of Elephant Island, 60³9.53' S, 5356.93’ W, 2889 m (Berge \& Vader 2005c).

Subfamily Astyrinae Pirlot, 1934

Amphilochinae Boeck, 1871: 129-130 (in part).

Tironidae Stebbing, 1906: 273 (in part).

Astyridae Pirlot, 1934: 175. 
Amphilochinae - Boeck 1876: 430-431 (in part).

Amphilochidae - G.O. Sars 1892: 212-213 (in part).

Tironidae - Stephensen 1928: 225 (in part).

Paramphithoidae - K.H. Barnard 1932: 170 (in part). — J.L. Barnard 1969: 389 (in part).

Astyridae - Gurjanova 1951: 596. - Birstein \& Vinogradov 1955: 253. - Birstein \& Vinogradova 1960: 152 (in part). — J.L. Barnard 1969: 159. — Bousfield 1979: 369 (discussion); 1982: 274 _ — Coleman \& J.L. Barnard 1991a: 263. — Andres \& Lott 1986: 133.

Astyrinae - Holman \& Watling 1983: 28.

Astryidae [sic] - Coleman \& J.L. Barnard 1991a: 263 (misspelling).

Stilipedidae - J.L. Barnard \& Karaman 1991: 701 (in part).

non Paramphithoidae G.O. Sars, 1883: 25.

non Stilipedidae Holmes, 1908: 535.

\section{Key to the genera of Antarctic Astyrinae}

1. All pereionites and pleonites without posterodorsal tooth genus Astyra Boeck, 1871

- Pereionite 7 and pleonites 1-3 with posterodorsal tooth genus Eclysis K.H. Barnard, 1932

Genus Astyra Boeck, 1871

Astyra Boeck, 1871: 53; type species: Astyra abyssi Boeck, 1871.

Chagosia Walker, 1909: 332-333; type species: Chagosia gardineri Walker, 1909.

Parastyra Pirlot, 1934: 176; type species: Parastyra longidactyla Pirlot, 1934.

Astyra - Boeck 1876: 442. — G.O. Sars 1892: 213. — Della Valle 1893: 693-694. — Gerstaecker \& Ortmann 1901: 502. — Stebbing 1906: 278. — Stephensen 1928: 228; 1931: 256 (discussion). — Gurjanova 1951: 596, 597. — Birstein \& Vinogradov 1955: 253-254. — J.L. Barnard 1969: 115, 161. - Holman \& Watling 1983: 31 (discussion). — Andres \& Lott 1986: 132. - J.L. Barnard \& Karaman 1991: 703-704. — Andres 1997: 82. — Berge 2003b: 2 (discussion). - Berge \& Vader 2005a: 1345 (discussion).

Parastyra - Gurjanova 1951: 596, 598.

\section{Etymology}

"Astyra, a town of Mysia, Mela, Pliny: Strabo calls it a hamlet, near which is a grove of Diana, thence named Astyrena: this Astyra is near Adramytrium, and to be distinguished from another near Abydos, which had a gold mine, Strabo. This last was a town of Troas; in ruins in Strabo's time" (MacBean

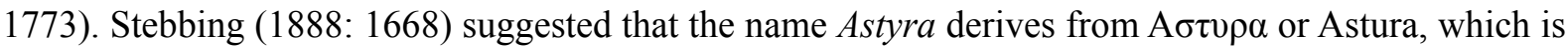
the name of a river in Asturia (Spain).

Astyra antarctica Andres, 1997

Astyra antarctica Andres, 1997: 81-89, figs 1-28.

\section{Distribution}

Elephant Island, 120 m (Andres 1997). 
Eclysis K.H. Barnard, 1932: 181-183; type species: Eclysis similis K.H. Barnard, 1932.

Eclysis-Gurjanova 1955: 189, 206. — J.L. Barnard 1969: 161,394.—McCain 1971: 160 (discussion). Bousfield 1979: 363, 369 (discussion). — Andres \& Lott 1986: 131-137. — J.L. Barnard \& Karaman 1991: 393, 702, 703, 706-707. — Berge \& Vader 2005a: 1345 (discussion); 2005b: 81; 2005c: 2-3. Eclyses - Andres \& Lott 1986: 133 (misspelling for Eclysis).

Epimeriella - Karaman \& J.L. Barnard 1979: 109-110 (in part).

non Epimeriella Walker, 1906: 17; type species: Epimeriella macronyx Walker, 1906.

Eclysis similis K.H. Barnard, 1932

Eclysis similis K.H. Barnard, 1932: 182, fig. 112.

Eclysis similis - Andres \& Lott 1986: 131-137, figs 1-2. — Berge \& Vader 2005c: 2 figs 1-3. De Broyer et al. 2007: 31 (ubi syn.).

\section{Distribution}

South Georgia and Weddell Sea: eastern shelf, 230-250 m (De Broyer et al. 2007); Ross Sea, 659741 m (Berge \& Vader 2005b).

Subfamily Stilipedinae Holmes, 1908

Stilipedinae Holmes, 1908: 535.

Tironidae - K.H. Barnard 1931: 427 (in part); 1932: 148, 153 (in part).

Stilipedinae - Holman \& Watling 1983: 27-28.

non Tironidae Stebbing, 1906: 273.

Genus Stilipes Holmes, 1908

Stilipes Holmes, 1908: 536; type species: Stilipes distinctus Holmes, 1908.

Cacao K.H. Barnard, 1931: 427-428; type species: Cacao lacteus K.H. Barnard, 1931.

Cacao - K.H. Barnard, 1932: 153. - Hurley 1954: 804.

Stilipes - Shoemaker 1964: 414. — J.L. Barnard 1969: 453-454. — Holman \& Watling 1983: 29 (discussion). —Andres \& Lott 1986: 132. — J.L. Barnard \& Karaman 1991: 707. — Berge 2003b: 2.

Stilipes macquariensis Berge, 2003

Stilipes macquariensis Berge, 2003a: 305, fig. 1.

Stilipes macquariensis - Berge, 2003b: 2, 4-5, figs 3-5.

\section{Distribution}

Macquarie Island, 956-959 m (Berge 2003a,b). 
Family Vicmusiidae Just, 1990

Vicmusiidae Just, 1990: 925; type genus: Vicmusia Just, 1990.

Acanthonotozomellidae Coleman \& J.L. Barnard, 1991a: 257 (in part).

Acanthonotozomatidae - Bushueva 1978: 450 (in part).

Iphimediidae - Watling \& Thurston 1989: 304 (in part). — J.L. Barnard \& Karaman 1991: 378 (in part). Vicmusiidae - Just 1995: 1007. — Coleman 2007: 130.

Acanthonotozomellidae - Coleman \& J.L. Barnard 1991b: 279.

non Acanthonotozomatidae Stebbing, 1906: 210.

non Iphimedinae Boeck, 1871: 98.

Genus Acanthonotozomopsis Watling \& Holman, 1980

Acanthonotozomopsis Watling \& Holman, 1980: 614; type species: Acanthonotozomella pushkini Bushueva, 1978.

Vicmusia Just, 1990: 930; type species: Vicmusia duplocoxa Just, 1990.

Acanthonotozomella - Bushueva, 1978: 450, 452 (in part).

Acanthonotozomopsis - De Broyer 1983: 291. — Watling \& Thurston 1989: 304, 310. — J.L. Barnard \&

Karaman 1991: 380. — Coleman \& J.L. Barnard 1991a: 257. — Coleman \& J.L. Barnard 1991b: 279. — Just 1995: 1005. — Coleman 2007: 130.

non Acanthonotozomella Schellenberg, 1926: 332; type species: Acanthonotozomella alata Schellenberg, 1926.

Acanthonotozomopsis pushkini (Bushueva, 1978)

Fig 341

Acanthonotozomella pushkini Bushueva, 1978: 450-453, unnumbered fig.

Acanthonotozomopsis pushkini - Watling \& Holman 1980: 614-615. — De Broyer 1983: 293-294, figs 94-95. - Watling \& Thurston 1989: 305, 310, fig. 3i. — Just 1995: 1005. — De Broyer et al. 2007: 228 (ubi syn.). - Coleman 2007: 130, fig. 86, pl. 4 fig. d, map 41. — Rauschert \& Arntz 2015: 59, pl. 52, unnumbered photograph.

\section{Material examined}

RV Polarstern cruises:

SOUTHERN OCEAN: 1 spec., cruise PS77, ANT-XXVII/3, CAMBIO, stn 211-5, Shag Rocks, $53^{\circ} 24.21^{\prime} \mathrm{S}, 42^{\circ} 41.65^{\prime} \mathrm{W}$ to $53^{\circ} 24.06^{\prime} \mathrm{S}, 42^{\circ} 42.58^{\prime} \mathrm{W}, 327-345 \mathrm{~m}$, Agassiz trawl, 14 Feb. 2011, coll. C. Havermans and H. Robert (RBINS, INV. 132656) [extraction E30 of 23.08.2012; Genbank nr, 28S: KT808687, 18S: KT808783]; 3 specs, cruise PS81, ANT-XXIX/3, stn 197-6, Bransfield Strait, $62^{\circ} 45.05^{\prime} \mathrm{S}, 57^{\circ} 26.68^{\prime} \mathrm{W}$ to $62^{\circ} 45.09^{\prime} \mathrm{S}, 57^{\circ} 26.47^{\prime} \mathrm{W}, 210-222 \mathrm{~m}$, black gravel mixed with sand and a little bit of mud, Rauschert dredge, 25 Feb. 2013, coll. C. d'Udekem d'Acoz and M. Verheye (RBINS, INV. 122871); 1 spec., cruise PS81, ANT-XXIX/3, stn 164-5, south of Dundee Island, $63^{\circ} 36.84^{\prime}$ S, $56^{\circ} 10.28^{\prime} \mathrm{W}$ to $63^{\circ} 36.72^{\prime} \mathrm{S}, 56^{\circ} 10.46^{\prime} \mathrm{W}, 121-122 \mathrm{~m}$, Rauschert dredge, 11 Feb. 2013 , coll. C. d'Udekem d'Acoz and M. Verheye (RBINS, 122886); 1 spec., cruise PS81, ANT-XXIX/3, stn 188-5, south-east of Dundee Island, $63^{\circ} 50.92^{\prime} \mathrm{S}, 55^{\circ} 37.66^{\prime} \mathrm{W}$ to $63^{\circ} 50.93^{\prime} \mathrm{S}, 55^{\circ} 37.52^{\prime} \mathrm{W}, 402-407 \mathrm{~m}$, Rauschert dredge, 20 Feb. 2013, coll. C. d'Udekem d'Acoz and M. Verheye (RBINS, INV. 132206). 
RV Seatruck, cruise REVOLTA II:

SOUTHERN OCEAN: 2 specs, stn REVO_128, Collect_ID: REVO_128, Adélie Coast, 66 38.7' S, 139 56.8' E, 91-93 m, 10 Jan. 2011, coll. N. Améziane, N. Bax, C. Gallut, A.C. Lautrédou and C. Robineau (MNHN-IU-2016-6586).

RV Seatruck, cruise REVOLTA III:

SOUTHERN OCEAN: 1 large spec., stn REVO_032, Collect_ID: REVO_509, Field_ID: CE000002396, Adélie Coast, $66^{\circ} 39^{\prime} \mathrm{S}, 140^{\circ} 02^{\prime} \mathrm{W}$ to $66^{\circ} 39^{\prime} \mathrm{S}, 140^{\circ} 02^{\prime} \mathrm{W}, 72-100 \mathrm{~m}$, beam trawl, 8 Feb. 2012, coll. G. Lecointre, A. Dettaï, J. Lanshere, C. Gallut and C. Ozouf, (MNHN-IU-2016-6602).

\section{Distribution}

Davis Sea, Enderby Land, South Shetland Islands, 24-45 m (De Broyer et al. 2007), Shag Rocks, South of Dundee Island, Bransfield Strait, Adélie Coast, down to 402-407 m (present material).

\section{Remarks}

The orange dotted colour pattern of A. pushkini (Fig. 340) is reminiscent of that of many Antarctic gorgonians but so far there is no direct evidence of symbiosis.

\section{Molecular taxonomy}

Combined COI and 28S rDNABayesian and Maximum Likelihood analyses of Antarctic Epimeria clearly show distinct clades for all the species described herein which were available for the molecular study (Bayesian tree on Fig. 342). The following clades were identified as species-level lineages by a range of species-delimitation methods in a previous study (Verheye et al. 2016a): (1) within Drakepimeria, Epimeria acanthochelon sp. nov., E. anguloce sp. nov., E. colemani sp. nov., E. corbariae sp. nov., E. cyrano sp. nov., E. havermansiana sp. nov., E. loerzae sp. nov., E. pandora sp. nov., E. pyrodrakon sp. nov., E. robertiana sp. nov. and E. similis; (2) within Subepimeria, E. adeliae sp. nov., E. iota sp. nov., E. teres sp. nov. and E. urvillei sp. nov.; (3) within Urepimeria, E. annabellae; (4) within Laevepimeria, E. walkeri, E. sp., E. cinderella sp. nov. and E. anodon sp. nov.; (5) within Epimeriella, E. macronyx; (6) within Hoplepimeria, E. quasimodo sp. nov., E. linseae sp. nov., E. cyphorachis sp. nov., E. rimicarinata, E. rubrieques, E. larsi, E. angelikae, E. inermis, E. gargantua sp. nov., E. robustoides and robusta. Most clades are well-supported by both posterior probabilities $(\geq 0.95)$ and bootstrap values $(\geq 70)$, except for Epimeria loerzae (supported by BV only), Epimeria similis (supported by PP only) and Epimeria quasimodo sp. nov. (not supported). However, the latter is supported by bootstrap values in the COI phylogeny, whereas the 28S rDNA might not be variable enough to separate it from the closely-related species E. linseae sp. nov. and E. cyphorachis sp. nov. (see Verheye et al. 2016a).

\section{General discussion}

\section{The Epimeria Pandora's box suggests that Antarctic and sub-Antarctic amphipods are taxonomically poorly known.}

More than 600 amphipod species have been recorded south of the Antarctic Polar Front (De Broyer \& Jażdżewska 2014; Zeidler \& De Broyer 2014). Recent classical morphological generic revisions (e.g., d'Udekem d'Acoz 2008, 2009; Krapp-Schickel \& De Broyer 2014) continue to increase this number with revisions of the genera Liljeborgia and Leucothoe, doubling the number of species. Furthermore, molecular studies suggest that other well documented Antarctic amphipod species consist of cryptic species complexes (see inter alia Verheye 2011; Baird et al. 2011; Havermans 2014). The present paper confirms this general trend by increasing nearly twofold the number of Antarctic Epimeria species, which are among the morphologically most spectacular amphipod species. Since the present sampling is geographically incomplete and largely restricted to the continental shelf, it is likely that more Antarctic 
and sub-Antarctic Epimeria species remain undetected. A rapid overview of the systematics of the related genus Alexandrella also indicates an underestimation of its diversity in the Southern Ocean, comparable to the level of Epimeria before the present study. If this reflects the average taxonomic knowledge of Southern Ocean amphipods as a whole, this would mean that for most genera and families, less than half of the Antarctic and sub-Antarctic species would currently be described. A minimal level of taxonomical knowledge is required for accurate ecological and biogeographical studies, and for conservation biology (e.g., Brad et al. 2015: 2). However, it seems that the current knowledge of Antarctic amphipods' taxonomy is only the tip of the iceberg.

\section{Why are Antarctic Epimeria so diverse?}

Excluding the sub-Antarctic/low Antarctic subgenus Metepimeria, for which no molecular data was available, Antarctic Epimeria do form a clade (Lörz et al. 2009; Verheye et al. 2016b; Verheye et al. 2017), which has been interpreted as a species flock (Lecointre et al. 2013). This Antarctic Epimeria clade exhibits a higher species richness and morphological diversity than all known Epimeria species from all the other oceans combined. However, this statement will have to be revisited in the future, as it appears that the diversity of tropical Indo-Pacific Epimeria has been underestimated (Verheye et al. 2017). The biology of Epimeria species is poorly known, but it seems that most species feed on a fairly large spectrum of (mostly living) biological items, although with species-specific preferences (Dauby et al. 2001a). Empirical observations carried out by the present authors during Antarctic cruises indicate that the abundance and the diversity of the genus Epimeria in the catches is directly proportional to the abundance of epifauna (gorgonians, erect bryozoans, sponges, etc.). This confirms the statements of De Broyer et al. (2001), who considered Epimeria species to be associated with epifauna. So, whilst most Epimeria species probably have no hyper-specialized trophic niches as it is the case for at least some Iphimediidae (Coleman 1989a, 1989b), they belong to the same benthic communities, characterized by an abundance of sessile fauna. In warm and temperate seas, large and medium-sized crustaceans from all kinds of habitats are predominantly decapods (e.g., Poupin \& Juncker 2010), whereas this crustacean order is extremely poor in species and morphotypes in the Southern Ocean (Kirkwood 1984; Griffiths et al. 2014; Basher \& Costello 2014). It has been suggested that the ecological niches left vacant by decapods when the Southern Ocean cooled down were largely occupied by large amphipods (Chapelle 2002; De Broyer et al. 2003). The increased size of many Antarctic amphipod species would be correlated with the abundance of oxygen in the Southern Ocean, since oxygen depletion is a factor limiting the size of amphipods (Chapelle \& Peck 1999; Chapelle 2002). In such optimal conditions, amphipod genera like Epimeria, which have an inherent propensity for large sizes, could have extensively radiated in the Southern Ocean.

Eurybathy and adaptation to deeper water are considered as important predispositions for diversification in Antarctic seas (Brey et al. 1996). During Pleistocene glaciations, the largest part of the continental shelf and upper slope was covered by a thick icesheet and the putative persisting glacial shelf refugia around Antarctica were presumably fairly deep, as the coastline was almost totally occupied by grounded iceshelves (Post et al. 2014: 49, Environmental Setting Map 3). In such conditions, the genus Epimeria, which includes many fairly eurybathic species extending their distribution down to the deep shelf and upper slope, was presumably better pre-adapted to survive glaciations than shallow-water stenobathic taxa. Epimeria could have diversified during interglacial periods, occupying the ecological niches left vacant after the extinction of such poorly pre-adapted crustaceans.

\section{Morphological patterns and morphofunctional aspects}

While all known extralimital Epimeria species exhibit a highly characteristic silhouette with dorsolaterally flattened dentate crests on several body segments, this is not the case of all Southern Ocean species. Only the subgenus Drakepimeria subgen. nov. really shares the classical outline of its extralimital relatives. The subgenus Pseudepimeria exhibits an even more processiform morphology, 
with a deeply sculptured body and unique robust clasping ambulatory pereiopods (presumably an adaptation for climbing on branching epifauna) and very small-sized, slender achelate gnathopods. Both Drakepimeria subgen. nov. and Pseudepimeria have the peduncle of antenna 1 more strongly dentate than in any other Epimeria. Other subgenera of Antarctic Epimeria usually exhibit a reduced crested pattern or a non crested silhouette. In Hoplepimeria subgen. nov., the dorsolateral teeth are absent and the mid-dorsal carinae are usually reduced in size and sharpness but not so much in number. Epimeria (H.) rubrieques subgen. nov. is an exception: this species exhibits huge (non-dorsolaterally flattened) dentiform mid-dorsal teeth. Hoplepimeria subgen. nov. species exhibit other unusual characters, such as a highly calcified body and distally very robust gnathopods, which are interpreted as putative synapomorphies. They are also usually very large and include the two largest known Epimeria species, namely E. gargantua sp. nov. and E. rubrieques, respectively reaching 80 and $70 \mathrm{~mm}$. In the subgenera Laevepimeria subgen. nov., Subepimeria and Urepimeria subgen. nov., the dorsal dentition is even less developed (and they are normally calcified). Species from these subgenera are also unusually small relative to Epimeria standards. The subgenus Metepimeria was not examined. The reasons for crested versus globular morphologies are unknown, and it is unclear which one is apomorphic. Only hypotheses can be raised concerning their function. Dentate morphologies might confer a disruptive appearance to species mostly climbing on epifauna (at depths where light is very reduced) and globular morphologies would be an advantage for predominantly non climbing species, as they would more or less mimic small pebbles or rounded sessile organisms. In Epimeriella and Laevepimeria subgen. nov., the morphology of the mandibles and lower lip is modified. The functional reason for these apomorphies is unknown. Finally, Epimeriella exhibits further unusual features, which might be linked to their pelagic or semipelagic life style: slender outline, very weak calcification, extreme reduction of the rostrum.

\section{Distribution patterns in Antarctic and sub-Antarctic Epimeria}

In the Southern Ocean, the Antarctic and sub-Antarctic regions, separated by the Antarctic Polar Front, are populated by two very different faunal assemblages (at least on the continental shelf) (De Broyer \& Koubbi 2014), and different biogeographical subregions are often recognized. For example, the area comprising the Scotia Arc and the Antarctic Peninsula (so-called Scotia Subregion or West Antarctica) has often been considered as distinct from the continental shelf surrounding the rest of the Antarctic continent (often referred as East Antarctica) (Hedgpeth 1969; De Broyer \& Koubbi 2014). This eastwest biogeographical split has not been observed in all benthic taxa (Griffiths et al. 2009; Koubbi et al. 2014), but it appears valid for amphipods (De Broyer \& Jażdżewska 2014). However, in the past, many Antarctic amphipod species were reported to have a circumpolar distribution (Lörz et al. 2009). Gene flow was assumed to be facilitated by the homogenizing effect of the strong circumpolar current system: the Antarctic westward-flowing Coastal Current (formerly East Wind Drift) close to the continent and the more northern eastward-flowing Antarctic Circumpolar Current (De Broyer \& Jażdżewska 2014). The relatively similar environmental conditions (such as isothermal waters or the continuous shelf) were also considered as an important homogenizing factor (De Broyer \& Jażdżewska 2014). Amphipodologists therefore often assumed that similar forms from distant locations in the Antarctic Region were a priori conspecifics. For example, Epimeria macrodonta was first collected in the Ross Sea, and later on, recorded almost all around Antarctica; before the present study, the conspecificity of these widely separated populations was usually not questioned. However, several molecular studies have revealed the presence of geographically restricted cryptic species within widespread nominal species, challenging the circumpolarity paradigm for benthic amphipods (Baird et al. 2011; Havermans et al. 2011; Havermans et al. 2014). For the genus Epimeria, Lörz et al. (2009) demonstrated that Epimeria robusta s. lat. consisted of two allopatric species: Epimeria robusta s. str. (Ross Sea) and E. robustoides (Weddell Sea). Lörz et al. (2011) demonstrated that Epimeria georgiana was a complex of largely allopatric, pseudocryptic species with a distribution apparently restricted to the Scotia Arc, the Antarctic Peninsula and the eastern Weddell Sea. The present study provides a more extensive assessment of distributional patterns within Epimeria. Our sampling shows that these patterns are variable among 
species, with a mixture of narrow range endemics, regional endemics and widely distributed species. It also demonstrates that many 'variable widely distributed species' are allopatric species complexes. The demonstrative example of the E. macrodonta complex is illustrated on Fig. 343. Bathymetric and distributional data for all Epimeria species of the Southern Ocean (largely based on specimens examined in this study) are summarised in Table 2.

Table 2 suggests the existence of different trends in bathymetric distributions among Epimeria species of the Southern Ocean:

- infralittoral species (0-15 m): E. monodon

- shelf species (30-100 $\mathrm{m}$ to $600-800 \mathrm{~m})$ : the vast majority of species

- lower shelf / upper slope species (350 to $1200 \mathrm{~m}$ ): E. angelikae, E. colemani sp. nov., E. cyphorachis sp. nov., E. cyrano sp. nov., E. rubrieques (sometimes also occurring at shallower depths)

- slope species (around $2000 \mathrm{~m}$ ): E. larsi, E. robertiana sp. nov.

This dataset is of course incomplete and the different types of distributions are not clear-cut. However, it seems that, with the exception of the infralittoral E. monodon and the deep-sea E. larsi and E. robertiana sp. nov., most Antarctic and sub-Antarctic Epimeria probably occupy a wide or relatively wide bathymetric stretch on the Antarctic continental shelf and upper slope. This is in agreement with previous general observations on the eurybathy of Antarctic amphipods (e.g., De Broyer et al. 2007). However, it should be noted that the diversity of Epimeria on the deep Antarctic continental slope (below $1000 \mathrm{~m}$ ) is likely to be underestimated because of limited sampling at these depths, and because deep-sea Epimeria species presumably have a patchy distribution, limited to local oases rich in epifauna.

The following apparent geographic distributions were established in combining our data with reliable records from the literature (Table 2):

- Magellanic (sub-Antarctic): E. acanthurus

- Macquarie Island (sub-Antarctic): E. ashleyi

- South Georgia + Shag Rocks: E. georgiana, E. intermedia, E. (Subepimeria) sp. 1

- Bruce Ridge: E. (Hoplepimeria) sp. subgen. nov.

- South Orkney Islands: E. linseae sp. nov., E. pulchra

- Elephant Island: E. heldi, E. vaderi

- South Orkney Islands to tip and west of Antarctic Peninsula: E. monodon

- Elephant Island to west and tip of Antarctic Peninsula: e.g., E. gargantua sp. nov., E. leukhoplites sp. nov., E. pandora sp. nov., E. similis

- tip of Antarctic Peninsula and South Shetland Islands + eastern shelf of the Weddell Sea (or even as far east as Prydz Bay) : E. atalanta sp. nov., E. anguloce sp. nov., E. pyrodrakon sp. nov.

- eastern shelf of the Weddell Sea: e.g., E. annabellae, E. kharieis sp. nov., E. robustoides, E. xesta sp. nov.

- eastern shelf of the Weddell Sea and Davis Sea: E. rubrieques

- eastern shelf of the Weddell Sea to Adélie Coast or western Ross Sea: Epimeria acanthochelon sp. nov., E. angelikae, E. havermansiana sp. nov.

- Davis Sea or Adélie Coast to Ross Sea: E. larsi, E. rimicarinata, E. robusta

- Adélie Coast: e.g., E. adeliae sp. nov., E. amoenitas sp. nov., E. anodon sp. nov., E. callista sp. nov., E. urvillei sp. nov.

- Western Ross Sea: e.g., E. macrodonta, E. schiaparelli

- South Orkney Islands or South Shetland Islands to Western Ross Sea: E. colemani sp. nov., E. inermis, E. macronyx. 
These observed distributions must be considered as very provisional, as they are based on a nonexhaustive dataset. The apparent regional absence of some species might be due to limited sampling. Distributional data are missing for large stretches of the Southern Ocean, which are listed in the last column of table 2. Moreover, some identifications were not backed up by molecular methods, and are therefore less reliable, especially for complexes of very similar species, which can exhibit individual and allometric variations.

Many species belong to species complexes, often but not always with allopatric distributions. The macrodonta complex in its strictest sense (excluding the distinctive E. loerzae sp. nov. and E. pyrodrakon sp. nov.) includes the extremely similar E. anguloce sp. nov. (Antarctic Peninsula to Prydz Bay), E. corbariae sp. nov. (Adélie Coast) and E. macrodonta (western Ross Sea). The pandora complex includes E. pandora sp. nov. (South Shetland Islands to tip of the Antarctic Peninsula) and E. havermansiana sp. nov. (eastern shelf of the Weddell Sea to Adélie Coast). The similis complex comprises E. similis (South Shetland Islands and tip of the Antarctic Peninsula) and E. acanthochelon sp. nov. (eastern shelf of the Weddell Sea to Adélie Coast). The robusta complex includes E. (Hoplepimeria) sp. subgen. nov. (Bruce Ridge), E. gargantua sp. nov. (tip of the Antarctic Peninsula), E. robustoides (eastern Weddell Sea) and E. robusta (Adélie Coast to western Ross Sea). The georgiana complex includes E. georgiana (South Georgia), E. linseae (South Orkney Islands), E. quasimodo sp. nov. and E. cyphorachis sp. nov. (South Shetland Islands and tip of Antarctic Peninsula, each one with a different depth optimum), and E. xesta sp. nov. (eastern shelf of the Weddell Sea). The grandirostris complex includes E. grandirostris (South Shetland Islands and Antarctic Peninsula), E. kharieis sp. nov. (eastern shelf of the Weddell Sea) and E. callista sp. nov. (Adélie Coast). Finally, the pulchra complex includes E. pulchra (South Orkney Islands), E. cf. debroyeri (South Shetlands / Antarctic Peninsula area), E. debroyeri sp. nov. (eastern shelf of the Weddell Sea) and E. amoenitas sp. nov. (Adélie Coast).

There are areas of higher and lower Epimeria diversity and endemism. Diversity is low north of the Polar Front, with one species only known from the Magellanic Region and one from the Macquarie Ridge. The South Georgia / Shag Rocks area is also poor in species (three or four), and comprises only endemics. The Scotia Arc area (south of South Georgia) is especially rich in Epimeria species, except for the area north of Livingstone Island in the Drake Passage, which exhibits a general low diversity in amphipods and other organisms (d'Udekem d'Acoz \& Verheye 2013; Gutt et al. 2013; Isla et al. 2013; Janussen \& Kersken 2013; Gutt et al. 2016; Kersken et al. 2016). The high diversity of the Scotia Arc has also been observed for other taxa, such as octopuses (Allcock et al. 2011), bivalves (Linse et al. 2007), and sea anemones (Rodríguez et al. 2007). The species richness of the Scotia region might be related to its geomorphologic complexity (Post et al. 2014), the heterogeneity of its benthic communities (Lockhart \& Jones 2008), and the occurrence of potential glacial refugia during the Pleistocene glaciations (Post et al. 2014). This region also includes more narrow range endemics than any other studied area (the eastern Weddell Sea and the Adélie Coast), e.g., the insular endemics $E$. georgiana, E. linseae sp. nov. and E. pulchra. As most Epimeria, these species presumably have poor dispersal capabilities and therefore, the deep-sea chasms surrounding their native insular plateau would be an efficient barrier.

Many Epimeria species (including very common ones) present around the tip of the Antarctic Peninsula and the South Shetland Islands have not been recorded on the eastern shelf of the Weddell Sea and vice versa. This might be explained by the unfavourable environmental conditions of the intermediate shelf region. On the western side of the Weddell Sea, Epimeria diversity dramatically decreases southwards and very few species have been recorded in the Larsen A and B areas, as it is the case for amphipods in general (d'Udekem d'Acoz \& Robert 2008). In the Larsen A and B areas, soft mud bottoms largely predominate (Gutt et al. 2008) and harbour low benthic diversity (Janussen 2012); hard bottoms rich in epifauna (especially Stylasteridae) are restricted to the margins of the bays (Gutt et al. 2008, 2011). 
Table 2. Distribution of Epimeria species and subgenera in the Southern Ocean.

$1=$ Magellan; $2=$ N.Zealand Sub-Antarctic Is. and Macquarie I.; $3=$ South Georgia, Shag Rocks; $4=$ Bruce Ridge; $5=$ South Orkney Islands; $6=$ Elephant and Clarence Is.; $7=$ S Shetland Is. (excl. Elephant Is.), tip and west of Antarctic Peninsula; $8=$ Larsen Area (western Weddell Sea except northern tip); 9 = eastern shelf of the Weddell Sea; $10=$ Princess Ragnhild Coast; $11=$ Davis Sea; $12=$ Adélie Coast and Oates Land; 13 = western Ross Sea.

\begin{tabular}{|c|c|c|c|c|c|c|c|c|c|c|c|c|c|c|}
\hline Distribution and bathymetry & depth $(\mathrm{m})$ & 1 & 2 & 3 & 4 & 5 & 6 & 7 & 8 & 9 & 10 & 11 & 12 & 13 \\
\hline \multicolumn{15}{|l|}{ Taxa } \\
\hline \multicolumn{15}{|l|}{ DRAKEPIMERIA subgen. nov. } \\
\hline acanthochelon sp. nov. & $204-791$ & & & & & & & & & + & + & & + & \\
\hline anguloce sp. nov. & $189-431$ & & & & & & & + & + & + & + & + & & \\
\hline colemani sp. nov. & $397-914$ & & & & & & & + & & + & + & + & + & + \\
\hline corbariae sp. nov. & $33-827$ & & & & & & & & & & & & + & \\
\hline cyrano sp. nov. & $867-955$ & & & & & & & & & + & & & & \\
\hline havermansiana sp. nov. & $189-573$ & & & & & & & & & + & + & + & + & \\
\hline leukhoplites sp. nov. & $131-298$ & & & & & & + & + & & & & & & \\
\hline loerzae sp. nov. & $102-298$ & & & & & + & + & + & & + & & & & \\
\hline macrodonta & 915 & & & & & & & & & & & & & + \\
\hline pandora sp. nov. & $90-483$ & & & & & & + & + & & & & & & \\
\hline pyrodrakon sp. nov. & $170-490$ & & & & & & & + & & + & + & & & \\
\hline reoproi & $48-307$ & & & & & & + & + & & & & & & \\
\hline robertiana sp. nov. & $1724-2190$ & & & & & & & & & + & & & & \\
\hline schiaparelli & $130-350$ & & & & & & & & & & & & & + \\
\hline similis & $90-483$ & & & & & & + & + & & & & & & \\
\hline vaderi & 332 & & & & & & + & & & & & & & \\
\hline sp. 1 & $151-300$ & & & & & & & & & & & & & + \\
\hline sp. 2 & $0-145$ & & & & & & + & & & & & & & \\
\hline \multicolumn{15}{|l|}{ EPIMERIELLA } \\
\hline atalanta sp. nov. & $189-405$ & & & & & & & & + & + & & & & \\
\hline macronyx & $0-1200$ & & & & & + & & + & & + & & + & + & + \\
\hline scabrosa & $329-366$ & & & & & & & & & & & & + & \\
\hline truncata & $100-622$ & & & & & & & + & & + & & & & \\
\hline \multicolumn{15}{|l|}{ HOPLEPIMERIA subgen. nov. } \\
\hline angelikae & $781-1194$ & & & & & & & & & + & & & + & \\
\hline cyphorachis sp. nov. & $413-990$ & & & & & & + & + & & & & & & \\
\hline gargantua sp. nov. & $404-580$ & & & & & & & + & & & & & & \\
\hline georgiana & $75-310$ & & & + & & & & & & & & & & \\
\hline heldi & $230-235$ & & & & & & + & & & & & & & \\
\hline inermis & $33-791$ & & & & & & + & + & & + & & + & + & + \\
\hline
\end{tabular}


d'UDEKEM d'ACOZ C. \& VERHEYE M.L., Epimeria of the Southern Ocean (Crustacea)

\begin{tabular}{|c|c|c|c|c|c|c|c|c|c|c|c|c|c|c|}
\hline Distribution and bathymetry & depth $(m)$ & 1 & 2 & 3 & 4 & 5 & 6 & 7 & 8 & 9 & 10 & 11 & 12 & 13 \\
\hline larsi & $1954-2154$ & & & & & & & & & & & & + & + \\
\hline linseae & $100-1014$ & & & & & + & & & & & & & & \\
\hline quasimodo sp. nov. & $131-407$ & & & & & & + & + & & & & & & \\
\hline rimicarinata & $337-540$ & & & & & & & & & & & + & & + \\
\hline robusta & $85-814$ & & & & & & & & & & & & + & + \\
\hline robustoides & $274-605$ & & & & & & & & & + & & & & \\
\hline rubrieques & $254-1030$ & & & & & & & & & + & & + & & \\
\hline xesta sp. nov. & $457-574$ & & & & & & & & & + & & & & \\
\hline sp. & $362-371$ & & & & + & & & & & & & & & \\
\hline \multicolumn{15}{|l|}{ LAEVEPIMERIA subgen. nov. } \\
\hline anodon sp. nov. & $525-791$ & & & & & & & & & & & & + & \\
\hline cinderella sp. nov. & $106-270$ & & & & & & + & + & & & & & + & \\
\hline walkeri & $170-889$ & & & & & & + & + & & + & & & + & + \\
\hline sp. & $258-273$ & & & & & & & + & & & & & & \\
\hline \multicolumn{15}{|l|}{ METEPIMERIA } \\
\hline acanthurus & $27-494$ & + & & & & & & & & & & & & \\
\hline ashleyi & $676-750$ & & + & & & & & & & & & & & \\
\hline intermedia $\mathrm{f} . \mathrm{A}$ & 75 & & & + & & & & & & & & & & \\
\hline intermedia f. B & $88-273$ & & & + & & & & & & & & & & \\
\hline \multicolumn{15}{|l|}{ PSEUDEPIMERIA } \\
\hline amoenitas sp. nov. & $461-573$ & & & & & & & & & & & & + & \\
\hline callista sp. nov. & $97-573$ & & & & & & & & & & & & + & \\
\hline debroyeri sp. nov. & $499-515$ & & & & & & & & & + & & & & \\
\hline cf. debroyeri & $248-298$ & & & & & & + & + & & & & & & \\
\hline grandirostris & $146-342$ & & & & & & + & + & & & & & & \\
\hline kharieis sp. nov. & $330-450$ & & & & & & & & & + & & & & \\
\hline oxicarinata & $127-267$ & & & & & & + & + & & & & & & \\
\hline pulchra & $50-190$ & & & & & + & & & & & & & & \\
\hline \multicolumn{15}{|l|}{ SUBEPIMERIA } \\
\hline adeliae sp. nov. & $750-788$ & & & & & & & & & & & & + & \\
\hline geodesiae & $115-135$ & & & & & & & & & & & & + & \\
\hline iota sp. nov. & $121-265$ & & & & & & + & + & & & & & & \\
\hline puncticulata & 175 & & & & & & & & & & & & & + \\
\hline teres sp. nov. & 196-202 & & & & & & & & + & & & & & \\
\hline urvillei sp. nov. & $52-54$ & & & & & & & & & & & & + & \\
\hline sp. 1 & $60-270$ & & & + & & & & & & & & & & \\
\hline sp. 2 & $765-840$ & & & & & & & & & + & & & & \\
\hline
\end{tabular}




\begin{tabular}{|c|c|c|c|c|c|c|c|c|c|c|c|c|c|c|c|}
\hline Distribution and bathymetry & depth (m) & 1 & 2 & 3 & 4 & 5 & 6 & 7 & 8 & 9 & 10 & 11 & 12 & 13 & \\
\hline \multicolumn{16}{|l|}{ UREPIMERIA subgen. nov. } \\
\hline annabellae & $159-459$ & & & & & & & & & + & & & & & \\
\hline extensa & $230-260$ & & & & & & & + & & & & & & & \\
\hline monodon & $0-15$ & & & & & + & & + & & & & & & & \\
\hline Number of taxa & & 1 & 1 & 4 & 1 & 5 & 17 & 23 & 3 & 19 & & 6 & 17 & 11 & total: 64 \\
\hline
\end{tabular}

Almost no data exist for the benthos of the Larsen $\mathrm{C}$ area, which is extremely difficult to reach and to sample due to its extreme ice coverage. Further south, no data is available for the waters situated east of Palmer Land, where the ice coverage is even more severe in summer (Post et al. 2014). In the southern Weddell Sea, off the Ronne shelf, high biomasses of epifaunal organisms such as bryozoans have been recorded and a high biomass of unidentified amphipods has been observed, although with low diversity (Voß 1988). Further east, off the deep Filchner Trough, the benthic communities appear to be even more impoverished (Voß 1988; Gerdes et al. 1992). This faunal impoverishment in the south and especially the southeast of the Weddell Sea might be a consequence of its heavy ice coverage during summer (Cavalieri \& Parkinson 2008; Post et al. 2014). This drastically reduces the primary production (Post et al. 2014), which impacts the higher trophic levels of the food web, including epifaunal organisms forming the habitat of most Epimeria species. As the vast majority of Epimeria species are strictly benthic, heavy and slow-moving organisms without larval stage (hence poorly dispersive), this wide unfavourable stretch easily acts as an efficient geographical barrier for the most stenoecious species. On the other hand, off the coastline spreading between the eastern shelf of the Weddell Sea and the distant Adélie Coast, stretches clogged with drifting ice during the Antarctic summer are much narrower (Post et al. 2014); hence obstacles to faunal exchanges are presumably less severe.

\section{Potential persistence of Antarctic Epimeria in shelf and upper slope refugia during glacial periods of the Pleistocene.}

The fauna of the Southern Ocean has been strongly influenced by the glacial cycles of the Pleistocene. The expansion of the ice sheets on the shelf during glacial periods largely eradicated the shelf fauna (Post et al. 2014). It was suggested that the eurybathic species could "escape" the inhospitable conditions by migrating onto the continental slope or into the "deep-sea" (e.g., Brandt 1991; Thatje et al. 2005), i.e., depths below $1000 \mathrm{~m}$, with the Antarctic continental shelf extending down to 400 and locally $1000 \mathrm{~m}$ (Post et al. 2014). For very eurybathic species extending their ranges well below $1000 \mathrm{~m}$, the populations occupying greater depths, devoid of grounded ice or iceshelves, could survive in situ during glacial periods and re-colonize the shelf after deglaciation. On the other hand, the moderately eurybathic and stenobathic species (restricted to the continental shelf and/or upper slope), which constitute the majority of species, would go extinct under that hypothesis. Therefore, the "deep-sea" refugia hypothesis fails to explain how the Antarctic benthic shelf and upper slope species survived the glacial periods. In a second scenario, species would have persisted in northern refugia like South Georgia, from where they could have recolonized the Antarctic shelf after the melting of the icesheet (Allcock \& Strugnel 2012; González-Wevar et al. 2013). A third scenario is the survival of some populations in ice-free continental shelf or upper slope refugia around Antarctica during glacial periods, and subsequent re-extension of their distributional range (Allcock \& Strugnell 2012). A fourth scenario would be survival under floating iceshelves (Post et al. 2014). A distinction between the third and fourth scenarios is difficult to establish, and in practice it is usually not recognized. During glaciations, ice-sheets extended diachronously, so that not all shelf areas were fully covered with grounded ice at the same time (Anderson et al. 2002). During the last glacial period, open-ocean polynyas with high primary production might also have been 
survival "hot spots" for shelf-inhabiting communities on the continental slope (Smith et al. 2010; Thatje et al.2008). Geological data suggest the possible existence of shelf refugia during the last glacial period in the Bransfield Strait, Prydz Bay, a small part of George V Land (i.e., not far away from Adélie Coast), the western Ross Sea near Cape Adare, and possibly, the Ronne and Filchner Troughs [Weddell Sea] (Thatje et al. 2005; Post et al. 2014). Recent molecular data on Antarctic isopods, cephalopods, gastropods and pycnogonids (e.g., Held \& Wägele 2005; Linse et al. 2007; Allcock \& Strugnell 2012; Strugnell et al. 2012; Dömel et al. 2015) support the idea of multiple glacial shelf refugia for these taxa on the margins of the Antarctic continental shelf (i.e., fairly deep shelf refugia). Such populations, which putatively survived in the lower part of their bathymetric range may have endured a selective pressure improving their adaptation to a deeper environment. In other words, glacial cycles would have favoured originally eurybathic lineages, and in some cases, they might even have increased their capacity to colonize greater depths. This would explain the observed higher occurrence of eurybathic species in the Southern Ocean than elsewhere (Brey et al. 1996).

In Antarctic Seas, the maximal abundance and diversity of the genus Epimeria has been observed between 100 and $700 \mathrm{~m}$, whereas one species is found intertidally and two species descend below 2000 $\mathrm{m}$. Moderate eurybathy is not uncommon in Antarctic Epimeria; e.g., E. corbariae sp. nov. was recorded between 33 and $827 \mathrm{~m}$. However, this is not an absolute rule and no extreme eurybathy was observed, as for some Lysianassoidea; e.g., Havermans et al. (2011) recorded Abyssorchomene sp. 1 between 310 and $4409 \mathrm{~m}$. During glaciation, an escape to the very deep sea would therefore not be possible for the majority of Epimeria species. Survival under floating iceshelves seems also rather unlikely. Indeed, no Epimeria species (and very few amphipod species) were found within muddy bays of the Larsen A and B, formerly covered by iceshelves, soon after their collapse (d'Udekem d'Acoz \& Robert 2008). These authors only record Epimeria species at the margins of the Larsen A and B, that were not recently glaciated. Survival during glaciations in a northern refugium, such as the Magellanic Region or South Georgia, followed by a recolonisation during a subsequent interglacial period, has been proposed for some highly dispersive organisms. The genetic signature of such survival in one northern refugium would be a genetic diversity gradually decreasing away from the refugium (González-Wevar et al. 2013). The genetic and distributional patterns observed in Epimeria species does not match with such a scenario.

Low Epimeria diversity is observed in these northern locations. Furthermore, Epimeria species found in these regions do not appear to extend their distribution onto the Antarctic shelf. The Magellanic Region (Patagonia to Falkland Islands) harbours only one Epimeria species, which is endemic. Beyond the Antarctic Polar Front, in the South Georgia / Shag Rocks area only endemic Epimeria species are observed and these are low in number (three or four species). This would suggest that many Epimeria species have a low capacity to cross deep-sea stretches and stretches with unfavourable ecological conditions (preventing a potential escape to and expansion from a northern insular refugium). More southern areas are inhabited by distinct, generally geographically-restricted, but morphologically very similar species, e.g., the georgiana, grandirostris, macrodonta and pulchra complexes. This pattern would point towards a long-term local persistence of regional endemic Epimeria species around Antarctica and their survival in multiple local refugia during glaciations.

Additional data (increased geographical and intraspecies sampling) are necessary to understand the role of the extensions and retreats of the icesheet during the Pleistocene glacial cycles in the phylogeography of Antarctic Epimeria. However, their restricted dispersal abilities would make them good models to infer the location of glacial shelf or upper slope refugia. 


\section{Vulnerability to anthropogenic changes, biogegionalisation and Marine Protected Areas}

Epimeria includes several endemic species with a narrow distributional range, especially in the Scotia Arc, where some species are even restricted to a single archipelago or ridge. Such species are considered as vulnerable. Furthermore, most Epimeria species are associated with large sessile organisms such as sponges, gorgonians and erect bryozoans (De Broyer et al. 2001). This slow growing erect epifaunal community is vulnerable to trawling by fishery vessels, currently operating in the Scotia Arc.

With a greatest diversity in Antarctic seas and a trend for local endemism, Epimeria should be considered as a key benthic taxon for refining the subdivision of the Southern Ocean into bioregions (see e.g., Douglass et al. 2014), monitoring the Antarctic environment in a context of global change (see e.g., Constable et al. 2014) and for taking relevant decisions in the delimitation of Antarctic Marine Protected Areas or MPAs (see e.g., Grant et al. 2014; Trathan et al. 2014; Hogg et al. 2016). Such policy decisions largely depend on ongoing mapping and analytic biogeographical studies on benthic Antarctic organisms (De Broyer \& Koubbi 2014). However, such studies are biased when they are based on 'composite species' consisting of several true species with different geographical and bathymetric distributions, and distinct ecological niches. In the current context of low funding for taxonomy (e.g., Coleman 2015), there are no good medium-term perspectives for a global improvement of the biodiversity knowledge of Antarctic amphipods. Therefore, in-depth integrative biodiversity studies focusing on fewer but wisely selected model taxa would improve the knowledge of the biogeography, ecology and phylogeography of the Antarctic fauna, in order to take informed policy decisions based on solid information. Among amphipods, Epimeria would be one of the best models for conducting such studies, as they have a marked trend for endemism (probably higher than in more dispersive amphipod taxa) and usually exhibit clear-cut and easily observable morphological differences between species (unlike, for example, many Lysianassoidea).

\section{Further perspectives}

The present paper is an important step towards a good understanding of Antarctic Epimeria biodiversity, but remains far from exhaustive. There are no records of Epimeria species from large undersampled stretches of the Southern Ocean, such as the Kerguelen Plateau, the Amundsen Sea, the Bellingshausen Sea and the eastern side of the Ross Sea. Sampling in these "maria incognita" might reveal additional, possibly endemic species. In more extensively sampled regions such as the Weddell Sea and the South Shetland Islands, more new species probably remain undetected, especially in deeper, less sampled areas, e.g., between 700 and $2500 \mathrm{~m}$. The understanding of Subepimeria's taxonomy, for instance, remains limited, due to scarce intraspecific sampling. Several species' delimitations remain unclear, e.g., E. inermis from the Antarctic Peninsula, the eastern Weddell Sea and the Adélie Coast. As most Epimeria species appear relatively poorly dispersive, they are prone to accumulate genetic differences among areas, therefore retaining historical patterns of genetic divergence. Such species are good model taxa to study the role of continental-shelf glacial refugia in shaping Southern Ocean's biodiversity.

\section{Acknowledgements}

The morphological part of this study was carried out by the first author and was funded by the Digit 3 program of BELSPO. The genetic study was carried out by the second author and was supported by a PhD fellowship from FRIA (FNRS, Belgium). The participation of the first author to the cruise ANT-XXIII/8 was carried out in the framework of the BIANZO II project, supported by the Scientific Research Programme on the Antarctic of the Belgian Federal Science Policy (BELSPO contract SD/ BA/02A). The travel expenses of the authors during ANT-XXIX/3 were funded by the Fonds Léopold III. The research programme led by Guillaume Lecointre REVOLTA 1124 supported by the Institut polaire français Paul Émile Victor (IPEV) and the Muséum national d'Histoire naturelle (MNHN) (via 
Laure Corbari) are acknowledged for giving us access to a biological material of invaluable interest. The CAML-CEAMARC cruise of RSV Aurora Australis (IPY project n ${ }^{\circ} 53$ ) were supported by the Australian Antarctic Division, the Japanese Science Foundation and the Institut polaire français Paul Émile Victor (IPEV) (programme ICOTA). Karin Sindemark Kronestedt (Naturhistoriska Riksmuseet, Stockholm) sent us the largest syntype (now lectotype) of Epimeria georgiana for study. Miranda Lowe (Natural History Museum, London) sent us the holotype of Epimeria inermis and the syntypes of E. macrodonta for study. We are deeply indebted to them for their support. This publication is registered as CAML (Census of Antarctic Marine Life) publication No. 165 and ANDEEP contribution No. 211. This is contribution no. 14 to the vERSO project and contribution no. 2 of the RERCTO project, funded by the Belgian Science Policy Office (BELSPO, contracts $n^{\circ} B R / 132 / A 1 / v E R S O$ and $n^{\circ} B R / 154 / A 1 /$ RECTO). We thank the Alfred-Wegener-Institut, Helmholtz-Zentrum für Polar- und Meeresforschung (AWI) and the captain, crew and chief scientists of various RV Polarstern expeditions for their efficiency, and especially those of the ANT-XXIII/8 and ANT-XXIX/3 expeditions (chief scientist in both cases: Julian Gutt), to which respectively the first and both authors took part. Present and past colleagues of the staff of the Royal Belgian Institute of Natural Sciences (especially Claude De Broyer, Gauthier Chapelle, Fabienne Nyssen, Henri Robert and Charlotte Havermans) are acknowledged for collecting specimens of invaluable importance. Stefan Hain (AWI) provided the RBINS with a small but very interesting collection of amphipods from Signy Island. Some colour photographs of Epimeria published herein were carried out by Frédéric Busson (Muséum national d'Histoire naturelle, Paris) and Cyril Gallut (Université Pierre et Marie Curie), Armin Rose (formerly AWI), Henri Robert (RBINS), Charlotte Havermans (RBINS), Gauthier Chapelle (formerly RBINS) and Martin Rauschert (AWI). The maps were generated by Anton Van de Putte (RBINS). Claude De Broyer carried out a critical reading of the manuscript and made useful remarks and suggestions. Sammy De Grave (Oxford University Museum of Natural History) improved the English and made some useful remarks. Charles Oliver Coleman (Museum für Naturkunde, Berlin) and Anne-Nina Lörz (formerly NIWA) kindly replied to various questions that we asked them on Epimeria. Michael Thurston (National Oceanography Centre, Southampton) gave us useful comments on nomenclatural issues. Finally, Wolf Arntz (AWI) provided us with printproofs of his colour guide on macrobenthic Antarctic organisms (co-authored with Martin Rauschert), before it was published.

\section{References}

Aghmich A., Taboada S., Toll L. \& Ballesteros M. 2016. First assessment of the rocky intertidal communities of Fildes Bay, King George Island (South Shetland Islands, Antarctica). Polar Biology 39: 189-198. https://doi.org/10.1007/s00300-015-1814-9

Allcock A.L., Barratt I., Eléaume M., Linse K., Norman M.D., Smith P.J., Steinke D., Stevens D.W. \& Strugnell J.M. 2011. Cryptic speciation and the circumpolarity debate: a case study on endemic Southern Ocean octopuses using the COI barcode of life. Deep Sea Research Part II: Tropical Studies in Oceanography 58: 242-249. https://doi.org/10.1016/j.dsr2.2010.05.016

Allcock A.L. \& Strugnell J.M. 2012. Southern Ocean diversity: new paradigms from molecular ecology. Trends in Ecology \& Evolution 27: 520-528. https://doi.org/10.1016/j.tree.2012.05.009

Anderson J.B., Shipp S.S., Lowe A.L., Wellner J.S. \& Mosola A.B. 2002. The Antarctic ice sheet during the Last Glacial Maximum and its subsequent retreat history : a review. Quaternary Science Reviews 21 (1-3): 49-70. https://doi.org/10.1016/S0277-3791(01)00083-X

Andres H.G. 1985. Die Gammaridea (Crustacea: Amphipoda) der Deutschen Antarktis-Expeditionen 1975/76 und 1977/78. 4. Acanthonotozomatidae, Paramphithoidae und Stegocephalidae. Mitteilungen aus den Hamburgischen Zoologischen Museum und Institut 82: 119-153. 
Andres H.G. 1997. First record of the taxon Astyra Boeck, 1871 from Antarctica(Crustacea, Gammaridea). Mitteilungen aus dem Hamburgischen Zoologischen Museum und Institut 94: 81-89.

Andres H.G. \& Lott N. 1986. Where to place Eclysis similis K.H. Barnard, 1932? Hints at its relationships and remarks on the systematic position of the Astyridae (Crustacea: Amphipoda). Mitteilungen aus den Hamburgischen Zoologischen Museum und Institut 83: 131-137.

Arntz W.E. \& Brey T. (eds) 2001. The expedition ANTARKTIS XVII/3 (EASIZ III) of RV "Polarstern" in 2000. Berichte zur Polar- und Meeresforschungen 402: 1-181. hdl:10013/epic.10407. Available from http://epic.awi.de/26581/1/BerPolarforsch2001402.pdf [accessed 11 Oct. 2016].

Arntz W.E. \& Brey T. (eds) 2003. Expedition ANTARKTIS XIX/5 (LAMPOS) of RV "Polarstern" in 2002. Berichte zur Polar- und Meeresforschungen 462: 1-120. hdl:10013/epic.10467.d001. Available from https://epic.awi.de/26641/1/BerPolarforsch2003462.pdf [accessed 27 Sep. 2016].

Arntz W.E. \& Brey T. (eds) 2005. The expedition ANTARKTIS XXI/2 (BENDEX) of RV "Polarstern" in 2003/2004. Berichte zur Polar- und Meeresforschungen 503: 1-149. hdl:10013/epic.22180.d001. Available from http://epic.awi.de/26169/1/Arn2005a.pdf [accessed 27 Sep. 2016].

Arntz W.E., Ernst W. \& Hempel I. (eds) 1990. The Expedition ANTARKTIS VII/4 (EPOS leg 3) and VII/5 of RV "Polarstern" in 1989. Berichte zur Polar- und Meeresforschungen 68: 1-214. hdl:10013/ epic.10068. Available from http://epic.awi.de/26245/1/BerPolarforsch199068.pdf [accessed 19 Oct. 2016].

Arntz W.E. \& Gutt J. (eds) 1997. The Expedition ANTARKTIS XIII/3 (EASIZ I) of "Polarstern" to the eastern Weddell Sea in 1996. Berichte zur Polarforschungen 249: 1-148. hdl:10013/epic.10252.d001. Available from http://epic.awi.de/26429/1/BerPolarforsch1997249.pdf [accessed 27 Sep. 2016].

Arntz W.E. \& Gutt J. (eds) 1999. The Expedition ANTARKTIS XV/3 (EASIZ II) of RV "Polarstern" in 1998. Berichte zur Polarforschungen 301: 1-229. hdl:10013/epic.10304.d001. Available from http:// epic.awi.de/26481/1/BerPolarforsch1999301.pdf [accessed 11 Oct. 2016].

Baird H.P., Miller K.J. \& Stark J.S. 2011. Evidence of hidden biodiversity, ongoing speciation and diverse patterns of genetic structure in giant Antarctic amphipods. Molecular Ecology 20: 3439-3454. https://doi.org/10.1111/j.1365-294X.2011.05173.x

Barnard J.L. 1958. Index to the families, genera and species of the gammaridean Amphipoda (Crustacea). Allan Hancock Foundation Publications, Occasional Paper 19: 1-145. Available from http://digitallibrary.usc.edu/cdm/ref/collection/p15799coll82/id/18014 [accessed 27 Sep. 2016].

Barnard J.L. 1961. Gammaridean Amphipoda. Galathea Report 5: 23-128. Available from http://www.zmuc.dk/inverweb/Galathea/Pdf_filer/Volume_05/galathea-vol.05-pp_023-128.pdf [accessed 27 Sep. 2016].

Barnard J.L. 1969. The families and genera of marine gammaridean Amphipoda. United States National Museum Bulletin 271: i-vi, 1-535. Available from http://biodiversitylibrary.org/page/32379802 [accessed 27 Sep. 2016].

Barnard J.L. \& Drummond M.M. 1978. Gammaridean Amphipoda of Australia, part III: the Phoxocephalidae. Smithsonian Contributions to Zoology 245: i-viii, 1-551. https://doi.org/10.5479/si.00810282.103

Barnard J.L. \& Karaman G.S. 1984. Australia as a major evolutionary centre for Amphipoda (Crustacea). Australian Museum Memoir 18: 45-61. Available from: http://australianmuseum.net.au/uploads/ journals/17624/371_complete.pdf [accessed 27 Sep. 2016].

Barnard J.L. \& Karaman G.S. 1991. The families and genera of marine gammaridean Amphipoda (except gammaroids). Records of the Australian Museum, Supplement 13, Parts 1 and 2: 1-866. Part 1: 
https://doi.org/10.3853/j.0812-7387.13.1991.91

and part 2: https://doi.org/10.3853/j.0812-7387.13.1991.367

Barnard K.H. 1930. Crustacea. Part XI. Amphipoda. British Antarctic ("Terra Nova") Expedition, 1910. Natural History Report, Zoology 8 (4): 307-454. Available from http://www.biodiversitylibrary.org/ item/195187\#page/7/mode/1up [accessed 12 Sep. 2017].

Barnard K.H. 1931. Diagnosis of new genera and species of amphipod Crustacea collected during the 'Discovery' Investigations, 1925-1927. Annals and Magazine of Natural History, Series 107 (40): 425-430. https://doi.org/10.1080/00222933108673327

Barnard K.H. 1932. Amphipoda. Discovery Report 5: 1-326, pl. 1. Available from http://biodiversitylibrary.org/page/5607801 [accessed 27 Sep. 2016].

Barnes D. 2007. A guide to Antarctic nearshore marine life. $2^{\text {nd }}$ edition: 1-20, pls 1-20. British Antarctic Survey, Cambridge.

Basher B. \& Costello M.J. 2014. Chapter 5.22. Shrimps (Crustacea: Decapoda). In: De Broyer C., Koubbi P., Griffiths H.J., Raymond B., d'Udekem d'Acoz C., et al. (eds) Biogeographic Atlas of the Southern Ocean: 190-194. Scientific Committee on Antarctic Research, Cambridge.

Bathmann U. (ed.) 2010. The Expedition of the Research Vessel "Polarstern" to the Antarctic in 2007/2008 (ANT-XXIV/2). Berichte zur Polar- und Meeresforschungen 604: 1-200. Available from http://epic.awi.de/29172/1/Bat2010a.pdf [accessed 19 Oct. 2016].

Beerman J. \& Raupach J.D. 2015. Hidden gems - an overloked Epimeria species from European waters. In: Costa F.O. \& Cunha M.R. (coord.). $16^{\text {th }}$ International Colloquium on Amphipoda: book of abstracts: 64. UA Editora, Aveiro.

Bellan-Santini D. 1972. Invertébrés marins des XII ${ }^{\text {èe }}$ et XV ${ }^{\text {ème }}$ Expéditions Antarctiques Françaises en Terre Adélie. 10. Amphipodes Gammariens. Téthys, Supplément 4: 157-238.

Bellan-Santini D. \& Ledoyer M. 1987. Gammariens (Crustacea, Amphipoda) des îles Marion et Prince Edward. Campagne MD 08 du MS «Marion Dufresne» en 1976. Bolletino del Museo Civico di Storia Naturale di Verona 13 (for 1986): 349-435.

Berge J. 2003a. The taxonomy of the amphipod genus Stilipes (Crustacea: Amphipoda: Stilipedidae), with the description of one new species. Organisms Diversity \& Evolution 3 (4): 305. https://doi.org/10.1078/1439-6092-00086

Berge J. 2003b. The taxonomy of the amphipod genus Stilipes (Crustacea: Amphipoda: Stilipedidae), with the description of one new species. Organisms Diversity \& Evolution 3, Electronic Supplement 16: 1-10. Available from http://www.senckenberg.de/odes/03-16.htm [accessed 27 Sep. 2016].

Berge J. \& Vader W. 2005a. The amphipod genus Alexandrella (Amphipoda, Stilipedidae): taxonomic status, allometric growth and description of two new species. Journal of Natural History 39 (17): 13271346. https://doi.org/10.1080/00222930400015566

Berge J. \& Vader W. 2005b. On the taxonomic status of the Antarctic amphipod crustacean genera Eclysis (Astyridae) and Bathypanoploea (Stilipedidae), with partial redescription of their type species and description of Bathypanoploea polarsterni n. sp. Organisms, Diversity \& Evolution 5: 81-83. https://doi.org/10.1016/j.ode.2004.05.002

Berge J. \& Vader W. 2005c. On the taxonomic status of the Antarctic amphipod crustacean genera Eclysis (Astyridae) and Bathypanoploea (Stilipedidae), with partial redescription of their type species and description of Bathypanoploea polarsterni n. sp. Organisms, Diversity \& Evolution 5, Electronic Supplement 3: 1-15. Available from http://www.senckenberg.de/odes/05-03.htm [accessed 27 Sep. 2016]. 
Birstein Y.A. \& Vinogradov M.E. 1955. Pelagicheskie gammaridy (Amphipoda, Gammaridea) KuriloKamchatskoi Vpadiny. [Pelagic gammaridea (Amphipoda, Gammaridea) at the Kourilo-Kamtchatka Trench]. Trudy Instituta Okeanologii Akademija Nauk SSSR 12: 210-287. [in Russian]

Birstein Y.A. \& Vinogradov M.E. 1958. Pelagicheskie gammaridy (Amphipoda, Gammaridea) severozapadnoi chasti Tikhogo Okeana. [Pelagic Gammaridea from the northwestern Pacific Ocean]. Trudy Instituta Okeanologii Akademija Nauk SSSR 27: 219-257. [in Russian]

Birstein Y.A. \& Vinogradova N.G. 1960. Pelagicheskie gammaridy tropischeskoi chasti Ticogo Okeana [Bottom ultra-abyssal Gammaridea of the north-western part of the Pacific ocean. I. Families Liljeborgiidae, Astyridae, Lepechinellidae, Gammaridae]. Trudy Instituta Okeanologii Akademija Nauk SSSR 34: 147-164. [in Russian]

Bloch D. 1788. Über zwey merkwürdigen Fischarten. Abhandlungen der Böhmischen Gesellschaft der Wissenschaften 3 (for 1787): 278-282. Available from http://reader.digitale-sammlungen.de/de/fs $1 /$ object/display/bsb10500873 00326.html [accessed 30 Sep. 2016].

Bloch M.E. 1797. Ichtyologie ou histoire naturelle, générale et particulière des poissons. Avec des figures enluminées, dessinées d'après nature. Part 12: i-ii, 1-142, 36 pls 397-432. Chez l'auteur, Berlin; dans le musée de Mr. Beygang, Leipzic. https://doi.org/10.5962/bhl.title.95488

Boeck A. 1861. Bemærkninger angaaende de ved de Norske kyster forekommende amphipoder. Forhandlinger ved de Skandinaviske Naturforskeres ottende møde [8 $8^{\text {th }}$ meeting]: 631-677.

Boeck A. 1869. Observations on the Amphipoda occuring on the Norwegian coasts. Annals and Magazine of Natural History ser. 43 (17): 325-340; 3 (18): 401-419. Available from http://biodiversitylibrary.org/ page/24740687 [accessed 13 Oct. 2016].

Boeck A. 1871. Crustacea Amphipoda borealia et arctica. Forhandlinger $i$ Videnskabs-Selskabet $i$ Christiana for 1870: 83-280. https://doi.org/10.5962/bhl.title.2056

Boeck A. 1876. De skandinaviske og arktiske amphipoder. Vol. 2: 161-712, pls 8-31. A.W. Brøgger, Christiania. https://doi.org/10.5962/bhl.title.10131

Bousfield E.L. 1979. A revised classification and phylogeny of amphipod crustaceans. Transactions of the Royal Society of Canada, Series 4 16: 343-390.

Bousfield E.L. 1982. Amphipoda. In: Parker S.P. (ed.) Synopsis and classification of living organisms. Volume 2: 254-294. McGeaw-Hill Book Company, New York.

Bousfield E.L. \& Hendrycks E.A. 1995. The amphipod superfamily Eusiroidea in the North American Pacific Region. 1. Family Eusiridae: systematics and distributional ecology. Amphipacifica 1 (4): 3-59.

Bousfield E.L. \& Shih C.-I. 1994. The phyletic classification of amphipod crustaceans: problems in resolution. Amphipacifica 1 (3): 76-134.

Brad T., Fišer C., Flot J.-F. \& Sarbu S.M. 2015. Niphargus dancaui sp. nov. (Amphipoda, Niphargidae) - a new species thriving in sulfidic groundwaters in southeastern Romania. European Journal of Taxonomy 164: 1-28. https://doi.org/10.5852/ejt.2015.164

Branch M.L., Griffths C.L., Kensley B. \& Sieg J. 1991. The benthic Crustacea of subantarctic Marion and Prince Edward Islands: Illustrated keys to the species and results of the 1982-1989 University of Cape Town surveys. South African Journal of Antarctic Research 21 (1): 3-44. Available from https:// repository.si.edu/handle/10088/10959 [accessed 27 Sep. 2016].

Brandt A. 1991. Zur Besiedlungsgeschichte des antarktischen Schelfes am Beispiel der Isopoda (Crustacea, Malacostraca). Berichte zur Polarforschung 98: 1-240. hdl:10013/epic.10098. Available from http://epic.awi.de/26275/1/BerPolarforsch199198.pdf [accessed 27 Sep. 2016]. 
Brandt A. 2000. Hypothese on Southern ocean peracarid evolution and radiation (Crustacea, Malacostraca). Antarctic Science 12 (3): 269-275. https://doi.org/10.1017/S095410200000033X

Brecko J., Mathys A., Dekoninck W., De Ceukelaire M., VandenSpiegel D. \& Semal P. 2016. Revealing invisible beauty, ultra detailed: the influence of low cost UV exposure on natural history specimens in 2D+ digitization. PLoS ONE 11 (8): e0161572. https://doi.org/10.1371/journal.pone.0161572

Brecko J., Mathys A., Dekoninck W., Leponce M., VandenSpiegel D. \& Semal P. 2014. Focus stacking: Comparing commercial top-end set-ups with semi-automatic low budget approach. A possible solution for mass digitization of type specimens. Zookeys 464: 1-23. https://doi.org:10.3897/zookeys.464.8615

Brey T., Dahm C., Gorny M., Klages M., Stiller M. \& Arntz W.E. 1996. Do Antarctic benthic invertebrates show an extended level of eurybathy? Antarctic Science 8 (1): 3-6. https://doi.org/10.1017/S0954102096000028

Bruzelius R.M. 1859. Bidrag till kännedomen om Skandinaviens Amphipoda Gammaridea. Konglinga Svenska Vetenskaps-Academiens Handlingar, Ny Fjold [new series] 3 (1): 1-104, pls 1-4. https://doi.org/10.5962/bhl.title.6480

Buchholz R. 1874. Crustaceen. Die zweite Deutsche Nordpolarfahrt in den Jahren 1869 und 1870 unter Führung des Kapitän Karl Koldewey. Zweiter Band. Wissenschaftliche Ergebnisse: 262-399, pls 1-15. F.A. Brockhaus, Leipzig. https://doi.org/10.5962/bhl.title.13241

Bushueva I.V. 1978. New species of Acanthonotozomella from the Davis Sea (East Antarctica). Zoologicheskij Zhurnal 57 (3): 450-453. [in Russian]

Butcher B.A., Smith M.A., Sharkey M.J. \& Quicke D.L.J. 2012. A turbo-taxonomic study of Thai Aleiodes (Aleiodes) and Aleiodes (Arcaleiodes) (Hymenoptera: Braconidae: Rogadinae) based largely on COI barcoded specimens, with rapid descriptions of 179 new species. Zootaxa 3457: 1-232.

Carus J.V. 1885. Prodromus faunae Mediterraneae sive descriptio animalium maris Mediterranei incolarum quam comparata silva rerum quatenus innotuit adiectis locis et nominibus vulgaribus eorumque autoribus in commodum zoologorum. Vol. I. Coelenterata, Echinodermata, Vermes, Arthropoda. E. Schweizerbart'sche Verlagshandlung (E. Koch), Stuttgart. https://doi.org/10.5962/bhl.title.11523

Cavalieri D.J. \& Parkinson C.L. 2008. Antarctic sea ice variability and trends, 1979-2006. Journal of Geophysical Research 113: C07004. https://doi.org/doi:10.1029/2007JC004564

Chapelle G. 2002. Antarctic and Baikal Amphipods: a key for understanding polar gigantism. Dissertation présentée pour l'obtention du grade de docteur en Sciences: 1-162. Institut royal des Sciences naturelles de Belgique. Université Catholique de Louvain - Faculté des Sciences, Louvain-laNeuve. Available from http://www.vliz.be/en/imis?module=ref\&refid=229442 [accessed 27 Sep. 2016].

Chapelle G. \& Peck L.S. 1999. Polar gigantism dictated by oxygen availability. Nature 399: 114-115. https://doi.org/10.1038/20099

Chevreux E. 1900. Amphipodes provenant des campagnes de l'Hirondelle. Résultats des Campagnes Scientifiques du Prince de Monaco 16. Imprimerie de Monaco, Monaco. https://doi.org/10.5962/bhl.title.2169

Chevreux E. 1911. Sur les amphipodes des Expéditions Antarctiques Françaises. Comptes Rendus Hebdomadaires des Séances de l'Académie des Sciences, Paris 153:1166-1168. http://biodiversitylibrary. org/page/7184704 [accessed 27 Sep. 2016].

Chevreux E. 1912. Deuxième expédition dans l'Antarctique, dirigée par le Dr. Charcot. 1908-1910. Diagnoses d'amphipodes nouveaux. Bulletin du Muséum national d'Histoire naturelle, Paris 18 (4): 208-218 (1-12 on reprints). http://biodiversitylibrary.org/page/34142291 [accessed 27 Sep. 2016]. 
Chevreux E. 1913. Amphipodes. In: Deuxième Expédition Antarctique Française (1908-1910) commandée par le Dr. Jean Charcot, Sciences Naturelles: Documents Scientifiques: 79-186. Masson et Cie Editeurs, Paris. https://doi.org/10.5962/bhl.title.6956

Chevreux E. \& Fage L. 1925. Amphipodes. Faune de France 9: 1-488. Paul Lechevalier, Paris. Available from http://faunedefrance.org/bibliotheque/docs/CHEVREUX\&FAGE(FdeFr09)Amphipodes.pdf [accessed 27 Sep. 2016].

Chilton C. 1912. The Amphipoda of the Scottish National Antarctic Expedition. Transactions of the Royal Society of Edinburgh 48 (3): 455-520, pls 1-2. http://biodiversitylibrary.org/page/41769498 [accessed 27 Sep. 2016].

Coleman C.O. 1988. Verbreitung und Biologie bentischer Amphipoden. In: Fütterer D.K. (ed.). Die Expedition ANTARKTIS-VI mit FS "Polarstern" 1987/1988. Berichte zur Polar- und Meeresforschungen 58: 51-52. hdl:10013/epic.10058.d001 Available from http://epic.awi.de/26235/1/ BerPolarforsch198858.pdf [accessed 21 Oct. 2016].

Coleman C.O. 1989a. On the nutrition of two Antarctic Acanthonotozomatidae (Crustacea: Amphipoda). Polar Biology 9 (5): 287-294. https://doi.org/doi:10.1007/BF00287425

Coleman C.O. 1989b. Gnathiphimedia mandibularis K.H. Barnard, 1930, an Antarctic amphipod (Acanthonotozomatidae, Crustacea) feeding on Bryozoa. Antarctic Science 1 (4): 343-344. https://doi.org/10.1017/S0954102089000519

Coleman C.O. 1990a. Two new Antarctic species of the genus Epimeria (Crustacea: Amphipoda: Paramphithoidae), with description of juveniles. Journal of the Royal Society of New Zealand 20 (2): 151-178. https://doi.org/10.1080/03036758.1990.10426723

Coleman C.O. 1990b. Bathypanoploea schellenbergi Holman \& Watling, 1983, an Antarctic amphipod (Crustacea) feeding on Holothuroidea. Ophelia 31 (3): 197-205. https://doi.org/10.1080/00785326.1990.10430862

Coleman C.O. 1991. Comparative fore-gut morphology of Antarctic Amphipoda (Crustacea) adapted to different food sources. Hydrobiologia 223: 1-9. https://doi.org/10.1007/BF00047623

Coleman C.O. 1992. Foregut morphology of Amphipoda (Crustacea). An example of its relevance for systematics. Ophelia 36 (2): 135-150. https://doi.org/10.1080/00785326.1992.10430364

Coleman C.O. 1994. A new Epimeria species (Crustacea: Amphipoda: Epimeriidae) and redescriptions of three other species in the genus from the Antarctic Ocean. Journal of Natural History 28 (3): 555576. https://doi.org/10.1080/00222939400770251

Coleman C.O. 1998a. Epimeria heldi, a new species of Amphipoda (Crustacea, Epimeriidae) from the Antarctic Ocean. Beaufortia 48(2): 17-25. Available from http://repository.naturalis.nl/document/548344 [accessed 27 Sep. 2016].

Coleman C.O. 1998b. Epimeria vaderi, a new species (Crustacea, Amphipoda, Epimeriidae) from the Antarctic Ocean. Mitteilungen aus dem Zoologischen Museum in Berlin 74 (2): 215-224. https://doi.org/10.1002/mmnz.19980740205

Coleman C.O. 2007. Synopsis of the Amphipoda of the Southern Ocean. Volume 2: Acanthonotozomellidae, Amathillopsidae, Dikwidae, Epimeriidae, Iphimediidae, Ochlesidae and Vicmusiidae. Bullelin de l'Institut Royal des Sciences Naturelles de Belgique, Biologie / Bulletin van het Koninklijk Belgisch Instituut voor Natuurwetenschappen, Biologie 77, supplement 2: 1-134.

Coleman C.O. 2015. Taxonomy in times of the taxonomic impediment - Examples from the community of expert on amphipod crustaceans. Journal of Crustacean Biology 35 (6): 729-740. https://doi.org/10.1163/1937240X-00002381 
Coleman C.O. \& Barnard J.L. 1991a. Revision of Iphimediidae and similar families (Amphipoda: Gammaridea). Proceedings of the Biological Society of Washington 104 (2): 253-268. Available from http://biodiversitylibrary.org/page/34808945 [accessed 21 Sep. 2016].

Coleman C.O. \& Barnard J.L. 1991b. Amatiguakius forsbergi, a new genus and species from Alaska (marine Amphipoda: Epimeriidae). Proceedings of the Biological Society of Washington 104 (2): 279287. Available from http://biodiversitylibrary.org/page/34808971 [accessed 21 Sep. 2016].

Coleman C.O. \& Jäger I. 2001. Acanthonotozomella rauscherti (Amphipoda, Acanthonotozomellidae), a new species from the Antarctic Ocean. Journal of Crustacean Biology 21 (2): 475-483. https://doi.org/10.1163/20021975-99990149

Constable A., Costa D., Murphy E., Hofmann E., Schofield O., Press A., Johnston N.M. \& Newman L. 2014. Chapter 9.3. Assessing status and change in Southern ocean ecosystems. In: De Broyer C., Koubbi P., Griffiths H.J., Raymond B., d'Udekem d'Acoz C. et al. (eds) Biogeographic Atlas of the Southern Ocean: 404-407. Scientific Committee on Antarctic Research, Cambridge.

Costa A. 1857. Ricerche sui crostacei amfipodi del regno di Napoli. Memorie della Reale Accademia delle Scienze, Napoli 1: 165-235, pls 1-4. https://doi.org/10.5962/bhl.title.2070

Costa A. 1867. Saggio della collezione de Crostacei del Mediterraneo. Annuario del Museo Zoologico della Università di Napoli Anno IV (1864): 38-46. Available from http://biodiversitylibrary.org/ page/11823452 [accessed 13 Oct. 2016].

Curtis J. 1824. British entomology, being illustrations and descriptions of the genera of insects found in Great Britain and Ireland; containing coloured figures from nature of the most rare and beautiful species, and in many instances of the plants upon which they are found. Vol. 1: plates 19-22. London. https://doi.org/10.5962/bhl.title.8148

Cuvier G. 1797 [An VI]. Tableau élémentaire de l'histoire naturelle des animaux. Imprimeur du corps législatif et de l'Institut national, Paris. https://doi.org/10.5962/bhl.title.11203

Cuvier G. 1800 [An VIII]. Leçons d'anatomie comparée. Tome 1. Contenant les organes $d u$ mouvement. Baudouin, imprimeur de l'Institut national des Sciences et des arts, Paris. https://doi.org/10.5962/bhl.title.49450

Dana J.D. 1852. On the classification of the Crustacea Choristopoda or Tetradecapoda. The American Journal of Science and Arts ser. 214 (41): 297-316. Available from http://biodiversitylibrary.org/ page/28136775 [accessed 11 Oct. 2016].

Dauby P., Nyssen F., De Broyer C. 2003. Amphipods as food sources for higher trophic levels in the Southern Ocean: a synthesis. In: Huiskes A.H.L., Gieskes W.W.C., Rozema J., Schorno R.M.L., van der Vies S.M. \& Wolff W.J. (eds) Antarctic biology in a global context: 129-134. Backhuys Publishers, Leiden.

Dauby P., Scailteur Y. \& De Broyer C. 2001 a. Trophic diversity within the eastern Weddell Sea amphipod community. Hydrobiologia 443: 69-86. https://doi.org/10.1023/A:1017596120422

Dauby P., Scailteur Y., Chapelle G. \& De Broyer C. 2001b. Potential impact of the main benthic amphipods on the eastern Weddell Sea shelf ecosystem (Antarctica). Polar Biology 24 (9): 657-662. https://doi.org/10.1007/s003000100265

De Broyer C. 1983. Recherches sur la systématique et l'évolution des crustacés amphipodes gammarides antarctiques et subantarctiques. Phd thesis: 1-468, pls 1-123. Université Catholique de Louvain, Louvain-la-Neuve, Belgium.

De Broyer C. \& Jażdżewska A. 2014. Chapter 5.17. Biogeographic patterns of Southern Ocean benthic amphipods. In: De Broyer C., Koubbi P., Griffiths H.J., Raymond B., d'Udekem d'Acoz C. et al. (eds) 
Biogeographic Atlas of the Southern Ocean: 155-165. Scientific Committee on Antarctic Research, Cambridge. Available from http://share.biodiversity.aq/Atlas/PDFS/Atlas_Chap.5.17-De-Broyer_\& Jazdzewska_2014.pdf [accessed 27 Sep. 2016].

De Broyer C., Jażdżewski K. \& Dauby P. 2003. Chapter 32. Biodiversity patterns in the Southern Ocean: lessons from Crustacea. In: Huiskes A.H.L., Gieskes W.W.C., Rozema J., Schorno R.M.L., van der Vies S.M. \& Wolff W.J. (eds) Antarctic biology in a global context: 201-214. Backhuys Publishers, Leiden.

De Broyer C. \& Klages M. 1991. A new Epimeria (Crustacea, Amphipoda, Paramphithoidae) from the Weddell Sea. Antarctic Science 3 (2): 159-166. https://doi.org/10.1017/S0954102091000196

De Broyer C. \& Koubbi P. 2014. Chapter 1.1. The biogeography of the Southern Ocean. In: De Broyer C., Koubbi P., Griffiths H.J., Raymond B., d'Udekem d'Acoz C. et al. (eds) Biogeographic Atlas of the Southern Ocean. Scientific Committee on Antarctic Research, Cambridge, pp. 2-9. Available from http://share.biodiversity.aq/Atlas/example_BASO_web.pdf [accessed 27 Sep. 2016].

De Broyer C., Koubbi P., Griffiths H., Raymond B., d'Udekem d'Acoz C., Van De Putte A., Danis B., David B., Grant S., Gutt J., Held C., Hosie G., Huettmann F., Post A., Ropert-Coudert Y. (ed.) 2014. Biogeographic atlas of the Southern Ocean. Scientific Committee on Antarctic Research, Cambridge, xii pp., 498 pp.

De Broyer C., Lowry J.K., Jażdżewski K. \& Robert H. 2007. Catalogue of the Gammaridean and Corophiidean Amphipoda (Crustacea) of the Southern Ocean with distribution and ecological data. Synopses of the Amphipoda of the Southern Ocean 1: 1-325. Institut Royal des Sciences Naturelles de Belgique, Brussels. Available from www.marinespecies.org/aphia.php? $\mathrm{p}=$ sourceget\&id=10098 [accessed 27 Sep. 2016].

De Broyer C., Scailteur Y., Chapelle G. \& Rauschert M. 2001. Diversity of epibenthic habitats of gammaridean amphipods in the eastern Weddell Sea. Polar Biology 24: 744-753. https://doi.org/10.1007/978-3-642-59419-9 8

Dell R.K. 1972. Antarctic benthos. Advances in Marine Biology 10: 1-216. https://doi.org/10.1016/S0065-2881(08)60416-2

Della Valle A. 1893. Gammarini del Golfo di Napoli. Fauna und Flora des Golfes von Neapel und der angrenzenden Meeres-Abschnitte 20: 1-948, pls 1-61. https://doi.org/10.5962/bhl.title.3710

Dömel J.S., Convey P. \& Leese F. 2015. Genetic data support independent glacial refugia and open ocean barriers to dispersal for the Southern Ocean sea spider Austropallene cornigera (Möbius, 1902). Journal of Crustacean Biology 35 (4): 480-490. https://doi.org/10.1163/1937240X-00002351

Douglass L., Beaver D., Raymond B., Constable A.J., Brandt A., Post A.L., Kaiser S., Grantham H.S. \& Nicoll R.A. 2014. Chapter 10.1. Benthic regional classification. In: De Broyer C., Koubbi P., Griffiths H.J., Raymond B., d'Udekem d'Acoz C. et al. (eds) Biogeographic Atlas of the Southern Ocean: 414-417. Scientific Committee on Antarctic Research, Cambridge.

d'Udekem d'Acoz C. 2008. Shelf and abyssal Liljeborgia Bate, 1861 of the Southern Ocean (Crustacea, Amphipoda, Liljeborgiidae). Bulletin de l'Institut Royal des Sciences Naturelles de Belgique, Biologie / Bulletin van het Koninklijk Belgisch Instituut voor Natuurwetenschappen, Biologie 78: 45-286.

d'Udekem d'Acoz C. 2009. New records of Liljeborgia from Antarctic and sub-antarctic seas, with the description of two new species (Crustacea: Amphipoda: Liljeborgiidae). Bulletin de l'Institut Royal des Sciences Naturelles de Belgique, Biologie / Bulletin van het Koninklijk Belgisch Instituut voor Natuurwetenschappen, Biologie 79: 243-304.

d'Udekem d'Acoz C. 2010. Contribution to the knowledge of European Liljeborgiidae (Crustacea, Amphipoda), with considerations on the family and its affinities. Bulletin de l'Institut Royal des 
Sciences Naturelles de Belgique, Biologie / Bulletin van het Koninklijk Belgisch Instituut voor Natuurwetenschappen, Biologie 80: 127-259.

d'Udekem d'Acoz C. 2012. On the genus Halirages (Crustacea, Amphipoda), with the description of two new species from Scandinavia and Arctic Europe. European Journal of Taxonomy 7: 1-32. https://doi.org/10.5852/ejt.2012.7

d'Udekem d'Acoz C. \& Robert H. 2008. Systematic and ecological diversity of amphipods. In: Gutt J. (ed.) The Expedition ANTARKTIS-XXIII/8 of the Research Vessel "Polarstern" in 2006/2007. Berichte zur Polar- und Meeresforschung 569: 48-56. hdl:10013/epic.28679. Available from https://epic.awi. de/27492/1/Gut2008b.pdf [accessed 27 Sep. 2016].

d'Udekem d'Acoz C. \& Verheye M. 2013. Taxocoenoses of amphipod crustaceans. In: Gutt J. (ed.) The Expedition of the Research Vessel "Polarstern" to the Antarctic in 2013 (ANT-XXIX/3). Berichte zur Polar- und Meeresforschung 665: 57-67. hdl:10013/epic.41835. Available from https://epic.awi. de/33372/8/BzPM_0665_2013_ANT_XXIX_3.pdf [accessed 27 Sep. 2016].

Duncan P.M. \& Sladen W.P. 1882. A description of the fossil Echinoidea of western Sind. The fossil Echinoidea from the Ranikot series of nummulitic strata in western Sind. Memoirs of the Geological Survey of India, Palaeontologica Indica, Series 14 Vol. 13 (2): 21-100, pls 5-20.

Fabricius J.C. 1775. Systema entomologiae, sistens insectorum, classes, ordines, genera, species, adiectis synonymis, locis, descripionibus, observationibus. In officina libraria Kortii, Flensbvrgi et Lipsiae. https://doi.org/10.5962/bhl.title.36510

Fabricius J.C. 1779. Reise nach Norwegen mit Bemerkungen aus der Naturhistorie und Oekonomie. Carl Ernst Bohn, Hamburg. Available from: https://play.google.com/store/books/details?id=QY8BAA AAYAAJ\&rdid=book-QY8BAAAAYAAJ\&rdot=1 [accessed $27 \mathrm{Sep} .2016$ ].

Faulskanger H.K. 2008. English - Quenya: 1-93. Available from http://folk.uib.no/hnohf/wordlists.htm [accessed 27 Sep. 2016].

Fütterer D.K. (ed.) 1988. Die Expedition ANTARKTIS-VI mit FS “Polarstern" 1987/1988. Berichte zur Polar- und Meeresforschungen 58: 1-267. hdl:10013/epic.10058.d001. Available from http://epic.awi. de/26235/1/BerPolarforsch198858.pdf [accessed 21 Oct. 2016].

Gerdes D., Klages M., Arntz W.E., Herman R.L., Galéron J. \& Hain S. 1992. Quantitative investigations on macrobenthos communities of the southeastern Weddell Sea shelf based on multibox corer samples. Polar Biology 12: 291-301. https://doi.org/10.1007/978-3-642-77595-6 34

Gerstaecker A. \& Ortmann A.E. 1901. Die Klassen und Ordnungen der Arthropoden wissenschaftlich dargestellt in Wort und Bild. Fünfter Band. II Abtheilung. Crustacea. (Zweite Hälfte: Malacostraca). C.F. Winter'sche Verlagshandlung, Leipzig. https://doi.org/10.5962/bhl.title.9999

Goës A. 1866. Crustacea Amphipoda maris Spetsbergiam alluentis, cum speciebus aliis arcticis enumerat. Öfversigt af Kongelige Vetenskaps-Akademiens Förhandlingar 8 (for 1865): 517-536, pls 36-41. Available from http://www.vliz.be/imisdocs/publications/277925.pdf [accessed 27 Sep. 2016].

Goldfuss G.A. 1809. Vergleichende Naturbeschreibung der Säugethiere. Im Verlage der Waltherschen Kunst- und Buchhandlung, Erlangen. https://doi.org/10.5962/bhl.title.102742

González-Wevar C.A., Saucède T., Morley S.A., Chown S.L. \& Poulin E. 2013. Extinction and recolonization of maritime Antarctica in the limpet Nacella concinna (Strebel, 1908) during the last glacial cycle: toward a model of Quaternary biogeography in shallow Antarctic invertebrates. Molecular Ecology 22: 5221-5236. https://doi.org/10.1111/mec.12465

Gosse P.H. 1855. A manual of marine zoology for the British Isles. Part I. John Van Voorst, Paternoster Row, London. https://doi.org/10.5962/bhl.title.3987 
Grant S.M., Koubbi P. \& Penhale P.A. 2014. Chapter 9.4. Conservation and management. In: De Broyer C., Koubbi P., Griffiths H.J., Raymond B., d'Udekem d'Acoz C. et al. (eds) Biogeographic Atlas of the Southern Ocean: 408-411. Scientific Committee on Antarctic Research, Cambridge.

Gray J.E. 1830-1835. Illustrations of Indian Zoology; chiefly selected from the collection of Major-general Hardwicke, F.R.S. Volume 1: 100 pls. Treutel, Wurtz, Jun. \& Richter, London. https://doi.org/10.5962/bhl.title.95127

Griffiths C.L. 1974. The Amphipoda of Southern Africa. Part 4. The Gammaridea and Caprellidea of the Cape Province east of Cape Agulhas. Annals of the South African Museum / Annale van die SuidAfrikaanse Museum 65 (9): 251-336. Available from http://biodiversitylibrary.org/page/40928457 [accessed 27 Sep. 2016].

Griffiths C. 1977. The South African Museum's Meiring Naude cruises. part 6. Amphipoda. Annals of the South African Museum Museum / Annale van die Suid-Afrikaanse Museum 74 (4): 105-123. Available from http://biodiversitylibrary.org/page/41212899 [accessed 13 Oct. 2016].

Griffiths H.J., Barnes D.K.A. \& Linse K. 2009. Towards a generalized biogeography of the Southern Ocean benthos. Journal of Biogeography36: 162-177. https://doi.org/10.1111/j.1365-2699.2008.01979.x

Griffiths H.J., Whittle R.J., Roberts S.J., Belcjhier S.J., Linse K. \& Thatje S. 2014. Chapter 5.21. Decapoda: crabs \& lobsters. In: De Broyer C., Koubbi P., Griffiths H.J., Raymond B., d'Udekem d'Acoz C. et al. (eds) Biogeographic Atlas of the Southern Ocean: 185-189. Scientific Committee on Antarctic Research, Cambridge.

Gurjanova E.F. 1951. Amphipods of the seas of the U.S.S.R. and adjacent waters (Amphipoda Gammaridea). Fauna of USSR 41. Publications of the Zoological Institute of the Academy of Sciences of USSR, Moscow [in Russian].

Gurjanova E.F. 1955. New species of gammarideans (Amphipoda, Gammaridea) from the northern part of the Pacific Ocean. Trudy Zoologicheskogo Instituta Leningrad 18: 166-218 [in Russian].

Gurjanova E.F. 1972. Some new species of amphipods (Amphipoda, Gammaridea) from the NorthWestern part of Pacific and High Arctic. Trudy Zoologicheskogo Instituta Leningrad 52: 129-200 [in Russian].

Gutt J. (ed.) 2008. The Expedition ANTARKTIS-XXIII/8 of the Research Vessel "Polarstern" in 2006/2007. Berichte zur Polar- und Meeresforschungen 569: 1-152. hdl:10013/epic.28679.d001. Available from http://epic.awi.de/27492/1/Gut2008b.pdf [accessed 19 Oct. 2016].

Gutt J. (ed.) 2013. The Expedition of the Research Vessel "Polarstern" to the Antarctic in 2013 (ANTXXIX/3). Berichte zur Polar- und Meeresforschungen 665: 1-154. https://epic.awi.de/33372/8/ BzPM_0665_2013_ANT_XXIX_3.pdf [accessed 20 Oct. 2016].

Gutt J., Alvaro M.C., Barco A., Böhmer A., Bracker A., David B., De Ridder C., Dorschel B., Eléaume M., Janussen D., Kersken D., López-González P.J., Martínez-Baraldés I., Schröder M., Segelken A. \& Teixidó N. 2016. Macroepibenthic communities at the tip of the Antarctic Peninsula, an ecological survey at different spatial scales. Polar Biology 39: 829-849. https://doi.org/10.1007/s00300-015-1797-6

Gutt J., Bohlmann H., Dimmler W., Kohlberg G., Langner S. \& Seiler J. 2008. Megabenthic community ecology — Life under ice-shelves. In: Gutt J. (ed.), The Expedition ANTARKTIS-XXIII/8 of the Research Vessel "Polarstern" in 2006/2007. Berichte zur Polar- und Meeresforschung 569: 27-30. hdl:10013/epic.28679. Available from https://epic.awi.de/27492/1/Gut2008b.pdf [accessed 27 Sep. 2016]. 
Gutt J., Barratt I., Domack E., d'Udekem d'Acoz C., Dimmler W., Grémare A., Heilmayer O., Isla E., Janussen D., Jorgensen E., Kock K.-H., Lehnert L.S., López-González P., Langner S., Linse K., Manjón-Cabeza M.E., Meißner M., Montiel A., Raes M., Robert H., Rose A., Sañé Schepisi E., Saucède T., Scheidat M., Schenke H.-W., Seiler J. \& Smith C. 2011. Biodiversity change after climate-induced ice-shelf collapse in the Antarctic. Deep-Sea Research II 58: 74-83. https://doi.org/10.1016/j.dsr2.2010.05.024

Gutt J., Piepenburg D. \& Segelken-Voigt A. 2013. Megabenthic distribution patterns. In: Gutt J. (ed.) The Expedition of the Research Vessel "Polarstern" to the Antarctic in 2013 (ANT-XXIX/3). Berichte zur Polar- und Meeresforschung 665: 25-29. hdl:10013/epic.41835. Available from https://epic.awi.de/33372/8/BzPM_0665_2013_ANT_XXIX_3.pdf[accessed 27 Sep. 2016].

Havermans H., Nagy Z.T., Sonet G., De Broyer C. \& Martin P. 2011. DNA barcoding reveals new insights into the diversity of Antarctics pecies of Orchomene s. lat. (Crustacea: Amphipoda: Lysianassoidea). Deep-Sea Research II 58: 230-241. https://doi.org/10.1016/j.dsr2.2010.09.028

Havermans H. 2014. Chapter 10.6. Phylogeographic patterns of the Lysianassoidea (Crustacea: Peracarida: Amphipoda). In: De Broyer C., Koubbi P., Griffiths H.J., Raymond B., d'Udekem d'Acoz C. et al. (eds) Biogeographic Atlas of the Southern Ocean: 441-447. Scientific Committee on Antarctic Research, Cambridge.

Hedgpeth J.W. 1969. Introduction to Antarctic zoogeography. Distribution of selected groups of marine invertebrates in waters south of $35^{\circ}$ S. In: Bushnell V.C. \& Hedgpeth J.W. (eds) Antarctic Map Folio Series, Folio 11: 1-29. American Association for the Advancement of Science, Washington, DC.

Held C. \& Wägele J.-W. 2005. Cryptic speciation in the giant Antarctic isopod Glyptonotus antarcticus (Isopoda: Valvifera: Chaetiliidae). Scientia Marina 69 (Supplement 1): 175-181. Available from http://www.icm.csic.es/scimar/index.php/secId/6/IdArt/117/ [accessed 27 Sep. 2016].

Hempel G. (ed.) 1985. Die Expedition ANTARKTIS III mit FS “Polarstern" 1984/85. Berichte zur Polarund Meeresforschungen 25: 1-222. Available from http://epic.awi.de/26202/1/BerPolarforsch198525. pdf [accessed 19 Oct. 2016].

Herbst J.F.W. 1791-1796. Versuch einer Naturgeschichte der Krabben und Krebse nebst einer systematischen Beschreibung ihrer verschiedenen Arten. Volume 2. Gottlieb August Langs, Berlin und Stralsund. https://doi.org/10.5962/bhl.title.64679

Hibbert T. \& Moore K. 2009. Field Identification Guide to Heard Island and McDonald Islands benthic invertebrates. A guide for scientific observers aboard fishing vessels. Australian Government, Australian Antarctic Division, Fisheries research and development Corporation, Kingston: 1-153. Available from https://www.ccamlr.org/en/system/files/HIMI\%20benthic\%20invertebrate $\% 20$ field $\% 20$ guide.pdf [accessed 27 Sep. 2016].

Hodgson T.V. 1907. On collecting in Antarctic seas. National Antarctic Expedition 1901-1904. Natural History 3: 1-10. https://doi.org/10.5962/bhl.title.18281

Hogg O.T., Huvenne V.A.I., Griffiths H.J., Dorschel B. \& Linse K. 2016. Landscape mapping at subAntarctic South Georgia provides a protocol for underpinning large-scale marine protected areas. Scientific Reports 6: 33163. https://doi.org/10.1038/srep33163

Holman H. \& Watling L. 1983. A revision of the Stilipedidae (Amphipoda). Crustaceana 44 (1): 29-53. https://doi.org/10.1163/156854083x00037

Holmes S.J. 1904. The Amphipoda of Southern New England. Bulletin of the Bureau of Fisheries 24: 459-529. https://doi.org/10.5962/bhl.title.33358 
Holmes S.J. 1908. The Amphipoda collected by the U.S. Bureau of Fisheries Steamer "Albatross" off the west coast of North America, in 1903 and 1904, with the descriptions of a new family and several new genera and species. Proceedings of The United States National Museum 35: 489-543. https://doi.org/10.5479/si.00963801.35-1654.489

Hope G. 1851. Catalogo dei crostacei italiani e di molti altri del Mediterraneo. Stabilimento Tipografico di Fr. Azzolino, Napoli. https://doi.org/10.5962/bhl.title.3924

Hurley D.E. 1954. Studies on the New Zealand amphipodan fauna. No. 10. A new species of Cacao. Transactions of the Royal Society of New Zealand 82 (3): 803-811. Available from http://rsnz.natlib. govt.nz/volume/rsnz_82/rsnz_82_03_009160.pdf [accessed 11 Oct. 2016].

Hurley D.E. 1957. Some Amphipoda, Isopoda and Tanaidacea from Cook Strait. Zoology Publications from Victoria University College 21: 1-20. Available from nzetc.victoria.ac.nz/downloads/Vic21Zool. pdf [accessed 27 Sep. 2016].

ICZN [International Commission on Zoological Nomenclature] 1999. International Code of Zoological Nomenclature. Fourth Edition adopted by the International Union of Biological Sciences. The International Trust for Zoological Nomenclature, the Natural History Museum, London. Available from http://www.iczn.org/iczn/index.jsp [accessed 27 Sep. 2016].

Isla E., Teixidó Ullod N., López P., Martinez-Baraldés I. \& Carrera L.H. 2013. Biodiversity and pelagic coupling. In: Gutt J. (ed.) The Expedition of the Research Vessel "Polarstern" to the Antarctic in 2013 (ANT-XXIX/3). Berichte zur Polar- und Meeresforschung 665: 29-40. hdl:10013/epic.41835. Available from https://epic.awi.de/33372/8/BzPM_0665_2013_ANT_XXIX_3.pdf [accessed 27 Sep. 2016].

Janussen D. 2012. Diversity of Weddell Sea Porifera and their role in the benthic communities. In: Knust R., Gerdes D. \& Mintenbeck K. (eds) The expedition of the Research vessel "Polarstern" to the Antarctic in 2011 (Ant-XXVII/3) (CAMBIO). Berichte zur Polar- und Meeresforschung 644: 25-29. hdl:10013/epic.39114. Available at http://epic.awi.de/30175/1/644-2012\%20ANT27-3\%20RKnust.pdf [accessed 27 Sep. 2016].

Janussen D. \& Kersken D. 2013. Prosperity and limitation of sponge shelf fauna. In: Gutt J. (ed.) The Expedition of the Research Vessel "Polarstern" to the Antarctic in 2013 (ANT-XXIX/3). Berichte zur Polar- und Meeresforschung 665: 41-45. hdl:10013/epic.41835. Available from https://epic.awi.de/33372/8/BzPM_0665_2013_ANT_XXIX_3.pdf[accessed 27 Sep. 2016].

Jones E.G., Tselepides A., Bagley P.M., Collins M.A. \& Priede I.G. 2003. Bathymetric distribution of some benthic and benthopelagic species attracted to baited cameras and traps in the deep eastern Mediterranean. Marine Ecology Progress Series 251: 75-86. https://doi.org/10.3354/meps251075

Just J. 1990. Vicmusia duplocoxa, gen. et sp. nov., (Crustacea: Amphipoda: Gammaridea) of the new family Vicmusiidae from Australian upper bathyal waters. Invertebrate Taxonomy 3 (7): 925-940. https://doi.org/10.1071/IT9890925

Just J. 1995. Acanthonotozomopsis Watling \& Holman, 1980, senior synonym of Vicmusia Just, 1990 (Crustacea : Amphipoda : Vicmusiidae). Invertebrate Taxonomy 9 (5): 1005-1008. https://doi.org/10.1071/IT9951005

Karaman G.S. \& Barnard J.L. 1979. Classificatory revisions in gammaridean Amphipoda (Crustacea), part I. Proceedings of the Biological Society of Washington 92 (1): 106-165. Available from http://biodiversitylibrary.org/page/35513813 [accessed 27 Sep. 2016].

Kattner G. (ed.) 1998. The expedition ANTARKTIS XIV/2 of RV "Polarstern" in 1996/97. Berichte zur Polarforschung 274: 1-87. hdl:10013/epic.10277 Available from http://epic.awi.de/26454/1/ BerPolarforsch1998274.pdf [accessed 27 Sep. 2016]. 
Kersken D., Feldmeyer B. \& Janussen D. 2016. Sponge communities of the Antarctic Peninsula: influence of environmental variables on species composition and richness. Polar Biology 39: 851-862. https://doi.org/10.1007/s00300-015-1875-9

Kirkwood J.M. 1984. A guide to the Decapoda of the Southern Ocean. ANARE Research Notes 11: 1-47.

Klages M. 1988. Zur Zoogeographie und bathymetrischen Verteilung antarktischer Gammariden (Crustacea; Amphipoda) eines ausgewählten Gebiets des südöstlichen Weddellmeeres. MSc thesis, Fachbereich Biologie / Chemie der Universität Bremen im Studiengang Biologie, Bremen.

Klages M. 1991. Biologischeund populations dynamische Untersuchungen an ausgewählten Gammariden (Crustacea: Amphipoda) des südöstlichen Weddellmeeres, Antarktis. PhD thesis, Universität Bremen, Bremen.

Klages M. \& Gutt J. 1990. Comparative studies on the feeding behaviour of high Antarctic amphipods (Crustacea) in laboratory. Polar Biology 11 (1): 73-79. https://doi.org/10.1007/BF00236524

Knust R., Gerdes D. \& Mintenbeck K. (eds) 2012. The Expedition of the Research Vessel "Polarstern"to the Antarctic in 2011 (ANT-XXVII/3) (CAMBIO). Berichte zur Polar- und Meeresforschungen 644: 1-200. Available from http://epic.awi.de/30175/1/644-2012\%20ANT27-3\%20RKnust.pdf [accessed 19 Oct. 2016].

Koubbi P., De Broyer C., Griffiths H., Raymond B., d’Udekem d'Acoz C., Van de Putte A., Danis B., Grant S., Gutt J., Held C., Hosie G., Huettmann, Post A., Ropert-Coudert Y., Stoddart M., Swadling K.M. \& Wadley V. 2014. Chapter 12. Conclusions: present and future of Southern Ocean Biogeography. In: De Broyer C., Koubbi P., Griffiths H.J., Raymond B., d'Udekem d'Acoz C. et al. (eds) Biogeographic Atlas of the Southern Ocean. Scientific Committee on Antarctic Research, Cambridge, pp. 470-475. Available from http://share.biodiversity.aq/Atlas/example_BASO_web.pdf [accessed 27 Sep. 2016].

Krapp-Schickel T. \& De Broyer C. 2014. Revision of Leucothoe (Amphipoda, Crustacea) from the Southern Ocean: a cosmopolitanism concept is vanishing. European Journal of taxonomy 80: 1-55. https://doi.org/10.5852/ejt.2014.80

Kunkel W. 1918. The Arthrostraca of Connecticut. State of Connecticut State Geological and Natural History Survey Bulletin 26: 1-261. https://doi.org/10.5962/bhl.title.33358

Latreille P.A. 1816. Amphithoé. In: Biot J.-B., Bosc L.-A.-G., Chaptal J.-A., Desmarest A.-G., Dutour M., Huzard J.-B., Lamarck J.-B.-P.-A. de Monet de, Latreille P.-A., Lucas J.-A.-H., Olivier G.-A., Palisot de Beauvois A.-M.-F.-J., Parmentier A.-G., Patrin E.-M.-L., Richard L.-C., Sonini C.-S., Thouin A., Tollard C., Vieillot L.-P., Virey J.-J. \& Yvart J.-A.-V. (eds) Nouveau dictionnaire d'histoire naturelle, appliquée aux arts, à l'agriculture, à l'économie rurale et domestique, à la médecine, etc. 2nd edition. Vol. 1: 470-471. Librairie Deterville, Imprimerie d'Abel Lanoë, Paris. https://doi.org/10.5962/bhl.title.20211

Leach W.E. 1814. Crustaceology. In: Brewster D. (ed.) The Edinburgh Encyclopcedia. Volume VII: 383-437. Printed for William Blackhood and John Waugh, John Murray, J.M. Richardson and the other propietors, Edinburgh. https://doi.org/10.5962/bhl.title.30911

Lecointre G., Améziane N., Boisselier M.-C., Bonillo C., Busson F. et al. 2013. Is the Species Flock Concept Operational? The Antarctic Shelf Case. PLoS ONE 8 (8): e68787. https://doi.org/10.1371/journal.pone.0068787

Ledoyer M. 1986. Crustacés amphipodes gammariens. Familles des Haustoriidae à Vitzjazianidae. Faune de Madagascar 59 (2): 599-1112. Editions de l'Orstom.

Ledoyer M. 1993. Paramphithoidae. In: Ruffo S. (ed.) The Amphipoda of the Mediterranean. Part 3. Gammaridea (Melphidippidae to Talitridae). Mémoires de l'Institut océanographique, Monaco: 616617. 
Lilljeborg W. 1865. On the Lysianassa magellanica H. Milne Edwards and on the Crustacea of the suborder Amphipoda and subfamily Lysianassina found an [sic] the coast of Sweden and Norway. The Royal Academy Press, Uppsala. https://doi.org/10.5962/bhl.title.6806

Lincoln R.J. 1979. British Marine Amphipoda: Gammaridea. British Museum (Natural History), London.

Linse K., Cope T., Lörz A.-N. \& Sands C. 2007. Is the Scotia Sea a centre of Antarctic marine diversification? Some evidence of cryptic speciation in the circum-Antarctic bivalve Lissarca notorcadensis (Arcoidea: Philobryidae). Polar Biology 30 (8): 1059-1068. https://doi.org/10.1007/s00300-007-0265-3

Lockhart S.J. \& Jones C.D. 2008. Biogeographic patterns of benthic invertebrate megafauna on shelf areas within the Southern Ocean Atlantic sector. CCAMLR Science 15: 167-192. Available from: https:// swfsc.noaa.gov/publications/CR/2008/2008Lockhart.pdf [accessed 27 Sep. 2016].

Lockyer N. 1907. Antarctic animals. Nature 77 (1985): 33-36. Available from http://biodiversitylibrary. org/page/28538932 [accessed 13 Oct. 2016].

Lörz A.-N. 2003. Untersuchungen zur Biodiversität antarktischer bentischer Amphipoda (Malacostraca, Crustacea) - Studies on the biodiversity of Antarctic benthic Amphipoda (Malacostraca, Crustacea). Berichte zur Polar- and Meeresforschungen 452: i-iv, 1-148. hdl:10013/epic.10457. Available from http://epic.awi.de/26631/1/BerPolarforsch2003452.pdf [accessed 27 Sep. 2016].

Lörz A.-N. 2009. Synopsis from two recent Ross Sea voyages with description of a new species of Epimeria (Epimeriidae, Amphipoda, Crustacea). Zootaxa 2167: 59-68.

Lörz A.-N. 2012. First records of Epimeriidae and Iphimediidae (Crustacea, Amphipoda) from Macquarie Ridge, with description of a new species and its juveniles. Zootaxa 3200: 49-60.

Lörz A.-N. \& Brandt A. 2004. Phylogeny of Antarctic Epimeria (Epimeriidae: Amphipoda). Journal of the Marine Biological Association of the United Kingdom 84: 179-190. https://doi.org/10.1017/S002531540400904Xh

Lörz A.-N. \& Coleman O. 2001. Epimeria reoproi n. sp., a new amphipod (Epimeriidae) from the Antarctic. Crustaceana 74(9): 991-1002. https://doi.org/10.1163/15685400152682728

Lörz A.-N. \& Coleman O. 2003. Dikwa andresi, a new amphipod crustacean (Dikwidae) from the Scotia Arc. Journal of the Marine Biological Association of the United Kingdom 83: 785-788. https://doi.org/10.1017/S002531540300780Xh

Lörz A.-N. \& Coleman O. 2009. Living gems: jewel-like creatures from the deep. Water \& Atmosphere 17 (1): 16-17. Available from https://www.niwa.co.nz/sites/niwa.co.nz/files/import/attachments/gems. pdf [accessed 27 Sep. 2016].

Lörz A.-N. \& Coleman O. 2014. Amazing new Amphipoda (Crustacea, Epimeriidae) from New Zealand's deep-sea. Zootaxa 3838 (4): 423-434. https://doi.org/10.11646/zootaxa.3838.4.2

Lörz A.-N. \& Held C. 2004. A preliminary molecular and morphological phylogeny of the Antarctic Epimeriidae and Iphimediidae (Crustacea, Amphipoda). Molecular Phylogenetics and Evolution 31: 4-15. https://doi.org/10.1016/j.ympev.2003.07.019

Lörz A.-N., Maas E.W., Linse K. \& Coleman C.O. 2009. Do circum-Antarctic species exist in peracarid Amphipoda? A case study in the genus Epimeria Costa, 1851 (Crustacea, Peracarida, Epimeriidae). Zookeys 18: 91-128. https://doi.org/10.3897/zookeys.18.103 
Lörz A.-N., Maas E.W., Linse K. \& Fenwick G.D. 2007. Epimeria schiaparelli sp. nov., an amphipod crustacean (family Epimeriiidae) from from the Ross Sea, Antarctica, with molecular characterisation of the species complex. Zootaxa 1402: 23-37.

Lörz A.-N., Smith P., Linse K. \& Steinke D. 2011. High genetic diversity within Epimeria georgiana (Amphipoda) from the southern Scotia Arc. Marine Biodiversity 42 (2): 137-159. https://doi.org/10.1007/s12526-011-0098-8

Lowry J.K. \& Myers A.A. 2013. A phylogeny and classification of the Senticaudata subord. nov. (Crustacea: Amphipoda). Zootaxa 3610 (1): 1-80. https://doi.org/10.11646/zootaxa.3610.1.1

Lowry J.K. \& Stoddart H.E. 2003. Crustacea: Malacostraca: Peracarida: Amphipoda, Cumacea, Mysidacea. In: Beesley P.L. \& Houston W.W.K. (eds) Zoological Catalogue of Australia. Vol. 19.2B: i-xii, 1-531. CSIRO Publishing, Melbourne.

MacBean A. 1773. A dictionary of ancient geography, explaining the local appellations in sacred, Grecian, and Roman history; exhibiting the extent of kingdoms, and situations of cities, \&c. Andillustrating the allusions and epithets in the Greek and Roman poets. The whole established by proper authorities, and designed for the use of schools: i-iv, 1-628. Printed for G. Robinson, in Pater Noster-Row; and T. Cadell, in the Strand, London. Available from https://archive.org/details/adictionaryanci00johngoog [accessed on 13 Oct. 2016].

McCain J.C. 1971. A new deep-sea species of Epimeria (Amphipoda, Paramphithoidae) from Oregon. Crustaceana 20 (2): 159-166. https://doi.org/10.1163/156854069X00187

Miers E.J. 1877. List of the species of Crustacea collected by the rev. A.E. Eaton at Spitzbergen in the Summer of 1873, with their localities and notes. Annals and Magazine of Natural History, Series 4 19: 131-140. Available from http://biodiversitylibrary.org/page/26456758 [accessed 18 Oct. 2016].

Milne Edwards H. 1840. Histoire naturelle des crustacés comprenant l'anatomie, la physiologie et la classification de ces animaux. Tome troisième: 1-638. Librairie encyclopédique de Roret, Paris. https://doi.org/10.5962/bhl.title.16170

Moore P.G. 1981. A functional interpretation of coxal morphology in Epimeria cornigera (Crustacea: Amphipoda: Paramphithoidae). Journal of the Marine Biological Association of the United Kingdom 61 (3): 749-757. https://doi.org/10.1017/S0025315400048189

Nicholls G.E. 1938. Amphipoda Gammaridea. Australasian Antarctic Expedition 1911-1914, Scientific Reports, Series C 2: 1-145 (+ Corrigendum).

Norman A.M. 1869. Shetland final dredging report. Part 11. On the Crustacea, Tunicata, Polyzoa, Echinodermata, Actinozoa, Hydrozoa, and Porifera. Report of the British Association for the advancement of science 38 (for 1868): 247-336. Available from http://biodiversitylibrary.org/page/29387922 [accessed 27 Sep. 2016].

Nyssen F. 2005. Role of Benthic Amphipods in Antarctic Trophodynamics: a Multidisciplinary Study. $\mathrm{PhD}$ thesis, Université de Liège, Belgium. Available from www.vliz.be/imisdocs/publications/119897. pdf [accessed 27 Sep. 2016].

Olaso I., Rauschert M. \& De Broyer C. 2000. Trophic ecology of the family Artetidraconidae (Pisces: Osteichtyes) and its impact on the eastern Weddell Sea benthic system. Marine Ecology Progress Series 194: 143-158. Available from http://www.int-res.com/articles/meps/194/m194p143.pdf [accessed 27 Sep. 2016].

Otto A.W. 1823. Beschreibung einiger neuen Mollusken und Zoophyten. Nova acta physico-medica Academiae Caesareae Leopoldino-Carolinae Naturae Curiosum / Verhandlungen der Kaiserlichen 
Leopoldinisch-Carolinischen Akademie der Naturforscher 11 (3): 273-314, pls 38-42. Available from http://biodiversitylibrary.org/page/37012711 [accessed 27 Sep. 2016].

Pirlot J.M. 1934. Les amphipodes de l'expédition du Siboga. Deuxième partie. Les amphipodes gammarides II. - Les amphipodes de la mer profonde. 2. Hyperopsidae, Pardaliscidae, Astyridae nov. fam., Tironidae, Calliopiidae, Paramphithoidae, Amathillopsidae nov. fam., Eusiridae, Gammaridae, Aoridae, Photidae, Ampithoidae, Jassidae. Siboga-Expeditie, Uitkomsten op Zoologisch, Botanisch, Oceanographisch en Geologisch Gebied 33 (d): i-vii, 167-235.

Post A.L., Meijers A.J.S., Fraser A.D., Meiners K.M., Ayers J., Bindoff N.L., Griffiths H.J., Van de Putte A.P., O’Brien P.E., Swadling K.M. \& Raymond B. 2014. Chapter 4. Environmental Setting. In: De Broyer C., Koubbi P., Griffiths H.J., Raymond B., d'Udekem d'Acoz C. et al. (eds) Biogeographic Atlas of the Southern Ocean: 46-64. Scientific Committee on Antarctic Research, Cambridge.

Poupin J. \& Juncker M. 2010. A guide to the decapod crustaceans of the South Pacific: 1-320. Published by CRISP and SPC, Noumea, New Caledonia. Available from www.crisponline.net [accessed 27 Sep. 2016].

Pyper W. 2010. Southern marine life in focus. Australian Antarctic Magazine 18: 1-4. Available from http://www.antarctica.gov.au/magazine/2006-2010/issue-18-2010 [accessed 1 Sep. 2017]

Rauschert M. \& Arntz W.E. 2015. Antarctic Macrobenthos. A Field Guide of the Invertebrates Living at the Antarctic Seafloor: Arntz \& Rauschert Selbstverlag, Deichweg.

Reibisch J. 1906. Faunistisch-biologische Untersuchungen über Amphipoden der Nordsee II. Teil. Meeresforschung im Kiel. Biologische Abteilung 6: 185-237, pls 8-9. Available from http:// biodiversitylibrary.org/page/14671207 [accessed 14 Oct. 2016].

Ren X. \& Huang L. 1991. Studies on Gammaridea and Caprellidea (Crustacea: Amphipoda) from the northwest waters off the Antarctic Peninsula. Studia Marina Sinica 32: 185-323.

Riedel A.L., Sagata K., Surbakti S., Tänzler R. \& Balke M. 2013. One hundred and one new species of Trigonopterus weevils from New Guinea. Zookeys 280: 1-150. https://doi.org/10.3897/zookeys.280.3906

Richardson M.G. 1977. The ecology (including physiological aspects) of selected Antarctic marine invertebrates associated with inshore macrophytes: 1-137. PhD thesis, University of Durham, UK.

Rodríguez E., López-González P.J., Gili. J.M. 2007. Biogeography of Antarctic sea anemones (Anthozoa, Actiniaria): what do they tell us about the origin of the Antarctic benthic fauna? Deep-Sea Research II 54: 1876-1904. https://doi.org/10.1016/j.dsr2.2007.07.013

Ross J.C. 1835. Account of the objects in the departments of natural history, seen and discovered during the present expedition. In: Ross J.C. Appendix to the narrative of a second voyage in search of a NorthWest passage and of a residence in the arctic regions during the years 1829, 1830, 1831, 1832, 1833: i-cxxvii. A.W. Webster, London. Available from: https://books.google.be/books?id=baM-AQAAMAAJ [accessed 27 Sep. 2016].

Ruffo S. 1949. Amphipodes (II). Résultats du Voyage de la Belgica en 1897-1899 sous le commandement de A. de Gerlache de Gomery: Rapports Scientifiques (1941-1949). Buschmann, Antwerp. Available from http://www.vliz.be/nl/open-marien-archief?module=ref\&refid=63697 [accessed 27 Sep. 2016].

Sars G.O. 1883. Oversigt af Norges crustaceer med foreløbige bemærkninger over de nye eller mindre bekjendte arter. I. (Podophthalmata - Cumacea - Isopoda - Amphipoda). Forhandlinger i VidenskabsSelskabet i Christiania for 1882 (18): 1-124, pls 1-6. Available from http://biodiversitylibrary.org/ page/43993705 [accessed 27 Sep. 2016]. 
Sars G.O. 1886. Crustacea I. Den Norske Nordhavs-Expedition 1876-1878, volume 6, zoology: 1-280, pls 1-21, 1 map, 1-96. Grøndahl \& søns Bogtrykkeri, Christiania. https://doi.org/10.5962/bhl.title.119038

Sars G.O. 1890-1895. An account of the Crustacea of Norway with short descriptions and figures of all the species. Vol. 1 Amphipoda: 1-711, pls 1-240, pls i-viii. Alb. Cammermeyers Forlag, Christiania \& Copenhagen. https://doi.org/10.5962/bhl.title.1164

Sars M. 1859. Oversigt over de i den norsk-arctiske region forekommende krebsdyr. Forhandlinger $i$ Videnskabs-Selskabet i Christiana for 1858: 122-168.

Schellenberg A. 1926. Die Gammariden der Deutschen Südpolar-Expedition 1901-1903. Deutsche Südpolar-Expedition, 1901-1903, im Auftrage des Reichsamtes des Innern, hrsg. von Erich von Drygalski 18 (Zool. 10): 235-414.

Schellenberg A. 1931. Gammariden und Caprelliden des Magellangebietes, Südgeorgiens und der Westantarktis. Further zoological results of the Swedish Antarctic Expedition 1901-1903 2 (6): 1-290, pl. 1.

Schellenberg A. 1939. Amphipoden des Kongo-Mundungsgebietes. Revue de Zoologie et de Botanique Africaine 32: 122-138.

Schnack-Schiel S. 1987. Die Winter-Expedition mit FS "Polarstern" in die Antarktis (ANT V/1-3). Berichte zur Polar- und Meeresforschungen 39: 1-258. Available from http://epic.awi.de/26216/1/ BerPolarforsch198739.pdf [accessed 19 Oct. 2016].

Serejo C.S. 2014. A new species of Stilipedidae (Amphipoda: Senticaudata) from the South Mid-Atlantic Ridge. Zootaxa 3852 (1): 133-140. https://doi.org/10.11646/zootaxa.3852.1.6

Shoemaker C.R. 1964. Seven new amphipods from the west coast of North America with notes on some unusual species. Proceedings of the United States National Museum 115 (3489): 391-429. https://doi.org/10.5479/si.00963801.115-3489.391

Shimomura M. \& Tomikawa K. 2016. Epimeria abyssalis sp.n. from Kuril-Kamchatka Trench (Crustacea, Amphipoda, Epimeriidae). ZooKeys 638: 125-142. https://doi.org/10.3897/zookeys.638.10329

Sieg J. \& Wägele J.W. 1990. Fauna der Antarktis. Verlag Paul Parey, Berlin und Hamburg.

Smith J.A., Hillenbrand C.-D., Pudsey C.J., Allen C.S. \& Graham A.G.C. 2010. The presence of polynyas in the Weddell Sea during the Last Glacial Period with implications for the reconstruction of sea-ice limits and ice sheet history. Earth and Planetary Science Letters 296 (3-4): 287-298. https://doi.org/10.1016/j.epsl.2010.05.008

Spence Bate C.S. 1857. A synopsis of the British Edriophthalmous Crustacea. Part I. Amphipoda. Annals and Magazine of Natural History, Series 219 (110): 135-152. http://biodiversitylibrary.org/ page/2256035 [accessed 27 Sep. 2016].

Spence Bate C.S. 1862. Catalogue of the specimens of amphipodous Crustacea in the collection of the British Museum. British Museum (Natural History), London. https://doi.org/10.5962/bhl.title.20901

Spence Bate C.S. \& Westwood J.O. 1861-1862. A History of British sessile-eyed Crustacea. Volume 1. John Van Voorst, London. https://doi.org/10.5962/bhl.title.10117

Stebbing T.R.R. 1883. The "Challenger" Amphipoda. Annals and Magazine of Natural History, Series 5 11 (63): 203-207. http://biodiversitylibrary.org/page/29222121 [accessed 27 Sep. 2016].

Stebbing T.R.R. 1888. Report on the Amphipoda collected by H.M.S. Challenger during the years $1873-$ 1876. Report on the Scientific Results of the Voyage of H.M.S. Challenger during the years 1873-76. Zoology 29. https://doi.org/10.5962/bhl.title.6513 [text only: plates missing]. Plates available from 
http://www.19thcenturyscience.org/HMSC/HMSC-Reports/Zool-67/htm/doc.html [accessed 27 Sep. 2016].

Stebbing T.R.R. 1895. A passage-at-arms over the Amphipoda. Natural science : a monthly review of scientific progress 6 (38): 259-268. Available from http://biodiversitylibrary.org/page/11565175 [accessed 17 Oct. 2016].

Stebbing T.R.R. 1906. Amphipoda. I. Gammaridea. Das Tierreich 21: 1-806. https://doi.org/10.5962/bhl.title.1224

Stebbing T.R.R. 1908. On two new species of northern Amphipoda. The Journal of the Linnean Society 30 (198): 191-196, pls 27-28. Available from http://biodiversitylibrary.org/page/31567523 [accessed on 13 Oct. 2016].

Stephensen K. 1928. Storkrebs II. Ringkrebs. Danmarks Fauna 32: 1-399. G.E.C. Gads Forlag, København. Available from http://biodiversitylibrary.org/page/36035319 [accessed 27 Sep. 2016].

Stephensen K. 1929. Amphipoda. Die Tierwelt der Nord-und Ostsee 10: 1-188. Akademische Verlagsgesellschaft, Leipzig.

Stephensen K. 1947. Tanaidacea, Isopoda, Amphipoda and Pycnogonida. Scientific Results of the Norwegian Antarctic Expeditions 1927-1928 et sqq. 2 (27): 1-90.

Strugnell J.M., Watts P.C., Smith P.J. \& Allcock A.L. 2012. Persistent genetic signatures of historic climatic events in an Antarctic octopus. Molecular Ecology 21: 2775-2787. https://doi.org/10.1111/j.1365-294X.2012.05572.x

Swainson W. \& Richardson J. 1832. Fauna boreali-americana. Part second, containing the birds. John Murray, London. https://doi.org/10.5962/bhl.title.63874

Thatje S., Hillenbrand C.-D. \& Larter R. 2005. On the origin of Antarctic marine benthic community structure. Trends in Ecology and Evolution 20 (10): 534-540. https://doi.org/10.1016/j.tree.2005.07.010

Thatje S., Hillebrand C.-D., Mackensen A. \& Larter R. 2008. Life hung by a thread: endurance of Antarctic fauna in glacial periods. Ecology 89 (3): 682-692. https://doi.org/10.1890/07-0498.1

Thurston M.H. 1972. The Crustacea Amphipoda of Signy Island, South Orkney Islands. British Antarctic Survey Scientific Reports 71: 1-133. Available from: http://nora.nerc.ac.uk/509215/1/The\%20 crustacea $\% 20$ amphipoda $\% 20$ of $\% 20$ Signy $\% 20$ Island, $\% 20$ South $\% 20$ Orkney $\% 20$ Islands $\% 20-\% 20$ BAS\%20Scientific\%20Report\%2071.pdf [accessed 27 Sep. 2016]

Tizard T.H., Moseley H.N., Buchanan J.Y. \& Murray J. 1885. The voyage of the H.M.S. Challenger. Narrative-Vol. I. Second part. Report on the Scientific Results of the Voyage of H.M.S. Challenger during the years 1873-76. Narrative 1 (2). https://doi.org/10.5962/bhl.title.6513

Tomikawa K. \& Komatsu H. 2009. New and rare species of the deep-sea Gammaridea (Crustacea: Amphipoda) off Pacific coast of northern Honshu, Japan. In: Fujita T. (ed.) Deep-sea Fauna and Pollutants of Pacific Coast of Northern Japan. National Museum of Nature and Science Monographs 39: 447-466. Available from https://www.kahaku.go.jp/research/researcher/papers/18724.pdf [accessed 27 Sep. 2016].

Trathan P.N., Collins M.A., Grant S.M., Belchier M., Barnes D.K.A., Brown J. \& Staniland I.J. 2014. The South Georgia and the South Sandwich Islands MPA: protecting a biodiverse oceanic island chain situated in the flow of the Antarctic Circumpolar Current. Advances in Marine Biology 69: 15-78. https://doi.org/10.1016/B978-0-12-800214-8.00002-5

Vargas S., Kelly M., Schnabel K., Mills S., Bowden D. \& Wörheide G. 2015. diversity in a cold Hot-Spot: DNA-barcoding reveals patterns of evolution among Antarctic desmosponges (class Desmospongiae, 
phylum Porifera. PLoS ONE 10 (6): e0127573. https://doi.org/10.1371/journal.pone.0127573, supplement S2. https://doi.org/10.1371/journal.pone.0127573.s002

Verheye M. 2011. Systématique et diversité génétique des Eusirus de 1'Océan Austral (Crustacea, Amphipoda, Eusiridae). Mémoire présenté en vue de l'obtention du diplôme de Master en Biologie des Organismes et Ecologie: 1-127, i-xxxvii. Université Catholique de Louvain, Louvain-la-Neuve.

Verheye M., Backeljau T. \& d'Udekem d'Acoz C. 2016a. Looking beneath the tip of the iceberg: diversification of the genus Epimeria on the Antarctic shelf (Crustacea, Amphipoda). In: Gutt J., David B. \& Isla E. (eds) High environmental variability and steep biological gradients in the waters off the northern Antarctic Peninsula. Polar Biology 39 (5): 925-945, online supplementary material https://doi.org/10.1007/s00300-016-1910-5

Verheye M., Martin P., Backeljau T. \& d'Udekem d'Acoz C. 2016b. DNA sequence data suggests abundant homoplasy in taxonomically important morphological characters of Eusiroidea (Crustacea, Amphipoda). Zoologica Scripta 45 (3): 300-321, supplements S1-S3. https://doi.org/10.1111/zsc.12153

Verheye M., Backeljau T. \& d'Udekem d'Acoz C. 2017. Locked in the Icehouse: evolution of an endemic Epimeria (Amphipoda, Crustacea) species flock on the Antarctic shelf. Molecular Phylogenetics and Evolution. 114: 14-33. https://doi.org/10.1016/j.ympev.2017.05.013

Voß J. 1988. Zoogeographie und Gemeinschaftsanalyse des Makrozoobenthos des Weddellmeeres (Antarktis). Berichte zur Polarforschung 45: 1-145. hdl:10013/epic.10045. Available from http://epic. awi.de/26222/1/BerPolarforsch198845.pdf [accessed 27 Sep. 2016].

Wakabara Y. \& Serejo C.S. 1999. Amathillopsidae and Epimeriidae (Crustacea, Amphipoda) from bathyal depths off the Brazilian coast. Zoosystema 21 (4): 625-645.

Walker A.O. 1903. Amphipoda of the "Southern Cross" Antarctic Expedition. Journal of the Linnean Society of London, Zoology 29: 38-64, pls 7-11. http://biodiversitylibrary.org/page/31597966 [accessed 27 Sep. 2016].

Walker A.O. 1906. Preliminary descriptions of new species of Amphipoda from the 'Discovery' Antarctic Expedition, 1902-1904. Annals and Magazine of Natural History, Series 7 18: 13-18. http:// biodiversitylibrary.org/page/19366255 [accessed 27 Sep. 2016].

Walker A.O. 1907. Crustacea. III. Amphipoda. National Antarctic Expedition 1901-1904. Natural History 3. https://doi.org/10.5962/bhl.title.18281

Walker A.O. 1909. Amphipoda Gammaridea from the Indian Ocean, British East Africa, and the Red Sea. Transactions of the Linnean Society of London, Series 2, Zoology 12: 323-344, pls 42-43. Available from http://biodiversitylibrary.org/page/26710778 [accessed 27 Sep. 2016].

Watling L. 1981. Amphipods from the Northwestern Atlantic: the genera Jerbarnia, Epimeria, and Harpinia. Sarsia 66 (3): 203-211.

Watling L. \& Holman H. 1980. New amphipoda from the Southern Ocean, with partial revisions of the Acanthonotozomatidae and Paramphithoidae. Proceedings of the Biological Society of Washington. Available from http://biodiversitylibrary.org/page/34599492 [accessed 27 Sep. 2016].

Watling L. \& Holman H. 1981. Additional acanthonotozomatid, paramphitoid and stegocephalid Amphipoda from the Southern Ocean. Proceedings of the Biological Society of Washington 94 (1): 181-227. Available from http://biodiversitylibrary.org/page/34608032 [accessed 27 Sep. 2016].

Watling L. \& Thurston M.H. 1989. Antarctica as an evolutionary incubator: evidence from cladistic biogeography of the family Iphimediidae. In: Crame J.A. (ed.) Origin and evolution of the Antarctic Biota. Geological Society Special Publication 47: 297-313. https://doi.org/10.1144/GSL.SP.1989.047.01.22 
White A. 1847. List of the specimens of Crustacea in the collection of the British Museum. British Museum, printed by order of the trustees [by E. Newman], London. https://doi.org/10.5962/bhl.title.1708

White A. 1850a. Description of two species of Crustacea in the British Museum. Proceedings of the Zoological Society of London 18: 95-97, pl. 16. http://biodiversitylibrary.org/page/12858795 [accessed 27 Sep. 2016].

White A. 1850b. List of the specimens of British animals in the collection of the British Museum. Part IV. Crustacea. https://doi.org/10.5962/bhl.title.1582

White A. 1857. A popular history of British Crustacea; comprising a familiar account of their classification and habits. Lovell Reeve, London. https://doi.org/10.5962/bhl.title.14410

Zeidler W. \& De Broyer C. 2014. Chapter 6.8. Amphipoda Hyperiidea. In: De Broyer C., Koubbi P., Griffiths H.J., Raymond B., d'Udekem d'Acoz C. et al. (eds) Biogeographic Atlas of the Southern Ocean: 303-308. Scientific Committee on Antarctic Research, Cambridge.

Manuscript received: 30 March 2016

Manuscript accepted: 12 July 2016

Published on: 17 October 2017

Topic editor: Rudy Jocqué

Desk editor: Jeroen Venderickx

Printed versions of all papers are also deposited in the libraries of the institutes that are members of the EJT consortium: Muséum national d'Histoire naturelle, Paris, France; Botanic Garden Meise, Belgium; Royal Museum for Central Africa, Tervuren, Belgium; Natural History Museum, London, United Kingdom; Royal Belgian Institute of Natural Sciences, Brussels, Belgium; Natural History Museum of Denmark, Copenhagen, Denmark; Naturalis Biodiversity Center, Leiden, the Netherlands; Museo Nacional de Ciencias Naturales-CSIC, Madrid, Spain. 


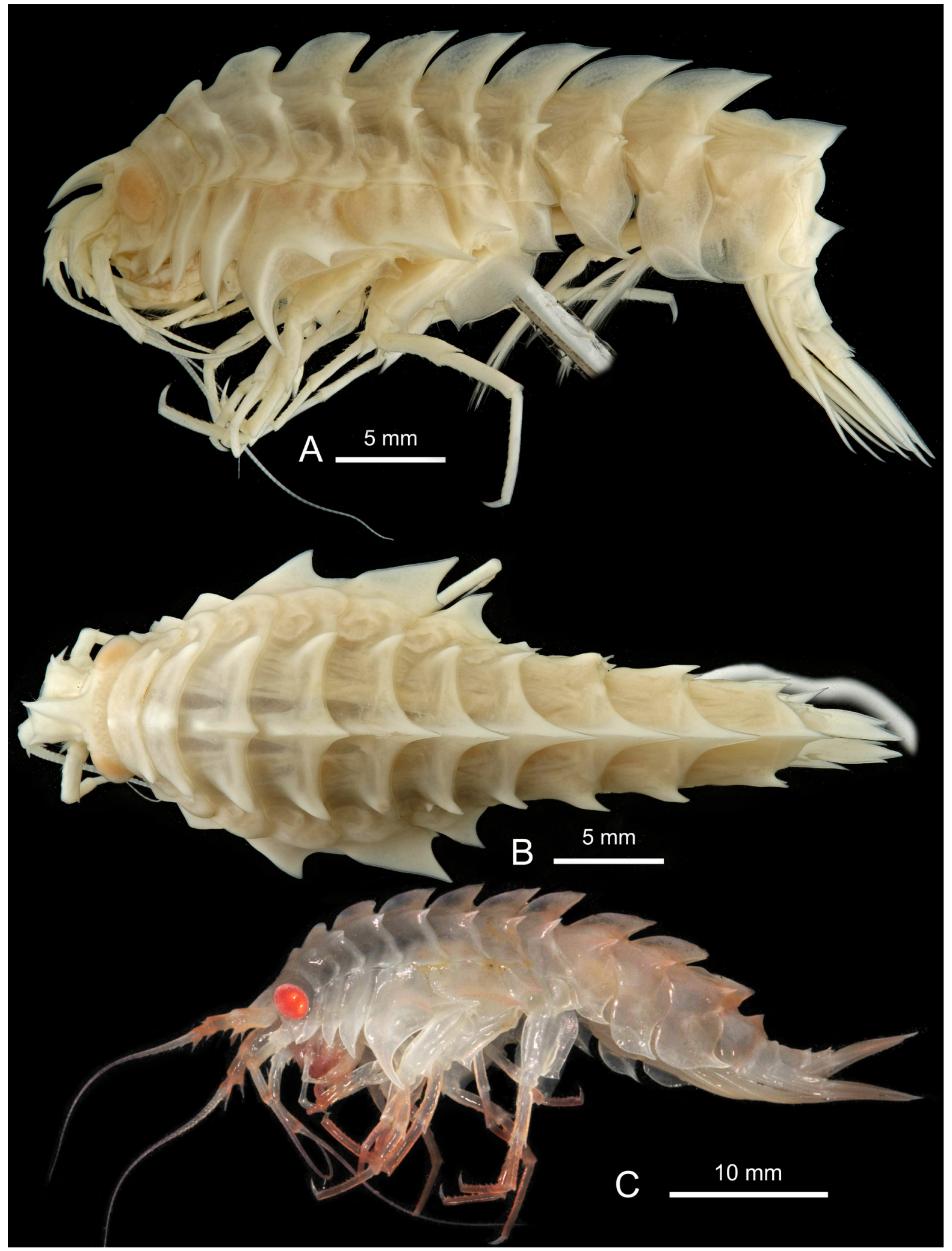

Fig. 1. Epimeria (Drakepimeria) acanthochelon subgen. et sp. nov. A-B. + , holotype, Adélie Coast, CEAMARC 1421, MNHN-IU-2014-7321. A. Lateral habitus. B. Dorsal habitus. C. Sex undetermined, paratype, Adélie Coast, REVOLTA III, Num_Collecte/Collect_ID: REVO_449, MNHN-IU-2009-2539, colour in life, photograph Cyril Galut. 


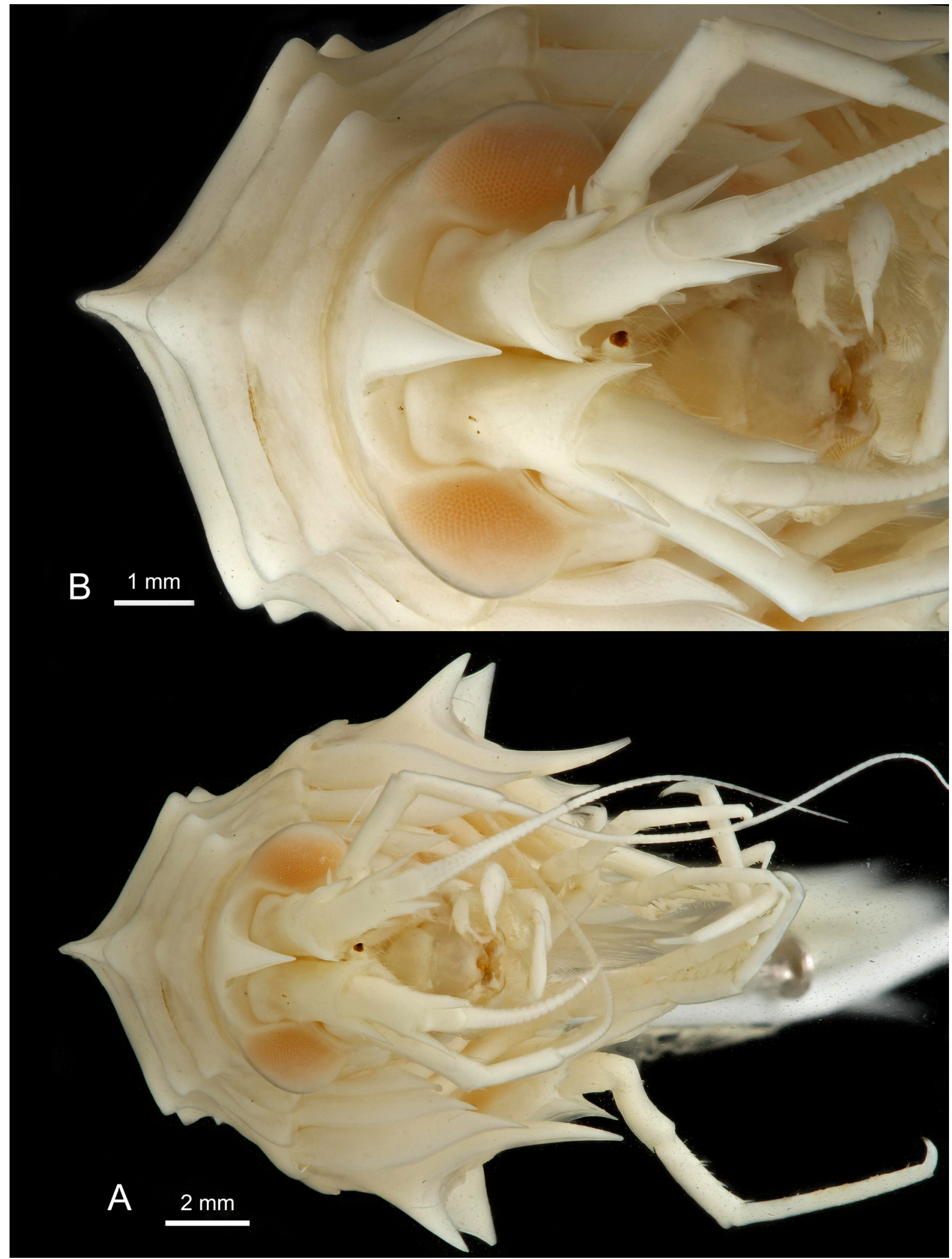

Fig. 2. Epimeria (Drakepimeria) acanthochelon subgen. et sp. nov., + , holotype, Adélie Coast, CEAMARC 1421, MNHN-IU-2014-7321. A. Facial habitus. B. Head in facial view. 


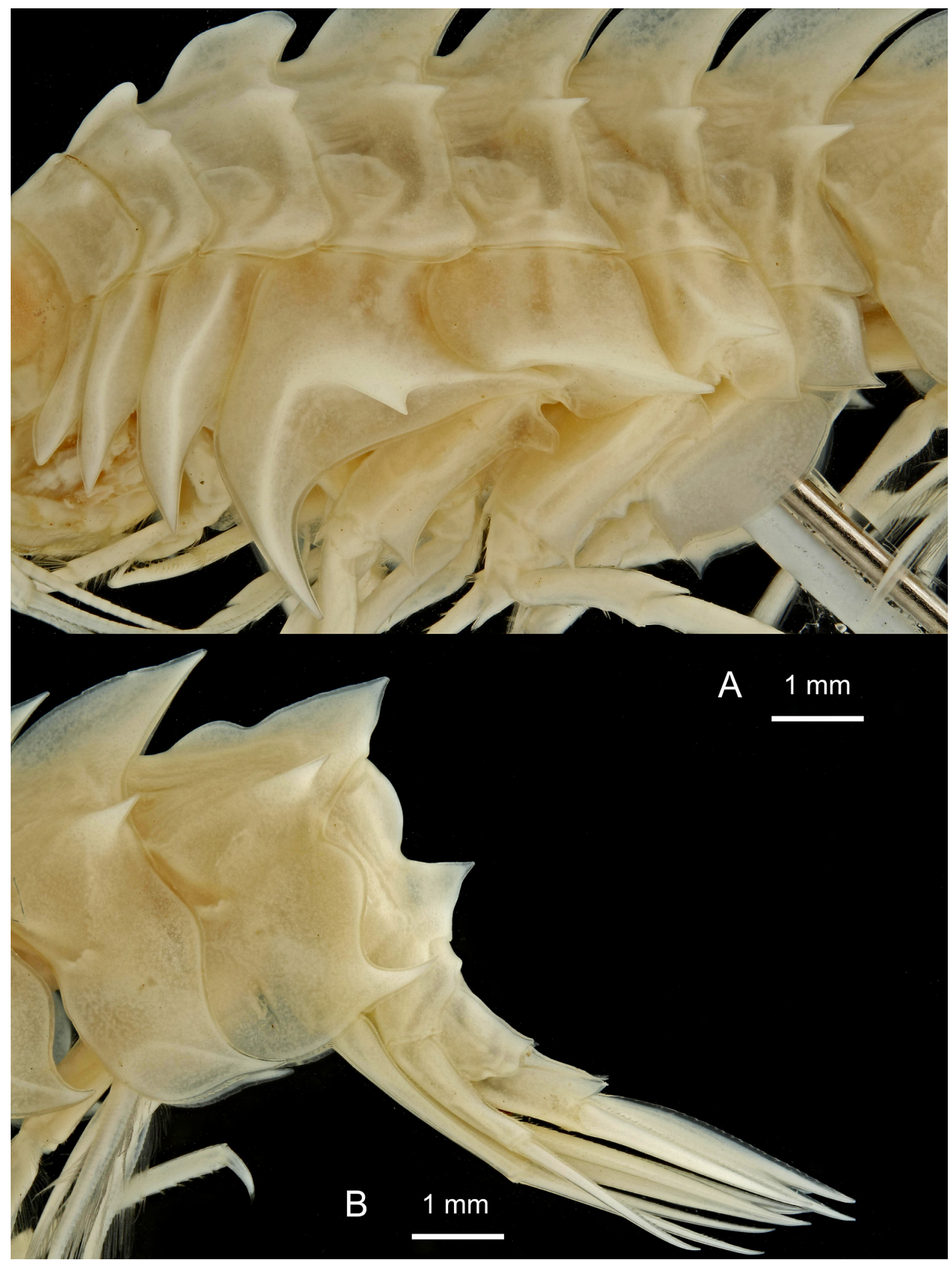

Fig. 3. Epimeria (Drakepimeria) acanthochelon subgen. et sp. nov., + , holotype, Adélie Coast, CEAMARC 1421, MNHN-IU-2014-7321. A. Coxae. B. Urosome and posterior part of pleosome. 


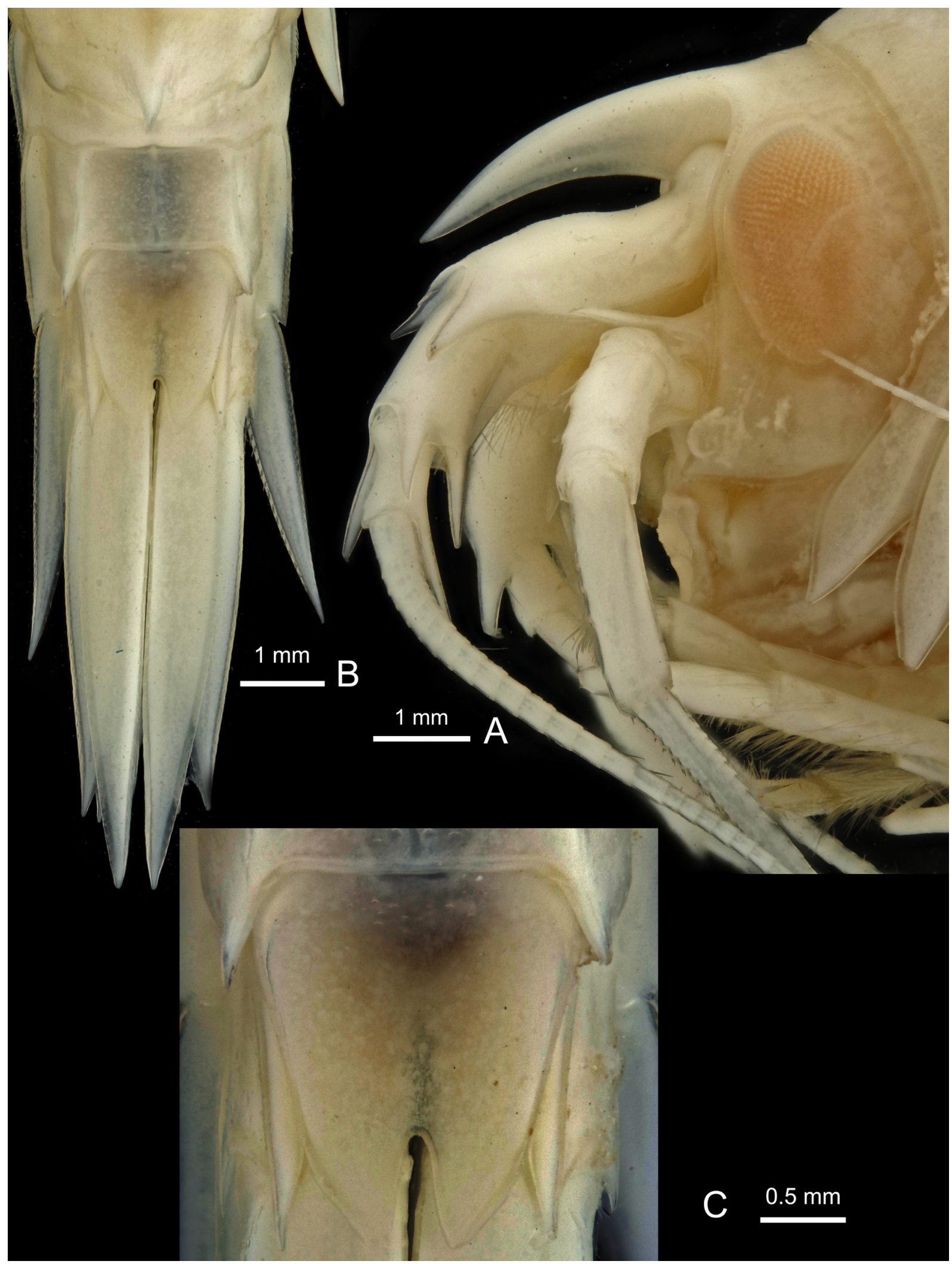

Fig. 4. Epimeria (Drakepimeria) acanthochelon subgen. et sp. nov., + , holotype, Adélie Coast, CEAMARC 1421, MNHN-IU-2014-7321. A. Head in lateral view. B. Urosome in dorsal view. C. Telson. 


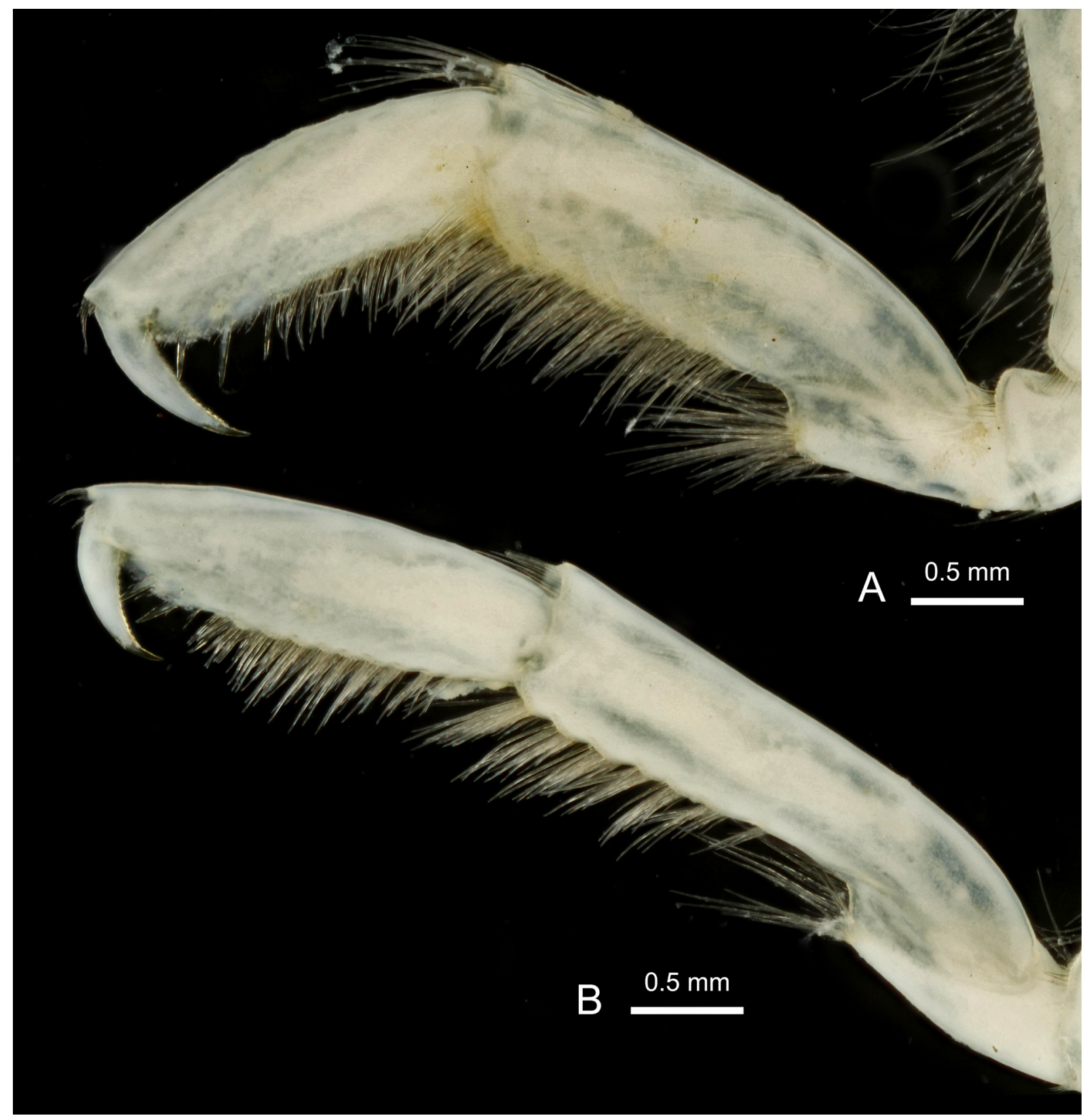

Fig. 5. Epimeria (Drakepimeria) acanthochelon subgen. et sp. nov., + , holotype, Adélie Coast, CEAMARC 1421, MNHN-IU-2014-7321. A. Gnathopod 1. B. Gnathopod 2. 


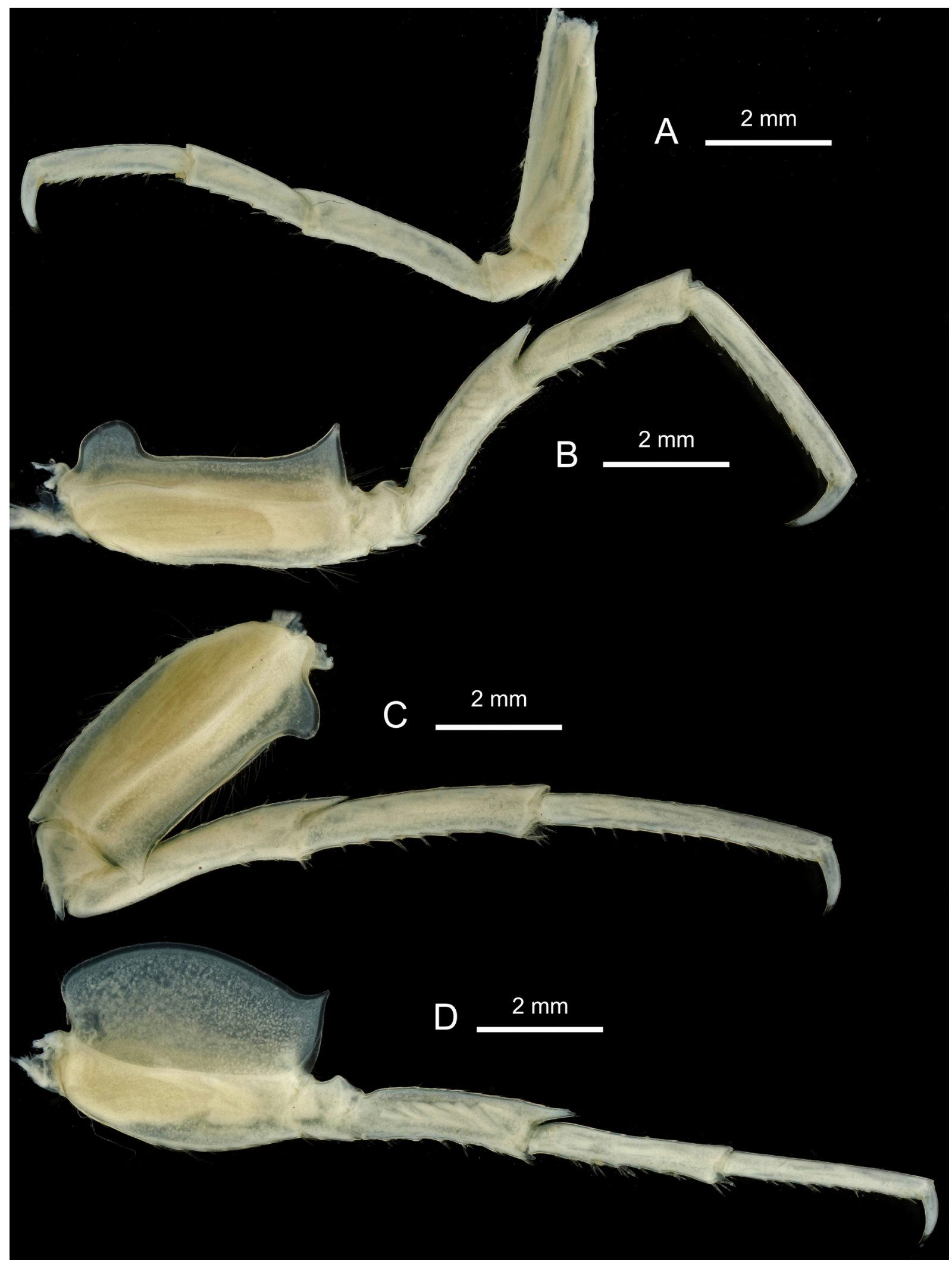

Fig. 6. Epimeria (Drakepimeria) acanthochelon subgen. etsp. nov.,, , holotype, Adélie Coast, CEAMARC 1421, MNHN-IU-2014-7321. A. Pereiopod 4. B. Pereiopod 5. C. Pereiopod 6. D. Pereiopod 7. 


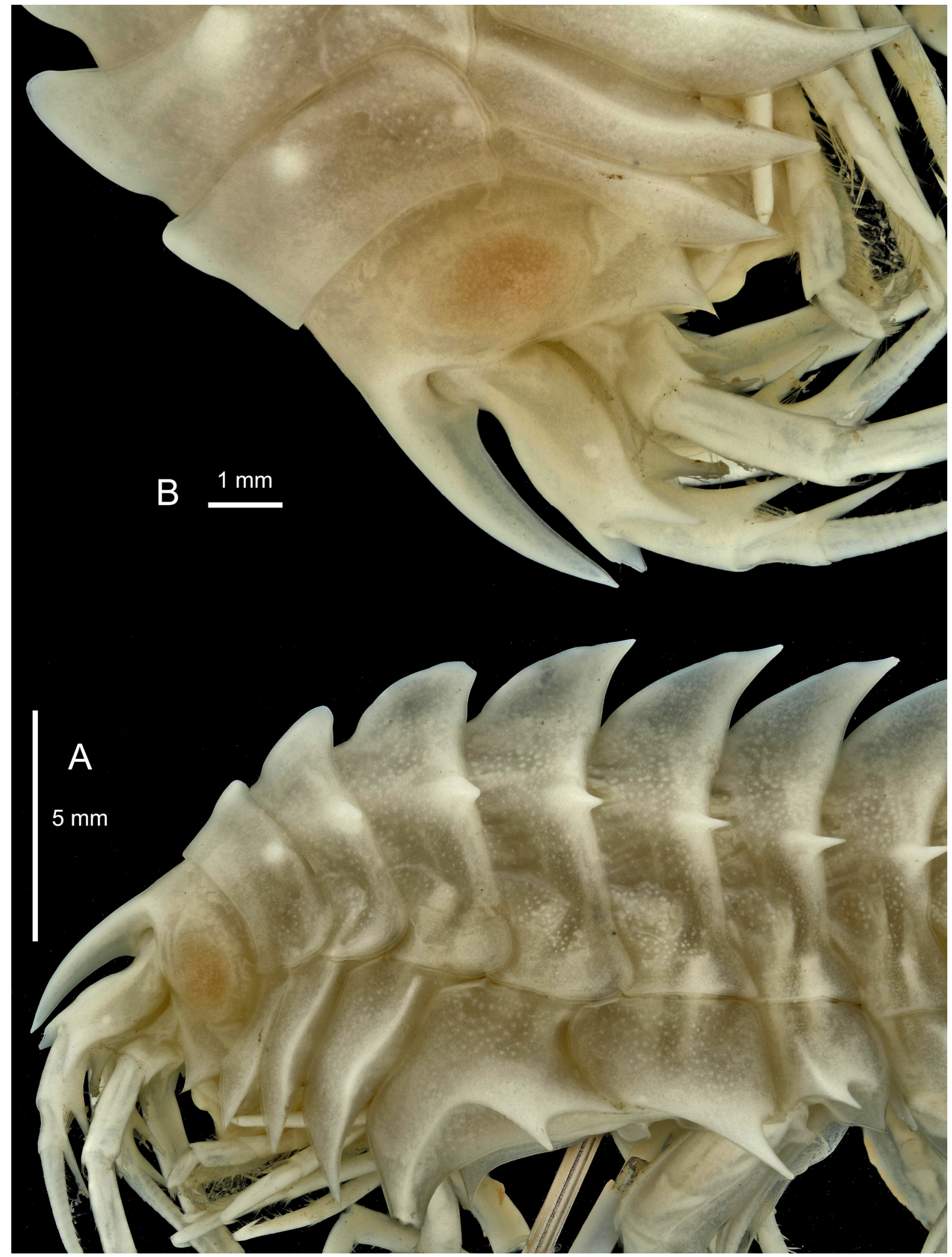

Fig. 7. Epimeria (Drakepimeria) acanthochelon subgen. et sp. nov., + , paratype, Adélie Coast, CEAMARC 1643, MNHN-IU-2014-4322. A. Anterior half in lateral view. B. Head and two first body segments in lateral view. 


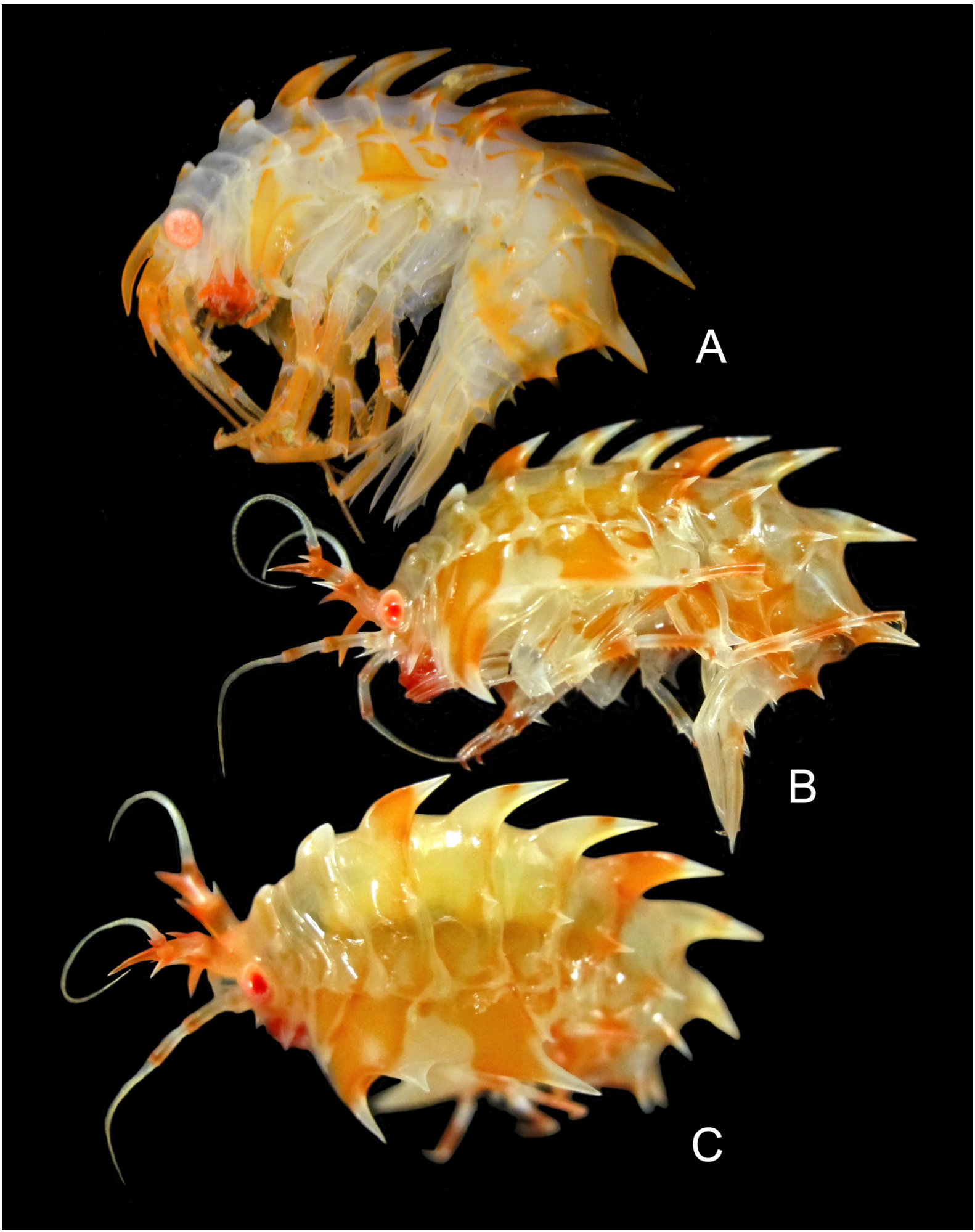

Fig. 8. Epimeria (Drakepimeria) anguloce subgen. et sp. nov., presumably $q+q$, habitus, colour in life. A. Paratype, Bransfield Strait, ANT-XXIX/3, stn 193-8, RBINS, INV. 132962 (photograph: C. d'Udekem d'Acoz). B. Western Weddell Sea, Larsen A, ANT-XXVII/3, stn 228-4, specimen not examined (photograph: C. Havermans and H. Robert). C. Western Weddell Sea, Larsen A, ANT-XXVII/3, stn 228-4, specimen not examined (photograph: C. Havermans and H. Robert). 


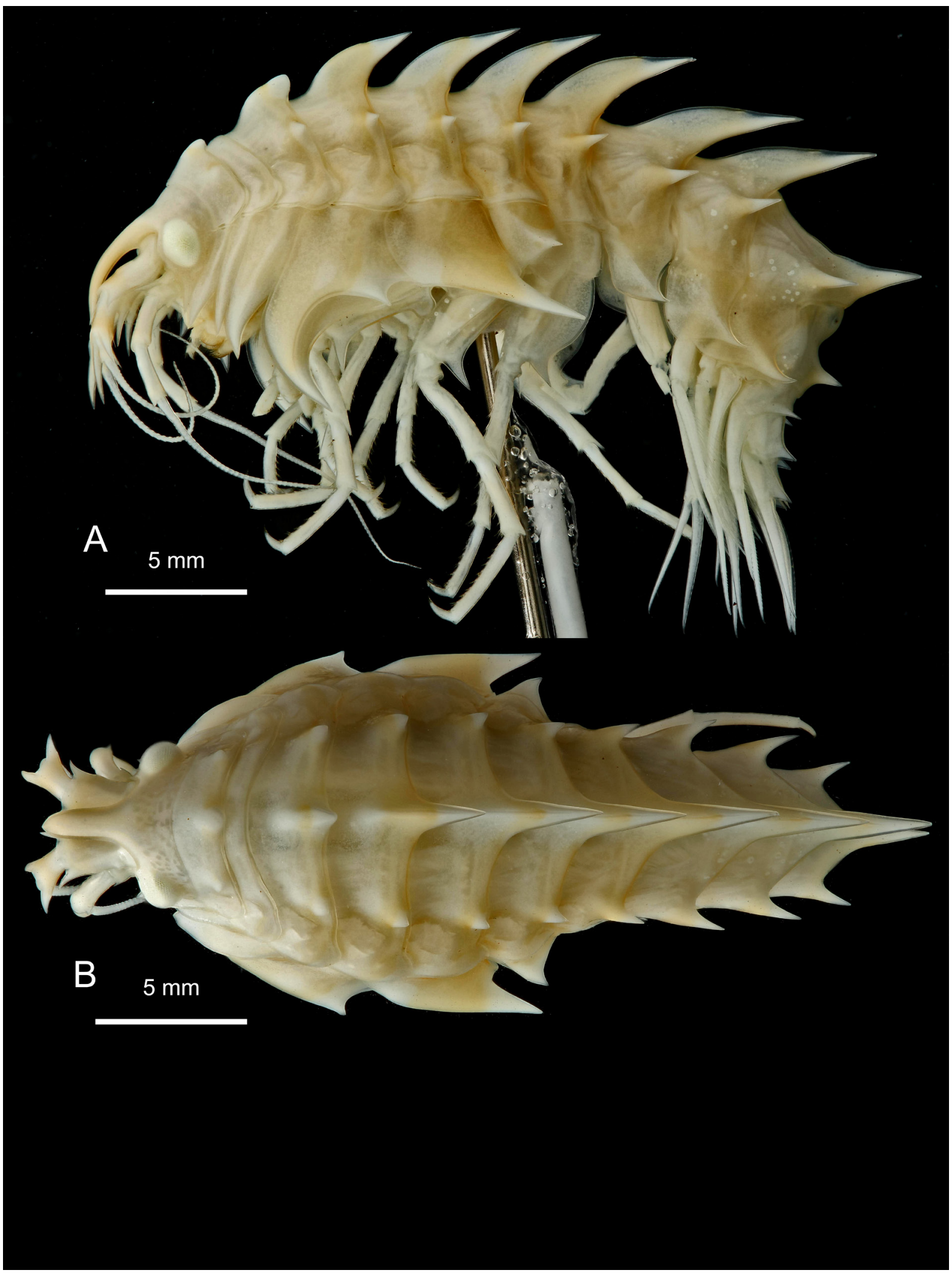

Fig. 9. Epimeria (Drakepimeria) anguloce subgen. et sp. nov., + , holotype, western Weddell Sea, Larsen A, ANT-XXVII/3, stn 228-3, RBINS, INV. 132961. A. Lateral habitus. B. Dorsal habitus. 


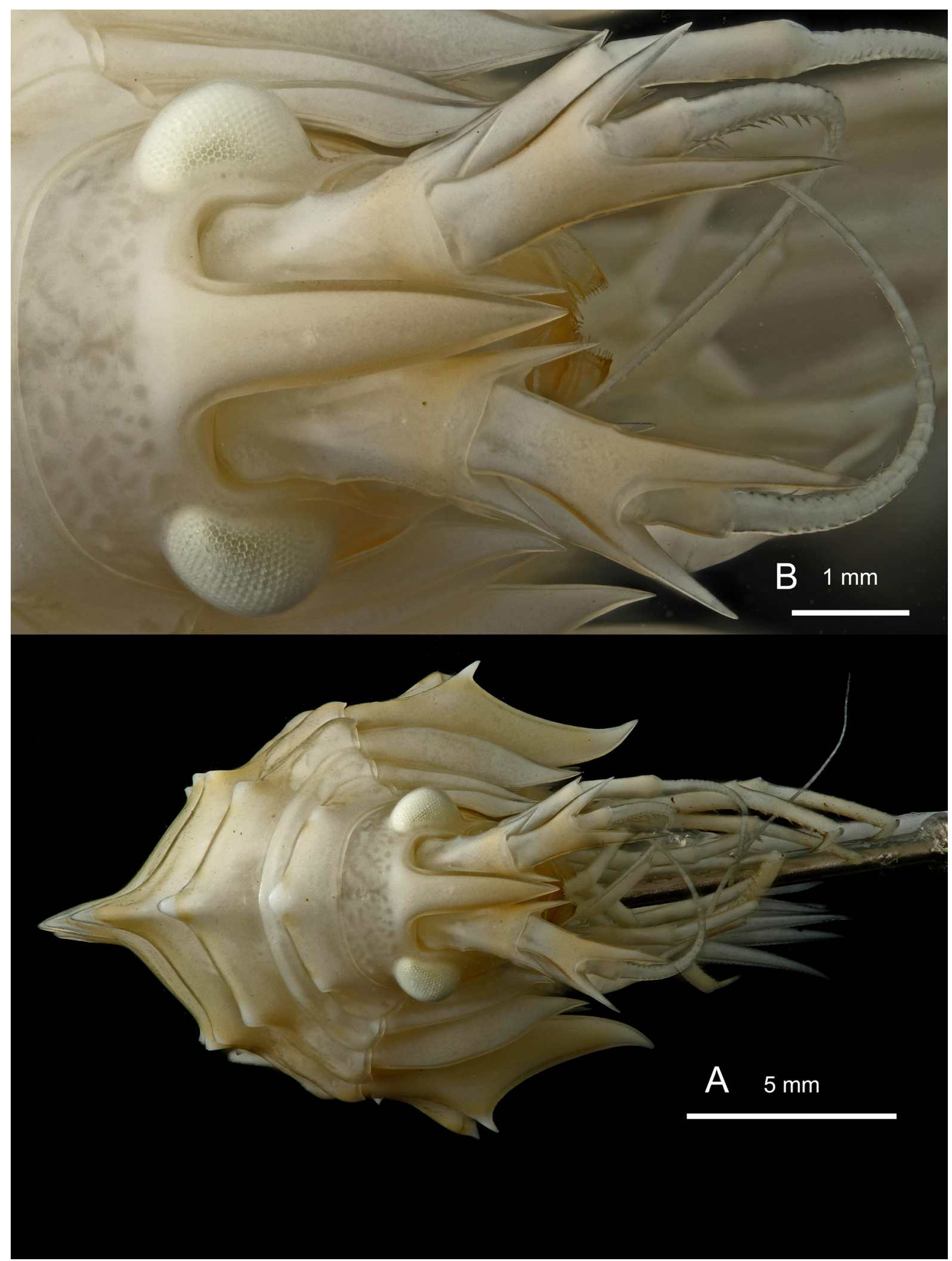

Fig. 10. Epimeria (Drakepimeria) anguloce subgen. et sp. nov., $q$, holotype, western Weddell Sea, Larsen A, ANT-XXVII/3, stn 228-3, RBINS, INV. 132961. A. Facial habitus. B. Head in facial view. 


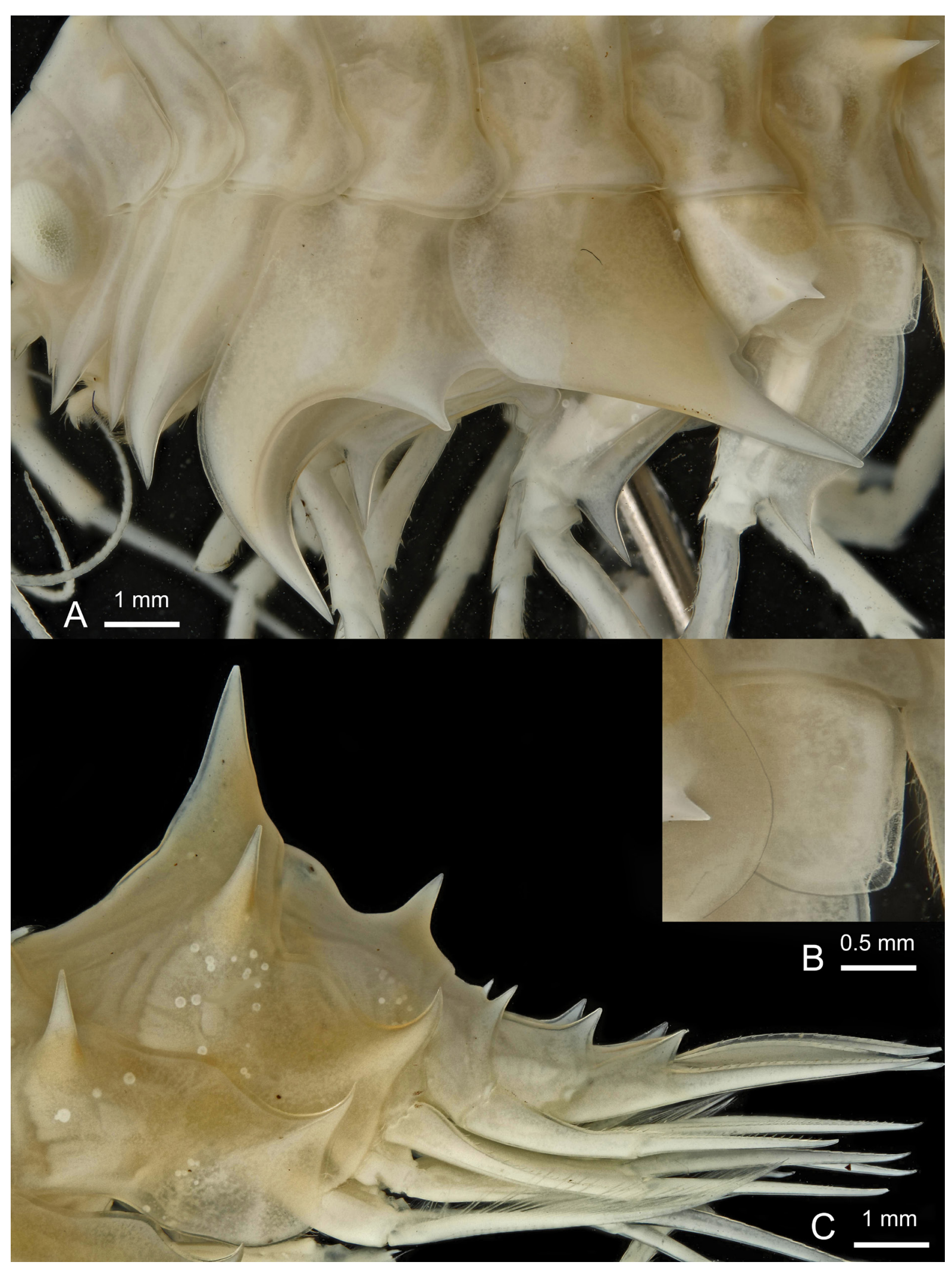

Fig. 11. Epimeria (Drakepimeria) anguloce subgen. et sp. nov., $q$, holotype, western Weddell Sea, Larsen A, ANT-XXVII/3, stn 228-3, RBINS, INV. 132961. A. Coxae. B. Coxa 7 and posterior part of coxa 6. C. Urosome and posterior part of pleosome. 


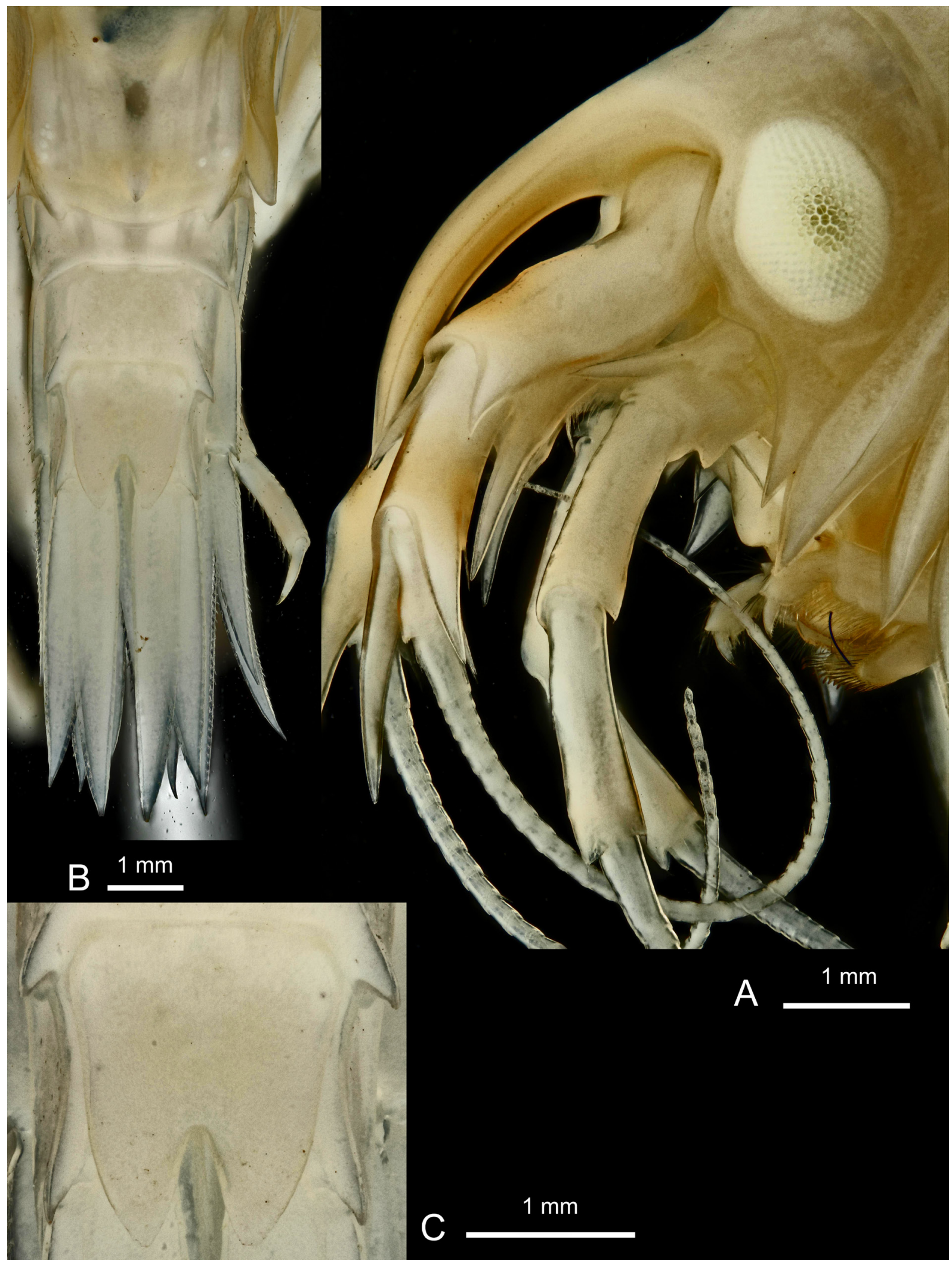

Fig. 12. Epimeria (Drakepimeria) anguloce subgen. et sp. nov., + , holotype, western Weddell Sea, Larsen A, ANT-XXVII/3, stn 228-3, RBINS, INV. 132961. A. Head in lateral view. B. Urosome in dorsal view. C. Telson. 


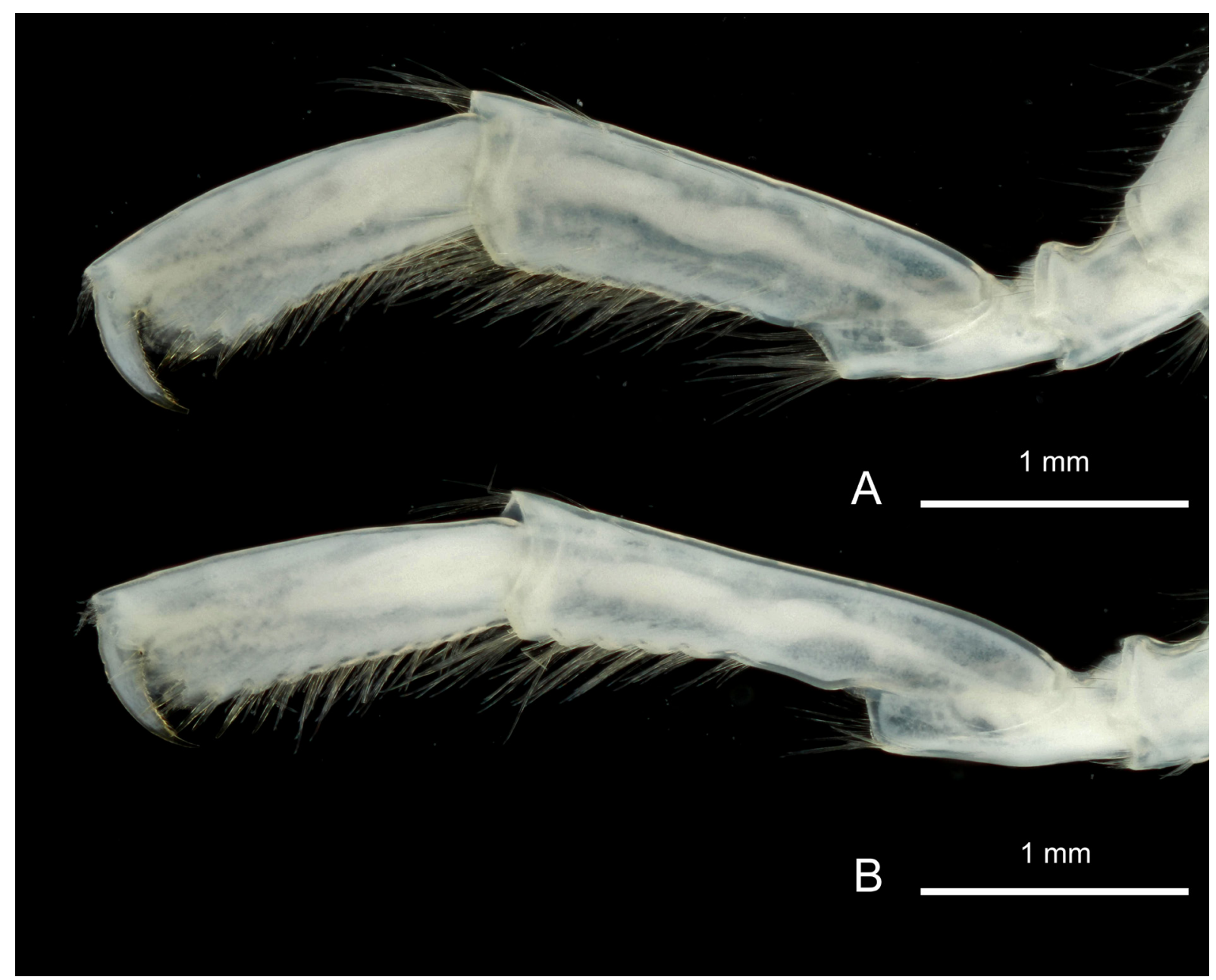

Fig. 13. Epimeria (Drakepimeria) anguloce subgen. et sp. nov., + , holotype, western Weddell Sea, Larsen A, ANT-XXVII/3, stn 228-3, RBINS, INV. 132961. A. Gnathopod 1. B. Gnathopod 2. 


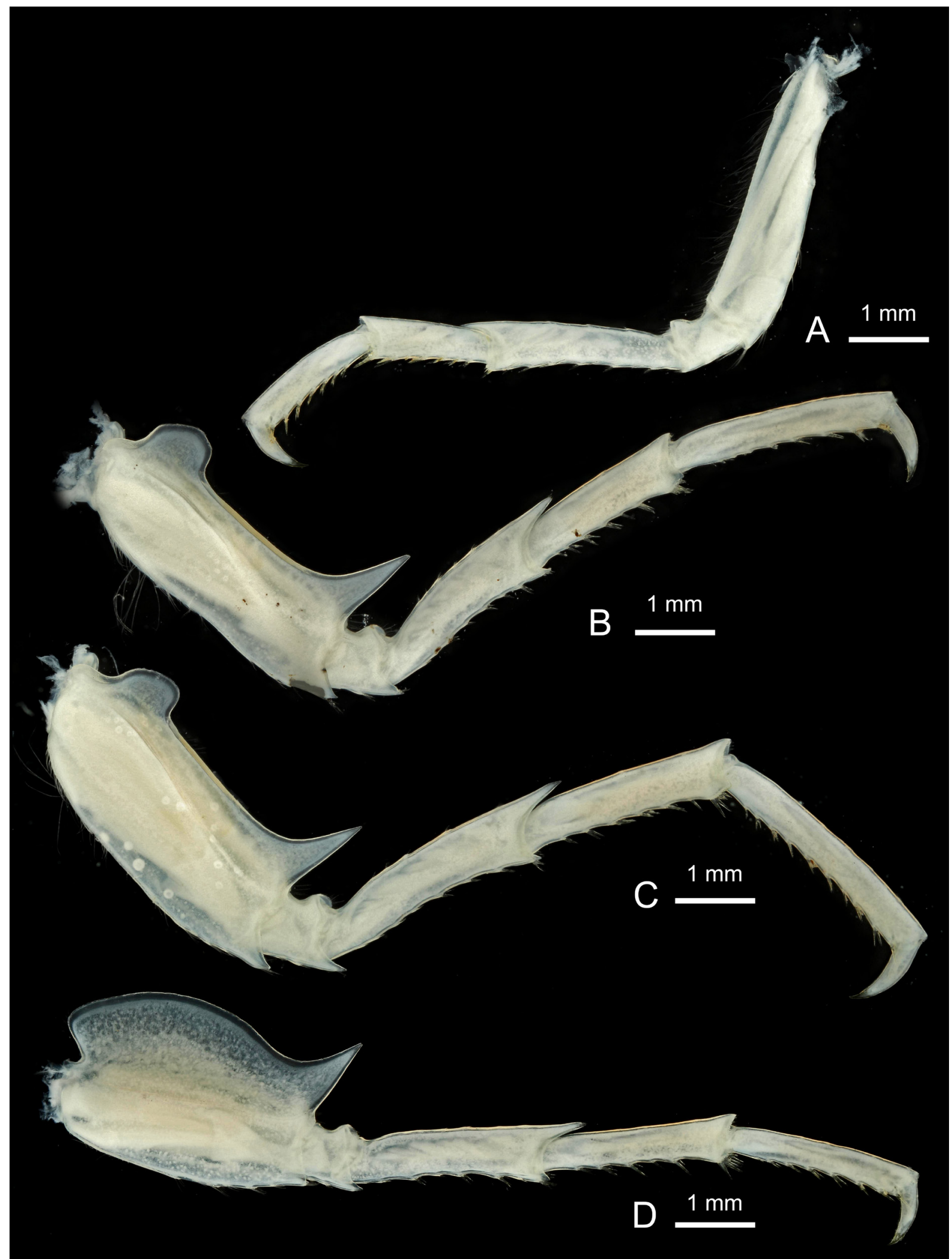

Fig. 14. Epimeria (Drakepimeria) anguloce subgen. et sp. nov.,, , holotype, western Weddell Sea, Larsen A, ANT-XXVII/3, stn 228-3, RBINS, INV. 132961. A. Pereiopod 4. B. Pereiopod 5. C. Pereiopod 6. D. Pereiopod 7. 


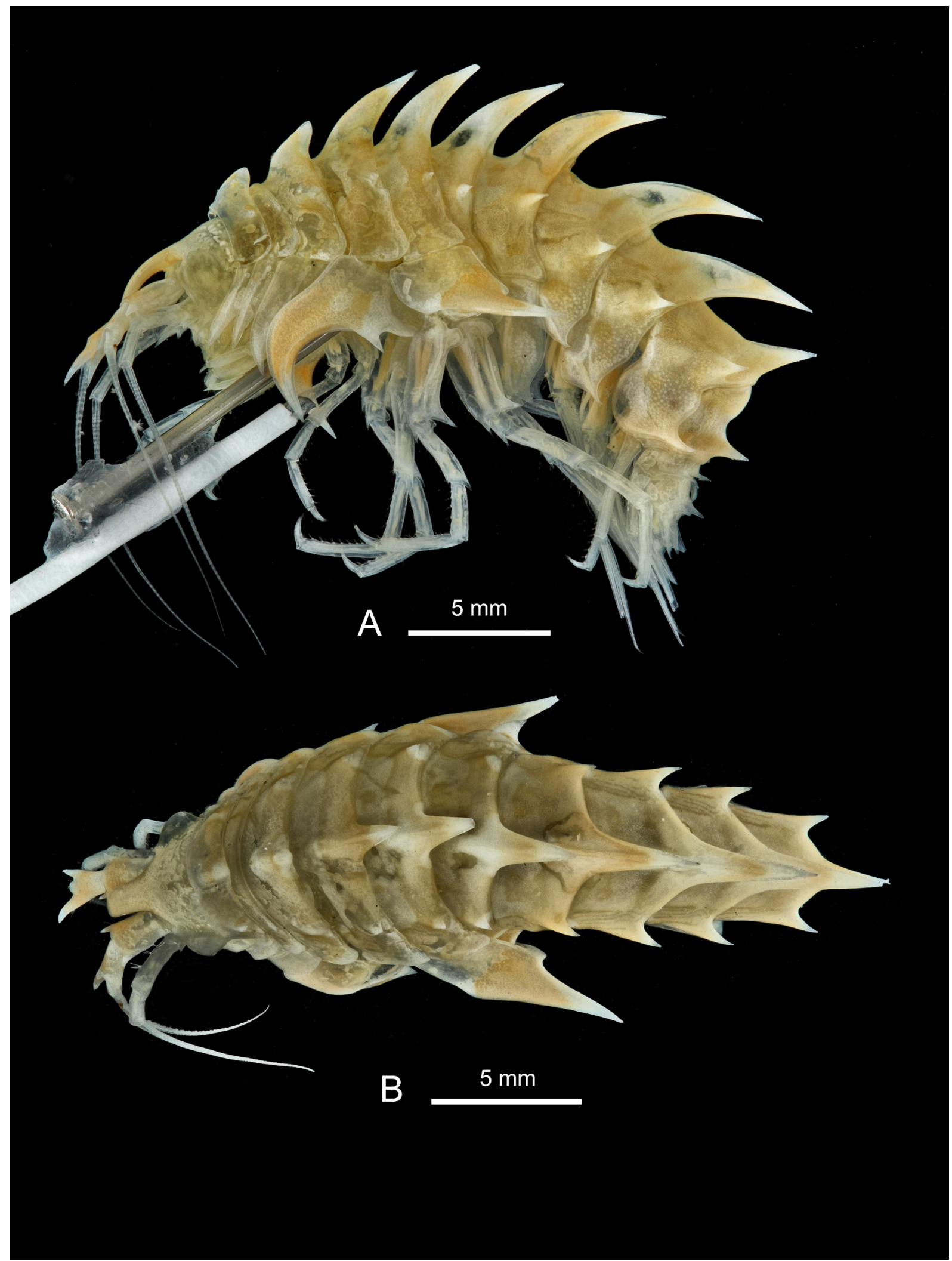

Fig. 15. Epimeria (Drakepimeria) anguloce subgen. et sp. nov.,, , non type, adult, eastern Weddell Sea, no station, ANT-XXIII/3, EASIZ I, specimen kept in aquarium, 18 Feb. 1996: 1 paratype, coll. C. De Broyer and G. Chapelle, RBINS, INV. 132995. A. Lateral habitus. B. Dorsal habitus. 


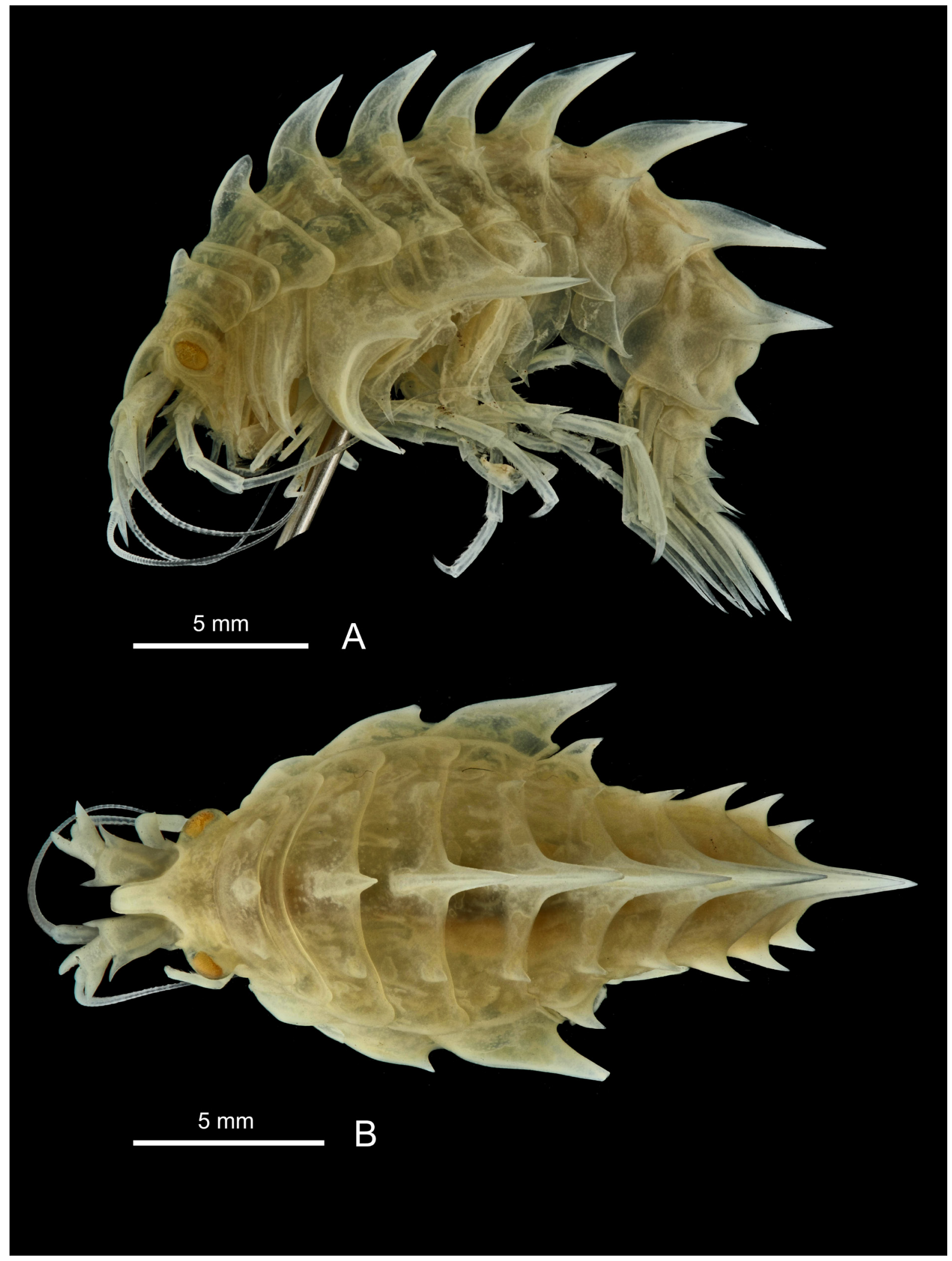

Fig. 16. Epimeria (Drakepimeria) anguloce subgen. et sp. nov., + , non type, adult, Prydz Bay, RV Marion Dufresne, cruise MD42 (SIBEX), stn 22-CP66, MNHN-IU-2014-4264. A. Lateral habitus. B. Dorsal habitus. 


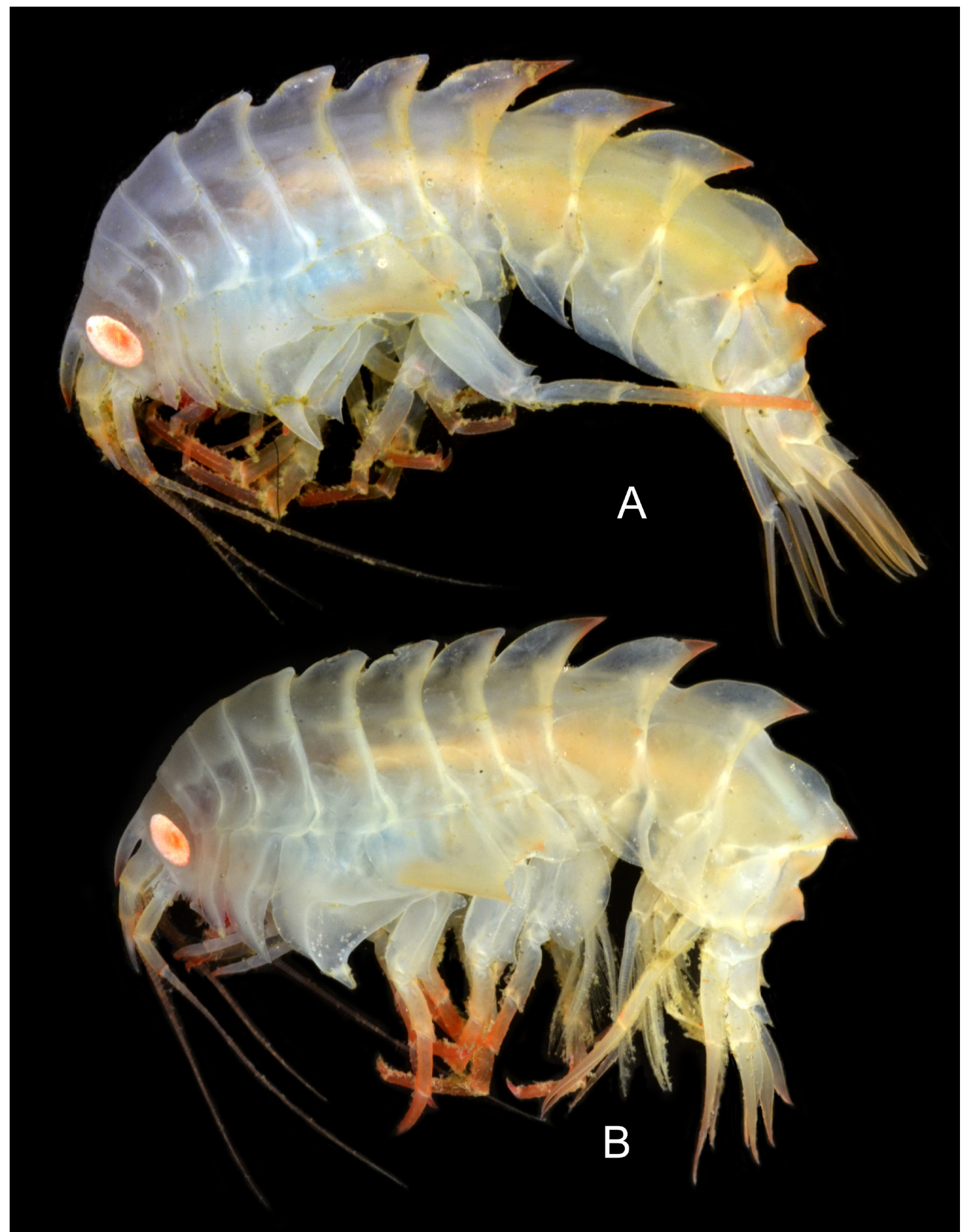

Fig. 17. Epimeria (Drakepimeria) colemani subgen. et sp. nov., presumably $q+$, paratypes, lateral habitus, colour in life. A. Bransfield Strait, ANT-XXIX/3, stn 193-8, RBINS, INV. 132976. B. Bransfield Strait, ANT-XXIX/3, stn 217-6, RBINS, INV. 122922A. 


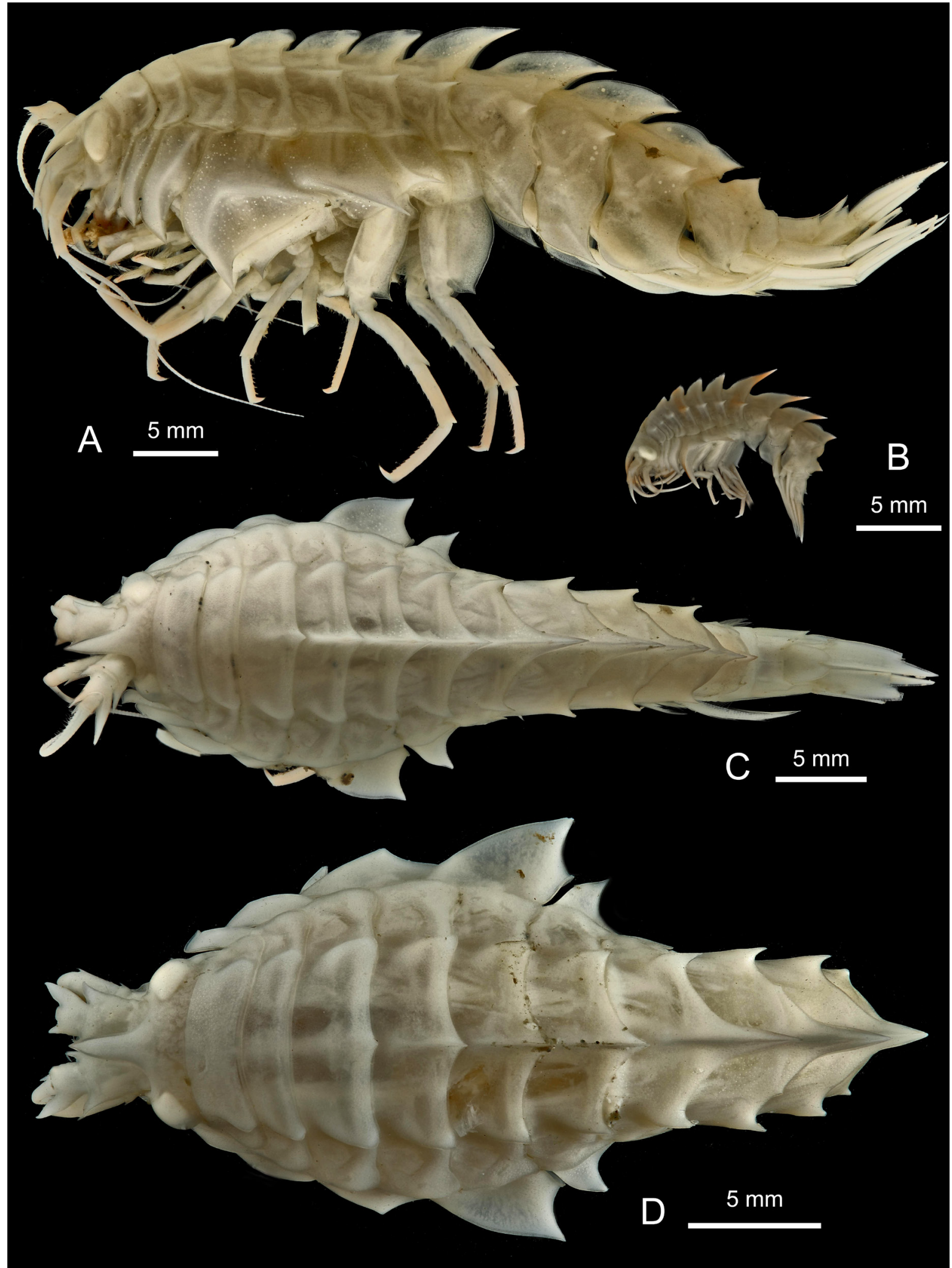

Fig. 18. Epimeria (Drakepimeria) colemani subgen. et sp. nov., A, C. + , holotype, adult, Bransfield Strait, ANT-XXIX/3, stn 196-8, RBINS, INV. 122942. B. Paratype (juvenile), eastern Weddell Sea, ANT-XXVII/8, stn 265-2. D. 9 , paratype (adult), eastern Weddell Sea, ANT-XXVII/8, stn 265-2, RBINS, INV. 132965. 


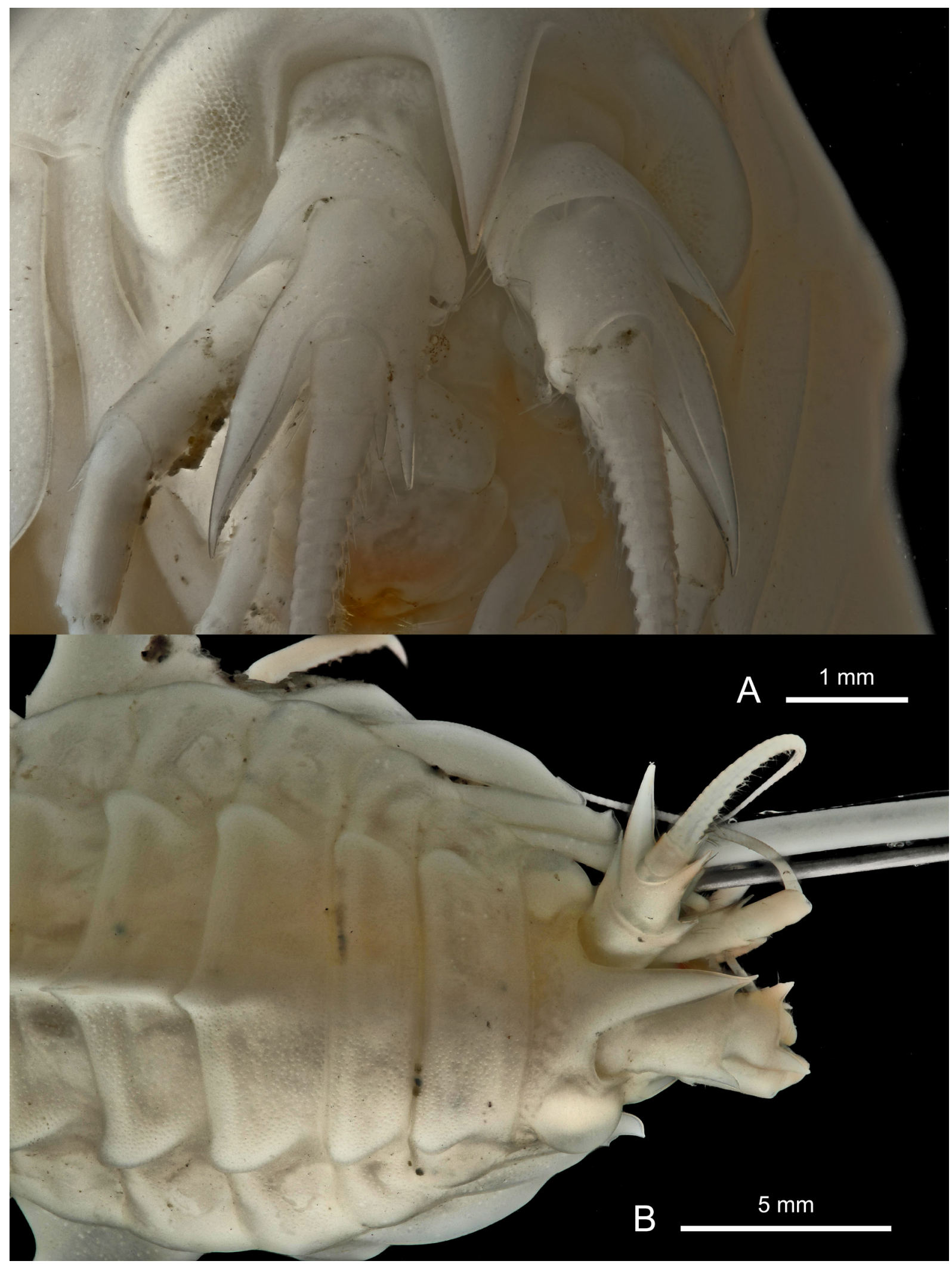

Fig. 19. Epimeria (Drakepimeria) colemani subgen. et sp. nov., A. + , holotype, Bransfield Strait, ANTXXIX/3, stn 196-8, RBINS, INV. 122942, head and antennae in frontal view. B. $q$, paratype, adult, eastern Weddell Sea, ANT-XXVII/8, stn 265-2, RBINS, INV. 132965, anterior half in dorsal view. 


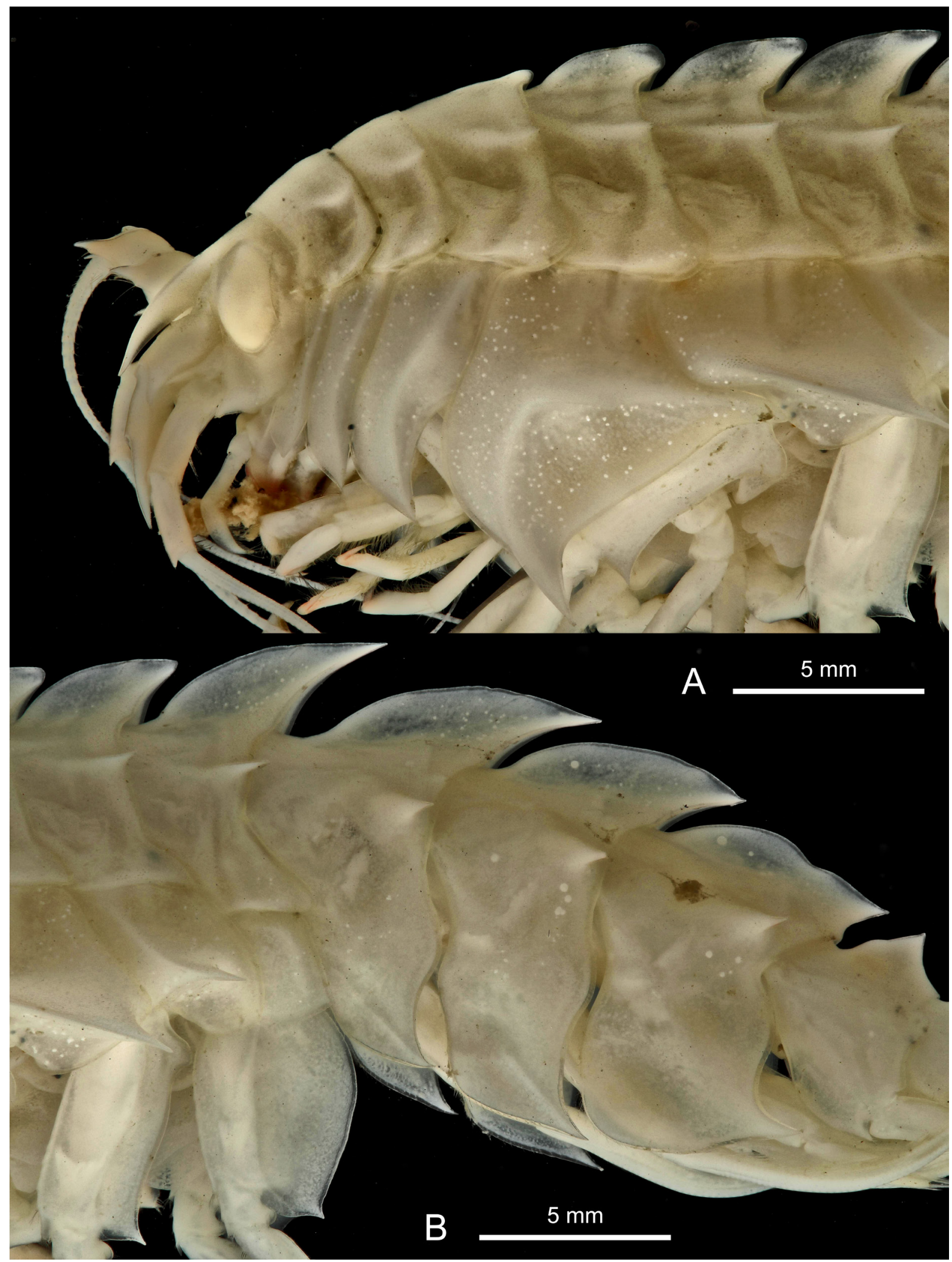

Fig. 20. Epimeria (Drakepimeria) colemani subgen. et sp. nov., + , holotype, Bransfield Strait, ANTXXIX/3, stn 196-8, RBINS, INV. 122942, anterior half in dorsal view. A. Anterior half. B. Posterior half. 


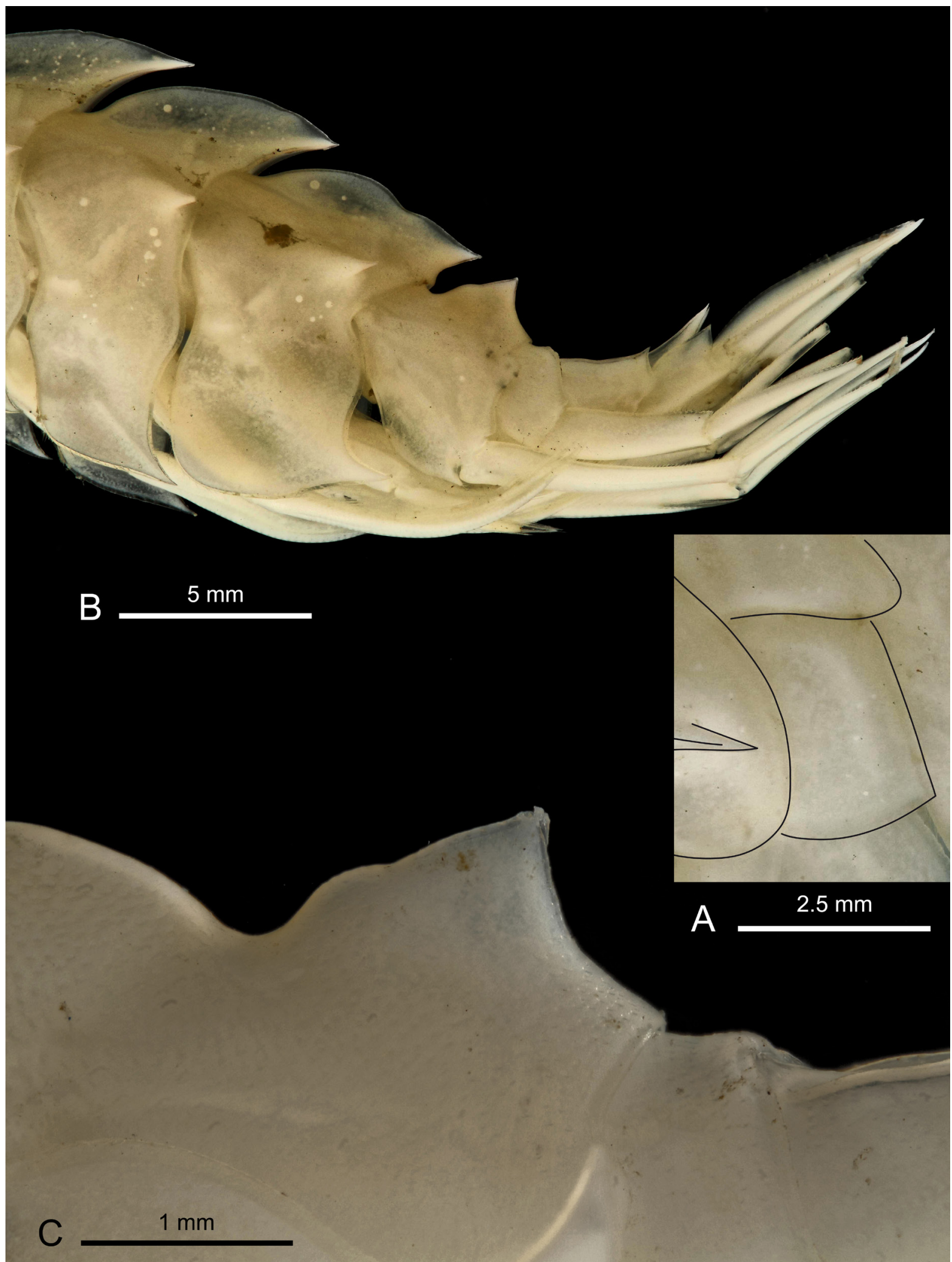

Fig. 21. Epimeria (Drakepimeria) colemani subgen. et sp. nov., A, B. + , holotype, Bransfield Strait, ANT-XXIX/3, stn 196-8, RBINS, INV. 122942. C. +, paratype, eastern Weddell Sea, ANT-XXVII/8, stn 265-2, RBINS, INV. 132965. A. Coxa 7 and posterior half of coxa 6. B. Pleon. C. Dorsal process of urosomite 1 and lateral profile or urosomite 2. 


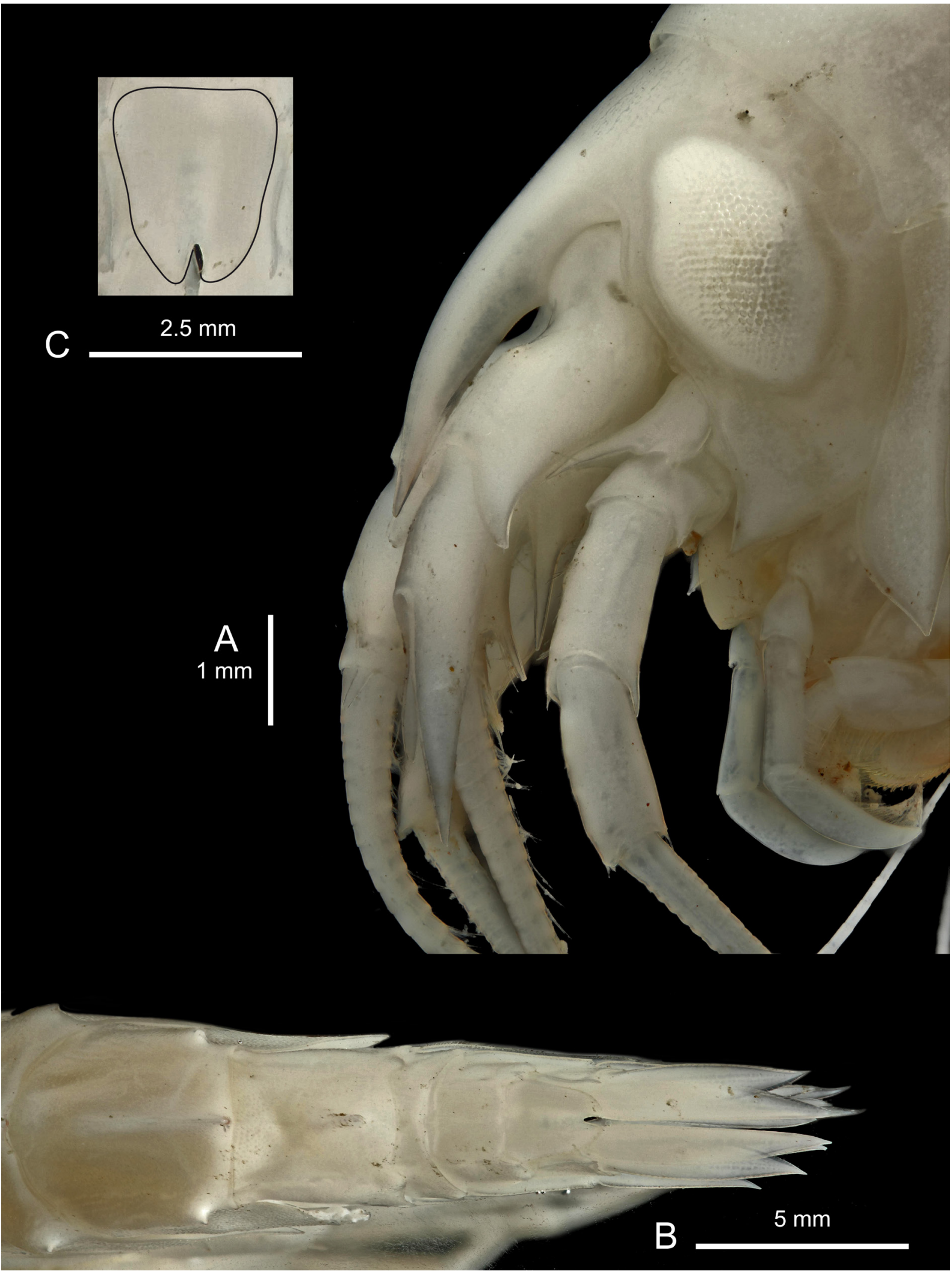

Fig. 22. Epimeria (Drakepimeria) colemani subgen. et sp. nov. A. + , paratype, eastern Weddell Sea, ANT-XXVII/8, stn 265-2, RBINS, INV. 132965. B, C. + holotype, Bransfield Strait, ANT-XXIX/3, stn 196-8, RBINS, INV. 122942. A. Head in lateral view. B. Urosome in dorsal view. C. Telson. 


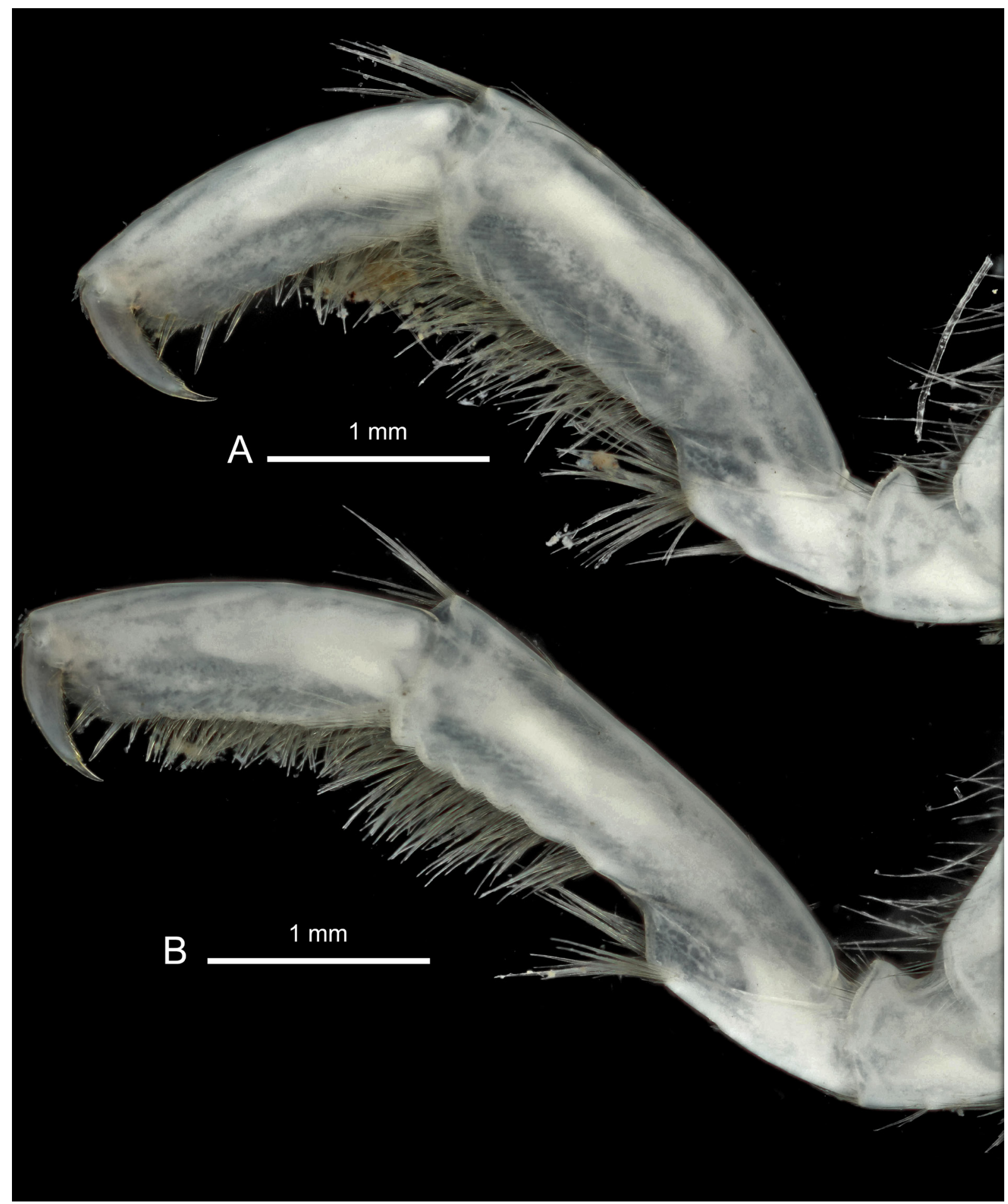

Fig. 23. Epimeria (Drakepimeria) colemani subgen. et sp. nov.,, , paratype, eastern Weddell Sea, ANTXXVII/8, stn 265-2, RBINS, INV. 132965. A. Gnathopod 1. B. Gnathopod 2. 


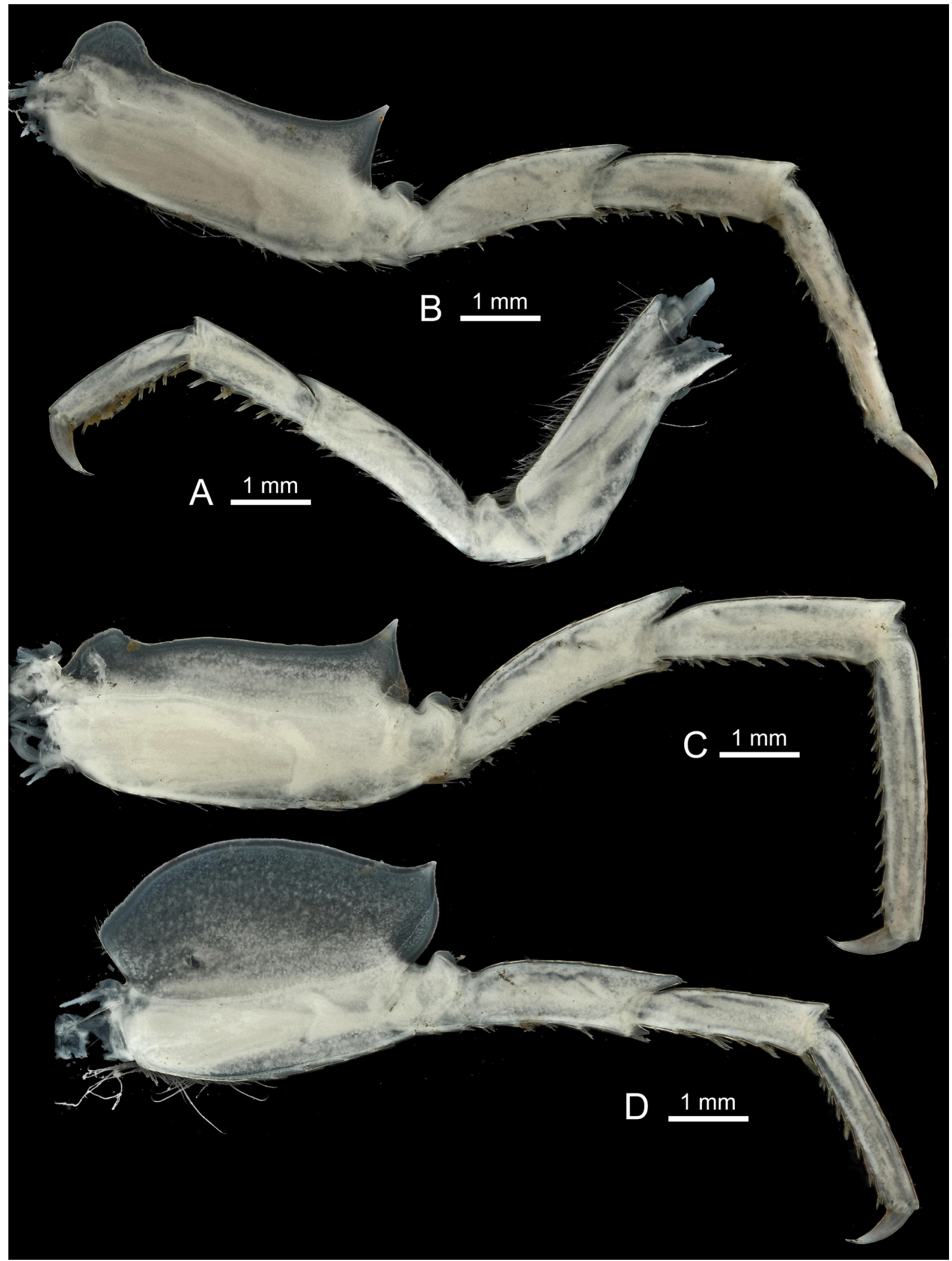

Fig. 24. Epimeria (Drakepimeria) colemani subgen. et sp. nov., + , paratype, eastern Weddell Sea, ANT-XXVII/8, stn 265-2, RBINS, INV. 132965. A. Pereiopod 4. B. Pereiopod 5. C. Pereiopod 6. D. Pereiopod 7. 


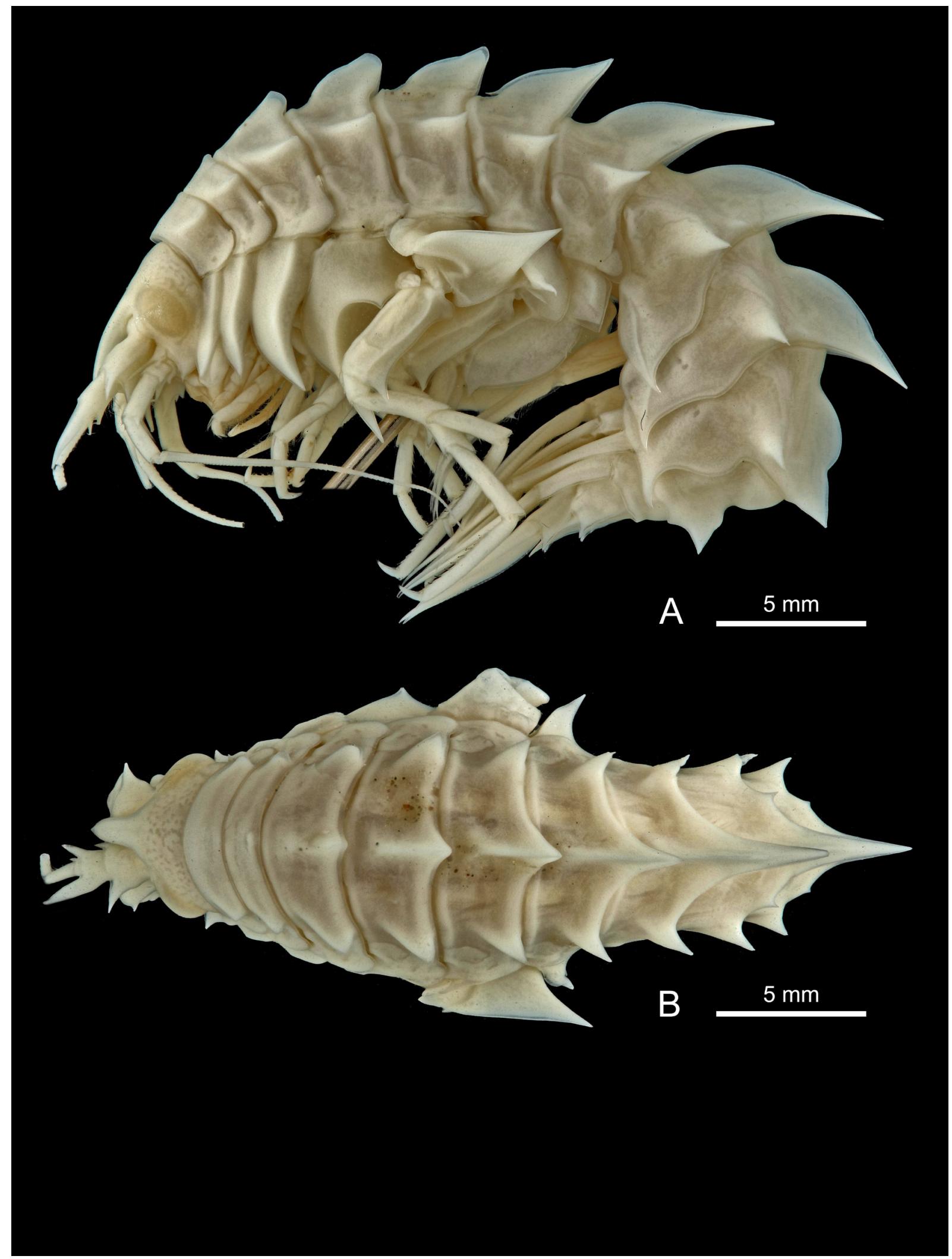

Fig. 25. Epimeria (Drakepimeria) colemani subgen. et sp. nov., adult $q$, Adélie Coast, CEAMARC 2724, MNHN-IU-2014-4337. A. Lateral habitus. B. Dorsal habitus. 


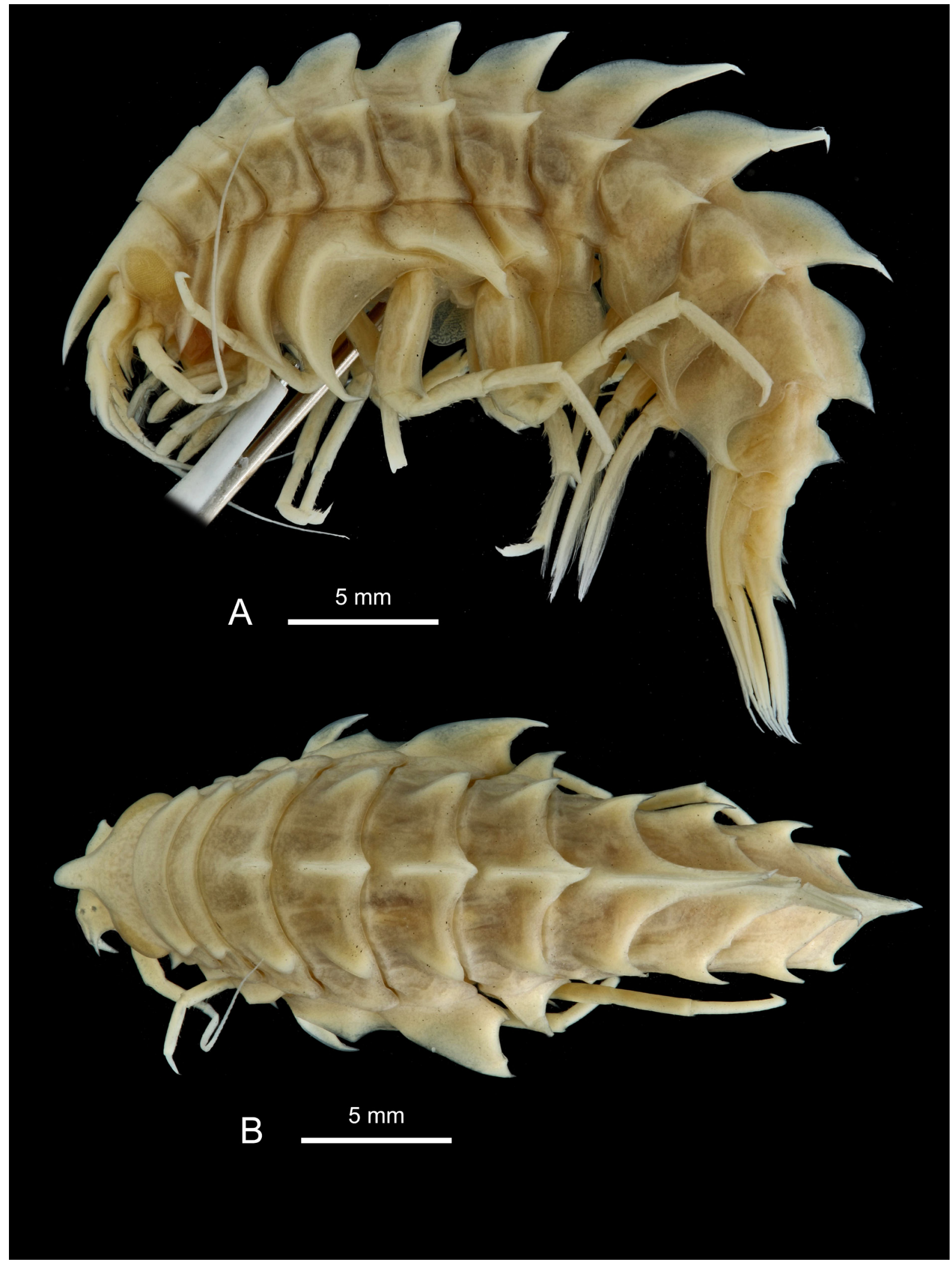

Fig. 26. Epimeria (Drakepimeria) colemani subgen. et sp. nov.,, , adult, Discovery Expedition 19021904, Ross Sea, W.Q. [Winter Quarters - hole 12], paralectotype of Epimeria macrodonta, BMNH 1907.6.6.259-262 (in part). A. Lateral habitus. B. Dorsal habitus. 


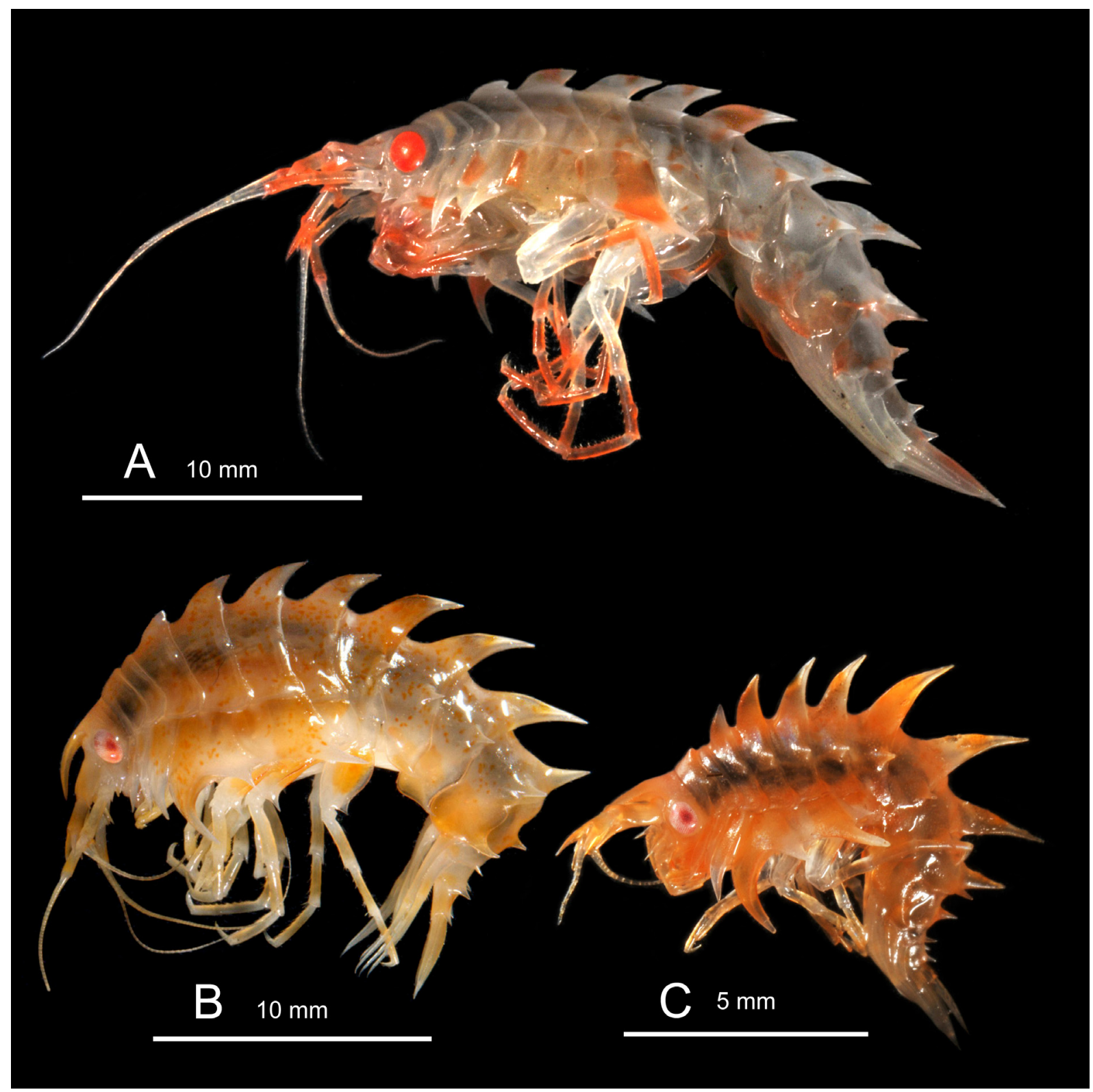

Fig. 27. Epimeria (Drakepimeria) corbariae subgen. et sp. nov., paratypes, Adélie Coast. Colour in life. A. CE- REVOLTA III, Collect_ID: REVO_449, CE-000002109, MNHN-IU-2009-2543. B. REVOLTA III, stn REVO_068, Collect_ID: REVO_493, CE-000002621, MNHN-IU-2009-2581. C. REVOLTA II, stn REVO_085, Collect_ID: REVO_191, CE-000001559, MNHN-IU-2014-4296. Photographs: Cyril Gallut (Université Pierre et Marie Curie). 


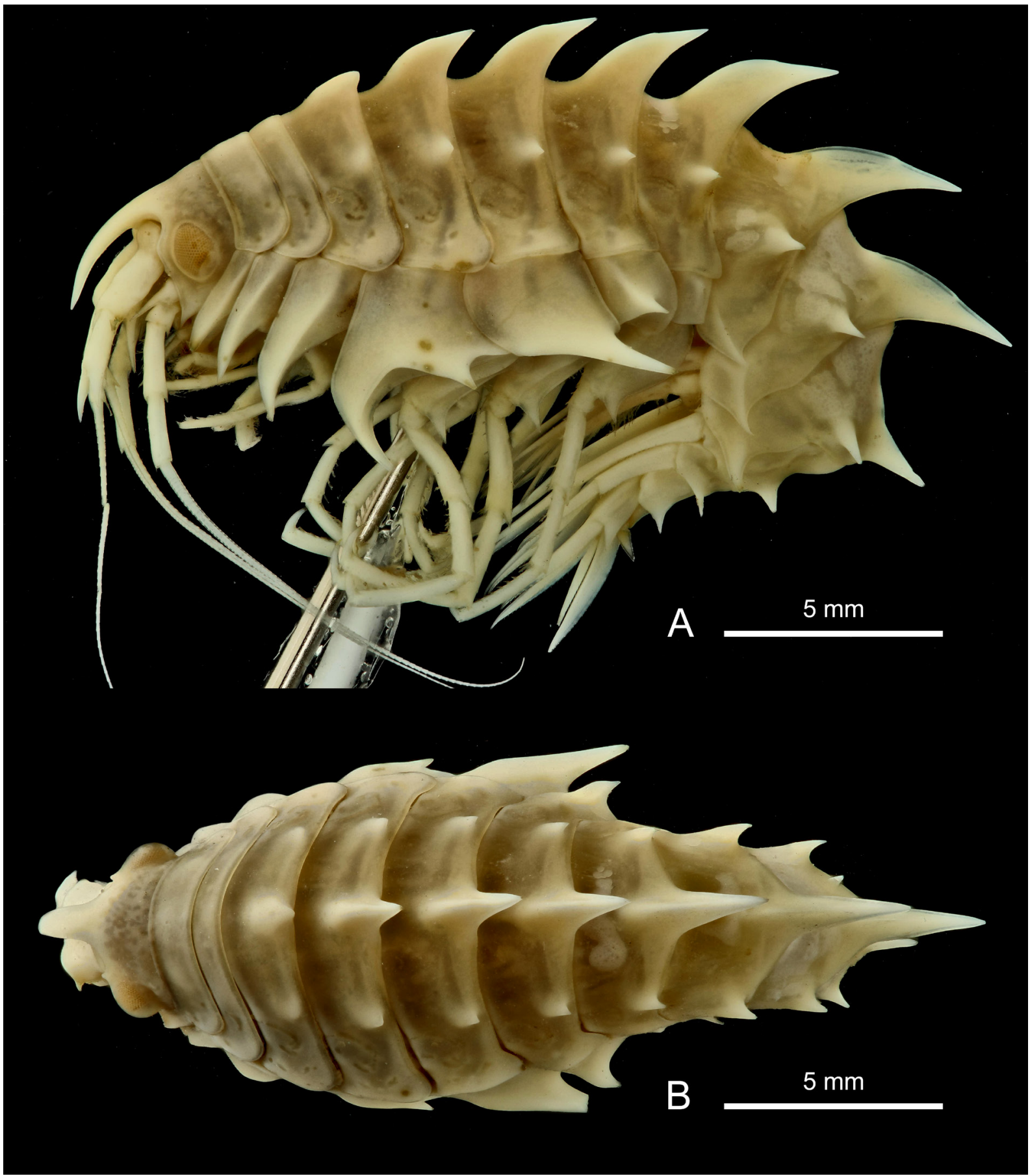

Fig. 28. Epimeria (Drakepimeria) corbariae subgen. et sp. nov.,, , holotype, Adélie Coast, REVOLTA I, REVO-007b, sample 249, MNHN-IU-2009-2570. A. Lateral habitus. B. Dorsal habitus. Note the absence of mid-dorsal tooth on the first body segment. 


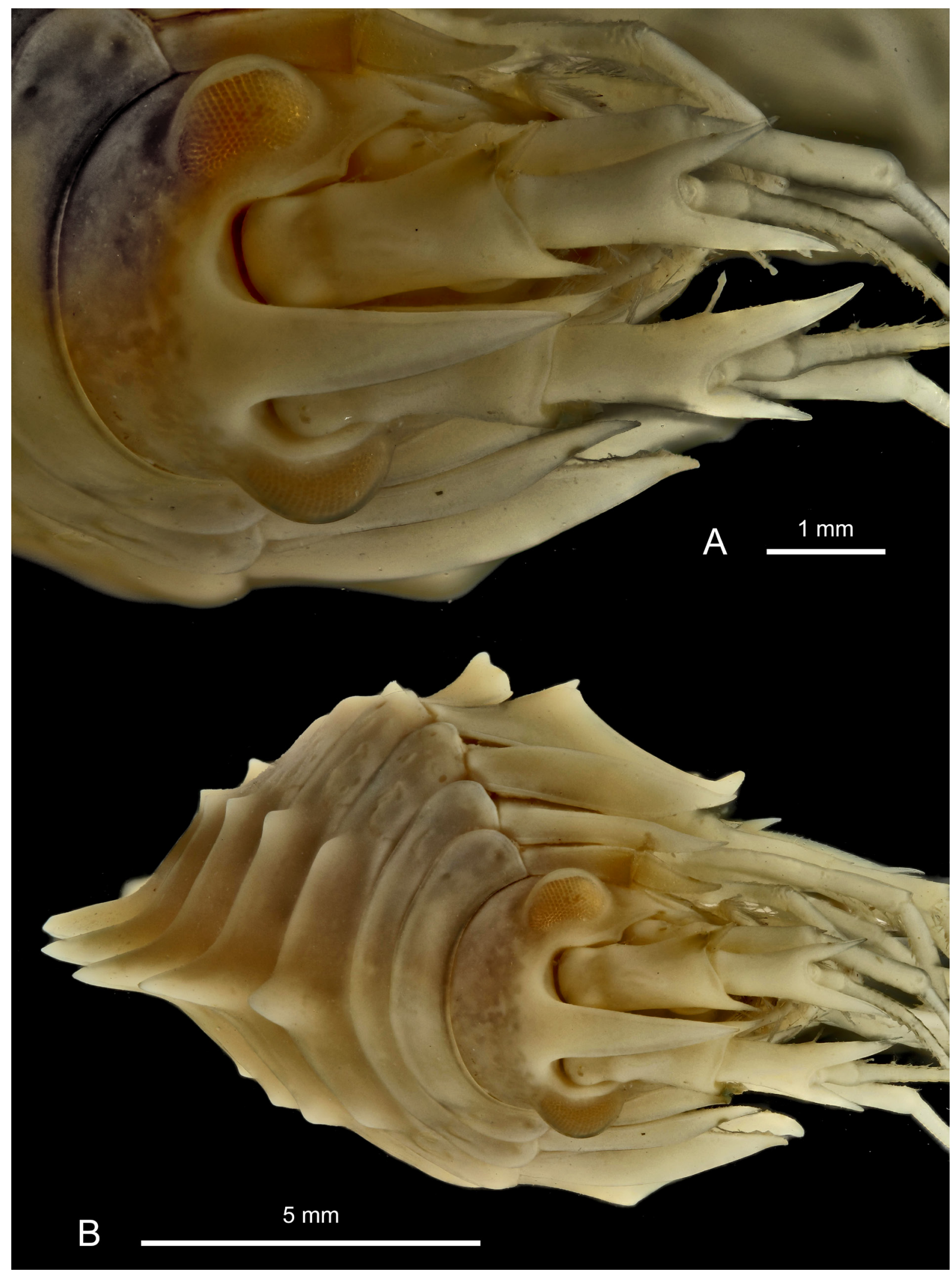

Fig. 29. Epimeria (Drakepimeria) corbariae subgen. et sp. nov.,, , holotype, Adélie Coast, REVOLTA I, REVO-007b, sample 249, MNHN-IU-2009-2570. A. Head in facial view. B. Facial habitus. 


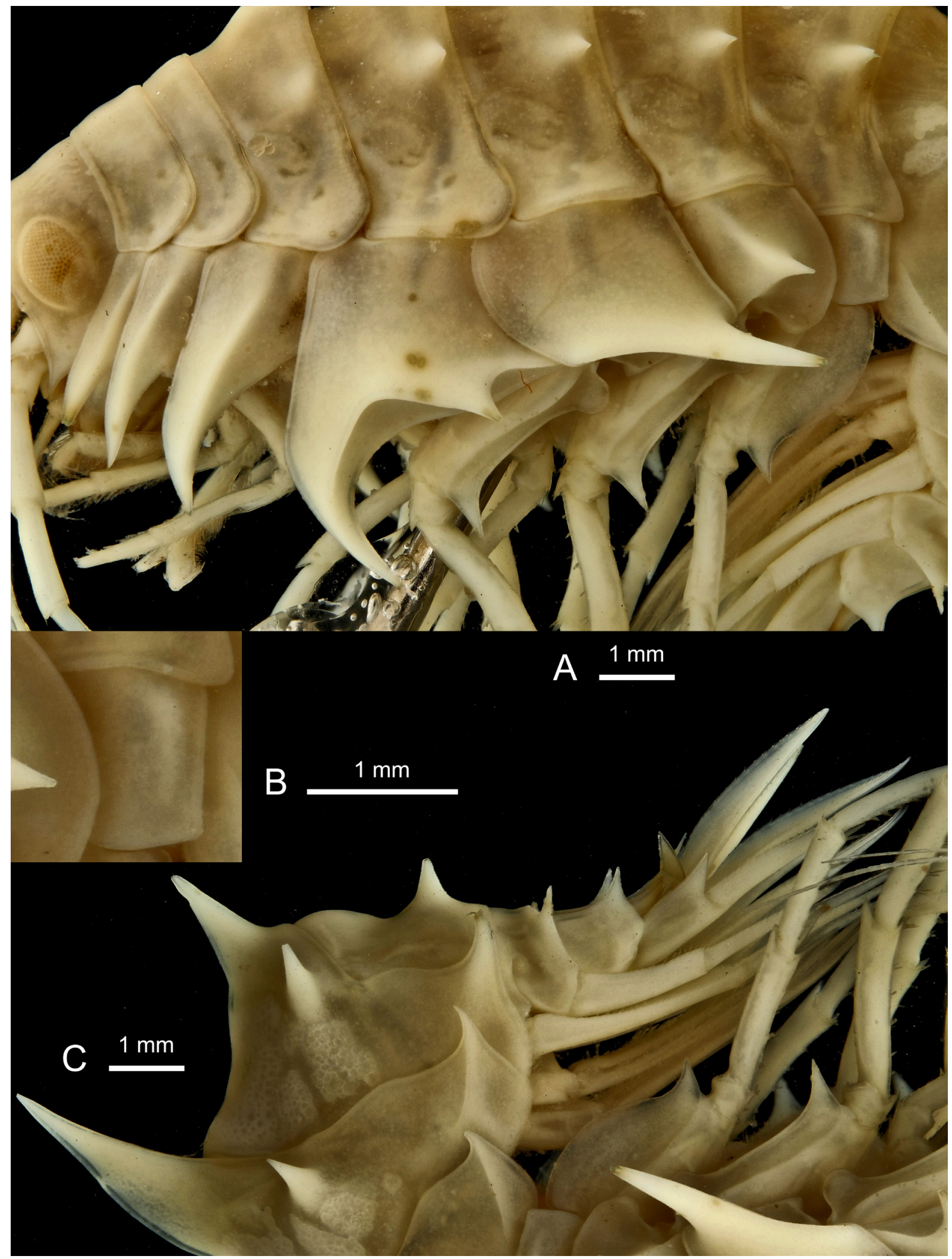

Fig. 30. Epimeria (Drakepimeria) corbariae subgen. et sp. nov., + , holotype, Adélie Coast, REVOLTA I, REVO-07b, sample 249, MNHN-IU-2009-2570. A. Coxae. B. Coxa 7 and posterior half of coxa 6. C. Urosome and pleonite 1 . 


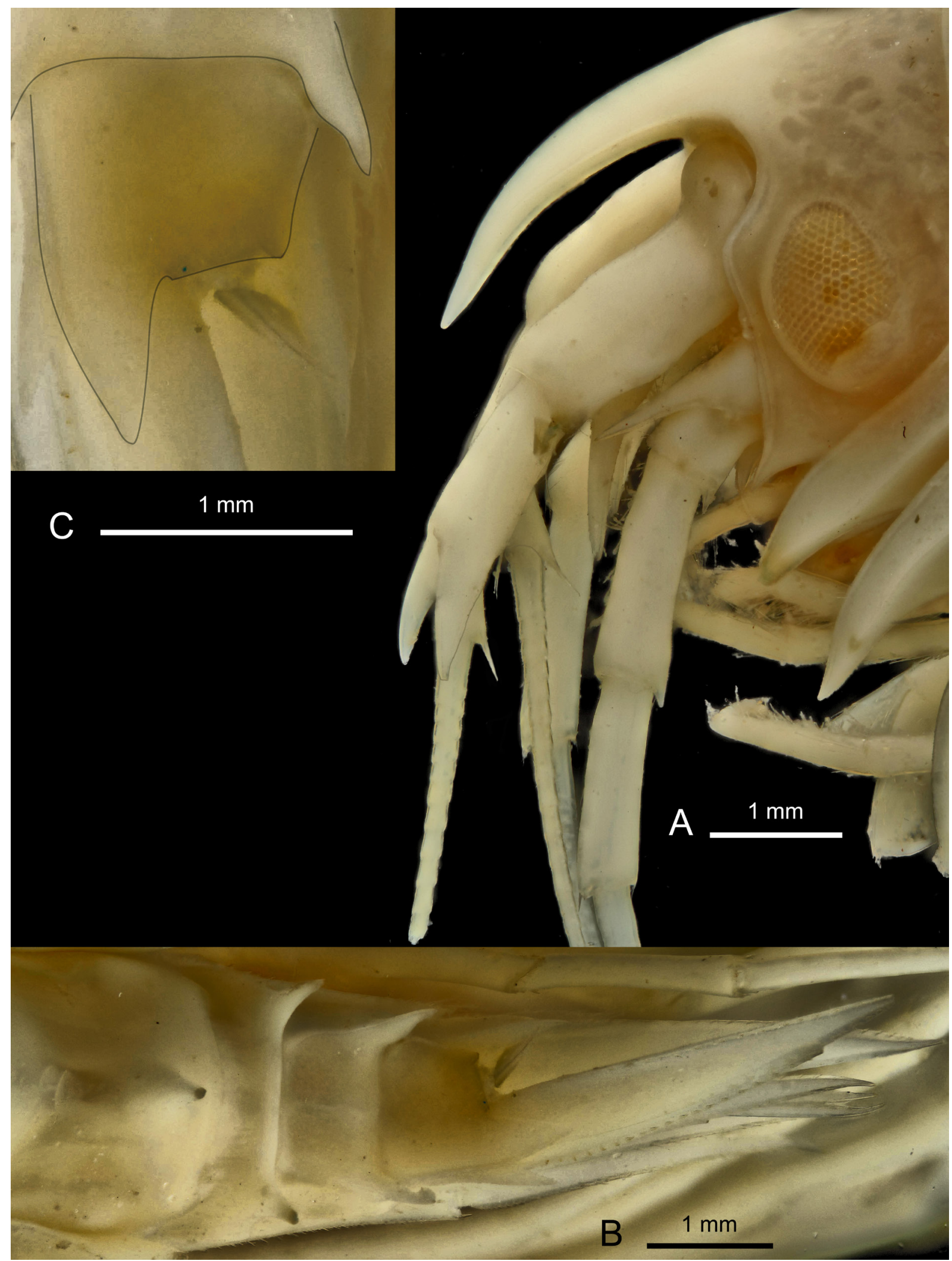

Fig. 31. Epimeria (Drakepimeria) corbariae subgen. et sp. nov., $q$, holotype, Adélie Coast, REVOLTA I, REVO-07b, sample 249, MNHN-IU-2009-2570. A. Head in lateral view. B. Urosome in dorsal view. C. Telson. 


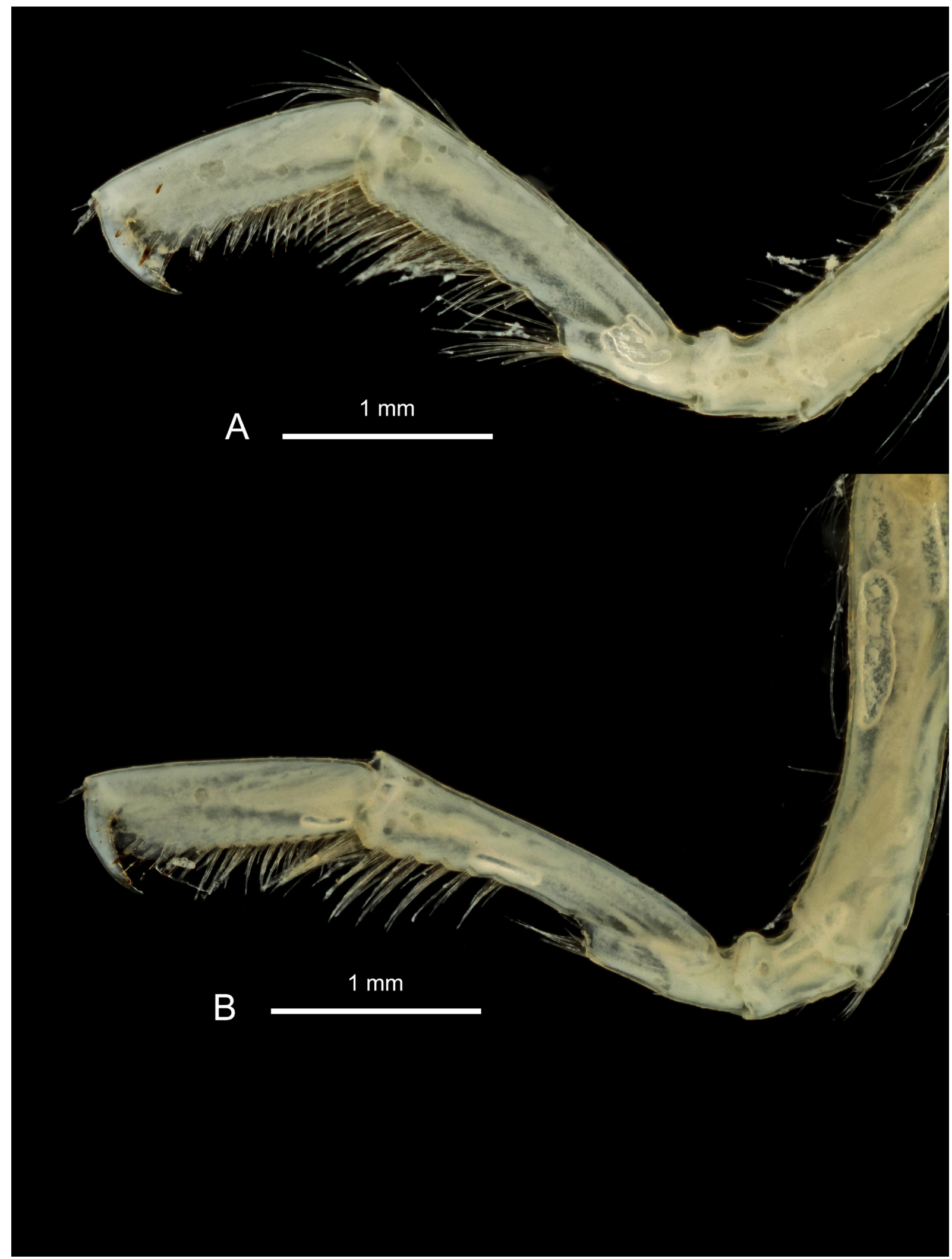

Fig. 32. Epimeria (Drakepimeria) corbariae subgen. et sp. nov., $q$, holotype, Adélie Coast, REVOLTA I, REVO-07b, sample 249, MNHN-IU-2009-2570. A. Gnathopod 1. B. Gnathopod 2. 


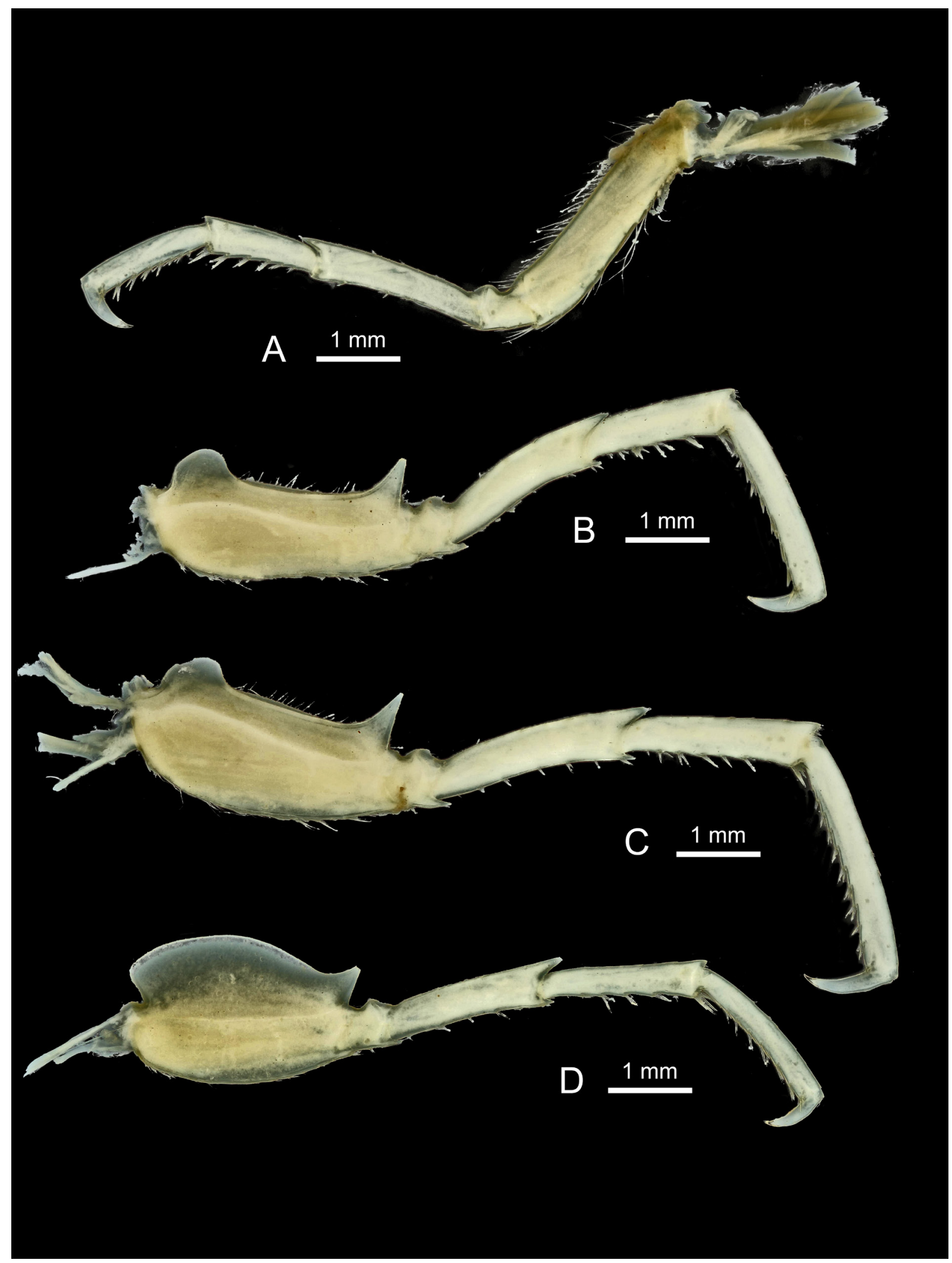

Fig. 33. Epimeria (Drakepimeria) corbariae subgen. et sp. nov., $q$, holotype, Adélie Coast, REVOLTA I, REVO-07b, sample 249, MNHN-IU-2009-2570. A. Pereiopod 4. B. Pereiopod 5. C. Pereiopod 6. D. Pereiopod 7. 


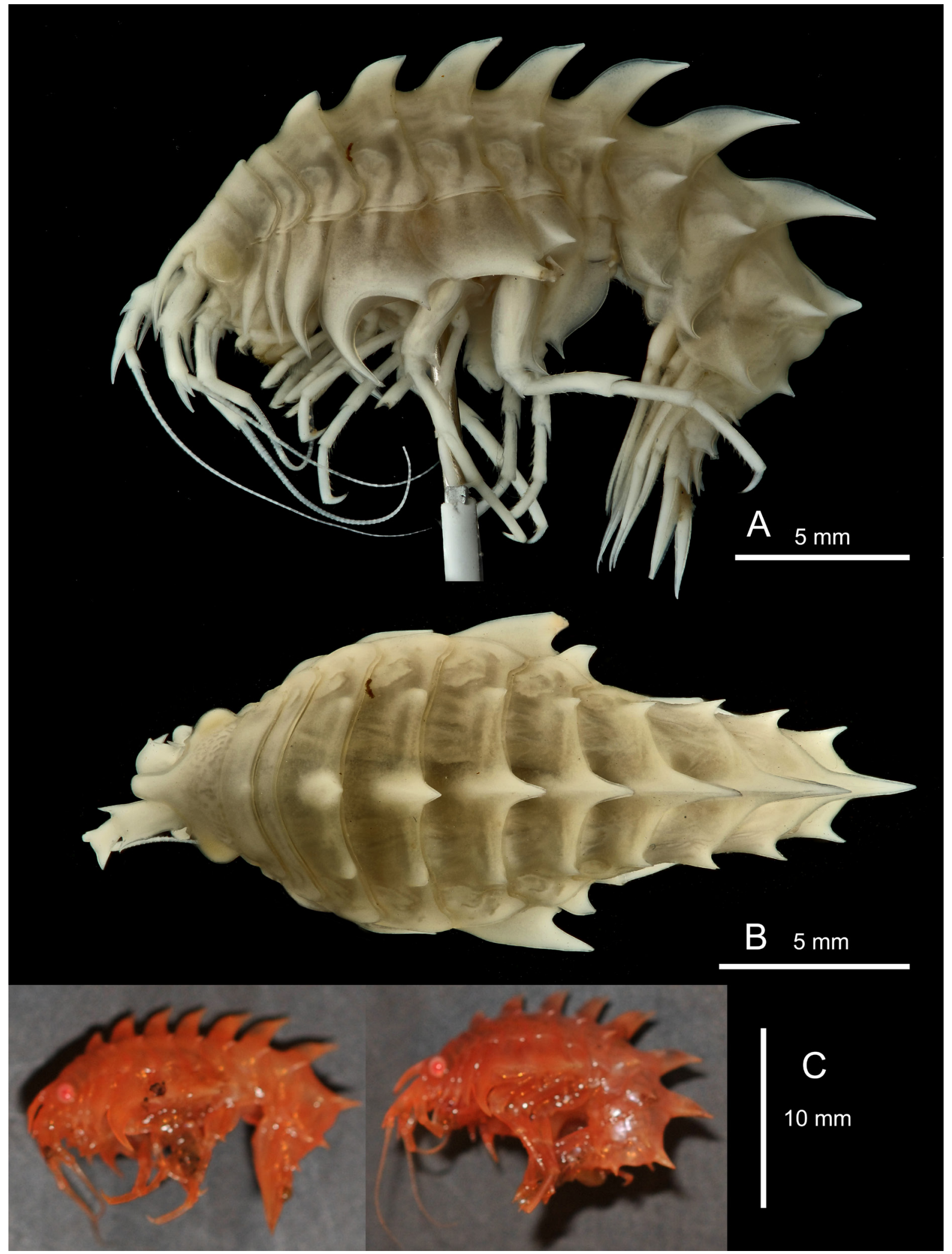

Fig. 34. Epimeria (Drakepimeria) corbariae subgen. et sp. nov.,, , paratype, Adélie Coast, REVO 481, MNHN-IU-2009-2563. A. Lateral habitus. B. Dorsal habitus. Note the presence of a trace of mid-dorsal tooth on the first body segment. C. $q$, , paratypes, Adélie Coast, REVOLTA II, stn REVO 162, MNHNIU-2014-7325, colour in life, photograph Cyril Gallut (Université Pierre et Marie Curie). 


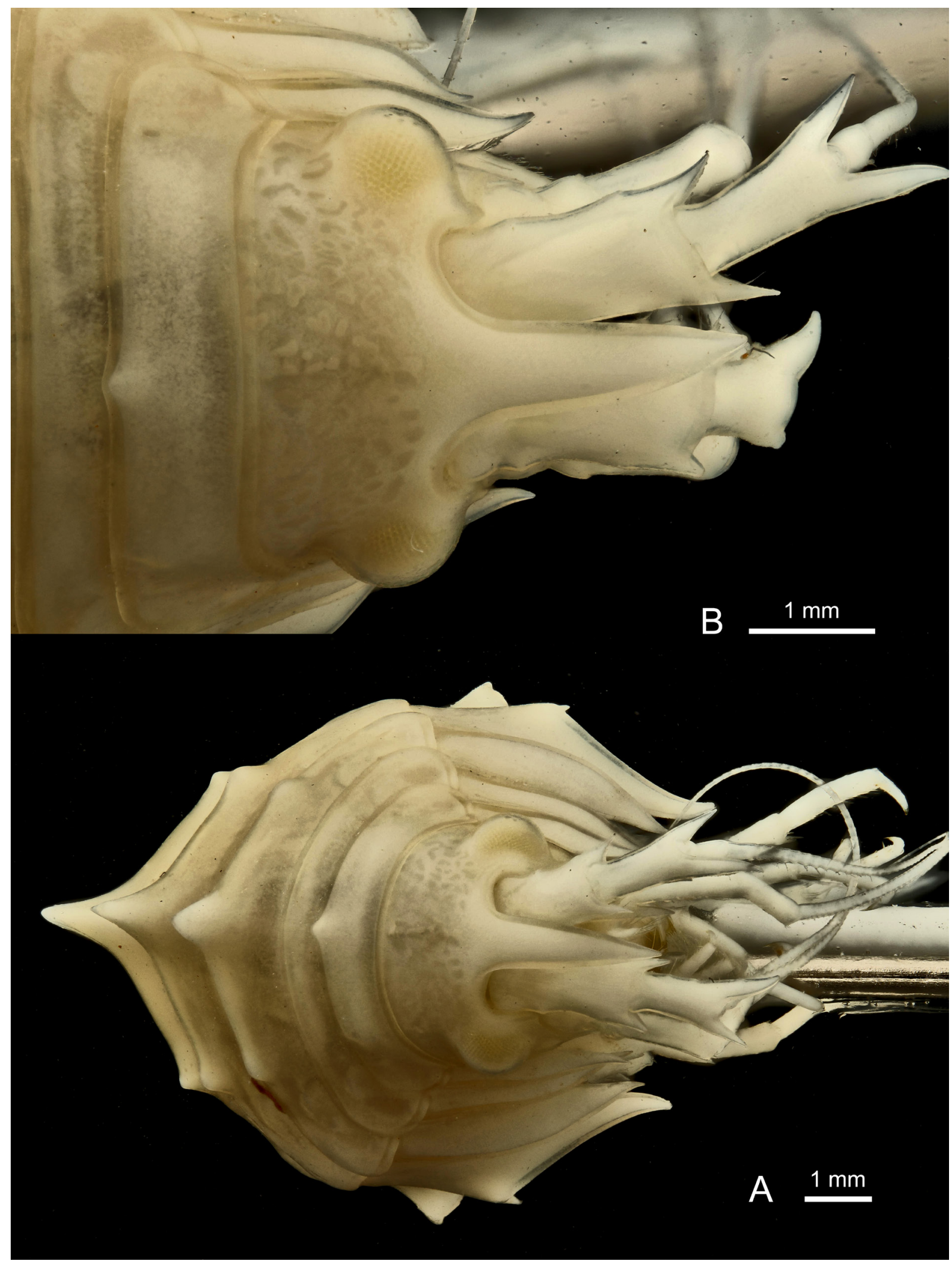

Fig. 35. Epimeria (Drakepimeria) corbariae subgen. et sp. nov., + , paratype, Adélie Coast, collect nr REVO_481, MNHN-IU-2009-2563. A. Facial habitus. B. Head in facial view. 


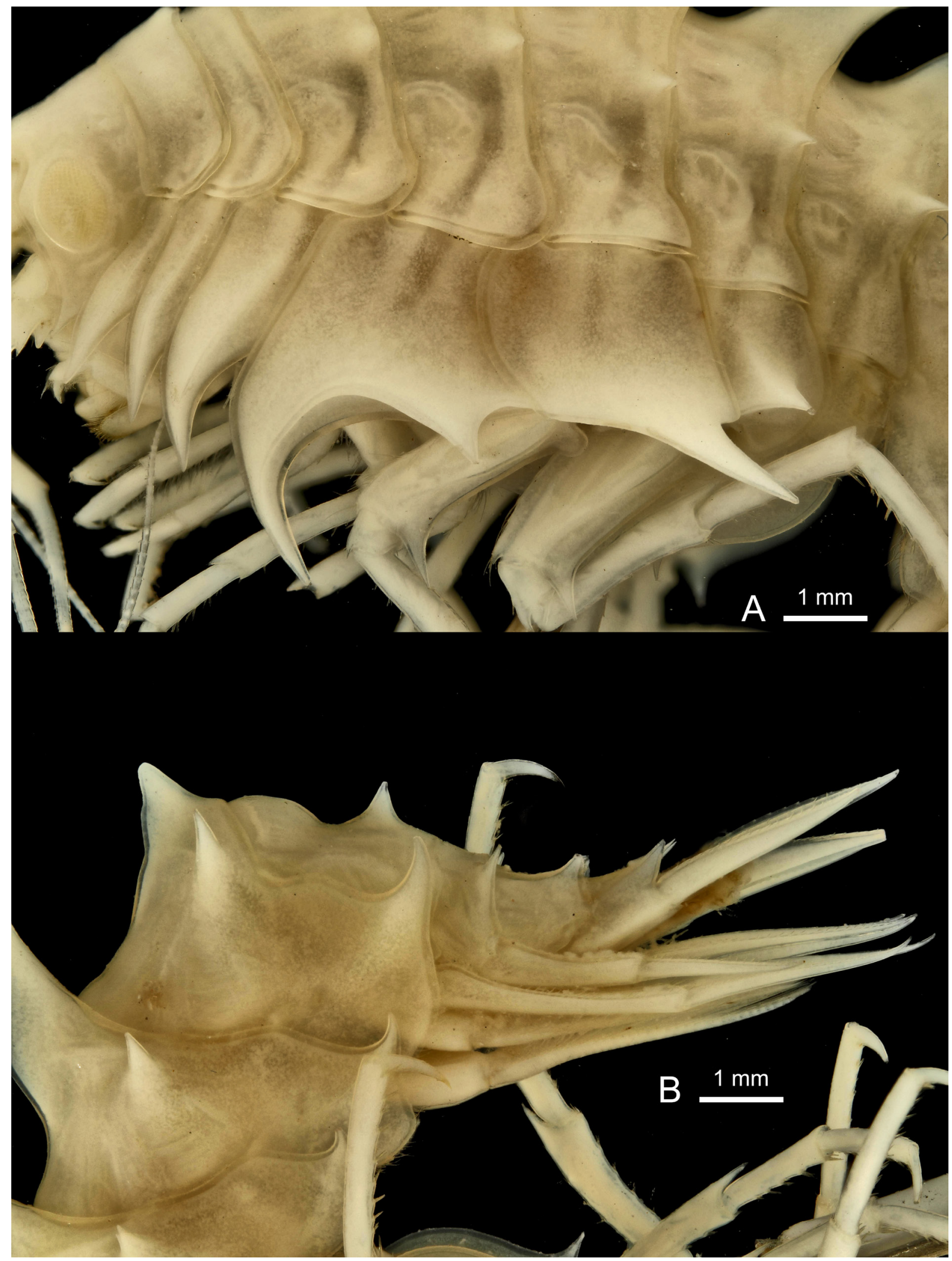

Fig. 36. Epimeria (Drakepimeria) corbariae subgen. et sp. nov., $q$, paratype, Adélie Coast, collect nr REVO_481, MNHN-IU-2009-2563. A. Coxae. B. Urosome. 


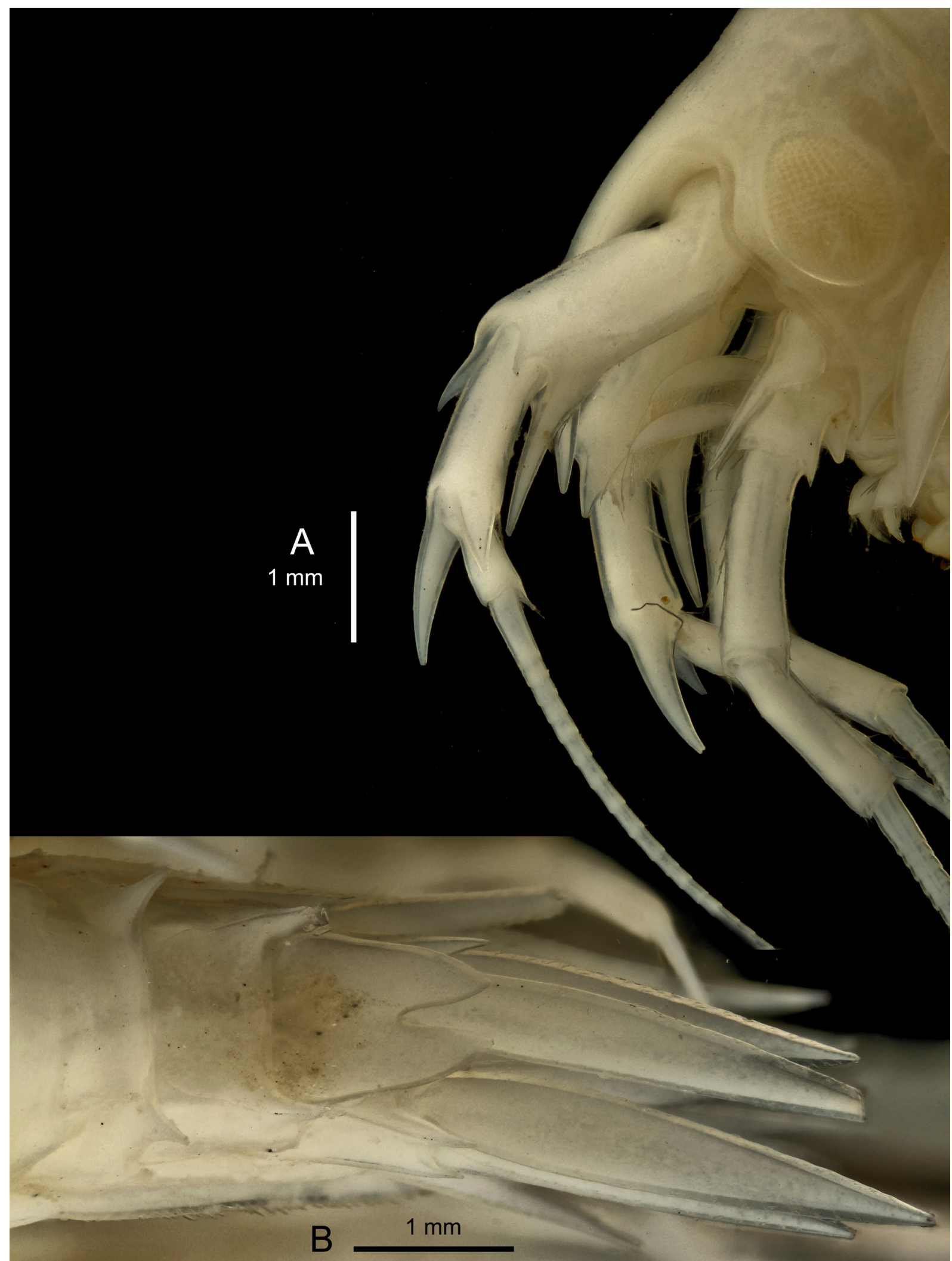

Fig. 37. Epimeria (Drakepimeria) corbariae subgen. et sp. nov., $q$, paratype, Adélie Coast, collect nr REVO_481, MNHN-IU-2009-2563. A. Head in lateral view. B. Urosome in dorsal view. 


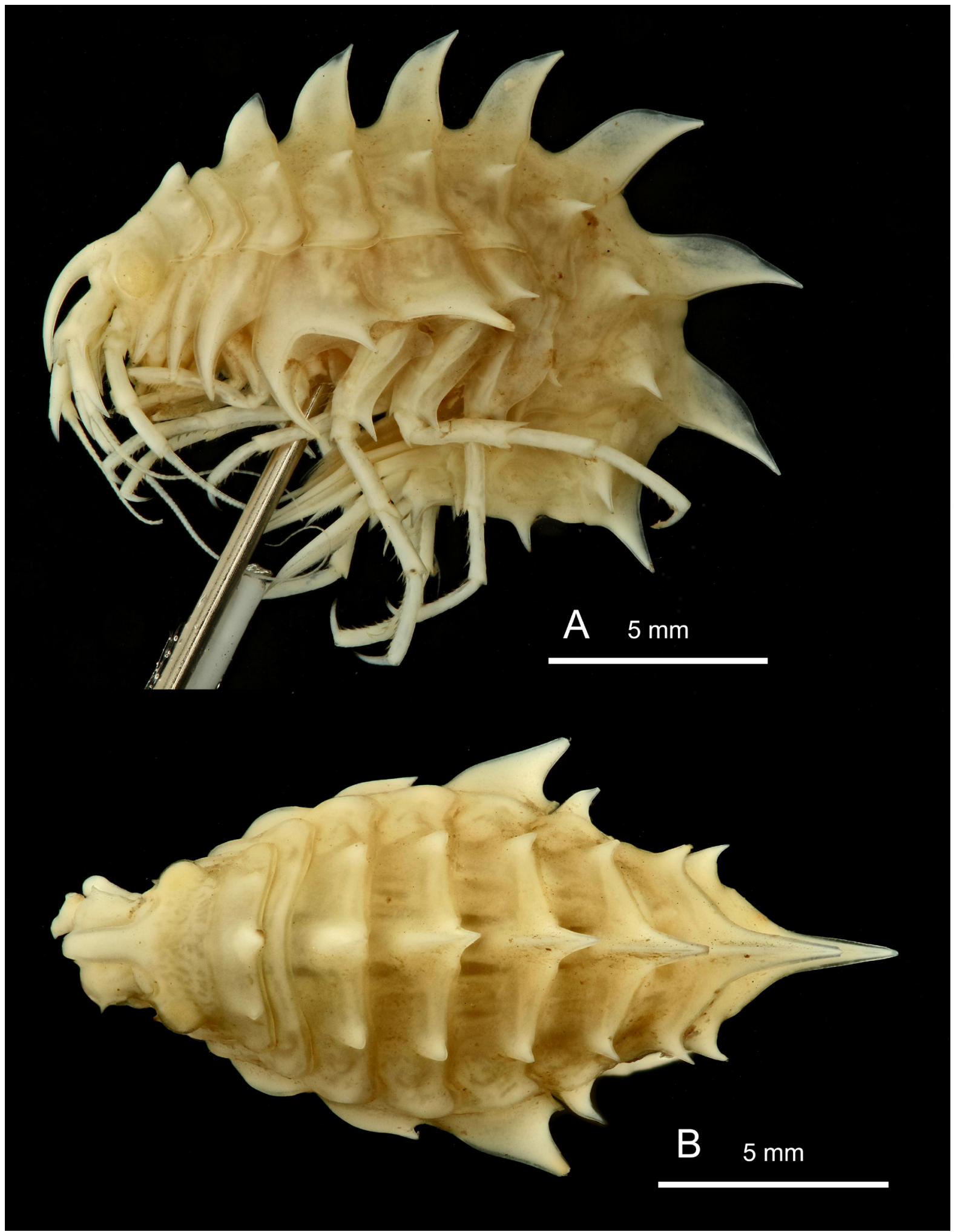

Fig. 38. Epimeria (Drakepimeria) corbariae subgen. et sp. nov., †, paratype, Adélie Coast, REVO 162, MNHN-IU-2014-7325. A. Lateral habitus. B. Dorsal habitus. Note the presence of a well-developed mid-dorsal tooth (and of a pair of weak dorsolateral teeth) on the first body segment; the wider projections broader and the body broader in lateral view than for the two other illustrated specimen. This morphological variant is unfrequent. 


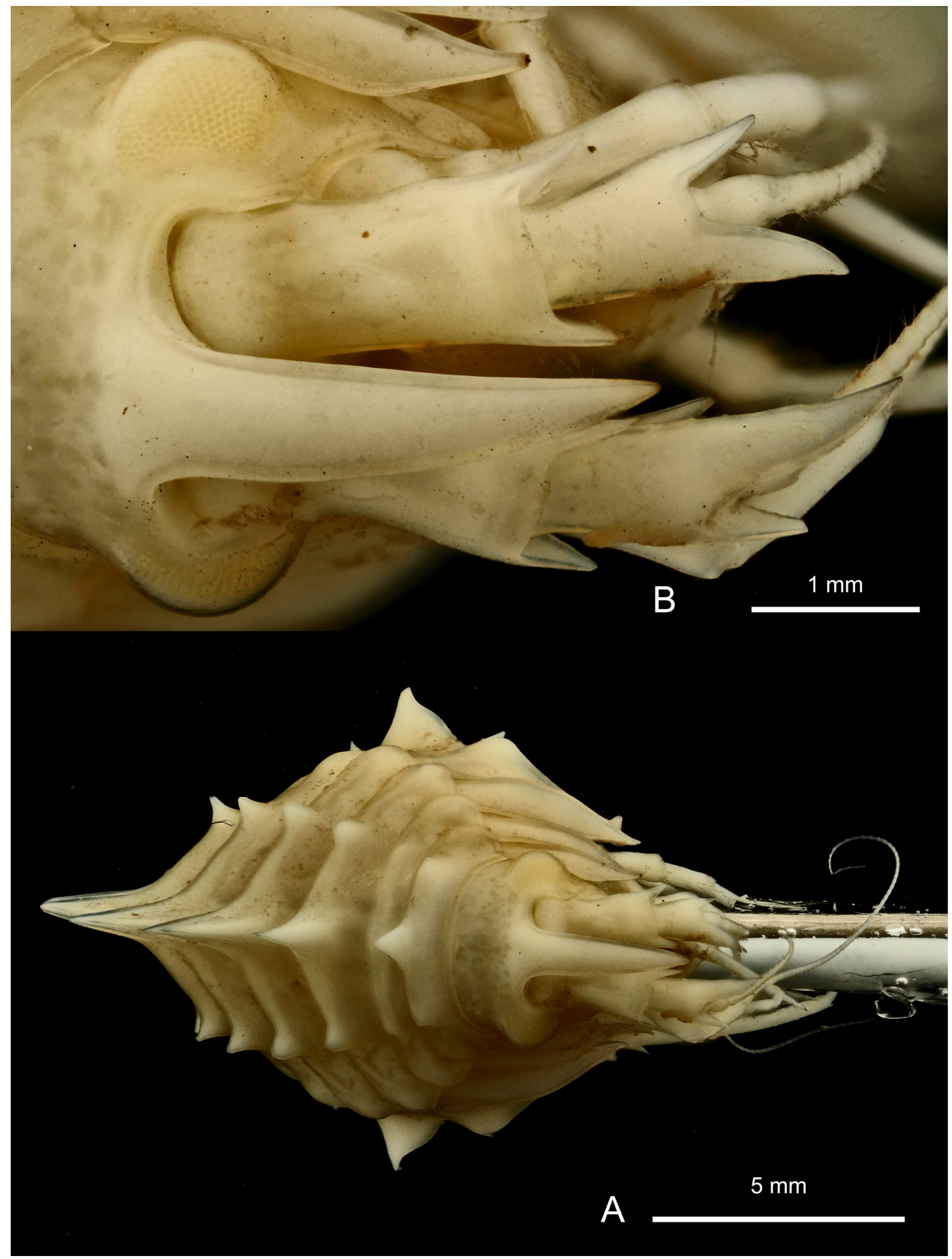

Fig. 39. Epimeria (Drakepimeria) corbariae subgen. et sp. nov.,, , paratype, Adélie Coast, REVO 162, MNHN-IU-2014-7325. A. Facial habitus. B. Head in facial view 


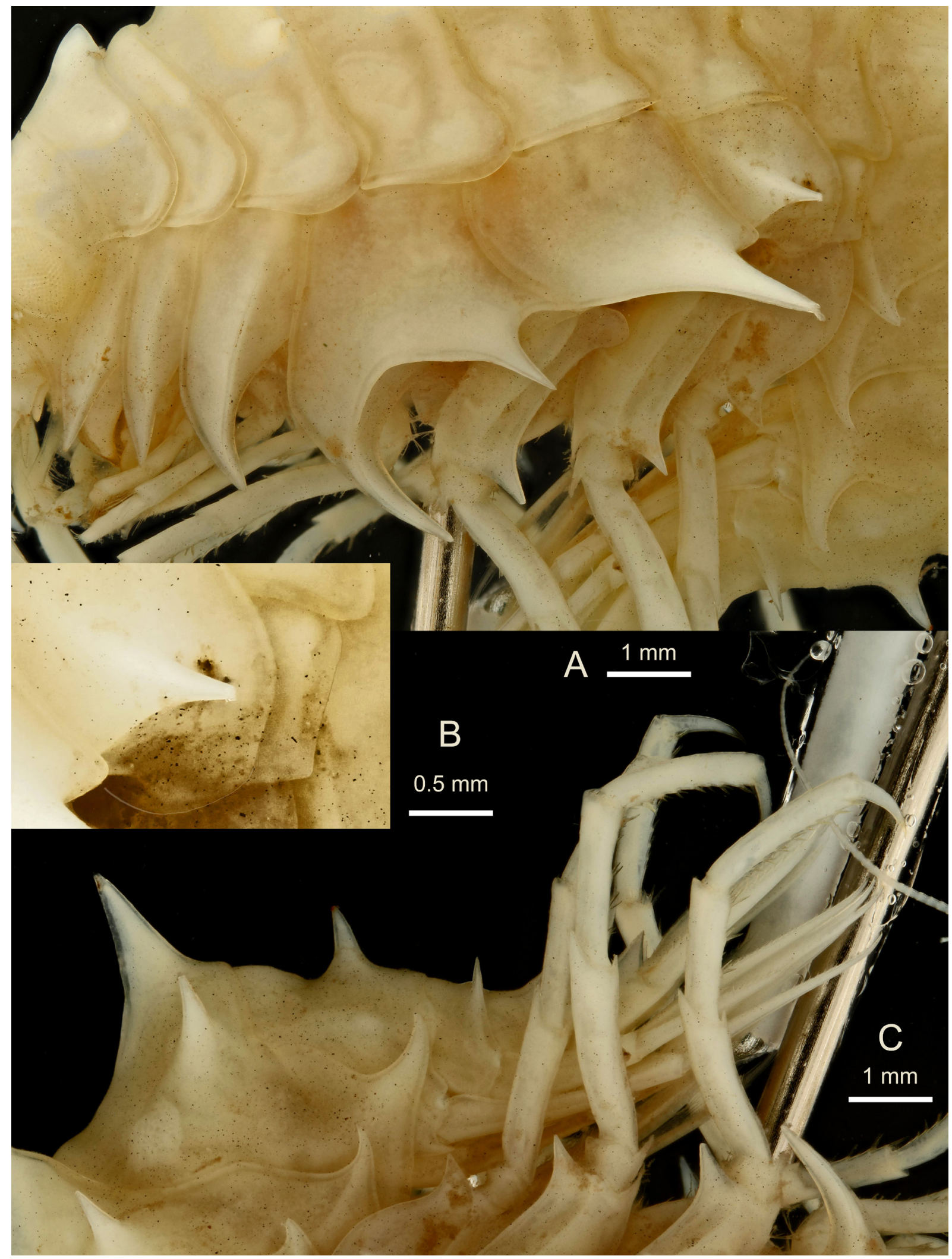

Fig. 40. Epimeria (Drakepimeria) corbariae subgen. et sp. nov., o , paratype, Adélie Coast, REVO 162, MNHN-IU-2014-7325. A. Coxae. B. Coxae 6-7. C. Urosome. 


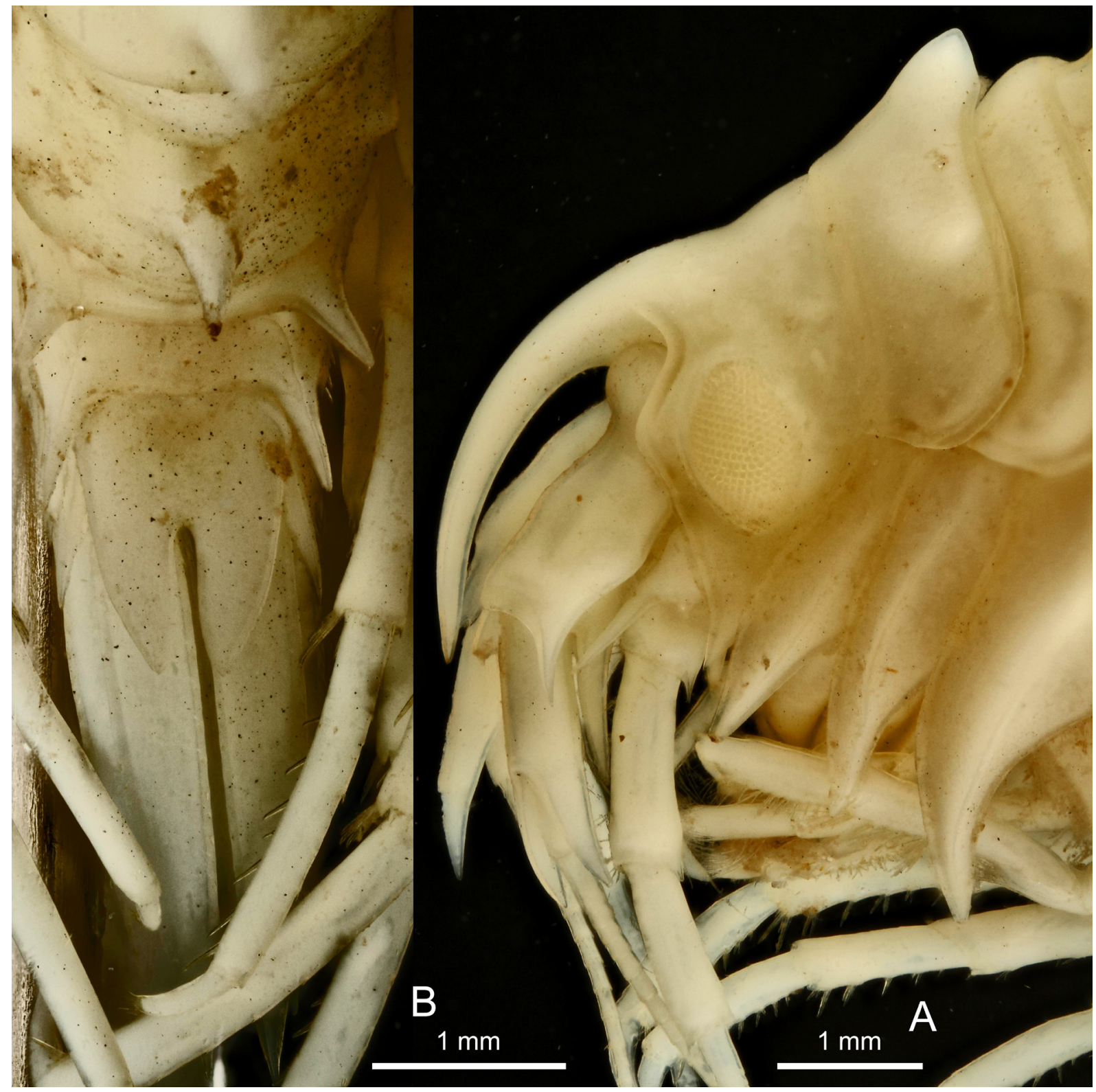

Fig. 41. Epimeria (Drakepimeria) corbariae subgen. et sp. nov.,, , paratype, Adélie Coast, REVO 162, MNHN-IU-2014-7325. A. Head in lateral view. B. Urosome in dorsal view. 


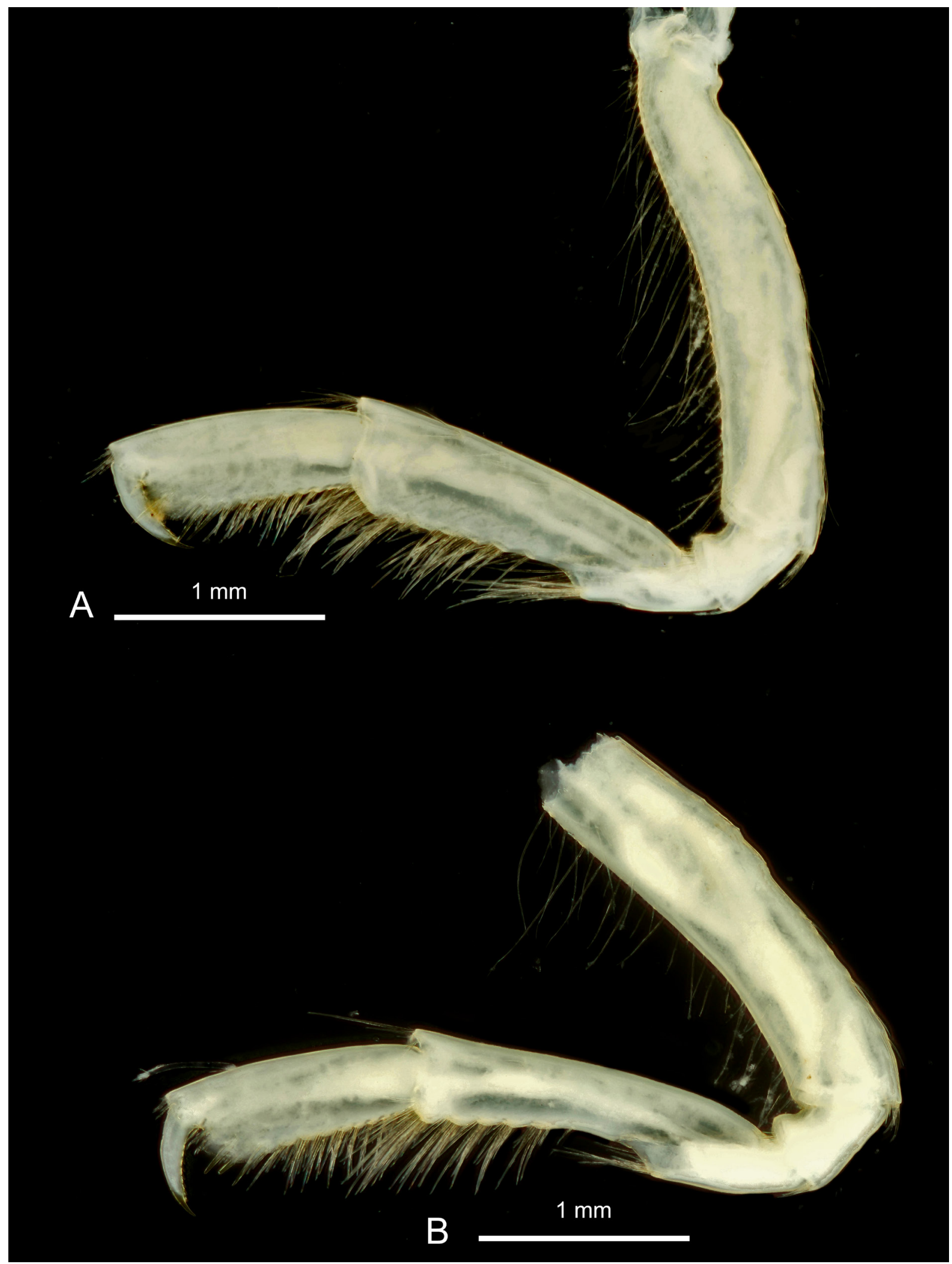

Fig. 42. Epimeria (Drakepimeria) corbariae subgen. et sp. nov.,, , paratype, Adélie Coast, REVO 162, MNHN-IU-2014-7325. A. Gnathopod 1. B. Gnathopod 2. 


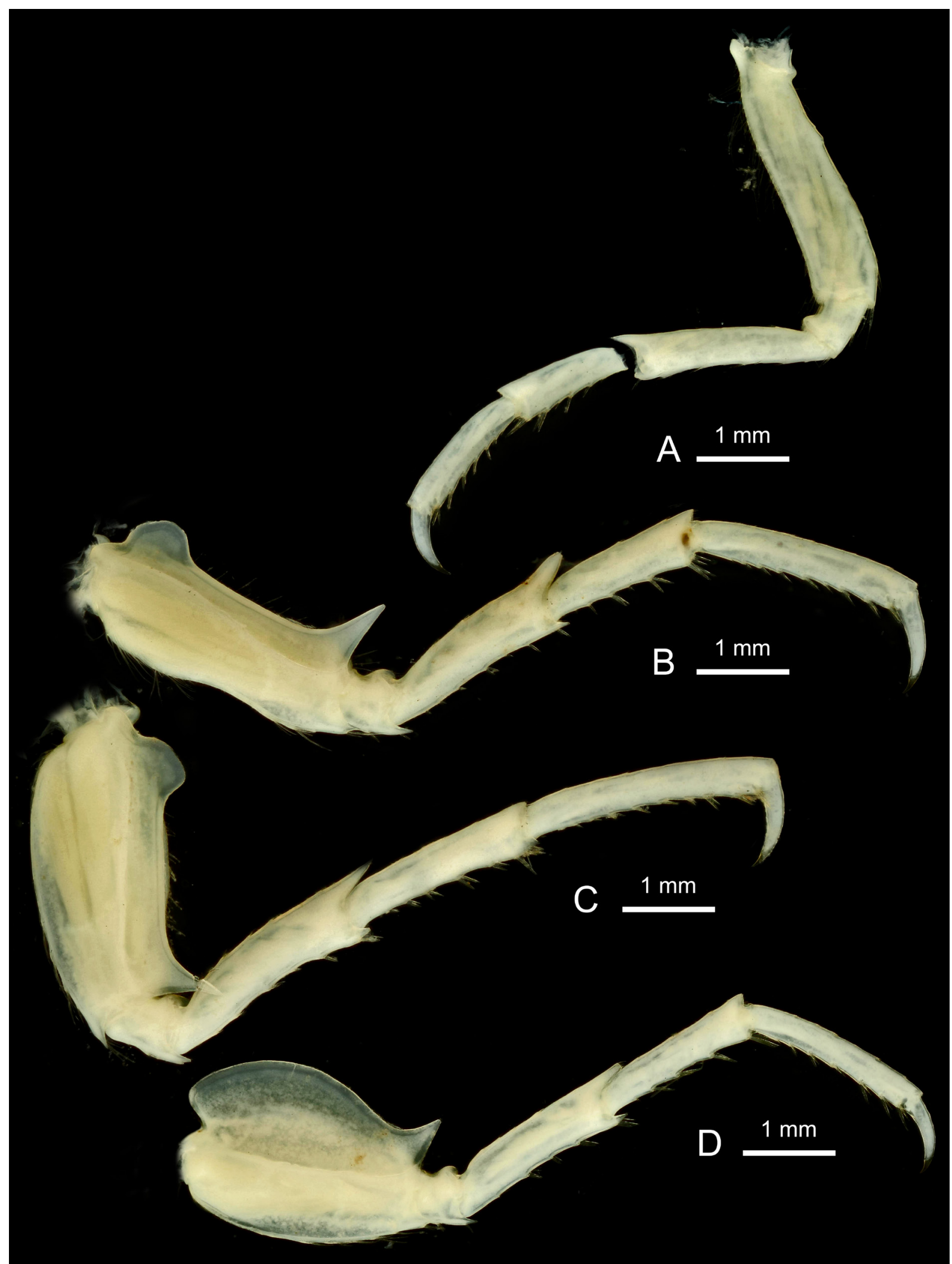

Fig. 43. Epimeria (Drakepimeria) corbariae subgen. et sp. nov.,, , paratype, Adélie Coast, REVO 162, MNHN-IU-2014-7325. A. Pereiopod 4. B. Pereiopod 5. C. Pereiopod 6. D. Pereiopod 7. 


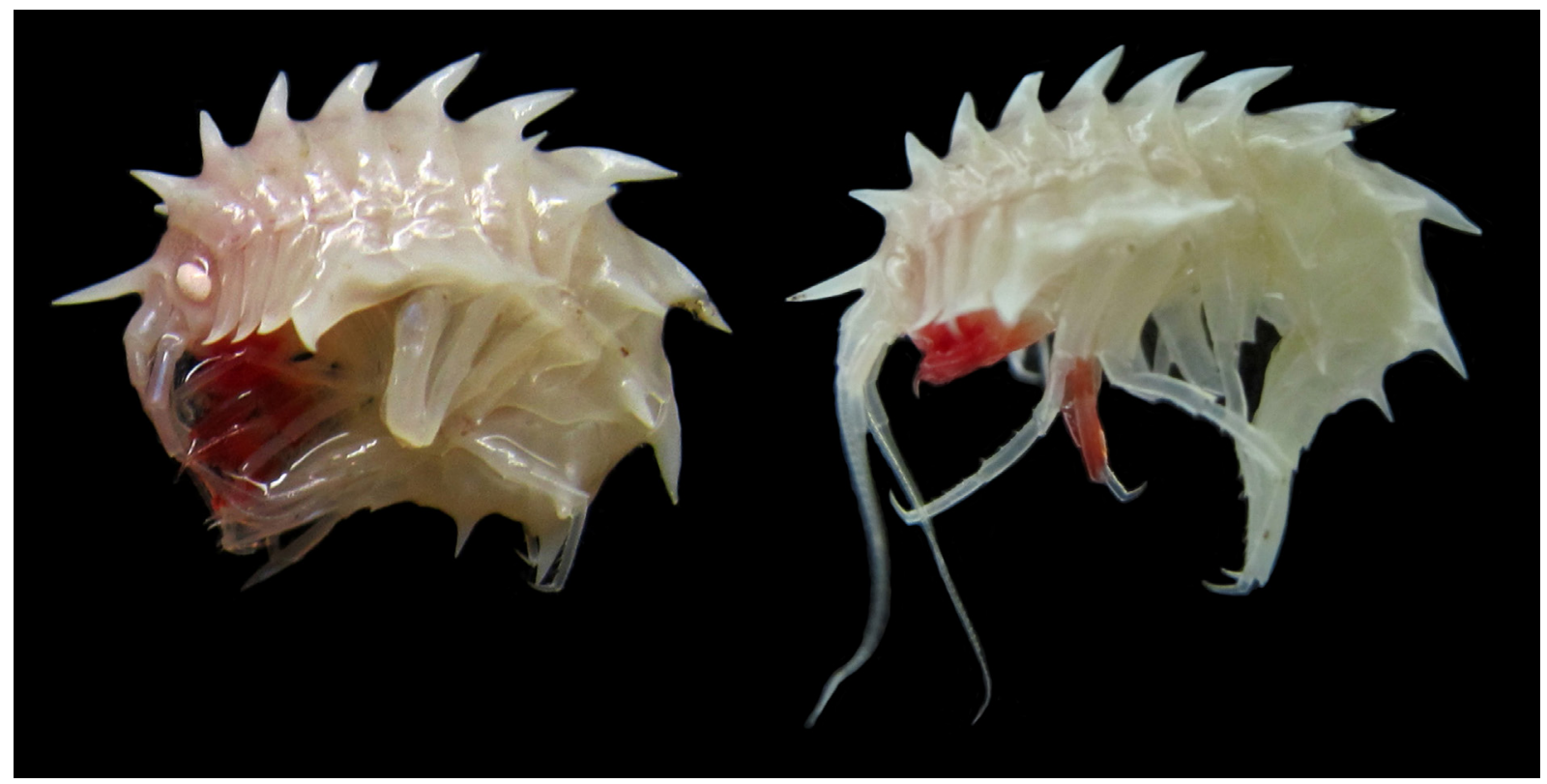

Fig. 44. Epimeria (Drakepimeria) cyrano subgen. et sp. nov., + , holotype, eastern Weddell Sea, ANT XXVII/3, stn 263-6, RBINS, INV. 132967, colour in life (photographs: Ch. Havermans and H. Robert). 


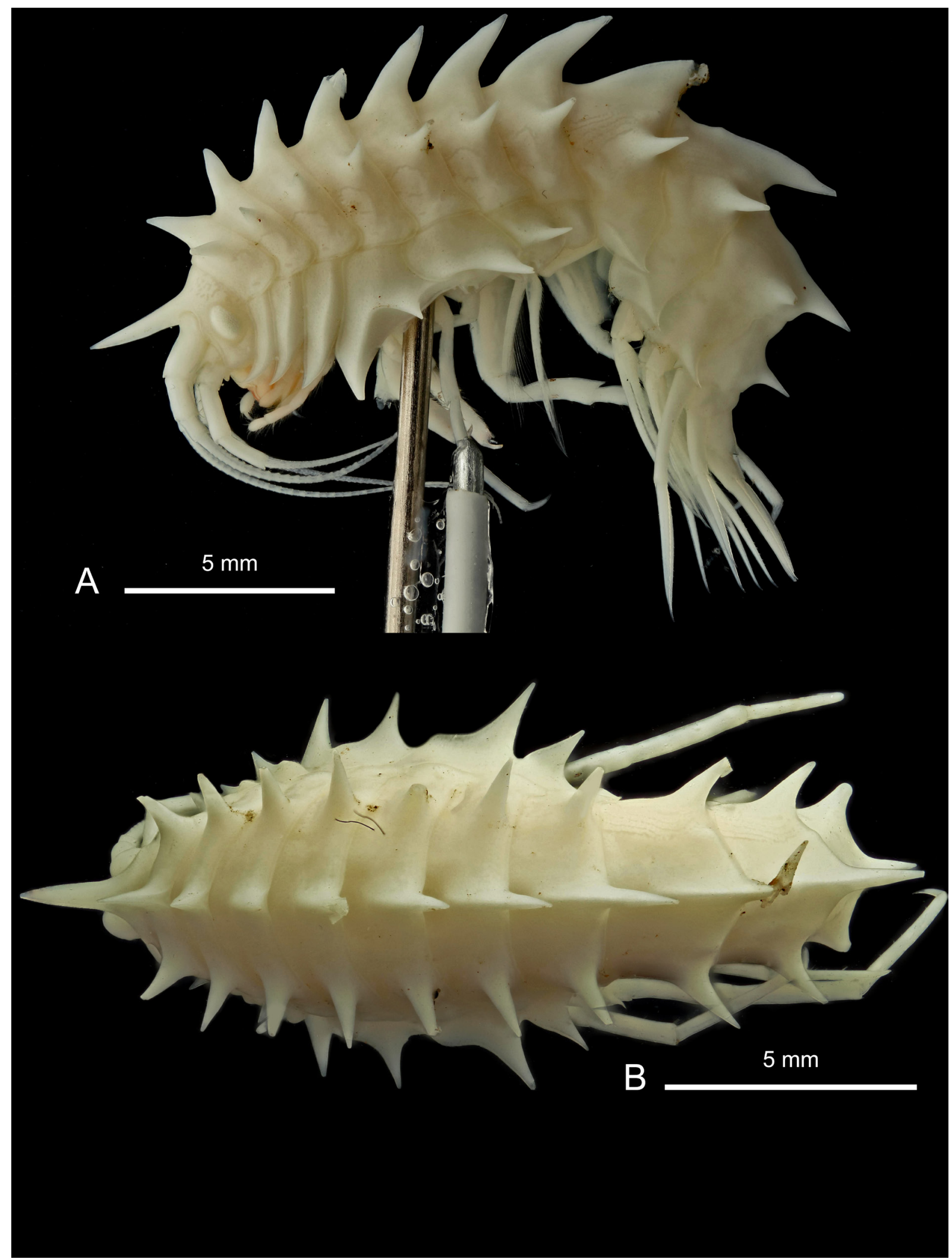

Fig. 45. Epimeria (Drakepimeria) cyrano subgen. et sp. nov.,, , holotype, eastern Weddell Sea, ANT XXVII/3, stn 263-6, RBINS, INV. 132967. A. Lateral habitus. B. Dorsal habitus. 


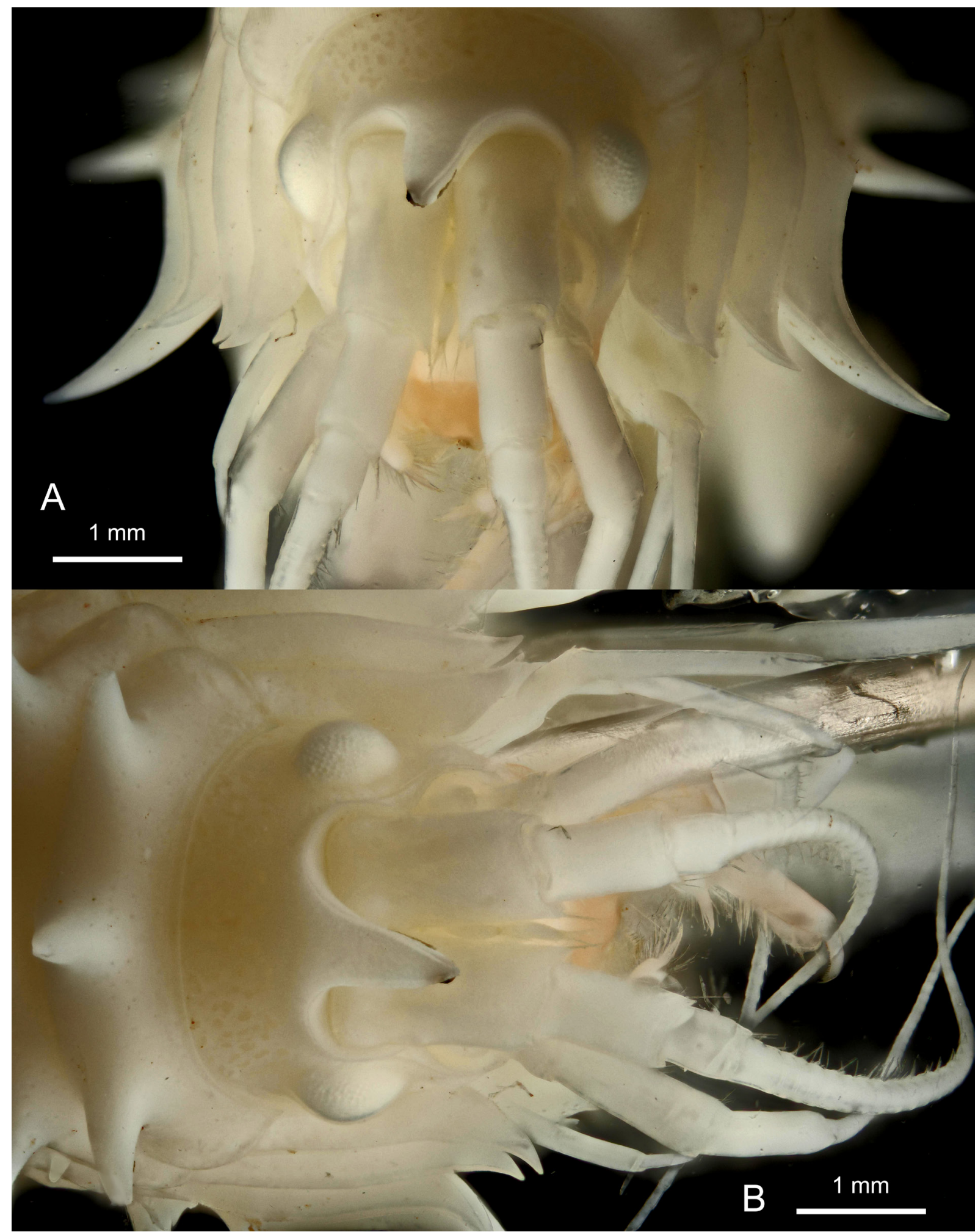

Fig. 46. Epimeria (Drakepimeria) cyrano subgen. et sp. nov., ㅇ, holotype, eastern Weddell Sea, ANT XXVII/3, stn 263-6, RBINS, INV. 132967. A. Head in frontal view. B. Head in dorsdal view. 


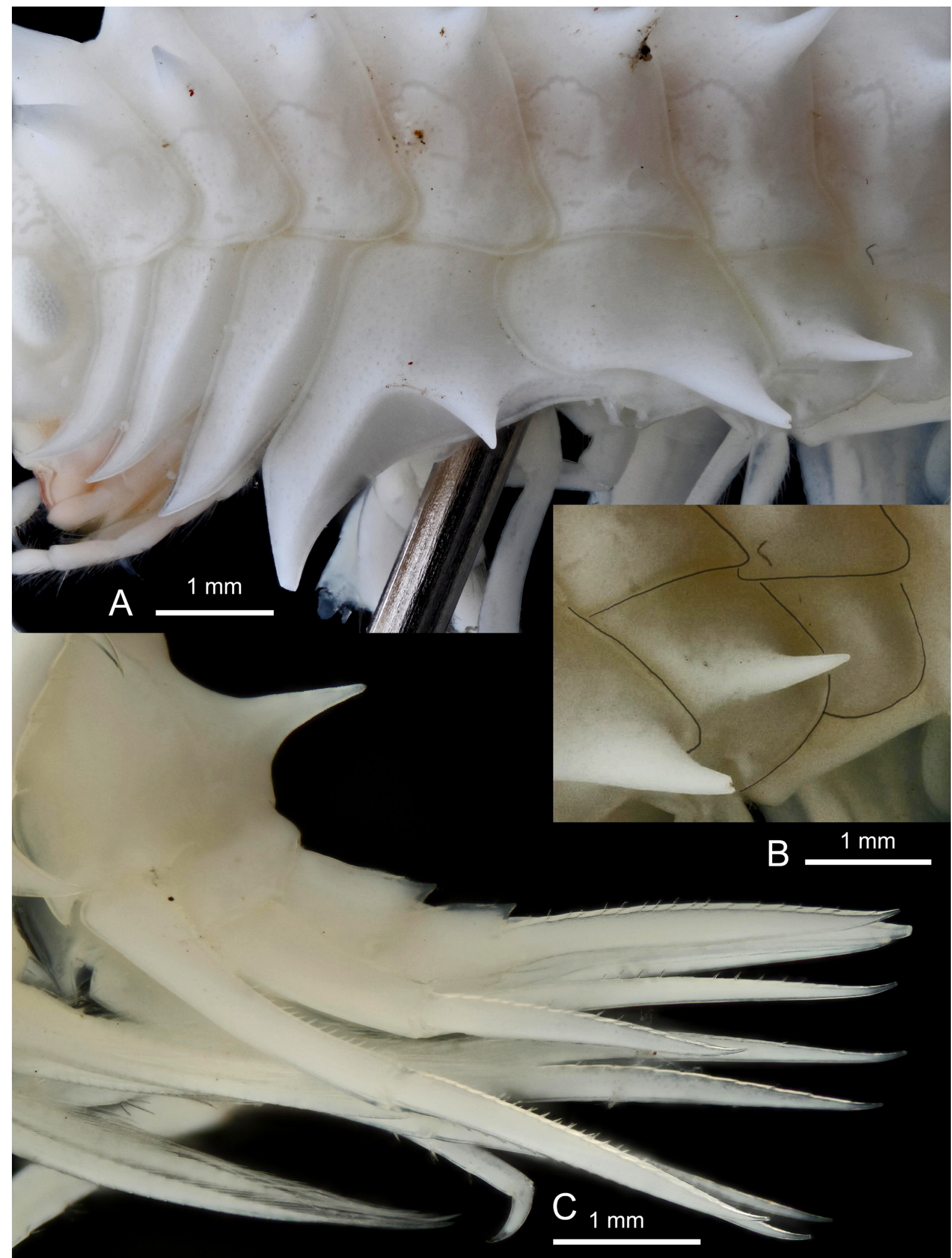

Fig. 47. Epimeria (Drakepimeria) cyrano subgen. et sp. nov.,, , holotype, eastern Weddell Sea, ANT XXVII/3, stn 263-6, RBINS, INV. 132967. A. Coxae 1-6. B. Coxae 6-7. C. Urosome in lateral view. 


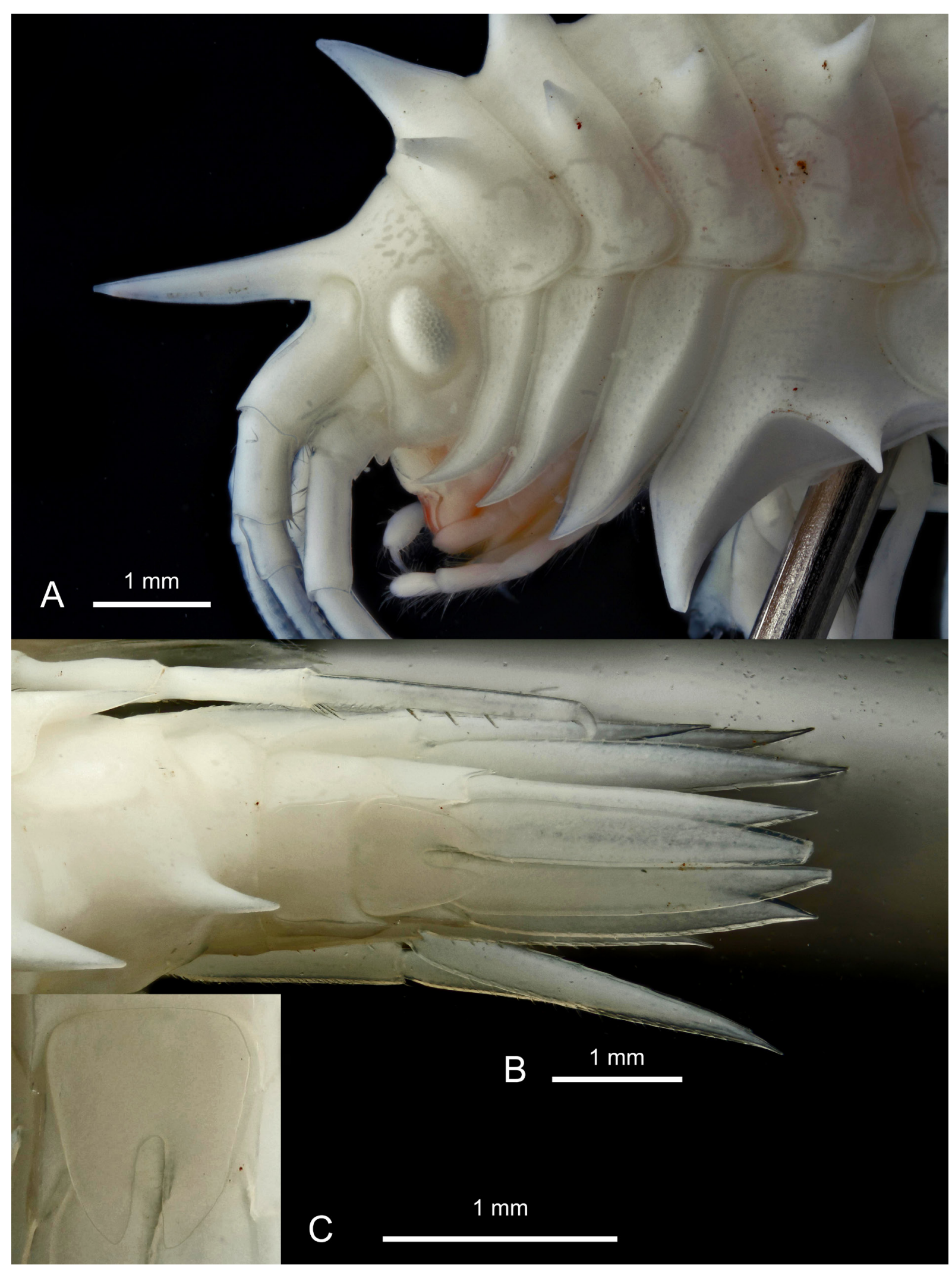

Fig. 48. Epimeria (Drakepimeria) cyrano subgen. et sp. nov.,, , holotype, eastern Weddell Sea, ANT XXVII/3, stn 263-6, RBINS, INV. 132967. A. Head in lateral view. B. Urosome in dorsal view. C. telson. 


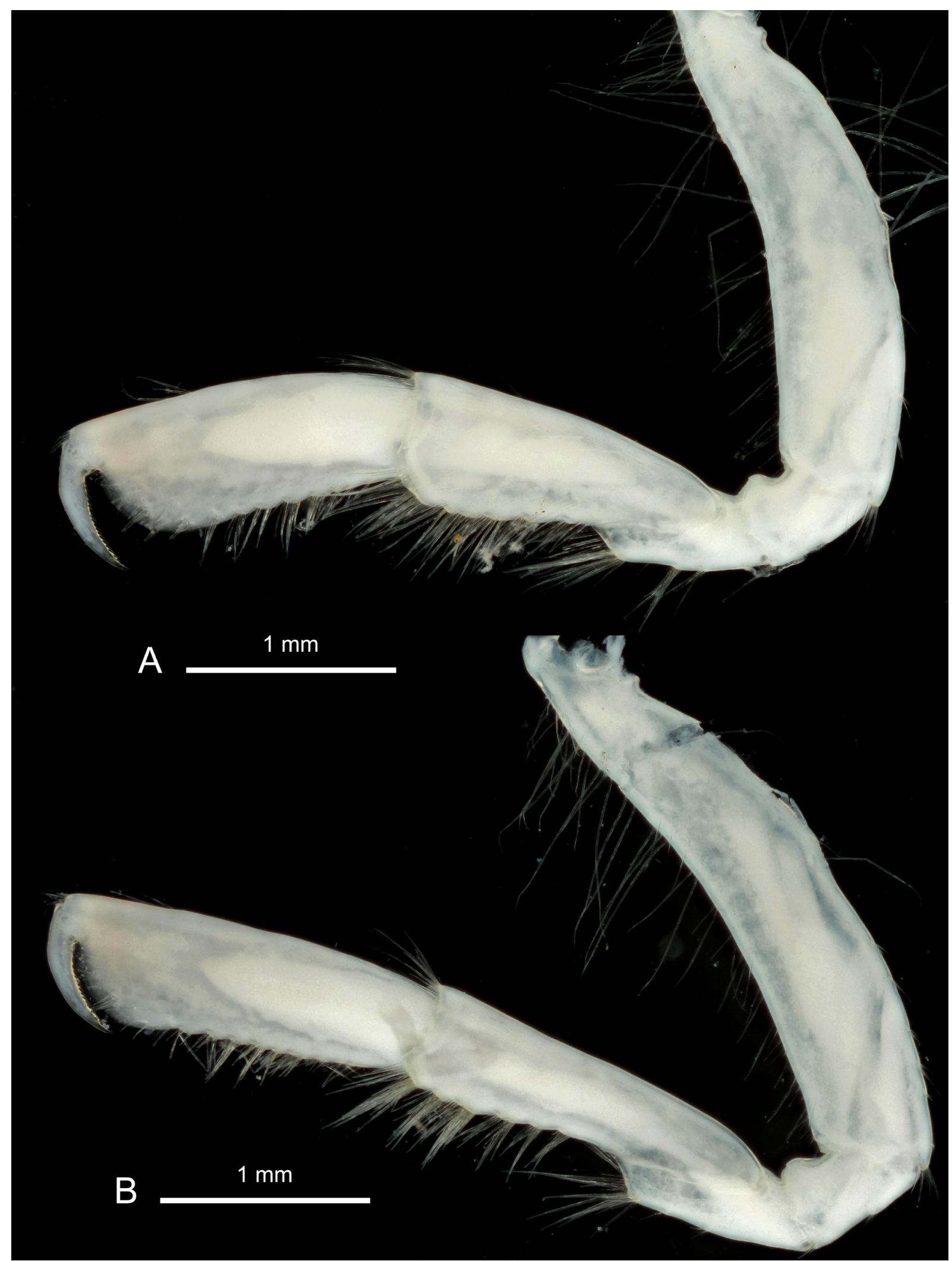

Fig. 49. Epimeria (Drakepimeria) cyrano subgen. et sp. nov., $q$, holotype, eastern Weddell Sea, ANT XXVII/3, stn 263-6, RBINS, INV. 132967. A. Gnathopod 1. B. Gnathopod 2. 


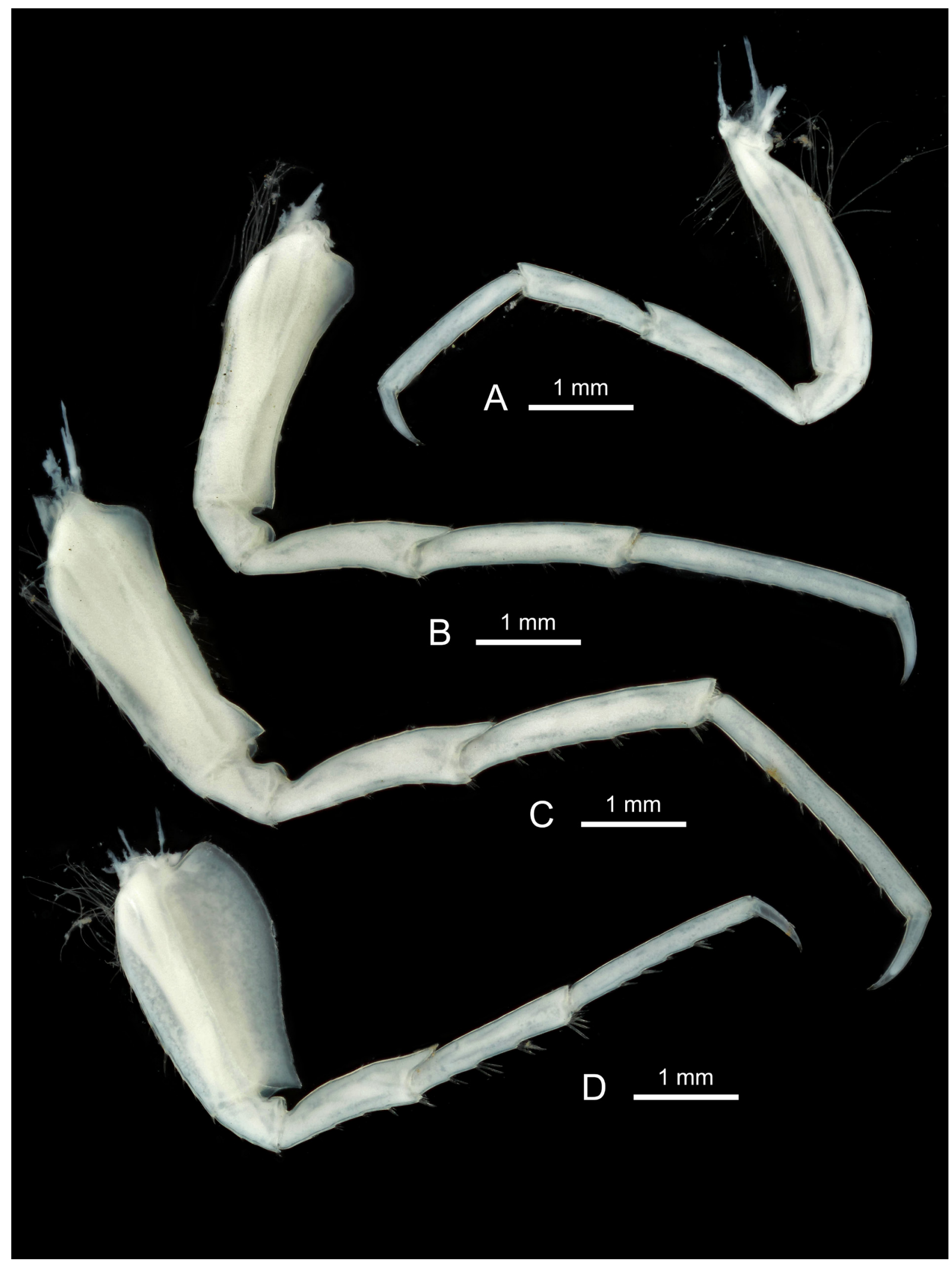

Fig. 50. Epimeria (Drakepimeria) cyrano subgen. et sp. nov., $ᄋ$, holotype, eastern Weddell Sea, ANT XXVII/3, stn 263-6, RBINS, INV. 132967. A. Pereiopod 4. B. Pereiopod 5. C. Pereiopod 6. D. Pereiopod 7. 


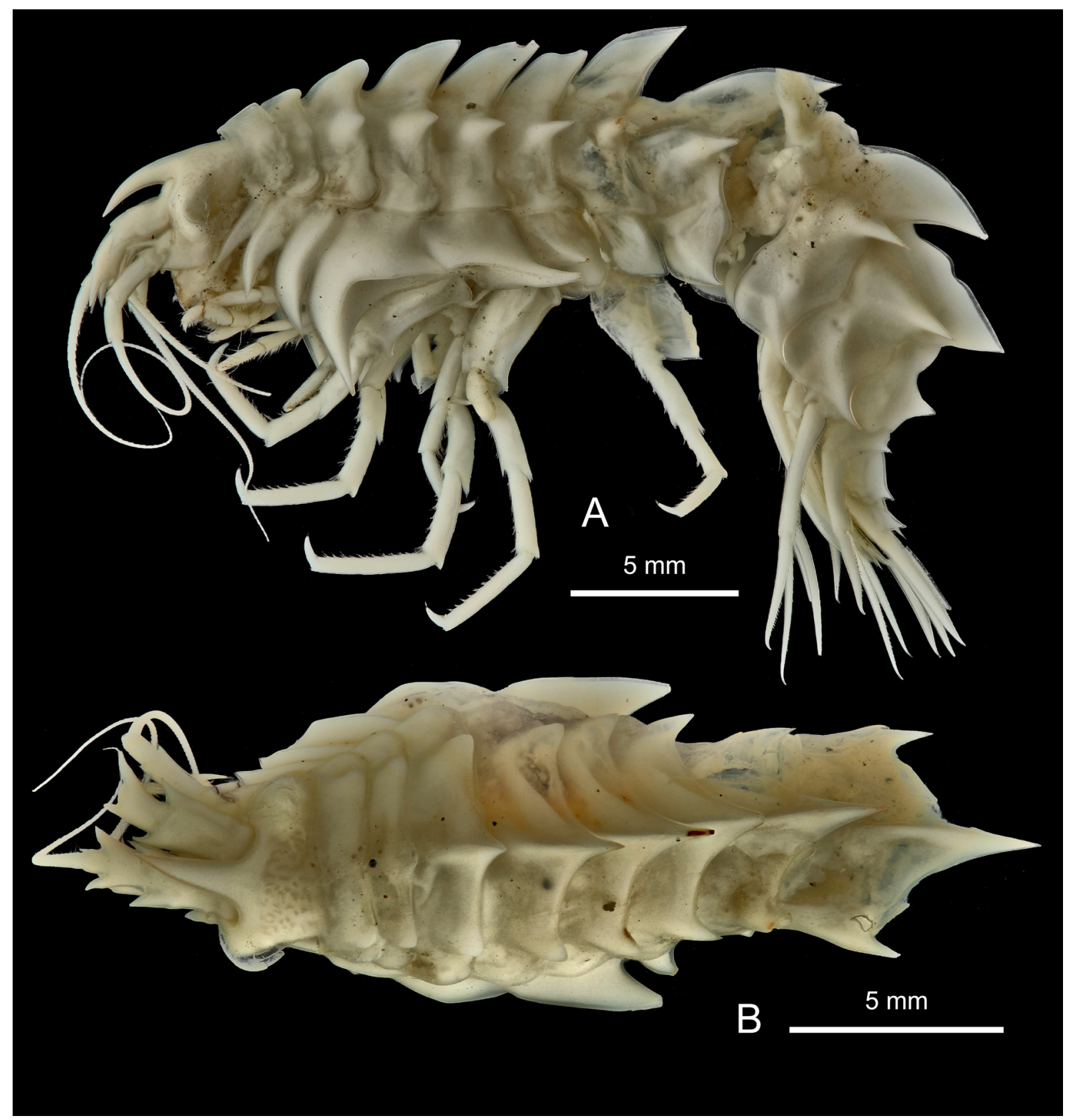

Fig. 51. Epimeria (Drakepimeria) havermansiana subgen. et sp. nov., sex undetermined, eastern Weddell Sea, ANT-XXVII/3, stn 300-1, RBINS, INV. 132964. A. Lateral habitus. B. Dorsal habitus. 


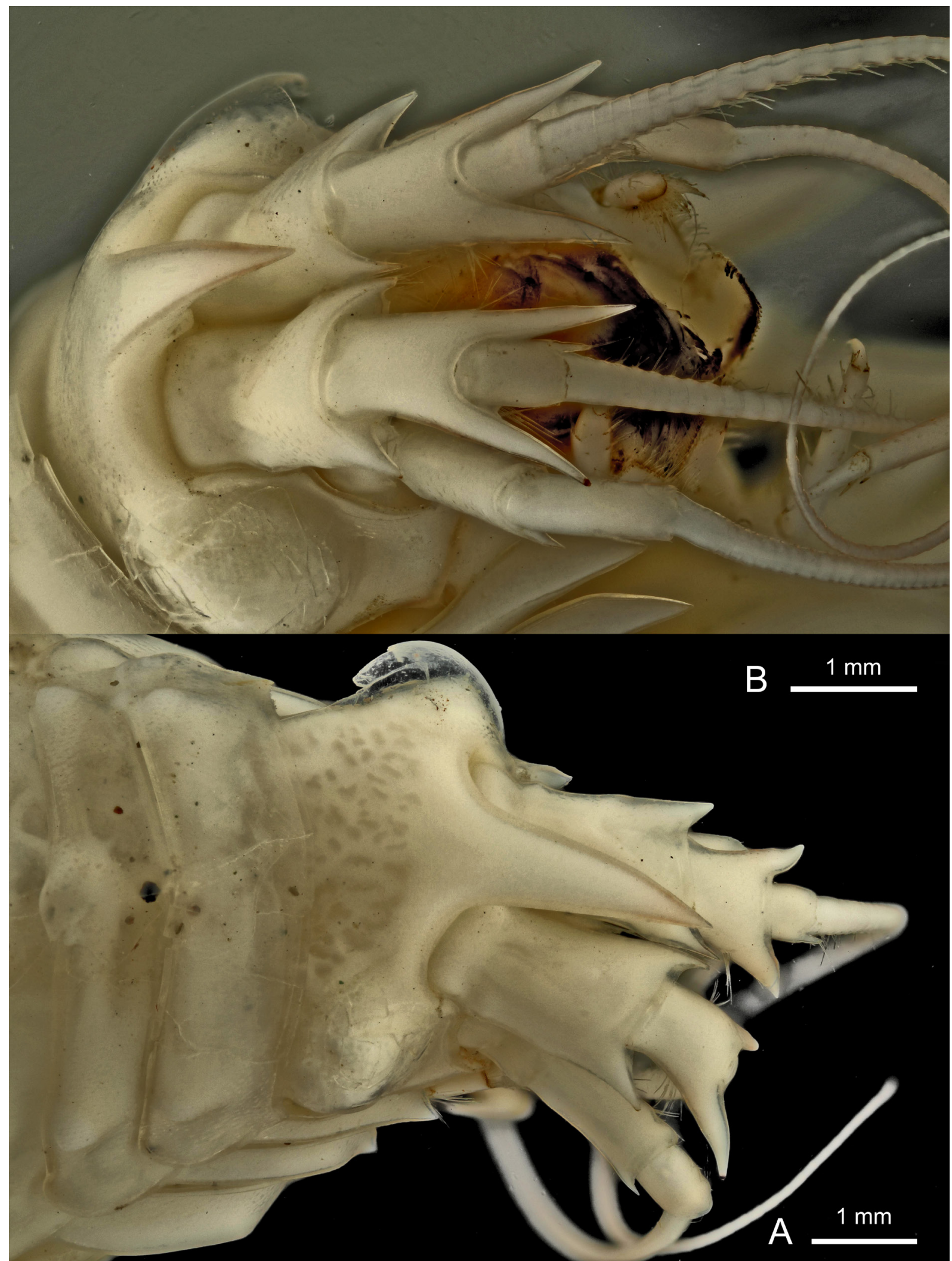

Fig. 52. Epimeria (Drakepimeria) havermansiana subgen. et sp. nov., holotype, sex undetermined, eastern Weddell Sea, ANT-XXVII/3, stn 300-1, RBINS, INV. 132964. A. Head in dorsal view. B. Head in facial view, peduncle of antennae. 


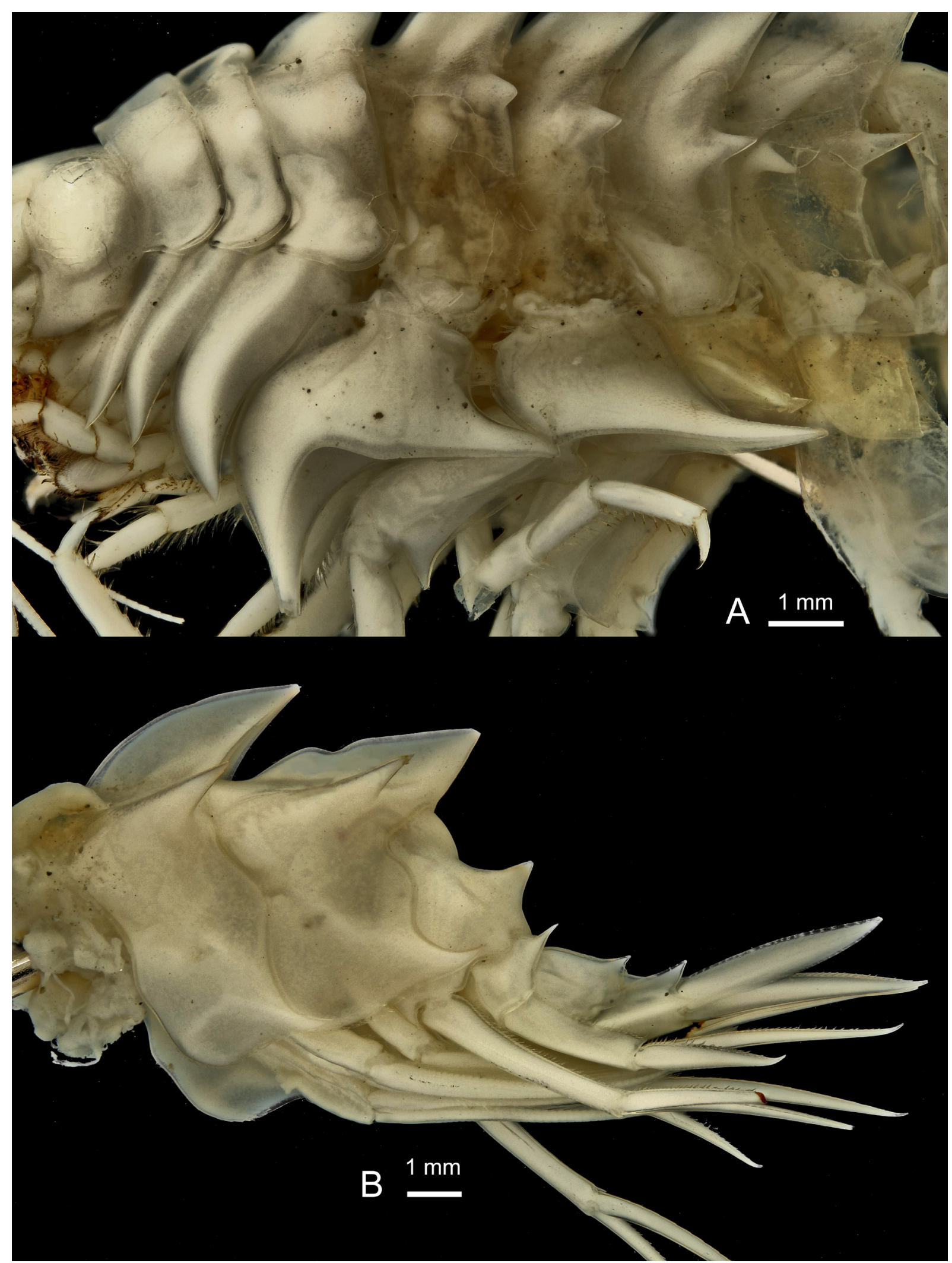

Fig. 53. Epimeria (Drakepimeria) havermansiana subgen. et sp. nov., holotype, sex undetermined, eastern Weddell Sea, ANT-XXVII/3, stn 300-1, RBINS, INV. 132964. A. Coxae 1-7. B. Pleonites 2-3, urosome. 


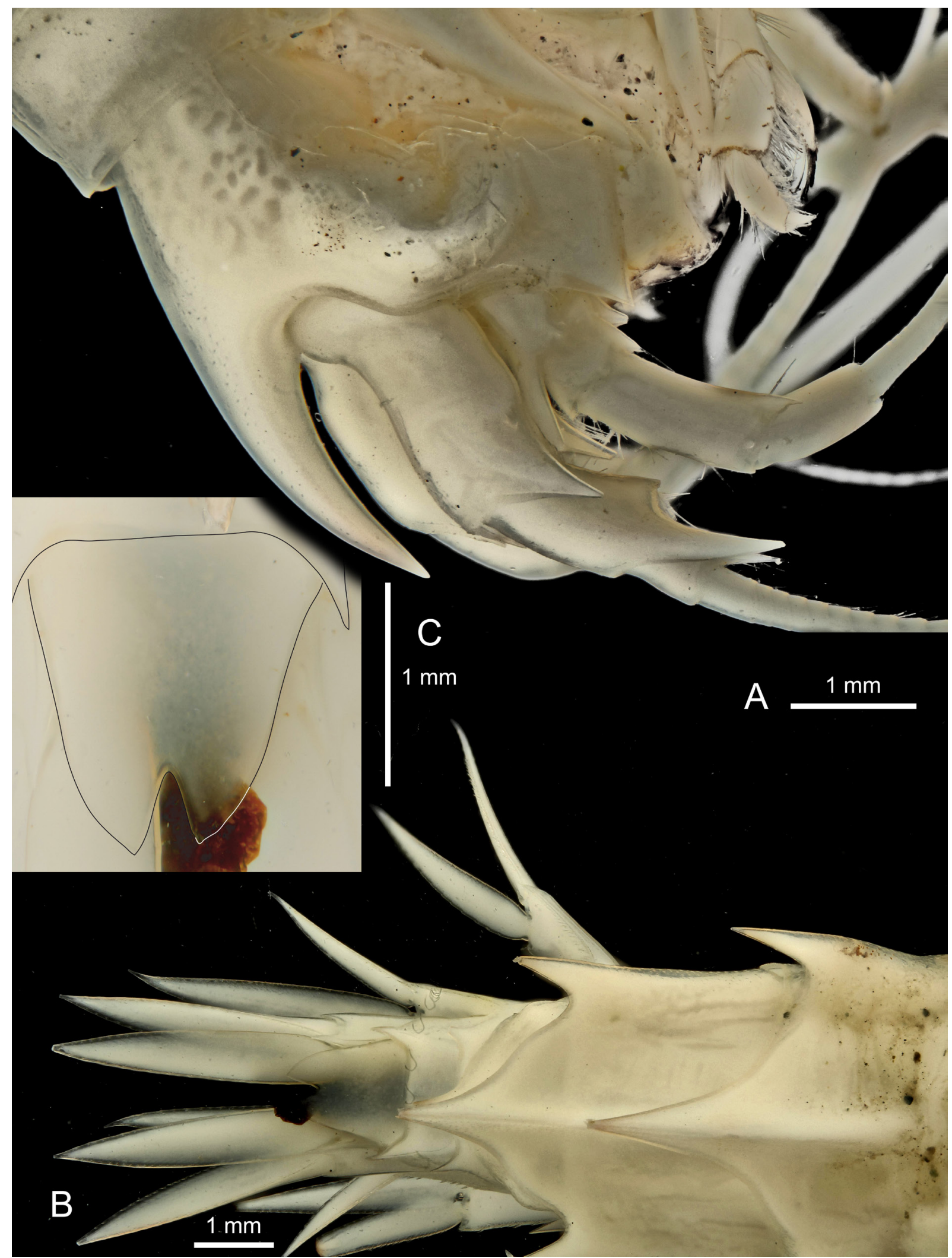

Fig. 54. Epimeria (Drakepimeria) havermansiana subgen. et sp. nov., holotype, sex undetermined, eastern Weddell Sea, ANT-XXVII/3, stn 300-1, RBINS, INV. 132964. A. Head in lateral view. B. Urosome in dorsal view. C. Telson. 


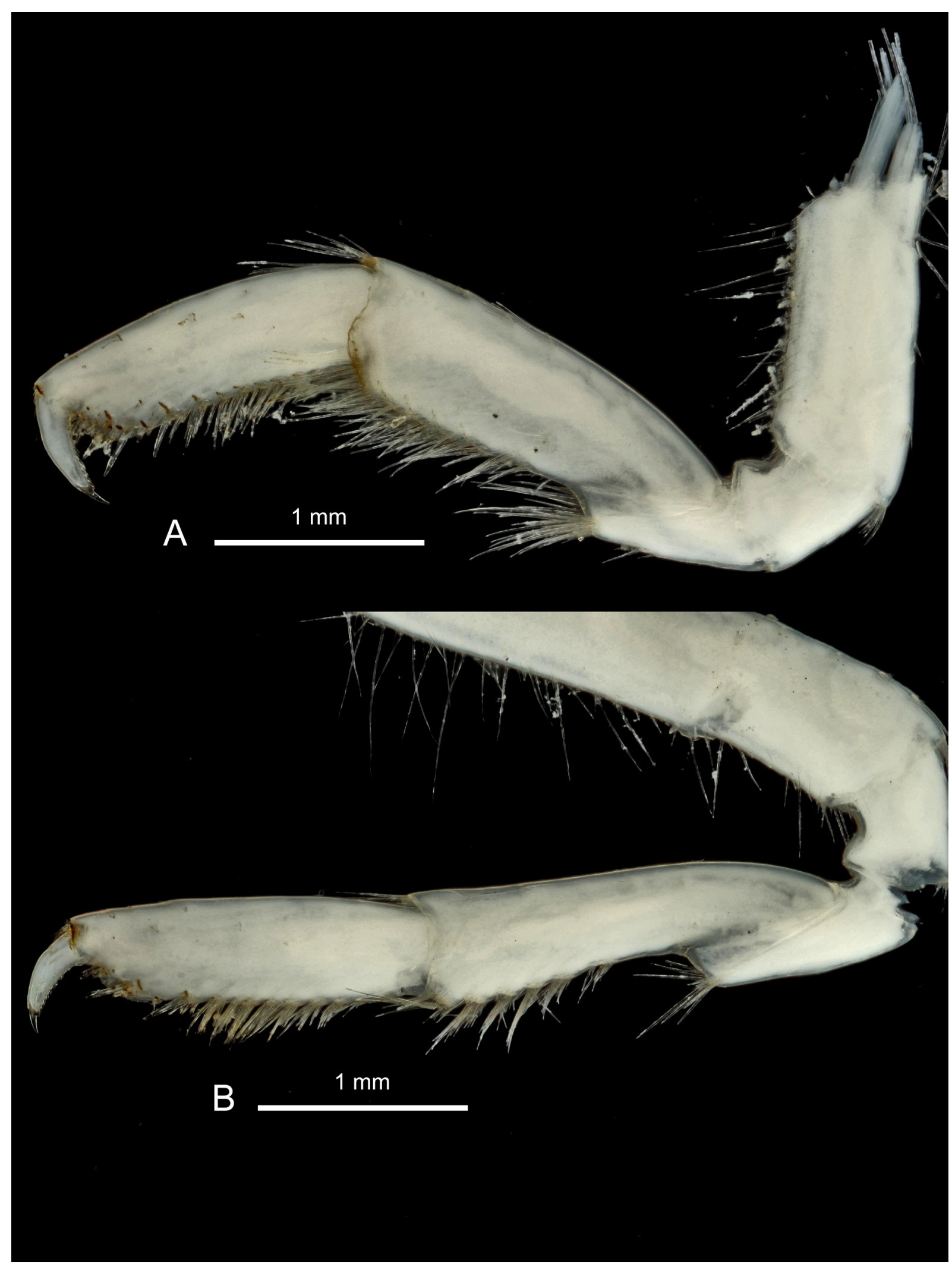

Fig. 55. Epimeria (Drakepimeria) havermansiana subgen. et sp. nov., holotype, sex undetermined, eastern Weddell Sea, ANT-XXVII/3, stn 300-1, RBINS, INV. 132964. A. Gnathopod 1. B. Gnathopod 2. 


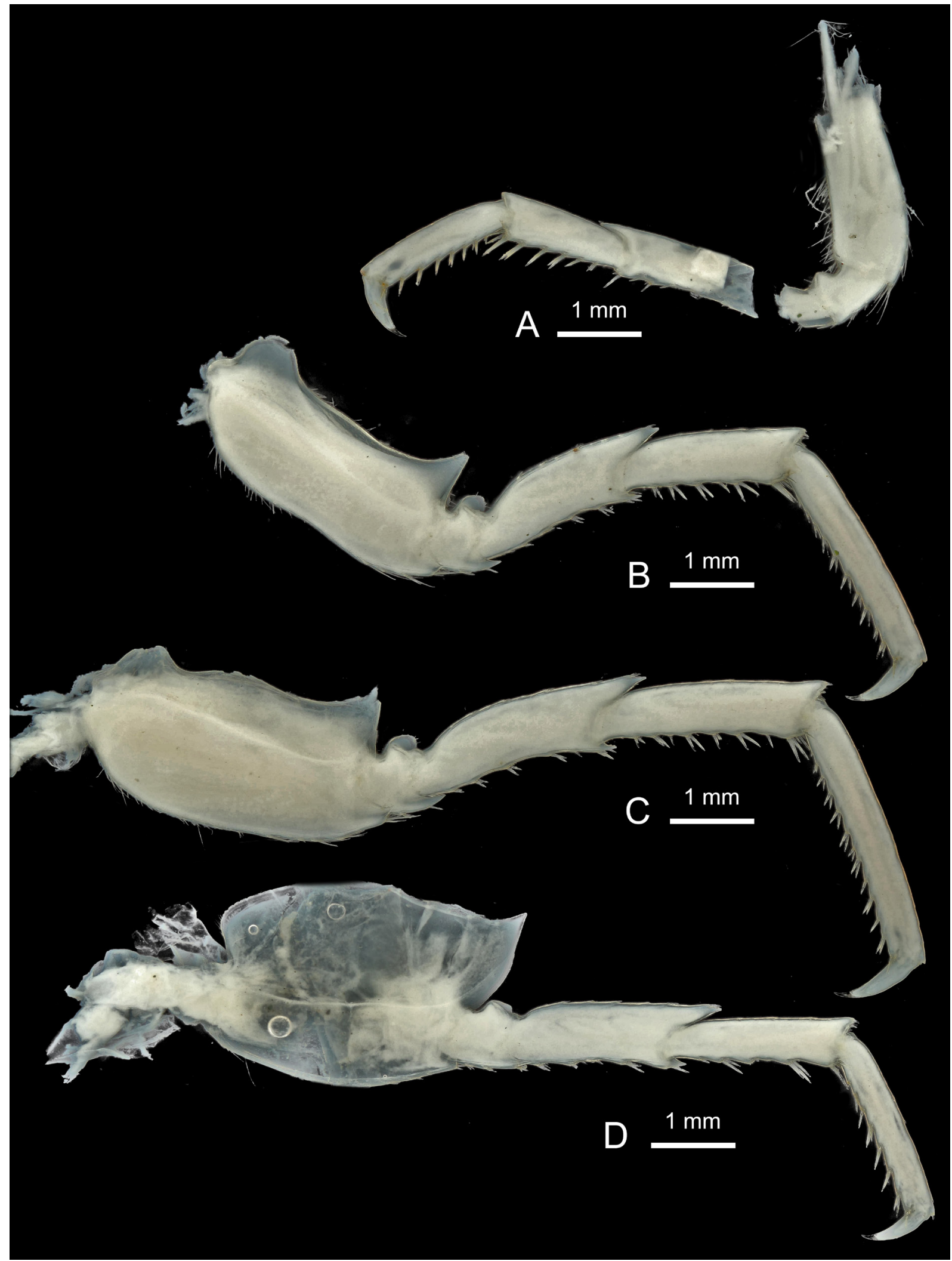

Fig. 56. Epimeria (Drakepimeria) havermansiana subgen. et sp. nov., holotype, sex undetermined, eastern Weddell Sea, ANT-XXVII/3, stn 300-1, RBINS, INV. 132964. A. Pereiopod 4. B. Pereiopod 5. C. Pereiopod 6. D. Pereiopod 7. 


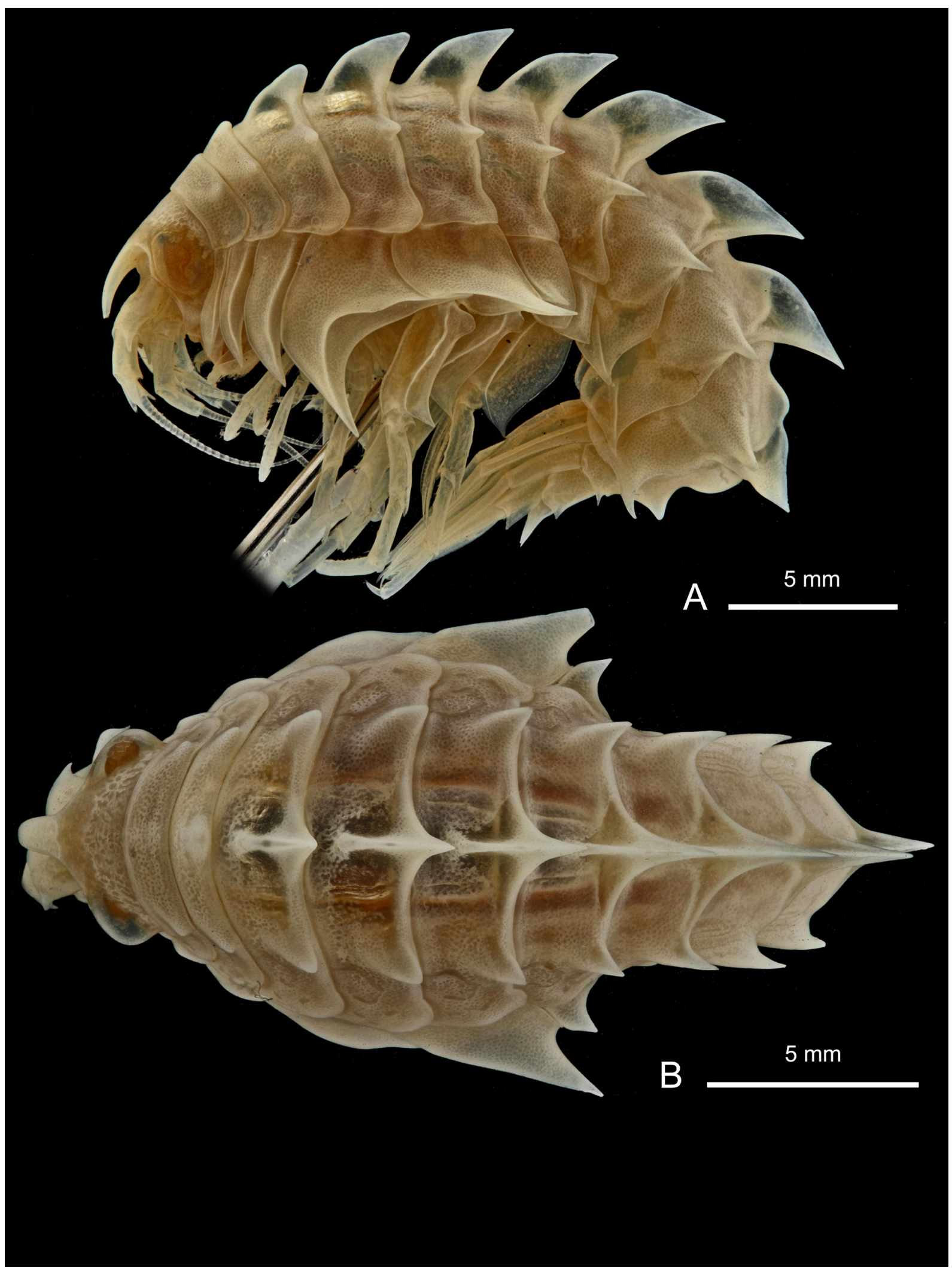

Fig. 57. Epimeria (Drakepimeria) havermansiana subgen. et sp. nov., adult $q$, Prydz Bay, MD42, stn 22, CP71, MNHN-IU-2014-4268. A. Lateral habitus. B. Dorsal habitus. 


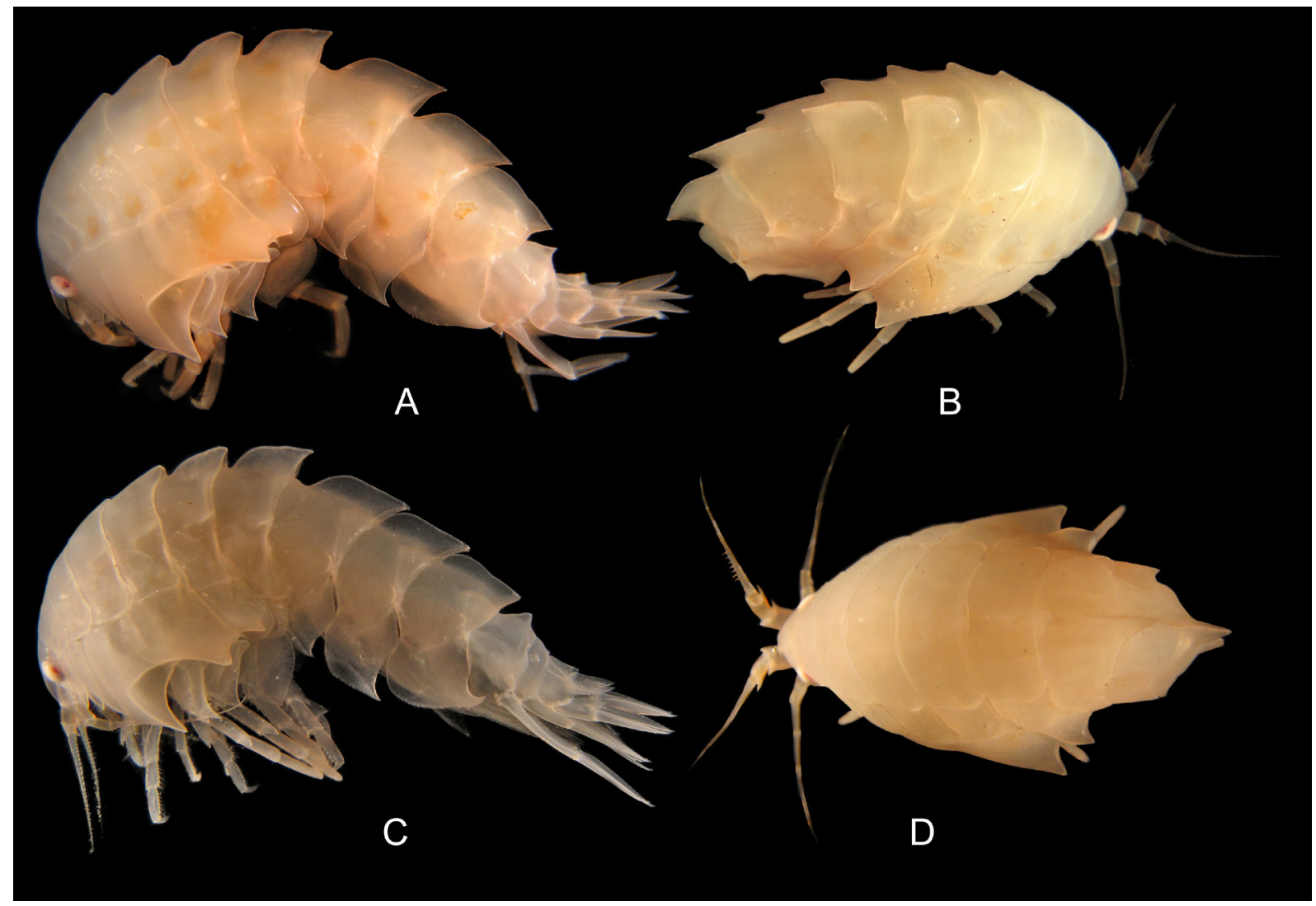

Fig. 58. Epimeria (Drakepimeria) leukhoplites subgen. et sp. nov., colour in life. A, B. Ovigerous ${ }$, holotype, Elephant Island, ANT-XXIII/8, stn 605-5, RBINS, INV. 122470. C, D. Ovigerous ${ }_{\text {, }}$ paratype, Elephant Island, ANT-XXIII/8, stn 614-3, RBINS, INV. 122473. 


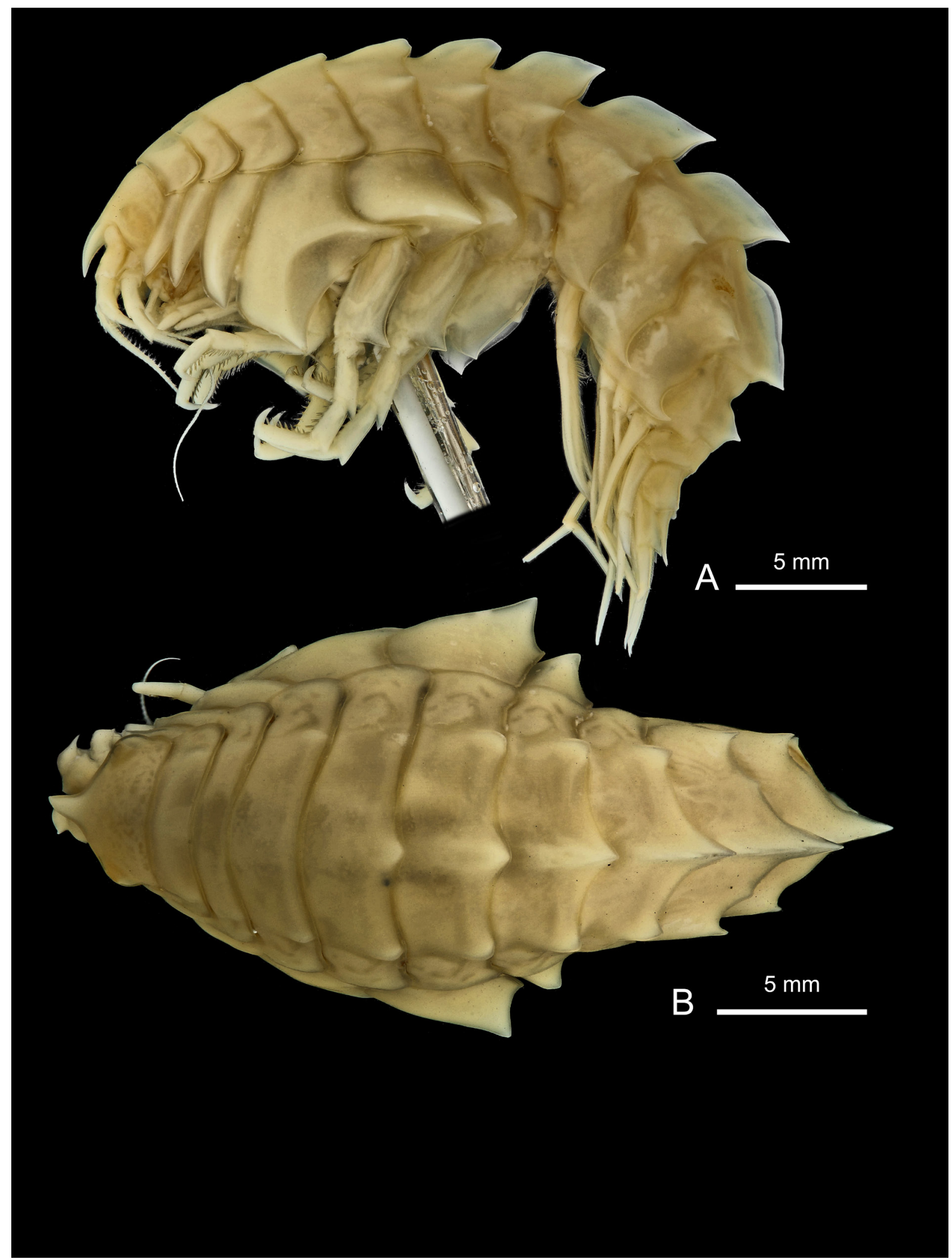

Fig. 59. Epimeria (Drakepimeria) leukhoplites subgen. et sp. nov., ovigerous $q$, holotype, Elephant Island, ANT-XXIII/8, stn 605-5, RBINS, INV. 122470. A. Lateral habitus. B. Dorsal habitus. 


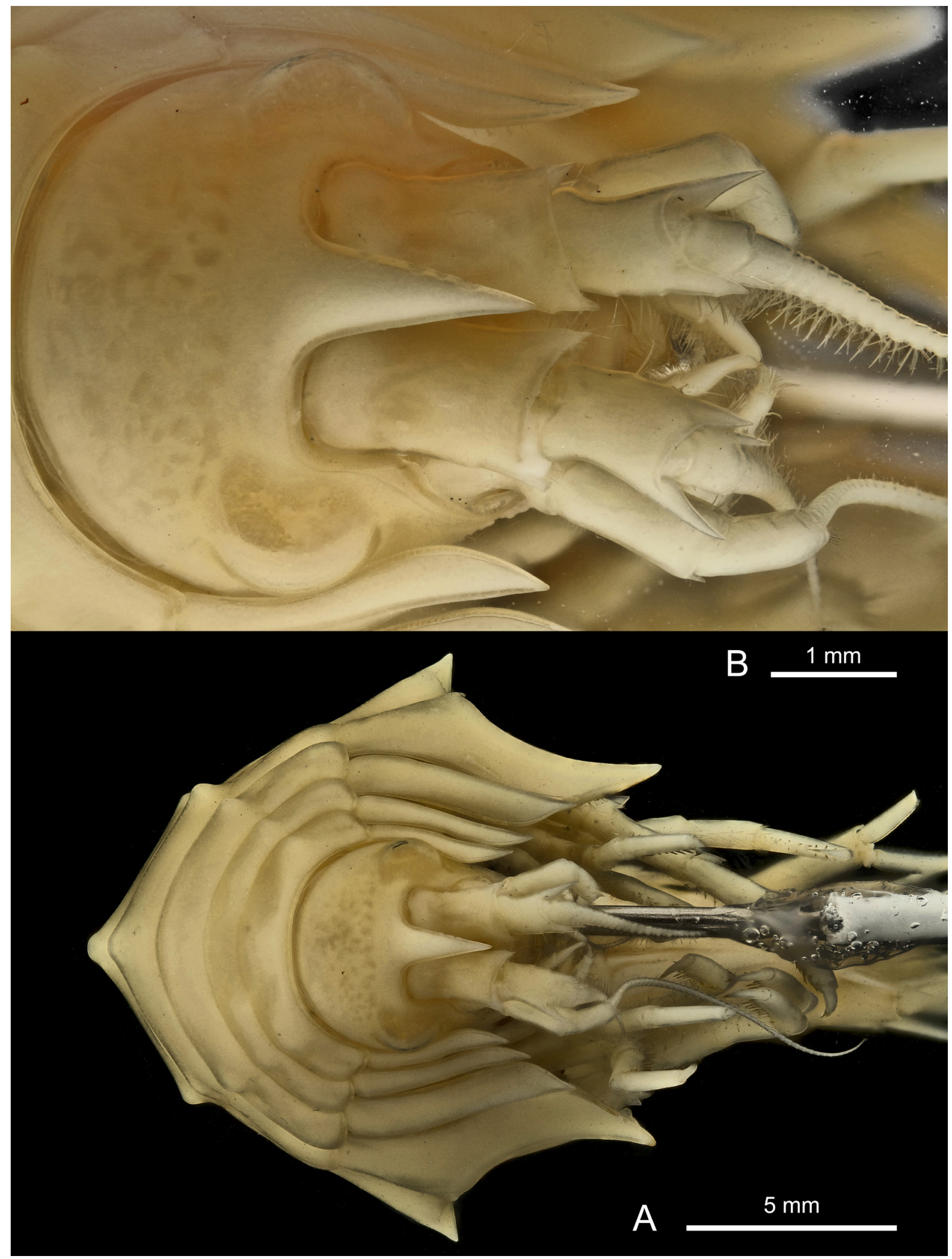

Fig. 60. Epimeria (Drakepimeria) leukhoplites subgen. et sp. nov., + , holotype, Elephant Island, ANTXXIII/8, stn 605-5, RBINS, INV. 122470. A. Facial habitus. B. Head in facial view. 

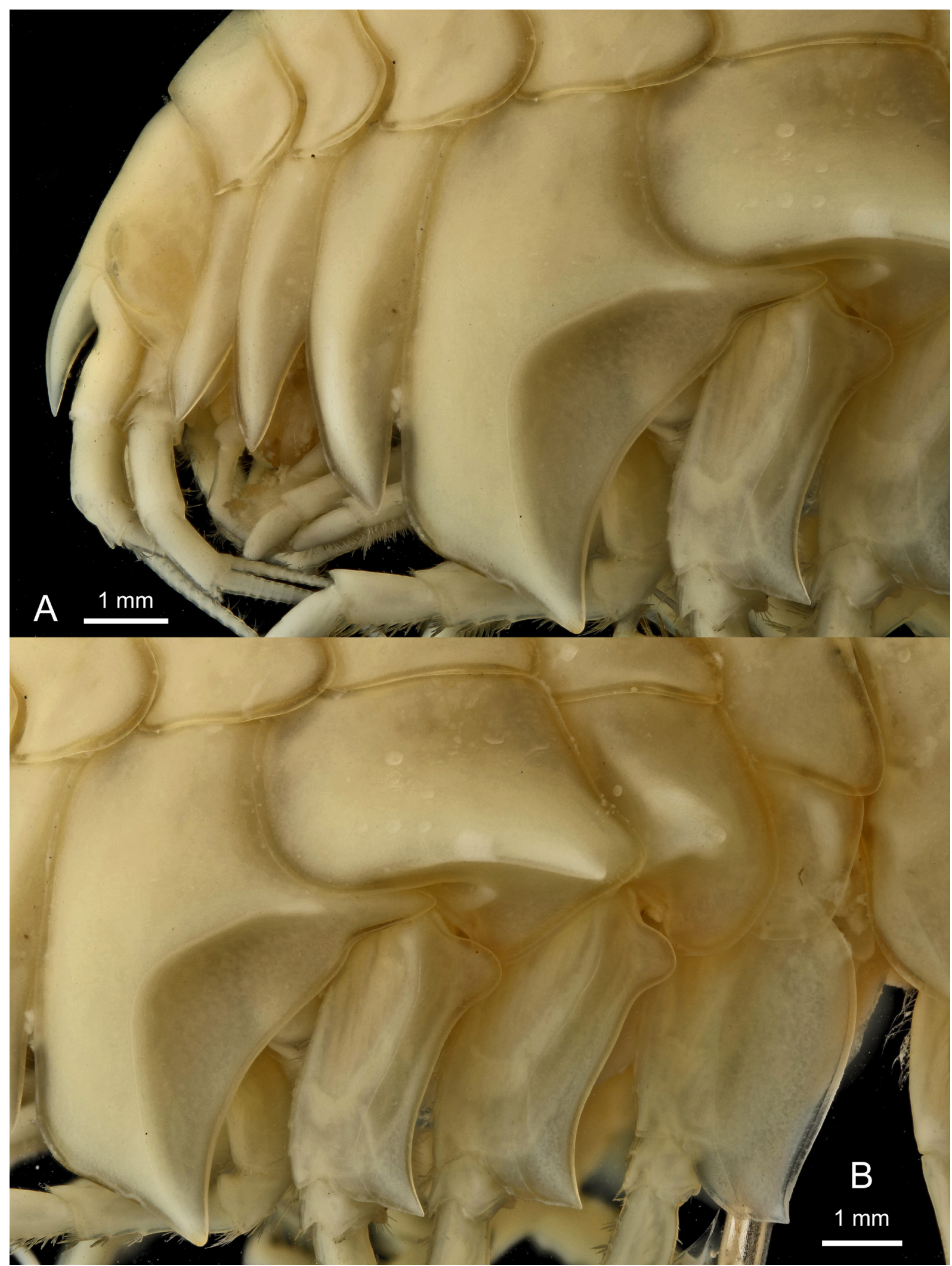

Fig. 61. Epimeria (Drakepimeria) leukhoplites subgen. et sp. nov., ${ }_{+}$, holotype, Elephant Island, ANTXXIII/8, stn 605-5, RBINS, INV. 122470. A. Anterior half. B. Coxae 4-7 and basis of pereiopods 5-7. 


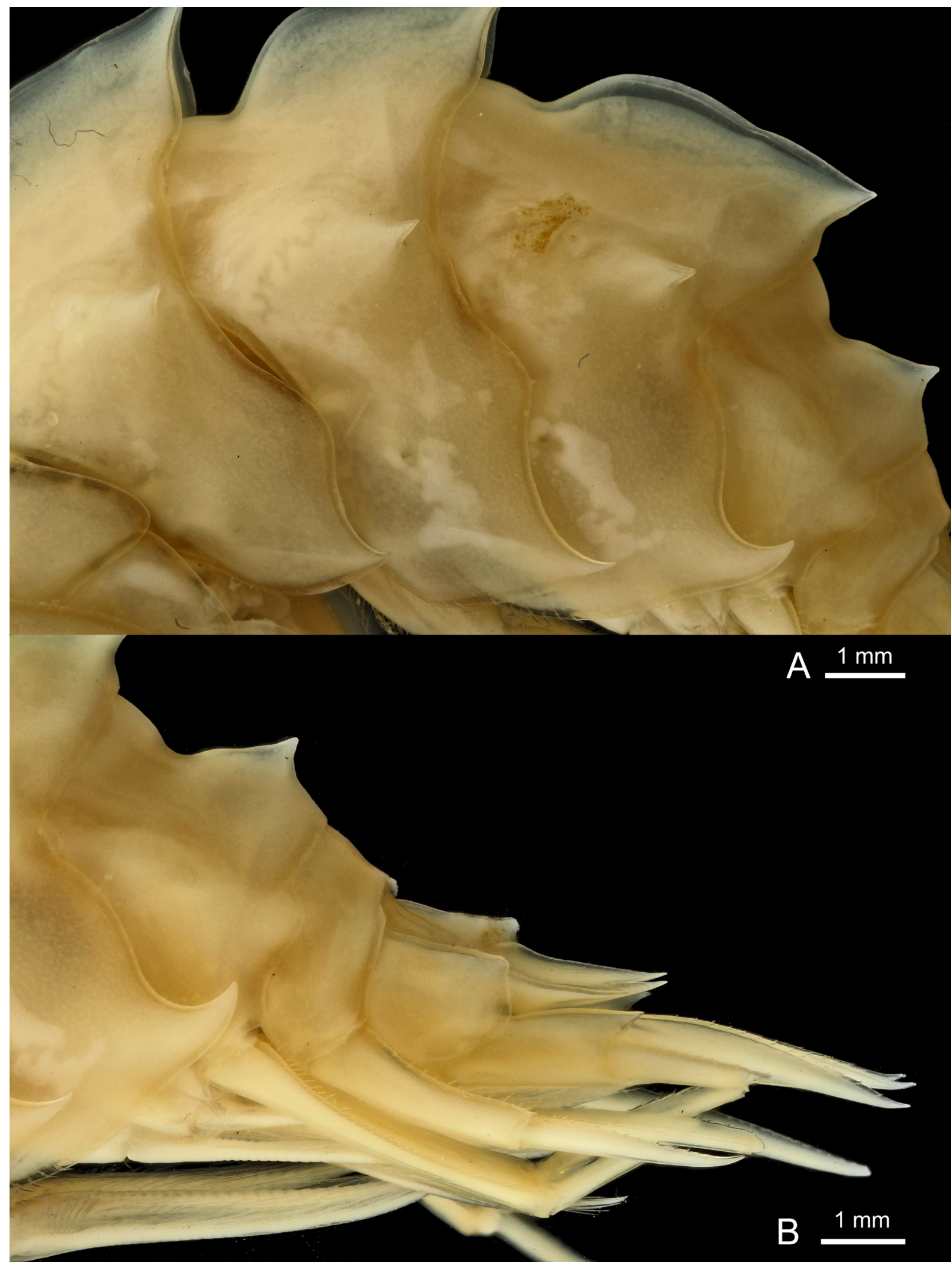

Fig. 62. Epimeria (Drakepimeria) leukhoplites subgen. et sp. nov., + , holotype, Elephant Island, ANTXXIII/8, stn 605-5, RBINS, INV. 122470. A. Pleosome. B. Urosome. 


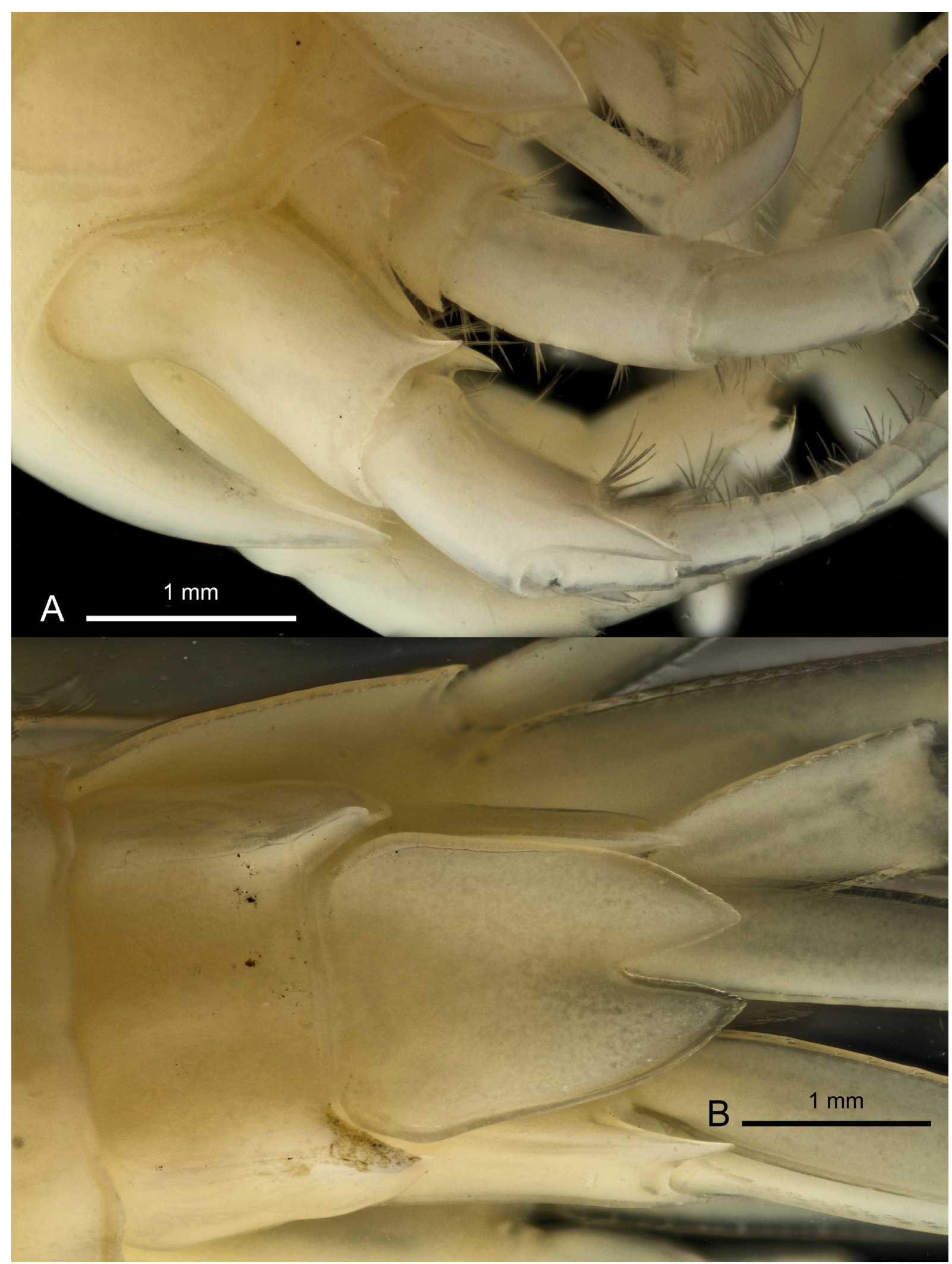

Fig. 63. Epimeria (Drakepimeria) leukhoplites subgen. et sp. nov. A. + , paratype, Elephant Island, ANT-XXIII/8, stn 614-3, RBINS, INV. 122473, rostrum and peduncle of antennae in lateral view. B. $q$ holotype, Elephant Island, ANT-XXIII/8, stn 605-5, RBINS, INV. 122470, telson. 


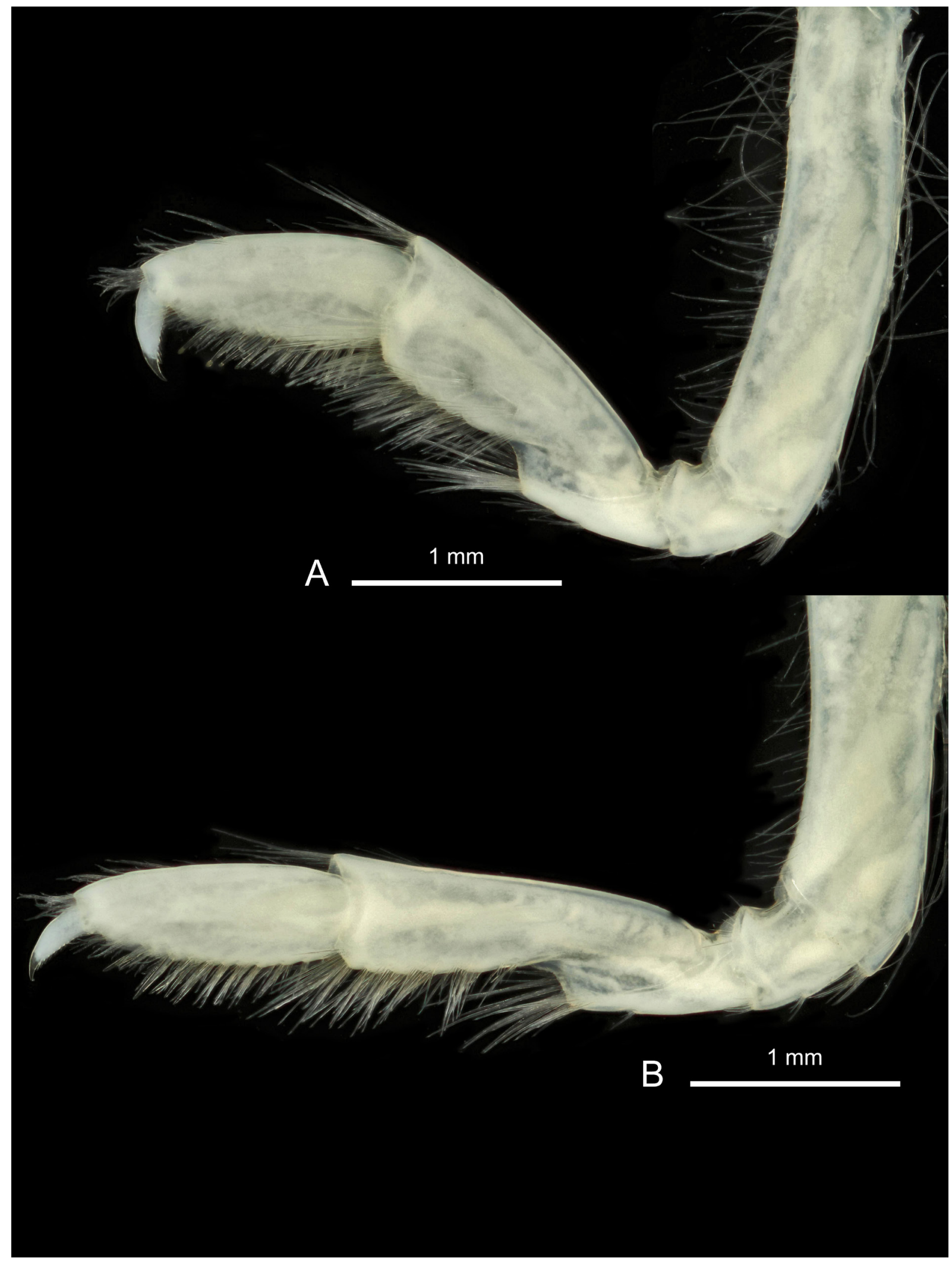

Fig. 64. Epimeria (Drakepimeria) leukhoplites subgen. et sp. nov.,, , paratype, Elephant Island, ANTXXIII/8, stn 614-3, RBINS, INV. 122473. A. Gnathopod 1. B. Gnathopod 2. 


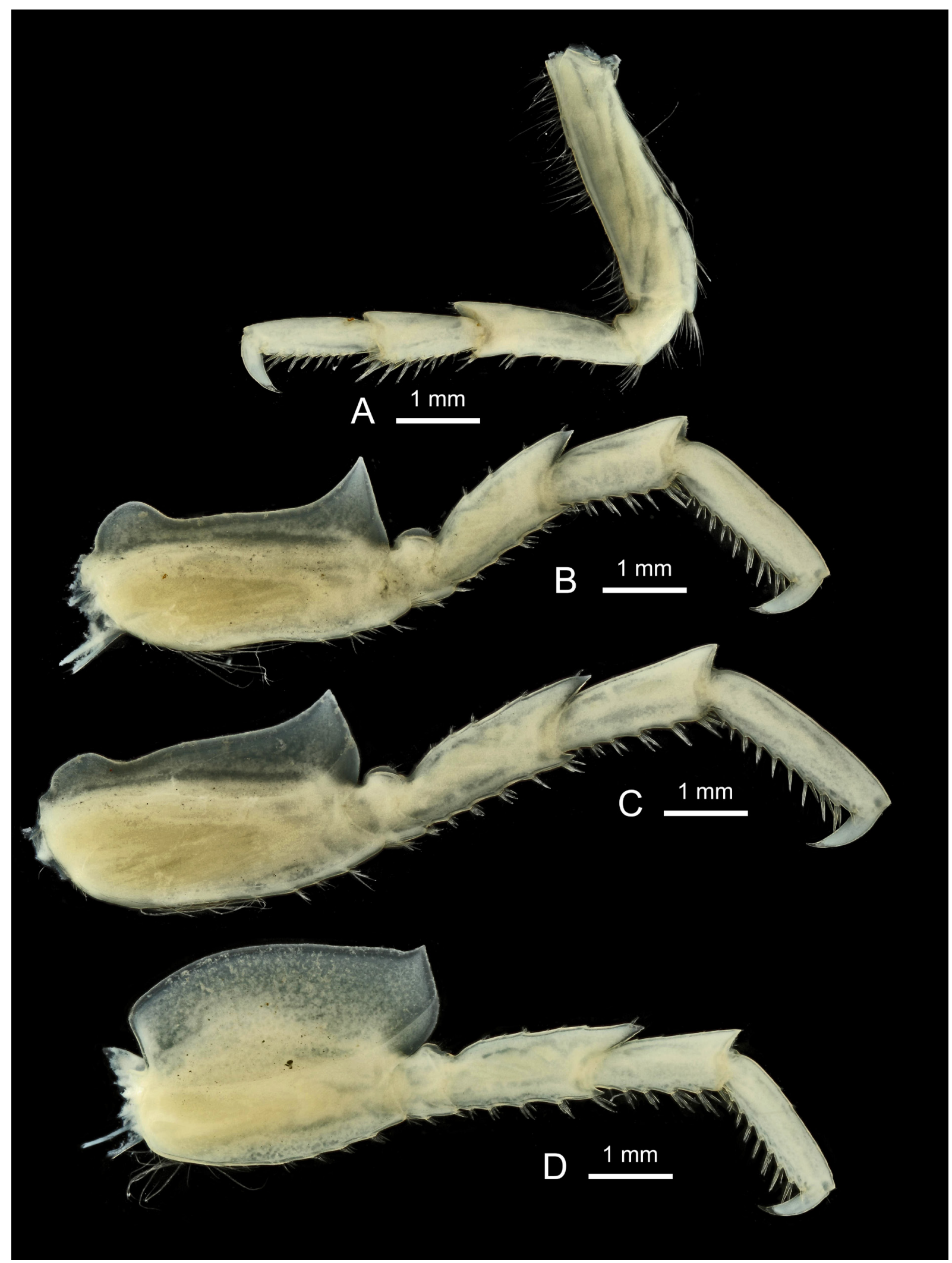

Fig. 65. Epimeria (Drakepimeria) leukhoplites subgen. et sp. nov.,, , paratype, Elephant Island, ANTXXIII/8, stn 614-3, RBINS, INV. 122473. A. Pereiopod 4. B. Pereiopod 5. C. Pereiopod 6. D. Pereiopod 7. 


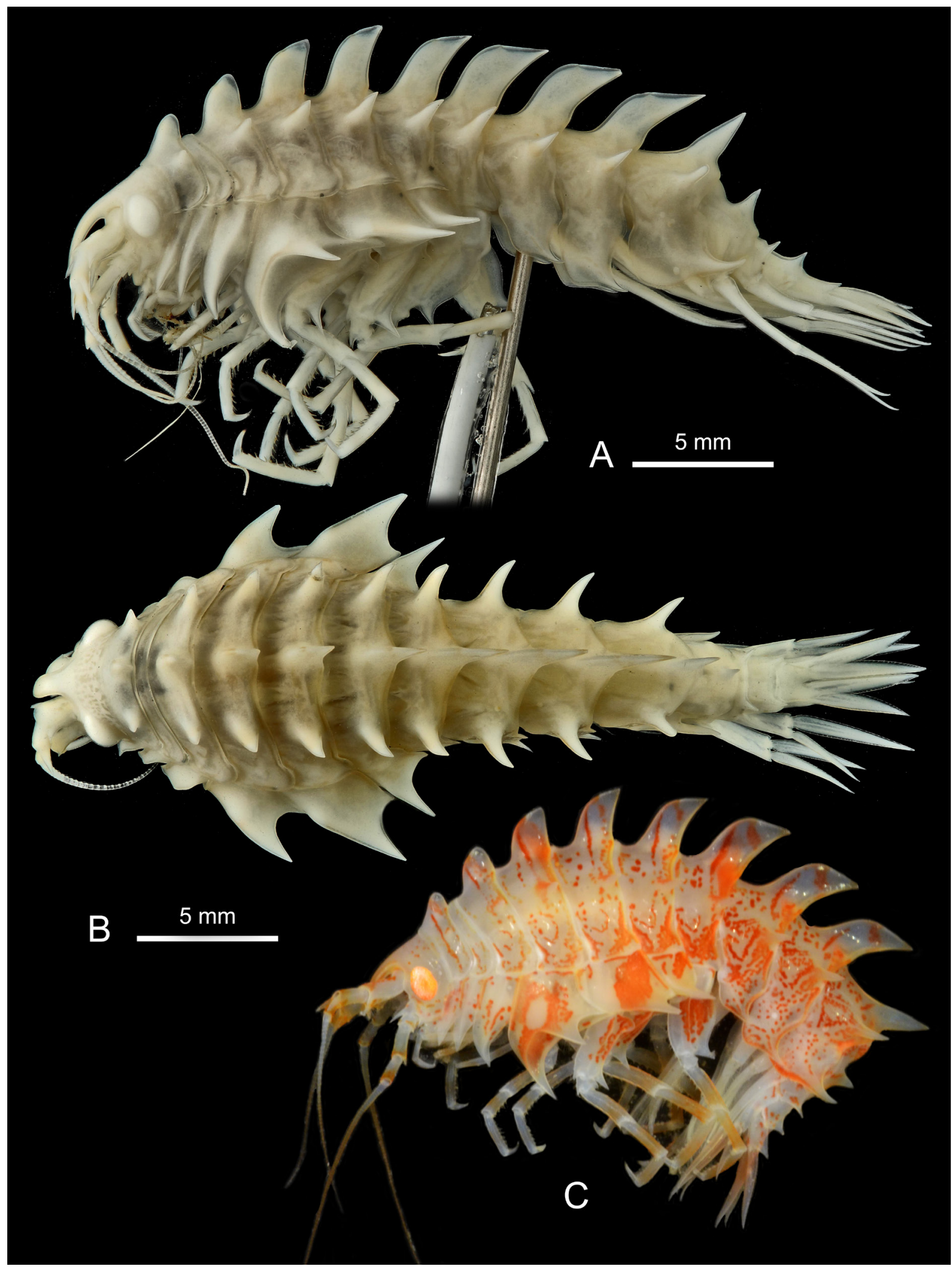

Fig. 66. Epimeria (Drakepimeria) loerzae subgen. et sp. nov. A-B,, , holotype, north of Joinville Island, ANT-XXIX/3, stn 116-9, RBINS, INV. 122929A. C. + , northwestern Weddell Sea, ANT-XXIX/3, stn 162-7, RBINS, INV. 122940 or 122955 or 122958. A. Lateral habitus. B. Dorsal habitus. C. Colour in life. 


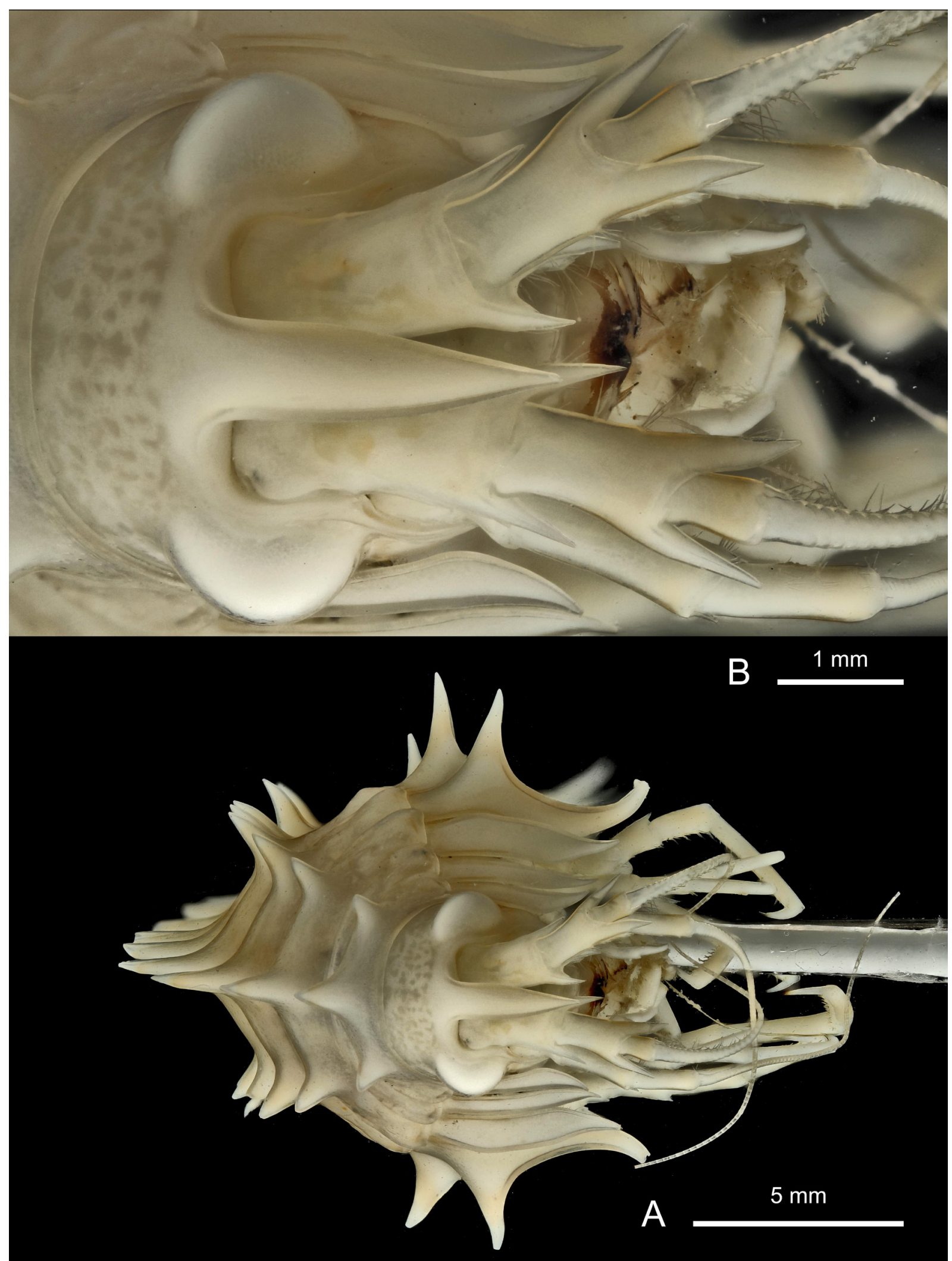

Fig. 67. Epimeria (Drakepimeria) loerzae subgen. et sp. nov.,, , holotype, north of Joinville Island, ANT-XXIX/3, stn 116-9, RBINS, INV. 122929A. A. Facial habitus. B. Head in frontal view. 


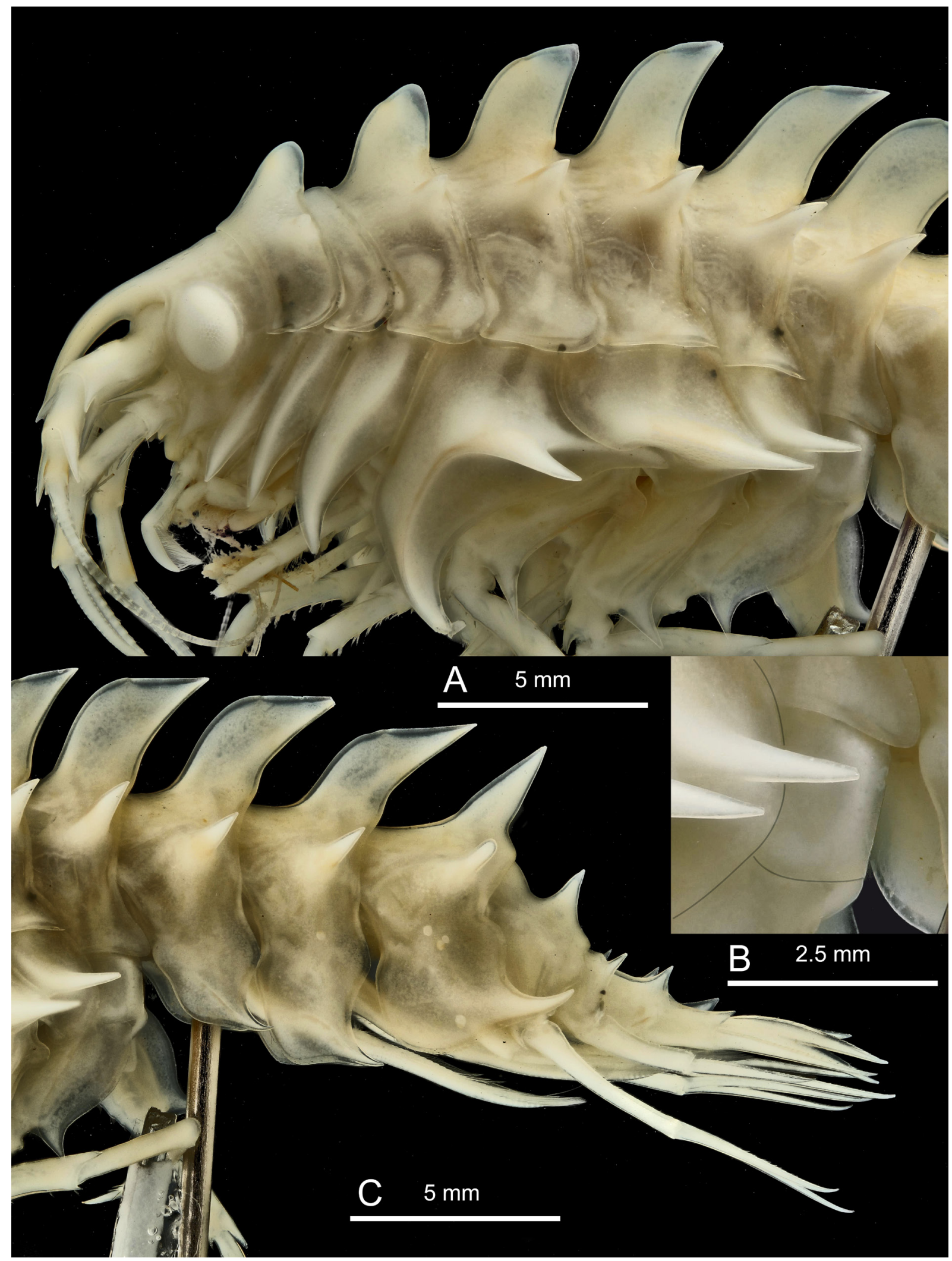

Fig. 68. Epimeria (Drakepimeria) loerzae subgen. et sp. nov.,, , holotype, north of Joinville Island, ANT-XXIX/3, stn 116-9, RBINS, INV. 122929A. A. Anterior half of body. B. Coxa 7 and posterior part of coxa 6 . C. Posterior half of body. 


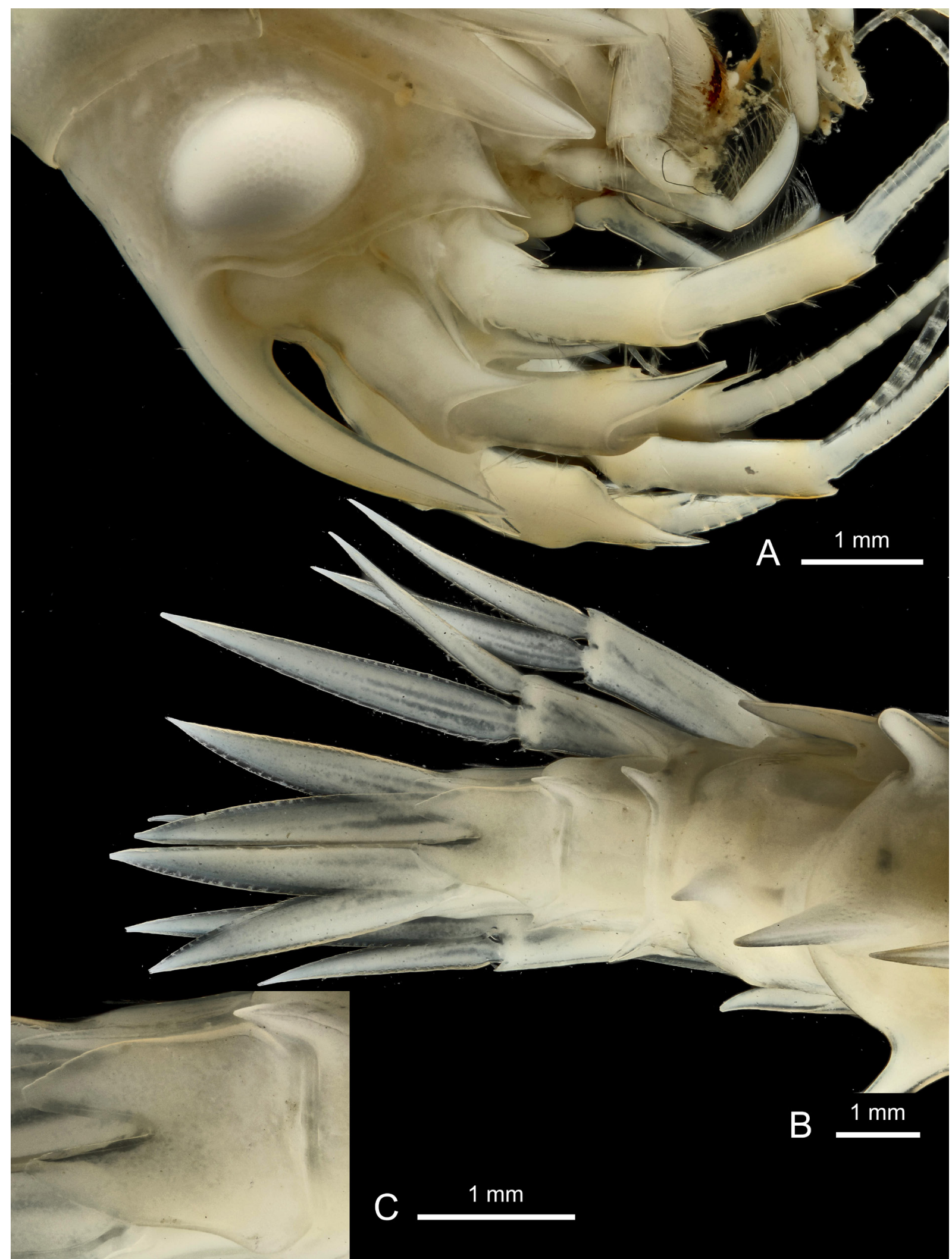

Fig. 69. Epimeria (Drakepimeria) loerzae subgen. et sp. nov.,, , holotype, north of Joinville Island, ANT-XXIX/3, stn 116-9, RBINS, INV. 122929A. A. Head in lateral view. B. Urosome in dorsal view. C. Telson. 


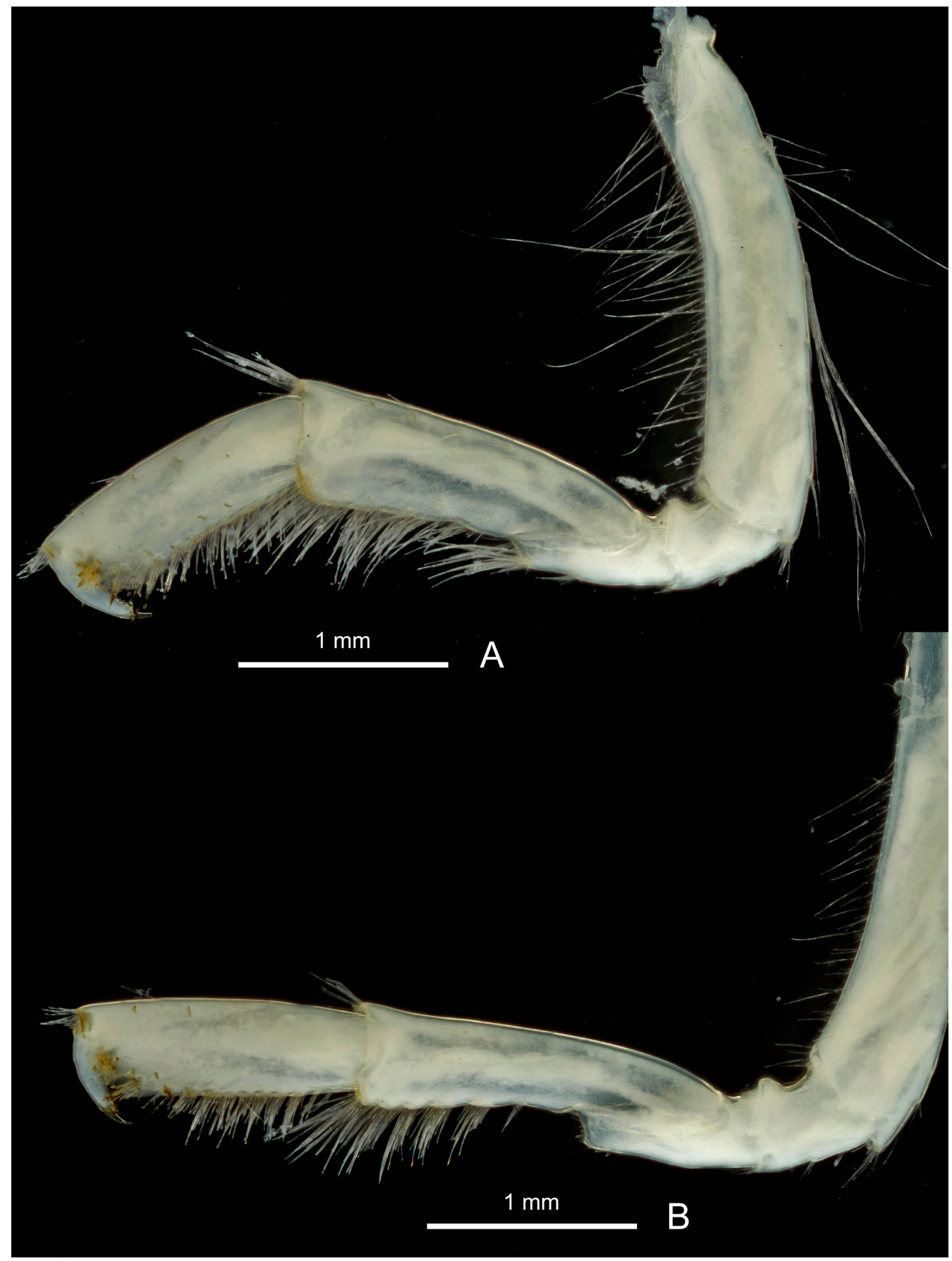

Fig. 70. Epimeria (Drakepimeria) loerzae subgen. et sp. nov.,, , paratype, north of Joinville Island, ANT-XXIX/3, stn 116-9, RBINS, INV. 122929B. A. Gnathopod 1. B. Gnathopod 2. 


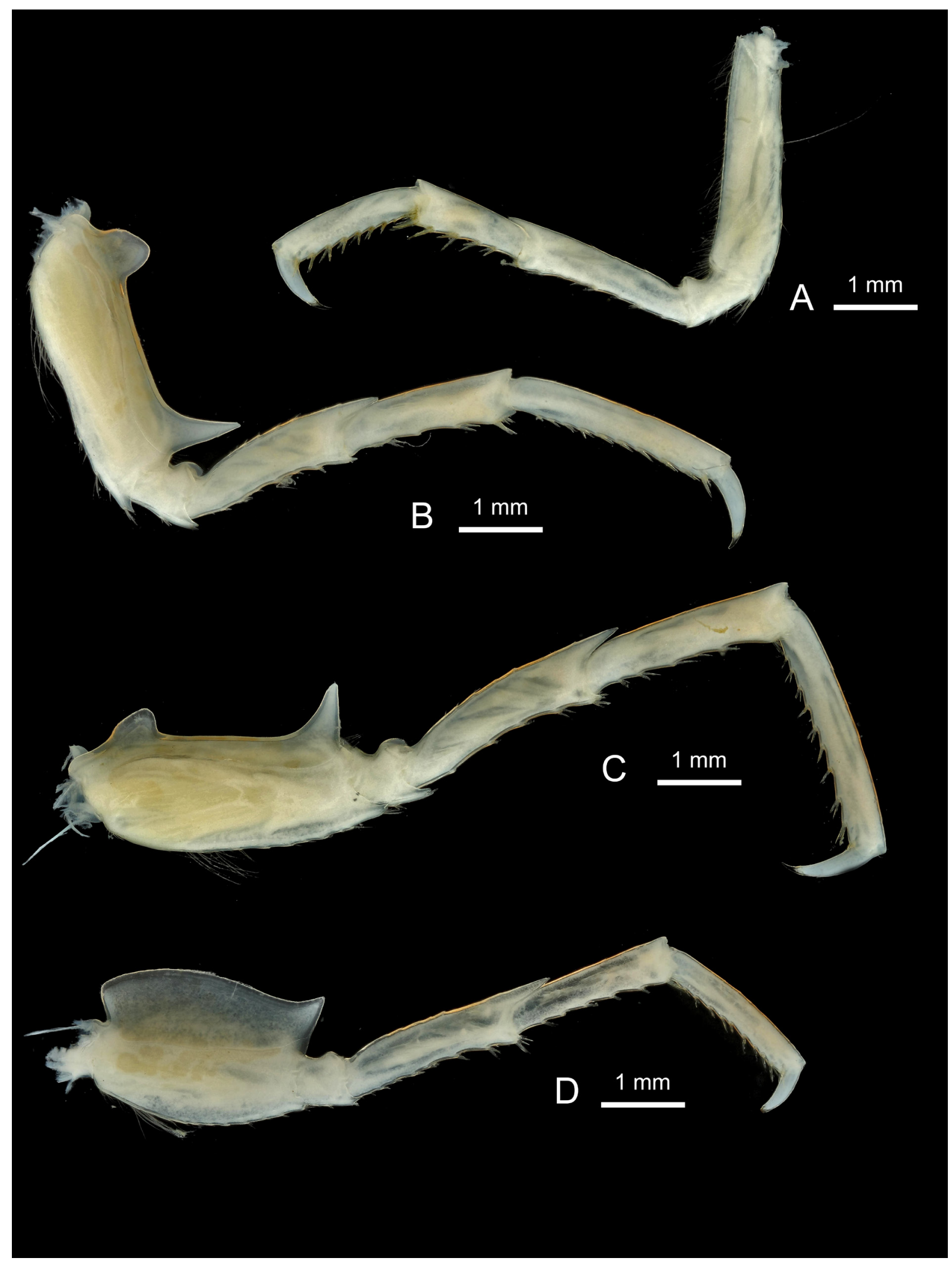

Fig. 71. Epimeria (Drakepimeria) loerzae subgen. et sp. nov.,, , paratype, north of Joinville Island, ANT-XXIX/3, stn 116-9, RBINS, INV. 122929B. A. Pereiopod 4. B. Pereiopod 5. C. Pereiopod 6. D. Pereiopod 7. 


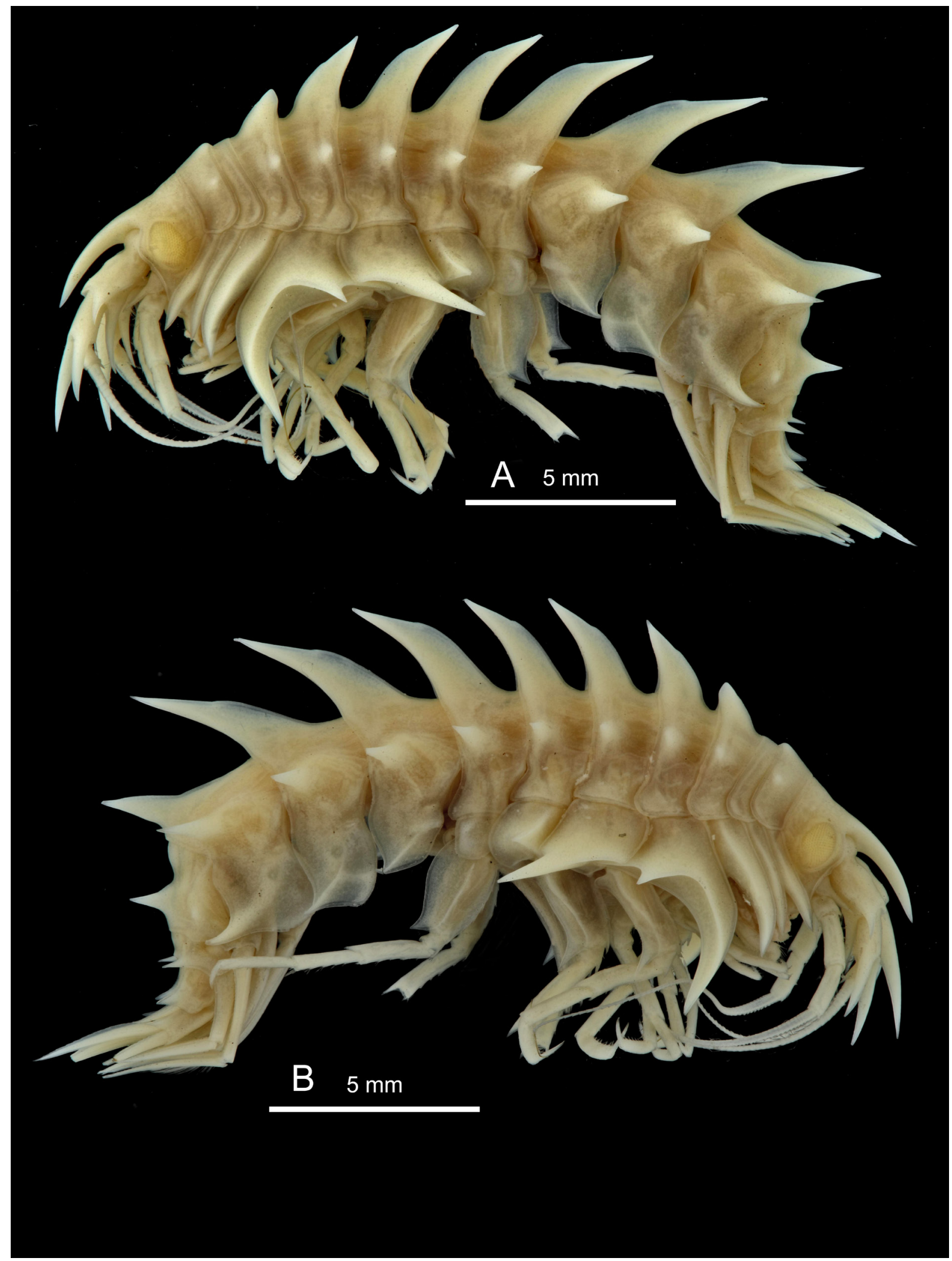

Fig. 72. Epimeria (Drakepimeria) macrodonta subgen. nov. Walker, 1906, sex undetermined, lectotype, RV Discovery, National Antarctic Expedition 1902-1904, Ross Sea, Winter Quarters - hole 12, 2 to 4.9.1903, J.107, BMNH 1907.6.6.259-262 (in part). A. Left habitus. B. Right habitus. 


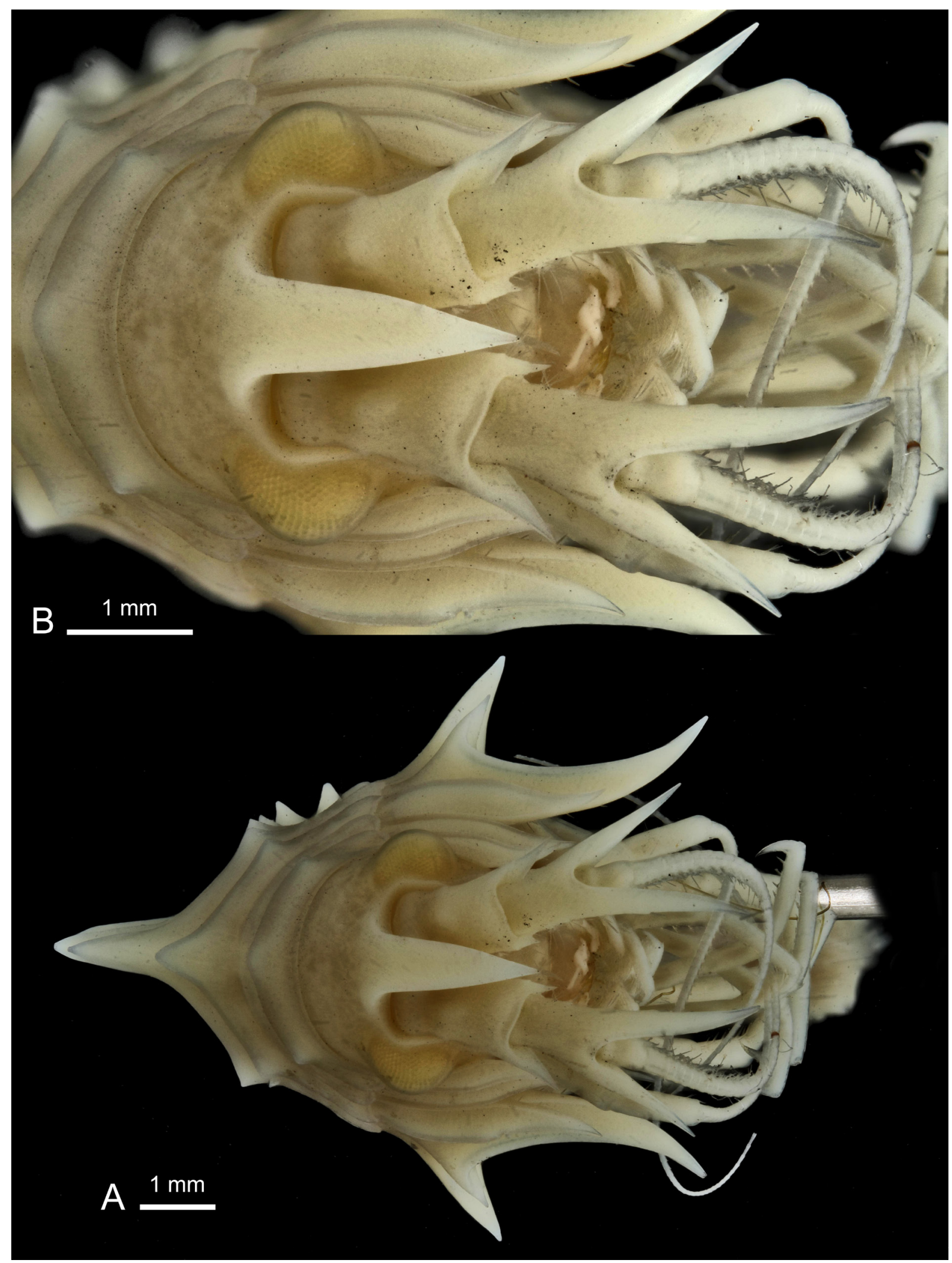

Fig. 73. Epimeria (Drakepimeria) macrodonta subgen. nov. Walker, 1906, sex undetermined, lectotype, RV Discovery, National Antarctic Expedition 1902-1904, Ross Sea, Winter Quarters - hole 12, 2 to 4.9.1903, J.107, BMNH 1907.6.6.259-262 (in part). A. Facial habitus. B. Head in frontal view. 


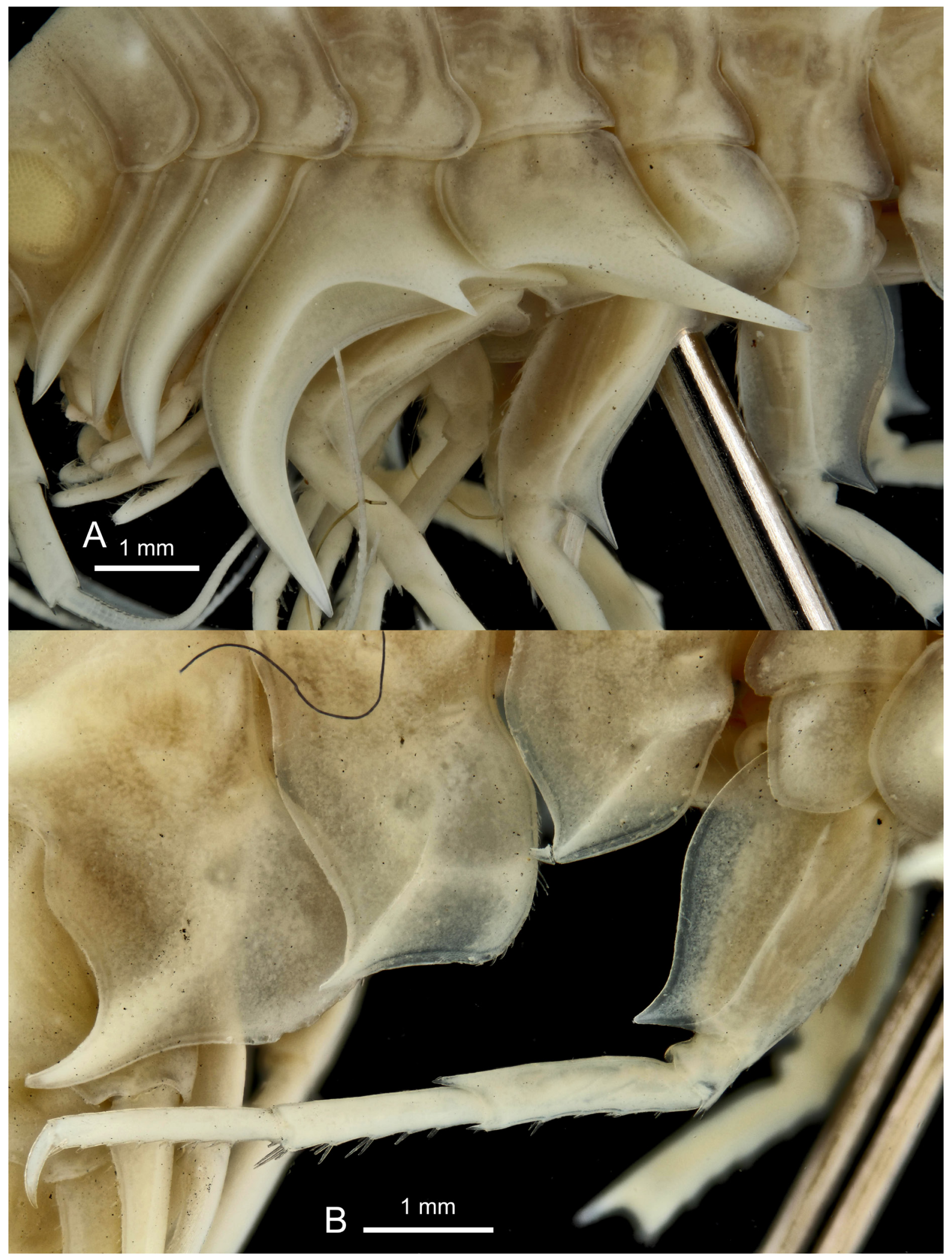

Fig. 74. Epimeria (Drakepimeria) macrodonta subgen. nov. Walker, 1906, sex undetermined, lectotype, RV Discovery, National Antarctic Expedition 1902-1904, Ross Sea, Winter Quarters - hole 12, 2 to 4.9.1903, J.107, BMNH 1907.6.6.259-262 (in part). A. Coxae 1-7, basis of pereiopods 5-7. B. Pereiopod 7 and epimeral plates 1-3. 


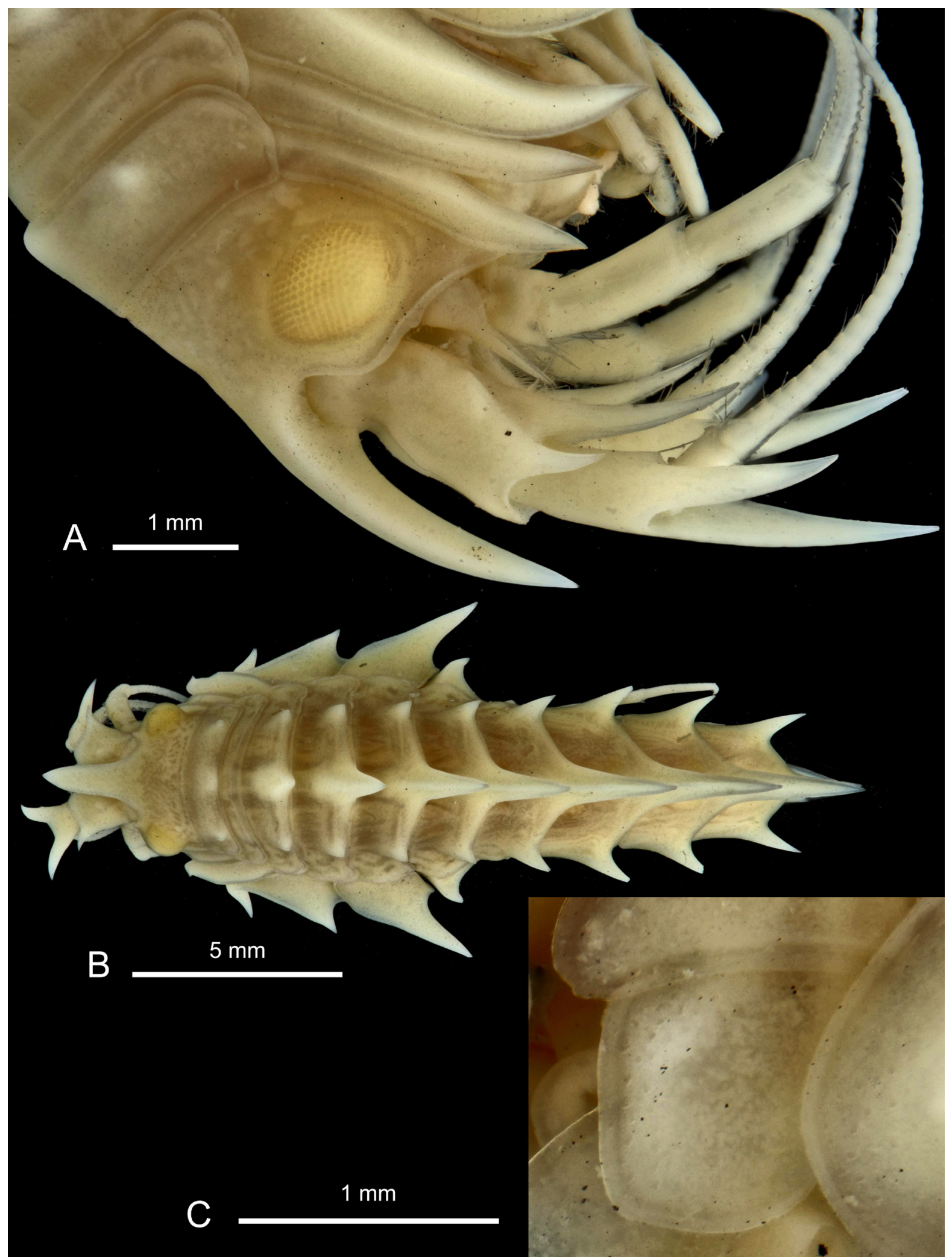

Fig. 75. Epimeria (Drakepimeria) macrodonta subgen. nov. Walker, 1906, sex undetermined, lectotype, RV Discovery, National Antarctic Expedition 1902-1904, Ross Sea, Winter Quarters - hole 12, 2 to 4.9.1903, J.107, BMNH 1907.6.6.259-262 (in part). A. Head in lateral view and coxae 1-3. B. Dorsal habitus. C. Coxa 7. 


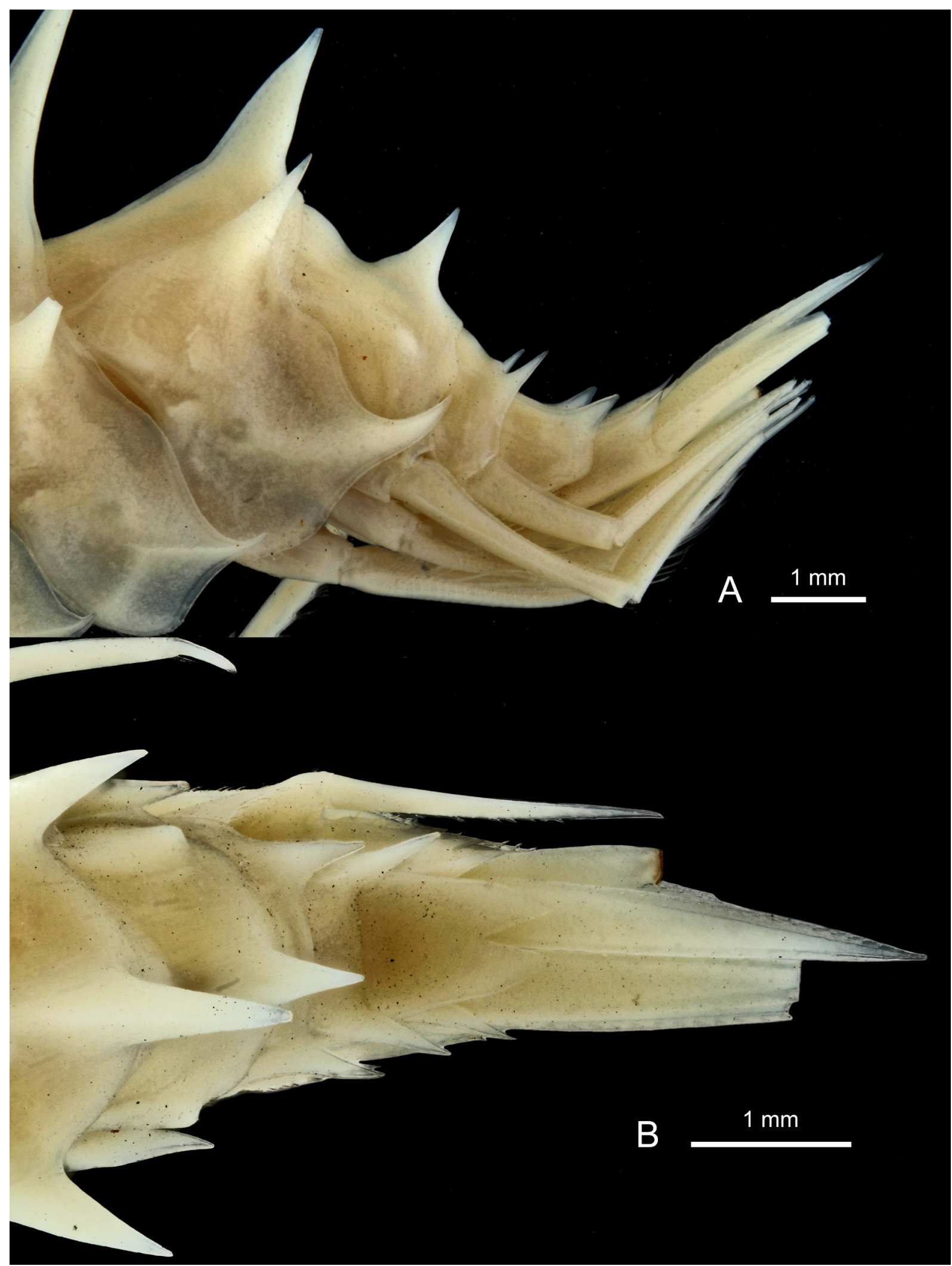

Fig. 76. Epimeria (Drakepimeria) macrodonta subgen. nov. Walker, 1906, sex undetermined, lectotype, RV Discovery, National Antarctic Expedition 1902-1904, Ross Sea, Winter Quarters - hole 12, 2 to 4.9.1903, J.107, BMNH 1907.6.6.259-262 (in part). A. Pleon in lateral view. B. Pleon in dorsal view. 


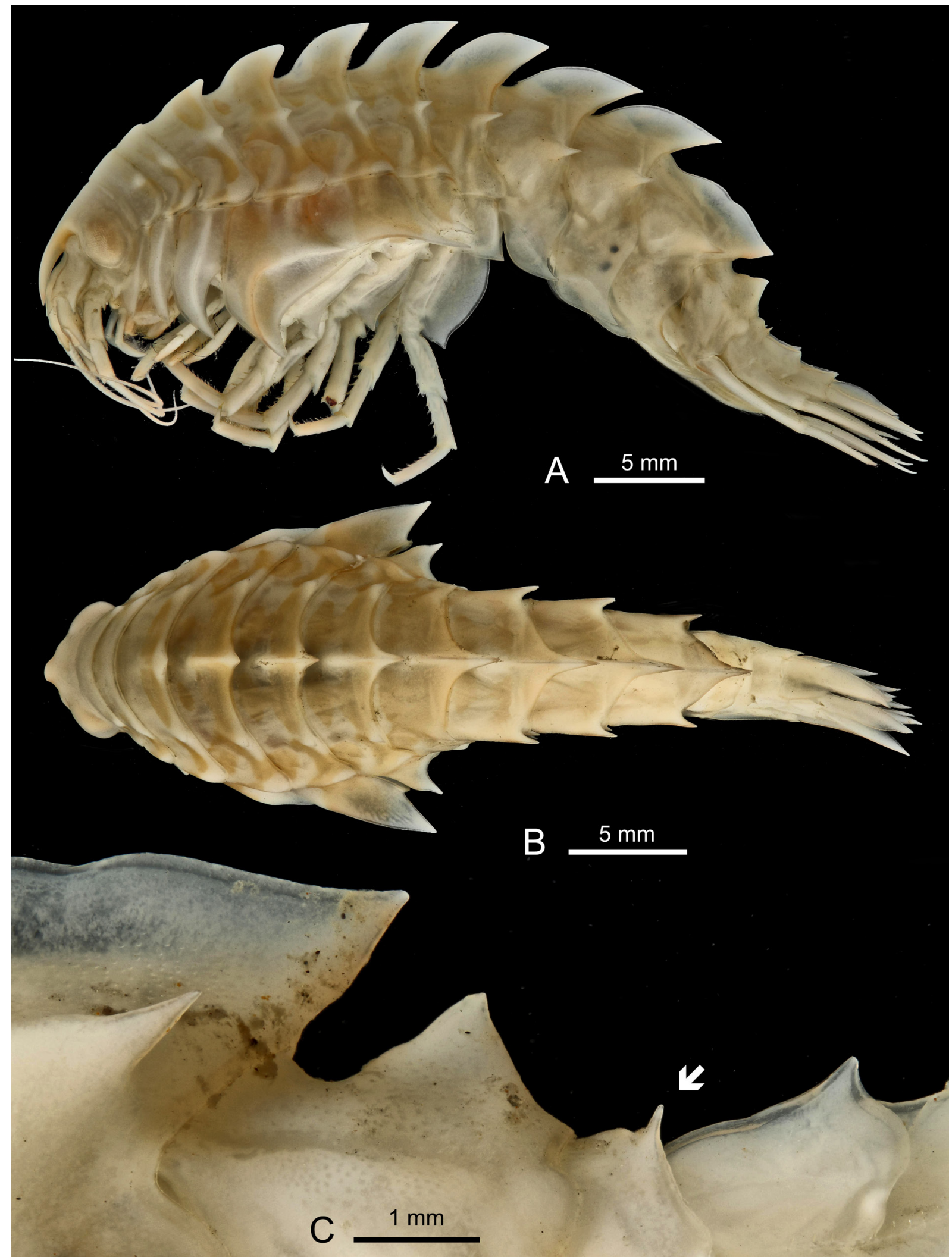

Fig. 77. Epimeria (Drakepimeria) pandora subgen. et sp. nov.,, , holotype, Bransfield Strait, ANTXXIX/3, stn 217-6, RBINS, INV. 122931A. A. Lateral habitus. B. Dorsal habitus. C. Dorsal profile of pleonite 3 and urosomites $1-3$. 


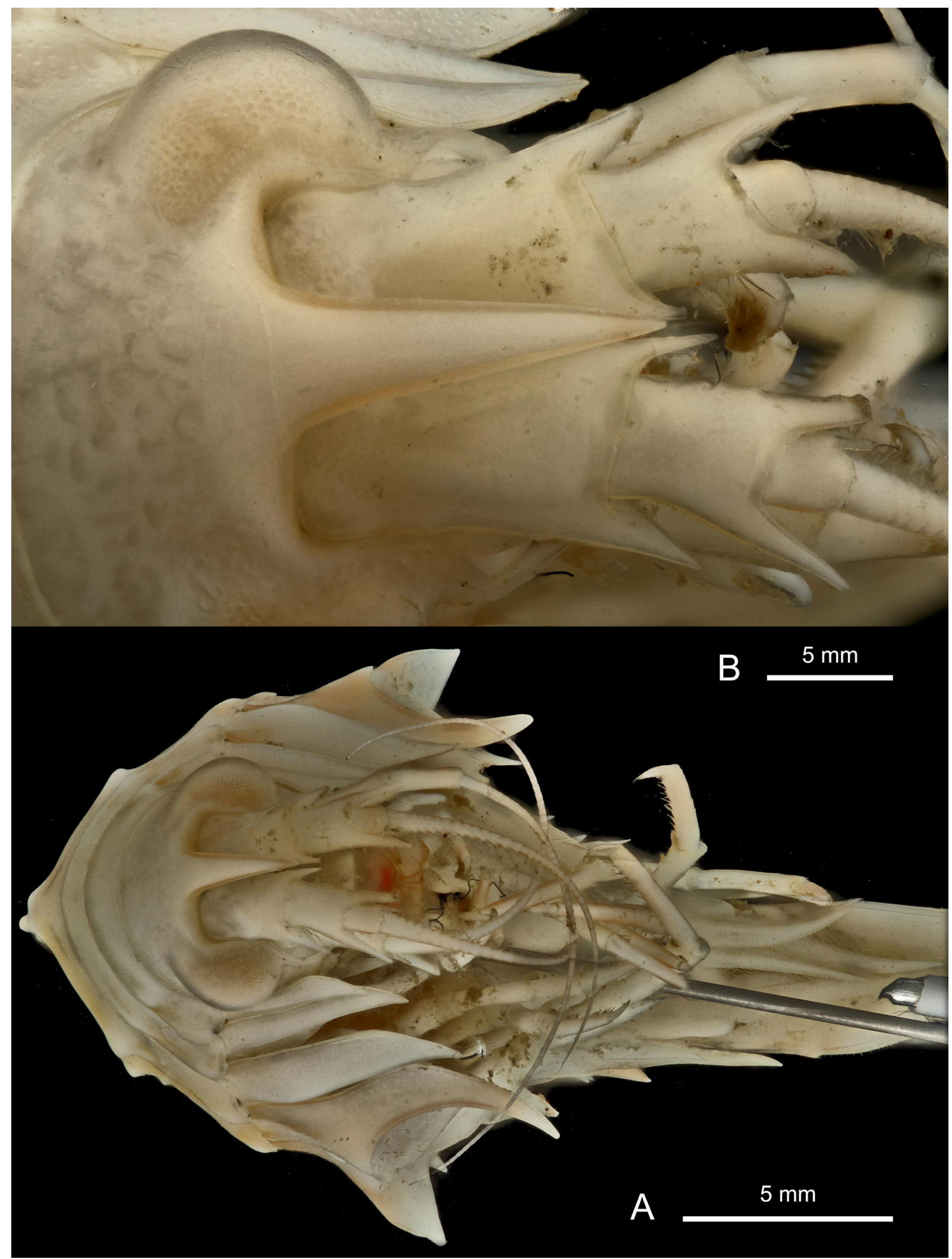

Fig. 78. Epimeria (Drakepimeria) pandora subgen. et sp. nov., + , holotype, Bransfield Strait, ANTXXIX/3, stn 217-6, RBINS, INV. 122931A. A. Frontal habitus. B. Head and peduncles of antenna 1 in dorsal view. 


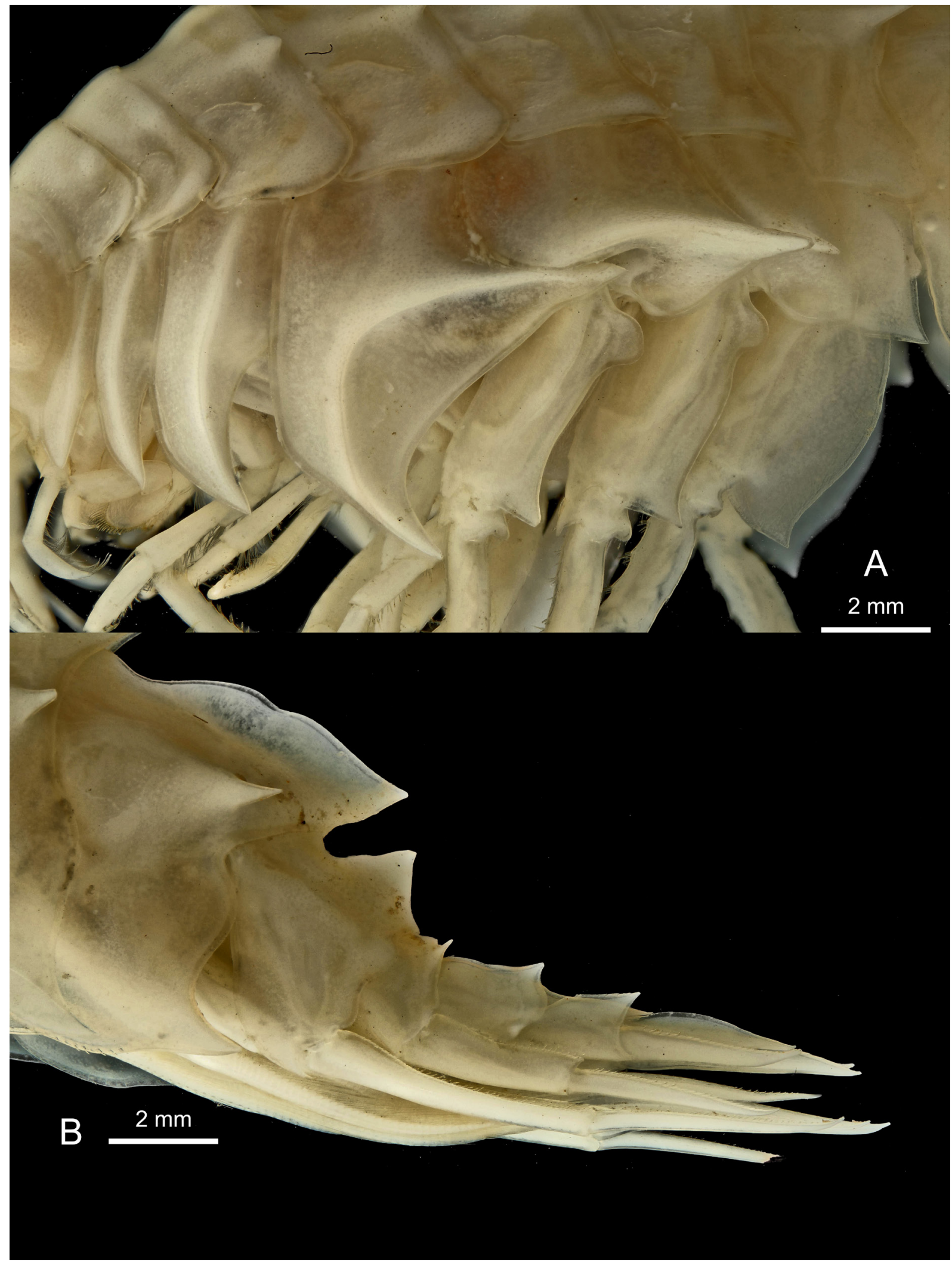

Fig. 79. Epimeria (Drakepimeria) pandora subgen. et sp. nov., ${ }_{+}$, holotype, Bransfield Strait, ANTXXIX/3, stn 217-6, RBINS, INV. 122931A. A. Coxae 1-7. B. Pleonite 3 and urosome. 


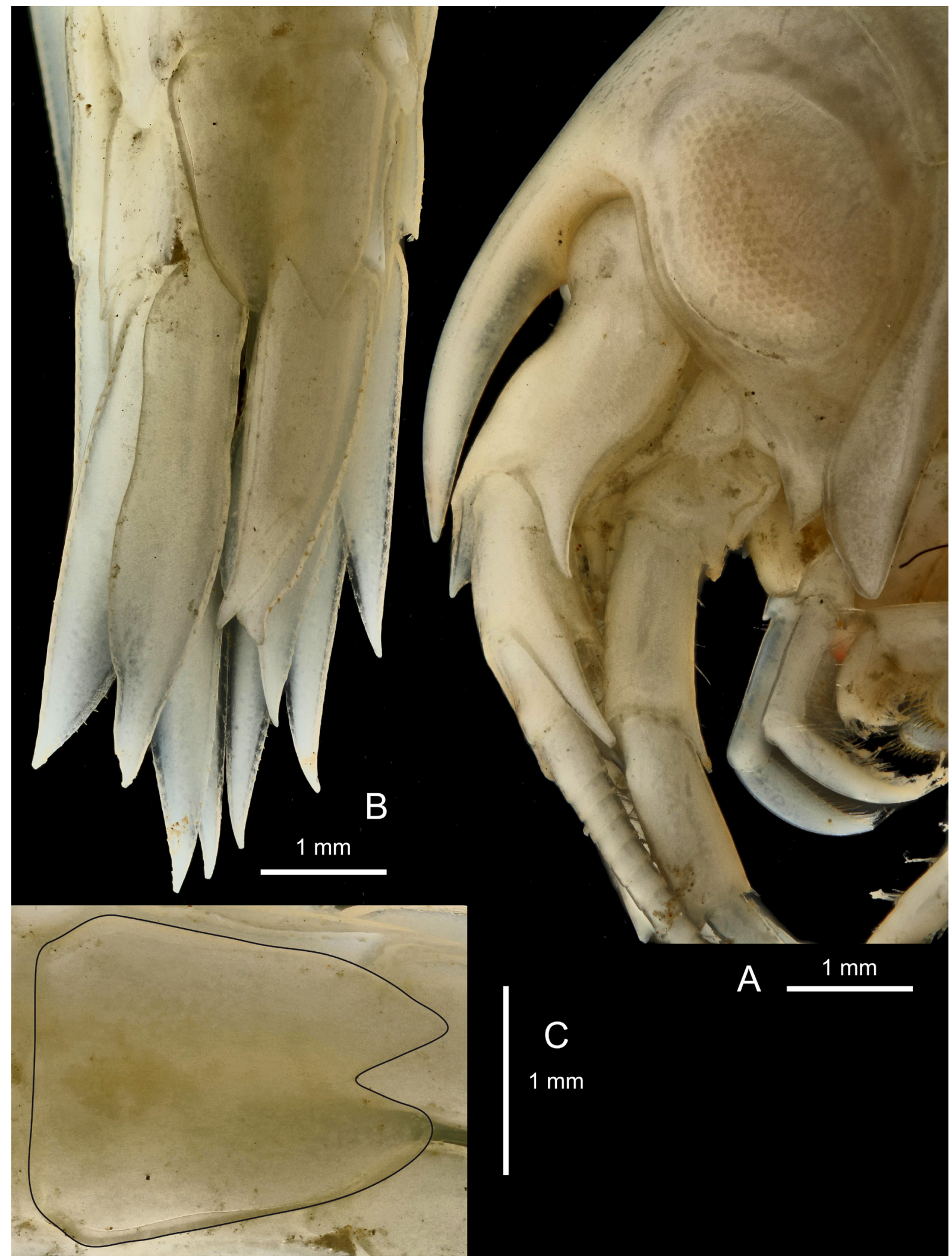

Fig. 80. Epimeria (Drakepimeria) pandora subgen. et sp. nov., + , holotype, Bransfield Strait, ANTXXIX/3, stn 217-6, RBINS, INV. 122931A. A. Head. B. Urosome in dorsal view. C. Telson. 


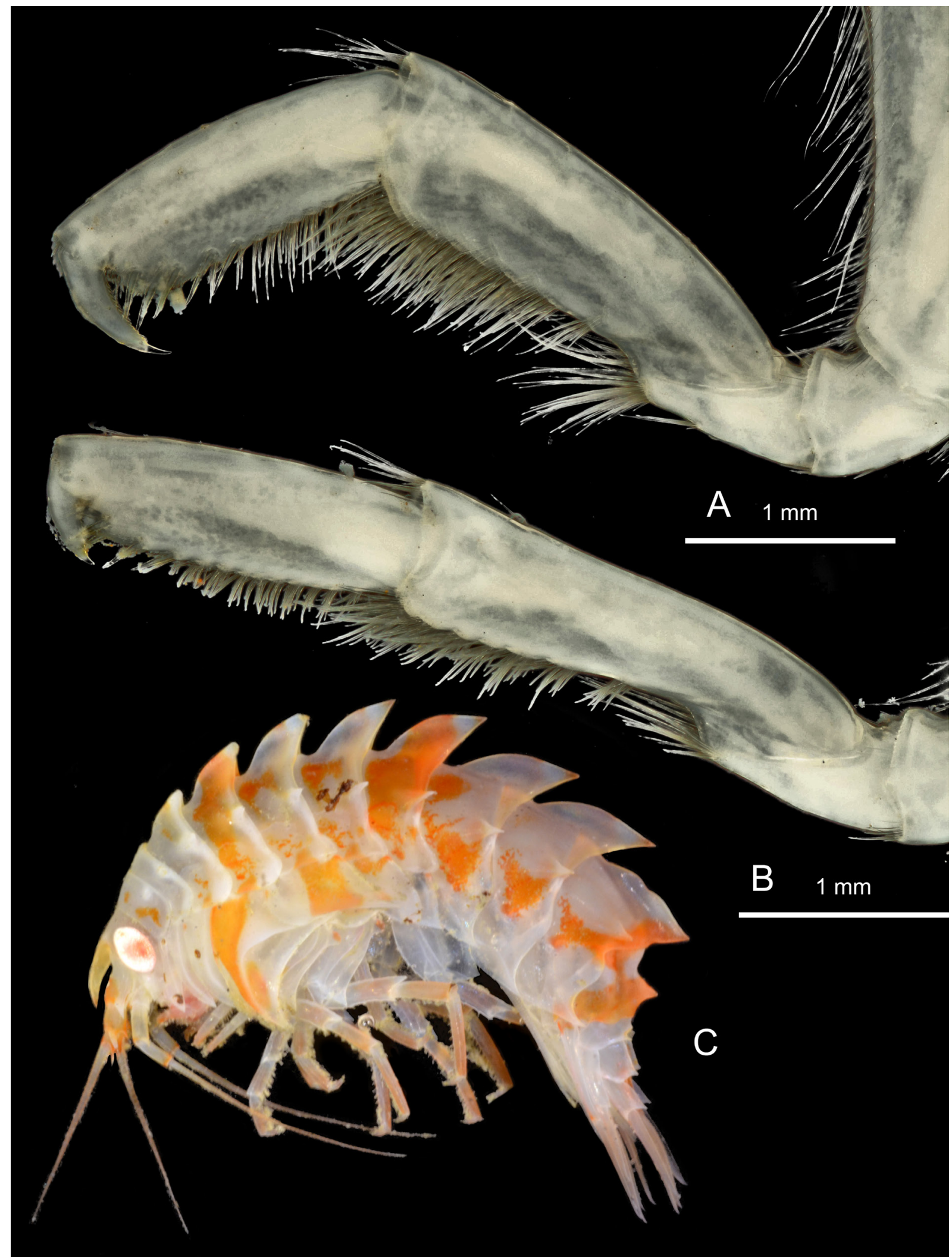

Fig. 81. Epimeria (Drakepimeria) pandora subgen. et sp. nov. A-B, $q$, holotype, Bransfield Strait, ANT-XXIX/3, stn 217-6, RBINS, INV. 122931A. C, + , paratype, Bransfield Strait, ANT-XXIX/3, stn 217-6, RBINS, INV. 122935. A. Gnathopod 1. B. Gnathopod 2. C. Colour in life. 


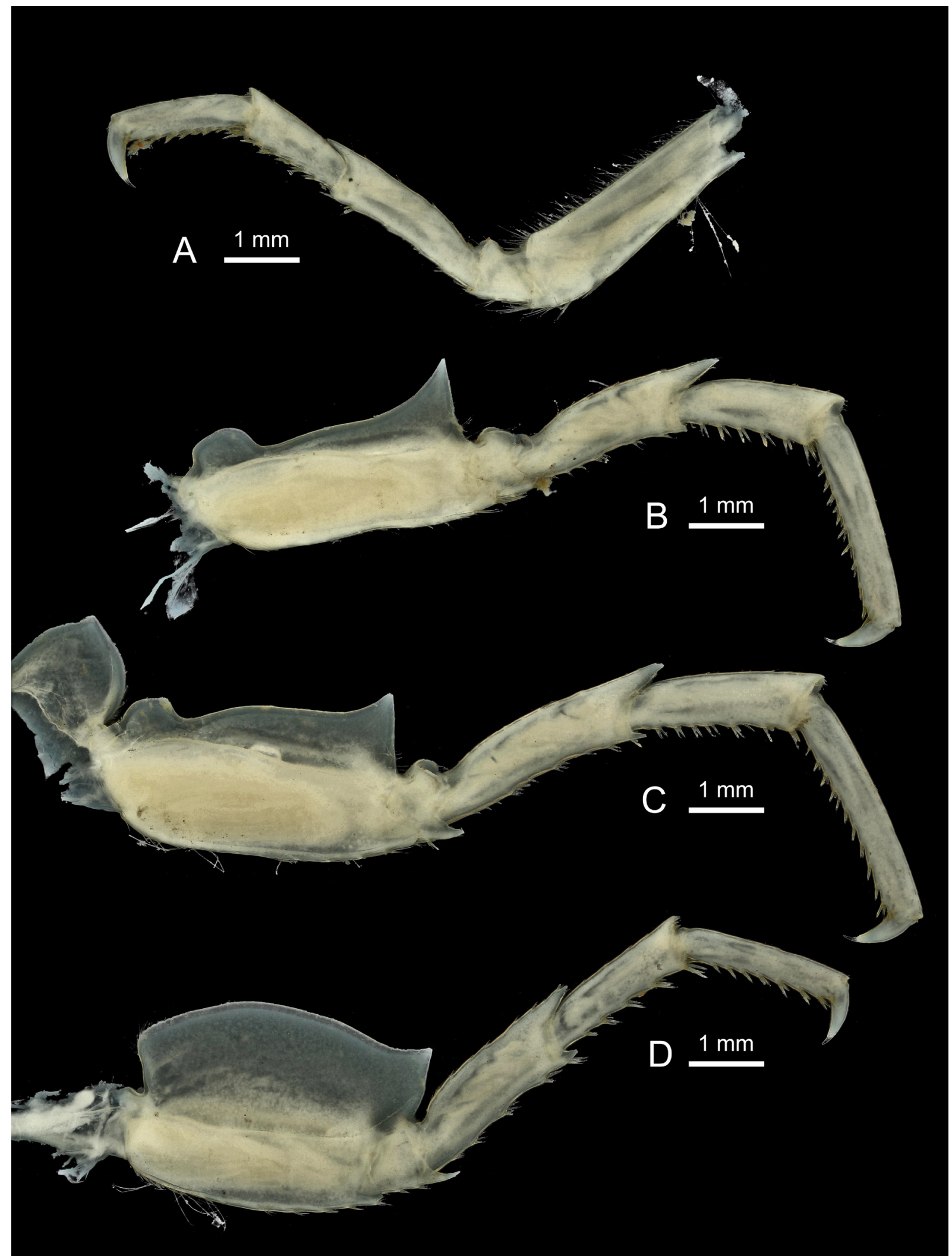

Fig. 82. Epimeria (Drakepimeria) pandora subgen. et sp. nov., + , holotype, Bransfield Strait, ANT-XXIX/3, stn 217-6, RBINS, INV. 122931A. A. Pereiopod 4. B. Pereiopod 5. C. Pereiopod 6. D. Pereiopod 7. 


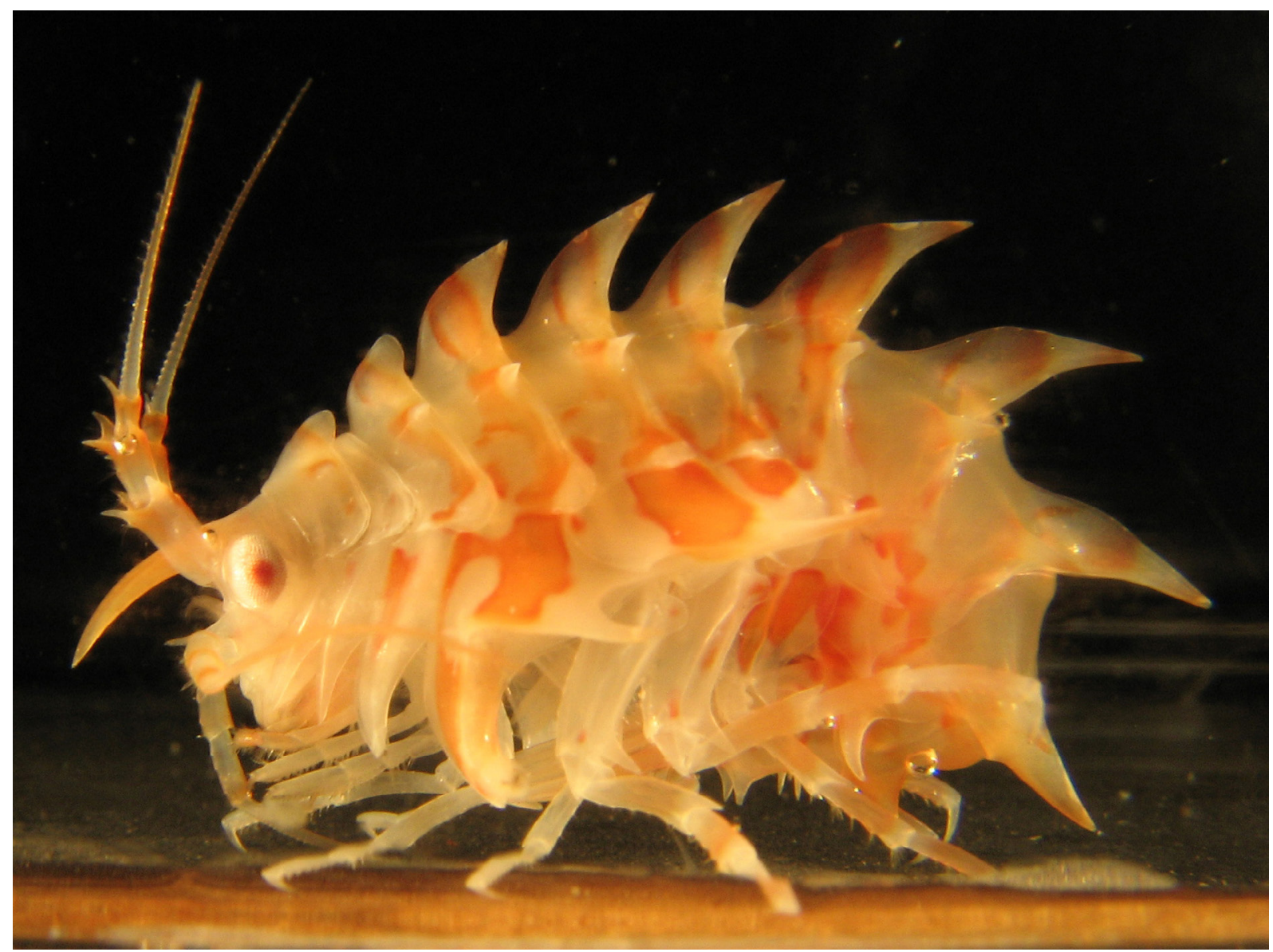

Fig. 83. Epimeria (Drakepimeria) pyrodrakon subgen. et sp. nov., paratype (presumably ${ }_{+}$), eastern Weddell Sea, ANT-XXIII/8, stn 603-5, RBINS, INV. 122560 or 122475, colour in life. 


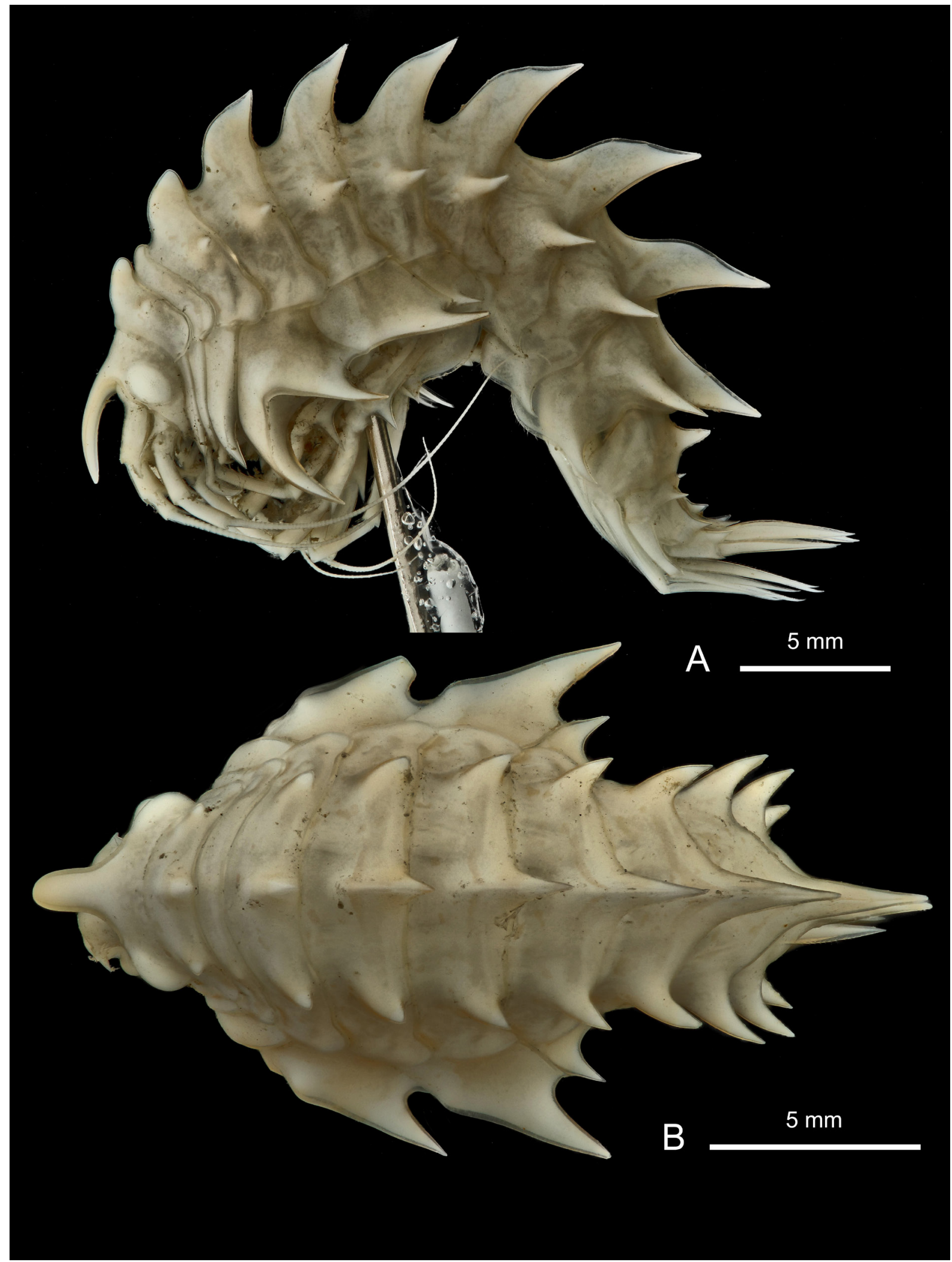

Fig. 84. Epimeria (Drakepimeria) pyrodrakon subgen. et sp. nov., + , holotype, Bransfield Strait, ANTXXIX/3, stn 193-8, RBINS, INV. 132973. A. Lateral habitus. B. Dorsal habitus. 


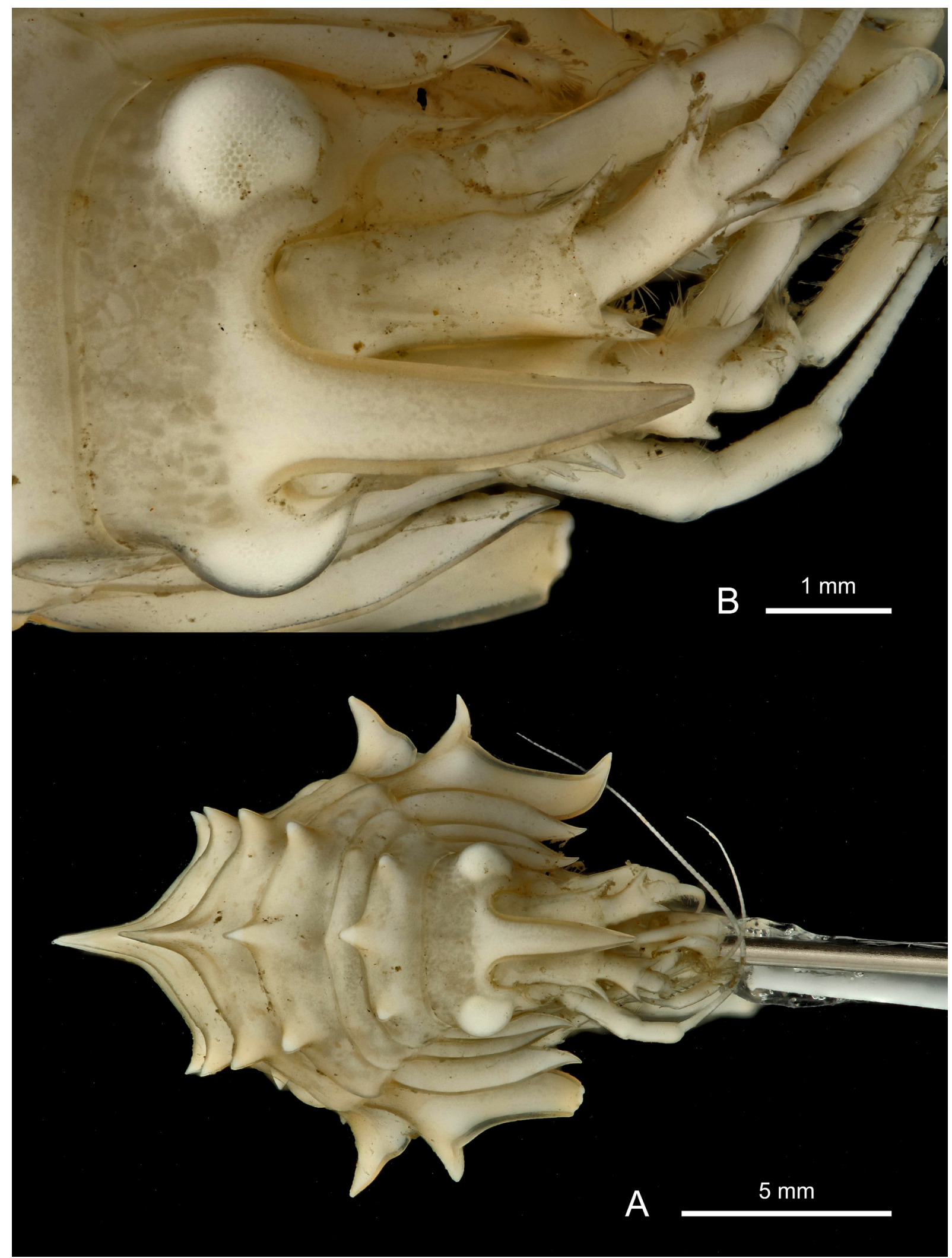

Fig. 85. Epimeria (Drakepimeria) pyrodrakon subgen. et sp. nov., + , holotype, Bransfield Strait, ANTXXIX/3, stn 193-8, RBINS, INV. 132973. A. Facial habitus. B. Head in facial view. 


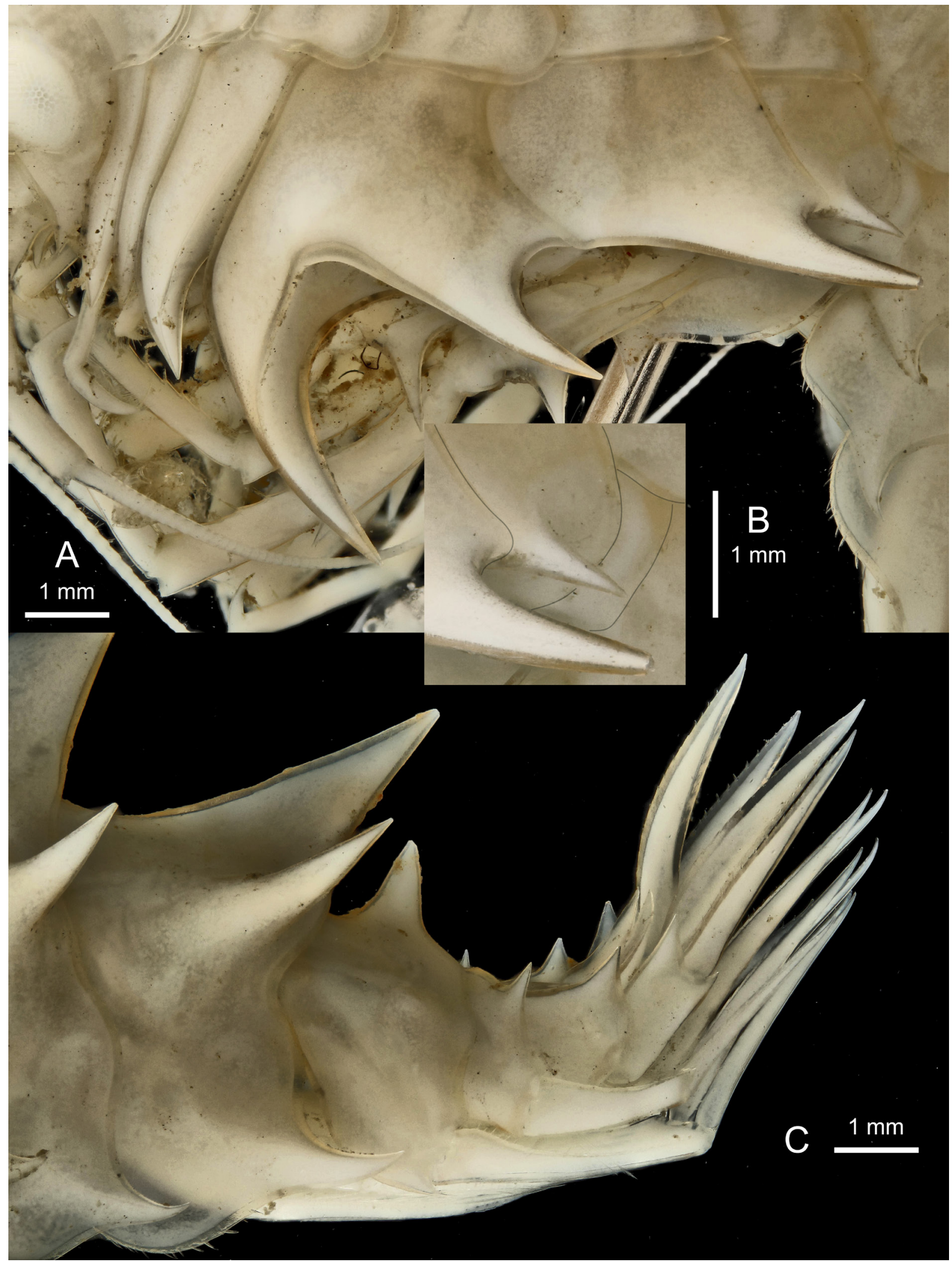

Fig. 86. Epimeria (Drakepimeria) pyrodrakon subgen. et sp. nov.,, , holotype, Bransfield Strait, ANTXXIX/3, stn 193-8, RBINS, INV. 132973. A. Coxae 1-7. B. Coxae 5-7. C. Pleonite 3 and urosome in lateral view. 


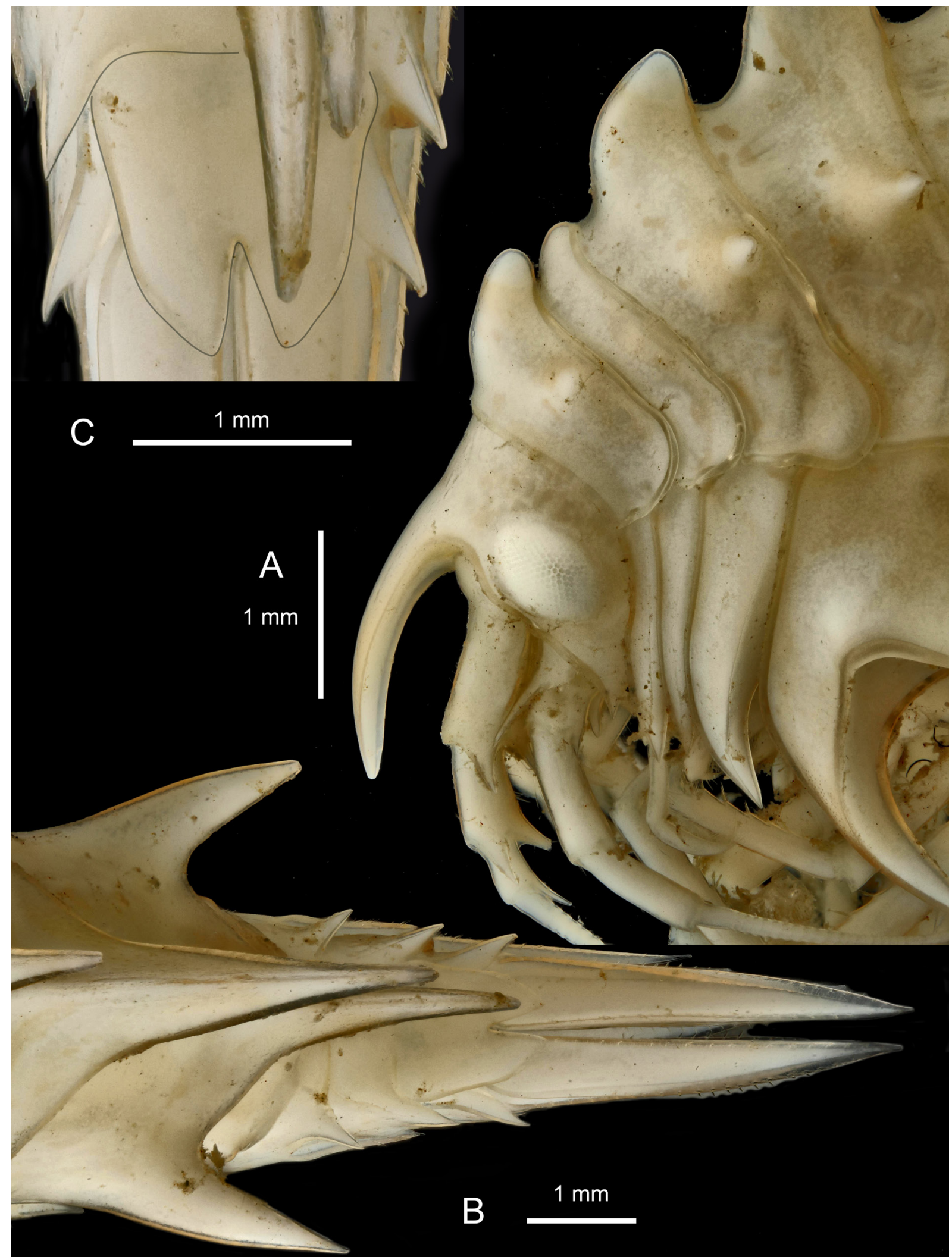

Fig. 87. Epimeria (Drakepimeria) pyrodrakon subgen. et sp. nov., + , holotype, Bransfield Strait, ANTXXIX/3, stn 193-8, RBINS, INV. 132973. A. Head and body segments 1-3 in lateral view. B. Pleonite 3 and urosome in dorsal view. C. Telson. 


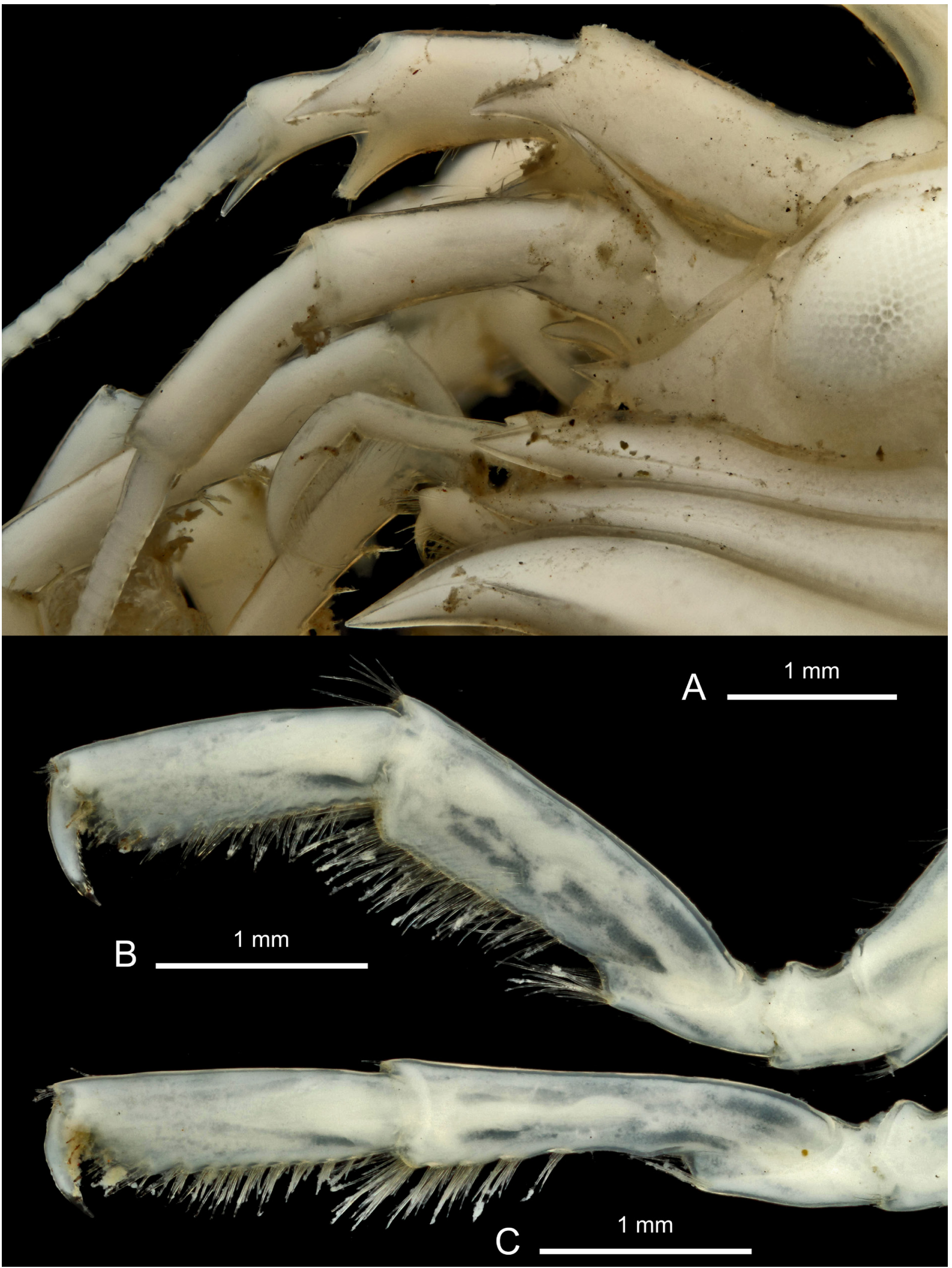

Fig. 88. Epimeria (Drakepimeria) pyrodrakon subgen. et sp. nov.,, , holotype, Bransfield Strait, ANTXXIX/3, stn 193-8, RBINS, INV. 132973. A. Peduncle of antennae in lateral view. B. Gnathopod 1. C. Gnathopod 2. 


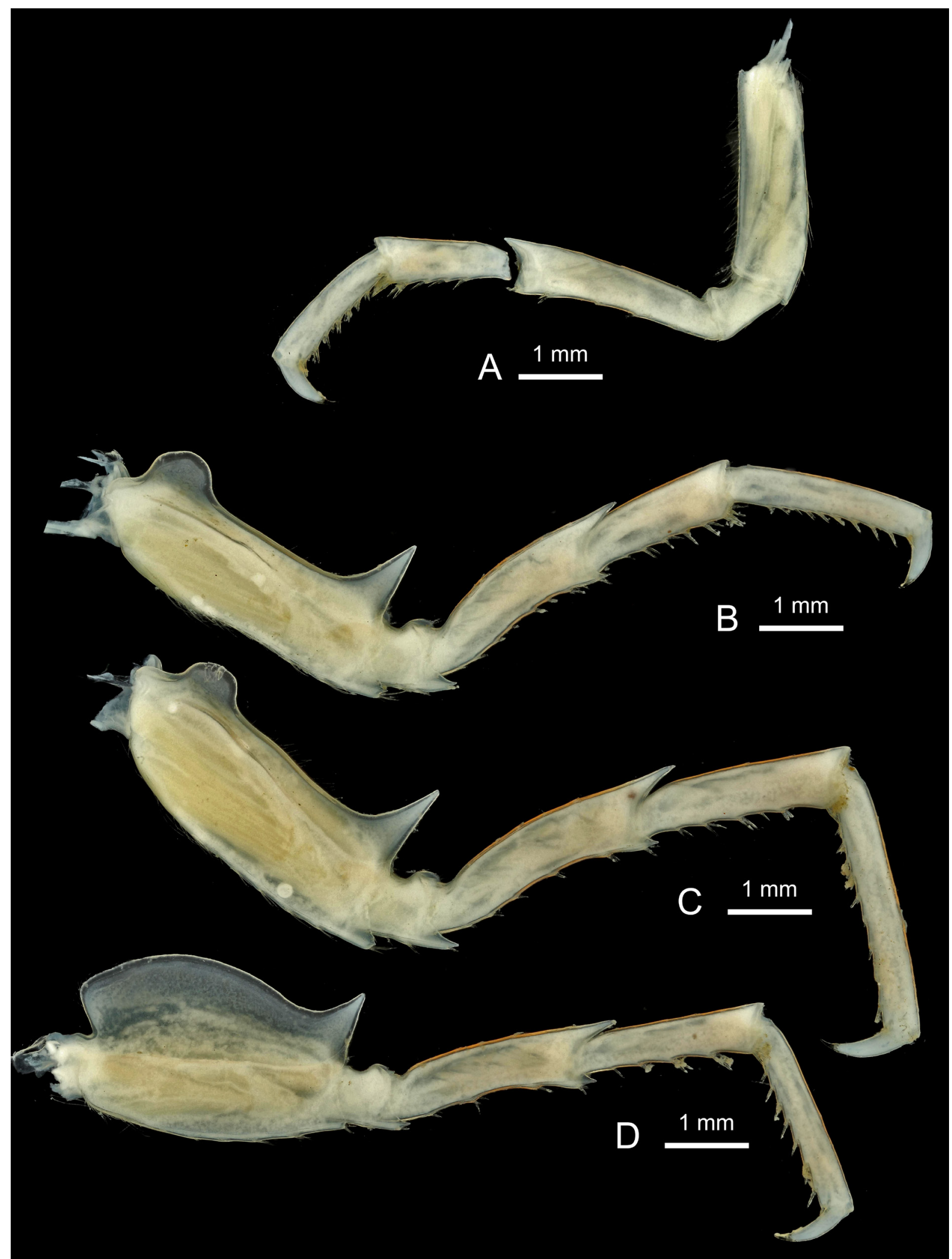

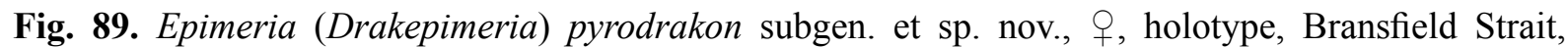
ANT-XXIX/3, stn 193-8, RBINS, INV. 132973. A. Pereiopod 4. B. Pereiopod 5. C. Pereiopod 6. D. Pereiopod 7. 


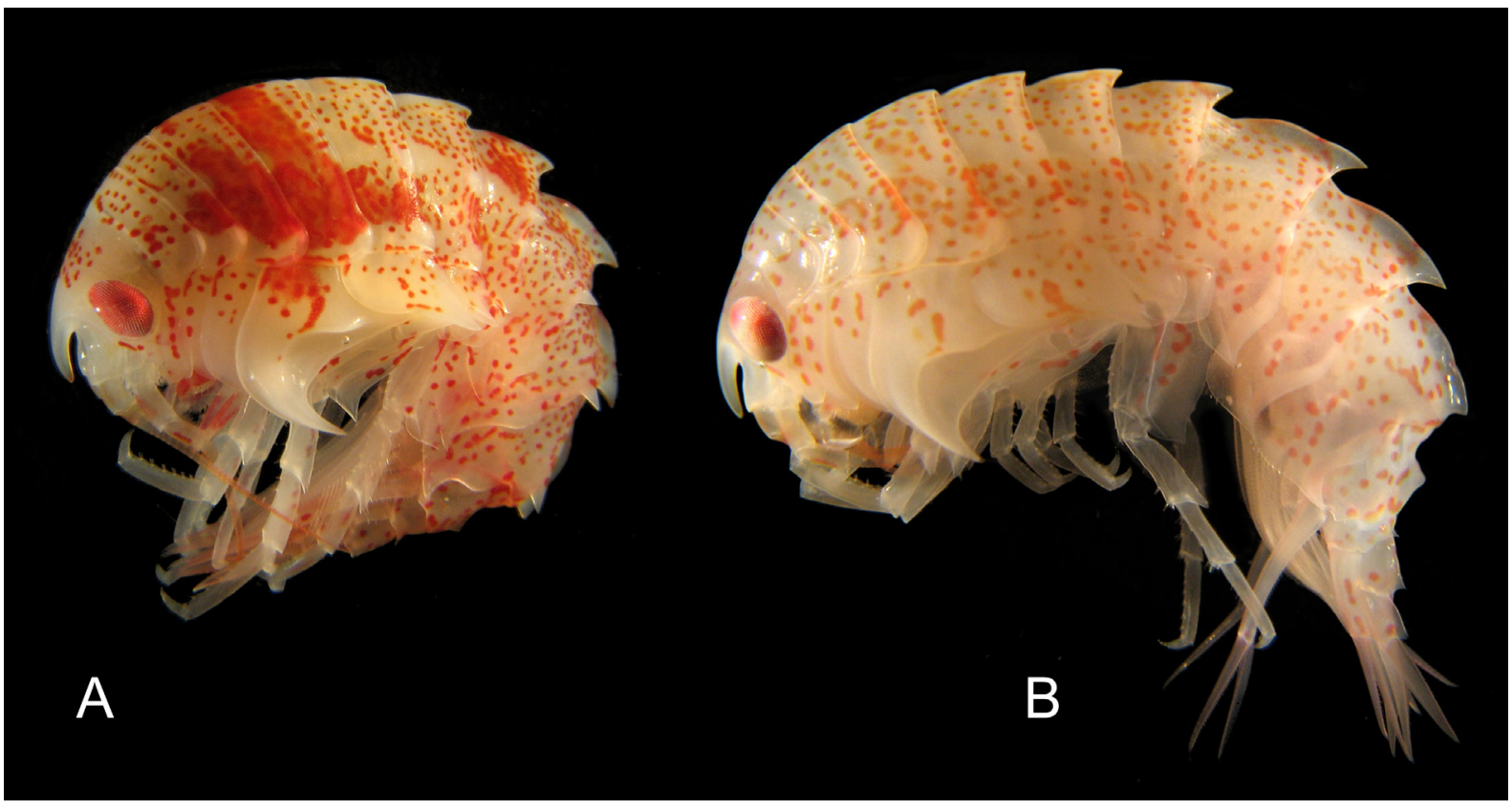

Fig. 90. Epimeria (Drakepimeria) reoproi subgen. nov. Lörz \& Coleman, 2001, q $q$, Elephant Island, ANT-XXIII/8, stn 614-3/4/5, colour in life. A. Colour morph with red patch, RBINS, INV. 122481A. B. Colour morph without red patch, RBINS, INV. 122477. 


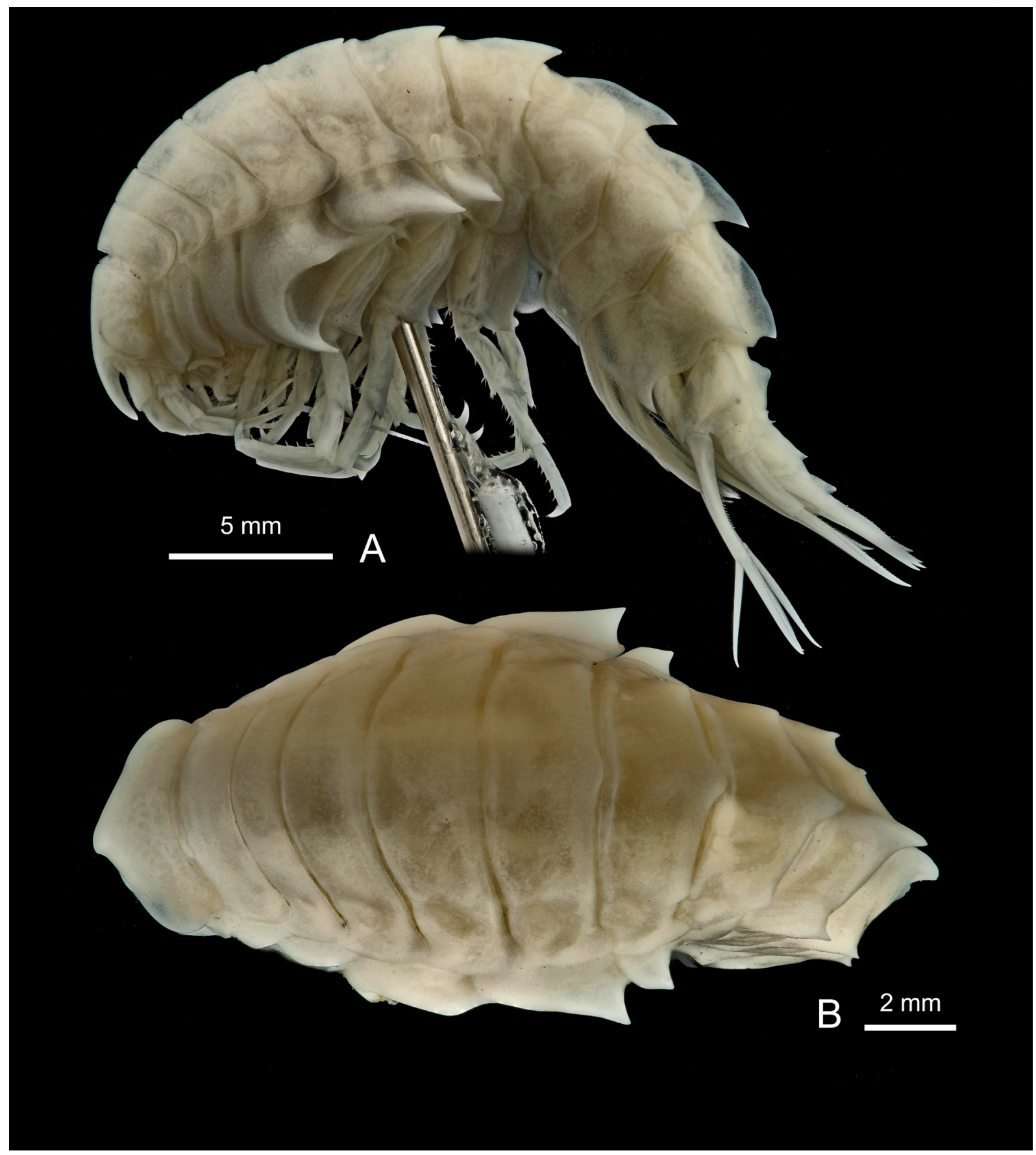

Fig. 91. Epimeria (Drakepimeria) reoproi subgen. nov. Lörz \& Coleman, 2001, +, Elephant Island, ANT-XXIII/8, stn 614-3/4/5, RBINS, INV. 122477. A. Lateral habitus. B. Dorsal habitus. 


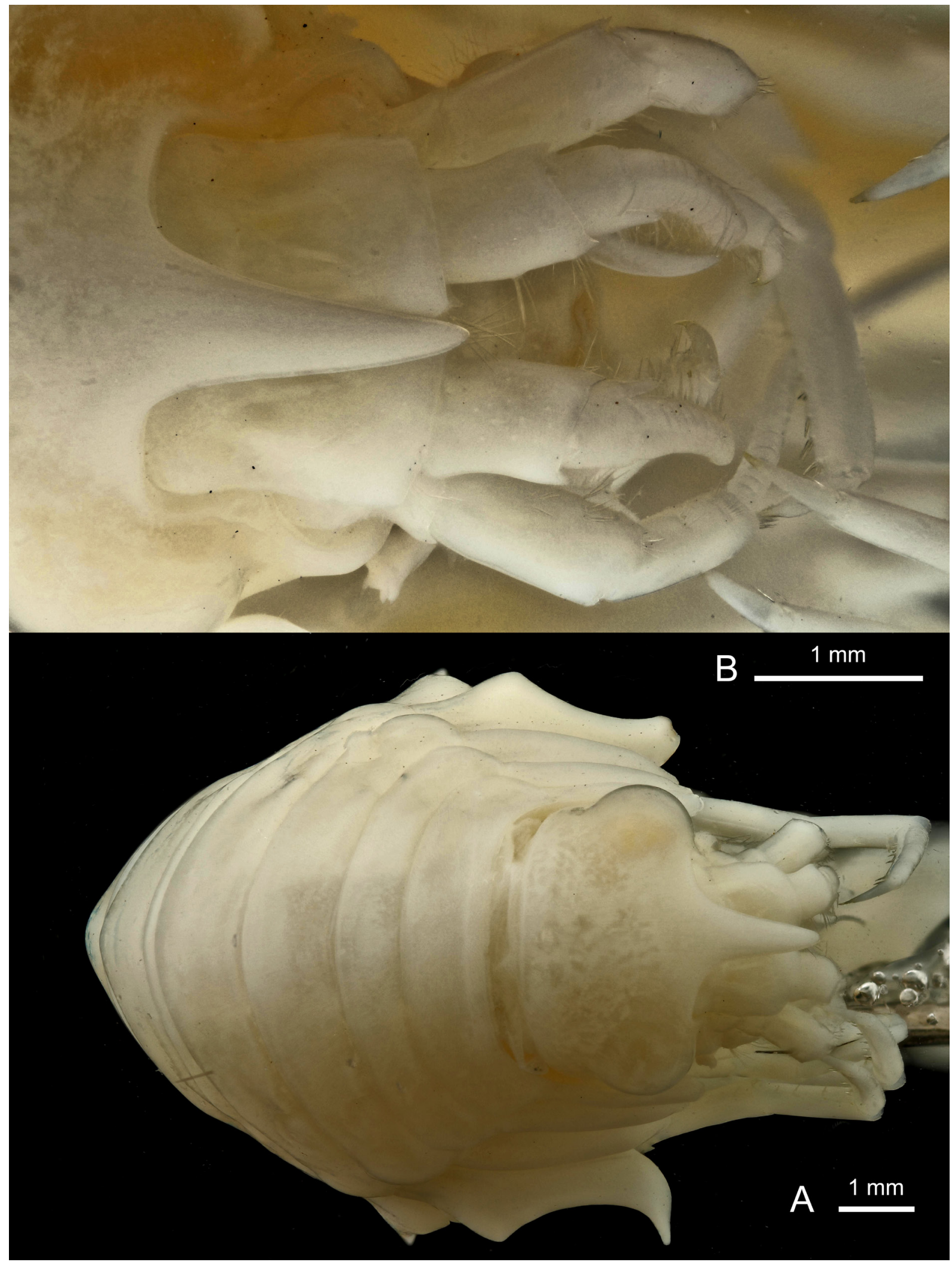

Fig. 92. Epimeria (Drakepimeria) reoproi subgen. nov. Lörz \& Coleman, 2001, + , Elephant Island, ANT-XXIII/8, stn 614-3/4/5, RBINS, INV. 122477. A. Facial habitus. B. Head in facial view. 


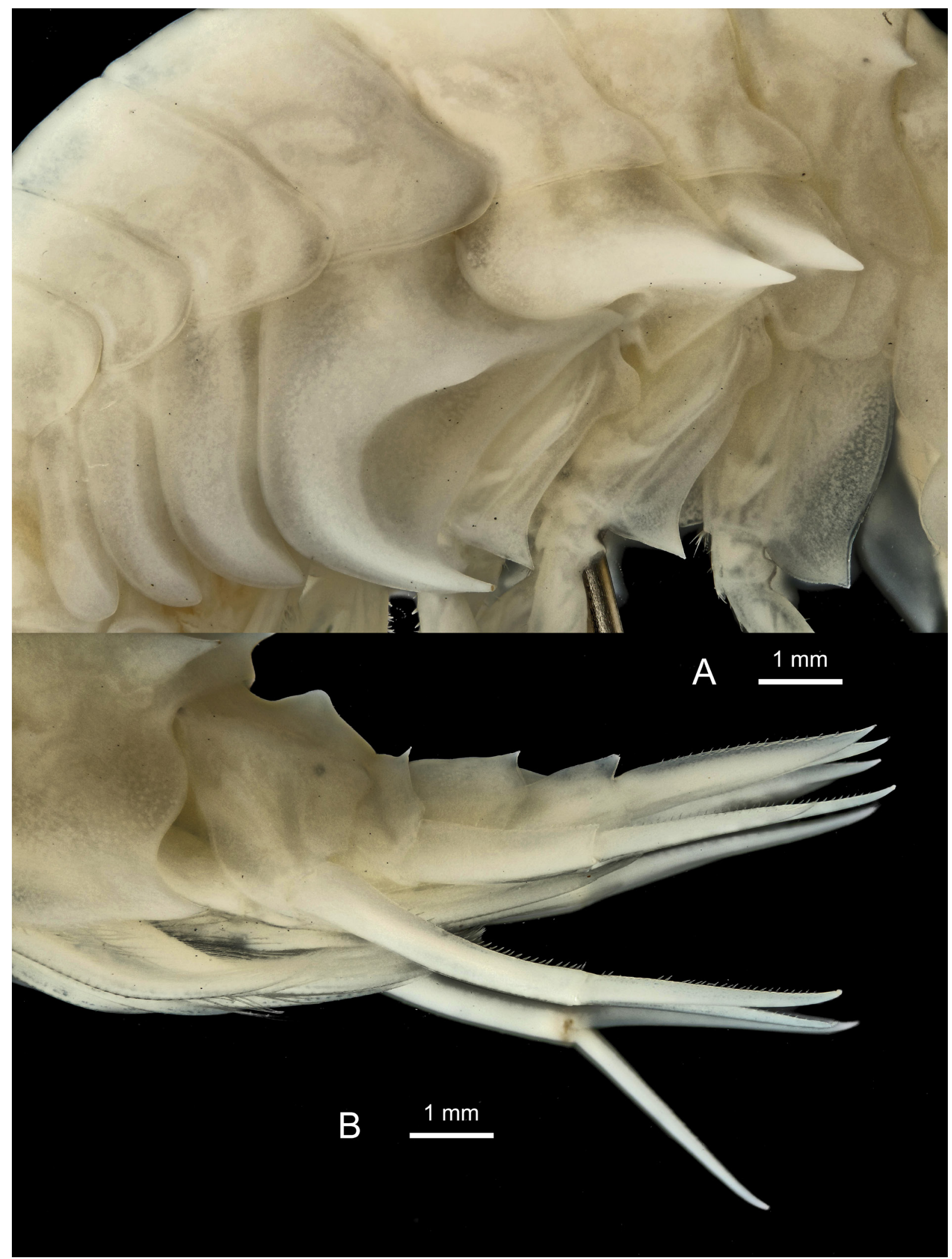

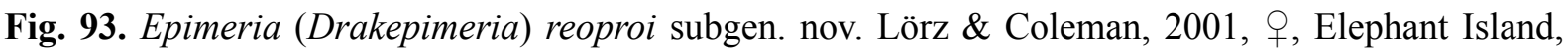
ANT-XXIII/8, stn 614-3/4/5, RBINS, INV. 122477. A. Coxae 1-7. B. Urosome. 


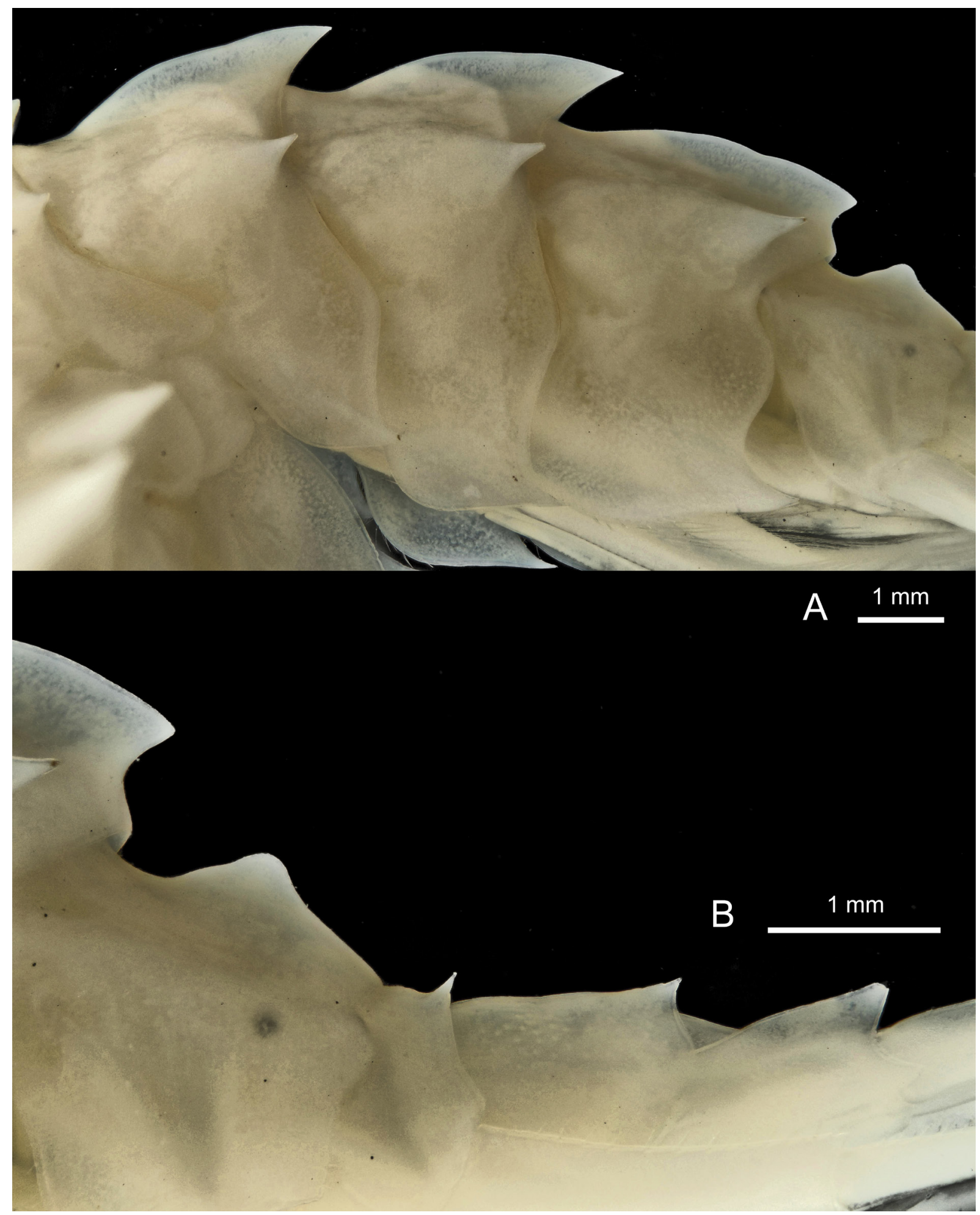

Fig. 94. Epimeria (Drakepimeria) reoproi subgen. nov. Lörz \& Coleman, 2001, + , Elephant Island, ANT-XXIII/8, stn 614-3/4/5, RBINS, INV. 122477. A. Pleosome. B. Profile of urosome. 


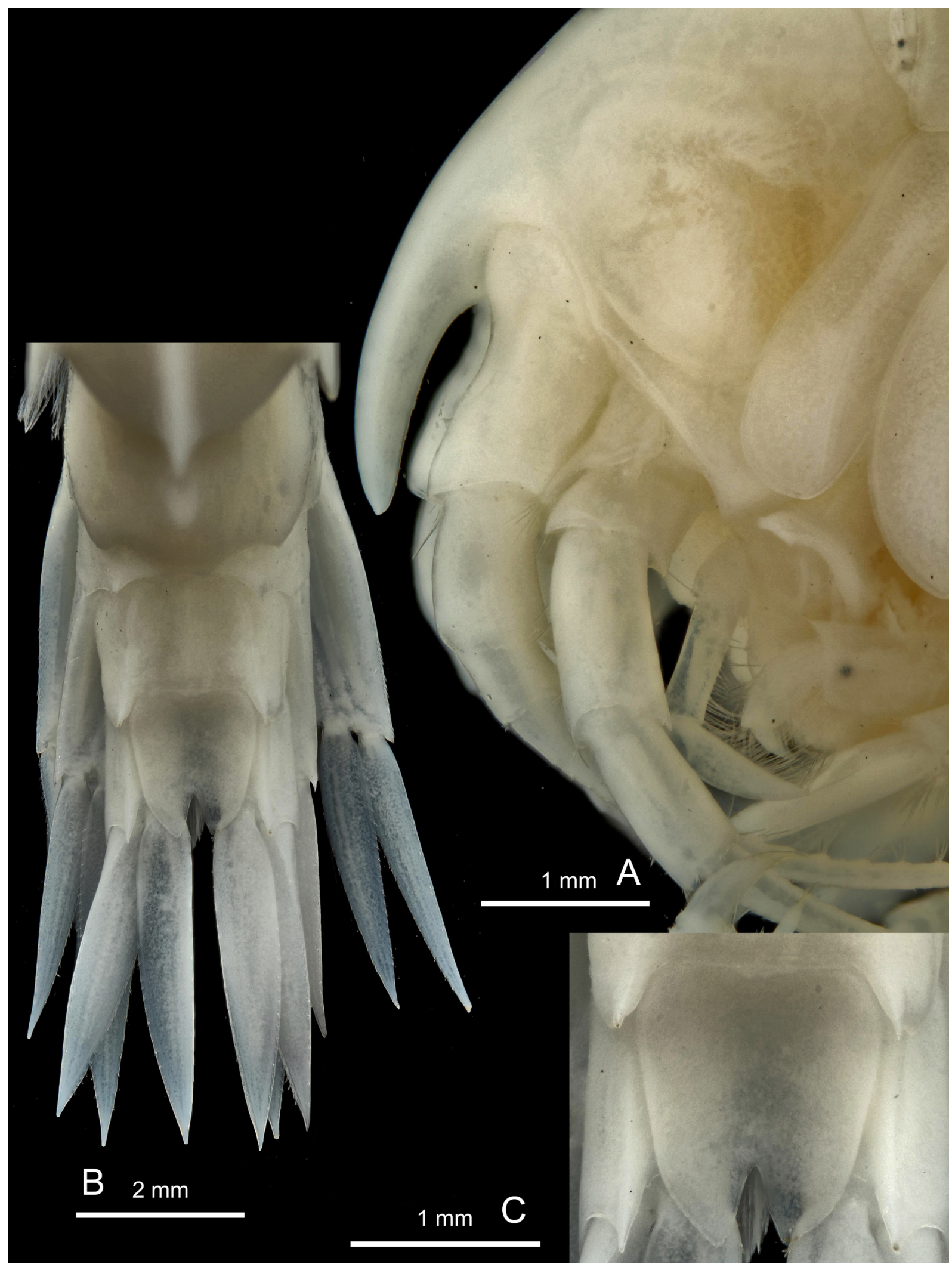

Fig. 95. Epimeria (Drakepimeria) reoproi subgen. nov. Lörz \& Coleman, 2001 , +, Elephant Island, ANT-XXIII/8, stn 614-3/4/5, RBINS, INV. 122477. A. Head in lateral view. B. Urosome in dorsal view. C. Telson. 


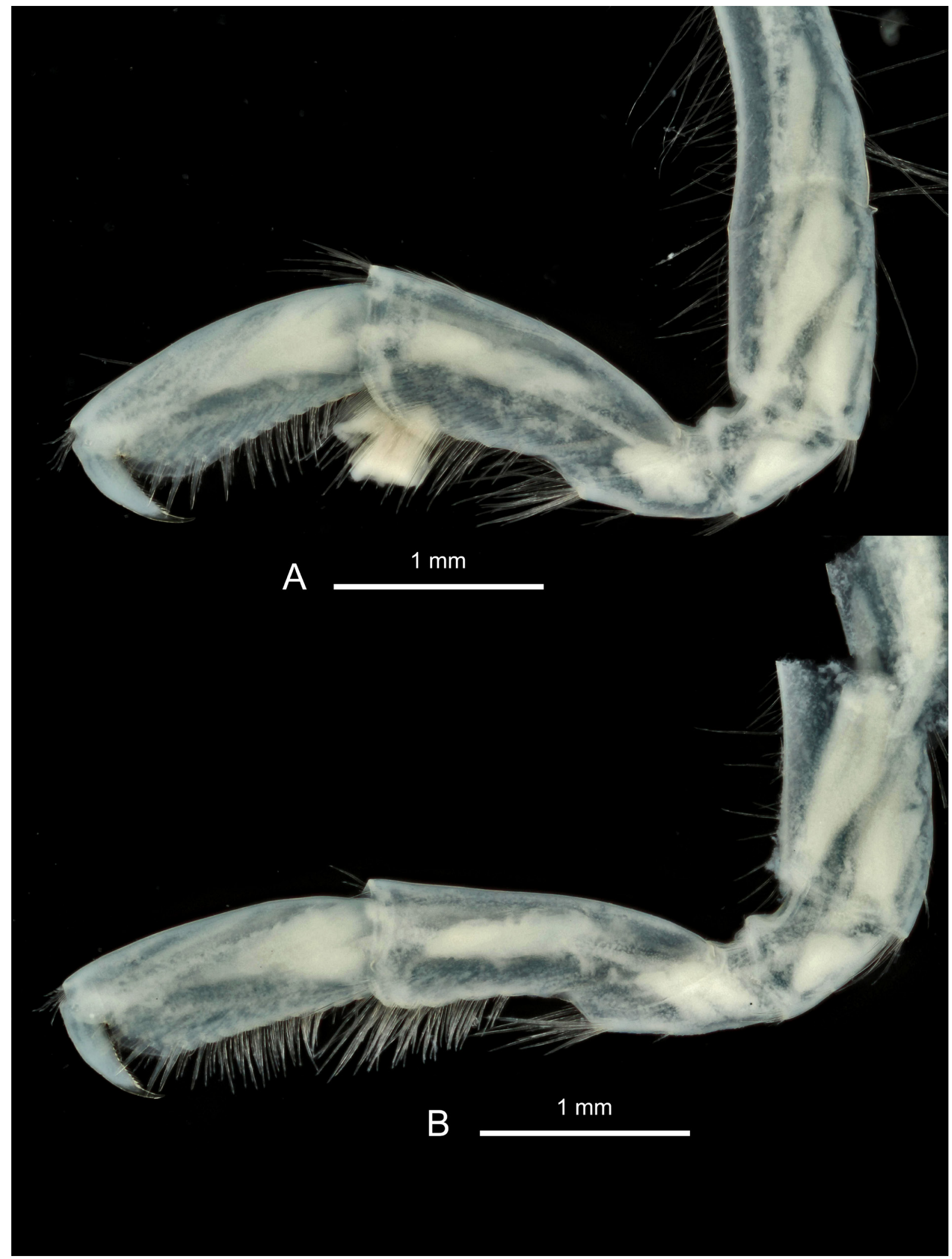

Fig. 96. Epimeria (Drakepimeria) reoproi subgen. nov. Lörz \& Coleman, 2001, q, Elephant Island, ANT-XXIII/8, stn 614-3/4/5, RBINS, INV. 122477. A. Gnathopod 1. B. Gnathopod 2. 


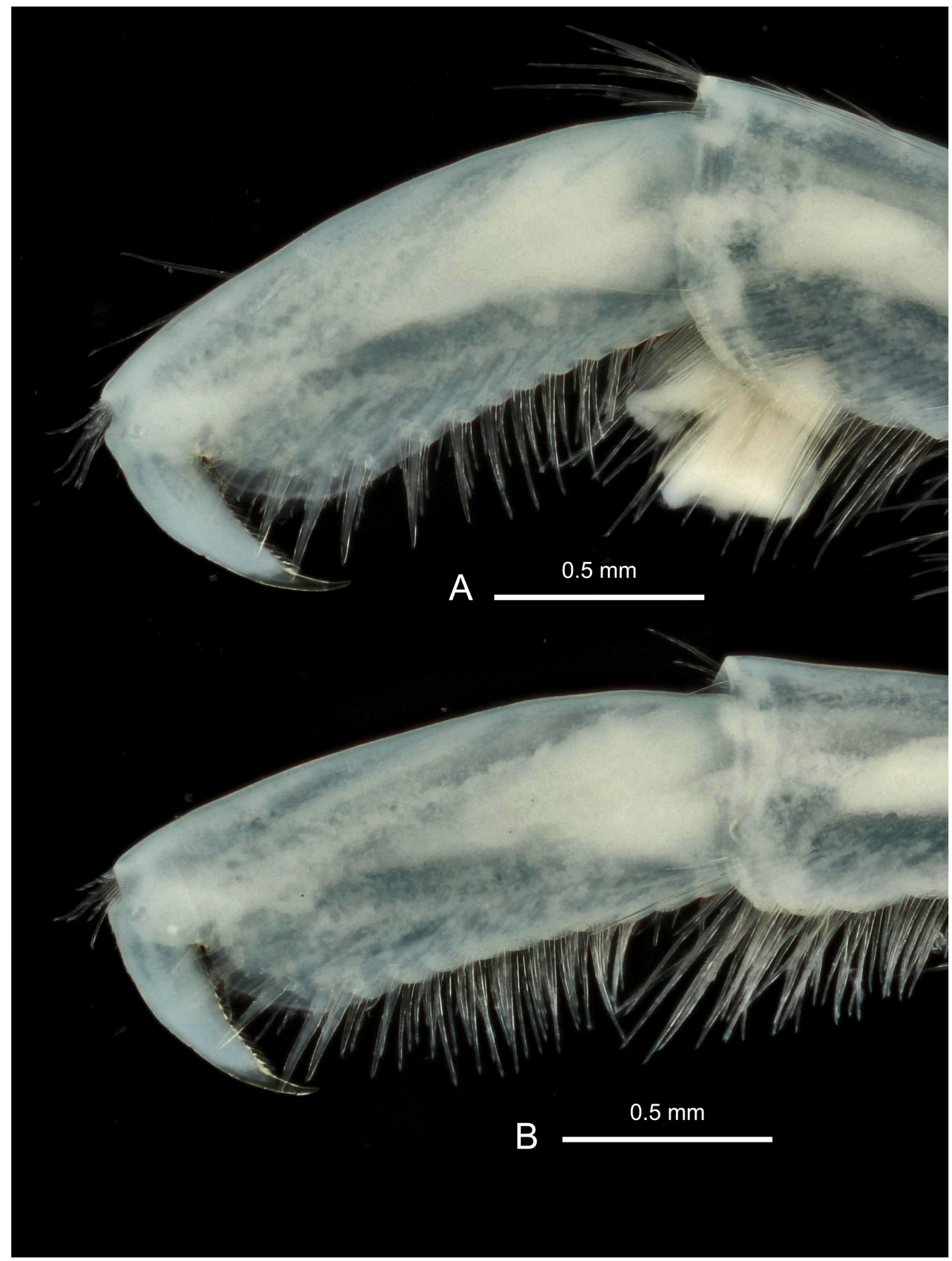

Fig. 97. Epimeria (Drakepimeria) reoproi subgen. nov. Lörz \& Coleman, 2001, + , Elephant Island, ANT-XXIII/8, stn 614-3/4/5, RBINS, INV. 122477. A. Propodus and dactylus of gnathopod 1. B. Propodus and dactylus of gnathopod 2. 


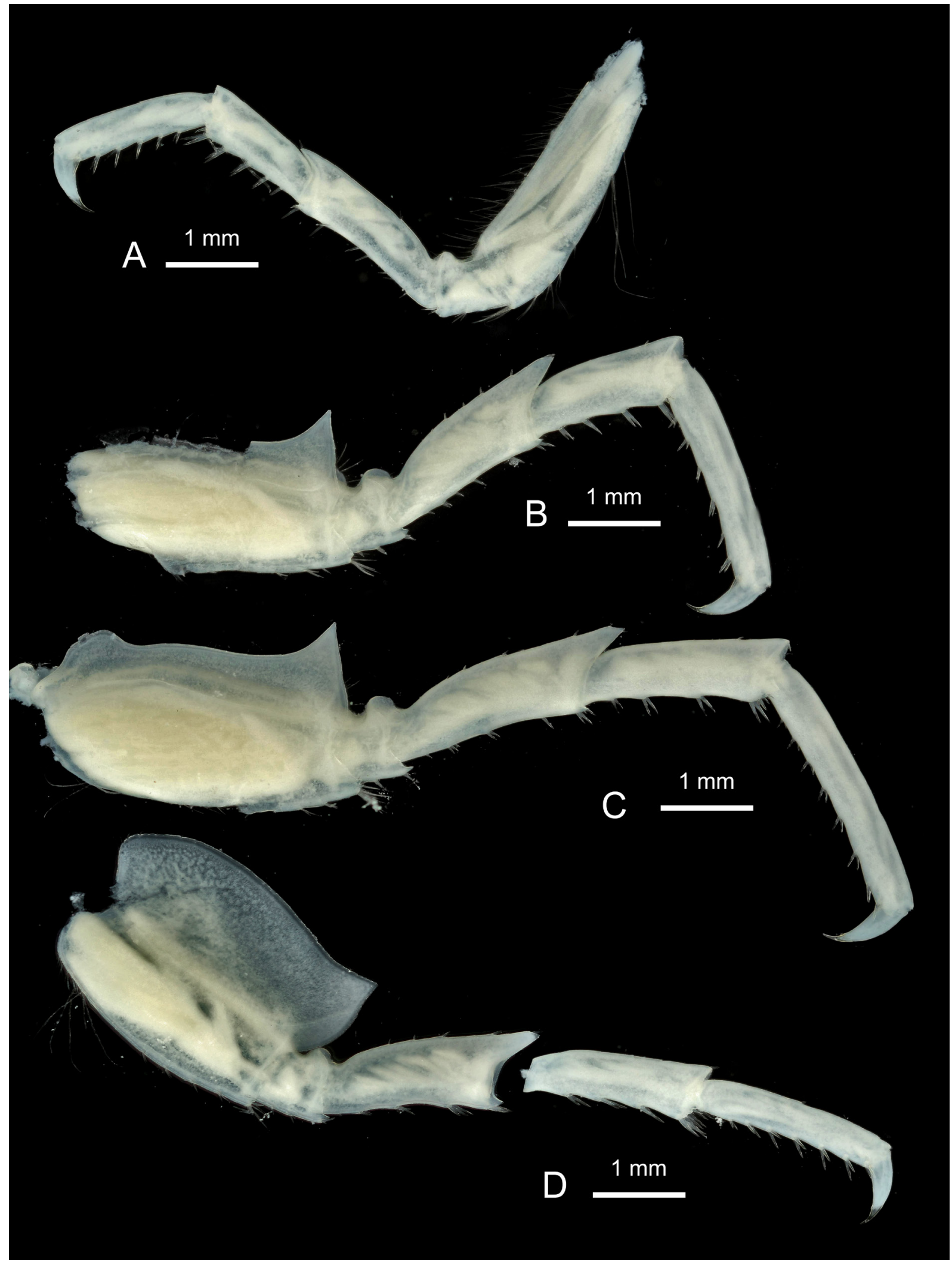

Fig. 98. Epimeria (Drakepimeria) reoproi subgen. nov. Lörz \& Coleman, 2001, + , Elephant Island, ANT-XXIII/8, stn 614-3/4/5, RBINS, INV.122477. A. Pereiopod 4. B. Pereiopod 5. C. Pereiopod 6. D. Pereiopod 7. 


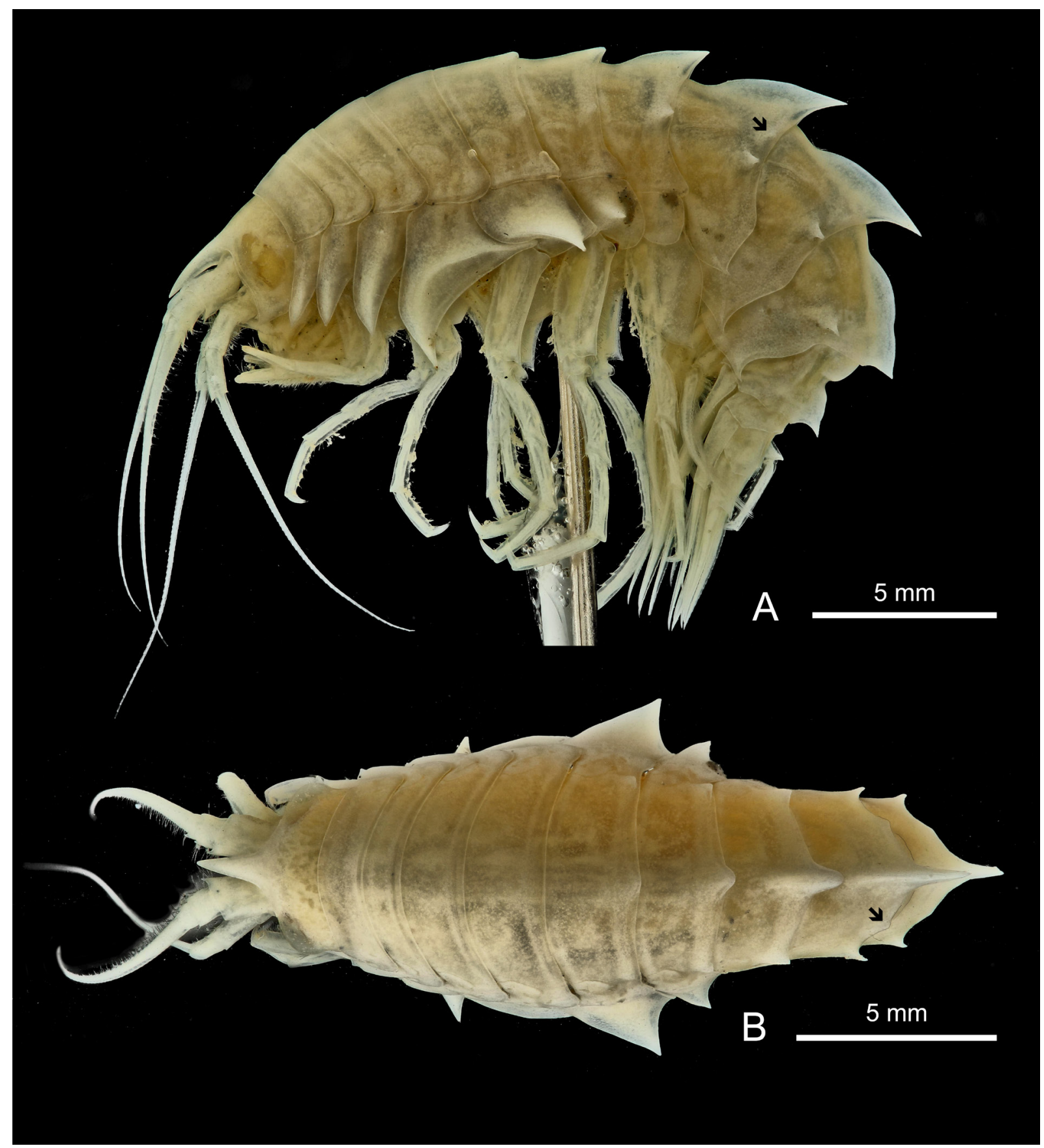

Fig. 99. Epimeria (Drakepimeria) robertiana subgen. et sp. nov., holotype, $\widehat{\partial}$, eastern Weddell Sea, ANT-XXIV/2, presumably stn 17-10, RBINS, INV. 132413. A. Lateral habitus. B. Dorsal habitus. 


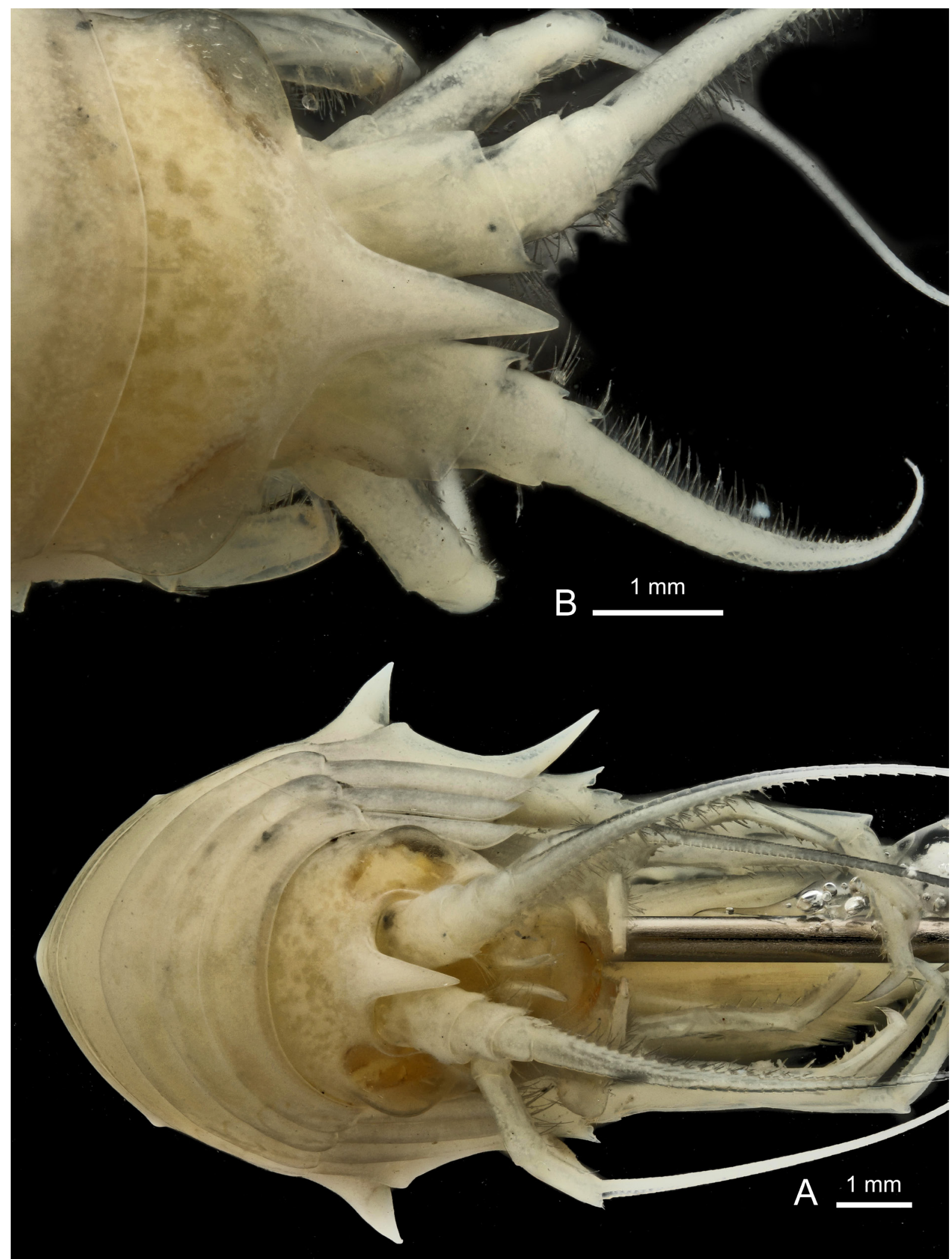

Fig. 100. Epimeria (Drakepimeria) robertiana subgen. et sp. nov., holotype, $\widehat{\partial}$, eastern Weddell Sea, ANT-XXIV/2, presumably stn 17-10, RBINS, INV. 132413. A. Facial habitus. B. Head in dorsal view. 


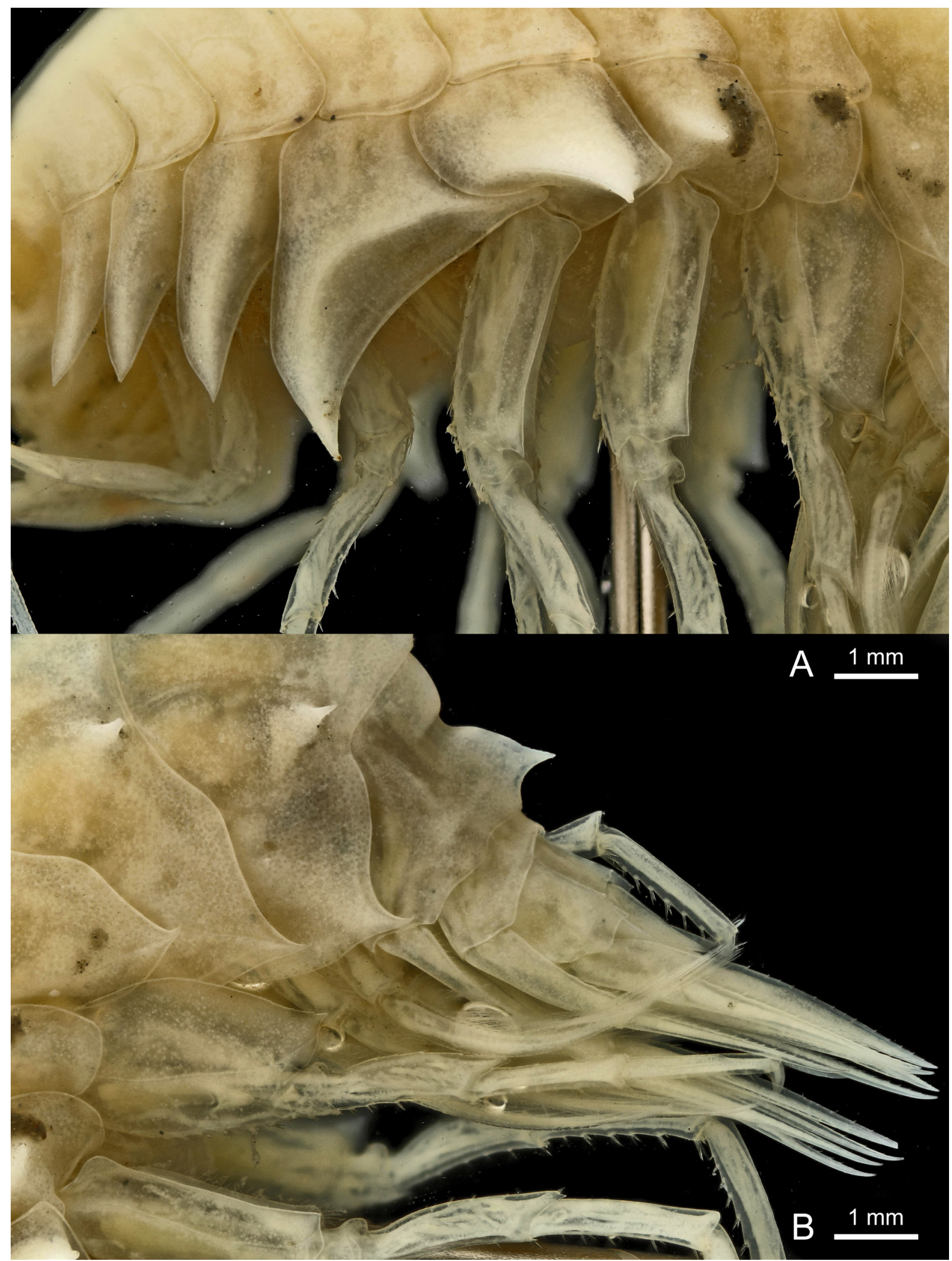

Fig. 101. Epimeria (Drakepimeria) robertiana subgen. et sp. nov., holotype, $\widehat{\jmath}$, eastern Weddell Sea, ANT-XXIV/2, presumably stn 17-10, RBINS, INV. 132413. A. Coxae 1-7. B. Urosome. 


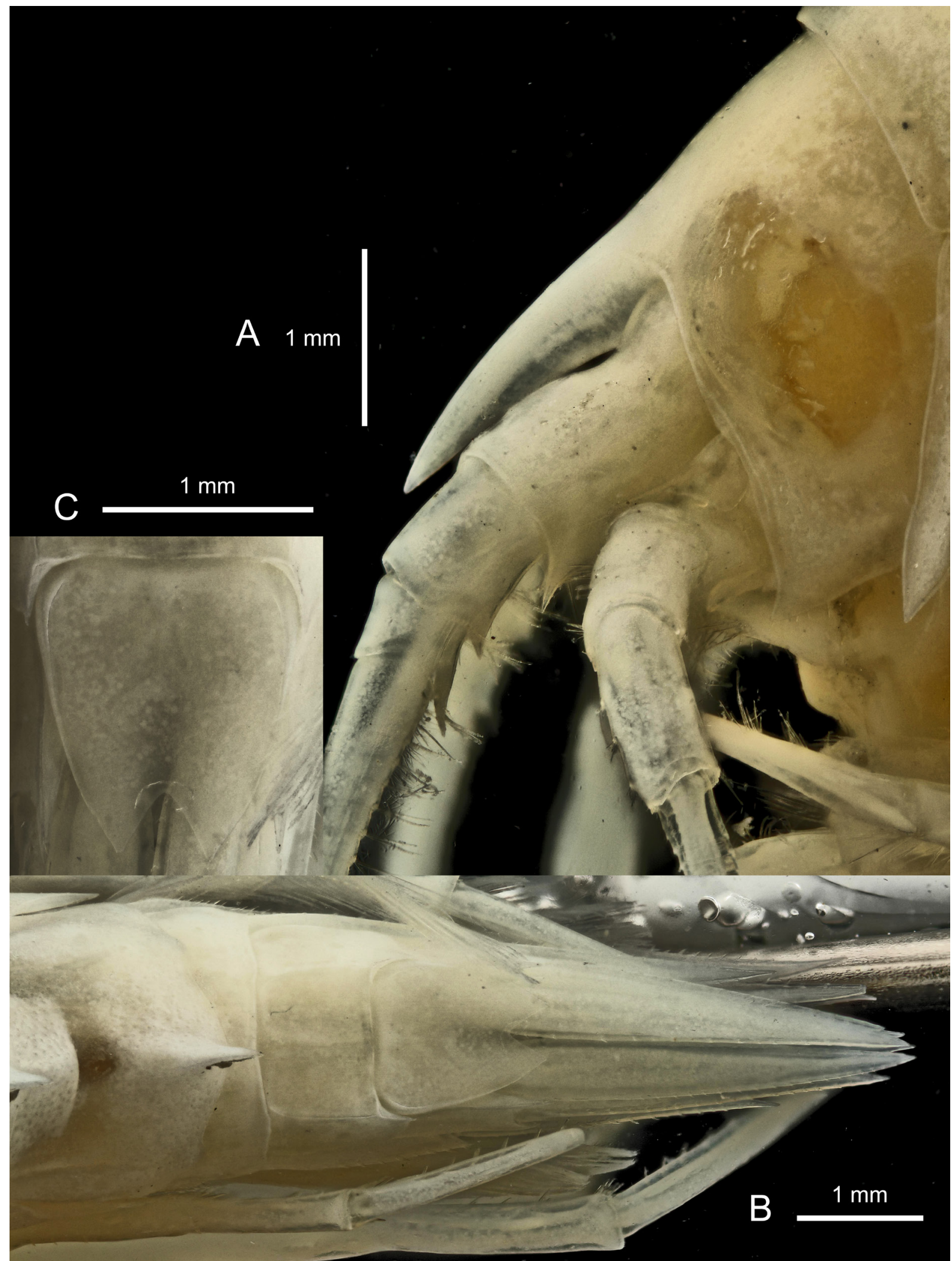

Fig. 102. Epimeria (Drakepimeria) robertiana subgen. et sp. nov., holotype, $\widehat{\jmath}$, eastern Weddell Sea, ANT-XXIV/2, presumably stn 17-10, RBINS, INV. 132413. A. Head in lateral view. B. Urosome in dorsal view. C. Telson. 


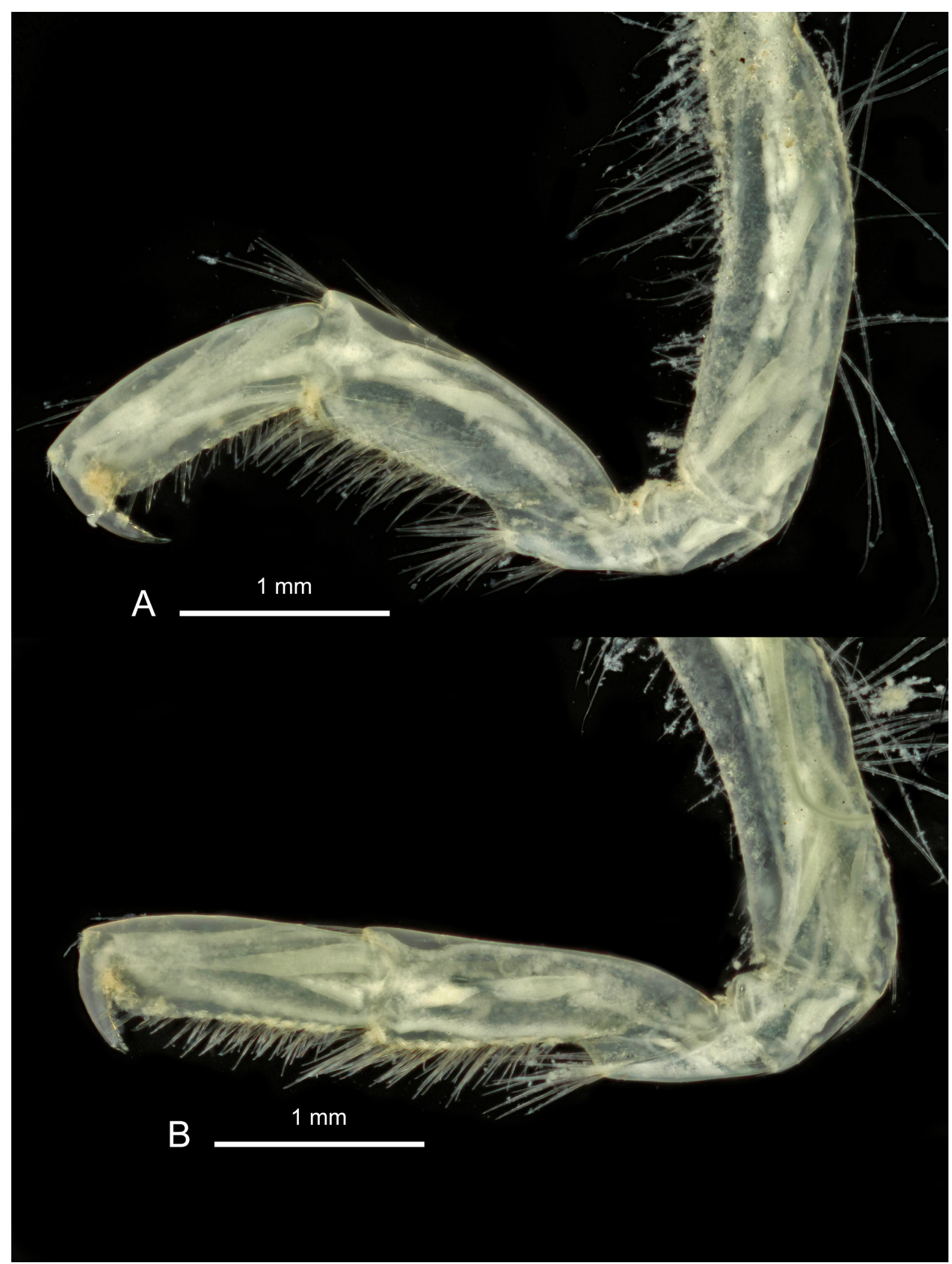

Fig. 103. Epimeria (Drakepimeria) robertiana subgen. et sp. nov., holotype, $\widehat{\jmath}$, eastern Weddell Sea, ANT-XXIV/2, presumably stn 17-10, RBINS, INV. 132413. A. Gnathopod 1. B. Gnathopod 2. 


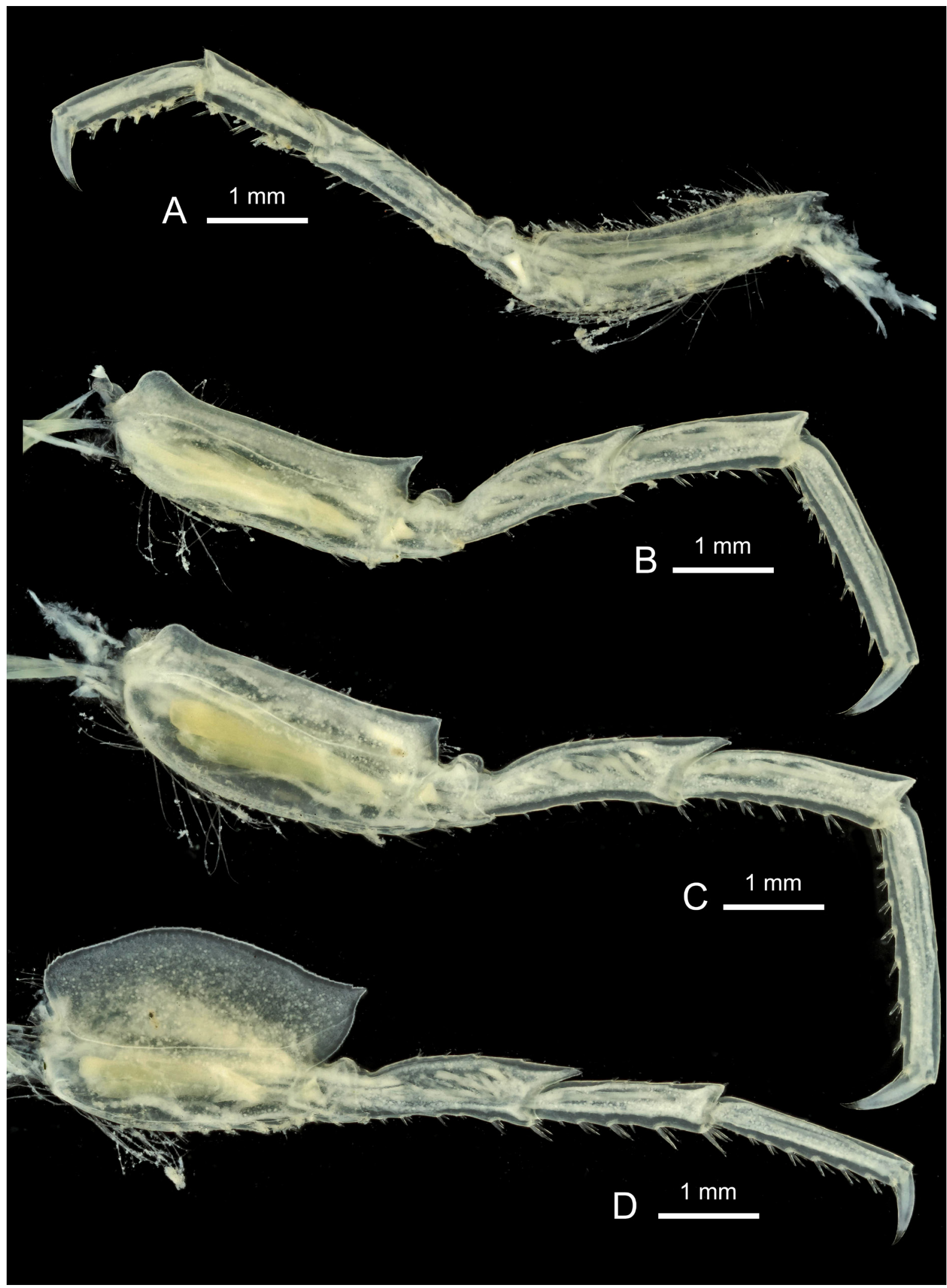

Fig. 104. Epimeria (Drakepimeria) robertiana subgen. et sp. nov., holotype, $\widehat{\partial}$, eastern Weddell Sea, ANT-XXIV/2, presumably stn 17-10, RBINS, INV. 132413. A. Pereiopod 4. B. Pereiopod 5. C. Pereiopod 6. D. Pereiopod 7. 


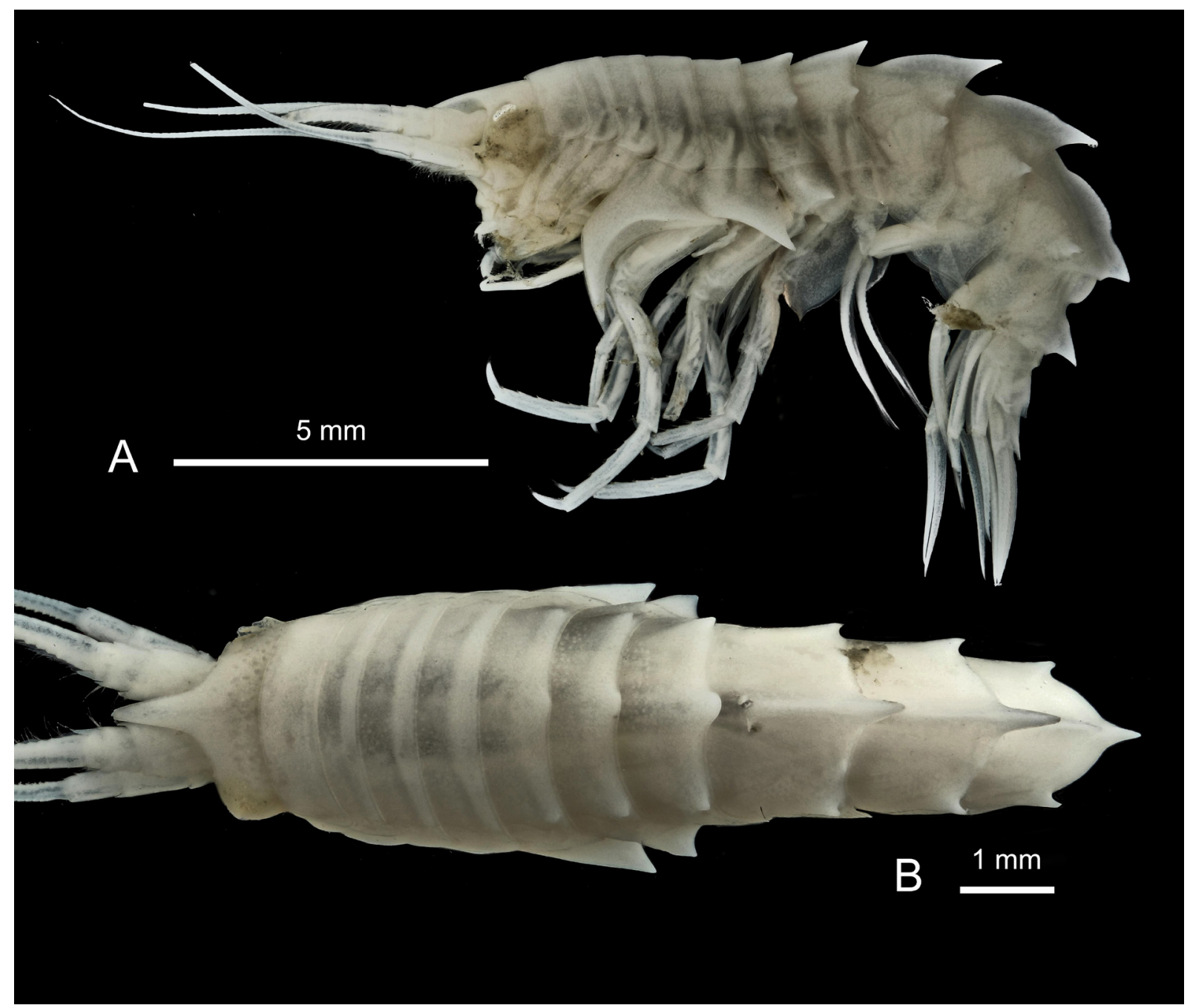

Fig. 105. Epimeria (Drakepimeria) robertiana subgen. et sp. nov., immature paratype (sex undetermined), eastern Weddell Sea, ANT-XXIV/2, stn 17-11, RBINS, INV. 132963. A. Lateral habitus. B. Dorsal habitus. 


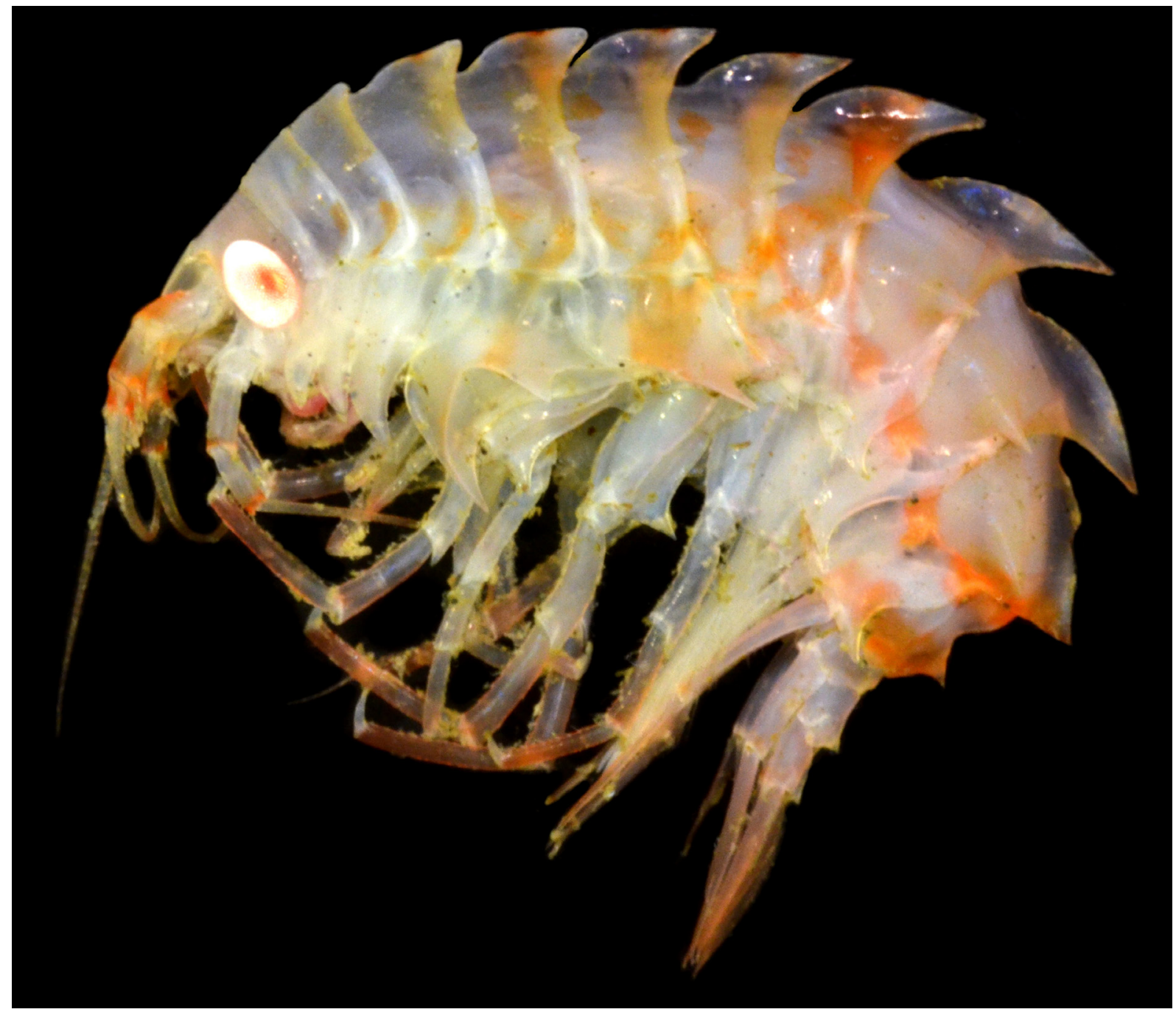

Fig. 106. Epimeria (Drakepimeria) similis subgen. nov. Chevreux, 1912, presumably + , Bransfield Strait, ANT-XXIX/3, stn 193-8, RBINS, INV. 122956A or 122956B, colour in life. 


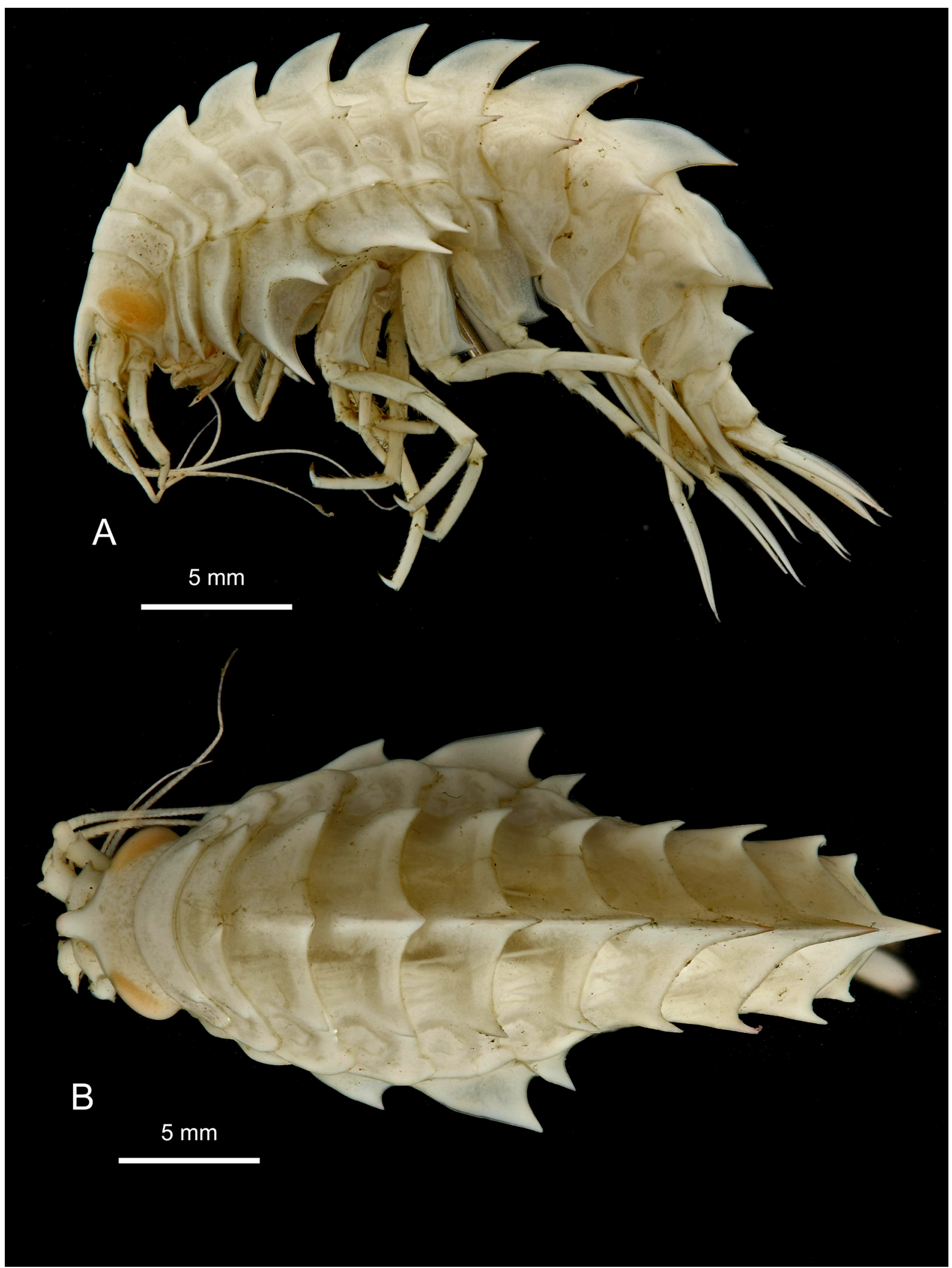

Fig. 107. Epimeria (Drakepimeria) similis subgen. nov. Chevreux, 1912, $q$, Bransfield Strait, ANTXXIX/3, stn 193-8, RBINS, INV. 122956A. A. Lateral habitus. B. Dorsal habitus. 


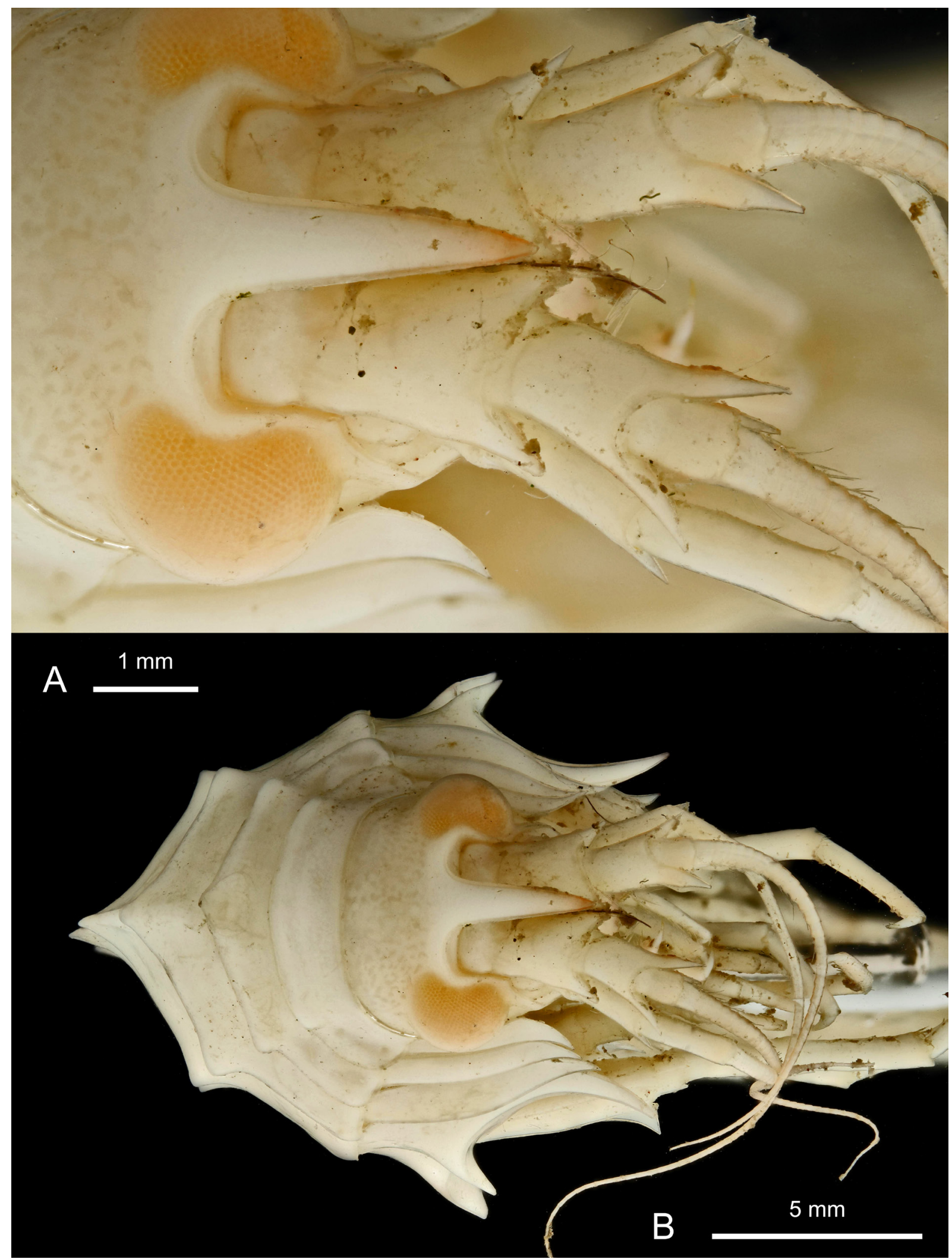

Fig. 108. Epimeria (Drakepimeria) similis subgen. nov. Chevreux, 1912, $q$, Bransfield Strait, ANTXXIX/3, stn 193-8, RBINS, INV. 122956A. A. Facial habitus. B. Head in facial view. 


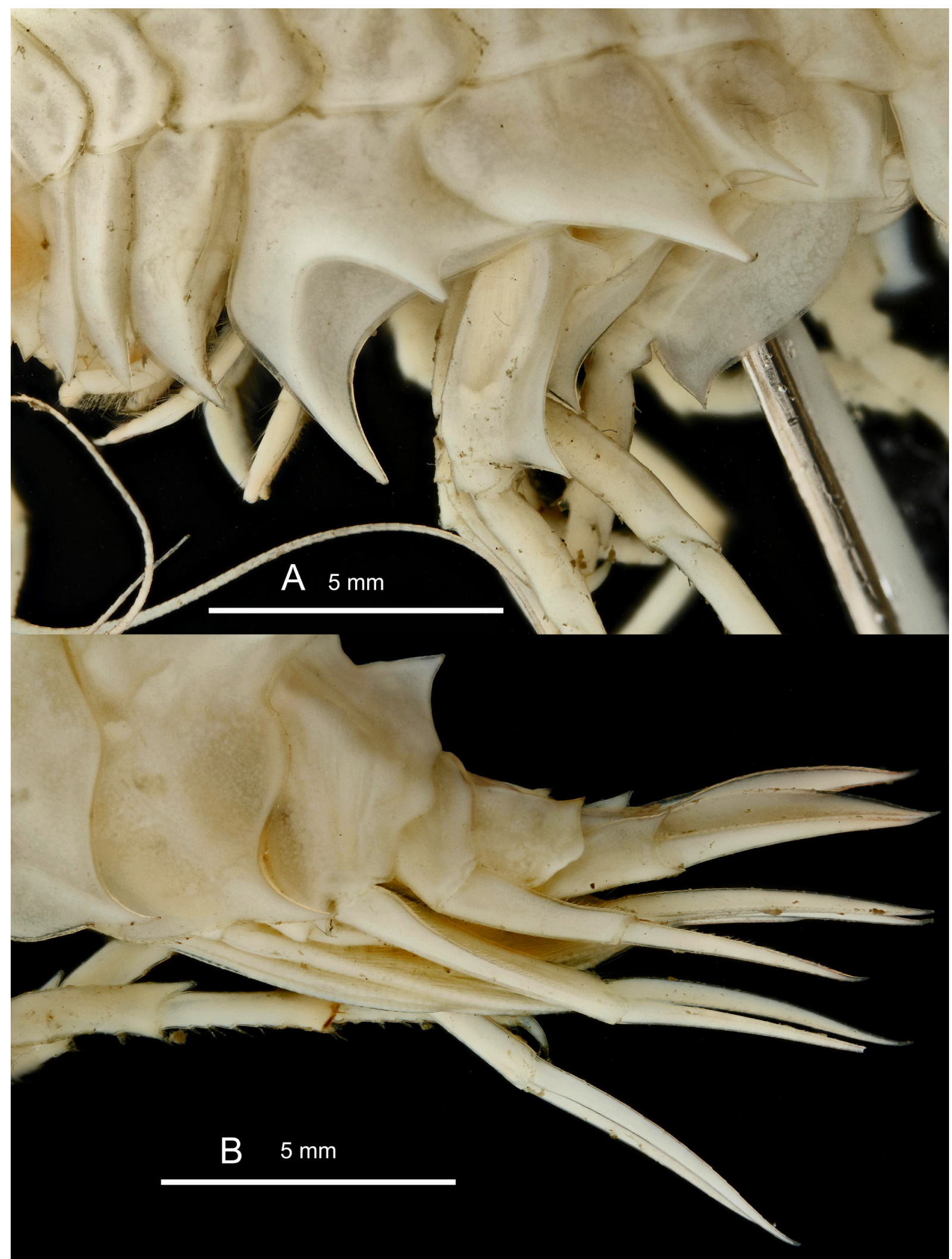

Fig. 109. Epimeria (Drakepimeria) similis subgen. nov. Chevreux, 1912, $q$, Bransfield Strait, ANTXXIX/3, stn 193-8, RBINS, INV. 122956A. A. Coxae 1-7. B. Urosome. 


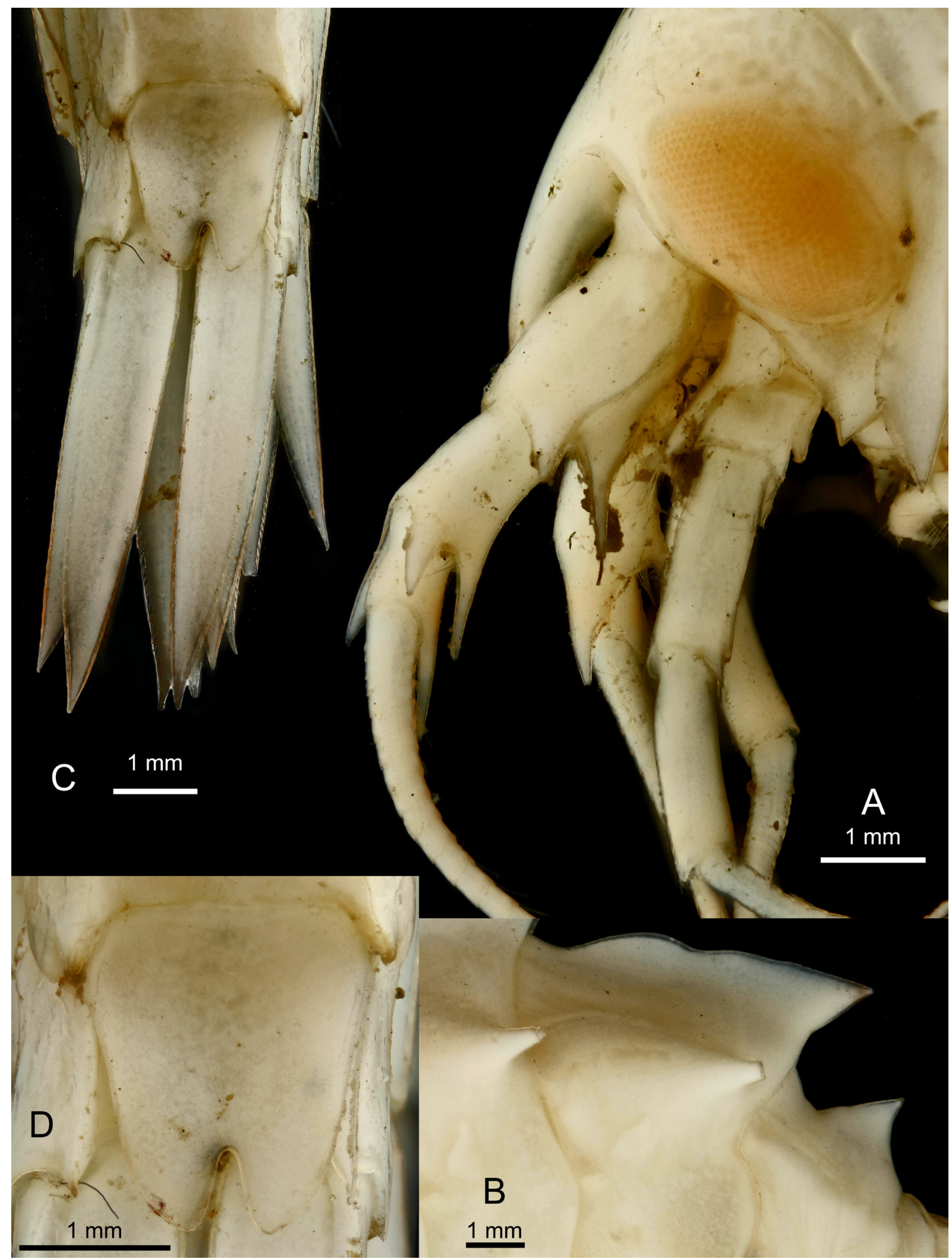

Fig. 110. Epimeria (Drakepimeria) similis subgen. nov. Chevreux, 1912, + , Bransfield Strait, ANTXXIX/3, stn 193-8, RBINS, INV. 122956A. A. Head in lateral view. B. Dorsal profile of pleonite 3 and urosomites 1-2. C. Urosome in dorsal view. D. Telson. 


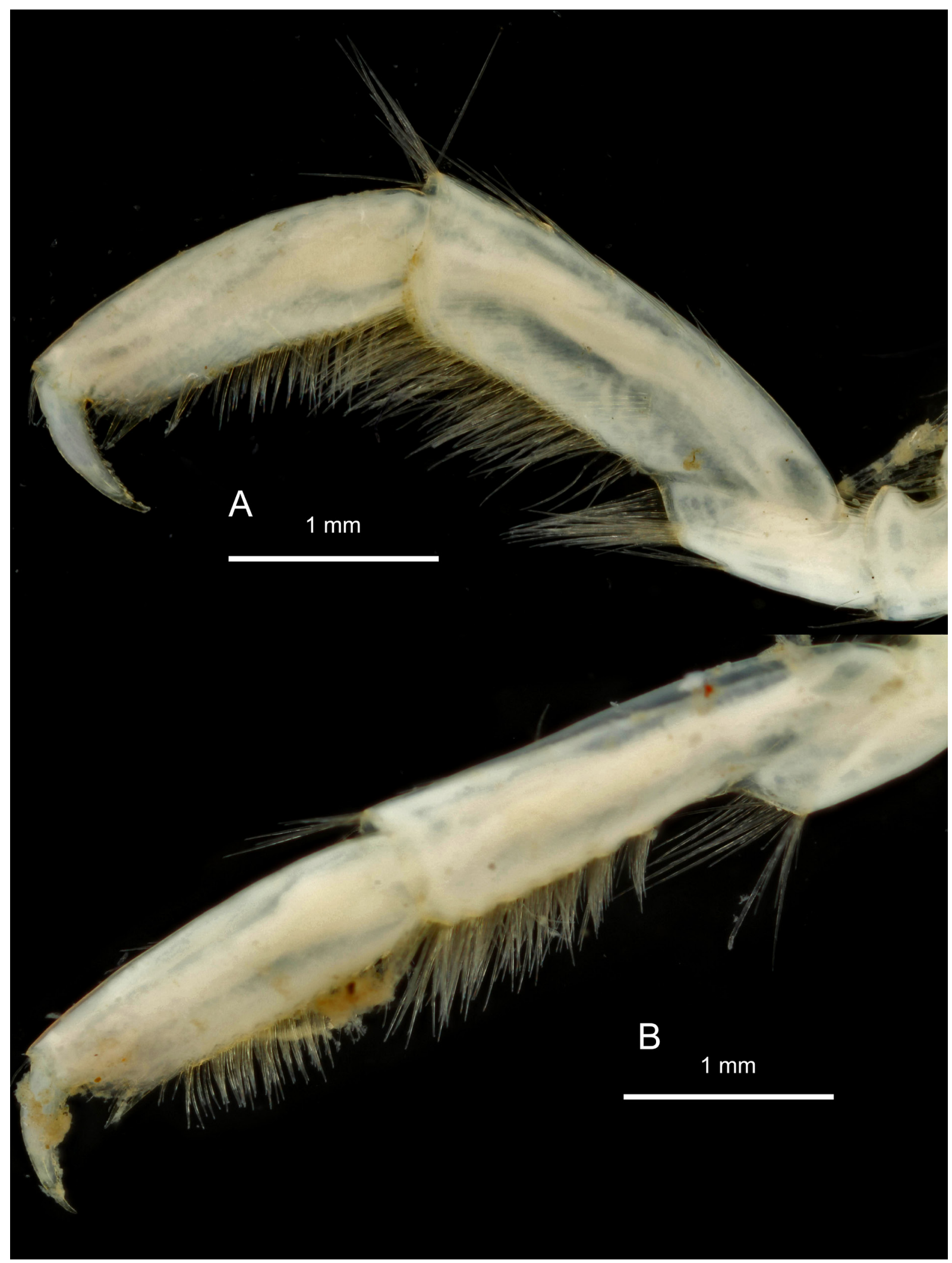

Fig. 111. Epimeria (Drakepimeria) similis subgen. nov. Chevreux, 1912, + , Bransfield Strait, ANTXXIX/3, stn 193-8, RBINS, INV. 122956A. A. Gnathopod 1. B. Gnathopod 2. 


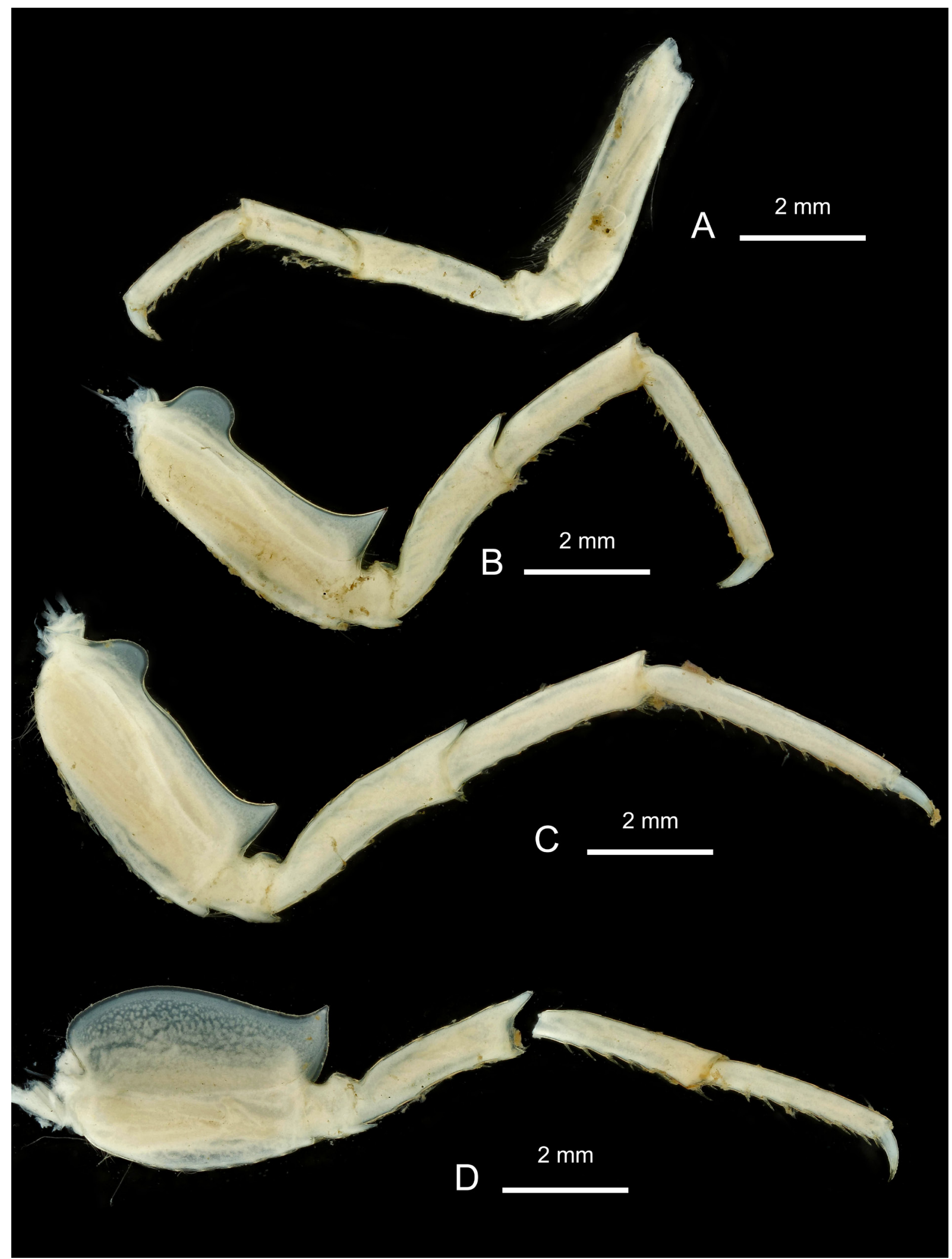

Fig. 112. Epimeria (Drakepimeria) similis subgen. nov. Chevreux, 1912, + , Bransfield Strait, ANT-XXIX/3, stn 193-8, RBINS, INV. 122956A. A. Pereiopod 4. B. Pereiopod 5. C. Pereiopod 6. D. Pereiopod 7. 


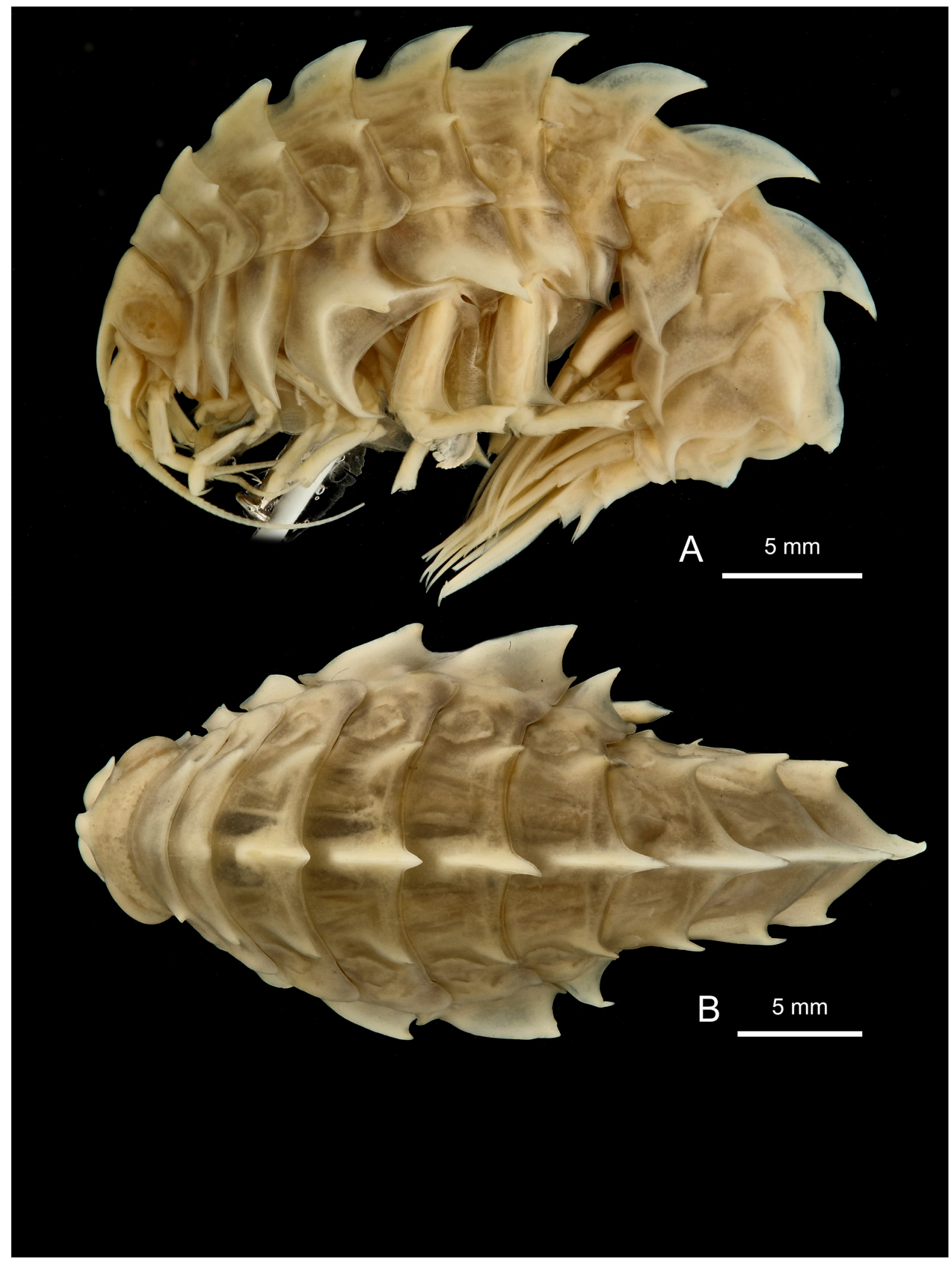

Fig. 113. Epimeria (Drakepimeria) similis subgen. nov. Chevreux, 1912, + , lectotype, undissected, Admiralty Bay, second French Antarctic expedition 1908-1910, dredging stn 17, MNHN-IU-2013-17865. A. Lateral habitus. B. Dorsal habitus. 


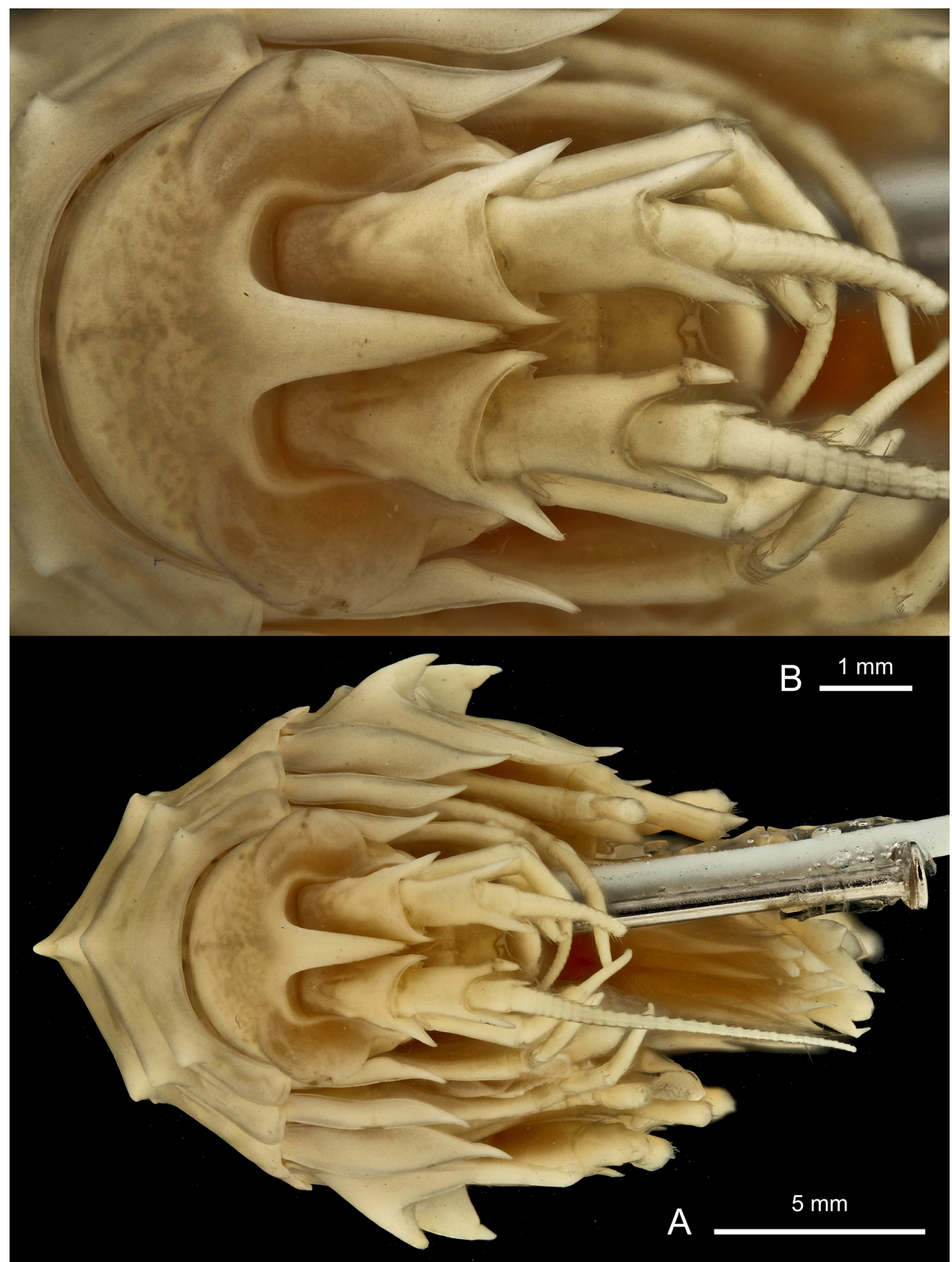

Fig. 114. Epimeria (Drakepimeria) similis subgen. nov. Chevreux, 1912, + , lectotype, undissected, second French Antarctic expedition 1908-1910, dredging stn 17, MNHN-IU-2013-17865. A. Facial habitus. B. Head in facial view. 

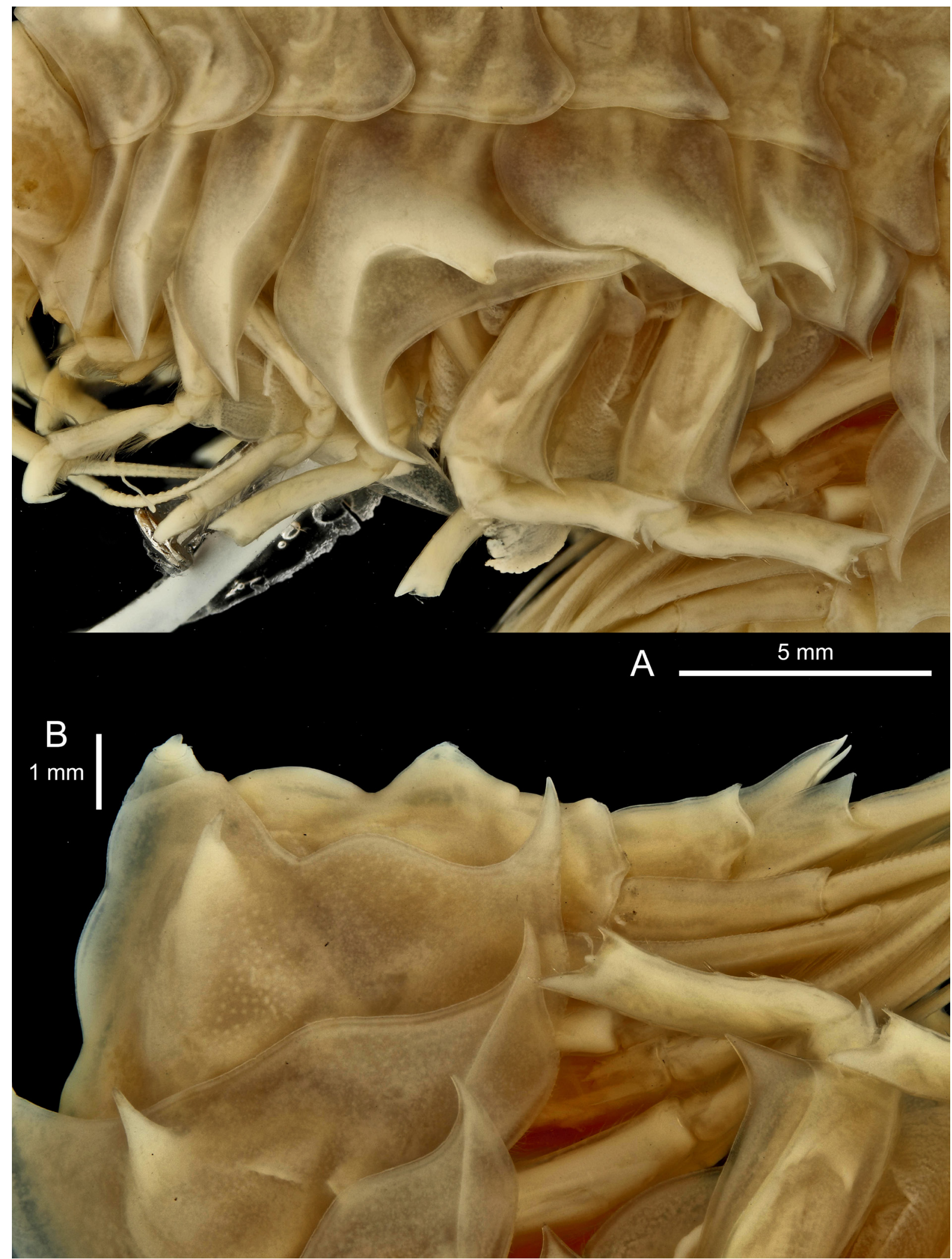

Fig. 115. Epimeria (Drakepimeria) similis subgen. nov. Chevreux, 1912, + , lectotype, undissected, Admiralty Bay, second French Antarctic expedition 1908-1910, dredging stn 17, MNHN-IU-2013-17865. A. Coxae 1-7. B. Pleonite 3 and urosome. 


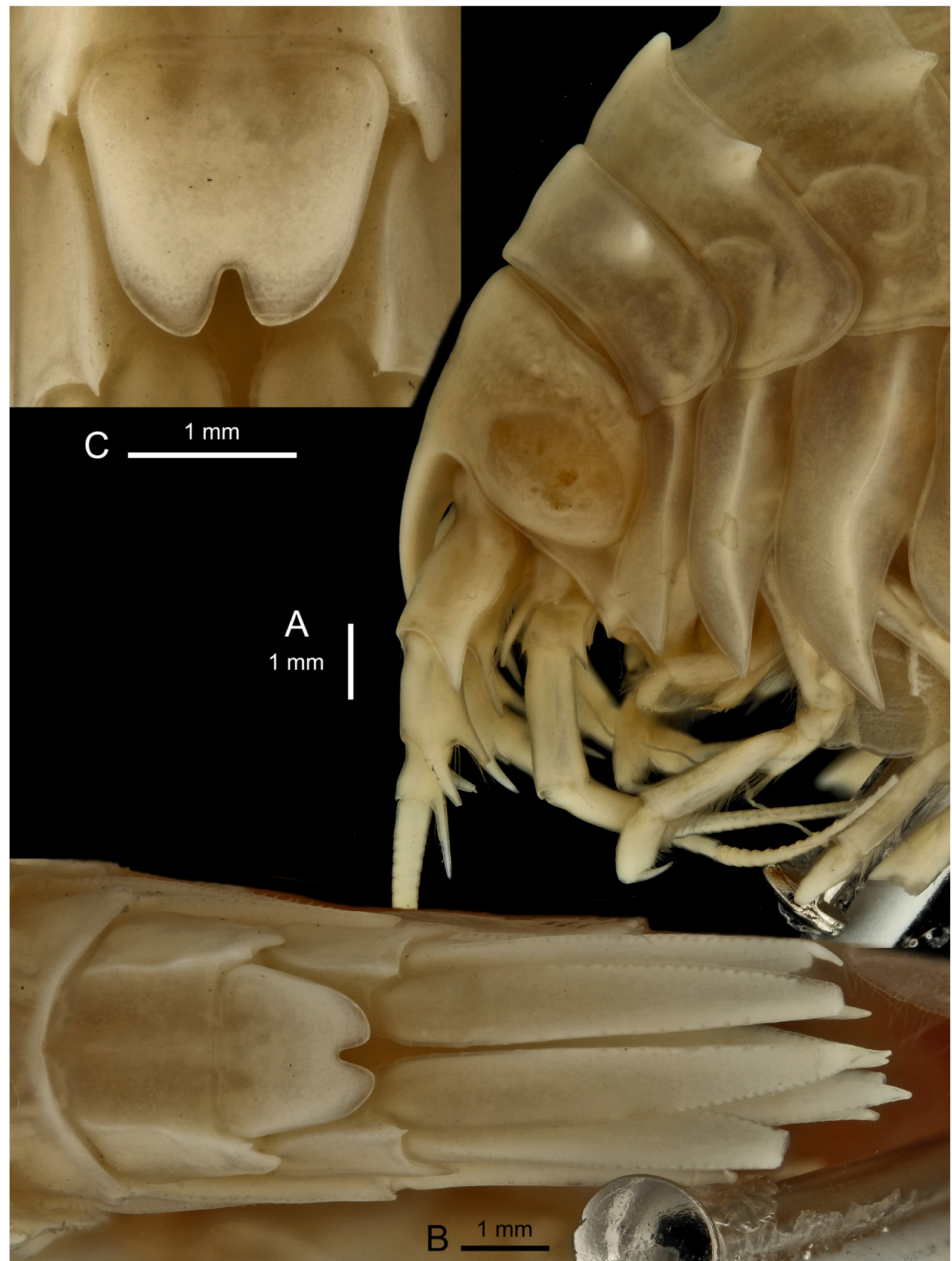

Fig. 116. Epimeria (Drakepimeria) similis subgen. nov. Chevreux, 1912, + , lectotype, undissected, Admiralty Bay, second French Antarctic expedition 1908-1910, dredging stn 17, MNHN-IU-2013-17865. A. Head and body segments 1-2 in lateral view. B. Urosome in dorsal view. C. Telson. 


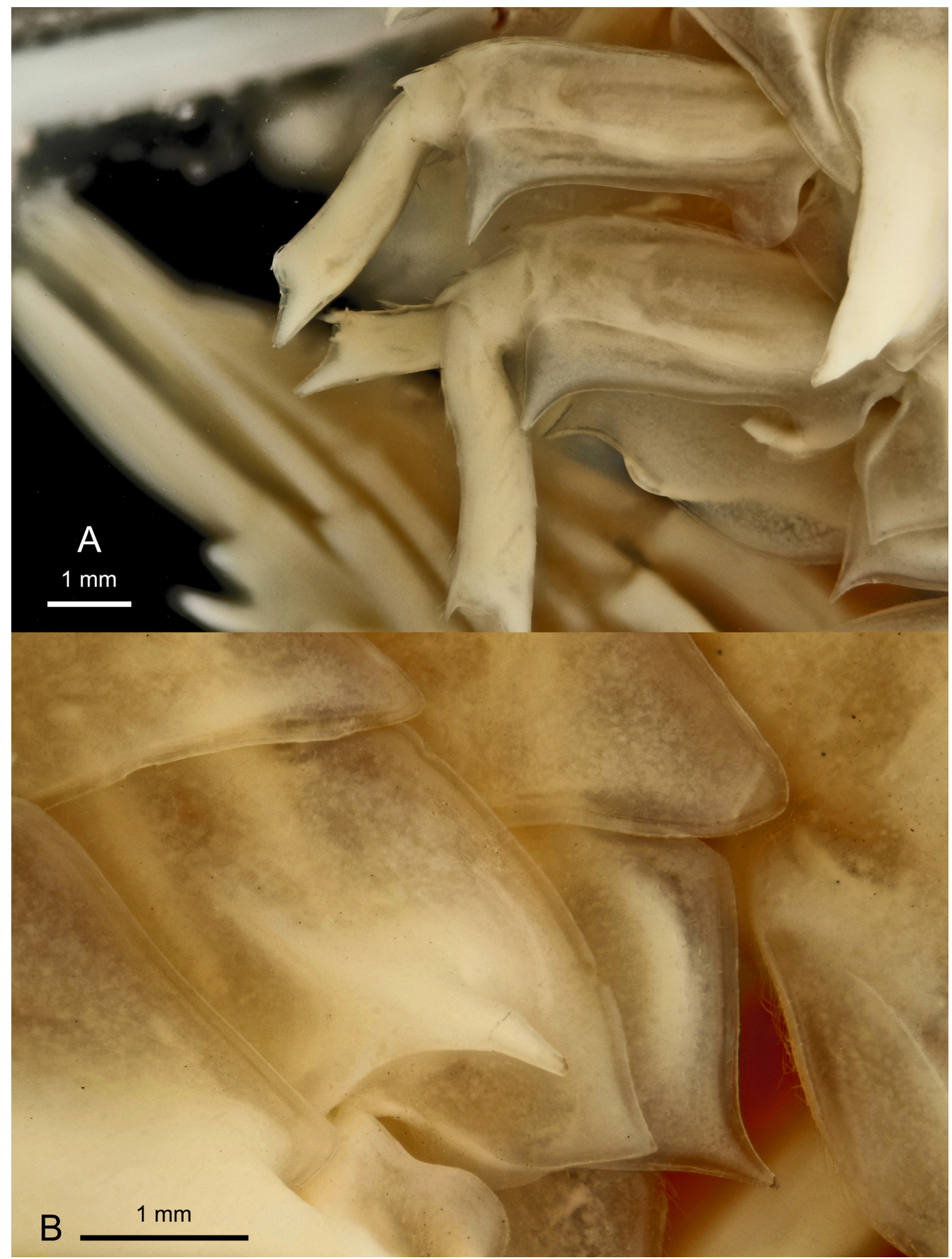

Fig. 117. Epimeria (Drakepimeria) similis subgen. nov. Chevreux, 1912, + , lectotype, undissected, Admiralty Bay, second French Antarctic expedition 1908-1910, dredging stn 17, MNHN-IU-2013-17865. A. Basis of pereiopods 1-7. B. Coxae 6-7. 


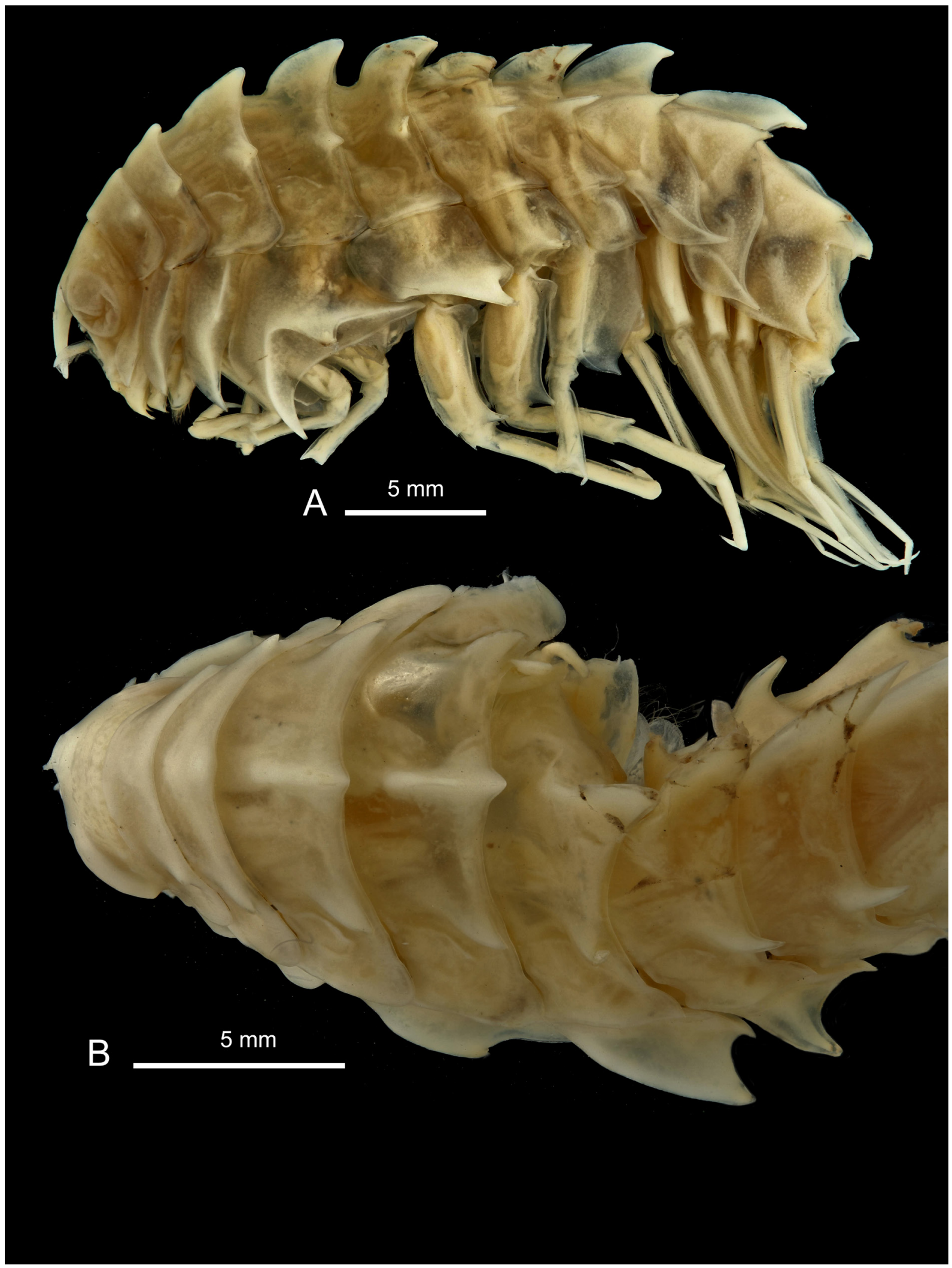

Fig. 118. Epimeria (Drakepimeria) similis subgen. nov. Chevreux, 1912, $q$, paralectotype, dissected, Admiralty Bay, second French Antarctic expedition 1908-1910, dredging stn 17, MNHN-IU-2013-17864. A. Lateral habitus. B. Dorsal habitus. 


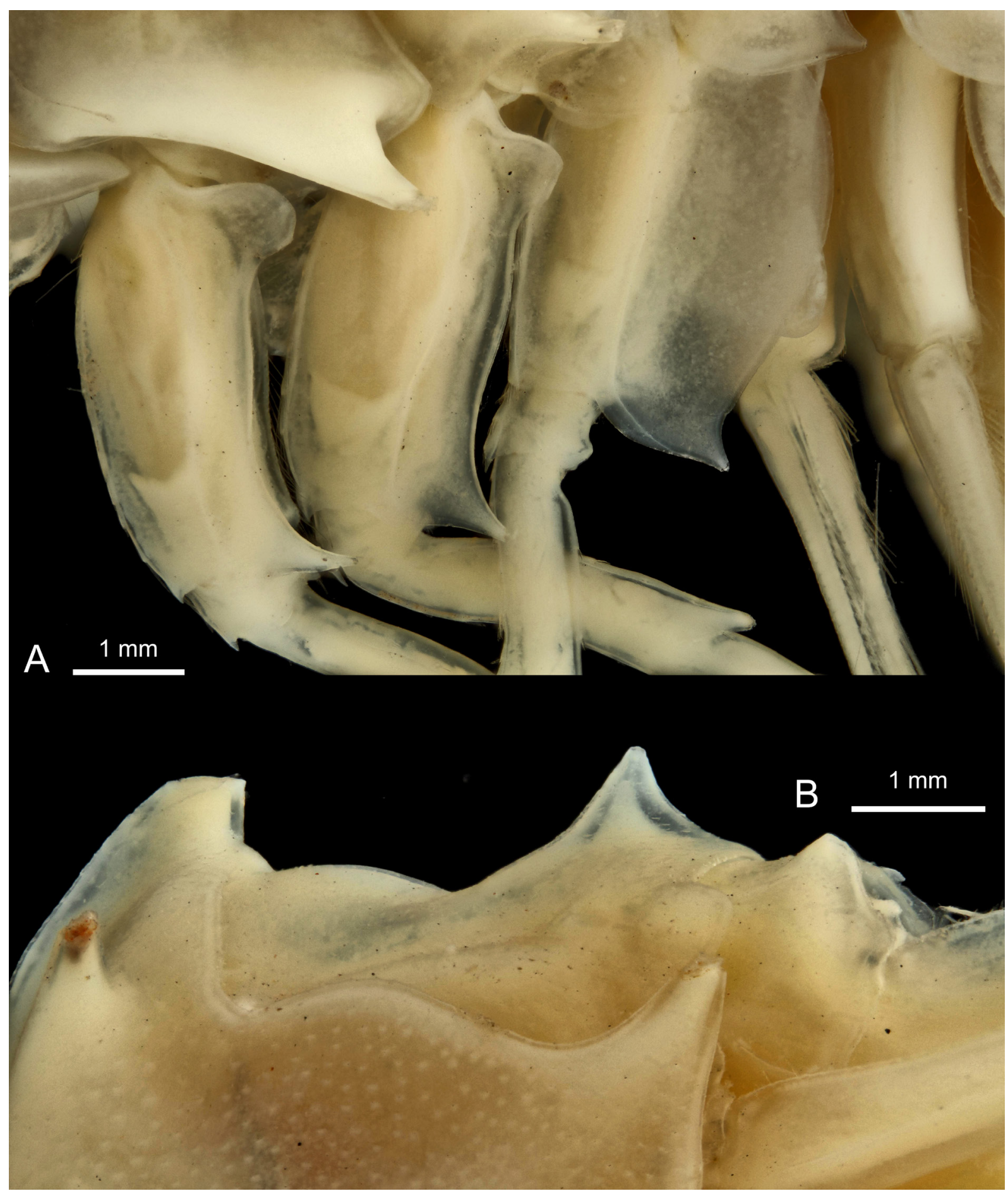

Fig. 119. Epimeria (Drakepimeria) similis subgen. nov. Chevreux, 1912, + , paralectotype, dissected, Admiralty Bay, second French Antarctic expedition 1908-1910, dredging stn 17, MNHN-IU-2013-17864. A. Basis of Pereiopods 5-7. B. Urosomites 1-2. 


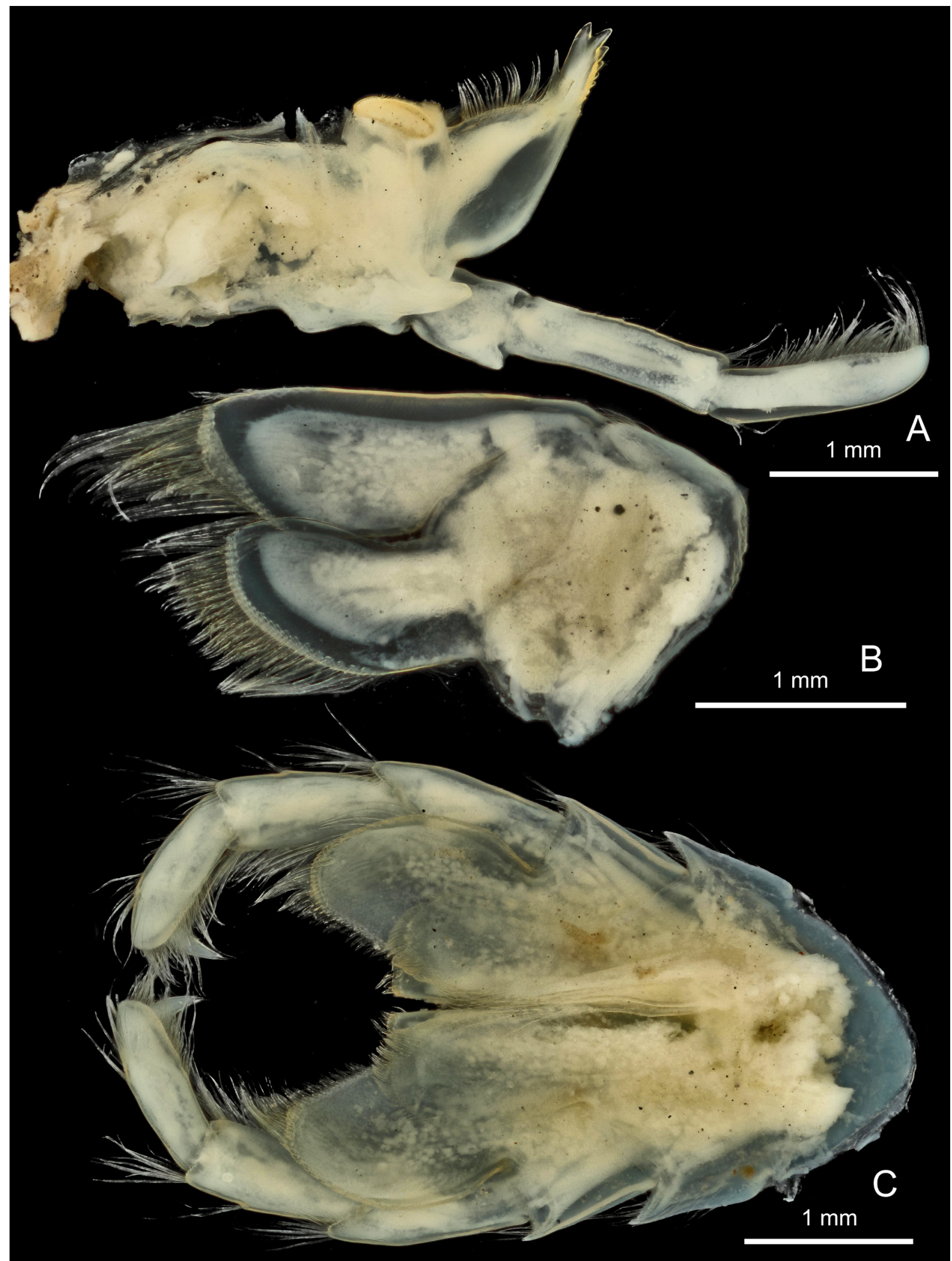

Fig. 120. Epimeria (Drakepimeria) similis subgen. nov. Chevreux, 1912, + , paralectotype, dissected, Admiralty Bay, second French Antarctic expedition 1908-1910, dredging stn 17. A. Mandible. B. Maxilla 2. C. Maxilliped. 


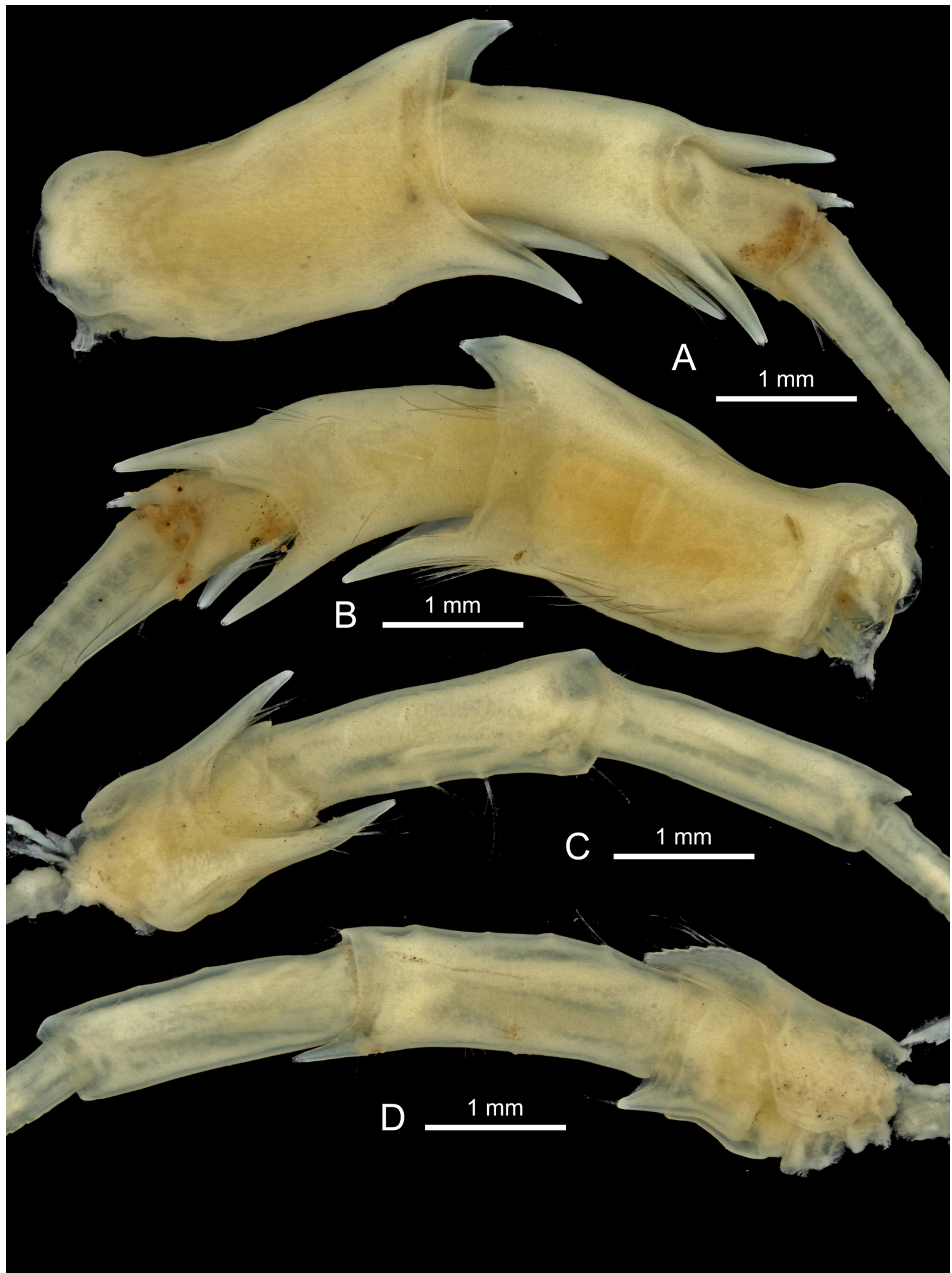

Fig. 121. Epimeria (Drakepimeria) similis subgen. nov. Chevreux, 1912, + , paralectotype, dissected, Admiralty Bay, second French Antarctic expedition 1908-1910, dredging stn 17, MNHN-IU-2013-17864. A. Right antenna 1 in dorsal view. B. Right antenna 1 in ventral view. C. Right antenna 2 in lateral view. D. Right antenna 2 in medial view. 


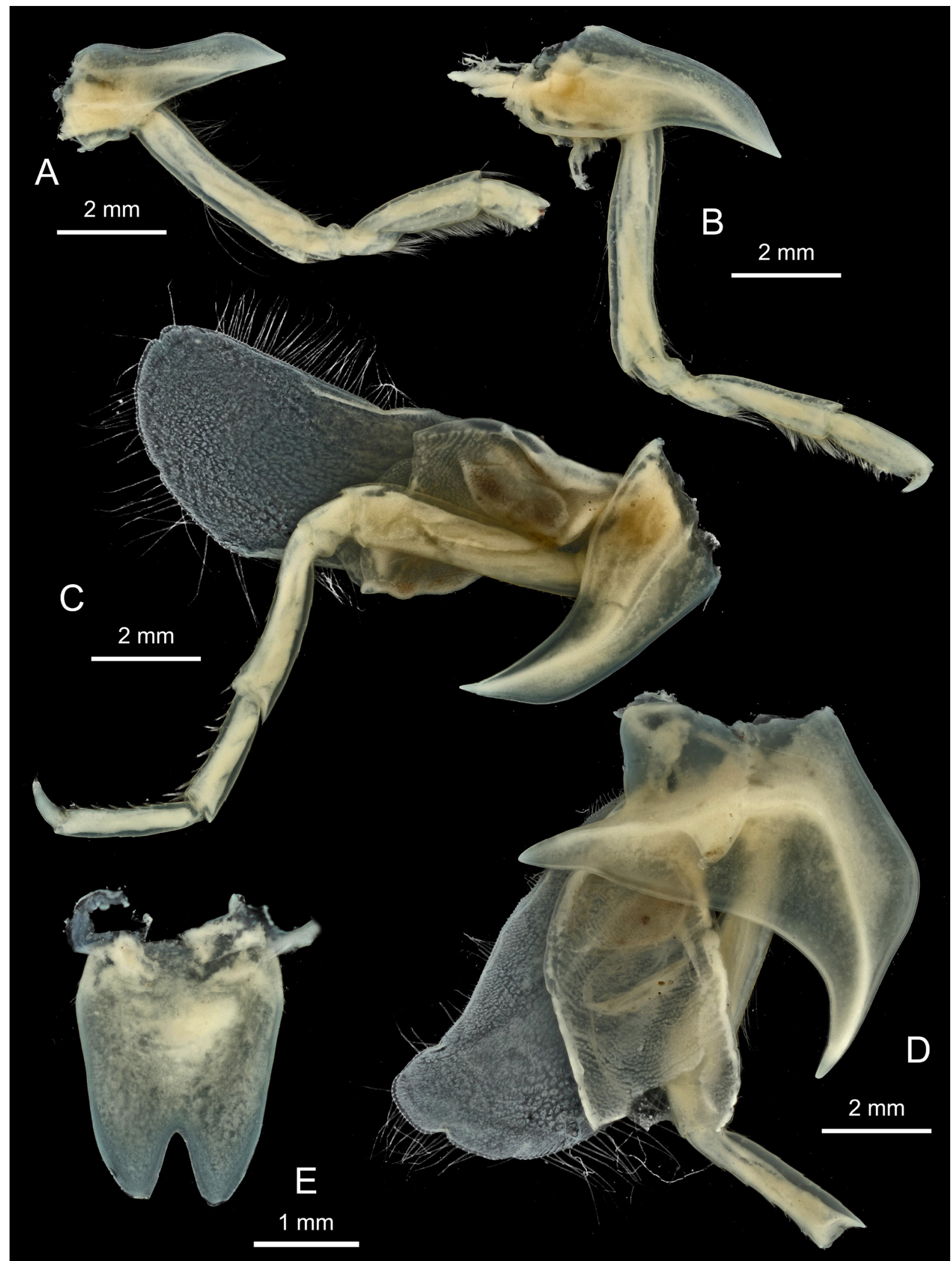

Fig. 122. Epimeria (Drakepimeria) similis subgen. nov. Chevreux, 1912, + , paralectotype, dissected, Admiralty Bay, second French Antarctic expedition 1908-1910, dredging stn 17, MNHN-IU-2013-17864. A. Gnathopod 1. B. Gnathopod 2. C. Pereiopod 3. D. Pereiopod 4. E. Telson. 


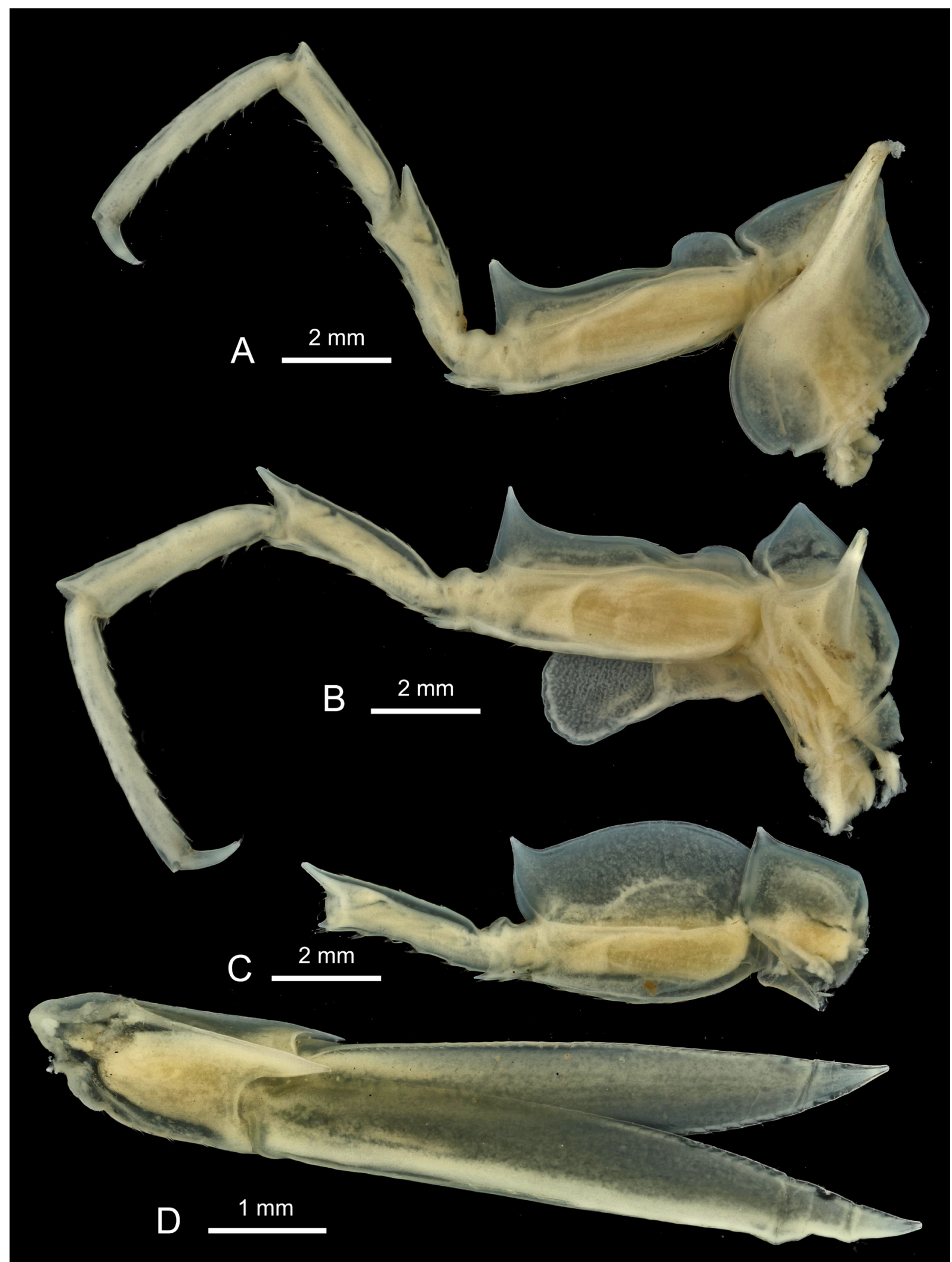

Fig. 123. Epimeria (Drakepimeria) similis subgen. nov. Chevreux, 1912, + , paralectotype, dissected, Admiralty Bay, second French Antarctic expedition 1908-1910, dredging stn 17, MNHN-IU-2013-17864. A. Pereiopod 5. B. Pereiopod 6. C. Pereiopod 7. D. Uropod 3. 

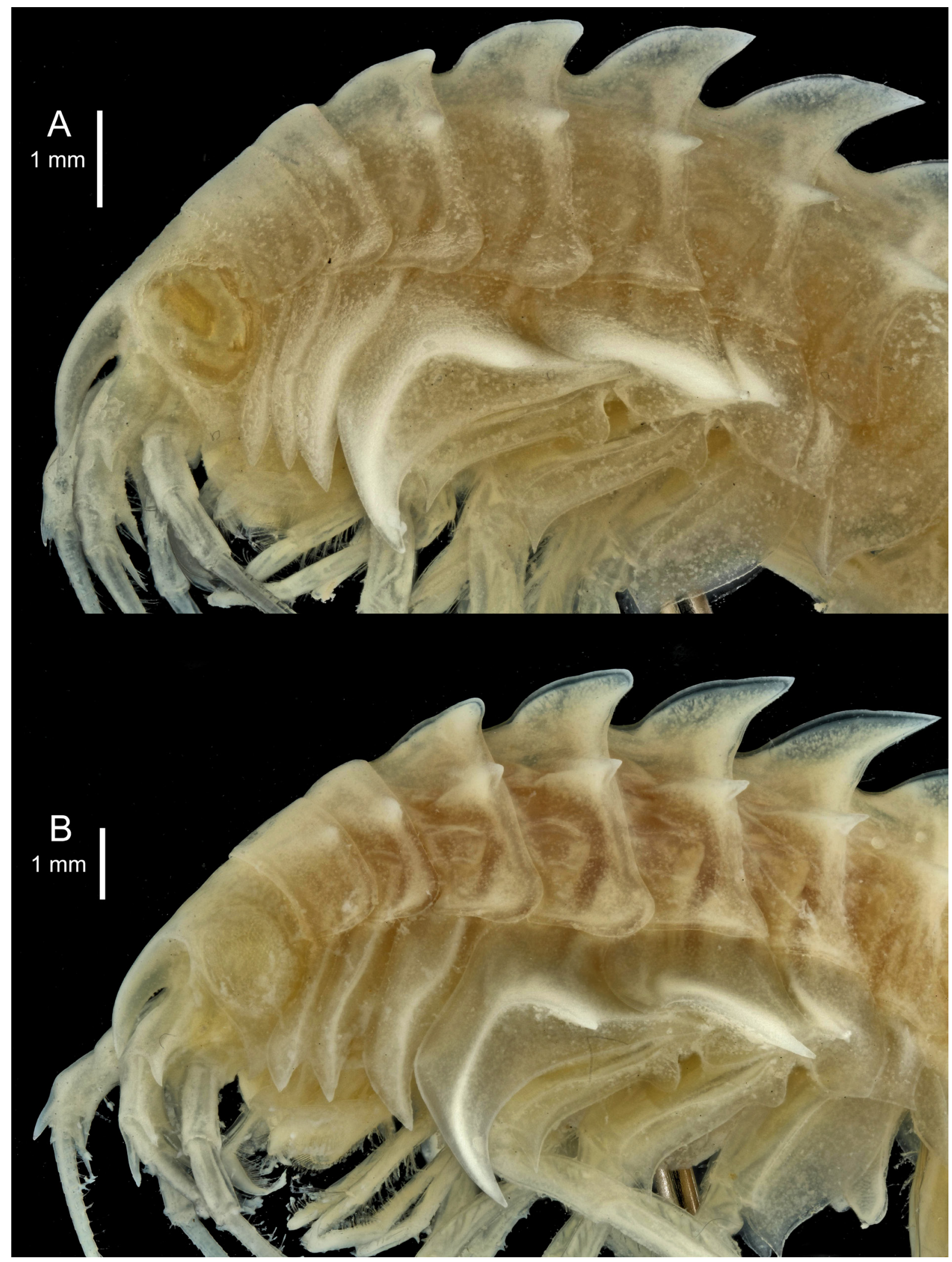

Fig. 124. Epimeria (Drakepimeria) similis subgen. nov. Chevreux, 1912, 우, Elephant Island, ANTXXIII/8, stn 654-6, INV. 132983. A-B. Anterior part of body. 


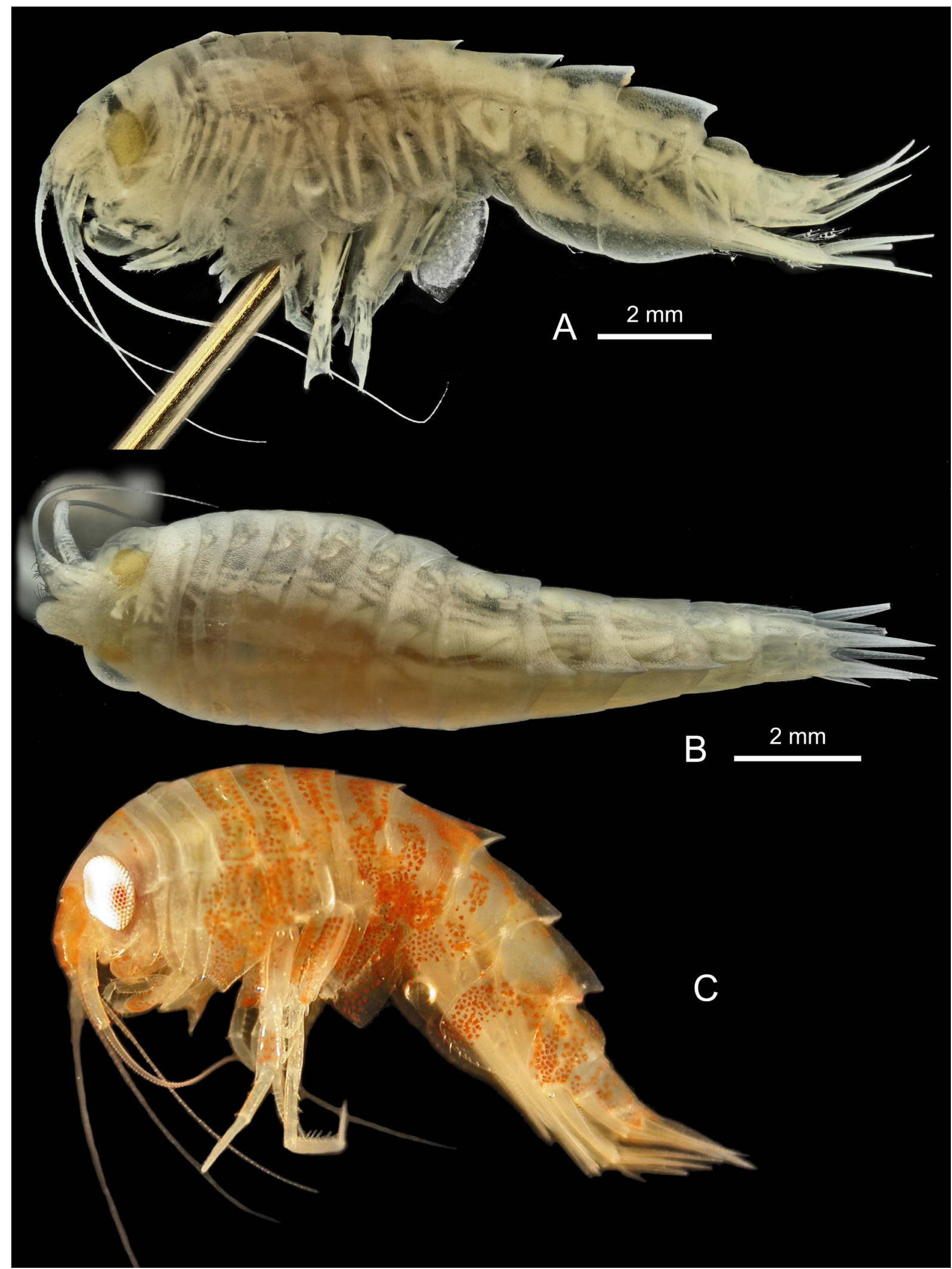

Fig. 125. Epimeria (Epimeriella) atalanta sp. nov., sex undetermined, holotype, western Weddell Sea, Larsen A, ANT-XXIII/8, stn 725-10, RBINS, INV. 122527. A. Lateral habitus. B. Dorsal habitus. C. Colour in life. 


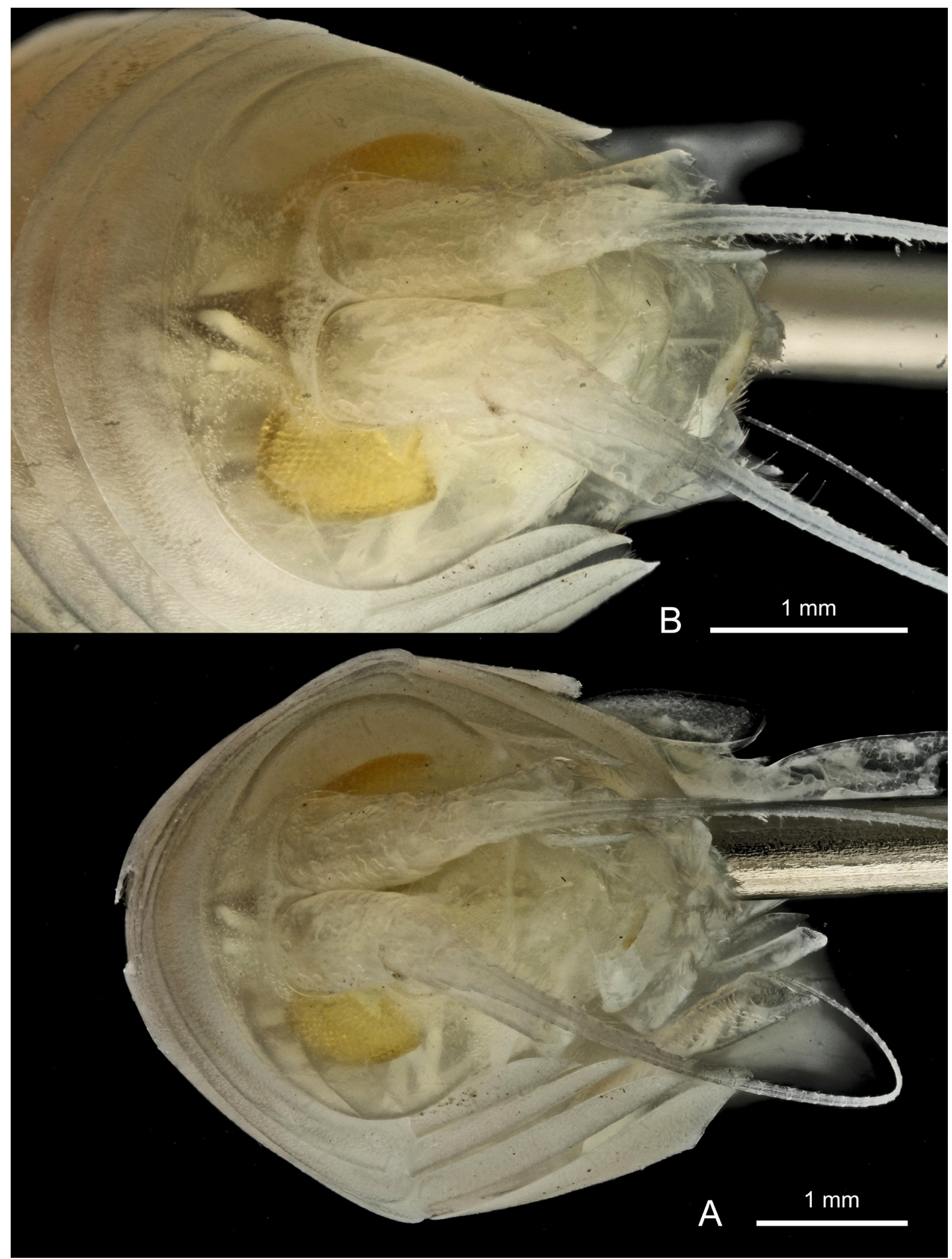

Fig. 126. Epimeria (Epimeriella) atalanta sp. nov., sex undetermined, holotype, western Weddell Sea, Larsen A, ANT-XXIII/8, stn 725-10, RBINS, INV. 122527. A. Facial habitus. B. Head in facial view. 


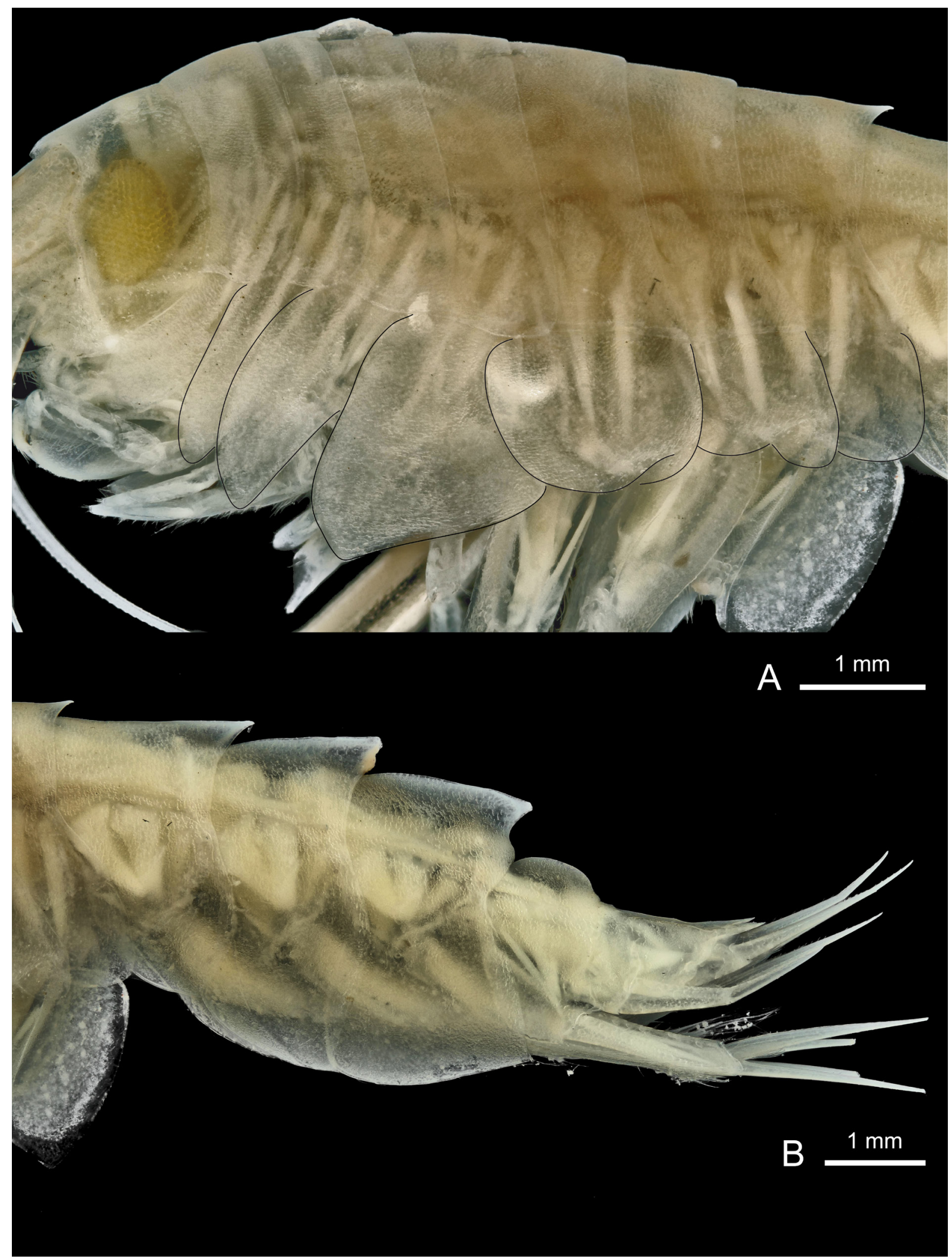

Fig. 127. Epimeria (Epimeriella) atalanta sp. nov., sex undetermined, holotype, western Weddell Sea, Larsen A, ANT-XXIII/8, stn 725-10, RBINS, INV. 122527. A. Anterior half. B. Posterior half. 


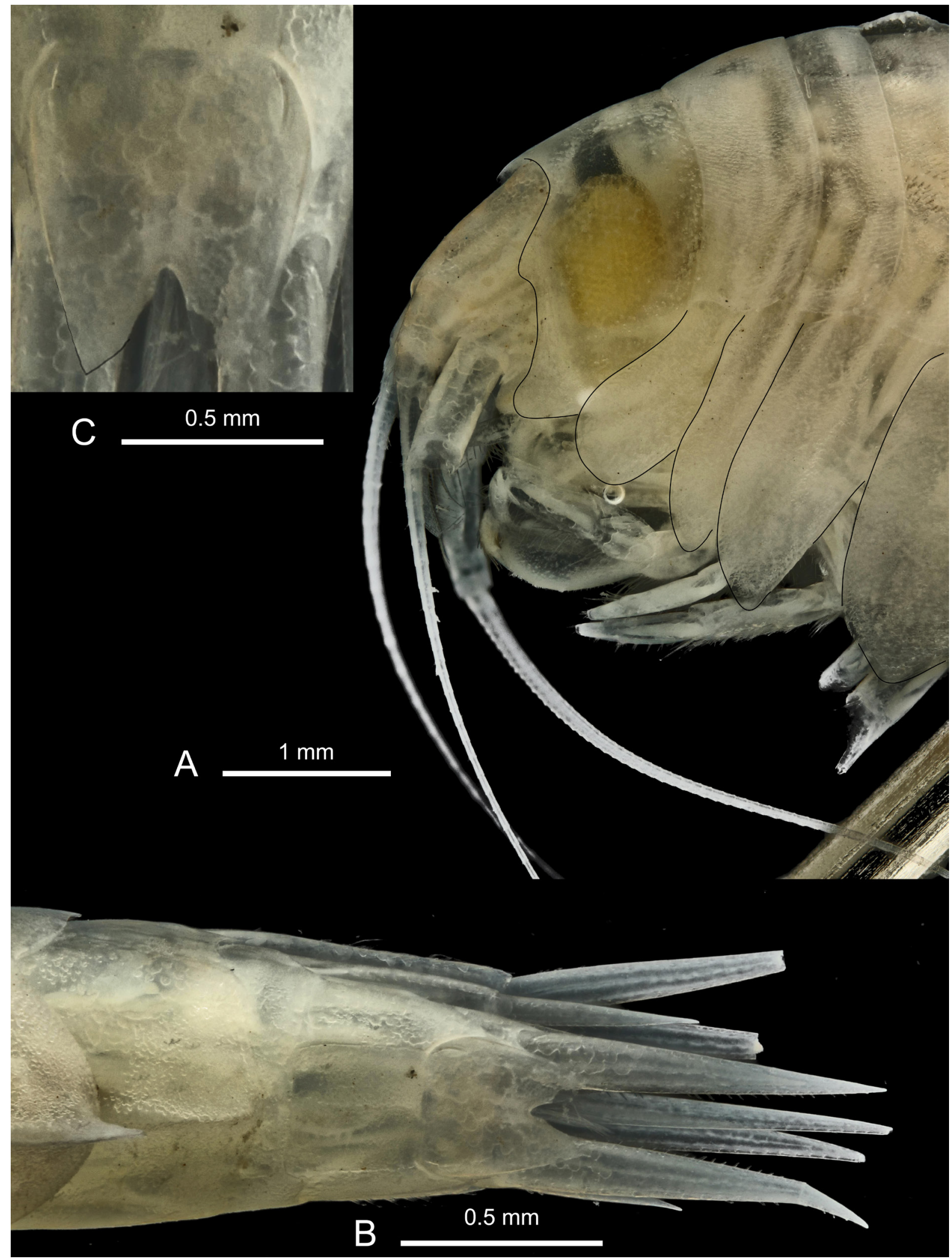

Fig. 128. Epimeria (Epimeriella) atalanta sp. nov., sex undetermined, holotype, western Weddell Sea, Larsen A, ANT-XXIII/8, stn 725-10, RBINS, INV. 122527. A. Head in lateral view. B. Urosome in dorsal view. C. Telson. 


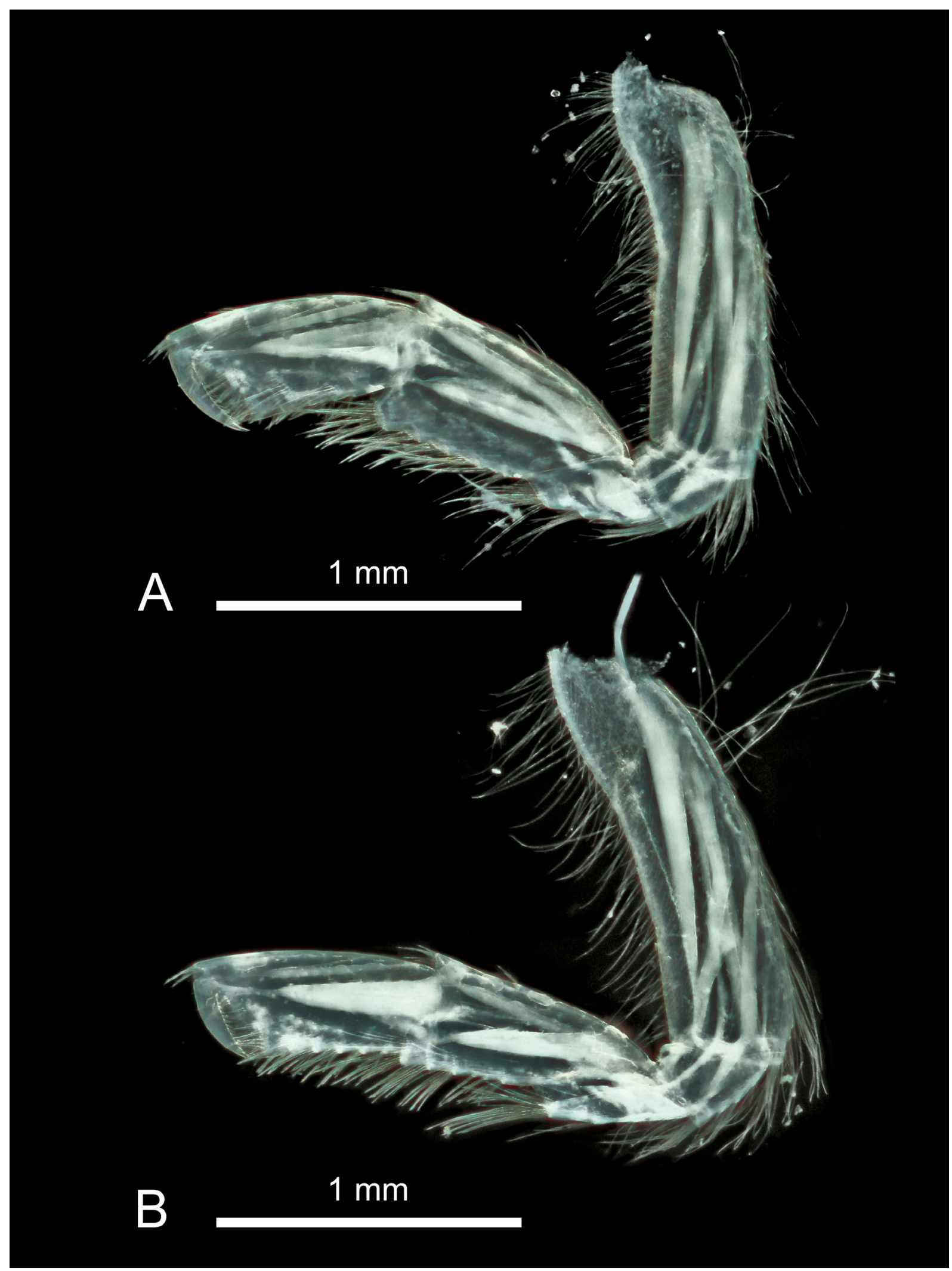

Fig. 129. Epimeria (Epimeriella) atalanta sp. nov., sex undetermined, holotype, western Weddell Sea, Larsen A, ANT-XXIII/8, stn 725-10, RBINS, INV. 122527. A. Gnathopod 1. B. Gnathopod 2. 


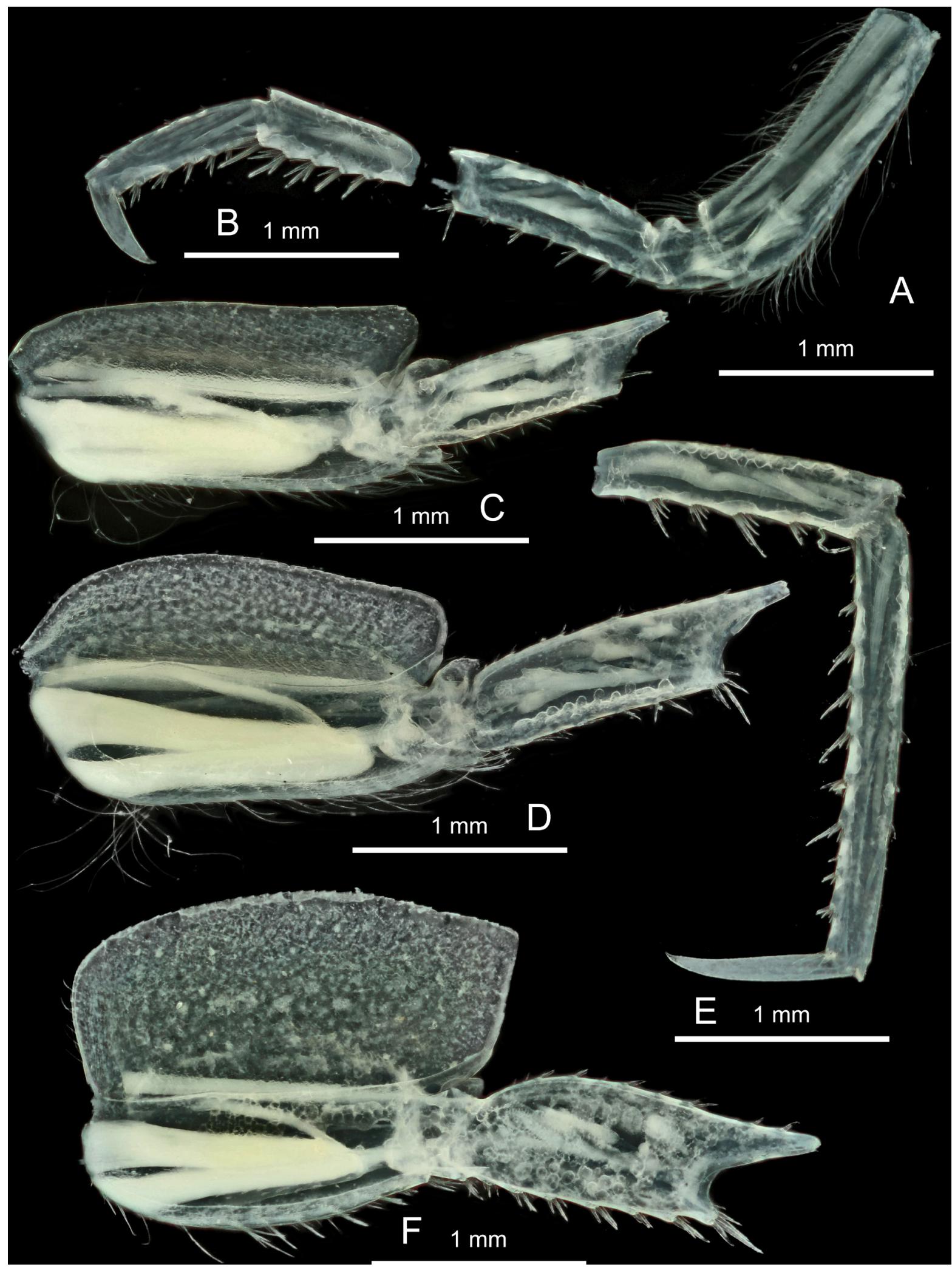

Fig. 130. Epimeria (Epimeriella) atalanta sp. nov., sex undetermined, holotype, western Weddell Sea, Larsen A, ANT-XXIII/8, stn 725-10, RBINS, INV. 122527. A. Pereiopod 4 (proximal part). B. Pereiopod 3 or 4 (tip). C. Periopod 5 (proximal part). D. Pereiopod 6 (proximal part). E. Presumably pereiopod 6 (distal part). F. Pereiopod 7 (proximal part). 


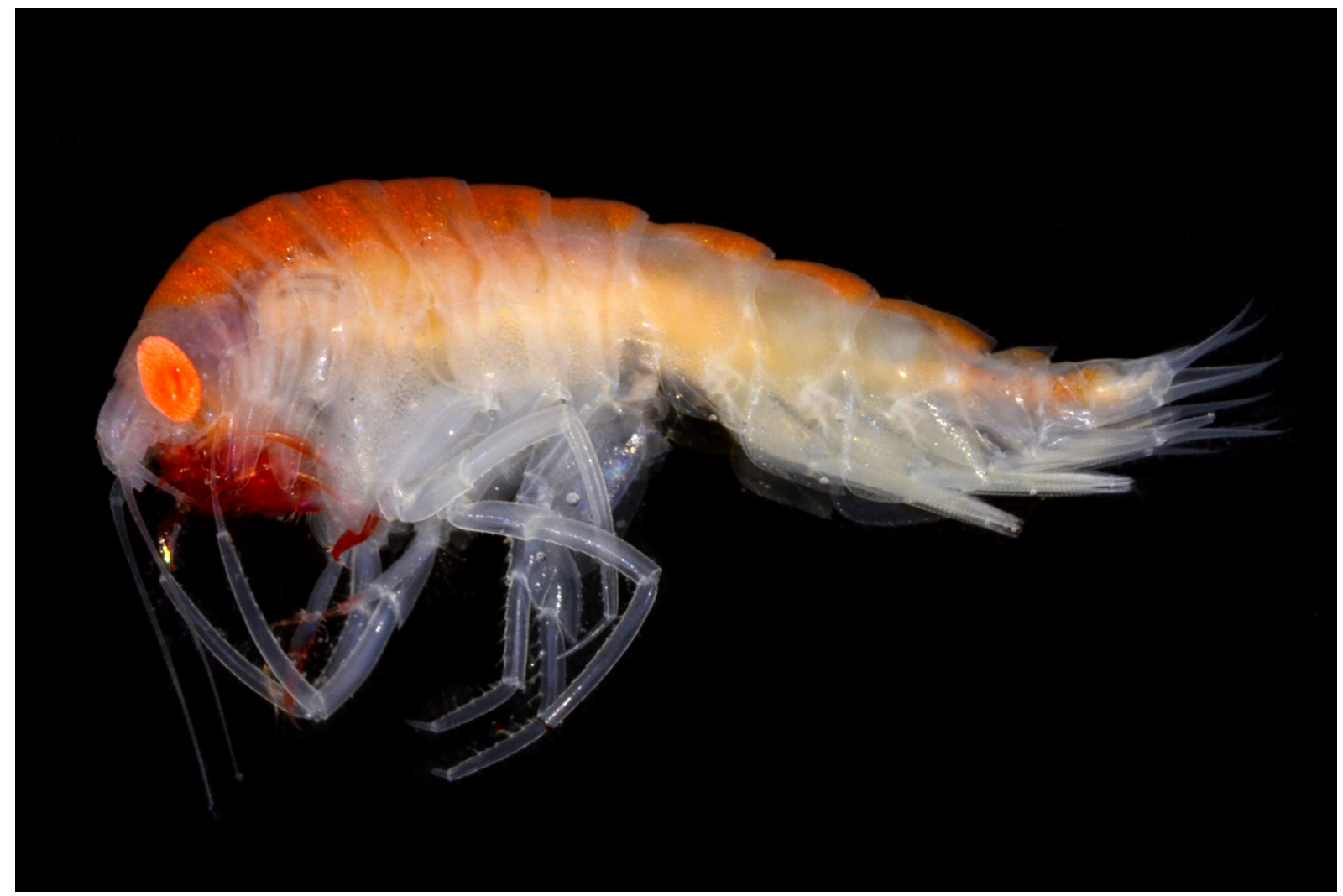

Fig. 131. Epimeria (Epimeriella) macronyx (Walker, 1906), sex undetermined, north of Livingstone Island, ANT-XXIX/3, stn 238-1, RBINS, INV. 122943, colour in life. 


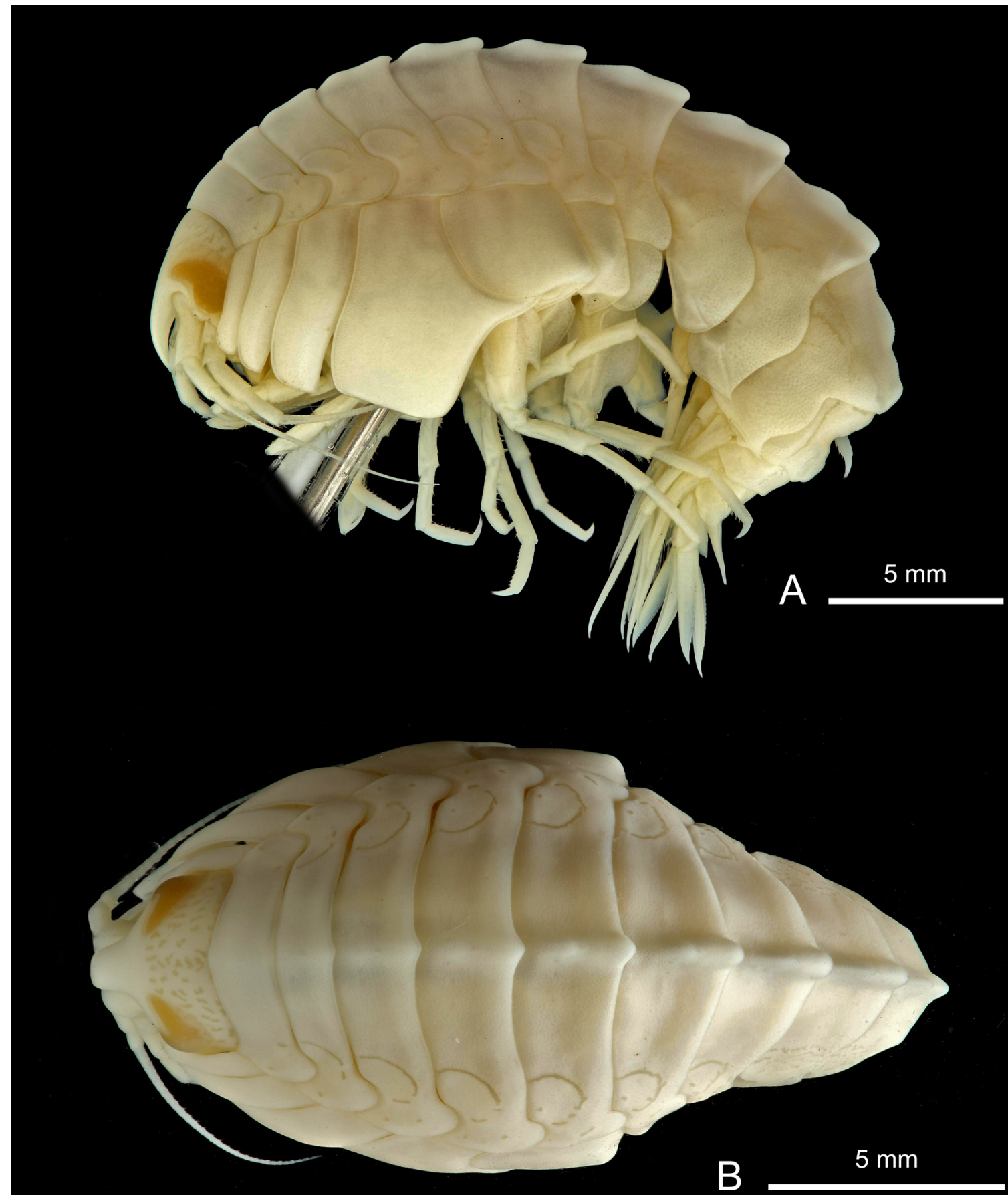

Fig. 132. Epimeria (Hoplepimeria) angelikae subgen. nov. Lörz \& Linse in Lörz et al., 2011, +, adult, Adélie Coast, CEAMARC 3410, MNHN-IU-2014-7343. A. Lateral habitus. B. Dorsal habitus. 


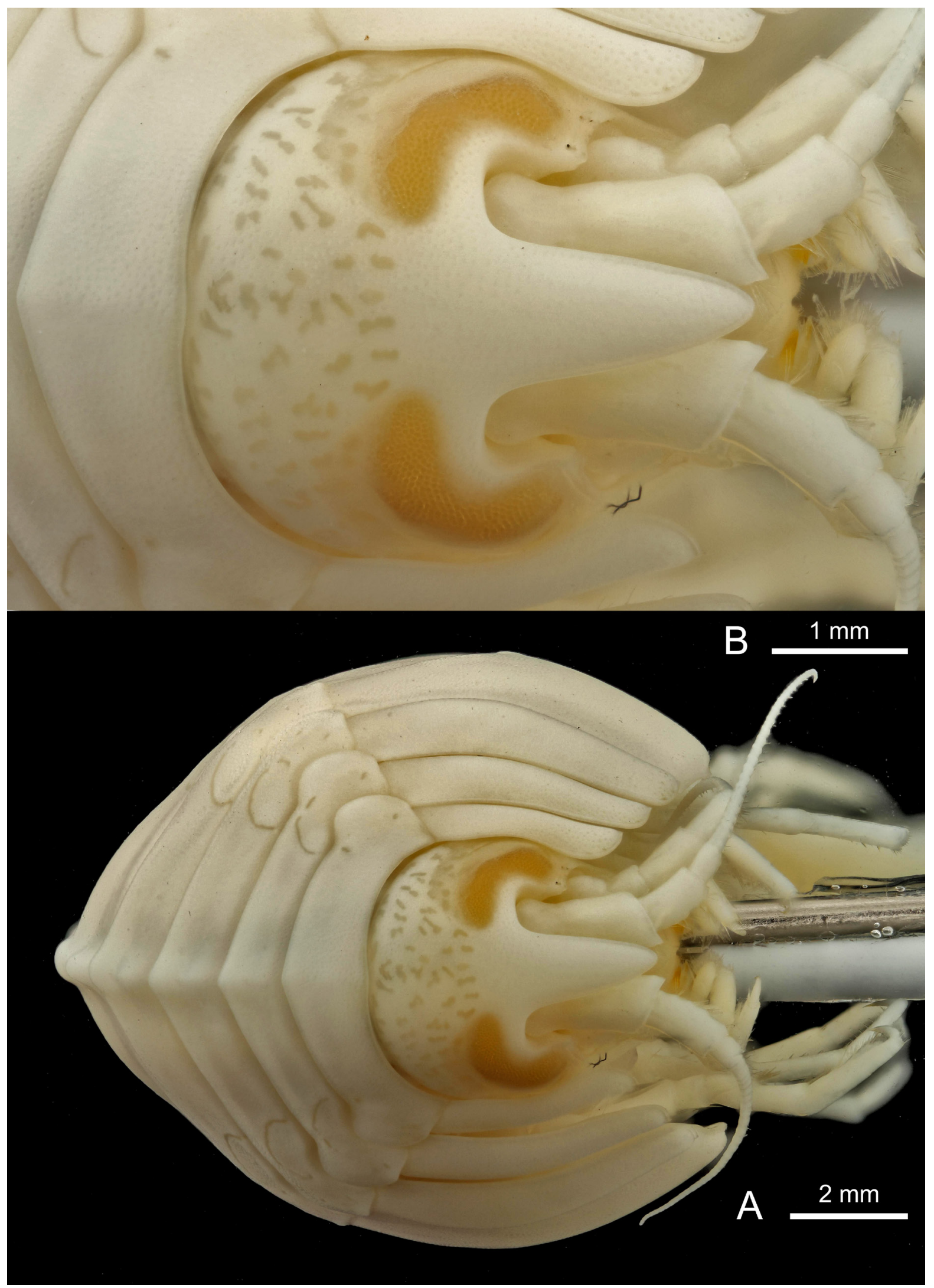

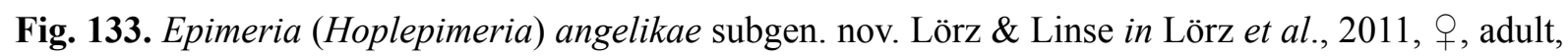
Adélie Coast, CEAMARC 3410, MNHN-IU-2014-7343. A. Facial habitus. B. Head in facial view. 


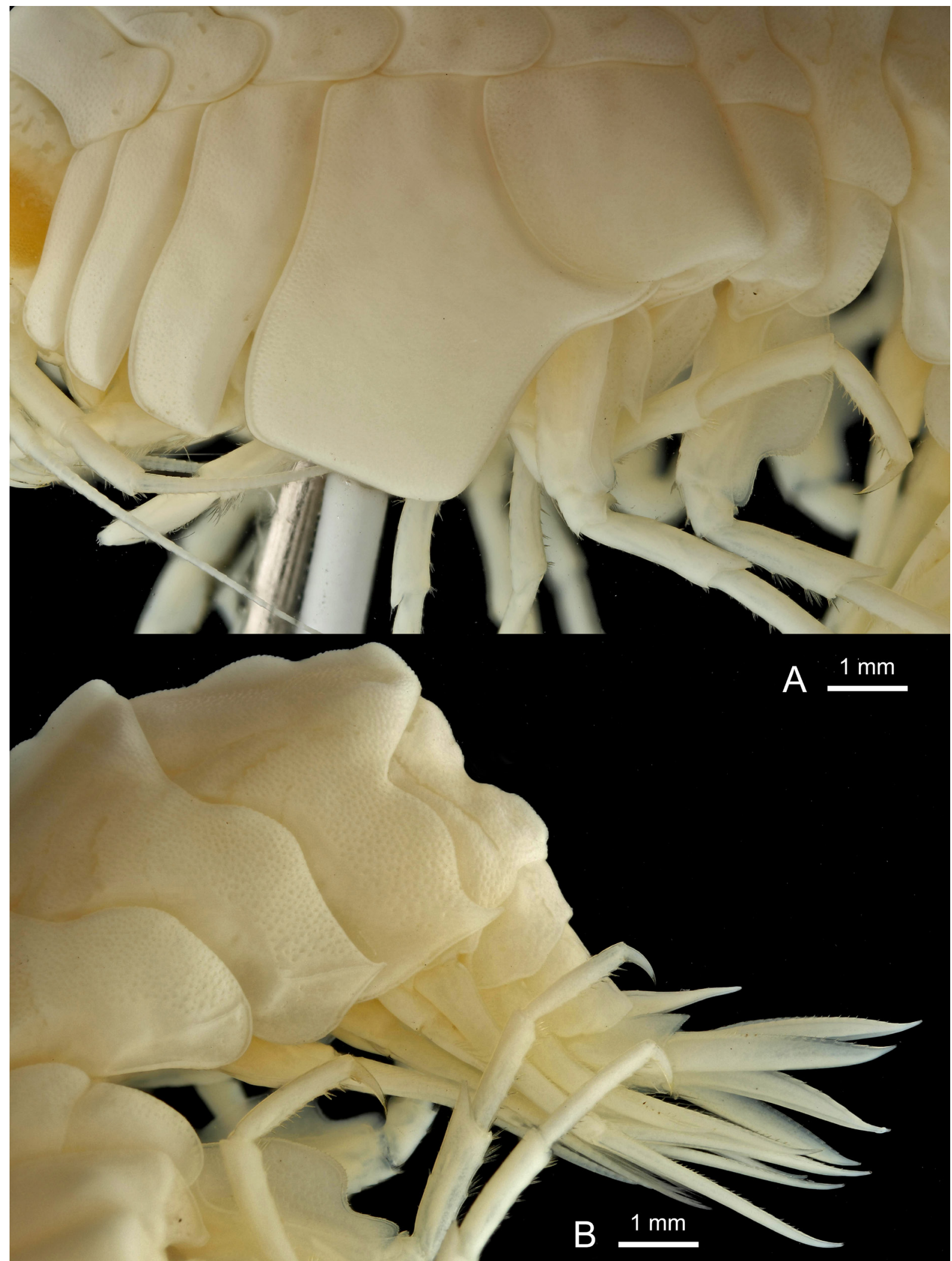

Fig. 134. Epimeria (Hoplepimeria) angelikae subgen. nov. Lörz \& Linse in Lörz et al., 2011, o, adult, Adélie Coast, CEAMARC 3410, MNHN-IU-2014-7343. A. Coxae 1-7. B. Pleon. 


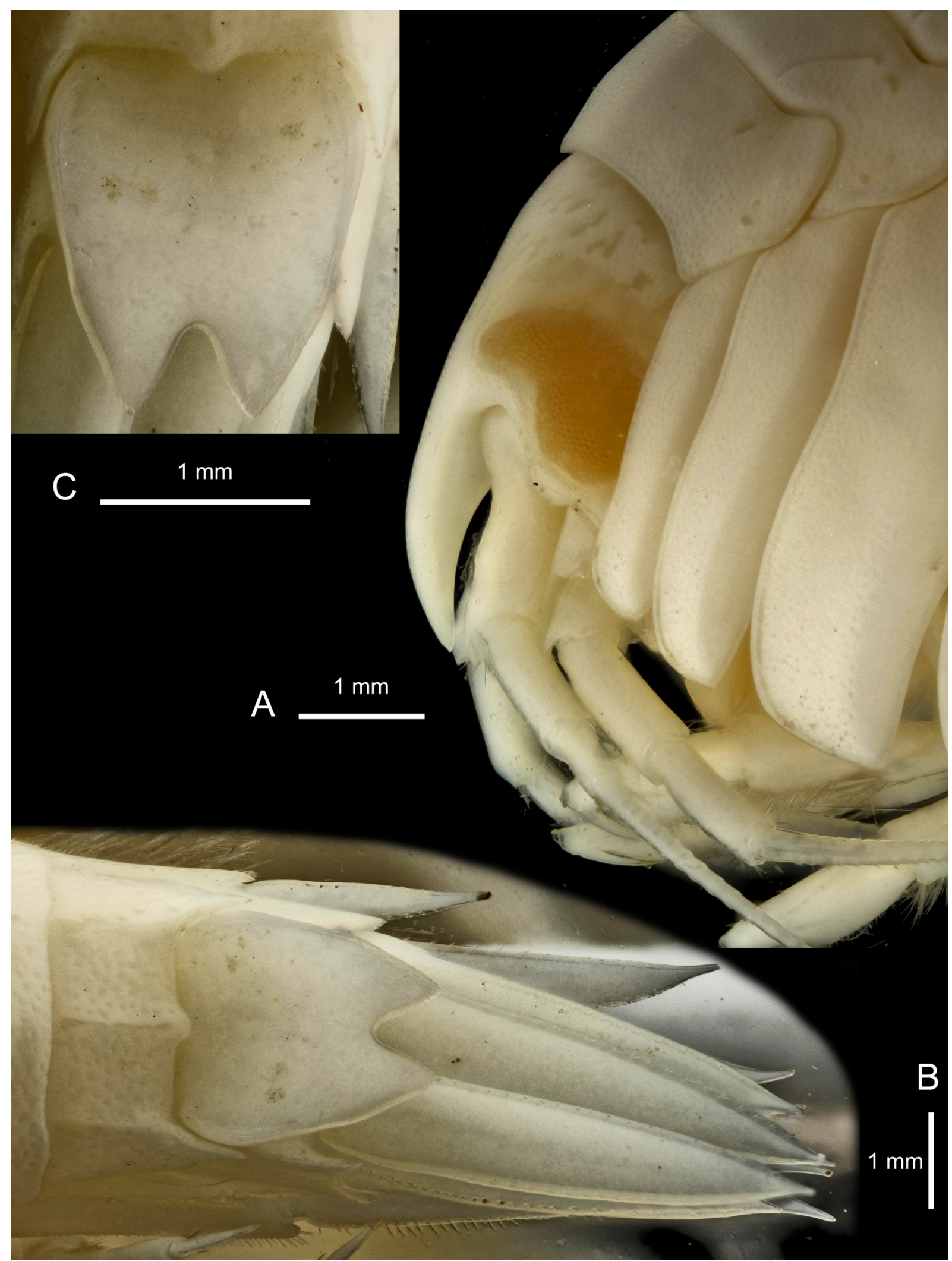

Fig. 135. Epimeria (Hoplepimeria) angelikae subgen. nov. Lörz \& Linse in Lörz et al., 2011, o, adult, Adélie Coast, CEAMARC 3410, MNHN-IU-2014-7343. A. Head in lateral view. B. Urosome in dorsal view. C. Telson. 


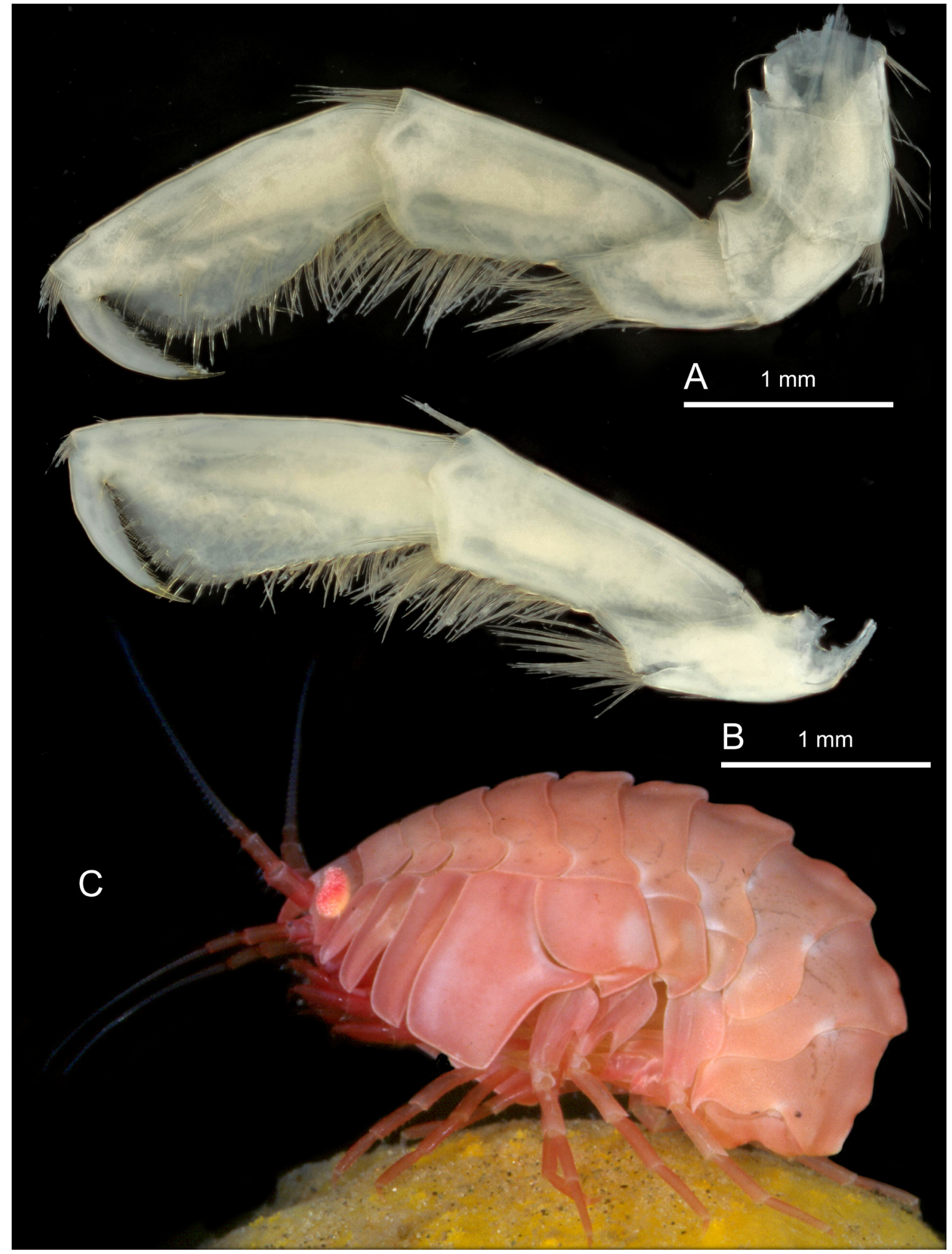

Fig. 136. Epimeria (Hoplepimeria) angelikae subgen. nov. Lörz \& Linse in Lörz et al., 2011. A-B, q, adult, Adélie Coast, CEAMARC 3410, MNHN-IU-2014-7343. C, eastern Weddell Sea, ANT-VII/4, no station. A. Gnathopod 1. B. Gnathopod 2. C. Habitus in colour. There is no evidence of symbiosis with sponges: there was simply a sponge in the aquarium used for photography. Colour photograph by Gauthier Chapelle (formerly RBINS). 


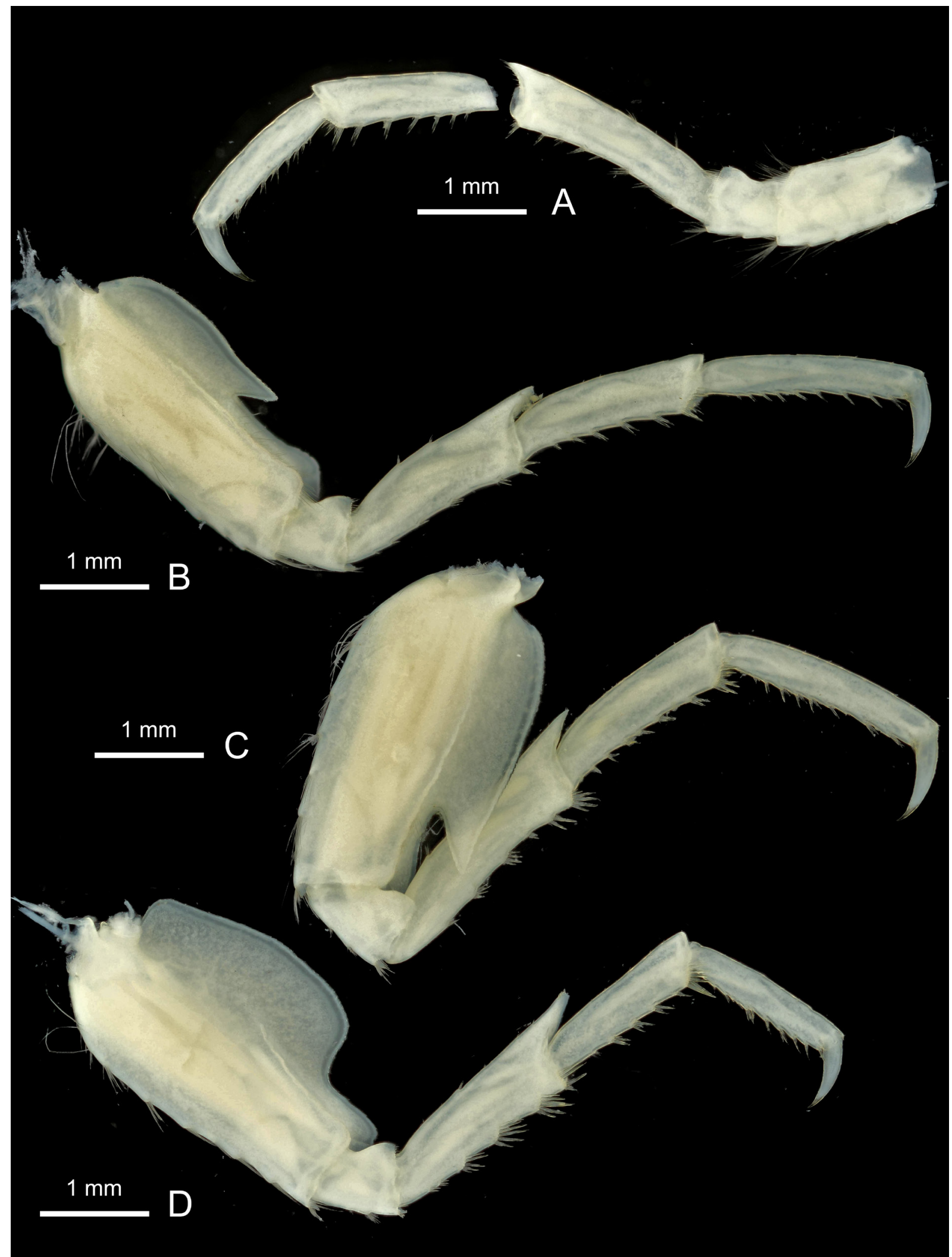

Fig. 137. Epimeria (Hoplepimeria) angelikae subgen. nov. Lörz \& Linse in Lörz et al., 2011, , adult, Adélie Coast, CEAMARC 3410, MNHN-IU-2014-7343. A. Pereiopod 4. B. Pereiopod 5. C. Pereiopod 6. D. Pereiopod 7. 


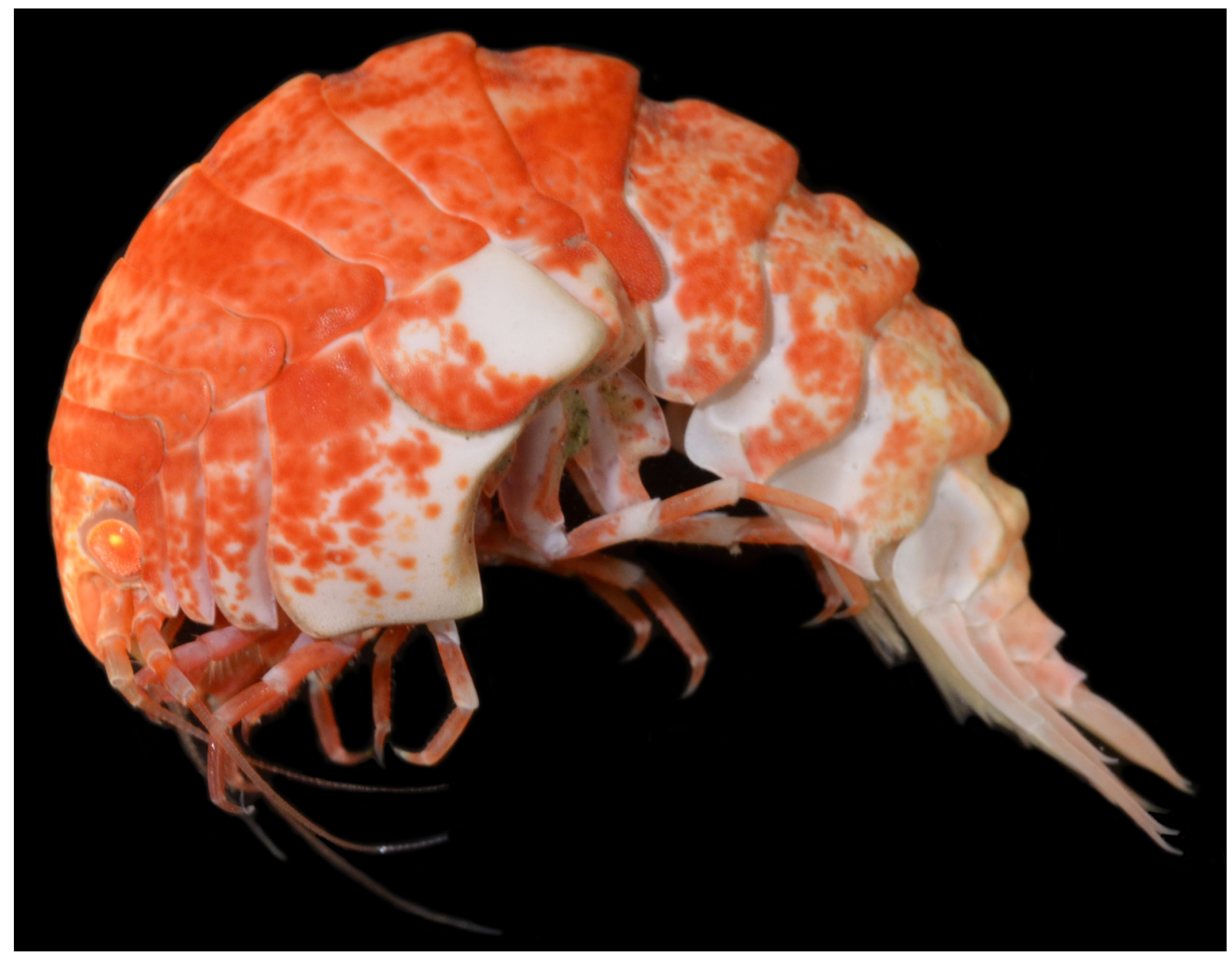

Fig. 138. Epimeria (Hoplepimeria) cyphorachis subgen. et sp. nov., $\uparrow$, holotype, Drake Passage, ANTXXIX/3, stn 249-2, RBINS, INV. 122936, colour in life. 


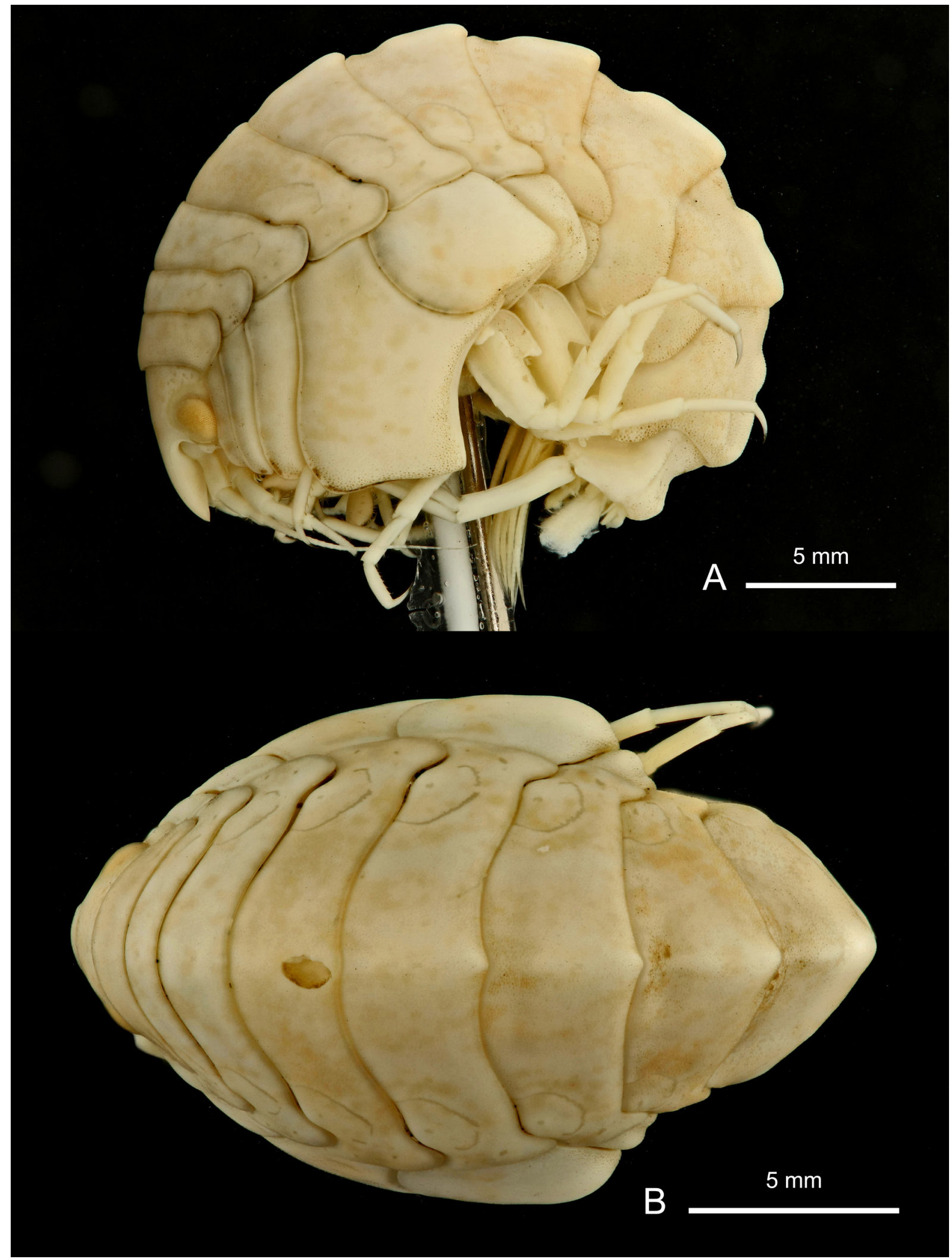

Fig. 139. Epimeria (Hoplepimeria) cyphorachis subgen. et sp. nov., $q$, holotype, Drake Passage, ANTXXIX/3, stn 249-2, RBINS, INV. 122936. A. Lateral habitus. B. Dorsal habitus. 


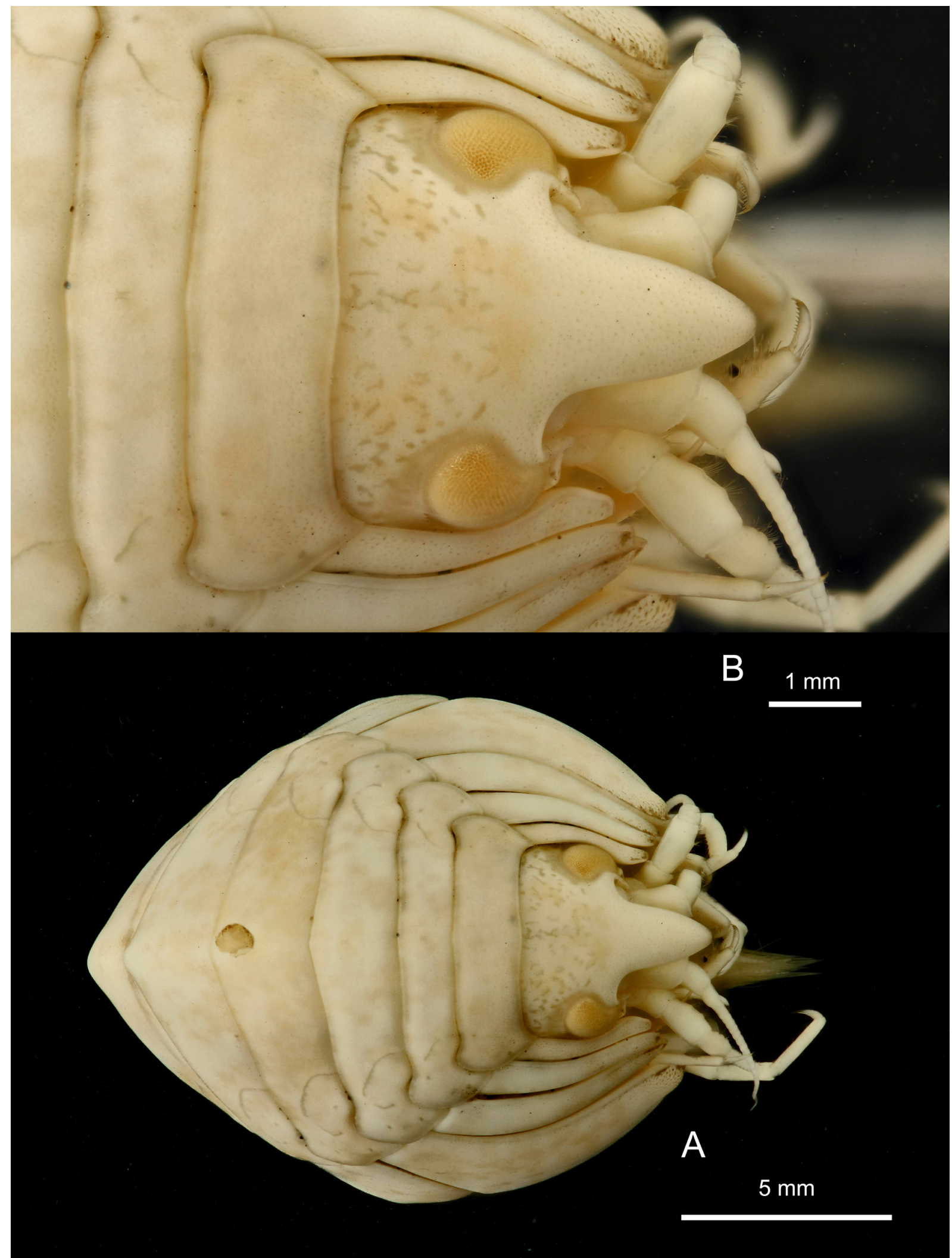

Fig. 140. Epimeria (Hoplepimeria) cyphorachis subgen. et sp. nov., $q$, holotype, Drake Passage, ANTXXIX/3, stn 249-2, RBINS, INV. 122936. A. Facial habitus. B. Head in facial view. 


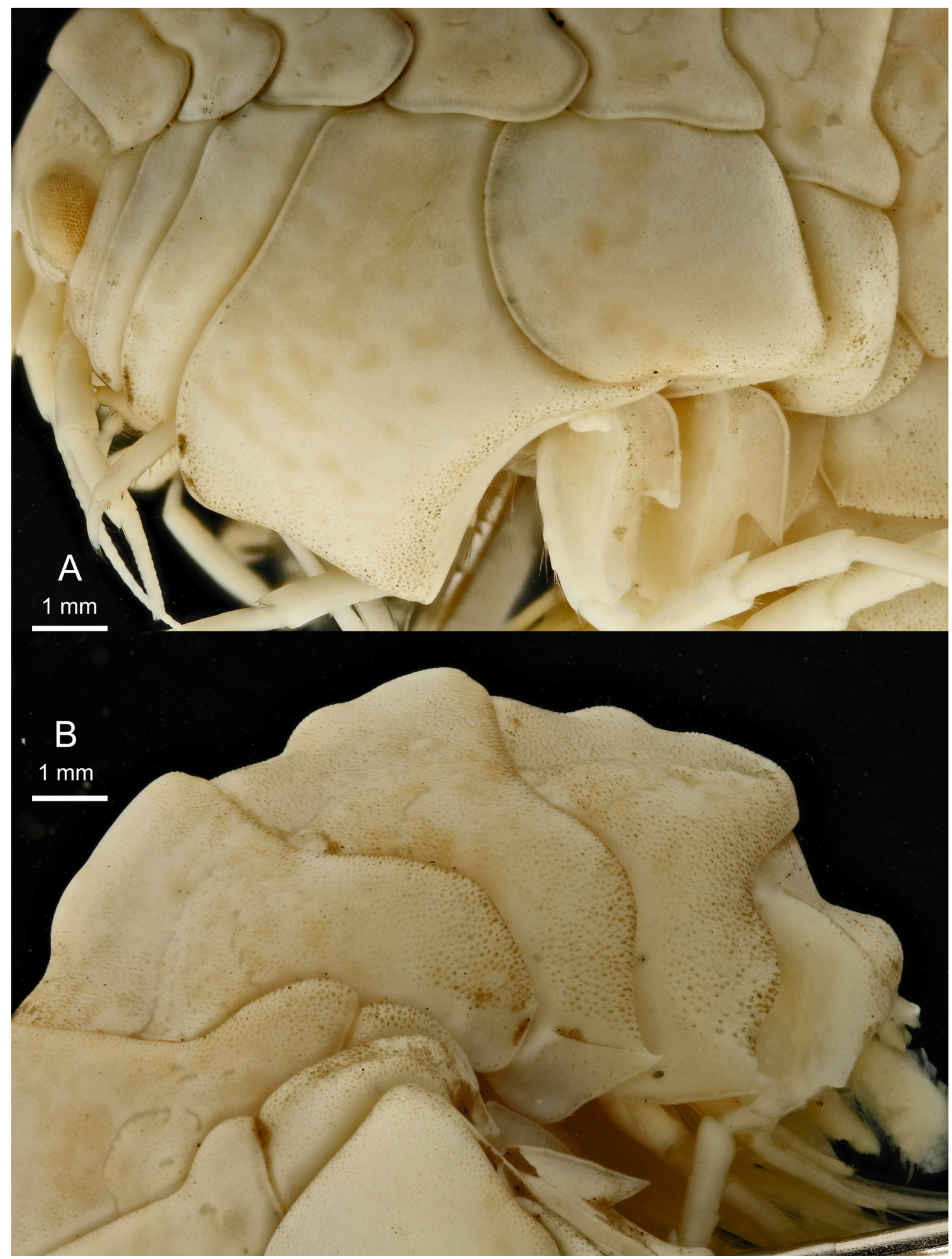

Fig. 141. Epimeria (Hoplepimeria) cyphorachis subgen. et sp. nov., + , holotype, Drake Passage, ANTXXIX/3, stn 249-2, RBINS, INV. 122936. A. Coxae 1-7. B. Pleosome and urosomite 1. 


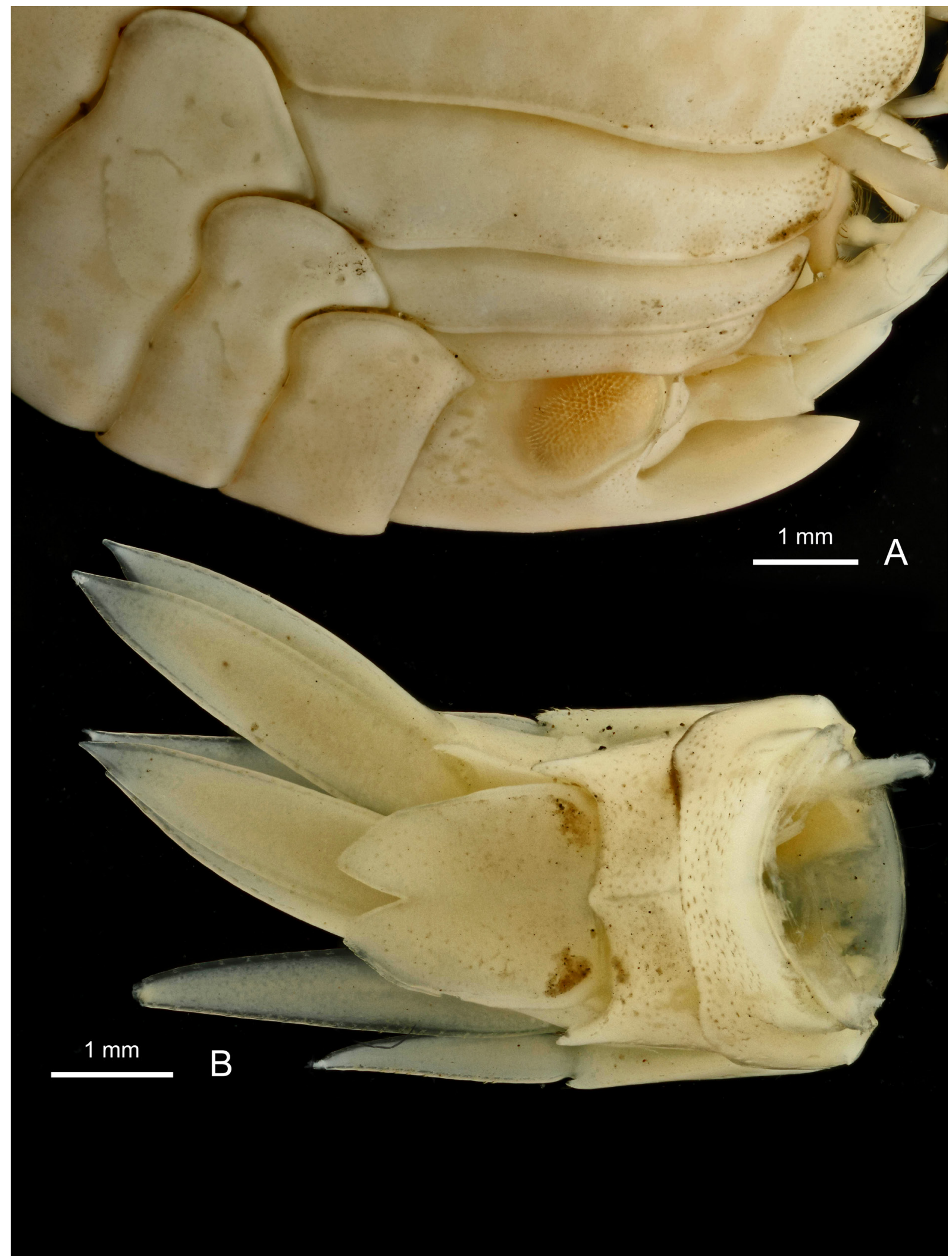

Fig. 142. Epimeria (Hoplepimeria) cyphorachis subgen. et sp. nov., $q$, holotype, Drake Passage, ANTXXIX/3, stn 249-2, RBINS, INV. 122936. A. Head in lateral view. B. Urosome in dorsal view. 


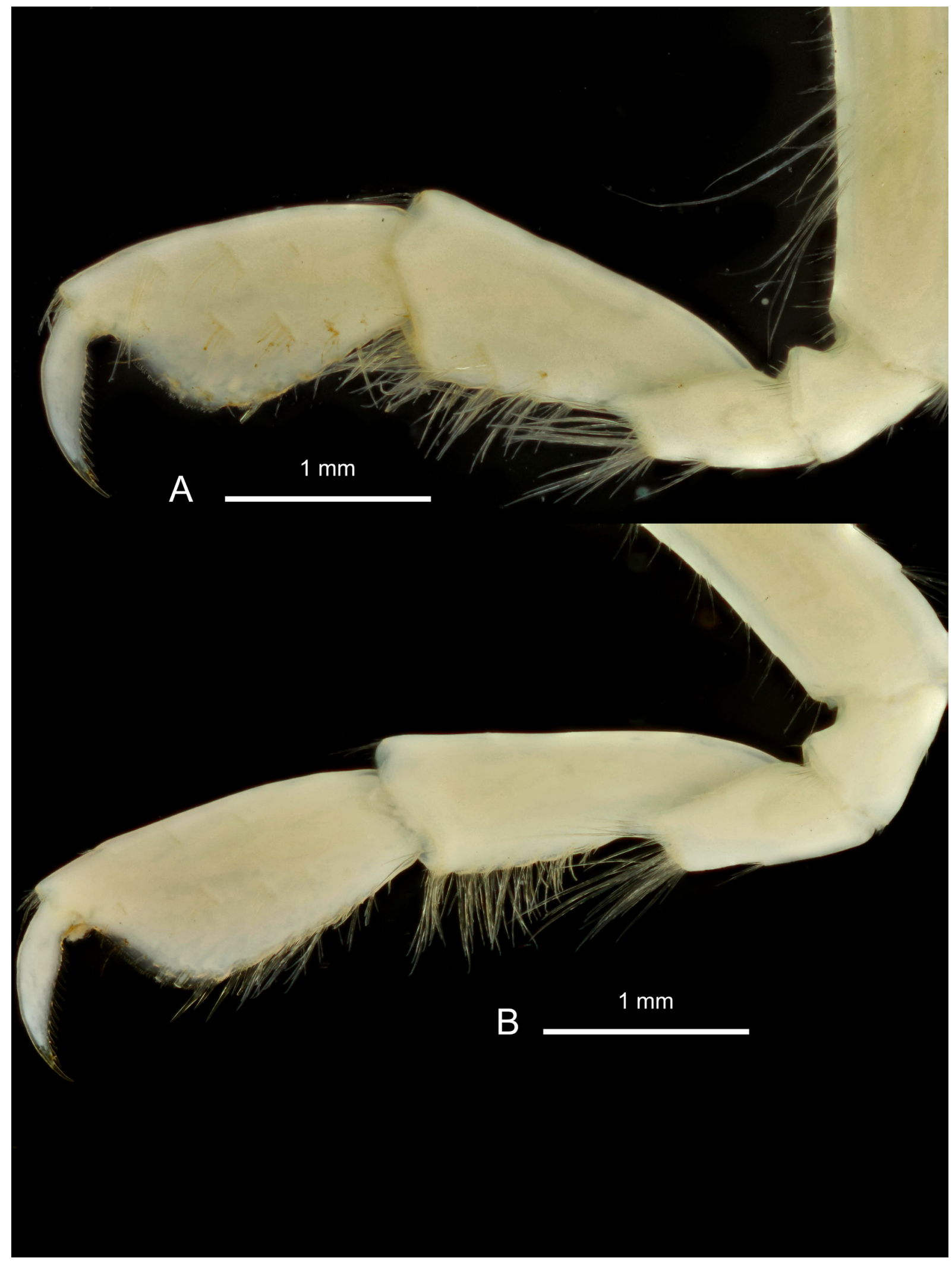

Fig. 143. Epimeria (Hoplepimeria) cyphorachis subgen. et sp. nov., $q$, holotype, Drake Passage, ANTXXIX/3, stn 249-2, RBINS, INV. 122936. A. Gnathopod 1. B. Gnathopod 2. 


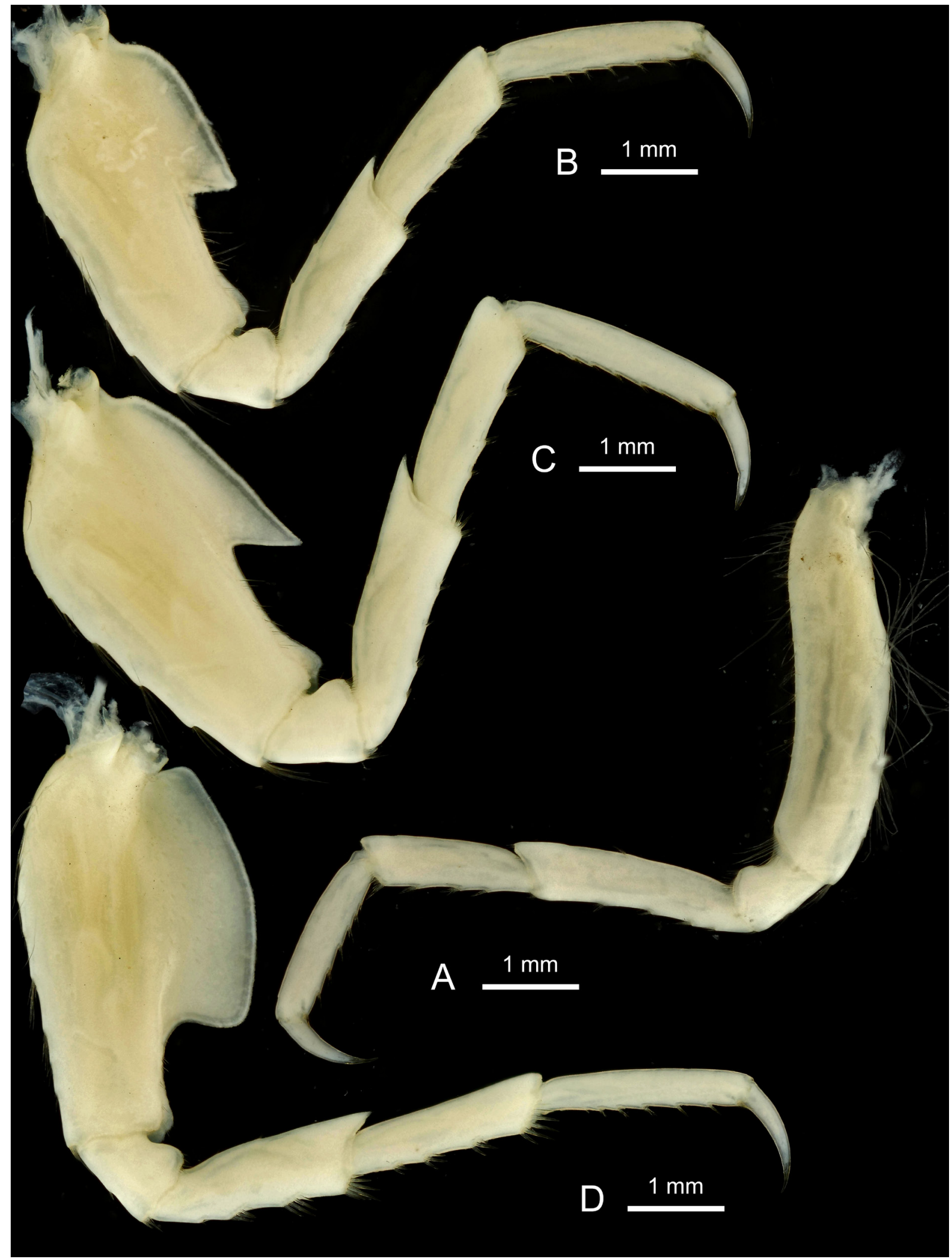

Fig. 144. Epimeria (Hoplepimeria) cyphorachis subgen. et sp. nov., + , holotype, Drake Passage, ANT-XXIX/3, stn 249-2, RBINS, INV. 122936. A. Pereiopod 4. B. Pereiopod 5. C. Pereiopod 6. D. Pereiopod 7. 


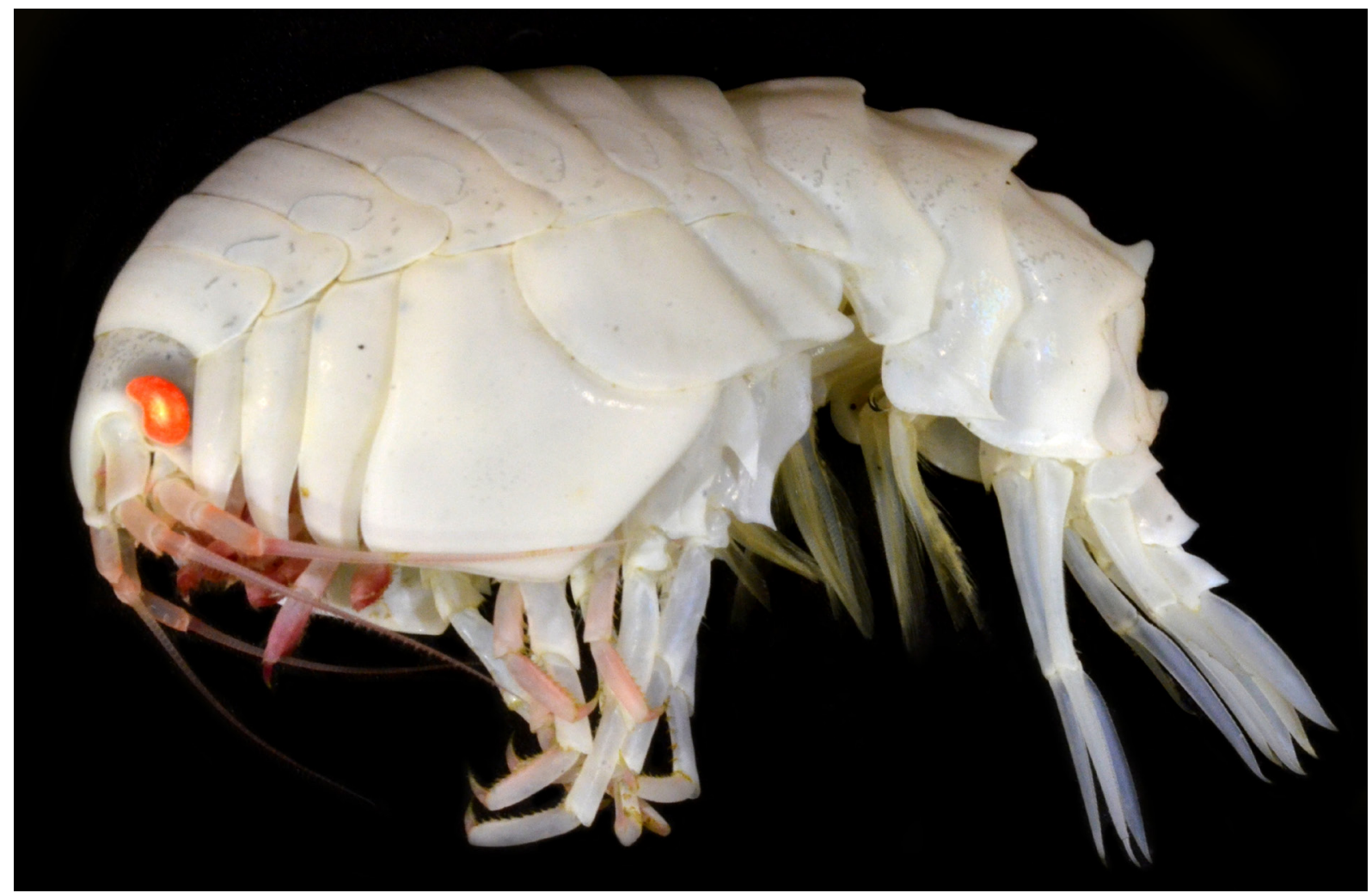

Fig. 145. Epimeria (Hoplepimeria) gargantua subgen. et sp. nov.,, , type series and probably holotype, Bransfield Strait, ANT-XXIX/3, stn 196-8, RBINS, INV. 122937, colour in life. 


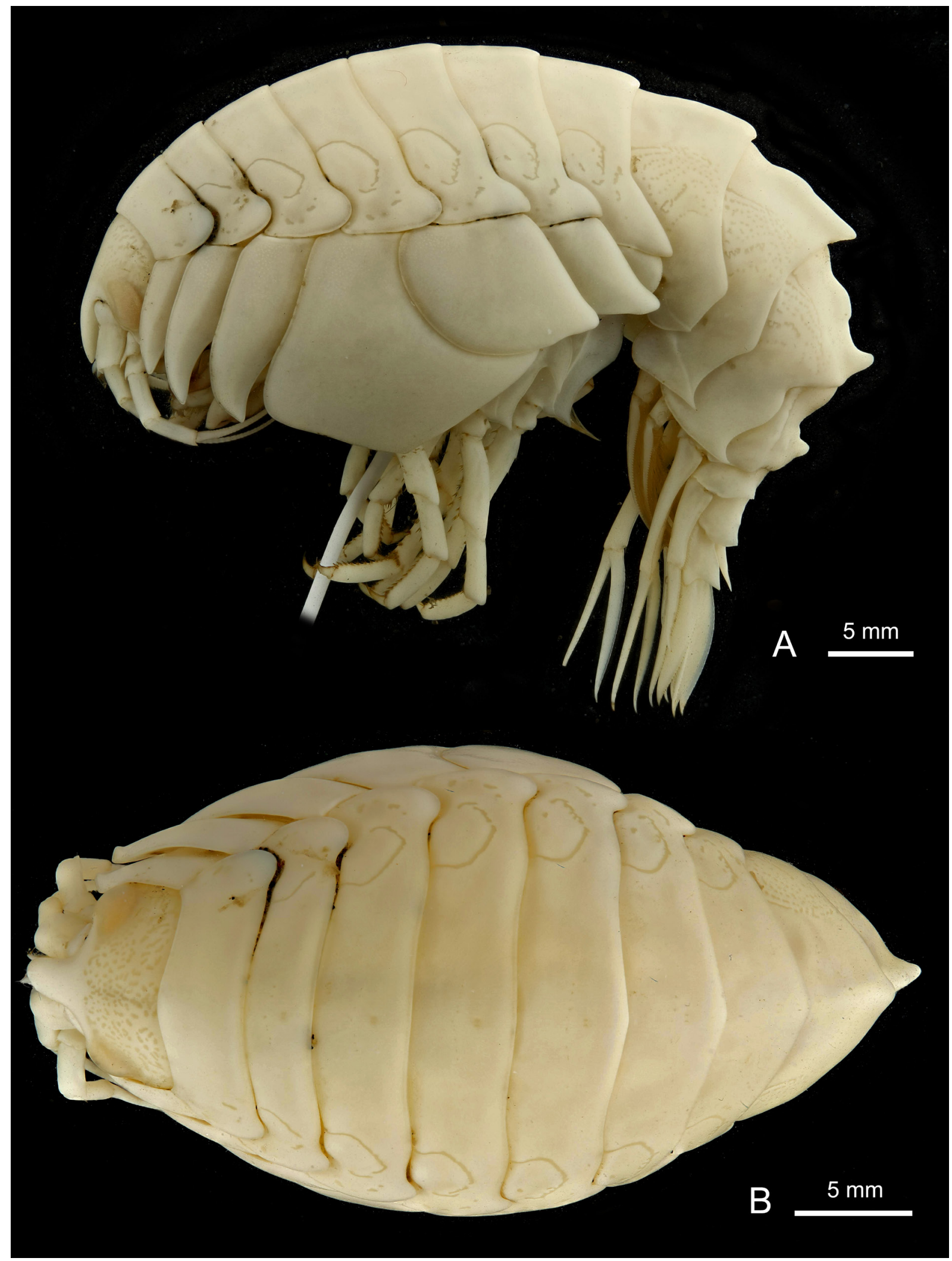

Fig. 146. Epimeria (Hoplepimeria) gargantua subgen. et sp. nov., + , holotype, Bransfield Strait, ANTXXIX/3, stn 196-8, RBINS, INV. 122937A. A. Lateral habitus. B. Dorsal habitus. 


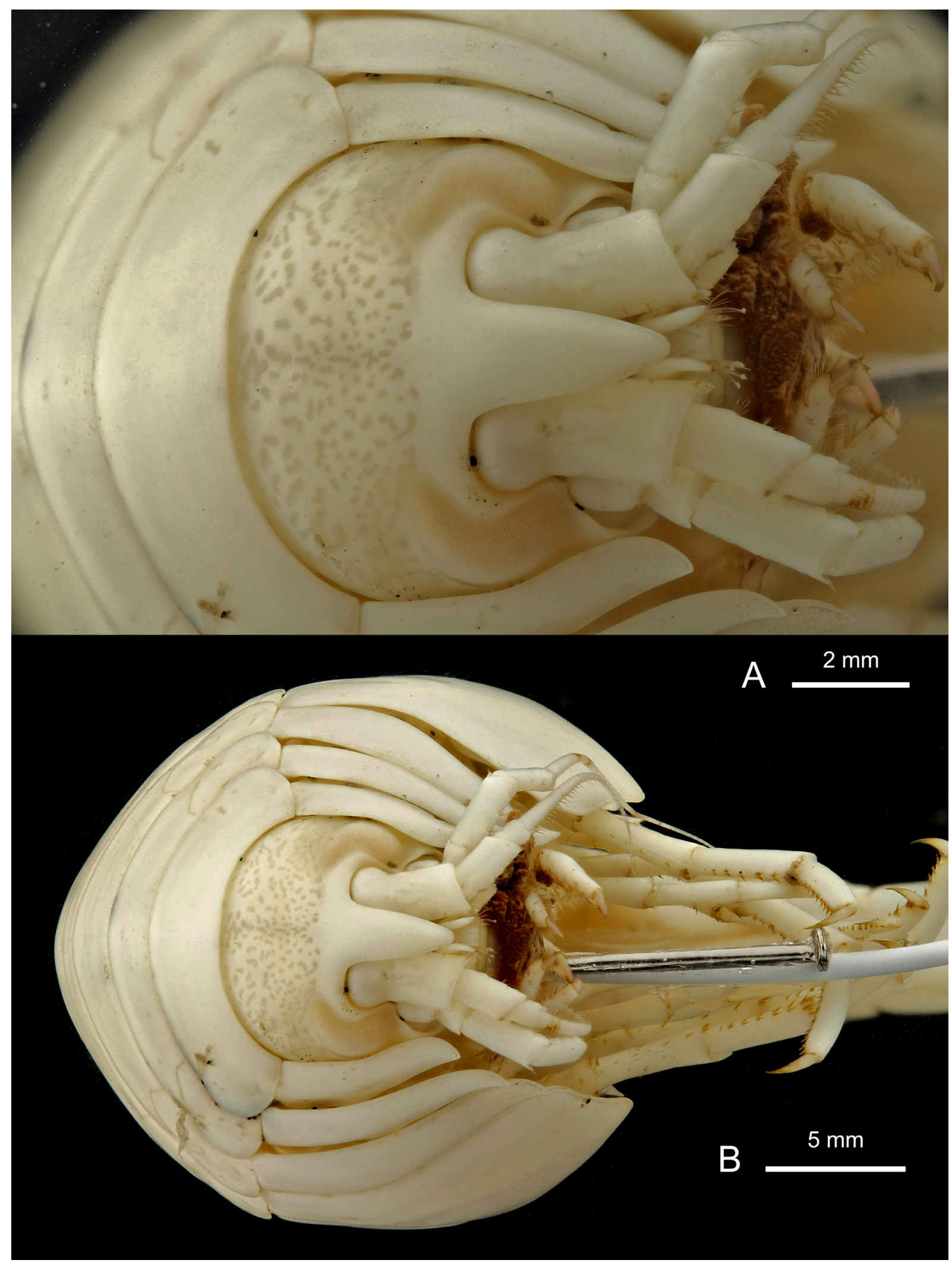

Fig. 147. Epimeria (Hoplepimeria) gargantua subgen. et sp. nov., + , holotype, Bransfield Strait, ANTXXIX/3, stn 196-8, RBINS, INV. 122937A. A. Facial habitus. B. Head in dorsal view. 


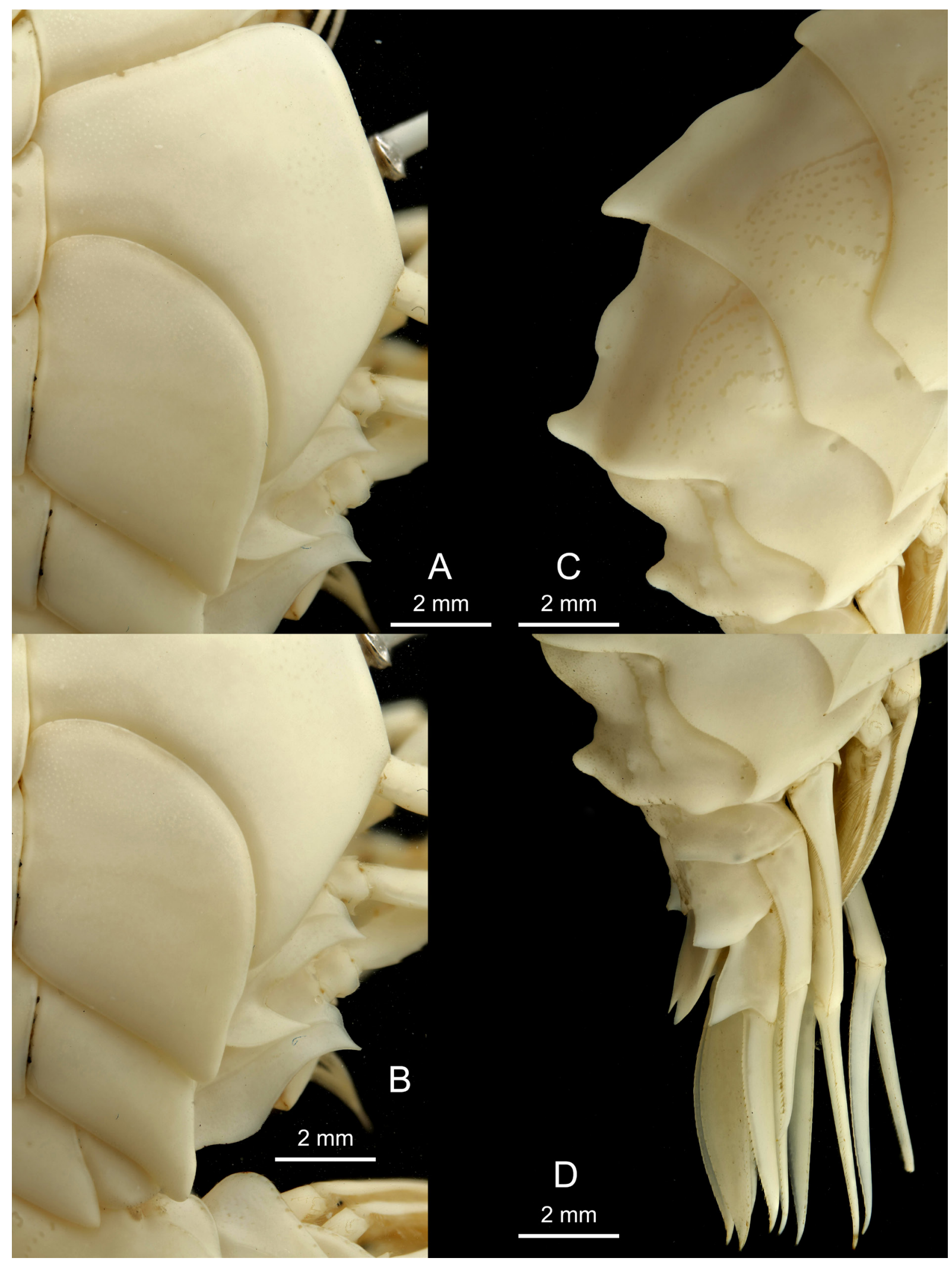

Fig. 148. Epimeria (Hoplepimeria) gargantua subgen. et sp. nov.,, , holotype, Bransfield Strait, ANTXXIX/3, stn 196-8, RBINS, INV. 122937A. A. Coxae 4-5. B. Coxae 5-7. C. Pleosome and urosomite 1. D. Urosome in lateral view. 


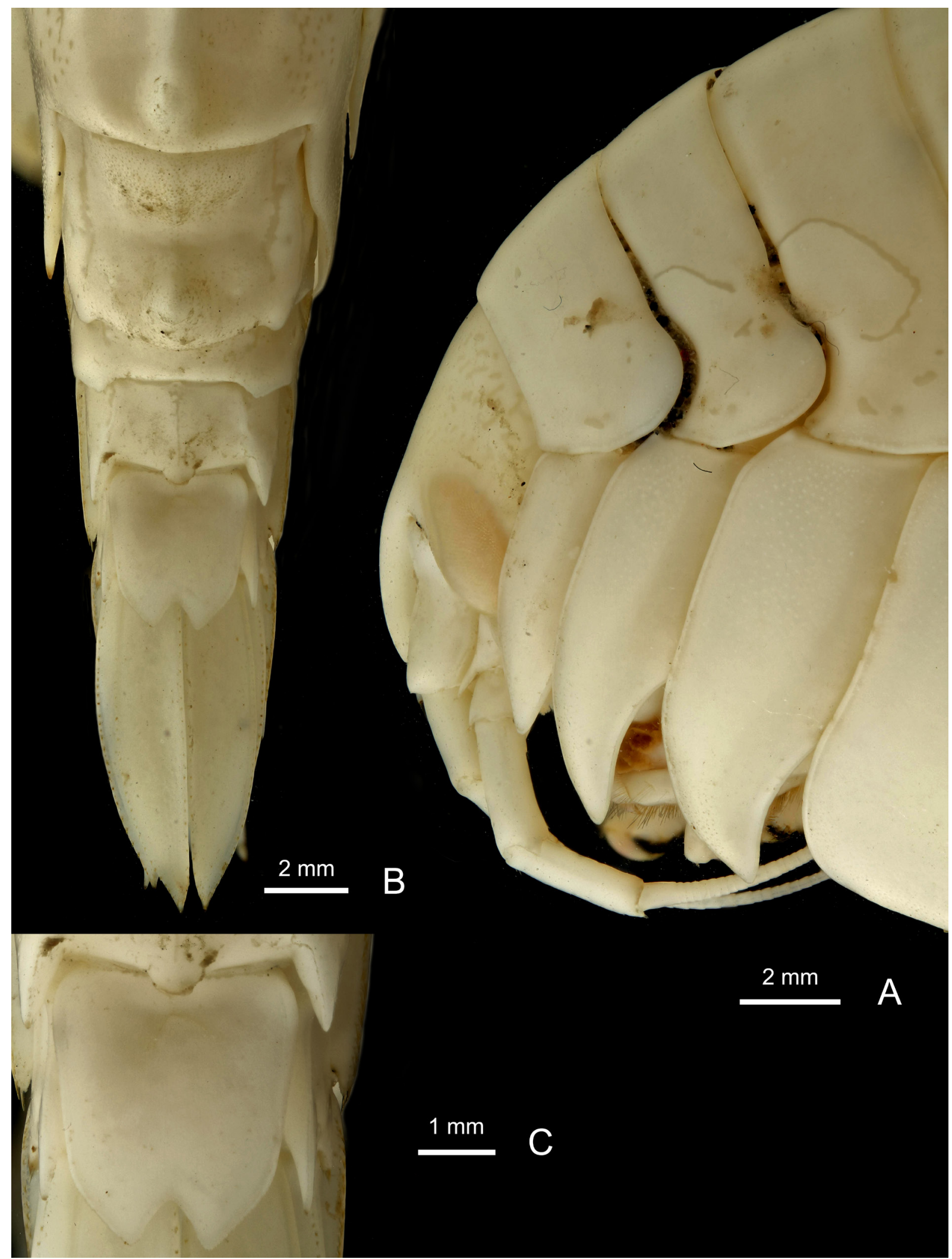

Fig. 149. Epimeria (Hoplepimeria) gargantua subgen. et sp. nov., $q$, holotype, Bransfield Strait, ANT-XXIX/3, stn 196-8, RBINS, INV. 122937A. A. Head in lateral view. B. Urosome in dorsal view. C. Telson. 


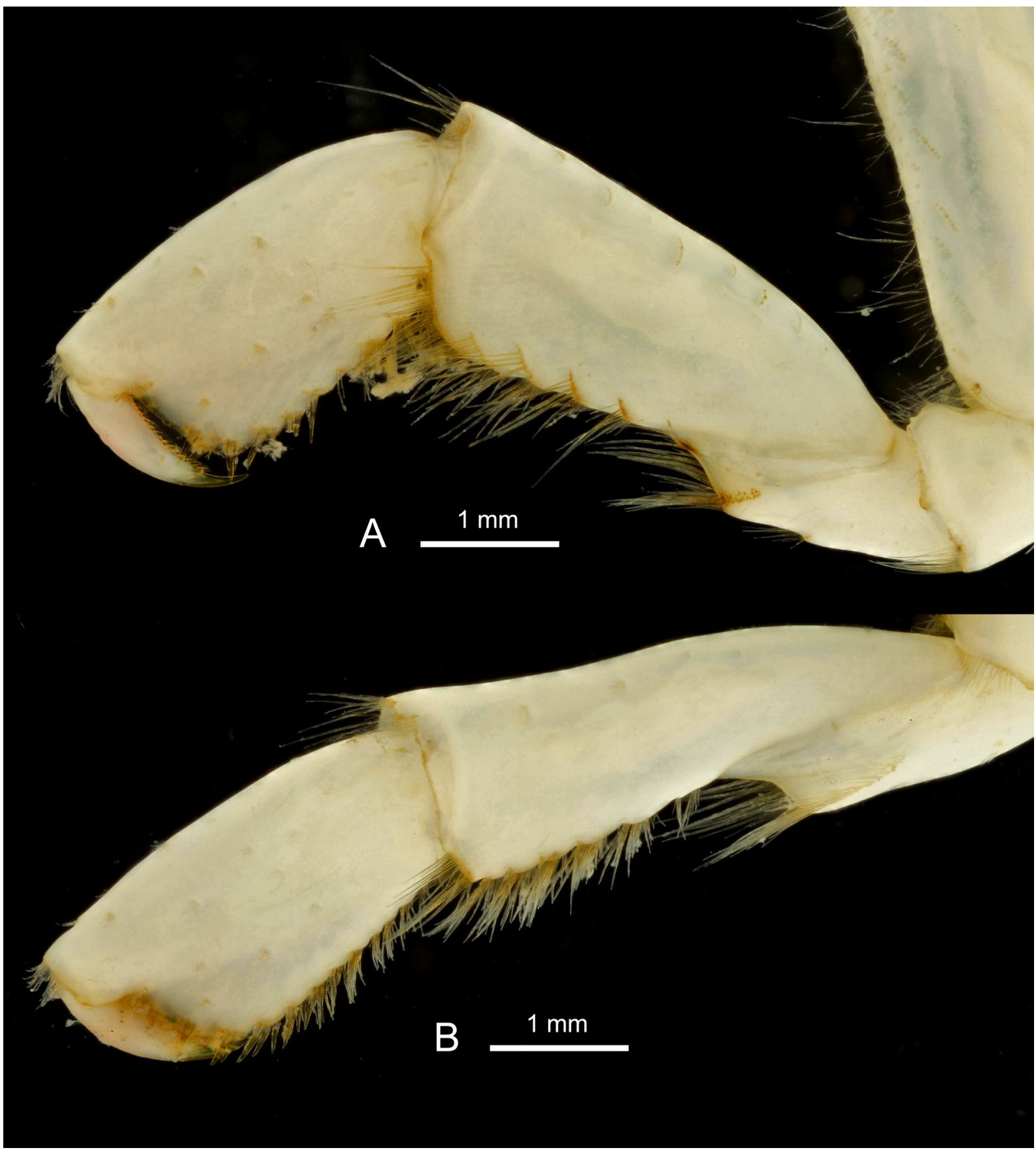

Fig. 150. Epimeria (Hoplepimeria) gargantua subgen. et sp. nov., + , holotype, Bransfield Strait, ANTXXIX/3, stn 196-8, RBINS, INV. 122937A. A. Gnathopod 1. B. Gnathopod 2. 


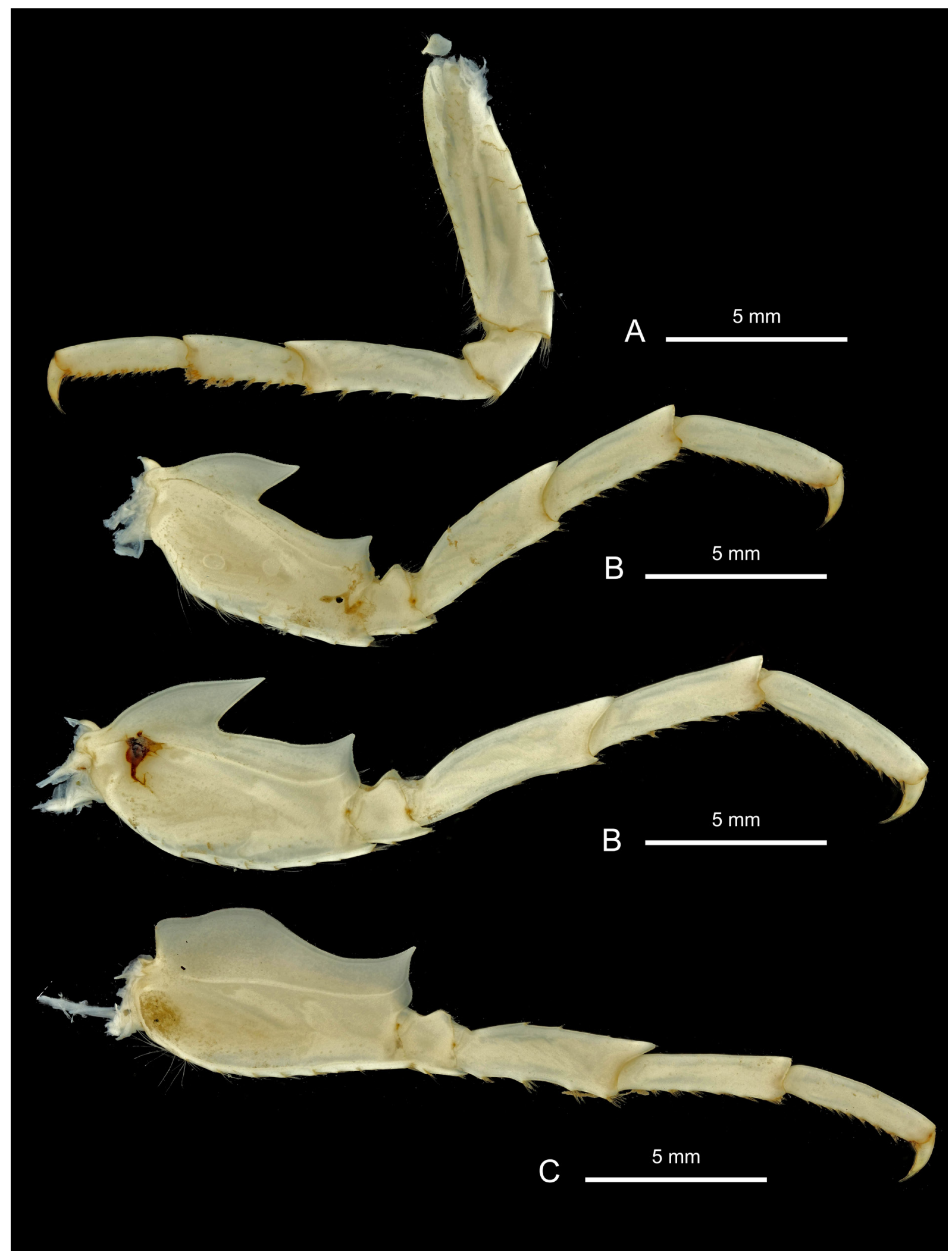

Fig. 151. Epimeria (Hoplepimeria) gargantua subgen. et sp. nov., + , holotype, Bransfield Strait, ANT-XXIX/3, stn 196-8, RBINS, INV. 122937A. A. Pereiopod 4. B. Pereiopod 5. C. Pereiopod 6. D. Pereiopod 7. 


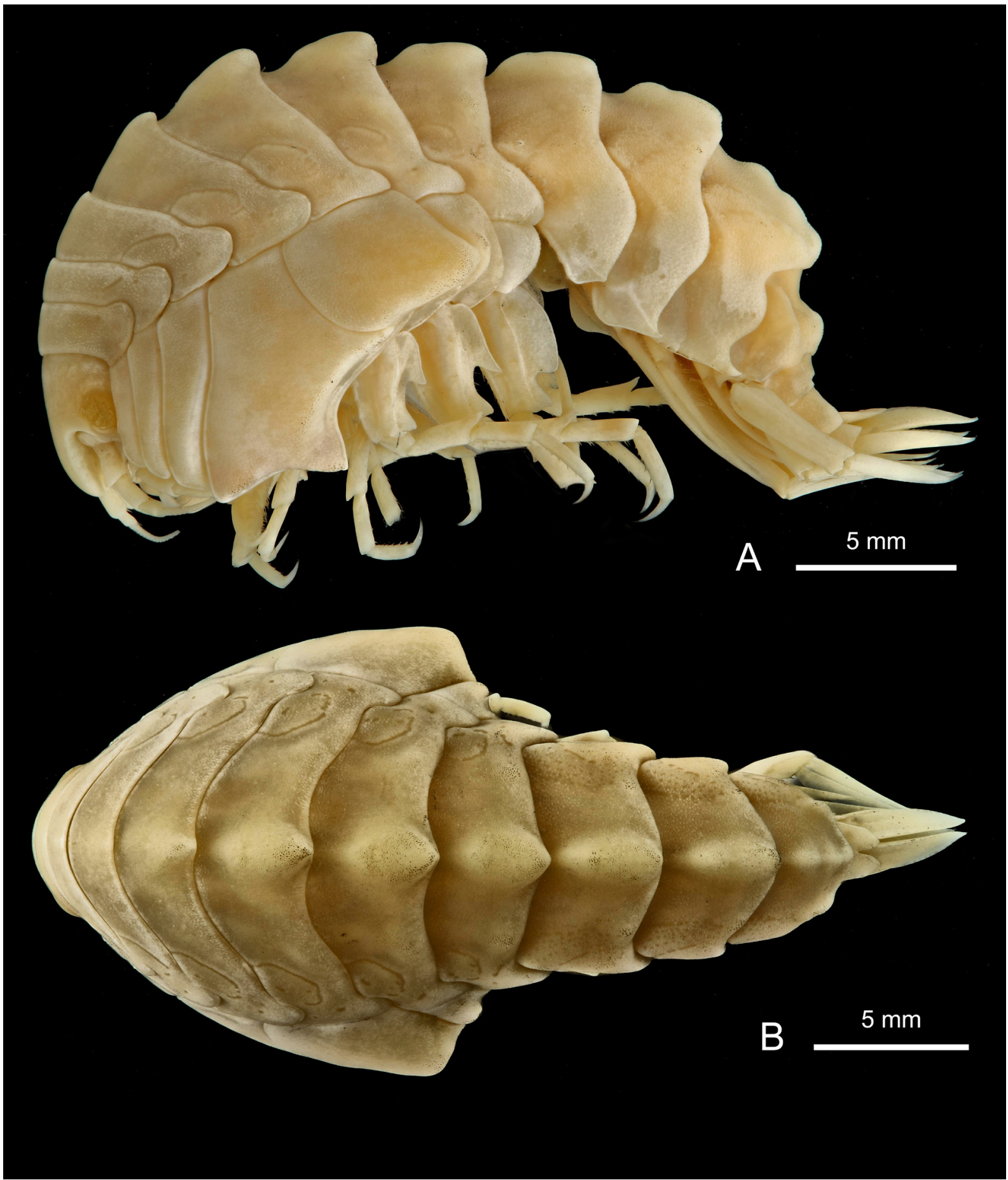

Fig. 152. Epimeria (Hoplepimeria) georgiana subgen. nov. (Schellenberg, 1931), + , lectotype, South Georgia, Swedish South Polar Expedition 1901-1903, stn 34, SMNH - type 673. A. Lateral habitus. B. Dorsal habitus. 


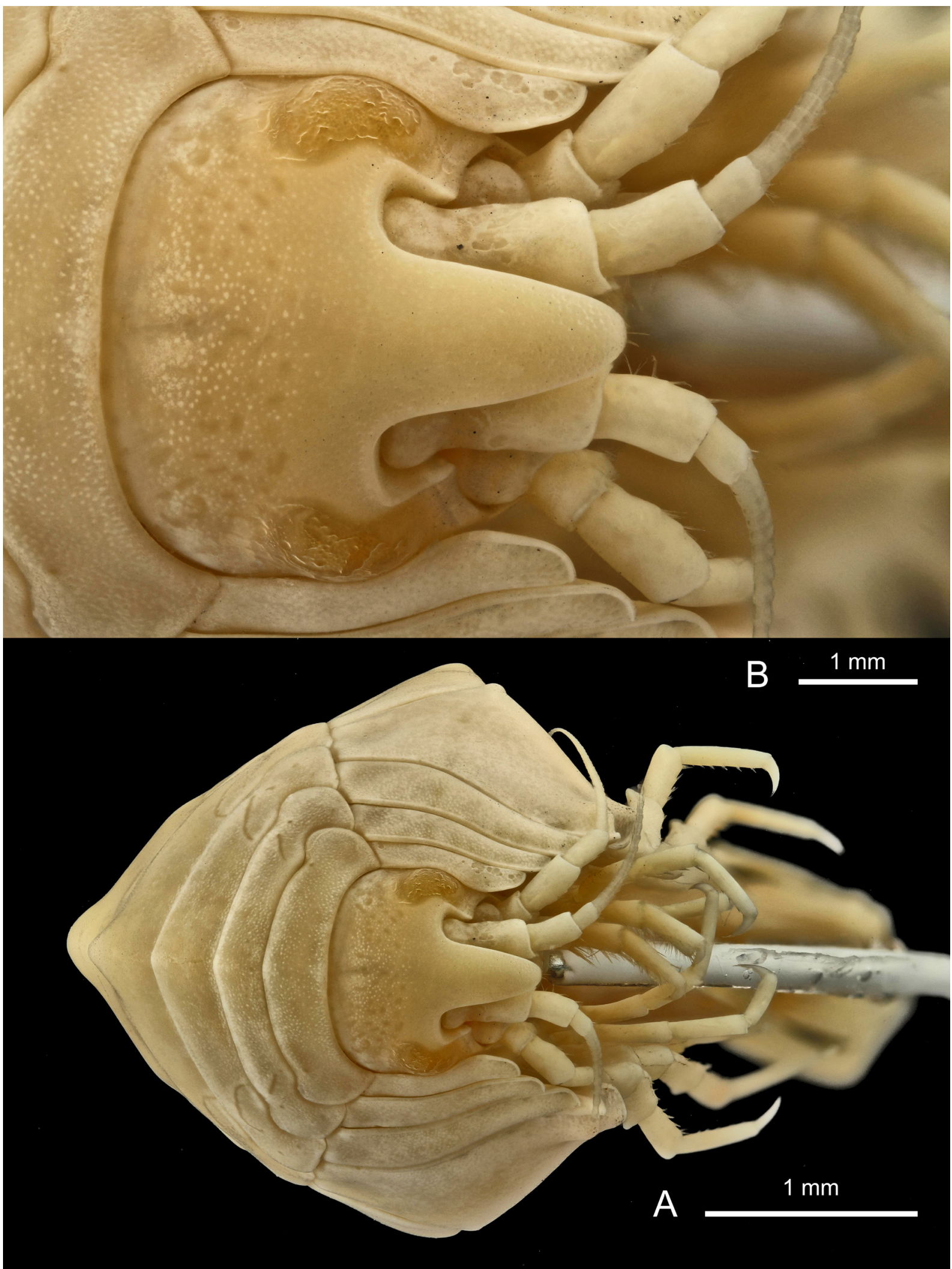

Fig. 153. Epimeria (Hoplepimeria) georgiana subgen. nov. (Schellenberg, 1931), ㅇ, lectotype, South Georgia, Swedish South Polar Expedition 1901-1903, stn 34, SMNH - type 673. A. Facial habitus. B. Head in dorsal view. 


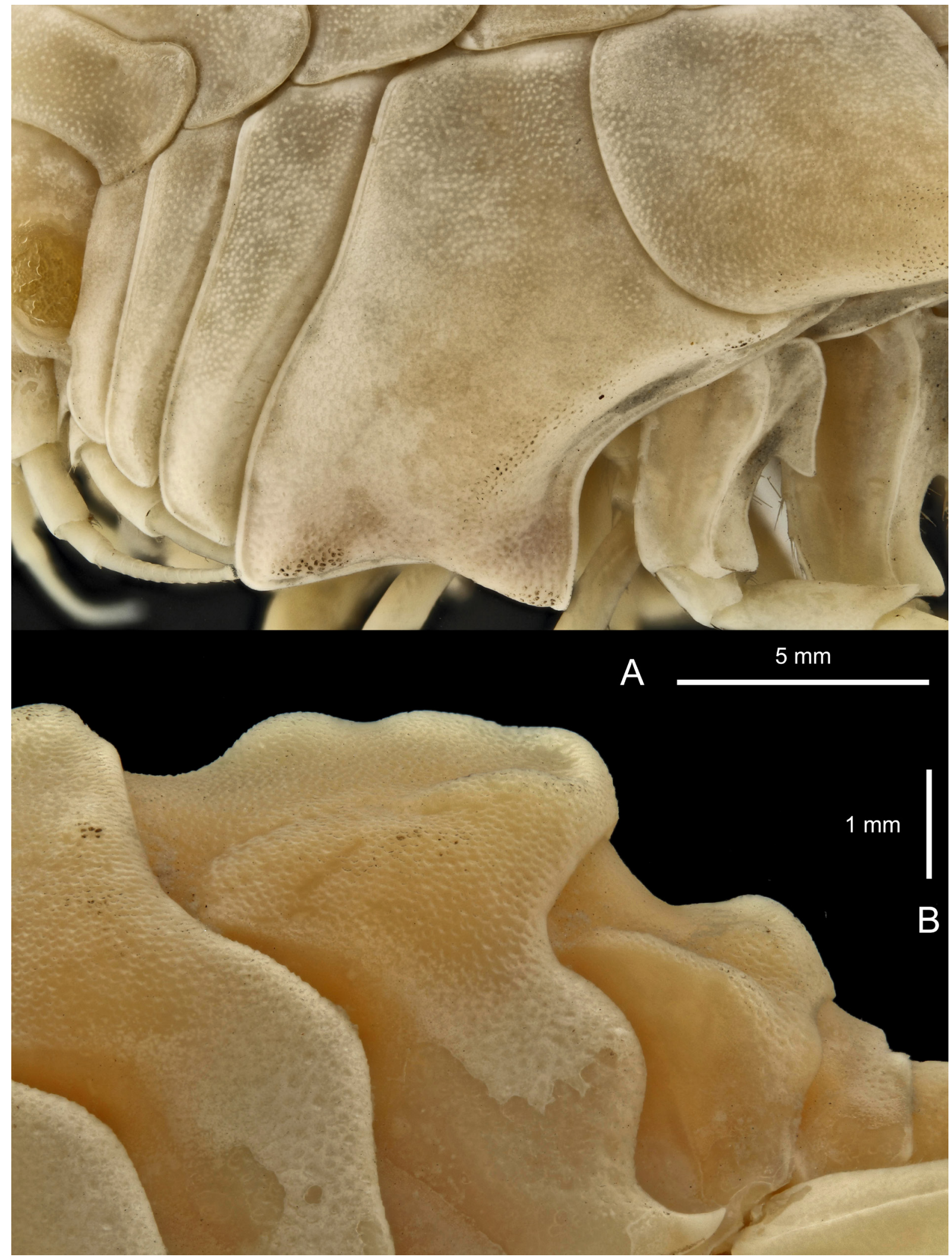

Fig. 154. Epimeria (Hoplepimeria) georgiana subgen. nov. (Schellenberg, 1931), +, lectotype, South Georgia, Swedish South Polar Expedition 1901-1903, stn 34, SMNH - type 673. A. Coxae 1-4. B. Dorsal profile of pleonite 3 and urosomites $1-2$. 


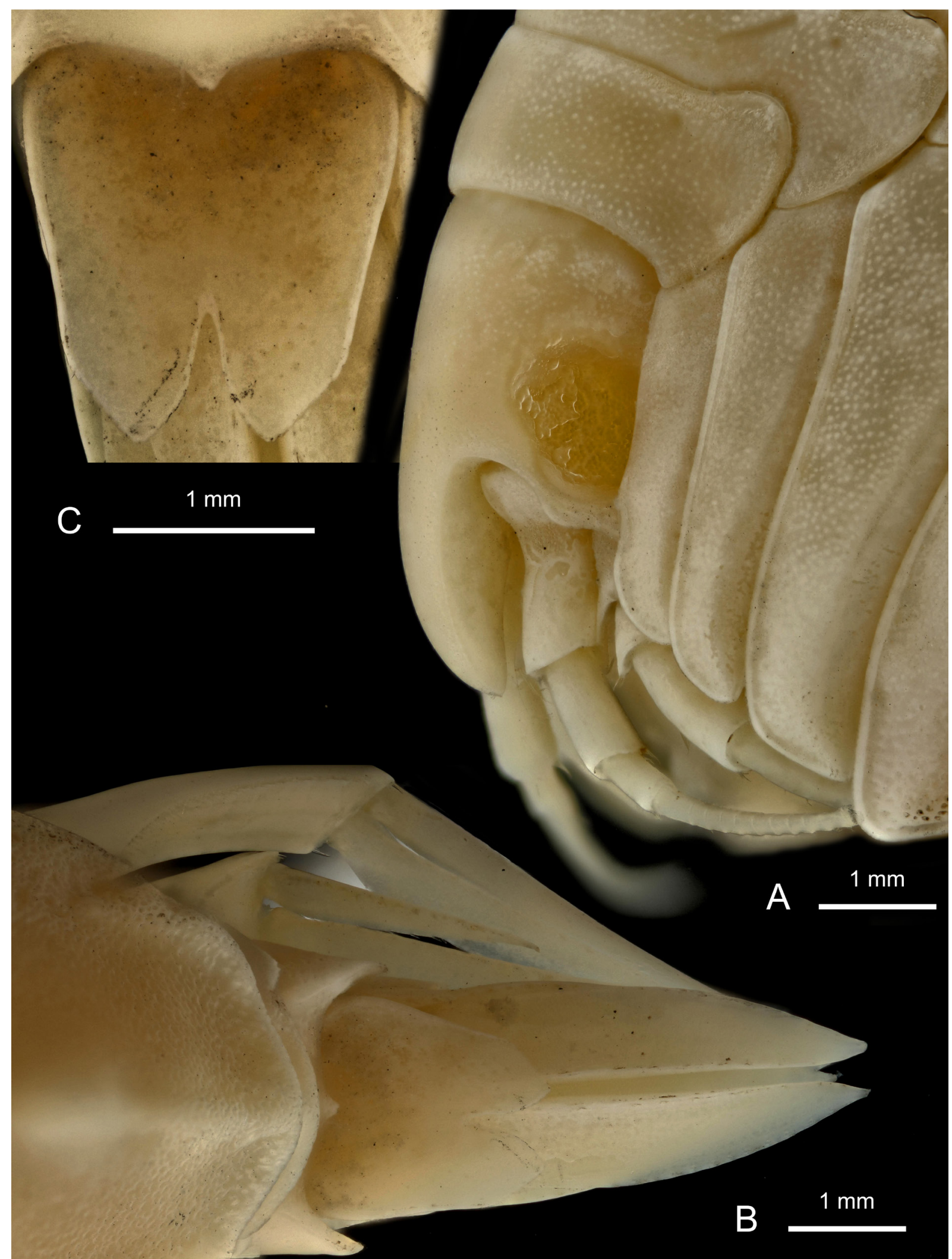

Fig. 155. Epimeria (Hoplepimeria) georgiana subgen. nov. (Schellenberg, 1931), Georgia, Swedish South Polar Expedition 1901-1903, stn 34, SMNH - type 673. A. Head in lateral view. B. Urosome in dorsal view. C. Telson. 


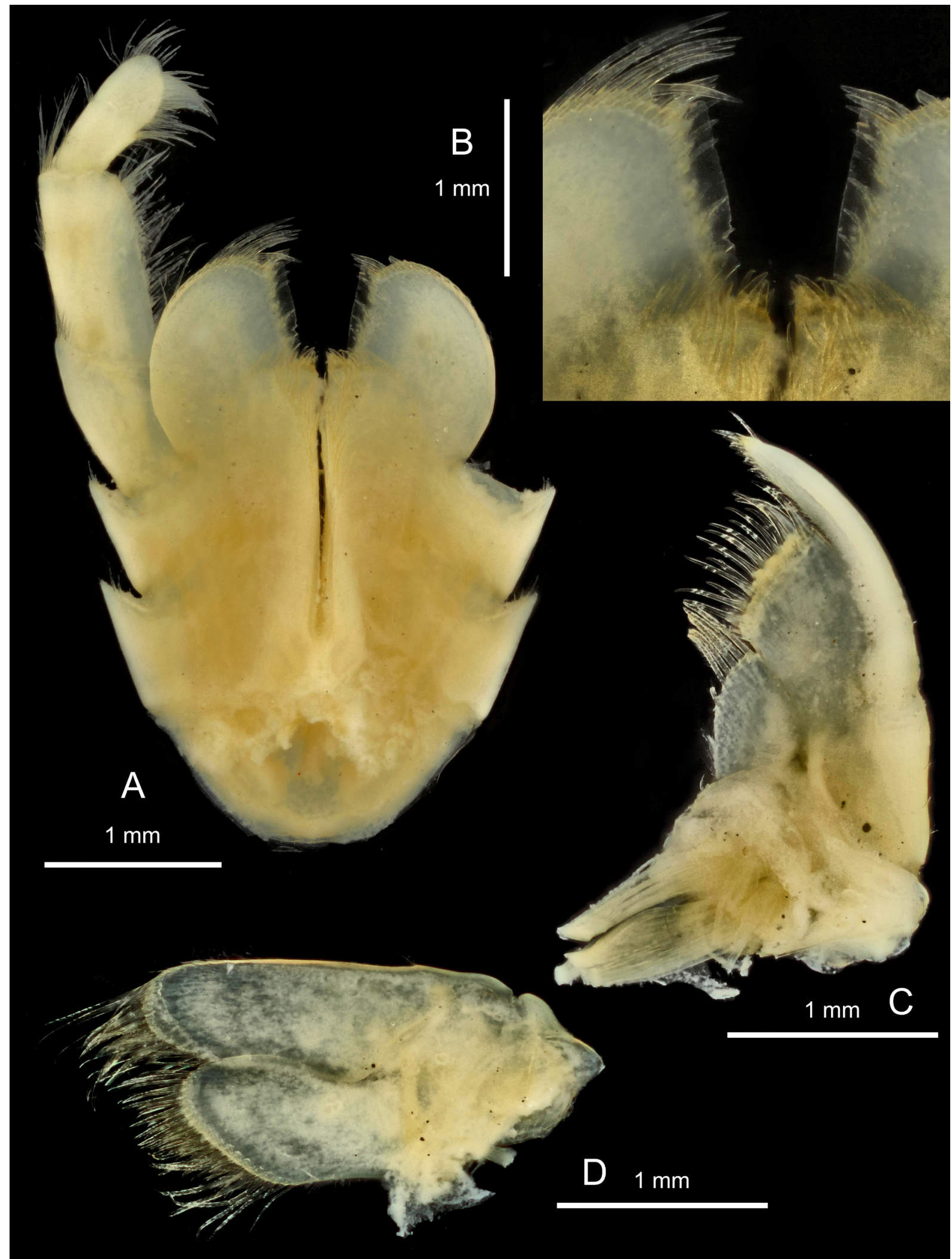

Fig. 156. Epimeria (Hoplepimeria) georgiana subgen. nov. (Schellenberg, 1931), + , lectotype, South Georgia, Swedish South Polar Expedition 1901-1903, stn 34, SMNH - type 673. A. Maxilliped. B. Plates of maxiliped (detail). C. Maxilla 1. D. Maxilla 2. 


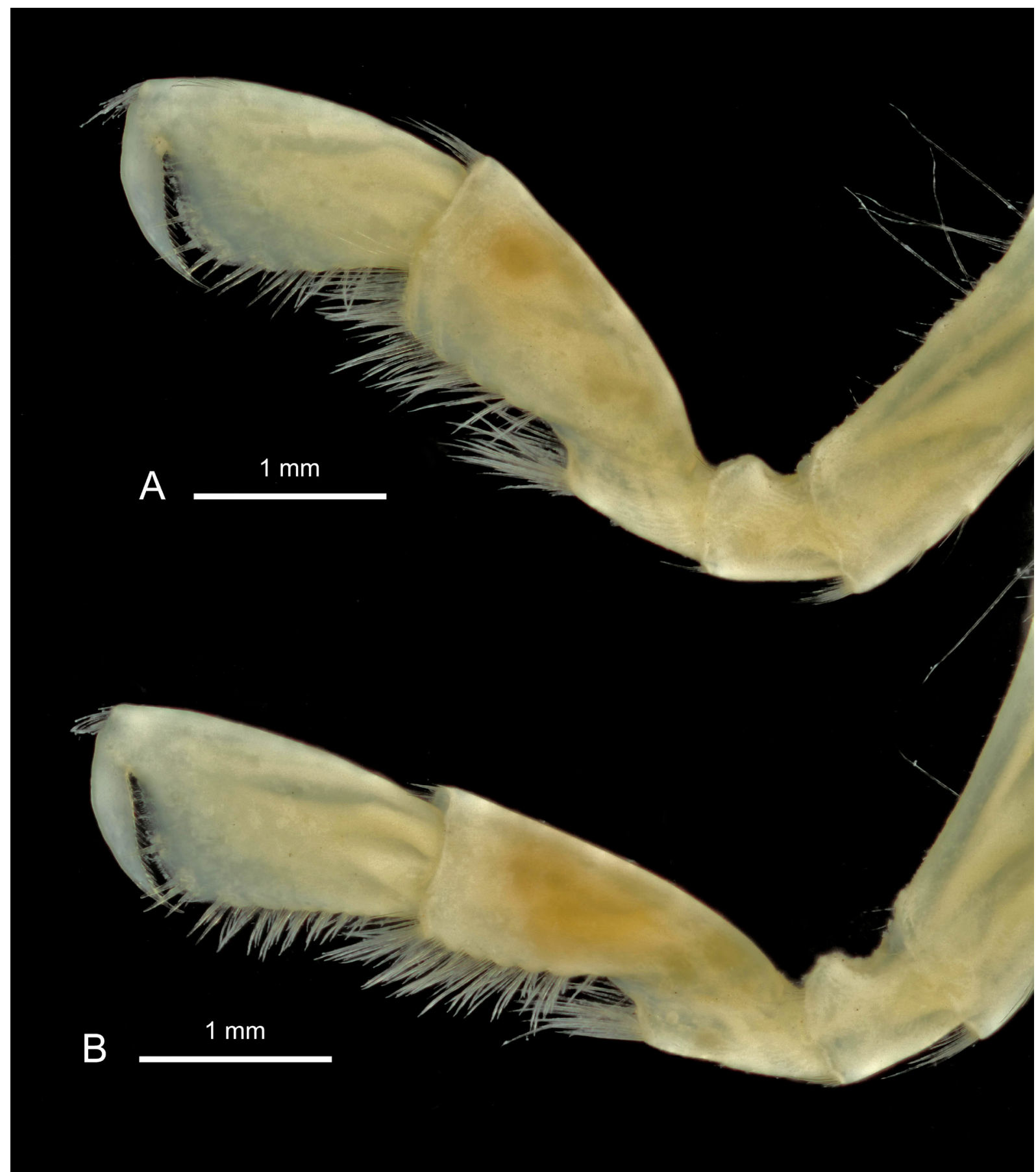

Fig. 157. Epimeria (Hoplepimeria) georgiana subgen. nov. (Schellenberg, 1931), , lectotype, South Georgia, Swedish South Polar Expedition 1901-1903, stn 34, SMNH - type 673. A. Gnathopod 1. B. Gnathopod 2. 


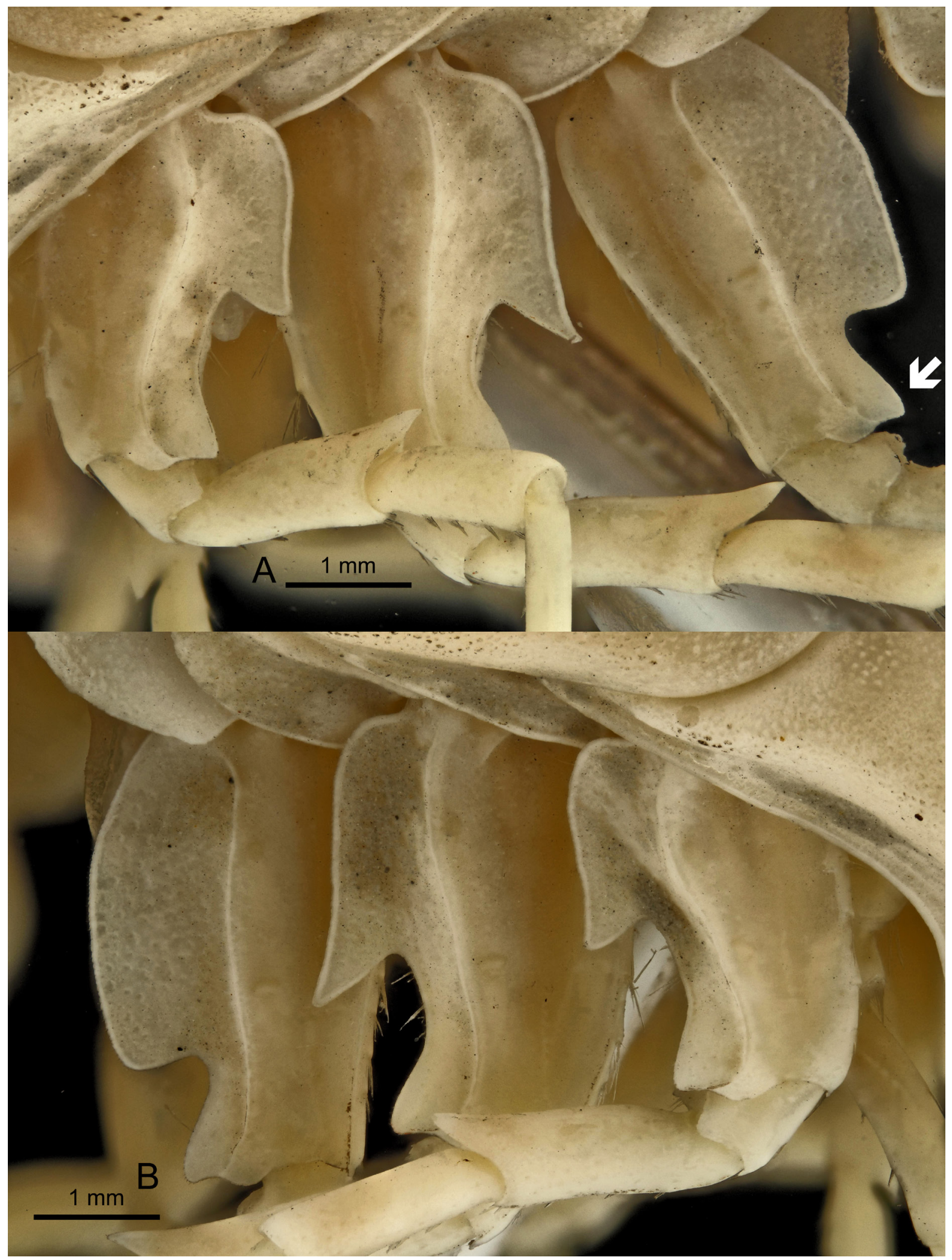

Fig. 158. Epimeria (Hoplepimeria) georgiana subgen. nov. (Schellenberg, 1931), + , lectotype, South Georgia, Swedish South Polar Expedition 1901-1903, stn 34, SMNH - type 673. A. Basis of left pereiopods 1-7 (a white arrow was added on the photograph to draw the attention on the shape of the posterodistal corner of pereiopod 7). B. Basis of right pereiopods 1-7. 


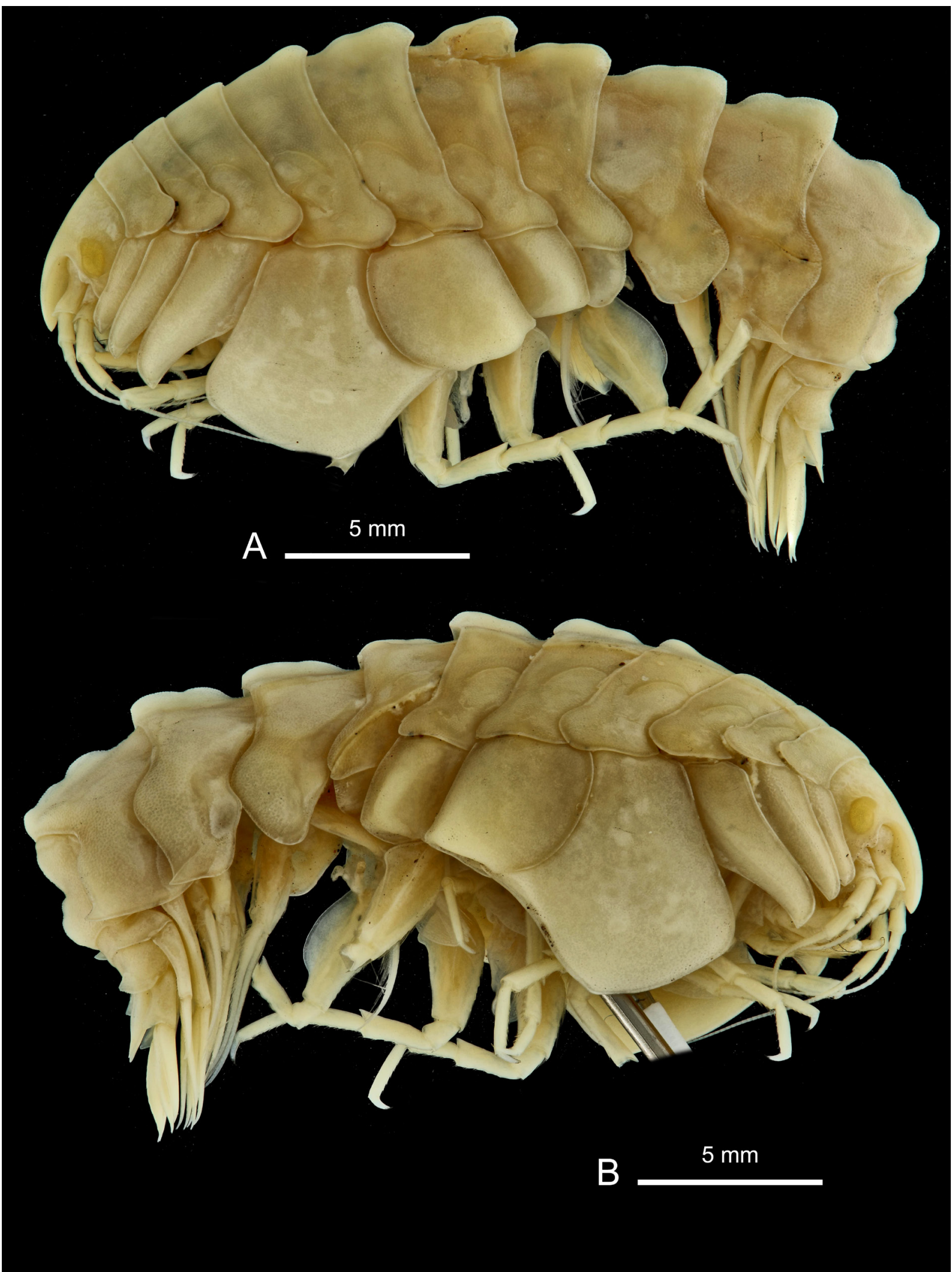

Fig. 159. Epimeria (Hoplepimeria) inermis subgen. nov. Walker, 1903, $q$, holotype, Ross Sea, Cape Adare, BMNH 1903.10.5.19. A. Left lateral habitus. B. Right lateral habitus. 


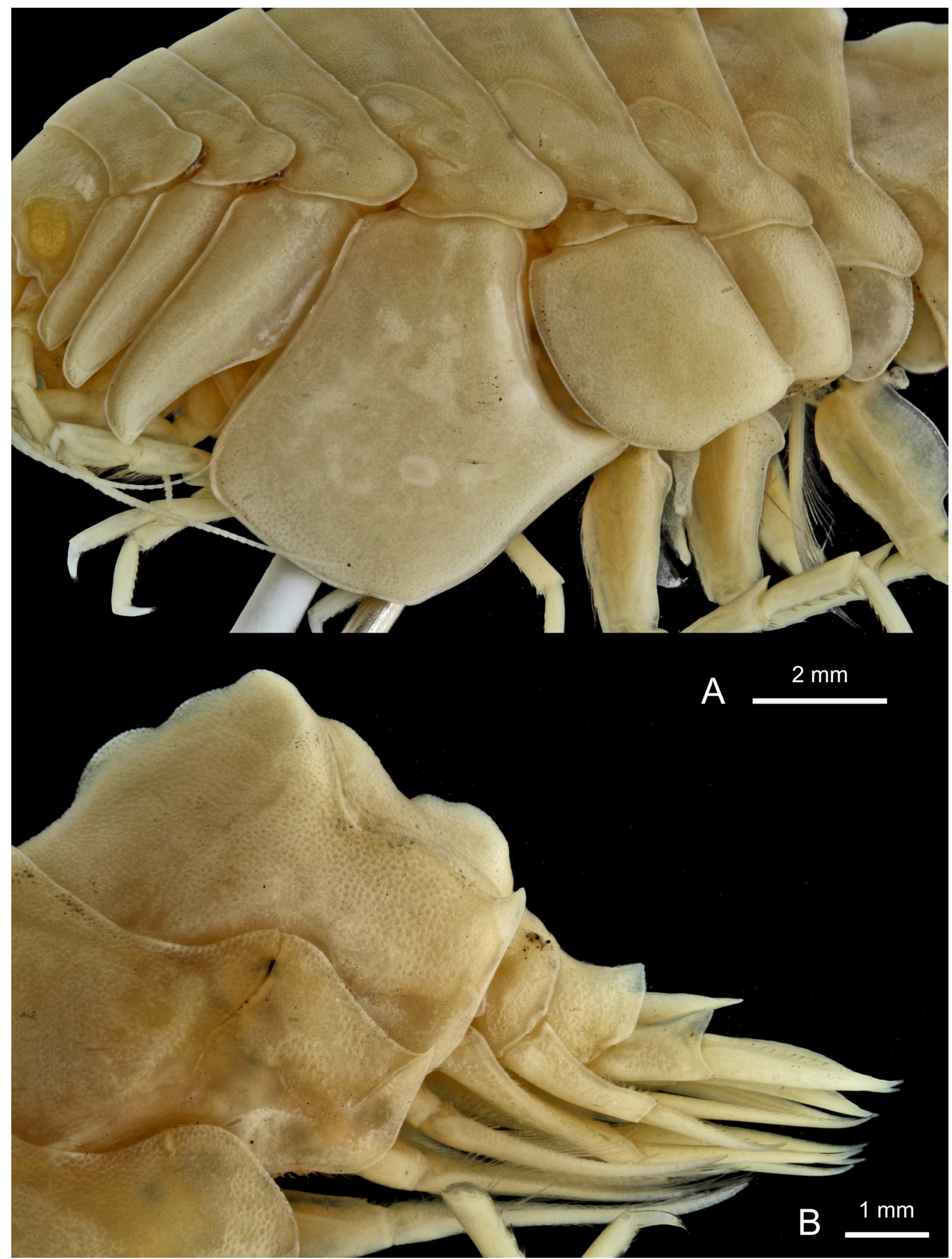

Fig. 160. Epimeria (Hoplepimeria) inermis subgen. nov. Walker, 1903, $q$, holotype, Ross Sea, Cape Adare, BMNH 1903.10.5.19. A. Coxae 1-7. B. Pleon in lateral view. 


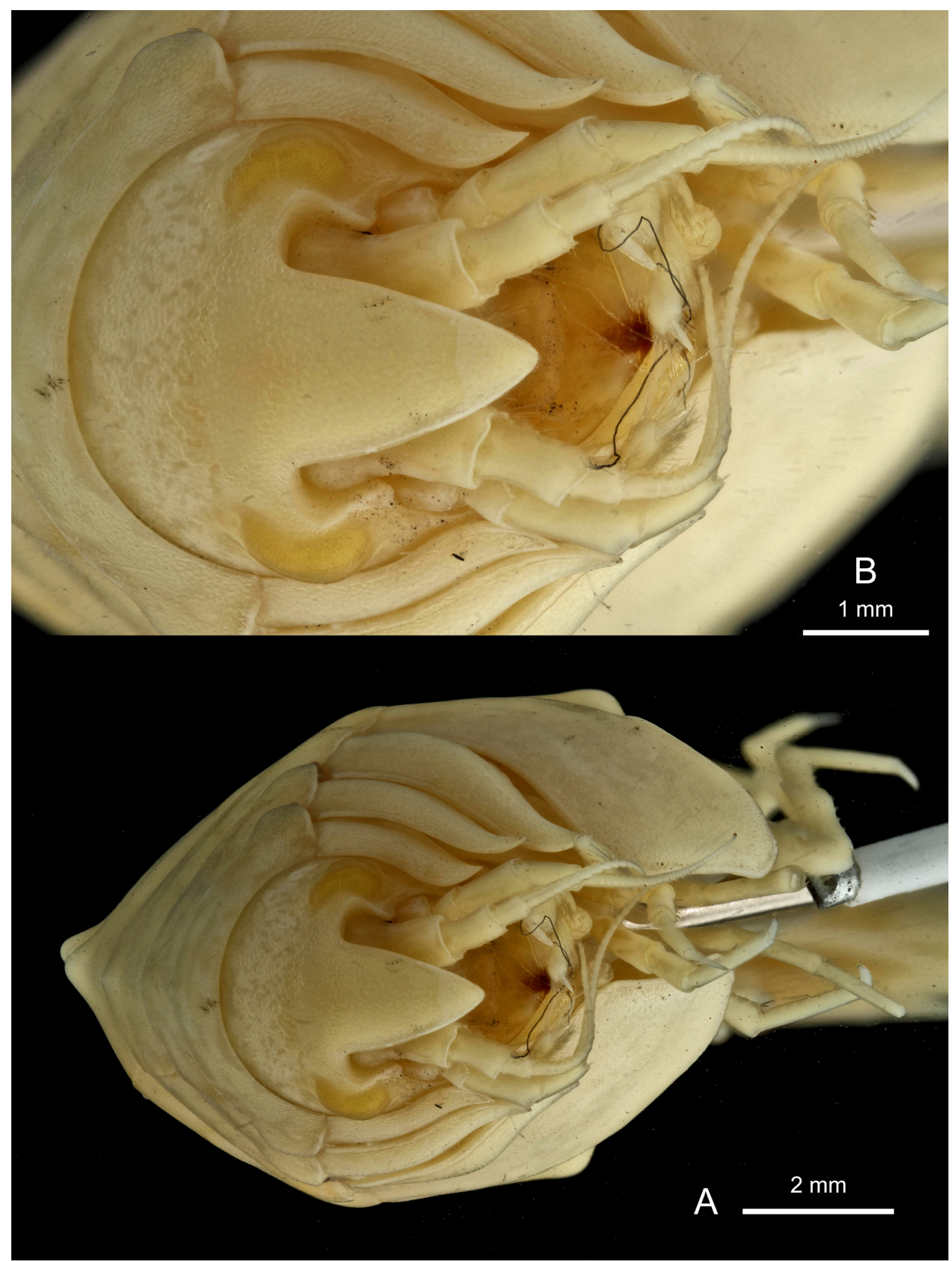

Fig. 161. Epimeria (Hoplepimeria) inermis subgen. nov. Walker, 1903, + , holotype, Ross Sea, Cape Adare, BMNH 1903.10.5.19. A. Facial habitus. B. Head in facial view. 

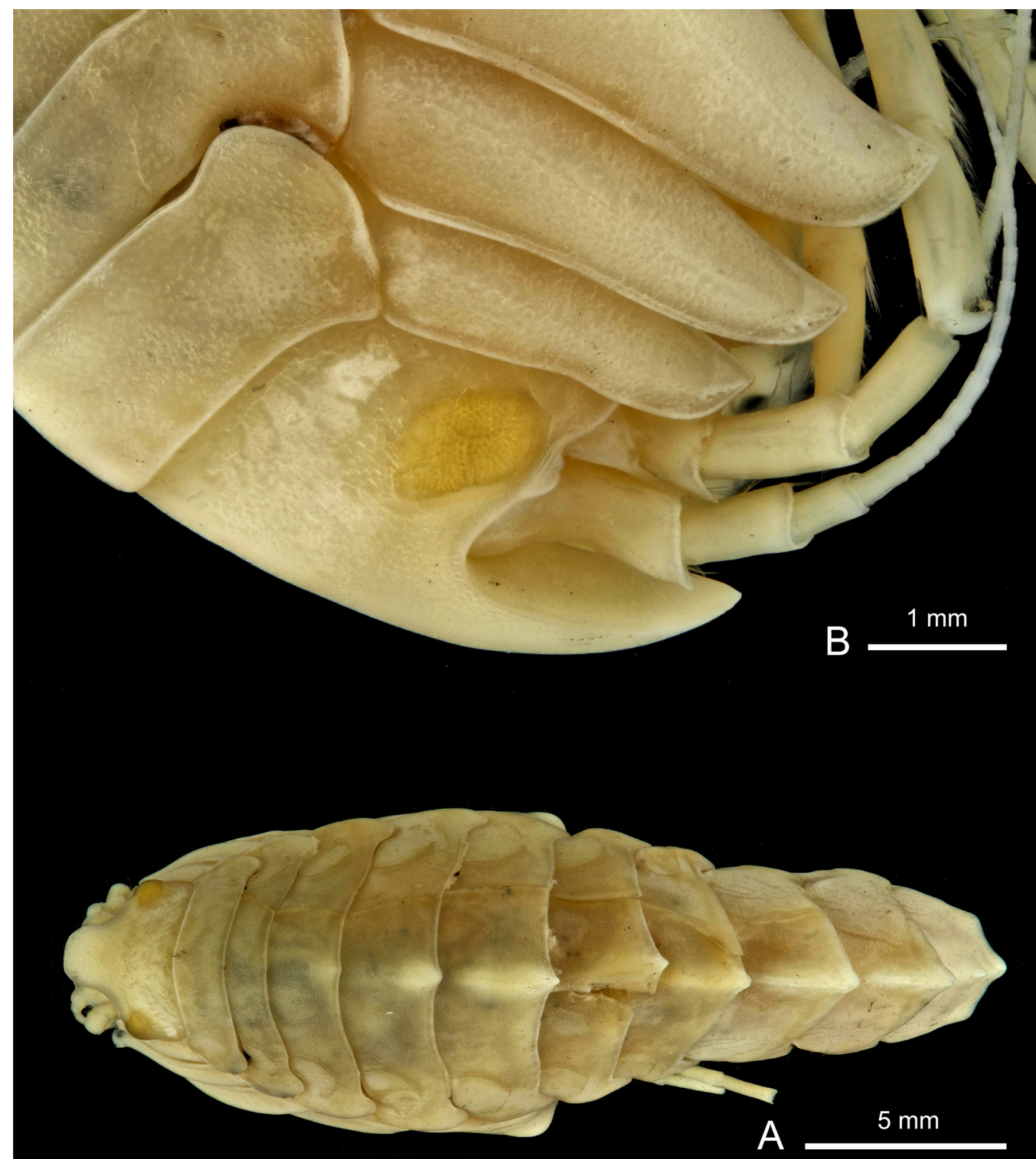

Fig. 162. Epimeria (Hoplepimeria) inermis subgen. nov. Walker, 1903, + , holotype, Ross Sea, Cape Adare, BMNH 1903.10.5.19. A. Head and coxae 1-3 in lateral view. B. Dorsal habitus. 

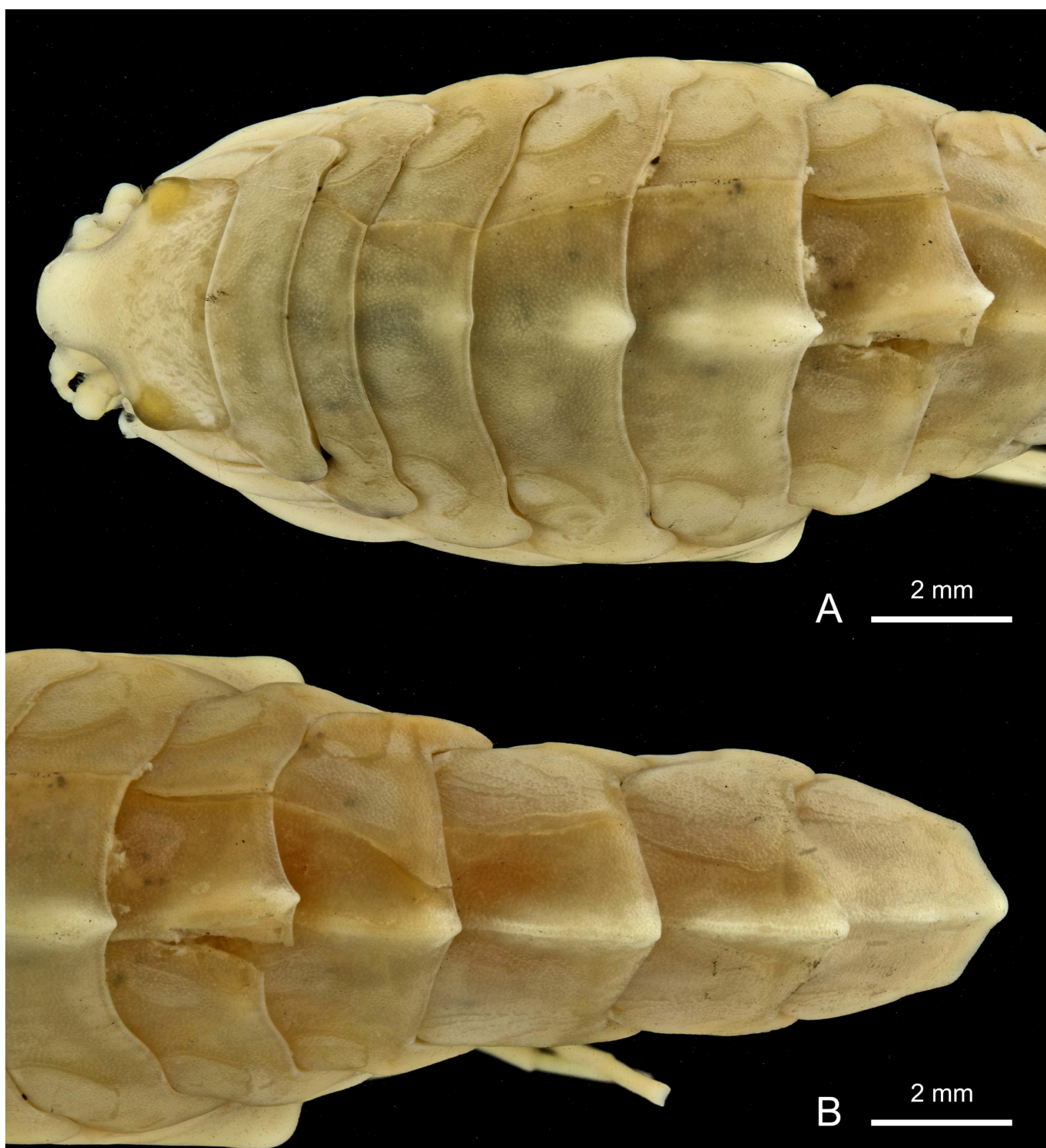

Fig. 163. Epimeria (Hoplepimeria) inermis subgen. nov. Walker, 1903, + , holotype, Ross Sea, Cape Adare, BMNH 1903.10.5.19. A. Anterior part of body in dorsal view. B. Posterior part of body in dorsal view. 


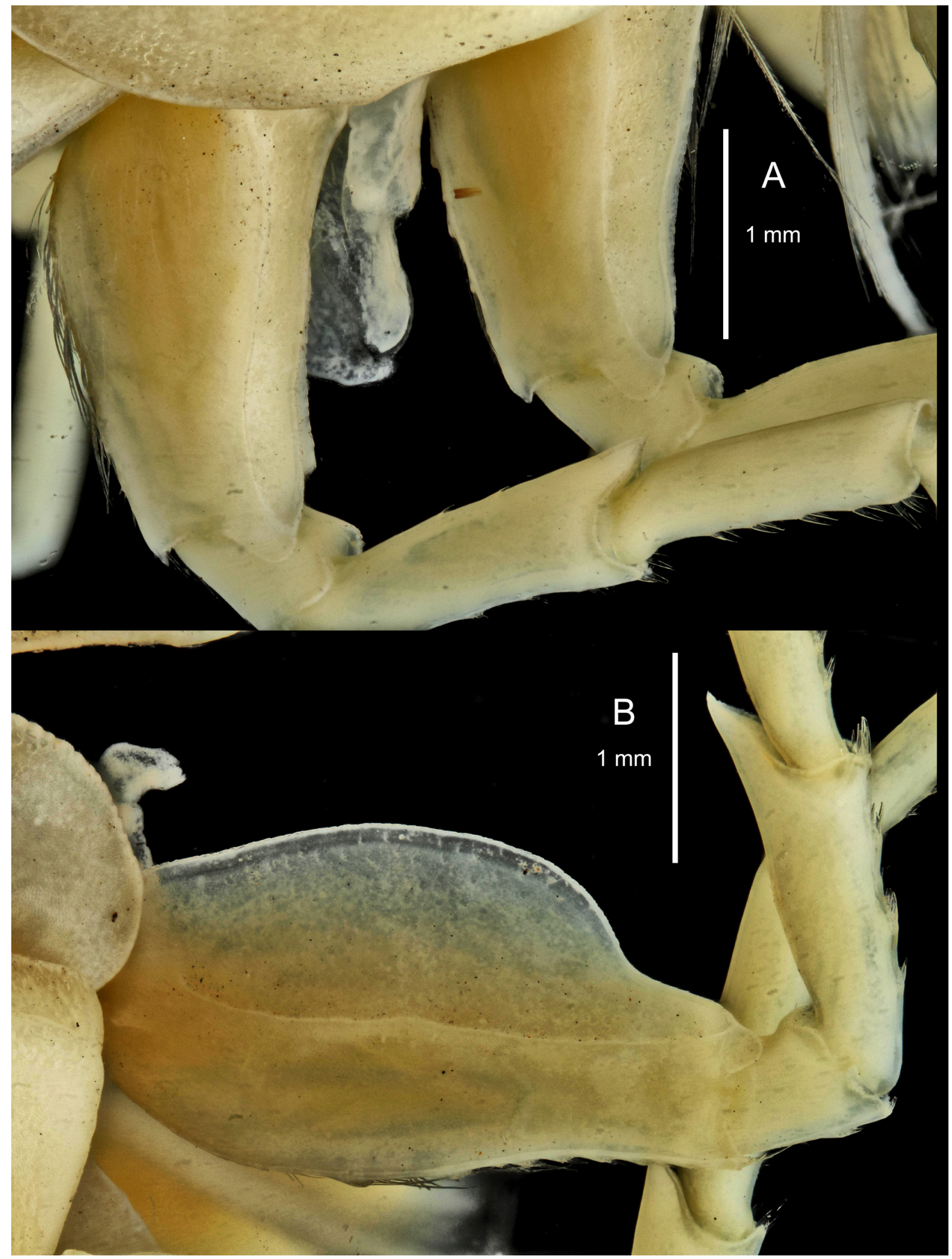

Fig. 164. Epimeria (Hoplepimeria) inermis subgen. nov. Walker, 1903, + , holotype, Ross Sea, Cape Adare, BMNH 1903.10.5.19. A. Basis of pereiopods 5-6. B. Basis of pereiopod 7. 


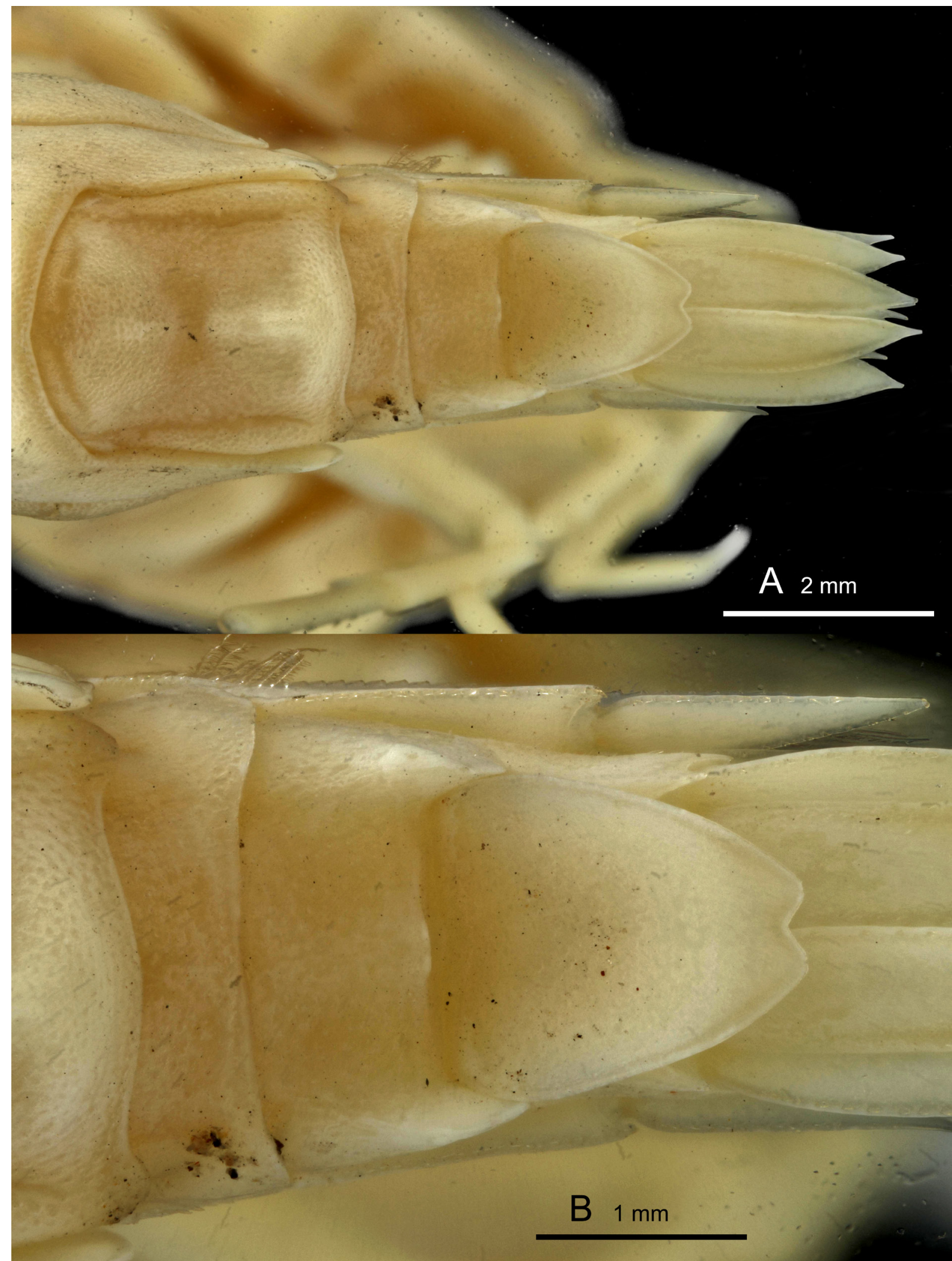

Fig. 165. Epimeria (Hoplepimeria) inermis subgen. nov. Walker, 1903, $q$, holotype, Ross Sea, Cape Adare, BMNH 1903.10.5.19. A. Urosome in dorsal view. B. Urosomites 2-3 and telson in dorsal view. 


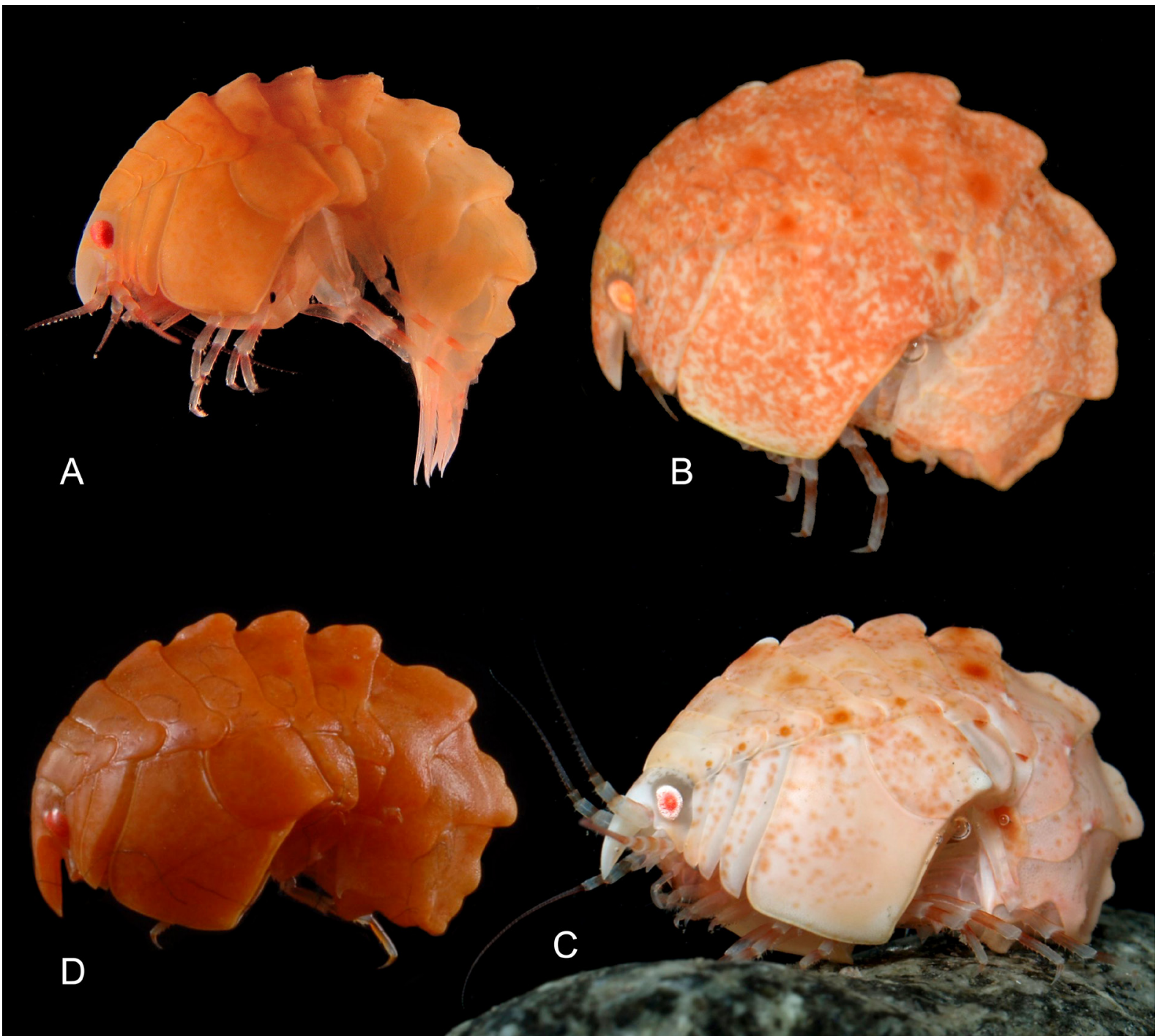

Fig. 166. Epimeria (Hoplepimeria) inermis subgen. nov. Walker, 1903, colour in life.A. $\$$, Elephant Island, ANT-XXIII/8, stn 654-7, RBINS, INV. 122514 (photograph: C. d'Udekem d'Acoz). B. + , Bransfield Strait, ANT-XXIX/3, stn 224-3, INV. 122945A (photograph: C. d'Udekem d'Acoz). C. Presumably o, eastern Weddell Sea, ANT-XXIV/2, stn 48-1, RBINS, INV. 132954 or 122897 or 122905 or 132459 (photograph: T. Riehl, University of Hamburg). D. Sex unrecorded, Adélie Coast, CEAMARC V3 1034, (specimen not examined). photograph: Frédéric Busson (MNHN). 


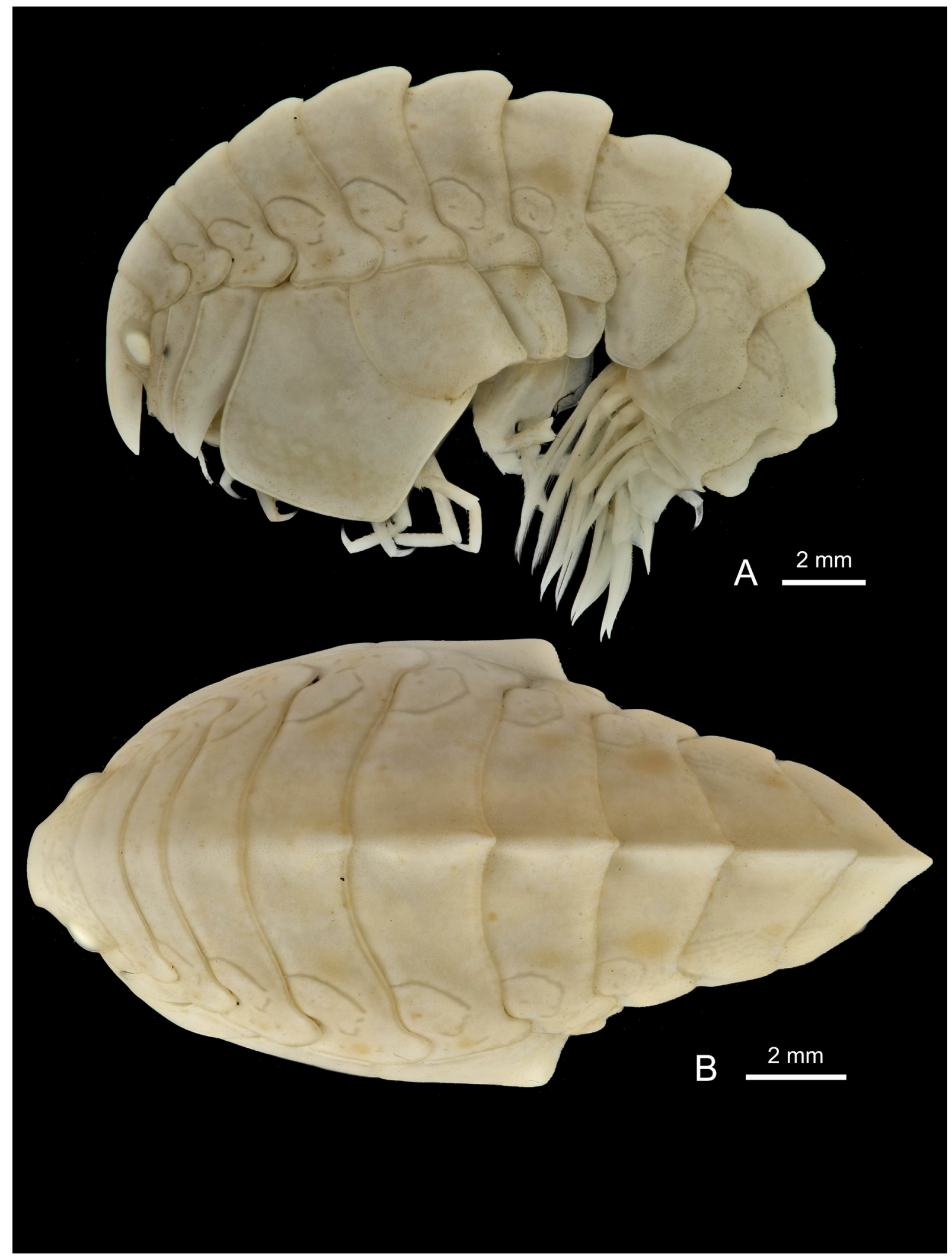

Fig. 167. Epimeria (Hoplepimeria) inermis subgen. nov. Walker, 1903, $q$, Bransfield Strait, ANTXXIX/3, stn 199-4, RBINS, INV. 132953. A. Lateral habitus. B. Dorsal habitus. 


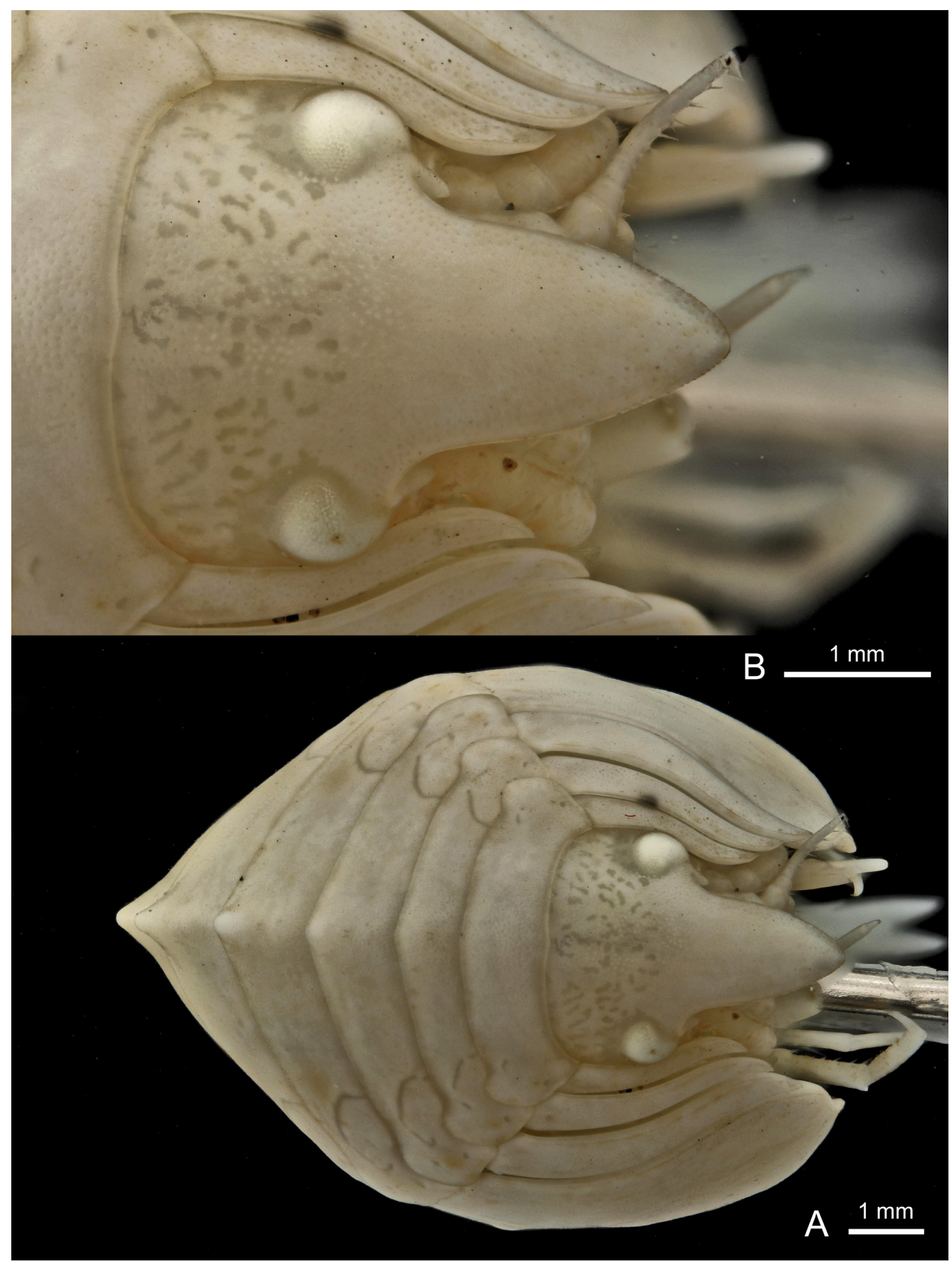

Fig. 168. Epimeria (Hoplepimeria) inermis subgen. nov. Walker, 1903, $q$, Bransfield Strait, ANTXXIX/3, stn 199-4, RBINS, INV. 132953. A. Facial habitus. B. Head in facial view. 


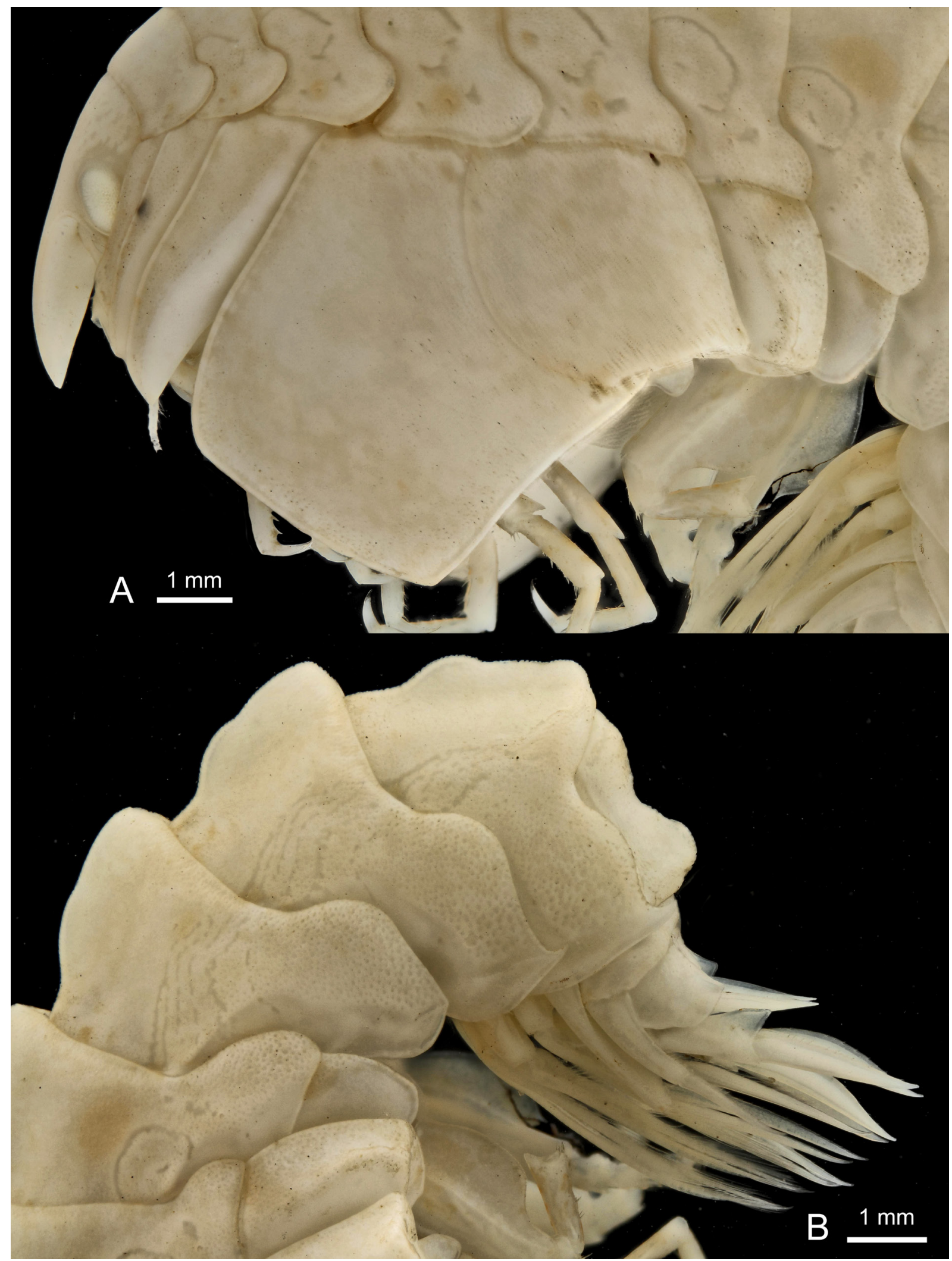

Fig. 169. Epimeria (Hoplepimeria) inermis subgen. nov. Walker, 1903, $q$, Bransfield Strait, ANTXXIX/3, stn 199-4, RBINS, INV. 132953. A. Anterior half of body. B. Posterior half of body. 


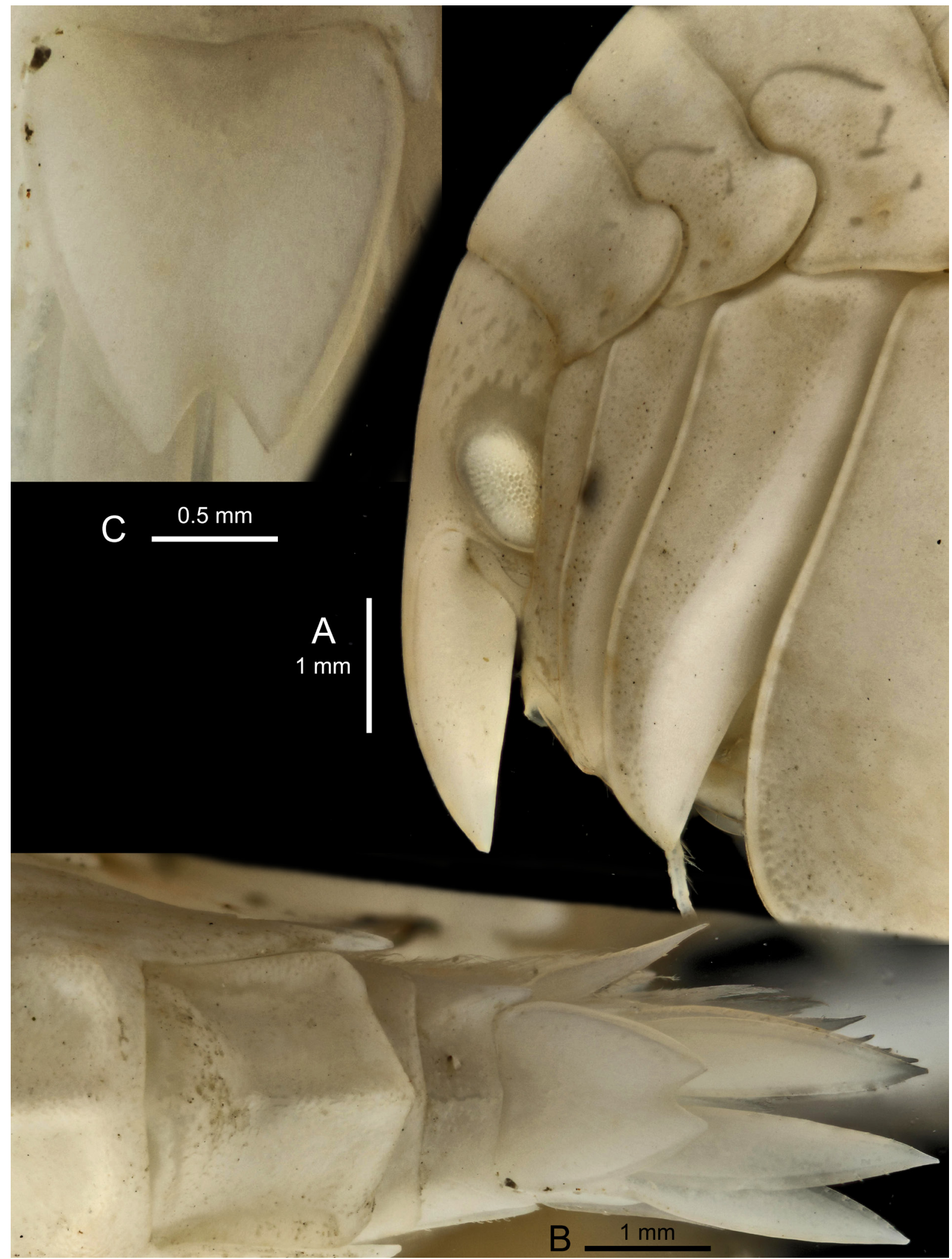

Fig. 170. Epimeria (Hoplepimeria) inermis subgen. nov. Walker, 1903, $q$, Bransfield Strait, ANTXXIX/3, stn 199-4, RBINS, INV. 132953. A. Head in lateral view. B. Urosome in dorsal view. C. Telson. 


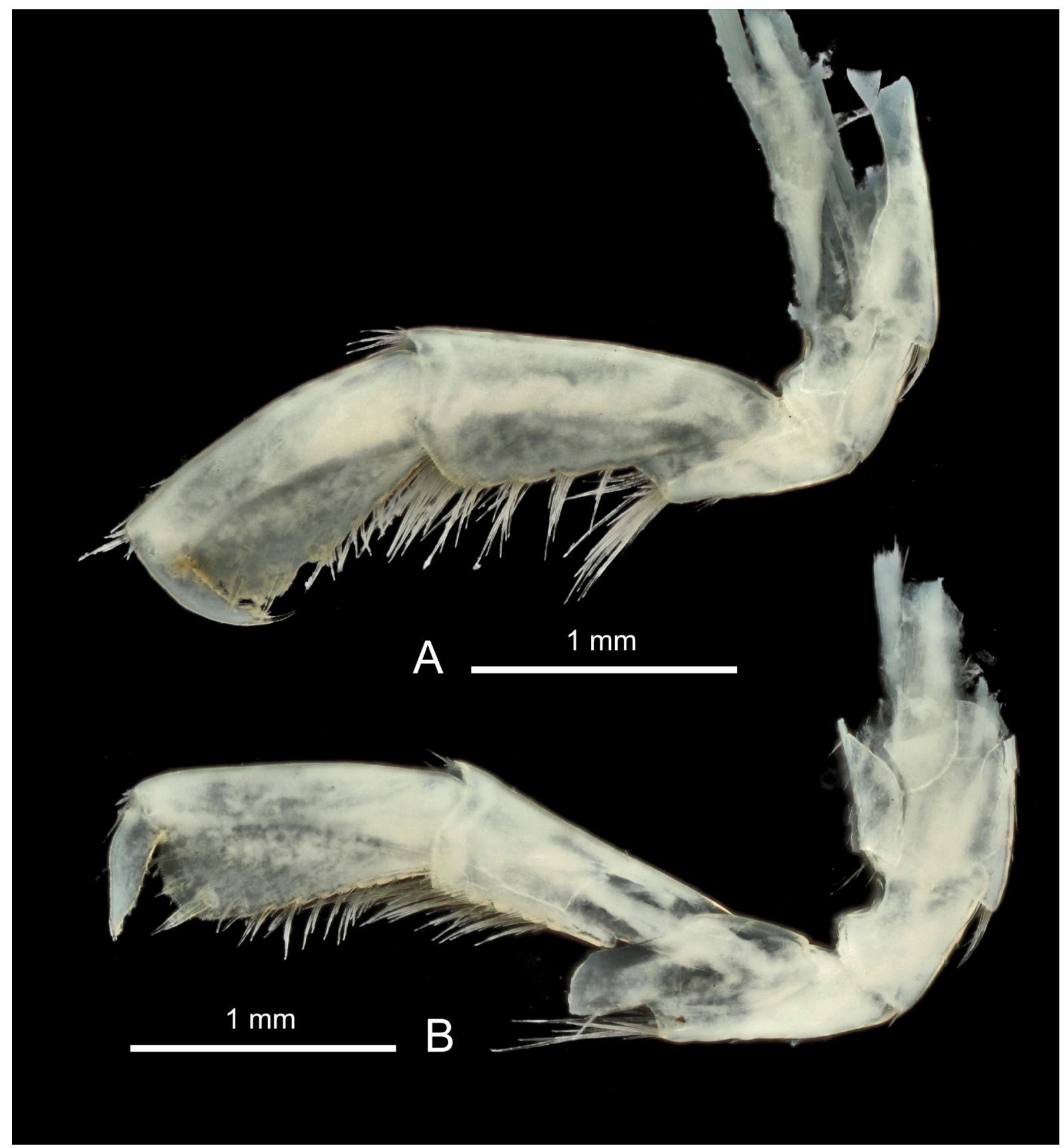

Fig. 171. Epimeria (Hoplepimeria) inermis subgen. nov. Walker, 1903, $q$, Bransfield Strait, ANTXXIX/3, stn 199-4, RBINS, INV. 132953. A. Gnathopod 1. B. Gnathopod 2. 


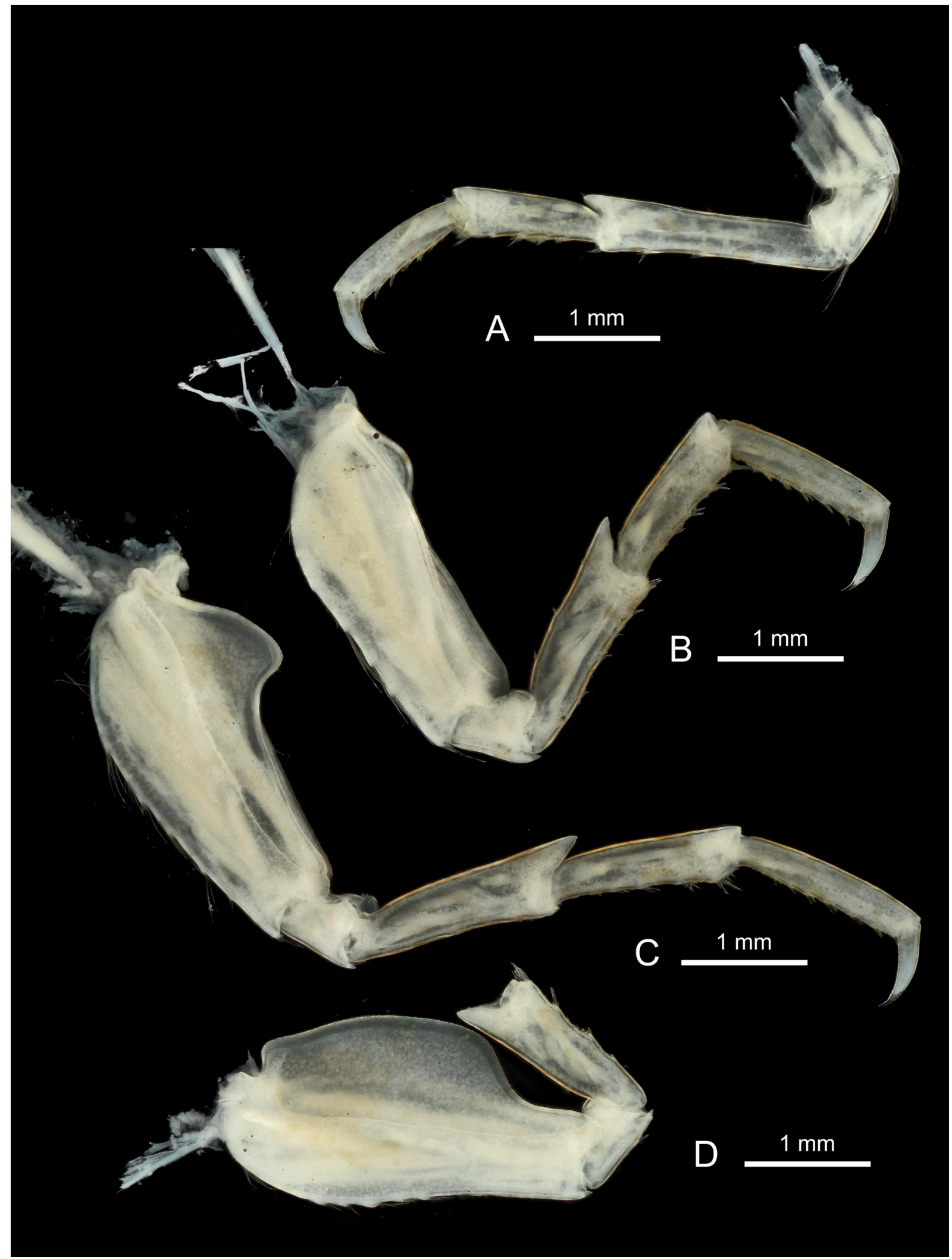

Fig. 172. Epimeria (Hoplepimeria) inermis subgen. nov. Walker, 1903, $q$, Bransfield Strait, ANTXXIX/3, stn 199-4, RBINS, INV. 132953. A. Pereiopod 4. B. Pereiopod 5. C. Pereiopod 6. D. Pereiopod 7. 


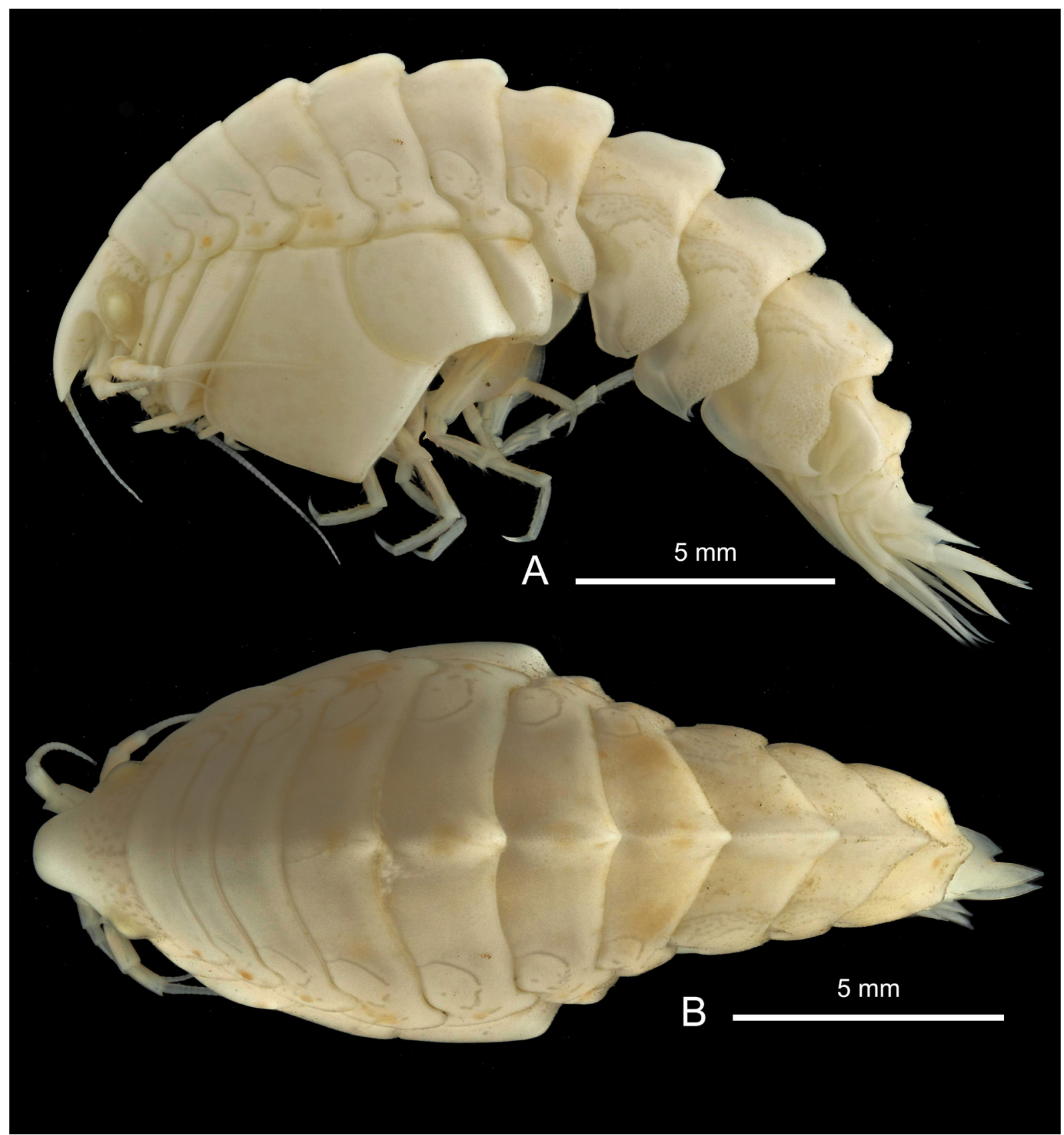

Fig. 173. Epimeria (Hoplepimeria) inermis subgen. nov. Walker, 1903, sex undetermined, eastern Weddell Sea, ANT-XXIV/2, stn 48-1, RBINS, INV. 132954. A. Lateral habitus. B. Dorsal habitus. 


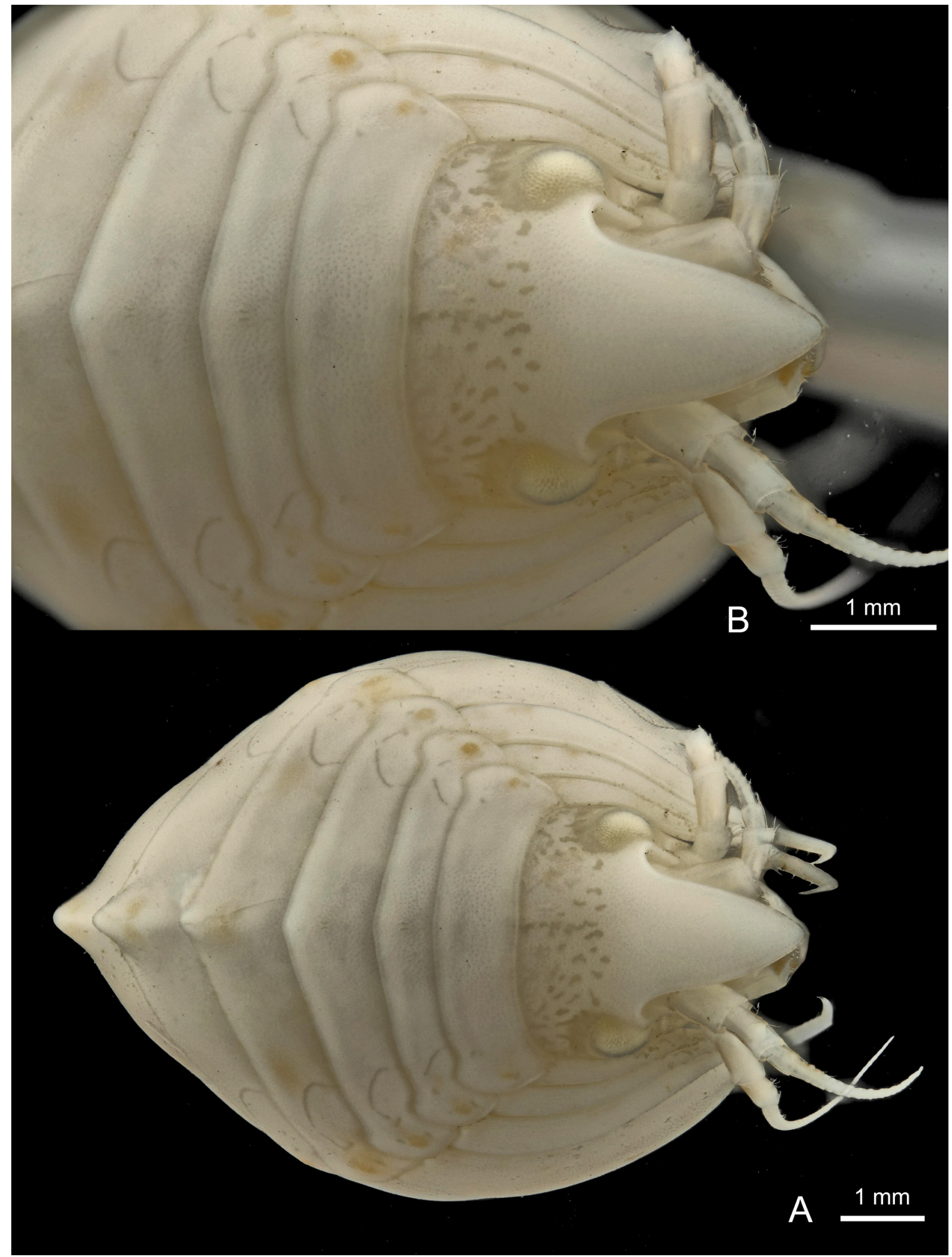

Fig. 174. Epimeria (Hoplepimeria) inermis subgen. nov. Walker, 1903, sex undetermined, eastern Weddell Sea, ANT-XXIV/2, stn 48-1, RBINS, INV. 132954. A. Facial habitus. B. Head in facial view. 


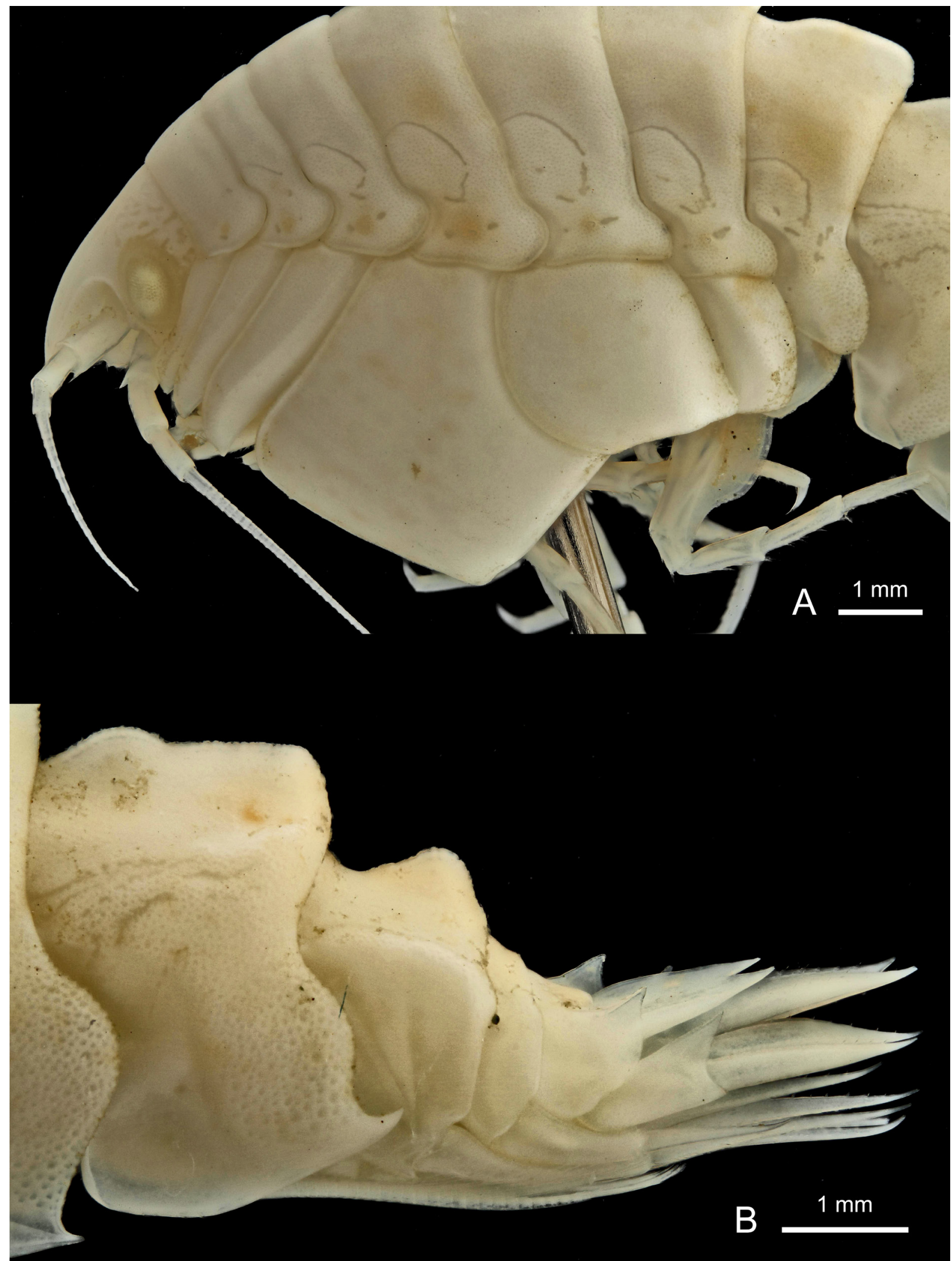

Fig. 175. Epimeria (Hoplepimeria) inermis subgen. nov. Walker, 1903, sex undetermined, eastern Weddell Sea, ANT-XXIV/2, stn 48-1, RBINS, INV. 132954. A. Anterior half. B. Pleonite 3 and urosome. 


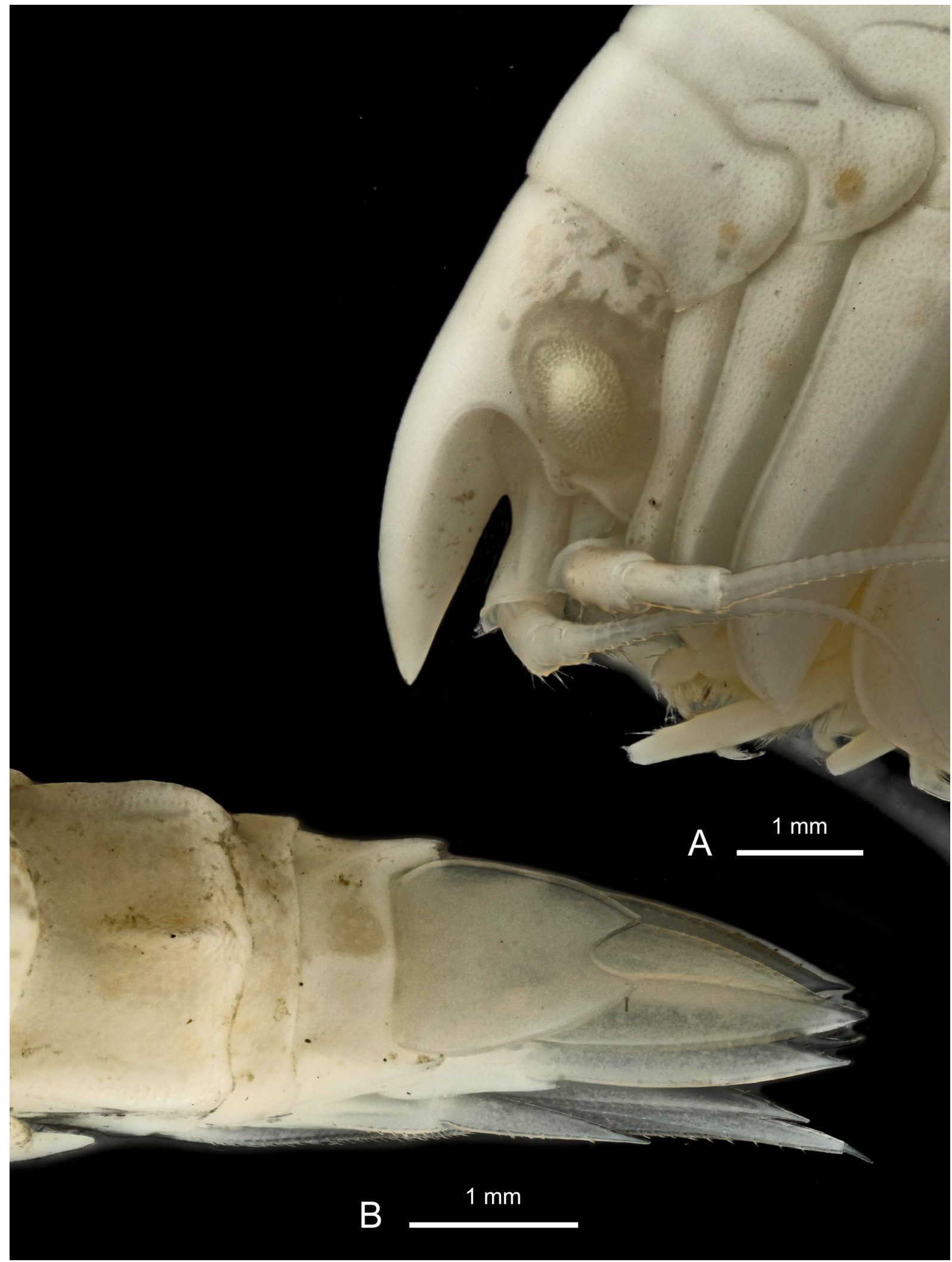

Fig. 176. Epimeria (Hoplepimeria) inermis subgen. nov. Walker, 1903, sex undetermined, eastern Weddell Sea, ANT-XXIV/2, stn 48-1, RBINS, INV. 132954. A. Head in lateral view. B. Urosome in dorsal view. 


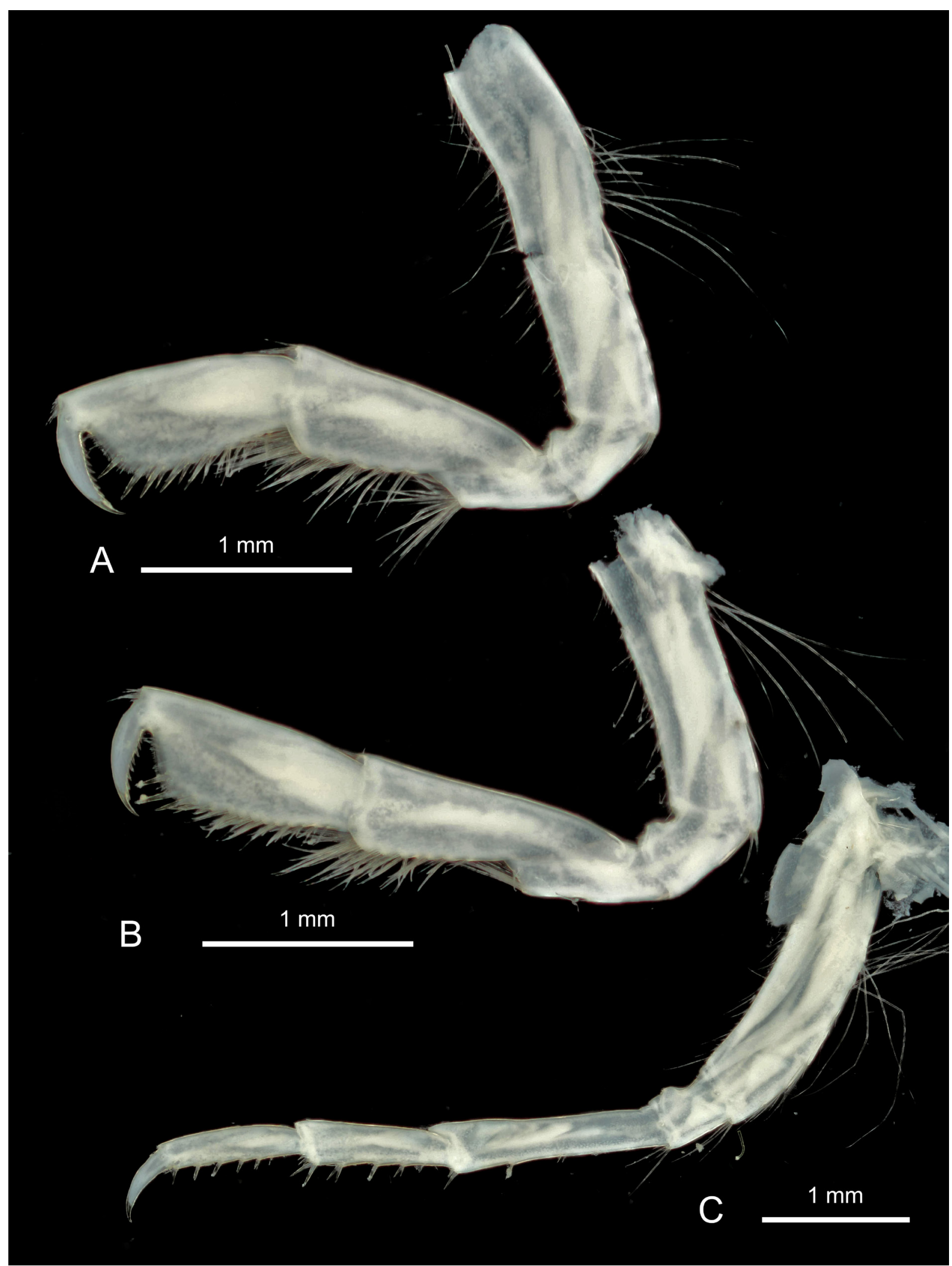

Fig. 177. Epimeria (Hoplepimeria) inermis subgen. nov. Walker, 1903, sex undetermined, eastern Weddell Sea, ANT-XXIV/2, stn 48-1, RBINS, INV. 132954. A. Gnathopod 1. B. Gnathopod 2. C. Pereiopod 4. 


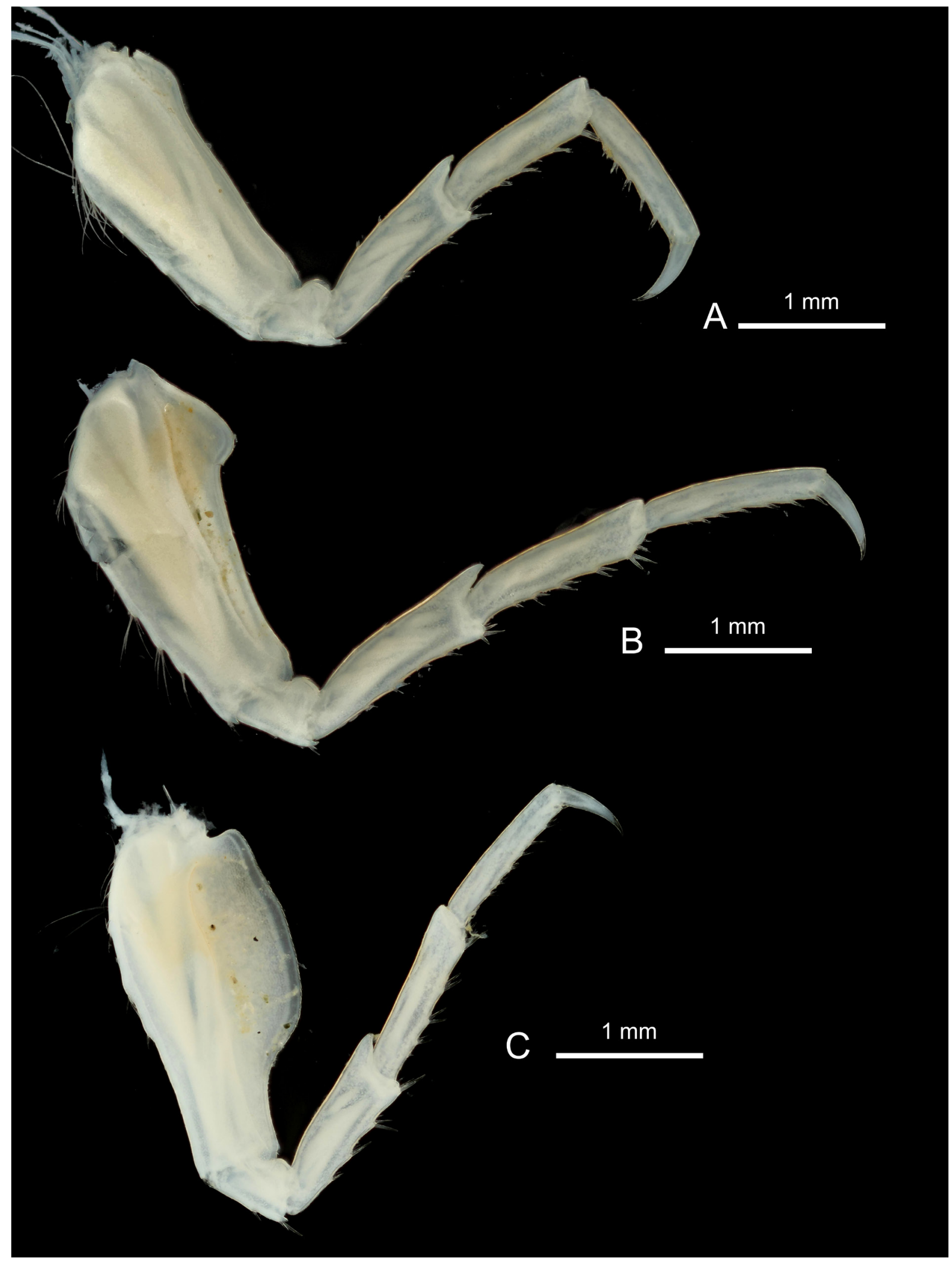

Fig. 178. Epimeria (Hoplepimeria) inermis subgen. nov. Walker, 1903, sex undetermined, eastern Weddell Sea, ANT-XXIV/2, stn 48-1, RBINS, INV. 132954. A. Pereiopod 5. B. Pereiopod 6. C. Pereiopod 7. 


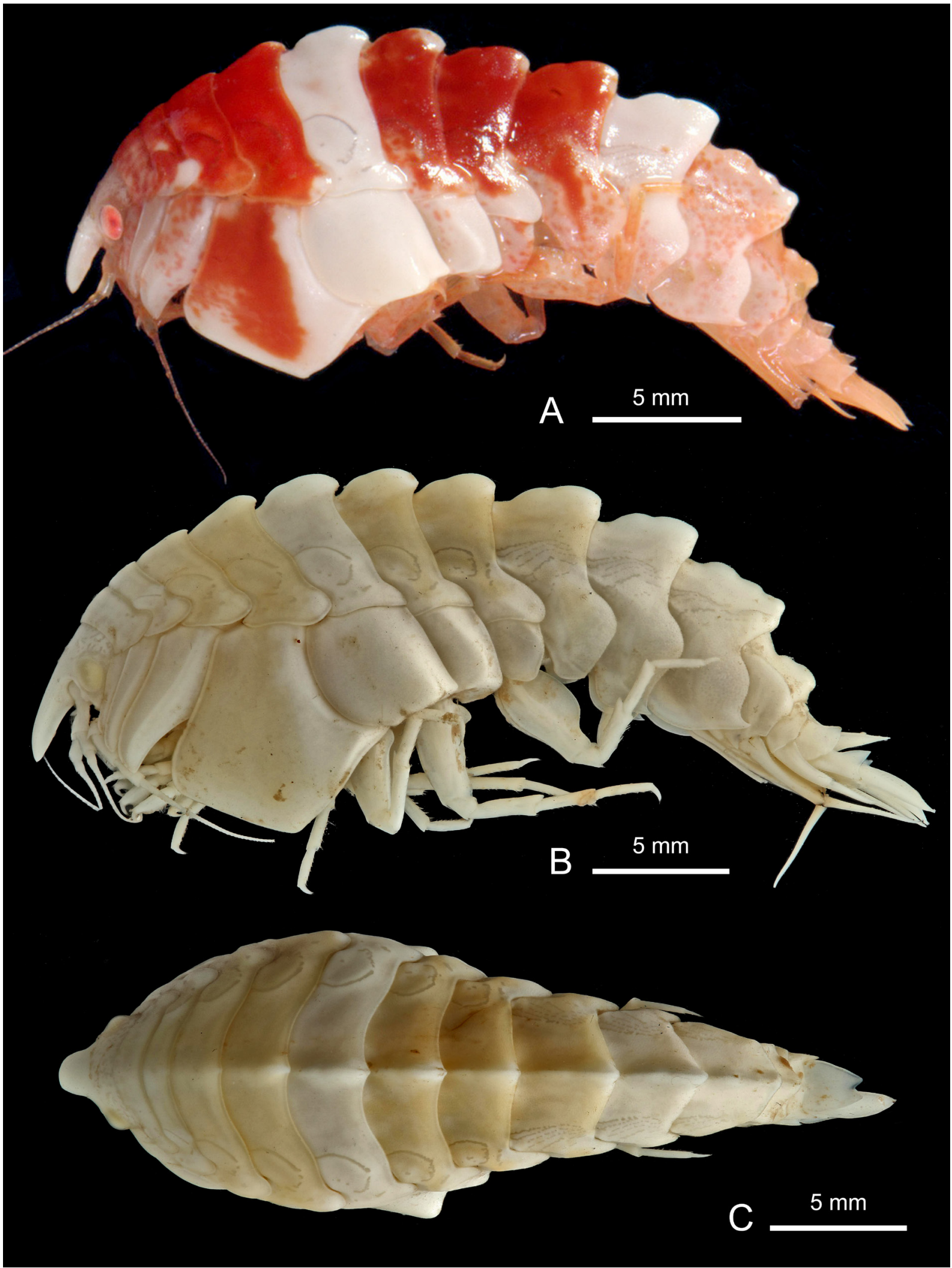

Fig. 179. Epimeria (Hoplepimeria) inermis subgen. nov. Walker, 1903, q, Adélie Coast, REVO 509, MNHN-IU-2009-2531. A. Lateral habitus, colour in life. B. Lateral habitus. C. Dorsal habitus. Colour photograph by Cyril Gallut ((Université Pierre et Marie Curie). 


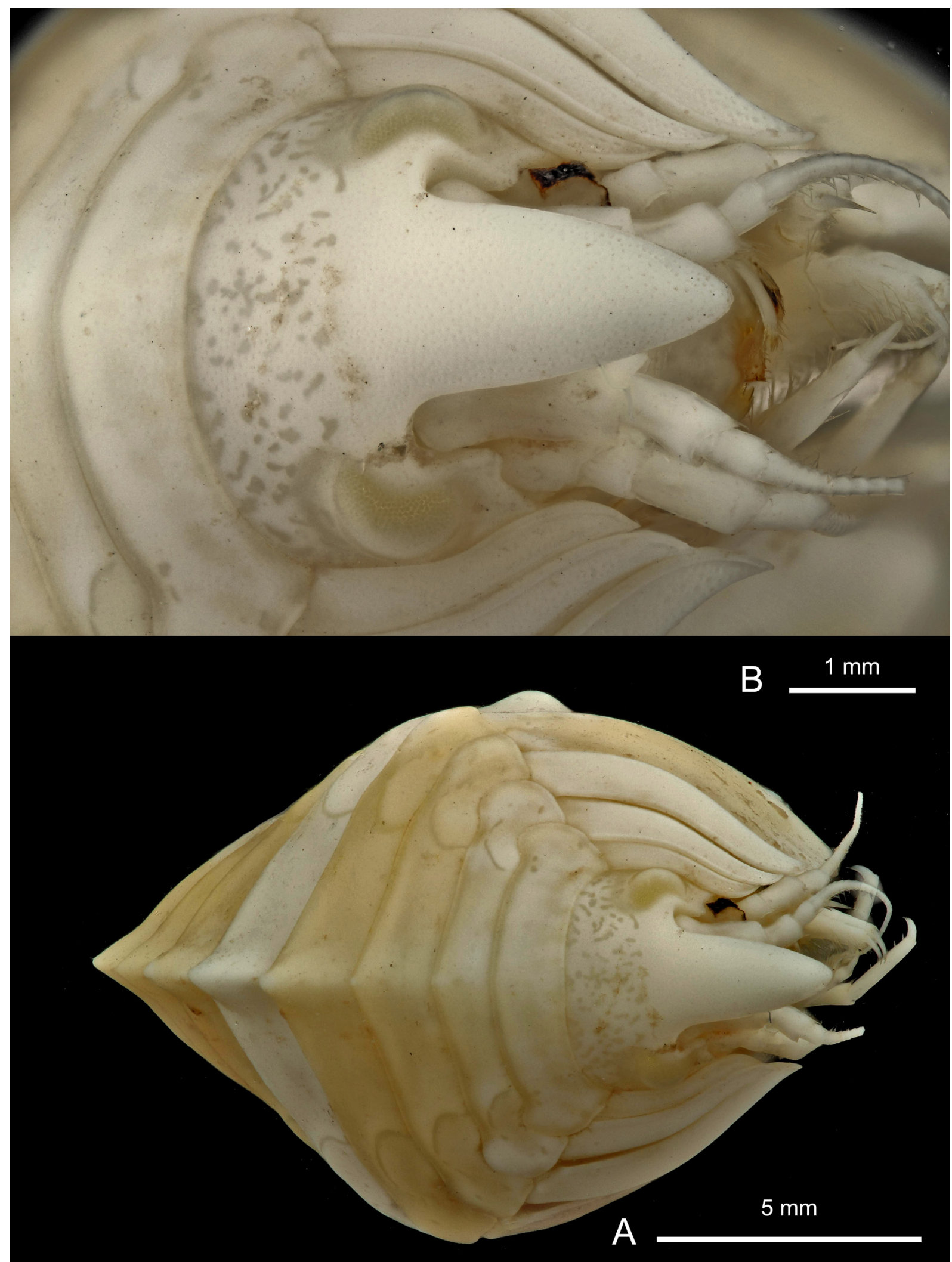

Fig. 180. Epimeria (Hoplepimeria) inermis subgen. nov. Walker, 1903, + , Adélie Coast, REVO 509, MNHN-IU-2009-2531. A. Facial habitus. B. Head in facial view. 


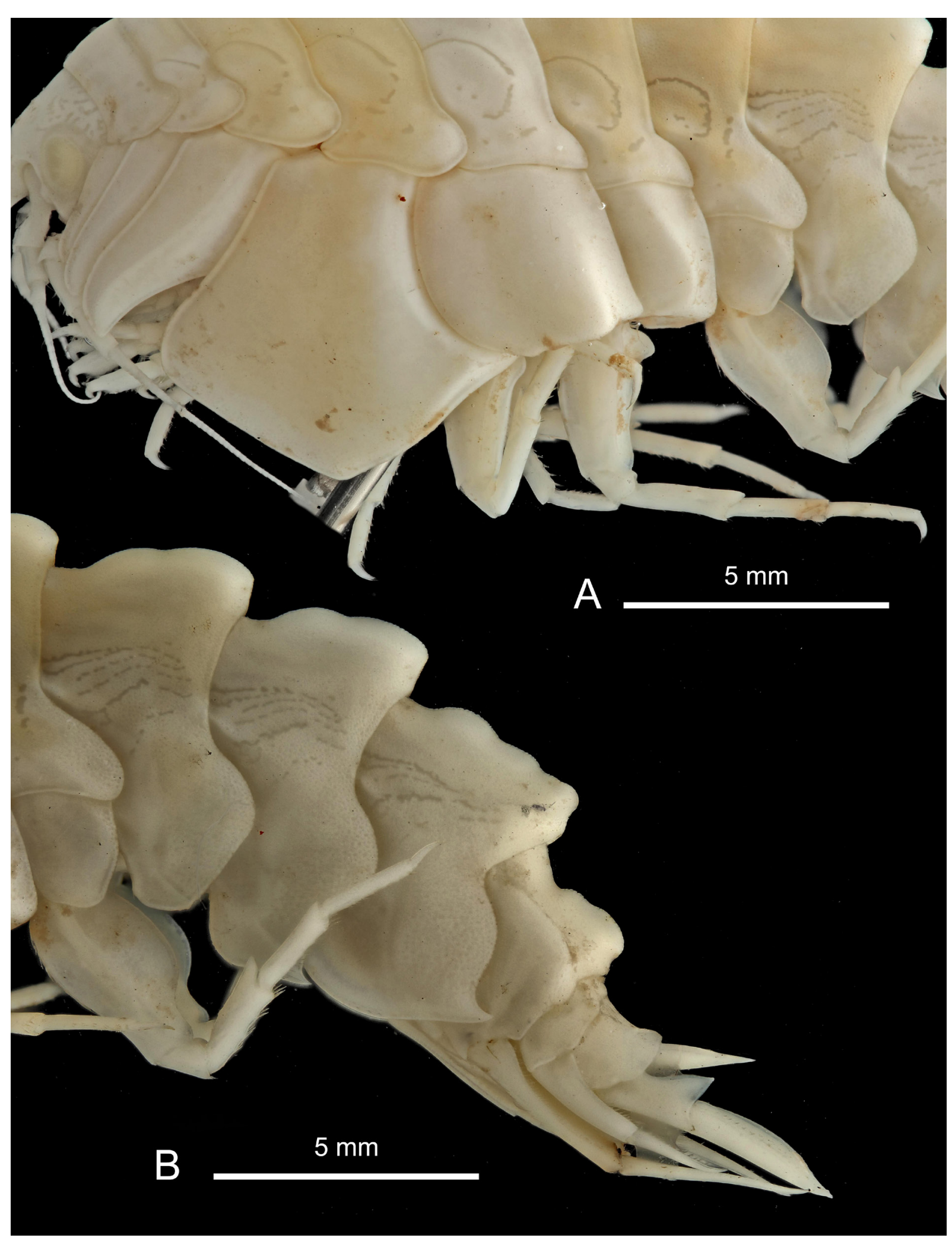

Fig. 181. Epimeria (Hoplepimeria) inermis subgen. nov. Walker, 1903, + , Adélie Coast, REVO 509, MNHN-IU-2009-2531. A. Coxae 1-7. B. Pleon. 


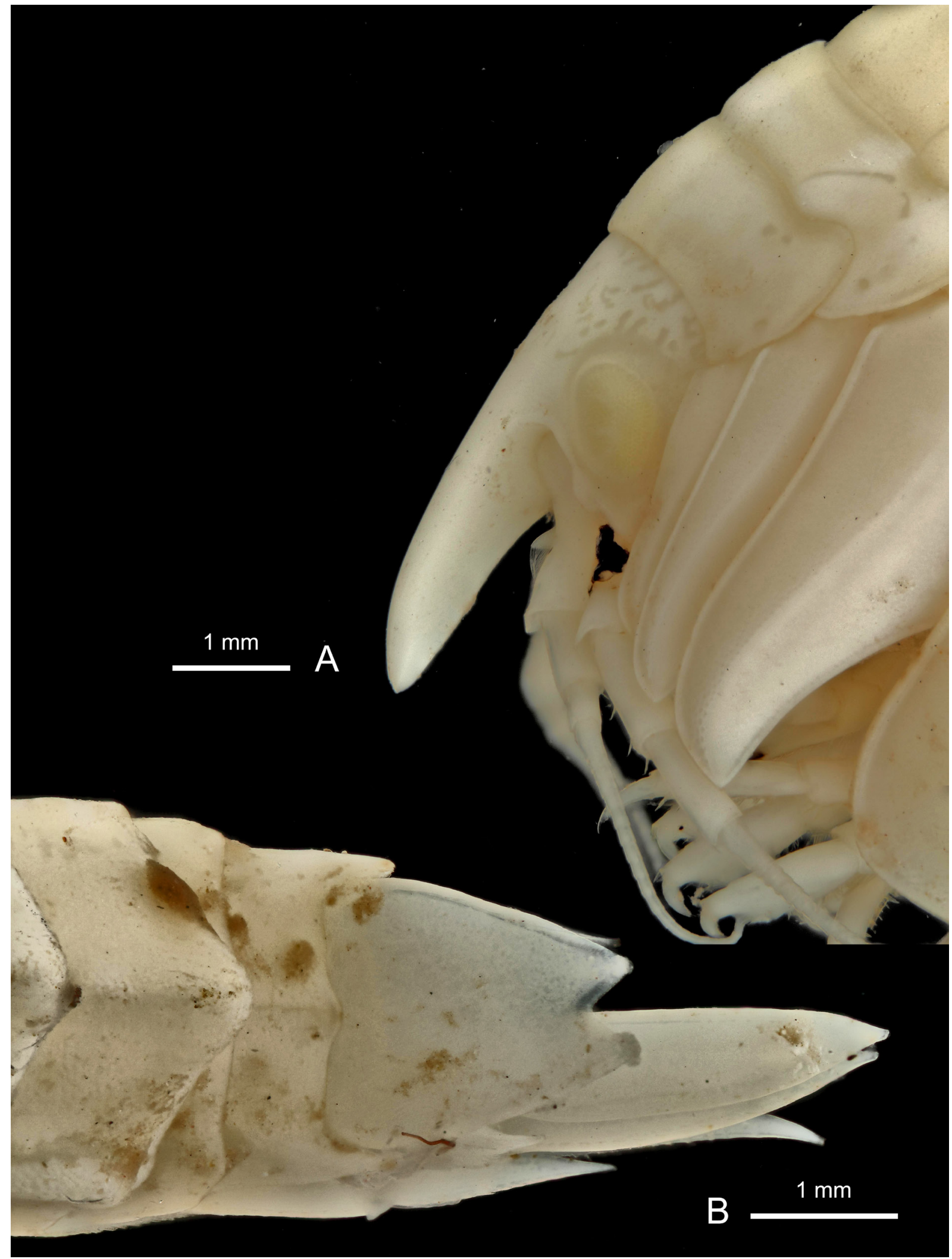

Fig. 182. Epimeria (Hoplepimeria) inermis subgen. nov. Walker, 1903, + , Adélie Coast, REVO 509, MNHN-IU-2009-2531. A. Head in lateral view. B. Urosome in dorsal view. 


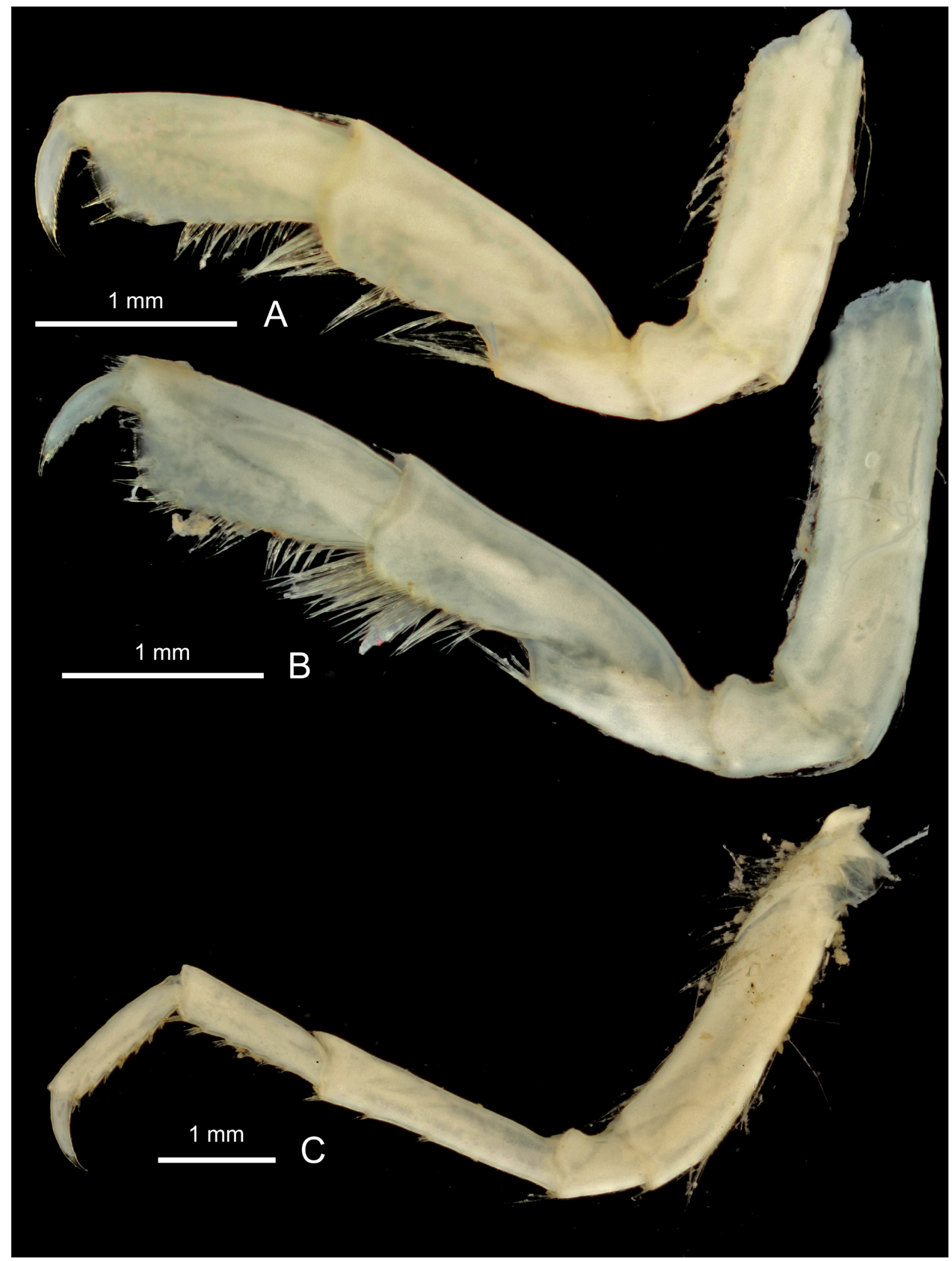

Fig. 183. Epimeria (Hoplepimeria) inermis subgen. nov. Walker, 1903, $q$, Adélie Coast, REVO 509, MNHN-IU-2009-2531. A. Gnathopod 1. B. Gnathopod 2. C. Pereiopod 4. 


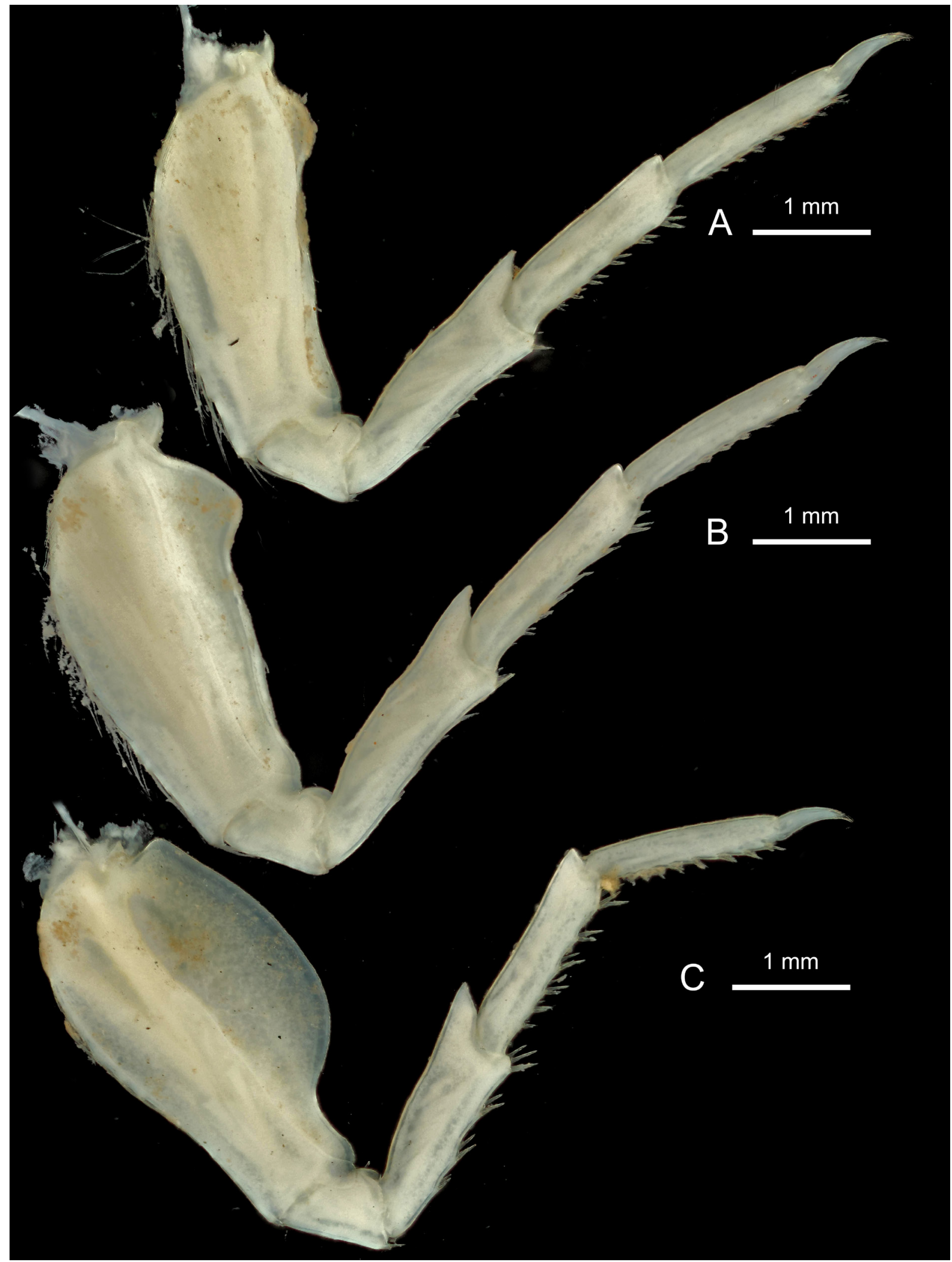

Fig. 184. Epimeria (Hoplepimeria) inermis subgen. nov. Walker, 1903, + , Adélie Coast, REVO 509, MNHN-IU-2009-2531. A. Pereiopod 5. B. Pereiopod 6. C. Pereiopod 7. 


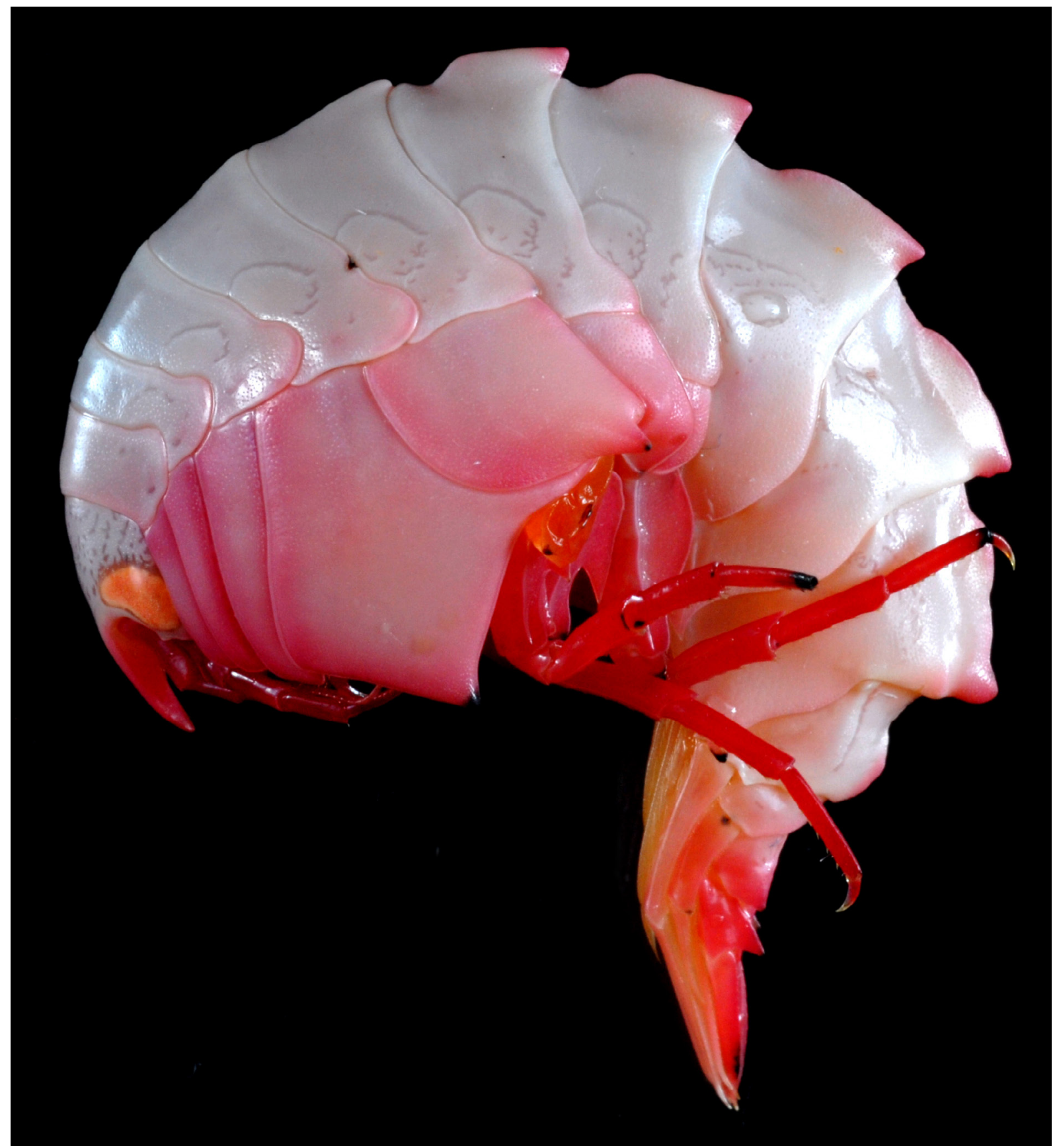

Fig. 185. Epimeria (Hoplepimeria) larsi subgen. nov. Lörz, 2009, sex undetermined (presumably 9), Adélie Coast, CEAMARC V3 2143, station ID CEAMARC-67A, Event ID 326, 65.743922 $\mathrm{S}$, $142.858913^{\circ} \mathrm{E}$ to $65.718697^{\circ} \mathrm{S}, 143.06026^{\circ} \mathrm{E}, 1957-2154 \mathrm{~m}$, colour in life (specimen not examined). Photograph: Frédéric Busson (MNHN). 


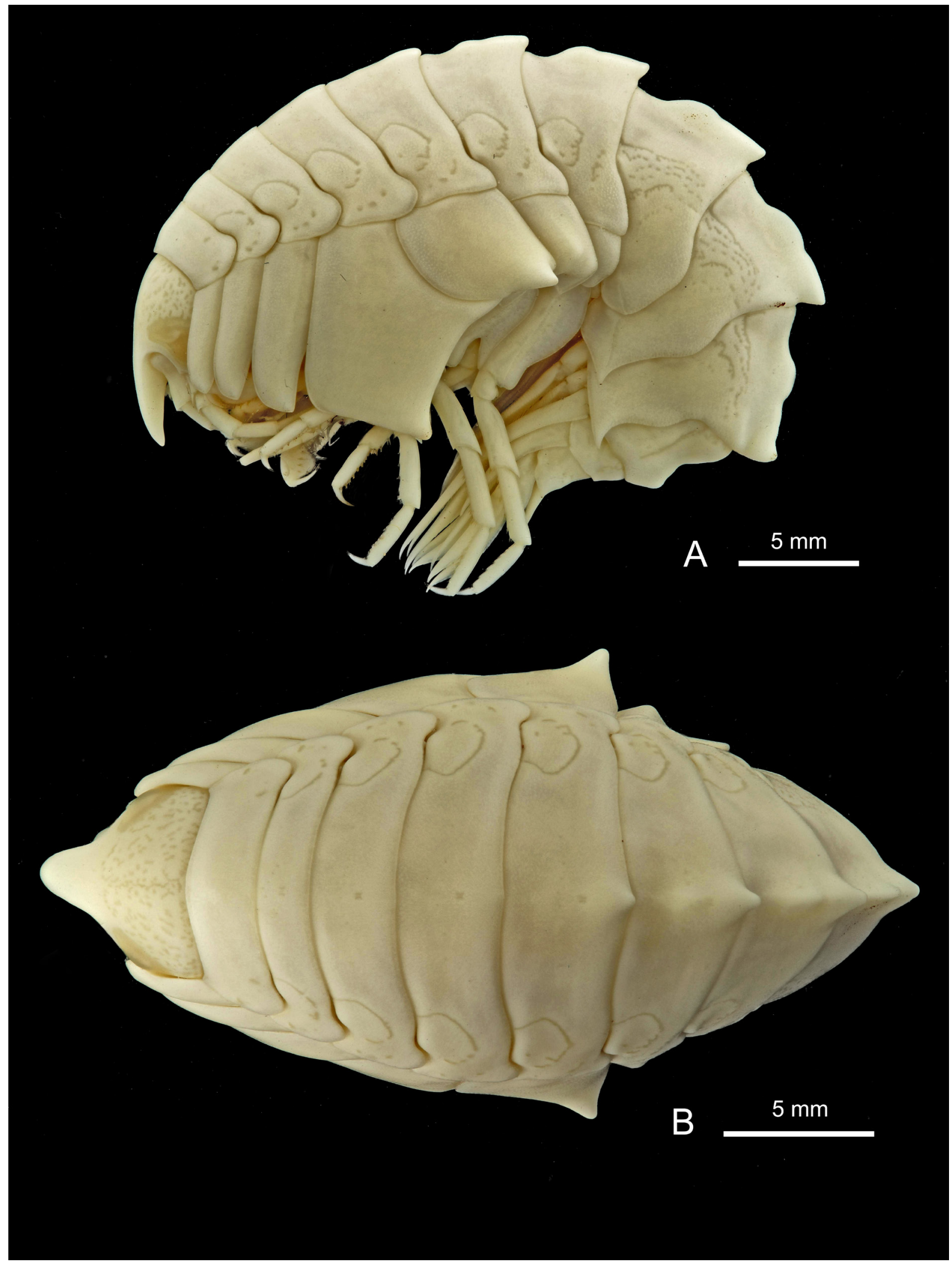

Fig. 186. Epimeria (Hoplepimeria) larsi subgen. nov. Lörz, 2009, †, Adélie Coast, CEAMARC 2173, RBINS, INV. 132718. A. Lateral habitus. B. Dorsal habitus. 


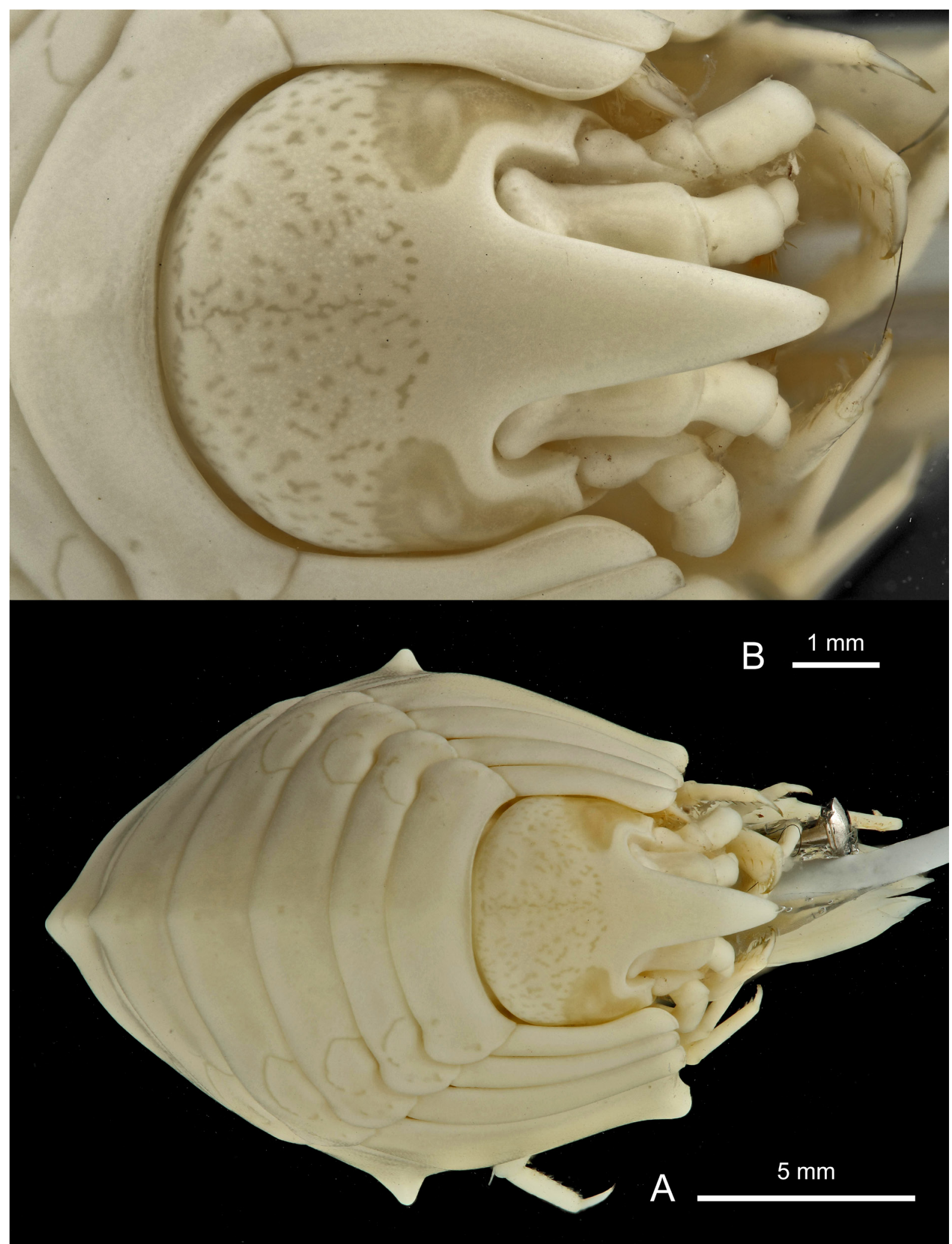

Fig. 187. Epimeria (Hoplepimeria) larsi subgen. nov. Lörz, 2009, ㅇ, Adélie Coast, CEAMARC 2173, RBINS, INV. 132718. A. Facial habitus. B. Head in dorsal view. 


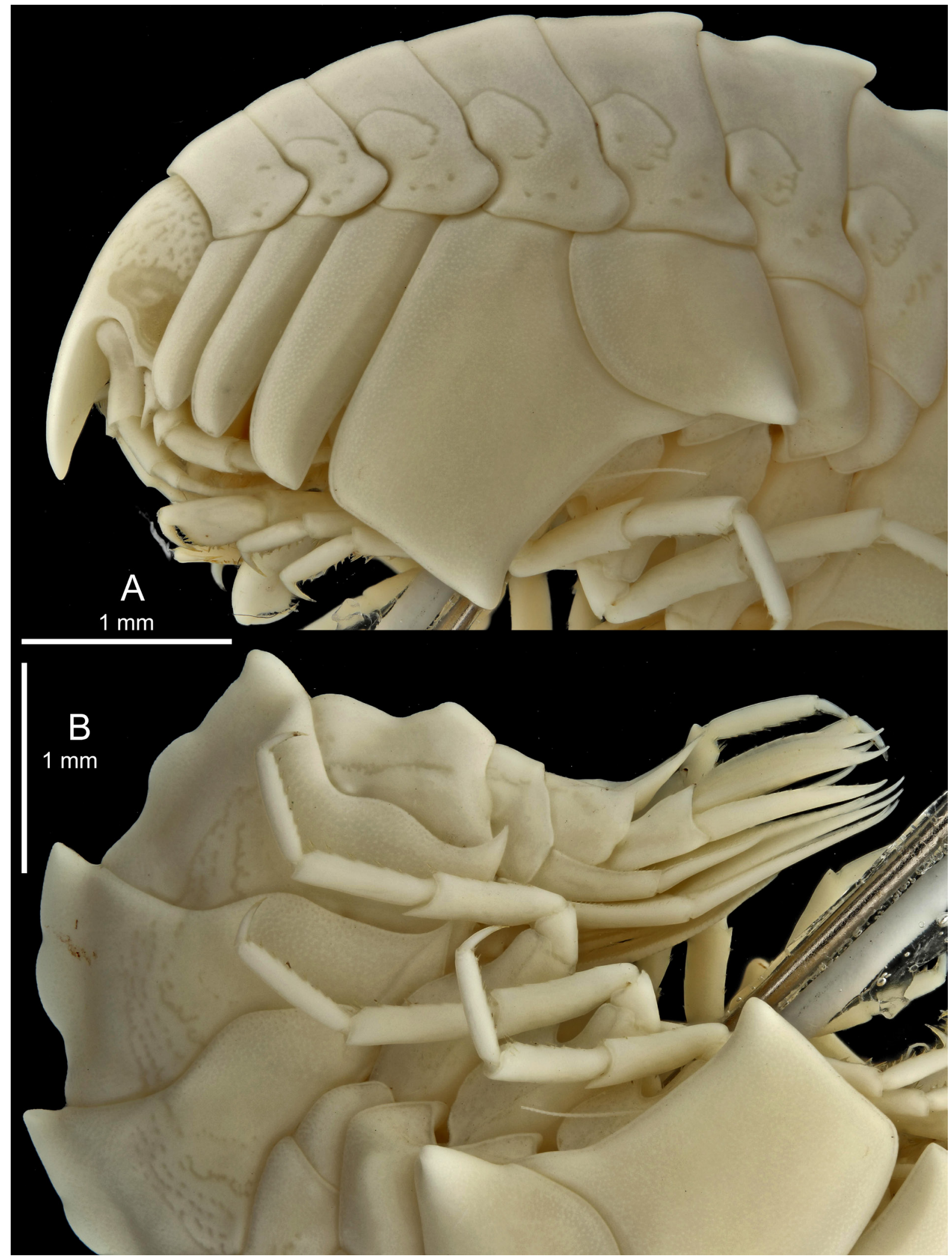

Fig. 188. Epimeria (Hoplepimeria) larsi subgen. nov. Lörz, 2009, , , Adélie Coast, CEAMARC 2173, RBINS, INV. 132718. A. Anterior half. B. Posterior half. 


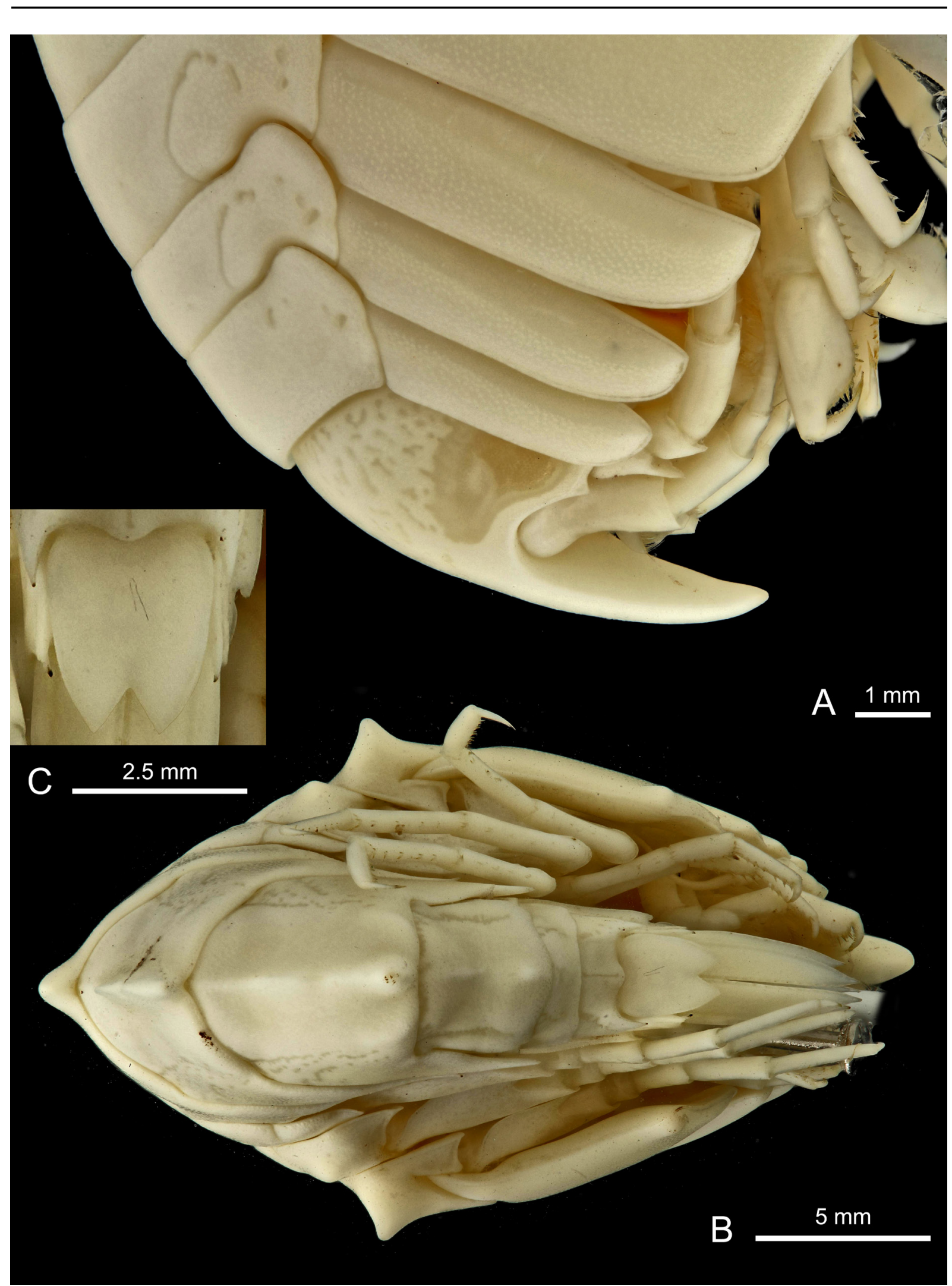

Fig. 189. Epimeria (Hoplepimeria) larsi subgen. nov. Lörz, 2009, , , Adélie Coast, CEAMARC 2173, RBINS, INV. 132718. A. Head and coxae 1-3 in lateral view. B. Urosome in dorsal view. C. Telson. 


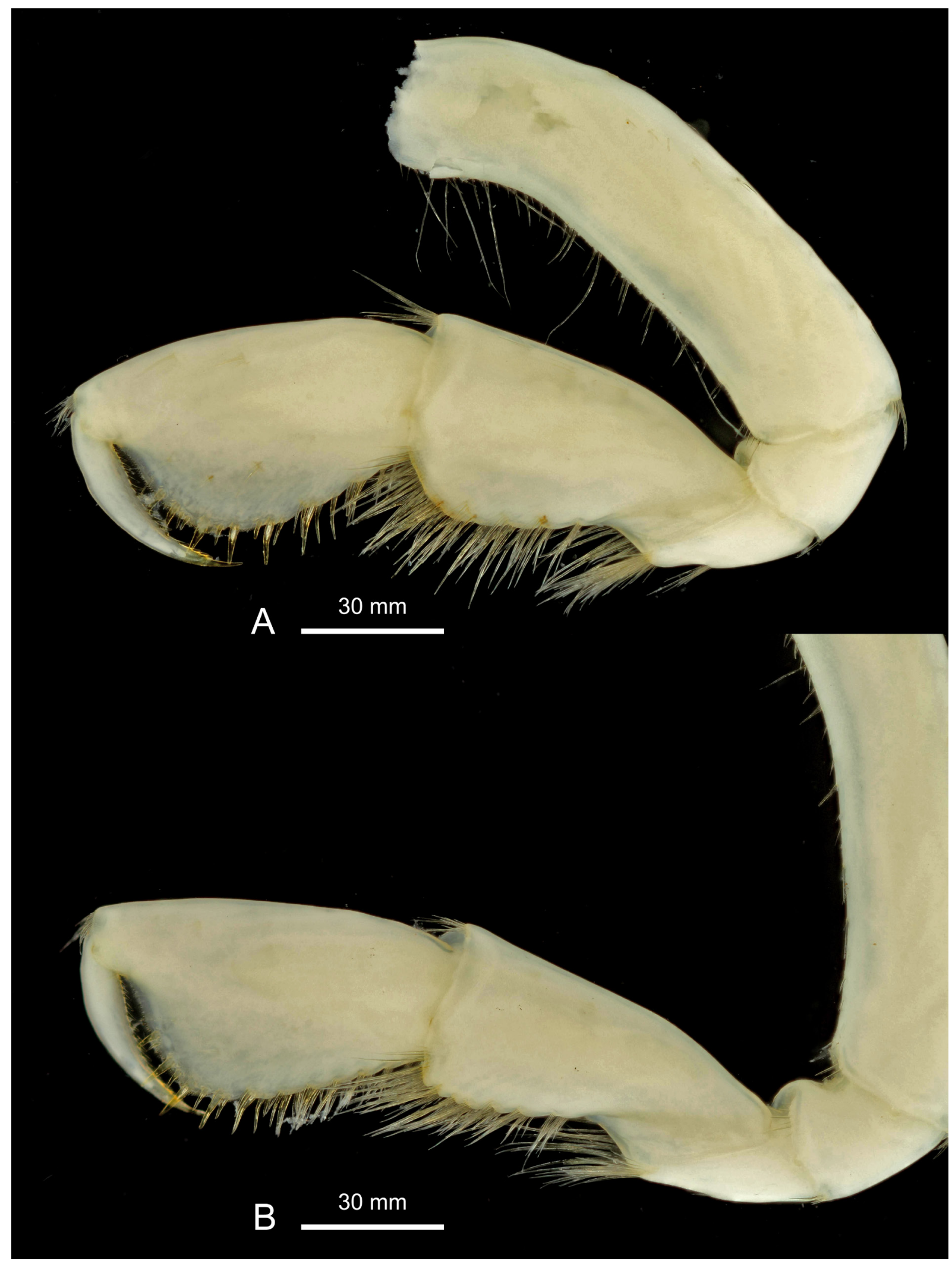

Fig. 190. Epimeria (Hoplepimeria) larsi subgen. nov. Lörz, 2009, †, Adélie Coast, CEAMARC 2173, RBINS, INV. 132718. A. Gnathopod 1. B. Gnathopod 2. 


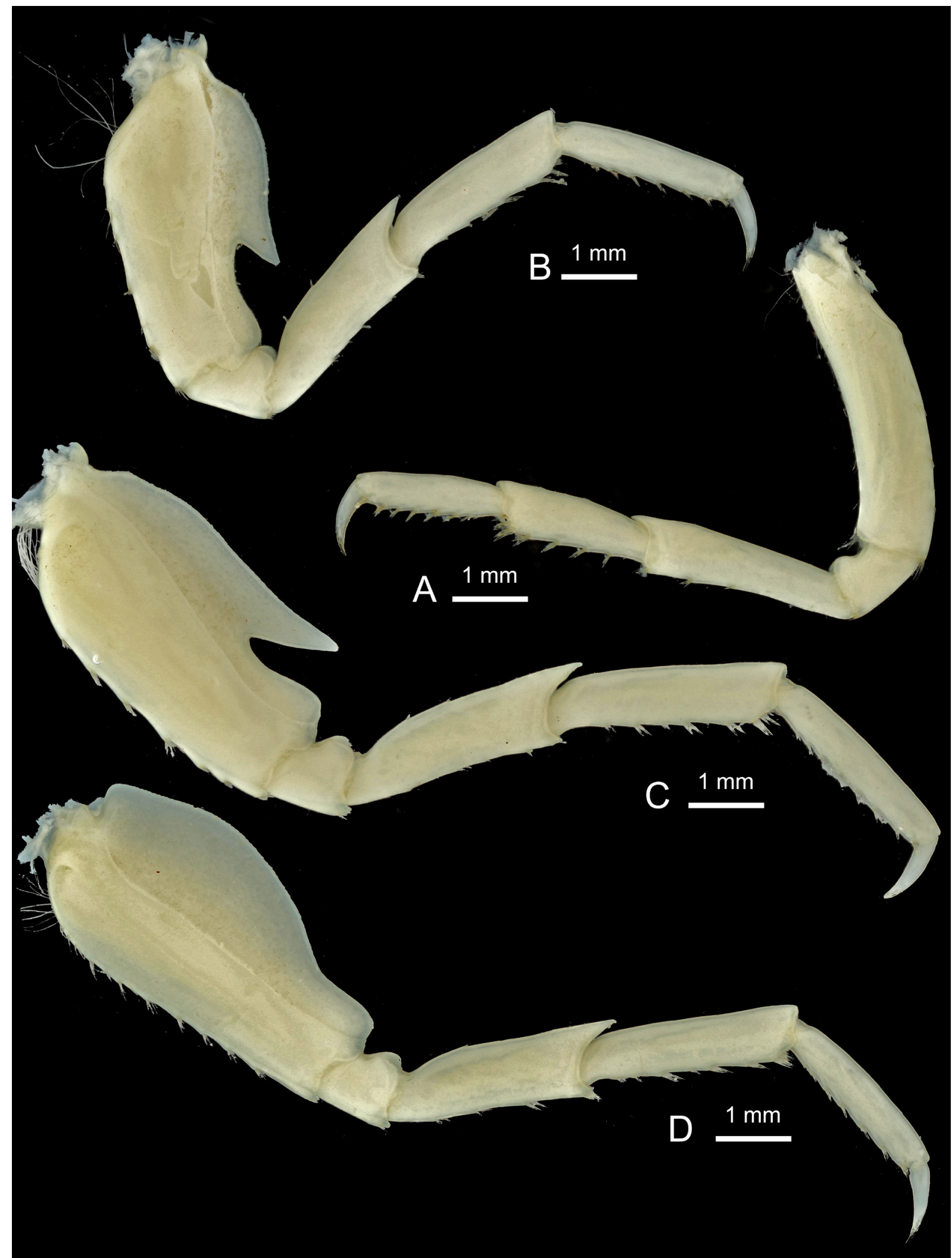

Fig. 191. Epimeria (Hoplepimeria) larsi subgen. nov. Lörz, 2009,, , Adélie Coast, CEAMARC 2173, RBINS, INV. 132718. A. Pereiopod 4. B. Pereiopod 5. C. Pereiopod 6. D. Pereiopod 7. 


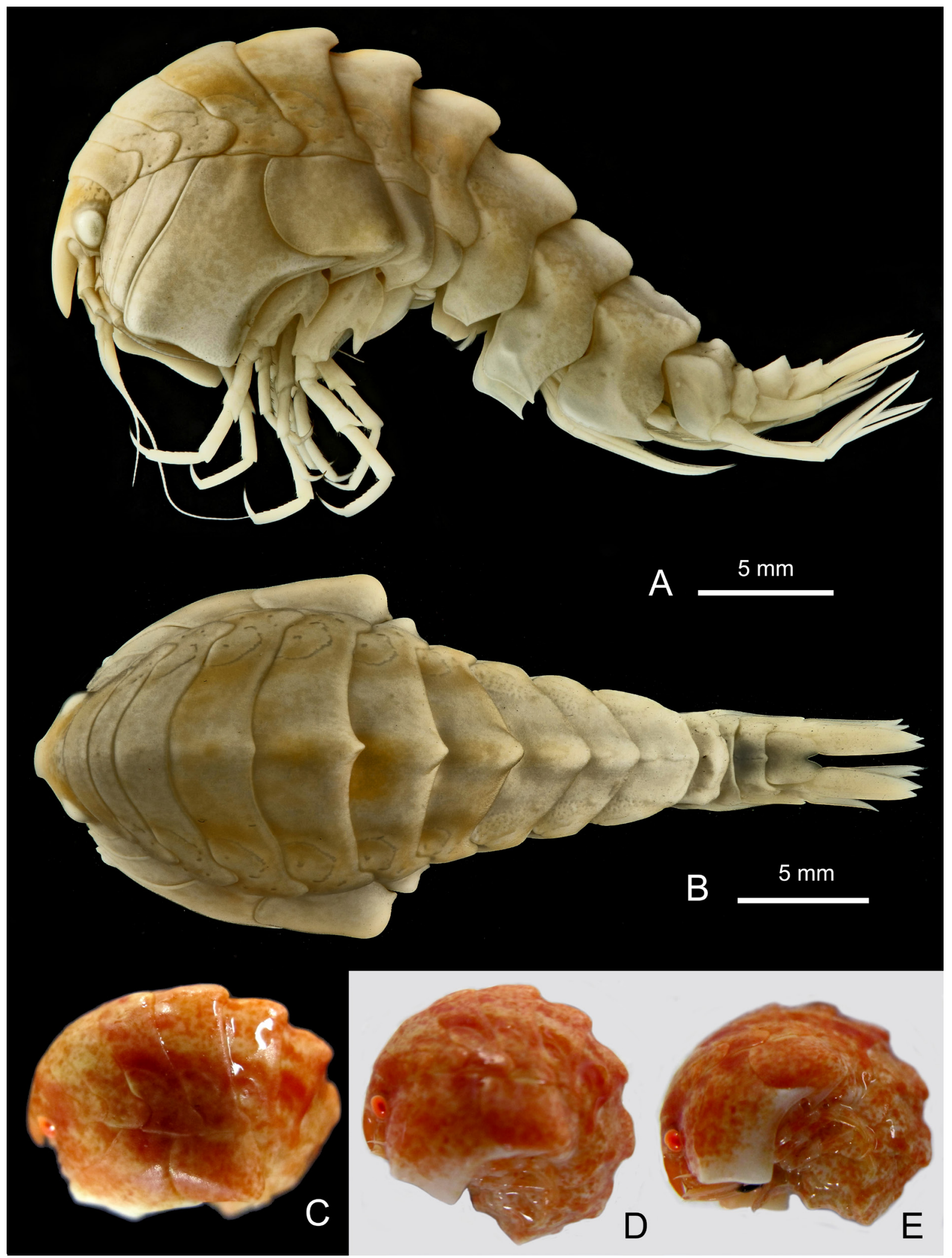

Fig. 192. Epimeria (Hoplepimeria) linseae subgen. et sp. nov. A-B, + , holotype, South Orkney Islands, ANT-XXVII/3, stn 217-6, RBINS, INV. 132958. C-E, South Orkney Islands, ANT-XXVII/3, stn 217-5, specimen not available. A. Lateral habitus. B. Dorsal habitus. C-E. Colour in life (photograph: H. Robert and C. Havermans, RBINS). 


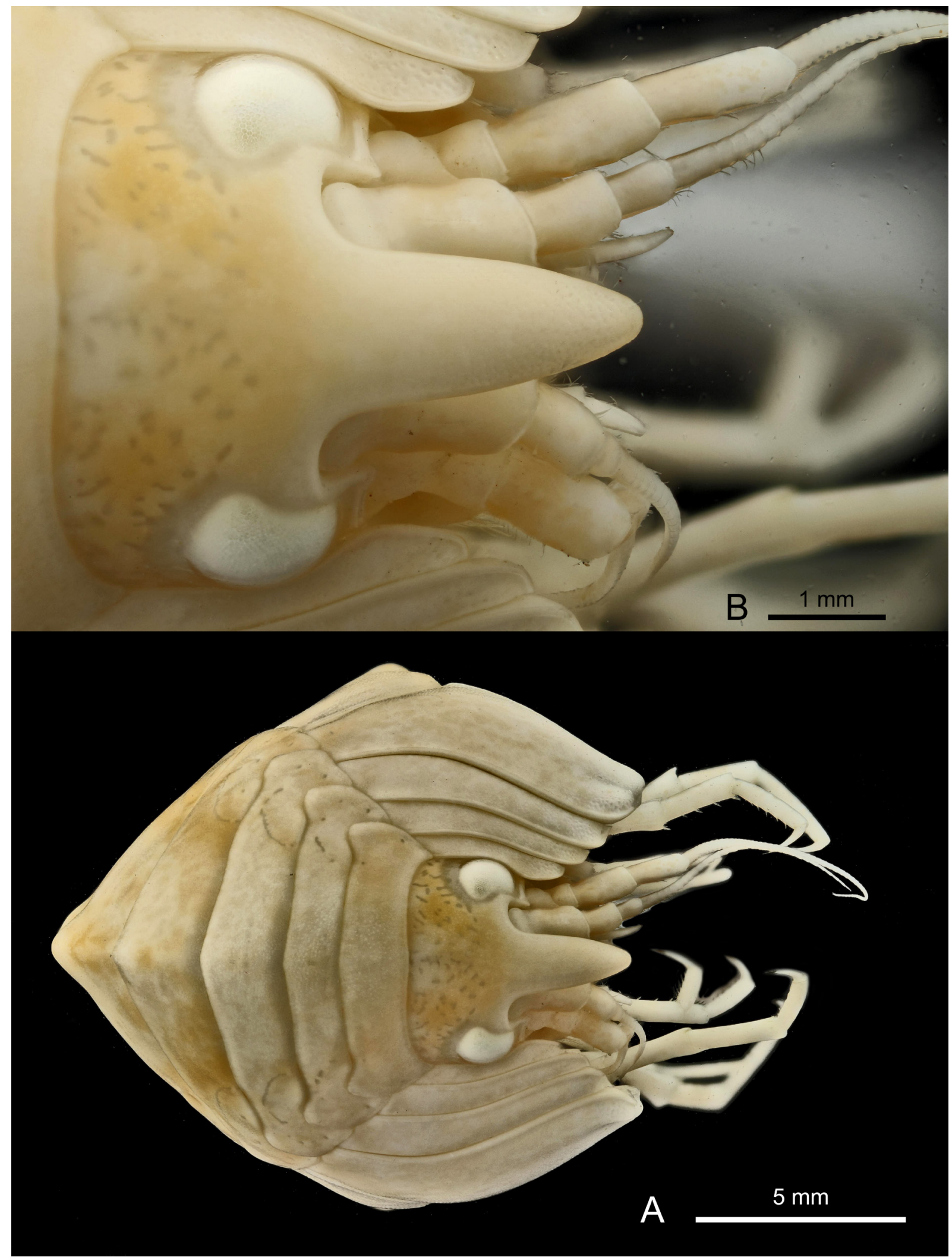

Fig. 193. Epimeria (Hoplepimeria) linseae subgen. et sp. nov., + , holotype, South Orkney Islands, ANT-XXVII/3, stn 217-6, RBINS, INV. 132958. A. Facial habitus. B. Head in facial view. 


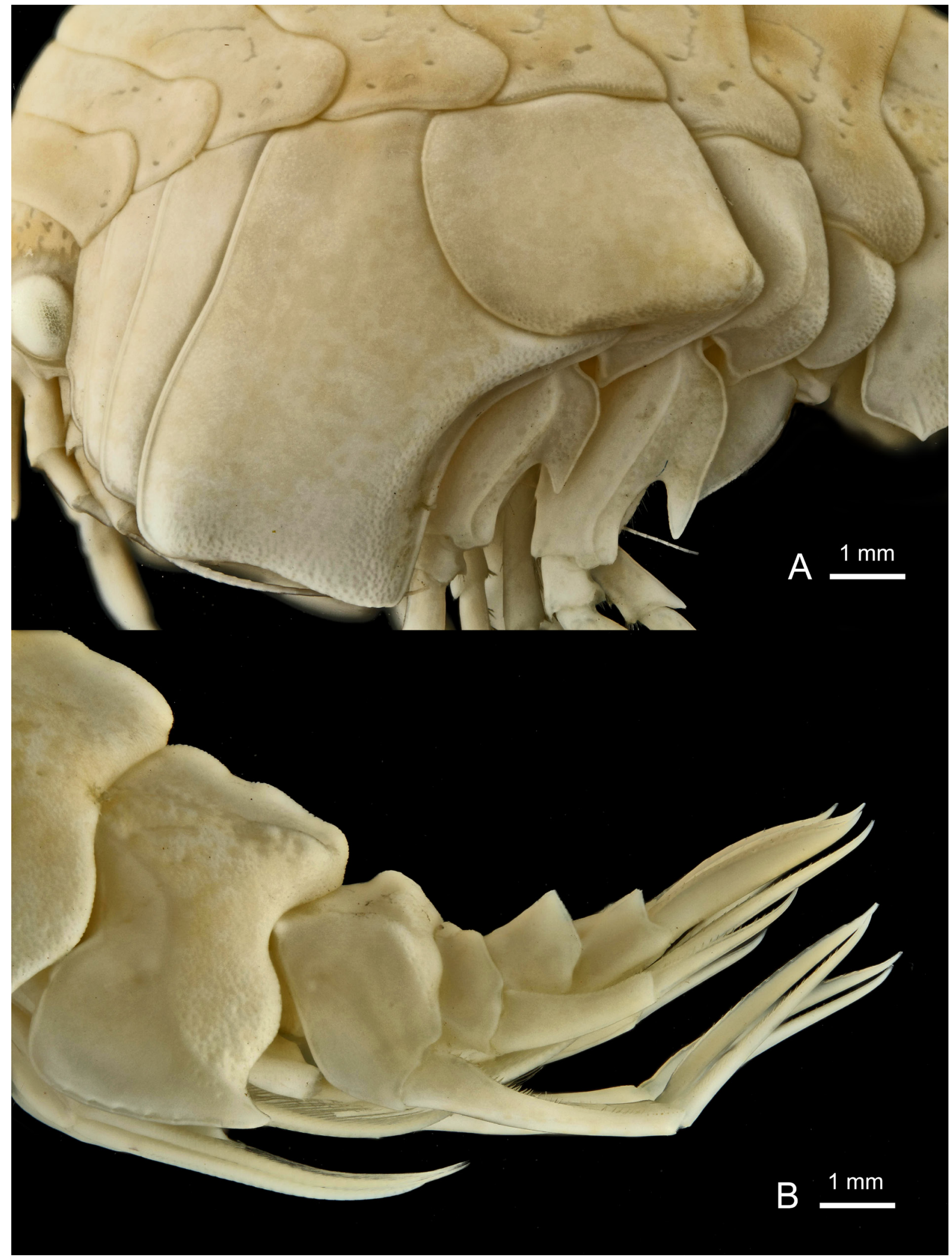

Fig. 194. Epimeria (Hoplepimeria) linseae subgen. et sp. nov., + , holotype, South Orkney Islands, ANT-XXVII/3, stn 217-6, RBINS, INV. 132958. A. Coxae 1-7. B. Pleonite 3 and urosome. 


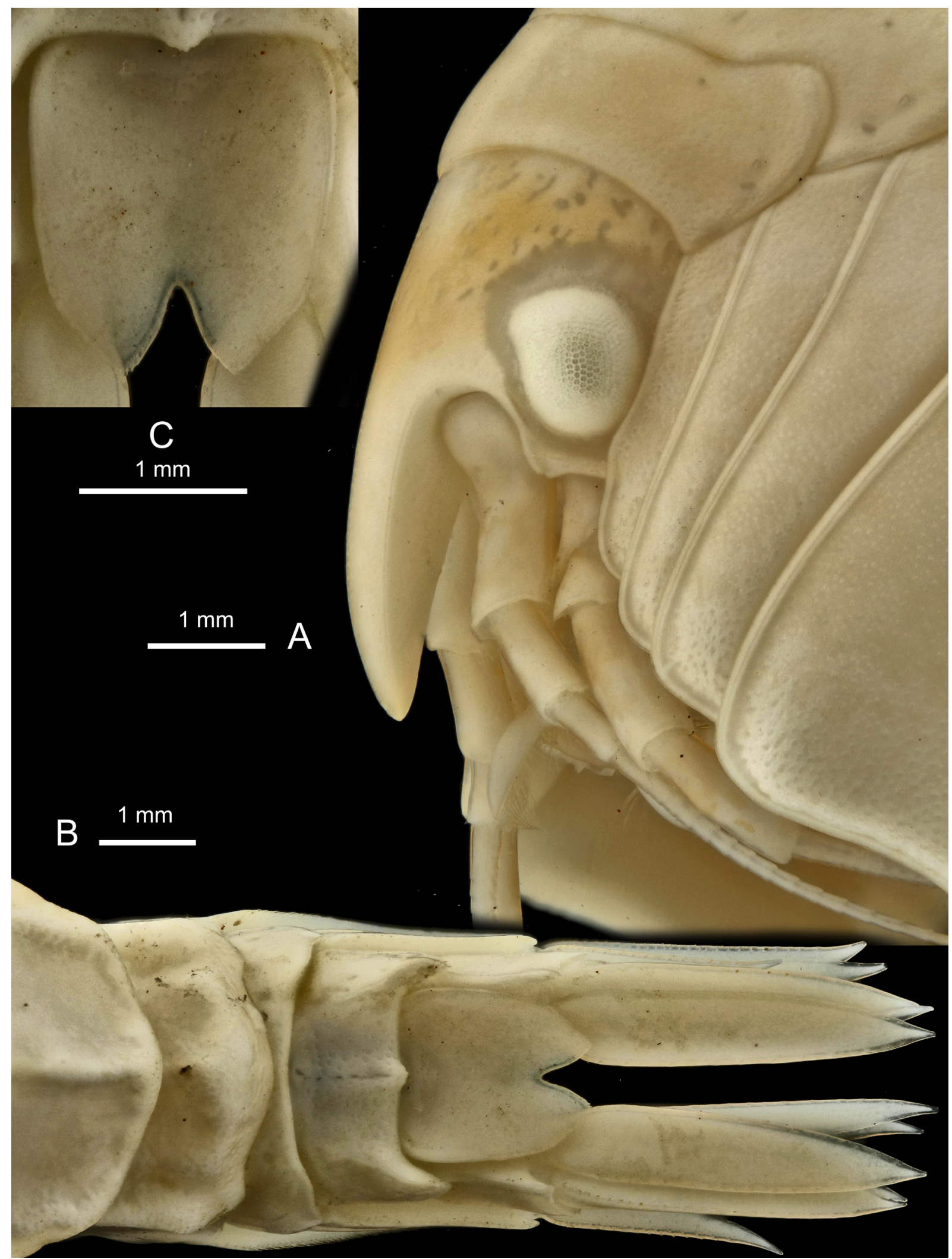

Fig. 195. Epimeria (Hoplepimeria) linseae subgen. et sp. nov., ${ }^{\circ}$, holotype, South Orkney Islands, ANT-XXVII/3, stn 217-6, RBINS, INV. 132958. A. Head in lateral view. B. Urosome in dorsal view. C. Telson. 


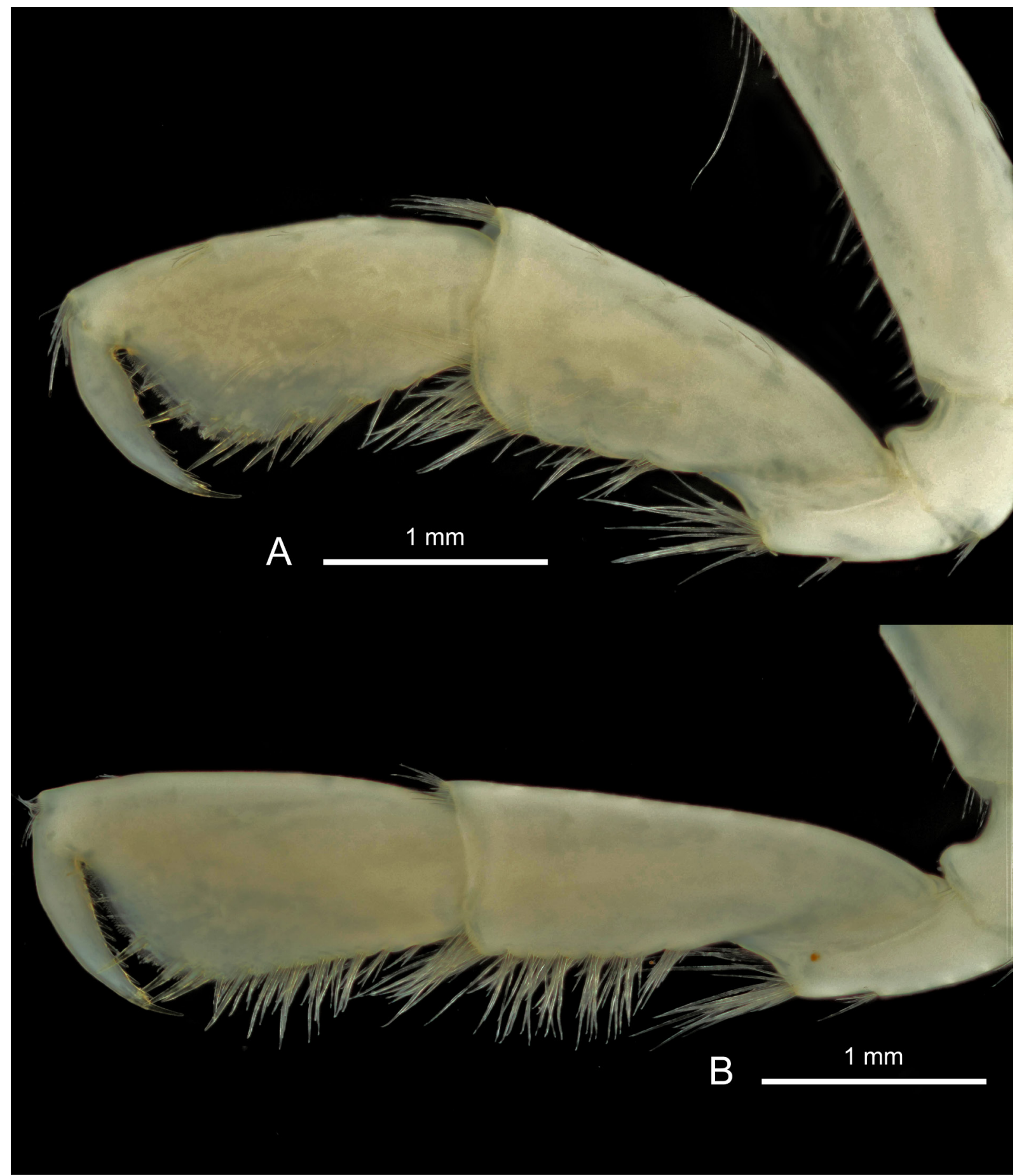

Fig. 196. Epimeria (Hoplepimeria) linseae subgen. et sp. nov., + , holotype, South Orkney Islands, ANT-XXVII/3, stn 217-6, RBINS, INV. 132958. A. Gnathopod 1. B. Gnathopod 2. 


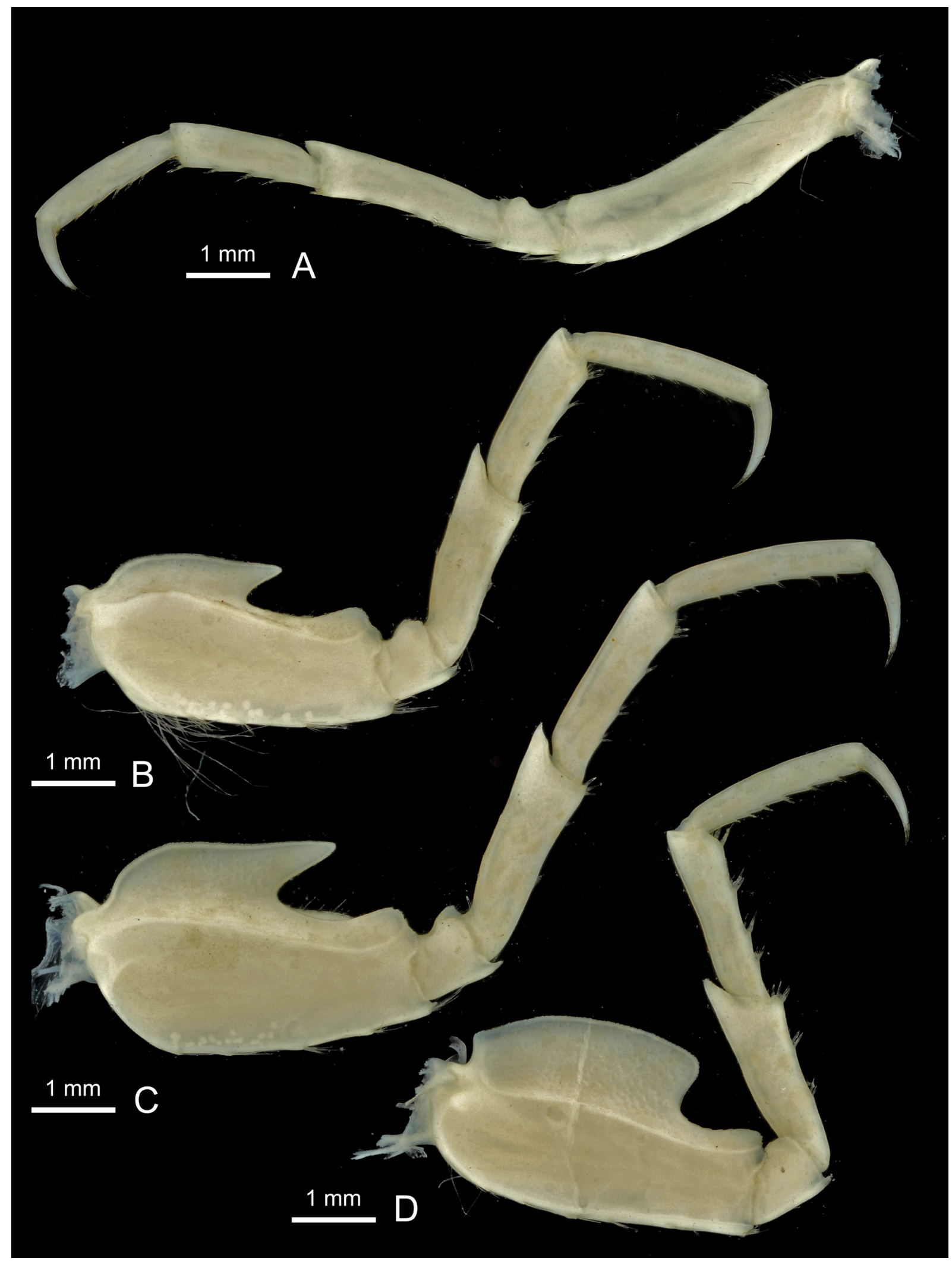

Fig. 197. Epimeria (Hoplepimeria) linseae subgen. et sp. nov., + , holotype, South Orkney Islands, ANT-XXVII/3, stn 217-6, RBINS, INV. 132958. A. Pereiopod 4. B. Pereiopod 5. C. Pereiopod 6. D. Pereiopod 7. 


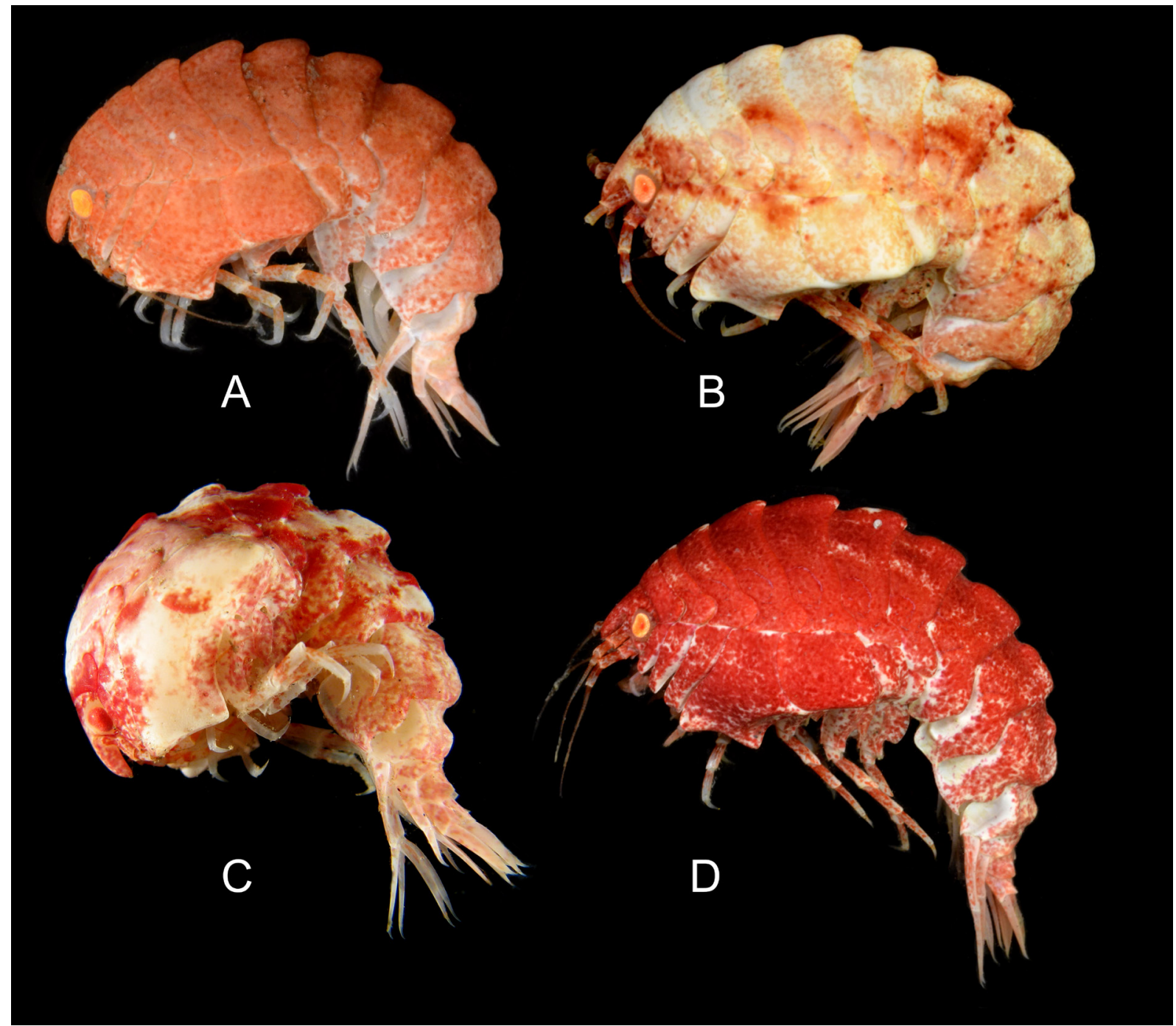

Fig. 198. Epimeria (Hoplepimeria) quasimodo subgen. et sp. nov., $q++$, paratypes, adult, colour in life. A. East of Joinville Island, ANT-XXIX/3, stn 160-3 (type locality), RBINS, INV. 122933. B. South of Dundee Island, ANT-XXIX/3, stn 164-4, RBINS, INV. 122923 or 122925. C. Elephant Island, ANTXXIII/8, stn 611-1 RBINS, INV. 122558. D. South of Dundee Island, ANT-XXIX/3, stn 164-4, RBINS, INV. 122923 or 122925. 


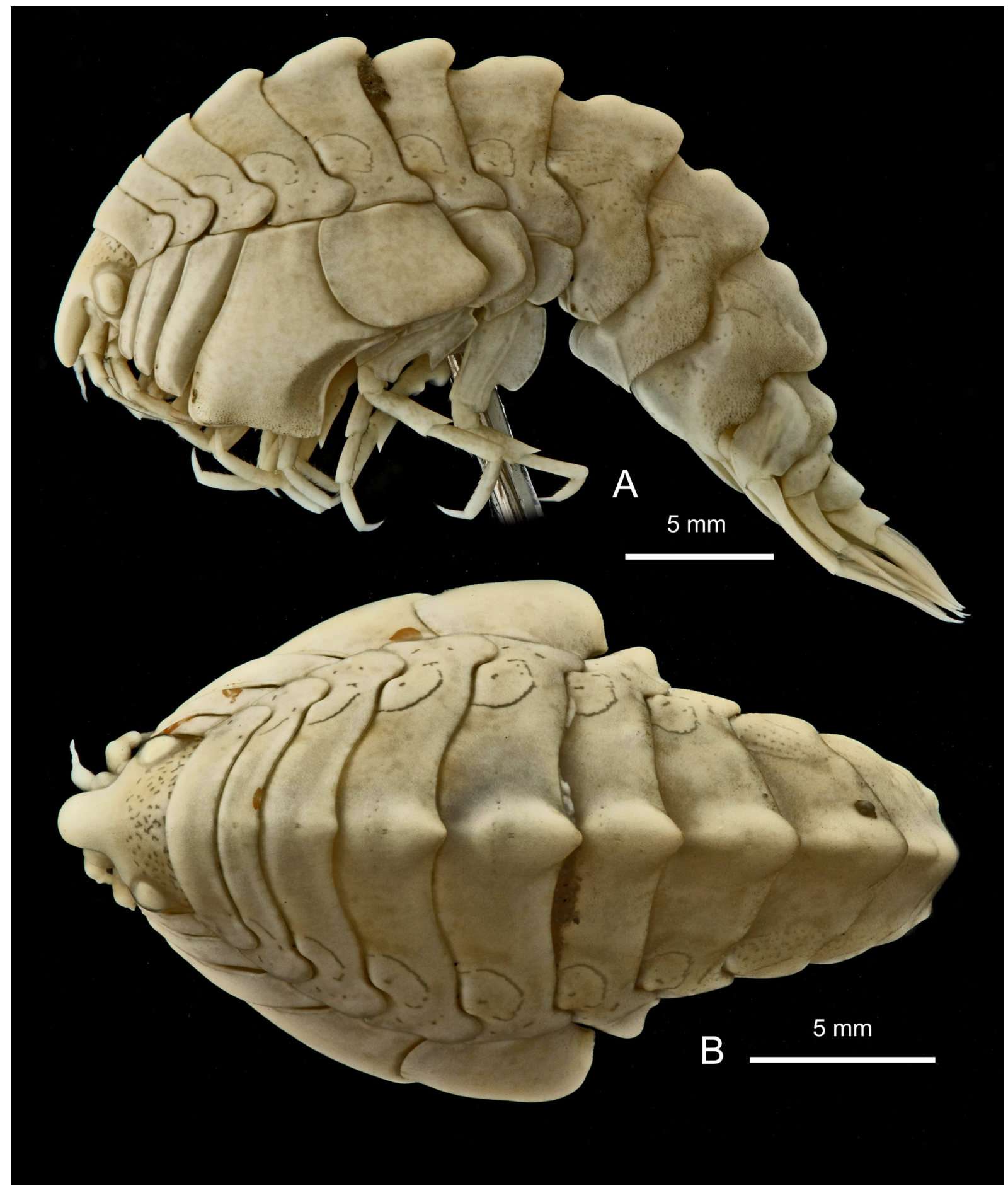

Fig. 199. Epimeria (Hoplepimeria) quasimodo subgen. et sp. nov.,, , holotype, East of Joinville Island, ANT-XXIX/3, stn 160-3, RBINS, INV. 122930A. A. Lateral habitus. B. Dorsal habitus. 


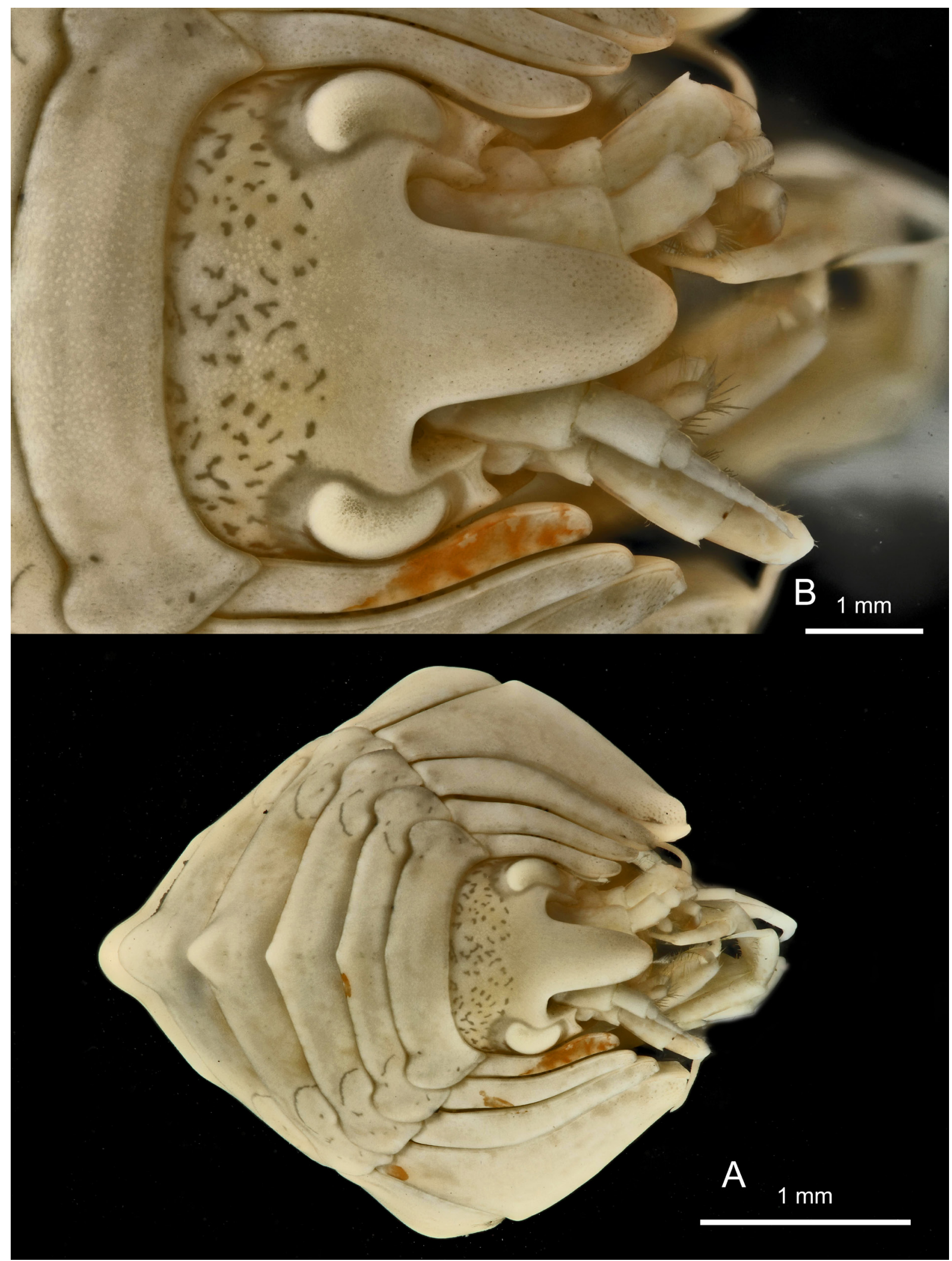

Fig. 200. Epimeria (Hoplepimeria) quasimodo subgen. et sp. nov., + , holotype, East of Joinville Island, ANT-XXIX/3, stn 160-3, RBINS, INV. 122930A. A. Facial habitus. C. Head in facial view. 


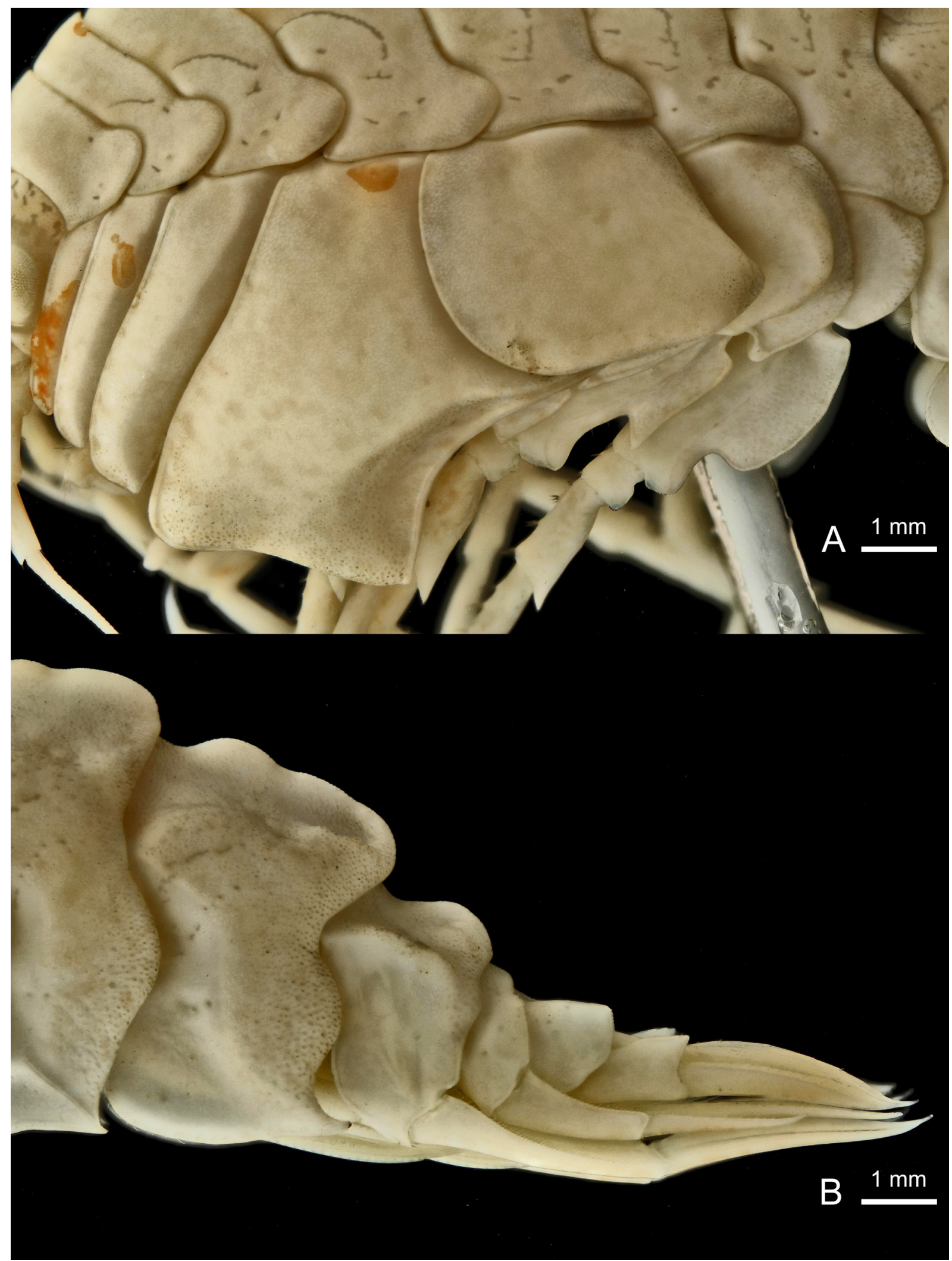

Fig. 201. Epimeria (Hoplepimeria) quasimodo subgen. et sp. nov.,, , holotype, East of Joinville Island, ANT-XXIX/3, stn 160-3, RBINS, INV. 122930A. A. Coxae 1-4. B. Pleonite 3 and urosome. 


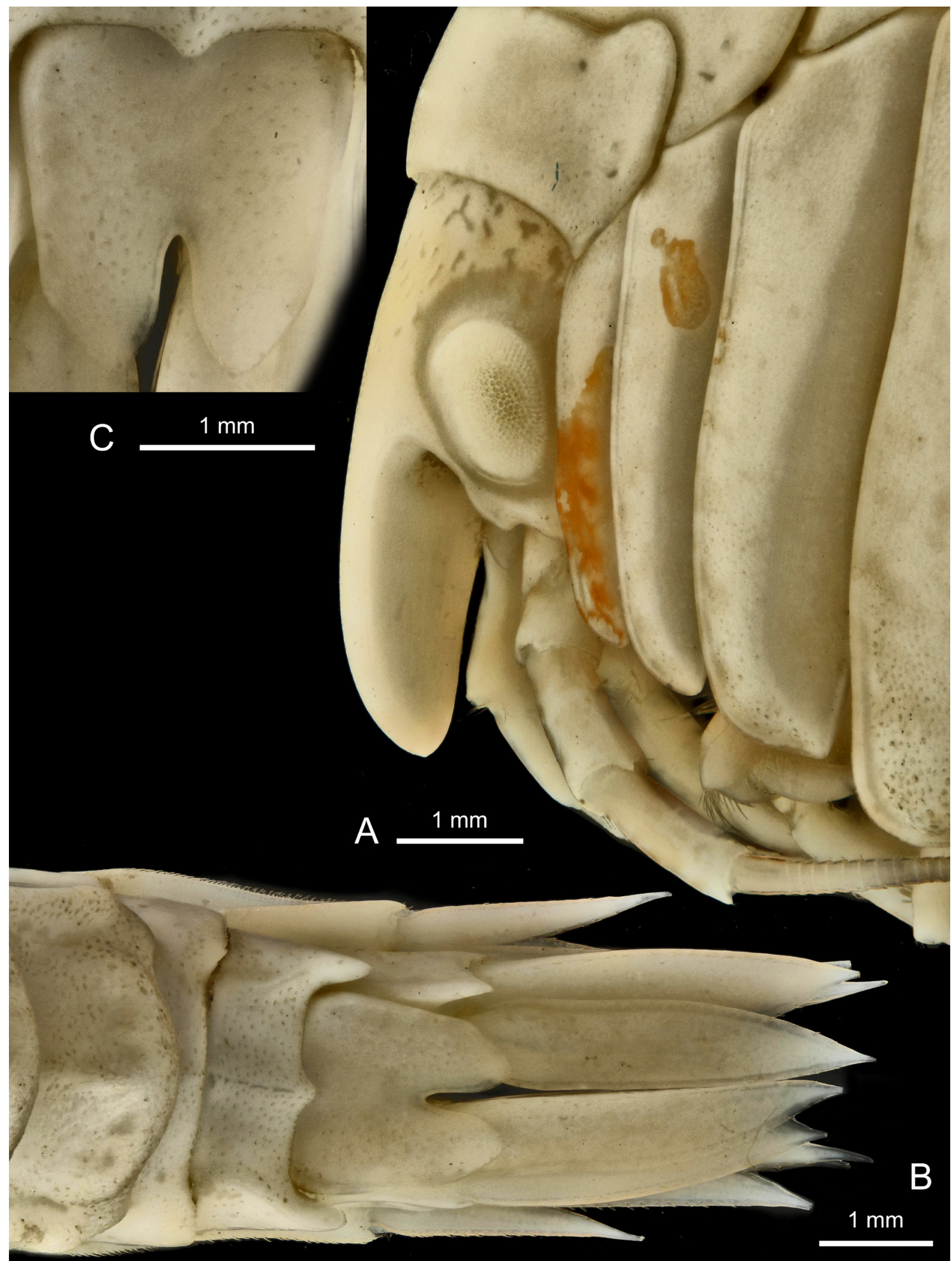

Fig. 202. Epimeria (Hoplepimeria) quasimodo subgen. et sp. nov., + , holotype, East of Joinville Island, ANT-XXIX/3, stn 160-3, RBINS, INV. 122930A. A. Head in lateral view. B. Urosome in dorsal view. C. Telson. 


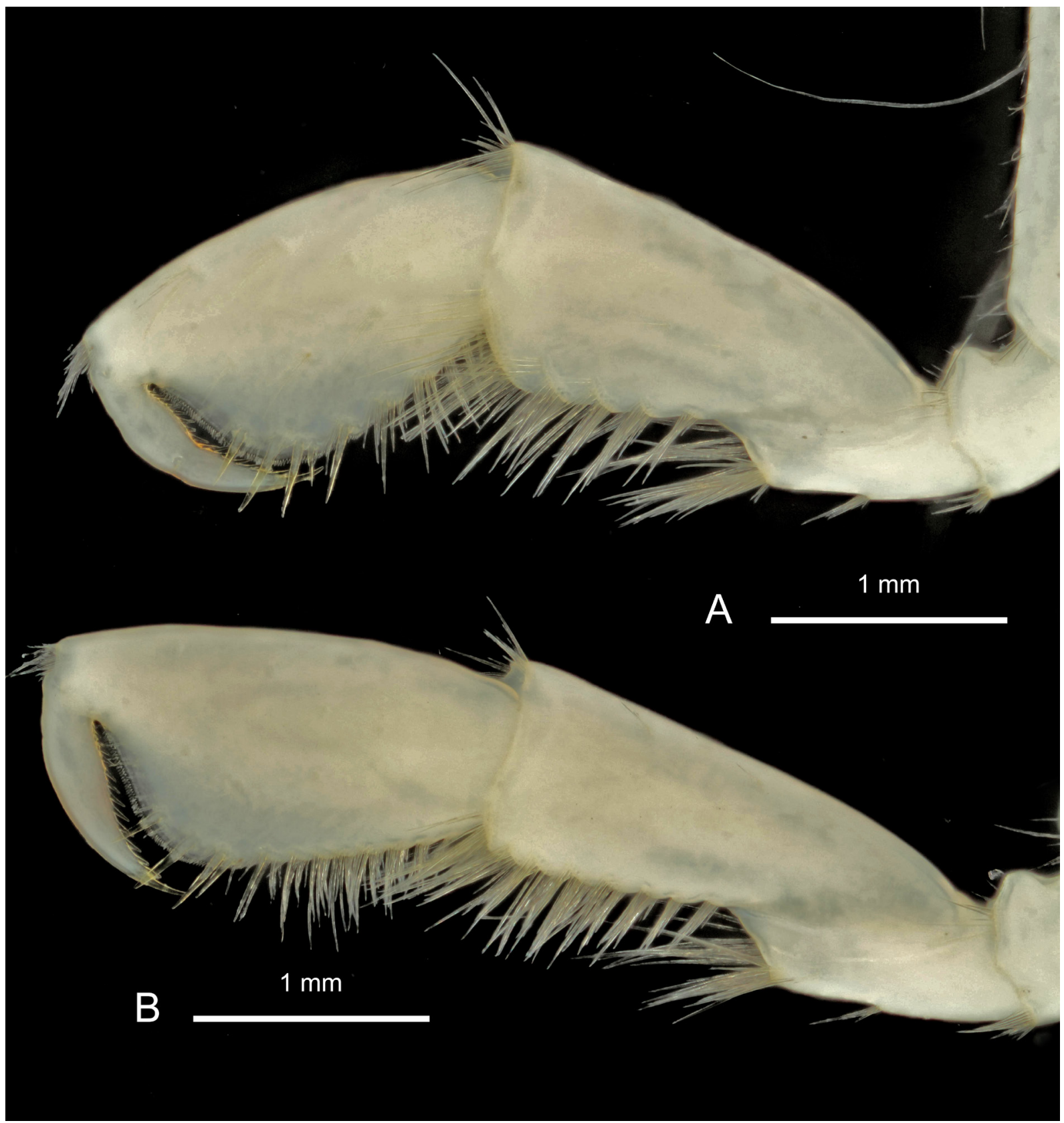

Fig. 203. Epimeria (Hoplepimeria) quasimodo subgen. et sp. nov., + , holotype, East of Joinville Island, ANT-XXIX/3, stn 160-3, RBINS, INV. 122930A. A. Gnathopod 1. B. Gnathopod 2. 


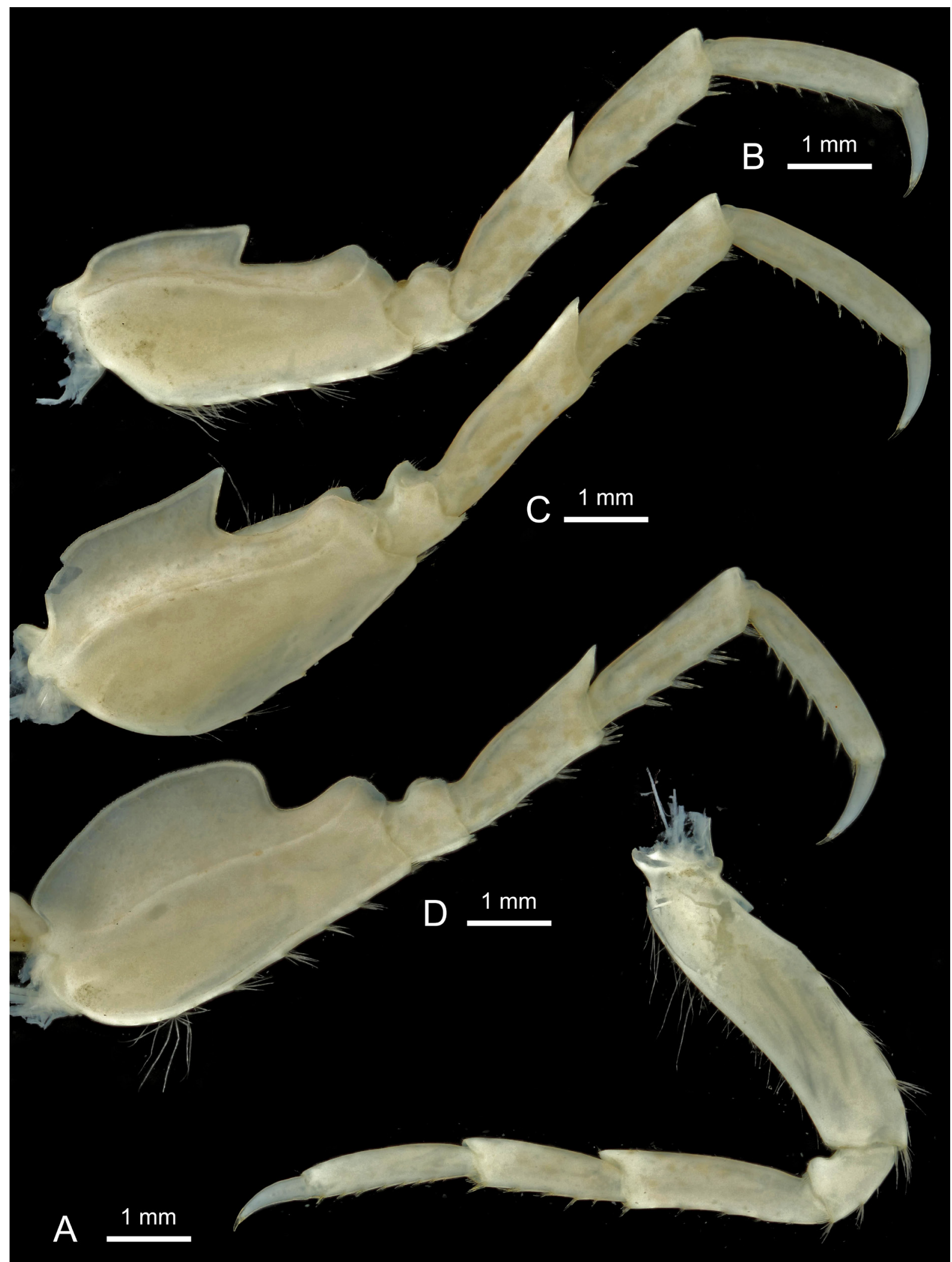

Fig. 204. Epimeria (Hoplepimeria) quasimodo subgen. et sp. nov.,, , holotype, East of Joinville Island, ANT-XXIX/3, stn 160-3, RBINS, INV. 122930A. A. Pereiopod 4. B. Pereiopod 5. C. Pereiopod 6. D. Pereiopod 7. 


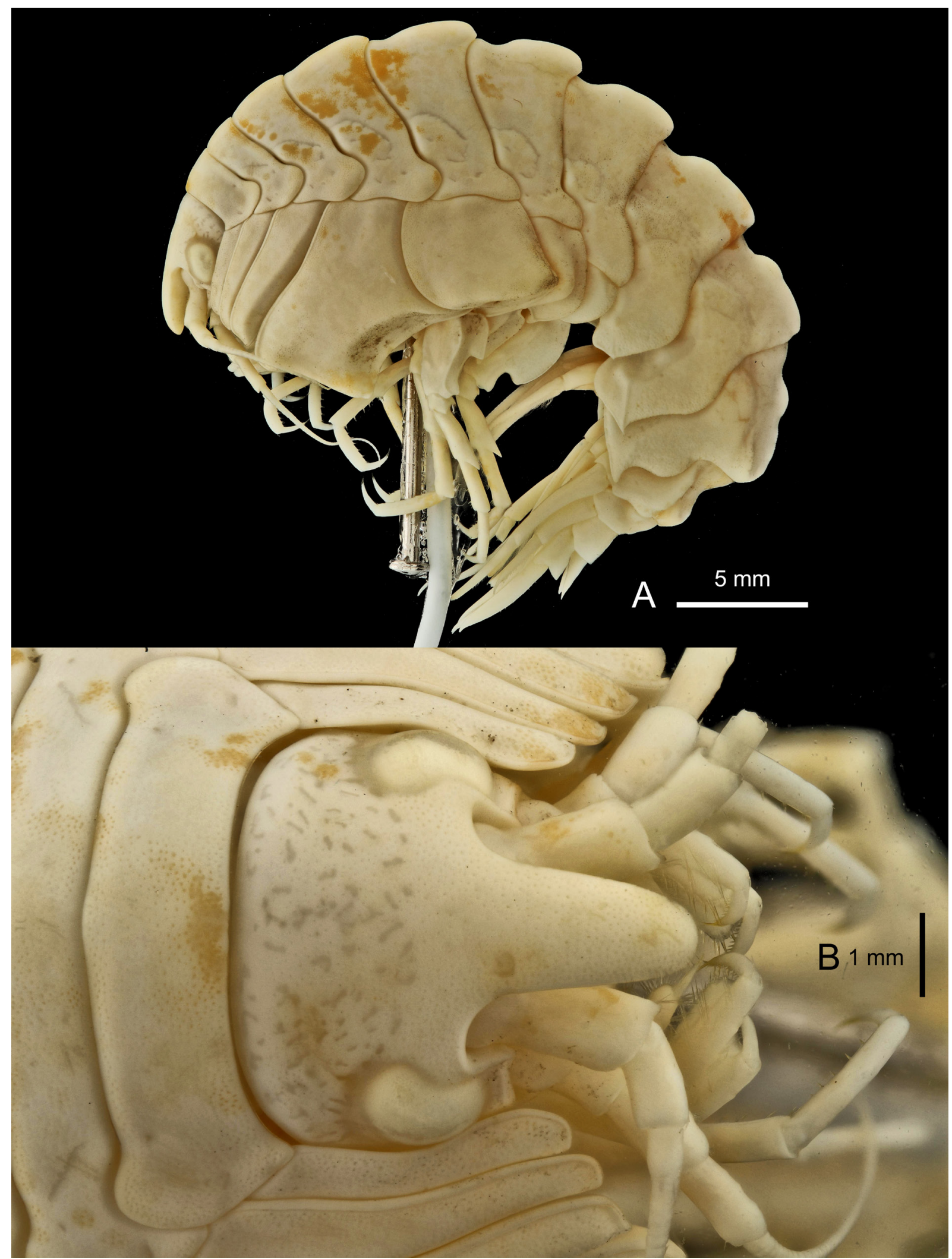

Fig. 205. Epimeria (Hoplepimeria) quasimodo subgen. et sp. nov., ${ }_{+}$, large paratype, northwestern Weddell Sea, ANT-XXIX/3, stn 185-3, RBINS, INV. 122921B. A. Habitus. B. Head in facial view. 


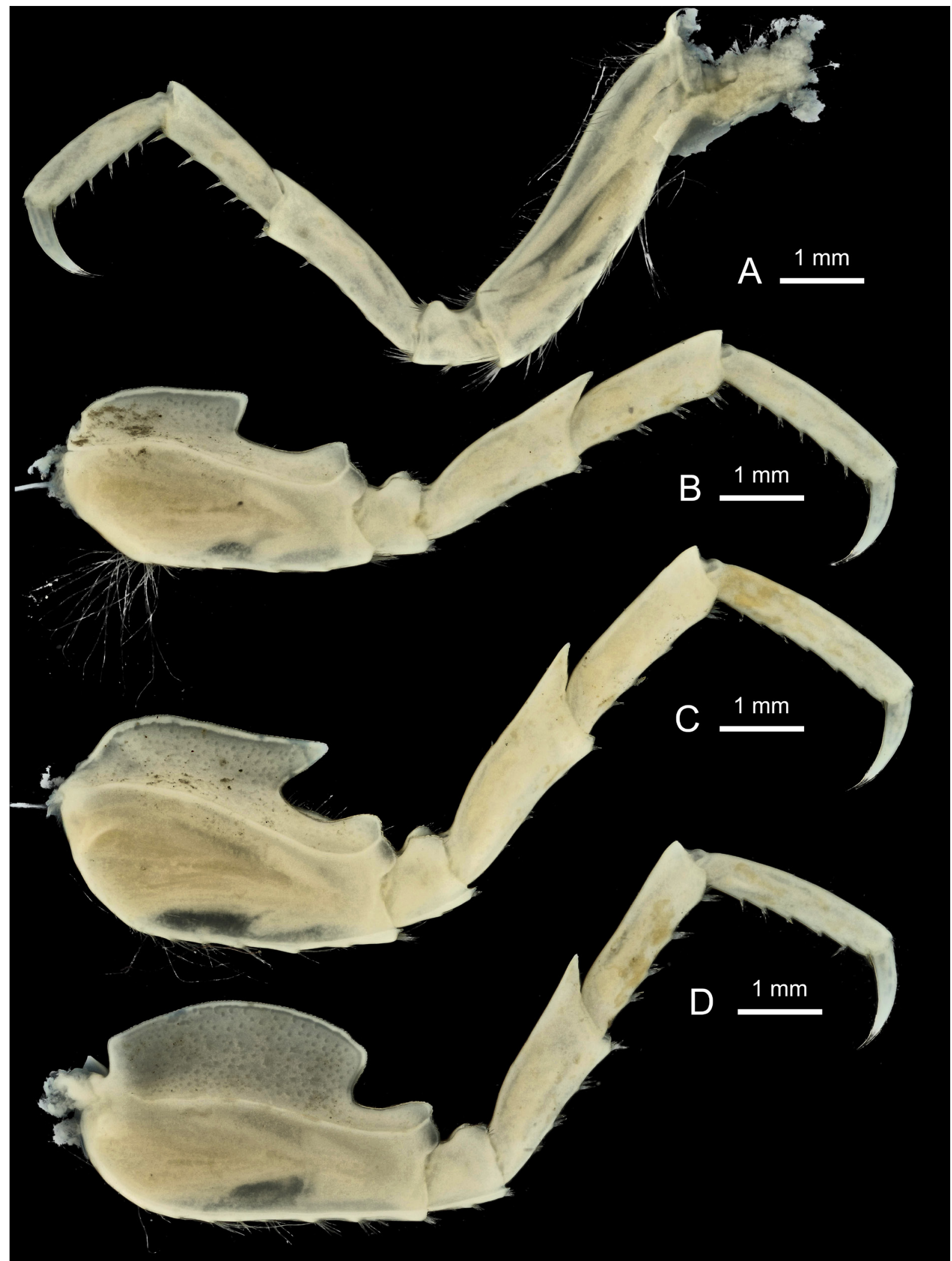

Fig. 206. Epimeria (Hoplepimeria) quasimodo subgen. et sp. nov., ${ }^{+}$, large paratype, northwestern Weddell Sea, ANT-XXIX/3, stn 185-3, RBINS, INV. 122921B. A. Pereiopod 4. B. Pereiopod 5. C. Pereiopod 6. D. Pereiopod 7. 

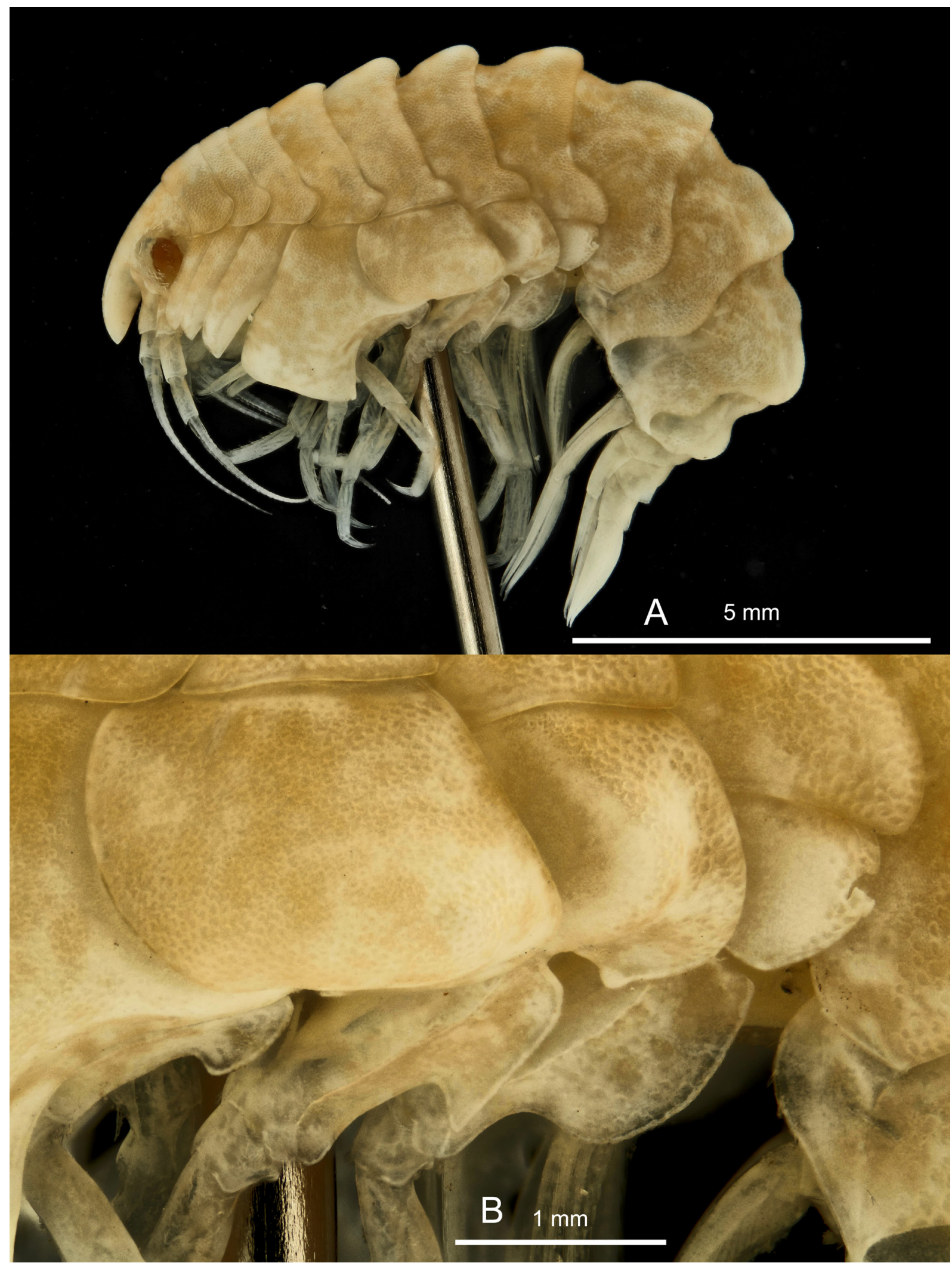

Fig. 207. Epimeria (Hoplepimeria) quasimodo subgen. et sp. nov., juvenile, Elephant Island, ANTXXIII/8, stn 605-1, RBINS, INV. 122506. A. Lateral habitus. B. Coxae and bases of pereiopods 5-7. 


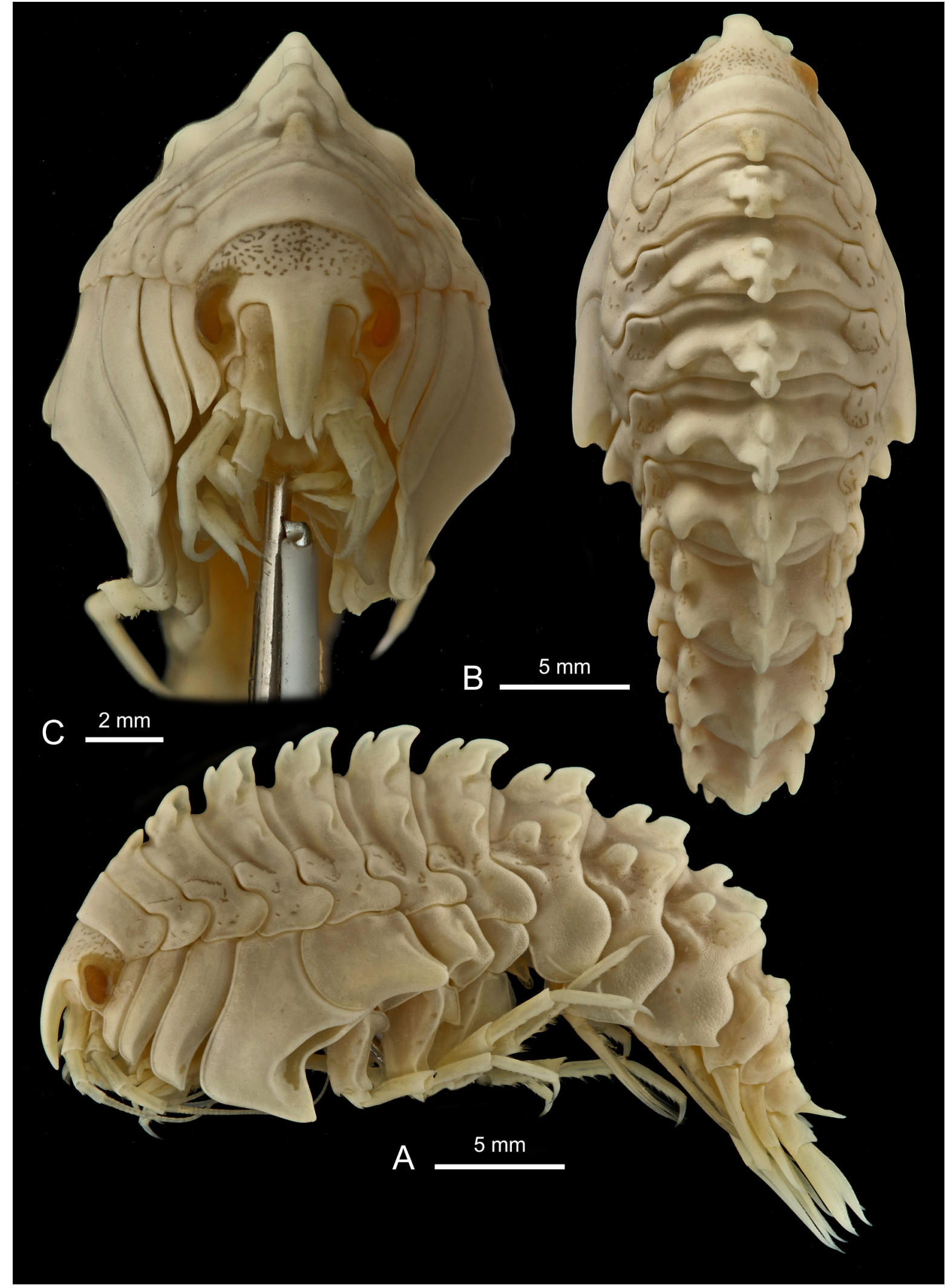

Fig. 208. Epimeria (Hoplepimeria) rimicarinata subgen. nov. Watling \& Holman, 1980, adult $\$$, Prydz Bay, MD2 stn 22- CP66, 26.185, MNHN-IU-2014-4265. A. Lateral habitus. B. Dorsal habitus. C. Facial habitus. 


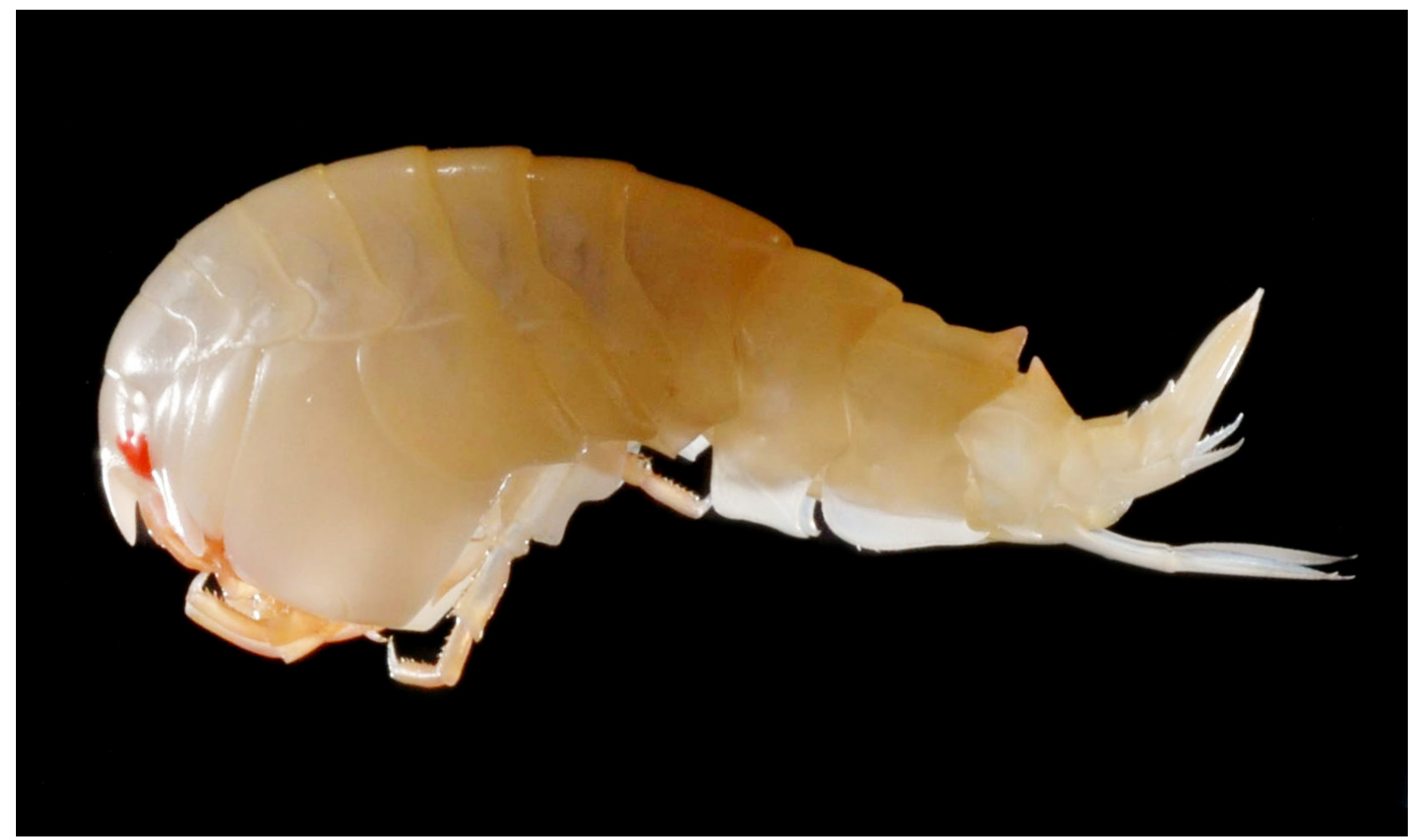

Fig. 209. Epimeria (Hoplepimeria) robusta subgen. nov. K.H. Barnard, 1930, sex undetermined, Adélie Coast, CEAMARC V3 1168, colour in life (photograph: Frédéric Busson, MNHN). Specimen not examined. 


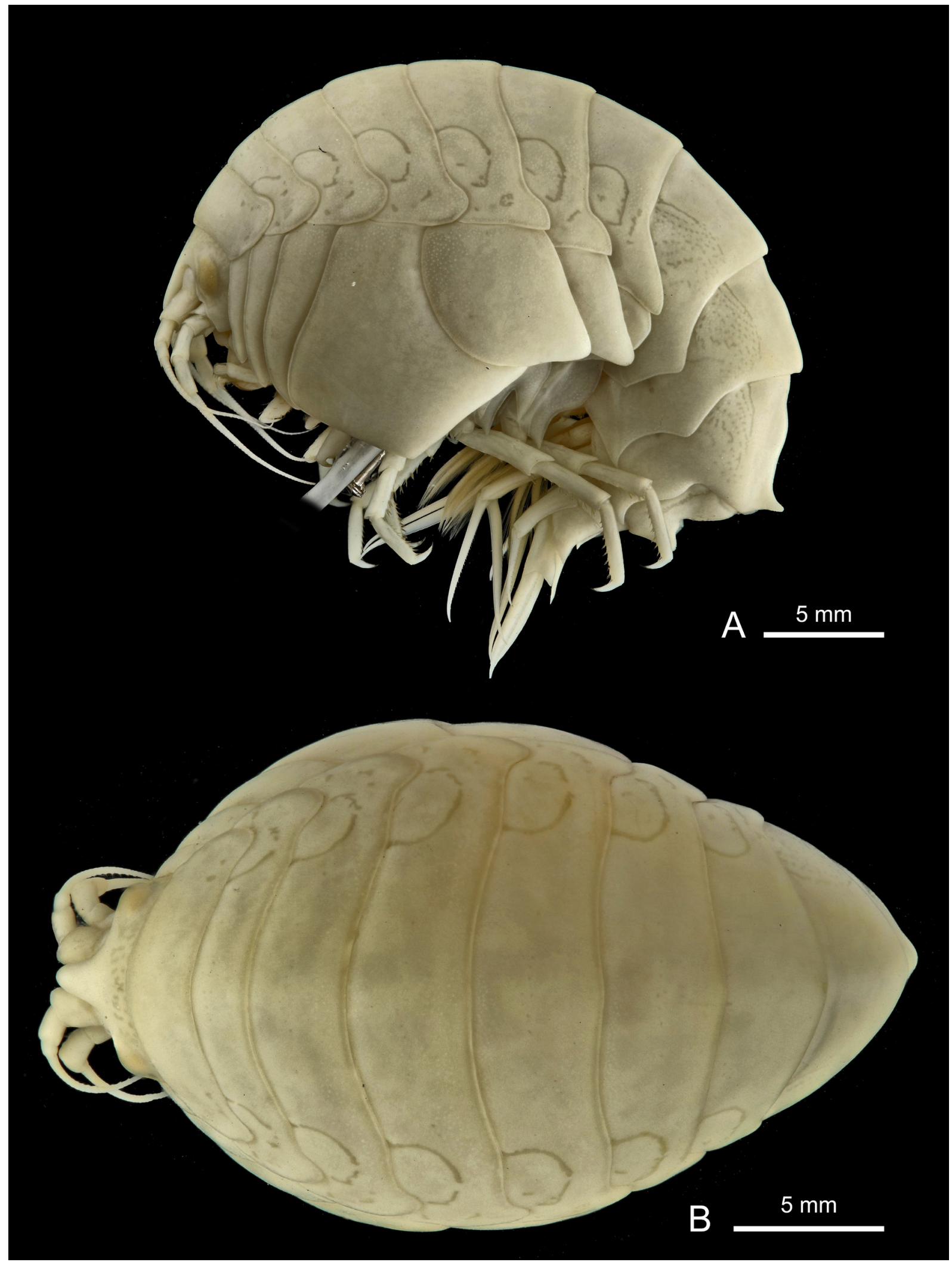

Fig. 210. Epimeria (Hoplepimeria) robusta subgen. nov. K.H. Barnard, 1930, adult ${ }_{\text {, }}$, Adélie Coast, Revolta I, REVO-043, MNHN-IU-2009-2571. A. Lateral habitus. B. Dorsal habitus. 


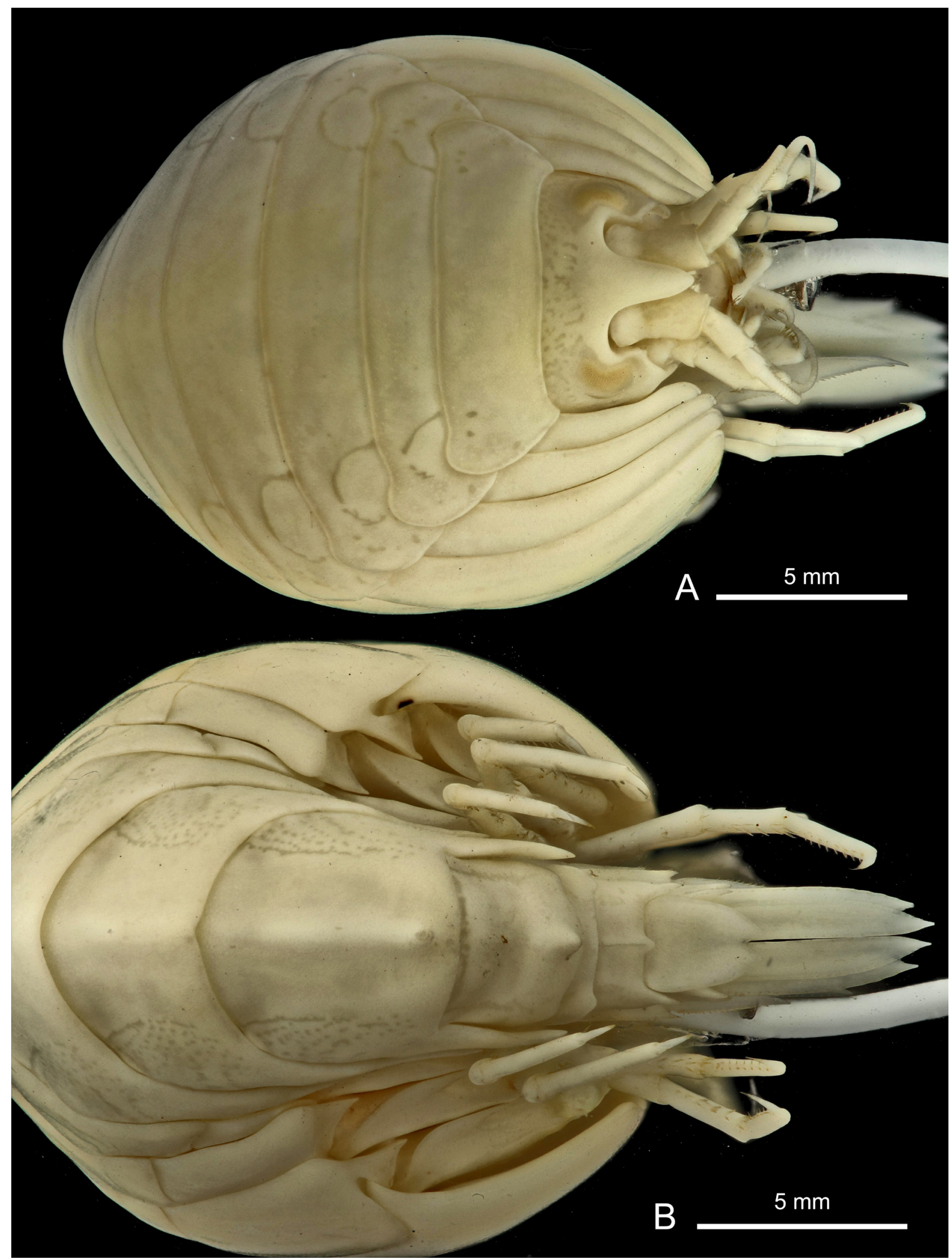

Fig. 211. Epimeria (Hoplepimeria) robusta subgen. nov. K.H. Barnard, 1930, adult $q$, Adélie Coast, Revolta I, REVO-043, MNHN-IU-2009-2571. A. Facial habitus. B. Urosome and pleon in dorsal view. 


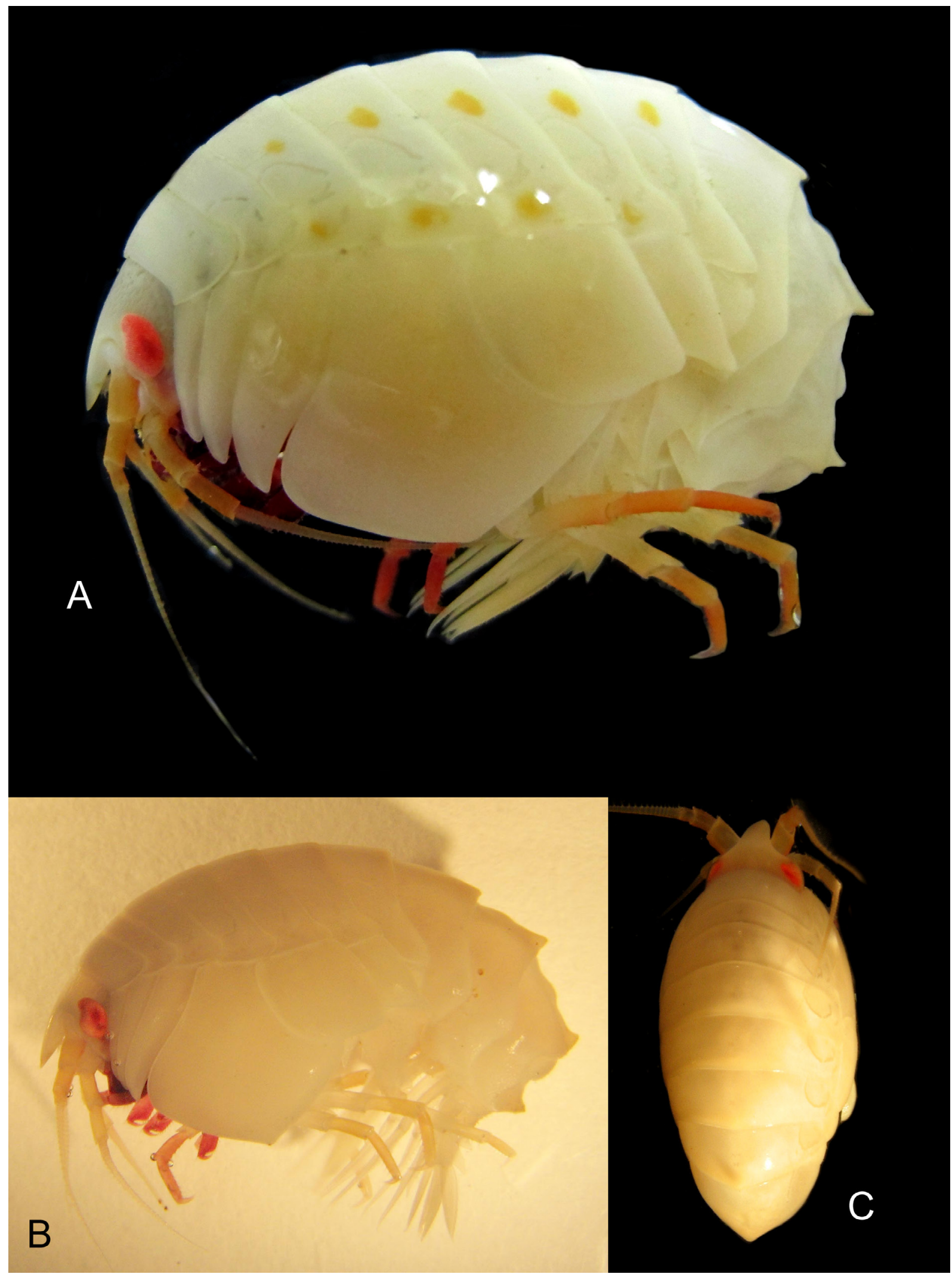

Fig. 212. Epimeria (Hoplepimeria) robustoides subgen. nov. Lörz \& Coleman in Lörz et al., 2009, colour in life. A. , , eastern Weddell Sea, ANT-XXVII/3, stn 265-2, RBINS, INV. 122894. B-C. , eastern Weddell Sea, ANT-XXIII/8, stn 603-5, RBINS, INV. 132985. 


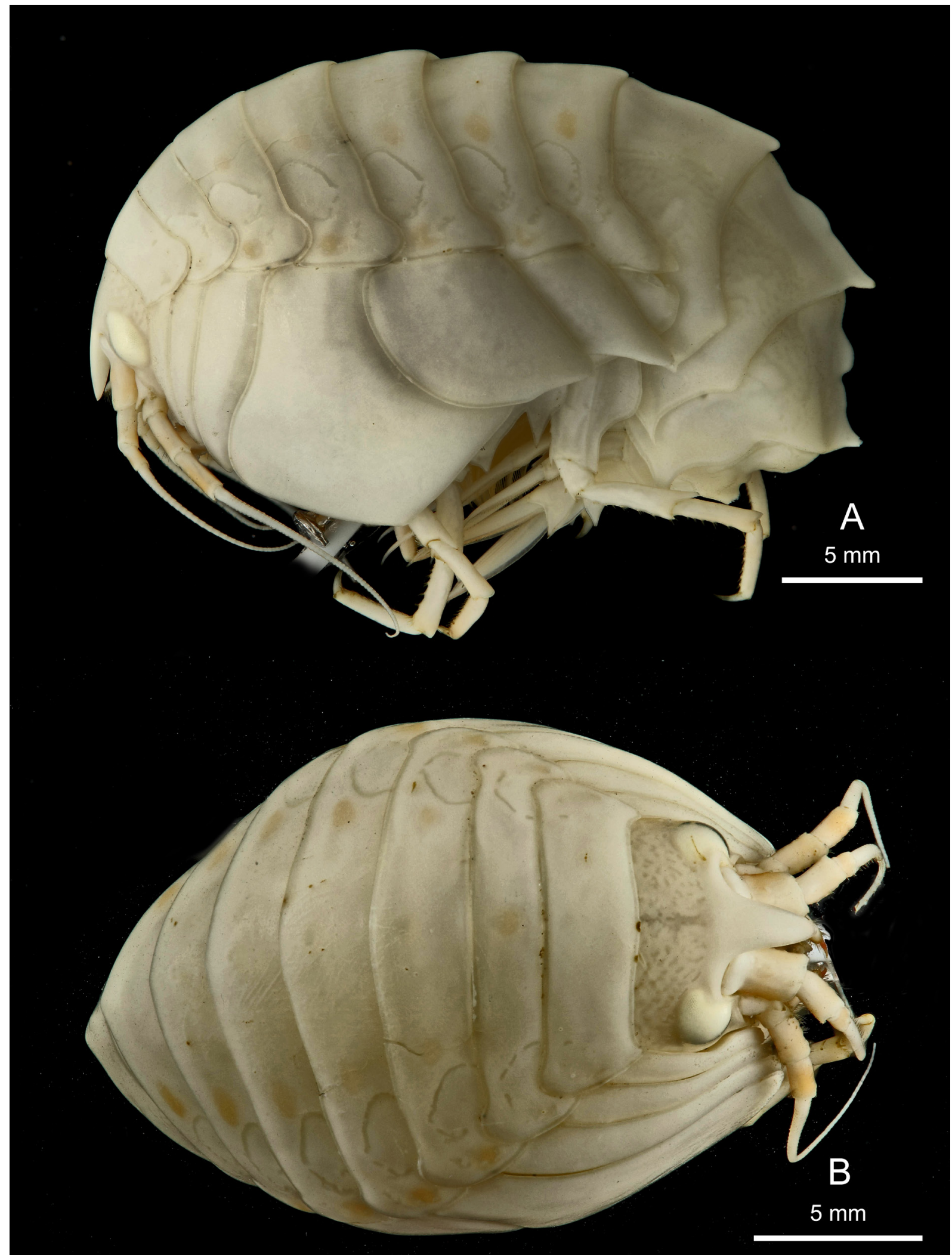

Fig. 213. Epimeria (Hoplepimeria) robustoides subgen. nov. Lörz \& Coleman in Lörz et al., 2009, +, eastern Weddell Sea, ANT-XXVII/3, stn 265-2, RBINS, INV. 122894. A. Lateral habitus. B. Facial habitus. 


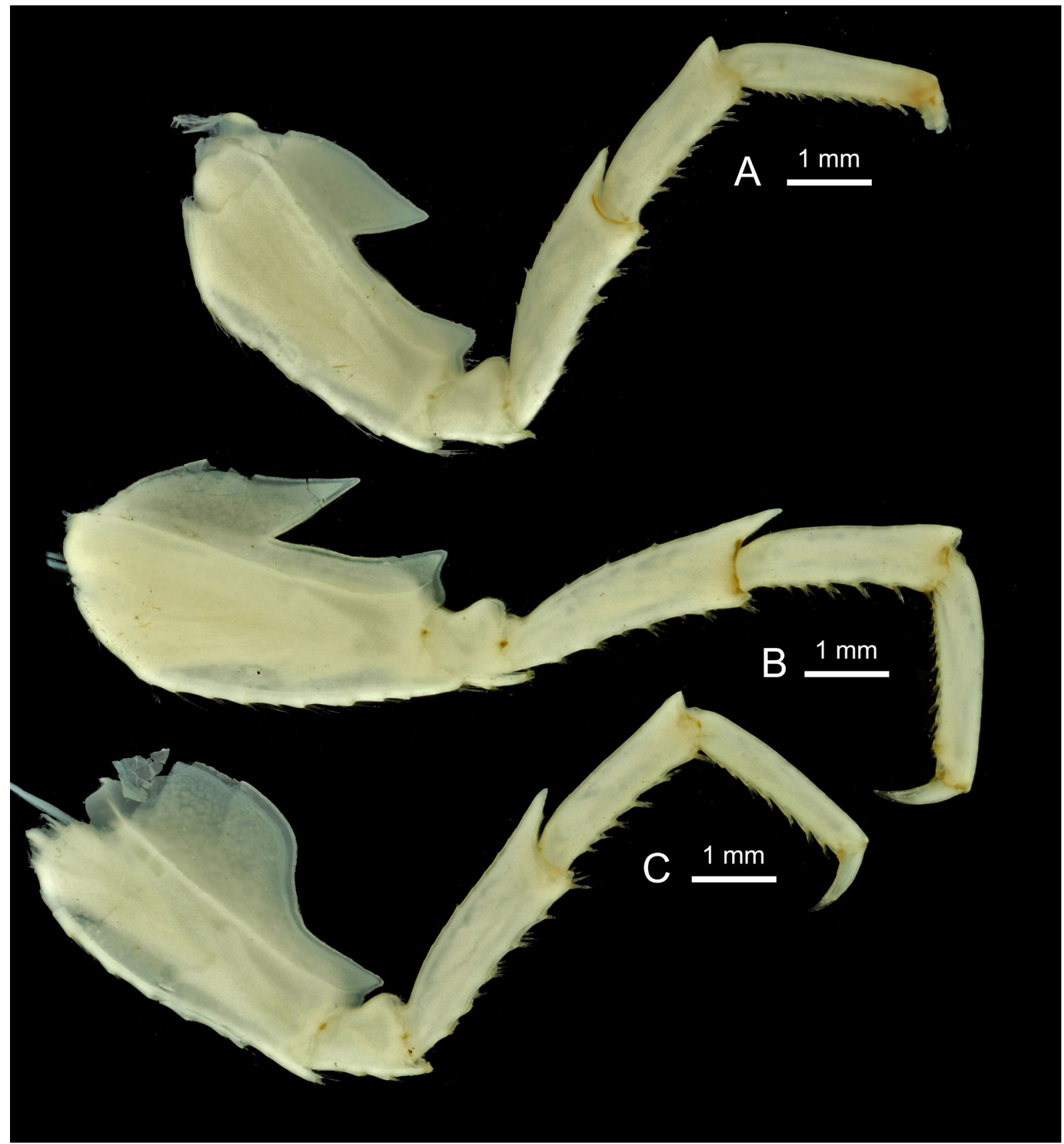

Fig. 214. Epimeria (Hoplepimeria) robustoides subgen. nov. Lörz \& Coleman in Lörz et al., 2009, $q$, eastern Weddell Sea, ANT-XXVII/3, stn 265-2, RBINS, INV. 122894. A. Pereiopod 5. B. Pereiopod 6. C. Pereiopod 7. 


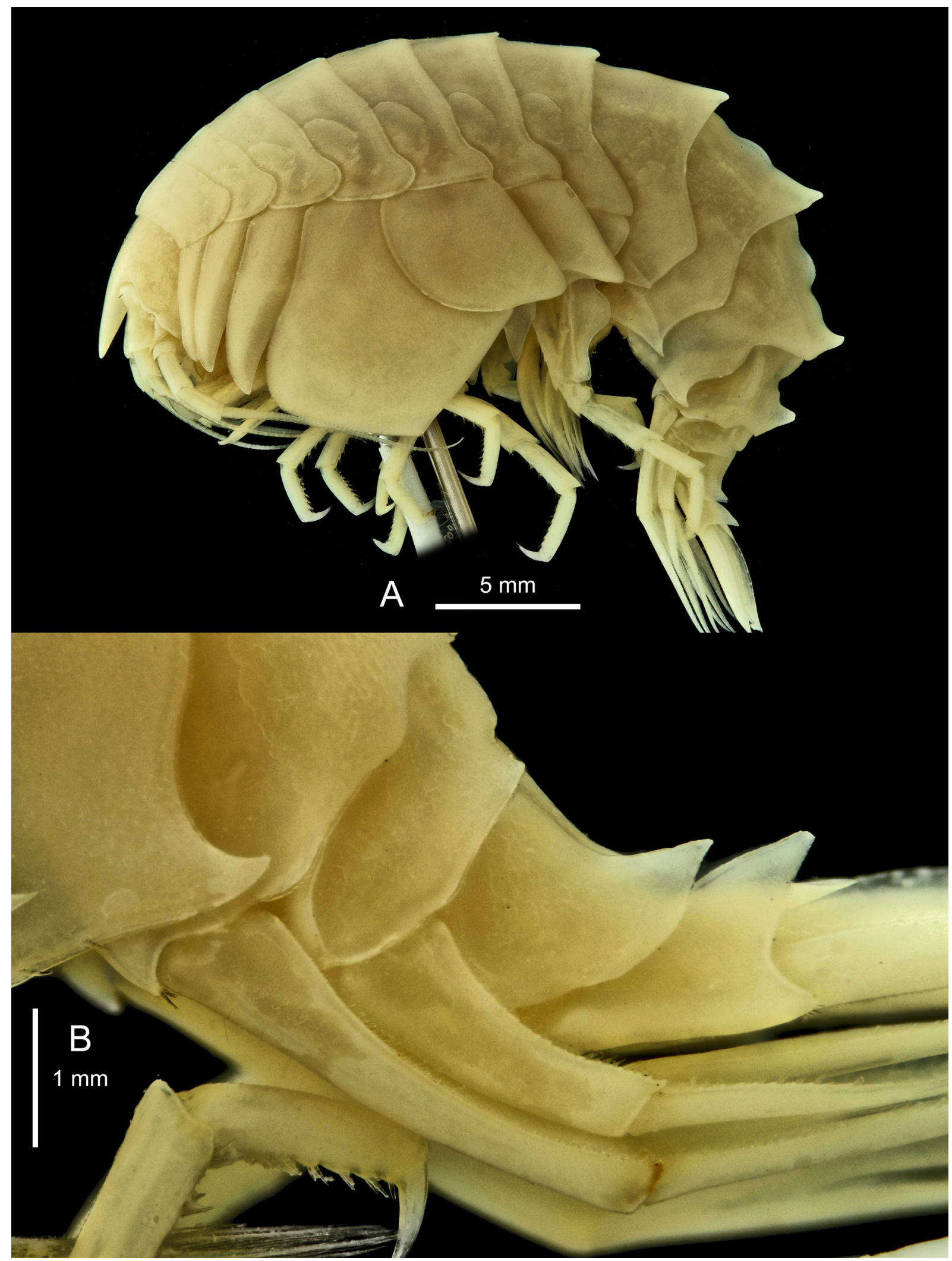

Fig. 215. Epimeria (Hoplepimeria) robustoides subgen. nov. Lörz \& Coleman in Lörz et al., 2009,, , eastern Weddell Sea, ANT-VII/4, stn 290, RBINS, INV. 132944. A. Lateral habitus. B. Segments 2 and 3 of urosome. 


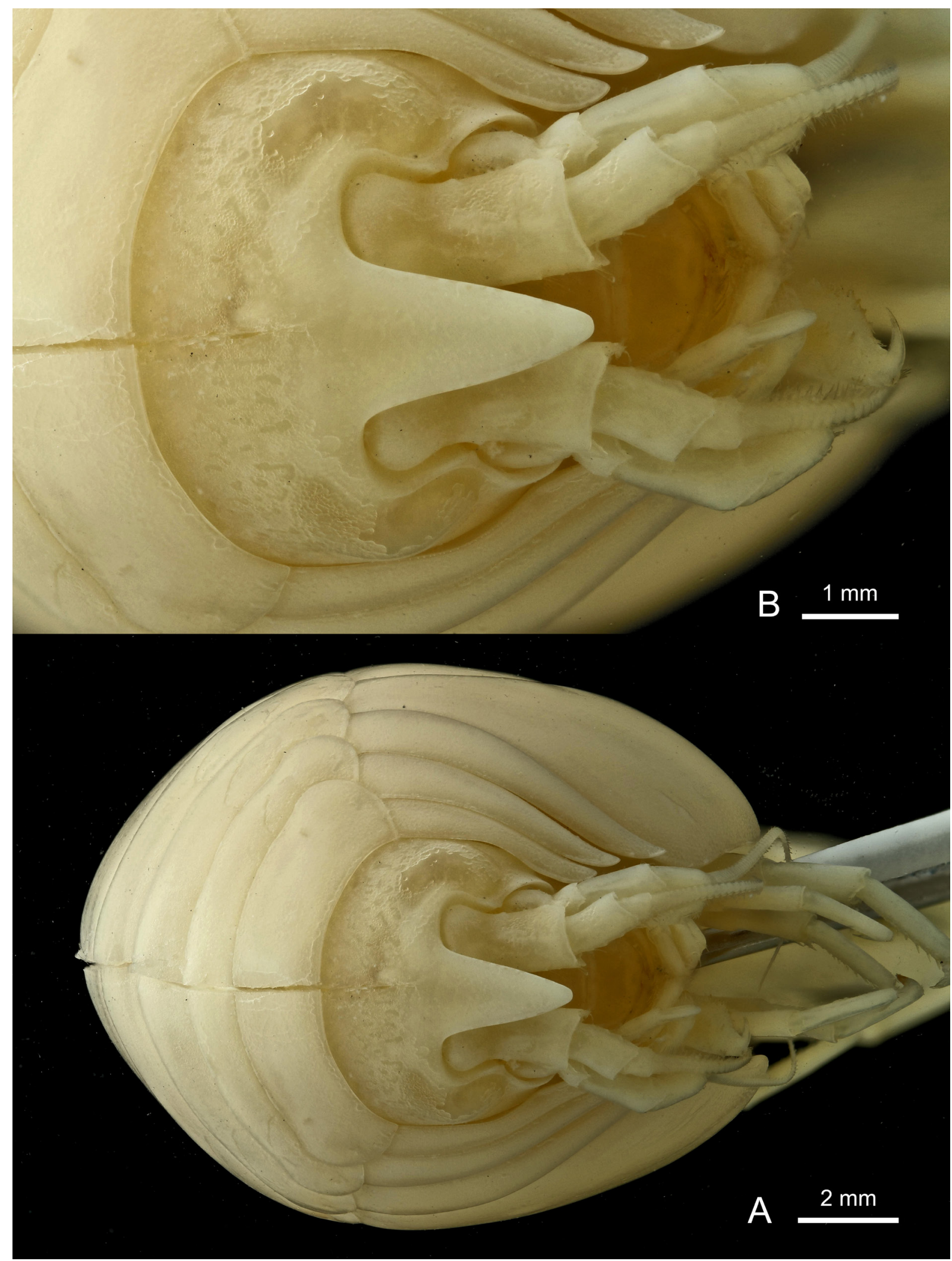

Fig. 216. Epimeria (Hoplepimeria) robustoides subgen. nov. Lörz \& Coleman in Lörz et al., 2009, +, eastern Weddell Sea, ANT-VII/4, stn 290. RBINS, INV. 132944. A. Facial habitus. B. Head in facial view. 


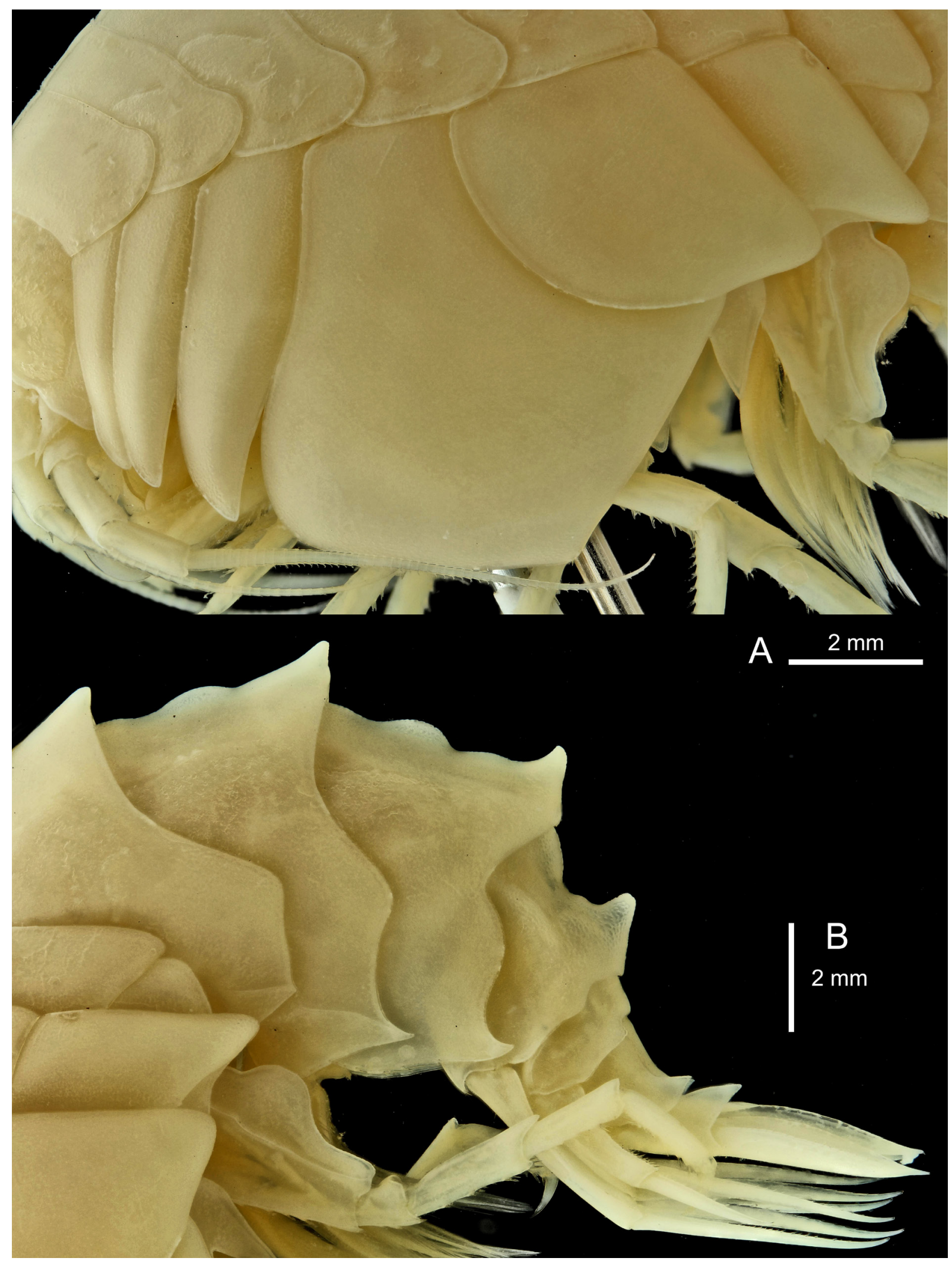

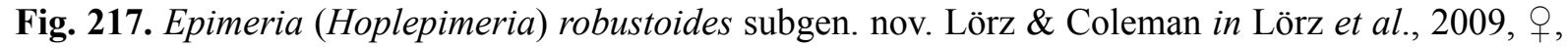
eastern Weddell Sea, ANT-VII/4, stn 290. RBINS, INV. 132944. A. Coxae 1-7. B. Pleon. 


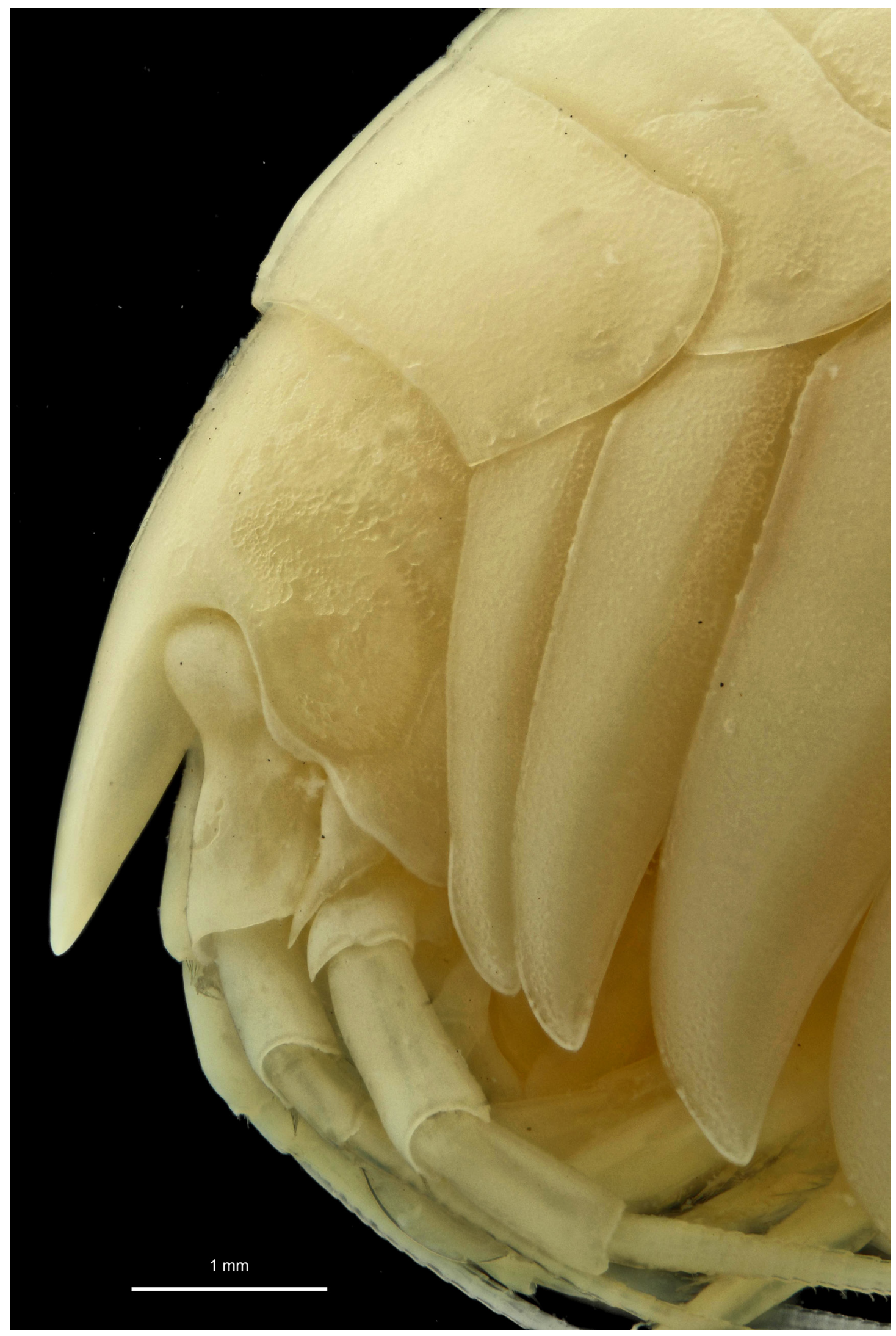

Fig. 218. Epimeria (Hoplepimeria) subgen. nov. robustoides Lörz \& Coleman in Lörz et al., 2009, q, eastern Weddell Sea, ANT-VII/4, stn 290. RBINS, INV. 132944. Head in lateral view and coxae 1-3. 


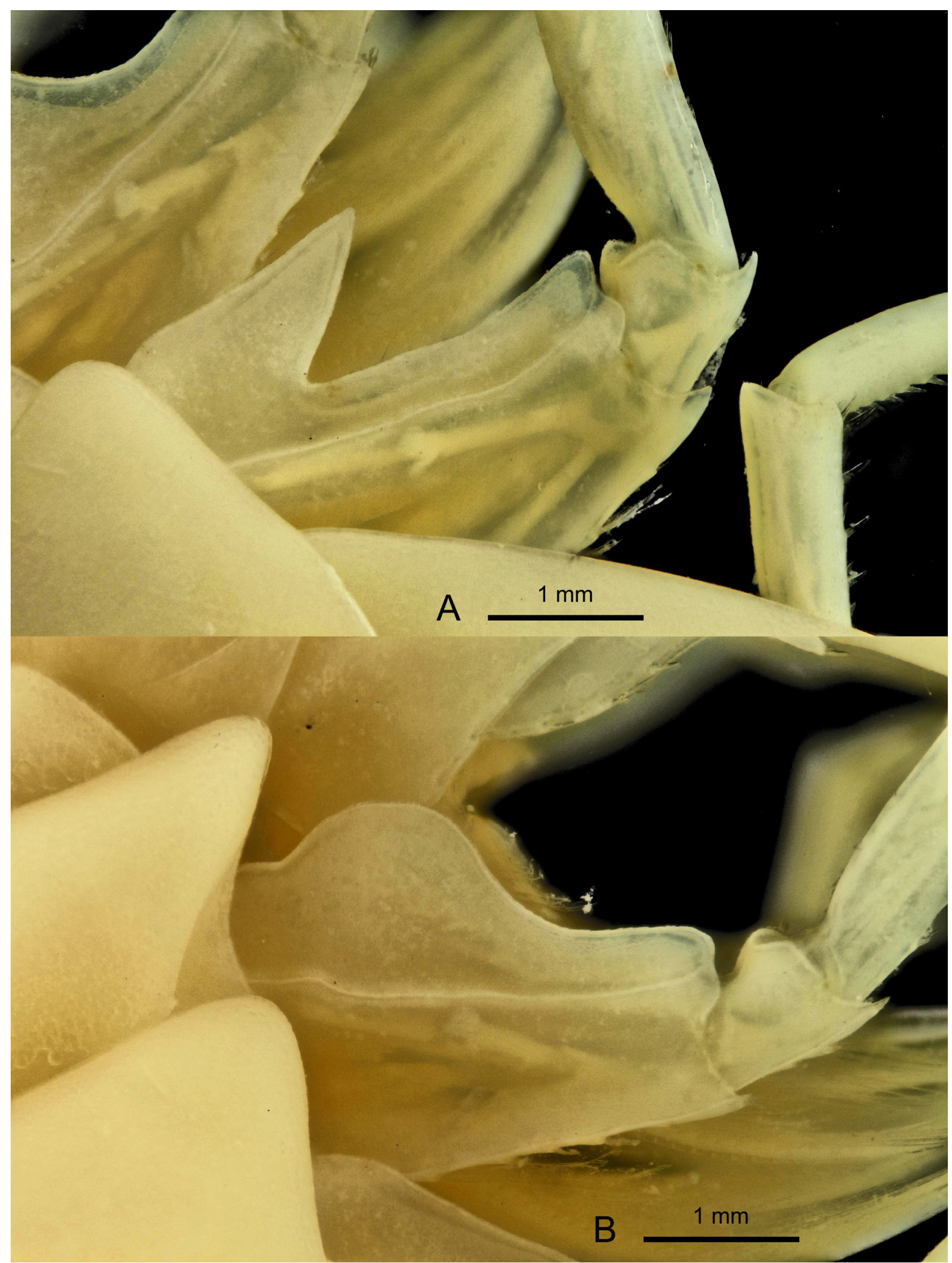

Fig. 219. Epimeria (Hoplepimeria) robustoides subgen. nov. Lörz \& Coleman in Lörz et al., 2009, q, eastern Weddell Sea, ANT-VII/4, stn 290. RBINS, INV. 132944. A. Basis of pereiopod 6. B. Basis of Pereiopod 7. 


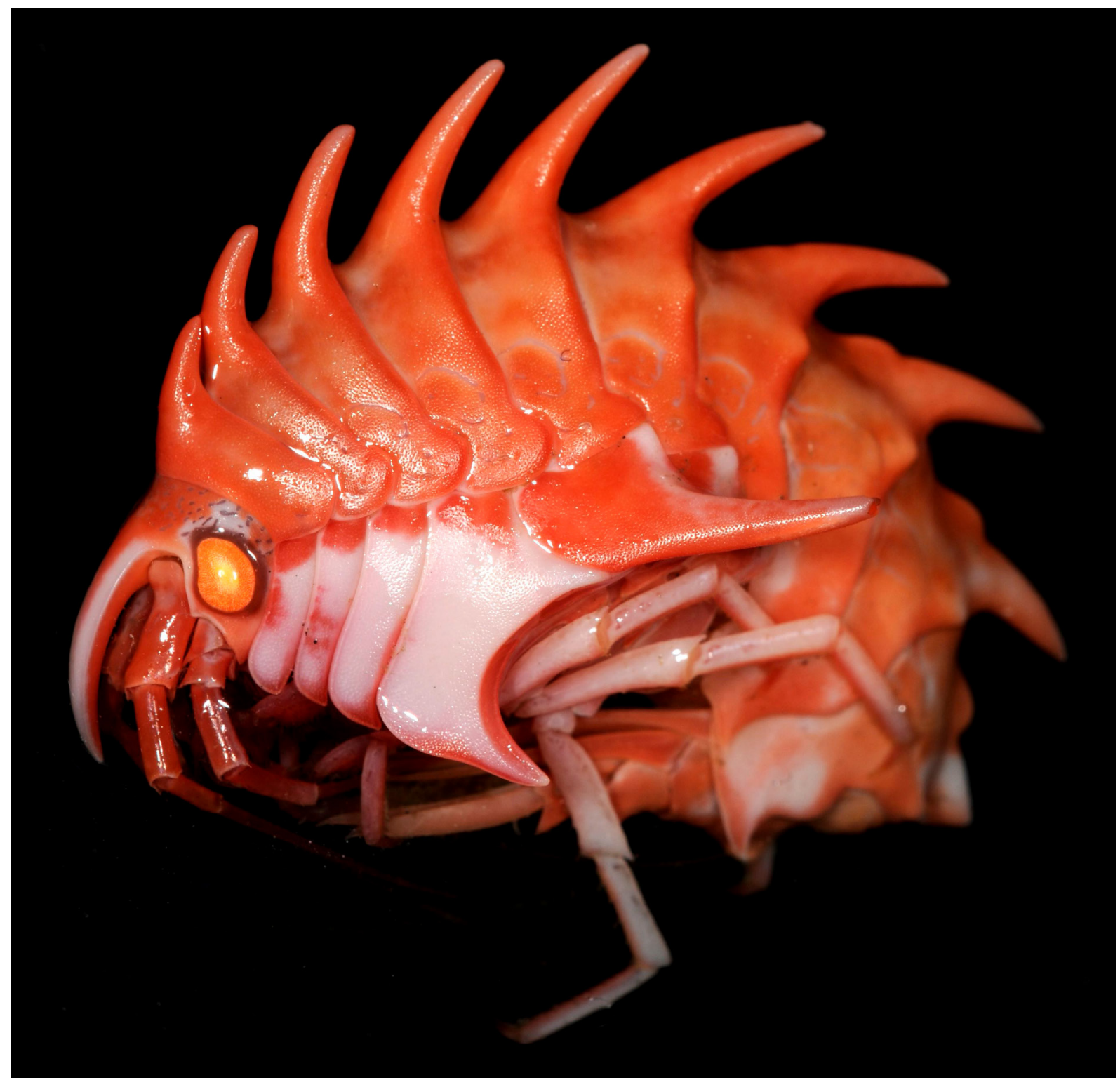

Fig. 220. Epimeria (Hoplepimeria) rubrieques subgen. nov. De Broyer \& Klages, 1991, presumably ${ }_{\text {, }}$ eastern Weddell Sea, ANT-XXIV/2, stn 48-1, RBINS, INV. 132943 or INV. 132410, colour in life (photograph: Armin Rose). 


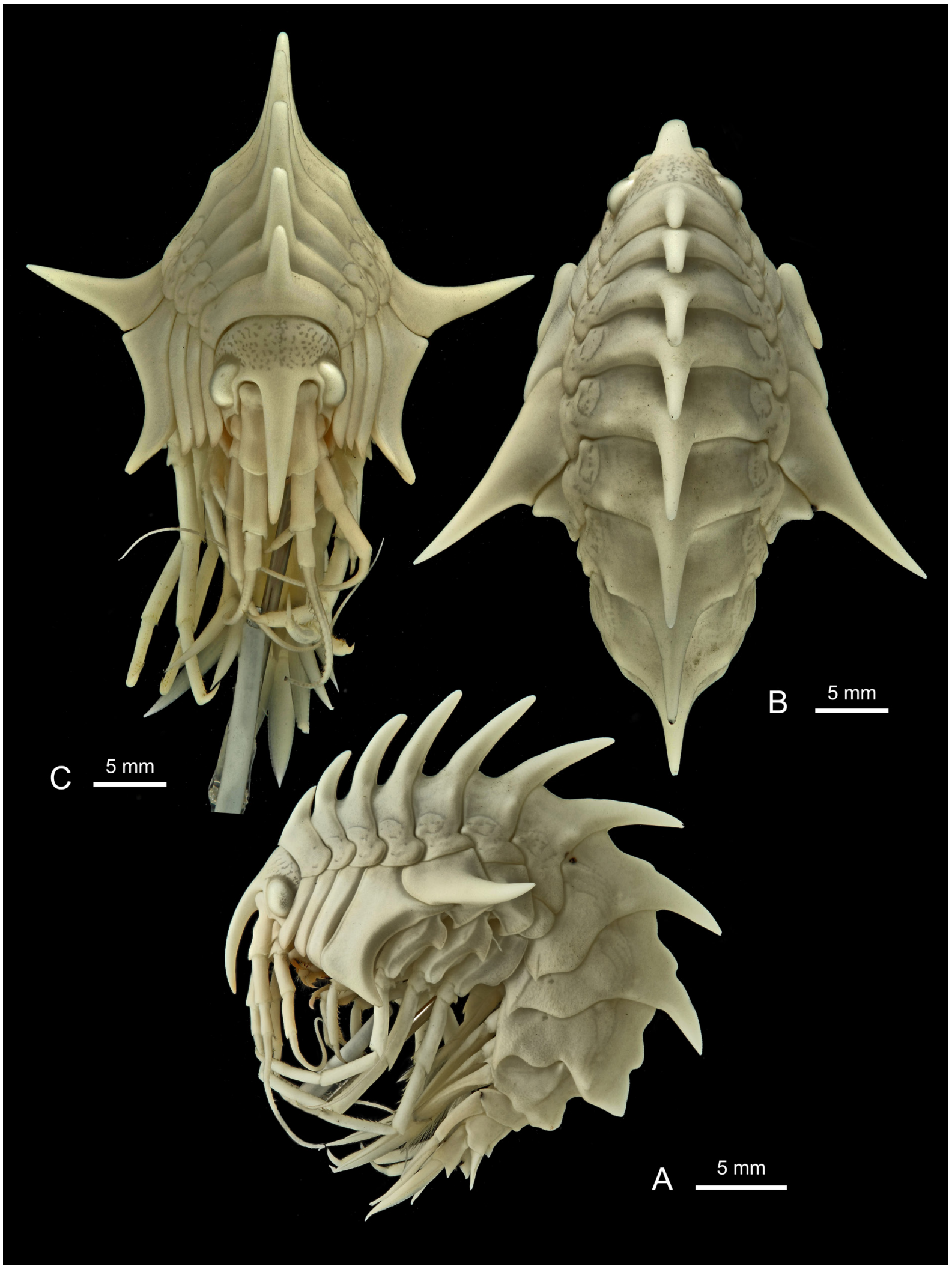

Fig. 221. Epimeria (Hoplepimeria) rubrieques subgen. nov. De Broyer \& Klages, 1991, presumably $q$, eastern Weddell Sea, ANT-XXIV/2, stn 48-1, RBINS, INV. 132943. A. Lateral habitus. B. Dorsal habitus. C. Facial habitus. 


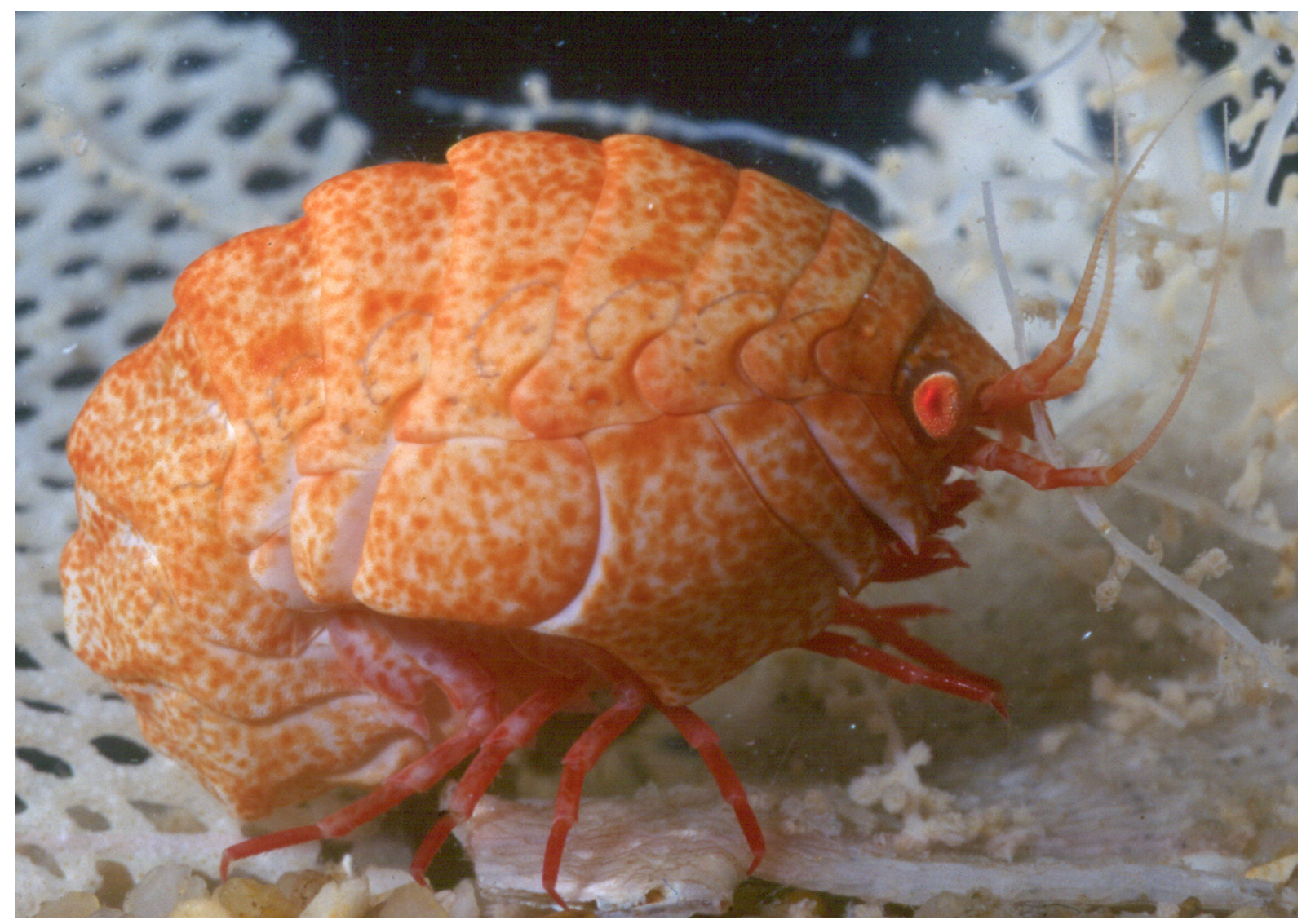

Fig. 222. Epimeria (Hoplepimeria) xesta subgen. et sp. nov., + , ANT-XIII/3, EASIZ I, no station, photography made in aquarium by G. Chapelle, 3 Mar. 1996: presumably one of the adult paratypes registered as RBINS, INV. 132994. 


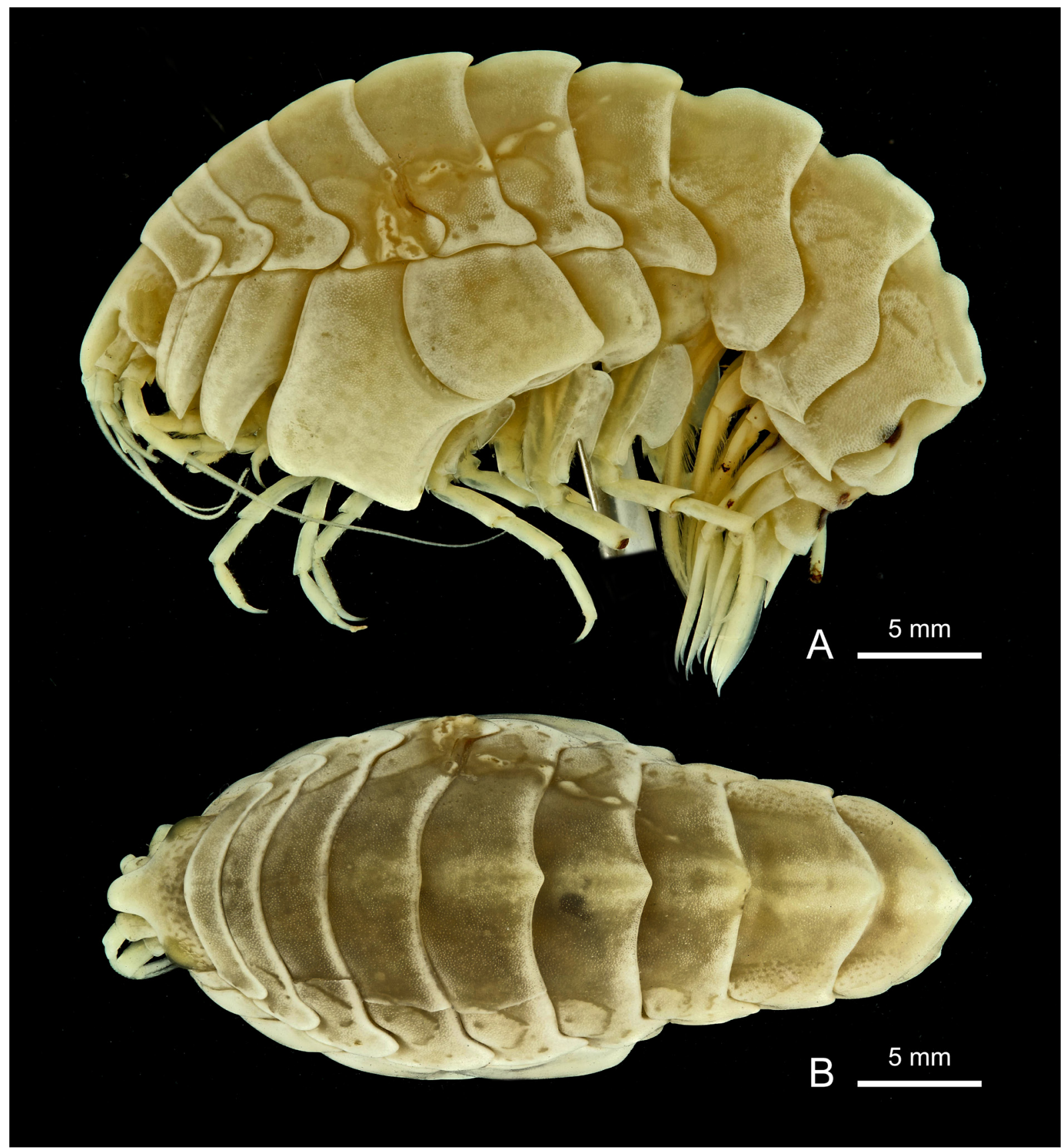

Fig. 223. Epimeria (Hoplepimeria) xesta subgen. et sp. nov., adult $q$, holotype, eastern shelf of Weddell Sea, ANT-VII/4, stn 226, RBINS, INV. 132946. A. Lateral habitus. B. Dorsal habitus. 


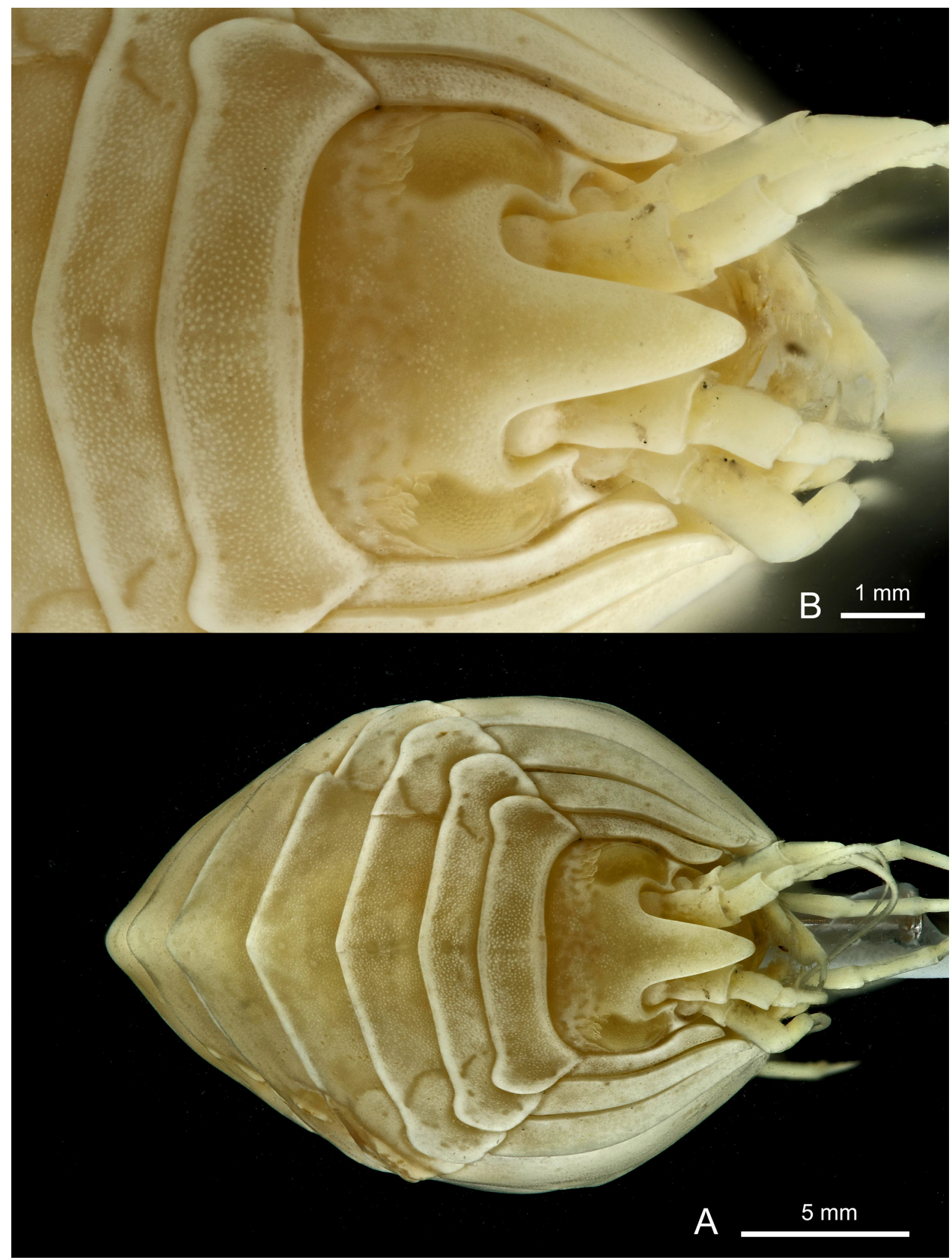

Fig. 224. Epimeria (Hoplepimeria) xesta subgen. et sp. nov., adult $q$, holotype, eastern shelf of Weddell Sea, ANT-VII/4, stn 226, RBINS, INV. 132946. A. Facial habitus. B. Head in facial view. 


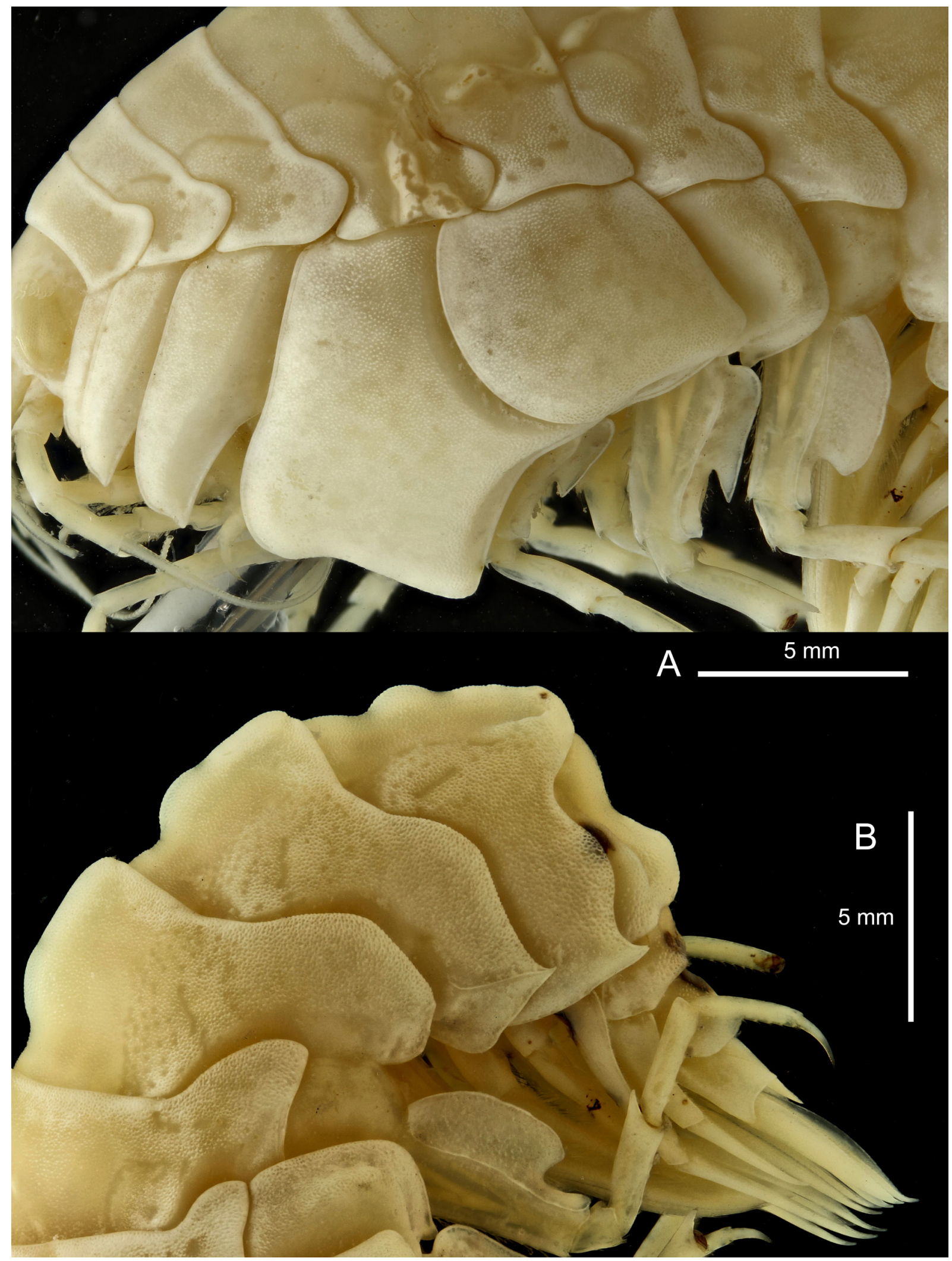

Fig. 225. Epimeria (Hoplepimeria) xesta subgen. et sp. nov., adult $q$, holotype, eastern shelf of Weddell Sea, ANT-VII/4, stn 226, RBINS, INV. 132946. A. Coxae. B. Pleon. 


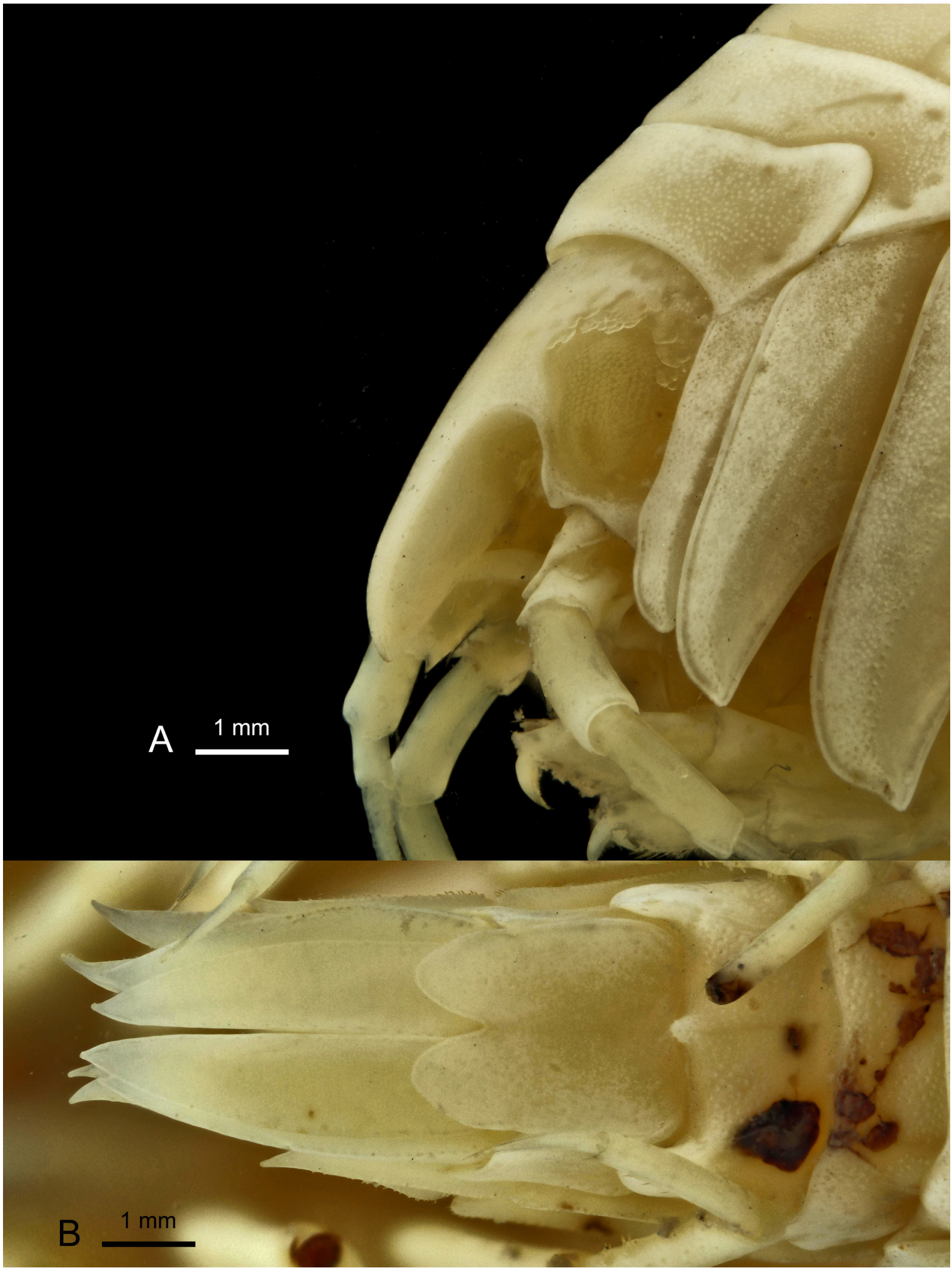

Fig. 226. Epimeria (Hoplepimeria) xesta subgen. et sp. nov., adult $\odot$, holotype, eastern shelf of Weddell Sea, ANT-VII/4, stn 226, RBINS, INV. 132946. A. Head in lateral view. B. Urosome in dorsal view. 


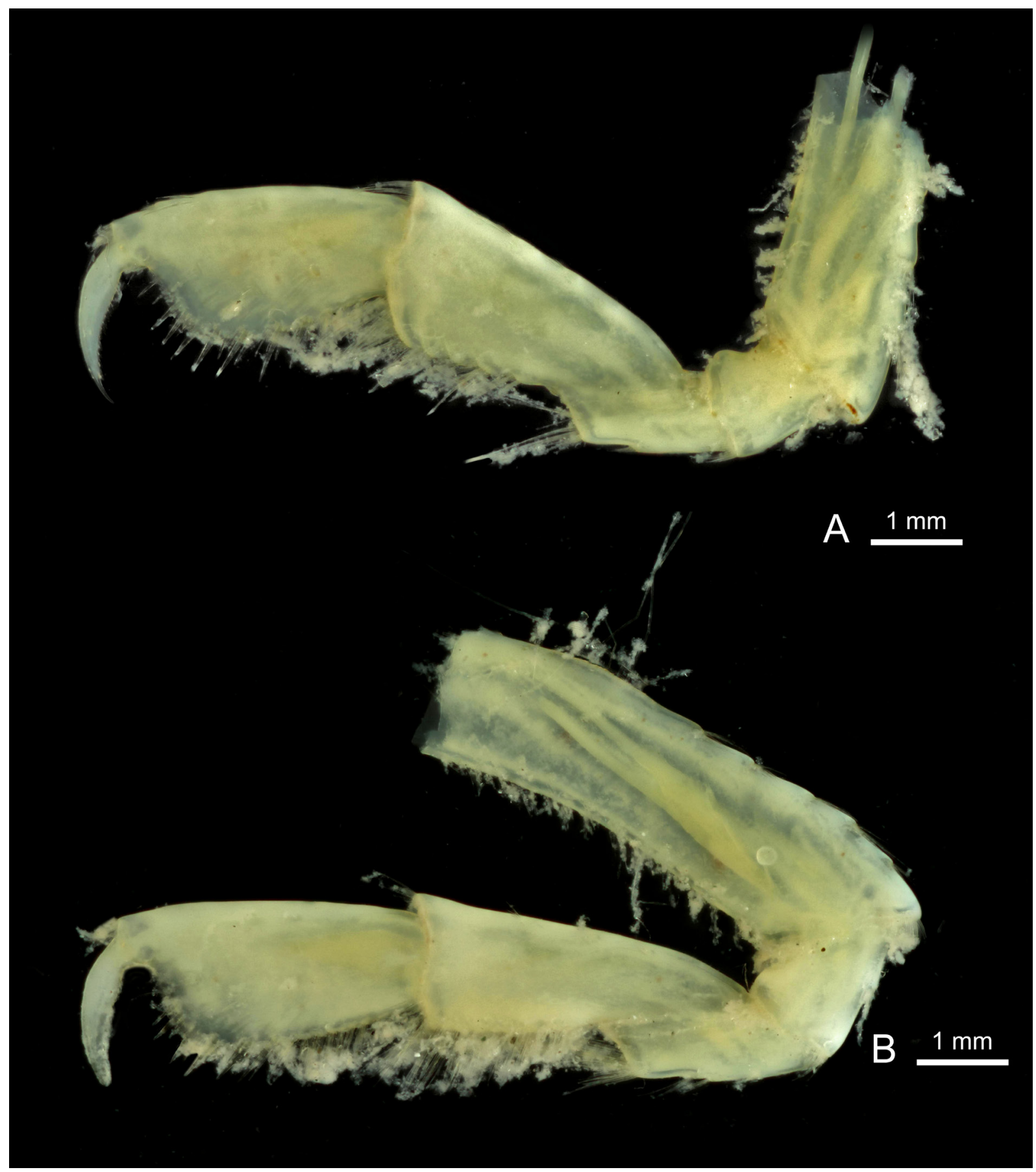

Fig. 227. Epimeria (Hoplepimeria) xesta subgen. et sp. nov., adult $q$, holotype, eastern shelf of Weddell Sea, ANT-VII/4, stn 226, RBINS, INV. 132946. A. Gnathopod 1. B. Gnathopod 2. 


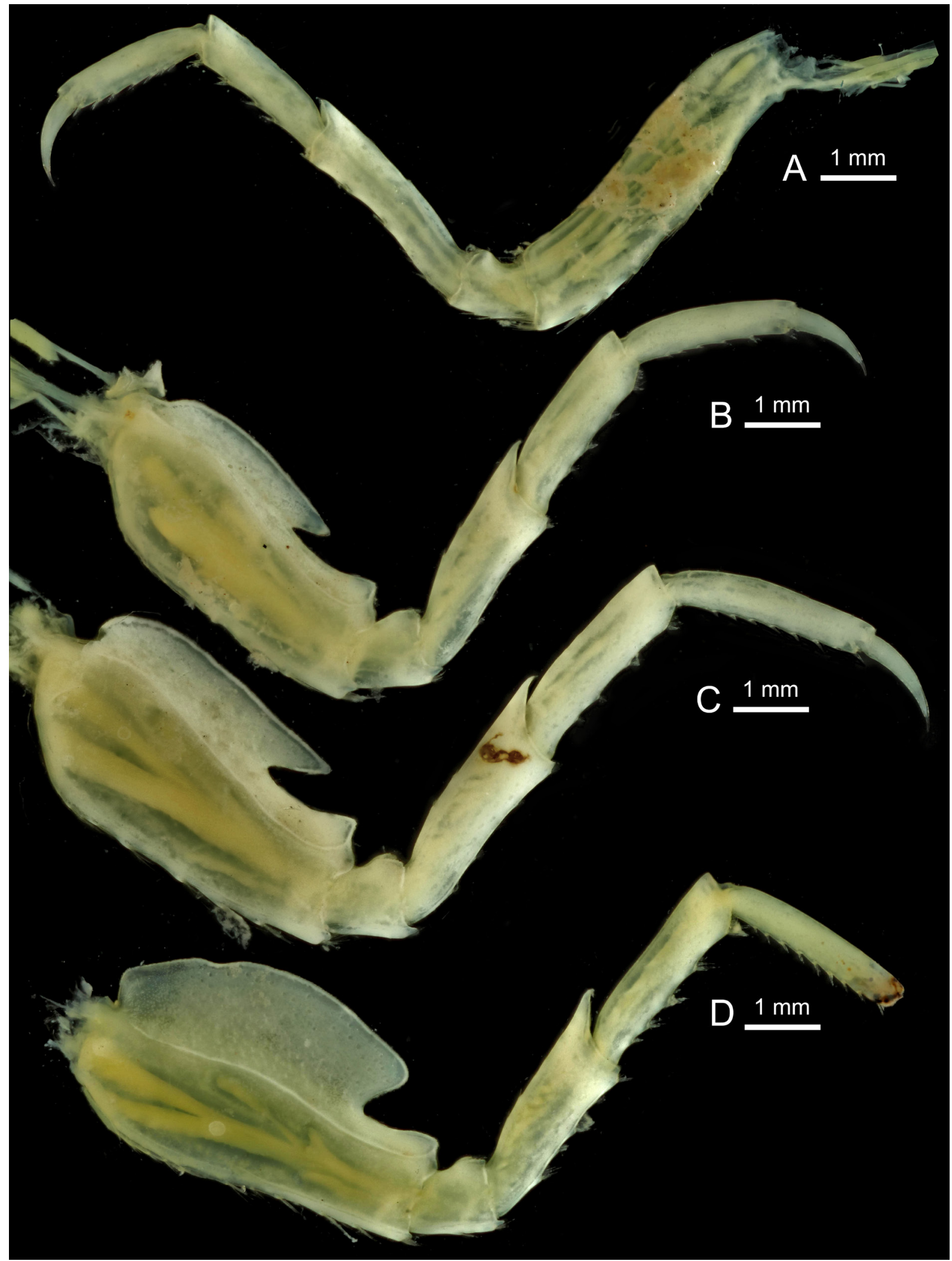

Fig. 228. Epimeria (Hoplepimeria) xesta subgen. et sp. nov., adult $q$, holotype, eastern shelf of Weddell Sea, ANT-VII/4, stn 226, RBINS, INV. 132946. A. Pereiopod 4. B. Pereiopod 5. C. Pereiopod 6. D. Pereiopod 7. 


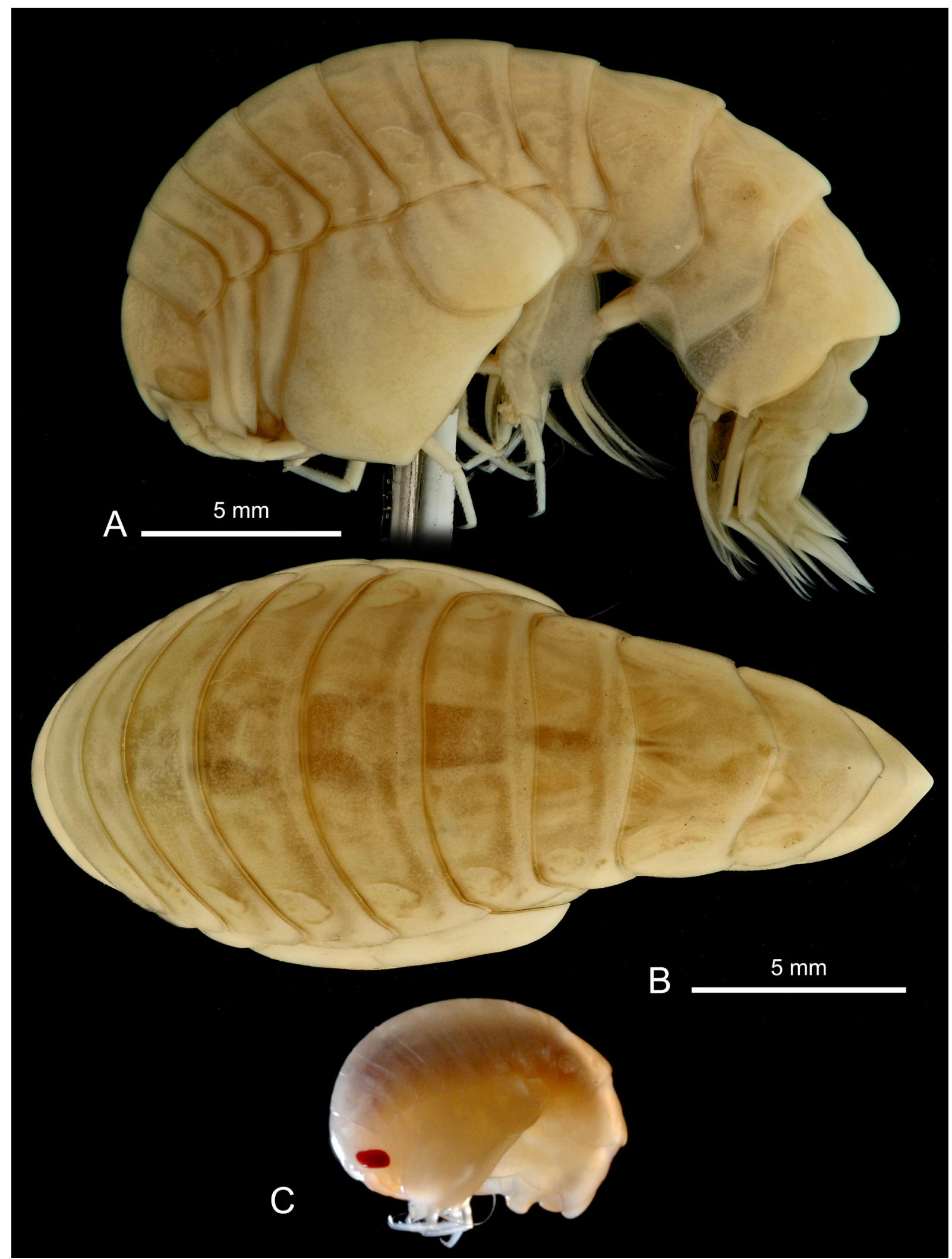

Fig. 229. Epimeria (Laevepimeria) anodon subgen. et sp. nov., sex undetermined, Adélie Coast. A-B, CEAMARC 2724, MNHN-IU-2014-4336. C, CEAMARC V3 1106 (photograph: Frédéric Busson, MNHN); specimen not examined. A. Lateral habitus. B. Dorsal habitus. C. Colour in life. 


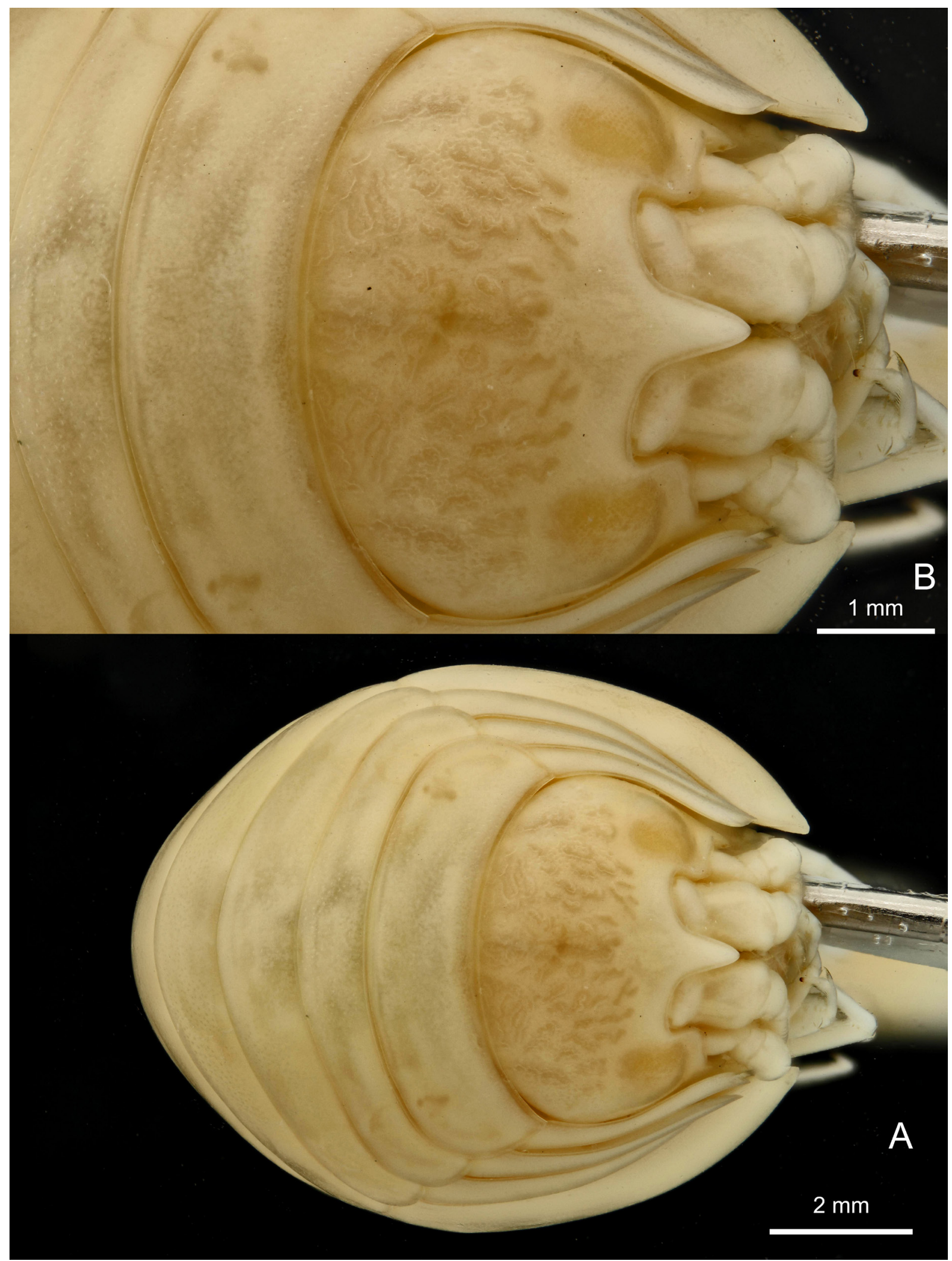

Fig. 230. Epimeria (Laevepimeria) anodon subgen. et sp. nov., sex undetermined, Adélie Coast, CEAMARC 2724, MNHN-IU-2014-4336. A. Facial habitus. B. Head in facial view. 


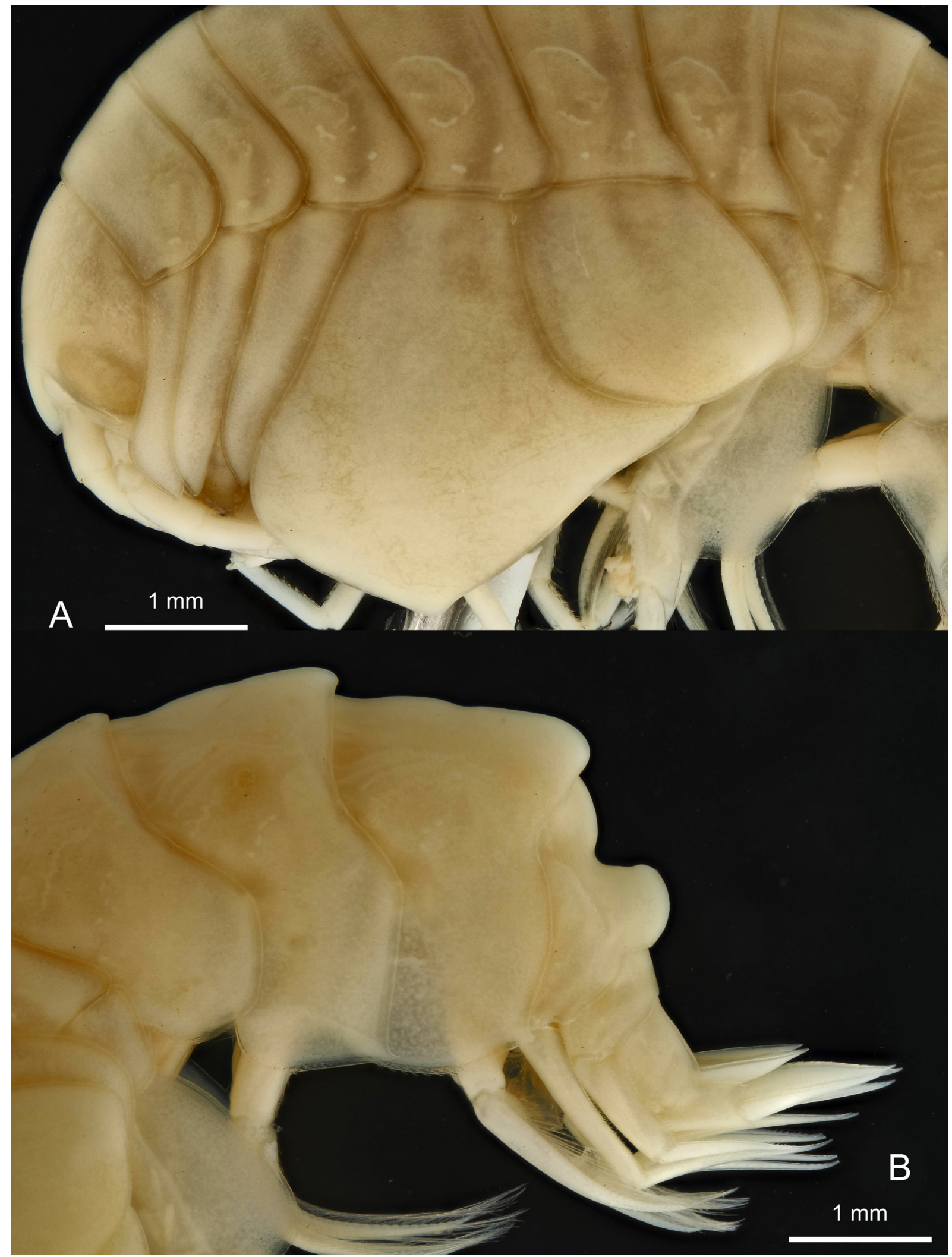

Fig. 231. Epimeria (Laevepimeria) anodon subgen. et sp. nov., sex undetermined, Adélie Coast, CEAMARC 2724, MNHN-IU-2014-4336. A. Anterior half. B. Posterior half. 


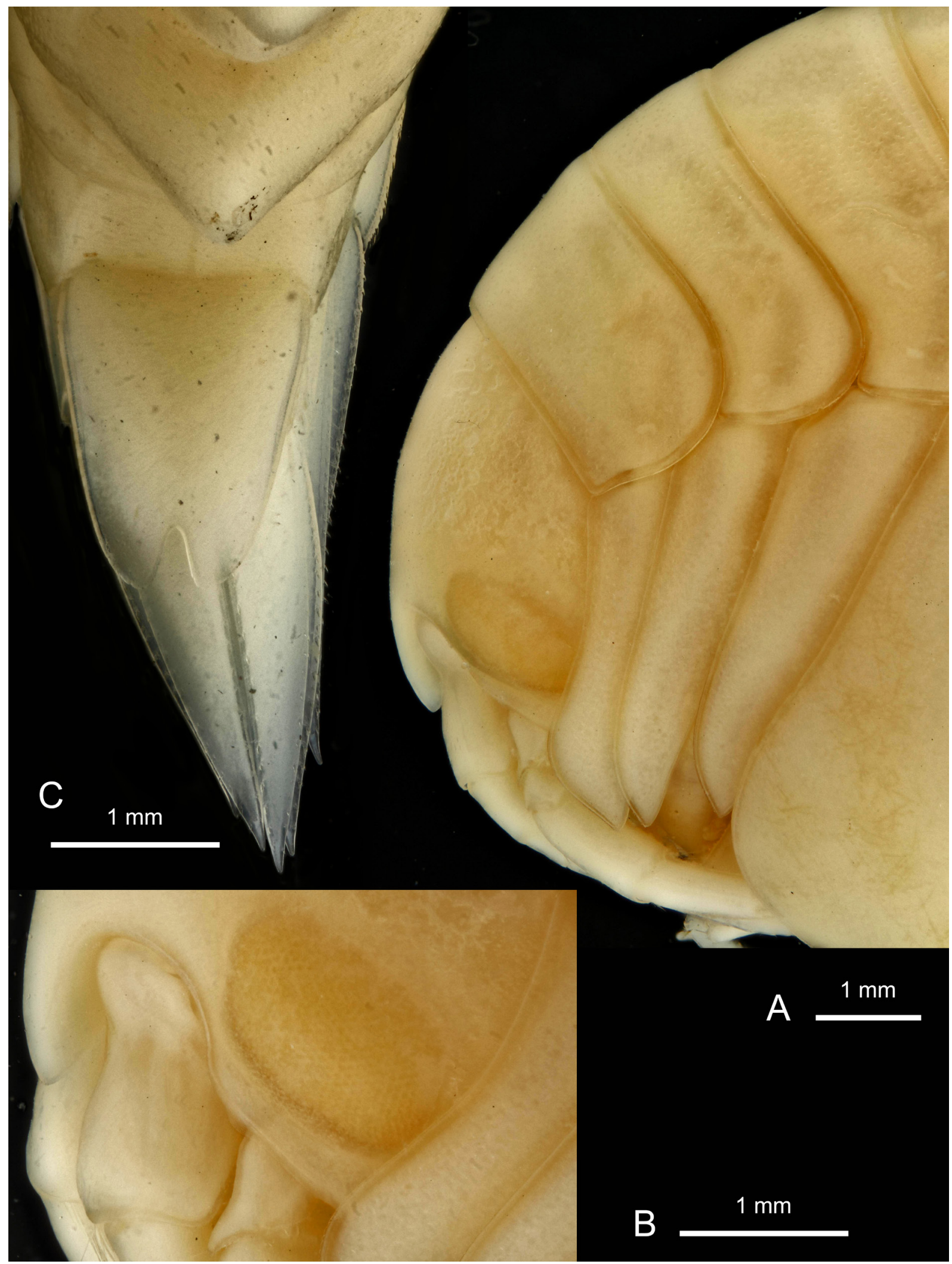

Fig. 232. Epimeria (Laevepimeria) anodon subgen. et sp. nov., sex undetermined, Adélie Coast, CEAMARC 2724, MNHN-IU-2014-4336. A. Head in lateral view. B. Urosome in dorsal view. C. Telson. 


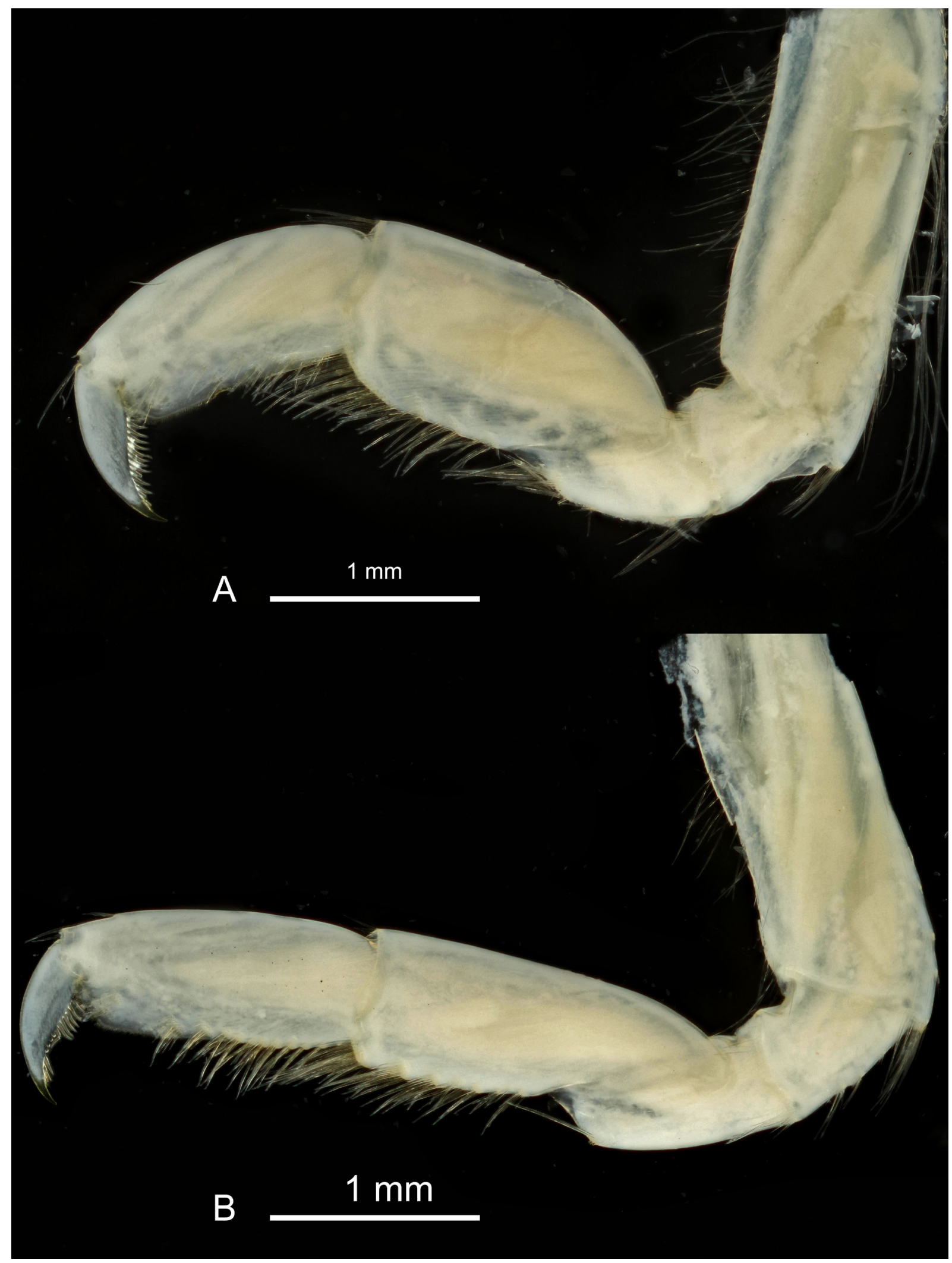

Fig. 233. Epimeria (Laevepimeria) anodon subgen. et sp. nov., sex undetermined, Adélie Coast, CEAMARC 2724, MNHN-IU-2014-4336. A. Gnathopod 1. B. Gnathopod 2. 


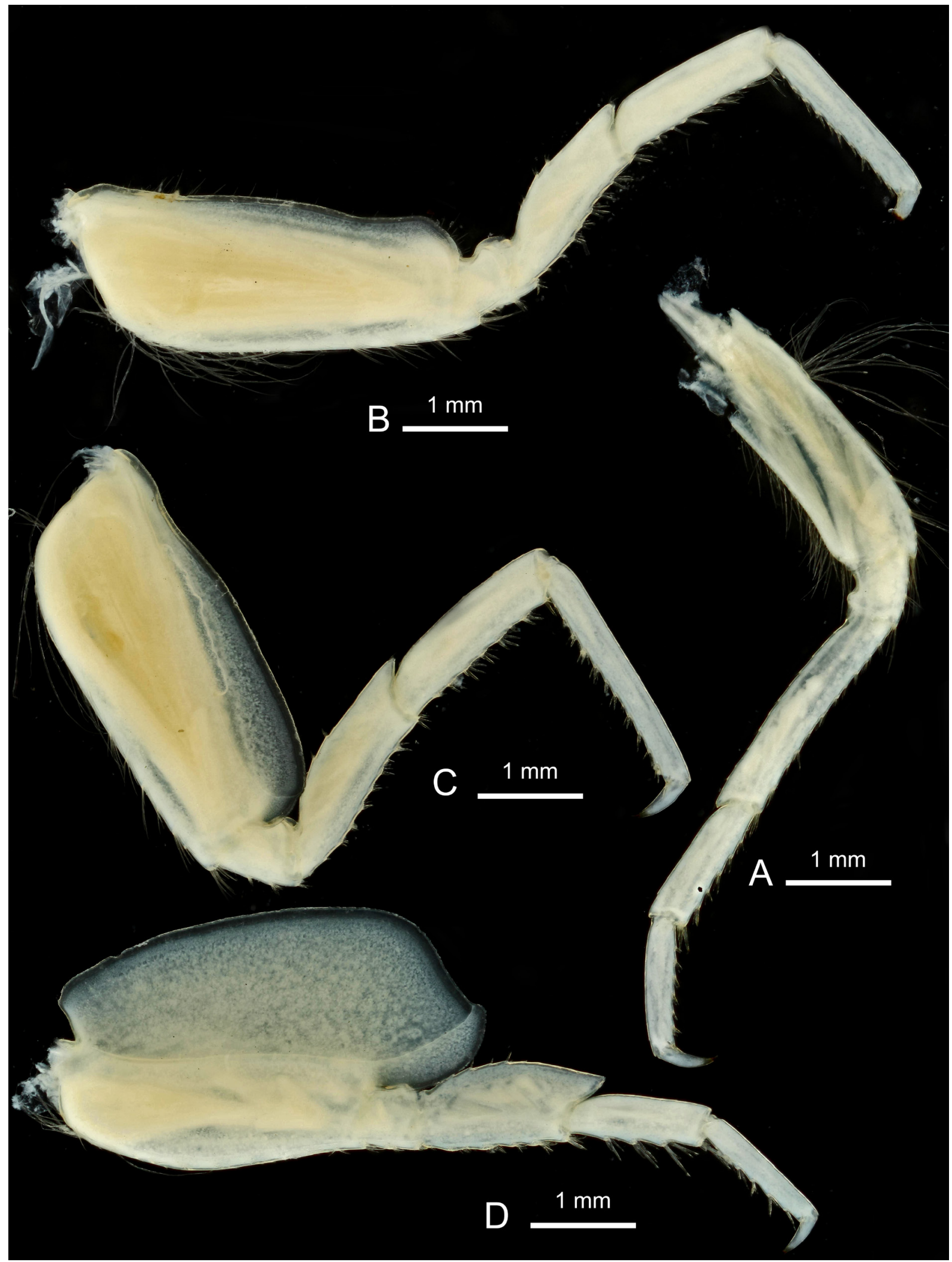

Fig. 234. Epimeria (Laevepimeria) anodon subgen. et sp. nov., sex undetermined, Adélie Coast, CEAMARC 2724, MNHN-IU-2014-4336. A. Pereiopod 4. B. Pereiopod 5. C. Pereiopod 6. D. Pereiopod 7. 


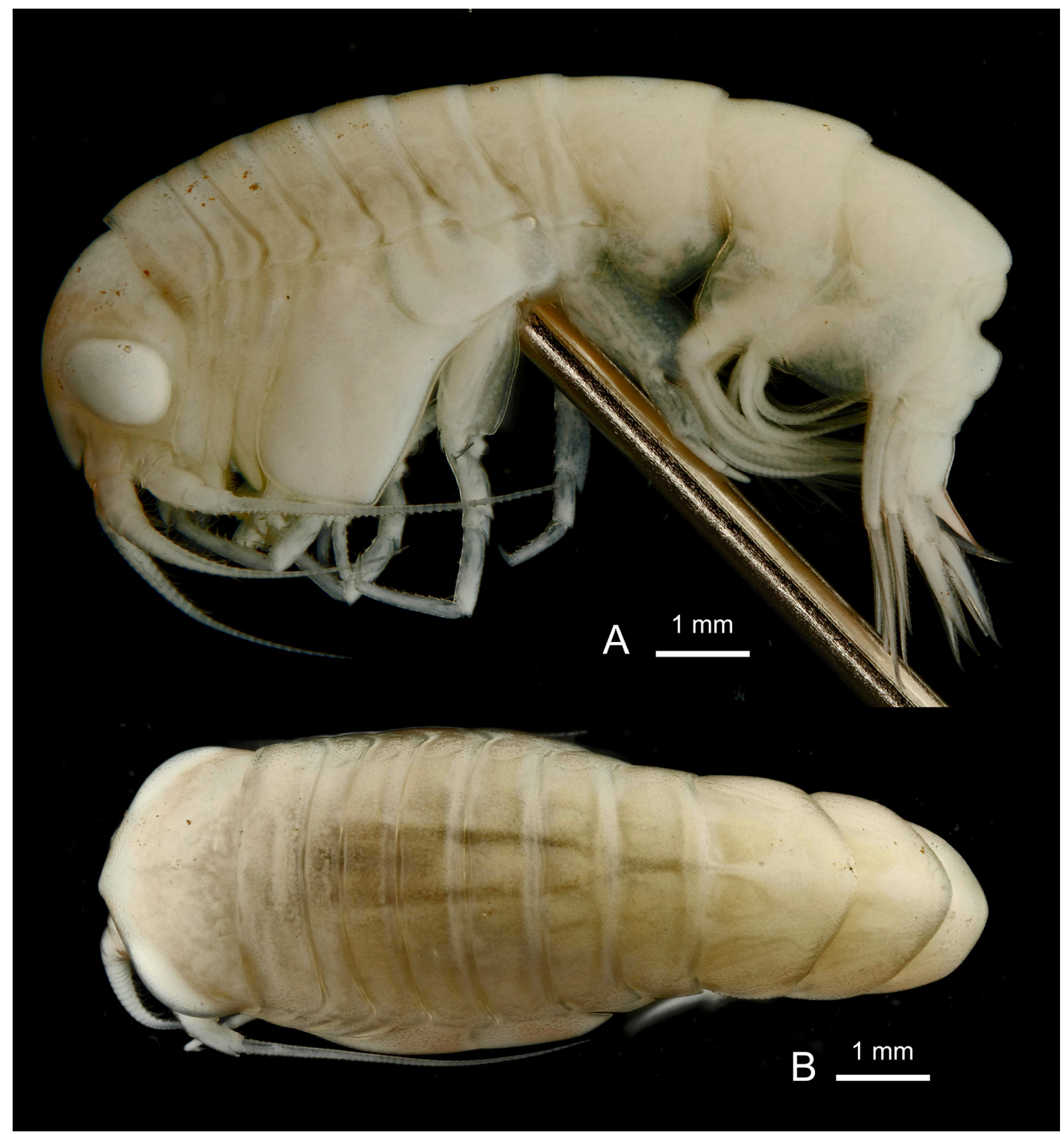

Fig. 235. Epimeria (Laevepimeria) cinderella subgen. et sp. nov., ô, holotype, northwestern Weddell Sea, ANT-XXIX/3, stn 188-5, RBINS, INV. 132956. A. Lateral habitus. B. Dorsal habitus. 


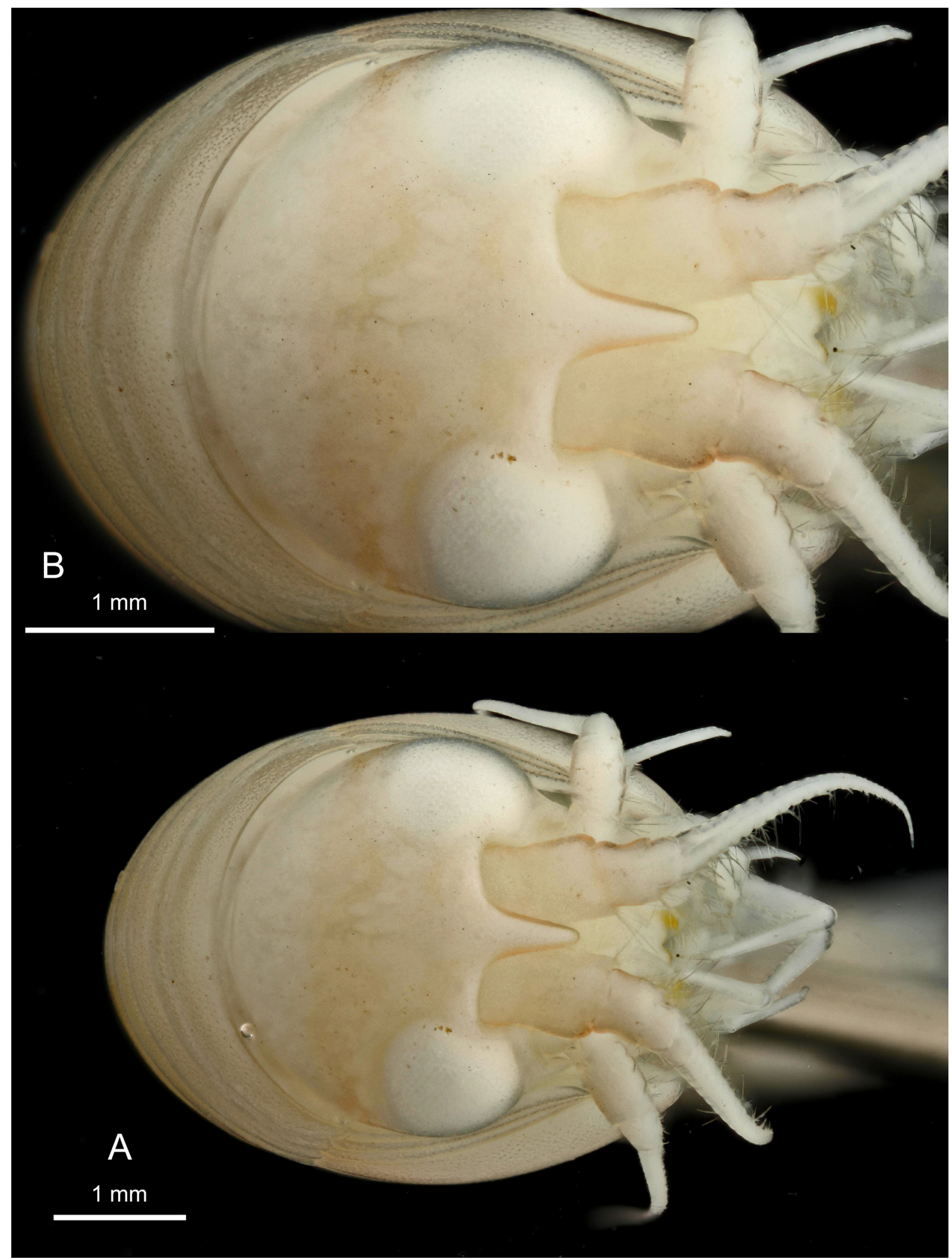

Fig. 236. Epimeria (Laevepimeria) cinderella subgen. et sp. nov., $\widehat{\jmath}$, holotype, northwestern Weddell Sea, ANT-XXIX/3, stn 188-5, RBINS, INV. 132956. A. Facial habitus. B. Head in facial view. 


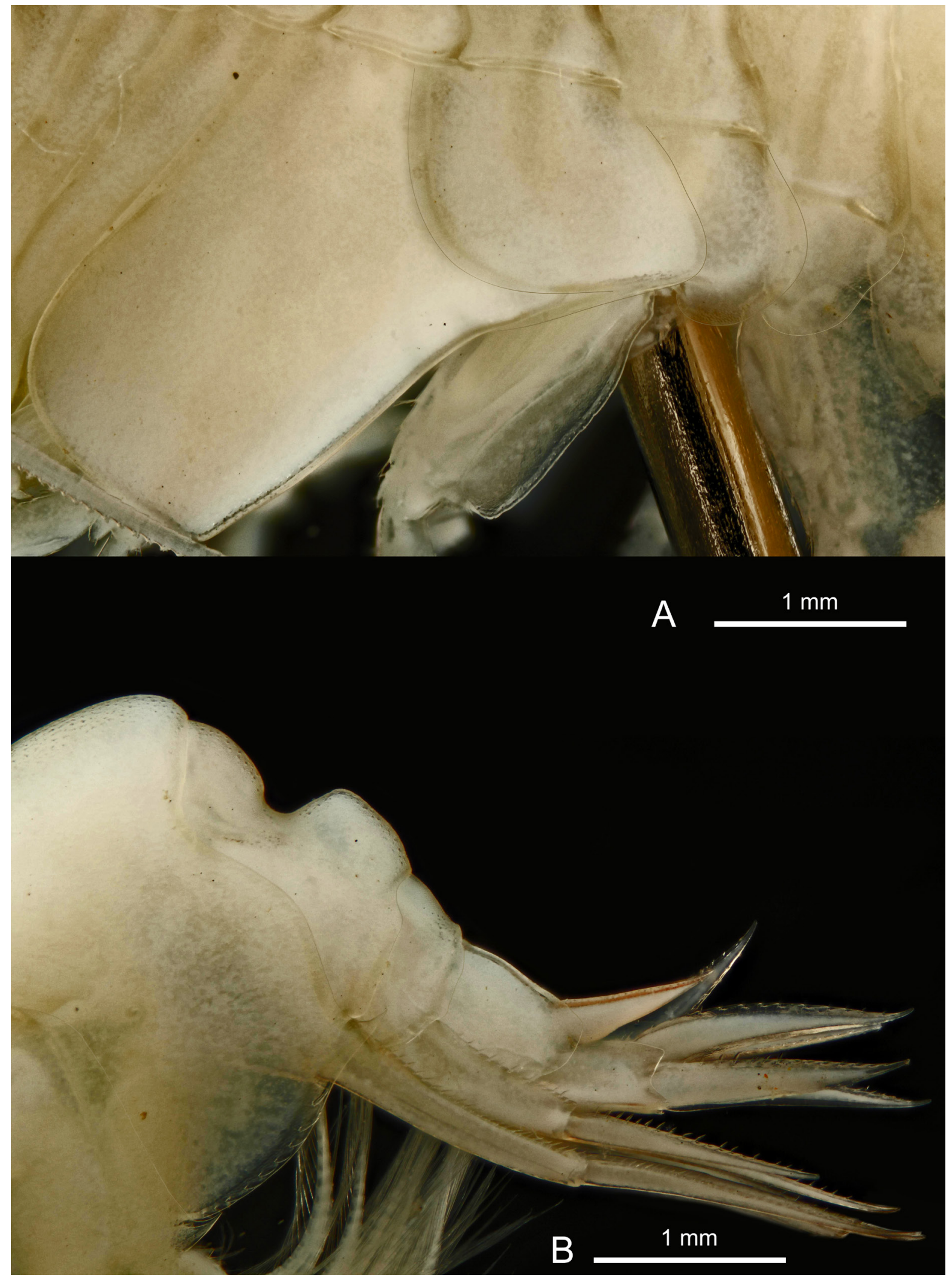

Fig. 237. Epimeria (Laevepimeria) cinderella subgen. et sp. nov., $\widehat{O}^{\lambda}$, holotype, northwestern Weddell Sea, ANT-XXIX/3, stn 188-5, RBINS, INV. 132956. A. Coxae 4-7. B. Pleonite 3 and urosome. 


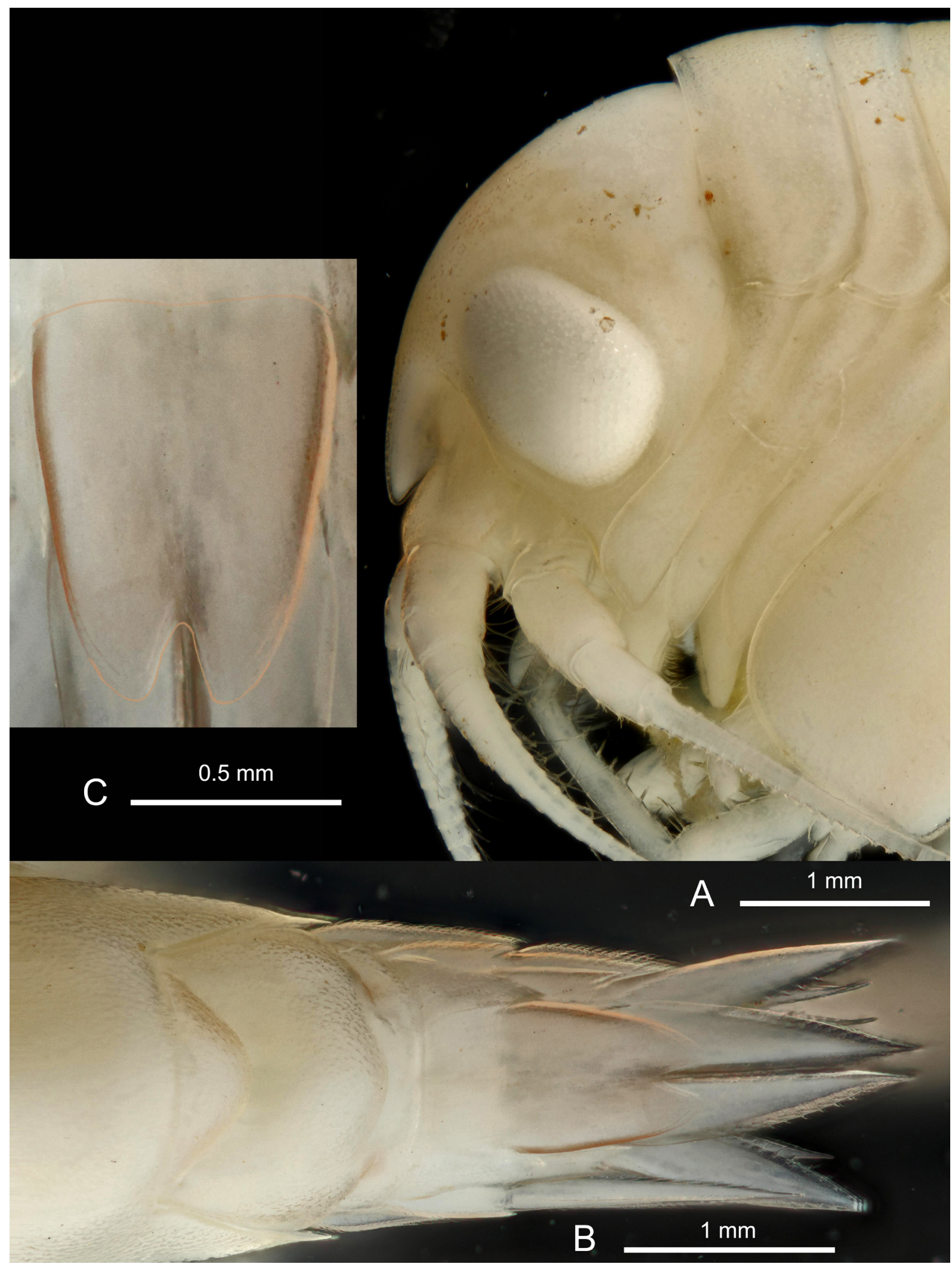

Fig. 238. Epimeria (Laevepimeria) cinderella subgen. et sp. nov., ${ }^{\lambda}$, holotype, northwestern Weddell Sea, ANT-XXIX/3, stn 188-5, RBINS, INV. 132956. A. Head in lateral view. B. Urosome in dorsal view. C. Telson. 


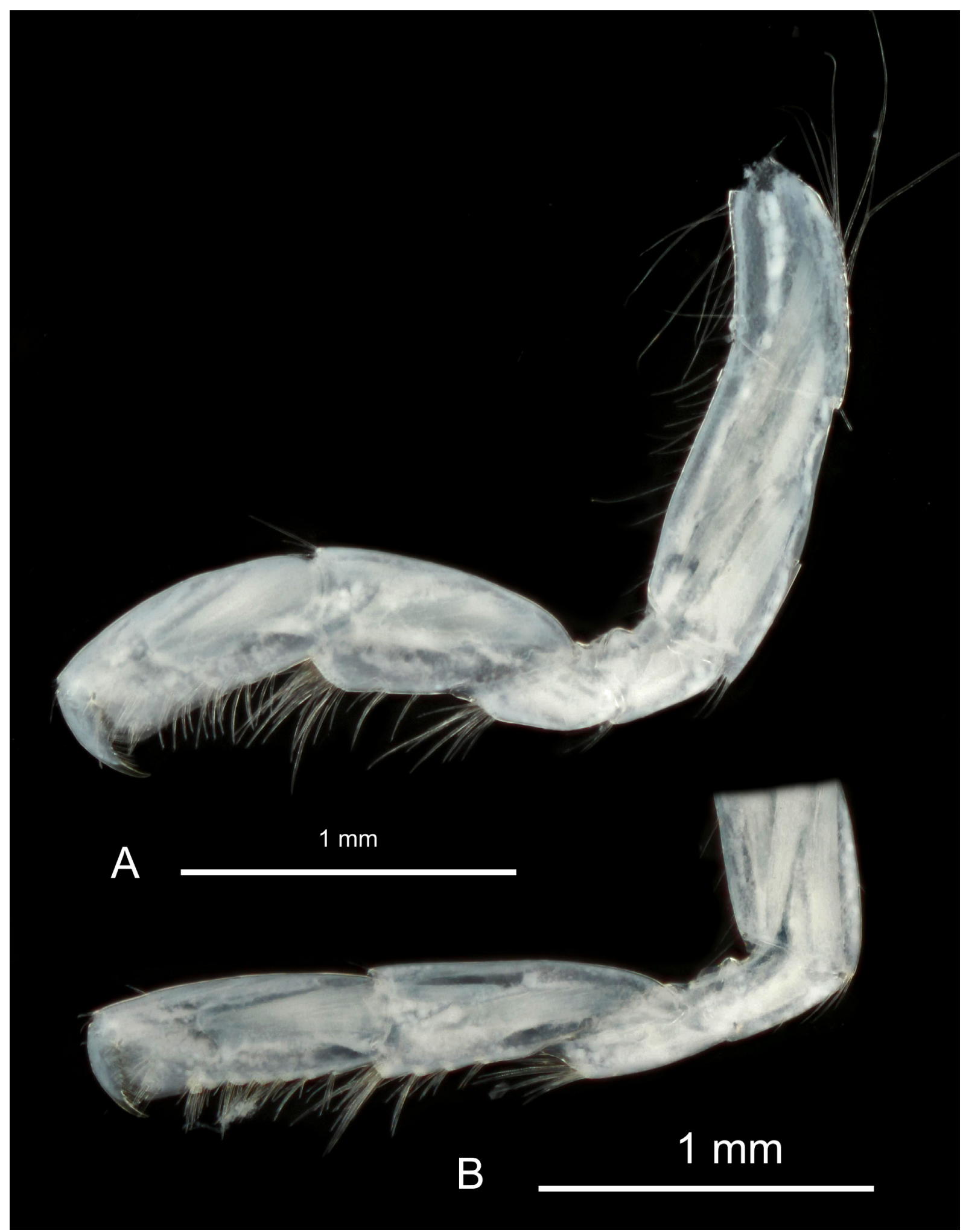

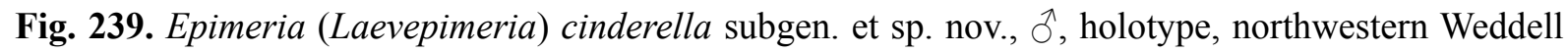
Sea, ANT-XXIX/3, stn 188-5, RBINS, INV. 132956. A. Gnathopod 1. B. Gnathopod 2. 


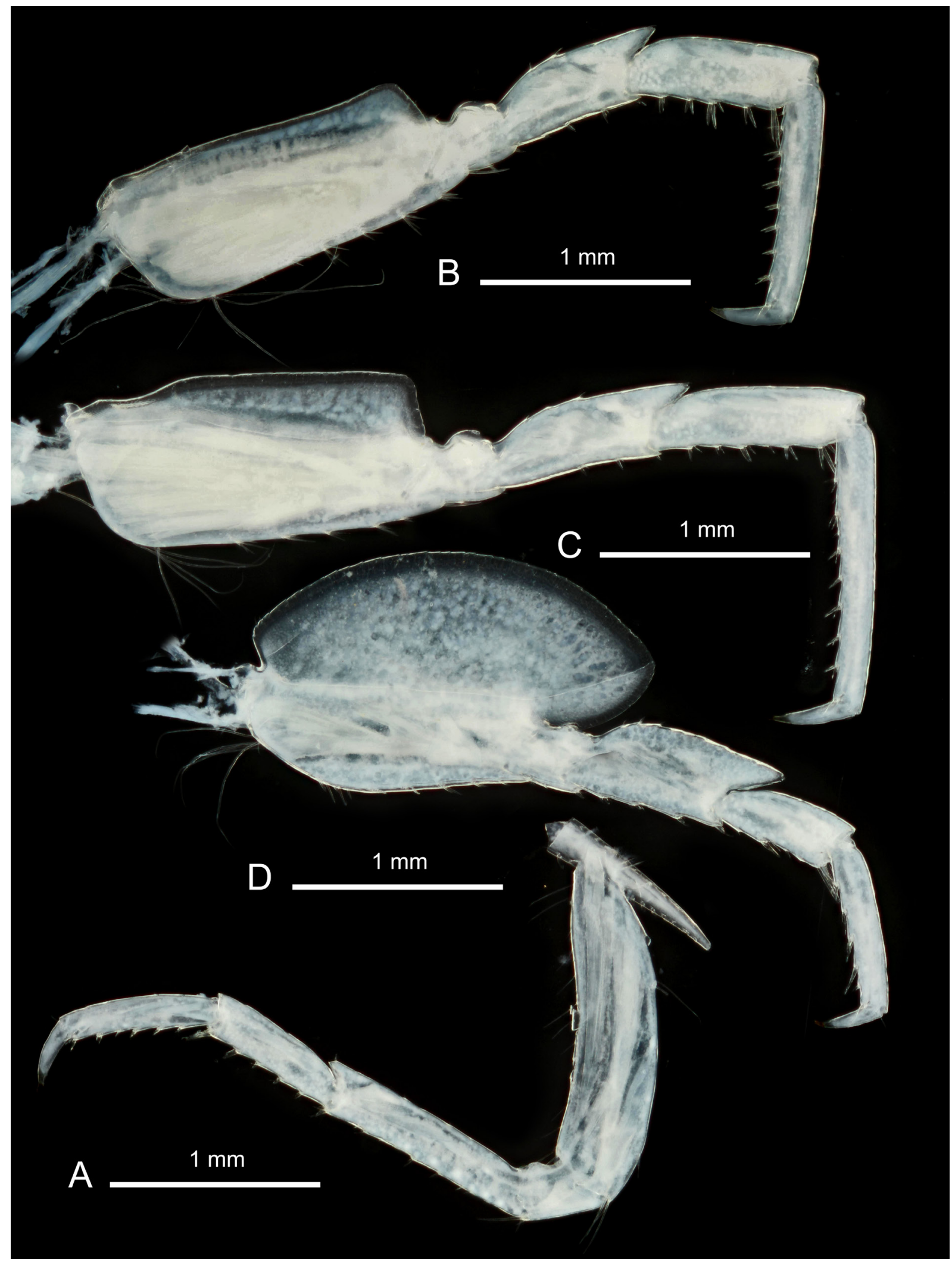

Fig. 240. Epimeria (Laevepimeria) cinderella subgen. et sp. nov., ${ }^{\lambda}$, holotype, northwestern Weddell Sea, ANT-XXIX/3, stn 188-5, RBINS, INV. 132956. A. Pereiopod 4. B. Pereiopod 5. C. Pereiopod 6. D. Pereiopod 7. 


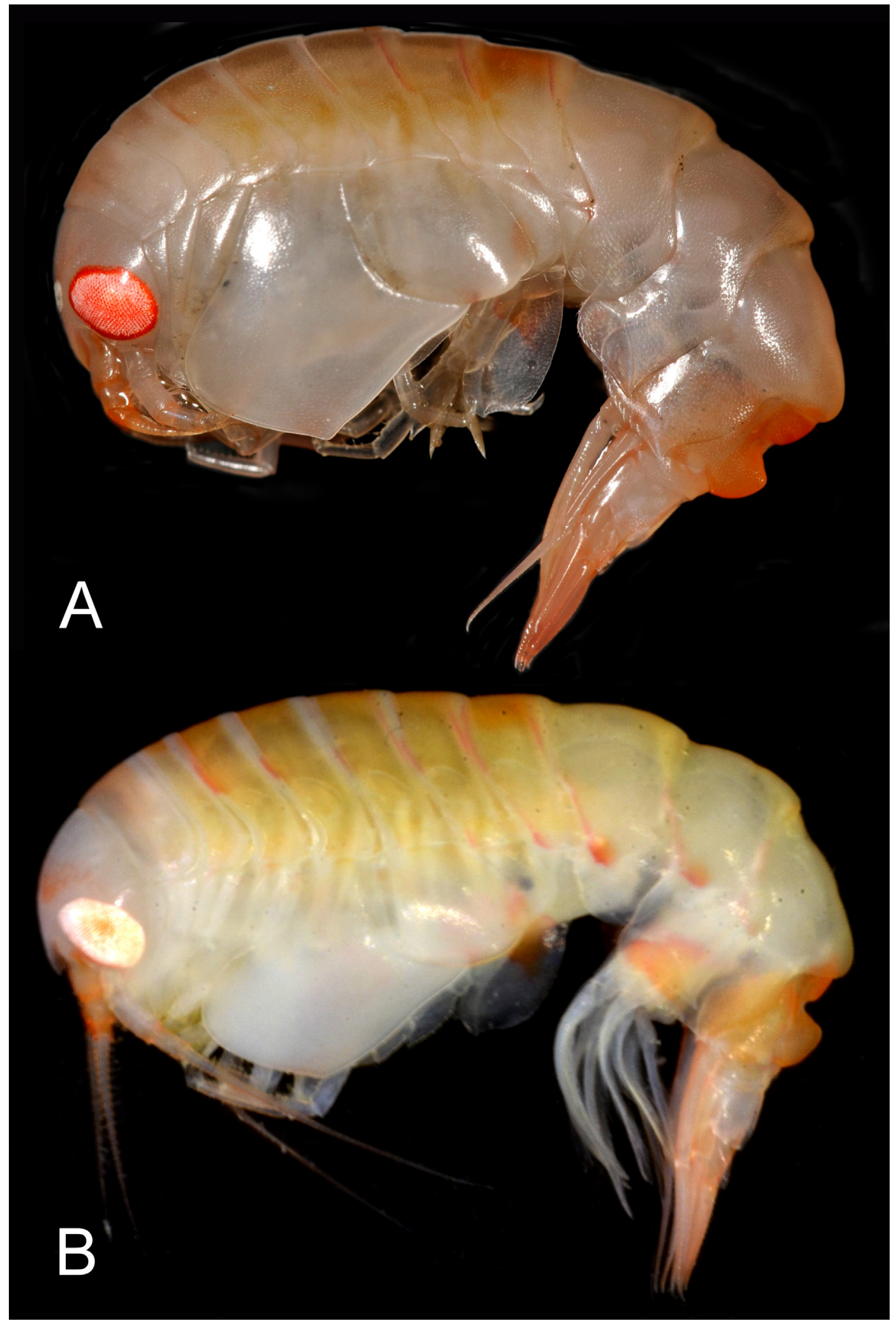

Fig. 241. Epimeria (Laevepimeria) walkeri subgen. nov. (K.H. Barnard, 1930), sex undetermined, colour in life. A. Paratype, southwest of King George Island, ANT-XXVII/3, stn 222-5, RBINS, INV. 132667 (photograph: Armin Rose). B. Holotype, Bransfield Strait, ANT-XXIX/3, stn 217-7, RBINS, INV 122944. 


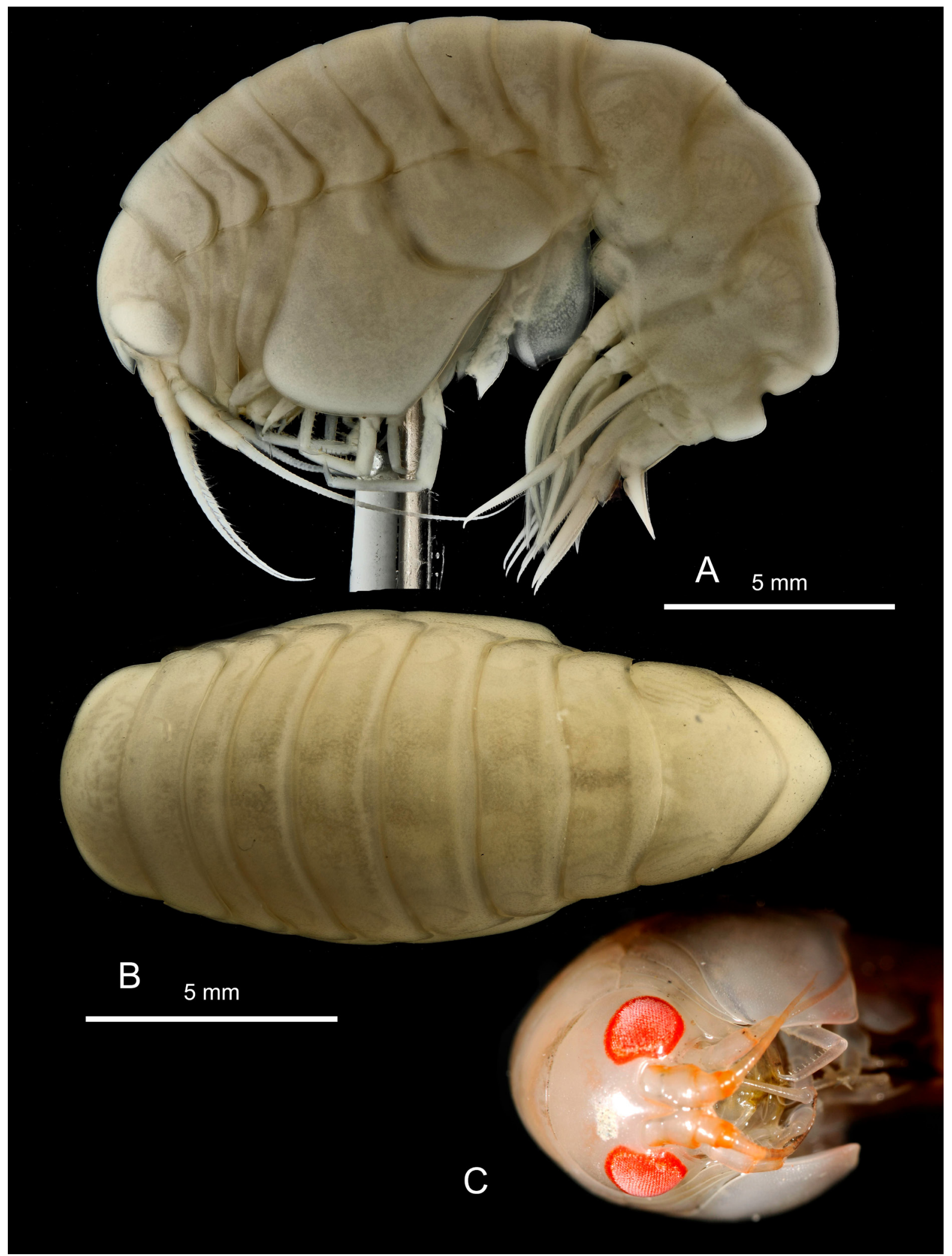

Fig. 242. Epimeria (Laevepimeria) walkeri subgen. nov. (K.H. Barnard, 1930). A-B, sex undetermined, Bransfield Strait, ANT-XXIX/3, stn 217-7, RBINS, INV. 122944. C, Paratype, southwest of King George Island, ANT-XXVII/3, stn 222-5, RBINS, INV. 132667. A. Lateral habitus. B. Dorsal habitus. C. Frontal view, colour in life (photograph: Armin Rose). 


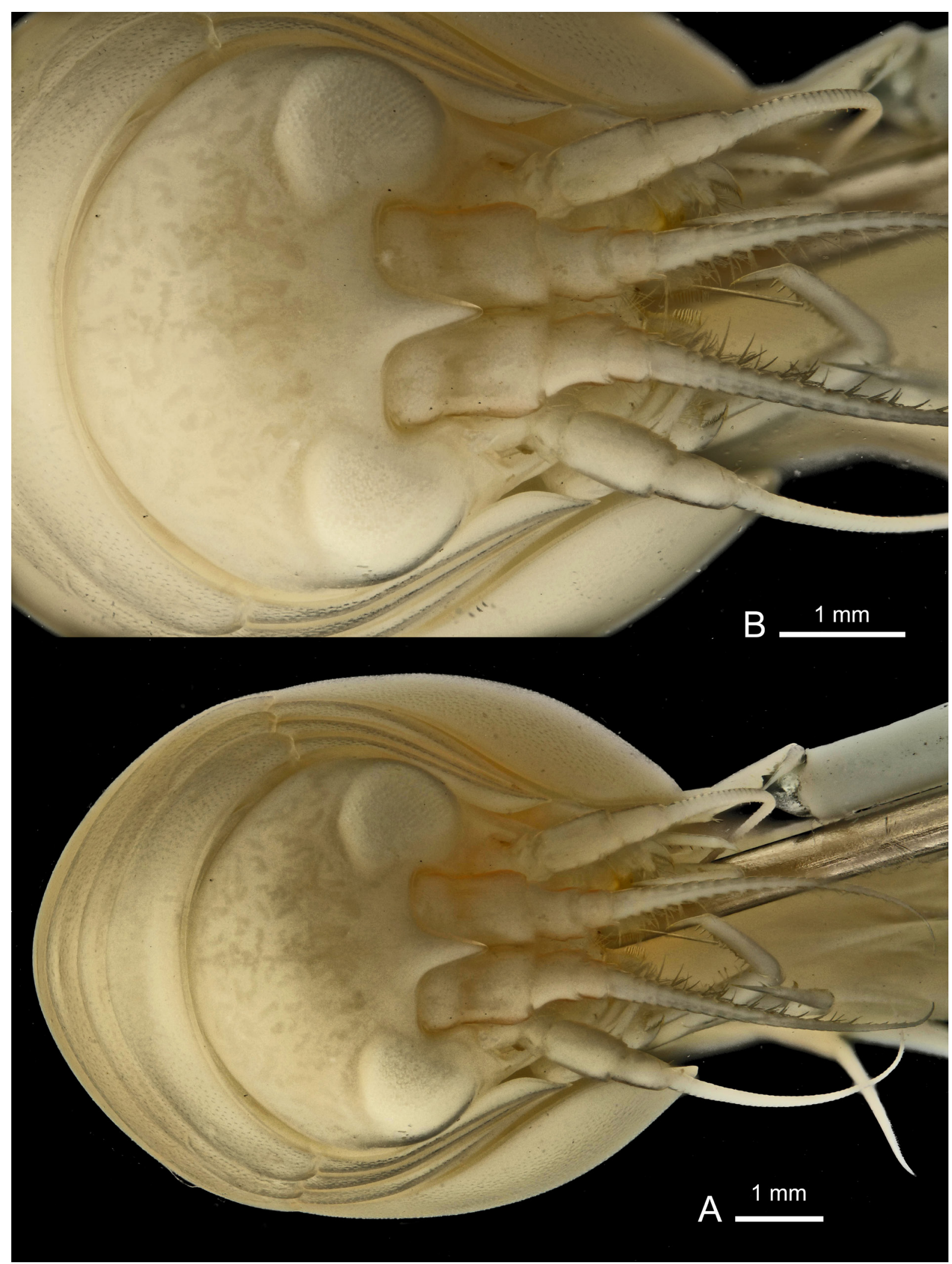

Fig. 243. Epimeria (Laevepimeria) walkeri subgen. nov. (K.H. Barnard, 1930), sex undetermined, Bransfield Strait, ANT-XXIX/3, stn 217-7, RBINS, INV. 122944. A. Facial habitus. B. Head in dorsal view. 


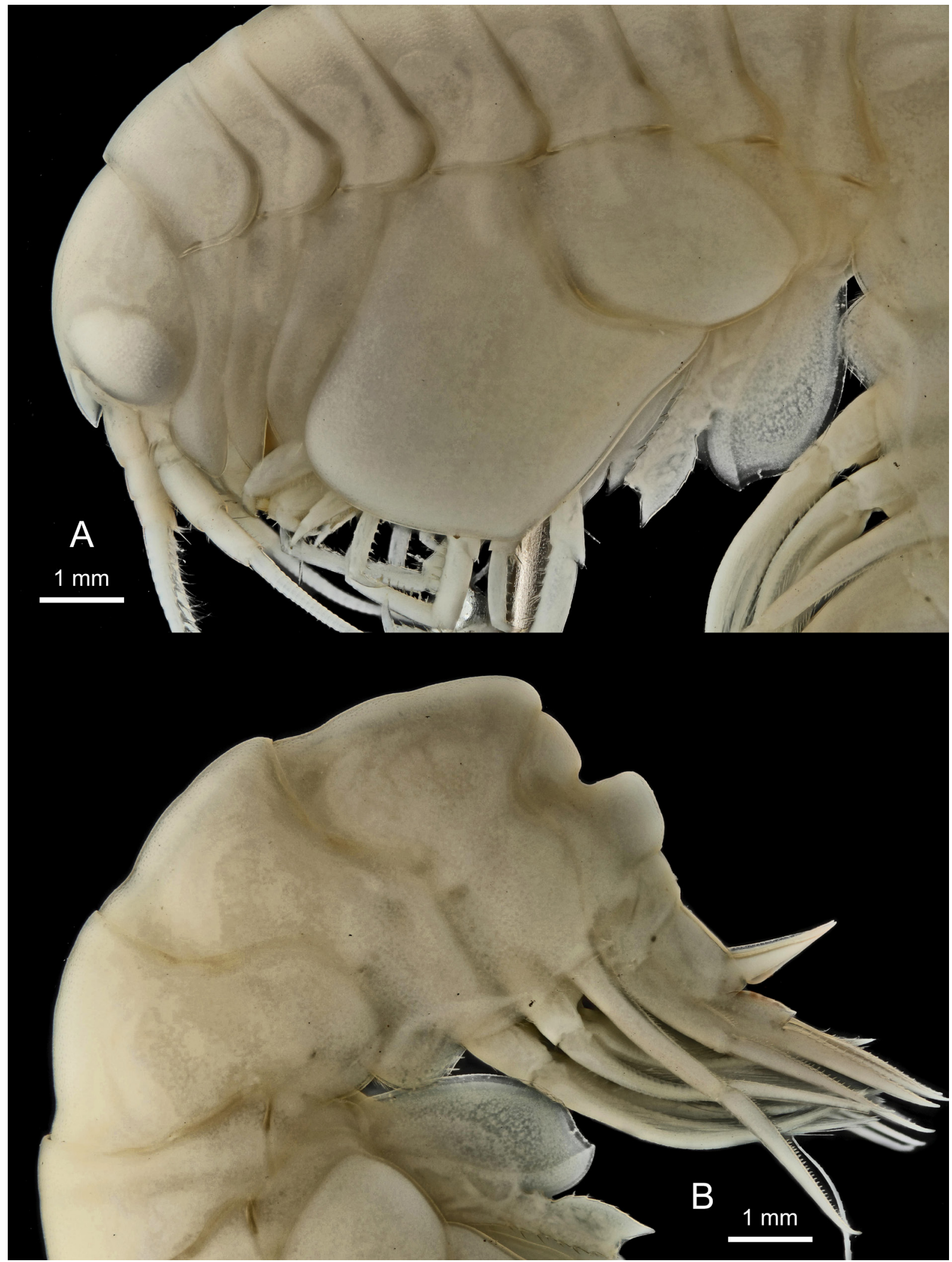

Fig. 244. Epimeria (Laevepimeria) walkeri subgen. nov. (K.H. Barnard, 1930), sex undetermined, Bransfield Strait, ANT-XXIX/3, stn 217-7, RBINS, INV. 122944. A. Anterior half. B. Posterior half. 


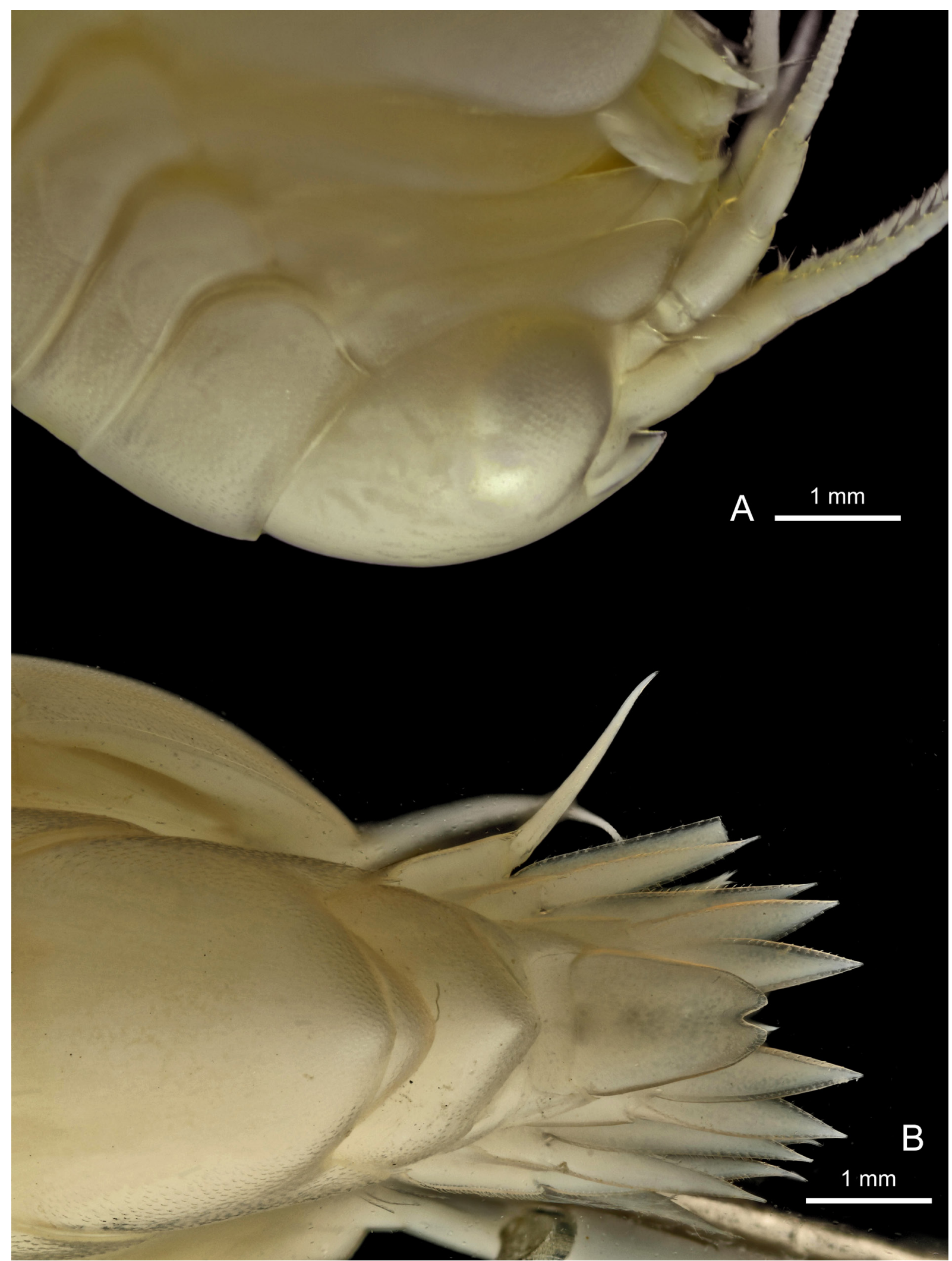

Fig. 245. Epimeria (Laevepimeria) walkeri subgen. nov. (K.H. Barnard, 1930), sex undetermined, Bransfield Strait, ANT-XXIX/3, stn 217-7, RBINS, INV. 122944. A. Head in lateral view and coxae 1-3. B. Urosome in dorsal view. 


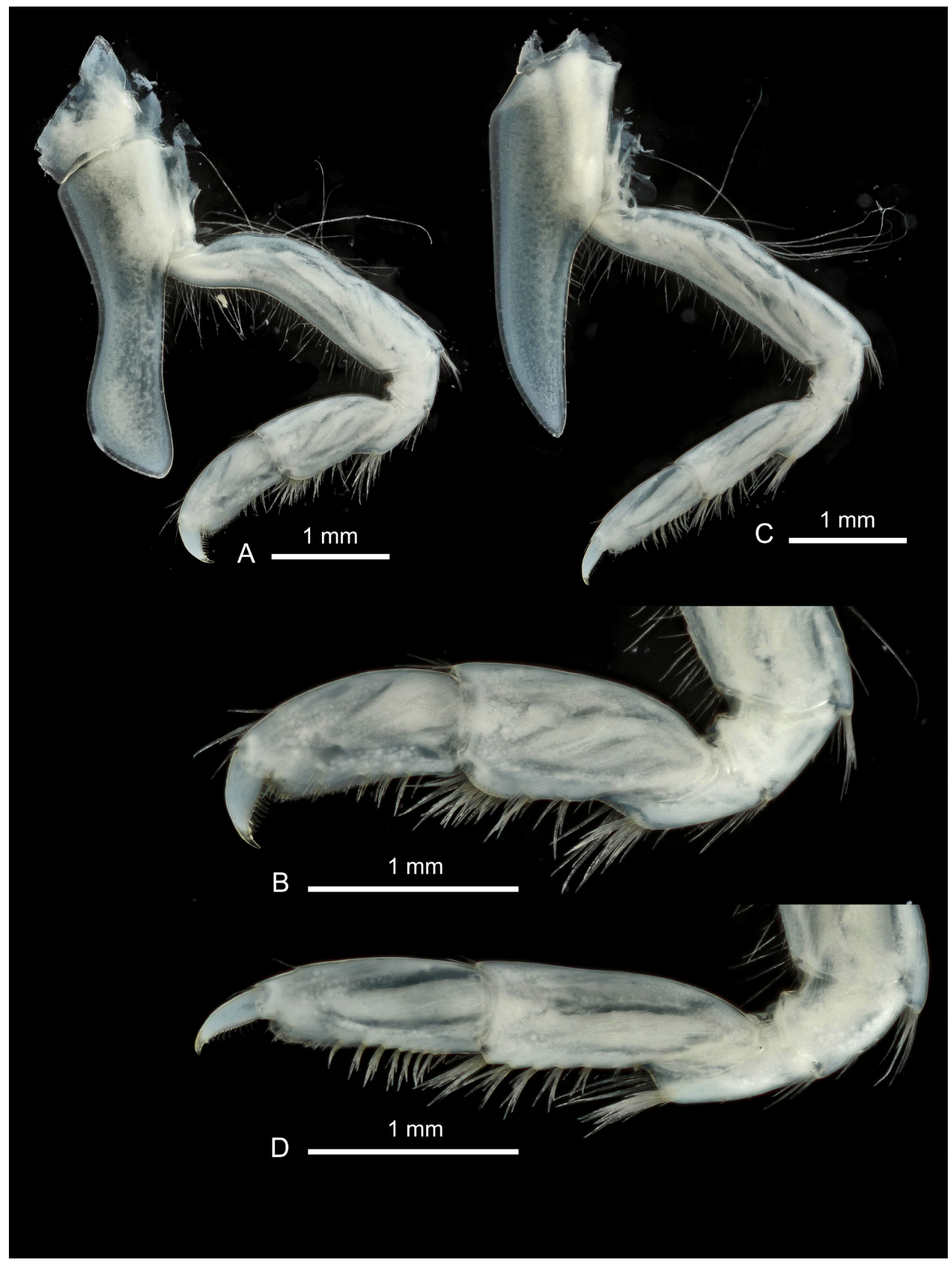

Fig. 246. Epimeria (Laevepimeria) walkeri subgen. nov. (K.H. Barnard, 1930), sex undetermined, Bransfield Strait, ANT-XXIX/3, stn 217-7, RBINS, INV. 122944. A. Gnathopod 1. B. Tip of gnathopod 1. C. Gnathopod 2. D. Tip of gnathopod 2. 


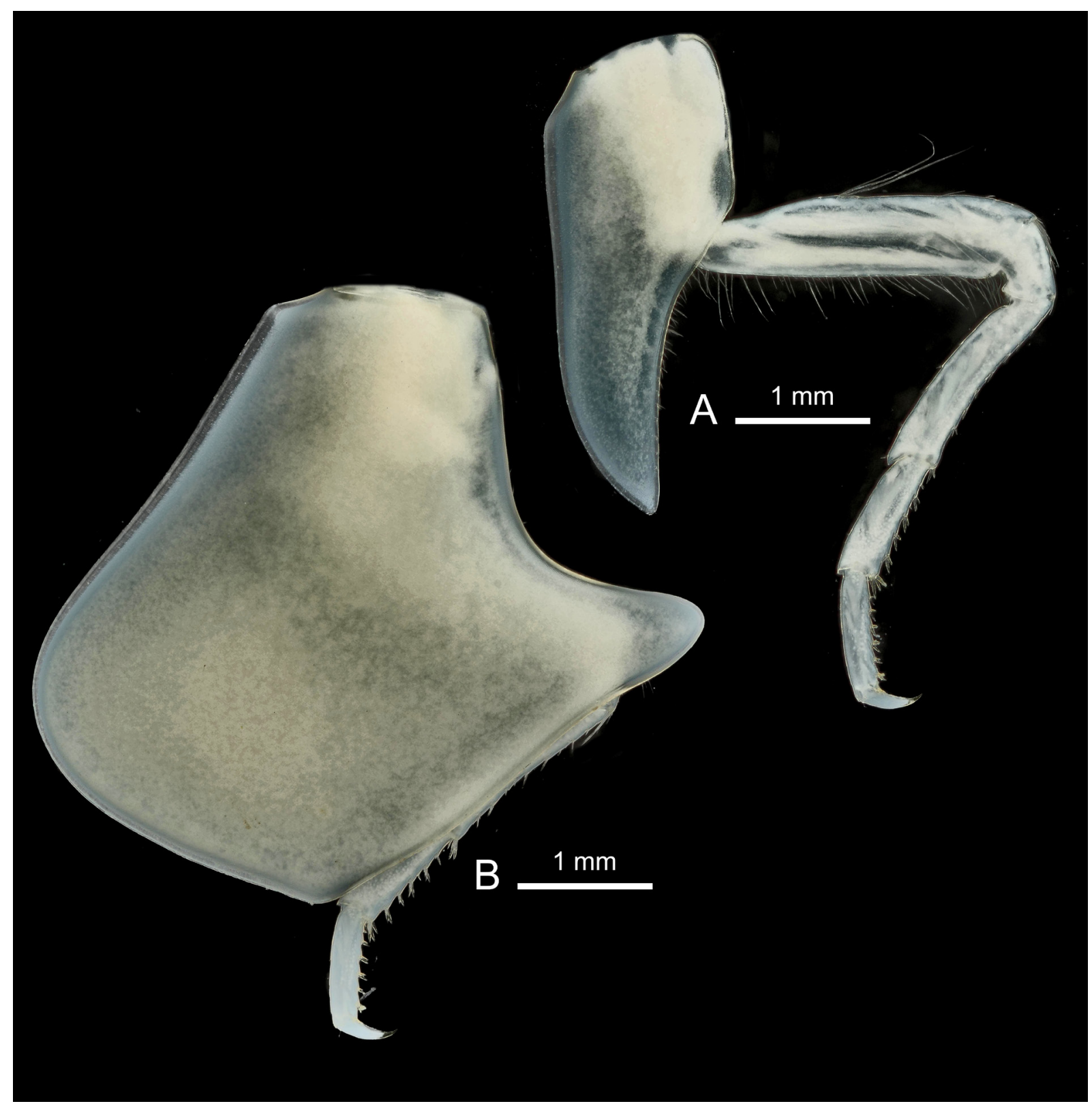

Fig. 247. Epimeria (Laevepimeria) walkeri subgen. nov. (K.H. Barnard, 1930), sex undetermined, Bransfield Strait, ANT-XXIX/3, stn 217-7, RBINS, INV. 122944. A. Pereiopod 3. B. Pereiopod 4. 


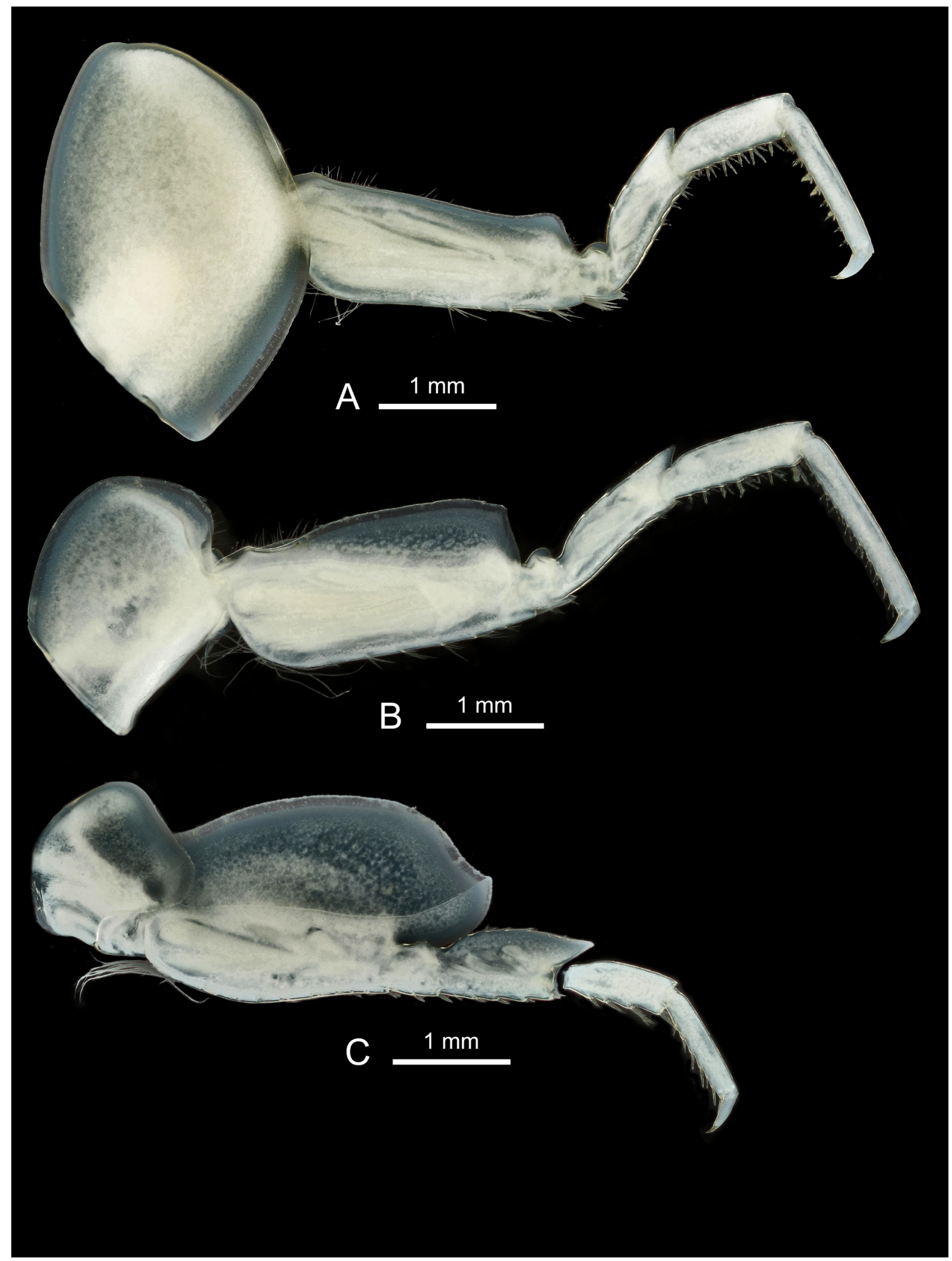

Fig. 248. Epimeria (Laevepimeria) walkeri subgen. nov. (K.H. Barnard, 1930), sex undetermined, Bransfield Strait, ANT-XXIX/3, stn 217-7, RBINS, INV. 122944. A. Pereiopod 5. B. Pereiopod 6. C. Pereiopod 7. 


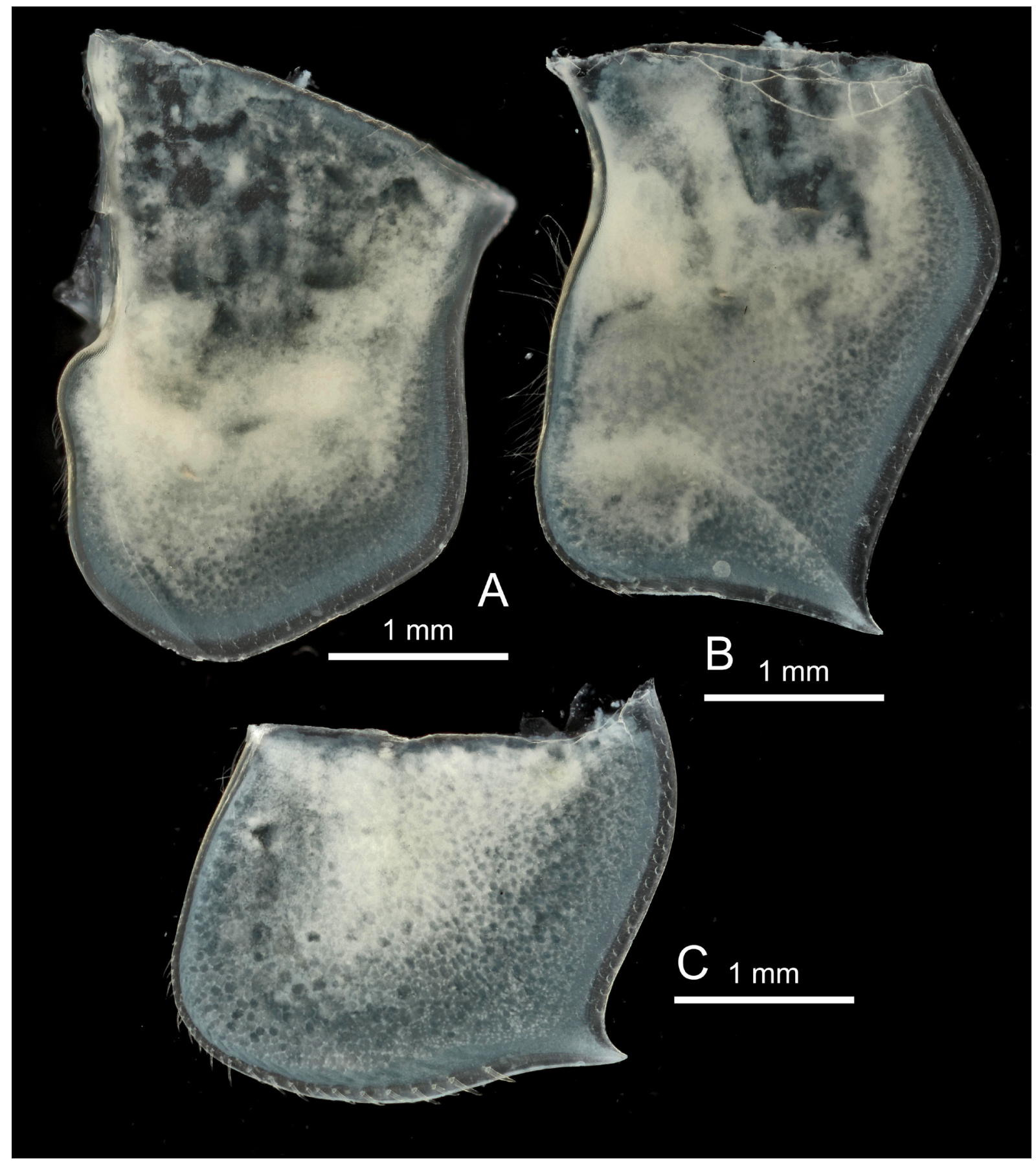

Fig. 249. Epimeria (Laevepimeria) walkeri subgen. nov. (K.H. Barnard, 1930), sex undetermined, Bransfield Strait, ANT-XXIX/3, stn 217-7, RBINS, INV. 122944. A. Epimera 1. B. Epimera 2. C. Epimera 3. 


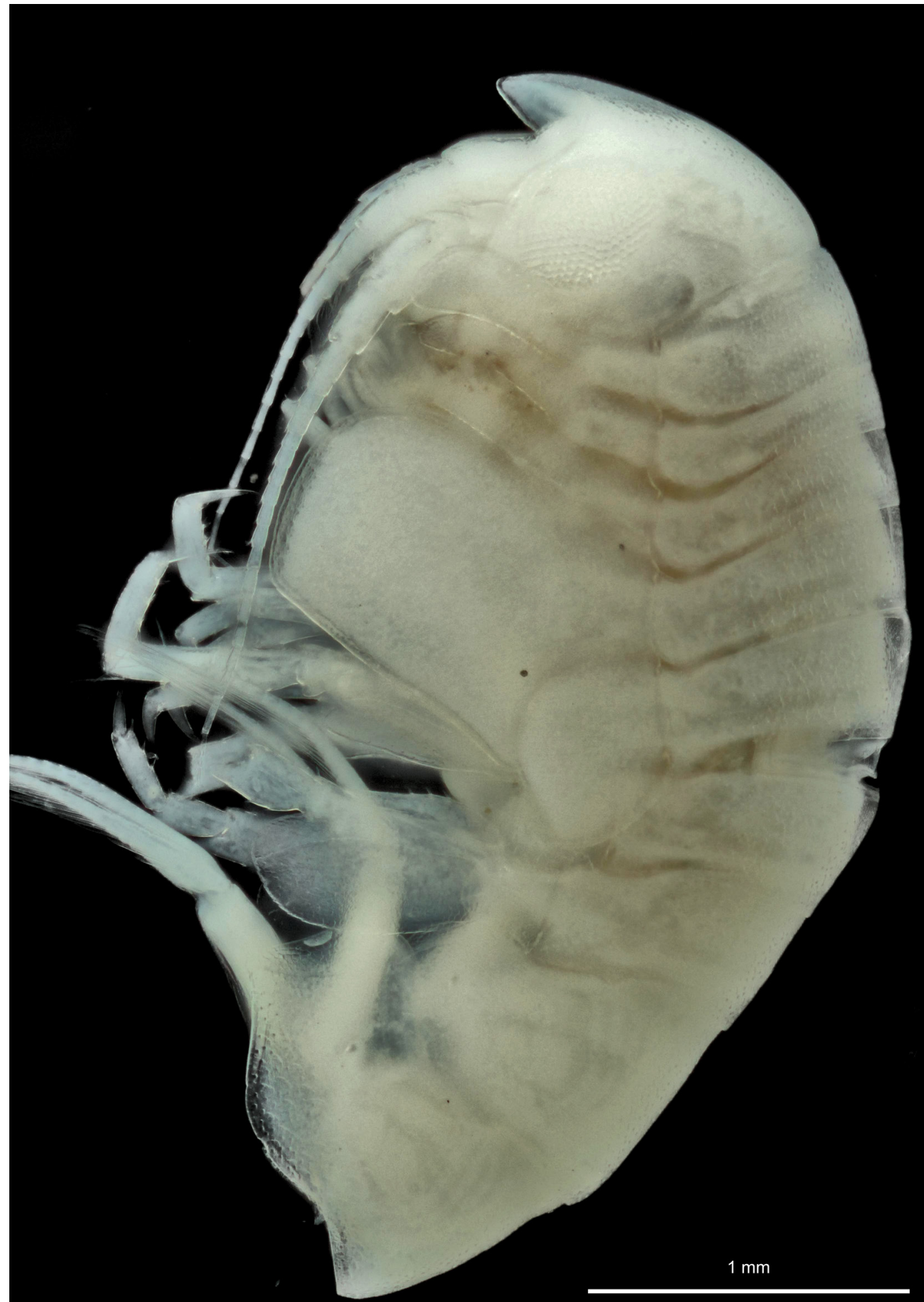

Fig. 250. Epimeria (Laevepimeria) sp. subgen. nov., sex undetermined, Bransfield Strait, ANT-XXIX/3, stn 197-5, RBINS, INV. 122932, lateral habitus (urosome missing: used for DNA analysis). 


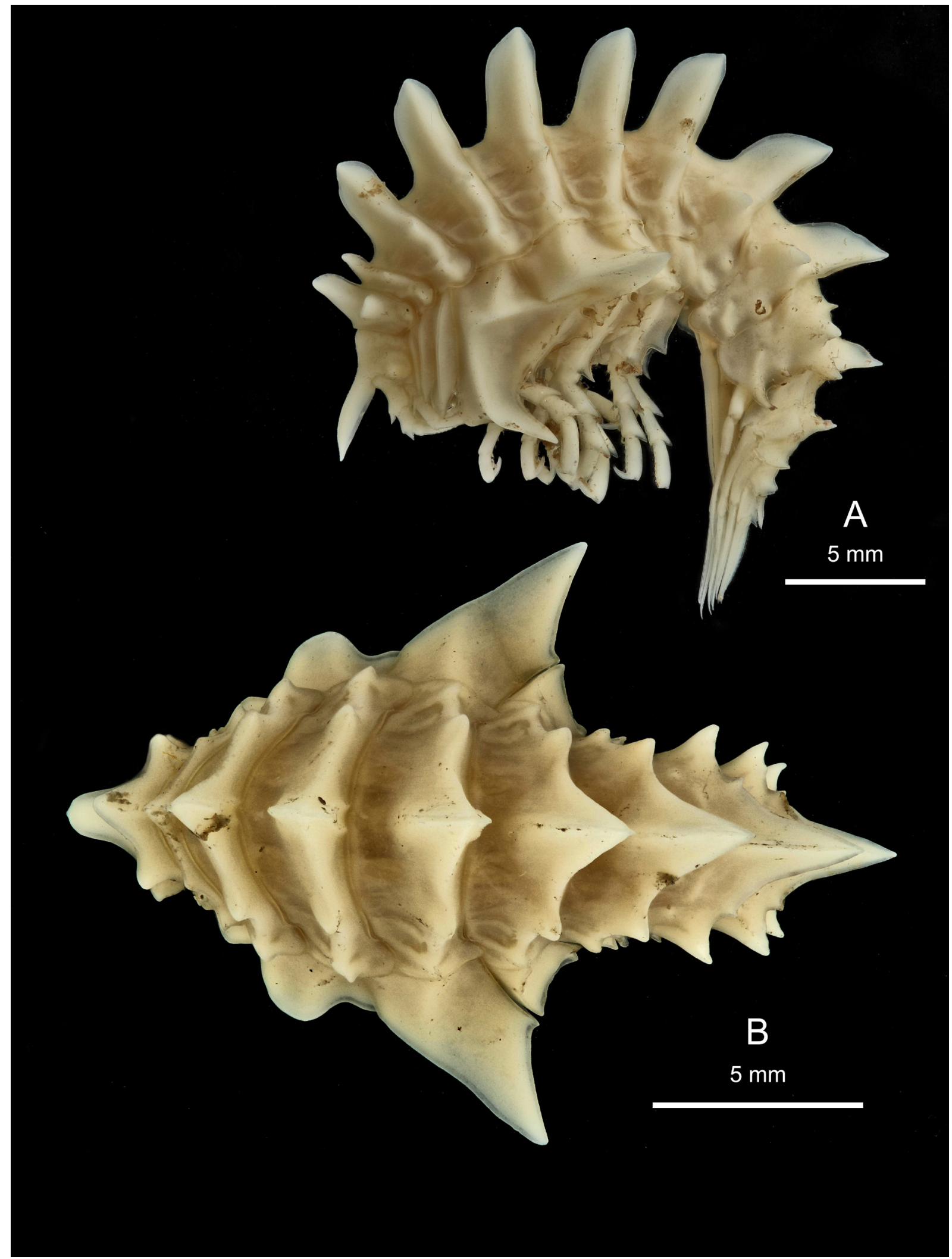

Fig. 251. Epimeria (Pseudepimeria) amoenitas sp. nov.,, , holotype, Adélie Coast, CEAMARC 3978, MNHN-IU-2014-4327. A. Lateral habitus. B. Dorsal habitus. 


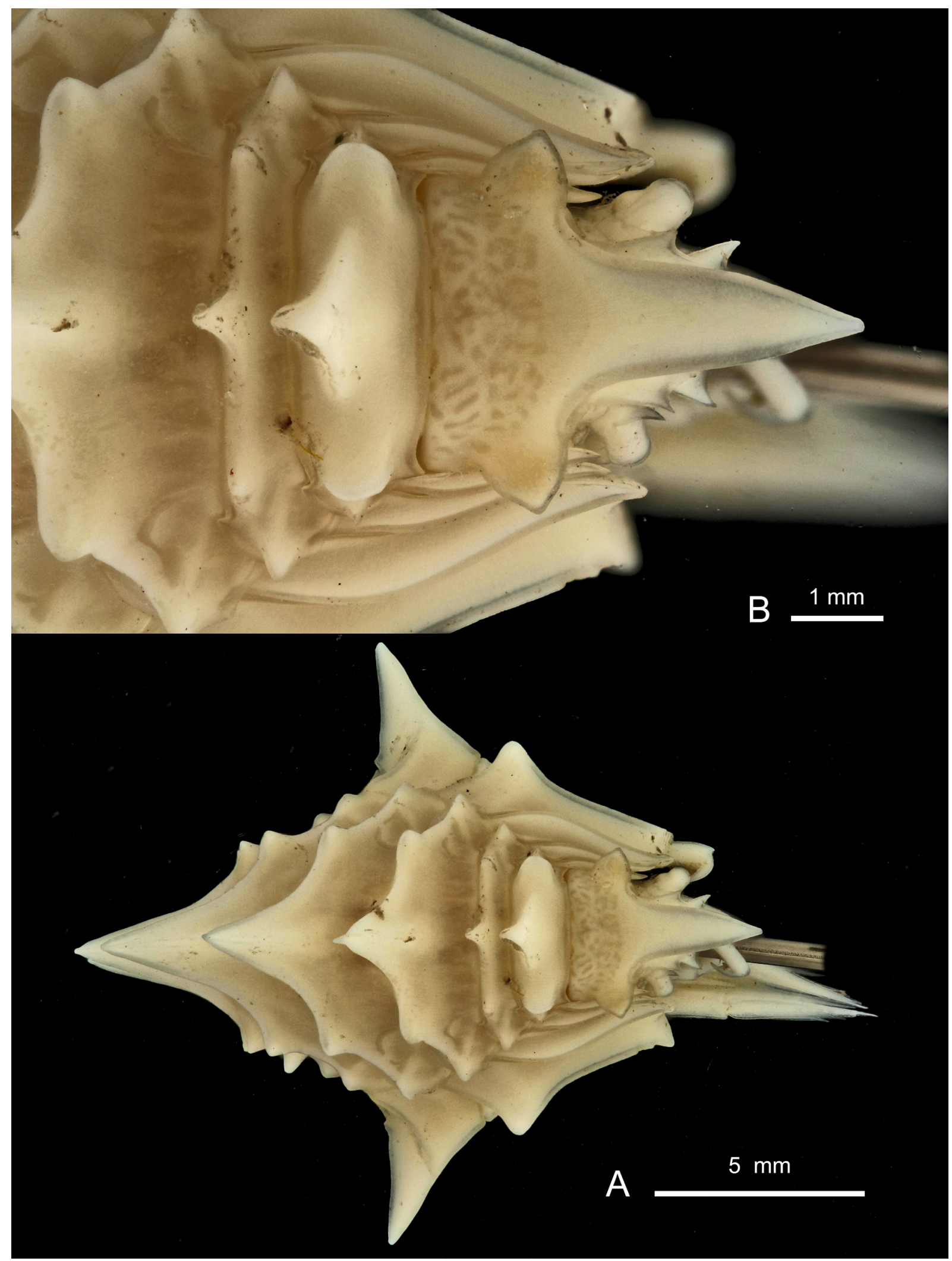

Fig. 252. Epimeria (Pseudepimeria) amoenitas sp. nov., + , holotype, Adélie Coast, CEAMARC 3978, MNHN-IU-2014-4327. A. Facial habitus. B. Head in facial view. 


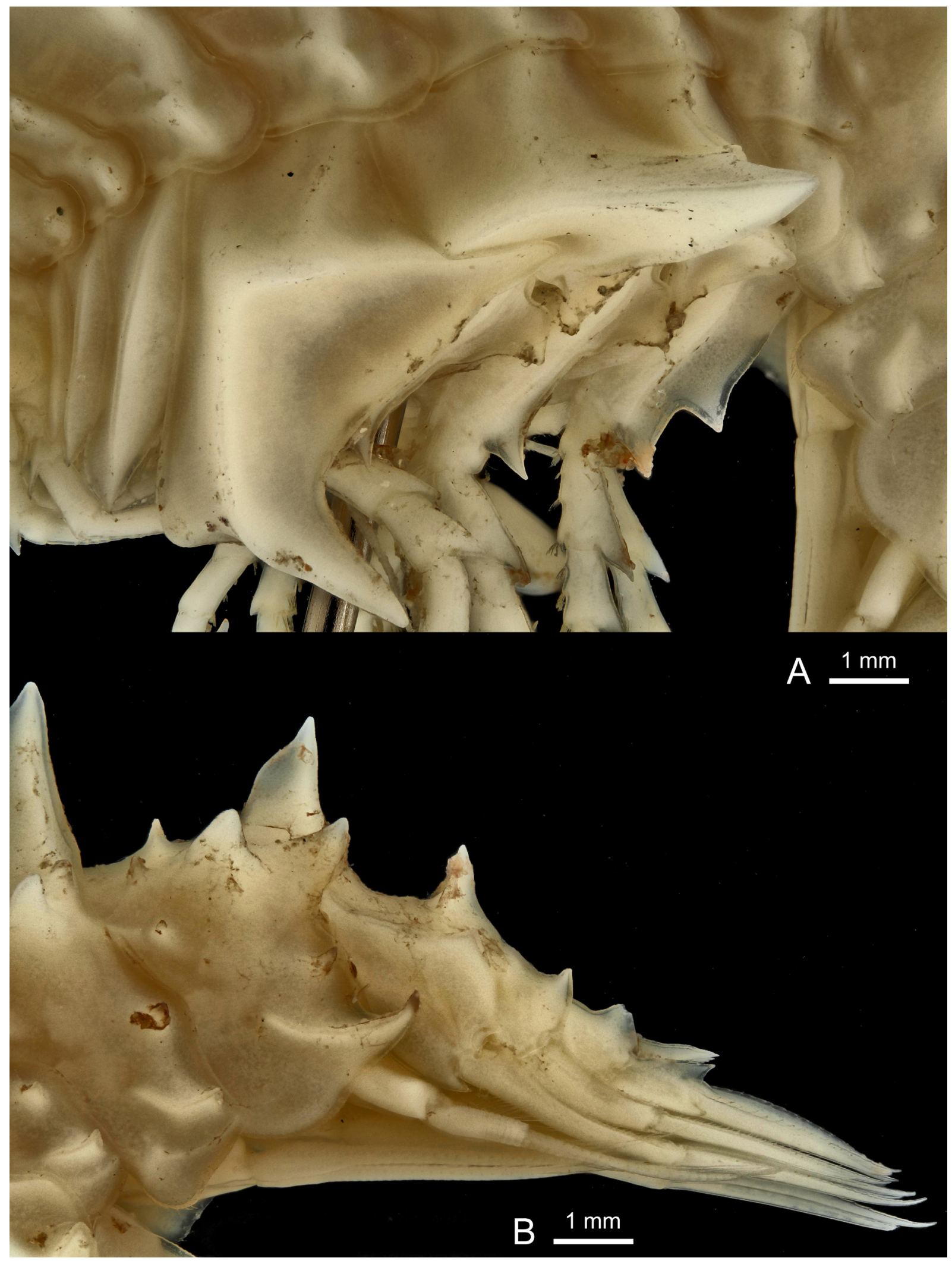

Fig. 253. Epimeria (Pseudepimeria) amoenitas sp. nov.,, , holotype, Adélie Coast, CEAMARC 3978, MNHN-IU-2014-4327. A. Coxae. B. Urosome and posterior part of pleosome. 


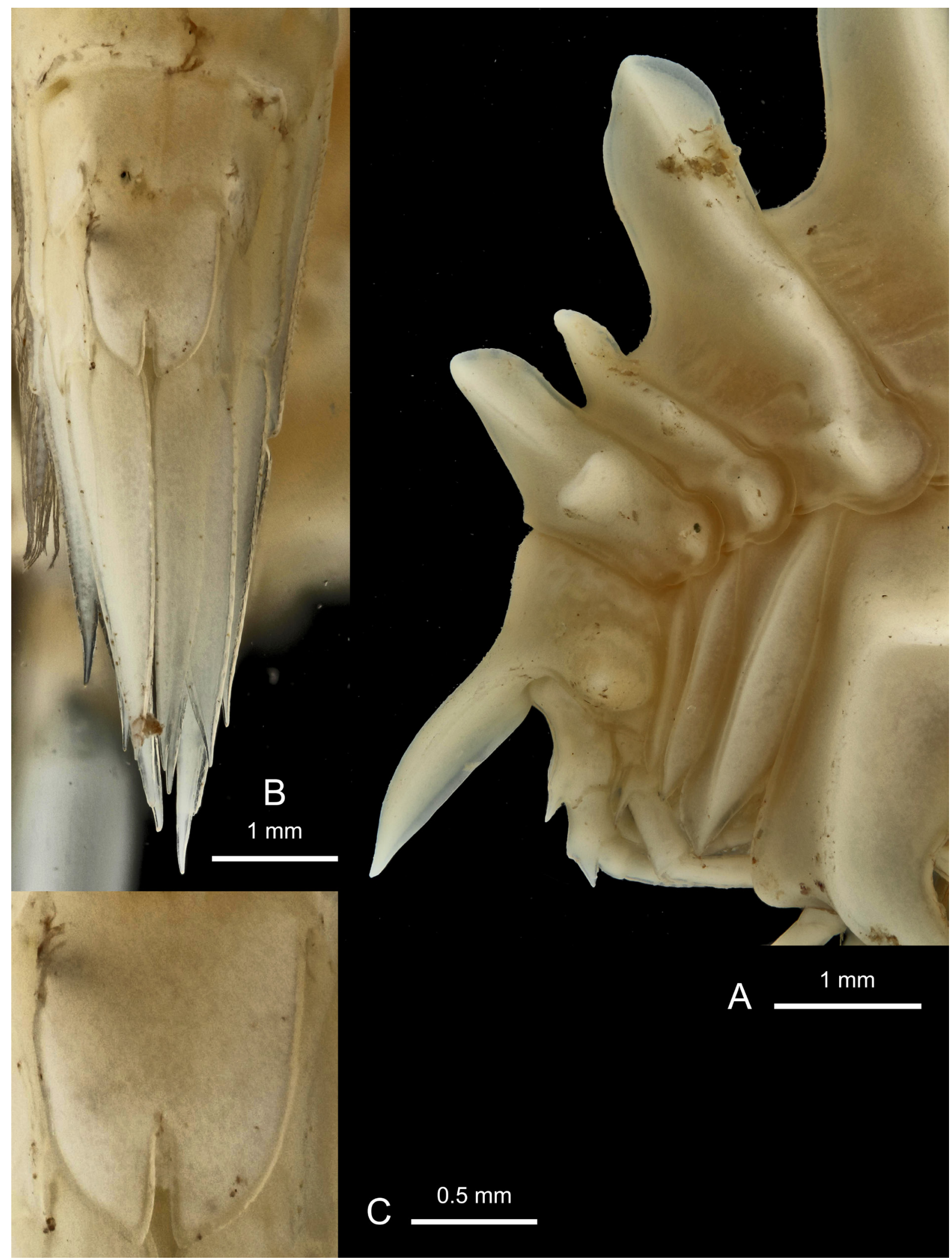

Fig. 254. Epimeria (Pseudepimeria) amoenitas sp. nov., + , holotype, Adélie Coast, CEAMARC 3978, MNHN-IU-2014-4327. A. Head in lateral view. B. Urosome in dorsal view. C. Telson. 


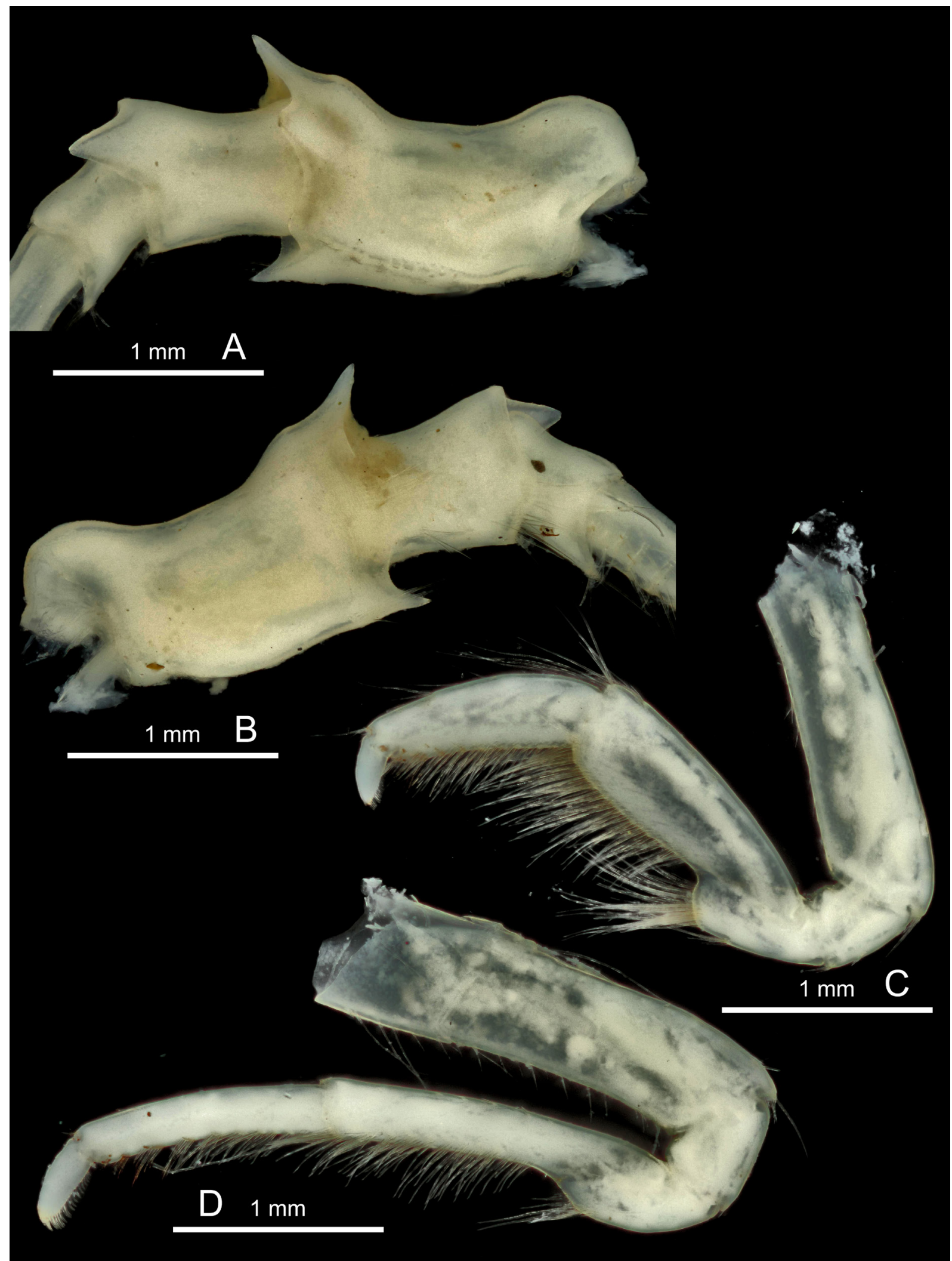

Fig. 255. Epimeria (Pseudepimeria) amoenitas sp. nov.,, , paratype, Adélie Coast, CEAMARC V3, stn 158, MNHN-IU-2014-4284. A. Peduncle of antenna 1 in lateral view. B. Peduncle of antenna 2 in medial view. C. Gnathopod 1. D. Gnathopod 2. 


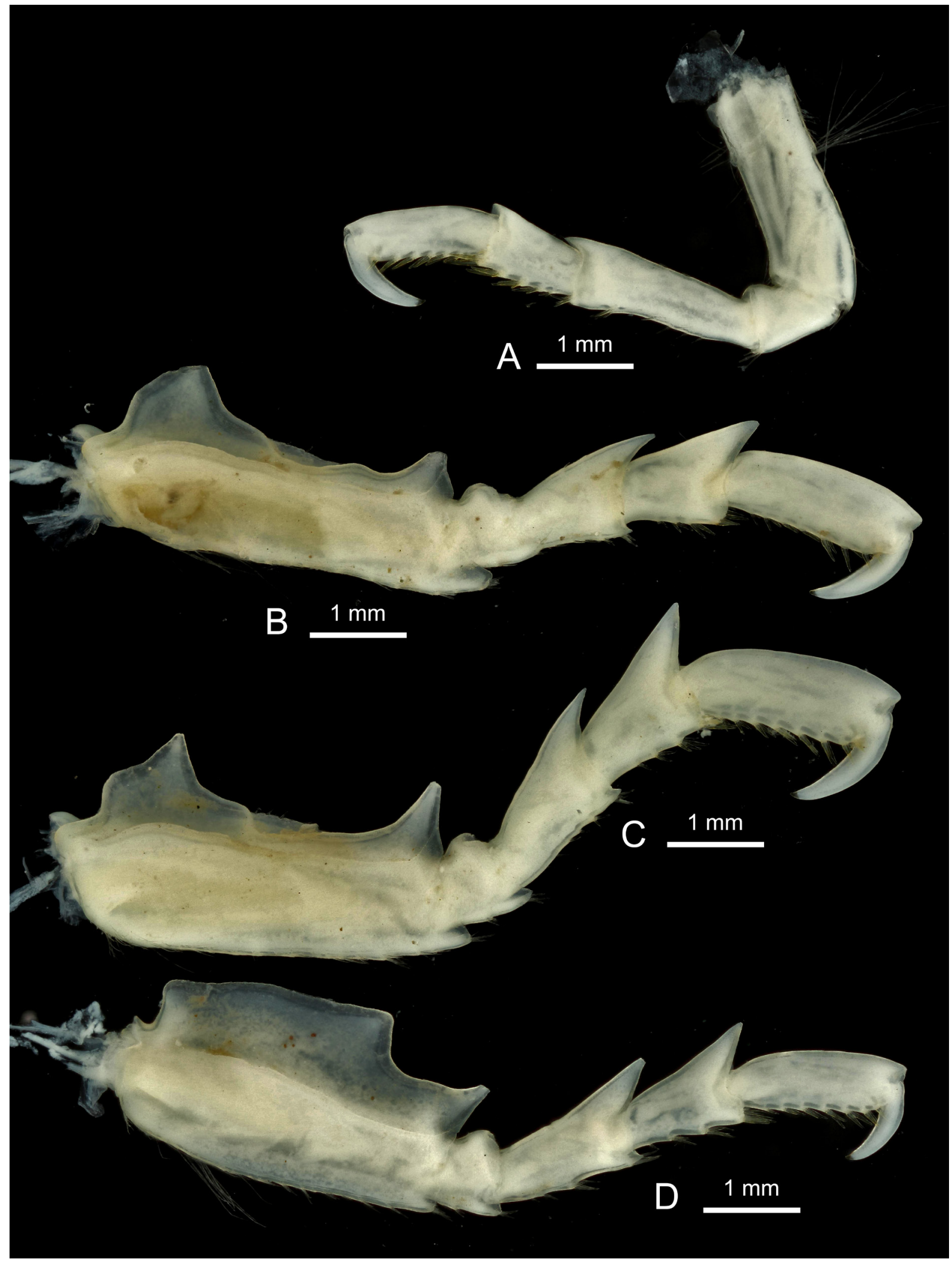

Fig. 256. Epimeria (Pseudepimeria) amoenitas sp. nov., + , paratype, Adélie Coast, CEAMARC V3, stn 158, MNHN-IU-2014-4284. A. Pereiopod 4. B. Pereiopod 5. C. Pereiopod 6. D. Pereiopod 7. 


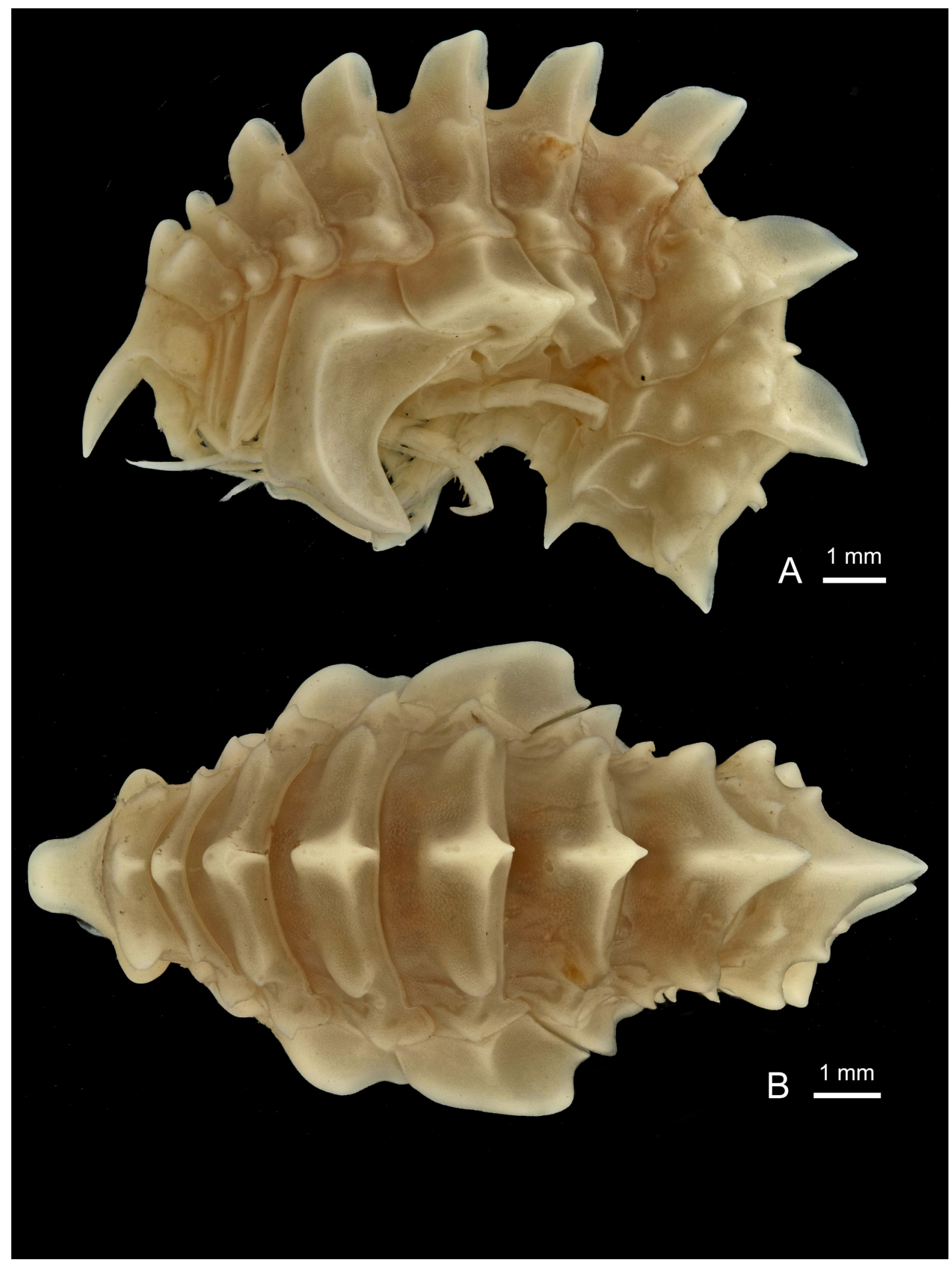

Fig. 257. Epimeria (Pseudepimeria) callista sp. nov., + , holotype, Adélie Coast, CEAMARC 3978, MNHN-IU-2014-7336. A. Lateral habitus. B. Dorsal habitus. 


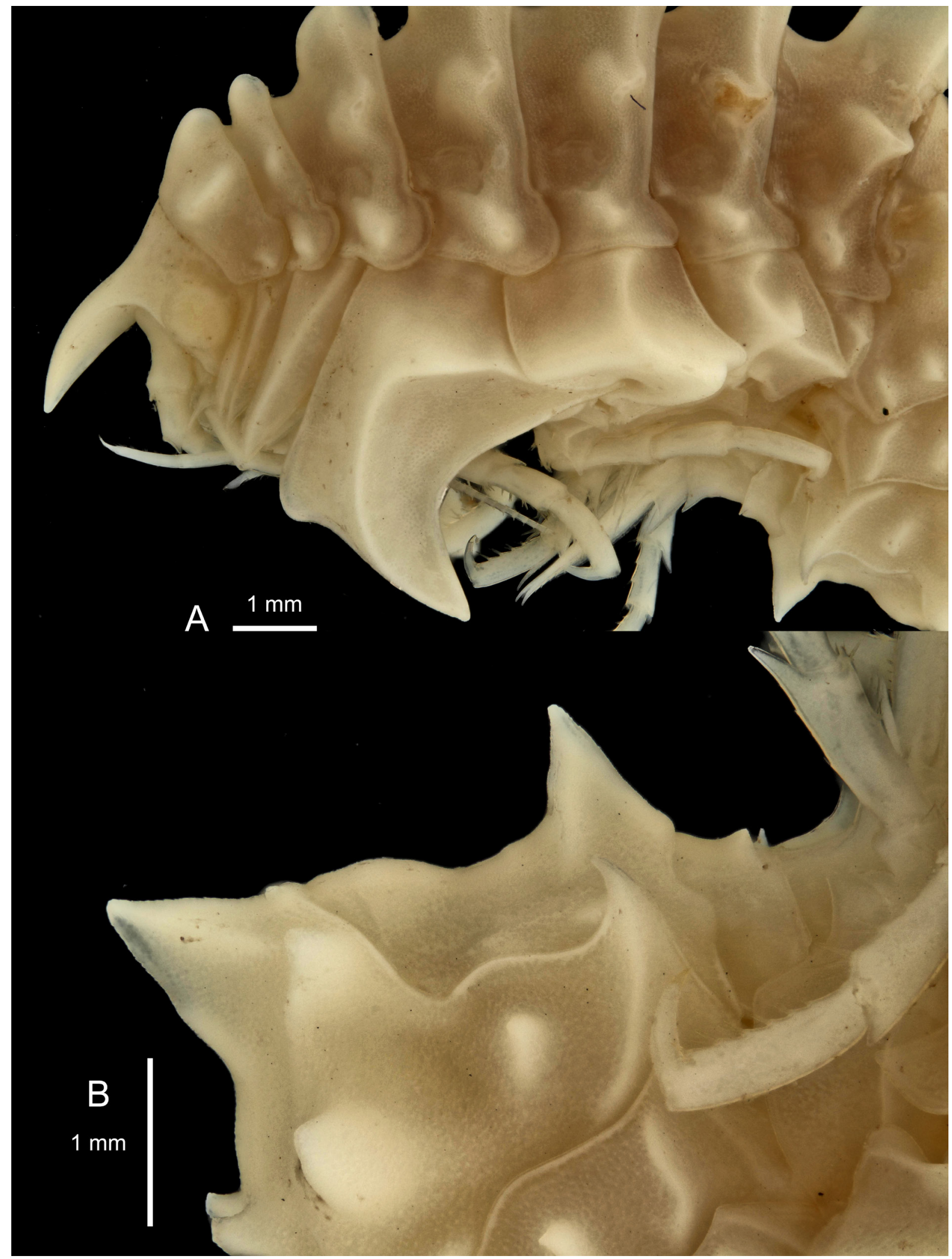

Fig. 258. Epimeria (Pseudepimeria) callista sp. nov., +, holotype, Adélie Coast, CEAMARC 3978, MNHN-IU-2014-7336. A. Anterior half. B. Pleonite 3, urosomites 1-3. 


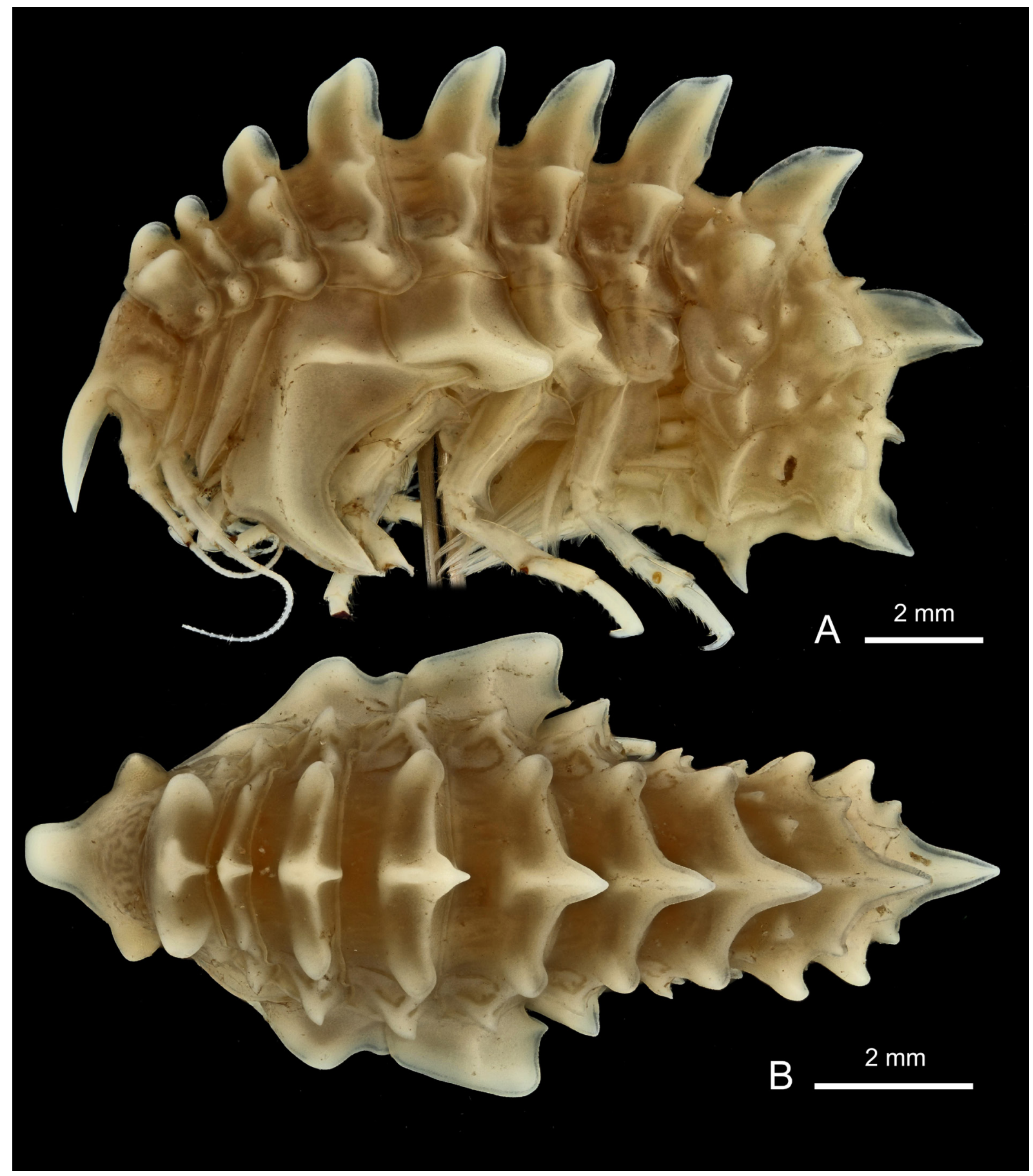

Fig. 259. Epimeria (Pseudepimeria) callista sp. nov., , paratype, Adélie Coast, CEAMARC 3978, MNHN-IU-2014-7337. A. Lateral habitus. B. Dorsal habitus. 


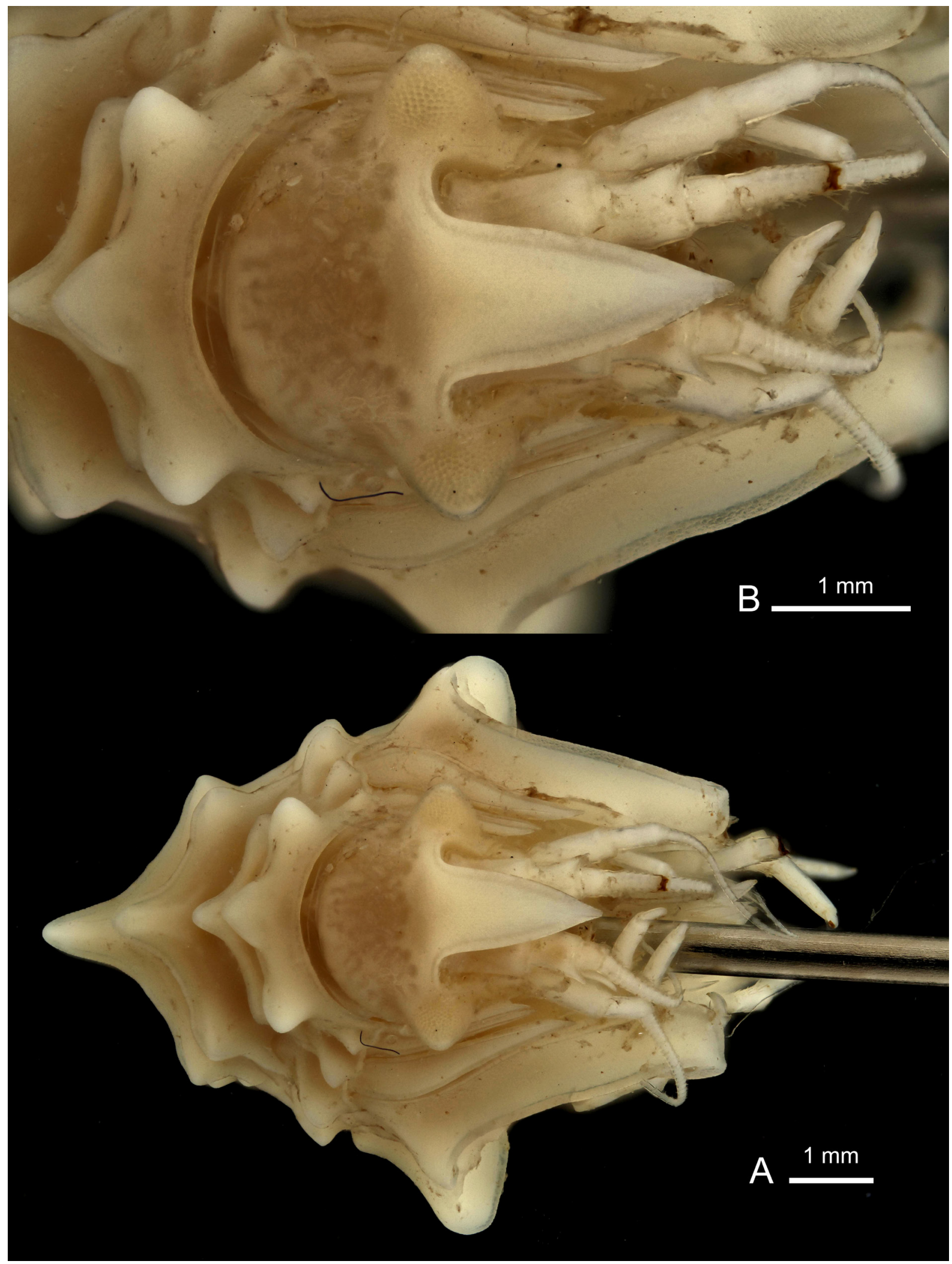

Fig. 260. Epimeria (Pseudepimeria) callista sp. nov., + , paratype, Adélie Coast, CEAMARC 3978, MNHN-IU-2014-7337. A. Facial habitus. B. Head in facial view. 


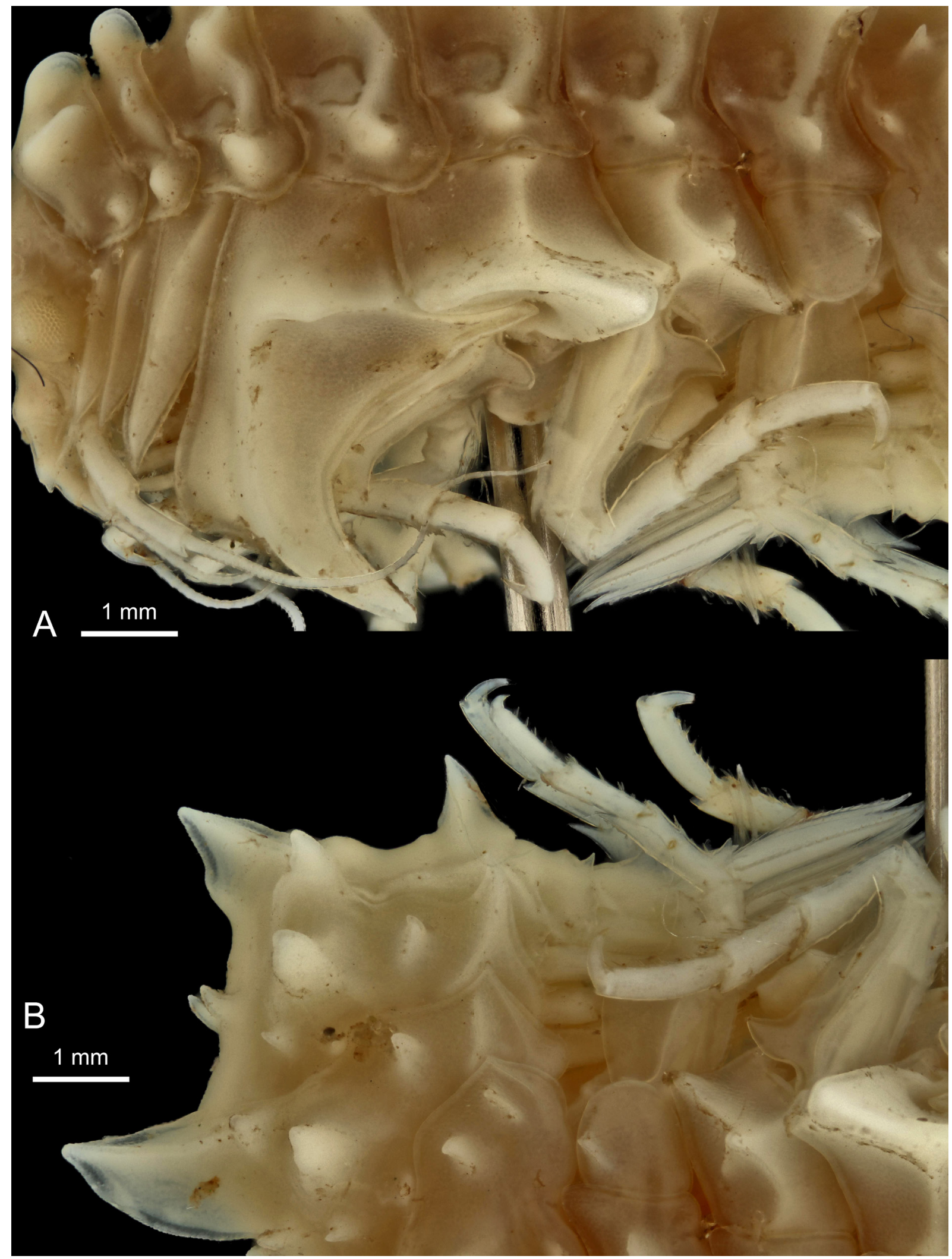

Fig. 261. Epimeria (Pseudepimeria) callista sp. nov., +, paratype, Adélie Coast, CEAMARC 3978, MNHN-IU-2014-7337. A. Coxae. B. Pleon. 


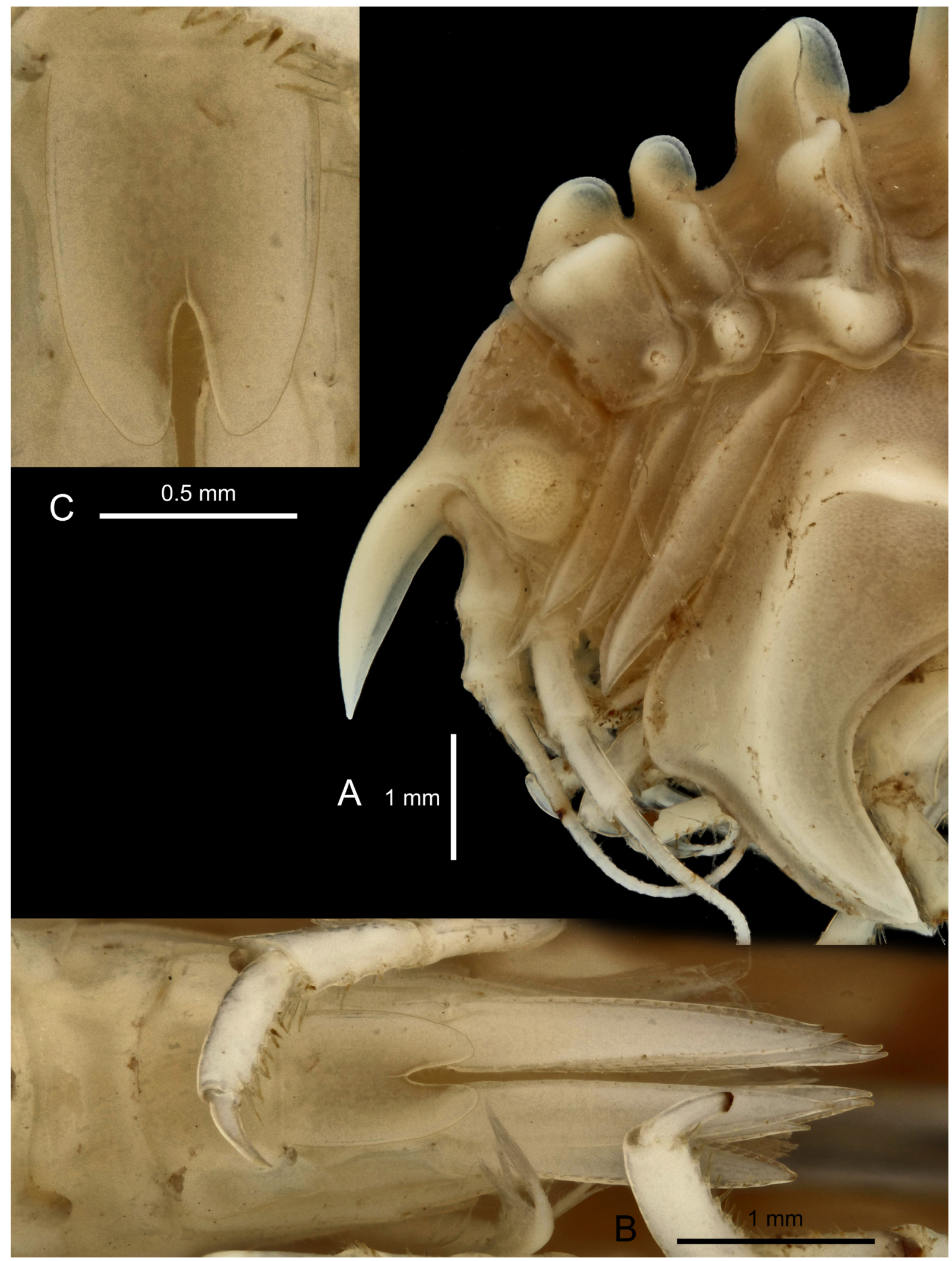

Fig. 262. Epimeria (Pseudepimeria) callista sp. nov., +, paratype, Adélie Coast, CEAMARC 3978, MNHN-IU-2014-7337. A. Head in lateral view. B. Urosome in dorsal view. C. Telson. 


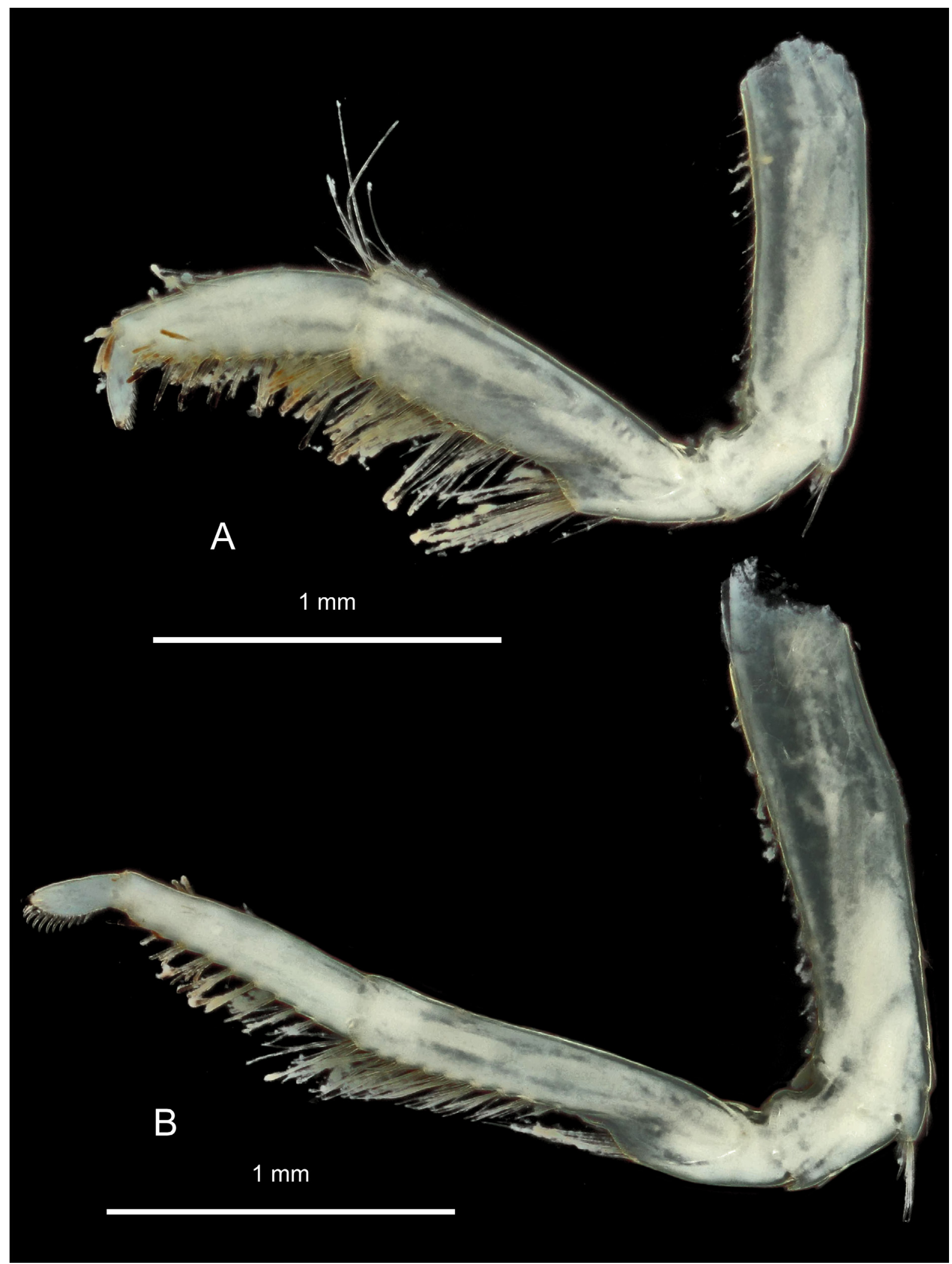

Fig. 263. Epimeria (Pseudepimeria) callista sp. nov., + , paratype, Adélie Coast, CEAMARC 3978, MNHN-IU-2014-7337. A. Gnathopod 1. B. Gnathopod 2. 


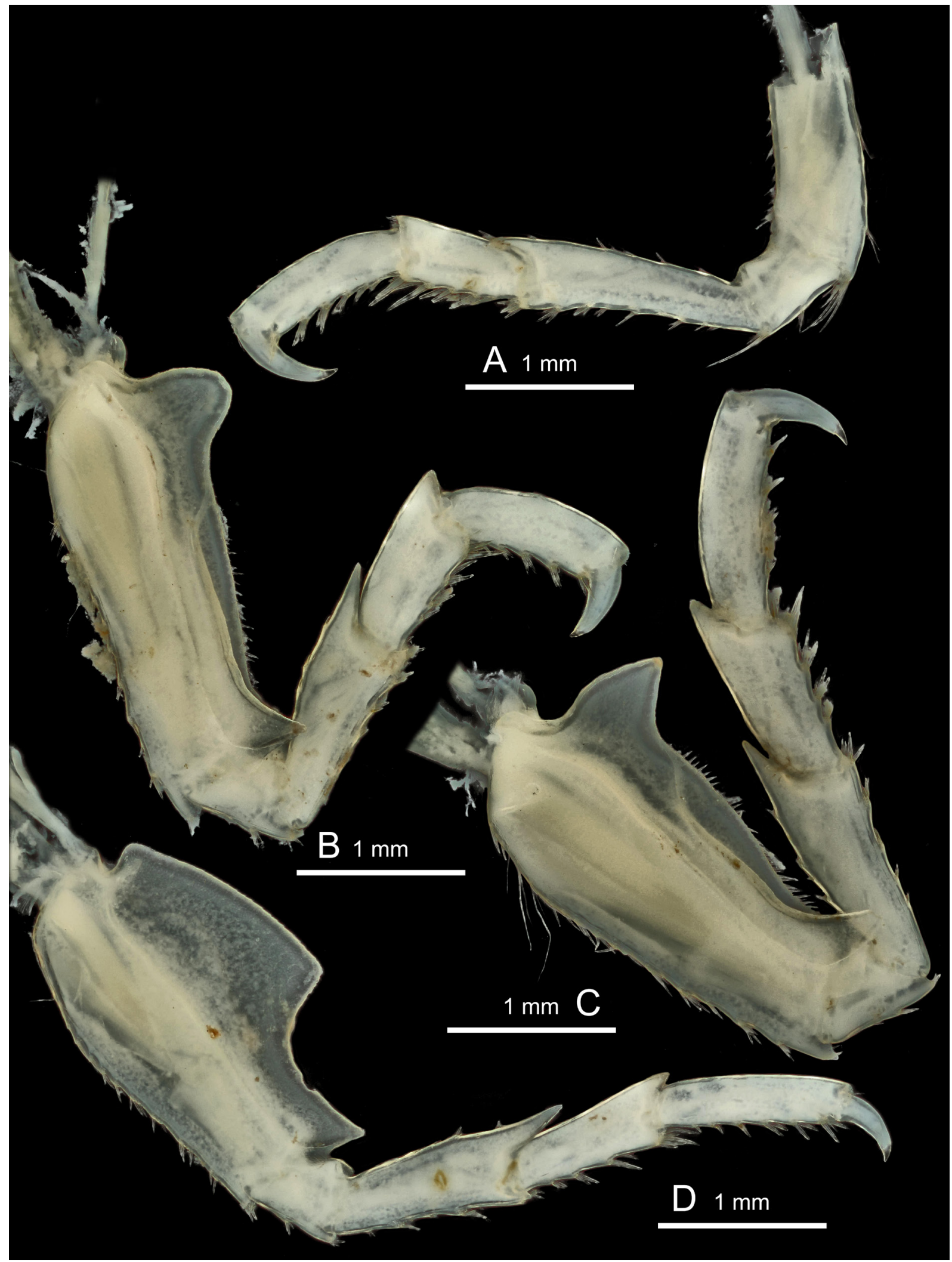

Fig. 264. Epimeria (Pseudepimeria) callista sp. nov., +, paratype, Adélie Coast, CEAMARC 3978, MNHN-IU-2014-7337. A. Pereiopod 4. B. Pereiopod 5. C. Pereiopod 6. D. Pereiopod 7. 


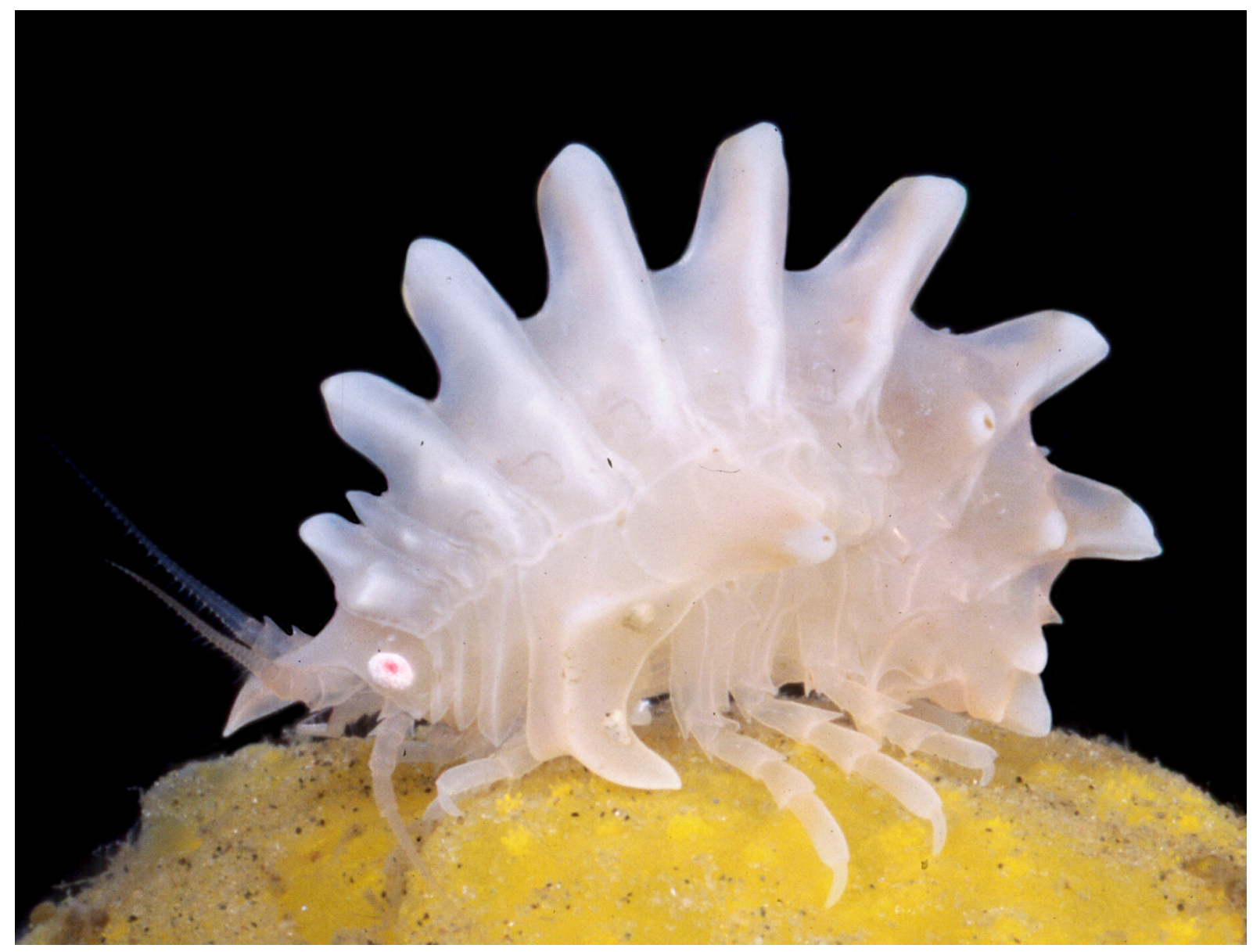

Fig. 265. Epimeria (Pseudepimeria) debroyeri sp. nov., presumably ${ }_{+}$, eastern Weddell Sea, ANTVII/4, station not indicated, but possibly holotype. Habitus in colour. There is no evidence of symbiosis with sponges: there was simply a sponge in the aquarium used for photography. Photograph Gauthier Chapelle. 


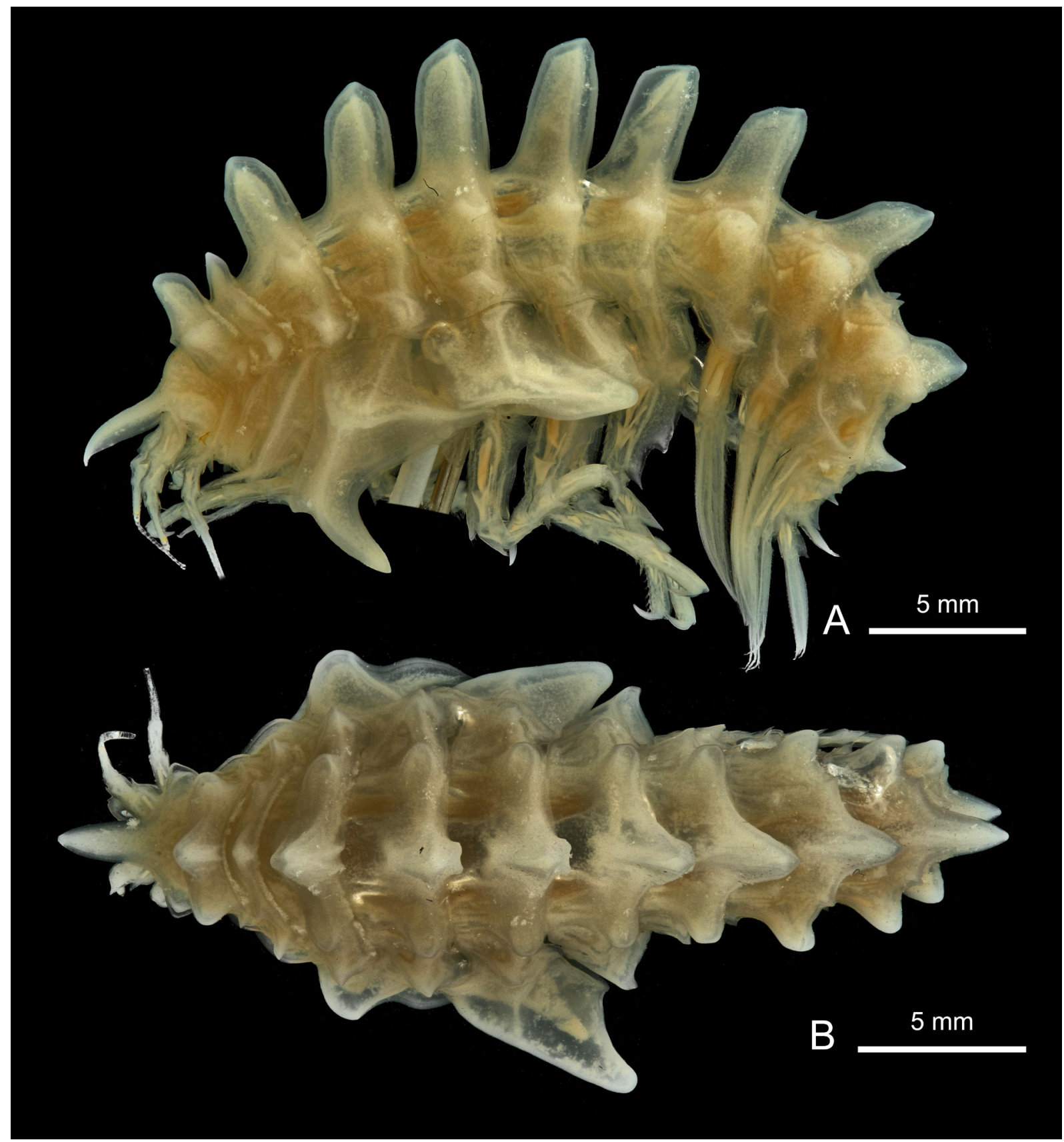

Fig. 266. Epimeria (Pseudepimeria) debroyeri sp. nov., $q$, holotype, eastern Weddell Sea, ANT-VII/4, stn 291, RBINS, INV. 132940. A. Lateral habitus. B. Dorsal habitus. 


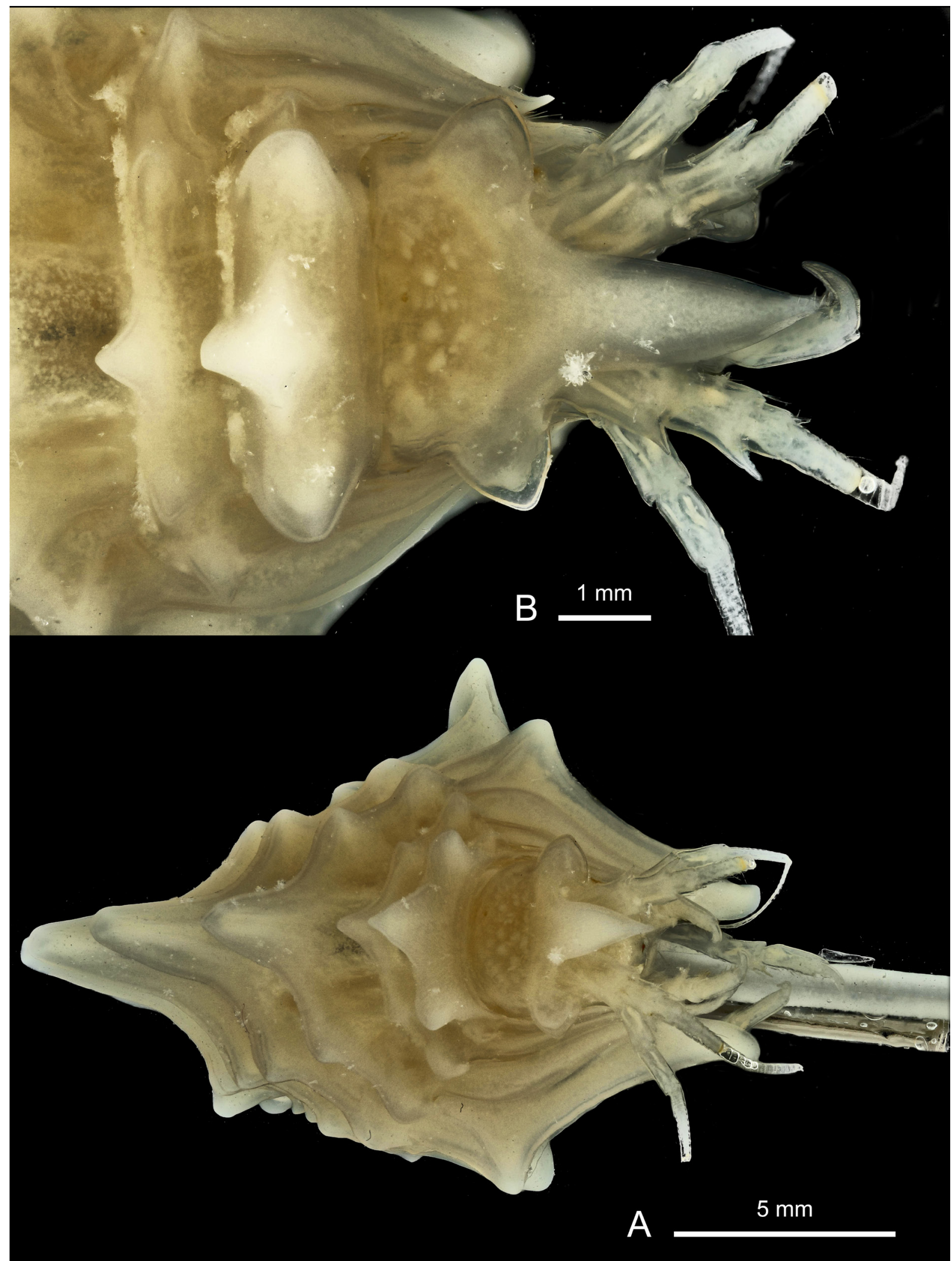

Fig. 267. Epimeria (Pseudepimeria) debroyeri sp. nov., + , holotype, eastern Weddell Sea, ANT-VII/4, stn 291, RBINS, INV. 132940. A. Facial habitus. B. Head in dorsal view. 


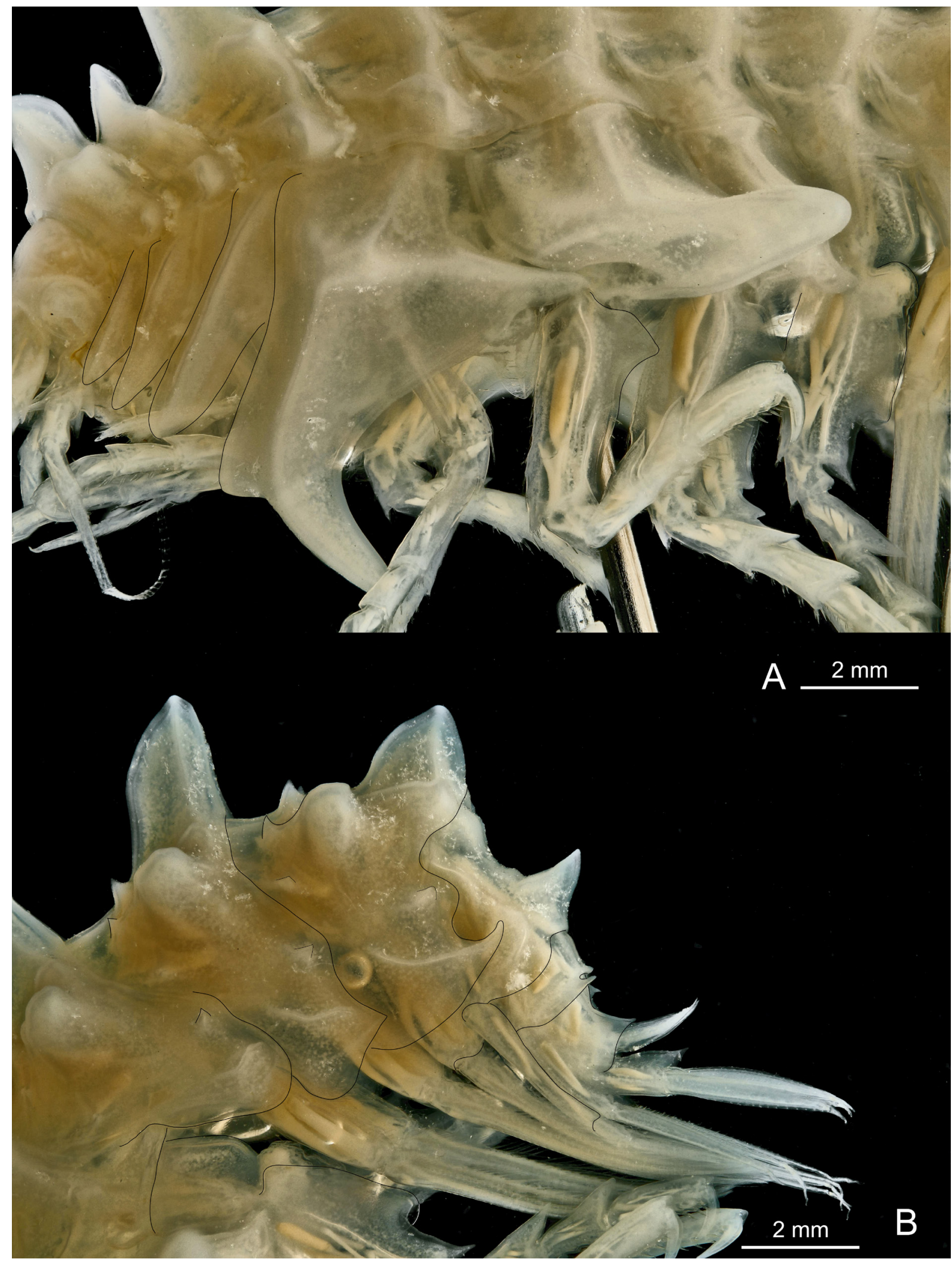

Fig. 268. Epimeria (Pseudepimeria) debroyeri sp. nov., + , holotype, eastern Weddell Sea, ANT-VII/4, stn 291, RBINS, INV. 132940. A. Coxae. B. Pleon. 


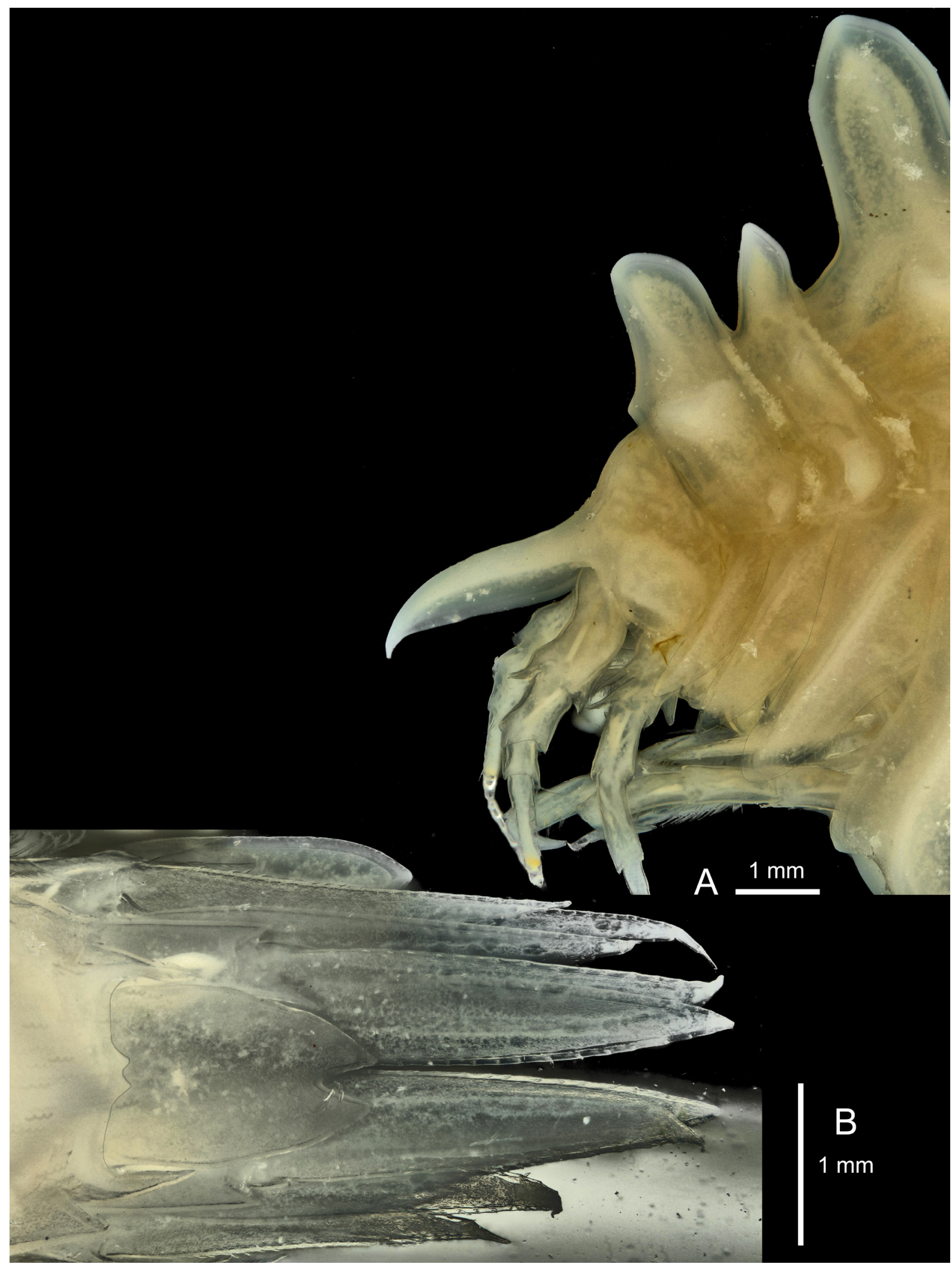

Fig. 269. Epimeria (Pseudepimeria) debroyeri sp. nov., + , holotype, eastern Weddell Sea, ANT-VII/4, stn 291, RBINS, INV. 132940. A. Head in lateral view. B. Urosome in dorsal view. 


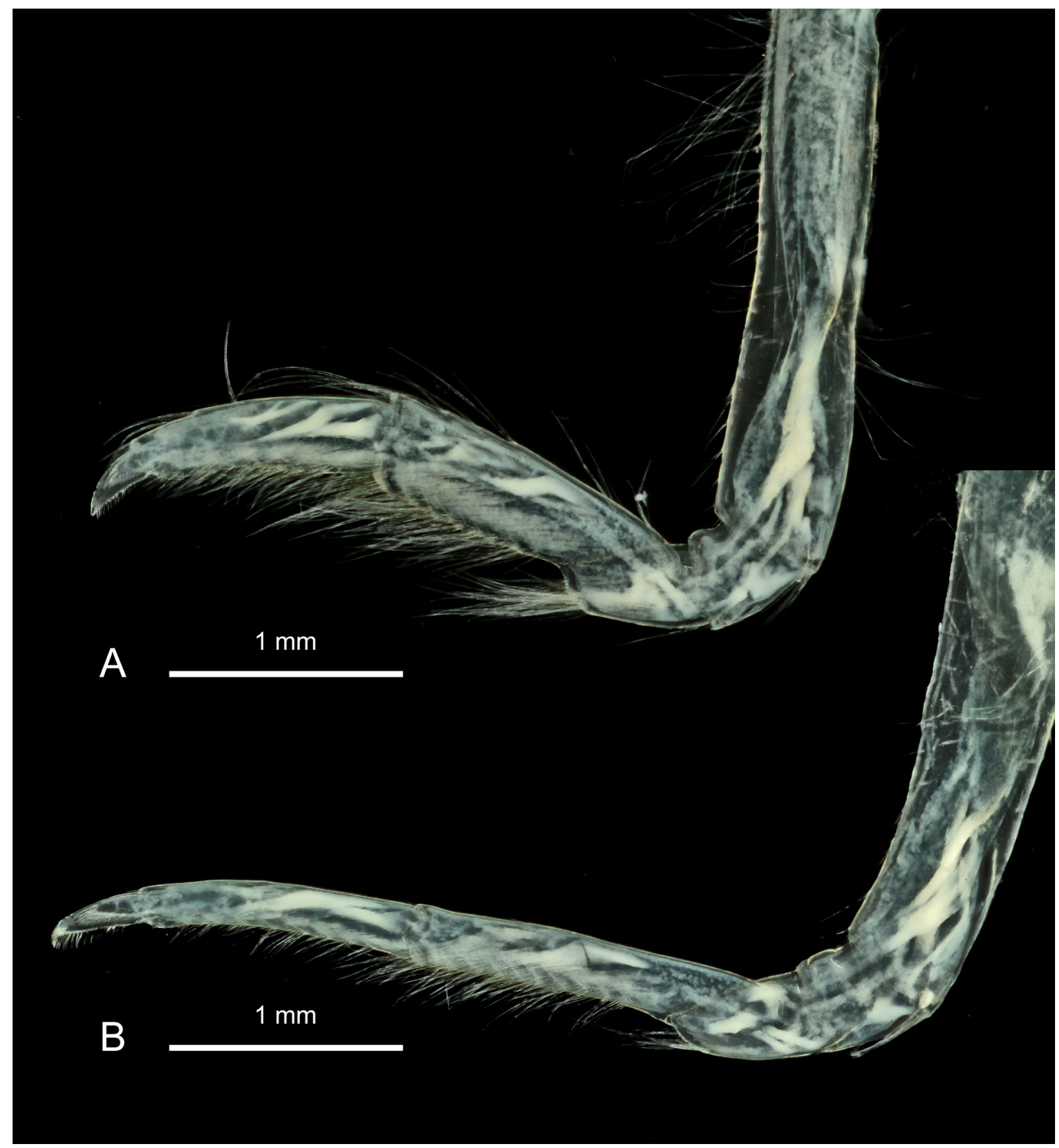

Fig. 270. Epimeria (Pseudepimeria) debroyeri sp. nov., + , holotype, eastern Weddell Sea, ANT-VII/4, stn 291, RBINS, INV. 132940. A. Gnathopod 1. B. Gnathopod 2. 


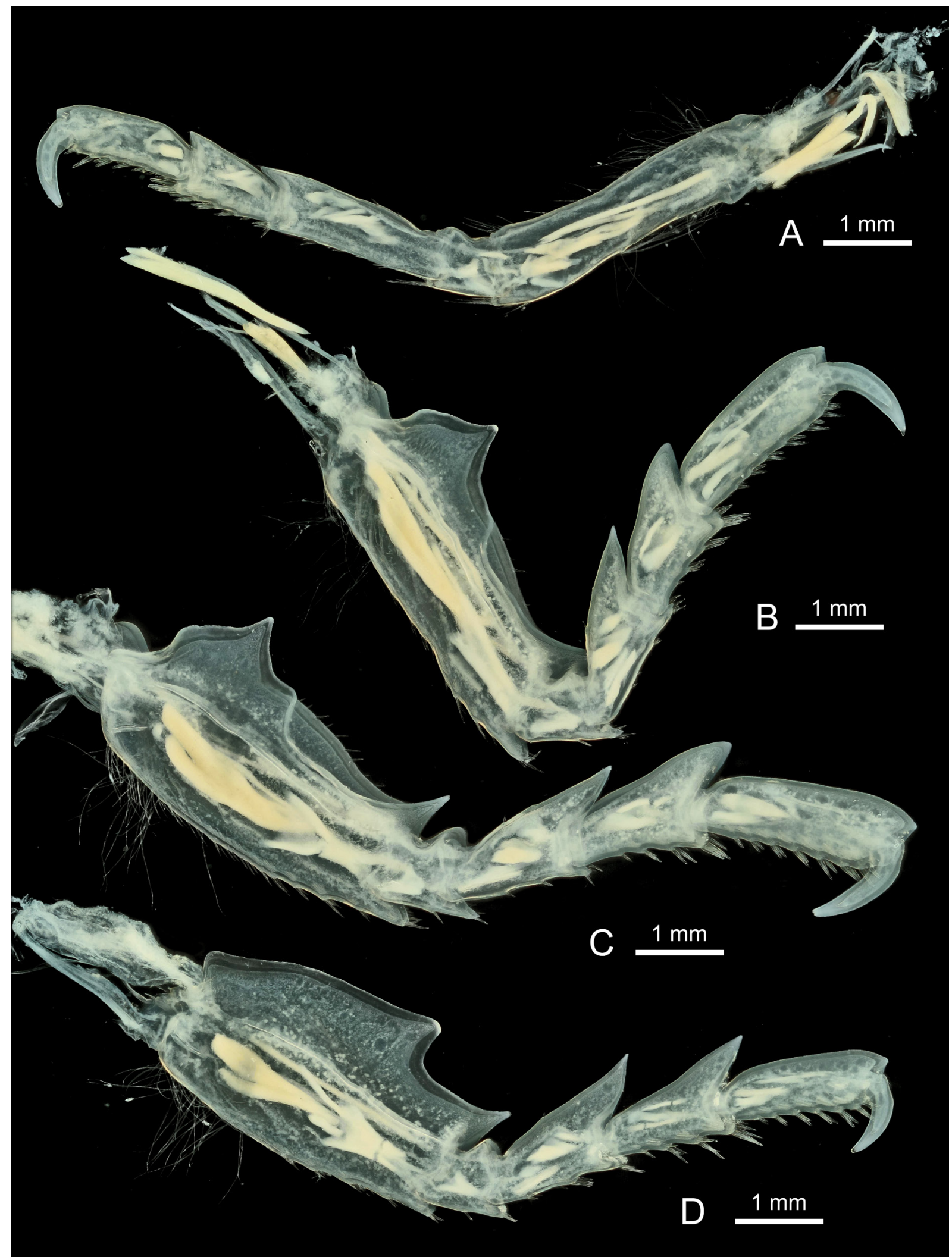

Fig. 271. Epimeria (Pseudepimeria) debroyeri sp. nov., + , holotype, eastern Weddell Sea, ANT-VII/4, stn 291, RBINS, INV. 132940. A. Pereiopod 4. B. Pereiopod 5. C. Pereiopod 6. D. Pereiopod 7. 


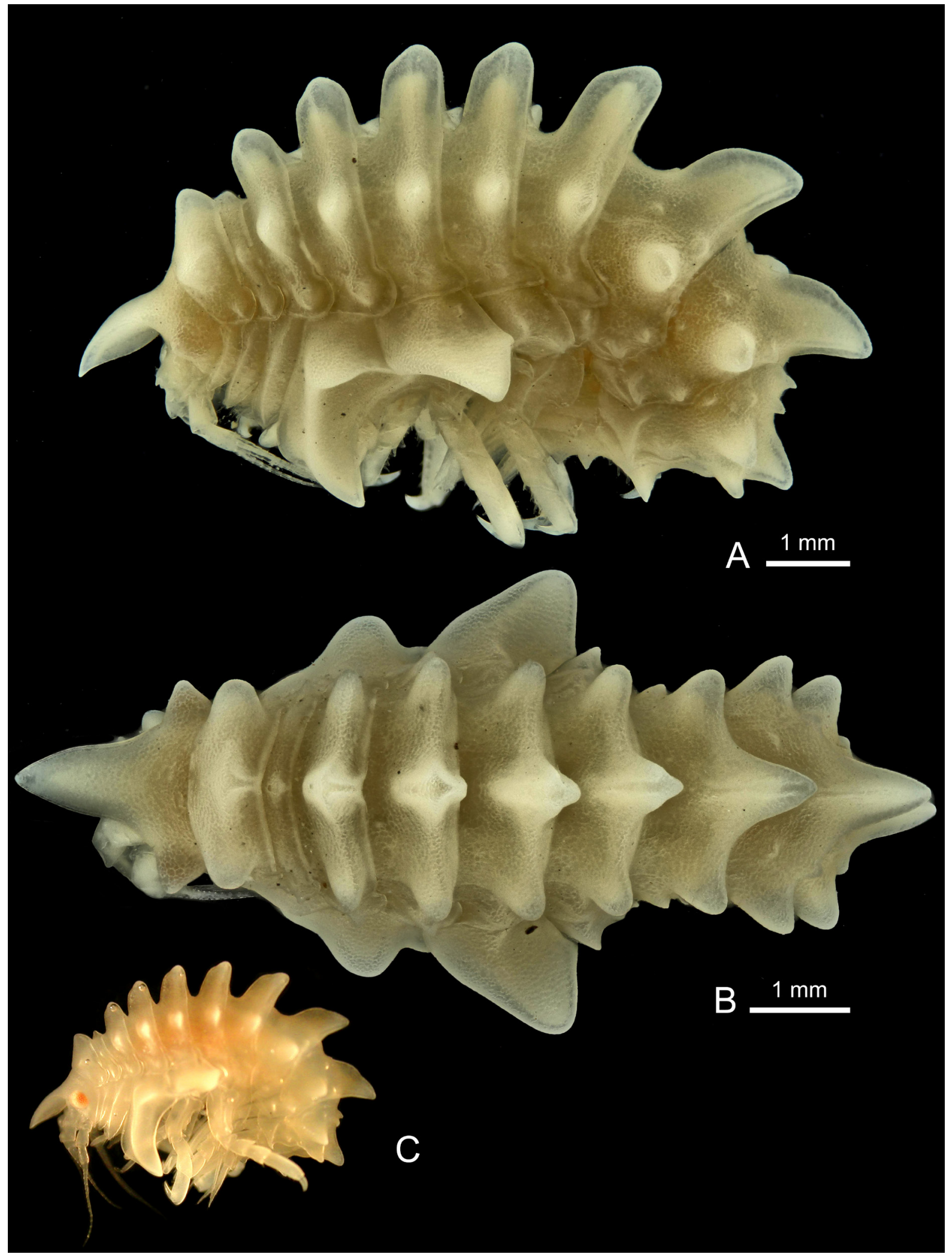

Fig. 272. Epimeria (Pseudepimeria) cf. debroyeri, juveniles. A-B, Elephant Island, ANT-XXIII/8, stn 614-3/4/5, RBINS, INV. 132941. C, northwestern Weddell Sea, ANT-XXIII/8, stn 728-2, RBINS, INV. 122524. colour in life (photograph: C. d'Udekem d'Acoz). A. Lateral habitus. B. Dorsal habitus. C. Colour in life. 


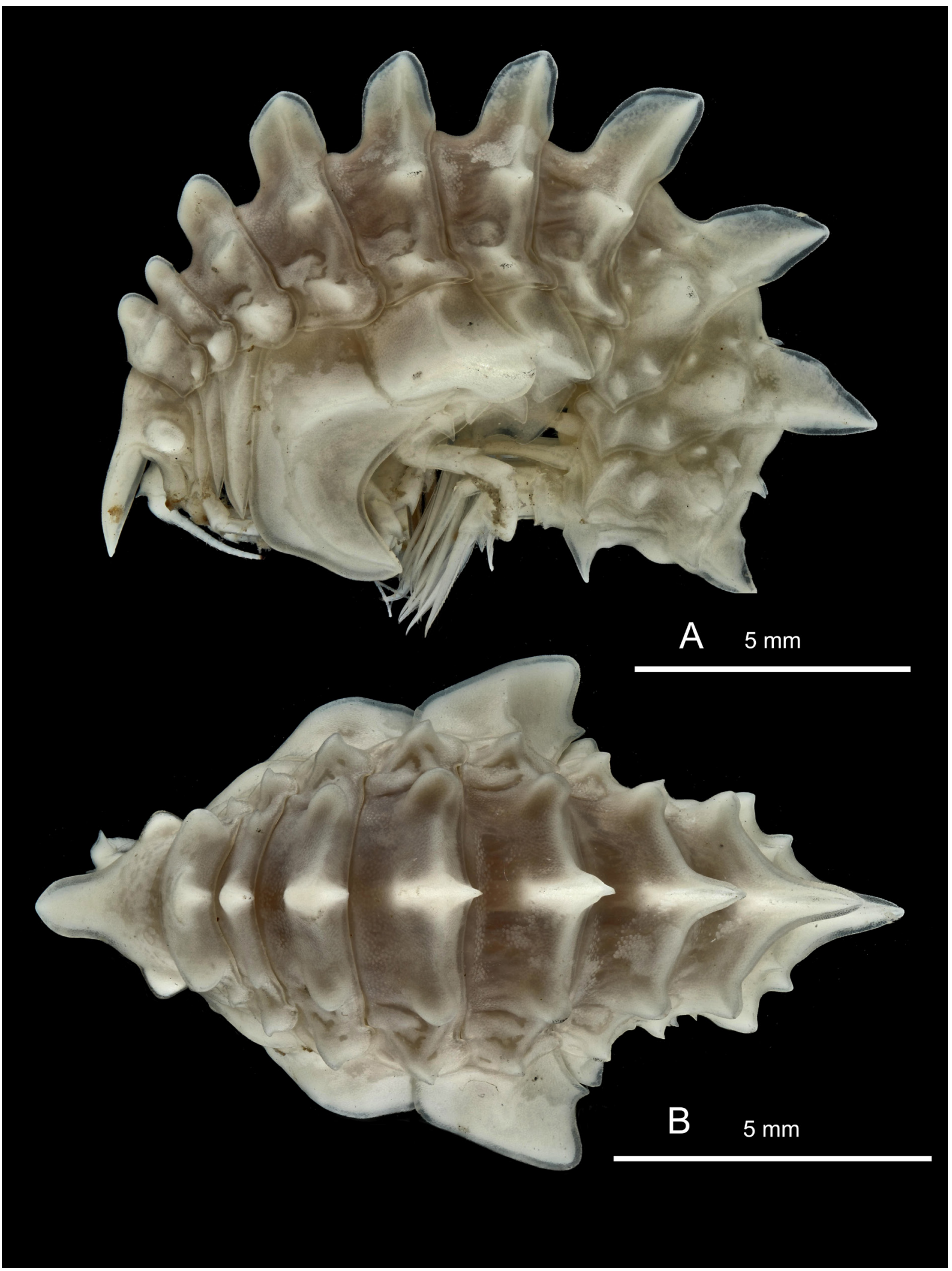

Fig. 273. Epimeria (Pseudepimeria) grandirostris (Chevreux, 1912), $q$, northwestern Weddell Sea, ANT-XXIX/3, stn 185-3, RBINS, INV. 122946. A. Lateral habitus. B. Dorsal habitus. 


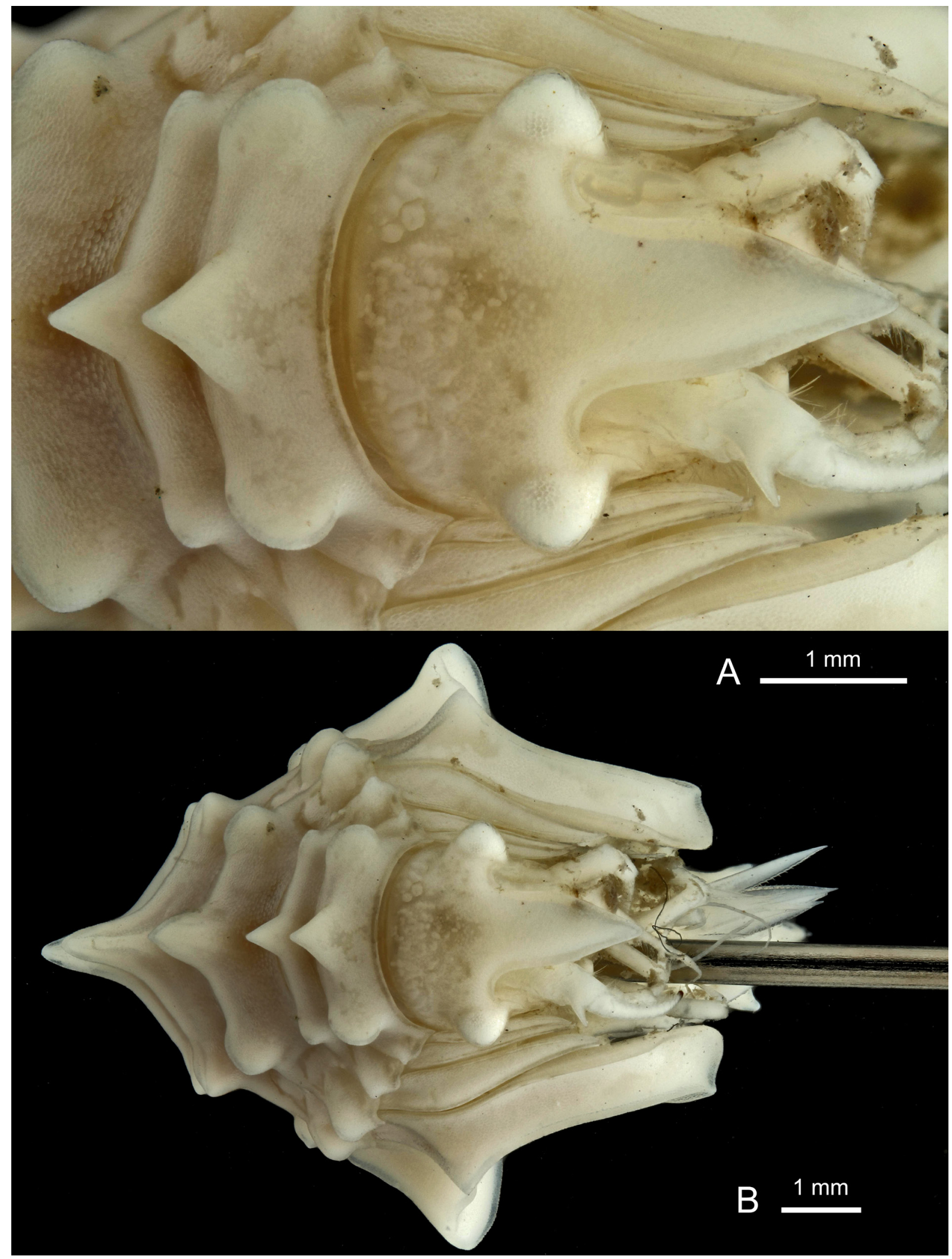

Fig. 274. Epimeria (Pseudepimeria) grandirostris (Chevreux, 1912), + , northwestern Weddell Sea, ANT-XXIX/3, stn 185-3, RBINS, INV. 122946. A. Facial habitus. B. Head in facial view. 


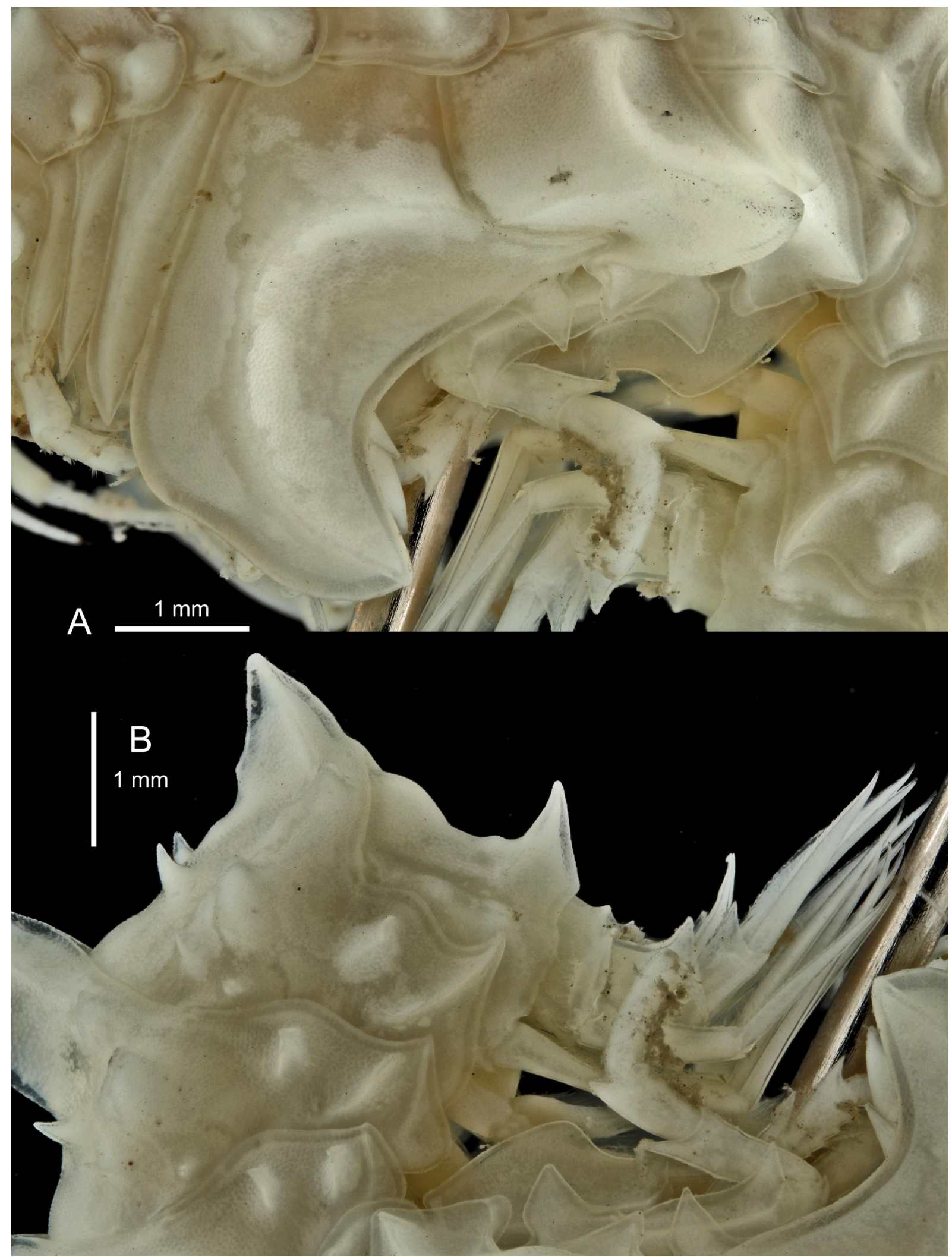

Fig. 275. Epimeria (Pseudepimeria) grandirostris (Chevreux, 1912), + , northwestern Weddell Sea, ANT-XXIX/3, stn 185-3, RBINS, INV. 122946. A. Coxae. B. Pleon. 


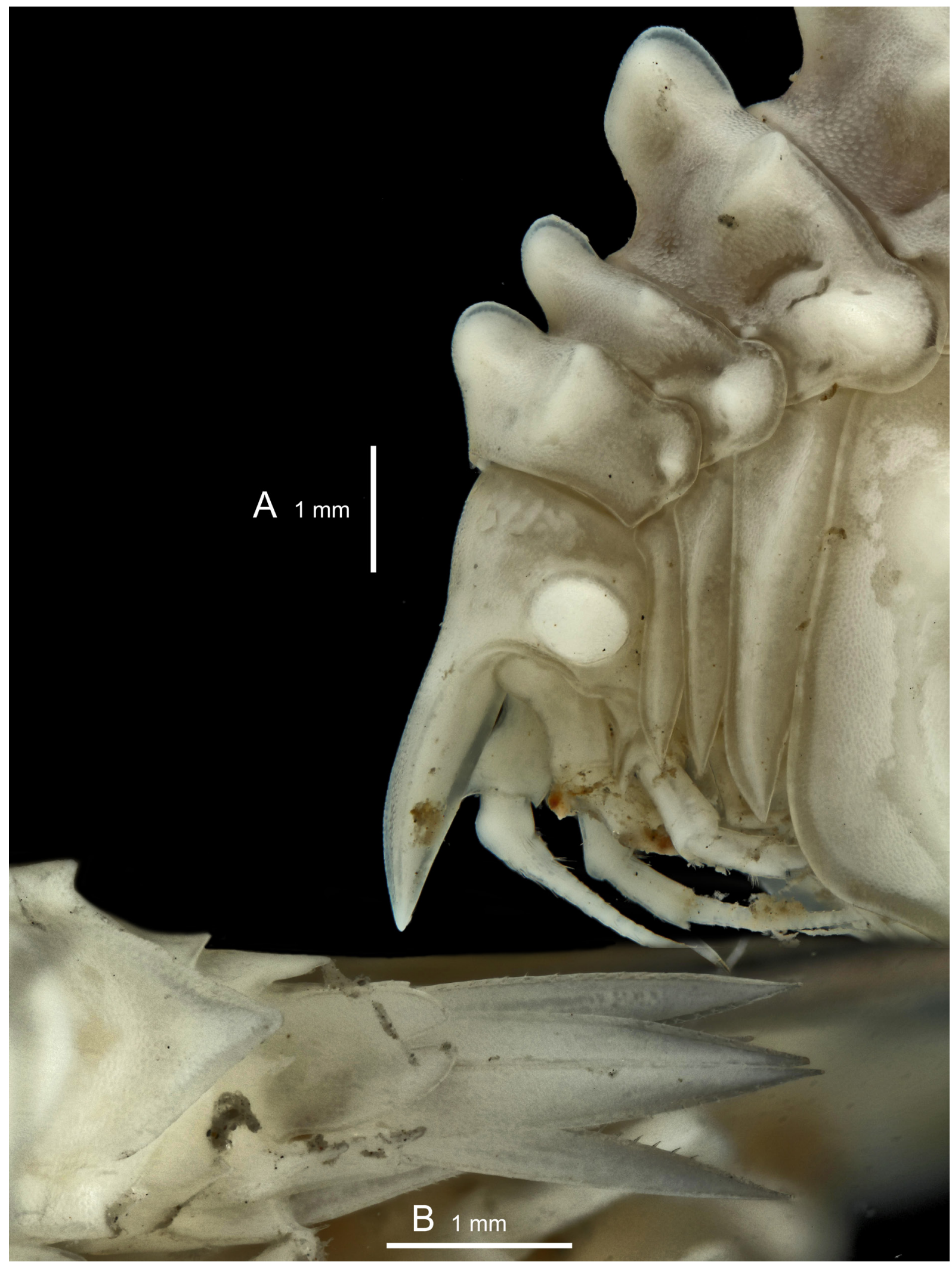

Fig. 276. Epimeria (Pseudepimeria) grandirostris (Chevreux, 1912), $q$, northwestern Weddell Sea, ANT-XXIX/3, stn 185-3, RBINS, INV. 122946. A. Head and pereionites 1-3. B. Urosome in dorsal view. 


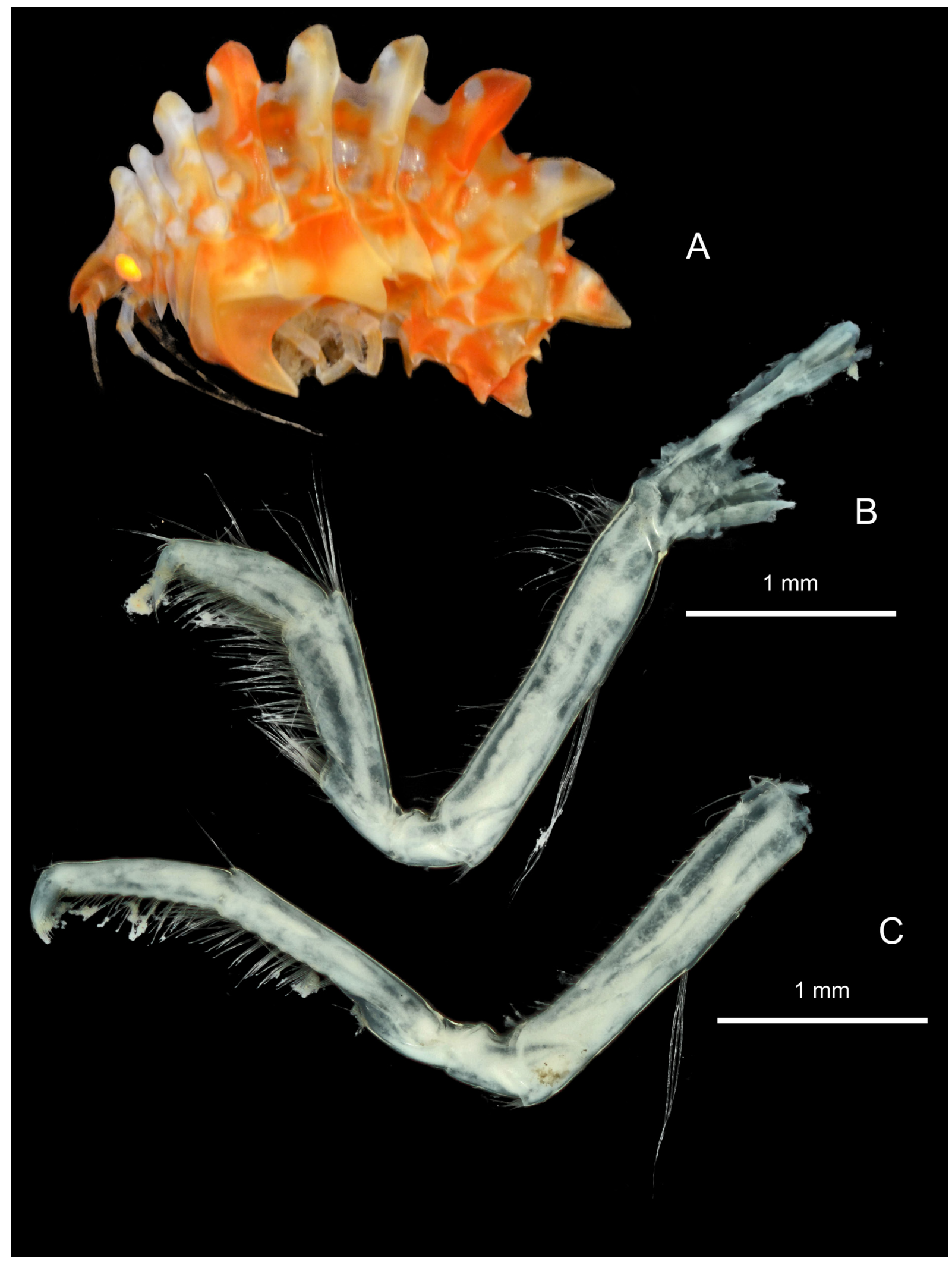

Fig. 277. Epimeria (Pseudepimeria) grandirostris (Chevreux, 1912), $q$, northwestern Weddell Sea, ANT-XXIX/3, stn 185-3, RBINS, INV. 122946. A. Lateral habitus with colour in life. B. Gnathopod 1. C. Gnathopod 2. 


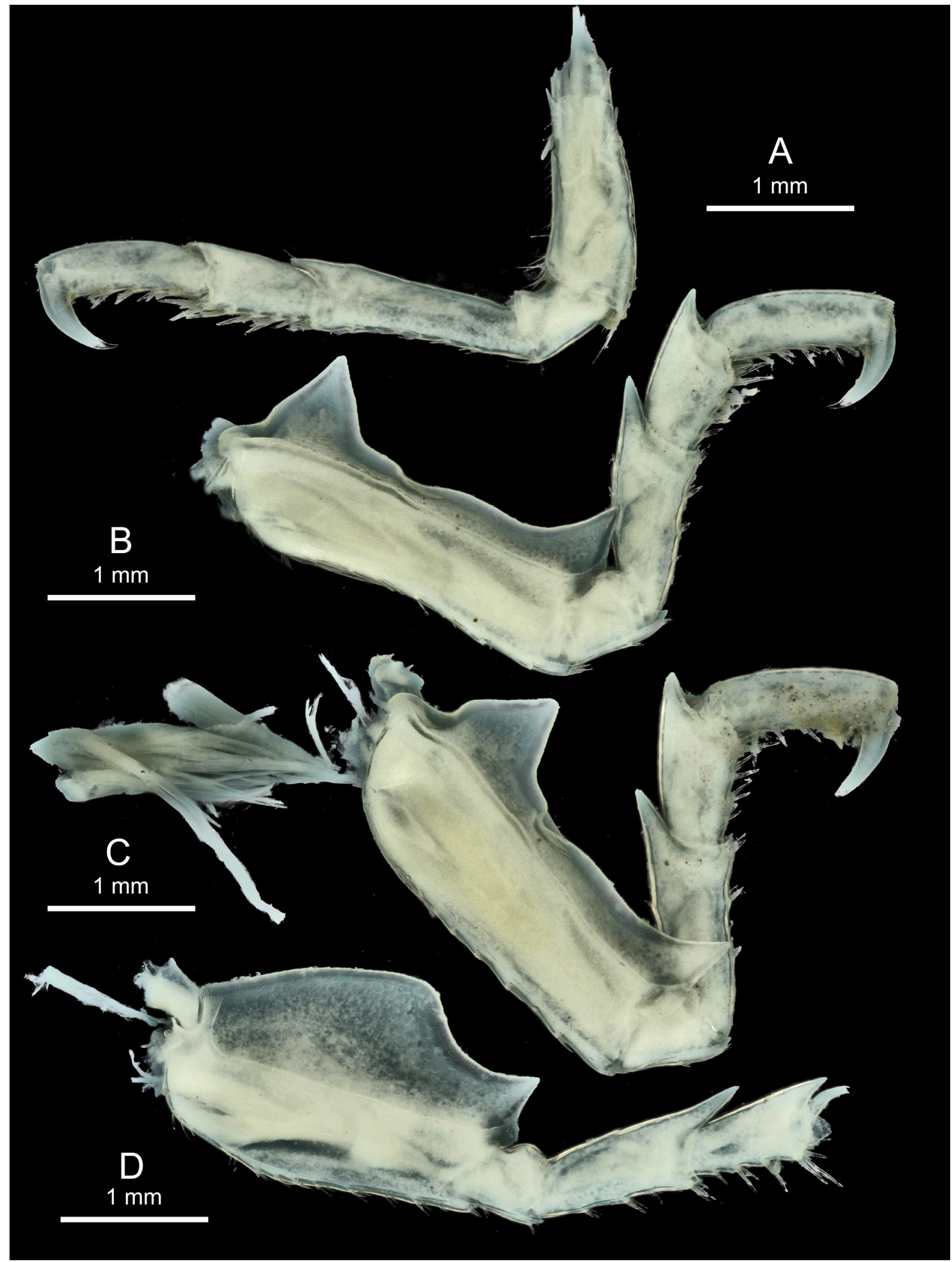

Fig. 278. Epimeria (Pseudepimeria) grandirostris (Chevreux, 1912), + , northwestern Weddell Sea, ANT-XXIX/3, stn 185-3, RBINS, INV. 122946. A. Pereiopod 4. B. Pereiopod 5. C. Pereiopod 6. D. Pereiopod 7. 


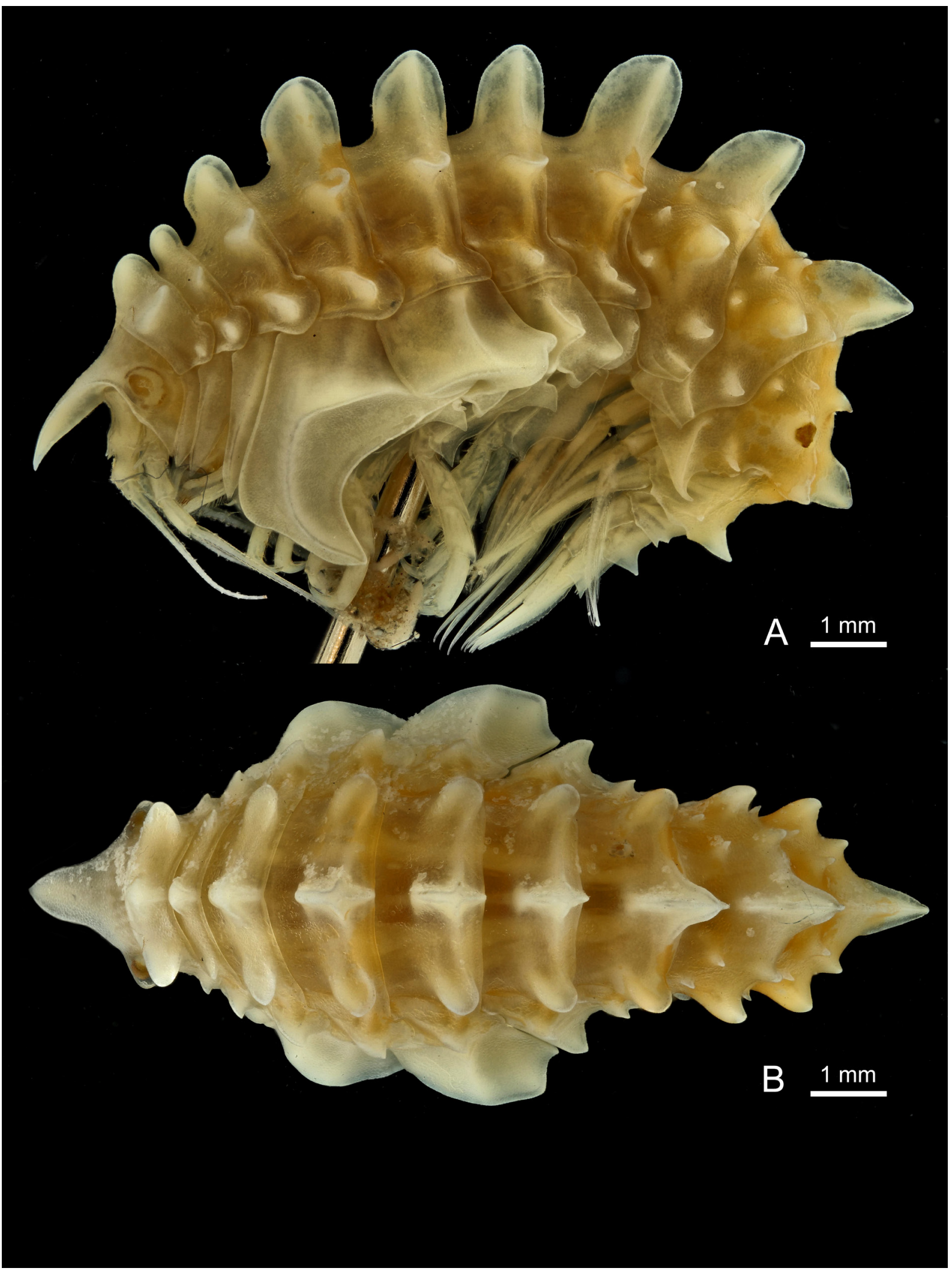

Fig. 279. Epimeria (Pseudepimeria) grandirostris (Chevreux, 1912), immature, Elephant Island, ANTXXIII/8, stn 605-1, RBINS, INV. 122530. A. Lateral habitus. B. Dorsal habitus. 


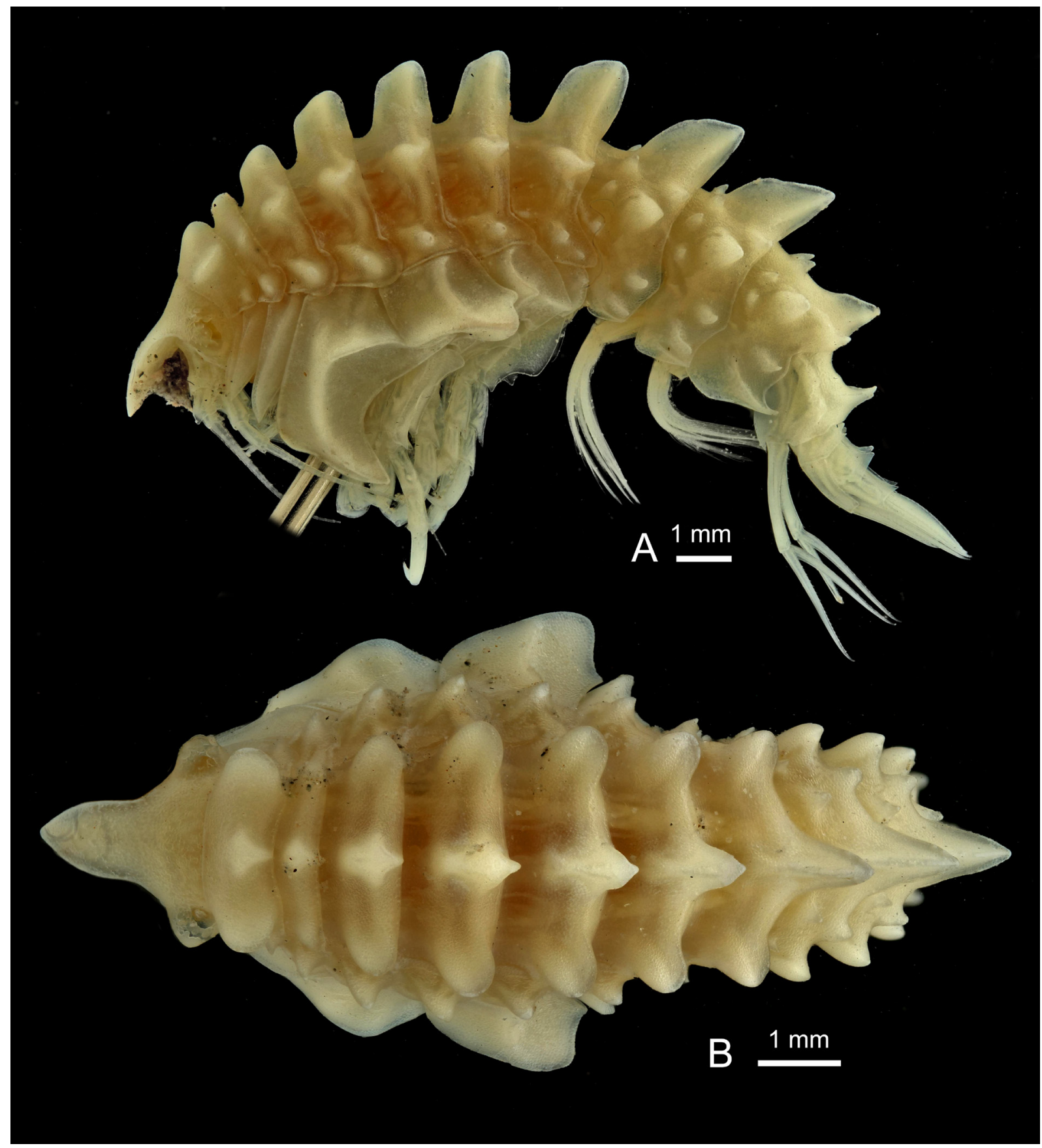

Fig. 280. Epimeria (Pseudepimeria) grandirostris (Chevreux, 1912), immature, Elephant Island, ANTXXIII/8, stn 608-1, RBINS, INV. 122626. A. Lateral habitus. B. Dorsal habitus. 


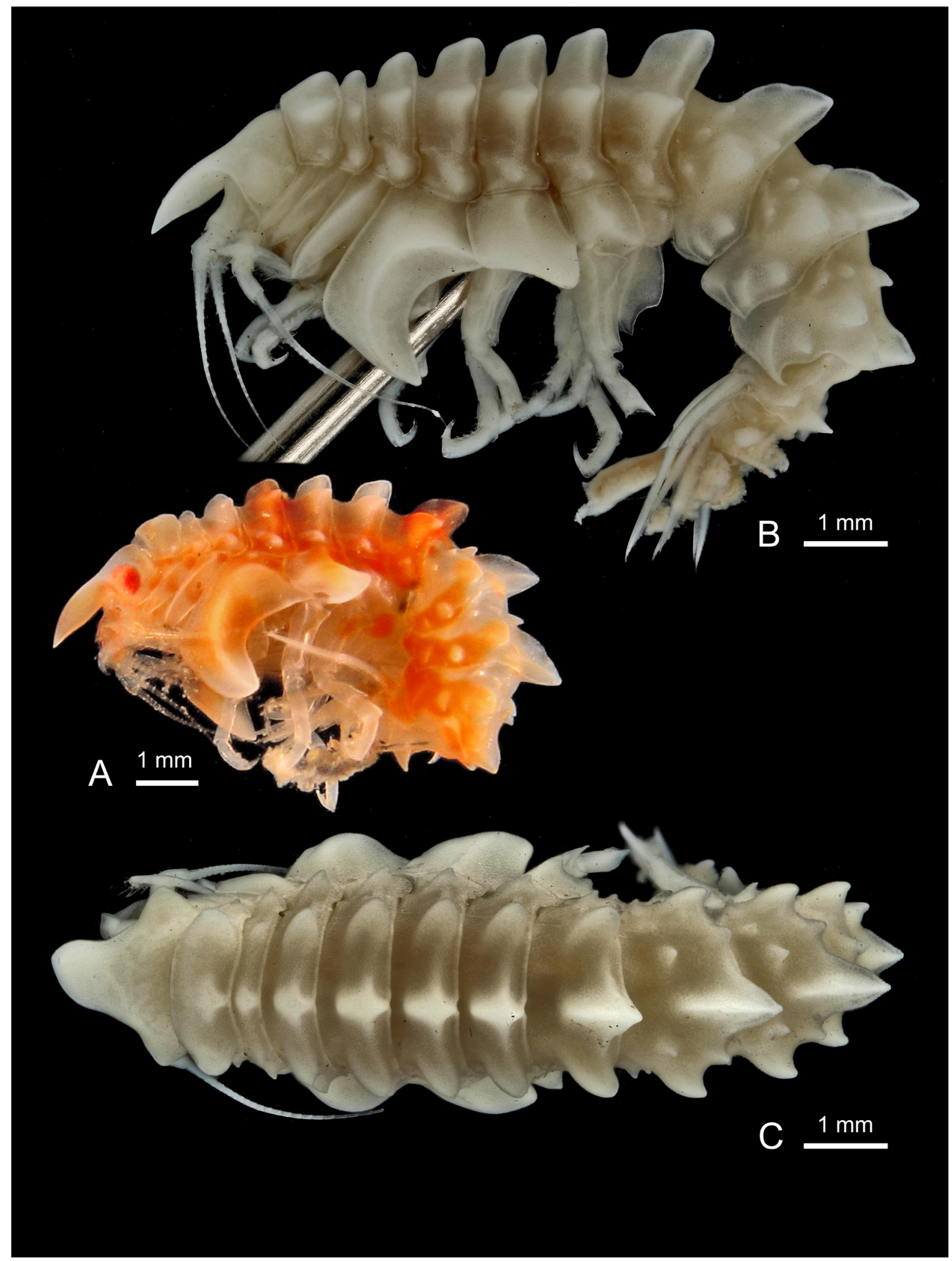

Fig. 281. Epimeria (Pseudepimeria) grandirostris (Chevreux, 1912), juvenile, Elephant Island, ANTXXIII/8, stn 654-6, RBINS, INV. 122484. A. Colour in life. B. Lateral habitus. C. Dorsal habitus. 


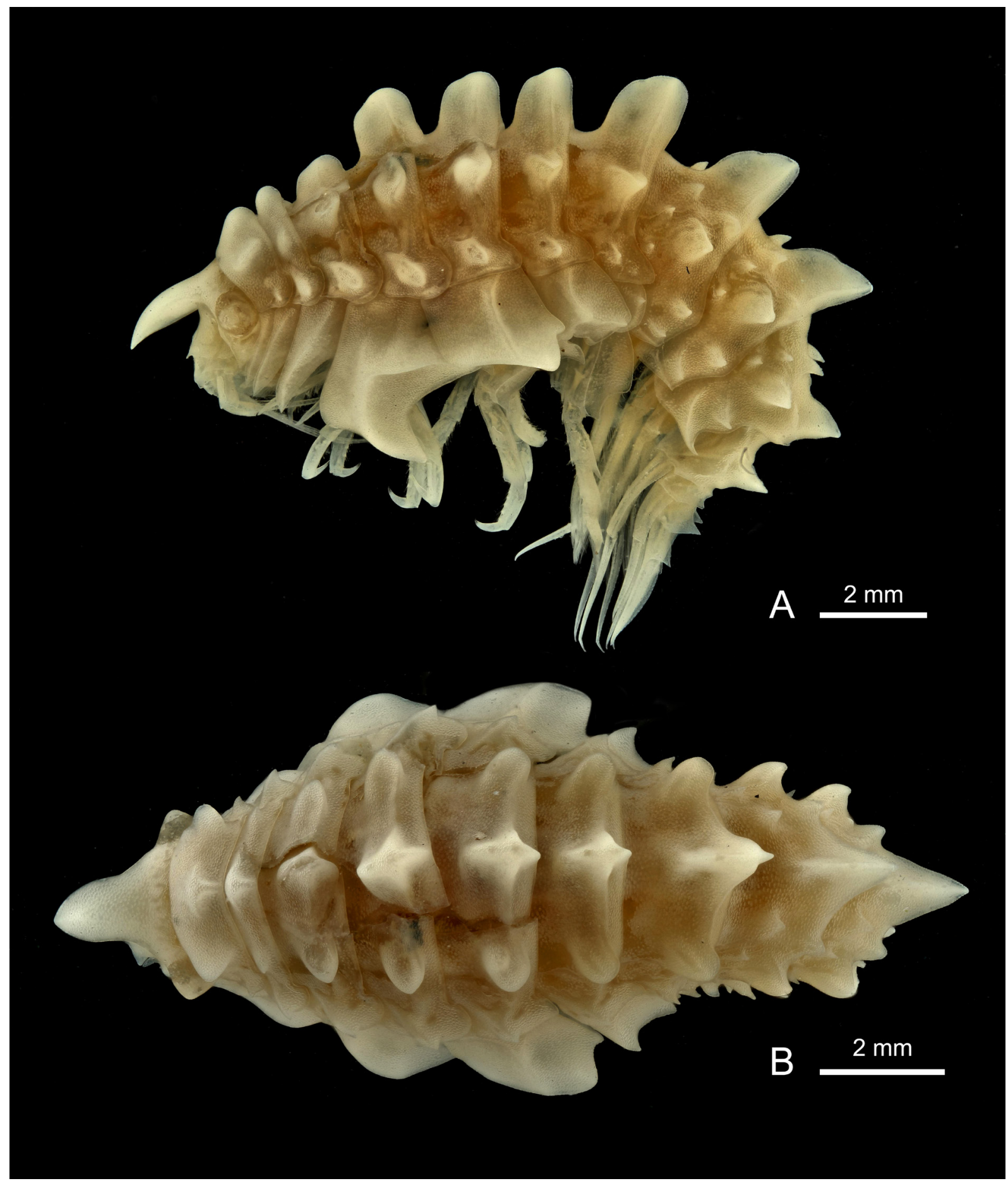

Fig. 282. Epimeria (Pseudepimeria) grandirostris (Chevreux, 1912), small juvenile, Elephant Island, ANT-XXIII/8, stn 614-3/4/5, RBINS, INV. 122523. A. Lateral habitus. B. Dorsal habitus. 


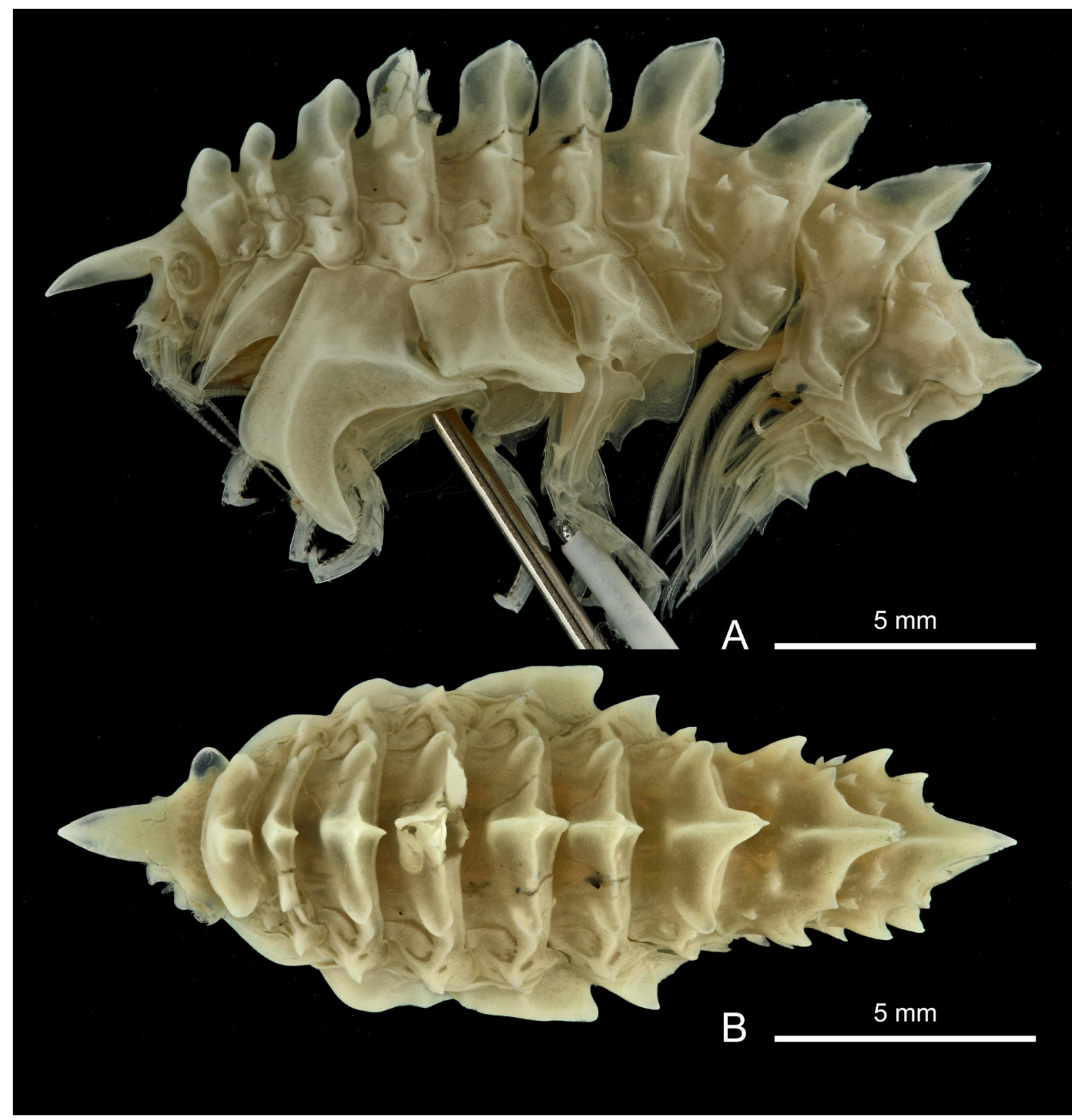

Fig. 283. Epimeria (Pseudepimeria) kharieis sp. nov., + , paratype, eastern Weddell Sea, ANT-VII/4, stn 281, RBINS, INV. 132939. A. Lateral habitus. B. Dorsal habitus. 


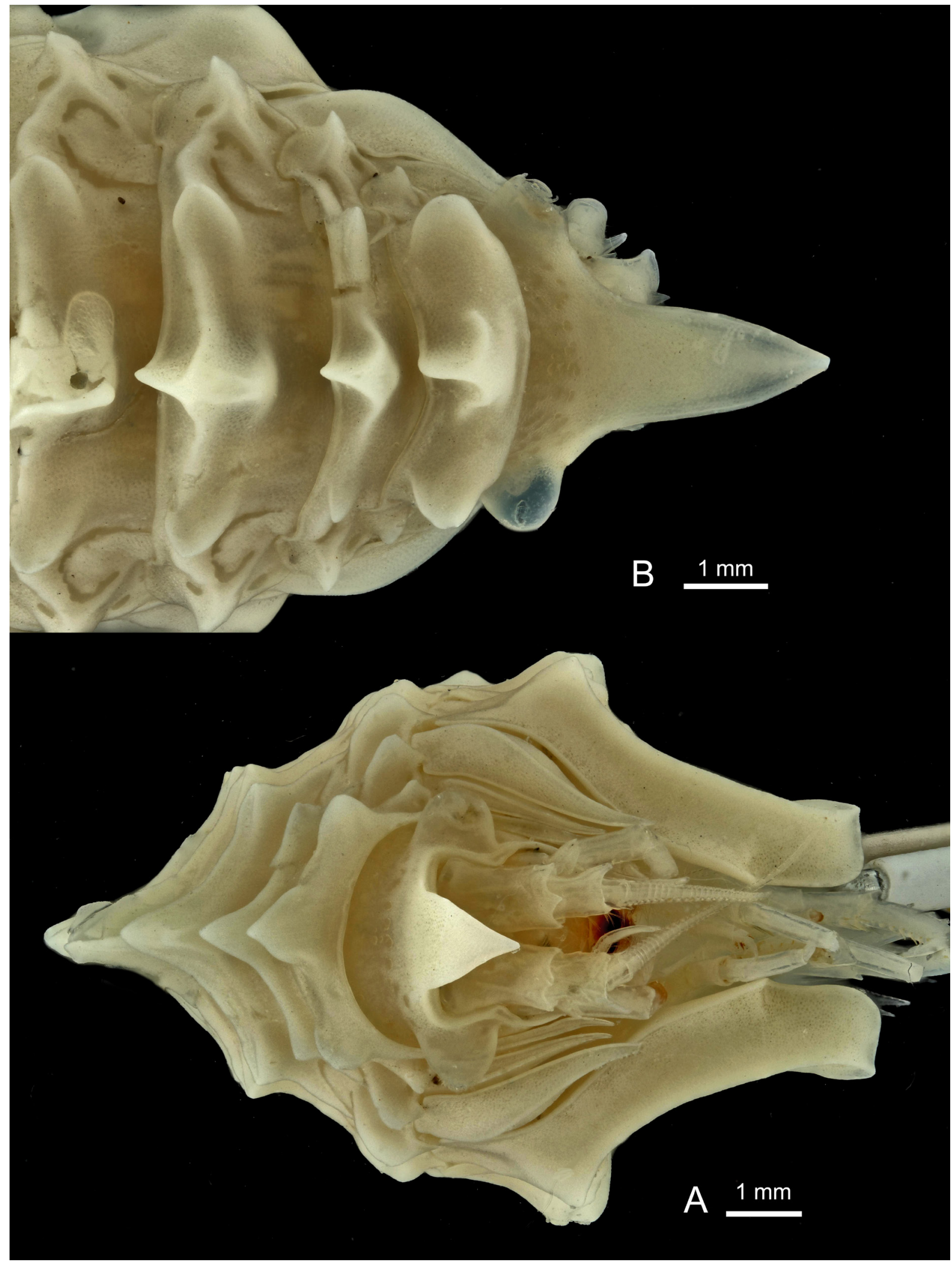

Fig. 284. Epimeria (Pseudepimeria) kharieis sp. nov.,, , paratype, eastern Weddell Sea, ANT-VII/4, stn 281, RBINS, INV. 132939. A. Facial habitus. B. Head and body segments 1-3 in dorsal view. 


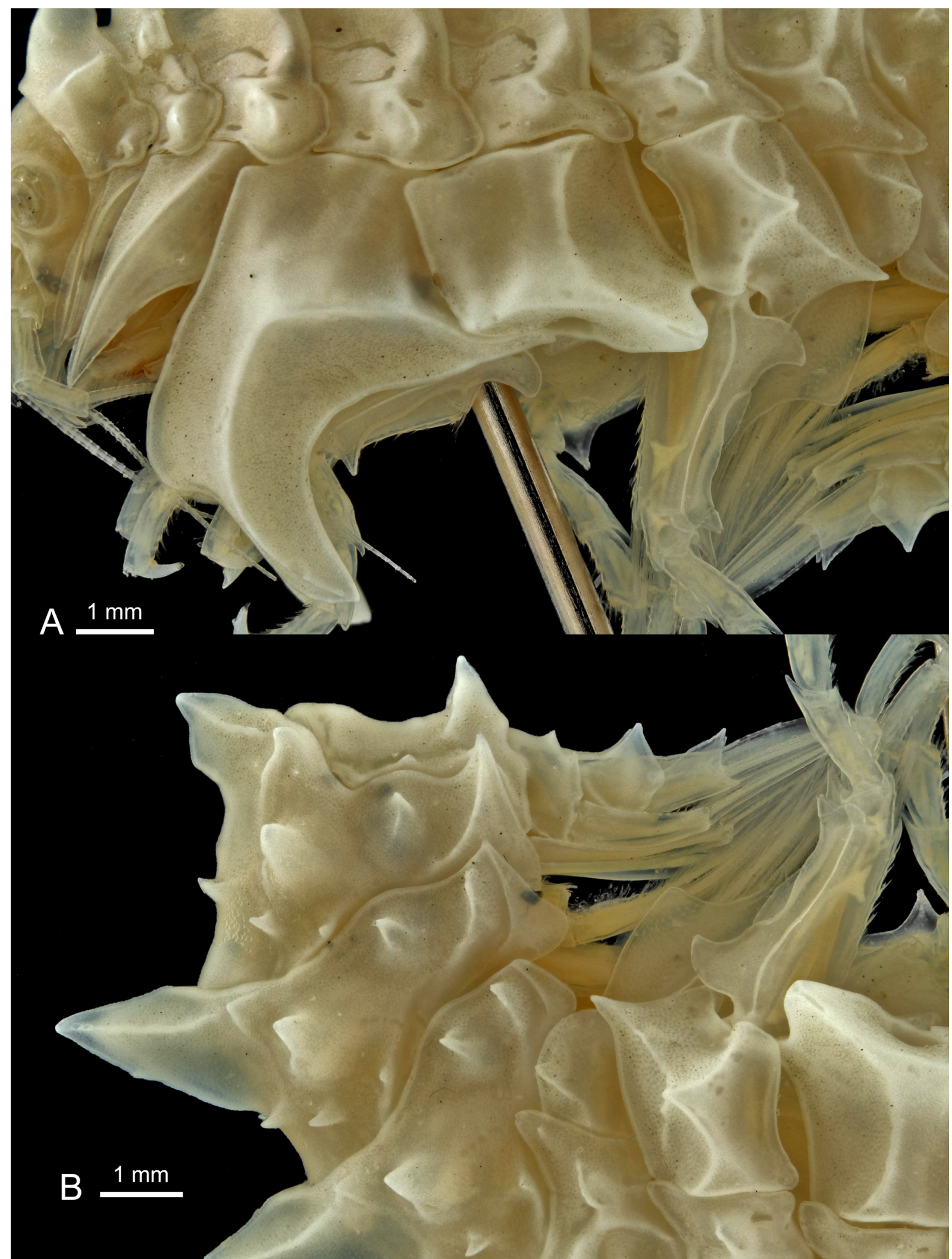

Fig. 285. Epimeria (Pseudepimeria) kharieis sp. nov.,, , holotype, eastern Weddell Sea, ANT-XV/3, stn 77, RBINS, INV. 132937. A. Coxae. B. Pleon. 


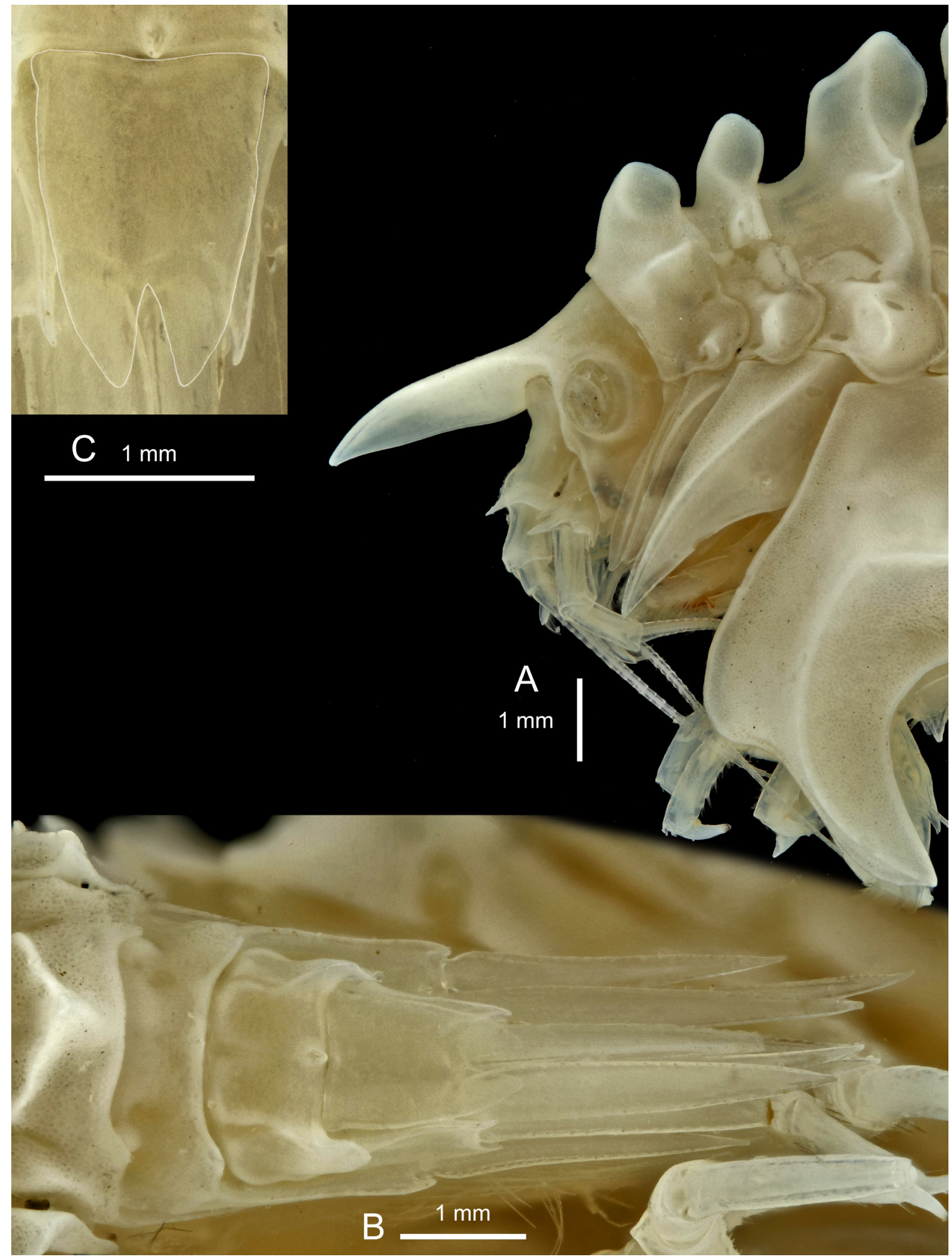

Fig. 286. Epimeria (Pseudepimeria) kharieis sp. nov.,, , holotype, eastern Weddell Sea, ANT-XV/3, stn 77, RBINS, INV. 132937. A. Head and body segments 1-3 in lateral view. B. Urosome in dorsal view. C. Telson. 


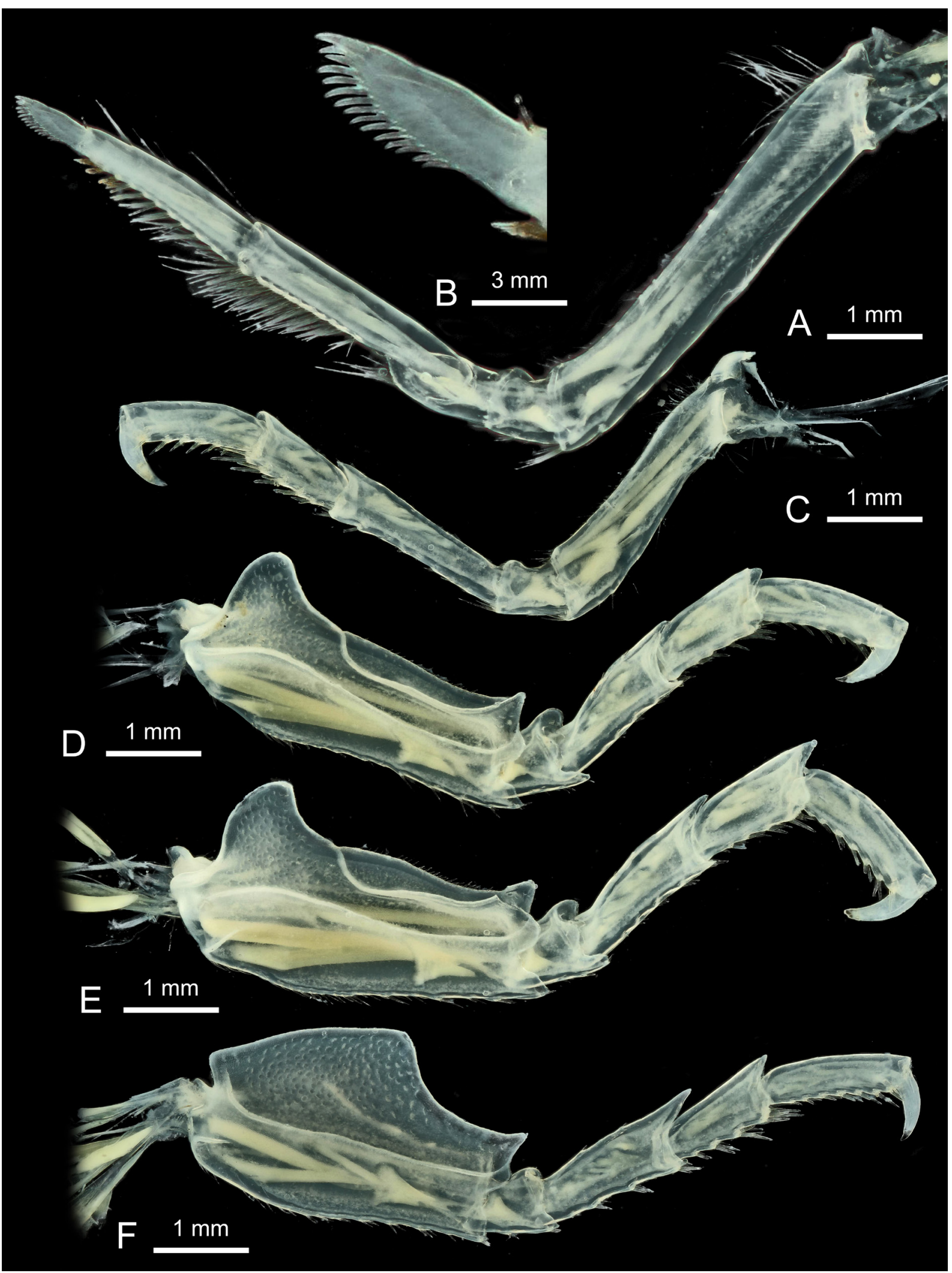

Fig. 287. Epimeria (Pseudepimeria) kharieis sp. nov.,, , holotype, eastern Weddell Sea, ANT-XV/3, stn 77, RBINS, INV. 132937. A. Gnathopod 2. B. Dactylus of gnathopod 2. C. Pereiopod 4. D. pereiopod 5. E. Pereiopod 6. F. Pereiopod 7. 


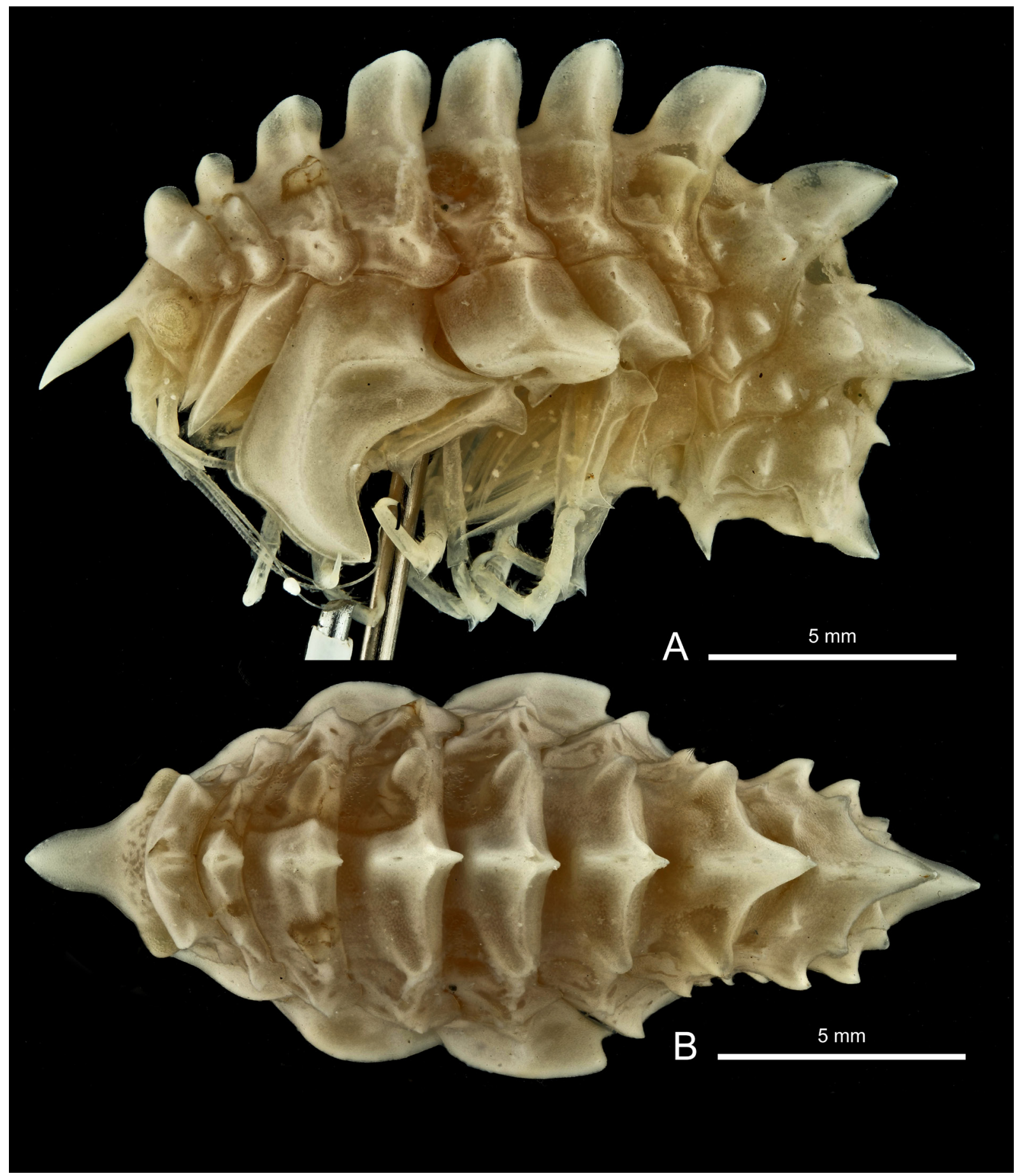

Fig. 288. Epimeria (Pseudepimeria) kharieis sp. nov., immature paratype, sex undetermined, eastern Weddell Sea, ANT-XV/3, st. 77, RBINS, INV. 132938. A. Lateral habitus. B. Dorsal habitus. 


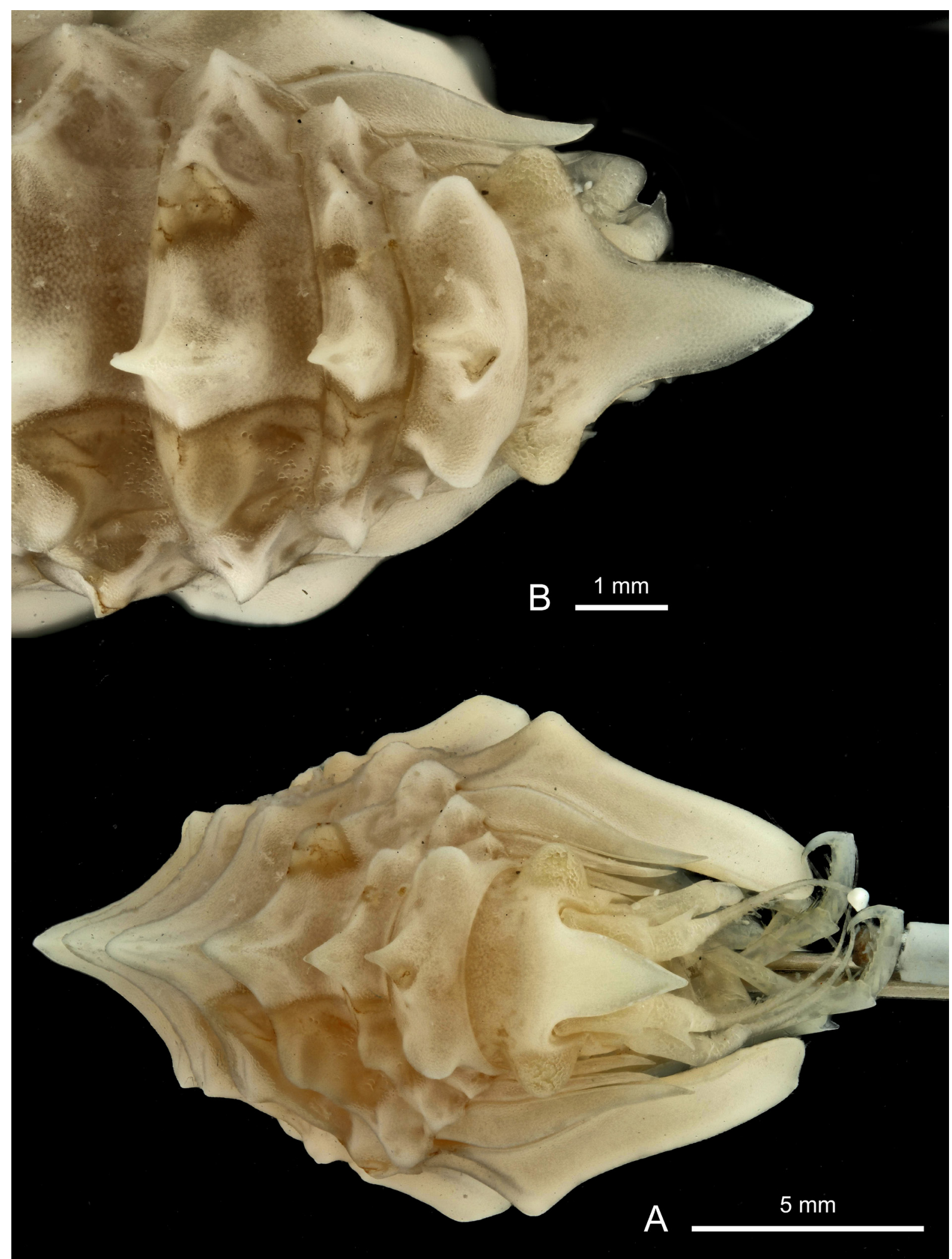

Fig. 289. Epimeria (Pseudepimeria) kharieis sp. nov., immature paratype, sex undetermined, eastern Weddell Sea, ANT-XV/3, st. 77, RBINS, INV. 132938. A. Facial habitus. B. Head and anterior pereion segments in dorsal view. 


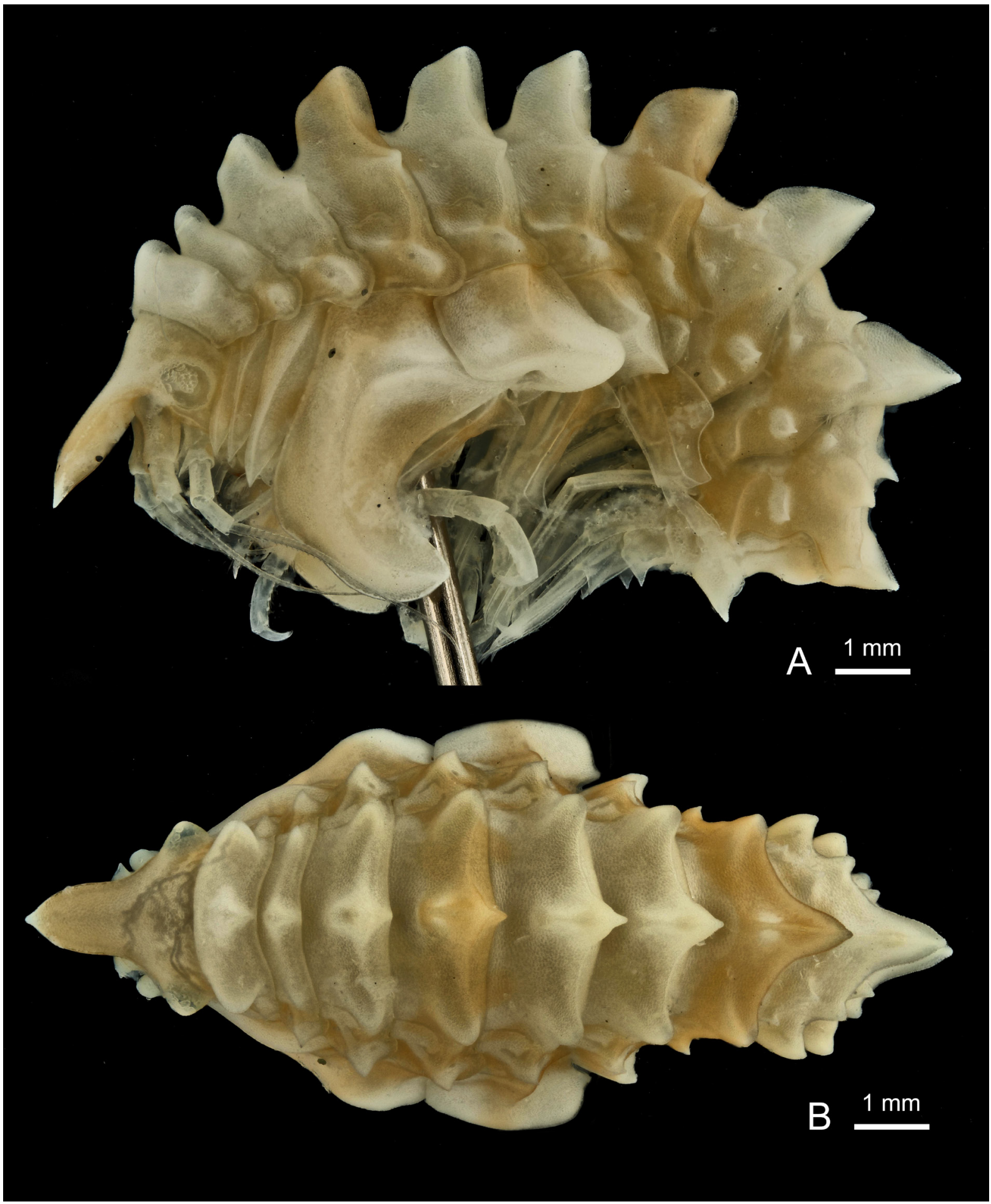

Fig. 290. Epimeria (Pseudepimeria) kharieis sp. nov., immature paratype, sex undetermined, eastern Weddell Sea, ANT-XV/3, stn 77, RBINS, INV. 132938. A. Lateral habitus. B. Dorsal habitus. 


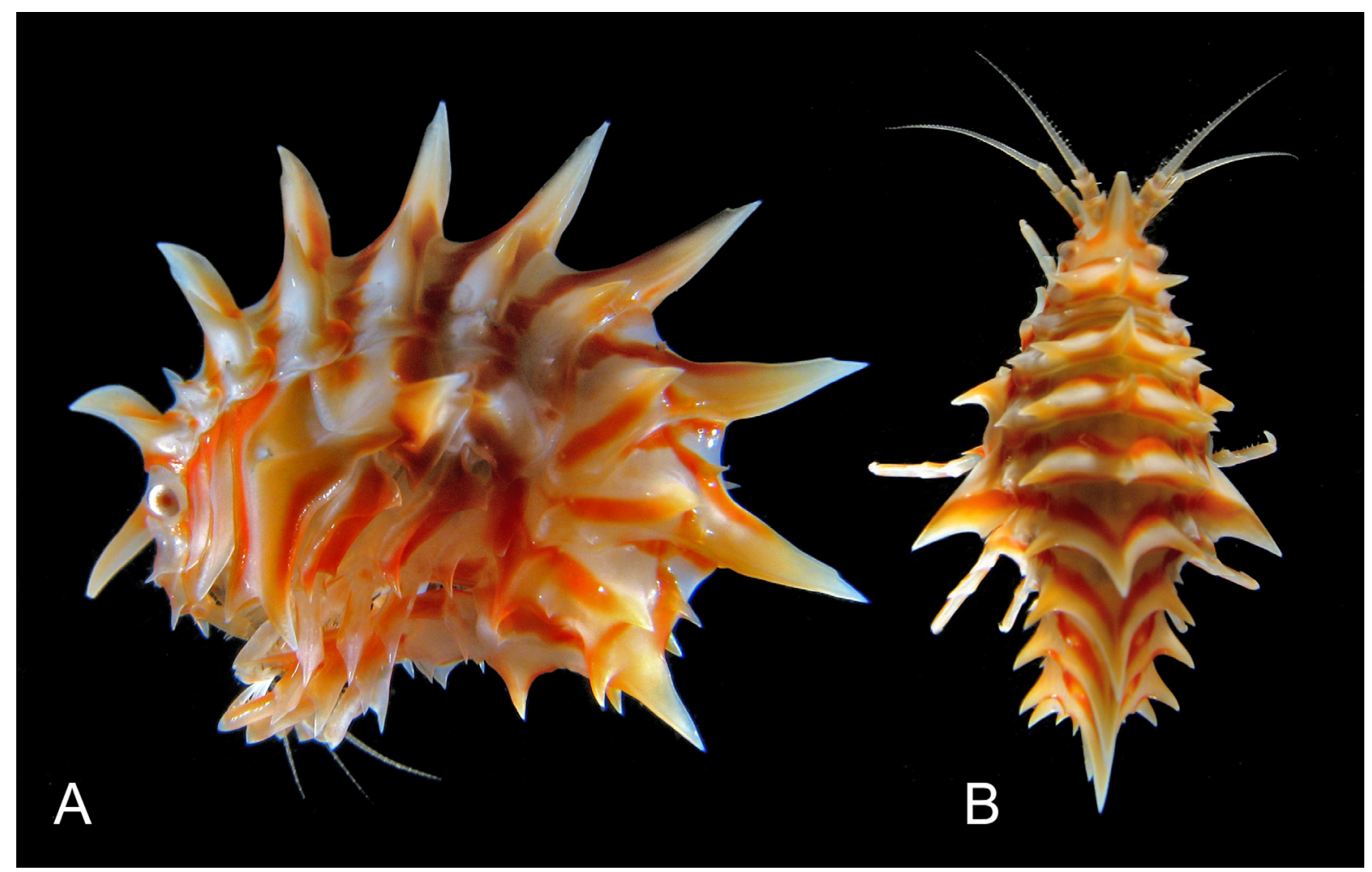

Fig. 291. Epimeria (Pseudepimeria) oxicarinata Coleman, 1990, adult + , Elephant Island, ANTXXIII/8, stn 605-5, RBINS, INV. 122482, colour in life. A. Lateral view. B. Dorsal view. 


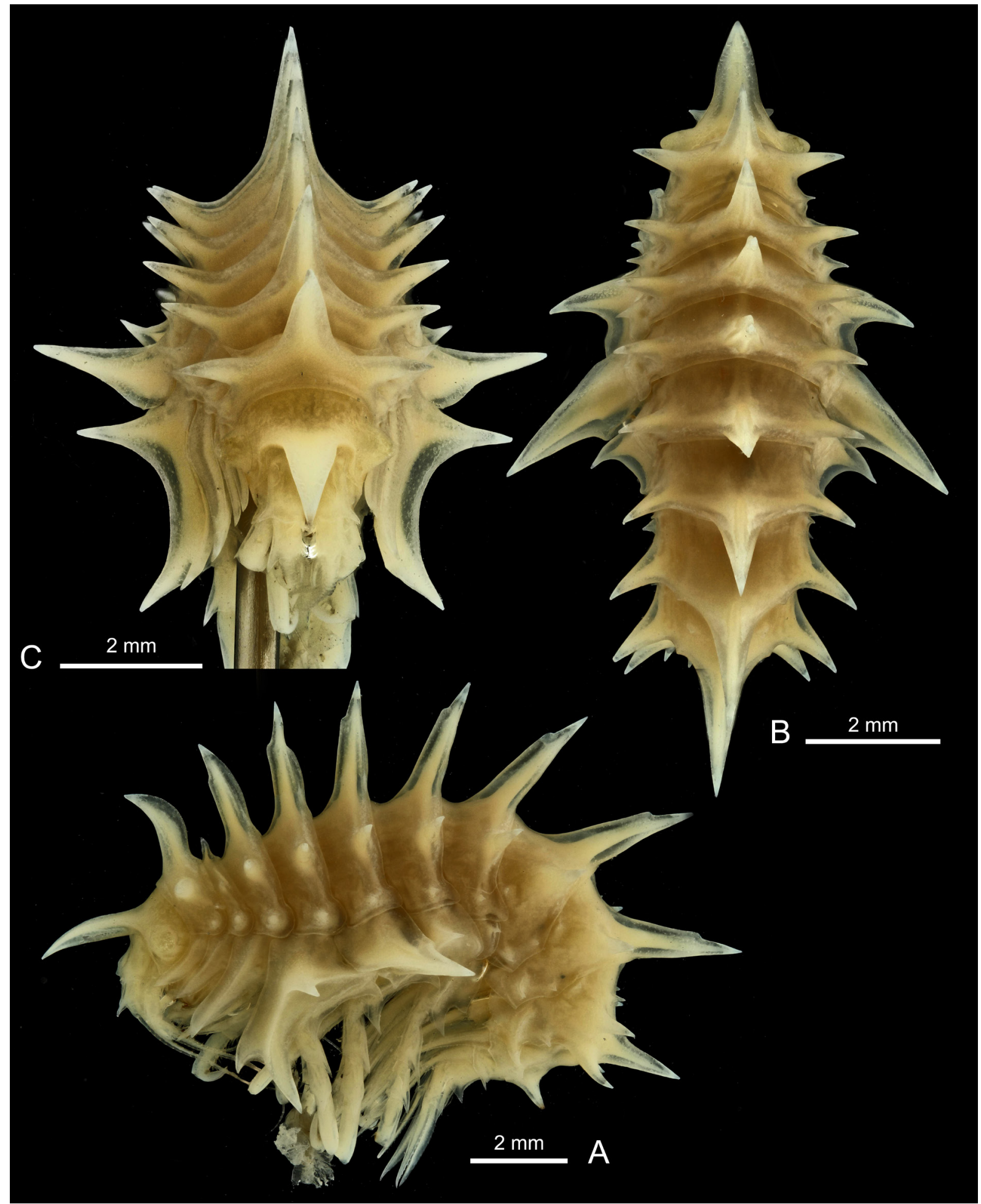

Fig. 292. Epimeria (Pseudepimeria) oxicarinata Coleman, 1990, medium-sized specimen, sex undetermined, Elephant Island, stn 614-3/4/5, RBINS, INV. 132942. A. Lateral habitus. B. Dorsal habitus. C. Frontal habitus. 


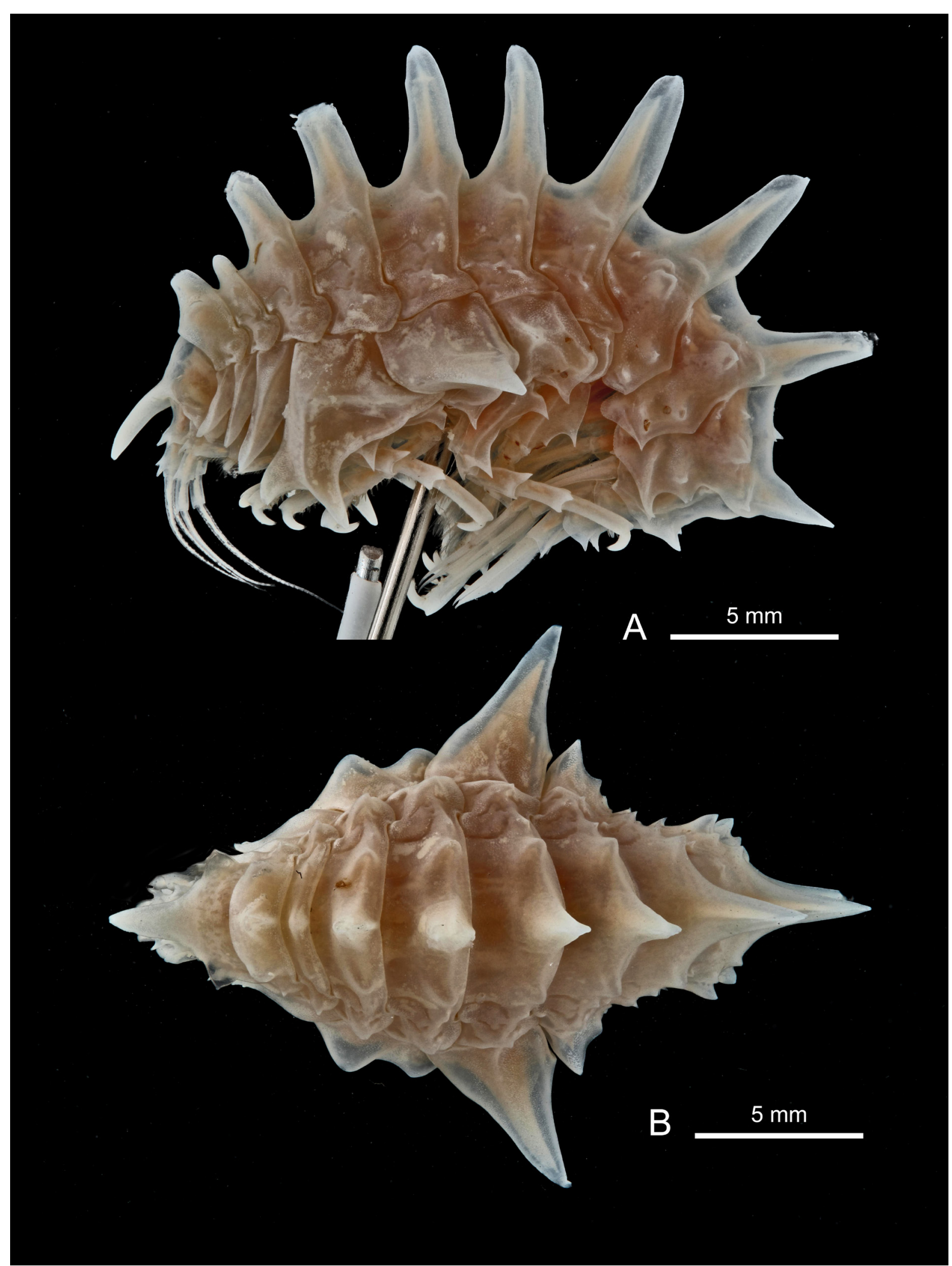

Fig. 293. Epimeria (Pseudepimeria) pulchra Coleman, 1990, adult + , Signy Island, SIGNY 1991/92, AGT 5, transect 1, RBINS, INV. 132687. A. Lateral view. B. Dorsal view. 


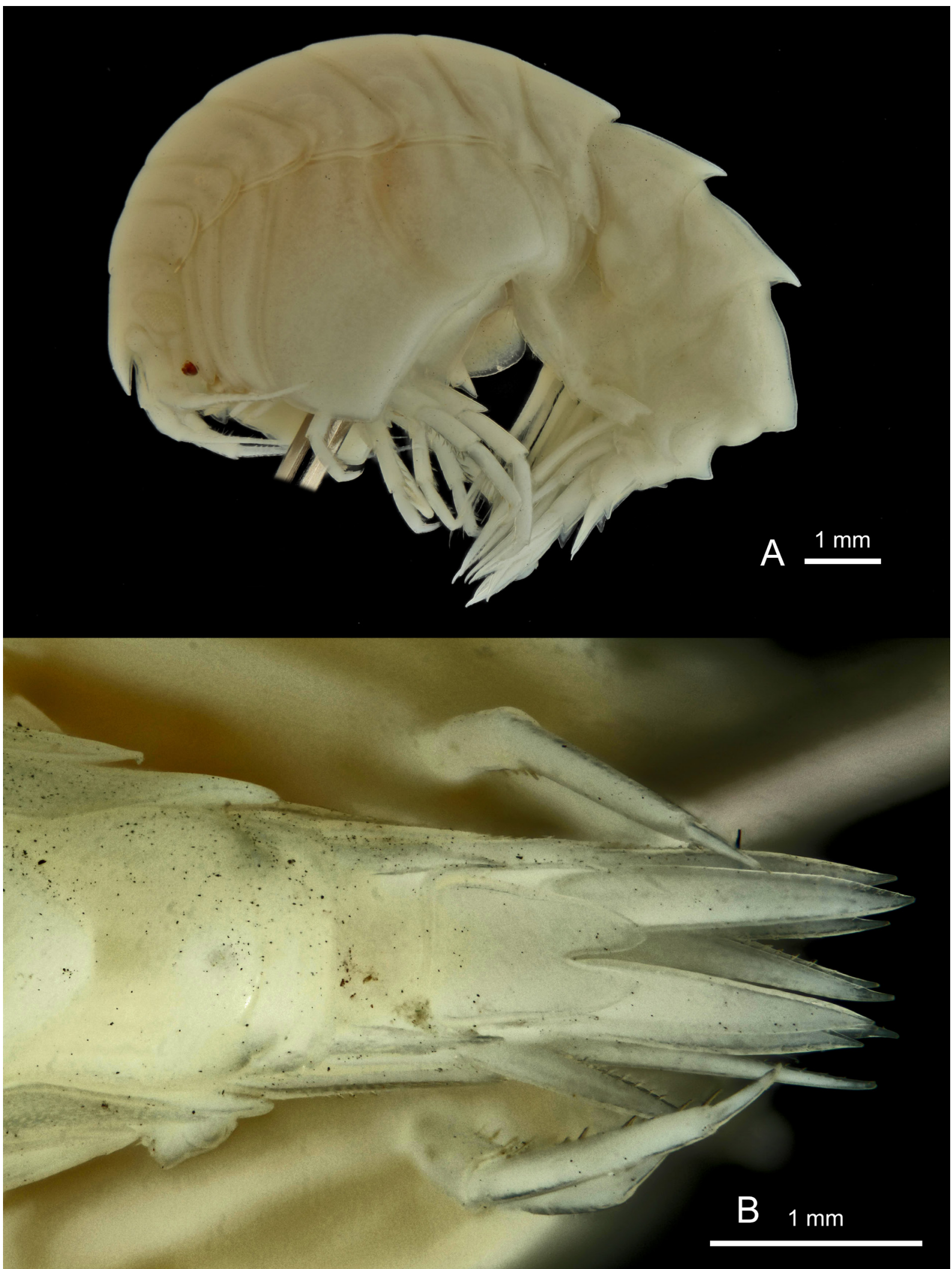

Fig. 294. Epimeria (Subepimeria) adeliae sp. nov., +, holotype, Adélie Coast, CEAMARC 2072, MNHN-IU-2014-4288. A. Lateral habitus. B. Urosome in dorsal view. 


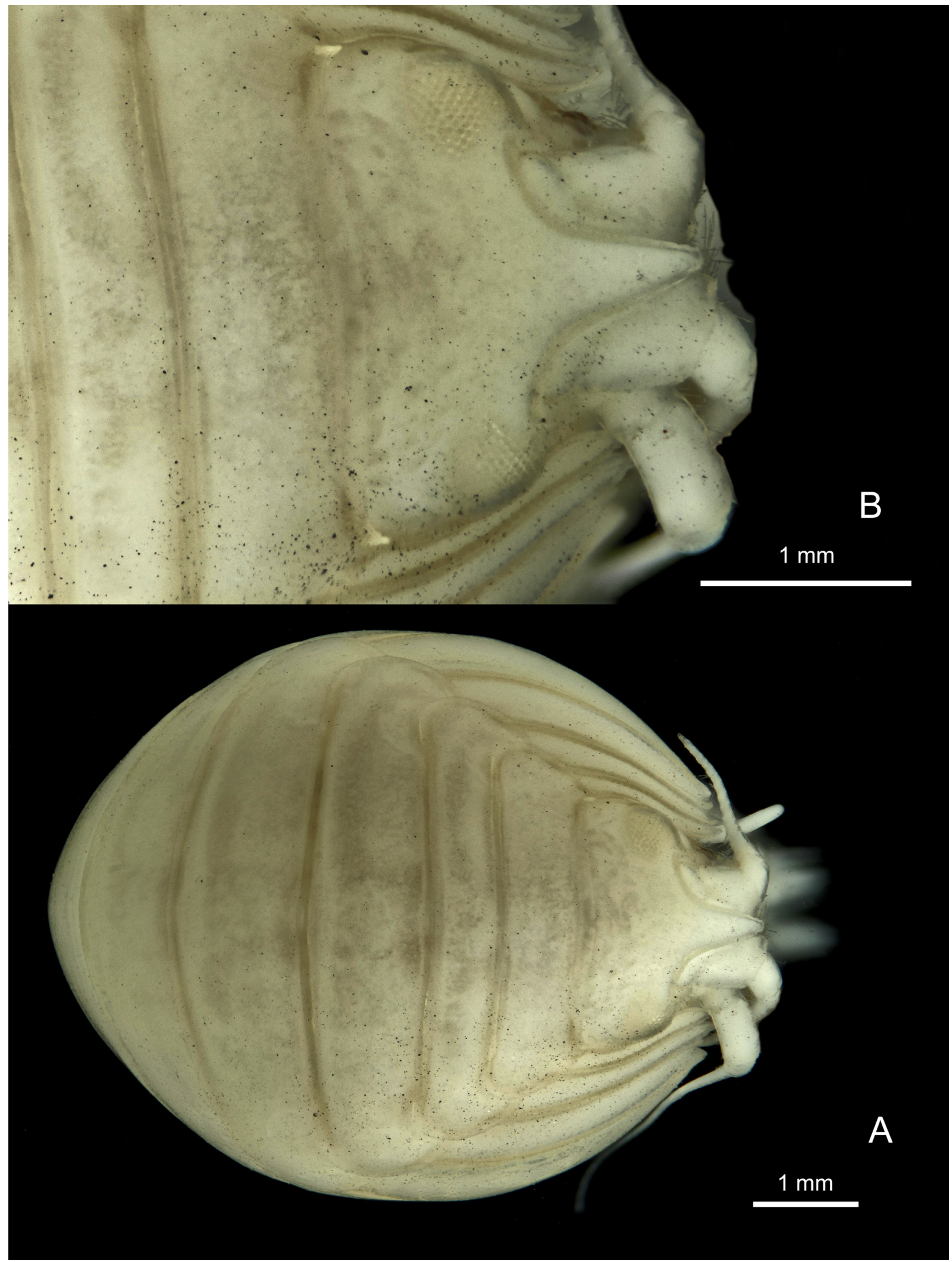

Fig. 295. Epimeria (Subepimeria) adeliae sp. nov., +, holotype, Adélie Coast, CEAMARC 2072, MNHN-IU-2014-4288. A. Facial habitus. B. Head in facial view. 


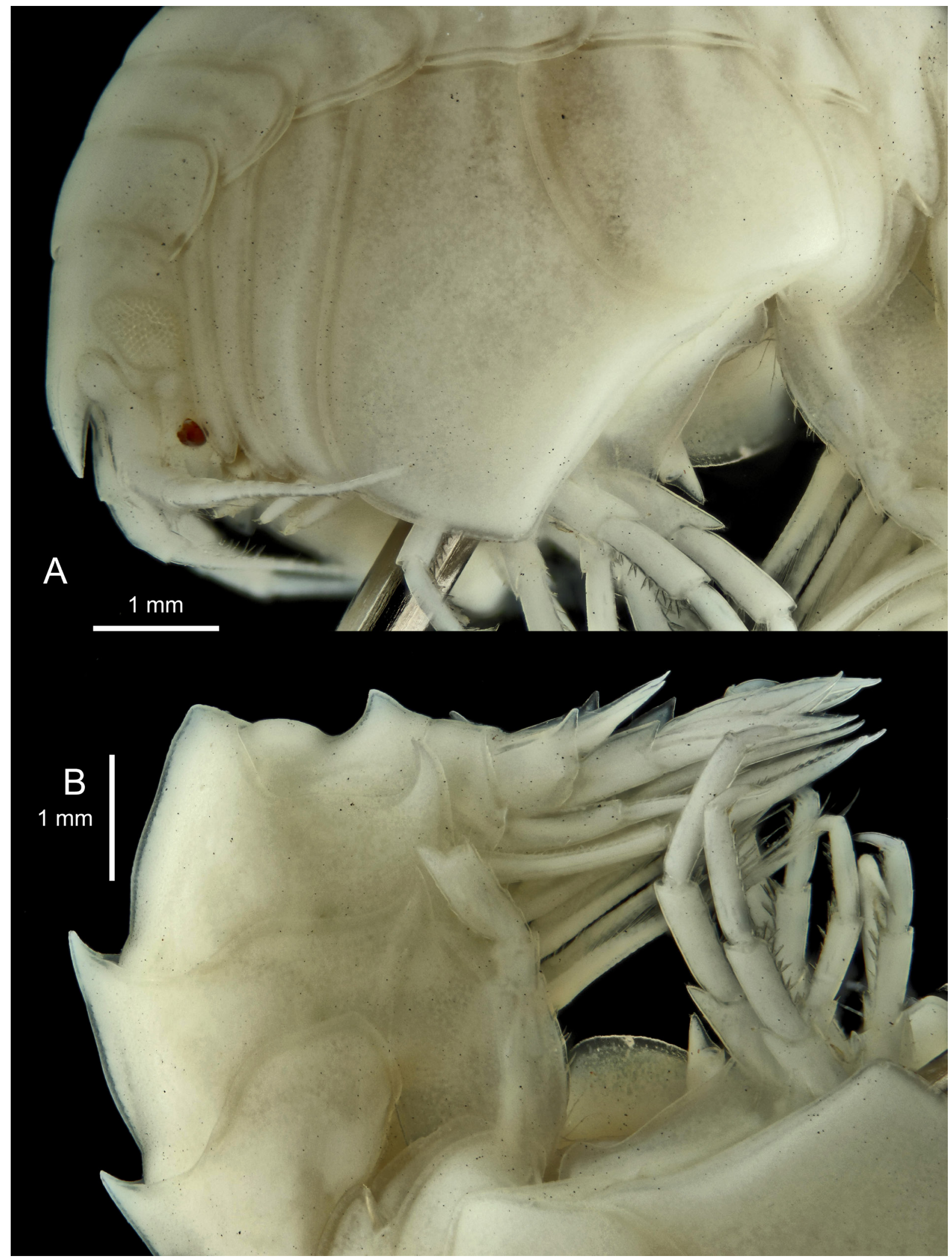

Fig. 296. Epimeria (Subepimeria) adeliae sp. nov., +, holotype, Adélie Coast, CEAMARC 2072, MNHN-IU-2014-4288. A. Anterior half in lateral view. B. Posterior half in lateral view. 


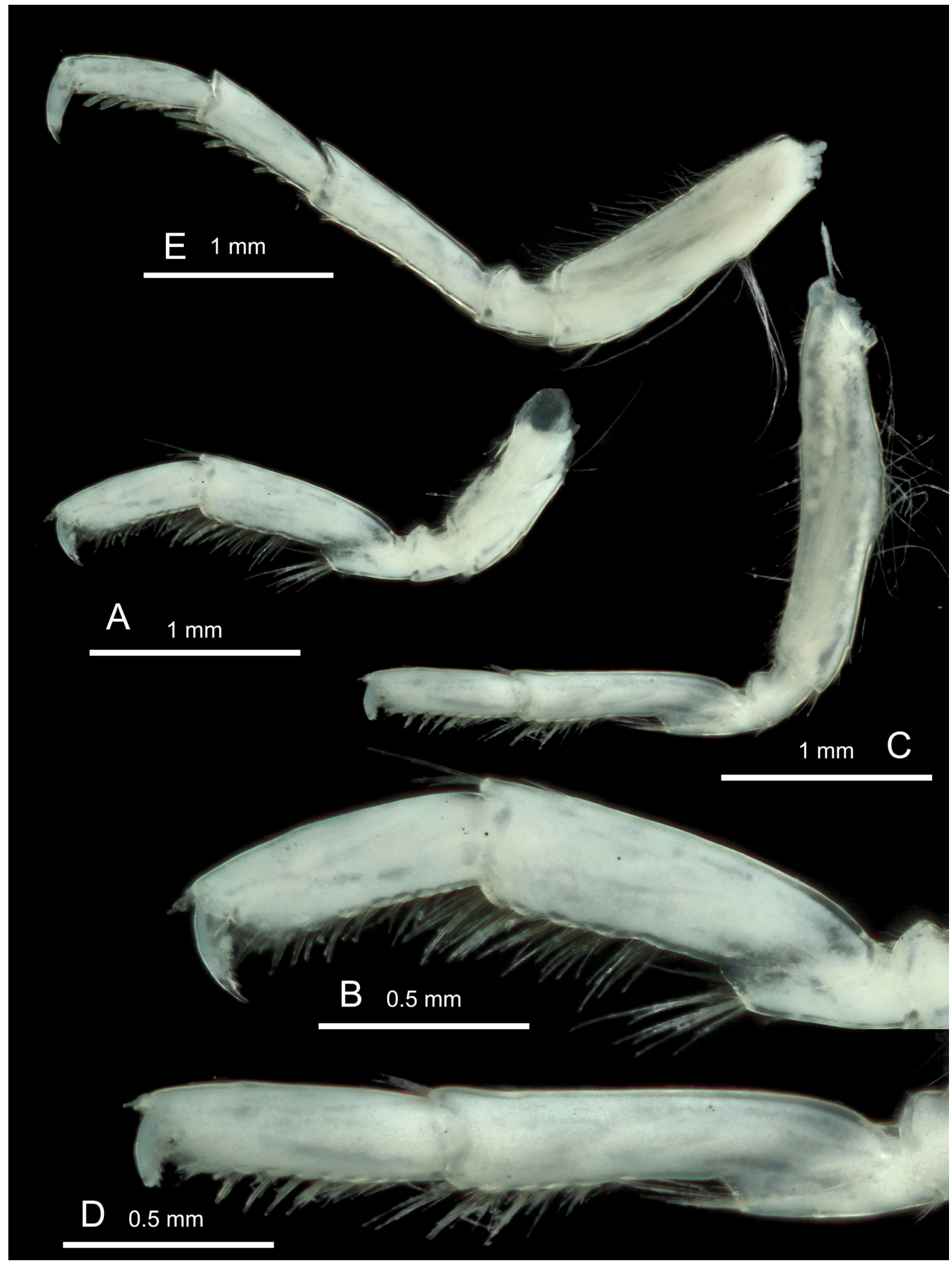

Fig. 297. Epimeria (Subepimeria) adeliae sp. nov., +, holotype, Adélie Coast, CEAMARC 2072, MNHN-IU-2014-4288. A. Gnathopod 1. B. Tip of Gn1. C. Gnathopod 2. D. Tip of Gn2. E. Pereiopod 4. 


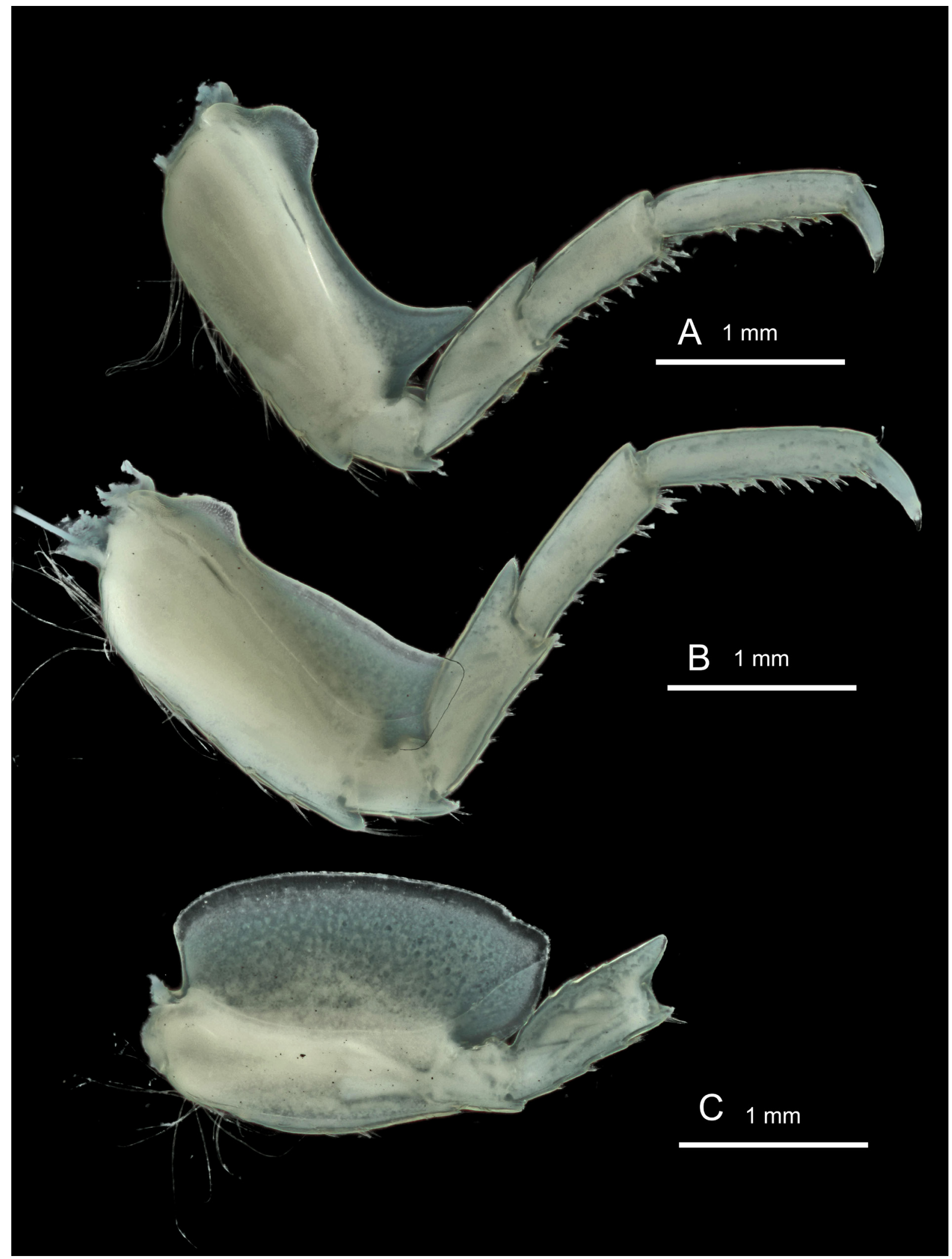

Fig. 298. Epimeria (Subepimeria) adeliae sp. nov., +, holotype, Adélie Coast, CEAMARC 2072, MNHN-IU-2014-4288. A. Pereiopod 5. B. Pereiopod 6. C. Pereiopod 7. 


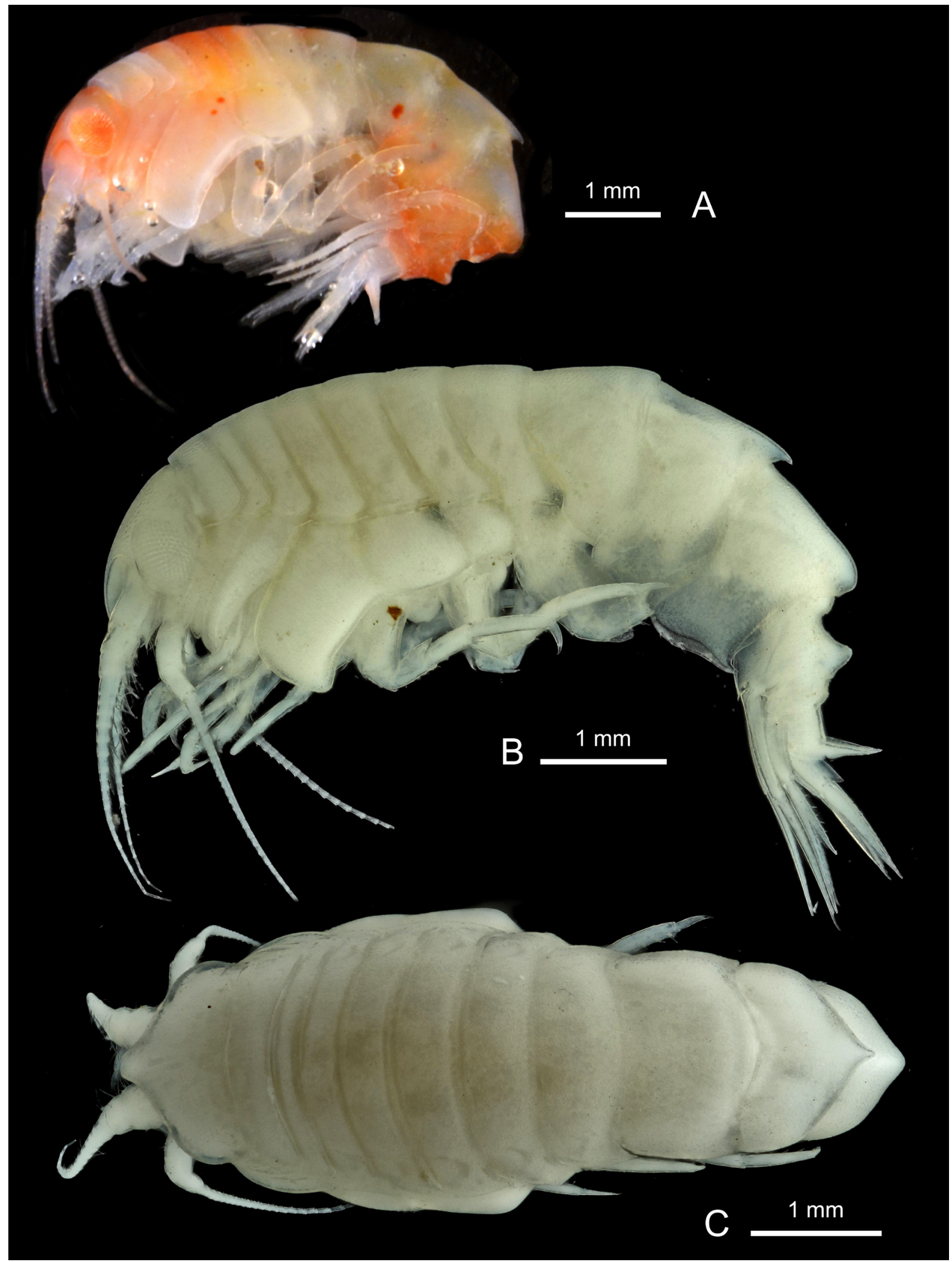

Fig. 299. Epimeria (Subepimeria) iota sp. nov., sex undetermined, holotype, Bransfield Strait, ANTXXIX/3, stn 197-6, RBINS, INV. 122947. A. Colour in life. B. Lateral habitus. C. Dorsal habitus. 


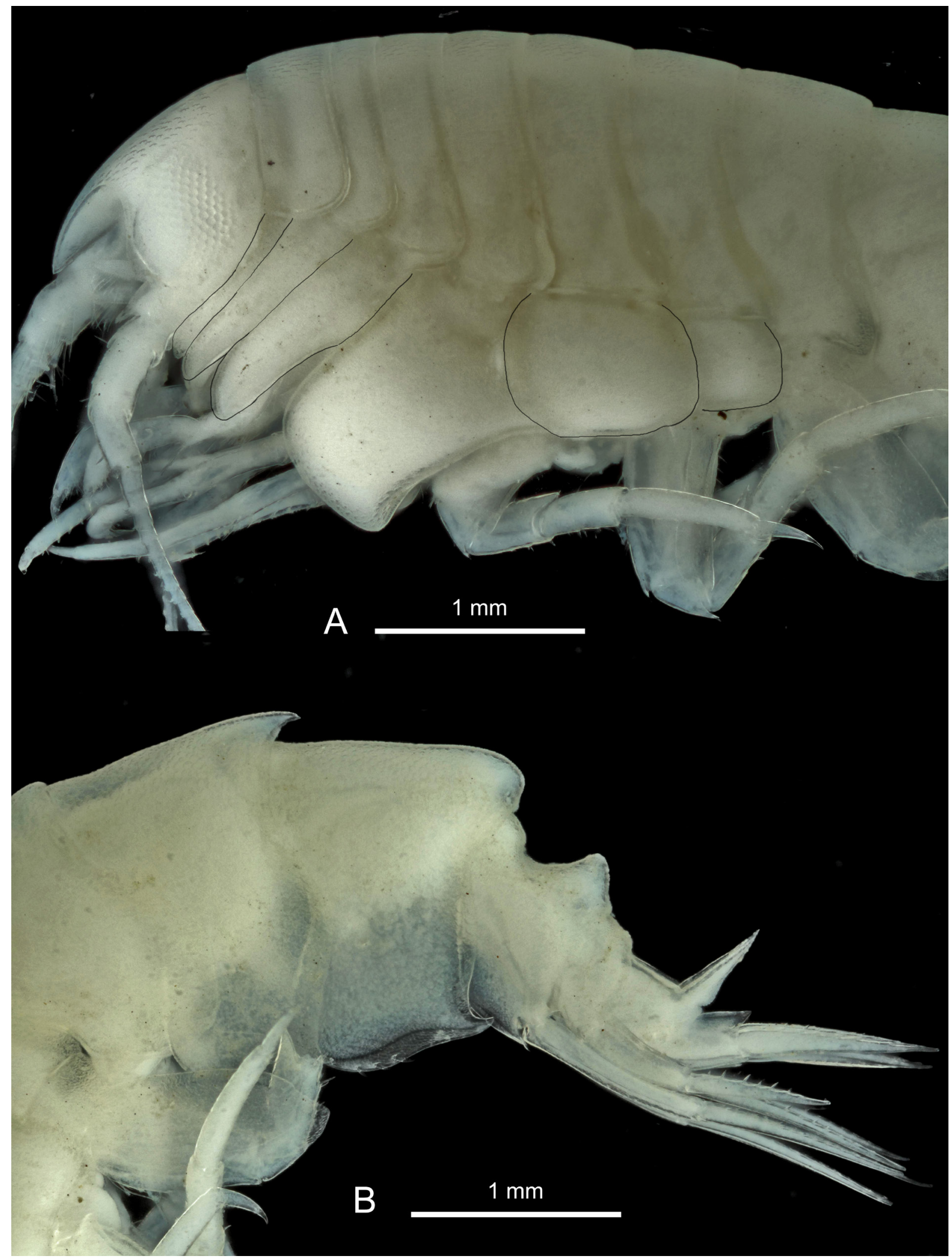

Fig. 300. Epimeria (Subepimeria) iota sp. nov., sex undetermined, holotype, Bransfield Strait, ANTXXIX/3, stn 197-6, RBINS, INV. 122947. A. Anterior half. B. Posterior half. 


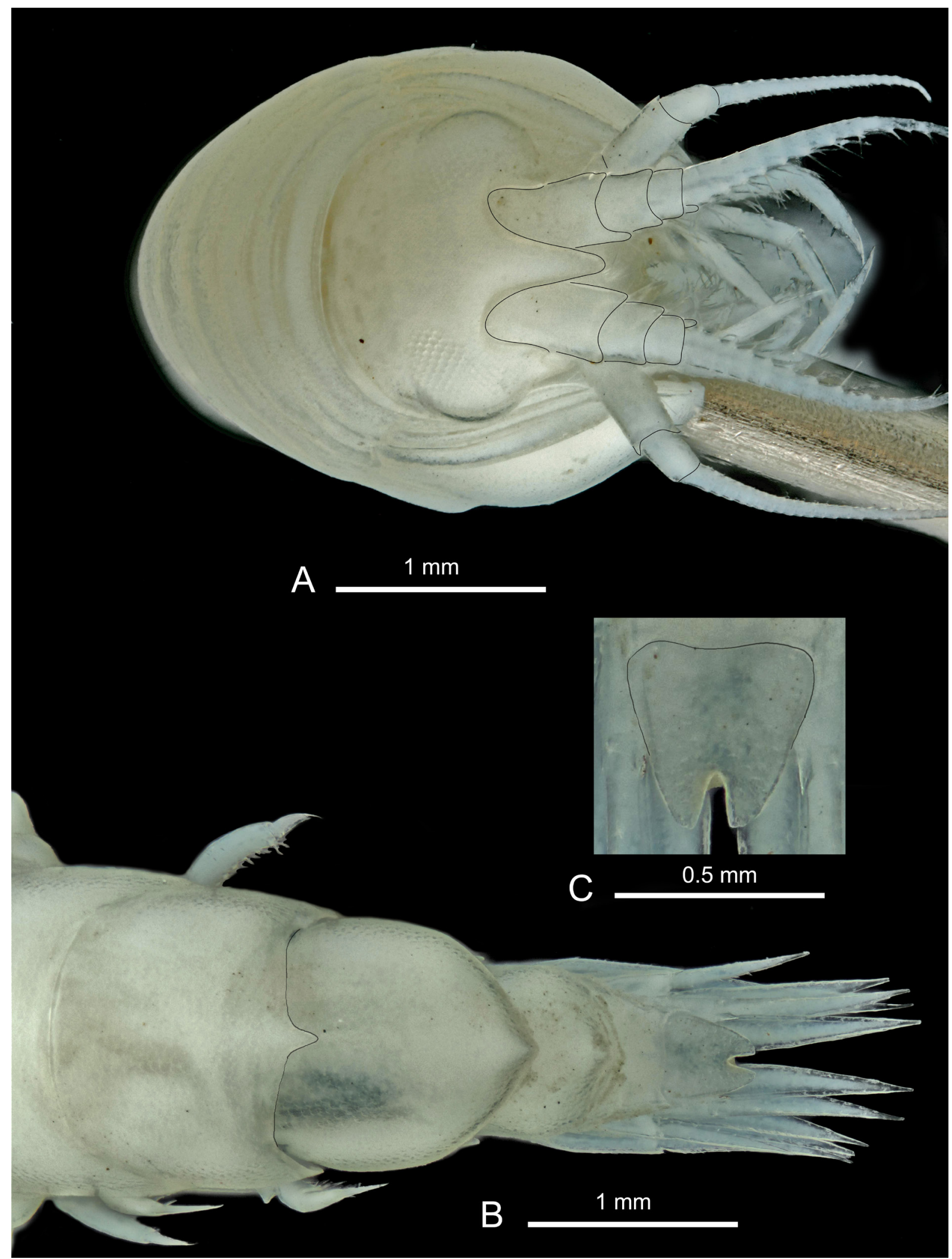

Fig. 301. Epimeria (Subepimeria) iota sp. nov., sex undetermined, holotype, Bransfield Strait, ANTXXIX/3, stn 197-6, RBINS, INV. 122947. A. Frontal view. B. Urosome in dorsal view. C. Telson. 


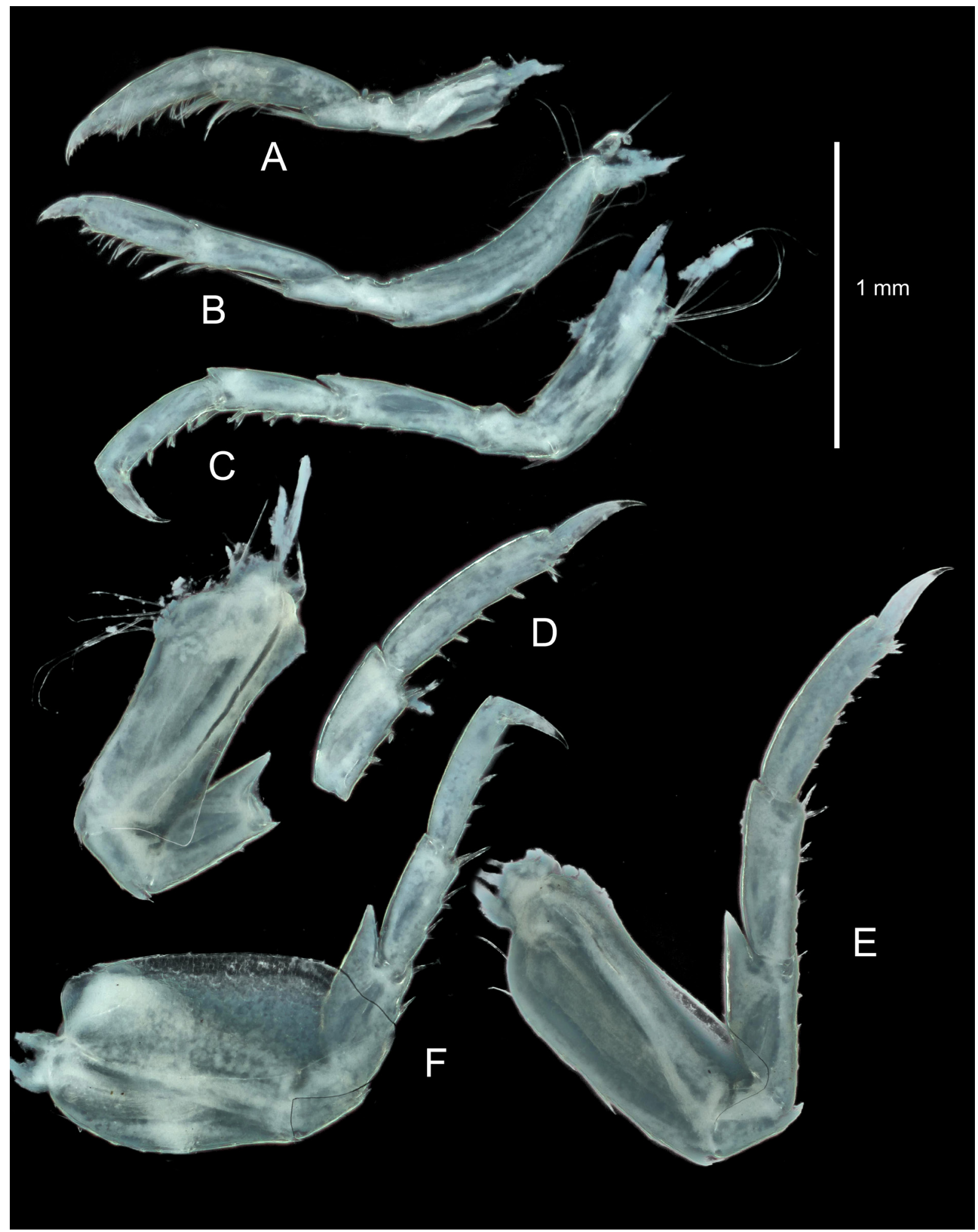

Fig. 302. Epimeria (Subepimeria) iota sp. nov., sex undetermined, holotype, Bransfield Strait, ANT-XXIX/3, stn 197-6, RBINS, INV. 122947. A. Gnathopod 1. B. Gnathopod 2. C. Pereiopod 4. D. Pereiopod 5. E. Pereiopod 6. F. Pereiopod 7. 


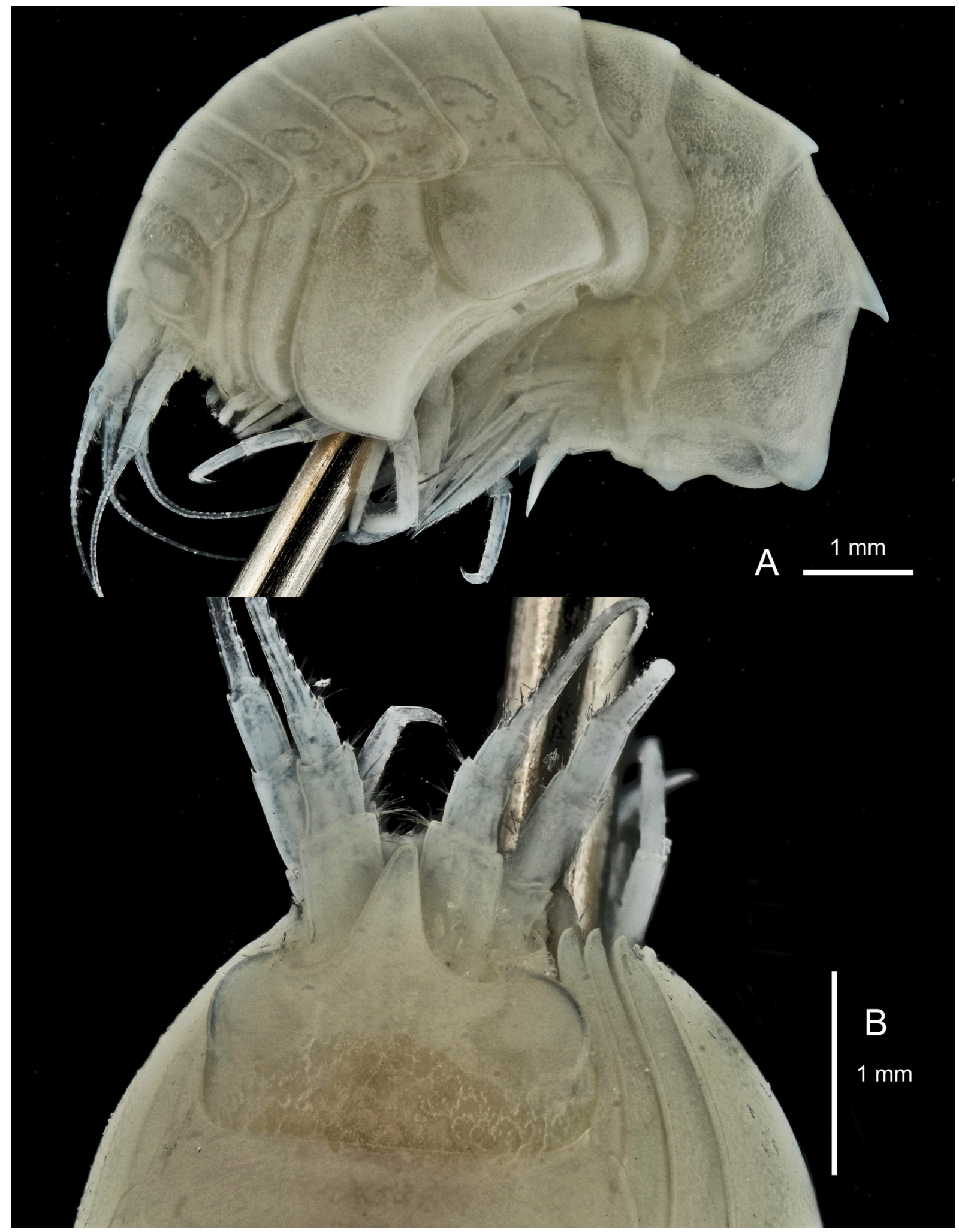

Fig. 303. Epimeria (Subepimeria) iota sp. nov., sex undetermined, paratype, Elephant Island, ANTXXIII/8, stn 605-3, RBINS, INV. 122519. A. Lateral habitus. B. Head in facial view. 


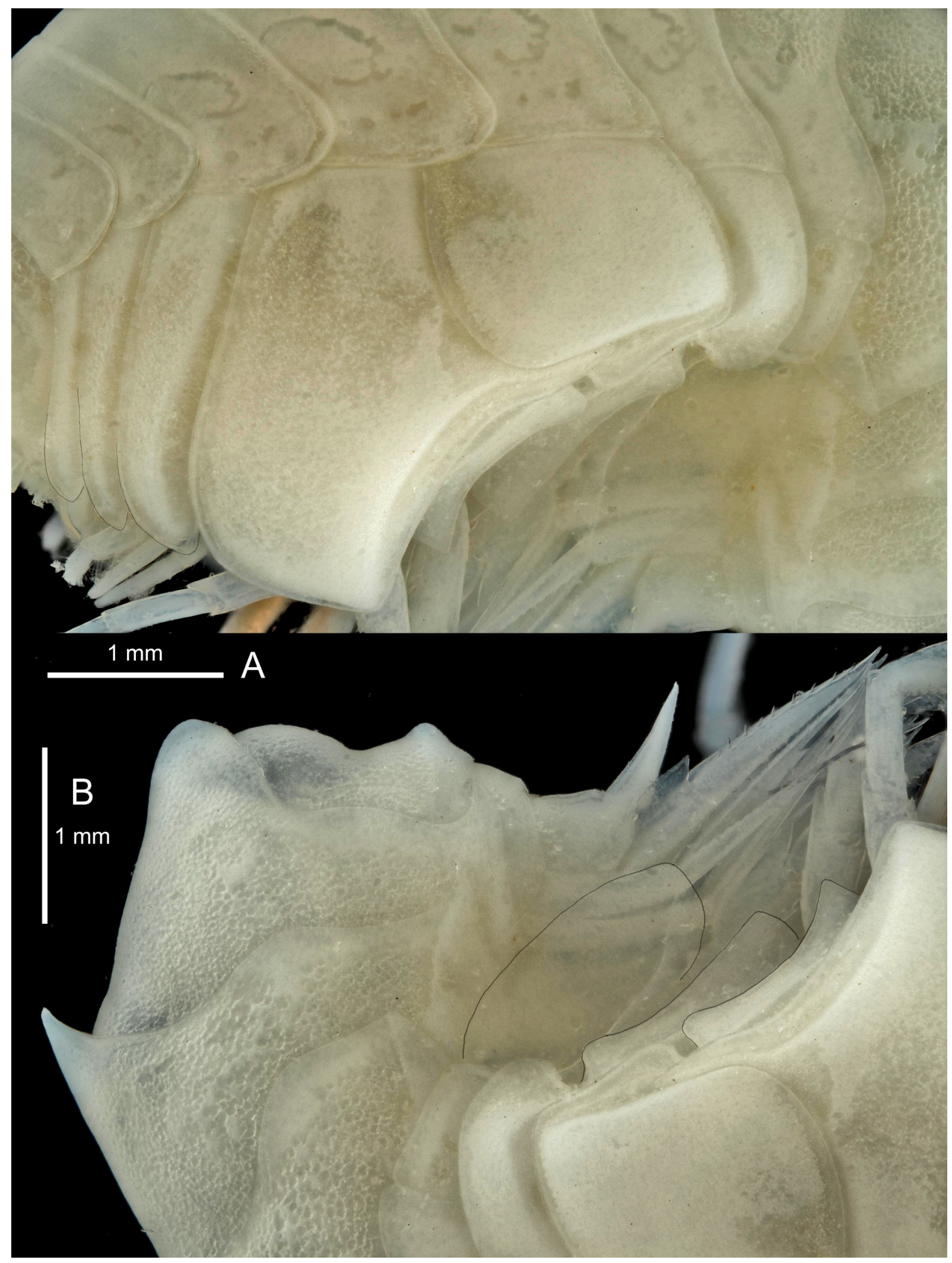

Fig. 304. Epimeria (Subepimeria) iota sp. nov., sex undetermined, paratype, Elephant Island, ANTXXIII/8, stn 605-3, RBINS, INV. 122519. A. Coxae 1-7. B. Posterior part of body. 


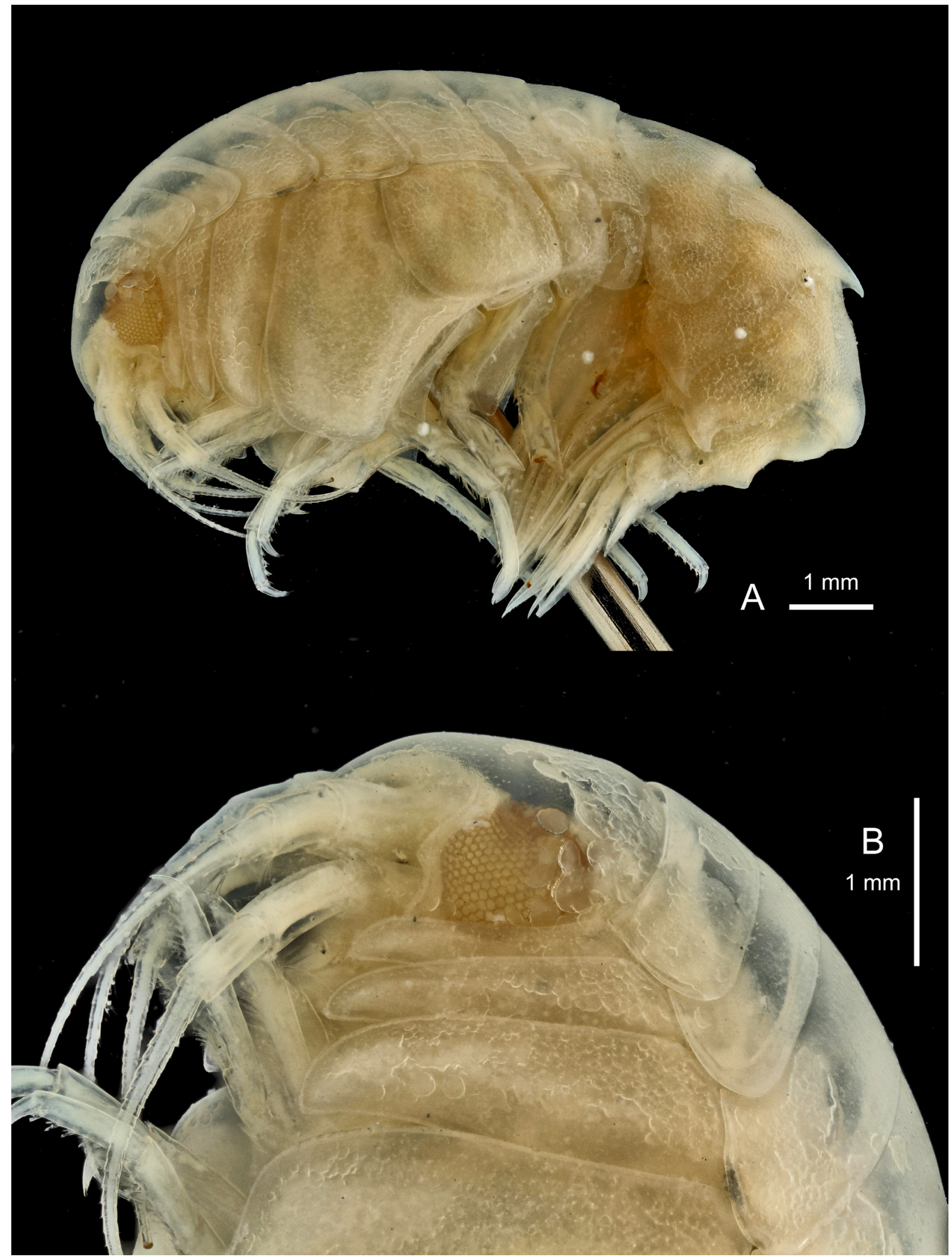

Fig. 305. Epimeria (Subepimeria) iota sp. nov., sex undetermined, paratype, Elephant Island, ANTXXIII/8, stn 614-3/4/5, RBINS, INV. 122525. A. Lateral habitus. B. Head an body segments 1-3 in lateral view. 


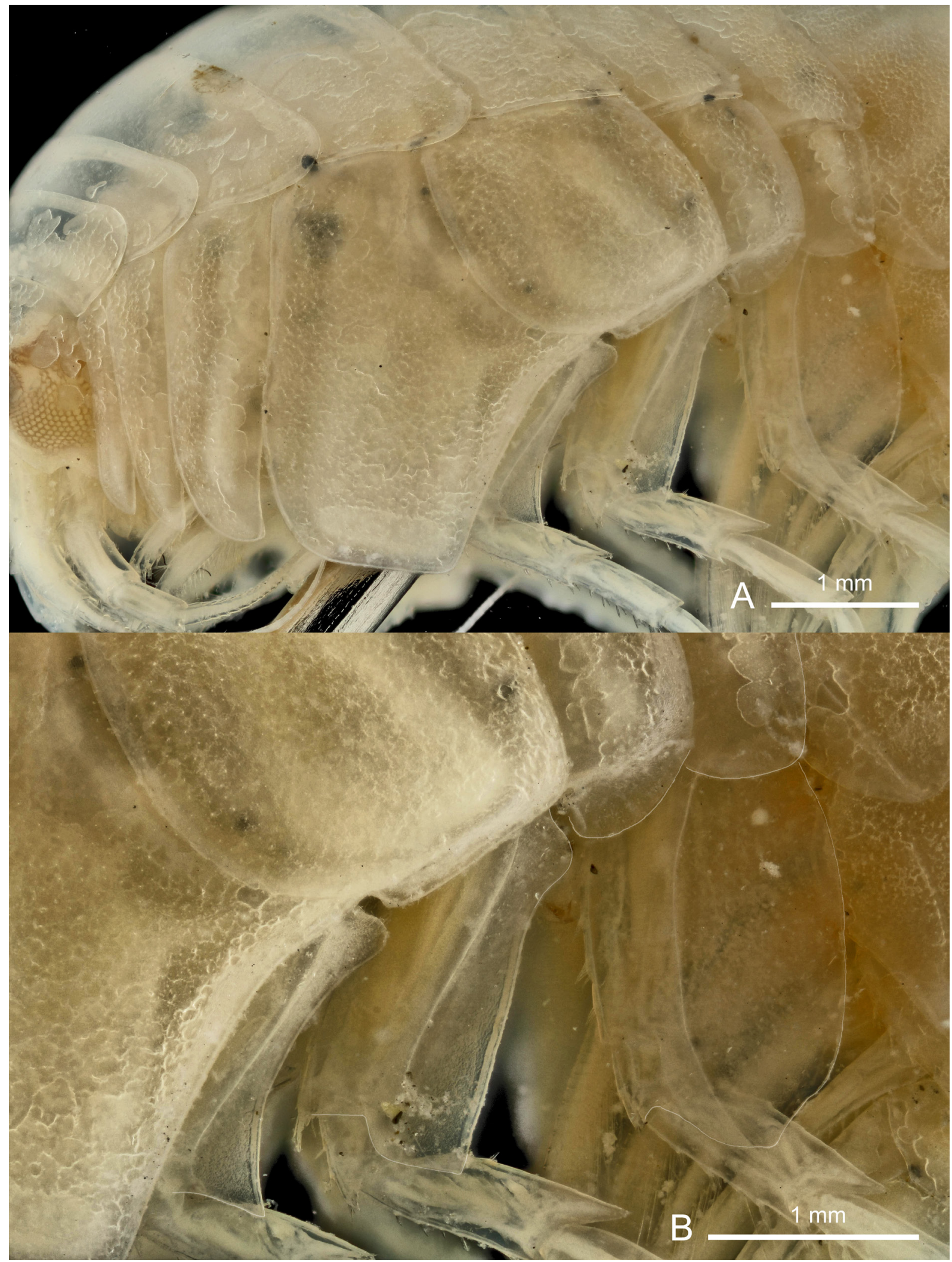

Fig. 306. Epimeria (Subepimeria) iota sp. nov., sex undetermined, paratype, Elephant Island, ANTXXIII/8, stn 614-3/4/5, RBINS, INV. 122525. A. Coxae 1-7. B. Basis of pereiopods 5-7. 


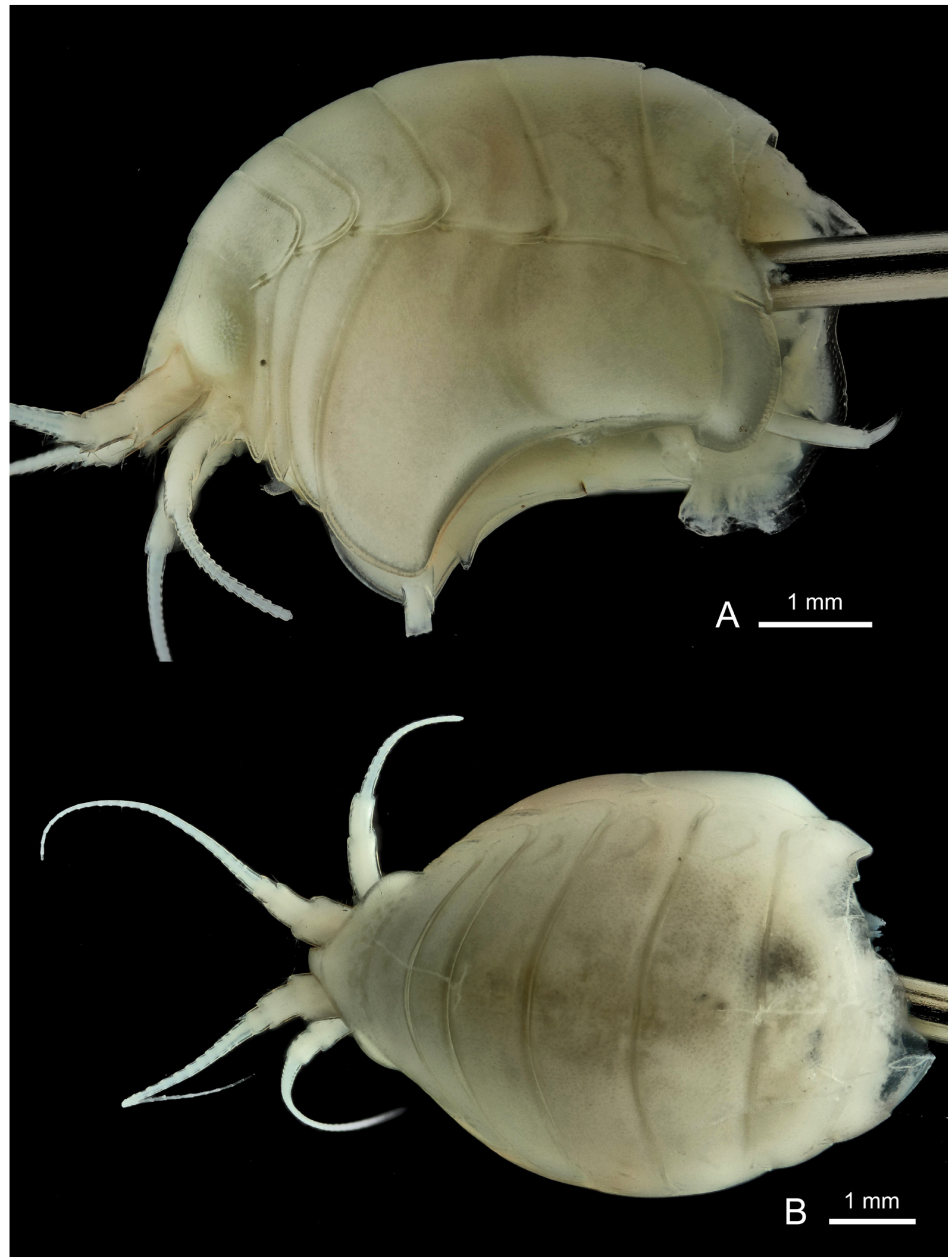

Fig. 307. Epimeria (Subepimeria) teres sp. nov., sex undetermined, holotype, Larsen B, ANT-XXVII/3, stn 248-2, RBINS, INV. 132951. A. Anterior half of body in lateral view. B. Anterior part of body in dorsal view. 


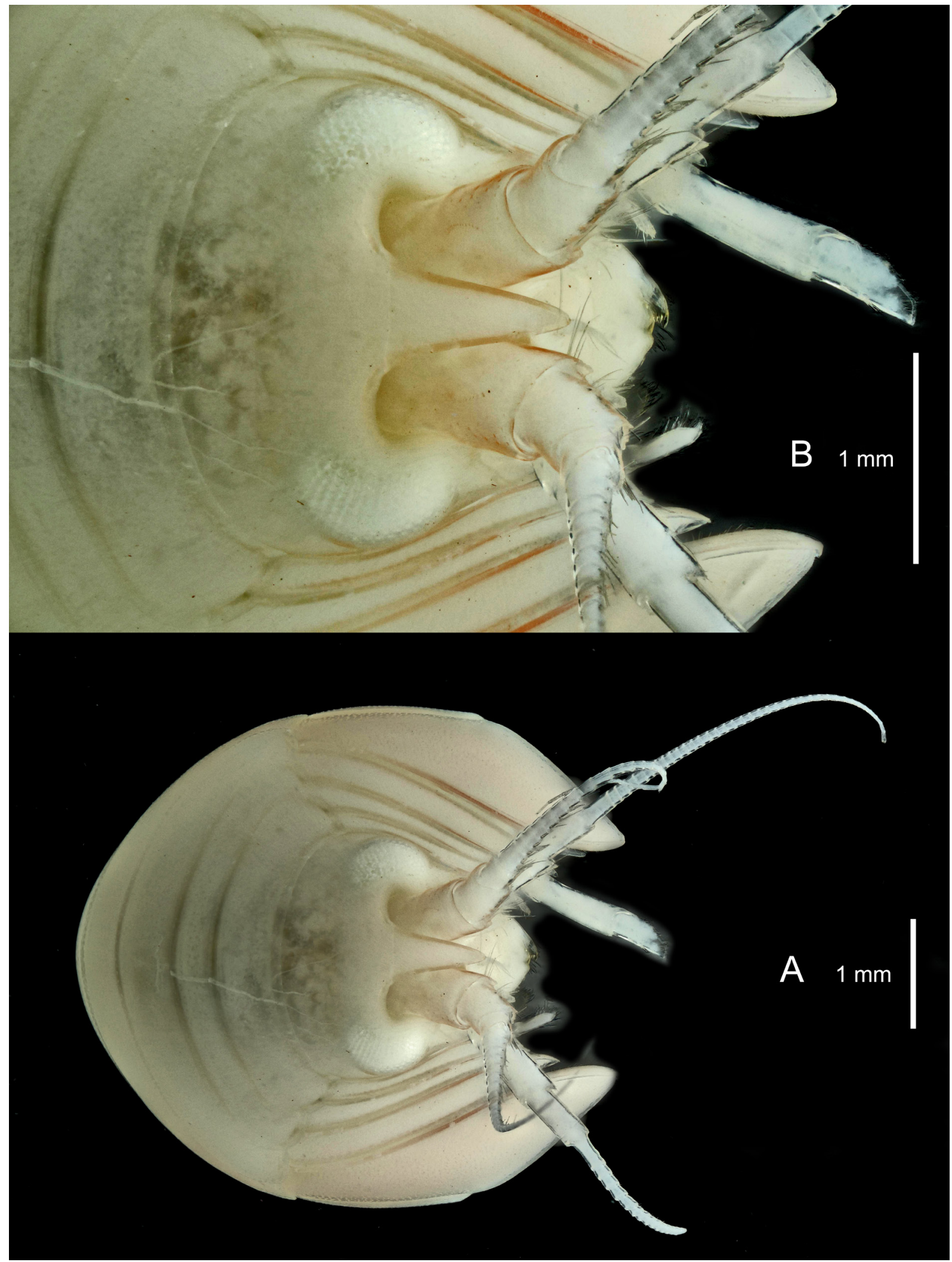

Fig. 308. Epimeria (Subepimeria) teres sp. nov., sex undetermined, holotype, Larsen B, ANT-XXVII/3, stn 248-2, RBINS, INV. 132951. A. Facial habitus. B. Head in facial view. 


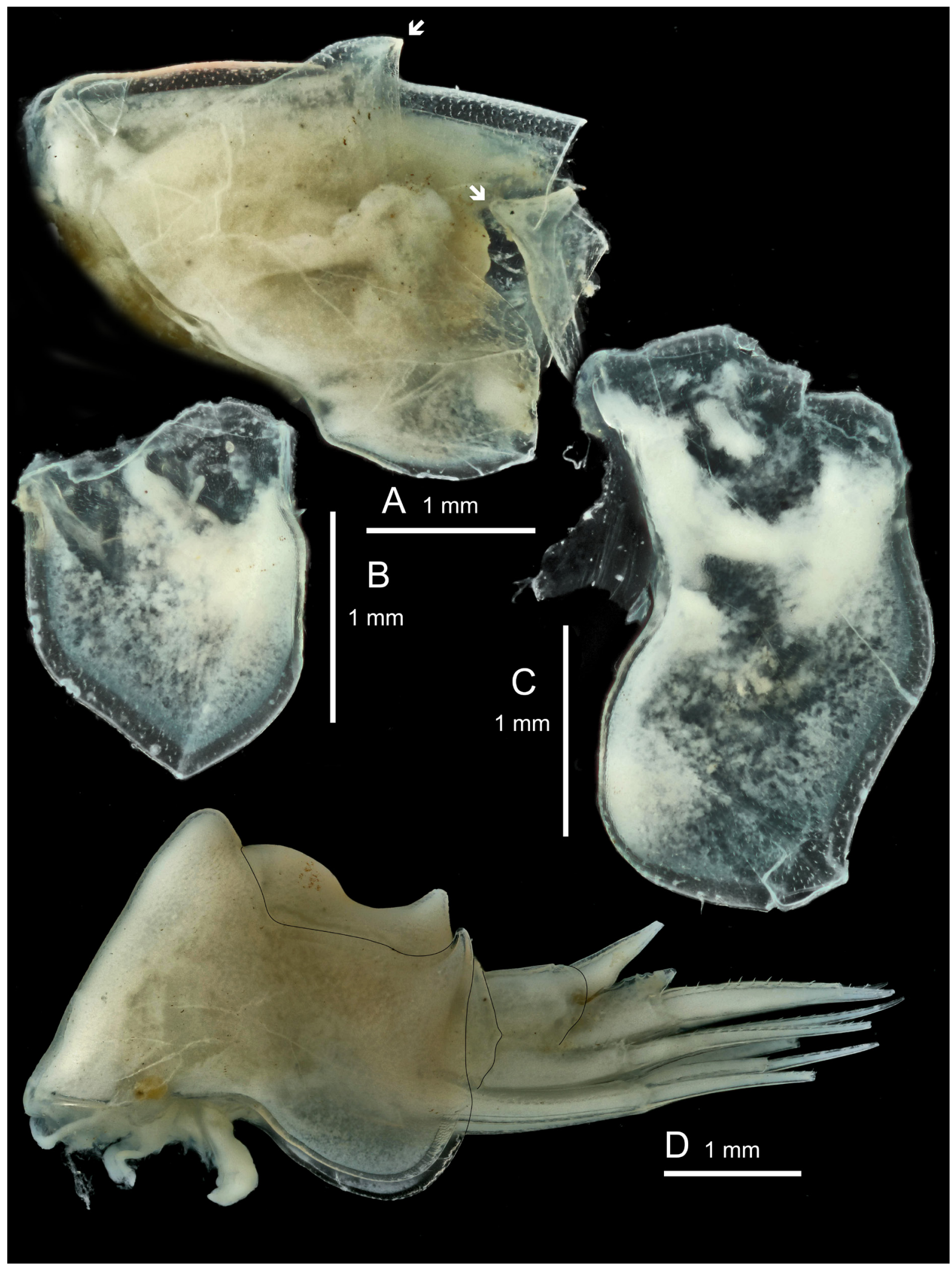

Fig. 309. Epimeria (Subepimeria) teres sp. nov., sex undetermined, holotype, Larsen B, ANT-XXVII/3, stn 248-2, RBINS, INV. 132951. A. Pleonites 1-2, fragments (left arrow: middle of posterior border of pleonite 1, which is longitudinally split in two; right arrow: putative posterodorsal tooth of pleonite 2). B. Epimera 1. C. Epimera 2. D. Pleonite 3 and urosome. 


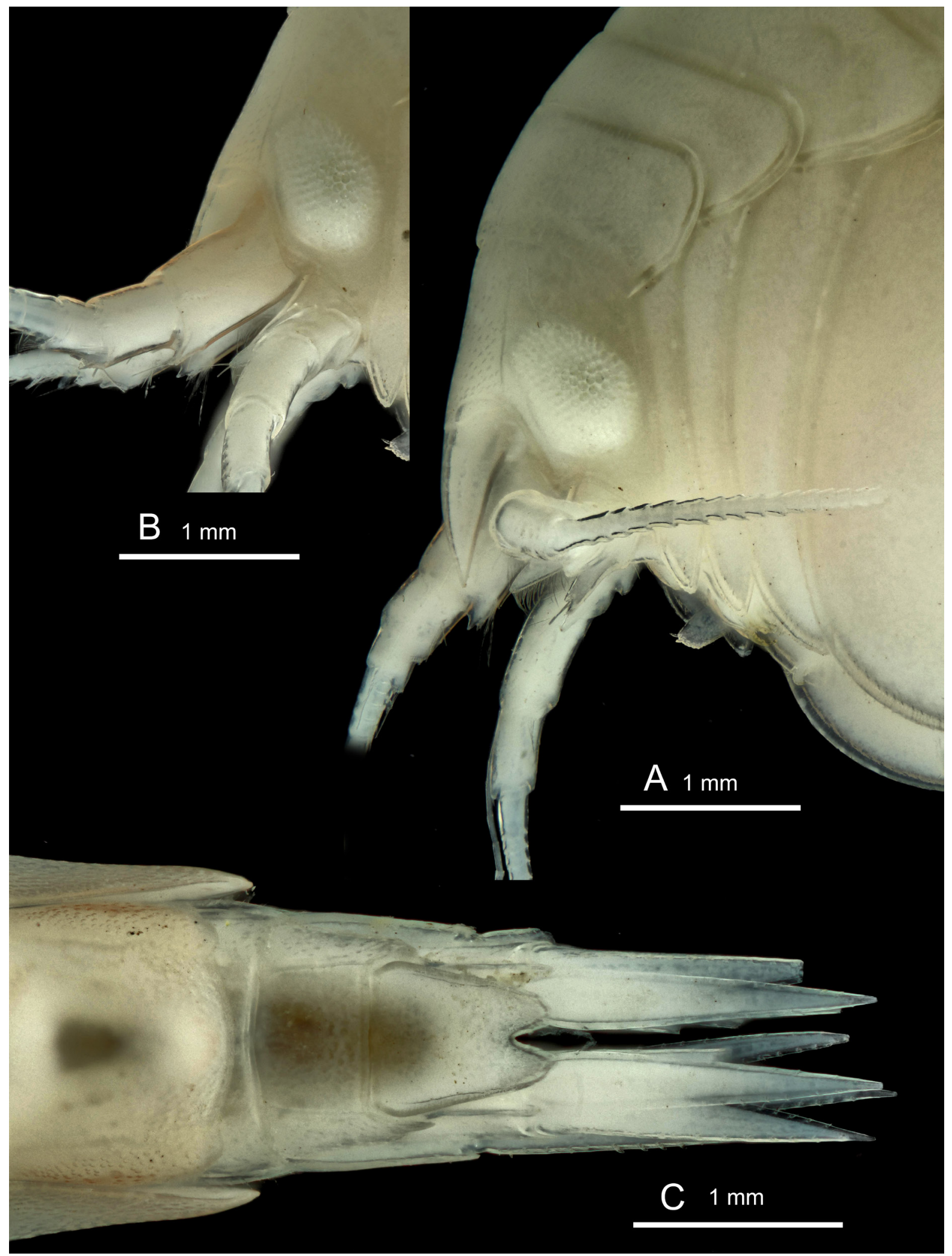

Fig. 310. Epimeria (Subepimeria) teres sp. nov., sex undetermined, holotype, Larsen B, ANT-XXVII/3, stn 248-2, RBINS, INV. 132951. A. Head and body segments 1-3 in lateral view (antenna 1 removed on one side to make the rostrum visible). B. Head in lateral view with antenna 1 before removal. C. Urosome in dorsal view. 


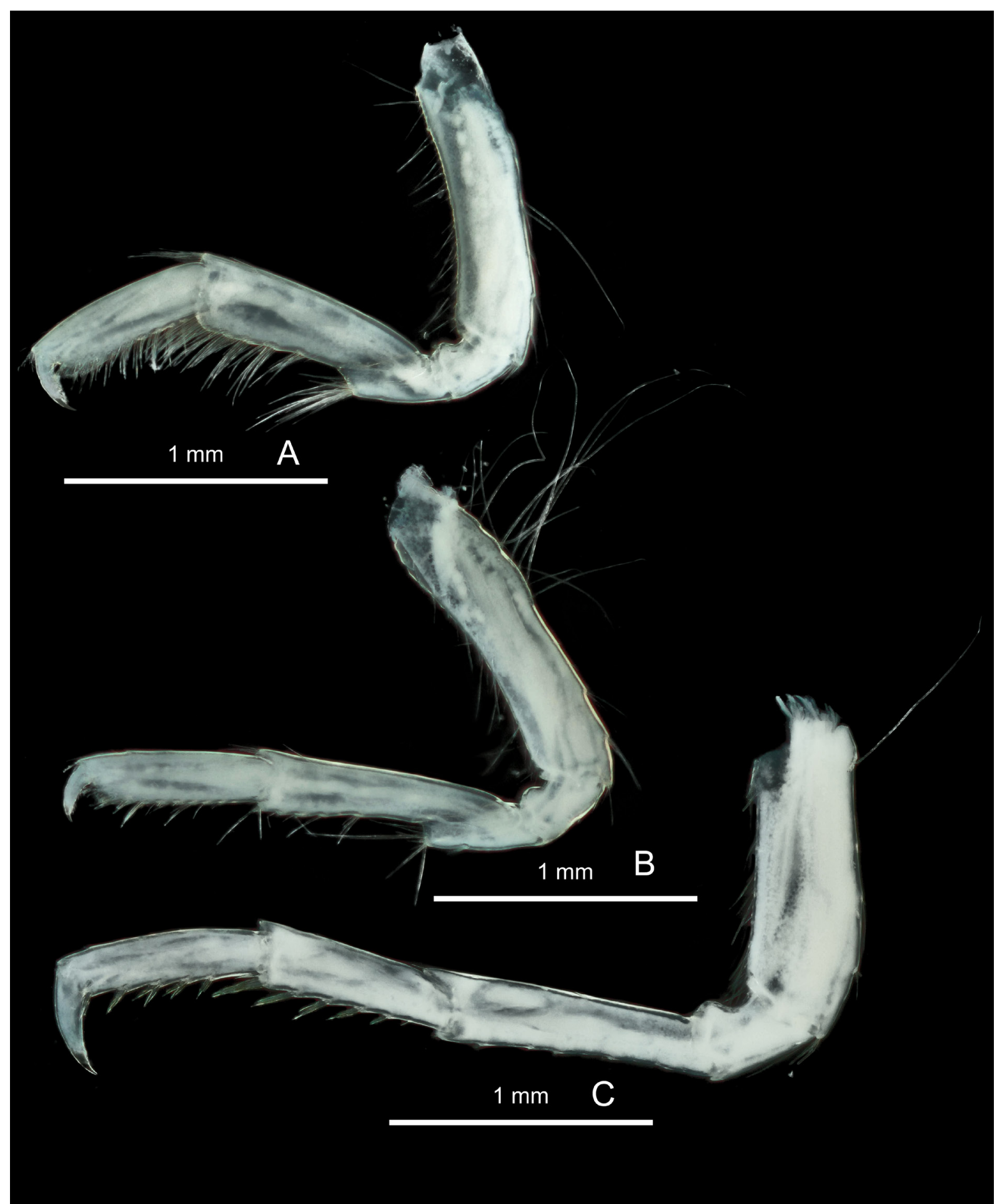

Fig. 311. Epimeria (Subepimeria) teres sp. nov., sex undetermined, holotype, western Weddell Sea, Larsen B, ANT-XXVII/3, stn 248-2, RBINS, INV. 132951. A. Gnathopod 1. B. Gnathopod 2. C. Pereiopod 3 or 4. 


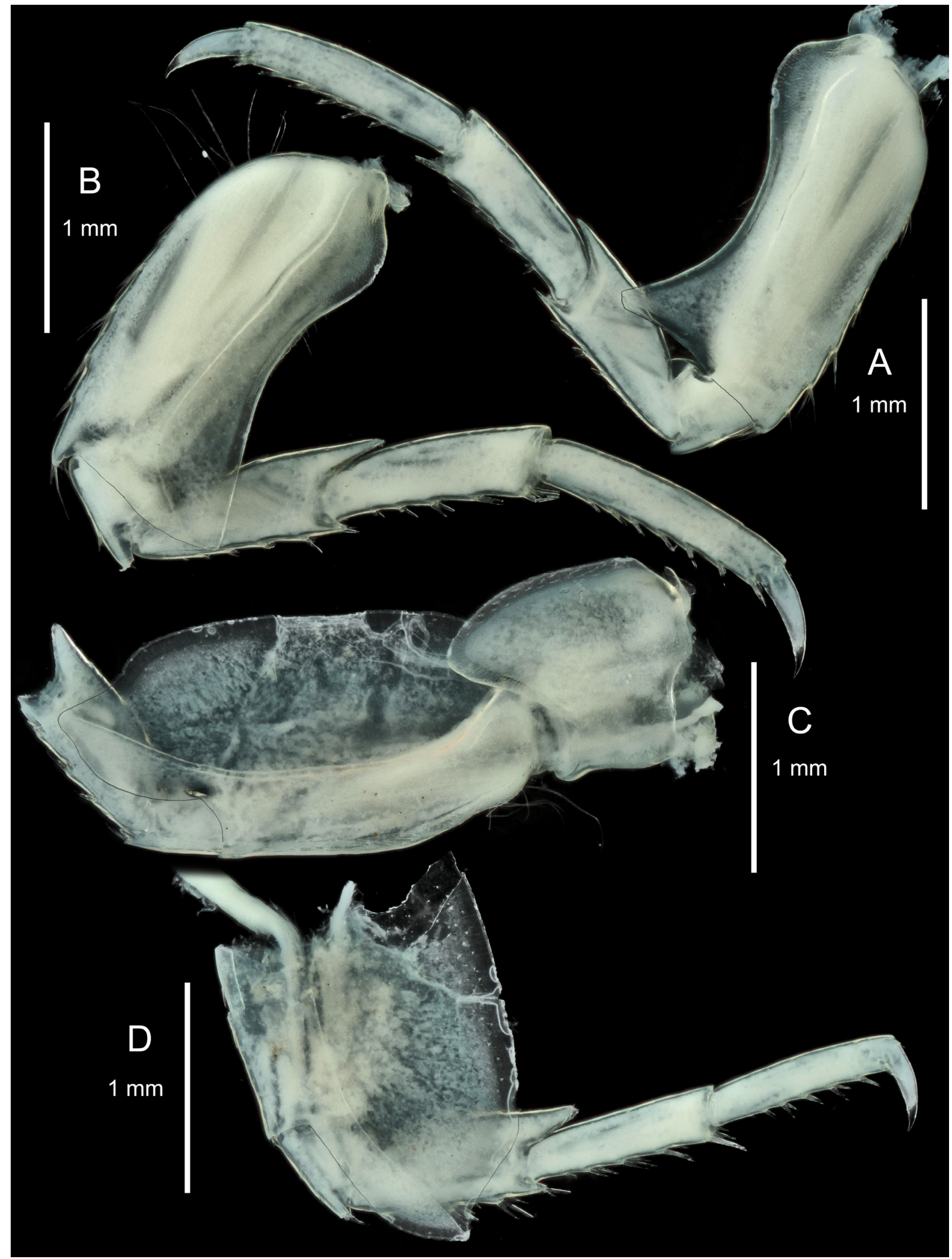

Fig. 312. Epimeria (Subepimeria) teres sp. nov., sex undetermined, holotype, Larsen B, ANT-XXVII/3, stn 248-2, RBINS, INV. 132951. A. Right pereiopod 5. B. Left pereiopod 6. C. Right pereiopod 7. D. Left pereiopod 7. 


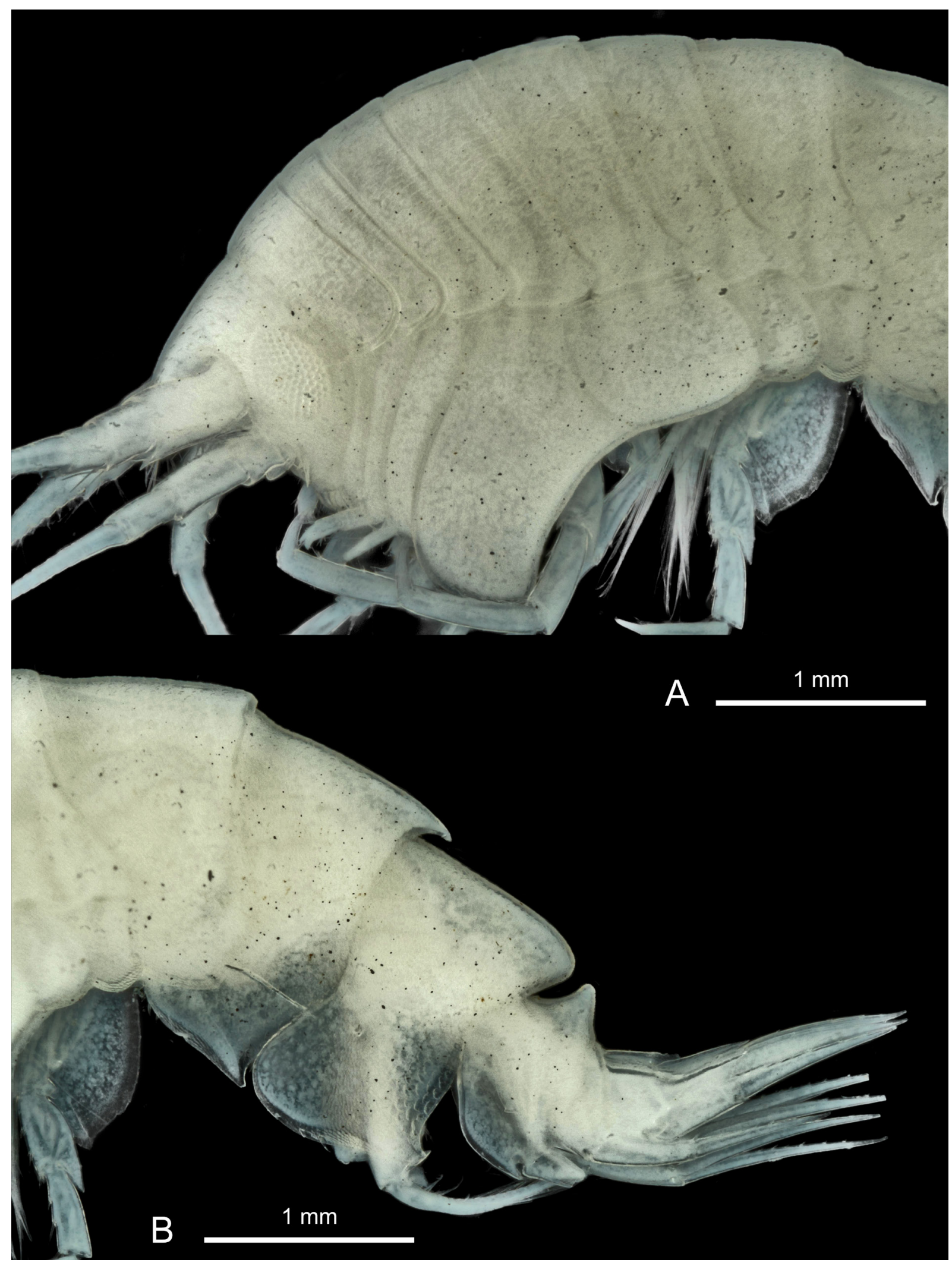

Fig. 313. Epimeria (Subepimeria) teres sp. nov., sex undetermined, juvenile paratype, Larsen B, ANTXXVII/3, stn 248-2, RBINS, INV. 122896. A. Anterior part. B. Posterior part. 


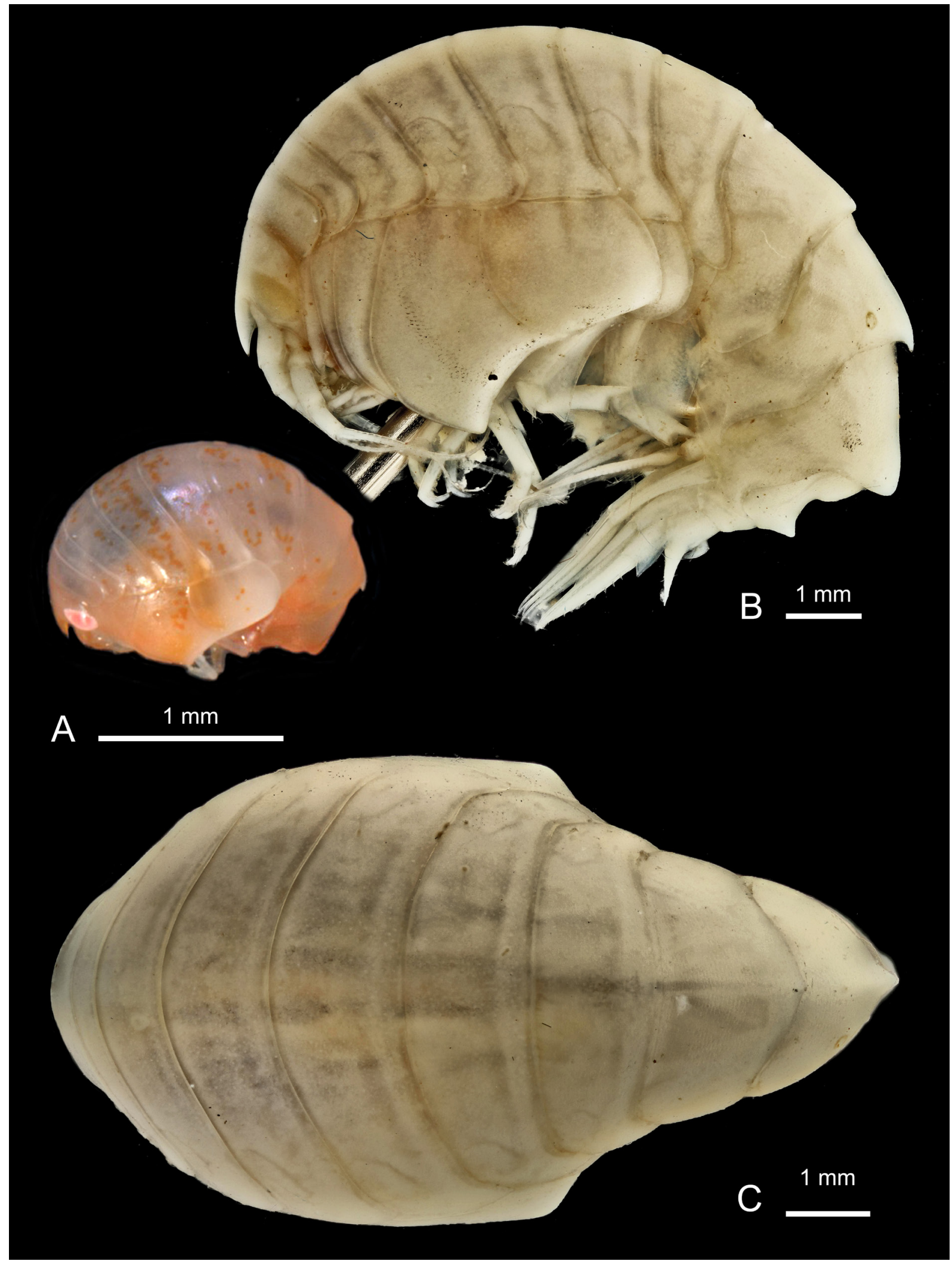

Fig. 314. Epimeria (Subepimeria) urvillei sp. nov., + , holotype, Adélie Coast, REVO_477, MNHNIU-2009-2578. A. Lateral habitus, colour in life. B. Lateral habitus C. Dorsal habitus. Colour photograph: Cyril Gallut (MNHN). 

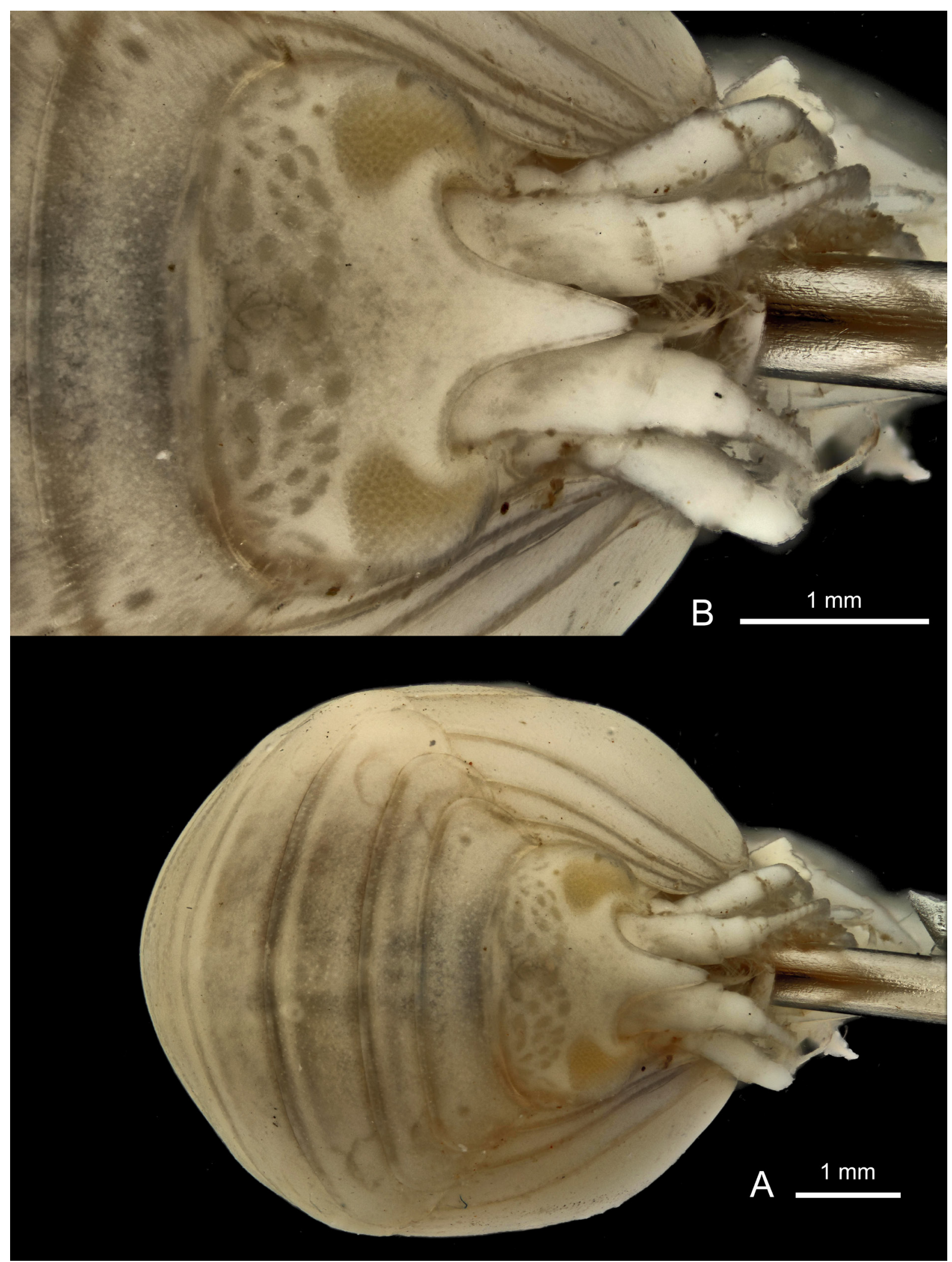

Fig. 315. Epimeria (Subepimeria) urvillei sp. nov., + , holotype, Adélie Coast, REVO_477, MNHNIU-2009-2578. A. Facial habitus. B. Head in facial view. 


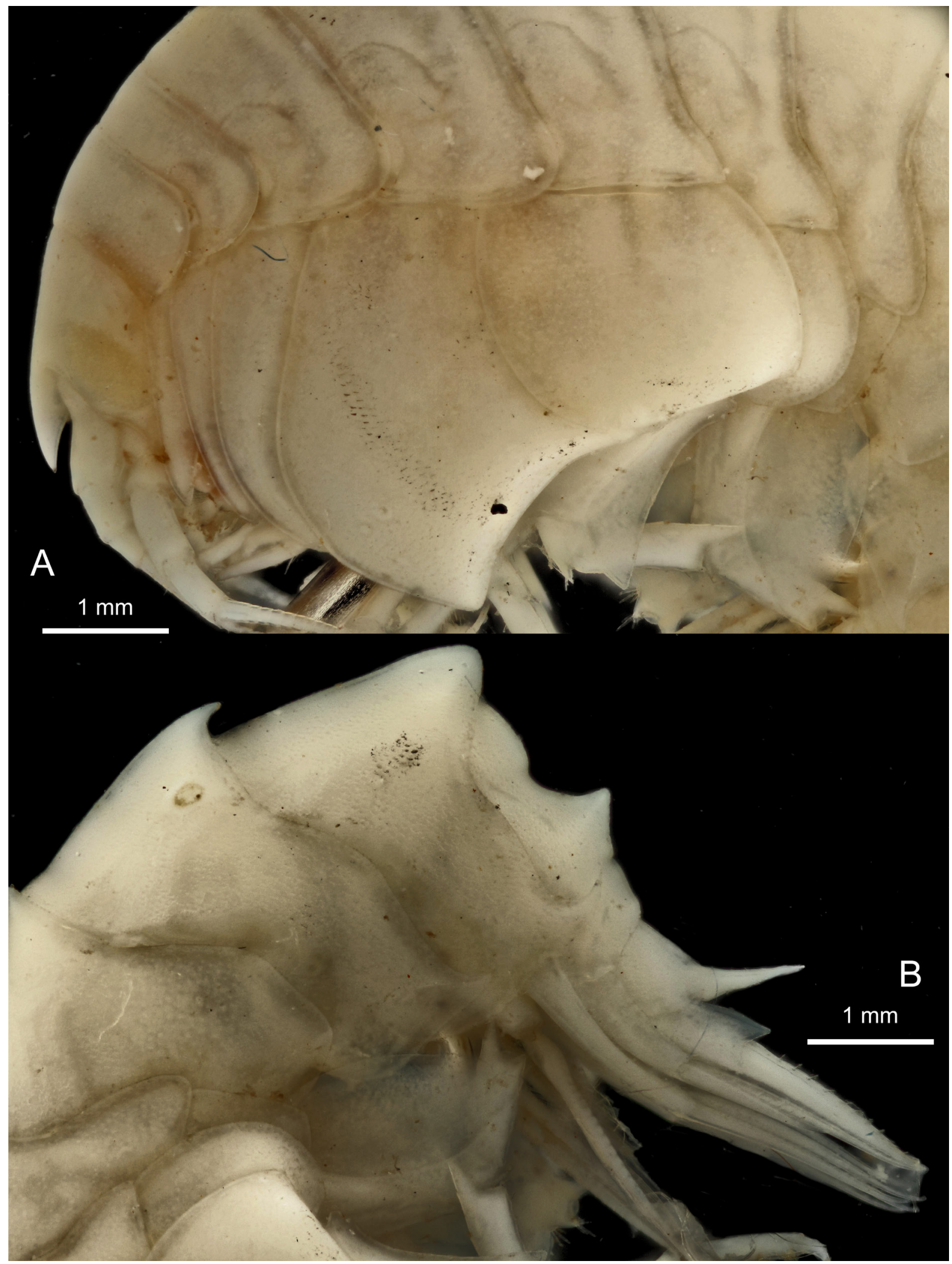

Fig. 316. Epimeria (Subepimeria) urvillei sp. nov., + , holotype, Adélie Coast, REVO_477, MNHNIU-2009-2578. A. Anterior half of body. B. Posterior half of body. 


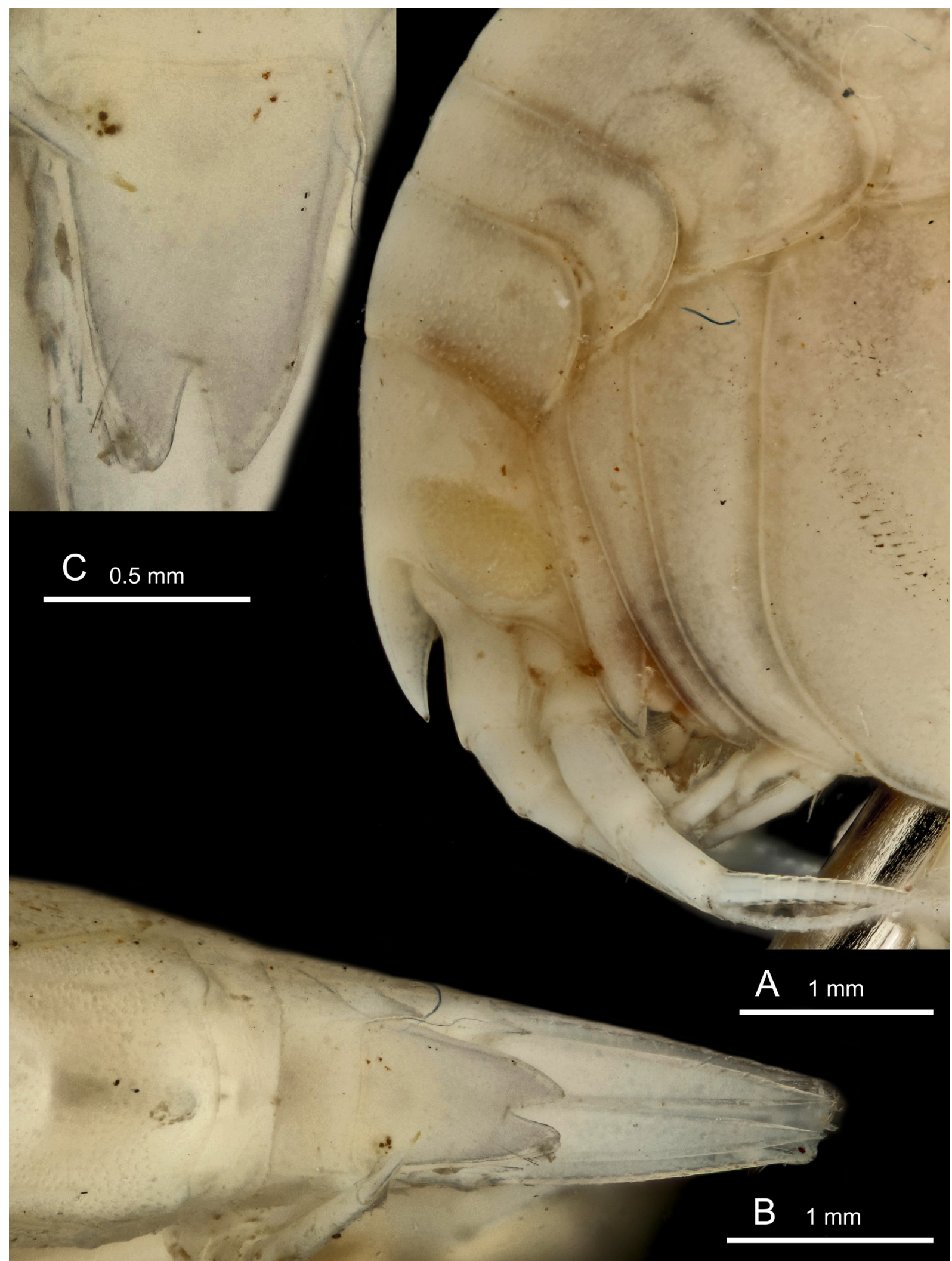

Fig. 317. Epimeria (Subepimeria) urvillei sp. nov., + , holotype, Adélie Coast, REVO_477, MNHNIU-2009-2578. A. Head and body segments 1-3 in lateral view. B. Urosome in dorsal view. C. Telson in dorsal view. 


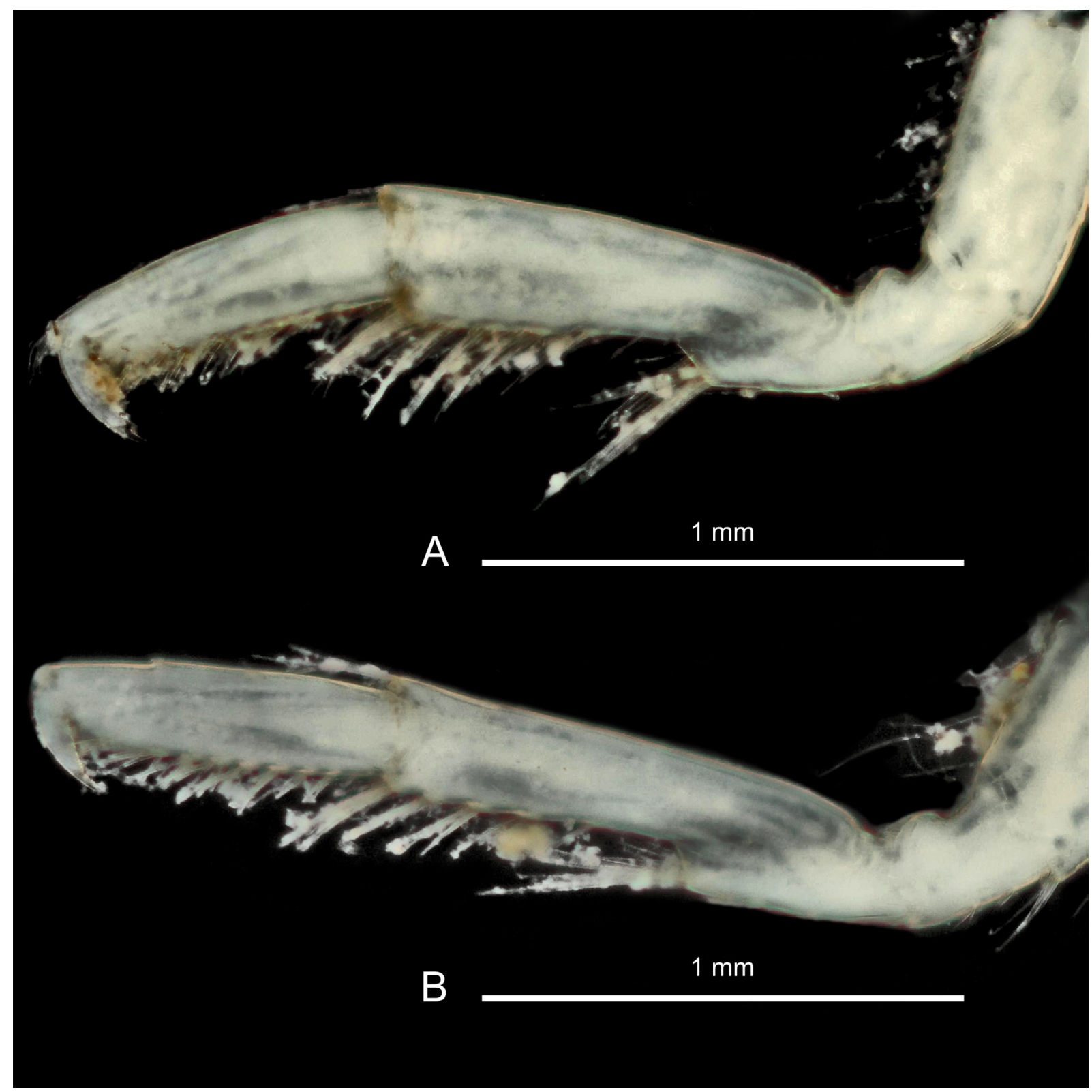

Fig. 318. Epimeria (Subepimeria) urvillei sp. nov., + , holotype, Adélie Coast, REVO_477, MNHNIU-2009-2578. A. Gnathopod 1. B. Gnathopod 2. 


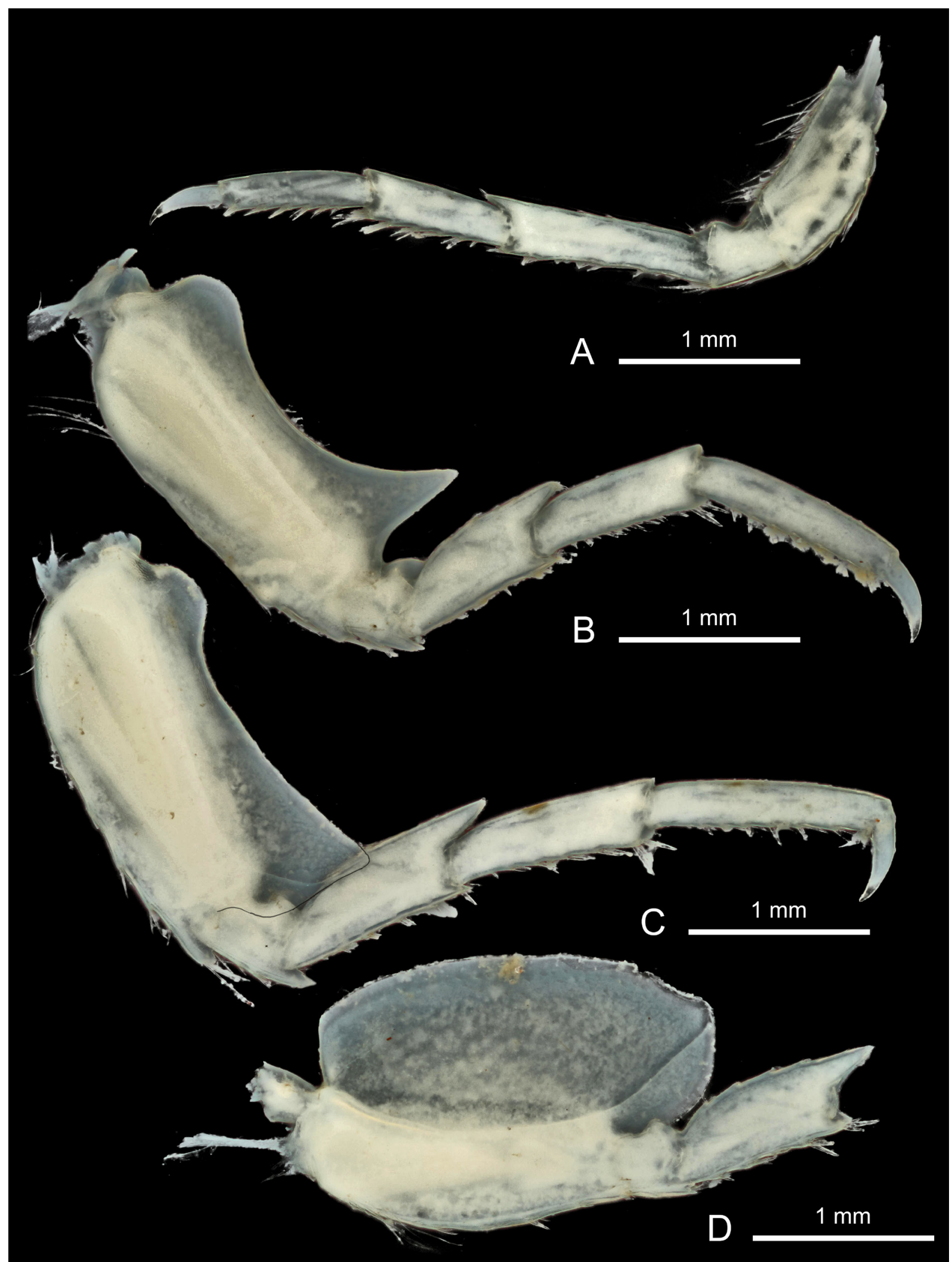

Fig. 319. Epimeria (Subepimeria) urvillei sp. nov., + , holotype, Adélie Coast, REVO_477, MNHNIU-2009-2578. A. Pereiopod 4. B. Pereiopod 5. C. Pereiopod 6. D. Pereiopod 7. 


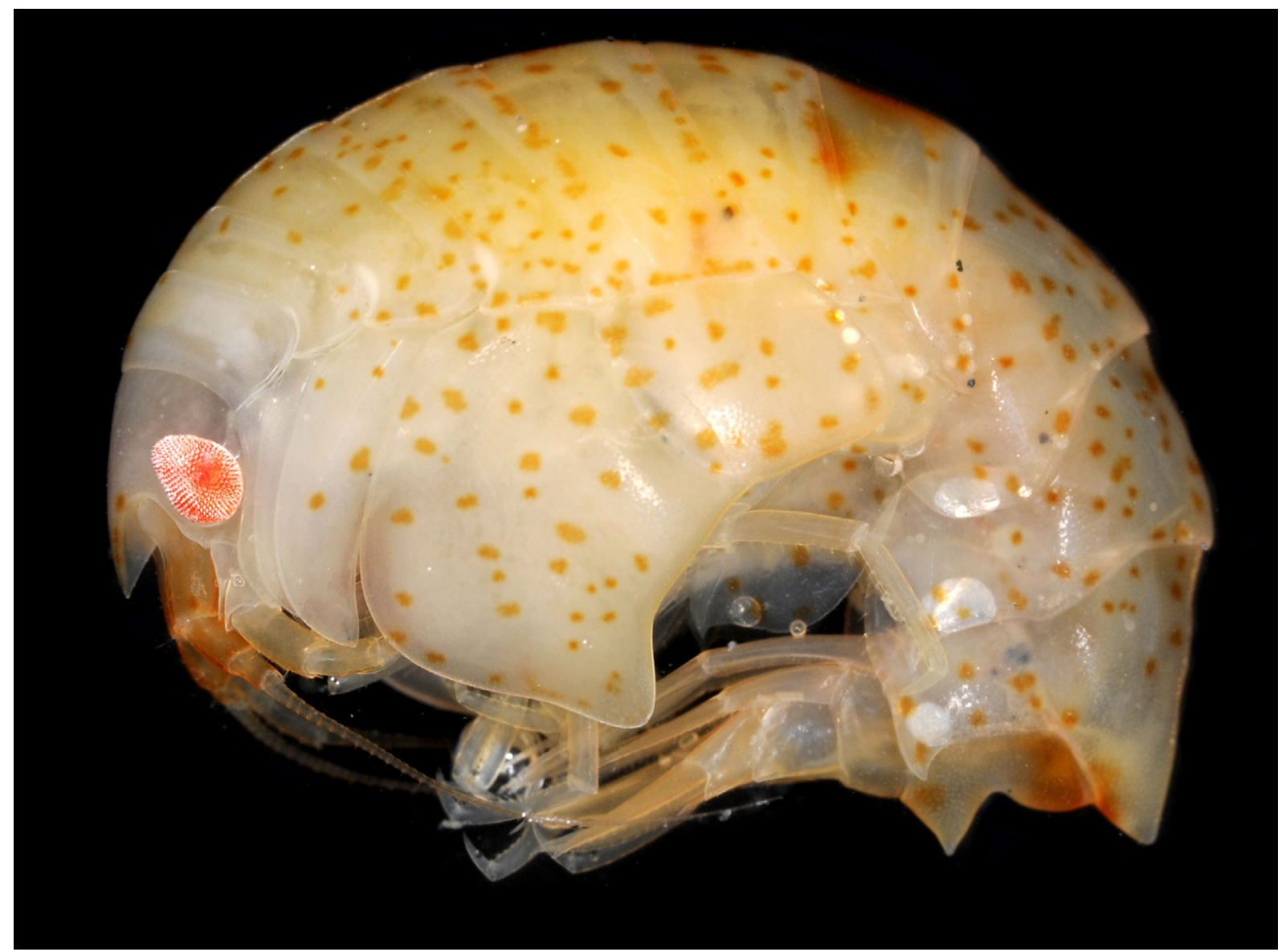

Fig. 320. Epimeria (Urepimeria) annabellae subgen. nov. Coleman, 1994, sex undetermined, eastern Weddell Sea, ANT-XXVII/3, stn 260-6, RBINS, INV. 132952. Lateral habitus (colour in life). Photograph: Armin Rose. 


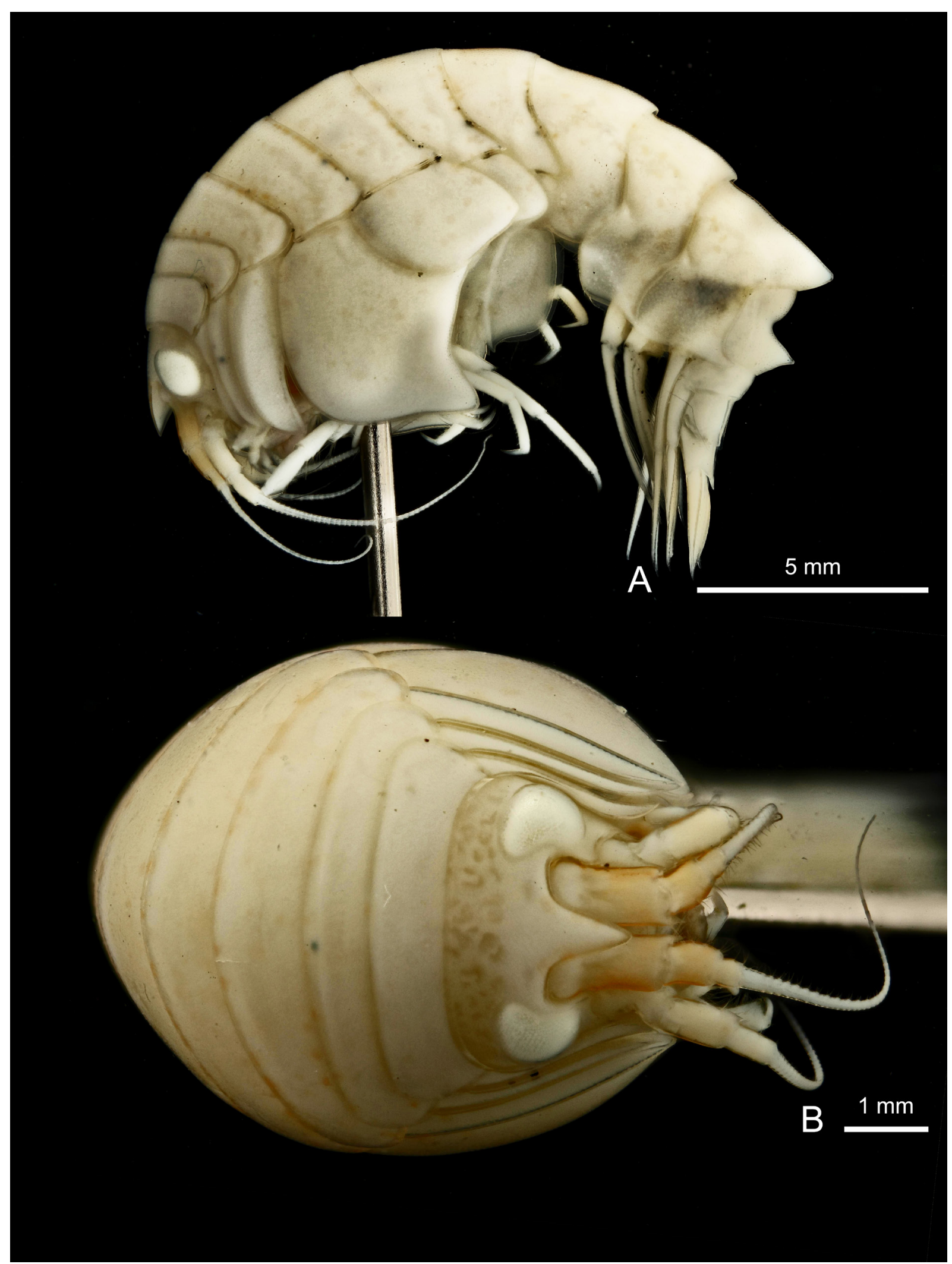

Fig. 321. Epimeria (Urepimeria) annabellae subgen. nov. Coleman, 1994, sex undetermined, eastern Weddell Sea, ANT-XXVII/3, stn 260-6, RBINS, INV. 132952. A. Lateral habitus. B. Frontal habitus. 


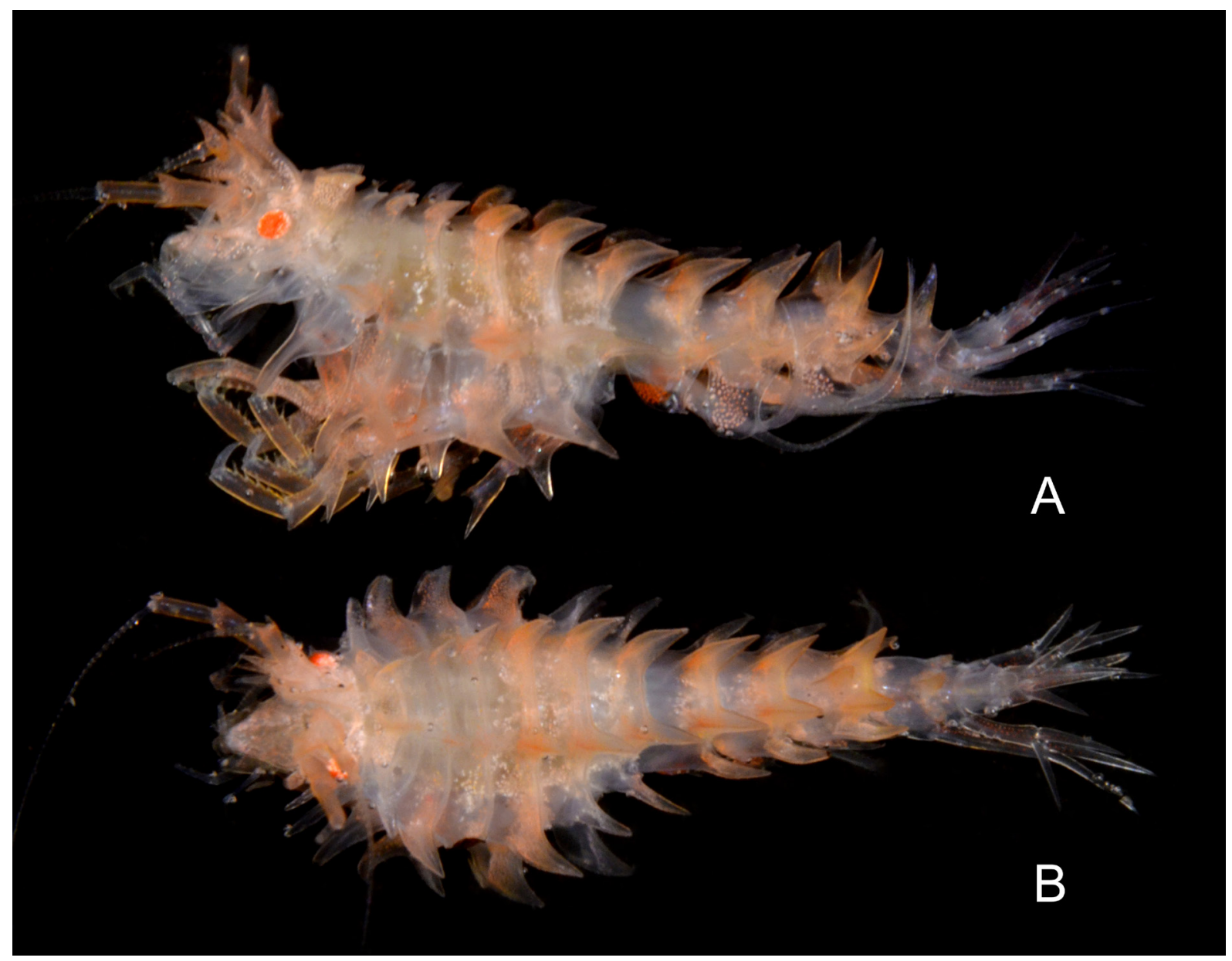

Fig. 322. Acanthonotozomoides oatesi (K.H. Barnard, 1930). Sex undetermined, adult specimen, Bransfield Strait, ANT-XXIX/3, stn 197-6, RBINS, INV. 122868. A. Lateral habitus. B. Dorsal habitus (colour in life). 


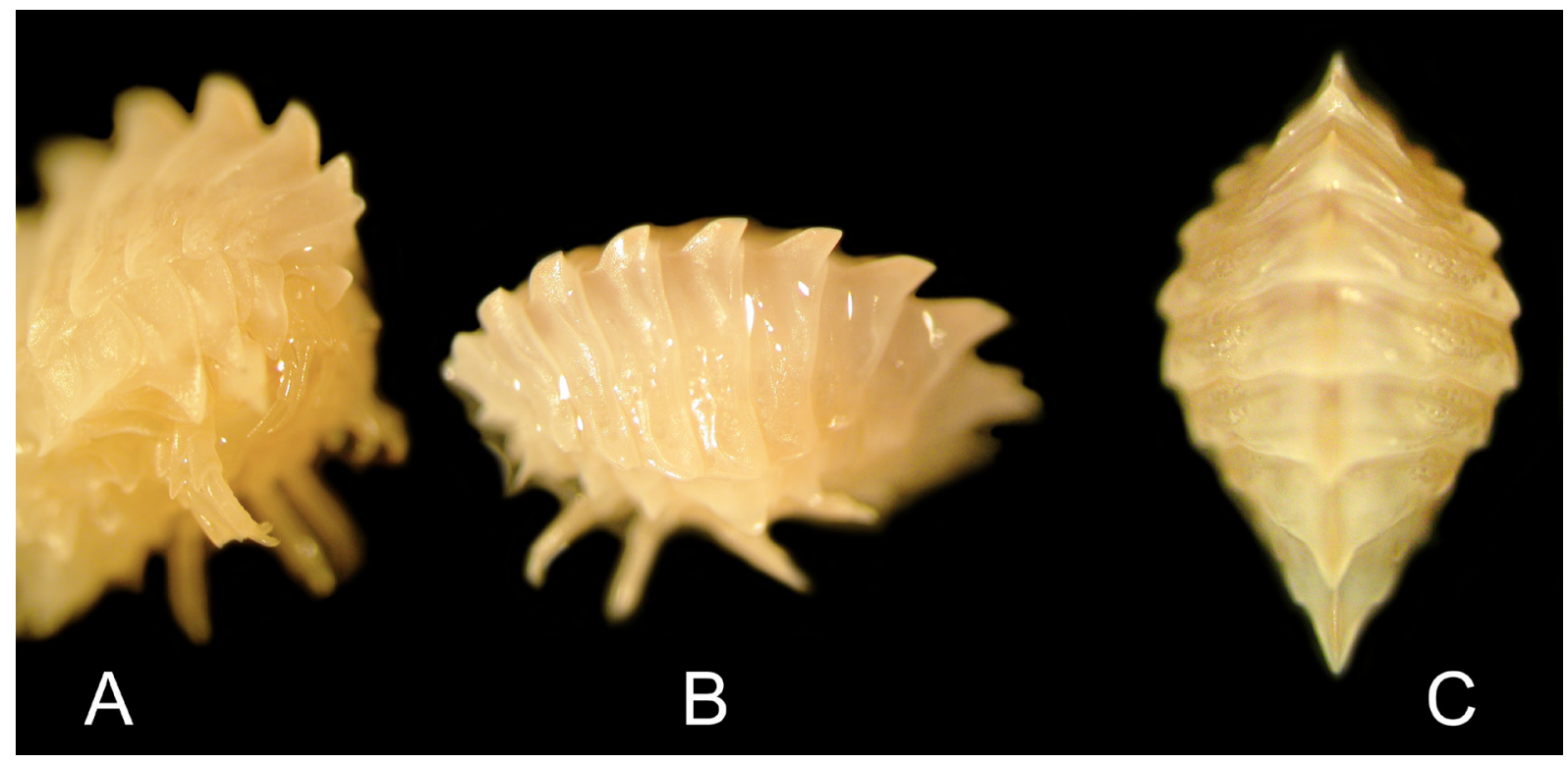

Fig. 323. Dikwa andresi Lörz \& Coleman, 2003, Sex undetermined, Burdwood Bank, ANT-XXVII/3, CAMBIO, stn 208-2, RBINS, INV. 132666. A. Semi-facial view. B. Semi-lateral view. C. Dorsal view (colour in life). Photographs: H. Robert and C. Havermans. 


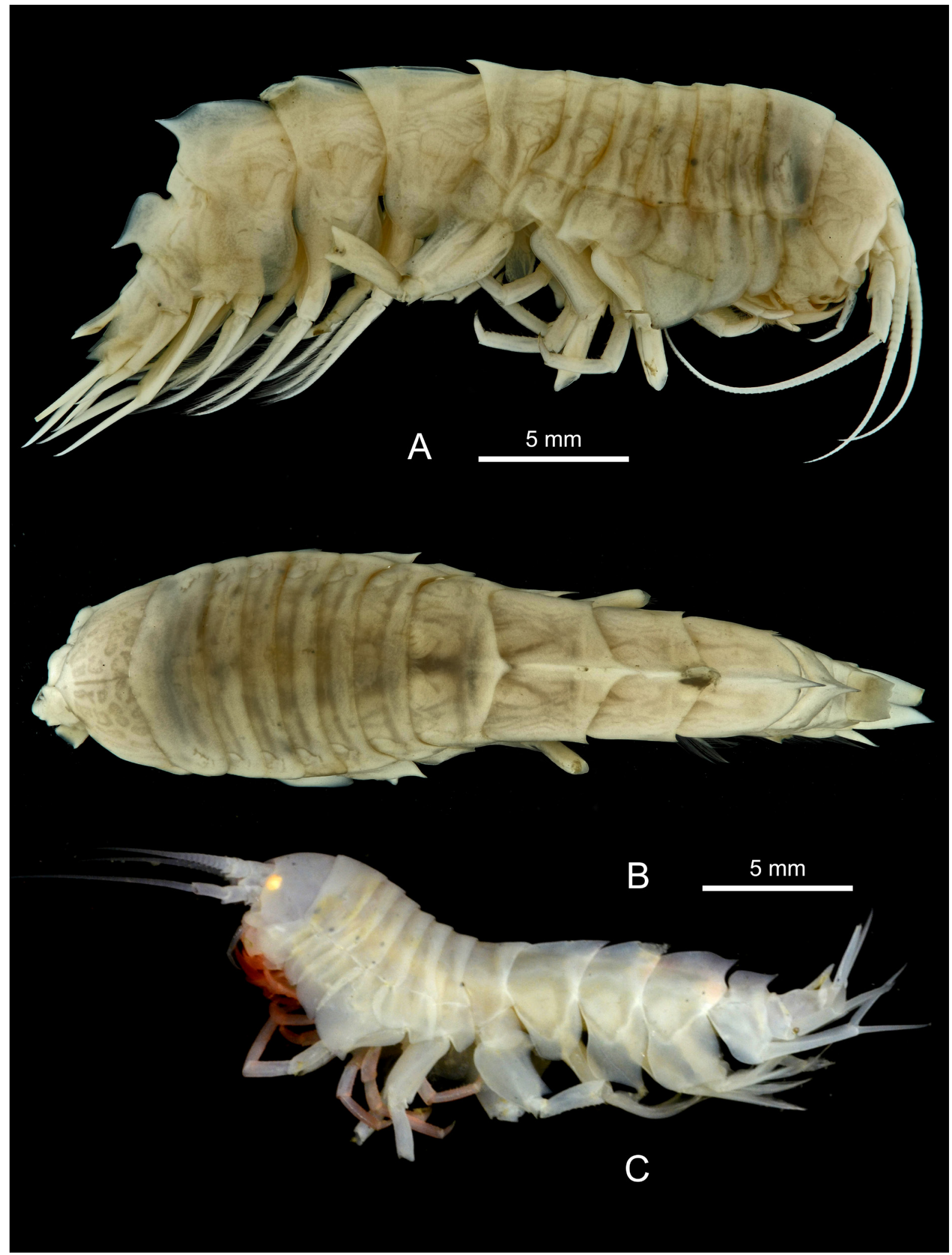

Fig. 324. Alexandrella chione sp. nov.,, , holotype, Bransfield Strait, ANT-XXIX/3, stn 227-2, Bransfield Strait, RBINS, INV. 122887. A. Lateral habitus. B. Dorsal habitus. C. Lateral habitus (colour in life). 


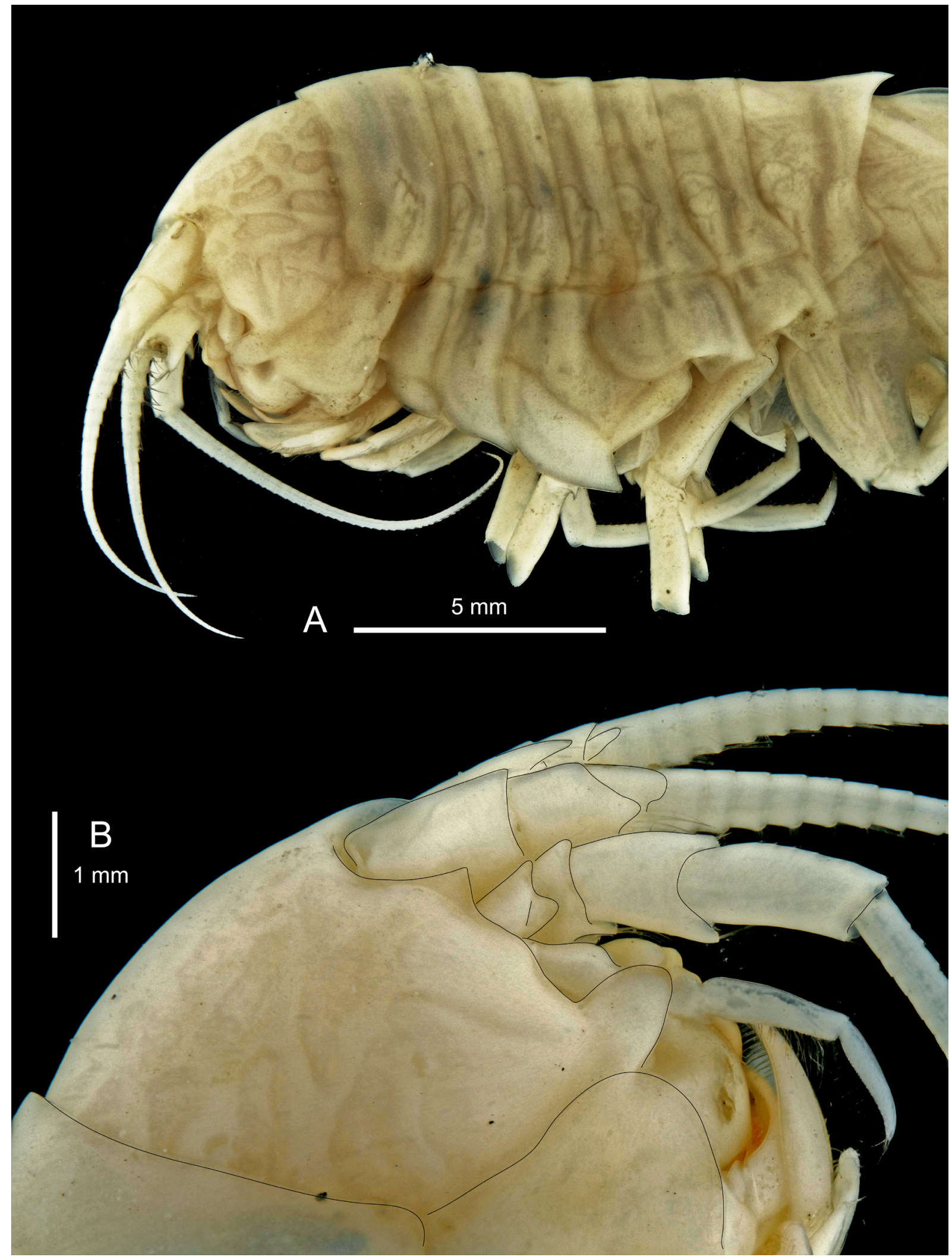

Fig. 325. Alexandrella chione sp. nov.,, , holotype, Bransfield Strait, ANT-XXIX/3, stn 227-2, RBINS, INV. 122887. A. Head and pereion. B. Head and peduncle of antennae (lateral view). 


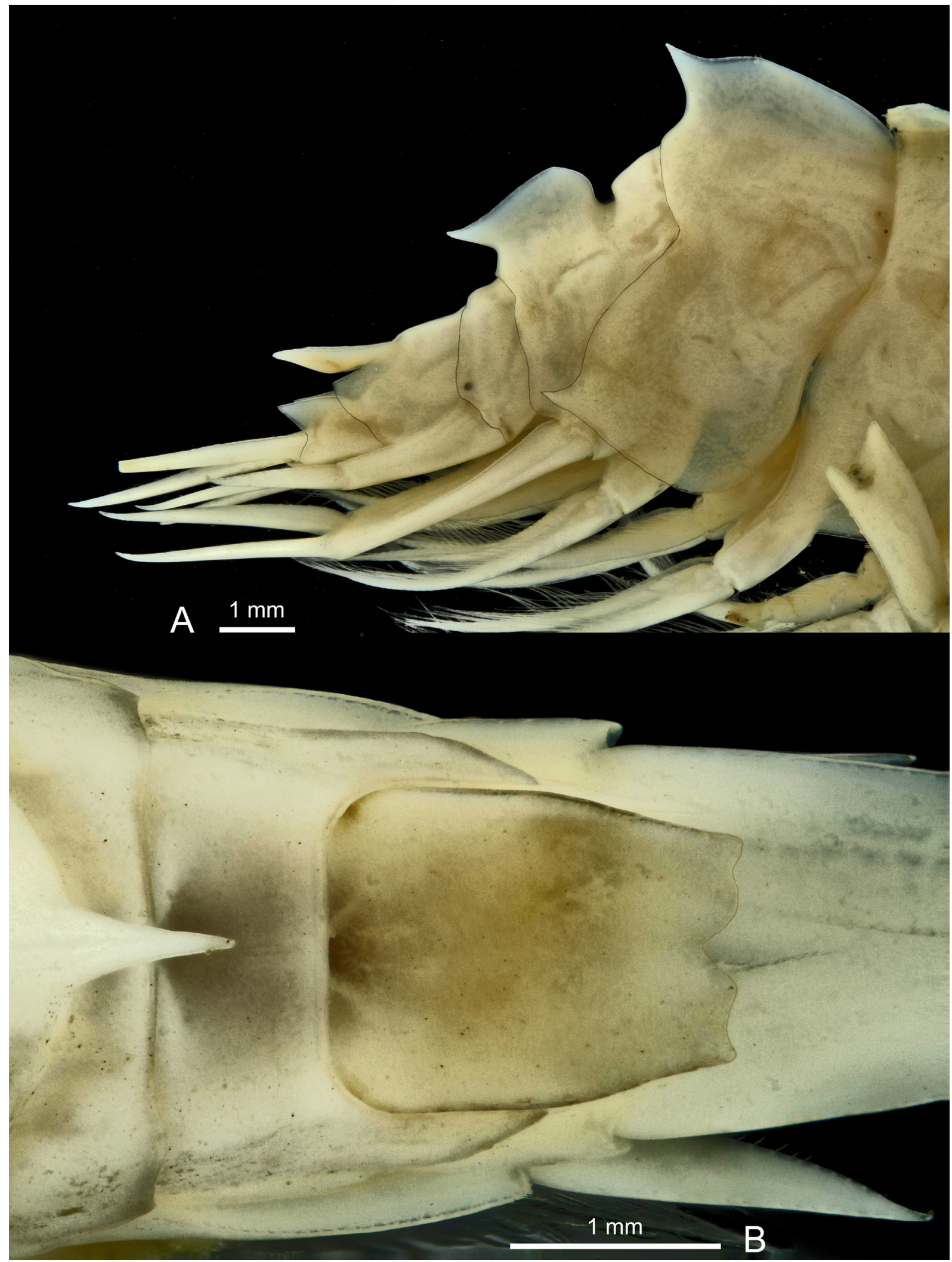

Fig. 326. Alexandrella chione sp. nov.,, , holotype, Bransfield Strait, ANT-XXIX/3, stn 227-2, RBINS, INV. 122887. A. Pleonite 3 and urosome in lateral view. B. Telson in dorsal view. 


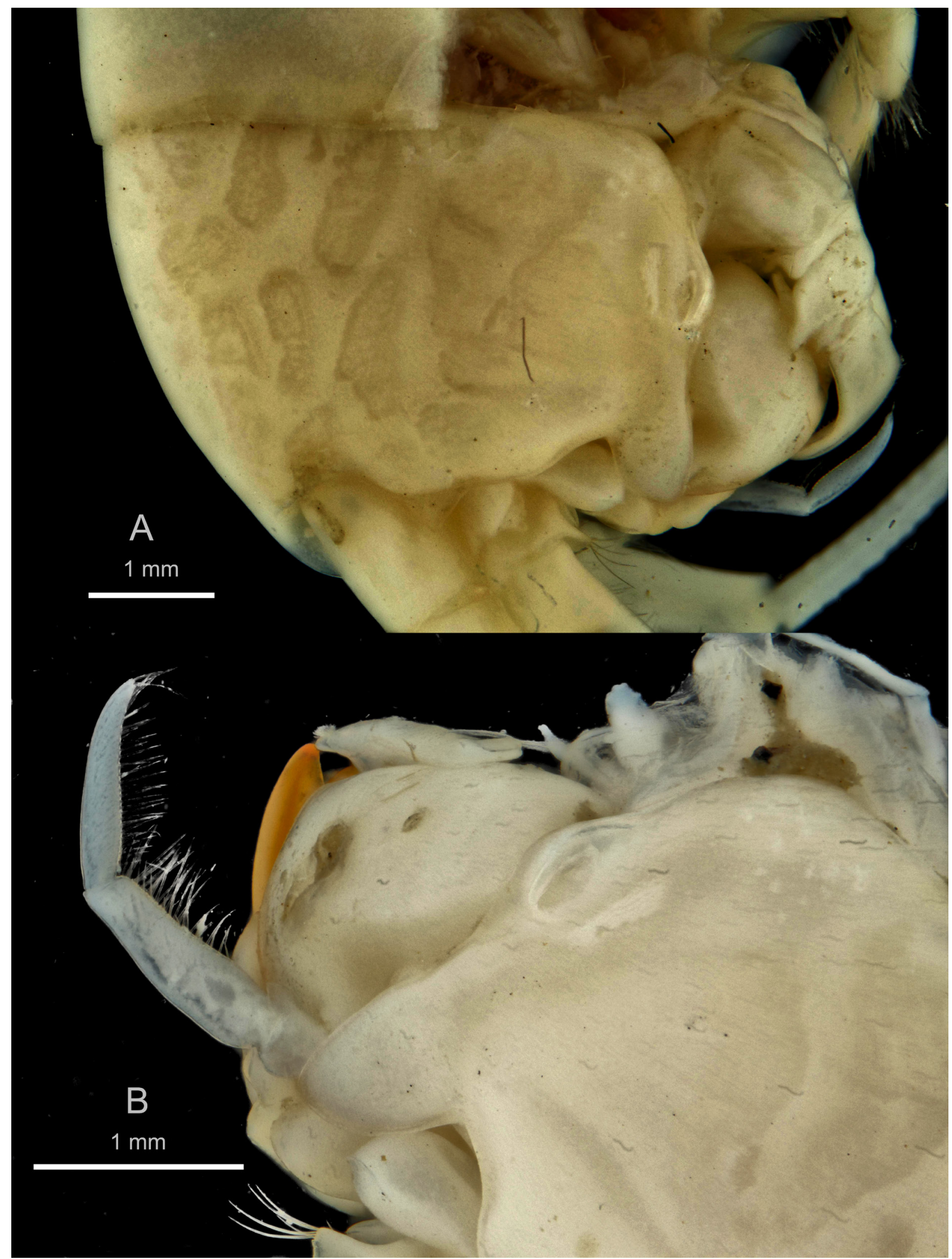

Fig. 327. Alexandrella chione sp. nov., + , holotype, Bransfield Strait, ANT-XXIX/3, stn 227-2, RBINS, INV. 122887. A. Head in lateral view. B. Anterior part of head showing the mandibular palp in lateral view. 


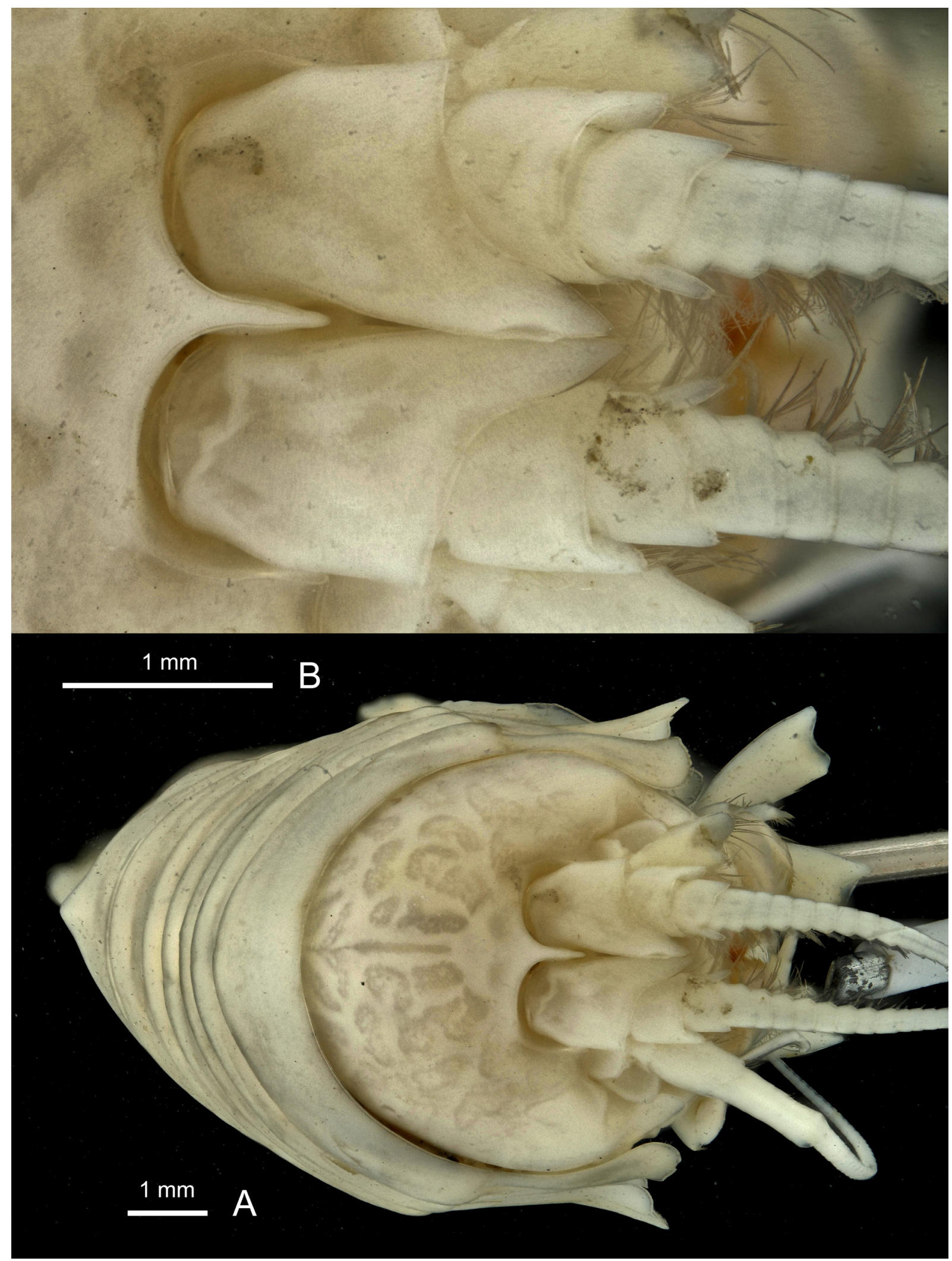

Fig. 328. Alexandrella chione sp. nov.,, , holotype, Bransfield Strait, ANT-XXIX/3, stn 227-2, RBINS, INV. 122887. A. Facial habitus. B. Rostrum and peduncles of antennae 1 in frontal view. 


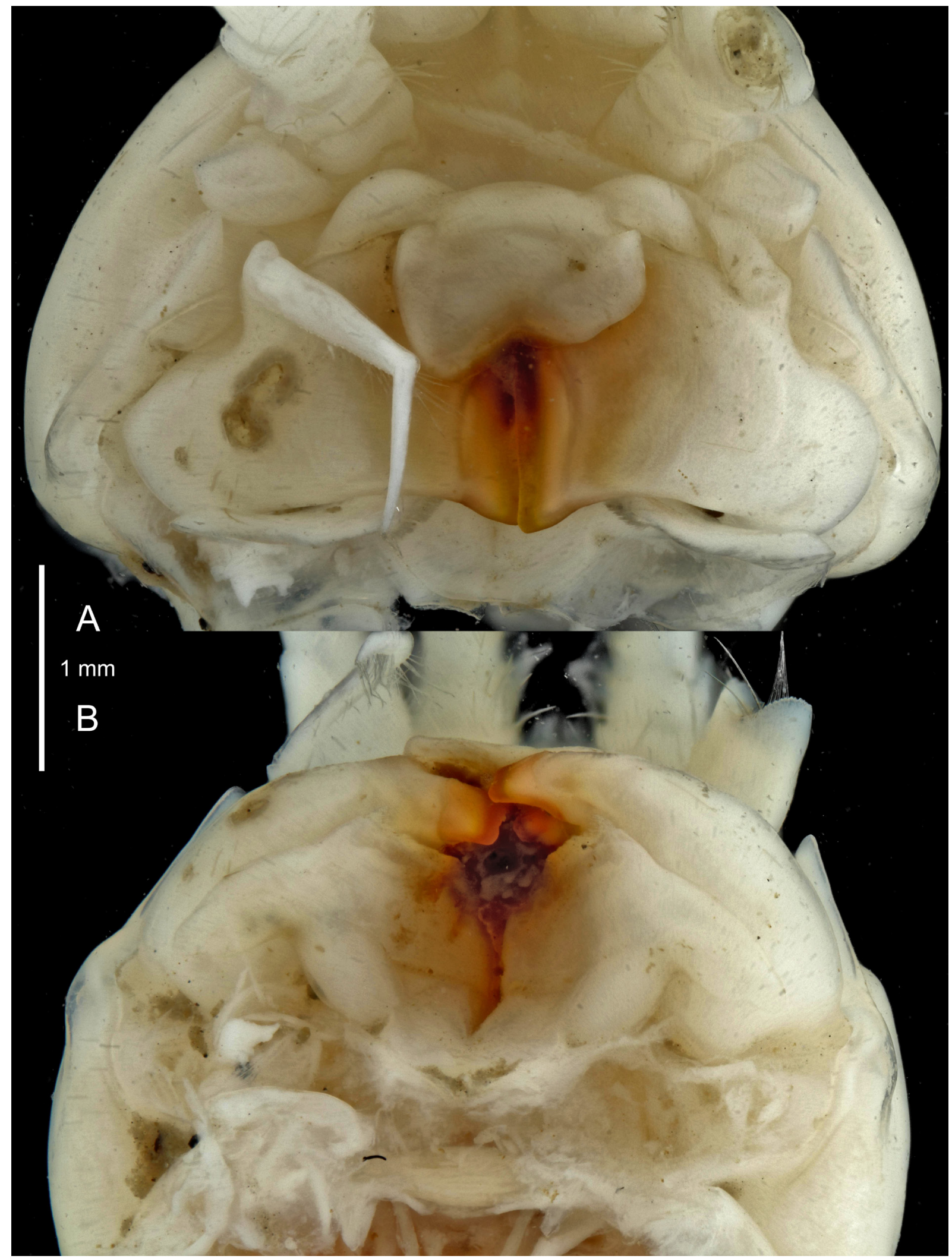

Fig. 329. Alexandrella chione sp. nov., + , holotype, Bransfield Strait, ANT-XXIX/3, stn 227-2, RBINS, INV. 122887. A. Mandible and lips in situ (frontal view). B. Mandible and lips in situ (ventral view). 


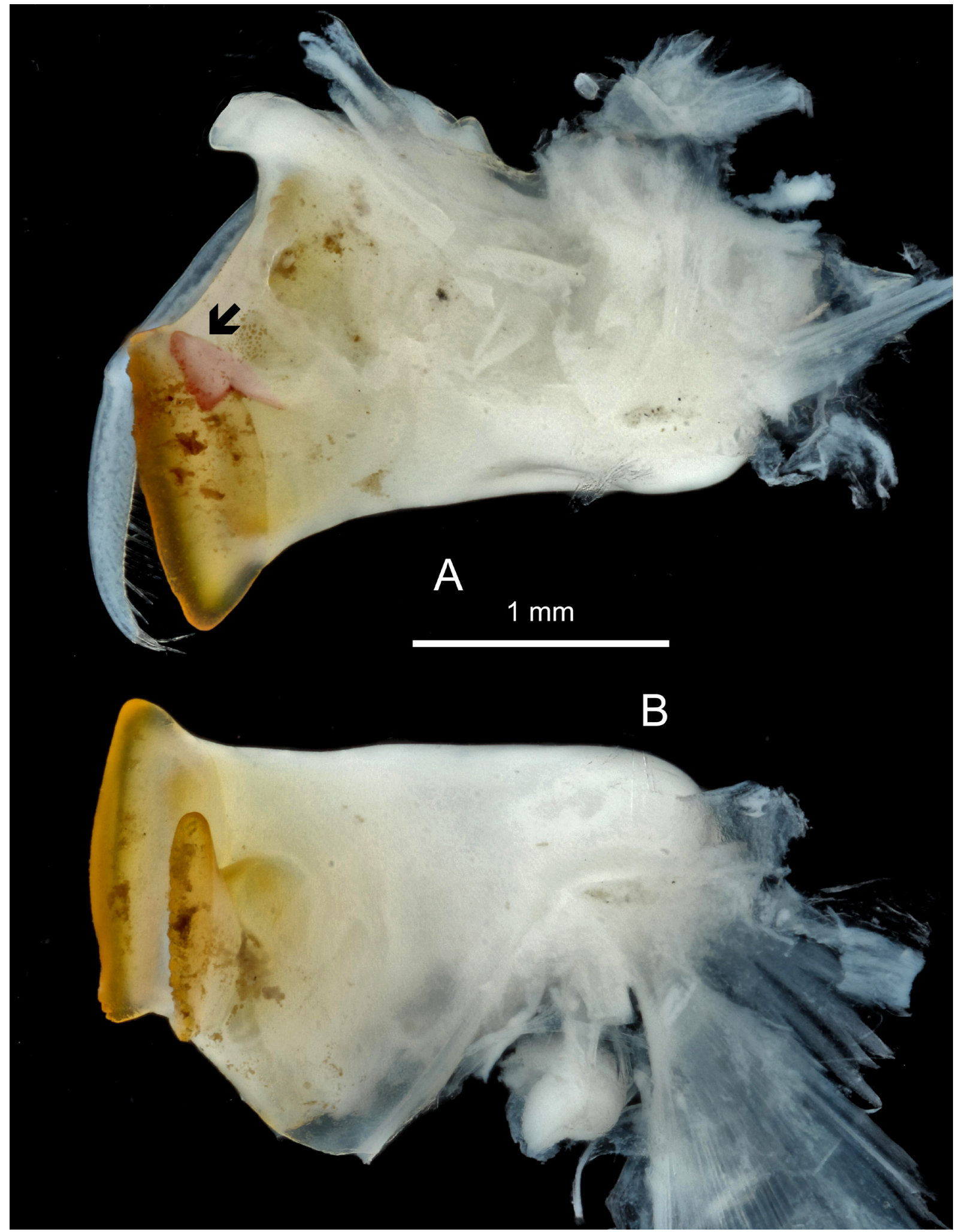

Fig. 330. Alexandrella chione sp. nov., +, holotype, Bransfield Strait, ANT-XXIX/3, stn 227-2, RBINS, INV. 122887. A. Right mandible. B. Left mandible. 


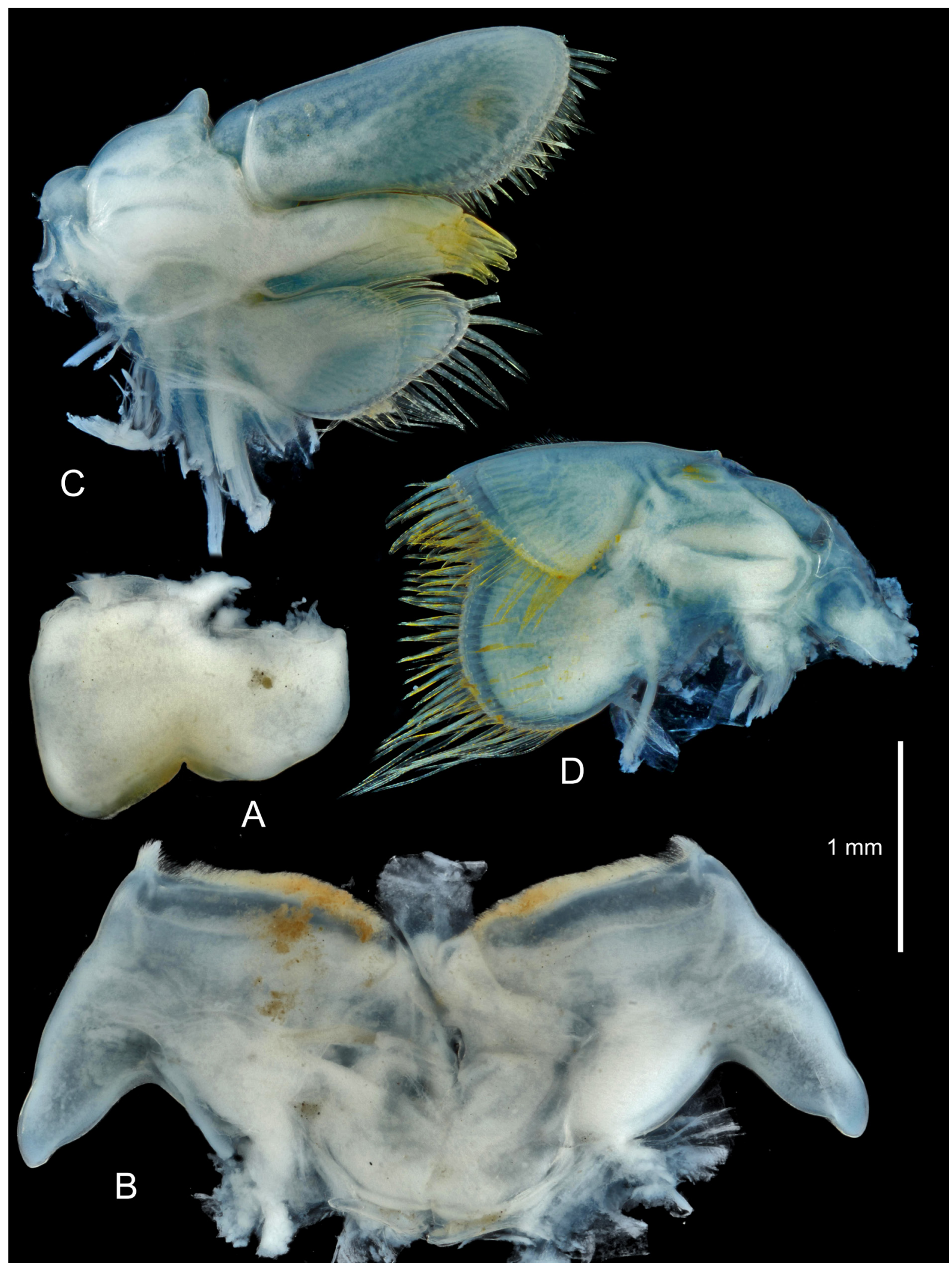

Fig. 331. Alexandrella chione sp. nov.,, , holotype, Bransfield Strait, ANT-XXIX/3, stn 227-2, RBINS, INV. 122887. A. Upper lip. B. Lower lip. C. Maxilla 1. D. Maxilla 2. 


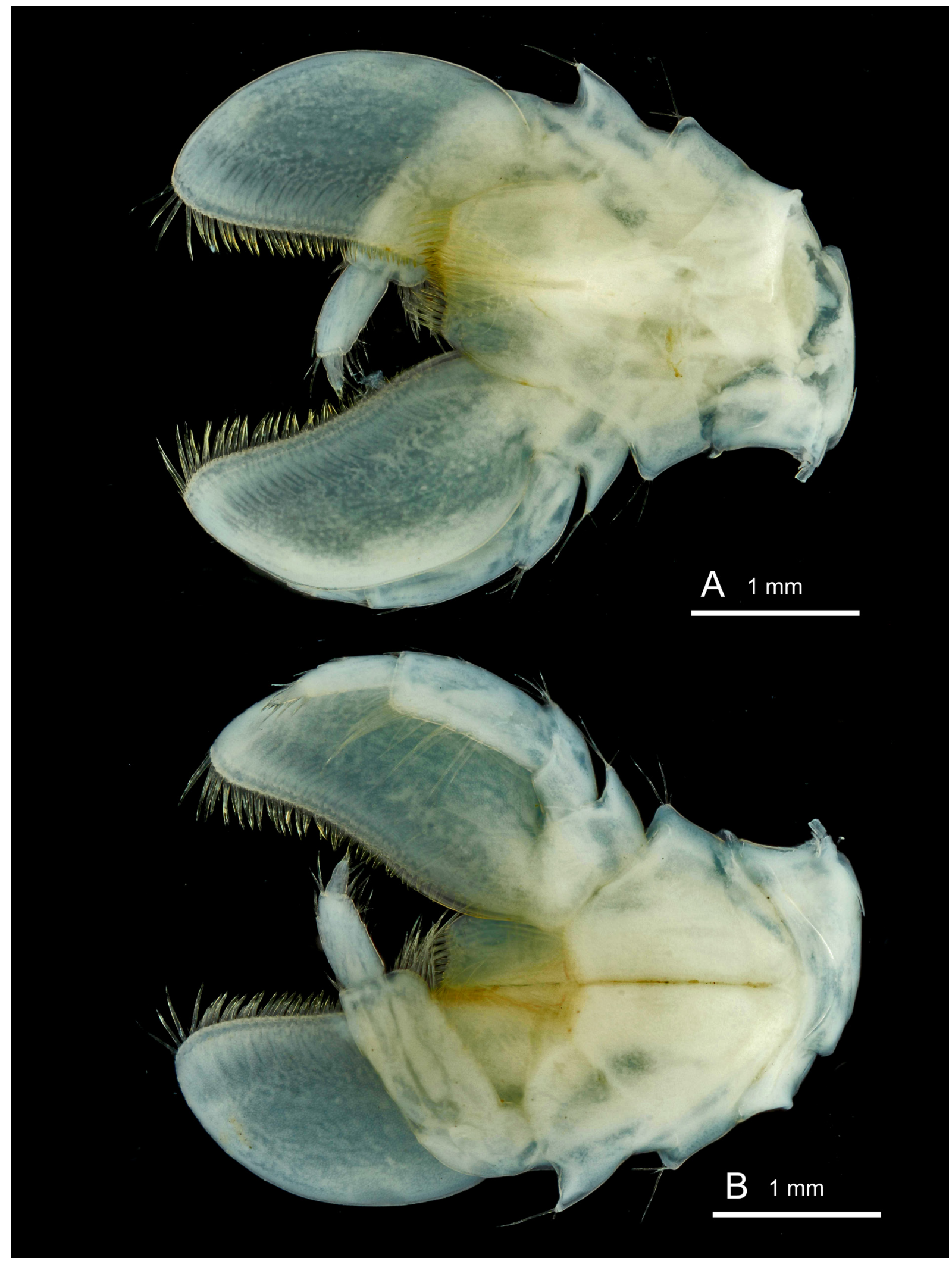

Fig. 332. Alexandrella chione sp. nov., + , holotype, Bransfield Strait, ANT-XXIX/3, stn 227-2, RBINS, INV. 122887. A. Maxilliped (oral side). B. Maxiliped (facial side). 


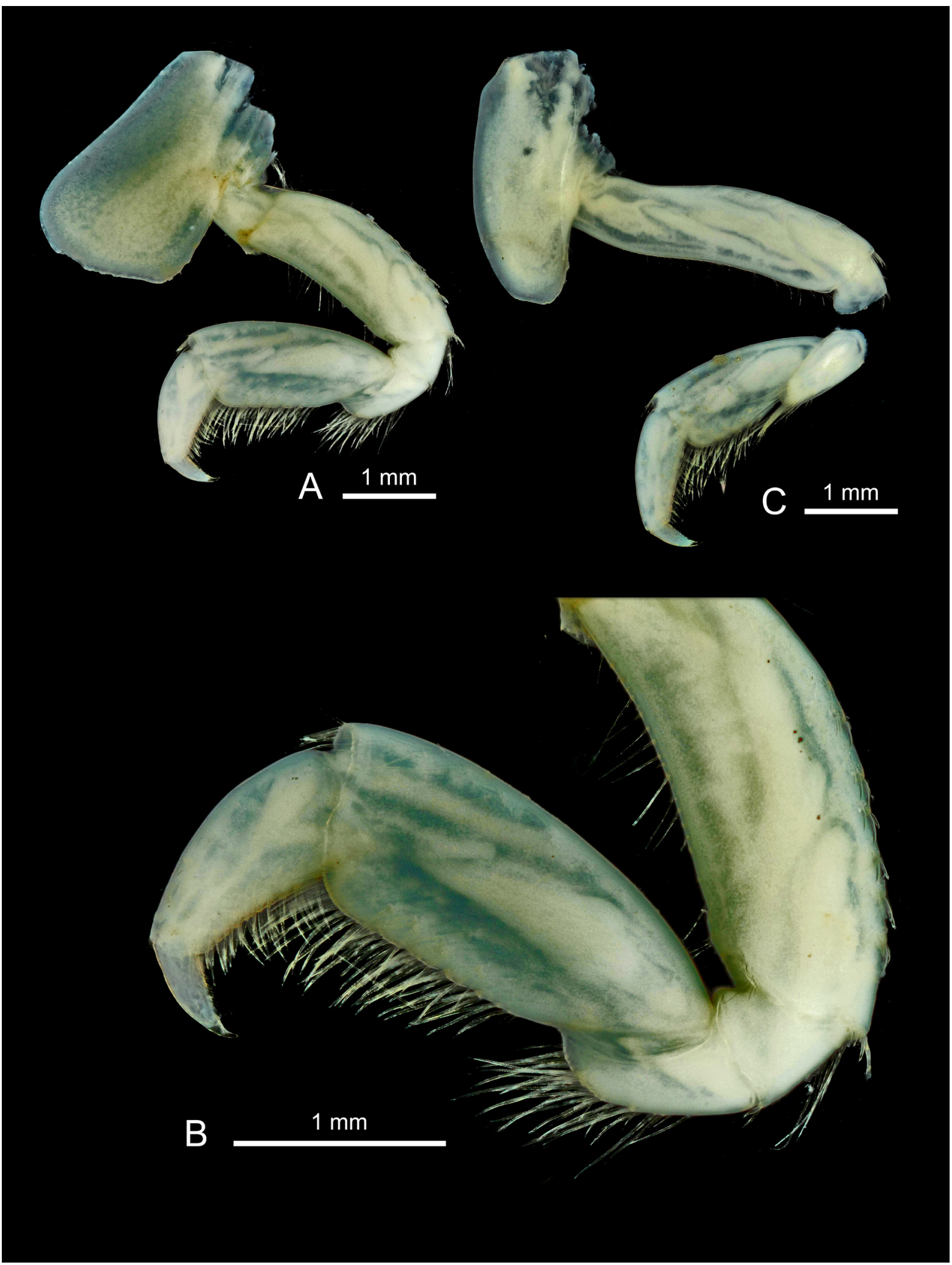

Fig. 333. Alexandrella chione sp. nov., + , holotype, Bransfield Strait, ANT-XXIX/3, stn 227-2, RBINS, INV. 122887. A. Gnathopod 1. B. Gnathopod 1 (enlarged). C. Gnathopod 2. 


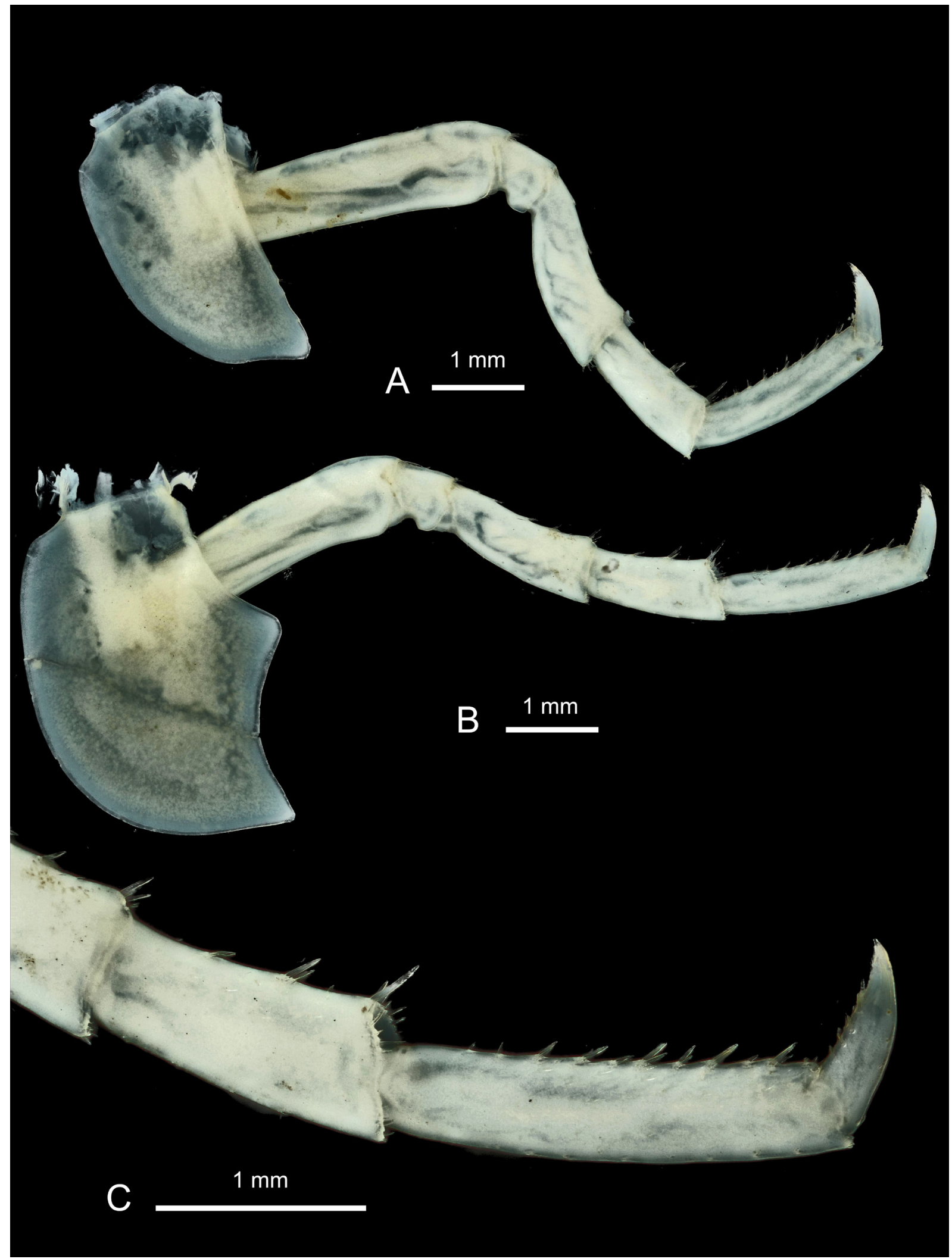

Fig. 334. Alexandrella chione sp. nov.,, , holotype, Bransfield Strait, ANT-XXIX/3, stn 227-2, RBINS, INV. 122887. A. Pereiopod 3. B. Pereiopod 4. C. Carpus, propodus and dactylus of pereiopod 4 (note the little teeth on the posterior border of the dactylus). 


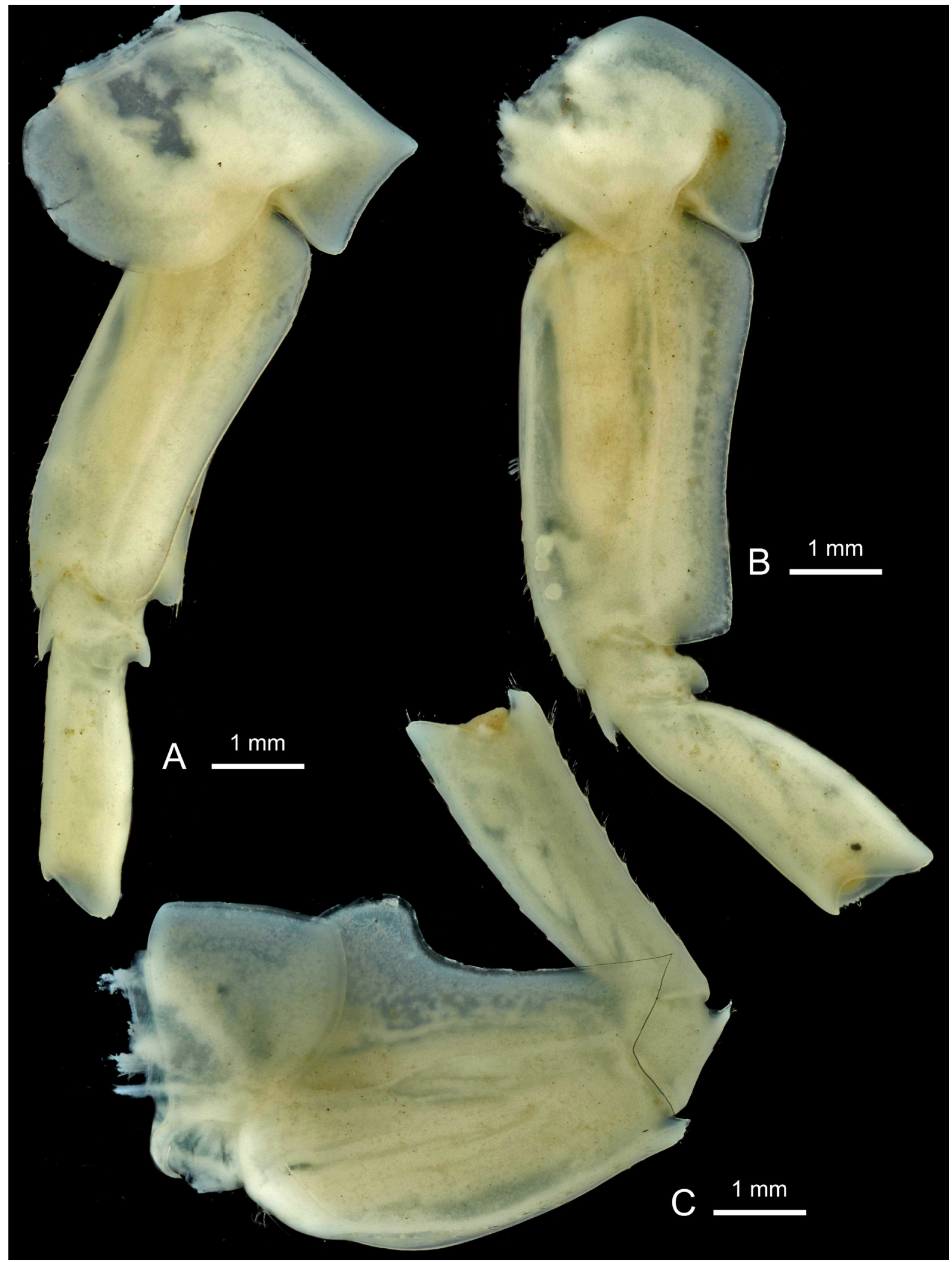

Fig. 335. Alexandrella chione sp. nov., + , holotype, Bransfield Strait, ANT-XXIX/3, stn 227-2, RBINS, INV. 122887. A. Pereiopod 5. B. Pereiopod 6. C. Pereiopod 7. 


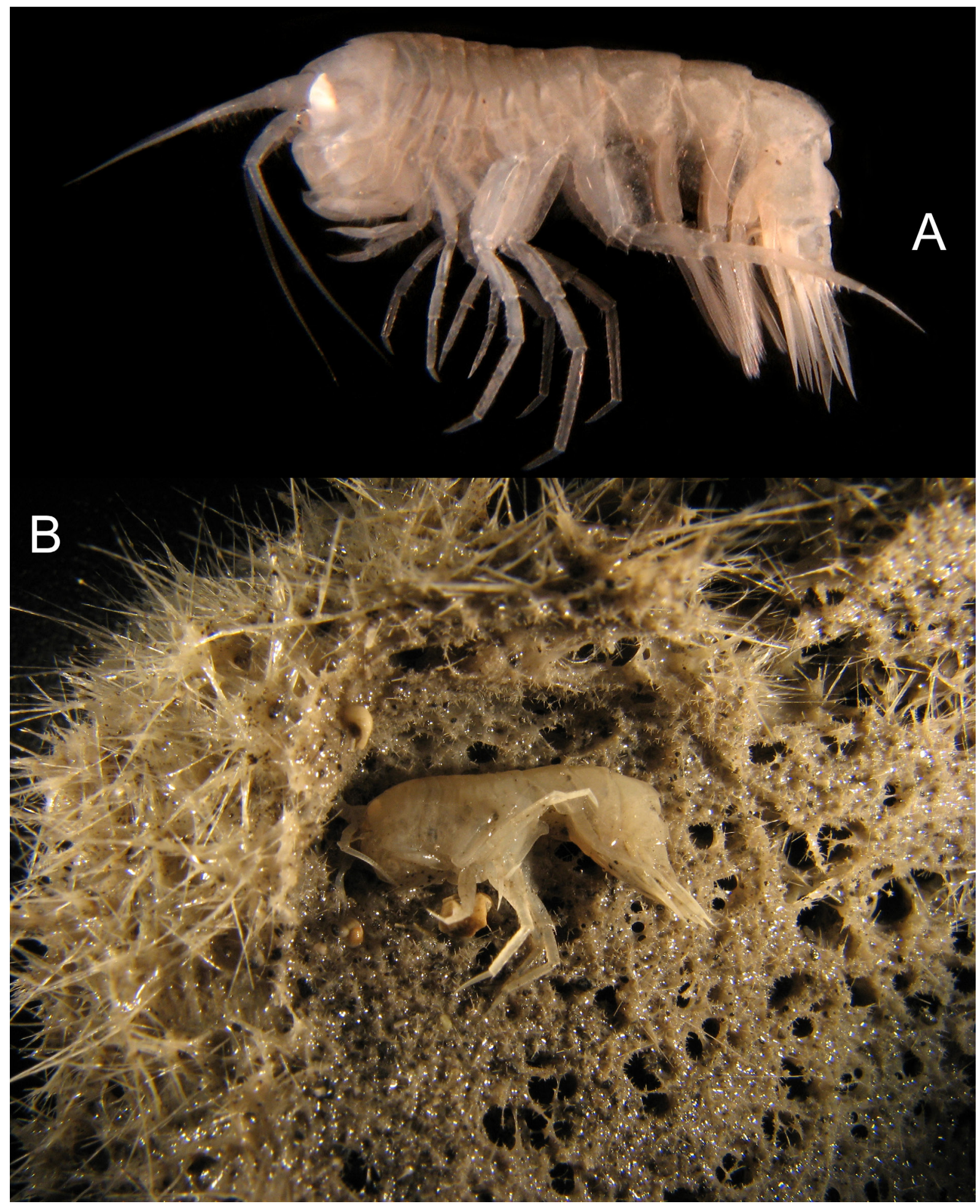

Fig. 336. Alexandrella mixta Nicholls, 1938, sex undetermined, s. lat. Adult, about $20 \mathrm{~mm}$, western Weddell Sea, Larsen A, ANT-XXIII/8, stn 725-6, RBINS, INV. 122305. A. Lateral habitus (colour in life). B. Same specimen (colour in life) with sponge from the same catch (note the striking colour similarity). Photographs: C. d'Udekem d'Acoz. 


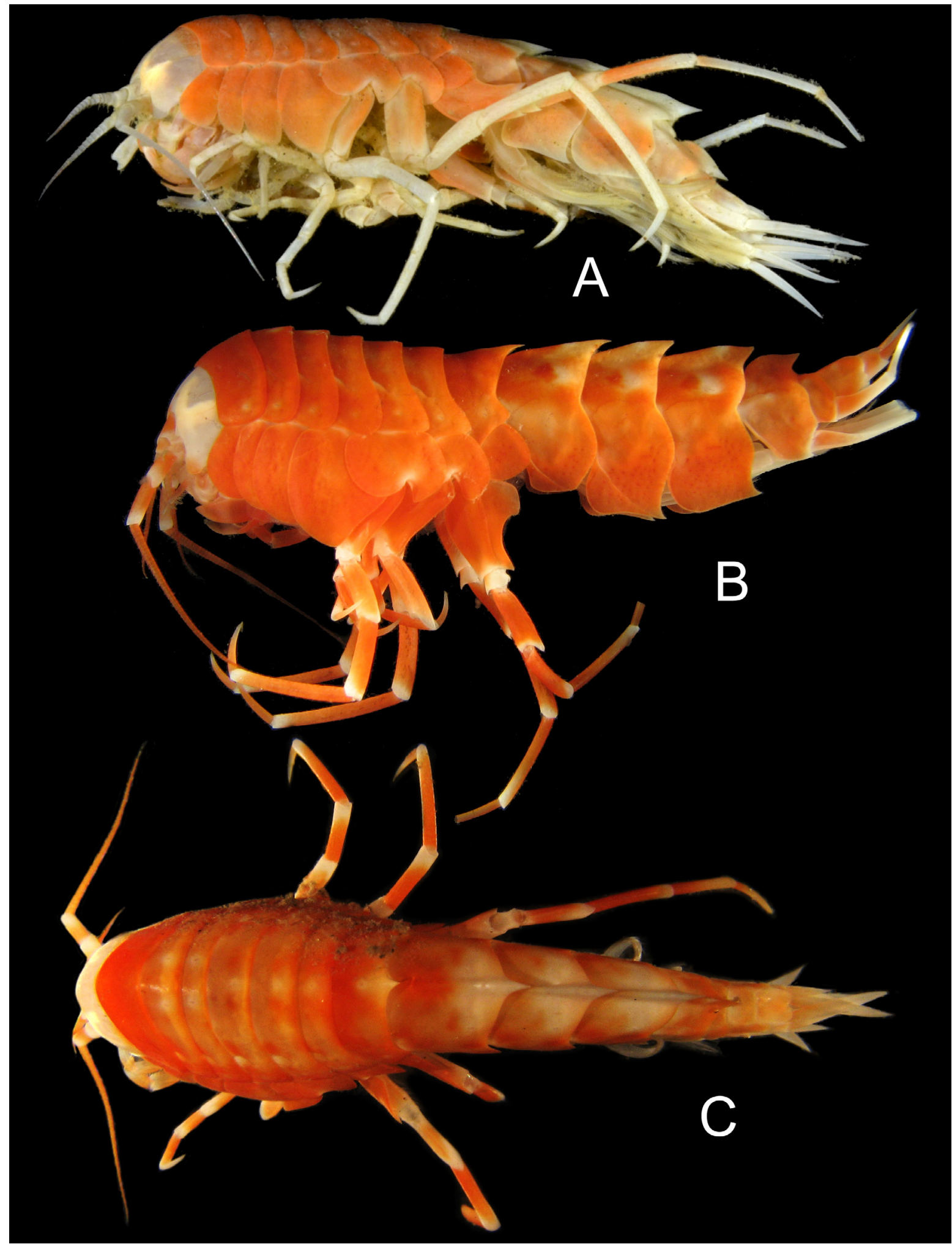

Fig. 337. Alexandrella pulchra Ren in Ren \& Huang, 1991, sex undetermined, lateral habitus (colour in life). A. Bransfield Strait, ANT-XXIX/3, stn 227-2, RBINS, INV. 122864. B. between Elephant Island and King George Island, ANT-XXIII/8, stn 662-1, RBINS, INV. 122304. C. Elephant Island, ANTXXIII/8, stn 654-6, RBINS, INV. 122440. A, B. Lateral habitus (A, slightly tilted). C. Dorsal habitus. Photographs: C. d'Udekem d'Acoz. 


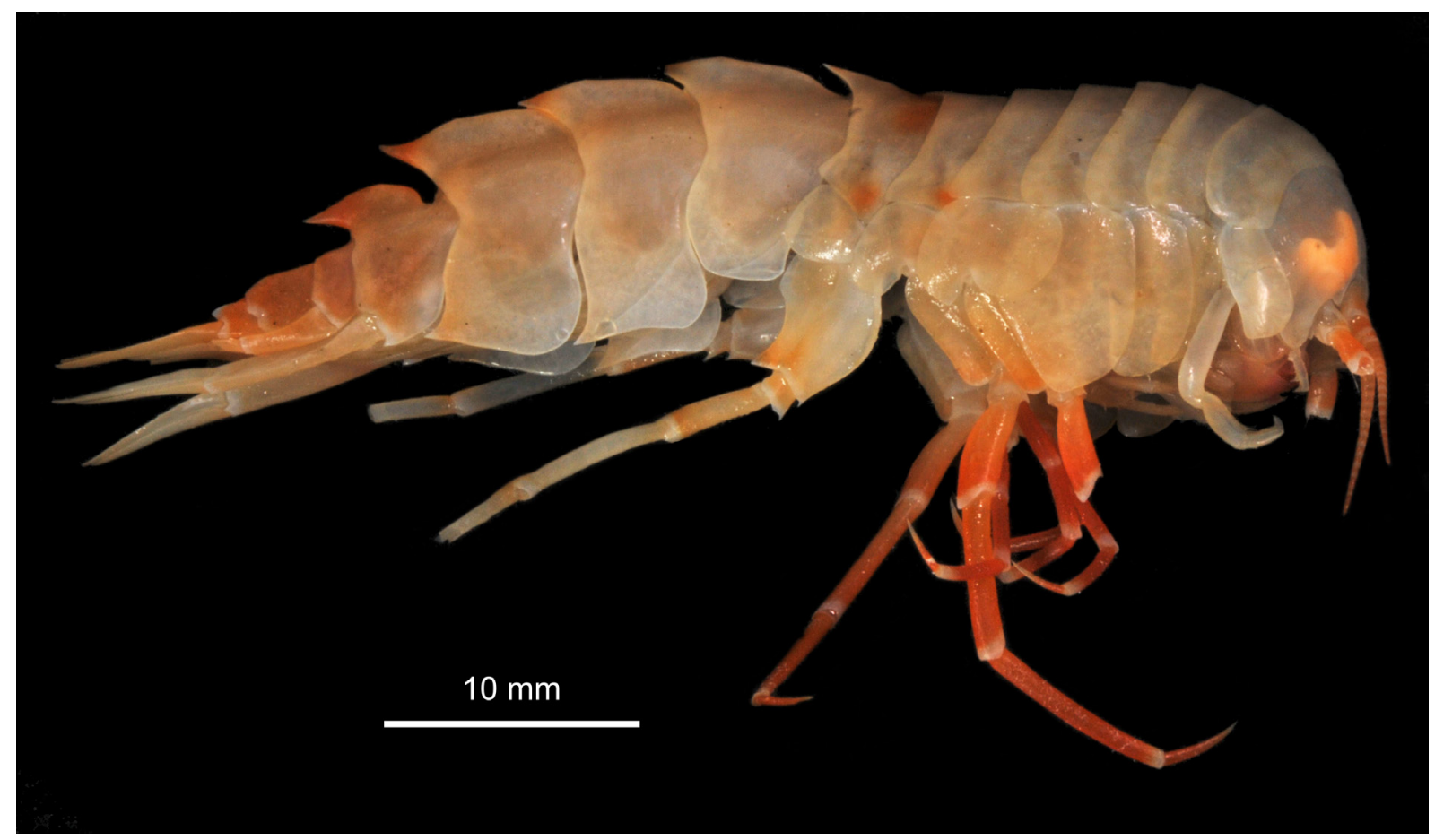

Fig. 338. Alexandrella sp. 1., sex undetermined, Adélie Coast, REVO_449, MNHN-IU-2009-2540. Lateral habitus (colour in life). Photograph: Cyril Gallut ((Université Pierre et Marie Curie). 


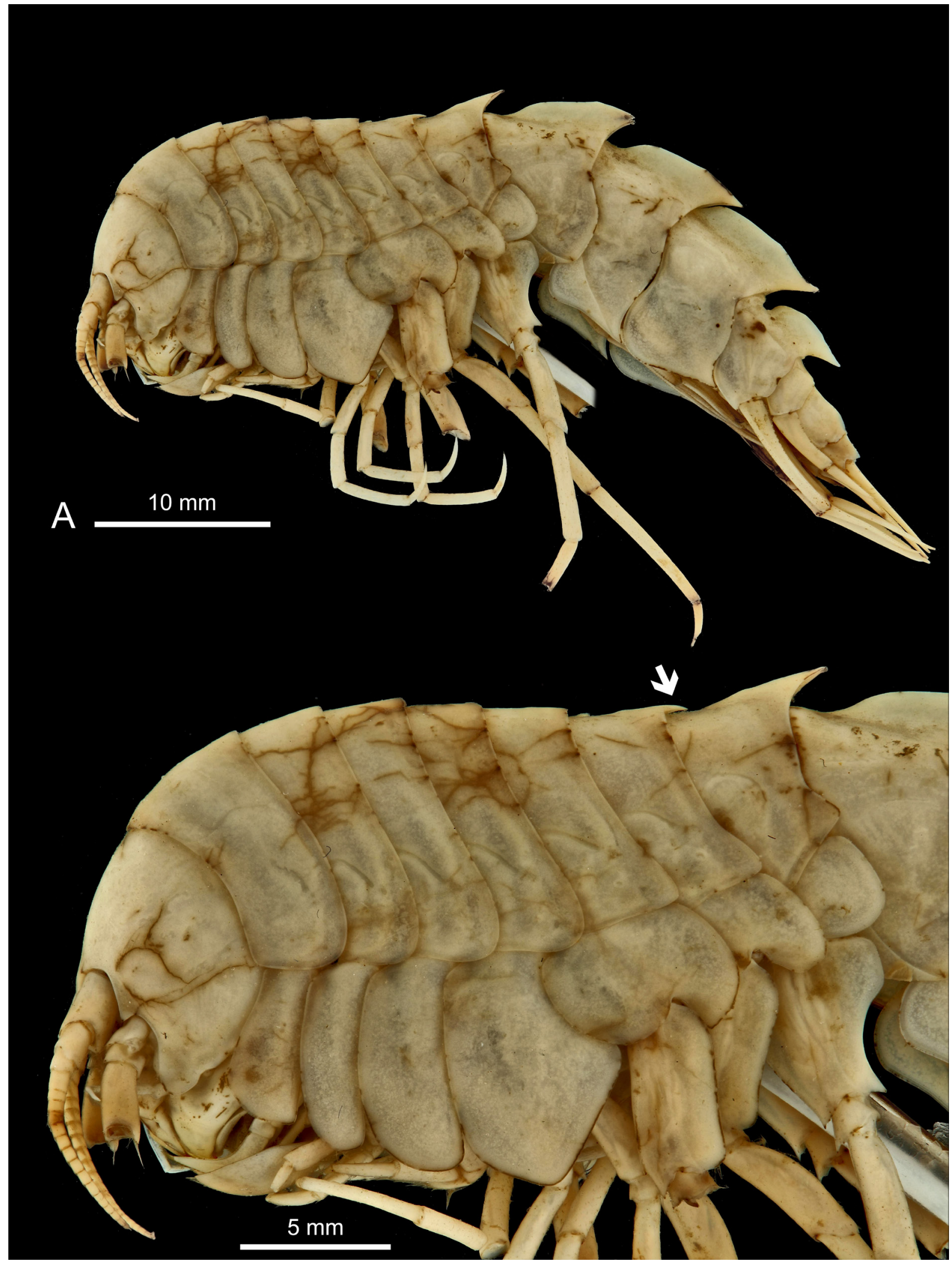

Fig. 339. Alexandrella sp. 1., sex undetermined, Adélie Coast, REVO_449, MNHN-IU-2009-2540. A. Lateral habitus. B. Lateral anterior view. 


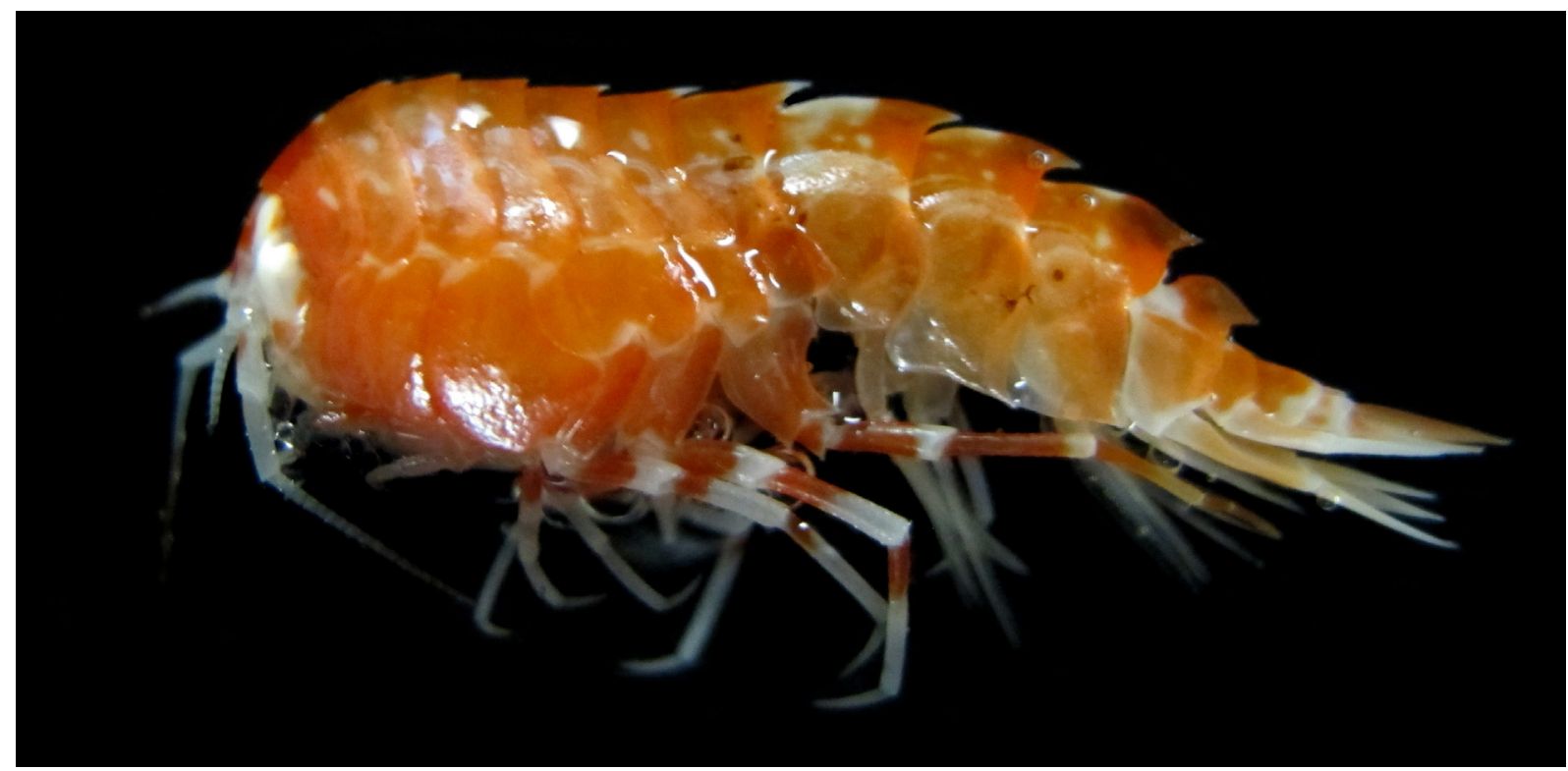

Fig. 340. Alexandrella sp. 2. Shag Rocks, ANT-XXVII/3, stn 211, specimen unavailable. Lateral habitus (colour in life). Photograph: H. Robert and Ch. Havermans (RBINS). 


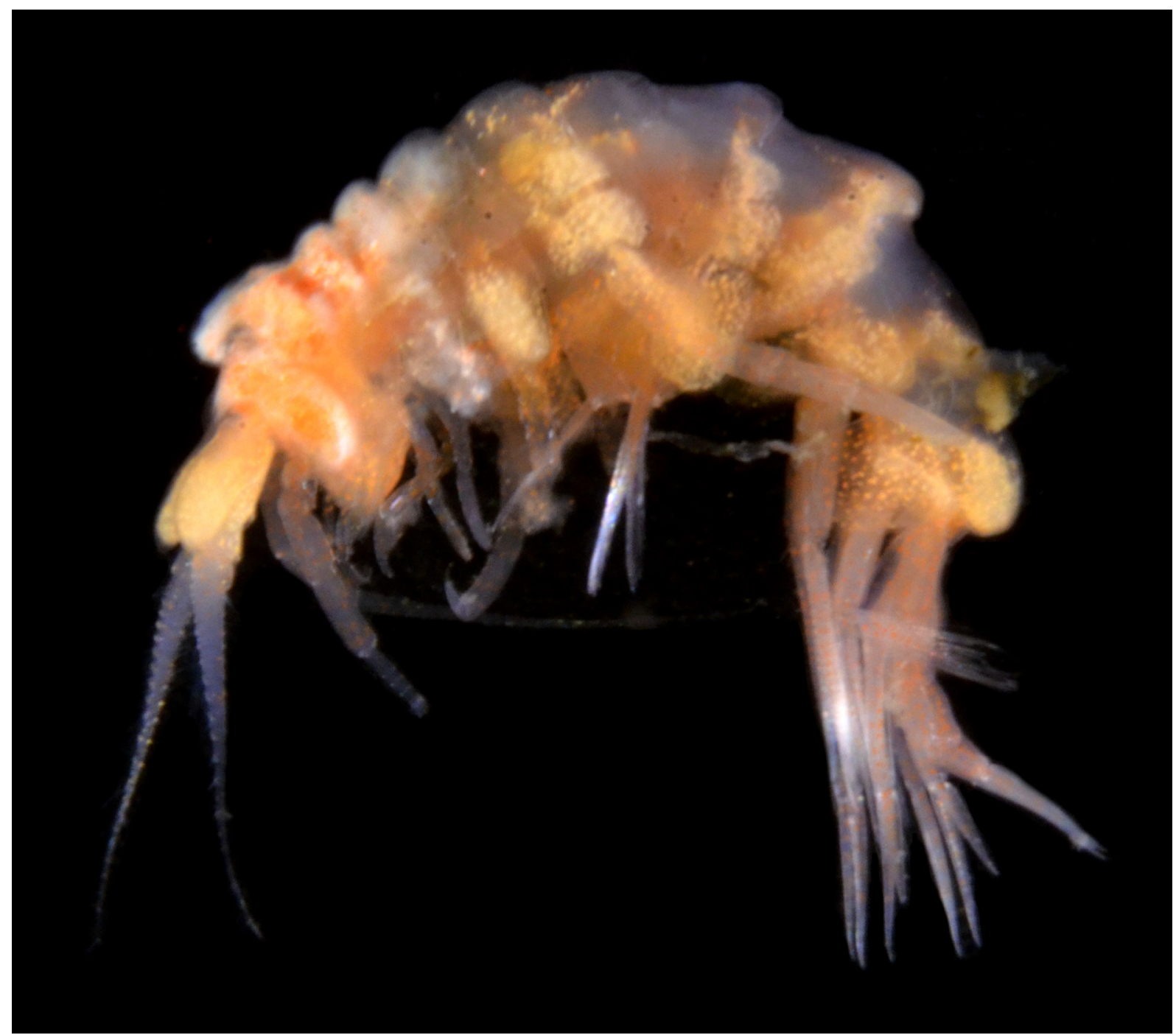

Fig. 341. Acanthonotozomopsis pushkini (Bushueva, 1978), sex undetermined, adult, Bransfield Strait, ANT-XXIX/3, stn 197-6, RBINS, INV. 122871. Lateral habitus (colour in life). Photograph: C. d'Udekem d'Acoz (RBINS). 


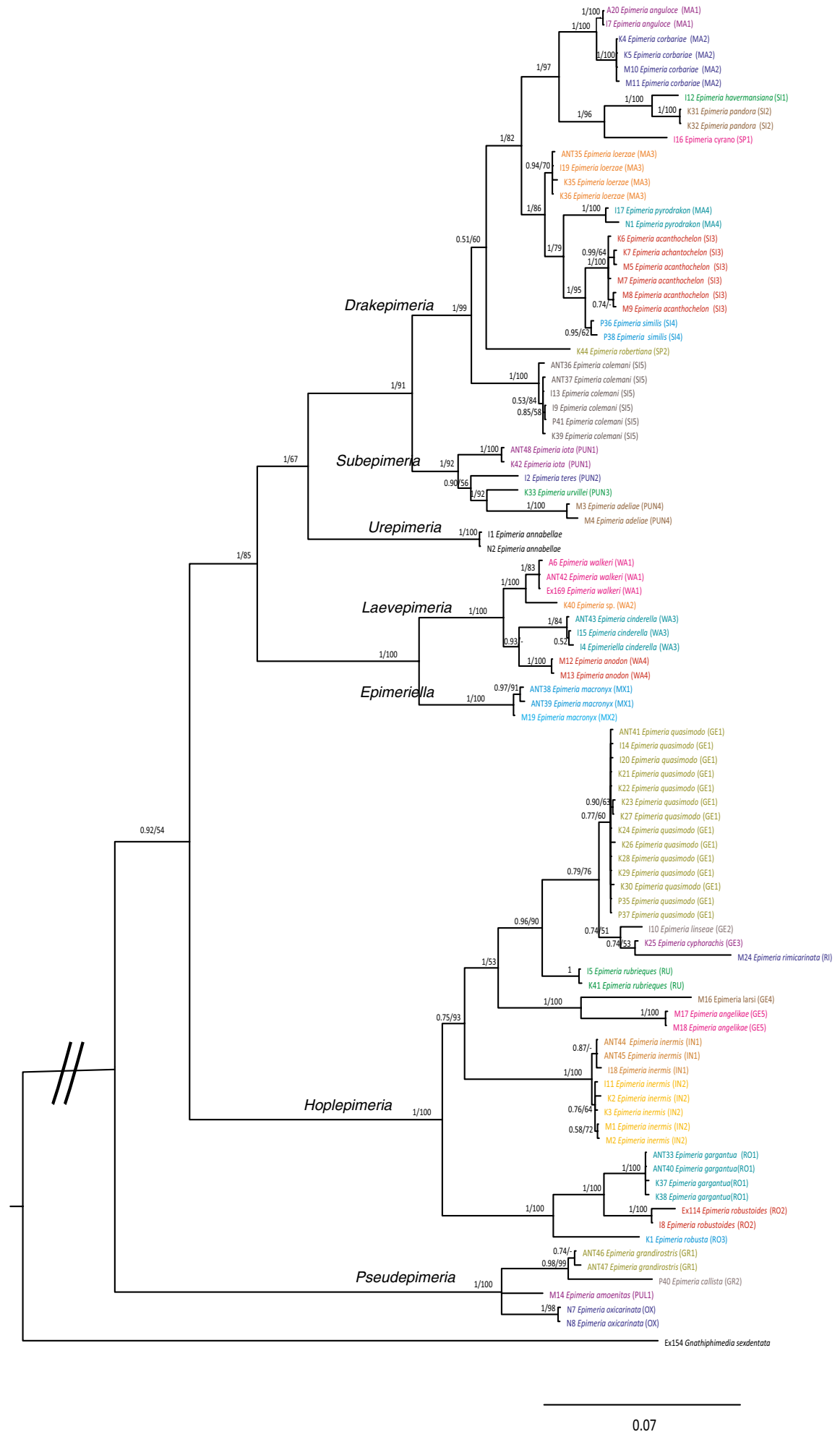

Fig. 342. Phylogenetic tree obtained by Bayesian analysis of the concatenated COI and $28 \mathrm{~S}$ sequences, updated from Verheye et al. (2016). Bayesian posterior probabilities and bootstrap values (from the Maximum Likelihood analysis) are indicated above the nodes of interest. Bootstrap values inferior to 50 are not indicated. Besides the species names are indicated the MOTUs codes used in Verheye et al. (2016). The Genbank accession number of the outgroup species: Gnathiphimedia sexdentata (Schellenberg, 1926) are KU870835 (COI) and KU759609 (28S). 

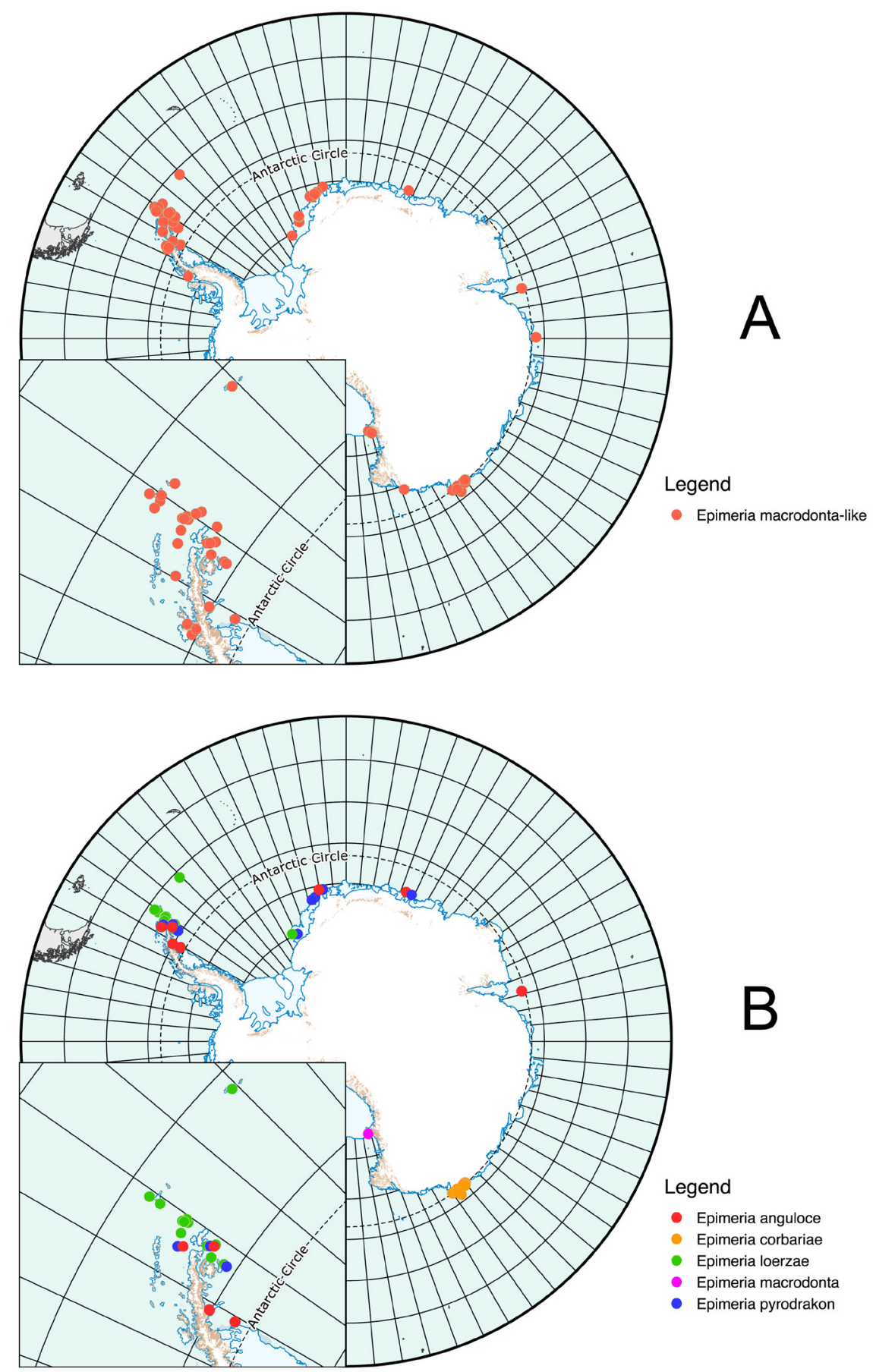

Fig. 343. Maps showing how the confusion of similar species can lead to spurious interpretations of the distribution of Antarctic organisms in hiding patterns of endemism. A. All records of Epimeria macrodonta-like species pulled together: records compiled by De Broyer et al. (2007) combined with present records. B. Records of the different Epimeria macrodonta-like species as defined in the present paper: E. anguloce sp. nov., E. corbariae sp. nov., E. loerzae sp. nov., E. macrodonta Walker, 1906, E. pyrodrakon sp. nov. 